\title{
Padrões de riqueza, diversidade e endemismo de répteis e anfíbios na América do Sul
}

Patterns of richness, diversity, and endemism of reptiles and amphibians in South America 


\title{
Padrões de riqueza, diversidade e endemismo de répteis e anfíbios na América do Sul
}

Patterns of richness, diversity, and endemism of reptiles and amphibians in South America

\begin{abstract}
Tese apresentada ao Instituto de Biociências da Universidade de São Paulo, para a obtenção de Título de Doutor em Zoologia, na Área de Herpetologia.
\end{abstract}

Orientador(a): Fernando Marques

São Paulo 
Teixeira Jr, Mauro

Padrões de riqueza, diversidade e endemismo de répteis e anfíbios na América do Sul

$314 \mathrm{pp}$.

Tese (Doutorado) - Instituto de Biociências da Universidade de São Paulo. Departamento de Zoologia.

1. Biogeografia 2. Macroecologia 3. Herpetologia I. Universidade de São Paulo. Instituto de Biociências. Departamento de Zoologia.

Comissão Julgadora:

$\operatorname{Prof}(a) . \operatorname{Dr}(a)$.

$\operatorname{Prof}(a) . \operatorname{Dr}(a)$.

$\operatorname{Prof}(a) \cdot \operatorname{Dr}(a)$.

$\operatorname{Prof}(a) . \operatorname{Dr}(a)$.

Prof(a). Dr(a).

Orientador(a) 


\section{AGRADECIMENTOS}

Agradeço às pessoas do Laboratório de Herpetologia que contribuíram através de inúmeras conversas e discussões, e me ajudaram a entender melhor certas ideias, conceitos e análises, ajudando de uma forma ou de outra a realização desta tese.

Agradeço especialmente à Roberta Damasceno, Renata Cecilia e Carolina Nisa por terem me ajudado diretamente lendo e fazendo comentários e sugestões sobre as primeiras versões desta tese.

Agradeço também a Karla Paresque com quem discuti muito sobre análises e me ajudou a descobrir programas e artigos que foram muito importantes tanto para me dar ideias do que fazer quanto para realizar as análises.

Agradeço também inúmeras outras pessoas que tenham me ajudado indiretamente conseguindo trazer algum ânimo e distração, especialmente nos últimos meses, o que foi, sem dúvida, essencial para eu conseguir ter algum mínimo de concentração e finalizar esta tese.

Agradeço também à CNPq pela bolsa de doutorado que me foi dada ao longo destes últimos quatro anos. 


\section{ÍNDICE}

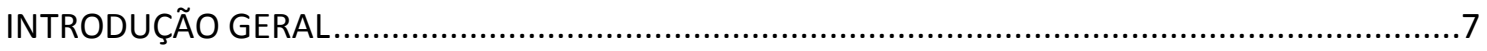

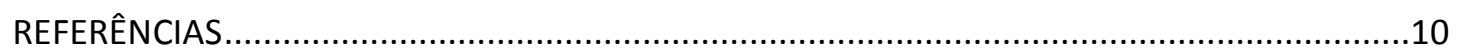

CAPÍTULO 1 - Uma exploração macroecológica dos padrões de distribuição de répteis e

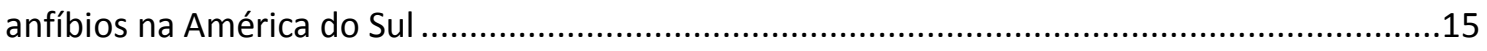

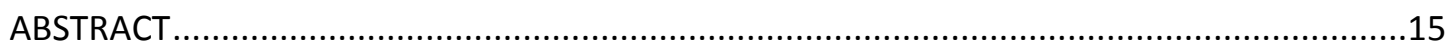

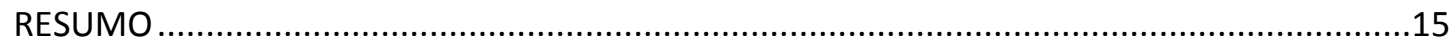

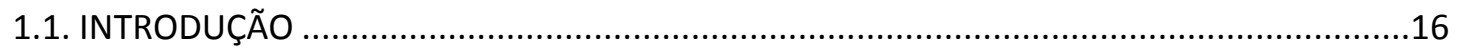

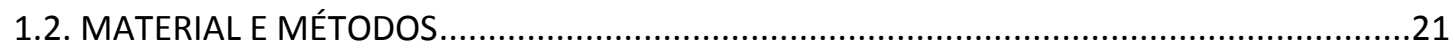

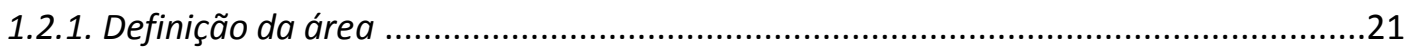

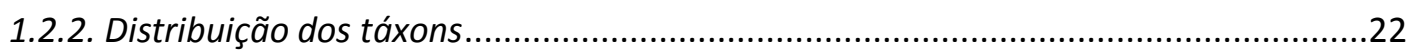

1.2.3. Medida de Riqueza, endemismo e diversidade beta/dissimilaridade ........................24

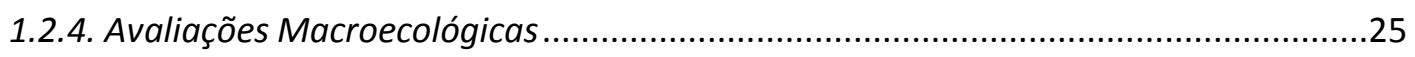

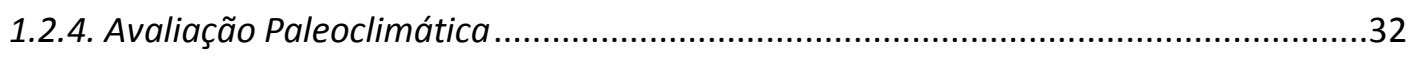

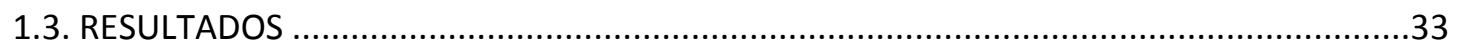

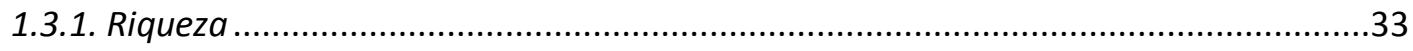

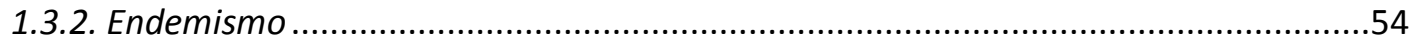

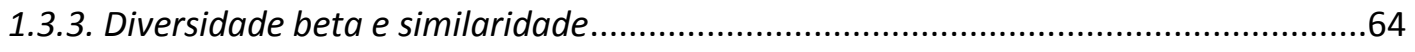

1.3.4. Paleomodelagem da América do Sul ...................................................................77

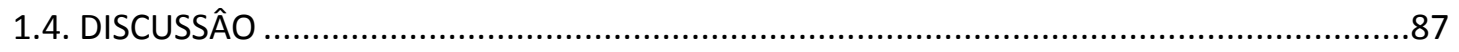

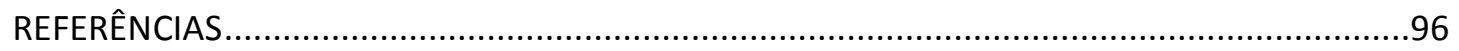

CAPITULO 2 - Quão bom é o esforço de amostragem na América do Sul? ..............................109

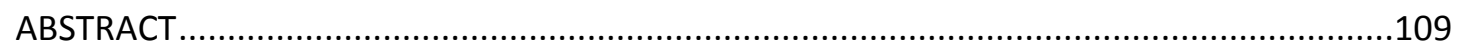

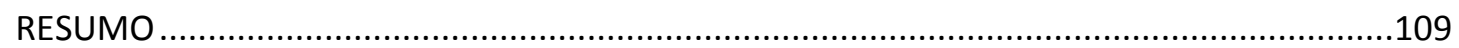

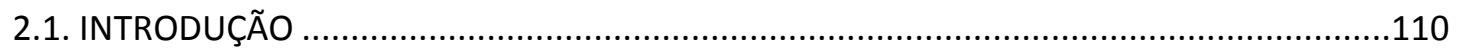

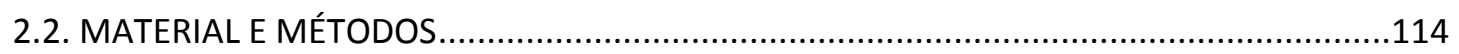

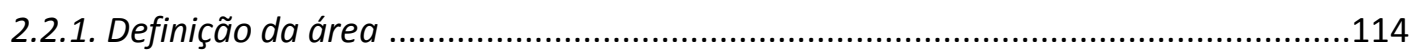

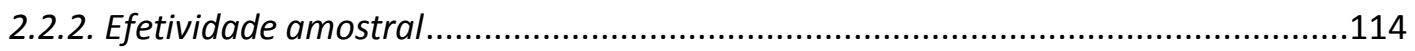

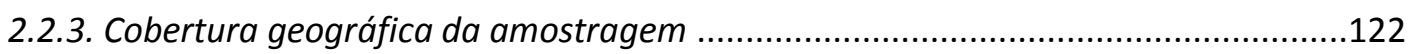

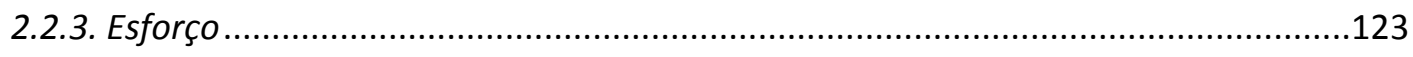

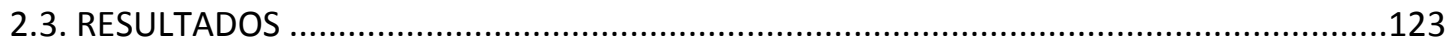

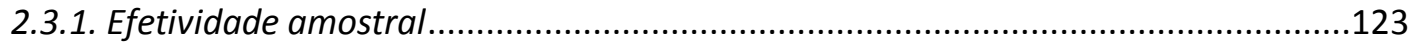

2.3.2. Cobertura geográfica da amostragem .............................................................139 
2.3.3. Esforço

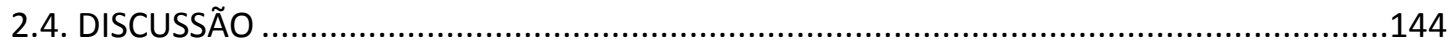

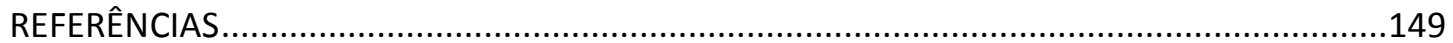

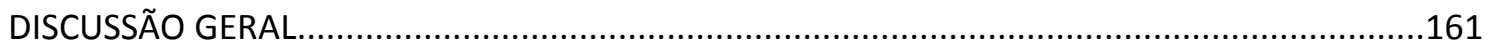

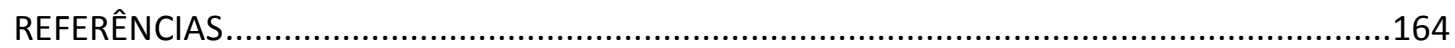

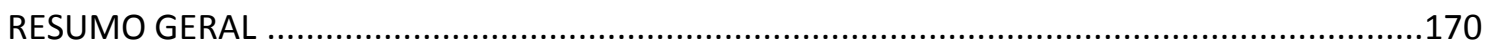

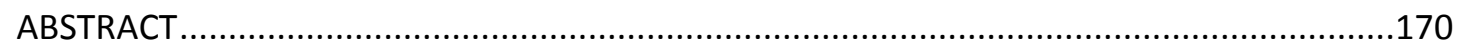

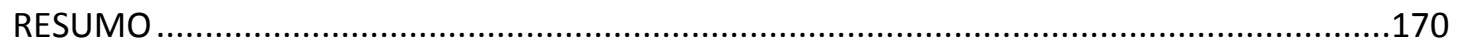

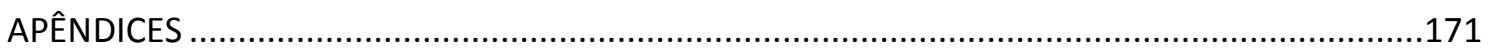

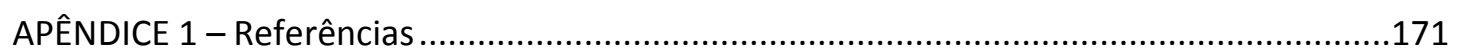

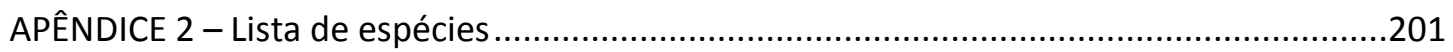

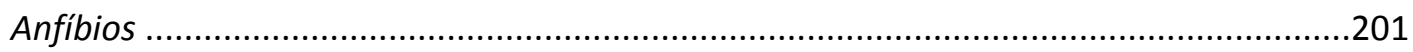

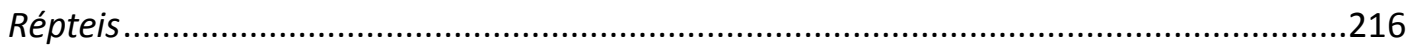

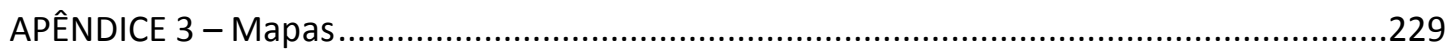

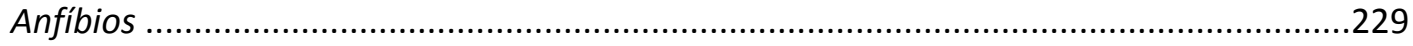

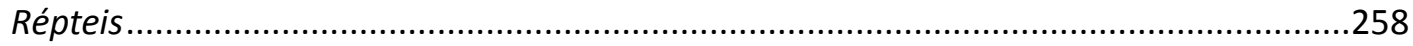

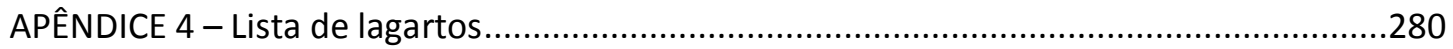

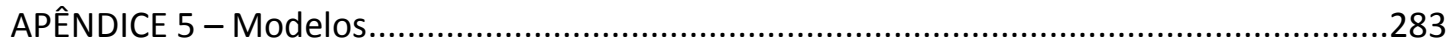

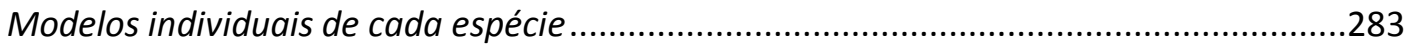

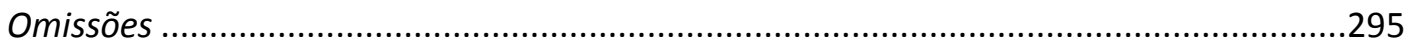

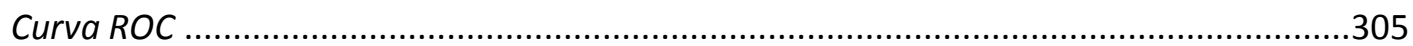




\section{INTRODUÇÃO GERAL}

Desde estudos clássicos, realizados Aristóteles, as pessoas vêm percebendo que o conteúdo biótico varia através da paisagem, com algumas espécies tendo distribuições pequenas, confinadas a áreas acima da linha das árvores no topo de montanhas, enquanto outras apresentam uma ocorrência mais ampla, por todas as áreas baixas (BUFFON 1761; FORSTER 1778; LINNAEUS 1781; ARISTOTÉLĒS 1952). Consequentemente estes autores começaram a postular uma série de teorias e leis que explicariam a existência de tais padrões. Inicialmente ideais religiosos permearam estas ideias, sendo vagarosamente substituídas por uma abordagem mais evolutiva (LINNAEUS 1781; DARWIN 1859; WALLACE 1876a,b).

Neste contexto trabalhos como de Sclater (1858) e Wallace (1876a,b), que dividiram o globo em unidades bióticas tiveram profunda influência na categorização biogeográfica do mundo (CRISCl et al. 2003; HUGGETT 2004; LOMOLINO et al. 2006; COX \& MOORE 2010). Embora biogeógrafos e ecólogos modernos usem técnicas mais avançadas, estes ainda buscam entender as mesmas questões levantadas por aqueles autores: por que as espécies ocorrem onde ocorrem? (LOMOLINO et al. 2006).

Desde então percebeu-se que espécies da fauna e flora ocorrem em estreita relação com fatores ambientais, resultando em uma distribuição não homogênea de riqueza, com muitas destas sendo típicas de determinados ambientes. Isso levou a diversas propostas de regionalização do mundo, incluindo a América do Sul (CABRERA \& YEPES 1940; FITTKAU 1969; SICK 1969; KUSCHEL, 1969; MÜLLER 1973; UDVARDY 1975; AB'SABER 1977; PIELOU 1979; BAILEY 1996; OLSON et al. 2001; MORRONE 2014, 2015). Apesar de diferentes arranjos ambientais, a Floresta Amazônica, a Floresta Atlântica, uma grande diagonal de vegetação aberta, e a região Andina são recorrentemente reconhecidas (FIGURA 1).

A ideia por trás de uma proposta de regionalização biótica se baseia principalmente na sobreposição da área de distribuição de diversos táxons (MORRONE 2014). Outros aspectos derivados desta co-ocorrência são a variação no número de táxons ao longo da paisagem, daqueles com distribuição restrita a cada área, e quão grande são e onde ocorrem quebras na composição biótica, correspondendo respectivamente a riqueza, endemismo e diversidade beta. 


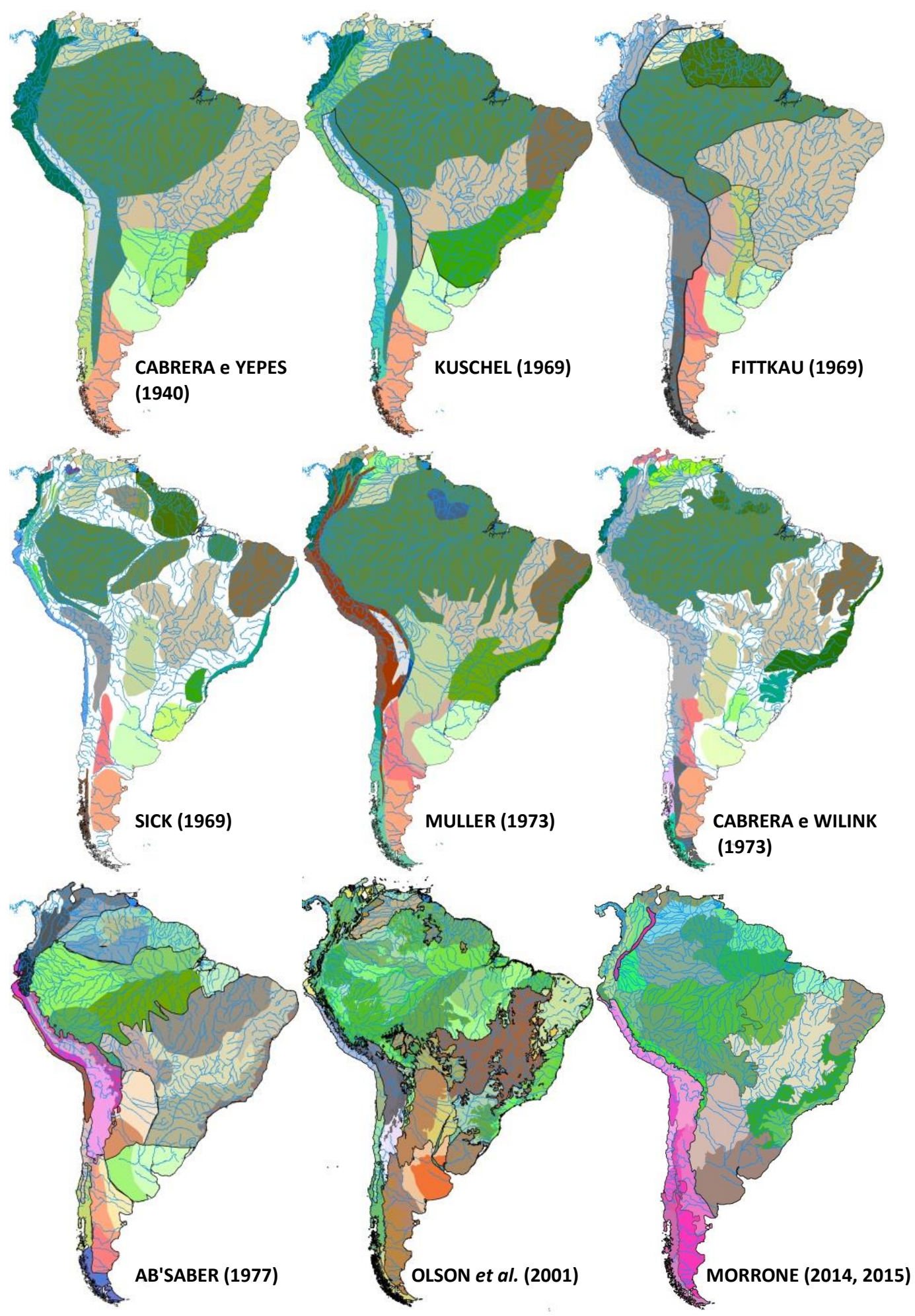

FIGURA 1. Exemplos de regionalização da América do Sul baseada na sua composição biótica, como proposto por diversos autores. Modificado de MORRONE (2011, 2014, 2015).

Diversos estudos buscam entender estes padrões de diversidade e riqueza, e levam em consideração a ocorrência das espécies, analisando-se amplas áreas ao longo de continentes, ou em uma escala global (GASTON 2000; MUTKE \& BARTHLOTT 2005; BARTHLOTT et al. 2007; MCKNIGHT et al. 2007; KIER et al. 2009; MELO et al. 2009; PYRON \& WIENS 2013; BENNIE et 
al. 2014; SILVA et al. 2014). Outros estudos relacionam valores de diversidade e riqueza, a variáveis ambientais, utilizando-se dados de distribuição de espécies, camadas climáticas e análises estatísticas, revelando-se tendências a áreas mais úmidas, como as Florestas Tropicais da Amazônia ou Mata Atlântica, bem como algumas áreas ao longo dos Andes, a apresentarem altos valores de riquezas, enquanto altos valores de diversidade beta são observados principalmente nos Andes (RAHBEK \& GRAVES 2001; DINIZ-FILHO et al. 2008; LOWENBERGNETO et al. 2008; MELO et al. 2009; VALDUJO et al. 2013).

Fatores ambientais têm sido frequentemente usados também para se modelar distribuições potenciais de espécies, ou para se avaliar a evolução do envelope climático das linhagens (RAXWORTHY et al. 2003; GRAHAM et al. 2004; TEIXEIRA JR et al. 2016). De maneira similar, modelagens de distribuições passadas das espécies, utilizando-se dados ambientais de períodos anteriores, como a última glaciação ou o último interglacial (CARNAVAL \& MORITZ 2008; CARBAVL et al. 2009; THOMÉ et al 2010), têm se tornado uma abordagem importante no entendimento das distribuições atuais dos táxons.

Outros estudos têm focado nos níveis de endemismos observados ao longo de amplas áreas do continente Sul-Americano, para os quais foram calculados índices (KIER et al. 2009) ou áreas de endemismo (CRACRAFT 1985; AVILA-PIRES 1995; SZUMIK \& GOLOBOFF 2004; NOGUEIRA et al. 2011; SZUMIK et al. 2012; GUEDES et al. 2014a; GUEDES et al. 2014b; OLIVEIRA et al. 2015; PRADO et al. 2015). Tais estudos se baseiam na sobreposição das distribuições das espécies, no tamanho de suas distribuições, e têm demonstrado a existência de altos níveis de endemismos ao longo dos Andes, e em áreas de Florestas Tropicais, como a Mata Atlântica do sudeste do Brasil.

Esta percepção de altas riquezas e endemismos em Florestas Tropicais tem concentrado nessas áreas tanto estudos que tentam entender e explorar estes aspectos, quanto ações de conservação (REDFORD et al. 1990; SÁNCHEZ-AZOFEIFA et al. 2005), em detrimento de ambientes abertos/secos, como os que compõem a grande Diagonal Seca (e.g Caatinga, Cerrado, Chaco e Matas Secas). Os quais foram considerados por muitos anos como ambientes empobrecidos, comportando uma fauna generalista e homogênea, com baixos níveis de endemismo (VANZOLINI 1963,1976,2003; VITT 1991). No entanto, dados mais recentes têm revelado assembleias de répteis bastante ricas ao longo da Diagonal Seca, e aparentemente restritas a essas áreas, como por exemplo, as regiões cobertas por amplos depósitos de areia ou platôs elevados (RODRIGUES 1991a,b,d,c,1992,1993; NOGUEIRA 2006; PAVAN 2007; PINTO \& CURCIO 2011; RECODER et al. 2011; RECODER et al. 2014). Estes novos 
levantamentos têm permitido assim uma compilação mais adequada da ocorrência das espécies, o que por sua vez permite uma avaliação mais precisa da riqueza e dos níveis de endemismo apresentados por esses ambientes abertos/secos (NOGUEIRA et al. 2011; GUEDES et al. 2014a; GUEDES et al. 2014b).

Assim para avaliar apropriadamente padrões de diversidade e endemismo, a informação básica indispensável, é a ocorrência das espécies, que precisa ser a mais representativa e acurada possível. Algumas técnicas têm sido propostas para se avaliar a qualidade das informações disponíveis, relacionando-as ao nível de esforço despendido em cada área, utilizando-se dados de ocorrência das espécies, de estimadores de riqueza em combinação com dados ambientais, ou de avaliações da densidade de pontos amostrais (SCHULMAN et al. 2007; BALLESTEROS-MEJIA et al. 2013).

O presente estudo tem por objetivo avaliar (1) os padrões de distribuição de répteis e anfíbios na América do Sul, em termos de sua riqueza, endemismo e diversidade beta/dissimilaridade, e buscar fatores ambientais e históricos que os expliquem; (2) assim como o tamanho do esforço de amostragem já realizado, e permitindo tais inferências.

\section{REFERÊNCIAS}

AB'SABER, A.N. (1977) Os Domínios Morfoclimáticos na América do Sul - Primeira Aproximação. Geomorfologia, 52, 1-22.

ARISTOTÉLĒS. (1952) Meteorologica - with a an english transaltion by H.D.P. Lee, M.A. William Henemann Ltd, London, $433 \mathrm{pp}$.

AVILA-PIRES, T.C.S. (1995) Lizards of Brazilian Amazonia (Reptilia: Squamata). Zoologische Mededelingen, 299, 1-706.

BAILEY, R.G. (1996) Ecosystem Geography. Springer-Verlag, New York,pp.

BALLESTEROS-MEJIA, L., KITCHING, I.J., JETZ, W., NAGEL, P. \& BECK, J. (2013) Mapping the biodiversity of tropical insects: species richness and inventory completeness of African sphingid moths. Global Ecology and Biogeography, 22, 586-595.

BARTHLOTT, W., HOSTERT, A., KIER, G., KOPER, W., KREFT, H., MUTKE, J., RAFIQPOOR, M.D. \& SOMMER, J.H. (2007) Geographic patterns of vascular plant diversity at continental to global scales. Erdkunde, 61, 305-315.

BENNIE, J.J., DUFFY, J.P., INGER, R. \& GASTON, K.J. (2014) Biogeography of time partitioning in mammals. Proceedings of the National Academy of Sciences of the United States of America, 111, 13727-13732.

BUFFON, G.L.L.C.D. (1761) Historie Naturelle générale et particulière avec la description du Cabinet du Roy. Vol. 9. L'Imprimeire Royale, Paris,pp.

CABRERA, A. \& YEPES, J. (1940) Mamíferos Sud-americanos (Vida, Constumbres y Descripción). História Natural Ediar, Buenos Aires, 370 pp. 
CARNAVAL, A.C., HICKERSON, M.J., HADDAD, C.F.B., RODRIGUES, M.T. \& MORITZ, C. (2009) Stability predicts genetic diversity in the Brazilian Atlantic forest hotspot. Science, 323,

CARNAVAL, A.C. \& MORITZ, C. (2008) Historical climate modelling predicts patterns of current biodiversity in the Brazilian Atlantic forest. Journal of Biogeography, 35, 1187-1201.

COX, C.B. \& MOORE, P.D. (2010) Biogeography - An Ecological and Evolutionary Approach. John Wiley \& Sons, Hoboken, NJ, USA, $498 \mathrm{pp}$.

CRACRAFT, J. (1985) Historical biogeography and patterns of differentiation within the South American avifauna: areas of endemism. Ornithological Monographs, 49-84.

CRISCI, J.V., KATINAS, L. \& POSADAS, P. (2003) Historical Biogeography: an introduction. Harvard University Press, Cambridge/London, 1-250 pp.

DARWIN, C.R. (1859) On the origin of species by means of natural selection. John Murray, London, $502 \mathrm{pp}$.

DINIZ-FILHO, J.A.F., RANGEL, T.F.L.V.B. \& BINI, L.M. (2008) Model selection and information theory in geographical ecology. Global Ecology and Biogeography, 17, 479-488.

FITTKAU, E.J. (1969) The fauna of South America. In: FITTKAU, E.J., ILLIES, J., KLINGE, H. \& SCHWABE, G.H. (Eds.) Biogeography and Ecology in South America. Dr. W. Junk B. V. Publishers, La Haya, 624-258 pp.

FORSTER, J.R. (1778) Observations made during a voyage round the world on physical geography, natural history, and ethic philosophy. G. Robinson, London,pp.

GASTON, K.J. (2000) Global patterns in biodiversity. Nature, 405, 220-227.

GRAHAM, C.H., RON, S.R., SANTOS, J.C., SCHNEIDER, C.J. \& MORITZ, C. (2004) Integrating phylogenetics and environmental niche models to explore speciation mechanisms in dendrobatid frogs. Evolution, 58, 1781-1793.

GUEDES, T.B., NOGUEIRA, C. \& MARQUES, O.A.V. (2014a) Diversity, natural history, and geographic distribution of snakes in the Caatinga, Northeastern Brazil. Zootaxa, 3863, 1-93.

GUEDES, T.B., SAWAYA, R.J. \& NOGUEIRA, C.D. (2014b) Biogeography, vicariance and conservation of snakes of the neglected and endangered Caatinga region, northeastern Brazil. Journal of Biogeography, 41, 919-931.

HUGGETT, R.J. (2004) Fundamentals of Biogeography. Routledge - Taylor \&Francis Group, London and New York, $439 \mathrm{pp}$.

KIER, G., KREFT, H., LEE, T.M., JETZ, W., IBISCH, P.L., NOWICKI, C., MUTKE, J. \& BARTHLOTT, W. (2009) A global assessment of endemism and species richness across island and mainland regions. Proceedings of the National Academy of Sciences of the United States of America, 106, 9322-9327.

KUSCHEL, G. (1969) Biogeography and Ecology of South American Coleoptera. In: FITTKAU, E.J., ILLIES, J., KLINGE, H. \& SCHWABE, G.H. (Eds.) Biogeography and Ecology in South America. Dr. W. Junk B. V. Publishers, La Haya, pp. 709-722.

LINNAEUS, C. (1781) On the increase of the habitable earth. In: Select Disertations from the Amœnitates Academicæ, a supplement to Mr. Stillingesleet's tracts relating to Natural Histoty. Vol. I. G. Robinson, London, pp. 71-127.

LOMOLINO, M.V., RIDDLE, B.R. \& BROWN, J.H. (2006) Biogeography. Sinauer Associates, Inc., Sunderland, MA, $845 \mathrm{pp}$.

LOWENBERG-NETO, P., DE CARVALHO, C.J.B. \& DINIZ-FILHO, J.A.F. (2008) Spatial congruence between biotic history and species richness of Muscidae (Diptera, Insecta) in the 
Andean and Neotropical regions. Journal of Zoological Systematics and Evolutionary Research, 46, 374-380.

MCKNIGHT, M.W., WHITE, P.S., MCDONALD, R.I., LAMOREUX, J.F., SECHREST, W., RIDGELY, R.S. \& STUART, S.N. (2007) Putting beta-diversity on the map: Broad-scale congruence and coincidence in the extremes. PLoS Biology, 5, 2424-2432.

MELO, A.S., RANGEL, T.F.L.V.B. \& DINIZ, J.A.F. (2009) Environmental drivers of beta-diversity patterns in New-World birds and mammals. Ecography, 32, 226-236.

MORRONE, J.J. (2006) Biogeographic areas and transition zones of Latin America and the Caribbean islands based on panbiogeographic and cladistic analyses of the entomofauna. Annual Review of Entomology, 51, 467-494.

MORRONE, J.J. (2011) América do Sul e a geografia da vida: comparação de algumas propostas de regionalização. In: CARVALHO, C.J.B. \& ALMEIDA, E.A.B. (Eds.) Biogeografia da Amrérica do Sul - Padrões \& Processos. Roca, São Paulo, pp. 14-40.

MORRONE, J.J. (2014) Biogeographical regionalisation of the Neotropical region. Zootaxa, 3782, 1-110.

MORRONE, J.J. (2015) Biogeographical regionalisation of the Andean region. Zootaxa, 3936, 207-236.

MÜLLER, P. (1973) The dispersal centers of terrestrial vertebrates in the Neotropical realm: a study in the evolution of the Neotropical biota and its native landscape. Dr. W. Junk, Haag, 1-244 pp.

MUTKE, J. \& BARTHLOTT, W. (2005) Patterns of vascular plant diversity at continental to global scales. Biologiske Skrifter, 55, 521-531.

NOGUEIRA, C., RIBEIRO, S., COSTA, G.C. \& COLLI, G. (2011) Vicariance and endemism in a Neotropical savanna hotspot: distribution patterns of Cerrado squamate reptiles. Journal of Biogeography, 38, 1907-1922.

OLIVEIRA, U., BRESCOVIT, A.D. \& SANTOS, A.J. (2015) Delimiting Areas of Endemism through Kernel Interpolation. PLOS ONE, 10,

OLSON, D.M., DINERSTEIN, E., WIKRAMANAYAKE, E.D., BURGUESS, N.D., POWELL, G.V.N., UNDERWOOD, E.C., D'AMICO, J.A., STRAND, J.C., LOUCKS, C.J., ALLNUTT, T.F., RICKETTS, T.H., KURA, Y., LAMOREUX, J.F., WETTENGEL, W.W., HEDAO, P. \& KASSEM, K.R. (2001) Terrestrial Ecoregions of the World: A New Map of Life on Earth. Bioscience, 51, 933-938.

PAVAN, D. (2007) Assembléias de répteis e anfíbios do Cerrado ao longo da bacia do rio Tocantins e o impacto do aproveitamento hidreletrico da região na sua conservação. PhD. Departamento de Zoologia, Insituto de Biociências, Universidade de São Paulo, São Paulo, 405 pp.

PIELOU, E.C. (1979) Biogeography. John Wiley and Sons, New York,pp.

PINTO, R.R. \& CURCIO, F.F. (2011) On the generic identity of Siagonodon brasiliensis, with the description of a new leptotyphlopid from Central Brazil (Serpentes: Leptotyphlopidae). Copeia, 53-63.

PRADO, J.R., BRENNAND, P.G.G., GODOY, L.P., LIBARDI, G.S., ABREU, E.F., ROTH, P.R.O., CHIQUITO, E.A. \& PERCEQUILLO, A.R. (2015) Species richness and areas of endemism of oryzomyine rodents (Cricetidae, Sigmodontinae) in South America: an NDM/VNDM approach. Journal of Biogeography, 42, 540-551. 
PYRON, R.A. \& WIENS, J.J. (2013) Large-scale phylogenetic analyses reveal the causes of high tropical amphibian diversity. Proceedings of the Royal Society B-Biological Sciences, 280, 1-10.

RAHBEK, C. \& GRAVES, G.R. (2001) Multiscale assessment of patterns of avian species richness. Proceedings of the National Academy of Sciences of the United States of America, 98, 4534-4539.

RAXWORTHY, C.J., MARTINEZ-MEYER, E., HORNING, N., NUSSBAUM, R.A., SCHNEIDER, G.E., ORTEGA-HUERTA, M.A. \& PETERSON, A.T. (2003) Predicting distributions of known and unknown reptile species in Madagascar. Nature, 426, 837-841.

RECODER, R.S., TEIXEIRA JR, M., CAMACHO, A., NUNES, P.M.S., MOTT, T., VALDUJO, P.H., GHELLERE, J.M.B., NOGUEIRA, C. \& RODRIGUES, M.T. (2011) Répteis da Estação Ecológica Serra Geral do Tocantins, Brasil Central. Biota Neotropica, 11, 1-19.

RECODER, R.S., WERNECK, F.D., TEIXEIRA JR, M., COLLI, G.R., SITES JR, J.W. \& RODRIGUES, M.T. (2014) Geographic variation and systematic review of the lizard genus Vanzosaura (Squamata, Gymnophthalmidae), with the description of a new species. Zoological Journal of the Linnean Society, 171, 206-225.

REDFORD, K.H., TABER, A. \& SIMONETTI, J.A. (1990) There is more to biodiversity than tropical rainforests. Conservation Biology, 4, 328-330.

RODRIGUES, M.T. (1991a) Herpetofauna das dunas interiores do rio São Francisco: Bahia: Brasil. 1. Introdução à área e descrição de um novo gênero de microteiideos (Calyptommatus) com notas sobre sua ecologia, distribuição e especiação (Sauria, Teiidae). Papéis Avulsos de Zoologia, 37, 285-320.

RODRIGUES, M.T. (1991b) Herpetofauna das dunas interiores do rio São Francisco: Bahia: Brasil. 2. Psilophthalmus: um novo gênero de microteiideos sem pálpebra (Sauria: Teiidae). Papéis Avulsos de Zoologia, 37, 321-327.

RODRIGUES, M.T. (1991c) Herpetofauna das dunas interiores do rio São Francisco: Bahia: Brasil. 3. Procellosaurinus: um novo gênero de microteiideo sem palpebra, com a redefinição do gênero Gymnophthalmus (Sauria: Teiidae). Papéis Avulsos de Zoologia, 37, 329-342.

RODRIGUES, M.T. (1991d) Herpetofauna das dunas interiores do rio São Francisco: Bahia: Brasil. 4. Uma nova espécie de Typhlops (Ophidia, Typhlopidae). Papéis Avulsos de Zoologia, 37, 343-346.

RODRIGUES, M.T. (1992) Herpetofauna das dunas interiores do rio São Francisco: Bahia: Brasil. 5. Duas novas espécies de Apostolepis (Ophidia, Colubridae). Memorias do Instituto Butantan, 54, 53-59.

RODRIGUES, M.T. (1993) Herpetofauna of paleoquaternary sand dunes of the middle São Francisco river: Bahia: Brazil. 6. Two new species of Phimophis (Serpentes: Colubridae) with notes on the origin of psammophilic adaptations. Papéis Avulsos de Zoologia, 38, 187-198.

SÁNCHEZ-AZOFEIFA, G.A., KALACSKA, M., QUESADA, M., CALVO-ALVARADO, J.C., NASSAR, J.M. \& RODRÍGUEZ, J.P. (2005) Need for Integrated Research for Sustainable Future in Tropical Dry Forest. Conservation Biology, 19, 285-286.

SCLATER, P.L. (1858) On the general Geographical Distribution of the Members of the Class Aves. Journal of the Proceedings of the Linnean Society of London, 2, 130-136. 
SCHULMAN, L., TOIVONEN, T. \& RUOKOLAINEN, K. (2007) Analysing botanical collecting effort in Amazonia and correcting for it in species range estimation. Journal of Biogeography, 34, 1388-1399.

SILVA, F., ALMEIDA-NETO, M. \& ARENA, M.V.N. (2014) Amphibian Beta Diversity in the Brazilian Atlantic Forest: Contrasting the Roles of Historical Events and Contemporary Conditions at Different Spatial Scales. PLOS ONE, 9, 1-9.

SICK, W.D. (1969) Geographical substance. Monographiae Biologicae, 19, 449-474.

SZUMIK, C., AAGESEN, L., CASAGRANDA, D., ARZAMENDIA, V., BALDO, D., CLAPS, L.E., CUEZZO, F., GOMEZ, J.M.D., DI GIACOMO, A., GIRAUDO, A., GOLOBOFF, P., GRAMAJO, C., KOPUCHIAN, C., KRETZSCHMAR, S., LIZARRALDE, M., MOLINA, A., MOLleraCh, M., NAVARRO, F., NOMDEDEU, S., PANIZZA, A., PEREYRA, V.V., SANDOVAL, M., SCROCCHI, G. \& ZULOAGA, F.O. (2012) Detecting areas of endemism with a taxonomically diverse data set: plants, mammals, reptiles, amphibians, birds, and insects from Argentina. Cladistics, 28, 317-329.

SZUMIK, C.A. \& GOLOBOFF, P.A. (2004) Areas of Endemism: An Improved Optimality Criterion. Systematic Biology, 53, 968-977.

TEIXEIRA JR, M., PRATES, I., SILVA-MARTINS, N.S., STRÜSSMANN, C. \& RODRIGUES, M.T. (2015) Molecular data reveal spatial and temporal patterns of diversification and a cryptic new species of lowland Stenocercus Duméril \& Bibron, 1837 (Squamata: Tropiduridae). Molecular Phylogenetics and Evolution, 94, 410-423.

THOMÉ, M.T.C., ZAMUDIO, K.R., GIOVANELLI, J.G.R., HADDAD, C.F.B., BALDISSERA JR, F.A. \& ALEXANDRINO, J. (2010) Phylogeography of endemic toads and post-Pliocene persistence of the Brazilian Atlantic Forest. Molecular Phylogenetics and Evolution, 55, 1018-1031.

UDVARDY, M.D.F. (1975) A classification of the biogeographical provinces of the world. IUCN Occasional Paper, 1-48.

VALDUJO, P.H., CARNAVAL, A.C.O.Q. \& GRAHAM, C.H. (2013) Environmental correlates of anuran beta diversity in the Brazilian Cerrado. Ecography, 36, 708-717.

VANZOLINI, P.E. (1963) Problemas faunísticos do cerrado. In: FERRI, M.G. (Ed.) II Simpósio sobre o Cerrado. EDUSP, São Paulo, pp. 305-321.

VANZOLINI, P.E. (1976) On the lizards of a Cerrado-Caatinga contact: evolutionary and zoogeographical implications (Sauria). Papéis Avulsos de Zoologia, 29, 111-119.

VANZOLINI, P.E. (2003) A contribution to the ecogeography of the Brasilian cerrados. Biologia Geral e Experimental, 4, 3-10.

VITT, L.J. (1991) An Introduction to the Ecology of Cerrado Lizards. Journal of Herpetology, 25, 79-90.

WALLACE, A.R. (1876a) The geographical distribution of animals. With a study of the relations of living and extinct faunas as elucidating the past changes of the earth's surface. Vol. 1. Harper and Brothers, New York, 503 pp.

WALLACE, A.R. (1876b) The geographical distribution of animals. With a study of the relations of living and extinct faunas as elucidating the past changes of the earth's surface. Vol. 2. Harper and Brothers, New York, 607 pp. 


\section{CAPÍTULO 1 - Uma exploração macroecológica dos padrões de distribuição de répteis e anfíbios na América do Sul}

\section{ABSTRACT}

The large amount of species across Tropical Forests have always caught the attention of researchers and conservationists. They have questioned why those areas are so much richer than other environments, creating dozens of hypothesis to explain it. Here I gather a large and carefully curated dataset of distribution data of over 4.9 thousands of species of reptiles and amphibians in South America. Then I assess patterns of richness, endemism, and beta diversity and the relationships between diversity and environmental factors, such as climate, soil and habitat structure. I also performed a similarity assessment and the palaeomodelling of biomes across South America in order to assess differences in diversity between regions. As a result, forest areas, especially the Amazon, harbors a widely distributed fauna, rendering a large local richness, but a relatively low species density, as well as, low dissimilarity across its area. Contrastingly, the fauna in opens areas and in the Andes show restricted distributions, rendering lower local richness, high dissimilarity, and high species density, except for the density of amphibians in open areas. Richness was strongly correlated with current environmental conditions, which suggests habitat filtering in harsh environments and higher niche packing in some environments. However, endemism and beta diversity were weakly correlated with current environmental conditions, suggesting others factors such as historical ones, as more influential on these patterns.

\section{RESUMO}

A grande riqueza de espécies nas áreas cobertas por Floresta Tropicais, sempre atraíram a atenção de pesquisadores e conservacionistas. Esta percepção gerou muitos questionamentos sobre o porquê de tais áreas apresentarem uma riqueza tão maior que outros tipos de ambientes, levando a dezenas de hipóteses para se explicar este fato. Neste estudo foi criado um banco de dados grande e cuidadosamente curado incluindo informações detalhadas de distribuição de cerca de cerca de 4.9 mil espécies de répteis e anfíbios na América do Sul. Foram então explorados os padrões de riqueza, endemismo e diversidade beta dessa fauna, assim como as relações desses padrões e fatores ambientais, como clima, solo e estrutura do ambiente. Foram também realizadas análises de similaridade faunística e a paleomodelagem dos biomas dessa região, para se tentar se explicar por que certas áreas são mais diversas que outras. Como resultado foi observado que áreas de Forestas, especialmente a Amazônica, apresentam no geral uma composição de espécies de ampla distribuição, gerando uma grande riqueza local, mas uma densidade de espécies relativamente baixa e uma alta similaridade, por toda sua extensão. Por outro lado, áreas Abertas e Andinas apresentam uma fauna com distribuição mais restrita e riqueza local mais baixa, porém com uma densidade de espécies razoavelmente alta nestas áreas, exceto nas áreas Abertas para anfíbios. Os valores de riqueza se mostraram fortemente relacionados às condições ambientais atuais, o que pode representar filtragem pelo ambiente (em hábitats mais severos), assim como uma maior possibilidade de subdivisão (empacotamento) de nichos. Endemismo e diversidade beta apresentaram relações mais fracas com o ambiente atual, sugerindo que outros fatores, com fatores históricos, podem ter maiores relações com estes padrões. 


\subsection{INTRODUÇÃO}

Medidas de valores biológicos como riqueza e diversidade vêm sendo observadas desde o início da biologia (BUFFON 1761; WALLACE 1876; ARISTOTÉLĒS 1952). As medidas básicas se referem à riqueza, correspondendo à simples contagem do número de táxons em uma determinada área, definida segundo algum critério biológico, geográfico ou político (MAGURRAN 1988,2004).

O termo diversidade muitas vezes é aplicado como sinônimo de riqueza, sendo considerada como "diversidade alfa" ou riqueza local, no entanto, a diversidade propriamente dita inclui também informações sobre a abundância relativa de cada táxon (TUOMISTO 2010a). Dessa maneira áreas com a maior parte dos indivíduos representando poucas espécies, apresentam uma dominância maior, assim o termo diversidade quantifica o número efetivo de uma determinada entidade de interesse, neste caso táxons (MAGURRAN 1988,2004; TUOMISTO 2010a).

Outros termos relacionados à diversidade abrangem a diversidade beta, que mede a dissimilaridade na composição entre áreas (WHITTAKER 1960; MAGURRAN 1988,2004), e diversidade gama, que representa a riqueza de espécies considerando todas as localidades dentro de uma paisagem (MAGURRAN 1988,2004; TUOMISTO 2010a). Diversidade beta pode ser medida através da simples divisão entre a diversidade alfa média (riqueza local média), e a diversidade gama (riqueza total) (WHITTAKER 1960; TUOMISTO 2010b). No entanto apesar de algumas variações desta fórmula terem sido feitas subsequentemente (WHITTAKER 1972; LANDE 1996; VEECH et al. 2002; TUOMISTO 2010b), a ideia de a diversidade beta quantificar a variação na composição de táxons continua a mesma.

Outra maneira de se quantificar a diferença na composição de espécies em áreas distintas é através de índices de similaridade (ou dissimilaridade), que em certos casos funcionam de maneira similar ao cálculo da diversidade beta (TUOMISTO 2010b). Parte destes índices usa apenas presença e ausência dos táxons em cada localidade (e.g. Jaccard, Dice, Levandowsky, etc.), enquanto outros incorporam também dados de abundância de cada táxon em cada localidade (JOHNSTON 1976). Alguns destes índices (e.g. Jaccard e Sørense) são frequentemente utilizados para se comparar a composição biótica entre áreas (CONDIT et al. 2002; TUOMISTO et al. 2003; BANDA-R et al. 2016). A quantidade de táxons compartilhados entre diferentes áreas vai influenciar na diversidade beta, e na dissimilaridade, as quais se espera que sejam altas, quando áreas distantes são utilizadas (e.g. uma áreas na Amazônia e uma na Patagônia), porém no caso de áreas próximas, ou mesmo adjacentes, a composição 
tende a ser bastante semelhante e a diversidade beta e a dissimilaridade tendem a ser baixas. Assim tais medidas são inversamente proporcionais ao tamanho da área de distribuição ocupada pelos táxons incluídos na análise.

Esta ideia de "restrição" aplicada à distribuição de táxons se reflete no endemismo (LOMOLINO et al. 2006). Ainda que o conceito de "endemismo" não fizesse parte do pensamento dos naturalistas que primeiro produziram regionalizações em termos de "regiões biogeográficas" ou "províncias zoogeográficas" (HUGGETT 2004; LOMOLINO et al. 2006), este era um ideal implícito. A sobreposição de áreas de distribuição restrita resulta em uma área com uma biota típica, um fenômeno que os biogeógrafos atuais se referem como "área de endemismo" (LOMOLINO et al. 2006; MORRONE 2009; COX \& MOORE 2010). No caso dos naturalistas, a percepção de que uma área apresenta uma biota típica, vinha de observações feitas em exemplares de museus ou de suas observações pessoais, realizadas através de viagens. Por exemplo, Wallace, que ao visitar diversas áreas da Floresta Amazônica, percebeu que a fauna de aves e macacos em diferentes interflúvios eram distintas umas das outras, propondo áreas de endemismo delimitadas pelos rios Solimões/Amazonas, Negro e Madeira (WALLACE 1854). Porém espécimes depositados em coleções de museus de história natural (HUGGETT 2004; LOMOLINO et al. 2006) eram naquela altura ainda pouco expressivos. No em tanto com o passar do tempo amplas coleções foram sendo realizadas e uma grande quantidade de dados geográficos se tornou disponível, tornando as distribuições dos táxons mais conhecidas e impulsionando a proposição de diversas áreas de endemismos para vários grupos taxonômicos (CRACRAFT 1985; AVILA-PIRES 1995; BEARD et al. 2000; CRISP et al. 2001; SILVA et al. 2004; SZUMIK \& GOLOBOFF 2004; NOGUEIRA et al. 2011; SZUMIK et al. 2012; CASAGRANDA \& GROSSO 2013; OLIVEIRA et al. 2015; PRADO et al. 2015; AZEVEDO et al. 2016)

As técnicas atuais de delimitação de áreas de endemismo incluem dois tipos de análises: as que utilizam algoritmos na delimitação da área (e.g. Analise de Parcimônia de Endemismo: PAE; o programa NDM), e as que não utilizam algoritmos (e.g. traço biogeográfico) (MORRONE 2009). O mais frequentemente utilizado é o NDM-VNDM (SZUMIK et al. 2002; SZUMIK \& GOLOBOFF 2004; FERRARI et al. 2010; SZUMIK et al. 2012; OLIVEIRA et al. 2015; PRADO et al. 2015) que apresenta resultados categóricos com base na pontuação que uma espécie recebe para ser considerada endêmica de uma área, em quantas espécies endêmicas uma área deve ter para ser definida como uma área de endemismo, e quão sobrepostas áreas deve ser para se produzir um consenso (SZUMIK et al. 2002; SZUMIK \& GOLOBOFF 2004). Assim este método leva em consideração uma série de valores definidos pelo usuário, de modo que os 
mesmos dados podem, consequentemente, resultar em áreas diferentes. Outros métodos utilizados para se avaliar endemismo, em uma abordagem mais quantitativa, também já foram propostos (DONY \& DENHOLM 1985; WILLIAMS et al. 1994; CRISP et al. 2001; SLATYER et al. 2007; OLIVEIRA et al. 2015). Estes se baseiam no nível de endemismo de cada táxon, considerando-o como uma característica continua, e inversamente proporcional ao tamanho da área de distribuição do táxon. De maneira que a contribuição de cada táxon é pesada pelo inverso do tamanho de sua área de distribuição. Dessa forma espécies com distribuição pequena, e sobrepostas produziriam um endemismo local alto quando comparados às áreas ocupadas apenas por espécies com ampla distribuição (DONY \& DENHOLM 1985; WILLIAMS et al. 1994; CRISP et al. 2001; SLATYER et al. 2007).

O porquê das espécies ocorrerem apenas em determinadas áreas é uma pergunta que vem sendo feita desde os primeiros naturalistas e diversas teorias foram criadas para se responder a essa pergunta. As primeiras explicações usualmente envolviam a criação divina, ou resultado de dispersão após o diluvio (HUGGETT 2004; LOMOLINO et al. 2006). Por outro lado, mais recentemente, esta questão vem sendo trabalhada de outras formas, e as hipóteses se encaixam geralmente em duas categorias (LOMOLINO et al. 2006): a ecológica, que leva em consideração as relações atuais dos organismos com as características dos ambientes (bióticas e abióticas) (GASTON 2000; BROWN 2014); e a histórica que se refere a alterações na paisagem ao longo do tempo e em como as linhagens se relacionaram com estas alterações (BROWN 2014).

Na Amazônia, por exemplo, como as áreas de endemismo observadas são coincidentes com os interflúvios de grandes rios, postulou-se a hipótese do rio com barreira física, o qual ou teria cortado a distribuição pretérita de um táxon durante seu estabelecimento, ou teria apenas barrado sua dispersão (WALLACE 1854; CRACRAFT 1985; HAYES \& SEWLAL 2004; RIBAS et $\boldsymbol{a l .}$ 2012). Pares de espécies irmãs, ou mesmo diferenças genéticas entre populações em margens opostas de rios vem sendo frequentemente relatadas na literatura (PELLEGRINO et al. 2005; PASSONI et al. 2008; SIEDCHLAG et al. 2010; FERNANDES et al. 2012; GEHRING et al. 2012; RIBAS et al. 2012). Porém em outros casos, o mesmo padrão não é observado, como em diversas espécies, ou linhagens, de lagartos em margens opostas apresentando grande proximidade genética, e populações de uma mesma margem sendo geneticamente bastante distintas (SOUZA et al. 2013; PRATES et al. 2015).

Outra hipótese que por muito tempo foi utilizada para se explicar muitos padrões observados, foi a dos refúgios pleistocênicos. Esta hipótese postula que durante as flutuações 
climáticas dos últimos milhões de anos alguns habitats teriam se mantido estruturalmente estáveis enquanto outros teriam se fragmentado e desaparecido, e as populações que se encontravam isoladas nestes refúgios se diferenciaram, produzindo assim um grande número de espécies restritas à pequenas áreas (HAFFER 1969,1974; VANZOLINI 1981; HAFFER \& PRANCE 2001). Esta hipótese foi utilizada para explicar padrões de distribuição de espécies, com uma ênfase especial na Amazônia, que teria se fragmentado e dado lugar a uma vegetação similar à savânica, enquanto apenas fragmentos florestados teriam restado mantendo as espécies típicas de floresta (HAFFER 1969; WILLIAMS \& VANZOLINI 1980; VANZOLINI 1981; HAFFER \& PRANCE 2001). Porém dados recentes mostram que inúmeros eventos de diversificação nos trópicos aparentemente são muito mais antigos, (GLOR et al. 2001; PRATES et al. 2015; TEIXEIRA JR et al. 2015), ou que no Pleistoceno o clima na verdade não era favorável a uma fragmentação de certos hábitats (WERNECK et al. 2010; LEITE et al. 2016), demonstrando que o processo em si pode até ter ocorrido, porém em um período muito anterior.

Dados climáticos do Holoceno e do final do Pleistoceno têm sido frequentemente utilizados em paleomodelagens, que geralmente acoplados a dados genéticos, testam cenários de diversificação, estruturação genética, expansões e retrações de distribuição e de tamanho populacional (HUGALL et al. 2002; CARNAVAL \& BATES 2007; CARNAVAL \& MORITZ 2008; CARNAVAL et al. 2009; LAWING \& POLLY 2011; AMARO et al. 2012; INGENLOFF \& PETERSON 2015; SOBRAL-SOUZA et al. 2015). Porém tais análises se restringem a períodos mais recentes pela limitação dos dados ambientais.

Dados climáticos atuais, obtidos pela interpolação de uma ampla rede de estações climáticas (HIJMANS et al. 2005), também têm sido de grande ajuda na avaliação da distribuição dos táxons, em vários casos prevendo sua ocorrência em áreas previamente não amostradas, através de modelagens de nicho potencial (RAXWORTHY et al. 2003), ou estimando sua distribuição potencial (GRAHAM et al. 2004; PHILLIPS \& DUDíK 2008; PEARSON 2010; LI et al. 2014), ou em outros casos na tentativa de se interpretar a ocorrência das espécies em termos de suas relações com o ambiente (DINIZ-FILHO et al. 2005; DINIZ-FILHO et al. 2008; DINIZ et al. 2009; FIELD et al. 2009). Esta abordagem macroecológica envolve achar correlações entre variações em dados biológicos (e.g. riqueza de espécies) e variações no ambiente, geralmente em dados climáticos em escalas espaciais bastante amplas (DINIZ-FILHO et al. 2005; DINIZ-FILHO et al. 2008; DINIZ et al. 2009; FIELD et al. 2009; MELO et al. 2009). Tendo em vista as mudanças climáticas que o mundo está enfrentando nos dias de hoje, avaliar quais são as relações existentes entre a diversidade e as características do ambiente é 
de grande relevância. Para isso uma ampla gama de ferramentas estatísticas tem sido desenvolvidas e utilizadas (RANGEL et al. 2006; RANGEL et al. 2010), assim como protocolos para eliminar possíveis artefatos estatísticos (DINIZ et al. 2003; DINIZ-FILHO et al. 2008).

Áreas como a América do Sul são especialmente promissoras neste aspecto por compreenderem uma ampla sorte de ecossistemas, abrangendo desde desertos secos até florestas chuvosas, de planícies costeiras quentes até topos de montanhas congeladas (GRAHAM 2011). Abrigando algumas áreas com um elevado número de táxons, tais como a Floresta Amazônica, com uma das maiores biodiversidade do mundo (MITTERMEIER et al. 2002; HOORN et al. 2010). Apesar desta ampla gama de ambientes as paisagens da América do Sul podem ser classificadas aproximadamente em três amplos grupos de ecossistemas: as (1) Florestas Úmidas, (2) áreas Abertas/Secas, e (3) a Região Andina (MORRONE 2011).

As áreas de Floresta úmida são em sua maioria dominadas por ambientes florestados, sombreados, com grande precipitação ao longo do ano todo ou com um período sazonal seco pouco expressivo. Geralmente portando grandes árvores e sub-bosque denso, com ampla cobertura de serapilheira, como a Mata Atlântica e Floresta Amazônica, cuja exuberância e riqueza têm por muito tempo atraído a atenção tanto de pesquisadores como de conservacionistas (REDFORD et al. 1990; SÁNCHEZ-AZOFEIFA et al. 2005). Este interesse tem levado a um maior conhecimento de suas riquezas, endemismos, e padrões filogenéticos e filogeográficos (HAFFER 1969; HAFFER 1992; HAFFER 1997; PELLEGRINO et al. 2005; RIBAS et al. 2005; MARTINS 2011; BATALHA et al. 2012).

Por outro lado as áreas Abertas/Secas apresentam uma vegetação composta por árvores de porte relativamente pequeno, muitas vezes sem um dossel, ou mesmo áreas cobertas exclusivamente por gramíneas, ou com apenas algumas pequenas plantas lenhosas. Sendo que seus componentes arbóreos, que não são associados a corpos d'água, perdem sua cobertura foliar durante uma estação seca bastante pronunciada, como no Cerrado, Matas Secas, Caatinga e Chaco. Esse aspecto seco e desprovido de verde tem deixados estes ambientes de lado por muito tempo por pesquisadores e conservacionistas (REDFORD et al. 1990; SÁNCHEZAZOFEIFA et al. 2005). Os primeiros estudos conduzidos em seus limites sugeriam que estes ambientes apresentavam um baixo número de espécies, com baixo nível de endemismos e uma fauna bastante similar homogeneamente distribuída (VANZOLINI 1963,1994). Por outro lado estudos recentes, em escala local e regional tanto no Cerrado como na Caatinga, sugerem que estas ideias iniciais eram resultado apenas de esforço de coleta incipiente, apresentando áreas com riqueza (COLLI et al. 2002; RODRIGUES 2003; NOGUEIRA et al. 2009; GUEDES et al. 
2014a) e endemismo (NOGUEIRA et al. 2011; GUEDES et al. 2014b) relativamente altos, complementados por evidência molecular (WERNECK et al. 2012; RECODER et al. 2014).

Já a região Andina apresenta tanto áreas úmidas quanto áreas muito secas, num extenso mosaico de ambientes, com áreas de florestas montanas (e.g. Yungas ou Matorral), ou áreas campestres (e.g. região da Puna), ou mesmo desertos nas vertentes pacificas da cordilheira (POSADAS \& ORTIZ-JAUREGUIZAR 2011; SCHAEFER 2011), comportando uma biota reconhecidamente rica em espécies e com alto endemismo (MYERS et al. 2000; SCHAEFER 2011).

Organismos ectotermos são especialmente interessantes em análises de fatores ambientais, devido à influência direta de condições climáticas no seu metabolismo e sobrevivência. Desta maneira répteis e anfíbios, que apresentam uma dependência de calor e água, respectivamente (DUELLMAN \& TRUEB 1994; VITT \& CALDWELL 2014; POUGH et al. 2015), se tornam organismos bastante promissores para tais análises. Na América do Sul cerca de 2100 espécies de répteis e 2800 espécies de anfíbios (FROST 2016; UETZ \& HOŠEK 2016) podem ser encontradas ocupando praticamente todos os ambientes, com exceção de áreas permanentemente cobertas por gelo.

Apesar de haver alguns mapas de diversidade, de ocorrência ou áreas de endemismo para alguns grupos de vertebrados (DASILVA \& OREN 1996; SILVA et al. 2004; TERRIBILE et al. 2008; FIELD et al. 2009; MELO et al. 2009; FERRARI et al. 2010; CASAGRANDA \& GROSSO 2013; PYRON \& WIENS 2013; OLIVEIRA et al. 2015; PRADO et al. 2015), uma análise em escala continental de riqueza, endemismo, diversidade beta e similaridade para herpetofauna ainda está faltando. Assim, este estudo tem por objetivo mapear diversos índices associados à distribuição das espécies/linhagens de répteis e anfíbios ocorrentes na América do Sul continental, para avaliar se os diferentes ambientes (e.g. áreas de Floresta, Abertas/secas e a região Andina) apresentam de fato diferenças nestes valores e como essas medidas estão relacionadas a fatores ambientais atuais, como clima, solo e estrutura da vegetação, e suas alterações desde o final do Pleistoceno.

\subsection{MATERIAL E MÉTODOS}

\subsubsection{Definição da área}

A área definida para as análises inclui toda a região continental da América do Sul e as ilhas próximas que estão representadas nas quadrículas que cobrem toda a região continental. As quadrículas apresentam $0.5^{\circ} \times 0.5^{\circ}$ de extensão, ocupando uma área desde $12.5^{\circ} \mathrm{N} \mathrm{e} 34.5^{\circ} \mathrm{W}$ 
até $56.0^{\circ} \mathrm{S}$ e $81.5^{\circ} \mathrm{W}$ (FIGURA 2). Para as comparações entre as áreas, as Eco-regiões (sensu OLSON et al. 2001) foram divididas em três grandes áreas: 1) região Andina, 2) Florestas Úmidas; e 3) áreas Abertas/Secas (FIGURA 2).
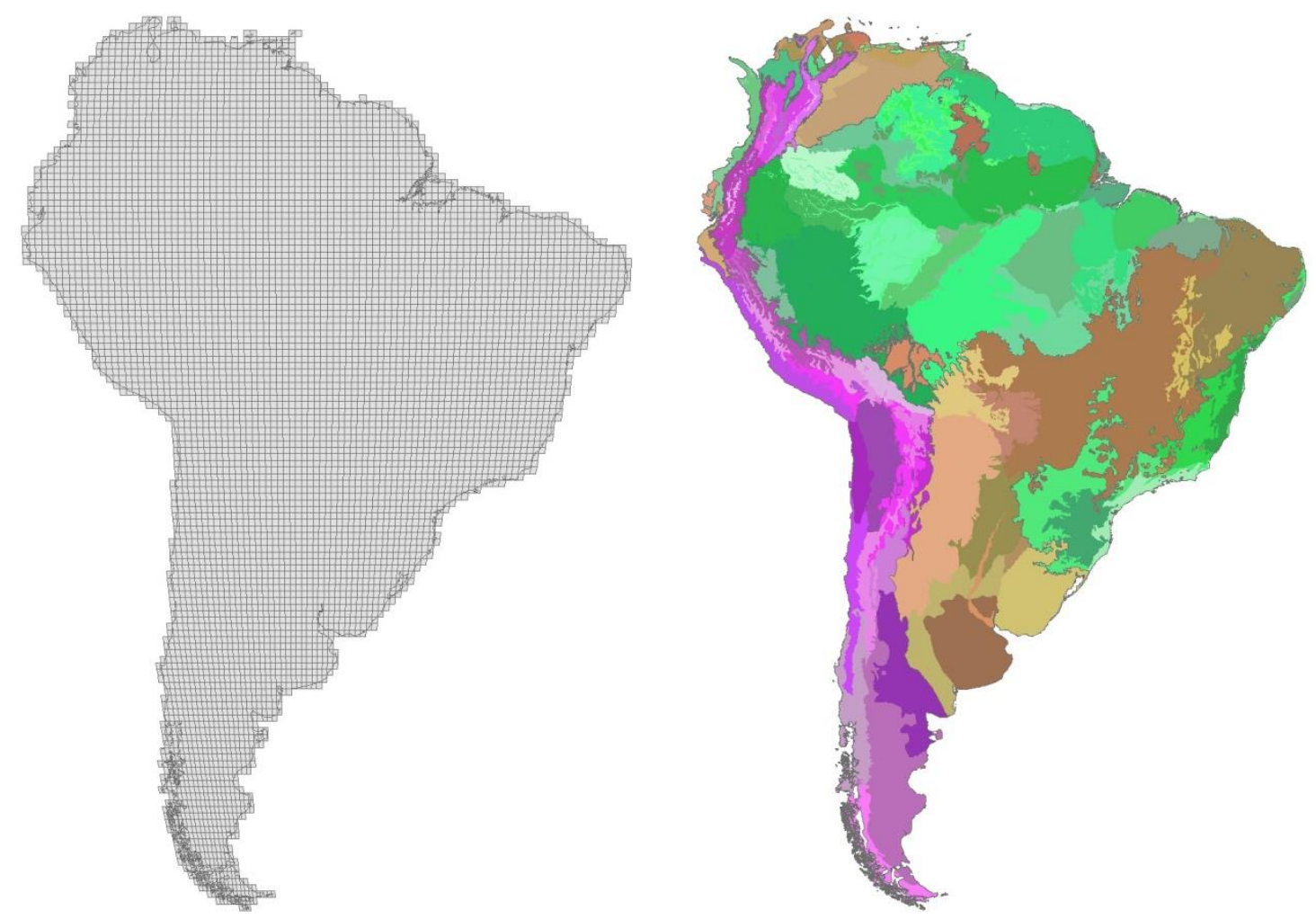

FIGURA 2. Grade de quadrículas cobrindo a América do Sul (esquerda) e Eco-regiões (direita) divididas em três áreas: região Andina (tons de roxo), Florestas (tons de verde) e áreas Abertas (tons de marrom).

\subsubsection{Distribuição dos táxons}

Para se estimar a distribuição dos répteis e anfíbios foram reunidos registros de ocorrência disponíveis em 2166 referências (APÊNDICE 1). Os registros publicados variaram entre material examinado em revisões taxonômicas, listas de espécies e notas de distribuição. No caso de registros em que a informação referente às coordenadas geográficas estava disponível, estas foram usadas. No entanto a maioria continha apenas nomes de localidades, como nomes de cidades (e.g. "São Paulo"), pontos geográficos específicos (e.g. "Alto da Serra de Cubatão"), ou descrições de áreas (e.g. "20 km a leste da junção da rodovia nacional 40 e provincial 22"), e as coordenadas foram então recuperadas através de buscas online (tierra.tutiempo.net, www.google.com) ou estimadas usando programas de sistema de informação geográfica (e.g. ArcGIS v.10.0 e Google Earth v.7.1.8) (ESRI 2011; GOOGLE 2017). Em muitos casos a única informação geográfica disponível eram pontos de ocorrência em mapas, que foram então geo-referenciados usando programas de sistema de informação 
geográfica (e.g. ArcGIS v.10.0 e Google Earth v.7.1.8) (ESRI 2011; GOOGLE 2017), e os registros usados na construção das distribuições.

Um potencial problema em registros de espécies é a incerteza quanto à correta identificação dos exemplares. Assim, os registos publicados foram utilizados em sua maioria sem alteração, pois foram considerados como tendo sido "verificados" pelo menos pelo especialista que o publicou. Porém espécimes disponíveis em coleções herpetológicas, tendo seus registros disponíveis em base de dados eletrônicas, frequentemente não são devidamente avaliados e sua identificação é potencialmente duvidosa. Assim os registros provenientes destas bases de dados foram considerados "não verificados", e não foram utilizados em sua totalidade. Foram considerados como "duvidosos" quando muito distantes dos pontos "verificados", ou fora de seus habitats naturais (e.g. espécies típicas da floresta Amazônica, com registros "não verificados" na região Andina), e assim descartados.

Com base nestes registros de ocorrência foram desenhados polígonos que representam as distribuições de cada espécie, utilizando-se os programas ArcGIS v.10.0 e Google Earth v.7.1.8 (ESRI 2011; GOOGLE 2017), considerando relevo, vegetação, hidrografia e altitude, para se definir as bordas dos polígonos.

Para anfíbios e serpentes inicialmente foram-se utilizados os polígonos disponíveis na base de dados da IUCN (IUCN 2017), mas como a maior parte dos polígonos apresentavam distribuições errôneas e muitas espécies estavam ausentes. Assim todas as espécies disponíveis tiveram suas distribuições checadas e editadas para se encaixarem aos seus pontos conhecidos de distribuição, e as que não estavam disponíveis foram então criadas.

Para espécies conhecidas apenas por um único ponto, o polígono não se estendeu muito além da localidade. Em casos onde não havia nenhuma barreira evidente ou mudança de relevo, altitude e vegetação por muitos quilômetros, as bordas do polígono foram desenhadas baseando-se no conhecimento disponível para espécies e/ou linhagens aparentadas, e/ou com ecologias semelhantes. Quando a localidade se posicionava em uma área relativamente isolada (e.g. ilha, topo de montanha), o polígono seguiu o contorno do relevo, altitude e vegetação similares ao do ponto.

Em muitos casos as espécies eram compostas por subespécies (e.g. subespécies de Uracentron azureum) (AVILA-PIRES 1995) ou linhagens geograficamente distintas (e.g. Phyllopezus pollicaris) (WERNECK et al. 2010), nestes casos as subespécies ou linhagens foram utilizadas como espécies plenas nas análises. Nos casos em que existem evidencias de linhagens distintas, mas cujas extensões geográficas são desconhecidas, as linhagens não foram analisadas separadamente (e.g. Iphisa elegans) (NUNES et al. 2012). 
Considerando uma área contendo um certo número de espécies, onde todas pertencentes a um mesmo gênero, e consequentemente a uma mesma família e ordem, e considerando uma segunda área com o mesmo número de espécies, porém de gêneros, e/ou famílias e/ou ordens diferentes, a diversidade de linhagens seria maior na segunda área. Assim a fim de se levar em consideração essa informação também foram criados polígonos referentes a cada categoria taxonômica (gênero, família, e ordem) que abrange as espécies ocorrentes na América do Sul, e incluídas nas análises.

\subsubsection{Medida de Riqueza, endemismo e diversidade beta/dissimilaridade}

As espécies foram classificadas em categorias ecológicas segundo seu tipo de utilização de habitat (e.g. arborícola, terrestre, aquática e fossorial), baseado nas informações disponíveis sobre cada espécie (APÊNDICE 2). Quando nenhuma informação estava disponível, a categorização foi baseada na informação ecológica para as espécies mais próximas, ou com morfologia similar. Para calcular a riqueza foram somadas as espécies, gêneros, famílias e ordens que intersectam com cada quadrícula, produzindo uma medida de riqueza geral, e separadamente para cada categoria ecológica.

Para calcular o endemismo, inicialmente foi medida a área de cada polígono em $\mathrm{km}^{2}$, em uma projeção sinusoidal. O inverso do tamanho da área do polígono de cada táxon foi considerado como um índice de endemismo individual (SLATYER et al. 2007), e estes foram somados por quadrícula, produzindo um índice de endemismo local. Estes cálculos foram realizados utilizando-se do programa ArcGIS v.10.0 (ESRI 2011).

Para os cálculos de diversidade beta e similaridade, em cada quadrícula foi armazenada a lista dos táxons que ali ocorrem, através da intersecção de cada quadrícula com os polígonos. Para diversidade beta foi utilizado o método de Whitakker (WHITTAKER 1960,1972),

$$
\beta_{w}=(S / \alpha)-1
$$

onde $S$ é o número total de táxons em todas as quadrículas consideradas (no caso as oito quadrículas adjacentes), e $\alpha$ a média do número de espécies na quadrícula considerada. 0 cálculo foi realizado no programa DIVA-GIS v.7.5.0.0 (HIJMANS et al. 2001).

Para o cálculo de dissimilaridade cada quadrícula contendo a lista de espécies cujos polígonos as intersectam, foi utilizada como localidade amostrada, e uma matriz de presença e ausência foi calculada utilizando-se da função as.data.frame como disponível no pacote base, com esta matriz binária foi calculada o índice de dissimilaridade de Jaccard (JACCARD 1902,1912; MAGURRAN 1988), 


$$
d_{J}(A, B)=\frac{a+b-j}{a+b}
$$

onde $j$ é o número de táxons compartilhadas entre ambas as quadrículas, $a$ é o numero de táxons na quadrícula $\mathrm{A}$, e $b$ é o número de táxons na quadrícula $\mathrm{B}$. Para cada par de quadrículas $(A, B)$ a quantidade de espécies compartilhadas é dividida pelo total de espécies existentes nas duas localidades, calculado através da função dist como disponível no pacote proxy (https://CRAN.R-project.org/package=proxy). A partir destes valores foi realizada uma análise de agrupamento baseado na média aritmética (Unweighted Pair Group Method with Arithmetic Mean: UPGMA) (ROHLF 1963; SNEATH \& SOKAL 1973),

$$
d_{(A \cup B), X}=\frac{|A| \cdot d_{A, X}+|B| \cdot d_{B, X}}{|A|+|B|}
$$

onde a cada passo as duas localidades $(A, B)$, ou os dois grupos com a menor dissimilaridade são combinadas em um grupo num nível superior $(A \cup B)$, no passo seguinte a distância entre este grupo e o novo calculado $(X)$, é dada pela média das distancias $d_{A, X}$ e $d_{B, X}$; utilizando-se da função hclust, como disponível no pacote stats. Estas análises de dissimilaridade foram realizadas em linguagem $R$ através do programa RStudio v.1.0.136 (RSTUDIO 2016).

\subsubsection{Avaliações Macroecológicas}

A fim de avaliar a relação das medidas calculadas (riqueza, endemismo e diversidade beta) com as características do ambiente em que ocorrem, foram utilizadas diversas variáveis ambientais. Estas incluíram altitude (ALT) e as 19 variáveis bio-climáticas disponíveis pelo WorldClim (www.worldclim.org) (HIJMANS et al. 2005) (BIO1: Temperatura média anual, BIO2: Amplitude média diária, BIO3: Isotermalidade (BIO2/BIO7) (* 100), BIO4: Sazonalidade na temperatura (desvio padrão*100), BIO5: Máxima temperatura do mês mais quente, BIO6: Máxima temperatura do mês mais frio, BIO7: Amplitude anual na temperatura (BIO5-BIO6), BI08: Temperatura média do trimestre mais úmido, BI09: Temperatura média do trimestre mais seco, BIO10: Temperatura média do trimestre mais quente, BIO11: Temperatura média do trimestre mais frio, BIO12: Precipitação anual, BIO13: Precipitação do mês mais úmido, BI014: Precipitação do mês mais seco, BI015: Sazonalidade na precipitação, BIO16: Precipitação do trimestre mais úmido, BI017: Precipitação do trimestre mais seco, BIO18: Precipitação do trimestre mais quente, BIO19: Precipitação do trimestre mais frio) (HIJMANS et al. 2005).

Como parte das espécies apresentam habitats fossoriais, foram também incluídas três variáveis relacionadas a características do solo a $0 \mathrm{~cm}$ da superfície (SAND: porcentagem de areia, CLAY: porcentagem de cascalho, SILT: porcentagem de silte) (www.soilgrids.org). 
Outra potencial fonte de variação na ocorrência das espécies é a heterogeneidade da estrutura do ambiente (STEIN et al. 2014). Embora existam camadas disponíveis relativas à cobertura vegetal, estas geralmente se baseiam em imagens de satélite tiradas apenas recentemente, o que pode implicar em áreas originalmente cobertas por florestas (com alta complexidade estrutural) sendo retratadas como áreas cobertas por vegetação aberta (com baixa complexidade estrutural). Dessa forma, uma camada foi criada aqui partindo-se das Ecoregiões, como disponibilizadas pelo WWF (wf.panda.org) (OLSON et al. 2001). Com base nos dados disponíveis sobre cada Eco-região, foi estimada a disponibilidade de quatros elementos estruturadores do ambiente: (1) árvores, (2) solo, (3) água, e (4) subsolo. Assim áreas onde arvores estão disponíveis em abundância, como florestas ombrófilas, receberam o valor de 1 para "árvores", enquanto áreas onde árvores são menos comuns, como florestas estacionais, receberam 0.75 , áreas de savanas 0.5 , restingas 0.25 , e áreas campestres 0.0 mesmo principio foi aplicado aos outros elementos, como por exemplo subsolo, onde áreas rochosas recebem 0 , e áreas arenosas recebem 1; ou solo, onde áreas alagadas periodicamente recebem 0.5 ou rochosas 1. Os valores de cada elemento tiveram sua média calculada por Eco-região (FIGURA 3; TABELA 1). A média foi então utilizada como um índice de estrutura ambiental (STR), e incluído como mais uma camada nas análises (FIGURA 4). Todas encaixadas na mesma resolução de $0.5^{\circ} \times 0.5^{\circ}$ graus das quadrículas.

TABELA 1. Eco-regiões, como definidas pela WWF (wf.panda.org), e seus elementos estruturais ambientais avaliados, e seus respectivos valores. Arv: árvores, Ter: terra, Agu: água, Sub: sub-solo e, Med: média dos valores.

\begin{tabular}{lccccc}
\hline Eco-região & Árvores & Solo & Água & Subsolo & Média \\
\hline Alto Paraná Atlantic forests & 1.00 & 1.00 & 0.25 & 1.00 & $\mathbf{0 . 8 1}$ \\
Amazon-Orinoco-Southern Caribbean mangroves & 1.00 & 0.00 & 1.00 & 0.00 & $\mathbf{0 . 5 0}$ \\
Apure-Villavicencio dry forests & 0.75 & 1.00 & 0.00 & 1.00 & $\mathbf{0 . 6 9}$ \\
Araucaria moist forests & 1.00 & 1.00 & 0.25 & 1.00 & $\mathbf{0 . 8 1}$ \\
Araya and Paria xeric scrub & 0.00 & 1.00 & 0.00 & 0.50 & $\mathbf{0 . 3 8}$ \\
Atacama desert & 0.00 & 1.00 & 0.00 & 0.50 & $\mathbf{0 . 3 8}$ \\
Atlantic Coast restingas & 0.25 & 1.00 & 0.00 & 1.00 & $\mathbf{0 . 5 6}$ \\
Atlantic dry forests & 0.75 & 1.00 & 0.00 & 1.00 & $\mathbf{0 . 6 9}$ \\
Bahia coastal forests & 1.00 & 1.00 & 0.50 & 1.00 & $\mathbf{0 . 8 8}$ \\
Bahia interior forests & 1.00 & 1.00 & 0.25 & 1.00 & $\mathbf{0 . 8 1}$ \\
Beni savanna & 0.50 & 1.00 & 0.00 & 1.00 & $\mathbf{0 . 6 3}$ \\
Bolivian montane dry forests & 0.75 & 1.00 & 0.00 & 1.00 & $\mathbf{0 . 6 9}$ \\
Bolivian Yungas & 0.75 & 1.00 & 0.25 & 1.00 & $\mathbf{0 . 7 5}$ \\
Caatinga & 0.50 & 1.00 & 0.00 & 1.00 & $\mathbf{0 . 6 3}$ \\
Caatinga Enclaves moist forests & 1.00 & 1.00 & 0.25 & 1.00 & $\mathbf{0 . 8 1}$ \\
Campos Rupestres montane savanna & 0.00 & 1.00 & 0.00 & 0.50 & $\mathbf{0 . 3 8}$ \\
Caqueta moist forests & 1.00 & 1.00 & 1.00 & 1.00 & $\mathbf{1 . 0 0}$ \\
Caribbean shrublands & 0.00 & 1.00 & 0.00 & 0.50 & $\mathbf{0 . 3 8}$ \\
\hline
\end{tabular}




\begin{tabular}{|c|c|c|c|c|c|}
\hline Eco-região & Árvores & Solo & Água & Subsolo & Média \\
\hline Catatumbo moist forests & 1.00 & 1.00 & 0.50 & 1.00 & 0.88 \\
\hline Cauca Valley dry forests & 0.75 & 1.00 & 0.00 & 1.00 & 0.69 \\
\hline Cauca Valley montane forests & 0.75 & 1.00 & 0.00 & 1.00 & 0.69 \\
\hline Central American dry forests & 0.75 & 1.00 & 0.00 & 1.00 & 0.69 \\
\hline Central Andean dry puna & 0.00 & 1.00 & 0.00 & 0.50 & 0.38 \\
\hline Central Andean puna & 0.00 & 1.00 & 0.00 & 0.50 & 0.38 \\
\hline Central Andean wet puna & 0.00 & 1.00 & 0.00 & 0.50 & 0.38 \\
\hline Cerrado & 0.50 & 1.00 & 0.00 & 1.00 & 0.63 \\
\hline Chilean matorral & 0.25 & 1.00 & 0.00 & 1.00 & 0.56 \\
\hline Chiquitano dry forests & 0.75 & 1.00 & 0.00 & 1.00 & 0.69 \\
\hline Chocó-DariÚn moist forests & 1.00 & 1.00 & 0.75 & 1.00 & 0.94 \\
\hline Cordillera Central páramo & 0.00 & 1.00 & 0.00 & 0.25 & 0.31 \\
\hline Cordillera de Merida páramo & 0.00 & 1.00 & 0.00 & 0.25 & 0.31 \\
\hline Cordillera La Costa montane forests & 0.75 & 1.00 & 0.25 & 1.00 & 0.75 \\
\hline Cordillera Oriental montane forests & 0.75 & 1.00 & 0.25 & 1.00 & 0.75 \\
\hline Dry Chaco & 0.50 & 1.00 & 0.00 & 1.00 & 0.63 \\
\hline Eastern Cordillera real montane forests & 0.75 & 1.00 & 0.25 & 1.00 & 0.75 \\
\hline Eastern Panamanian montane forests & 0.75 & 1.00 & 0.25 & 1.00 & 0.75 \\
\hline Ecuadorian dry forests & 0.75 & 1.00 & 0.00 & 1.00 & 0.69 \\
\hline Espinal & 0.25 & 1.00 & 0.00 & 1.00 & 0.56 \\
\hline Guajira-Barranquilla xeric scrub & 0.00 & 1.00 & 0.00 & 0.50 & 0.38 \\
\hline Guayaquil flooded grasslands & 0.50 & 1.00 & 1.00 & 0.50 & 0.75 \\
\hline Guianan freshwater swamp forests & 1.00 & 0.50 & 1.00 & 0.50 & 0.75 \\
\hline Guianan Highlands moist forests & 1.00 & 1.00 & 0.75 & 1.00 & 0.94 \\
\hline Guianan moist forests & 1.00 & 1.00 & 1.00 & 1.00 & 1.00 \\
\hline Guianan piedmont and lowland moist forests & 1.00 & 1.00 & 1.00 & 1.00 & 1.00 \\
\hline Guianan savanna & 0.50 & 1.00 & 0.00 & 1.00 & 0.63 \\
\hline Gurupa varzeá & 1.00 & 1.00 & 1.00 & 1.00 & 1.00 \\
\hline High Monte & 0.00 & 1.00 & 0.00 & 0.50 & 0.38 \\
\hline Humid Chaco & 0.50 & 1.00 & 0.25 & 1.00 & 0.69 \\
\hline Humid Pampas & 0.00 & 1.00 & 0.25 & 1.00 & 0.56 \\
\hline Iquitos varzeá & 1.00 & 1.00 & 1.00 & 1.00 & 1.00 \\
\hline Japurá-Solimoes-Negro moist forests & 1.00 & 1.00 & 1.00 & 1.00 & 1.00 \\
\hline Juruá-Purus moist forests & 1.00 & 1.00 & 1.00 & 1.00 & 1.00 \\
\hline La Costa xeric shrublands & 0.00 & 1.00 & 0.00 & 0.50 & 0.38 \\
\hline Lake & 0.00 & 0.00 & 1.00 & 0.00 & 0.25 \\
\hline Lara-Falcón dry forests & 0.75 & 1.00 & 0.00 & 1.00 & 0.69 \\
\hline Lesser Antillean dry forests & 0.75 & 1.00 & 0.00 & 1.00 & 0.69 \\
\hline Llanos & 0.50 & 1.00 & 0.25 & 1.00 & 0.69 \\
\hline Low Monte & 0.00 & 1.00 & 0.00 & 0.50 & 0.38 \\
\hline Madeira-Tapajós moist forests & 1.00 & 1.00 & 1.00 & 1.00 & 1.00 \\
\hline Magdalena-Urabá moist forests & 1.00 & 1.00 & 0.75 & 1.00 & 0.94 \\
\hline Magdalena Valley dry forests & 0.75 & 1.00 & 0.00 & 1.00 & 0.69 \\
\hline Magdalena Valley montane forests & 0.75 & 1.00 & 0.25 & 1.00 & 0.75 \\
\hline Magellanic subpolar forests & 0.25 & 1.00 & 0.25 & 0.50 & 0.50 \\
\hline Malpelo Island xeric scrub & 0.00 & 1.00 & 0.00 & 0.50 & 0.38 \\
\hline Maracaibo dry forests & 0.75 & 1.00 & 0.00 & 1.00 & 0.69 \\
\hline Marajó varzeá & 1.00 & 1.00 & 1.00 & 1.00 & 1.00 \\
\hline
\end{tabular}




\begin{tabular}{|c|c|c|c|c|c|}
\hline Eco-região & Árvores & Solo & Água & Subsolo & Média \\
\hline Maranhòo Babapu forests & 1.00 & 1.00 & 0.75 & 1.00 & 0.94 \\
\hline 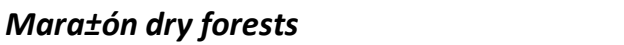 & 0.75 & 1.00 & 0.00 & 1.00 & 0.69 \\
\hline Mato Grosso seasonal forests & 0.75 & 1.00 & 0.20 & 1.00 & 0.74 \\
\hline Mesoamerican Gulf-Caribbean mangroves & 1.00 & 0.00 & 1.00 & 0.00 & 0.50 \\
\hline Monte Alegre varzeá & 1.00 & 1.00 & 1.00 & 1.00 & 1.00 \\
\hline Napo moist forests & 1.00 & 1.00 & 1.00 & 1.00 & 1.00 \\
\hline Negro-Branco moist forests & 1.00 & 1.00 & 1.00 & 1.00 & 1.00 \\
\hline Northeastern Brazil restingas & 0.25 & 1.00 & 0.00 & 1.00 & 0.56 \\
\hline Northern Andean páramo & 0.00 & 1.00 & 0.00 & 0.50 & 0.38 \\
\hline Northwestern Andean montane forests & 0.75 & 1.00 & 0.25 & 1.00 & 0.75 \\
\hline Orinoco Delta swamp forests & 0.75 & 0.75 & 0.50 & 0.50 & 0.63 \\
\hline Orinoco wetlands & 0.25 & 0.50 & 0.50 & 0.25 & 0.38 \\
\hline Pantanal & 0.50 & 0.50 & 1.00 & 0.50 & 0.63 \\
\hline Pantepui & 0.25 & 1.00 & 0.25 & 0.50 & 0.50 \\
\hline Paráguana xeric scrub & 0.00 & 1.00 & 0.00 & 0.50 & 0.38 \\
\hline Paraná flooded savanna & 0.50 & 0.50 & 0.50 & 0.25 & 0.44 \\
\hline Patagonian steppe & 0.00 & 1.00 & 0.00 & 0.50 & 0.38 \\
\hline PatÝa Valley dry forests & 0.75 & 1.00 & 0.00 & 1.00 & 0.69 \\
\hline Pernambuco coastal forests & 1.00 & 1.00 & 0.75 & 1.00 & 0.94 \\
\hline Pernambuco interior forests & 1.00 & 1.00 & 0.25 & 1.00 & 0.81 \\
\hline Peruvian Yungas & 0.75 & 1.00 & 0.50 & 1.00 & 0.81 \\
\hline Purus-Madeira moist forests & 1.00 & 1.00 & 1.00 & 1.00 & 1.00 \\
\hline Purus varzeá & 1.00 & 1.00 & 1.00 & 1.00 & 1.00 \\
\hline Rio Negro campinarana & 0.25 & 1.00 & 0.50 & 1.00 & 0.69 \\
\hline Rock and Ice & 0.00 & 1.00 & 0.00 & 0.00 & 0.25 \\
\hline Santa Marta montane forests & 0.75 & 1.00 & 0.25 & 1.00 & 0.75 \\
\hline Santa Marta páramo & 0.00 & 1.00 & 0.00 & 0.25 & 0.31 \\
\hline Sechura desert & 0.00 & 1.00 & 0.00 & 0.50 & 0.38 \\
\hline Serra do Mar coastal forests & 1.00 & 1.00 & 0.75 & 1.00 & 0.94 \\
\hline Sin·Valley dry forests & 0.75 & 1.00 & 0.00 & 1.00 & 0.69 \\
\hline Solim§es-Japurá moist forests & 1.00 & 1.00 & 1.00 & 1.00 & 1.00 \\
\hline South American Pacific mangroves & 1.00 & 0.00 & 1.00 & 0.00 & 0.50 \\
\hline Southern Andean steppe & 0.00 & 1.00 & 0.00 & 0.50 & 0.38 \\
\hline Southern Andean Yungas & 0.75 & 1.00 & 0.25 & 1.00 & 0.75 \\
\hline Southern Atlantic mangroves & 1.00 & 0.00 & 1.00 & 0.00 & 0.50 \\
\hline Southern Cone Mesopotamian savanna & 0.50 & 1.00 & 0.00 & 1.00 & 0.63 \\
\hline Southwest Amazon moist forests & 1.00 & 1.00 & 1.00 & 1.00 & 1.00 \\
\hline Tapajós-Xingu moist forests & 1.00 & 1.00 & 1.00 & 1.00 & 1.00 \\
\hline Tocantins/Pindare moist forests & 1.00 & 1.00 & 1.00 & 1.00 & 1.00 \\
\hline Trinidad and Tobago moist forests & 1.00 & 1.00 & 0.75 & 1.00 & 0.94 \\
\hline Tumbes-Piura dry forests & 0.75 & 1.00 & 0.00 & 1.00 & 0.69 \\
\hline Uatuma-Trombetas moist forests & 1.00 & 1.00 & 1.00 & 1.00 & 1.00 \\
\hline Ucayali moist forests & 1.00 & 1.00 & 1.00 & 1.00 & 1.00 \\
\hline Uruguayan savanna & 0.00 & 1.00 & 0.00 & 1.00 & 0.50 \\
\hline Valdivian temperate forests & 0.75 & 1.00 & 0.00 & 1.00 & 0.69 \\
\hline Venezuelan Andes montane forests & 0.75 & 1.00 & 0.00 & 1.00 & 0.69 \\
\hline Western Ecuador moist forests & 1.00 & 1.00 & 0.75 & 1.00 & 0.94 \\
\hline Xingu-Tocantins-Aráguaia moist forests & 1.00 & 1.00 & 1.00 & 1.00 & 1.00 \\
\hline
\end{tabular}




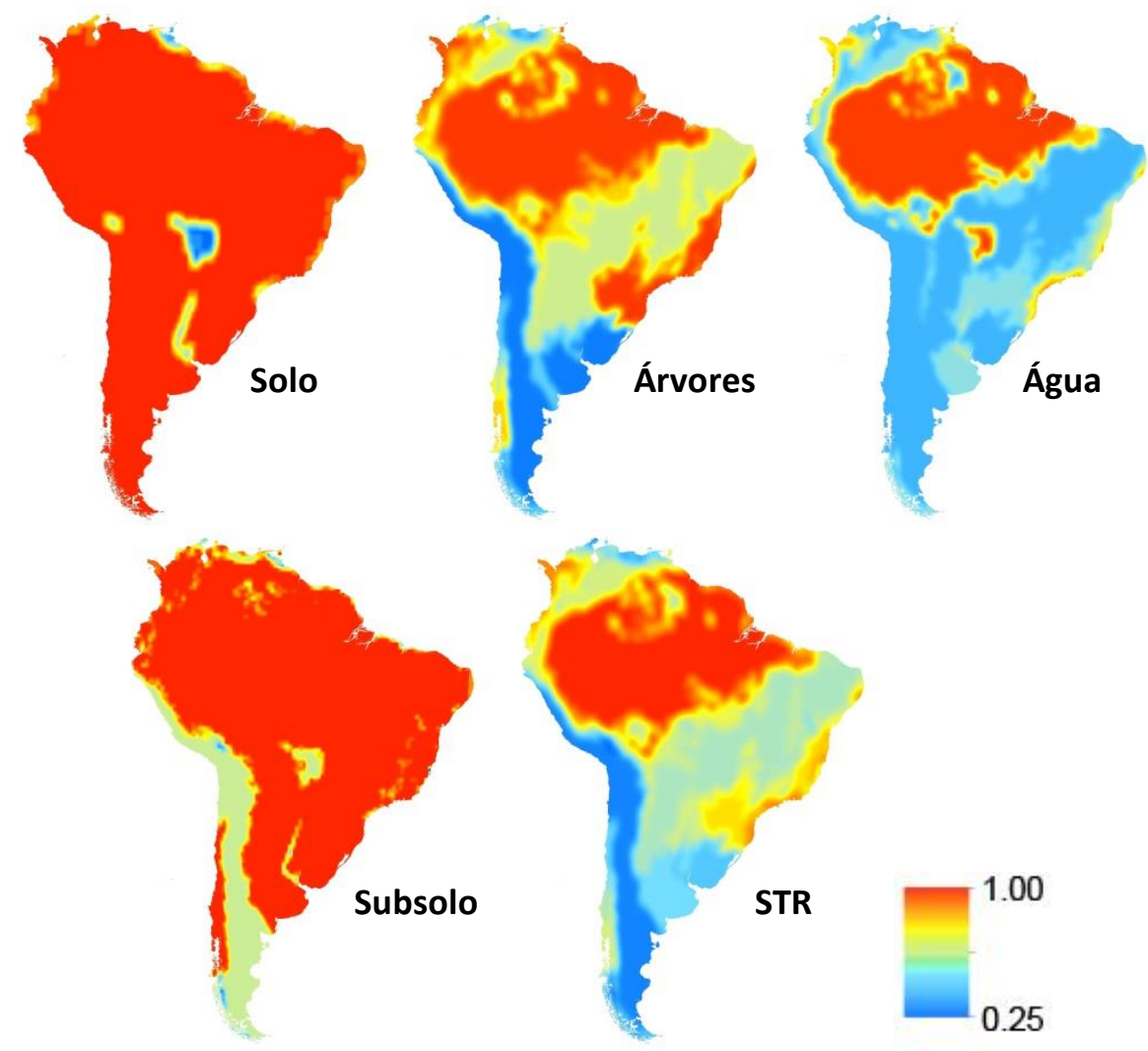

FIGURA 3. Variáveis de heterogeneidade estrutural do ambiente representando proporção disponível de solo, árvores, água, subsolo e a combinação de todas (STR)

Para se avaliar a relação entre as variáveis calculadas (riqueza, endemismo e diversidade beta) e as variáveis ambientais ( $\mathrm{BIO1}, \mathrm{BIO} 2, \mathrm{BIO}, \mathrm{BIO} 4, \mathrm{BIO}$, $\mathrm{BIO}, \mathrm{BIO}$, $\mathrm{BIO}$, $\mathrm{BIO}, \mathrm{BIO} 10$, BIO11, BIO12, BIO13, BIO14, BIO15, BIO16, BIO17, BIO18, BIO19, SAND, CLAY, SILT, STR) foi inicialmente calculada uma regressão múltipla linear incluindo a variável calculada (como variável resposta), e todas as ambientais (como explanatórias) para se remover as variáveis que apresentam o fator de inflação de variância (Variance Inflation Factor: VIF) mais alto, evitando-se assim problemas de multicolinearidade (BADGLEY \& FOX 2000). O VIF é uma função da correlação parcial, assim quando o VIF é alto para uma variável, isso significa que esta é altamente correlacionada com uma ou mais variáveis (MONTGOMERY et al. 2012). Porém se decidir o quão alto um valor de VIF é para indicar alta correlação ainda é discutível, e nenhuma regra clara existe. Trabalhos utilizando valores de VIF para evitar problemas de multicolinearidade variam desde VIF maior que 2 a maior que 20 (BOWERMAN \& O'CONNELL 2000; OLIVEIRA-FILHO \& FONTES 2000; KAPS \& LAMBERSON 2004; O'BRIEN 2007; CVETKOVIC et al. 2009; MELO et al. 2009; ZUUR et al. 2010; SANTOS et al. 2012; VASCONCELOS et al. 2014; BREGOVIĆ \& ZAGMAJSTER 2016; GONZÁLEZ-MAYA et al. 2016), sendo 3 ou 10 os valores mais comumente utilizados. Aqui se optou por uma abordagem mais restritiva, utilizando-se um valor de corte de três. Foi realizado um procedimento iterativo 
onde todas as variáveis foram incluídas, e a com maior VIF foi removida, e a análise repetida, e a próxima variável a apresentar o VIF mais alto também removida, e o procedimento repetido até todas a variáveis apresentaram VIF menor que 3 (BOOTH et al. 1994; BADGLEY \& FOX 2000; MELO et al. 2009). Estas análises foram realizadas no programa SAM v.4.0 (RANGEL et al. 2010).

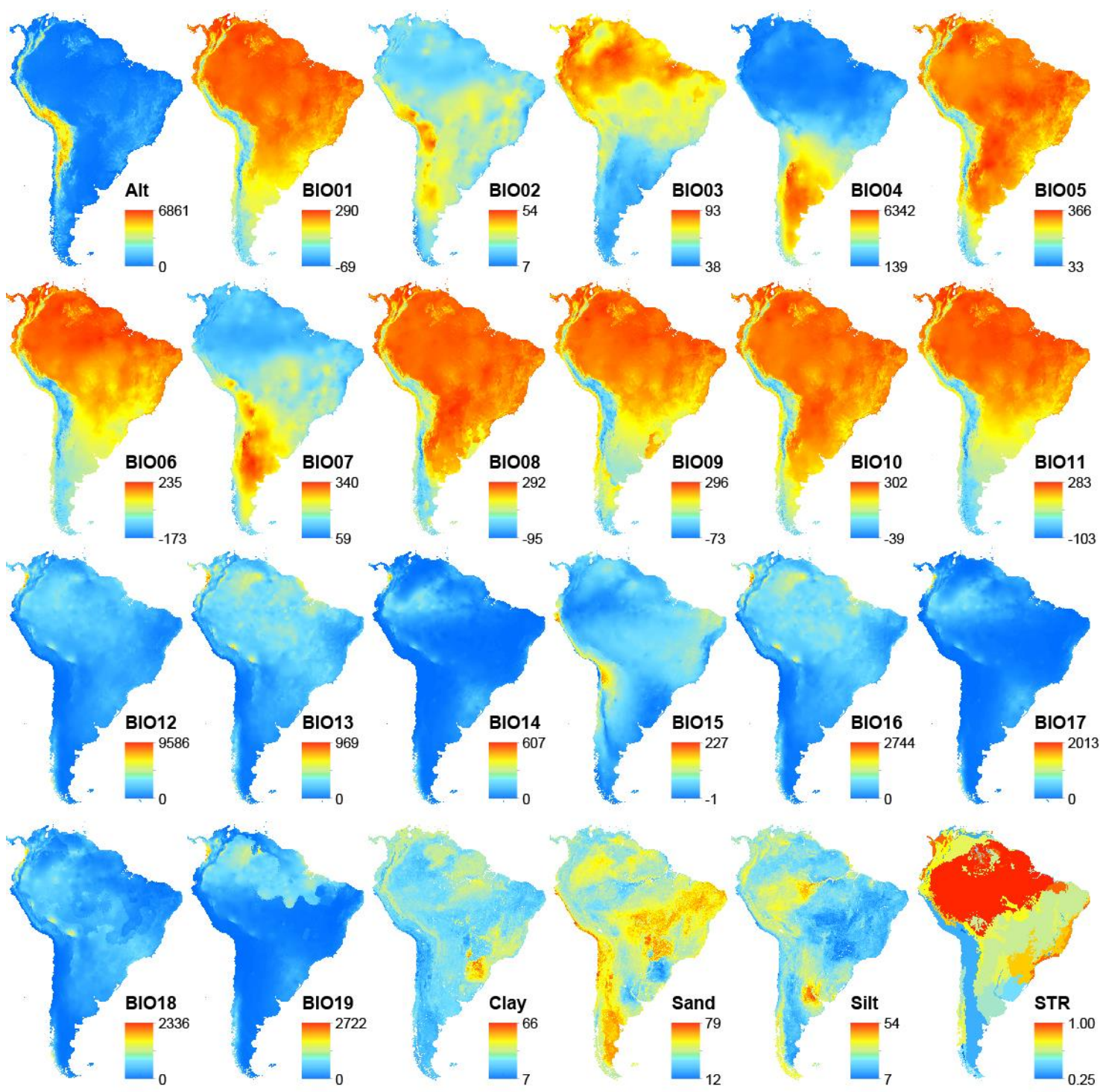

FIGURA 4. Variáveis ambientais utilizadas na modelagem de riqueza. Alt = Atitude; $\mathrm{BIO}=$ Temperatura média anual; $\mathrm{BIO} 2$ = Amplitude térmica média diária; $\mathrm{BIO}=$ Isotermalidade; $\mathrm{BIO} 4=$ Sazonalidade térmica; $\mathrm{BIO5}=$ Temperatura máxima do mês mais quente; $\mathrm{BIO6}=$ Temperatura máxima do mês mais frio; $\mathrm{BIO7} \mathrm{=} \mathrm{Amplitude} \mathrm{térmica} \mathrm{anual;} \mathrm{BIO}=$ = Temperatura média do trimestre mais úmido; $\mathrm{BIO9} \mathrm{=}$ Temperatura média do trimestre mais seco; $\mathrm{BIO} 10$ = Temperatura média do trimestre mais quente; $\mathrm{BIO} 11$ = Temperatura média do trimestre mais frio; $\mathrm{BIO} 12$ = Precipitação anual; $\mathrm{BIO} 13$ = Precipitação do mês mais úmido; $\mathrm{BIO} 14$ = Precipitação do mês mais seco; $\mathrm{BIO} 15$ = Sazonalidade na precipitação; $\mathrm{BIO} 16=$ Precipitação do trimestre mais úmido; $\mathrm{BIO} 17=$ = Precipitação do trimestre mais seco; $\mathrm{BIO} 18==$ Precipitação do trimestre mais quente; BIO19 = Precipitação do trimestre mais frio; Clay = porcentagem de cascalho; Sand = Porcentagem de areia; Silt = Porcentagem de silte; STR = estrutura do ambiente. 
Dados espaciais em geral apresentam uma grande auto-correlação de valores (e.g. áreas mais próximas tendem a apresentar valores mais parecidos, e áreas mais distantes tendem a apresentar valores mais distintos). Diversas sbondagem podem ser utilizadas parta se acessar a auto-correlação espacial das variáveis, sendo e indicie I de Moran (MORAN 1950), o mais comum, definido por

$$
I=\frac{n}{S_{0}} \frac{\sum_{i=1}^{n} \sum_{j=1}^{n} w_{i j} z_{i} z_{j}}{\sum_{i=1}^{n} z_{i}^{2}}
$$

onde $z_{i}$ é o desvio entre o valo de uma localidade $i$ e a média $\left(x_{i}-\bar{X}\right), w_{i, j}$ é o matriz de pesos espaciais entre $i$ e $j, n$ é 'numero total de localidades, e $S_{0}$ é o agregado das matrizes espaciais $\left(S_{0}=\sum_{i=1}^{n} \sum_{j=1}^{n} w_{i j}\right)$. Os valores resultantes variam entre -1 e 1 , com valores mais próximos de -1 indicando auto-correlação negativa, e valores próximos de 1 auto-correlação positiva, e próximos de 0 indicam valores aleatórios (ISHIZAWA \& STEVENS 2007; TU \& XIA 2008).

Apesar de ser uma característica intrínseca aos dados, isso pode afetar o resultado de análises estatísticas (DINIZ et al. 2003; DINIZ et al. 2009; HAWKINS 2012). Assim para se realizar a escolha da melhor combinação de variáveis que explica a variável medida (e.g. escolha do modelo adequado mínimo) é necessário minimizar o efeito da auto-correlação espacial das variáveis. Este procedimento pode ser feito seguindo-se o protocolo proposto por DINIZ-FILHO et al. (2008), onde mais uma variável é incluída para se remover o efeito da autocorrelação. Esta variável é definida pelo termo auto-regressivo $\rho \mathbf{W}_{\gamma}$ onde $\mathbf{W}$ é a matriz de conectividade, $\gamma$ é a variável medida (e.g. riqueza, endemismo ou diversidade beta), $\rho$ é o coeficiente auto-regressivo. A matriz de conectividade foi calculada pelo critério de Gabriel, onde para cada par de pontos $(A$ e $B)$ um círculo é traçado de raio $A B$, se o circulo não inclui nenhum outro ponto em seu interior a conexão $A B$ é feita, caso contrário não (FORTIN \& DALE 2005), e assim todas as quadrículas são de alguma forma conectadas às outras.

Na seleção de modelos então foram incluídas todas as variáveis explanatórias com VIF menor que 3, como variáveis "flutuantes" e mais o resultado do modelo auto-regressivo como variável "fixa" (e.g. presente em todos os modelos). A escolha do melhor modelo foi realizada através do critério de informação de Akaike corrigido (AICc) (HURVICH \& TSAI 1989; BURNHAM \& ANDERSON 2002)

$$
\mathrm{AICc}=\mathrm{AIC}+\frac{2 k(k+1)}{n-k-1}
$$

onde $n$ representa o tamanho da amostra, $k$ o número de parâmetros, e AIC a medida do critério de informação de Akaike (AKAIKE 1974), definido como

$$
\mathrm{AIC}=n \log \left(\frac{\sum \hat{\epsilon}_{i}^{2}}{n}\right)+2 k
$$


onde $n$ representa o número de observações, $\hat{\epsilon}$ é resíduo estimado de um modelo em particular, e $k$ o número de parâmetros (AKAIKE 1974; BURNHAM \& ANDERSON 2002). Com o valor de AIC para cada modelo $i$ foi calculado o $\Delta_{i}$, o qual é a diferença entre $\mathrm{AIC}_{i}$ e o AIC mais baixo calculado, com valores de $\triangle \mathrm{AIC}$ menores que 2 indicando modelos tão adequados quando o que apresenta o mínimo AIC (BURNHAM \& ANDERSON 2002; DINIZ-FILHO et al 2008). Embora este valor seja arbitrário, o $\Delta_{i}$ pode ser usado para calcular o peso de Akaike para cada modelo $\left(w_{i}\right)$, que indica a probabilidade do modelo ser mesmo o melhor modelo explanatório, definido como

$$
w_{i}=\frac{\exp \left(-1 / 2 \Delta_{i}\right)}{\sum_{i}\left[\exp \left(-1 / 2 \Delta_{i}\right)\right]}
$$

onde $\exp \left(-1 / 2 \Delta_{i}\right)$ aproxima a verossimilhança do modelo. $O$ cálculo das regressões iniciais, o cálculo do modelo auto-regressivo e a seleção de modelos foram realizadas no programa SAM V.4.0 (RANGEL et al. 2010).

\subsubsection{Avaliação Paleoclimática}

Para avaliar variações na paisagem Sul Americana ao longo do tempo foram calculados modelos de distribuição potencial dos biomas da América do Sul para o tempo presente, e projetados para o Holoceno médio (cerca 6 mil anos atrás), Último Máximo Glacial (cerca de 22 mil anos atrás), e último interglacial (cerca 120 mil anos atrás). Esta análise baseou-se em camadas paleo-climáticas disponíveis no WorldClim (www.worldclim.org) (HIJMANS et al. 2005; OTTO-BLIESNER et al. 2006), com as mesmas 19 variáveis bio-climáticas definidas acima (BIO01-19). Dez mil pontos aleatórios foram distribuídos por toda a superfície da América do Sul (FIGURA 5), classificados de acordo com sua sobreposição aos biomas Sul Americanos. Neste caso foi utilizado uma modificação do esquema de Biomas/Eco-regiões disponíveis pelo WWF (wf.panda.org). Os biomas, como apresentados pelo WWF, incluem áreas bastante distintas e distantes (e.g. Floresta Amazônica e Floresta Atlântica incluídos em um mesmo bioma), para que cada bioma possa ter seu envelope climático acessado o mais acuradamente pela modelagem. Assim foi escolhida outra configuração de biomas, baseada na original da WWF, mas que representasse melhor a distinção entre as áreas, resultando em: Amazônia, Caatinga, Cerrado, Chaco, Chocó, Desertos costeiros, Espinal, Florestas temperadas, Llanos e Lavrado, Manguezal, Mata Atlântica, Mata Seca, Matorral, Monte, Pampas, Patagônia, Puna, Savanas Alagadas e Yungas (FIGURA 5).

Com os pontos provenientes de cada bioma, cada um foi modelado para o tempo presente e para as três datas do passado ( 6 mil, 22 mil e 120 mil anos atras), através do algoritmo de máxima entropia, pelo programa MaxEnt v. 3.3.3k (PHILLIPS \& DUDík 2008). 
Foram separados $25 \%$ dos pontos para teste, e calculadas 15 réplicas para cada modelo. Foi definindo um limiar de corte mínimo de $10 \%$ dos pontos, e elevado o número máximo de iterações para 5000. Para a criação do modelo final foi calculada a média entre as réplicas cortadas. A qualidade dos modelos foi avaliada pela curva da Característica de Operação do Receptor (Receiver Operating Characteristic: curva ROC) e o cálculo da área sob a curva (Area Under the Curve: $\mathrm{AUC}$ ), onde quanto maior o valor de $\mathrm{AUC}$, mais distante o modelo previsto está de uma previsão aleatória (DELONG et al. 1988; PHILLIPS et al. 2006).

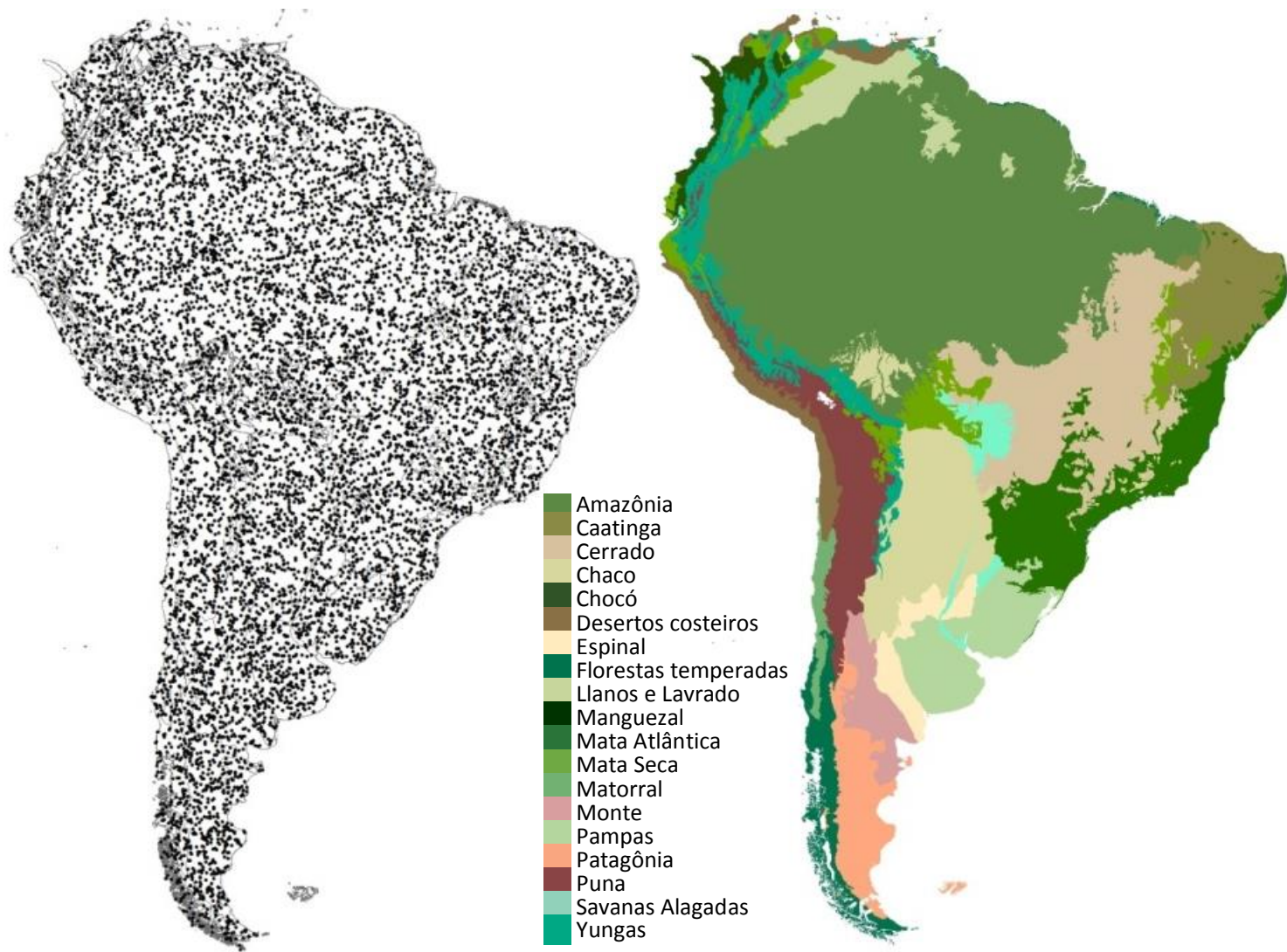

FIGURA 5. Dez mil pontos aleatórios distribuídos pela América do Sul (esquerda) e utilizados na modelagem dos biomas como definidos aqui (direita).

\subsection{RESULTADOS}

\subsubsection{Riqueza}

\subsubsection{Répteis}

Os polígonos referentes a um total de 2139 espécies, 232 gêneros, 36 famílias, e três ordens (APÊNDICE 3) produziram uma riqueza taxonômica $\left(S_{\text {polR }}\right)$ local média de 149 (variando entre 0 e 308) (FIGURA 6). A riqueza média das áreas Abertas foi de 157 (44-281; 1508 táxons no total), das Florestas 238 (85-308; 1634 táxons no total), e da região Andina 53 (0-271; 1535 táxons no total). 

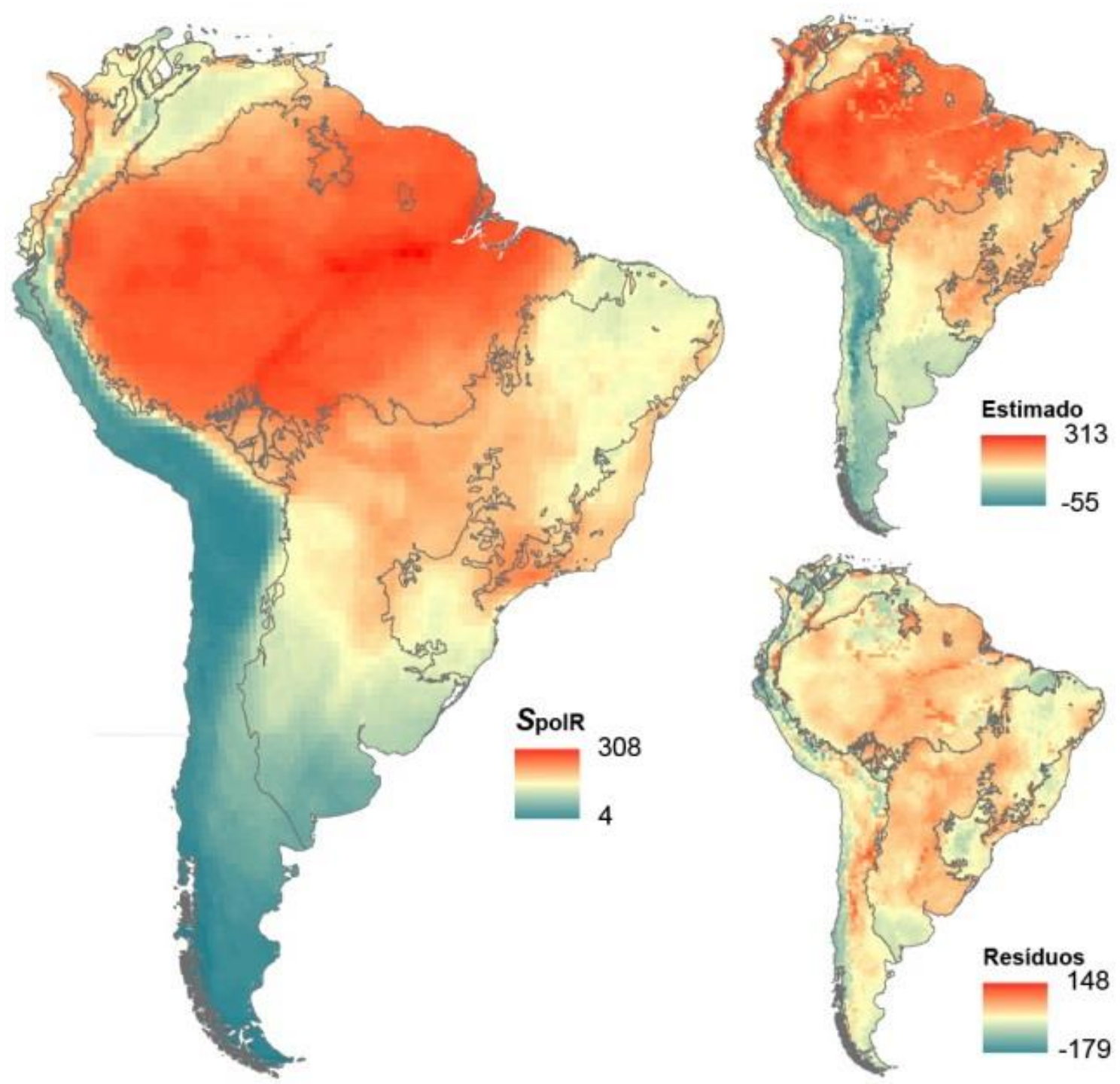

FIGURA 6. Riqueza taxonômica de répteis calculada pela sobreposição dos polígonos $\left(S_{\text {polk }}\right)$ de espécies, gêneros, famílias e ordens, valores estimados na análise de regressão da $S_{\text {polr }}$ e seus resíduos.

A riqueza local média de espécies terrestres foi de 65 (0-142; 1719 espécies no total); a média das áreas Abertas foi de 68 (15-124; 972 espécies no total), das Florestas 103 (32-142; 1053 espécies no total), e da região Andina 24 (0-120; 1109 espécies no total) (FIGURA 7). A riqueza local média de espécies arborícolas foi de 21 (0-66; 428 espécies no total); a média das áreas Abertas foi de 15 (0-52; 283 espécies no total), das Florestas 42 (2-61; 338 espécies no total), e da região Andina 7 (0-66; 276 espécies no total) (FIGURA 7). A riqueza local média de espécies aquáticas foi de 11 (0-38; 128 espécies no total); a média das áreas Abertas foi de 9 (0-31; 100 espécies no total), das Florestas 24 (3-38; 123 espécies no total), e da região andina 1 (0-24; 64 espécies no total) (FIGURA 7). A riqueza local média de espécies fossoriais foi de 10 (2-26; 400 espécies no total); a média das áreas Abertas foi de 13 (2-26; 265 espécies no total), das Florestas 14 (2-24; 272 espécies no total), e da região Andina 3 (0-19; 166 espécies no total) (FIGURA 7). 
As regressões das variáveis ambientais pelas riquezas (FIGURA 8) resultaram em 10 variáveis explanatórias (ALT, BIO02, BIO03, BIO15, BIO18, BIO19, CLAY, SAND, SILT, STR) com VIF < 3 (FIGURA 9-10), e as regressões explicaram desde 0.564 a 0.837 da variação observada nas riquezas $\left(n=6147 ; S_{\text {polR }}: r^{2}=0.819 ; S_{\text {polR ter }}: r^{2}=0.771 ; S_{\text {polR arb }}: r^{2}=0.837 ; S_{\text {polR aqu }}: r^{2}=0.742 ; S_{\text {polR }}\right.$ fos: $\mathrm{r}^{2}=0.564$ ) (TABELA 2).
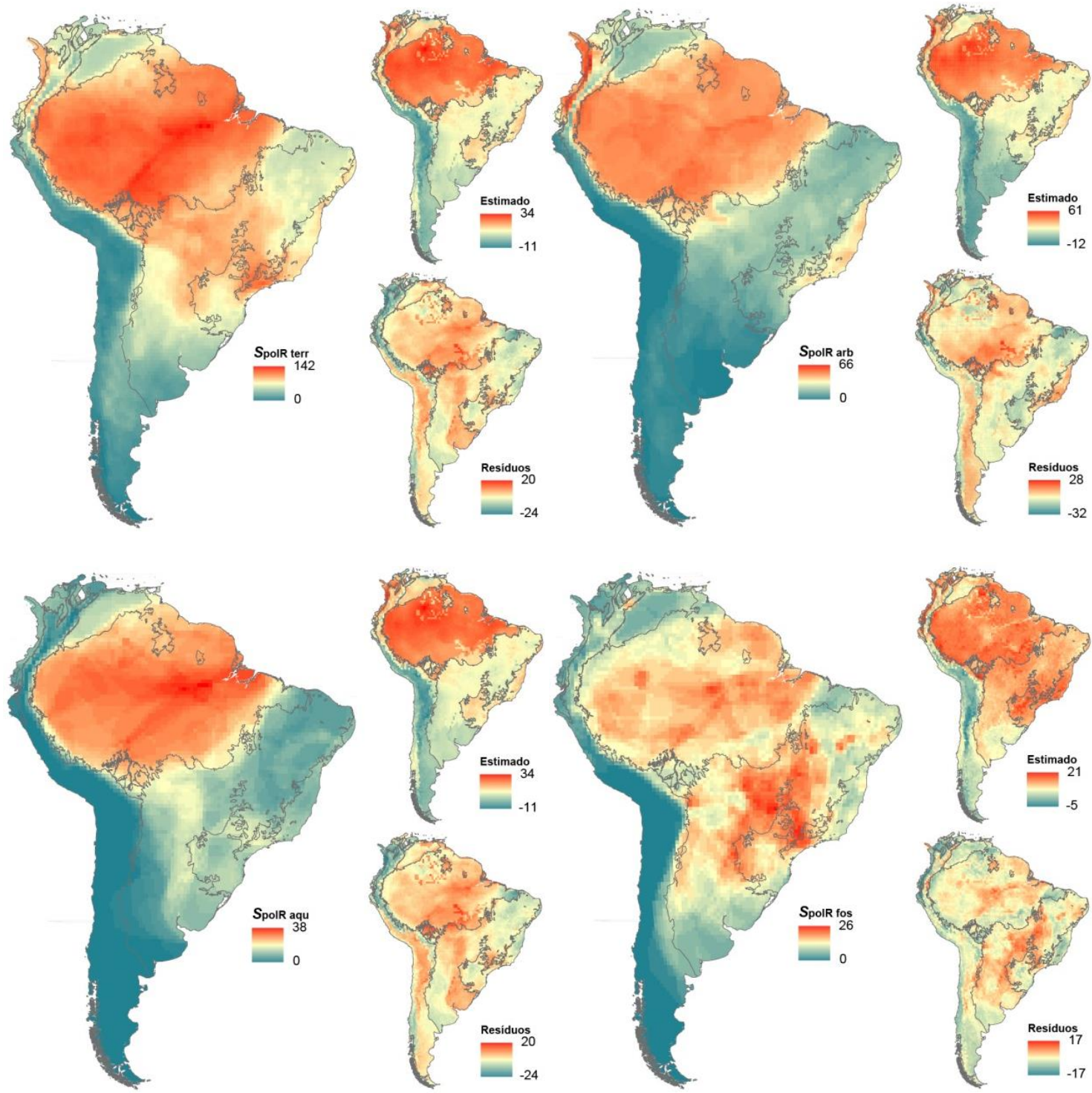

FIGURA 7. Riqueza de espécie de répteis terrestres $\left(S_{\text {polR ter }}\right)$, arborícolas $\left(S_{\text {polR arb }}\right)$, aquáticas $\left(S_{\text {polR aqu }}\right)$, fossoriais $\left(S_{\text {polR fos }}\right)$, os valores estimadas pelas regressões, e seus resíduos. 

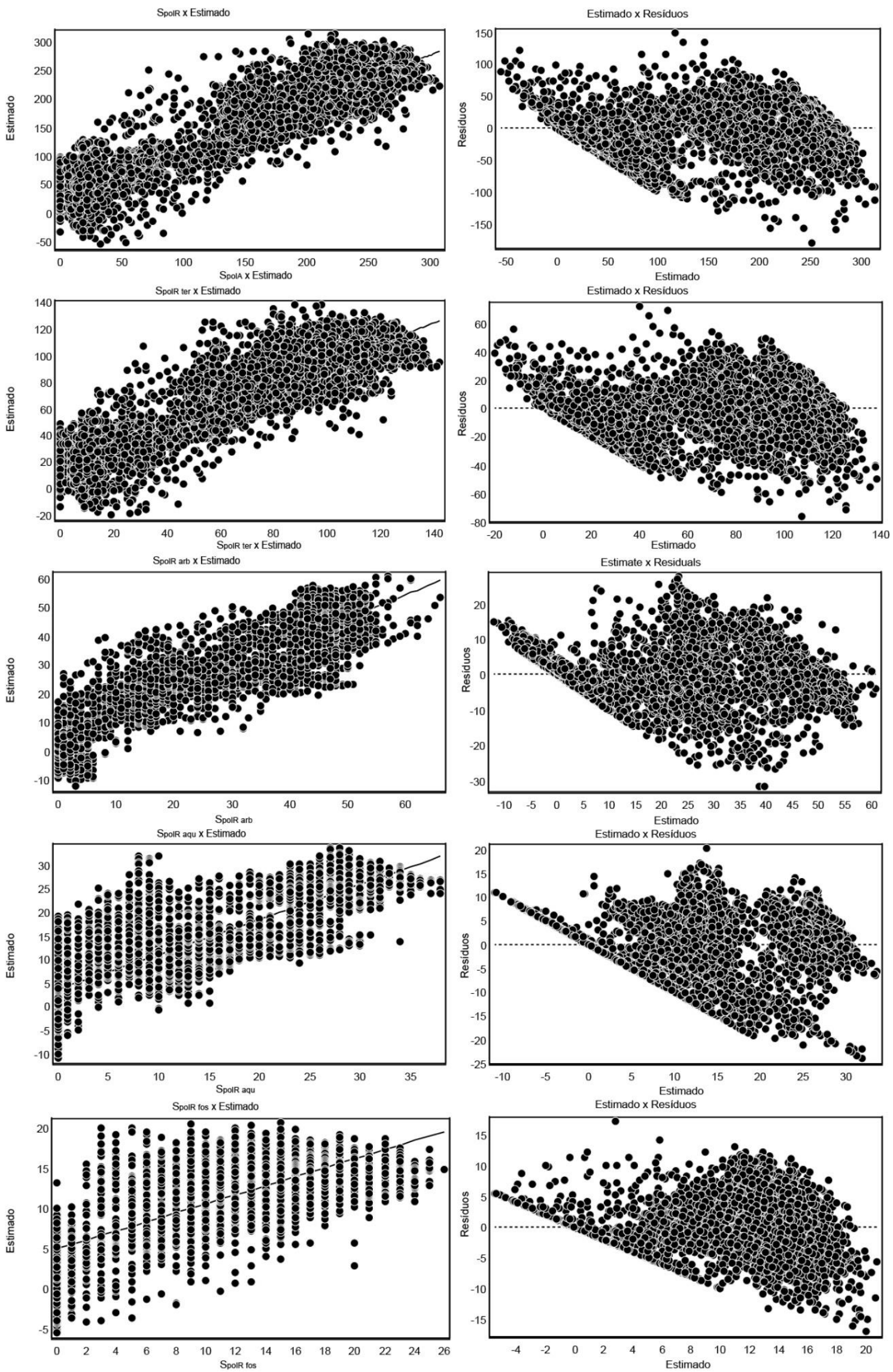

FIGURA 8. Resultados da análise de regressão múltipla para riqueza de répteis $\left(S_{\text {polR }}\right)$, terrestres $\left(S_{\text {polR }}\right.$ ter $)$, arborícolas $\left(S_{\text {polR arb }}\right)$, aquáticas $\left(S_{\text {polR aqu }}\right)$, fossoriais $\left(S_{\text {polR fos }}\right)$, como variável resposta, e 10 variáveis explanatórias. 

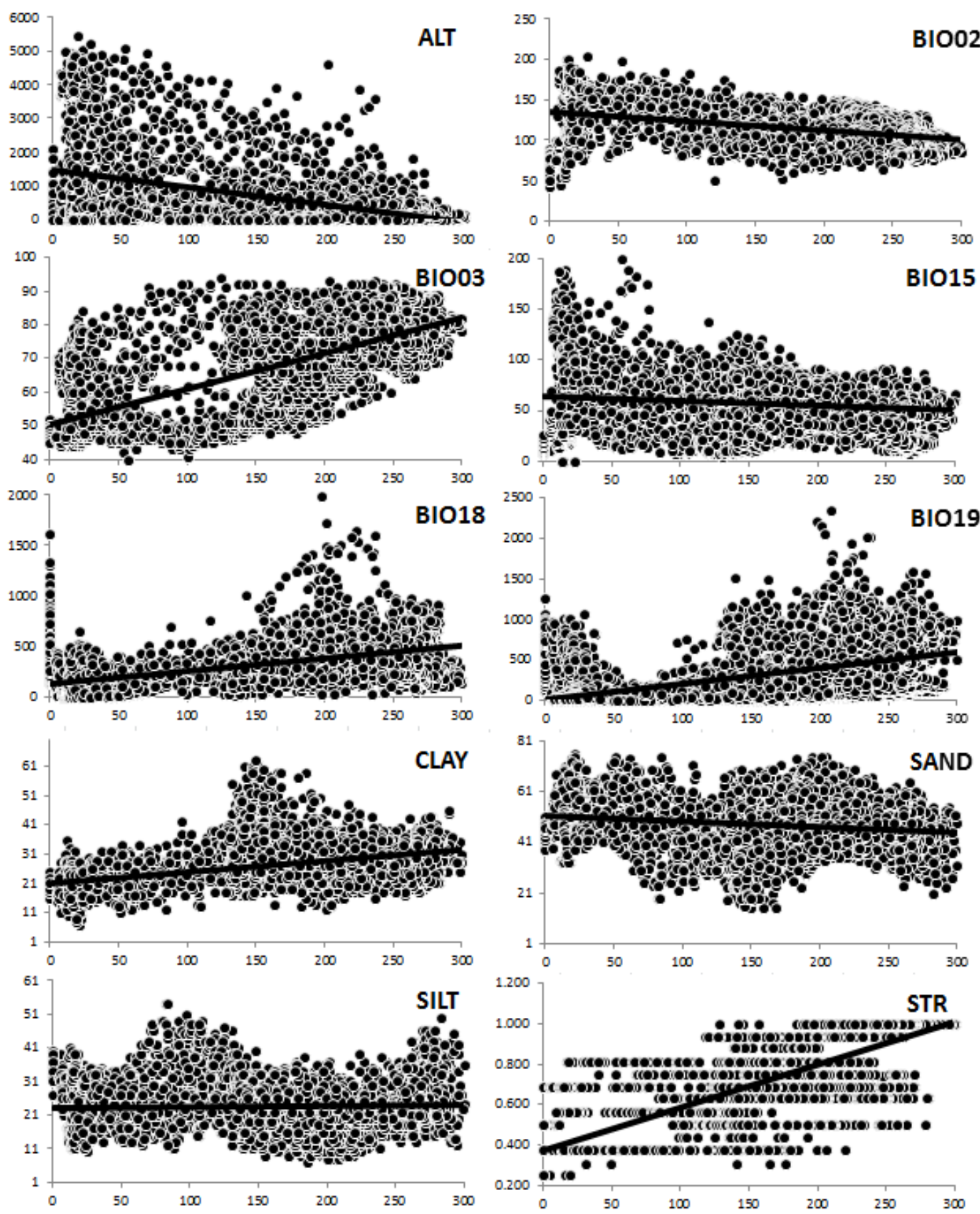

FIGURA 9. Relação da riqueza taxonômica de répteis $\left(S_{\text {polR }}\right)$ e as 10 variáveis explanatórias com VIF menor que 3. ALT: altitude, BIO2: Amplitude média diária, BIO3: Isotermalidade (BIO2/BIO7) (* 100), BIO15: Sazonalidade na precipitação, BIO18: Precipitação do trimestre mais quente, BIO19: Precipitação do trimestre mais frio, CLAY: porcentagem de cascalho no solo, SAND: porcentagem de areia no solo; SILT: porcentagem de silte no solo, STR: índice de estrutura ambiental. 


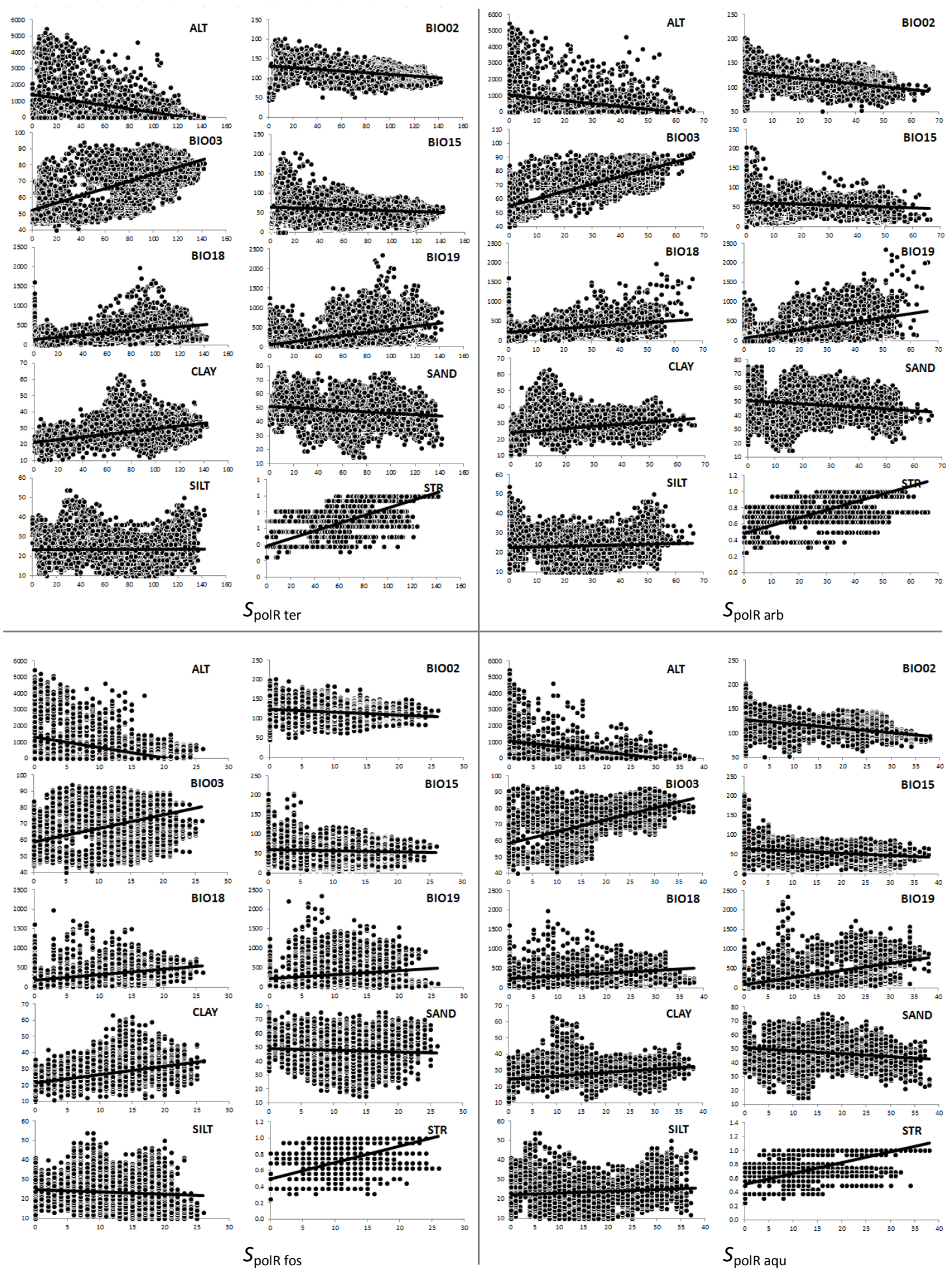

FIGURA 10. Relação entre a riqueza de répteis terrestres $\left(S_{\text {polR ter }}\right)$, arborícolas $\left(S_{\text {polR arb }}\right)$, fossoriais $\left(S_{\text {polR }}\right.$ fos) e aquáticos ( $\left.S_{\text {polR aqu }}\right)$, e as 10 variáveis explanatórias com VIF menor que 3. ALT: altitude, BIO2: Amplitude média diária, BIO3: Isotermalidade (BIO2/BIO7) (* 100), BIO15: Sazonalidade na precipitação, BIO18: Precipitação do trimestre mais quente, BIO19: Precipitação do trimestre mais frio, CLAY: porcentagem de cascalho no solo, SAND: porcentagem de areia no solo; SILT: porcentagem de silte no solo, STR: índice de estrutura ambiental. 
TABELA 2. Resultados das análises de regressão múltipla para a riqueza taxonômica de répteis $\left(S_{\text {polk }}\right)$, para riqueza de espécies de répteis terrestres $\left(S_{\text {polR ter }}\right)$, para riqueza de espécies de répteis arborícolas $\left(S_{\text {polR arb }}\right)$, para riqueza de espécies de répteis aquáticas ( $\left.S_{\text {polR aqu }}\right)$, para riqueza de espécies de répteis fossoriais $\left(S_{\text {polR fos }}\right)$, como variáveis resposta, e 10 variáveis explanatórias. ALT: altitude, BIO2: Amplitude média diária, BIO3: Isotermalidade (BIO2/BIO7) $(* 100)$, BIO15: Sazonalidade na precipitação, BIO18: Precipitação do trimestre mais quente, BIO19: Precipitação do trimestre mais frio, CLAY: porcentagem de cascalho no solo, SAND: porcentagem de areia no solo; SILT: porcentagem de silte no solo, STR: índice de estrutura ambiental. VIF: fator de inflação de variância; Coef.:coeficiente de regressão; C.P.: coeficiente padronizado.

\begin{tabular}{l|c|cc|cc|cc|cc|cc}
\hline \multirow{2}{*}{ Variável } & \multirow{2}{*}{ VIF } & \multicolumn{2}{|c|}{$\boldsymbol{S}_{\text {poIR }}$} & \multicolumn{2}{c|}{$\boldsymbol{S}_{\text {polR ter }}$} & \multicolumn{2}{c|}{$\boldsymbol{S}_{\text {polR arb }}$} & \multicolumn{2}{c|}{$\boldsymbol{S}_{\text {polR aqu }}$} & \multicolumn{2}{c}{$\boldsymbol{S}_{\text {polR fos }}$} \\
& & Coef. & C.P. & Coef. & C.P. & Coef. & C.P. & Coef. & C.P. & Coef. & C.P. \\
\hline Constante & & -198.97 & 0 & -83.293 & 0 & -49.38 & 0 & -27.75 & 0 & -10.20 & 0 \\
ALT & 1.781 & -0.028 & -0.304 & -0.011 & -0.264 & -0.002 & -0.122 & -0.003 & -0.207 & -0.002 & -0.343 \\
BIO02 & 2.233 & 0.361 & 0.096 & 0.160 & 0.096 & -0.01 & -0.011 & 0.049 & 0.098 & 0.039 & 0.140 \\
BIO03 & 2.536 & 2.574 & 0.395 & 0.956 & 0.332 & 0.668 & 0.459 & 0.260 & 0.300 & 0.090 & 0.187 \\
BIO15 & 1.704 & -0.045 & -0.015 & -0.023 & -0.017 & -0.041 & -0.060 & -0.042 & -0.102 & 0.007 & 0.032 \\
BIO18 & 1.472 & 0.047 & 0.119 & 0.028 & 0.160 & 0.006 & 0.070 & $<.001$ & -0.007 & 0.005 & 0.186 \\
BIO19 & 1.97 & -0.012 & -0.050 & -0.008 & -0.076 & $<0.001$ & 0.008 & 0.003 & 0.105 & -0.003 & -0.162 \\
CLAY & 1.311 & 1.273 & 0.112 & 0.572 & 0.114 & -0.015 & -0.006 & -0.028 & -0.018 & 0.191 & 0.228 \\
SAND & 1.408 & 0.248 & 0.034 & 0.151 & 0.047 & 0.063 & 0.039 & 0.023 & 0.024 & 0.024 & 0.046 \\
SILT & 1.283 & -0.711 & -0.065 & -0.408 & -0.084 & -0.038 & -0.015 & 0.028 & 0.019 & -0.128 & -0.157 \\
STR & 2.739 & 174.58 & 0.448 & 83.146 & 0.482 & 40.94 & 0.470 & 27.563 & 0.531 & 10.475 & 0.362 \\
\hline
\end{tabular}

Os correlogramas divididos em 25 classes de distância indicam que mesmo após a extração dos resíduos, todas as medidas de riqueza continuam ainda apresentando uma certa auto-correlação, com um padrão geral onde classes de distância menores tendem a ter valores positivamente auto-correlacionados, classes de distância intermediárias tendem a ter valores negativamente auto-correlacionados, e classes de distância mais altas voltam a apresentar valores positivamente auto-correlacionados (FIGURA 11).

A matriz de conectividade, baseada no critério de Gabriel, calculou 12160 conexões entre as quadrículas, apresentando uma distância mínima de 31.7914 km, média de 54.216 km, e máxima de 189.538 km, e desvio padrão de 6.217 (FIGURA 12). O modelo autoregressivo baseado para cada variável resposta $\left(S_{\text {polR }}, S_{\text {polR ter }}, S_{\text {polR arb }}, S_{\text {polR aqu }}\right.$ e $\left.S_{\text {polR fos }}\right)$, nas variáveis explanatórias (ALT, BIO02, BIO03, BIO13, BIO15, BIO18, CLAY, SAND, SILT e STR), e na matriz de conectividade, foi calculado ( $n=6147, \rho=0.998 ; S_{\text {polR }}: r^{2}=0.02 ; S_{\text {polR ter }}: r^{2}=0.262 ; S_{\text {polR arb }}: r^{2}=0.216$; $S_{\text {polR aqu }}: r^{2}=0.203 ; S_{\text {polR fos }}: r^{2}=0.192$ ) (TABELA 3; FIGURAS 13) e incluído como uma variável fixa $\left(M_{A} R_{R}\right)$, presente em todos os modelos, na seleção de modelos. 


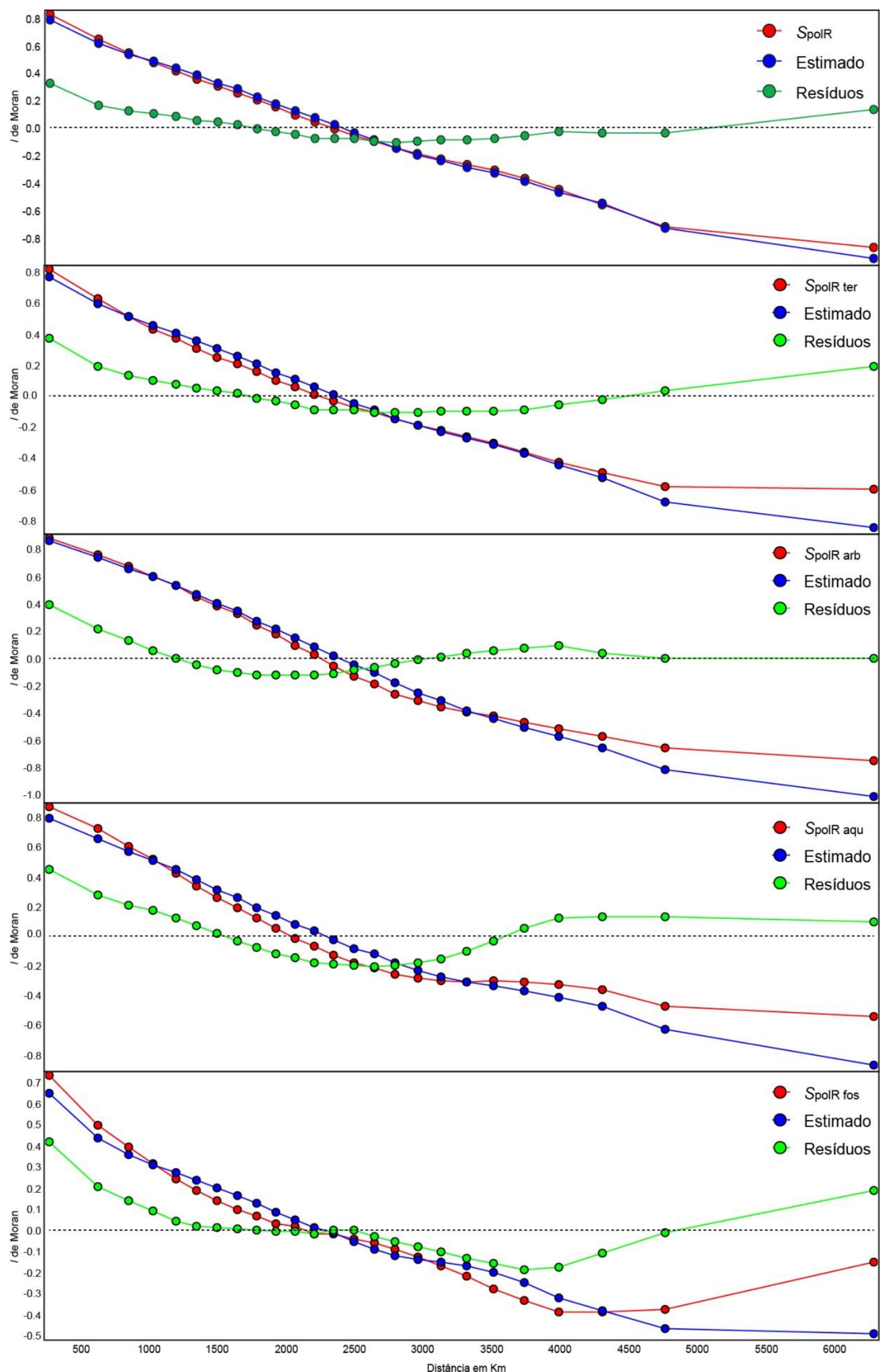

FIGURA 11. Correlograma do I de Moran para a riqueza taxonômica de répteis $\left(S_{\text {polR }}\right)$, de espécies de répteis terrestres $\left(S_{\text {polR ter }}\right)$, arborícolas $\left(S_{\text {polR arb }}\right)$, aquáticos $\left(S_{\text {polR aqu }}\right)$, e fossoriais $\left(S_{\text {polR fos }}\right)$, e para os valores estimados e os resíduos da regressão destas pelas variáveis ambientais. 
TABELA 3. Resultados dos cálculos dos modelos autoregressivos para a riqueza taxonômica de répteis $\left(S_{\text {polR }}\right)$, para riqueza de espécies de répteis terrestres $\left(S_{\text {polR ter }}\right)$, arborícolas $\left(S_{\text {polR arb }}\right)$, aquáticos $\left(S_{\text {polR aqu }}\right)$, fossoriais $\left(S_{\text {polR fos }}\right)$, como variáveis resposta, e 10 variáveis explanatórias. Coef.:coeficiente de regressão; C.P.: coeficiente padronizado. ALT: altitude, BIO2: Amplitude média diária, BIO3: Isotermalidade (BIO2/BIO7) (* 100), BIO15: Sazonalidade na precipitação, BIO18: Precipitação do trimestre mais quente, BIO19: Precipitação do trimestre mais frio, CLAY: porcentagem de cascalho no solo, SAND: porcentagem de areia no solo; SILT: porcentagem de silte no solo, STR: índice de estrutura ambiental.

\begin{tabular}{l|cc|cc|cc|cc|cc}
\hline \multirow{2}{*}{ Variável } & \multicolumn{2}{|c|}{$\boldsymbol{S}_{\text {polR }}$} & \multicolumn{2}{c|}{$\boldsymbol{S}_{\text {polR ter }}$} & \multicolumn{2}{c|}{$\boldsymbol{S}_{\text {polR arb }}$} & \multicolumn{2}{c|}{$\boldsymbol{S}_{\text {polR aqu }}$} & \multicolumn{2}{c}{$\boldsymbol{S}_{\text {polR fos }}$} \\
& Coef. & C.P. & Coef. & C.P. & Coef. & C.P. & Coef. & C.P. & Coef. & C.P. \\
\hline Constante & 0 & 0 & -83.293 & 0 & 0.22 & 0 & 0.391 & 0 & 0.924 & 0 \\
ALT & -0.322 & -0.322 & -0.011 & -0.264 & $<0.001$ & -0.133 & $<0.001$ & -0.23 & $<0.001$ & -0.287 \\
BIO02 & 0.029 & 0.029 & 0.160 & 0.096 & $<0.001$ & 0.061 & 0.001 & 0.087 & -0.001 & -0.062 \\
BIO03 & -0.354 & -0.354 & 0.956 & 0.332 & -0.009 & -0.391 & -0.009 & -0.383 & -0.008 & -0.197 \\
BIO15 & -0.111 & -0.111 & -0.023 & -0.017 & $<0.001$ & -0.095 & -0.001 & -0.089 & -0.002 & -0.103 \\
BIO18 & 0.111 & 0.111 & 0.028 & 0.160 & $<0.001$ & 0.216 & $<0.001$ & 0.068 & $<0.001$ & -0.027 \\
BIO19 & -0.021 & -0.021 & -0.008 & -0.076 & $<0.001$ & 0.007 & $<0.001$ & 0.041 & $<0.001$ & -0.030 \\
CLAY & 0.101 & 0.101 & 0.572 & 0.114 & 0.002 & 0.064 & $<0.001$ & $<0.001$ & 0.005 & 0.079 \\
SAND & 0.071 & 0.071 & 0.151 & 0.047 & 0.001 & 0.056 & 0.001 & 0.043 & 0.002 & 0.052 \\
SILT & -0.125 & -0.125 & -0.408 & -0.084 & -0.004 & -0.107 & -0.003 & -0.073 & -0.007 & -0.103 \\
STR & 0.105 & 0.105 & 83.146 & 0.482 & 0.294 & 0.225 & 0.244 & 0.167 & -0.158 & -0.069 \\
\hline
\end{tabular}

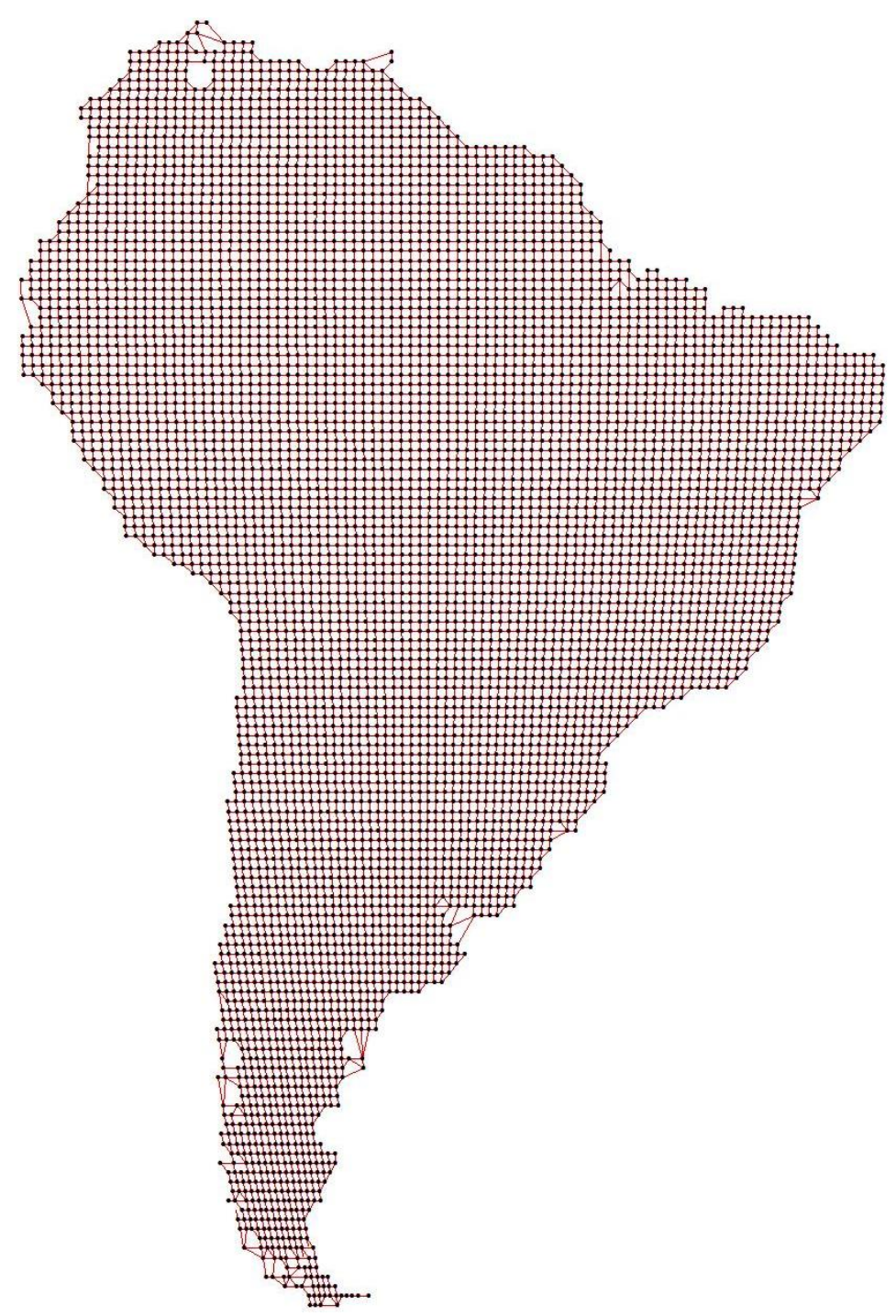

FIGURA 12. Mapa representando a matriz de conectividade entre as quadrículas baseada no critério de Gabriel. Pontos pretos: centroide das quadrículas; Linhas vermelhas tracejadas: conexões. 

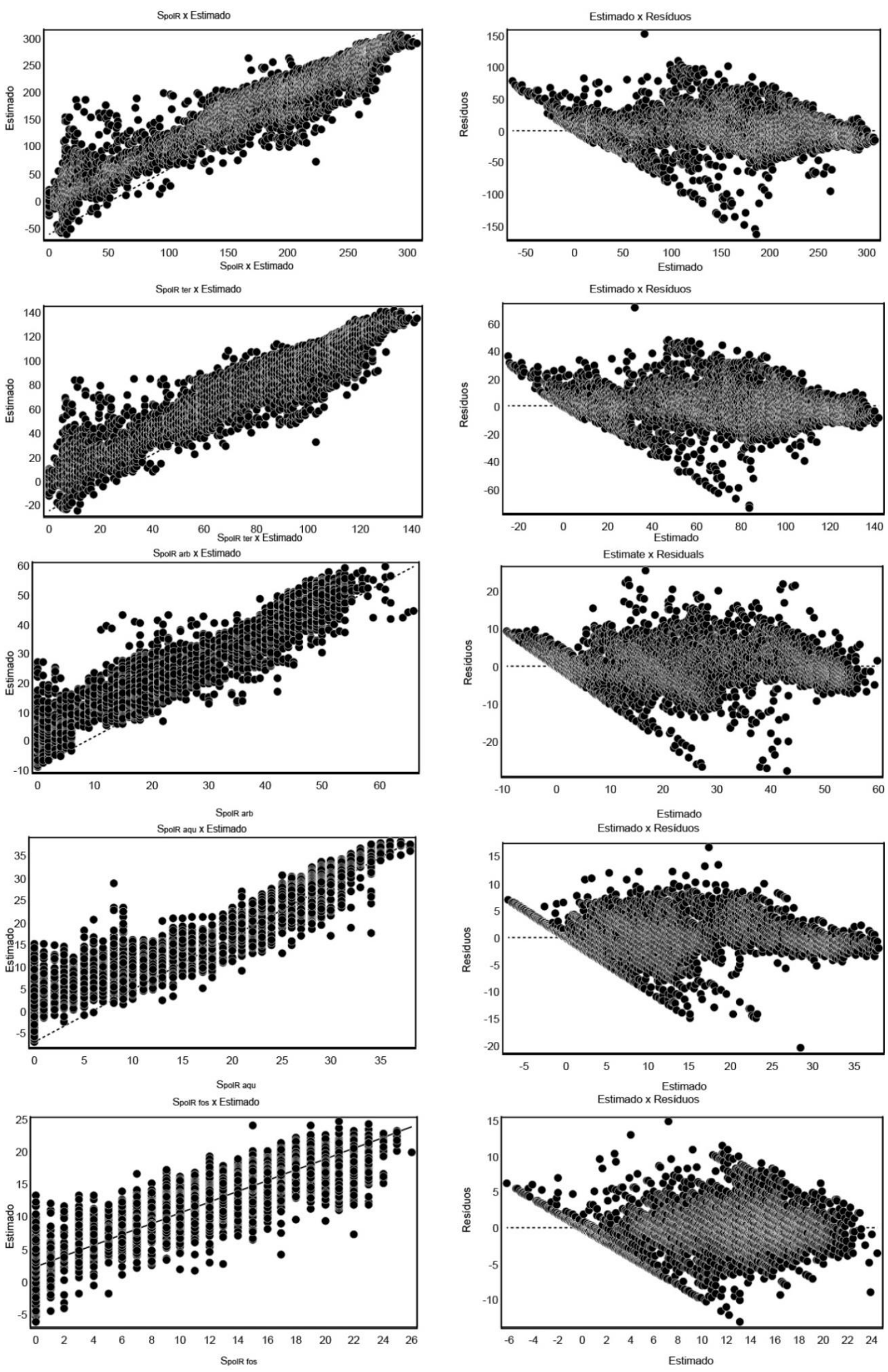

FIGURA 13. Resultados do modelo auto-regressivo para riqueza de répteis $\left(S_{\text {polk }}\right)$, terrestres $\left(S_{\text {polR ter }}\right)$, arborícolas $\left(S_{\text {polR arb }}\right)$, aquáticas $\left(S_{\text {polR aqu }}\right)$, fossoriais $\left(S_{\text {polR fos }}\right)$, como variável resposta, e 10 variáveis explanatórias. 
O procedimento de seleção de modelos aplicado para cada variável de riqueza [riqueza taxonômica de répteis $\left(S_{\text {polR }}\right)$, de espécies de répteis terrestres $\left(S_{\text {polR ter }}\right)$, arborícolas $\left(S_{\text {polR arb }}\right)$, aquáticas ( $\left.S_{\text {polR aqu }}\right)$, e fossoriais $\left(S_{\text {polR fos }}\right)$ ], como variável resposta, tendo as variáveis ambientais (ALT, BIO02, BIO03, BIO15, BIO18, BIO19, CLAY, SAND, SILT e STR) como variáveis explanatórias, testou 1023 modelos para cada riqueza. Entre dois e cinco modelos apresentaram $\triangle \mathrm{AICC}<2$, explicando entre $82 \%$ e $94 \%$ da variação observada. A probabilidade de que o modelo com menor AICc para $S_{\text {polR }}$ seja o melhor modelo é de $46 \%$, para $S_{\text {polR ter }} 55 \%$, $S_{\text {pol arb }}$ e $S_{\text {pol aqu }} 16 \%$ e $S_{\text {polr fos }} 35 \%$ (TABELA 4). O modelo auto-regressivo apresentou o maior coeficiente de regressão, e os valores dos coeficientes de cada variável diminuíram em magnitude, variando entre 0.009 e 0.114 , e foram de forma geral, correlacionados negativamente à ALT, BIO15, BIO19 e SILT e positivamente à BIO02, BIO03, BIO18, CLAY, SAND e STR, com maiores valores relacionados à ALT, BIO02 e STR (TABELA 5).

TABELA 4. Resultado do procedimento de seleção de modelos lineares $\left(r^{2}\right)$ que melhor explicam a variação observada na riqueza taxonômica de répteis $\left(S_{\text {polk }}\right)$, de répteis terrestres $\left(S_{\text {polR ter }}\right)$, arborícolas $\left(S_{\text {polR arb }}\right)$, aquáticos ( $\left.S_{\text {polr aqu }}\right)$ e fossoriais $\left(S_{\text {polr fos }}\right)$, definidos pelo Critério de Informação de Akaike (AICC) e peso de Akaike $\left(w_{i}\right)$. Foram avaliados 1023 modelos para cada riqueza, aqui são mostrados apenas os que apresentam $\triangle \mathrm{AICC}$ menores que 2. ALT: altitude, BIO2: Amplitude média diária, BIO3: Isotermalidade (BIO2/BIO7) (* 100), BIO15: Sazonalidade na precipitação, BIO18: Precipitação do trimestre mais quente, BIO19: Precipitação do trimestre mais frio, CLAY: porcentagem de cascalho no solo, SAND: porcentagem de areia no solo; SILT: porcentagem de silte no solo, STR: índice de estrutura ambiental.

\begin{tabular}{|c|c|c|c|c|c|}
\hline Riqueza & Variáveis & $r^{2}$ & AICc & $\triangle \mathrm{AICc}$ & $\operatorname{AlCc}_{\mathrm{i}}$ \\
\hline \multirow{2}{*}{$S_{\text {polR }}$} & ALT, BIO02, BIO03, BIO18, BIO19, CLAY, SAND, SILT, STR & 0.925 & 56171.198 & 0 & 0.459 \\
\hline & ALT, BIO02, BIO03, BIO15, BIO18, BIO19, CLAY, SAND, SILT, STR & 0.925 & 56172.537 & 1.339 & 0.235 \\
\hline \multirow{2}{*}{$S_{\text {polR ter }}$} & ALT, BIO02, BIO03, BIO18, BIO19, CLAY, SAND, SILT, STR & 0.913 & 47034.405 & 0 & 0.555 \\
\hline & ALT, BIO02, BIO03, BIO15, BIO18, BIO19, CLAY, SAND, SILT, STR & 0.913 & 52966.745 & 1.387 & 0.277 \\
\hline \multirow{5}{*}{$S_{\text {polR arb }}$} & ALT, BIO03, BIO15, BIO18, SAND, STR & 0.941 & 36189.625 & 0 & 0.160 \\
\hline & ALT, BIO03, BIO15, BIO18, SAND, SILT, STR & 0.941 & 36190.995 & 1.371 & 0.080 \\
\hline & ALT, BIO02, BIO03, BIO15, BIO18, SAND, STR & 0.941 & 36191.271 & 1.647 & 0.070 \\
\hline & ALT, BIO03, BIO15, BIO18, CLAY, SAND, STR & 0.941 & 36191.396 & 1.771 & 0.066 \\
\hline & ALT, BIO03, BIO15, BIO18, BIO19, SAND, STR & 0.941 & 36191.451 & 1.826 & 0.064 \\
\hline \multirow{5}{*}{$S_{\text {polR aqu }}$} & ALT, BIO02, BIO03, BIO15, BIO19, STR & 0.923 & 31514.198 & 0 & 0.164 \\
\hline & ALT, BIO02, BIO03, BIO15, BIO19, SAND, STR & 0.923 & 31515.667 & 1.469 & 0.079 \\
\hline & ALT, BIO02, BIO03, BIO15, BIO19, CLAY, STR & 0.923 & 31515.792 & 1.594 & 0.074 \\
\hline & ALT, BIO02, BIO03, BIO15, BIO18, BIO19,, STR & 0.923 & 31516.076 & 1.878 & 0.064 \\
\hline & ALT, BIO02, BIO03, BIO15, BIO19, SILT, STR & 0.923 & 31516.139 & 1.941 & 0.062 \\
\hline \multirow{4}{*}{$S_{\text {polR fos }}$} & ALT, BIO02, BIO03, BIO18, BIO19, CLAY, SAND, SILT, STR & 0.823 & 29429.329 & 0 & 0.355 \\
\hline & ALT, BIO02, BIO03, BIO18, BIO19, CLAY, SILT, STR & 0.823 & 29429.957 & 0.627 & 0.259 \\
\hline & ALT, BIO02, BIO03, BIO15, BIO18, BIO19, CLAY, SAND, SILT, STR & 0.823 & 29430.271 & 0.942 & 0.222 \\
\hline & ALT, BIO02, BIO03, BIO15, BIO18, BIO19, CLAY, SILT, STR & 0.823 & 29430.877 & 1.548 & 0.164 \\
\hline
\end{tabular}


TABELA 5. Parâmetros calculados para o melhor modelo que explica a variação na riqueza taxonômica de répteis $\left(S_{\text {polR }}\right)$, riqueza de espécies de répteis terrestres $\left(S_{\text {polR ter }}\right)$, arborícolas $\left(S_{\text {polR arb }}\right)$, aquáticos $\left(S_{\text {polR }}\right.$ aqu), fossoriais $\left(S_{\text {polR fos }}\right)$ de acordo com o Critério de informação de Akaike (AICC). Coef.: coeficiente; C.P.: coeficiente padronizado. ALT: altitude, BIO2: Amplitude média diária, BIO3: Isotermalidade (BIO2/BIO7) (* 100), BIO15: Sazonalidade na precipitação, BIO18: Precipitação do trimestre mais quente, BIO19: Precipitação do trimestre mais frio, CLAY: porcentagem de cascalho no solo, SAND: porcentagem de areia no solo; SILT: porcentagem de silte no solo, STR: índice de estrutura ambiental, MARR: Modelo Auto Regressivo

\begin{tabular}{l|cc|cc|cc|cc|cc}
\hline \multirow{2}{*}{ Variáveis } & \multicolumn{2}{|c|}{$S_{\text {polR }}$} & \multicolumn{2}{c|}{$S_{\text {polR ter }}$} & \multicolumn{2}{c|}{$S_{\text {polR arb }}$} & \multicolumn{2}{c}{$S_{\text {polR aqu }}$} & \multicolumn{2}{c}{$S_{\text {polR fos }}$} \\
& Coef. & C.P. & Coef. & C.P. & Coef. & C.P. & Coef. & C.P. & Coef. & C.P. \\
\hline Constante & -50.23 & 0 & -18.411 & 0 & -9.092 & 0 & -3.23 & 0 & -2.357 & 0 \\
ALT & -0.007 & -0.078 & -0.002 & -0.059 & $<0.001$ & -0.023 & $<0.001$ & -0.025 & $<0.001$ & -0.077 \\
BIO02 & 0.087 & 0.023 & 0.033 & 0.020 & - & - & 0.006 & 0.012 & 0.01 & 0.034 \\
BIO03 & 0.643 & 0.099 & 0.208 & 0.072 & 0.119 & 0.081 & 0.032 & 0.036 & 0.022 & 0.045 \\
BIO15 & - & - & 0.006 & 0.037 & -0.008 & -0.011 & -0.005 & -0.012 & - & - \\
BIO18 & 0.012 & 0.031 & - & - & 0.001 & 0.011 & - & - & 0.001 & 0.040 \\
BIO19 & -0.003 & -0.012 & -0.002 & -0.016 & - & - & $<0.001$ & 0.013 & $<0.001$ & -0.038 \\
CLAY & 0.324 & 0.029 & 0.128 & 0.026 & - & - & - & - & 0.043 & 0.051 \\
SAND & 0.063 & 0.009 & 0.034 & 0.010 & - & - & - & - & 0.006 & 0.010 \\
SILT & -0.176 & -0.016 & -0.089 & -0.018 & 0.012 & 0.007 & - & - & -0.03 & -0.036 \\
STR & 44.394 & 0.114 & 18.545 & 0.108 & 7.092 & 0.081 & 3.271 & 0.063 & 2.366 & 0.082 \\
MAR & 0.746 & 0.749 & 0.777 & 0.78 & 0.826 & 0.822 & 0.878 & 0.868 & 0.774 & 0.773 \\
\hline
\end{tabular}

\subsubsection{Anfíbios}

Os polígonos referentes a um total de 2828 espécies, 182 gêneros, 30 famílias, e três ordens (APÊNDICE 3) produziram uma riqueza taxonômica $\left(S_{\text {pola }}\right)$ local média de 87 (variando entre 0 e 247) (FIGURA 14).A riqueza média das áreas Abertas foi de 66 (10-184; 1221 táxons no total), das Florestas 135 (36-247; 2020 táxons no total), e da região Andina 34 (0-239; 1753 táxons no total).

A riqueza local média de espécies terrestres foi de 27 (0-104; 1916 espécies no total); a média das áreas Abertas foi de 23 (3-66; 627 espécies no total), das Florestas 40 (7-92; 1121 espécies no total), e da região Andina 9 (0-104; 1156 espécies no total) (FIGURA 15). A riqueza local média de espécies arborícolas foi de 25 (0-124; 1475 espécies no total); a média das áreas Abertas foi de 14 (0-66; 530 espécies no total), das Florestas 43 (0-120; 962 espécies no total), e da região Andina 7 (0-124; 901 espécies no total) (FIGURA 15). A riqueza local média de espécies aquáticas foi de 7 (0-23; 259 espécies no total); a média das áreas Abertas foi de 6 (0-18; 130 espécies no total), das Florestas 10 (0-23; 177 espécies no total), e da região Andina 1 (0-10; 106 espécies no total) (FIGURA 15). A riqueza local média de espécies fossoriais foi de 2 (0-11; 82 espécies no total); a média das áreas Abertas foi de 1.5 ( $0-6 ; 26$ espécies no total), das Florestas 4 (0-9; 69 espécies no total), e da região Andina 0.4 (0-11; 44 espécies no total) (FIGURA 15). 
As regressões das variáveis ambientais pelas riquezas (FIGURA 16) resultaram em 10 variáveis explanatórias (ALT, BIO02, BIO03, BIO15, BIO18, BIO19, CLAY, SAND, SILT, STR) com VIF < 3 (FIGURA 17-18), e as regressões explicaram desde 0.61 a 0.79 da variação observada nas riquezas $\left(n=6147 ; S_{\text {polA }}: r^{2}=0.795 ; S_{\text {polA ter: }}: r^{2}=0.704 ; S_{\text {polA arb }}: r^{2}=0.727 ; S_{\text {polA aqu: }} r^{2}=0.613 ; S_{\text {polA fos }}\right.$ : $\left.r^{2}=0.674\right)($ TABELA 6$)$.

Os correlogramas divididos em 25 classes de distância indicam que mesmo após a extração dos resíduos, todas as medidas de riqueza continuam ainda apresentando uma certa auto-correlação. Classes de distância menores tendem a ter valores positivamente autocorrelacionados, classes de distância intermediarias tendem a ter valores negativamente autocorrelacionados, e classes de distância mais altas voltam a apresentar valores positivamente auto-correlacionados (FIGURA 19).
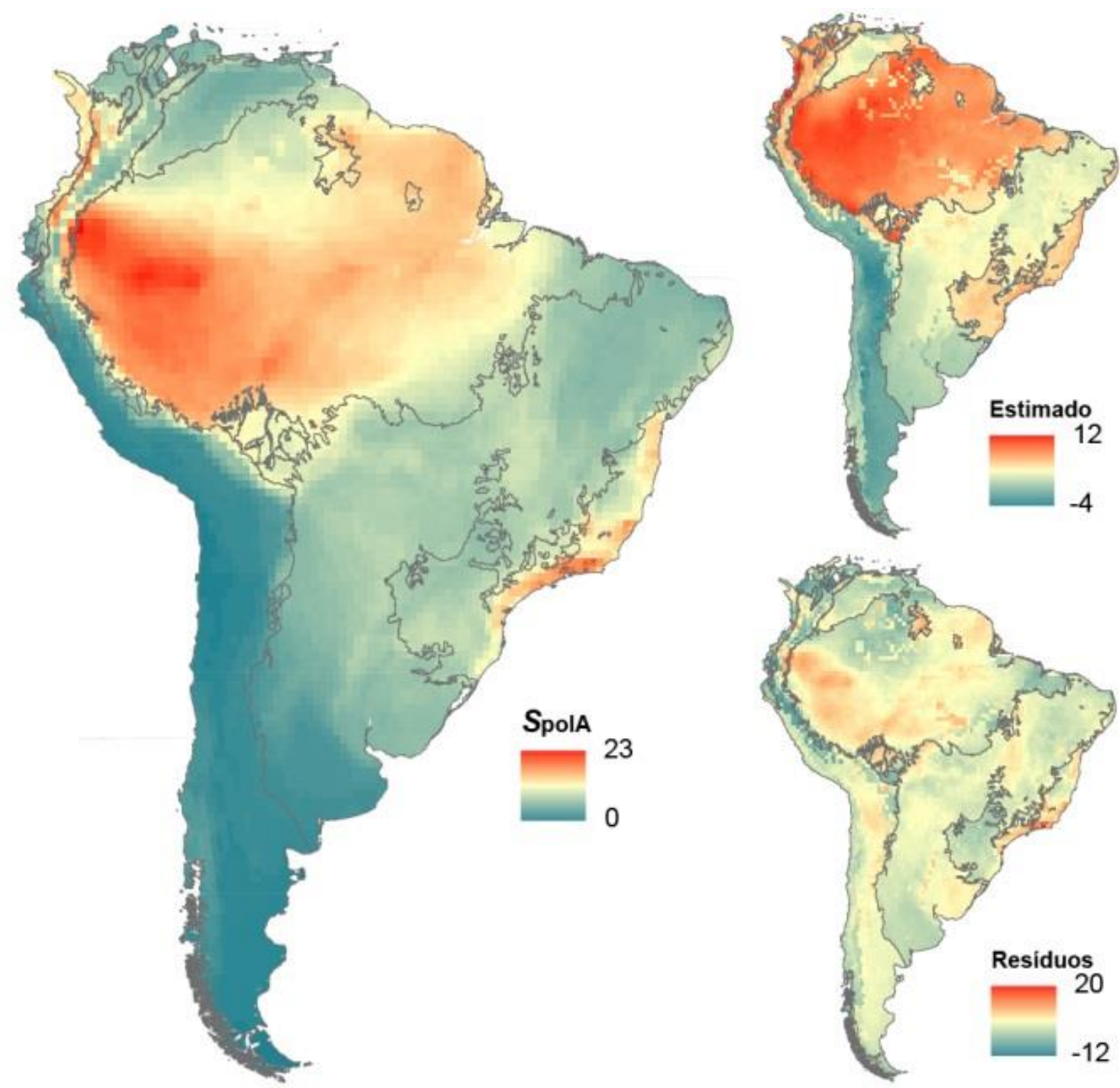

FIGURA 14. Riqueza taxonômica de anfíbios calculada pela sobreposição dos polígonos $\left(S_{\text {pola }}\right)$ de espécies, gêneros, famílias e ordens, valores estimados na análise de regressão da $S_{\text {pola }}$ e seus resíduos. 

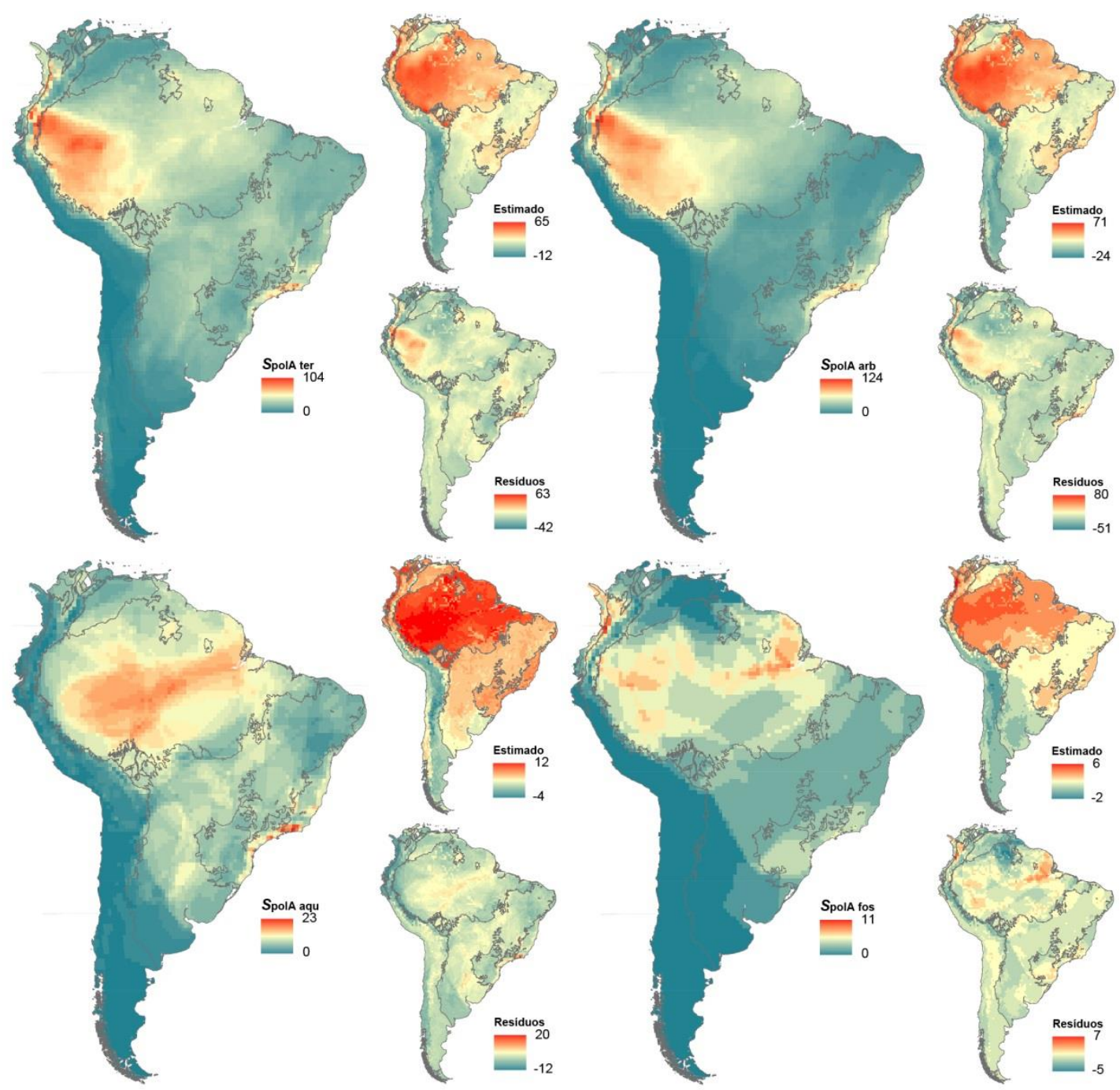

FIGURA 15. Riquezas referentes às espécies de anfíbios terrestres ( $\left.S_{\text {polA ter }}\right)$, arborícolas $\left(S_{\text {pola arb }}\right)$, aquáticas $\left(S_{\text {polA aqu }}\right)$, fossoriais $\left(S_{\text {polA fos }}\right)$, e os valores estimadas, e seus resíduos.

TABELA 6. Resultados das análises de regressão múltipla para a riqueza taxonômica de anfíbios $\left(S_{\text {pola }}\right)$, para riqueza de espécies de anfíbios terrestres $\left(S_{\text {pola ter }}\right)$, para riqueza de espécies de anfíbios arborícolas $\left(S_{\text {polA arb }}\right)$, para riqueza de espécies de anfíbios aquáticas $\left(S_{\text {polA aqu }}\right)$, para riqueza de espécies de anfíbios fossoriais $\left(S_{\text {pola fos }}\right)$, como variáveis resposta, e 10 variáveis explanatórias. VIF: fator de inflação de variância; Coef.:coeficiente de regressão; C.P.: coeficiente padronizado. ALT: altitude, BIO2: Amplitude média diária, BIO3: Isotermalidade (BIO2/BIO7) (* 100), BIO15: Sazonalidade na precipitação, BIO18: Precipitação do trimestre mais quente, BIO19: Precipitação do trimestre mais frio, CLAY: porcentagem de cascalho no solo, SAND: porcentagem de areia no solo; SILT: porcentagem de silte no solo, STR: índice de estrutura ambiental.

\begin{tabular}{|c|c|c|c|c|c|c|c|c|c|c|c|}
\hline \multirow{2}{*}{ Variável } & \multirow{2}{*}{ VIF } & \multicolumn{2}{|c|}{$S_{\text {polA }}$} & \multicolumn{2}{|c|}{$S_{\text {polA ter }}$} & \multicolumn{2}{|c|}{$S_{\text {polA arb }}$} & \multicolumn{2}{|c|}{$S_{\text {polA aqu }}$} & \multicolumn{2}{|c|}{$S_{\text {polA fos }}$} \\
\hline & & Coef. & C.P. & Coef. & C.P. & Coef. & C.P. & Coef. & C.P. & Coef. & C.P. \\
\hline Constante & 0 & -108.80 & 0 & -36.158 & 0 & -44.714 & 0 & -8.505 & 0 & -4.031 & 0 \\
\hline ALT & 1.781 & -0.006 & -0.102 & -0.002 & -0.130 & $<0.001$ & 0.011 & -0.001 & -0.270 & $<0.001$ & -0.078 \\
\hline BIO02 & 2.233 & -0.061 & -0.025 & 0.005 & 0.006 & -0.070 & -0.070 & 0.007 & 0.035 & -0.002 & -0.021 \\
\hline BIO03 & 2.536 & 1.348 & 0.315 & 0.480 & 0.350 & 0.587 & 0.338 & 0.077 & 0.216 & 0.052 & 0.338 \\
\hline BIO15 & 1.704 & -0.214 & -0.107 & -0.081 & -0.127 & -0.155 & -0.191 & 0.006 & 0.036 & -0.009 & -0.132 \\
\hline BIO18 & 1.472 & 0.041 & 0.158 & 0.020 & 0.240 & 0.020 & 0.189 & $<0.001$ & 0.040 & $<0.001$ & 0.100 \\
\hline BIO19 & 1.970 & -0.017 & -0.108 & -0.009 & -0.180 & -0.012 & -0.194 & $<0.001$ & -0.069 & $<0.001$ & 0.046 \\
\hline CLAY & 1.311 & 0.332 & 0.045 & -0.010 & -0.004 & -0.057 & -0.019 & 0.028 & 0.045 & 0.017 & 0.062 \\
\hline SAND & 1.408 & 0.050 & 0.010 & 0.044 & 0.029 & 0.018 & 0.009 & -0.003 & -0.008 & 0.010 & 0.058 \\
\hline SILT & 1.283 & 0.246 & 0.034 & 0.157 & 0.068 & 0.231 & 0.079 & 0.044 & 0.073 & -0.018 & -0.069 \\
\hline STR & 2.739 & 138.462 & 0.539 & 37.163 & 0.453 & 53.377 & 0.514 & 10.97 & 0.513 & 3.765 & 0.412 \\
\hline
\end{tabular}



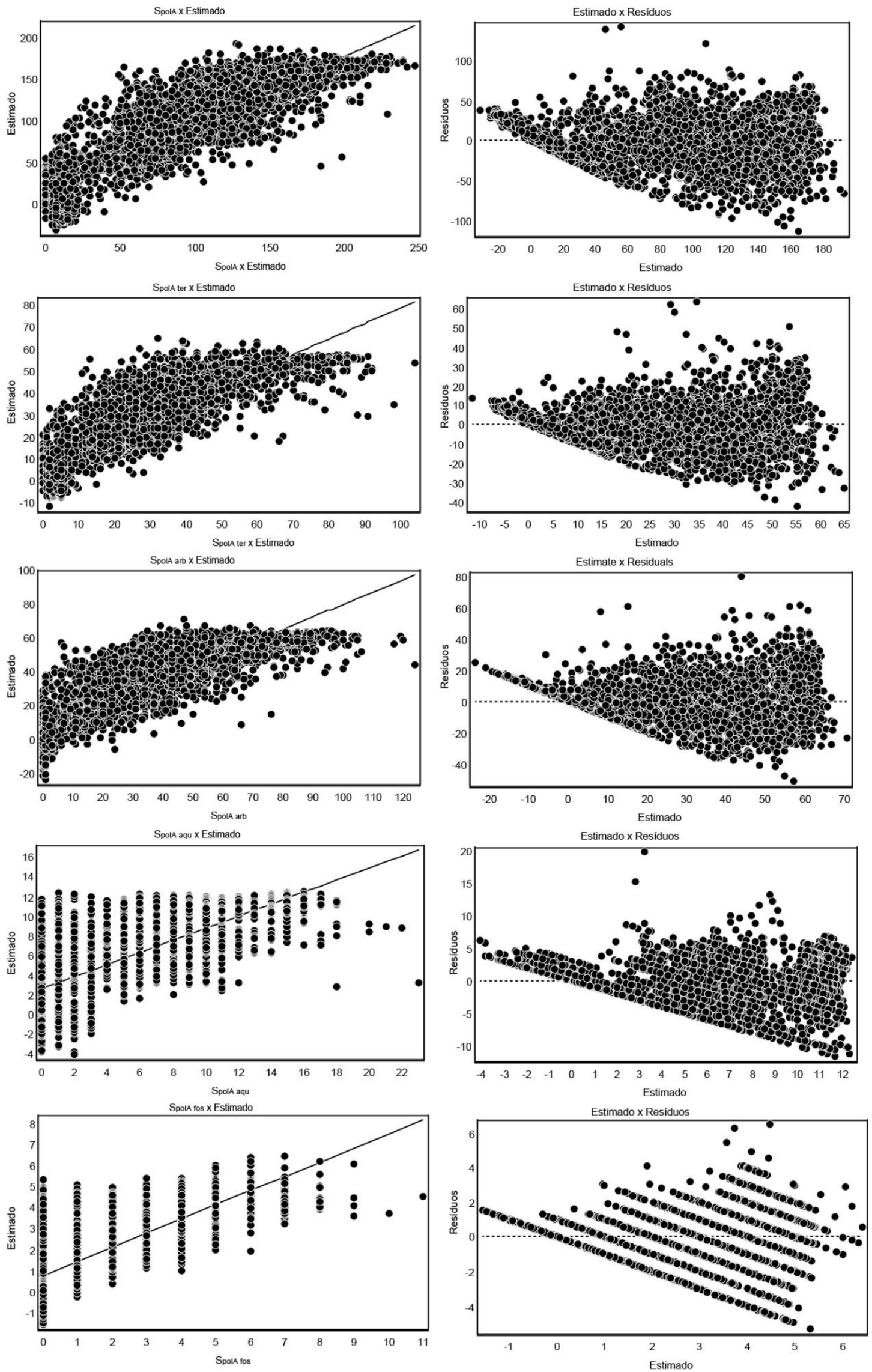

FIGURA 16. Resultados da análise de regressão múltipla para riqueza de anfíbios $\left(S_{\text {polA }}\right)$, terrestres $\left(S_{\text {polA }}\right.$ ter $)$, arborícolas $\left(S_{\text {polA arb }}\right)$, aquáticas $\left(S_{\text {polA aqu }}\right)$, fossoriais $\left(S_{\text {polA fos }}\right)$, como variável resposta, e 10 variáveis explanatórias. 

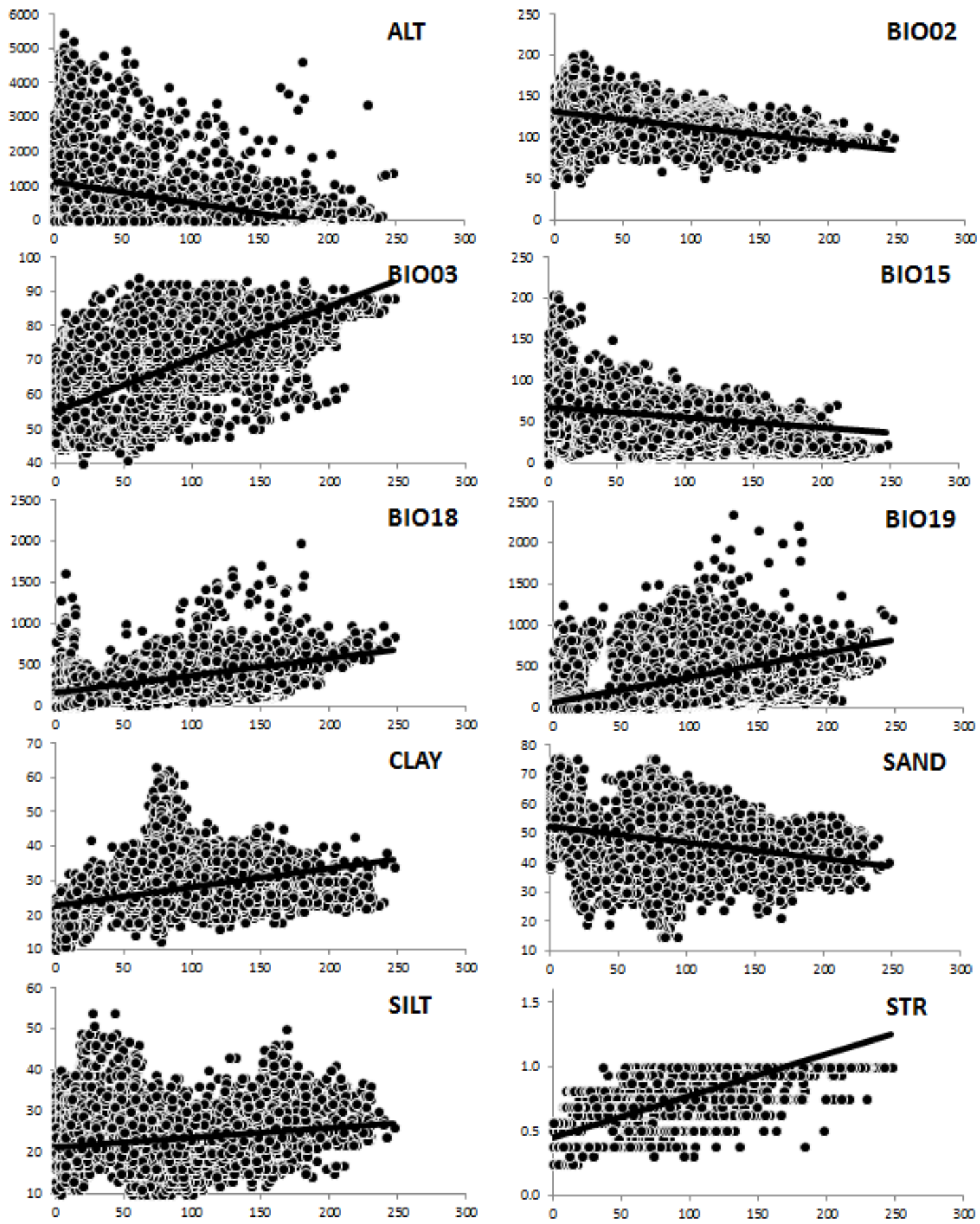

FIGURA 17. Relação da riqueza taxonômica de anfíbios $\left(S_{\text {polA }}\right)$ e as 10 variáveis explanatórias com VIF menor que 3. ALT: altitude, BIO2: Amplitude média diária, BIO3: Isotermalidade (BIO2/BIO7) (* 100), BIO15: Sazonalidade na precipitação, BIO18: Precipitação do trimestre mais quente, BIO19: Precipitação do trimestre mais frio, CLAY: porcentagem de cascalho no solo, SAND: porcentagem de areia no solo; SILT: porcentagem de silte no solo, STR: índice de estrutura ambiental. 


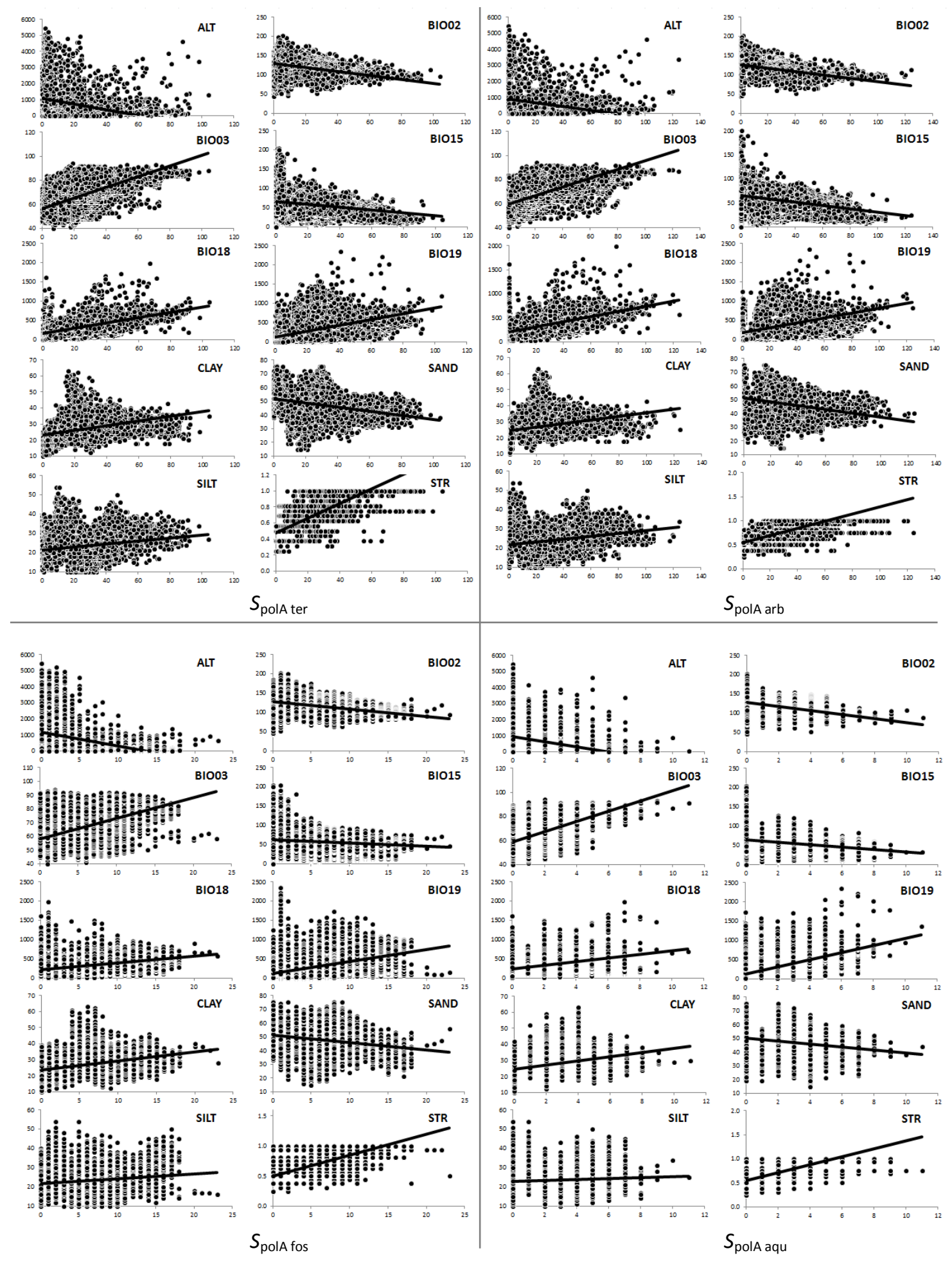

FIGURA 18. Relação entre a riqueza de anfíbios terrestres $\left(S_{\text {polA ter }}\right)$, arborícolas $\left(S_{\text {polA arb }}\right)$, fossoriais $\left(S_{\text {polA }}\right.$ fos) e aquáticos ( $S_{\text {polA aqu }}$ ), e as 10 variáveis explanatórias com VIF menor que 3. ALT: altitude, BIO2: Amplitude média diária, BIO3: Isotermalidade (BIO2/BIO7) (*100), BIO15: Sazonalidade na precipitação, BIO18: Precipitação do trimestre mais quente, BIO19: Precipitação do trimestre mais frio, CLAY: porcentagem de cascalho no solo, SAND: porcentagem de areia no solo; SILT: porcentagem de silte no solo, STR: índice de estrutura ambiental. 
A matriz de conectividade baseada no critério de Gabriel calculou 12160 conexões entre as quadrículas, apresentando uma distância mínima de 317914 km, média de 54216 km, máxima de 189538 km, e desvio padrão de 6217 km (FIGURA 12). O modelo auto-regressivo baseado para cada variável resposta $\left(S_{\text {polA }}, S_{\text {polA ter, }} S_{\text {polA arb, }} S_{\text {polA aqu }}\right.$ e $\left.S_{\text {polA fos }}\right)$, nas variáveis explanatórias (ALT, BIO02, BIO03, BIO13, BIO15, BIO18, CLAY, SAND, SILT e STR), e na matriz de conectividade, foi calculado $\left(n=6147 ; \rho=0.998 ; S_{\text {polA }}: r^{2}=0.217 ; S_{\text {polA ter }}: r^{2}=0.160 ; S_{\text {polA arb }}\right.$ : $r^{2}=0.149 ; S_{\text {polA aqu }}: r^{2}=0.613 ; S_{\text {polA fos }}: r^{2}=0.13$ ) (TABELA 7; FIGURAS 20) e incluídos como uma variável fixa $\left(M A R_{A}\right)$, presente em todos os modelos na seleção de modelos.

O procedimento de seleção de modelos aplicado para cada variável de riqueza (riqueza taxonômica de anfíbios $\left(S_{\text {polA }}\right)$, anfíbios terrestres $\left(S_{\text {polA ter }}\right)$, aquáticos $\left(S_{\text {polA aqu }}\right)$, e fossoriais $\left(S_{\text {polA }}\right.$ fos), como variável resposta, tendo as variáveis ambientais (ALT, BIO02, BIO03, BIO15, BIO18, BIO19, CLAY, SAND, SILT e STR), como variáveis explanatórias, testou 1023 modelos. Entre quatro e doze modelos apresentaram $\Delta \mathrm{AICC}<2$, explicando entre $86 \%$ e $92 \%$ da variação observada. A probabilidade de que o modelo com menor AICc para $S_{\text {polA }}$ e $S_{\text {polA ter }}$ e $S_{\text {pol arb }}$ seja o melhor modelo é de $27 \%$, para $S_{\text {pola fos }}$ de $7 \%$, e para $S_{\text {pol aqu }}$ de $5 \%$ (TABELA 8 ). O modelo autoregressivo apresentou o maior coeficiente de regressão, e os valores dos coeficientes de cada variável diminuíram em magnitude, variando entre 0.002 e 0.123 , e foram de forma geral relacionadas negativamente à $\mathrm{ALT}, \mathrm{BIO02,} \mathrm{BIO15} \mathrm{e} \mathrm{BIO19} \mathrm{e} \mathrm{positivamente} \mathrm{à} \mathrm{BIO03,} \mathrm{BIO18,}$ CLAY, SAND, SILT e STR, com maiores valores relacionados a STR e BIO03 (TABELA 17).

TABELA 7. Resultados dos cálculos dos modelos auto-regressivo para a riqueza taxonômica de anfíbios $\left(S_{\text {polA }}\right)$, para riqueza de espécies de répteis terrestres $\left(S_{\text {polA ter }}\right)$, arborícolas $\left(S_{\text {polA arb }}\right)$, aquáticos $\left(S_{\text {polA aqu }}\right)$, fossoriais $\left(S_{\text {polA fos }}\right)$, como variáveis resposta, e 10 variáveis explanatórias. Coef.:coeficiente de regressão; C.P.: coeficiente padronizado. ALT: altitude, BIO2: Amplitude média diária, BIO3: Isotermalidade (BIO2/BIO7) (* 100), BIO15: Sazonalidade na precipitação, BIO18: Precipitação do trimestre mais quente, BIO19: Precipitação do trimestre mais frio, CLAY: porcentagem de cascalho no solo, SAND: porcentagem de areia no solo; SILT: porcentagem de silte no solo, STR: índice de estrutura ambiental.

\begin{tabular}{l|cc|cc|cc|cc|cc}
\hline \multirow{2}{*}{ Variável } & \multicolumn{2}{|c|}{$\boldsymbol{S}_{\text {polA }}$} & \multicolumn{2}{c|}{$\boldsymbol{S}_{\text {polA ter }}$} & \multicolumn{2}{c|}{$\boldsymbol{S}_{\text {polA arb }}$} & \multicolumn{2}{c|}{$\boldsymbol{S}_{\text {polA aqu }}$} & \multicolumn{2}{c}{$\boldsymbol{S}_{\text {polA fos }}$} \\
& Coef. & C.P. & Coef. & C.P. & Coef. & C.P. & Coef. & C.P. & Coef. & C.P. \\
\hline Constante & 0.554 & 0 & 0.505 & 0 & 0.425 & 0 & 0.753 & 0 & -4.031 & 0 \\
ALT & $<0.001$ & -0.113 & $<0.001$ & -0.149 & $<0.001$ & -0.009 & $<0.001$ & -0.21 & $<0.001$ & -0.078 \\
BIO02 & $<0.001$ & -0.067 & $<0.001$ & -0.027 & $<0.001$ & -0.031 & -0.001 & -0.075 & -0.002 & -0.021 \\
BIO03 & -0.011 & -0.417 & -0.009 & -0.334 & -0.009 & -0.342 & -0.011 & -0.346 & 0.052 & 0.338 \\
BIO15 & -0.001 & -0.091 & $<0.001$ & -0.073 & -0.002 & -0.130 & $<0.001$ & -0.018 & -0.009 & -0.132 \\
BIO18 & $<0.001$ & 0.170 & $<0.001$ & 0.171 & $<0.001$ & 0.161 & $<0.001$ & -0.002 & $<0.001$ & 0.100 \\
BIO19 & $<0.001$ & -0.002 & $<0.001$ & 0.032 & $<0.001$ & -0.004 & $<0.001$ & -0.038 & $<0.001$ & 0.046 \\
CLAY & 0.005 & 0.122 & 0.005 & 0.096 & 0.005 & 0.112 & 0.003 & 0.048 & 0.017 & 0.062 \\
SAND & $<0.001$ & 0.035 & $<0.001$ & 0.030 & $<0.001$ & 0.015 & 0.001 & 0.039 & 0.010 & 0.058 \\
SILT & -0.003 & -0.068 & -0.002 & -0.032 & -0.002 & -0.049 & $<0.001$ & -0.015 & -0.018 & -0.069 \\
STR & 0.221 & 0.144 & 0.047 & 0.028 & 0.171 & 0.112 & 0.152 & 0.081 & 3.765 & 0.412 \\
\hline
\end{tabular}




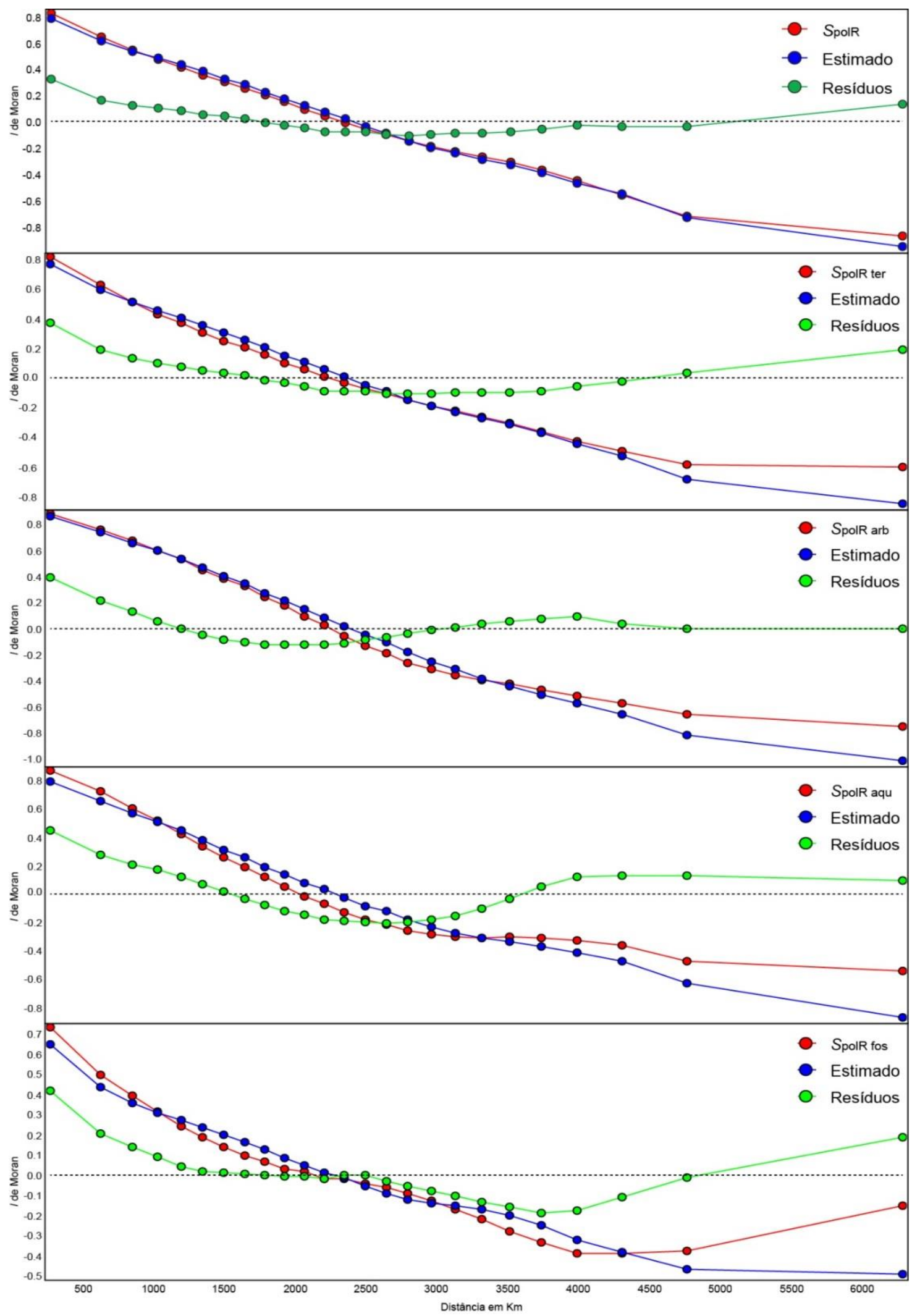

FIGURA 19. Correlograma do I de Moran para a riqueza taxonômica de anfíbios $\left(S_{\text {pola }}\right)$, de anfíbios terrestres $\left(S_{\text {polA ter }}\right)$, arborícolas $\left(S_{\text {polA arb }}\right)$, aquáticos $\left(S_{\text {polA aqu }}\right)$, fossoriais $\left(S_{\text {polA fos }}\right)$, e para os valores estimados e os resíduos da regressão destas pelas variáveis ambientais. 
TABELA 8. Resultado do procedimento de seleção de modelos lineares $\left(r^{2}\right)$ que melhor explicam a variação observada na riqueza taxonômica de anfíbios $\left(S_{\text {polA }}\right)$, de anfíbios terrestres $\left(S_{\text {polA ter }}\right)$, arborícolas $\left(S_{\text {polA arb }}\right)$, aquáticos ( $\left.S_{\text {polA aqu }}\right)$ e fossoriais ( $S_{\text {polA fos }}$ ), definidos pelo Critério de Informação de Akaike (AICC) e peso de Akaike $\left(\boldsymbol{w}_{\mathrm{i}}\right)$. Foram avaliados 1023 modelos para cada riqueza, aqui são mostrados apenas os que apresentam $\triangle \mathrm{AICC}$ menores que 2. ALT: altitude, BIO2: Amplitude média diária, BIO3: Isotermalidade (BIO2/BIO7) (* 100), BIO15: Sazonalidade na precipitação, BIO18: Precipitação do trimestre mais quente, BIO19: Precipitação do trimestre mais frio, CLAY: porcentagem de cascalho no solo, SAND: porcentagem de areia no solo; SILT: porcentagem de silte no solo, STR: índice de estrutura ambiental.

\begin{tabular}{|c|c|c|c|c|c|}
\hline Riqueza & Variáveis por modelo & $r^{2}$ & AICc & $\triangle \mathrm{AICc}$ & $\operatorname{AICc}_{\mathrm{i}}$ \\
\hline \multirow{4}{*}{$S_{\text {pola }}$} & ALT, BIO03, BIO15, BIO18, BIO19, CLAY, SILT, STR & 0.924 & 51083.126 & 0 & 0.273 \\
\hline & ALT, BIO02, BIO03, BIO15, BIO18, BIO19, CLAY, SILT, STR & 0.924 & 51084.182 & 1.056 & 0.161 \\
\hline & ALT, BIO03, BIO15, BIO18, BIO19, CLAY, STR & 0.924 & 51084.663 & 1.537 & 0.127 \\
\hline & ALT, BIO03, BIO15, BIO18, BIO19, CLAY, SAND, SILT, STR & 0.924 & 51085.005 & 1.879 & 0.107 \\
\hline \multirow{4}{*}{$S_{\text {pola ter }}$} & ALT, BIO03, BIO15, BIO18, BIO19, SILT, STR & 0.896 & 38956.157 & 0 & 0.274 \\
\hline & ALT, BIO03, BIO15, BIO18, BIO19, SAND, SILT, STR & 0.896 & 38956.785 & 0.628 & 0.2 \\
\hline & ALT, BIO02, BIO03, BIO15, BIO18, BIO19, SILT, STR & 0.896 & 38958.024 & 1.867 & 0.108 \\
\hline & ALT, BIO03, BIO15, BIO18, BIO19, CLAY, SILT, STR & 0.896 & 38958.08 & 1.923 & 0.105 \\
\hline \multirow{4}{*}{$S_{\text {polA arb }}$} & BIO02, BIO03, BIO15, BIO18, BIO19, SILT, STR & 0.914 & 40721.762 & 0 & 0.272 \\
\hline & BIO02, BIO03, BIO15, BIO18, BIO19, CLAY, SILT, STR & 0.914 & 40723.019 & 1.257 & 0.145 \\
\hline & BIO02, BIO03, BIO15, BIO18, BIO19, SAND, SILT, STR & 0.914 & 40723.571 & 1.808 & 0.11 \\
\hline & ALT, BIO02, BIO03, BIO15, BIO18, BIO19, SILT, STR & 0.914 & 40723.626 & 1.863 & 0.107 \\
\hline \multirow{11}{*}{$S_{\text {polA aqu }}$} & ALT, BIO03, BIO19, CLAY, SILT, STR & 0.867 & 23943.307 & 0 & 0.051 \\
\hline & ALT, BIO03, BIO19, SILT, STR & 0.867 & 23943.451 & 0.144 & 0.047 \\
\hline & ALT, BIO02, BIO03, BIO19, SILT, STR & 0.867 & 23944.216 & 0.91 & 0.032 \\
\hline & ALT, BIO02, BIO03, BIO19, CLAY, SILT, STR & 0.868 & 23944.356 & 1.049 & 0.030 \\
\hline & ALT, BIO03, BIO18, BIO19, SILT, STR & 0.867 & 23944.416 & 1.109 & 0.029 \\
\hline & ALT, BIO03, BIO18, BIO19, CLAY, SILT, STR & 0.867 & 23944.614 & 1.307 & 0.027 \\
\hline & ALT, BIO03, BIO15, BIO19, CLAY, SILT, STR & 0.867 & 23944.652 & 1.345 & 0.026 \\
\hline & ALT, BIO03, BIO15, BIO19, SILT, STR & 0.867 & 23944.853 & 1.546 & 0.024 \\
\hline & ALT, BIO03, BIO15, BIO18, BIO19, SILT, STR & 0.867 & 23945.138 & 1.831 & 0.020 \\
\hline & ALT, BIO02, BIO03, BIO18, BIO19, SILT, STR & 0.867 & 23945.161 & 1.854 & 0.020 \\
\hline & ALT, BIO03, BIO19, CLAY, SAND, SILT, STR & 0.867 & 23945.297 & 1.990 & 0.019 \\
\hline \multirow{12}{*}{$S_{\text {pola fos }}$} & ALT, BIO03, BIO15, BIO18, CLAY, SILT, STR & 0.880 & 12877.337 & 0 & 0.071 \\
\hline & ALT, BIO03, BIO15, BIO18, CLAY, SAND, SILT, STR & 0.880 & 12877.412 & 0.075 & 0.068 \\
\hline & ALT, BIO03, BIO15, BIO18, SILT, STR & 0.880 & 12877.651 & 0.314 & 0.061 \\
\hline & ALT, BIO03, BIO15, BIO18, BIO19, CLAY, SAND, SILT, STR & 0.880 & 12877.855 & 0.518 & 0.055 \\
\hline & ALT, BIO03, BIO15, BIO18, SAND, SILT, STR & 0.880 & 12878.224 & 0.886 & 0.046 \\
\hline & ALT, BIO03, BIO15, BIO18, BIO19, CLAY, SILT, STR & 0.880 & 12878.313 & 0.976 & 0.044 \\
\hline & ALT, BIO03, BIO15, BIO18, BIO19, SILT, STR & 0.880 & 12878.787 & 1.450 & 0.034 \\
\hline & ALT, BIO02, BIO03, BIO15, BIO18, CLAY, SAND, SILT, STR & 0.880 & 12878.837 & 1.500 & 0.034 \\
\hline & ALT, BIO03, BIO15, BIO18, BIO19, SAND, SILT, STR & 0.880 & 12878.964 & 1.626 & 0.032 \\
\hline & ALT, BIO03, BIO15, BIO18, CLAY, SAND, STR & 0.880 & 12879.152 & 1.815 & 0.029 \\
\hline & ALT, BIO03, BIO15, BIO18, SAND, STR & 0.880 & 12879.161 & 1.824 & 0.029 \\
\hline & ALT, BIO02, BIO03, BIO15, BIO18, CLAY, SILT, STR & 0.880 & 12879.176 & 1.839 & 0.028 \\
\hline
\end{tabular}



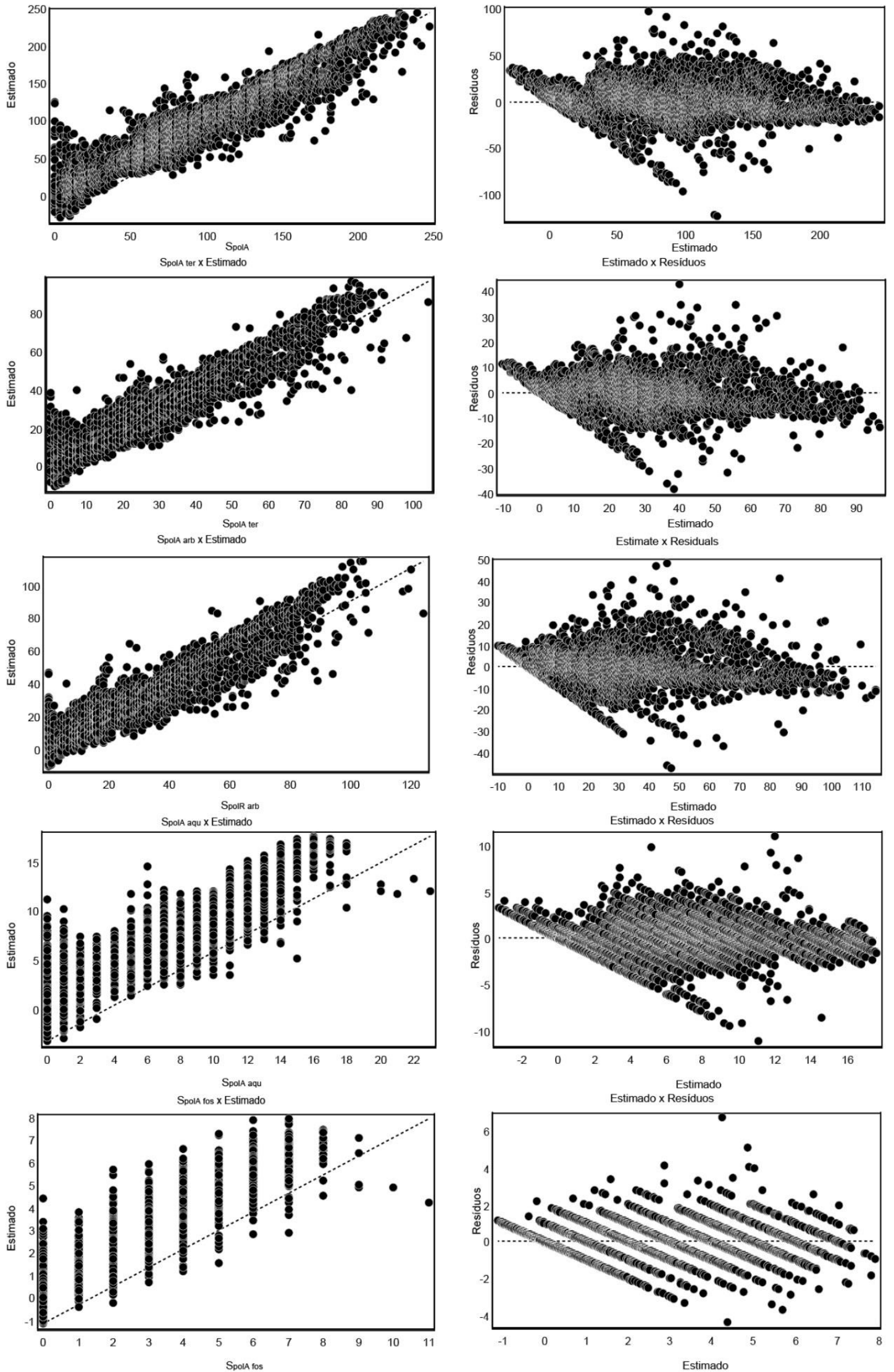

FIGURA 20. Resultados do modelo auto-regressivo para riqueza de anfíbios $\left(S_{\text {pola }}\right)$, terrestres $\left(S_{\text {pola ter }}\right)$, arborícolas $\left(S_{\text {polA arb }}\right)$, aquáticas $\left(S_{\text {polA aqu }}\right)$, fossoriais $\left(S_{\text {polA fos }}\right)$, como variável resposta, e 10 variáveis explanatórias. 
TABELA 9. Parâmetros calculados para o melhor modelo que explica a variação na riqueza taxonômica de anfíbios $\left(S_{\text {polA }}\right)$, riqueza de espécies de anfíbios terrestres $\left(S_{\text {polA ter }}\right)$, , riqueza de espécies de anfíbios aquáticas $\left(S_{\text {polA aqu }}\right)$, riqueza de espécies de anfíbios fossoriais $\left(S_{\text {polA fos }}\right)$, de acordo com o Critério de informação de Akaike (AICC). ALT: altitude, BIO2: Amplitude média diária, BIO3: Isotermalidade (BIO2/BIO7) (*100), BIO15: Sazonalidade na precipitação, BIO18: Precipitação do trimestre mais quente, BIO19: Precipitação do trimestre mais frio, CLAY: porcentagem de cascalho no solo, SAND: porcentagem de areia no solo; SILT: porcentagem de silte no solo, STR: índice de estrutura ambiental.

\begin{tabular}{lcc|cc|cc|cc|cc}
\hline \multirow{2}{*}{ Variáveis } & \multicolumn{2}{c|}{$\boldsymbol{S}_{\text {polA }}$} & \multicolumn{2}{c|}{$\boldsymbol{S}_{\text {polA ter }}$} & \multicolumn{2}{c|}{$\boldsymbol{S}_{\text {polA arb }}$} & \multicolumn{2}{c|}{$\boldsymbol{S}_{\text {polA aqu }}$} & \multicolumn{2}{c}{$\boldsymbol{S}_{\text {polA fos }}$} \\
& Coef. & C.P. & Coef. & C.P. & Coef. & Coef. & C.P. & Coef. & C.P. & Coef. \\
\hline Constante & -25.892 & 0 & -6.113 & 0 & -7.947 & 0 & -1.101 & 0 & -0.55 & 0 \\
ALT & -0.002 & -0.025 & $<0.001$ & -0.024 & - & - & $<0.001$ & -0.036 & $<0.001$ & -0.014 \\
BIO02 & - & - & - & - & -0.012 & -0.012 & - & - & - & - \\
BIO03 & 0.315 & 0.073 & 0.089 & 0.065 & 0.105 & 0.061 & 0.012 & 0.033 & 0.008 & 0.054 \\
BIO15 & -0.052 & -0.026 & -0.015 & -0.023 & -0.027 & -0.033 & - & - & -0.002 & -0.021 \\
BIO18 & 0.009 & 0.035 & 0.004 & 0.043 & 0.003 & 0.033 & - & - & $<0.001$ & 0.012 \\
BIO19 & -0.004 & -0.023 & -0.002 & -0.035 & -0.002 & -0.034 & $<0.001$ & -0.013 & - & - \\
CLAY & 0.070 & 0.009 & - & - & - & - & 0.005 & 0.008 & 0.002 & 0.008 \\
SAND & - & - & - & - & - & - & - & - & - & - \\
SILT & 0.053 & 0.007 & 0.025 & 0.011 & 0.039 & 0.013 & 0.006 & 0.01 & -0.003 & -0.012 \\
STR & 31.495 & 0.123 & 6.766 & 0.083 & 9.178 & 0.088 & 1.596 & 0.075 & 0.553 & 0.061 \\
MAR $_{\text {A }}$ & 0.772 & 0.777 & 0.815 & 0.813 & 0.824 & 0.825 & 0.857 & 0.84 & 0.854 & 0.836 \\
\hline
\end{tabular}

\subsubsection{Endemismo}

\subsubsection{Répteis}

Os polígonos referentes a um total de 2139 espécies, 232 gêneros, 36 famílias, e três ordens (APÊNDICE 3) apresentaram índices de endemismo individual médio de 0.0003 (variando entre 0 e 0.011$)$. O índice local de endemismo $\left(E_{R}\right)$ médio foi de $0.004(0-0.023)$ (FIGURA 21). O endemismo médio das áreas Abertas foi de 0.0003 (0-0.0115), das Florestas 0.0003 (0-0.0236), e da região Andina 0.0009 (0-0.0148).

A regressão das variáveis ambientais pelo endemismo resultou em 10 variáveis explanatórias (FIGURA 22) (ALT, BIO02, BIO03, BIO15, BIO18, BIO19, CLAY, SAND, SILT, STR) com VIF < 3 (FIGURA 23), e explicou apenas $8.8 \%$ da variação observada no endemismo ( $n=$ $\left.6147 ; r^{2}=0.088\right)$ (TABELA 10). 

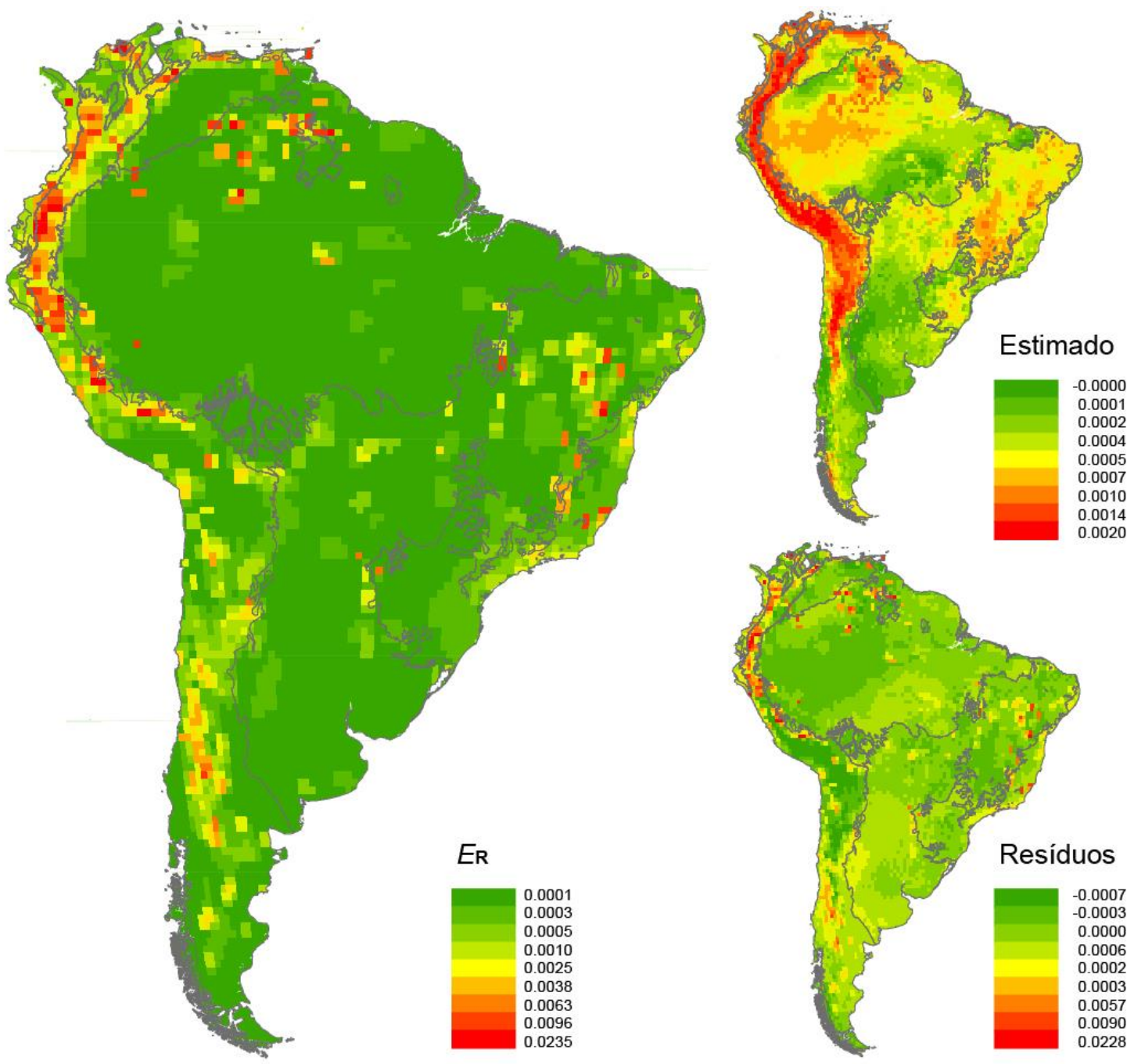

FIGURA 21. Índices de endemismo calculados $\left(E_{\mathrm{R}}\right)$ pelo pela soma local do inverso da área do polígonos de espécies, gêneros, famílias e ordens de répteis; valores estimados na análise de regressão da $S_{\text {polR }} \mathrm{e}$ seus resíduos.
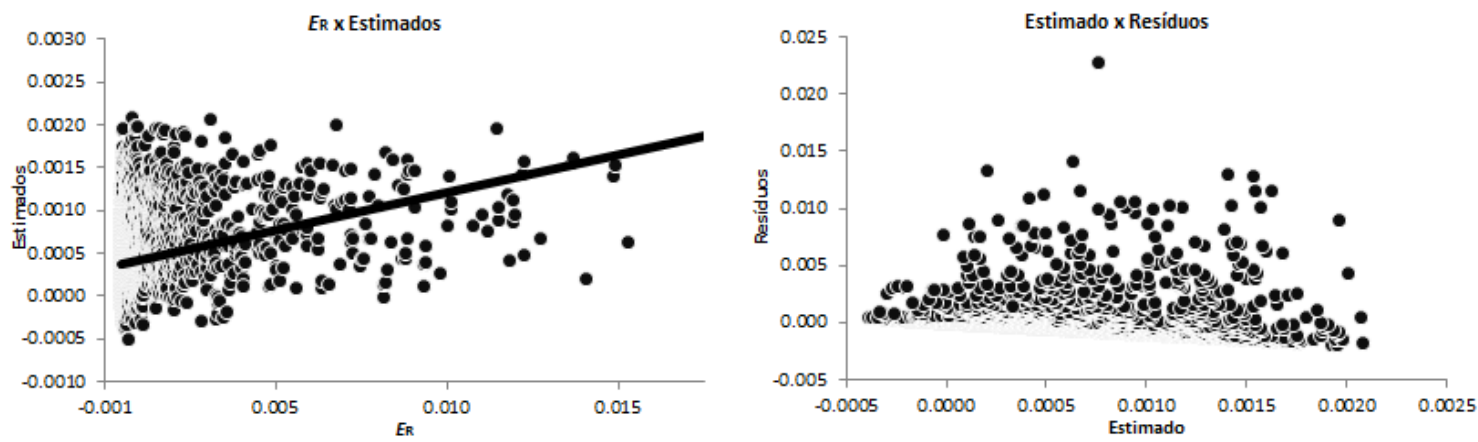

FIGURA 22. Resultados da análise de regressão múltipla para o índice de endemismo local de répteis $\left(E_{\mathrm{R}}\right)$ como variável resposta, e 10 variáveis explanatórias ambientais. 

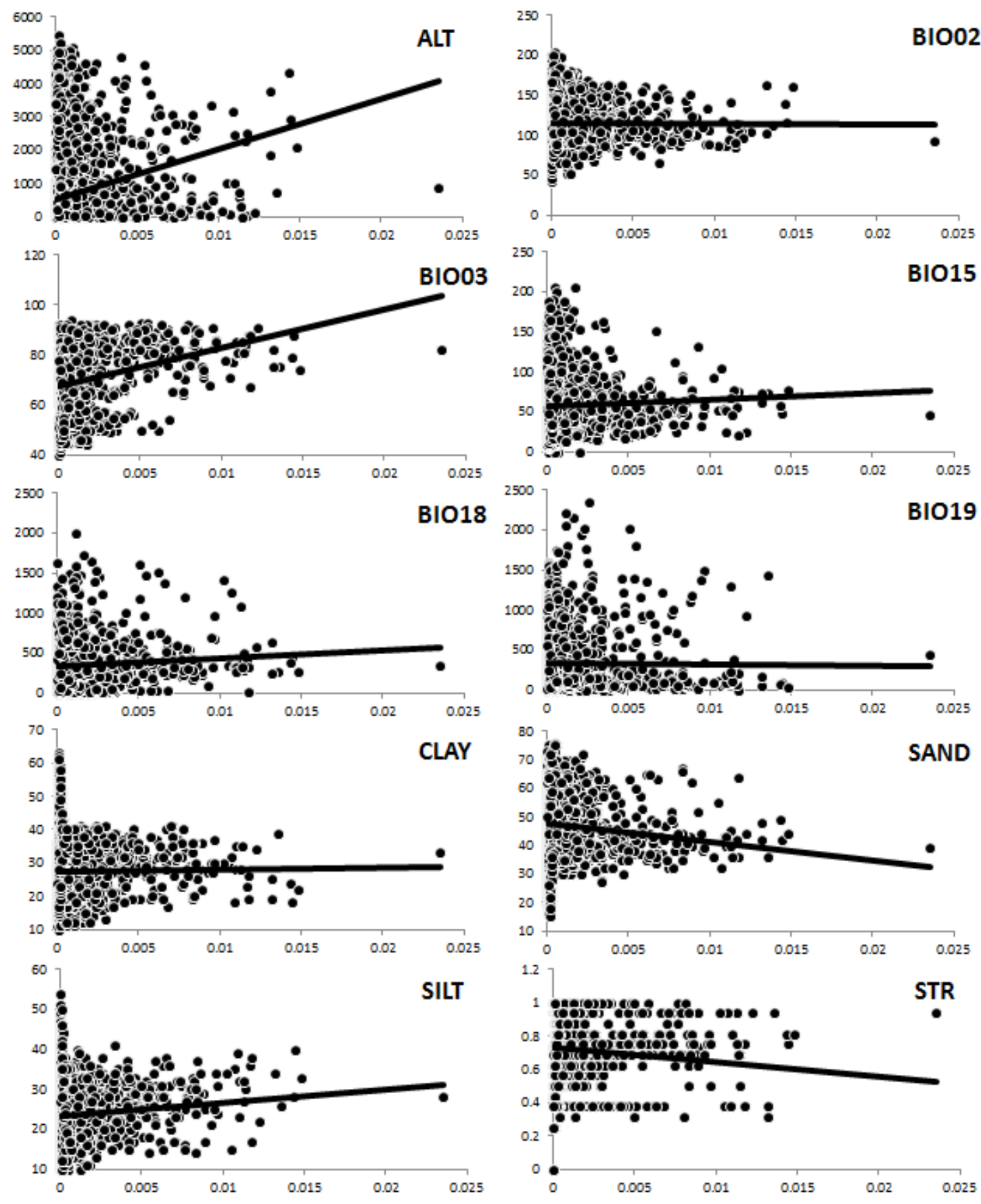

FIGURA 23. Relação do nível de endemismo de répteis $\left(E_{R}\right)$ e as 10 variáveis explanatórias com VIF menor que 3. ALT: altitude, BIO2: Amplitude média diária, BIO3: Isotermalidade (BIO2/BIO7) (* 100), BIO15: Sazonalidade na precipitação, BIO18: Precipitação do trimestre mais quente, BIO19: Precipitação do trimestre mais frio, CLAY: porcentagem de cascalho no solo, SAND: porcentagem de areia no solo; SILT: porcentagem de silte no solo, STR: índice de estrutura ambiental. 
TABELA 10. Resultados das análises de regressão múltipla para o nível de endemismo répteis $\left(E_{\mathrm{R}}\right)$, como variável resposta, e 10 variáveis explanatórias. VIF: fator de inflação de variância; Coef.: coeficiente de regressão; C.P.: coeficiente padronizado. ALT: altitude, BIO2: Amplitude média diária, BIO3: Isotermalidade (BIO2/BIO7) (* 100), BIO15: Sazonalidade na precipitação, BIO18: Precipitação do trimestre mais quente, BIO19: Precipitação do trimestre mais frio, CLAY: porcentagem de cascalho no solo, SAND: porcentagem de areia no solo; SILT: porcentagem de silte no solo, STR: índice de estrutura ambiental.

\begin{tabular}{lccc}
\hline Variável & VIF & Coef. & C.P. \\
\hline Constante & & $<0.001$ & 0 \\
ALT & 1.781 & $<0.001$ & 0.182 \\
BIO02 & 2.233 & $<0.001$ & -0.085 \\
BIO03 & 2.536 & $<0.001$ & 0.251 \\
BIO15 & 1.704 & $<0.001$ & -0.040 \\
BIO18 & 1.472 & $<0.001$ & 0.043 \\
BIO19 & 1.97 & $<0.001$ & -0.073 \\
CLAY & 1.311 & $<0.001$ & 0.021 \\
SAND & 1.408 & $<0.001$ & -0.071 \\
SILT & 1.283 & $<0.001$ & 0.011 \\
STR & 2.739 & 0.001 & -0.192 \\
\hline
\end{tabular}

O correlograma dividido em 25 classes de distância indica que mesmo após a extração dos resíduos ainda existe uma certa auto-correlação. Classes de distância menores tendem a ter valores positivamente auto-correlacionados, classes de distância intermediarias tendem a ter valores negativamente auto-correlacionados, e classes de distância mais altas voltam a apresentar valores positivamente auto-correlacionados (FIGURA 24).

A matriz de conectividade, baseada no critério de Gabriel, calculou 12160 conexões entre as quadrículas, apresentando uma distância mínima de 31.791 km, média de 54.216 km, máxima de 189.538 km, e desvio padrão de 6.217 (FIGURA 12). O modelo auto-regressivo baseado no endemismo como variável resposta $\left(E_{R}\right)$, nas variáveis explanatórias $(\mathrm{ALT}, \mathrm{BIO02}$, BIO03, BIO13, BIO15, BIO18, CLAY, SAND, SILT e STR), e na matriz de conectividade, foi calculado ( $n=6147 ; \rho=0.998, r^{2}=0.028$ ) (TABELA 11; FIGURA 25) e incluído como uma variável fixa $\left(M A R_{E R}\right)$, presente em todos os modelos na seleção de modelos.

O procedimento de seleção de modelos aplicado para o nível de endemismo de répteis

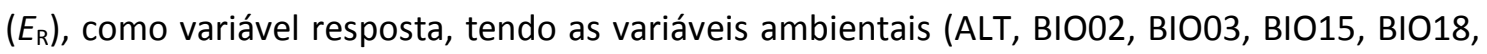
BIO19, CLAY, SAND, SILT e STR) como variáveis explanatórias, testou 1023 modelos. Quatro modelos apresentaram $\triangle \mathrm{AICc}<2$, explicando cerca de $25 \%$ da variação observada. A probabilidade de que o modelo com menor AICc para $E_{R}$ seja o melhor modelo é de apenas 17\% (TABELA 12). Com a inclusão do modelo auto-regressivo ele apresentou o maior coeficiente de regressão, e os valores dos coeficientes de cada variável diminuíram em magnitude, variando entre 0.023 e 0.153, e foram relacionadas negativamente à BIO02, $\mathrm{BIO} 15$, BIO19, CLAY, STR e positivamente à ALT, BIO03 e SAND, com maiores valores nas variáveis BIO03 e ALT (TABELA 13). 


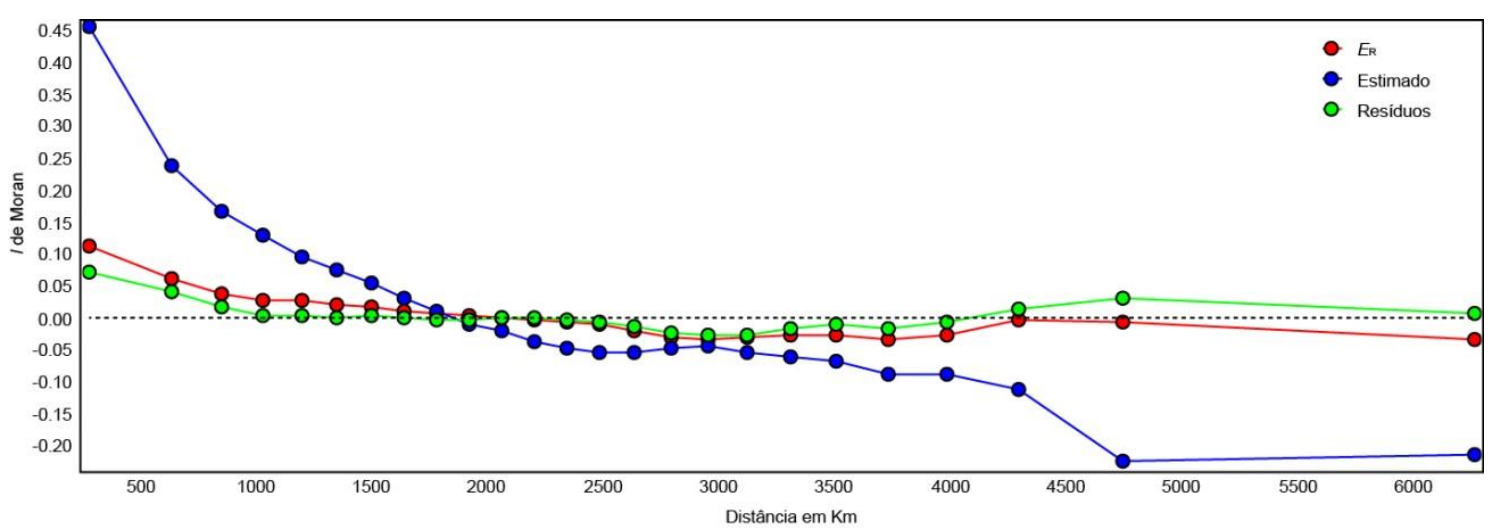

FIGURA 24. Correlograma do I de Moran para o nível de endemismo répteis $\left(E_{\mathrm{R}}\right)$, e para os valores estimados e os resíduos da regressão destas pelas variáveis ambientais.

TABELA 11. Resultados dos cálculos do modelo auto-regressivo para a nível de endemismo de répteis $\left(E_{\mathrm{R}}\right)$, como variáveis resposta, e 10 variáveis explanatórias. Coef.: coeficiente de regressão; C.P.: coeficiente padronizado. ALT: altitude, BIO2: Amplitude média diária, BIO3: Isotermalidade (BIO2/BIO7) (* 100), BIO15: Sazonalidade na precipitação, BIO18: Precipitação do trimestre mais quente, BIO19: Precipitação do trimestre mais frio, CLAY: porcentagem de cascalho no solo, SAND: porcentagem de areia no solo; SILT: porcentagem de silte no solo, STR: índice de estrutura ambiental.

\begin{tabular}{lcc}
\hline Variável & \multicolumn{2}{c}{$E_{\mathrm{R}}$} \\
\hline Constante & Coef. & C.P. \\
ALT & 0.465 & 0 \\
BIO02 & 0.033 & 0.201 \\
BIO03 & $<0.001$ & -0.008 \\
BIO15 & -0.004 & -0.242 \\
BIO18 & -0.002 & -0.278 \\
BIO19 & $<0.001$ & 0.259 \\
CLAY & $<0.001$ & -0.055 \\
SAND & $<0.001$ & 0.041 \\
SILT & $<0.001$ & 0.046 \\
STR & -0.002 & -0.017 \\
\hline
\end{tabular}
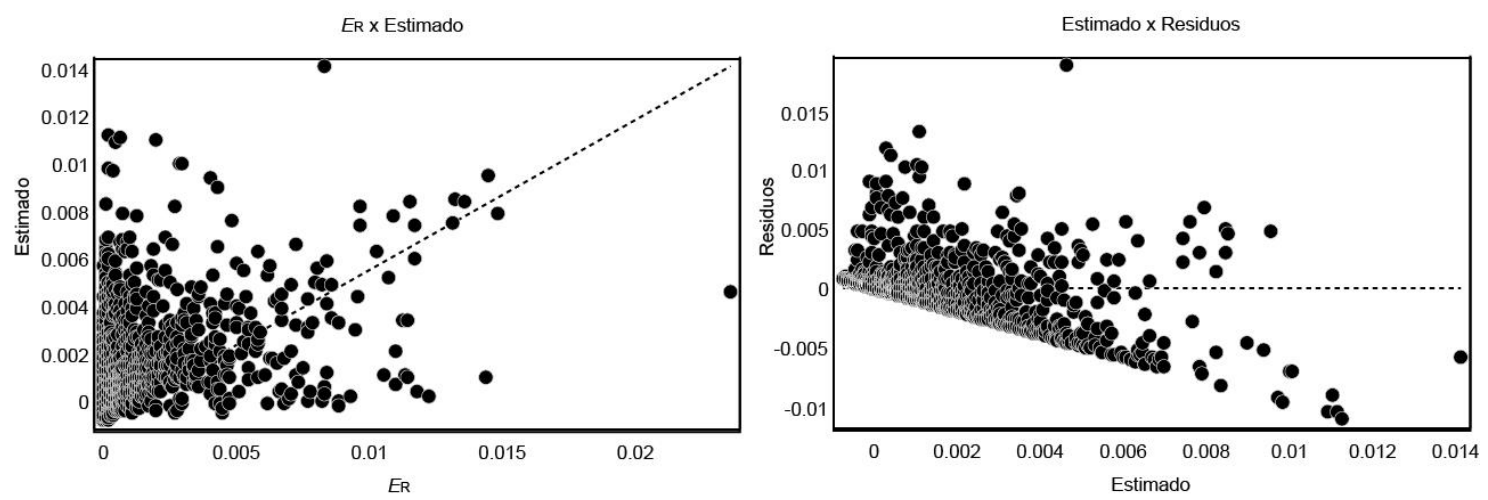

FIGURA 25. Resultados do modelo auto-regressivo para endemismo de répteis $\left(E_{R}\right)$ como variável resposta, e 10 variáveis explanatórias ambientais. 
TABELA 12. Resultado do procedimento de seleção de modelos que melhor explicam a variação observada no nível de endemismo $\left(E_{R}\right)$, definidos pelo Critério de Informação de Akaike (AICc) e peso de Akaike $\left(\mathbf{w}_{\mathrm{i}}\right)$. Foram avaliados 1023 modelos para cada riqueza, aqui são mostrados apenas os que apresentam $\triangle \mathrm{AICC}$ menores que 2. ALT: altitude, BIO2: Amplitude média diária, BIO3: Isotermalidade (BIO2/BIO7) (*100), BIO15: Sazonalidade na precipitação, BIO18: Precipitação do trimestre mais quente, BIO19: Precipitação do trimestre mais frio, CLAY: porcentagem de cascalho no solo, SAND: porcentagem de areia no solo; SILT: porcentagem de silte no solo, STR: índice de estrutura ambiental.

\begin{tabular}{lcccc}
\hline Variáveis & $\mathbf{r}^{2}$ & AICC & AAICC & ${\text { AICC } \mathbf{w}_{\mathbf{i}}}^{\mathbf{2}}$ \\
\hline ALT, BIO02, BIO03, BIO15, BIO19, SILT, SAND, STR & 0.249 & -66871.625 & 0 & 0.168 \\
\hline ALT, BIO02, BIO03, BIO15, BIO18, BIO19, SAND, SILT, STR & 0.249 & -66871.162 & 0.463 & 0.133 \\
\hline ALT, BIO02, BIO03, BIO15, BIO19, SAND, STR & 0.249 & -66870.059 & 1.566 & 0.077 \\
\hline ALT, BIO02, BIO03, BIO15, BIO18, BIO19, SAND, STR & 0.249 & -66869.831 & 1.794 & 0.069 \\
\hline ALT, BIO02, BIO03, BIO18, BIO19, CLAY, SILT, SAND, STR & 0.249 & -66869.706 & 1.919 & 0.064 \\
\hline ALT, BIO02, BIO03, BIO18, BIO19, SILT, SAND, STR & 0.249 & -66869.692 & 1.933 & 0.064 \\
\hline
\end{tabular}

TABELA 13. Parâmetros calculados para o melhor modelo que explica a variação no nível de endemismo $\left(E_{R}\right)$, de acordo com o Critério de informação de Akaike (AICC). ALT: altitude, BIO2: Amplitude média diária, BIO3: Isotermalidade (BIO2/BIO7) (* 100), BIO15: Sazonalidade na precipitação, BIO18: Precipitação do trimestre mais quente, BIO19: Precipitação do trimestre mais frio, CLAY: porcentagem de cascalho no solo, SAND: porcentagem de areia no solo; SILT: porcentagem de silte no solo, STR: índice de estrutura ambiental.

\begin{tabular}{lcc}
\hline Variáveis & Coef. & $E_{\mathrm{R}}$ \\
\hline Constante & $<0.001$ & 0 \\
ALT & $<0.001$ & 0.101 \\
BIO02 & $<0.001$ & -0.034 \\
BIO03 & $<0.001$ & 0.153 \\
BIO15 & $<0.001$ & -0.032 \\
BIO19 & $<0.001$ & -0.054 \\
CLAY & $<0.001$ & -0.040 \\
SAND & $<0.001$ & 0.023 \\
STR & $<0.001$ & -0.079 \\
MAR & 0.432 & 0.424 \\
\hline
\end{tabular}

\subsubsection{Anfíbios}

Os polígonos referentes a um total de 2828 espécies, 182 gêneros, 30 famílias, e três ordens (APÊNDICE 3) apresentaram índices de endemismo individual médio de 0.002 (variando entre 0 a 0.155). 0 índice local médio de endemismo $\left(E_{A}\right)$ foi de $0.0018(0-0.138)$ (FIGURA 26). O endemismo médio das áreas Abertas foi de 0.001 (0-0.073), das Florestas 0.002 (0-0.131), e da região Andina 0.004 (0-0.138).

A regressão das variáveis ambientais pelo endemismo (FIGURA 27) resultaram em 10 variáveis explanatórias (ALT, BIO02, BIO03, BIO15, BIO18, BIO19, CLAY, SAND, SILT, STR) com 
VIF < 3 (FIGURA 28), e explicou apenas $9.4 \%$ da variação observada no endemismo ( $n=6147$; $\left.r^{2}=0.094\right)($ TABELA 14).
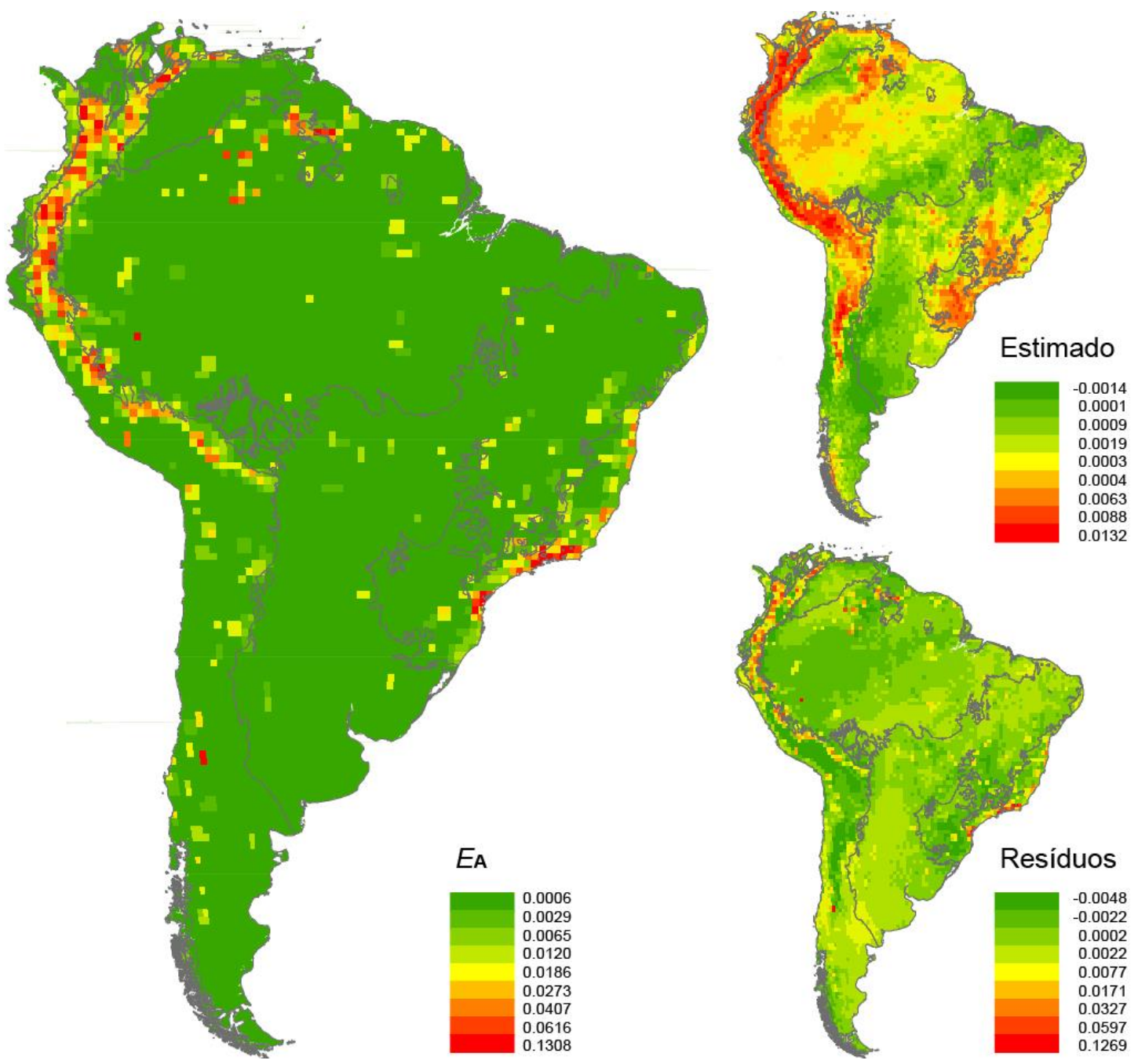

FIGURA 26. Nível de endemismo calculado pelo inverso da área do polígonos $\left(E_{\mathrm{A}}\right)$ de espécies, gêneros, famílias e ordens de anfíbios, valores estimados na análise de regressão da $E_{\mathrm{A}}$ e seus resíduos.
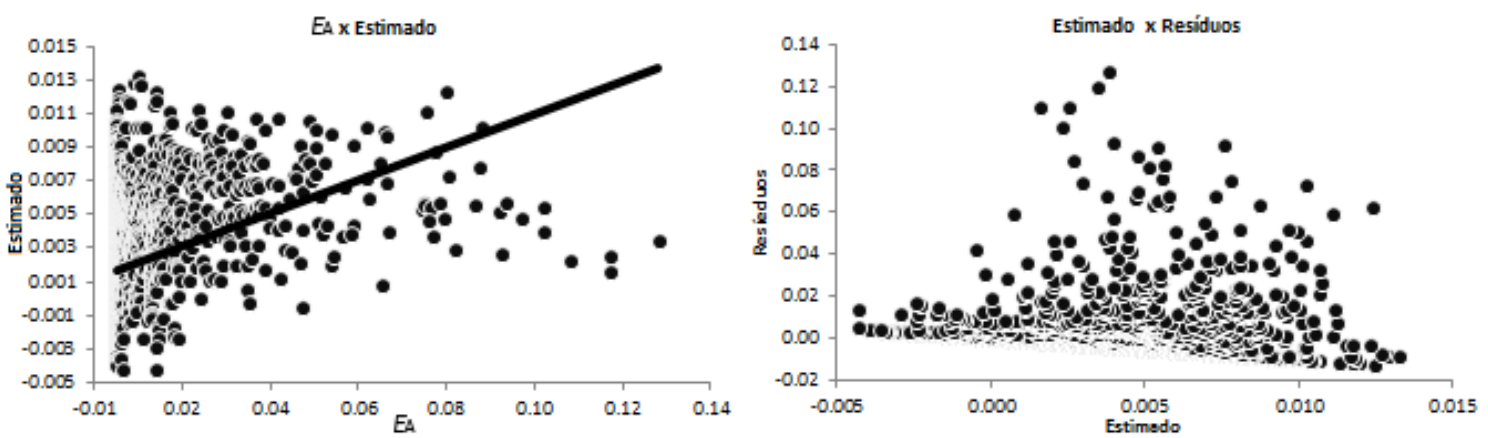

FIGURA 27. Resultados da análise de regressão múltipla do endemismo de anfíbios $\left(E_{\mathrm{A}}\right)$ como variável resposta, e 10 variáveis explanatórias. 

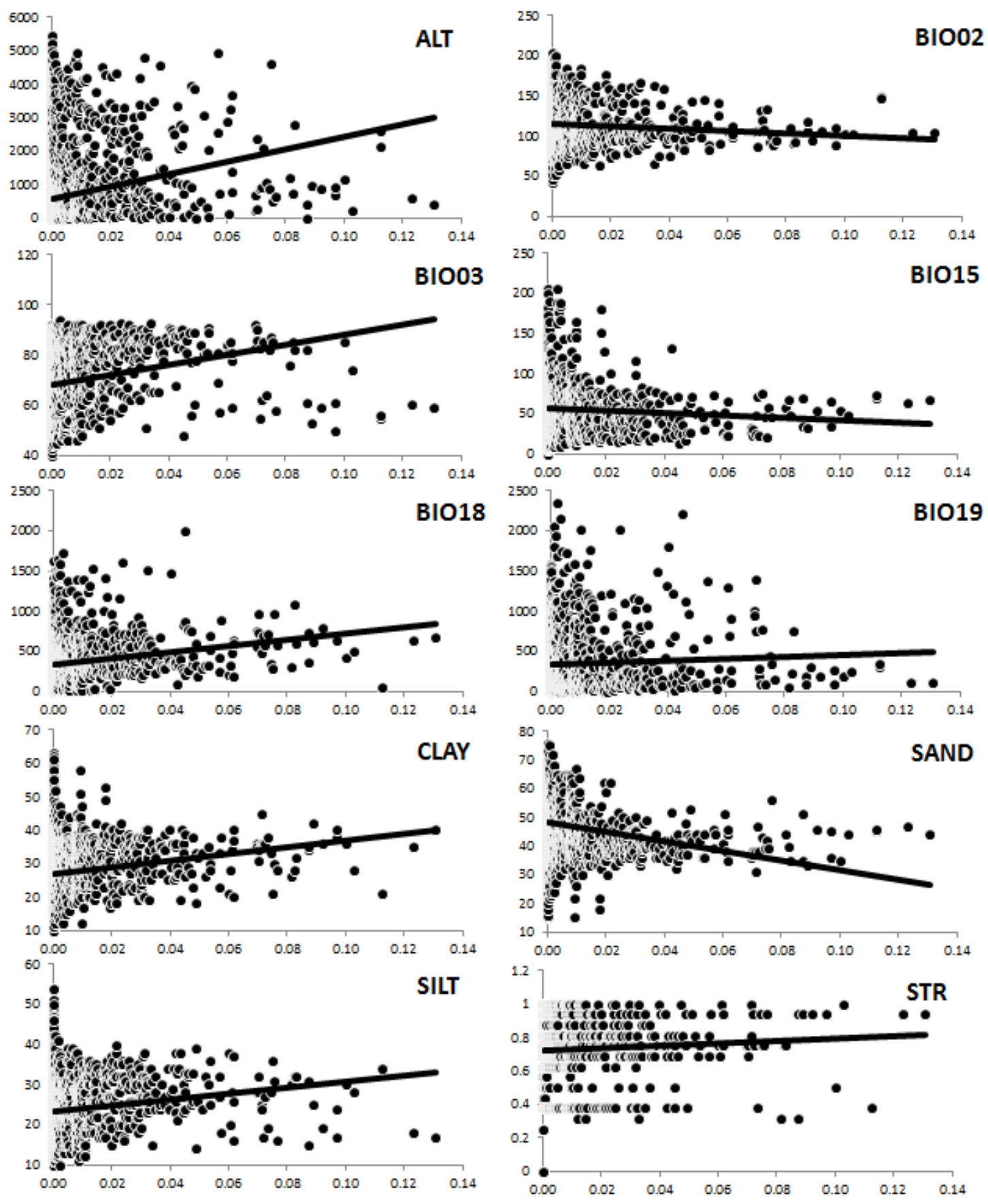

FIGURA 28. Relação do nível de endemismo de anfíbios $\left(E_{\mathrm{A}}\right)$ e as 10 variáveis explanatórias com VIF menor que 3. ALT: altitude, BIO2: Amplitude média diária, BIO3: Isotermalidade (BIO2/BIO7) (* 100), BIO15: Sazonalidade na precipitação, BIO18: Precipitação do trimestre mais quente, BIO19: Precipitação do trimestre mais frio, CLAY: porcentagem de cascalho no solo, SAND: porcentagem de areia no solo; SILT: porcentagem de silte no solo, STR: índice de estrutura ambiental. 
TABELA 14. Resultados das análises de regressão múltipla para o nível de endemismo de anfíbios $\left(E_{\mathrm{A}}\right)$, como variável resposta, e 10 variáveis explanatórias. VIF: fator de inflação de variância; Coef.:coeficiente de regressão; C.P.: coeficiente padronizado. ALT: altitude, BIO2: Amplitude média diária, BIO3: Isotermalidade (BIO2/BIO7) (* 100), BIO15: Sazonalidade na precipitação, BIO18: Precipitação do trimestre mais quente, BIO19: Precipitação do trimestre mais frio, CLAY: porcentagem de cascalho no solo, SAND: porcentagem de areia no solo; SILT: porcentagem de silte no solo, STR: índice de estrutura ambiental.

\begin{tabular}{lccc}
\hline Variável & VIF & Coef. & C.P. \\
\hline Constante & 0 & 0.003 & 0 \\
ALT & 1.781 & $<0.001$ & 0.245 \\
BIO02 & 2.233 & $<0.001$ & -0.139 \\
BIO03 & 2.536 & $<0.001$ & 0.118 \\
BIO15 & 1.704 & $<0.001$ & -0.067 \\
BIO18 & 1.472 & $<0.001$ & 0.113 \\
BIO19 & 1.97 & $<0.001$ & -0.065 \\
CLAY & 1.311 & $<0.001$ & 0.098 \\
SAND & 1.408 & $<0.001$ & -0.052 \\
SILT & 1.283 & $<0.001$ & -0.012 \\
STR & 2.739 & -0.004 & -0.097 \\
\hline
\end{tabular}

Mesmo após a extração dos resíduos o correlograma dividido em 25 classes de distância, ainda apresenta uma certa auto-correlação. Isso revela um padrão geral de classes de distância menores tendendo a ter valores positivamente auto-correlacionados, classes de distância intermediarias com valores negativamente auto-correlacionados, e classes de distância mais altas voltando a apresentar valores positivamente auto-correlacionados (FIGURA 29).

A matriz de conectividade, baseada no critério de Gabriel, calculou 12160 conexões entre as quadrículas, apresentando uma distância mínima de 31.7914 km, média de 54.216 km, e máxima de 189.538 km, e desvio padrão de 6.217 (FIGURA 12). O modelo autoregressivo baseado no endemismo como variável resposta $\left(E_{R}\right)$, nas variáveis explanatórias (ALT, BIO02, BIO03, BIO13, BIO15, BIO18, CLAY, SAND, SILT e STR), e na matriz de conectividade, foi calculado ( $n=6147 ; \rho=0.998, r^{2}=0.217$ ) (TABELA 15; FIGURA 30) e incluído como uma variável fixa $\left(\mathrm{MAR}_{\mathrm{EA}}\right)$, presente em todos os modelos na seleção de modelos.

O procedimento de seleção de modelos aplicado para o nível de endemismo de anfíbios $\left(E_{\mathrm{A}}\right)$, como variável resposta, tendo as variáveis ambientais (ALT, BIO02, BIO03, BIO15, BIO18, BIO19, CLAY, SAND, SILT e STR) como variáveis explanatórias testou 1023 modelos. Dois modelos apresentaram $\triangle \mathrm{AICc}<2$, explicando cerca de $23 \%$ da variação observada. A probabilidade de que o modelo com menor AICc para $E_{\mathrm{A}}$ seja o melhor modelo é de $49 \%$ (TABELA 16). Com a inclusão do modelo auto-regressivo ele apresentou a maior relação com os dados, e assim os valores dos coeficientes de cada variável diminuíram em magnitude, variando entre 0.030 e 0.149, e foram negativamente relacionadas à $\mathrm{BIO02,} \mathrm{BIO} 15, \mathrm{BIO} 19$, SAND, STR e positivamente à ALT, BIO03, BIO18 e CLAY, com maiores valores relacionados a ALT e BIO02 (TABELA 17). 


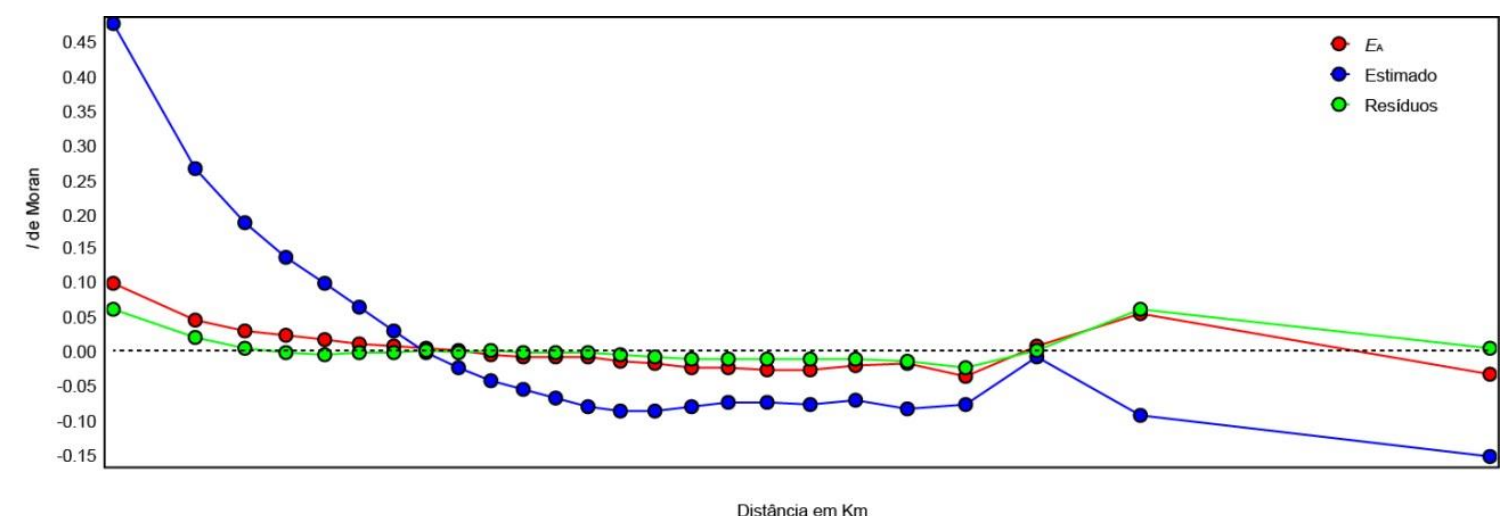

FIGURA 29. Correlograma do I de Moran para o nível de endemismo anfíbios $\left(E_{\mathrm{A}}\right)$, e para os valores estimados e os resíduos da regressão destas pelas variáveis ambientais.

TABELA 15. Resultados dos cálculos do modelo auto-regressivo para a nível de endemismo de anfíbios $\left(E_{\mathrm{A}}\right)$, como variáveis resposta, e 10 variáveis explanatórias. Coef.: coeficiente de regressão; C.P.: coeficiente padronizado. ALT: altitude, BIO2: Amplitude média diária, BIO3: Isotermalidade (BIO2/BIO7) (* 100), BIO15: Sazonalidade na precipitação, BIO18: Precipitação do trimestre mais quente, BIO19: Precipitação do trimestre mais frio, CLAY: porcentagem de cascalho no solo, SAND: porcentagem de areia no solo; SILT: porcentagem de silte no solo, STR: índice de estrutura ambiental.

\begin{tabular}{lcc}
\hline \multirow{2}{*}{ Variável } & \multicolumn{2}{c}{$E_{\mathrm{A}}$} \\
\hline Constante & Coef. & C.P. \\
ALT & -0.038 & 0 \\
BIO02 & $<0.001$ & 0.039 \\
BIO03 & 0.002 & 0.034 \\
BIO15 & -0.002 & -0.028 \\
BIO18 & -0.001 & -0.037 \\
BIO19 & $<0.001$ & 0.011 \\
CLAY & $<0.001$ & -0.019 \\
SAND & -0.003 & -0.024 \\
SILT & $<0.001$ & -0.001 \\
STR & 0.004 & 0.03 \\
\hline
\end{tabular}

EA x Estimado

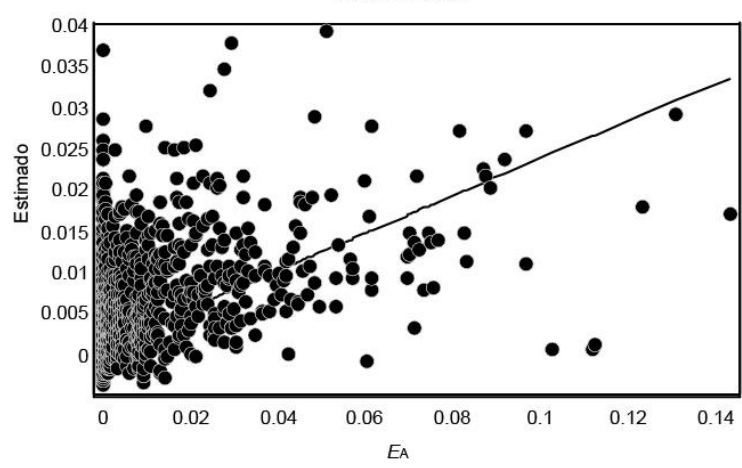

Estimado $\times$ Residuos

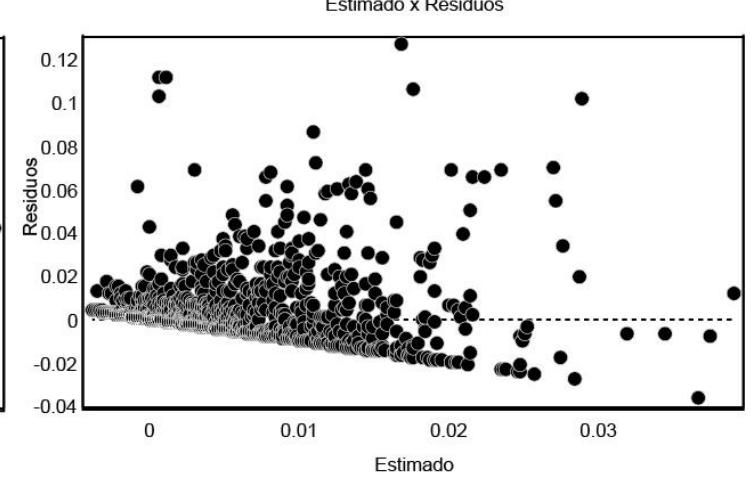

FIGURA 30. Resultados do modelo auto-regressivo para o nível de endemismo de anfíbios $\left(E_{\mathrm{A}}\right)$, como variável resposta, e 10 variáveis explanatórias. 
TABELA 16. Resultado do procedimento de seleção de modelos lineares $\left(r^{2}\right)$ que melhor explicam a variação observada no nível de endemismo de anfíbios $\left(E_{\mathrm{A}}\right)$, definidos pelo Critério de Informação de Akaike (AICC) e peso de Akaike $\left(\mathbf{w}_{\mathbf{i}}\right)$. Foram avaliados 1023 modelos para cada riqueza, aqui são mostrados apenas os que apresentam $\triangle \mathrm{AICC}$ menores que 2. ALT: altitude, BIO2: Amplitude média diária, BIO3: Isotermalidade (BIO2/BIO7) (* 100), BIO15: Sazonalidade na precipitação, BIO18: Precipitação do trimestre mais quente, BIO19: Precipitação do trimestre mais frio, CLAY: porcentagem de cascalho no solo, SAND: porcentagem de areia no solo; SILT: porcentagem de silte no solo, STR: índice de estrutura ambiental.

\begin{tabular}{|c|c|c|c|c|}
\hline Variáveis & $r^{2}$ & AICc & $\triangle \mathrm{AICc}$ & AlCc $w_{i}$ \\
\hline ALT, BIO02, BIO03, BIO15, BIO18, BIO19, CLAY, SAND, STR & 0.226 & -43103.469 & 0 & 0.489 \\
\hline ALT, BIO02, BIO03, BIO15, BIO18, BIO19, CLAY, SAND, SILT, STR & 0.226 & -43101.812 & 1.657 & 0.213 \\
\hline
\end{tabular}

TABELA 17. Parâmetros calculados para o melhor modelo que explica a variação no nível de endemismo de anfíbios $\left(E_{\mathrm{A}}\right)$, de acordo com o Critério de informação de Akaike (AICC). ALT: altitude, BIO2: Amplitude média diária, BIO3: Isotermalidade (BIO2/BIO7) (* 100), BIO15: Sazonalidade na precipitação, BIO18: Precipitação do trimestre mais quente, BIO19: Precipitação do trimestre mais frio, CLAY: porcentagem de cascalho no solo, SAND: porcentagem de areia no solo; SILT: porcentagem de silte no solo, STR: índice de estrutura ambiental.

\begin{tabular}{lcc}
\hline Variáveis & Coef. & $E_{\mathrm{A}}$ \\
\hline Constante & 0.002 & C.P. \\
ALT & $<0.001$ & 0 \\
BIO02 & $<0.001$ & 0.149 \\
BIO03 & $<0.001$ & -0.086 \\
BIO15 & $<0.001$ & 0.073 \\
BIO18 & $<0.001$ & -0.040 \\
BIO19 & $<0.001$ & 0.069 \\
CLAY & $<0.001$ & -0.041 \\
SAND & $<0.001$ & 0.059 \\
STR & -0.002 & -0.030 \\
MAR $_{\text {EA }}$ & 0.385 & -0.060 \\
\hline
\end{tabular}

\subsubsection{Diversidade beta e similaridade}

\subsubsection{Répteis}

Na análise quantitativa de dissimilaridade, os polígonos referentes a um total de 2139 espécies, 232 gêneros, 36 famílias, e três ordens (APÊNDICE 3) produziram uma diversidade beta $\left(\beta_{\mathrm{R}}\right)$ média de 24 (variando entre -0.6 e 108) (FIGURA 31). A diversidade beta média das áreas Abertas foi de 22 (0-46), das Florestas 30 (0-59), e da região Andina 16 (-0.6-108).

A regressão da diversidade beta pelas variáveis ambientais (FIGURA 32) resultou em 10 variáveis explanatórias (ALT, BIO02, BIO03, BIO15, BIO18, BIO19, CLAY, SAND, SILT, STR) com VIF < 3 (FIGURA 33), e a regressão explicou 57\% da variação observada no endemismo ( $n=$ 6147; $\left.r^{2}=0.575\right)($ TABELA 18). 

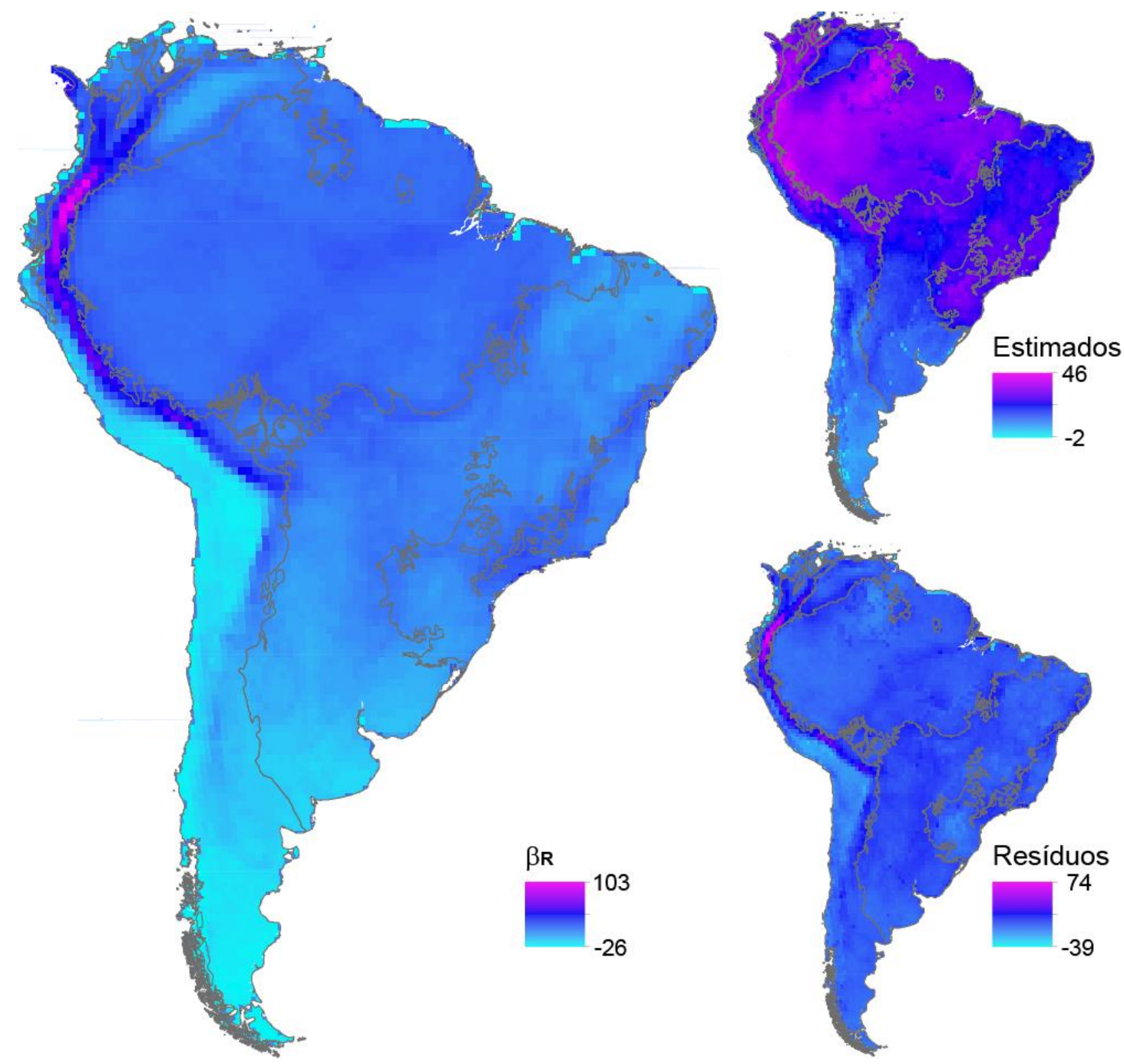

FIGURA 31. Diversidade beta calculado pela sobreposição das distribuições $\left(\beta_{\mathrm{R}}\right)$ de espécies, gêneros, famílias e ordens de répteis, valores estimados na análise de regressão e seus resíduos.
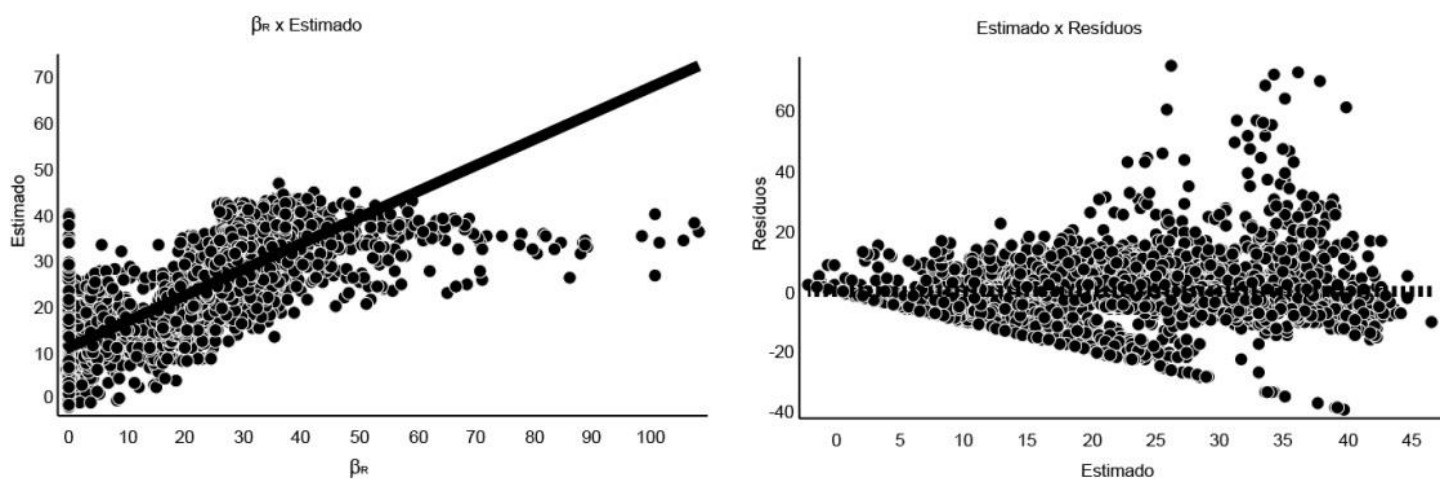

FIGURA 32. Resultados da análise de regressão múltipla para diversidade beta de répteis $\left(\beta_{\mathrm{R}}\right)$ como variável resposta, e 10 variáveis explanatórias. 

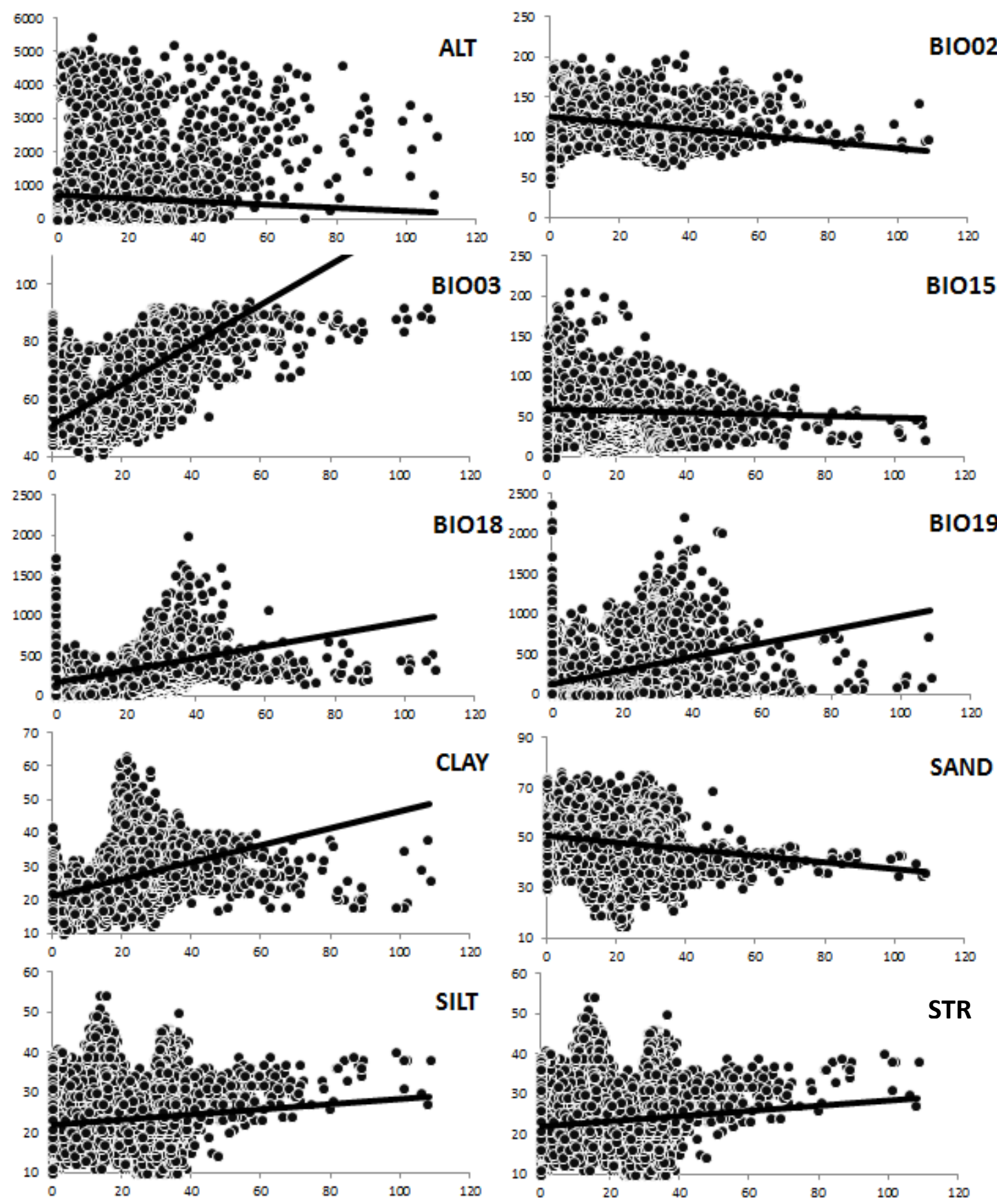

FIGURA 33. Relação da diversidade beta de répteis $\left(\beta_{\mathrm{R}}\right)$ e as 10 variáveis explanatórias com VIF menor que 3. ALT: altitude, BIO2: Amplitude média diária, BIO3: Isotermalidade (BIO2/BIO7) (* 100), BIO15: Sazonalidade na precipitação, BIO18: Precipitação do trimestre mais quente, BIO19: Precipitação do trimestre mais frio, CLAY: porcentagem de cascalho no solo, SAND: porcentagem de areia no solo; SILT: porcentagem de silte no solo, STR: índice de estrutura ambiental. 
TABELA 18. Resultados das análises de regressão múltipla da diversidade beta de répteis $\left(\beta_{\mathrm{R}}\right)$ e 10 variáveis explanatórias. VIF: fator de inflação de variância; Coef.:coeficiente de regressão; C.P.: coeficiente padronizado. ALT: altitude, BIO2: Amplitude média diária, BIO3: Isotermalidade (BIO2/BIO7) (* 100), BIO15: Sazonalidade na precipitação, BIO18: Precipitação do trimestre mais quente, BIO19: Precipitação do trimestre mais frio, CLAY: porcentagem de cascalho no solo, SAND: porcentagem de areia no solo; SILT: porcentagem de silte no solo, STR: índice de estrutura ambiental.

\begin{tabular}{lccc}
\hline Variável & VIF & Coef. & C.P. \\
\hline Constante & & -32.17 & 0 \\
ALT & 1.781 & 0.001 & 0.078 \\
BIO02 & 2.233 & 0.043 & 0.080 \\
BIO03 & 2.536 & 0.466 & 0.501 \\
BIO15 & 1.704 & -0.052 & -0.120 \\
BIO18 & 1.472 & 0.007 & 0.121 \\
BIO19 & 1.97 & -0.005 & -0.147 \\
CLAY & 1.311 & 0.304 & 0.188 \\
SAND & 1.408 & 0.040 & 0.038 \\
SILT & 1.283 & -0.042 & -0.026 \\
STR & 2.739 & 16.874 & 0.303 \\
\hline
\end{tabular}

O correlograma dividido em 25 classes de distância indica que mesmo após a extração dos resíduos, existe uma certa auto-correlação, com um padrão geral onde classes de distância menores tendem a ter valores positivamente auto-correlacionados, classes de distância intermediarias tendem a ter valores negativamente auto-correlacionados, mas próximos de valores aleatórios, e classes de distância mais altas alternando entre positivamente, negativamente e positivamente auto-correlacionados (FIGURA 34).

A matriz de conectividade, baseada no critério de Gabriel, calculou 12160 conexões entre as quadrículas, apresentando uma distância mínima de 31.791 km, média de 54.216 km, máxima de 189.538 km, e desvio padrão de 6.217 (FIGURA 12). O modelo auto-regressivo baseado na diversidade beta de répteis $\left(\beta_{\mathrm{R}}\right)$ como variável resposta, nas variáveis explanatórias (ALT, BIO02, BIO03, BIO13, BIO15, BIO18, CLAY, SAND, SILT e STR), e na matriz de conectividade, foi calculado ( $n=6147 ; \rho=0.998, r^{2}=0.127$ ) (TABELA 19; FIGURA 35) e incluídos como uma variável fixa $\left(\mathrm{MAR}_{\beta \mathrm{R}}\right)$, presente em todos os modelos na seleção de modelos.

$\mathrm{O}$ procedimento de seleção de modelos aplicado à diversidade beta de répteis $\left(\beta_{\mathrm{R}}\right)$, como variável resposta, tendo as variáveis ambientais (ALT, BIO02, BIO03, BIO15, BIO18, BIO19, CLAY, SAND, SILT e STR), como variáveis explanatórias, testou 1023 modelos. Dois modelos apresentaram $\triangle \mathrm{AICc}<2$, explicando cerca de $75 \%$ da variação observada. $A$ probabilidade de que o modelo com menor AICc para $\beta_{\mathrm{R}}$ seja o melhor modelo é de $15 \%$ (TABELA 20). Com a inclusão do modelo auto-regressivo ele apresentou a maior coeficiente, e os valores dos coeficientes de cada variável diminuíram em magnitude, variando entre $0.012 \mathrm{e}$ 0.111, e foram negativamente relacionadas à $\mathrm{BIO15}$ e BIO19, e positivamente à $\mathrm{ALT}, \mathrm{BIO02}$, BIO03, BIO18, CLAY, SAND e STR, com maiores valores relacionados a BIO03 e STR (TABELA 21). 
TABELA 19. Resultados dos cálculos do modelo auto-regressivo para a diversidade beta répteis $\left(\beta_{\mathrm{R}}\right)$, como variável resposta, e 10 variáveis explanatórias. Coef.: coeficiente de regressão; C.P.: coeficiente padronizado. ALT: altitude, BIO2: Amplitude média diária, BIO3: Isotermalidade (BIO2/BIO7) (* 100), BIO15: Sazonalidade na precipitação, BIO18: Precipitação do trimestre mais quente, BIO19: Precipitação do trimestre mais frio, CLAY: porcentagem de cascalho no solo, SAND: porcentagem de areia no solo; SILT: porcentagem de silte no solo, STR: índice de estrutura ambiental.

\begin{tabular}{lcc}
\hline Variável & \multicolumn{2}{c}{$\beta_{\mathrm{R}}$} \\
\hline Constante & Coef. & C.P. \\
ALT & 0.187 & 0 \\
BIO02 & $<0.001$ & 0.145 \\
BIO03 & 0.001 & 0.041 \\
BIO15 & -0.006 & -0.136 \\
BIO18 & -0.006 & -0.291 \\
BIO19 & $<0.001$ & -0.021 \\
CLAY & $<0.001$ & -0.094 \\
SAND & 0.007 & 0.099 \\
SILT & 0.003 & 0.062 \\
STR & 0.003 & 0.046 \\
\hline
\end{tabular}

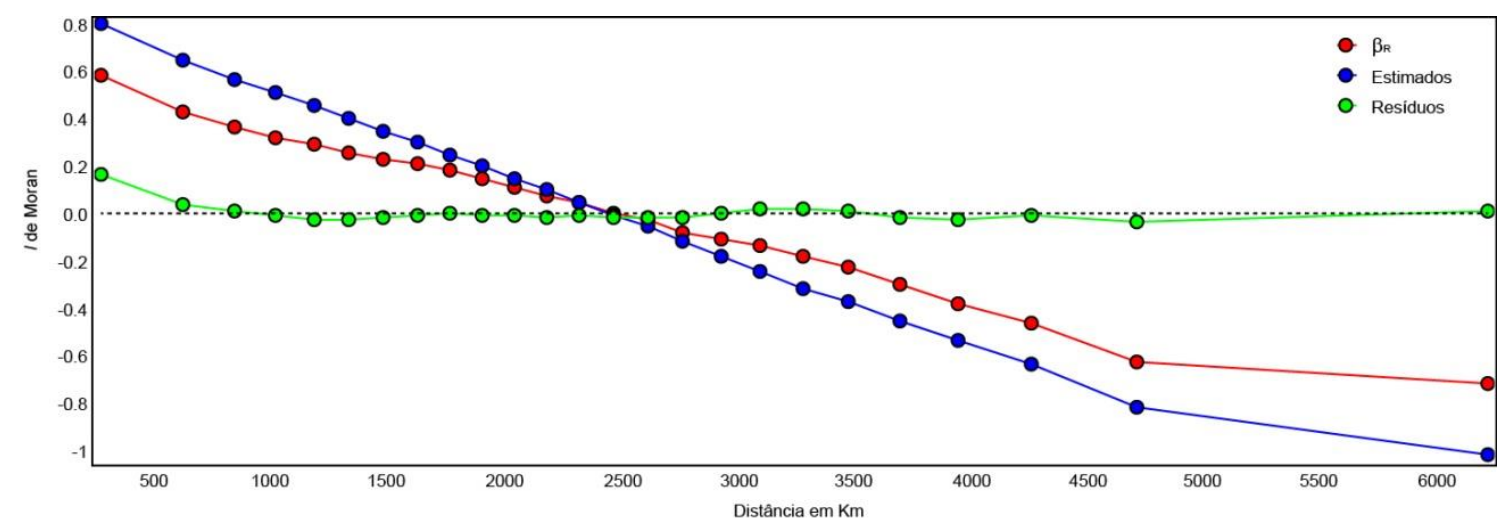

FIGURA 34. Correlograma do I de Moran para a diversidade beta de répteis $\left(\beta_{\mathrm{R}}\right)$, e para os valores estimados e os resíduos da regressão destas pelas variáveis ambientais.
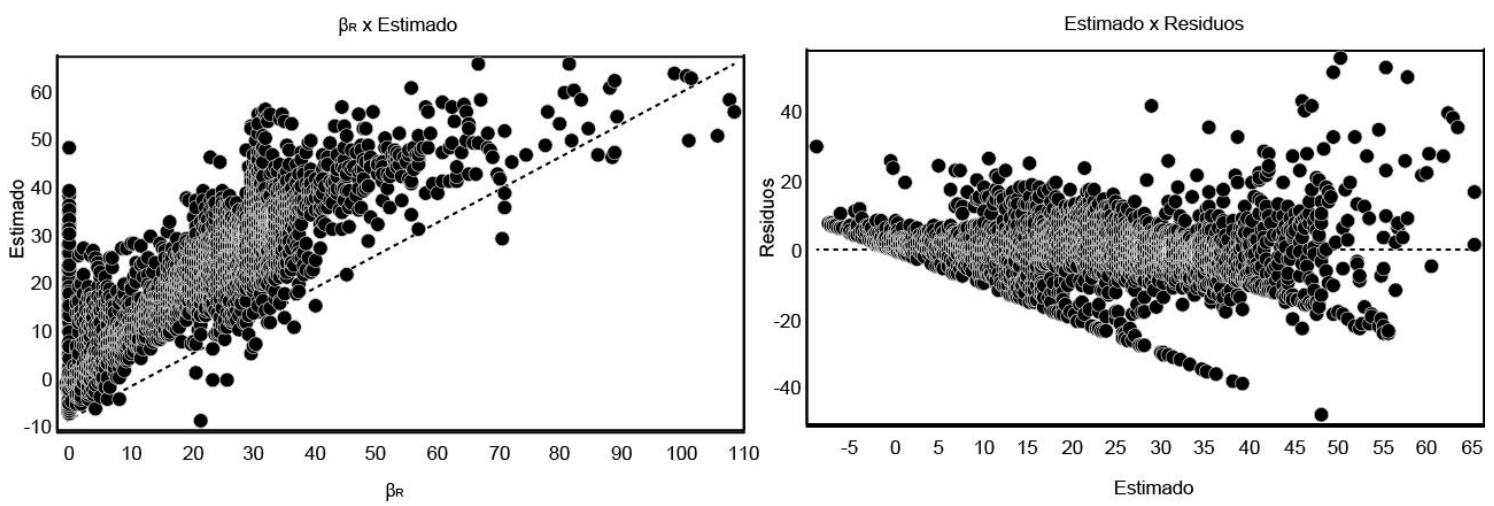

FIGURA 35. Resultados do modelo auto-regressivo para a diversidade beta répteis $\left(\beta_{\mathrm{R}}\right)$, como variável resposta, e 10 variáveis explanatórias. 
$\mathrm{Na}$ análise qualitativa de dissimilaridade os polígonos referentes a um total de 2139 espécies, 232 gêneros, 36 famílias, e três ordens (APÊNDICE 3) foram sobrepostos gerando 1067255 registros, distribuídos em 6374 quadrículas. A dissimilaridade variou entre 0 e 0.974 , e quando submetida aos três valores de corte $(0.5,0.7$ e 0.9) geraram 136, 34 e 3 grupos, respectivamente. Nas áreas Abertas geraram 20, 9, e 2 grupos, nas Florestas 23, 9 e 2 grupos, e na região Andina 116, 28, e 3 grupos, áreas respectivamente nos valores de corte de 0.5, 0.7 e 0.9 (FIGURA 36).

TABELA 20. Resultado do procedimento de seleção de modelos lineares $\left(r^{2}\right)$ que melhor explicam a variação observada na diversidade beta de répteis $\left(\beta_{\mathrm{R}}\right)$, definidos pelo Critério de Informação de Akaike (AICC) e peso de Akaike $\left(w_{i}\right)$. Foram avaliados 1023 modelos para cada riqueza, aqui são mostrados apenas os que apresentam $\triangle \mathrm{AICC}$ menores que 2. ALT: altitude, BIO2: Amplitude média diária, BIO3: Isotermalidade (BIO2/BIO7) (* 100), BIO15: Sazonalidade na precipitação, BIO18: Precipitação do trimestre mais quente, BIO19: Precipitação do trimestre mais frio, CLAY: porcentagem de cascalho no solo, SAND: porcentagem de areia no solo; SILT: porcentagem de silte no solo, STR: índice de estrutura ambiental.

\begin{tabular}{lcccc}
\hline Variáveis & $\mathbf{r}^{\mathbf{2}}$ & AICc & $\Delta$ AICc & ${\text { AICc } \mathbf{w}_{\mathbf{i}}}$ \\
\hline ALT, BIO02, BIO03, BIO15, BIO18, BIO19, CLAY, STR & 0.753 & 39552.669 & 0 & 0.154 \\
\hline ALT, BIO02, BIO03, BIO15, BIO18, BIO19, CLAY, SAND, SILT, STR & 0.753 & 39552.842 & 0.173 & 0.141 \\
\hline BIO02, BIO03, BIO15, BIO18, BIO19, CLAY, STR & 0.753 & 39553.373 & 0.704 & 0.108 \\
\hline ALT, BIO02, BIO03, BIO15, BIO18, BIO19, CLAY, SILT, STR & 0.753 & 39553.428 & 0.759 & 0.106 \\
\hline ALT, BIO03, BIO15, BIO18, BIO19, CLAY, SAND, STR & 0.753 & 39554.051 & 1.382 & 0.077 \\
\hline ALT, BIO02, BIO03, BIO15, BIO18, BIO19, CLAY, SAND, SILT, STR & 0.753 & 39554.214 & 1.544 & 0.071 \\
\hline BIO02, BIO03, BIO15, BIO18, BIO19, CLAY, SAND, STR & 0.753 & 39554.366 & 1.696 & 0.066 \\
\hline
\end{tabular}

TABELA 21. Parâmetros calculados para o melhor modelo que explica a variação na diversidade beta de répteis $\left(\beta_{\mathrm{R}}\right)$, de acordo com o Critério de informação de Akaike (AICC). ALT: altitude, BIO2: Amplitude média diária, BIO3: Isotermalidade (BIO2/BIO7) (* 100), BIO15: Sazonalidade na precipitação, BIO18: Precipitação do trimestre mais quente, BIO19: Precipitação do trimestre mais frio, CLAY: porcentagem de cascalho no solo, SAND: porcentagem de areia no solo; SILT: porcentagem de silte no solo, STR: índice de estrutura ambiental.

\begin{tabular}{lcc}
\hline Variáveis & Coef. & $\beta_{\mathrm{R}}$ \\
\hline Constante & -6.823 & C.P. \\
ALT & $<0.001$ & 0 \\
BIO02 & 0.011 & 0.013 \\
BIO03 & 0.103 & 0.020 \\
BIO15 & -0.011 & 0.111 \\
BIO18 & 0.001 & -0.024 \\
BIO19 & -0.001 & 0.024 \\
CLAY & 0.061 & -0.034 \\
STR & 3.529 & 0.038 \\
\hline
\end{tabular}



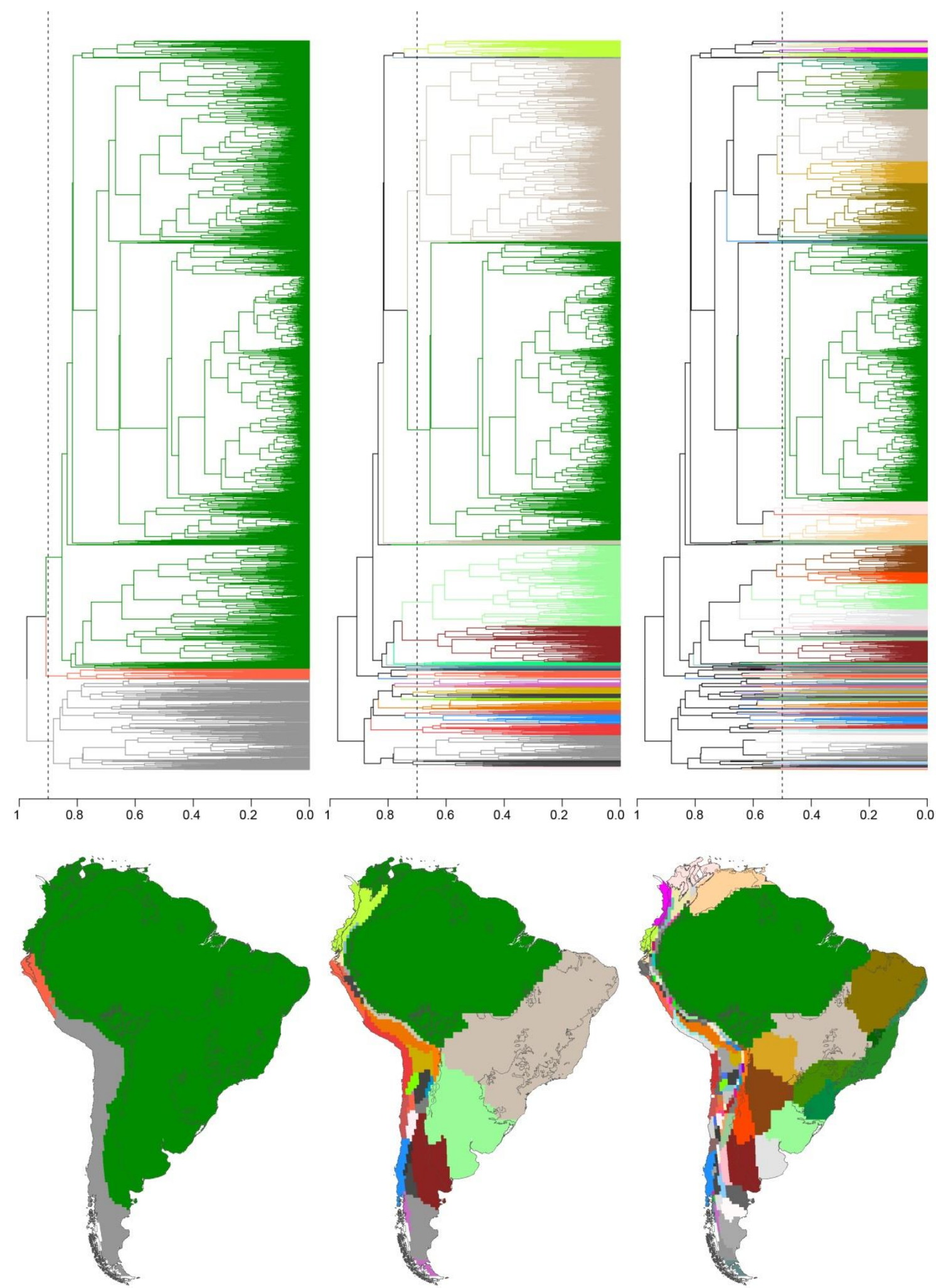

FIGURA 36. Dendrograma de dissimilaridade, baseado no índice de Jaccard (em cima), e distribuição os das áreas definidas por ela (em baixo), calculados pela sobreposição das distribuições de espécies, gêneros, famílias e ordens de répteis, divididos em três níveis de corte diferente 0.9 (esquerda), 0.7 (centro) e 0.5 (direita). 


\subsubsection{Anfíbios}

Os polígonos referentes a um total de 2828 espécies, 182 gêneros, 30 famílias, e 3 ordens (APÊNDICE 3) foram sobrepostos e a diversidade beta calculada por quadrícula $\left(\beta_{\mathrm{A}}\right)$ variou entre -0.5 a 147 (FIGURA 37), com as áreas Abertas apresentando uma média 10 (variando entre 0 e 49), as Florestas de 20 (0-75), e a região Andina de 11 (-0.5-147).

A regressão das variáveis ambientais pela diversidade beta (FIGURA 38) resultou em 10 variáveis explanatórias (ALT, BIO02, BIO03, BIO15, BIO18, BIO19, CLAY, SAND, SILT, STR) com VIF < 3 (FIGURA 39), e a regressão explicou 0.529 da variação observada no endemismo ( $n=$ $\left.6147 ; r^{2}=0.529\right)$ (TABELA 22).
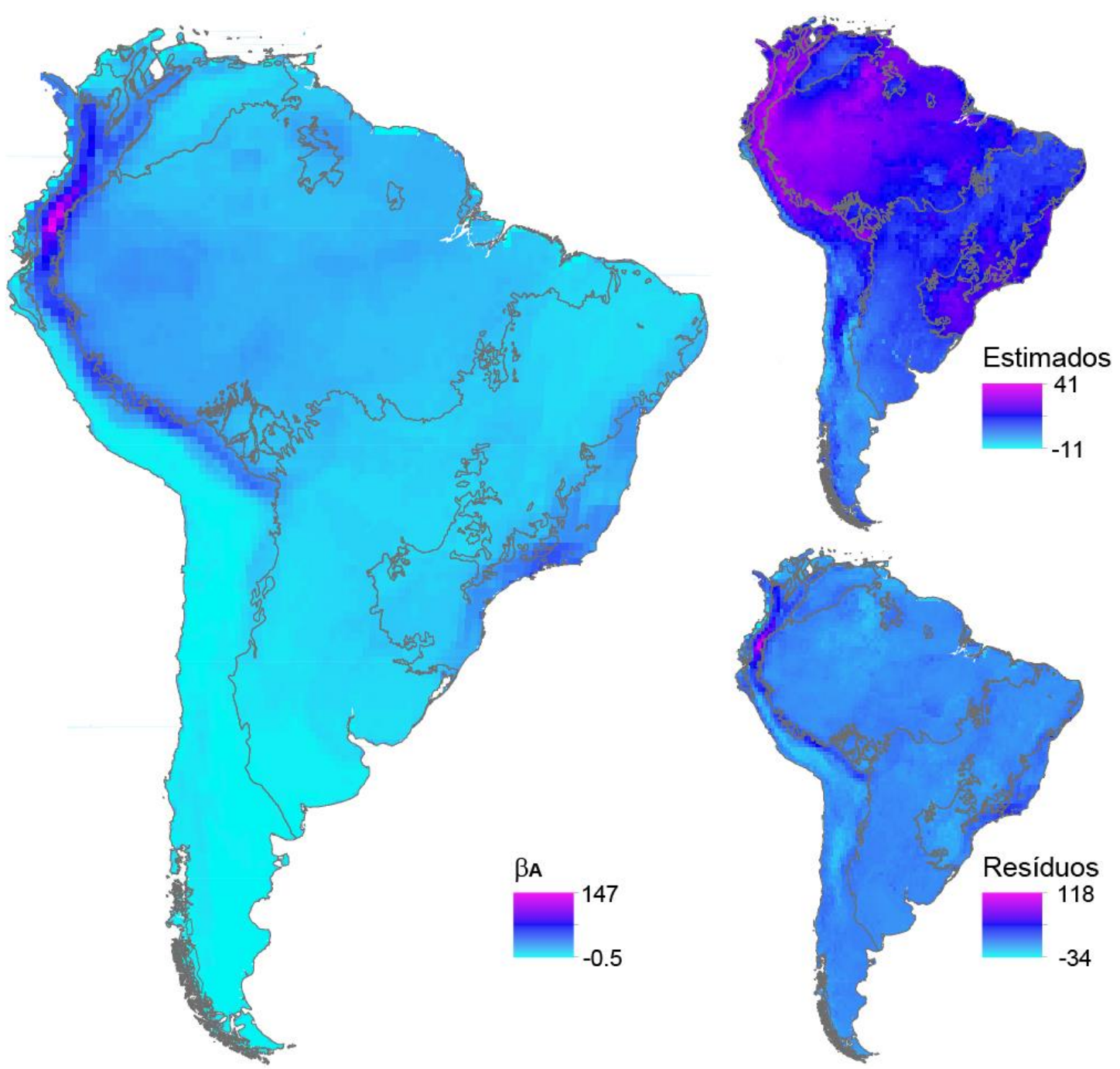

FIGURA 37. Diversidade beta calculado pela sobreposição das distribuições $\left(\beta_{\mathrm{A}}\right)$ de espécies, gêneros, famílias e ordens de anfíbios, valores estimados na análise de regressão e seus resíduos. 

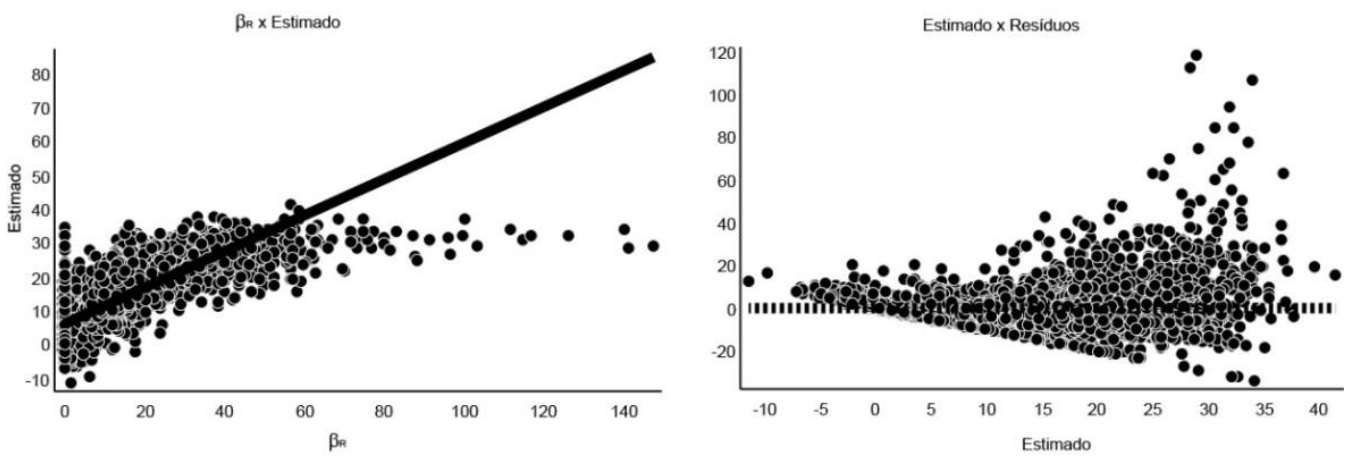

FIGURA 38. Resultados da análise de regressão múltipla para diversidade beta de anfíbios $\left(\beta_{\mathrm{A}}\right)$ como variável resposta, e 10 variáveis explanatórias ambientais.

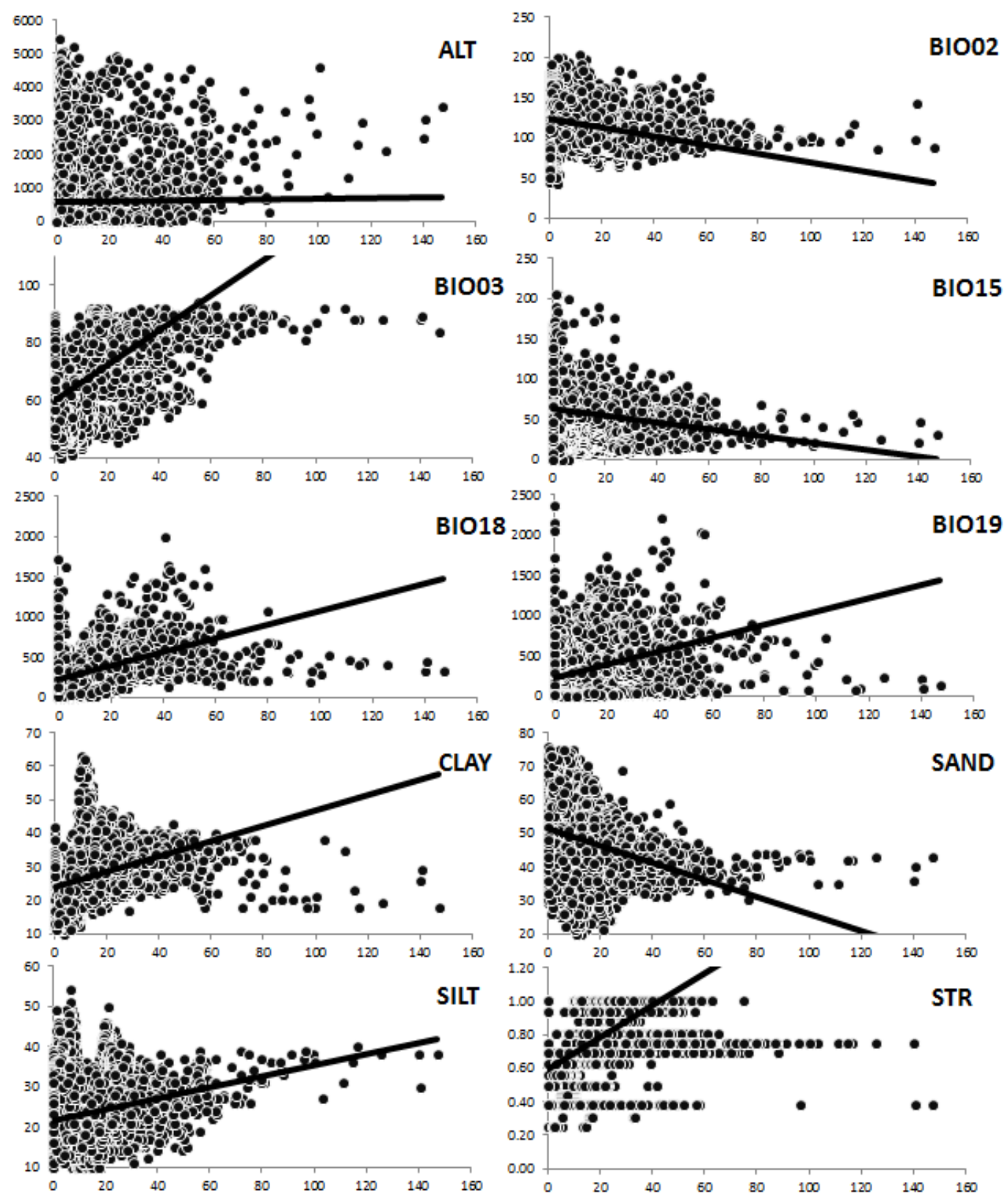

FIGURA 39. Relação da diversidade beta de anfíbios $\left(\beta_{\mathrm{A}}\right)$ e as 10 variáveis explanatórias com VIF menor que 3. ALT: altitude, BIO2: Amplitude média diária, BIO3: Isotermalidade (BIO2/BIO7) (* 100), BIO15: Sazonalidade na precipitação, BIO18: Precipitação do trimestre mais quente, BIO19: Precipitação do trimestre mais frio, CLAY: porcentagem de cascalho no solo, SAND: porcentagem de areia no solo; SILT: porcentagem de silte no solo, STR: índice de estrutura ambiental. 
TABELA 22. Resultados das análises de regressão múltipla para a diversidade beta de anfíbios $\left(\beta_{\mathrm{A}}\right)$, como variável resposta, e 10 variáveis explanatórias. VIF: fator de inflação de variância; Coef.:coeficiente de regressão; C.P.: coeficiente padronizado. ALT: altitude, BIO2: Amplitude média diária, BIO3: Isotermalidade (BIO2/BIO7) (* 100), BIO15: Sazonalidade na precipitação, BIO18: Precipitação do trimestre mais quente, BIO19: Precipitação do trimestre mais frio, CLAY: porcentagem de cascalho no solo, SAND: porcentagem de areia no solo; SILT: porcentagem de silte no solo, STR: índice de estrutura ambiental.

\begin{tabular}{lccc}
\hline Variável & VIF & $\begin{array}{c}\beta_{\mathrm{A}} \\
\text { Coef. }\end{array}$ & C.P. \\
\hline Constante & & -18.592 & 0 \\
ALT & 1.781 & 0.003 & 0.238 \\
BIO02 & 2.233 & -0.059 & -0.110 \\
BIO03 & 2.536 & 0.383 & 0.414 \\
BIO15 & 1.704 & -0.085 & -0.197 \\
BIO18 & 1.472 & 0.010 & 0.187 \\
BIO19 & 1.970 & -0.007 & -0.195 \\
CLAY & 1.311 & 0.219 & 0.136 \\
SAND & 1.408 & -0.032 & -0.031 \\
SILT & 1.283 & 0.066 & 0.042 \\
STR & 2.739 & 12.632 & 0.228 \\
\hline
\end{tabular}

O correlograma dividido em 25 classes de distância indica que mesmo após a extração dos resíduos, ainda existe uma certa auto-correlação, com um padrão geral onde classes de distância menores tendem a ter valores positivamente auto-correlacionados, e classes de distância intermediarias e mais altas alternam entre negativamente e positivamente autocorrelacionados (FIGURA 40).

A matriz de conectividade, baseada no critério de Gabriel, calculou 12160 conexões entre as quadrículas, apresentando uma distância mínima de 31.7914 km, média de 54.216 km, e máxima de $189.538 \mathrm{~km}$, e desvio padrão de 6.217 (FIGURA 12). O modelo autoregressivo baseado na diversidade beta de anfíbios $\left(\beta_{\mathrm{R}}\right)$ como variável resposta, nas variáveis explanatórias (ALT, BIO02, BIO03, BIO13, BIO15, BIO18, CLAY, SAND, SILT e STR), e na matriz de conectividade, foi calculado ( $n=6147 ; \rho=0.998, r^{2}=0.119$ ) (TABELA 23; FIGURA 41) e incluídos como uma variável fixa $\left(\mathrm{MAR}_{\beta A}\right)$, presente em todos os modelos, na seleção de modelos, tendo as mesmas variáveis ambientais como explanatórias, e cada valor de riqueza como variável resposta.

O procedimento de seleção de modelos aplicado à diversidade beta de anfíbios $\left(\beta_{A}\right)$, como variável resposta, tendo as variáveis ambientais (ALT, BIO02, BIO03, BIO15, BIO18, BIO19, CLAY, SAND, SILT e STR), como variáveis explanatórias, e testou 1023 modelos. Dois modelos apresentaram $\triangle \mathrm{AICC}<2$, explicando cerca de $75 \%$ da variação observada. A probabilidade de que o modelo com menor AICc para $\beta_{\mathrm{A}}$ seja o melhor modelo é de $68 \%$ (TABELA 24). Com a inclusão do modelo auto-regressivo ele apresentou a maior relação com os dados, e assim os valores dos coeficientes de cada variável diminuíram em magnitude, 
variando entre 0.027 e 0.097, e foram negativamente relacionadas à $\mathrm{BIO} 2$, $\mathrm{BIO} 15, \mathrm{BIO} 19$ e SAND e positivamente à ALT, BIO03, BIO18, CLAY, SAND e STR, com maiores valores relacionados a $\mathrm{BIOO3}$ (TABELA 25).

$\mathrm{O}$ procedimento de seleção de modelos aplicado à diversidade beta de anfíbios $\left(\beta_{\mathrm{A}}\right)$, como variável resposta, tendo as variáveis ambientais (ALT, BIO02, BIO03, BIO15, BIO18, BIO19, CLAY, SAND, SILT e STR), como variáveis explanatórias, e testou 1023 modelos com apenas um modelo apresentando $\triangle A I C c<2$ (TABELA 24), explicando 0.529 da variação observada, com o maior coeficiente de regressão apresentado pela $\mathrm{BIO03}(0.411)$, seguindo por ALT (0.23), STR (0.228), BIO15 (-0.197), BIO19 (-0.195) e BIO18 (0.185) (TABELA 25), definindo de maneira geral áreas com temperatura e precipitação mais estáveis, alta altitude, alta complexidade estrutural do ambiente, como áreas que apresentam maior diversidade beta.

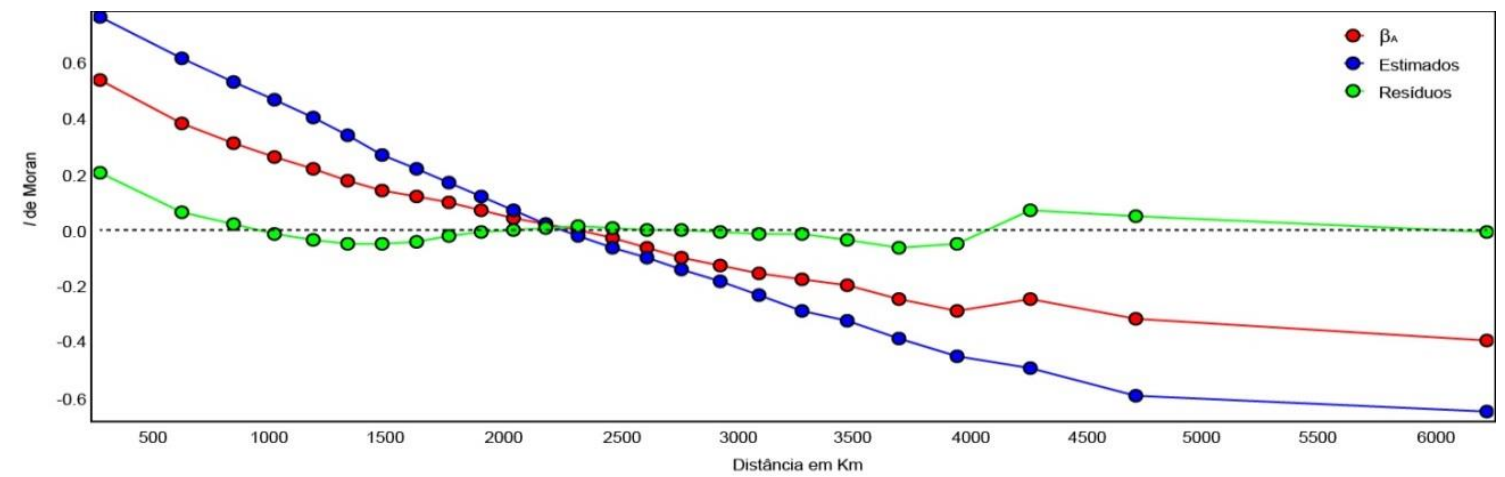

FIGURA 40. Correlograma do I de Moran para a diversidade beta anfíbios $\left(\beta_{A}\right)$, e para os valores estimados e os resíduos da regressão destas pelas variáveis ambientais.

TABELA 23. Resultados dos cálculos do modelo auto-regressivo para a diversidade beta anfíbios $\left(\beta_{\mathrm{A}}\right)$, como variáveis resposta, e 10 variáveis explanatórias. Coef.: coeficiente de regressão; C.P.: coeficiente padronizado. ALT: altitude, BIO2: Amplitude média diária, BIO3: Isotermalidade (BIO2/BIO7) (* 100), BIO15: Sazonalidade na precipitação, BIO18: Precipitação do trimestre mais quente, BIO19: Precipitação do trimestre mais frio, CLAY: porcentagem de cascalho no solo, SAND: porcentagem de areia no solo; SILT: porcentagem de silte no solo, STR: índice de estrutura ambiental.

\begin{tabular}{lcc}
\hline Variável & \multicolumn{1}{c}{$\beta_{\mathrm{A}}$} & \\
\hline Constante & Coef. & C.P. \\
ALT & 0.673 & 0 \\
BIO02 & $<0.001$ & 0.173 \\
BIO03 & $<0.001$ & -0.002 \\
BIO15 & -0.007 & -0.164 \\
BIO18 & -0.004 & -0.206 \\
BIO19 & $<0.001$ & 0.045 \\
CLAY & $<0.001$ & -0.090 \\
SAND & 0.005 & 0.064 \\
SILT & -0.002 & -0.046 \\
STR & 0.001 & 0.019 \\
\hline
\end{tabular}



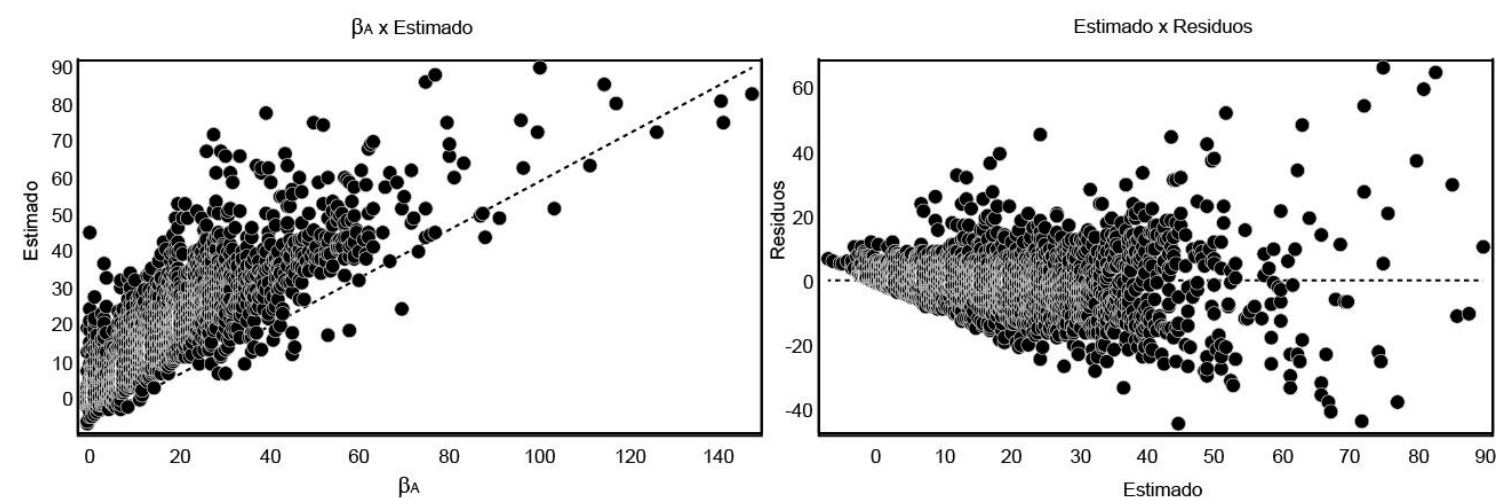

FIGURA 41. Resultados do modelo auto-regressivo para diversidade beta anfíbios $\left(\beta_{\mathrm{A}}\right)$, como variável resposta, e 10 variáveis explanatórias.

TABELA 24. Resultado do procedimento de seleção de modelos lineares $\left(r^{2}\right)$ que melhor explicam a variação observada na diversidade beta anfíbios $\left(\beta_{A}\right)$,, definidos pelo Critério de Informação de Akaike (AICc) e peso de Akaike $\left(\mathbf{w}_{\mathrm{i}}\right)$. Foram avaliados 1023 modelos para cada riqueza, aqui são mostrados apenas o que apresentou $\triangle \mathrm{AICc}$ menor que 2. ALT: altitude, BIO2: Amplitude média diária, BIO3: Isotermalidade (BIO2/BIO7) (* 100), BIO15: Sazonalidade na precipitação, BIO18: Precipitação do trimestre mais quente, BIO19: Precipitação do trimestre mais frio, CLAY: porcentagem de cascalho no solo, SAND: porcentagem de areia no solo; SILT: porcentagem de silte no solo, STR: índice de estrutura ambiental.

\begin{tabular}{|c|c|c|c|c|}
\hline Variáveis & $r^{2}$ & AICc & $\triangle \mathrm{AICc}$ & AICc $\mathbf{w}_{\mathrm{i}}$ \\
\hline ALT, BIO02, BIO03, BIO15, BIO18, BIO19, CLAY, SAND, STR & 0.754 & 39628.733 & 0 & 0.678 \\
\hline ALT, BIO02, BIO03, BIO15, BIO18, BIO19, CLAY, SAND, SILT, STR & 0.754 & 39630.661 & 1.928 & 0.259 \\
\hline
\end{tabular}

TABELA 25. Parâmetros calculados para o melhor modelo que explica a variação na diversidade beta anfíbios $\left(\beta_{\mathrm{A}}\right)$, de acordo com o Critério de informação de Akaike (AICC). ALT: altitude, BIO2: Amplitude média diária, BIO3: Isotermalidade (BIO2/BIO7) (* 100), BIO15: Sazonalidade na precipitação, BIO18: Precipitação do trimestre mais quente, BIO19: Precipitação do trimestre mais frio, CLAY: porcentagem de cascalho no solo, SAND: porcentagem de areia no solo; SILT: porcentagem de silte no solo, STR: índice de estrutura ambiental.

\begin{tabular}{lcc}
\hline Variáveis & \multicolumn{2}{c}{$\beta_{\mathrm{A}}$} \\
\hline Constante & Coef. & C.P. \\
ALT & -2.129 & 0 \\
BIO02 & $<0.001$ & 0.053 \\
BIO03 & -0.021 & -0.039 \\
BIO15 & 0.091 & 0.097 \\
BIO18 & -0.017 & -0.038 \\
BIO19 & 0.003 & 0.050 \\
CLAY & -0.001 & -0.042 \\
SAND & 0.043 & 0.027 \\
STR & -0.021 & -0.021 \\
MAR $_{\text {BA }}$ & 2.336 & 0.042 \\
\hline
\end{tabular}

$\mathrm{Na}$ análise qualitativa de dissimilaridade, os polígonos referentes a um total de 2828 espécies, 182 gêneros, 30 famílias, e três ordens (APÊNDICE 3) foram sobrepostos gerando 54667 registros, distribuídos em 6174 quadrículas. A dissimilaridade variou entre 0 e 0.944, e 
quando submetida aos três valores de corte $(0.5,0.7$ e 0.9$)$ geraram 154, 40 e 4 grupos respectivamente. Nas áreas Abertas foram gerados 32, 13, e 3 grupos, nas Florestas 41, 15 e 4, e na região Andina 124, 30, e 3 grupos, respectivamente nos valores de corte de 0.5, 0.7 e 0.9 (FIGURA 42).

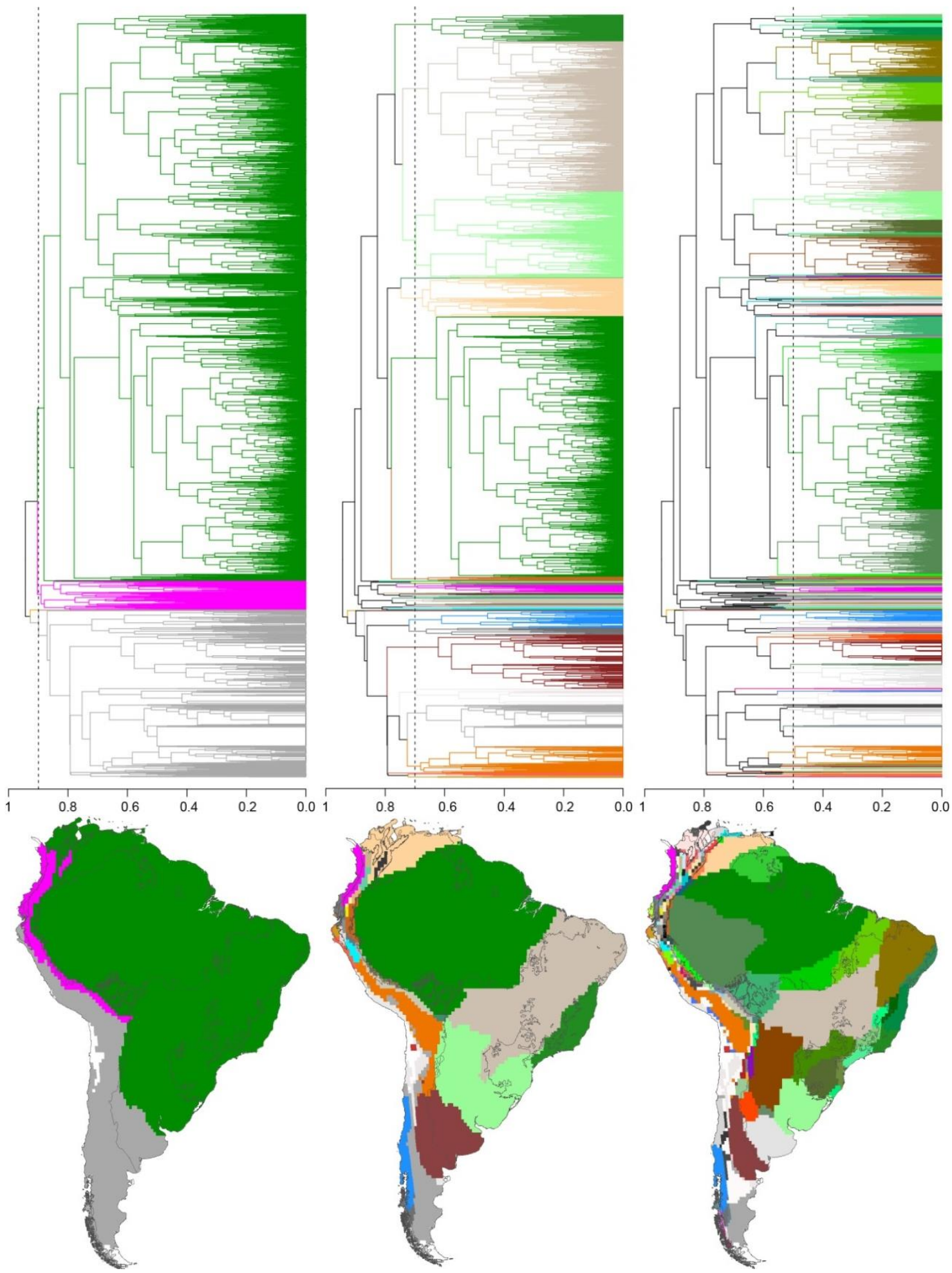

FIGURA 42. Dendrograma de dissimilaridade, baseado no índice de Jaccard (em cima), e distribuição os das áreas definidas por ela (em baixo), calculada pela sobreposição das distribuições de espécies, gêneros, famílias e ordens de anfíbios, divididos em três níveis de corte diferente 0.9 (esquerda), 0.7 (centro) e 0.5 (direita). 
No nível de corte de 0.9 três agrupamentos maiores de táxons foram observados, um ocupando quase que exclusivamente a porção central e sul da região Andina, um ocupando parte da porção central e norte da Região Andina, e outro ocupando quase exclusivamente as região das Florestas úmidas e áreas abertas/secas (FIGURA 42). No nível de corte de 0.7 novos agrupamentos são recuperados, como uma área que coincide em parte com a Mata Atlântica, que se agrupa à um agrupamento que inclui praticamente toda a parte central das áreas abertas

\subsubsection{Paleomodelagem da América do Sul}

As modelagens dos biomas produziram modelos com AUC variando entre 0.78 e 0.992 (Bioma: AUC \pm desvio padrão. Amazônia: $0.78 \pm 0.006$; Mata Seca: $0.912 \pm 0.009$; Florestas Temperadas: $0.97 \pm 0.002$; Chaco: $0.938 \pm 0.003$; Patagônia: $0.964 \pm 0.002$; Savanas Alagadas: $0.973 \pm 0.008$; Campos: $0.957 \pm 0.003$; Matorral: $0.992 \pm 0.002$; Desertos: $0.969 \pm 0.004$; Manguezais: $0.935 \pm$ 0.036; Mata Atlântica: $0.934 \pm 0.004$; Yungas: $0.942 \pm 0.009$; Caatinga: $0.97 \pm 0.002$; Pampas: $0.96 \pm 0.002$; Cerrado: $0.906 \pm 0.004$; Llanos: $0.97 \pm 0.007$; Chocó: 0.971 \pm 0.01 ; Espinal: $0.98 \pm 0.002$; Monte: $0.978 \pm 0.002$ ), enquanto que a taxa de omissão e sobreprevisão foram maiores na Amazônia e na Mata Seca (FIGURA 43).

Os modelos atuais dos biomas se encaixaram razoavelmente bem nas áreas ocupadas pelos respectivos biomas (FIGURA 44), embora cada modelo individualmente demonstre que algumas áreas coincidentemente sobre-previstas também por outros. Por exemplo, o modelo da Mata Seca ocupa boa parte da área da Caatinga, da Mata Atlântica e do Cerrado. O modelo dos Yungas previu áreas da Serra do Espinhaço e da região do Pantepui no escudo das Guianas. E o modelo das florestas do Chocó previu áreas da Amazônia, e vice e versa (FIGURA 45).

Os modelos projetados para o Holoceno médio (c.a. 6 mil anos atrás) previram uma região Andina um tanto semelhante ao observado nos dias de hoje, porém a região leste da Amazônia foi prevista como tendo sido ocupada por algum tipo de clima não existente atualmente na América do Sul (FIGURA 46). As condições climáticas que nos dias de hoje se relacionam com as Matas Secas apresentavam uma área ainda mais ampla, ocupando uma região que se estendia entre a Mata Atlântica, ocupando parte desta, até partes de onde hoje é a Amazônia. De maneira semelhante, áreas com clima similar ao dos Yungas atuais podiam ser encontradas em áreas onde hoje é a Amazônia (FIGURA 47).

Os modelos projetados para o auge do período glacial (c.a. 22 mil anos atrás) previram uma grande mudança na paisagem da América do Sul quando comparado com os dias de hoje (FIGURA 48). Esses modelos sugerem uma área menor ocupada pel clima típico de Amazônia, 
restrito à onde hoje é sua porção central, e partes do leste e oeste. Enquanto climas típicos dos Yungas se ocorriam em praticamente toda a bacia Amazônica, atingindo áreas na costa Atlântica. O clima típico de Mata Atlântica se distribuía para oeste do atual. E os climas típicos dos biomas do sul, como Patagônia, Pampas, Monte e Espinal, se fragmentaram (FIGURA 49).

Amazônia

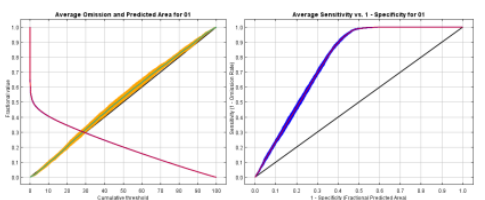

Chaco

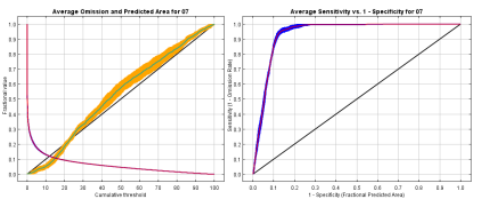

Puna

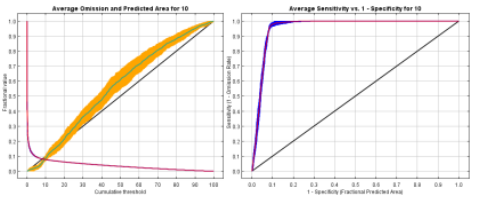

Manguezal

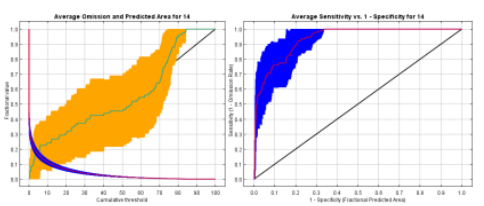

Caatinga

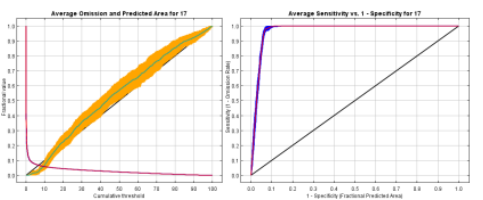

Llanos e Lavrado

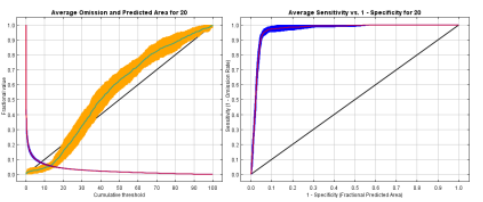

Monte

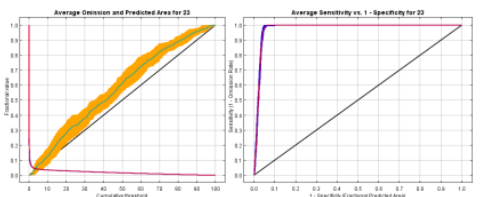

Mata Seca
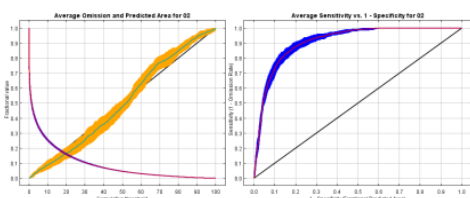

Patagônia

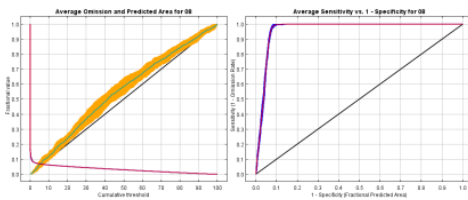

Matorral

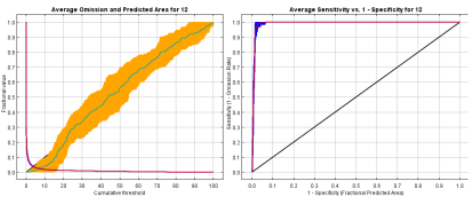

Mata Atlântica

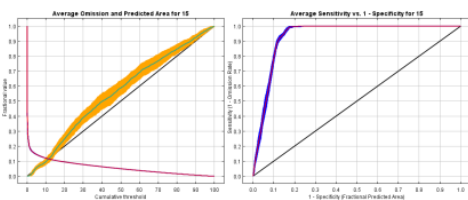

Pampas

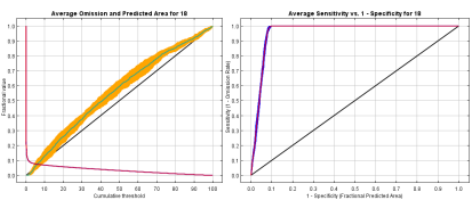

Chocó

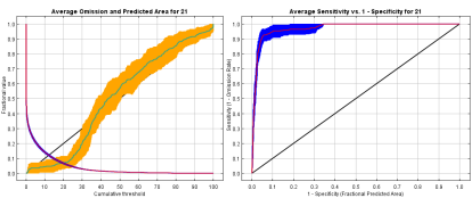

Legenda (Omissão)

Área média

Área média +/- um desvio padrão Omissão média nos dados de teste Omissão média +/- um desvio padrão Omissão predita
Florestas Temperadas

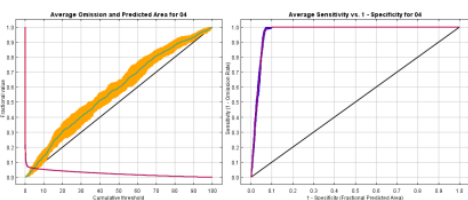

Savanas Alagadas

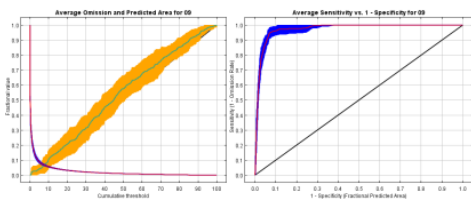

Desertos costeiros

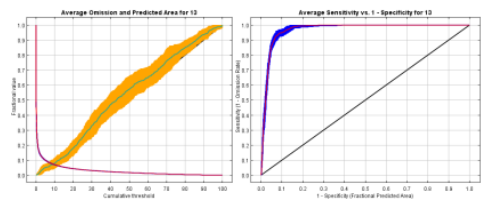

Yungas

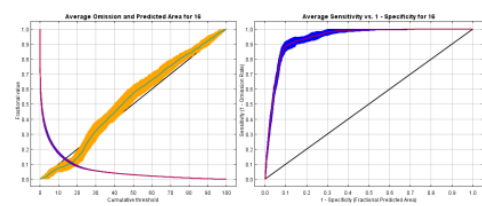

Cerrado

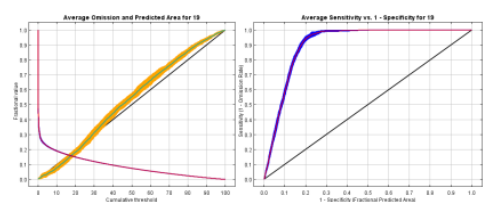

Espinal

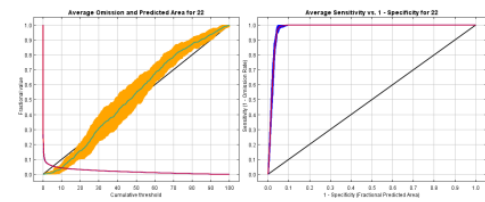

Legenda (Sensibilidade)

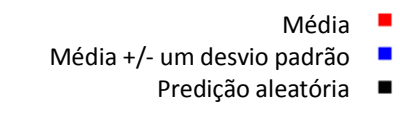

FIGURA 43. Gráficos mostrando distribuição da omissão (esquerda) de dados nas modelagens e a curva ROC (direita). 


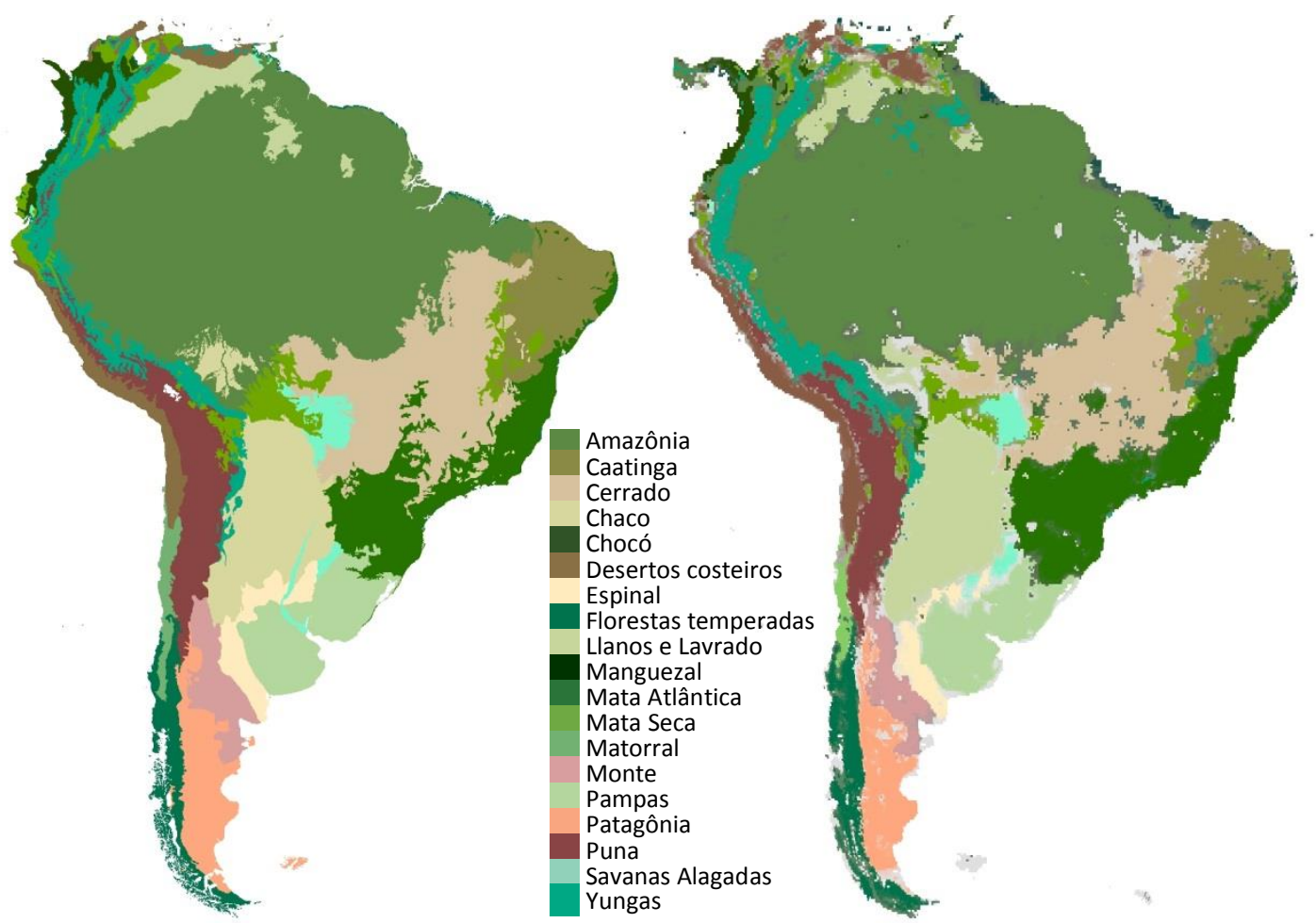

FIGURA 44. Distribuição dos biomas como definidos para a modelagem (esquerda), e resultado dos modelos para cada bioma (direita).

Os modelos projetados para auge do último período interglacial (c.a. 120 mil anos atrás), previram outra grande mudança com relação ao observado atualmente (FIGURA 50). Novamente o clima típico de Amazônia se apresentou restrito à região oeste da Amazônia atual, e o clima típico de Mata Atlântica se localizava onde hoje se localizam os Pampas. 0 clima típico de Yungas e o das Matas Secas ocupavam boa parte do que hoje é a Mata Atlântica, enquanto o clima típico dos campos altos Andinos da Puna ocupava uma área que se estendia pelo Monte e Patagônia (FIGURA 51). 


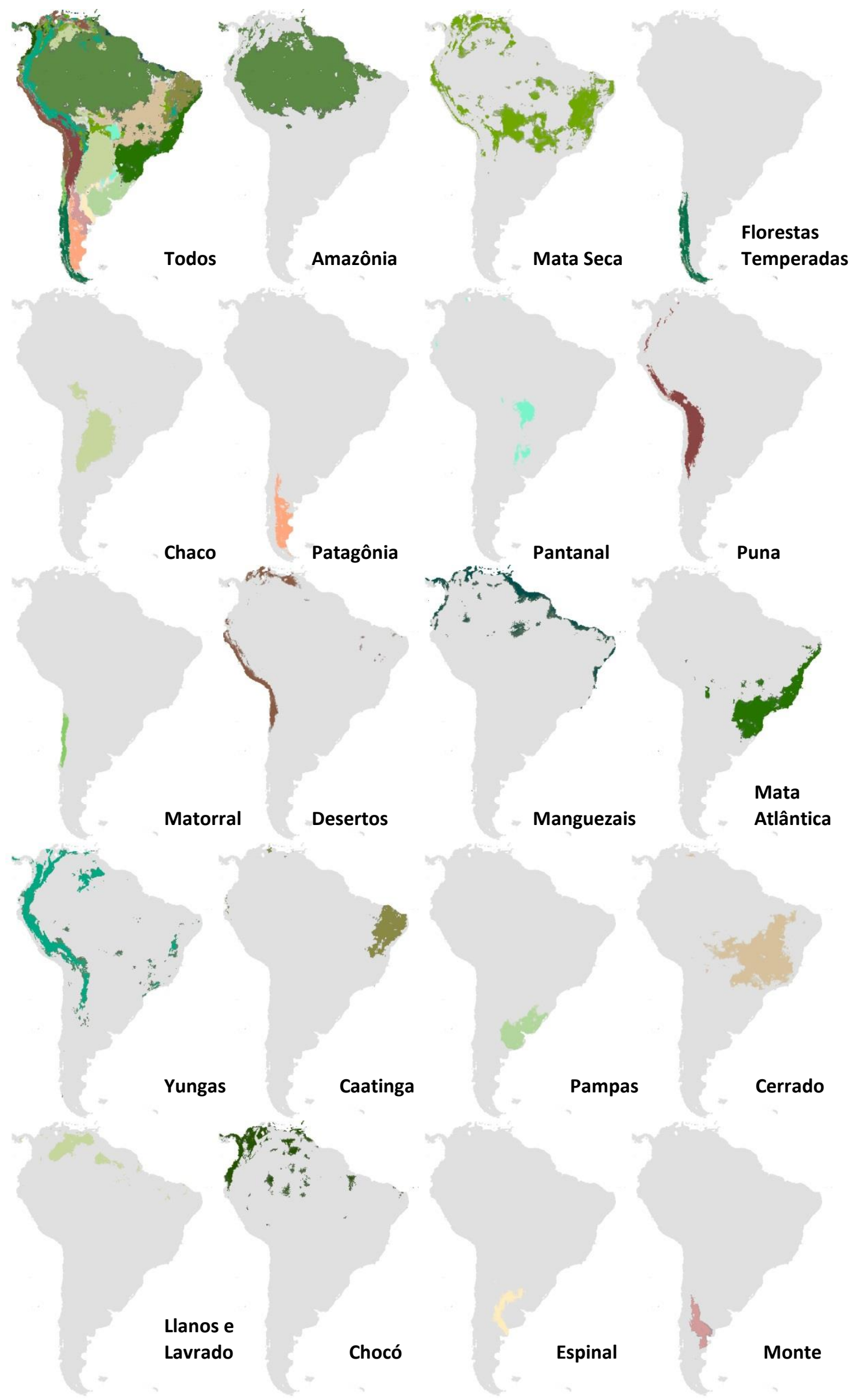

FIGURA 45. Modelagem de cada bioma individualmente, para o tempo presente. 


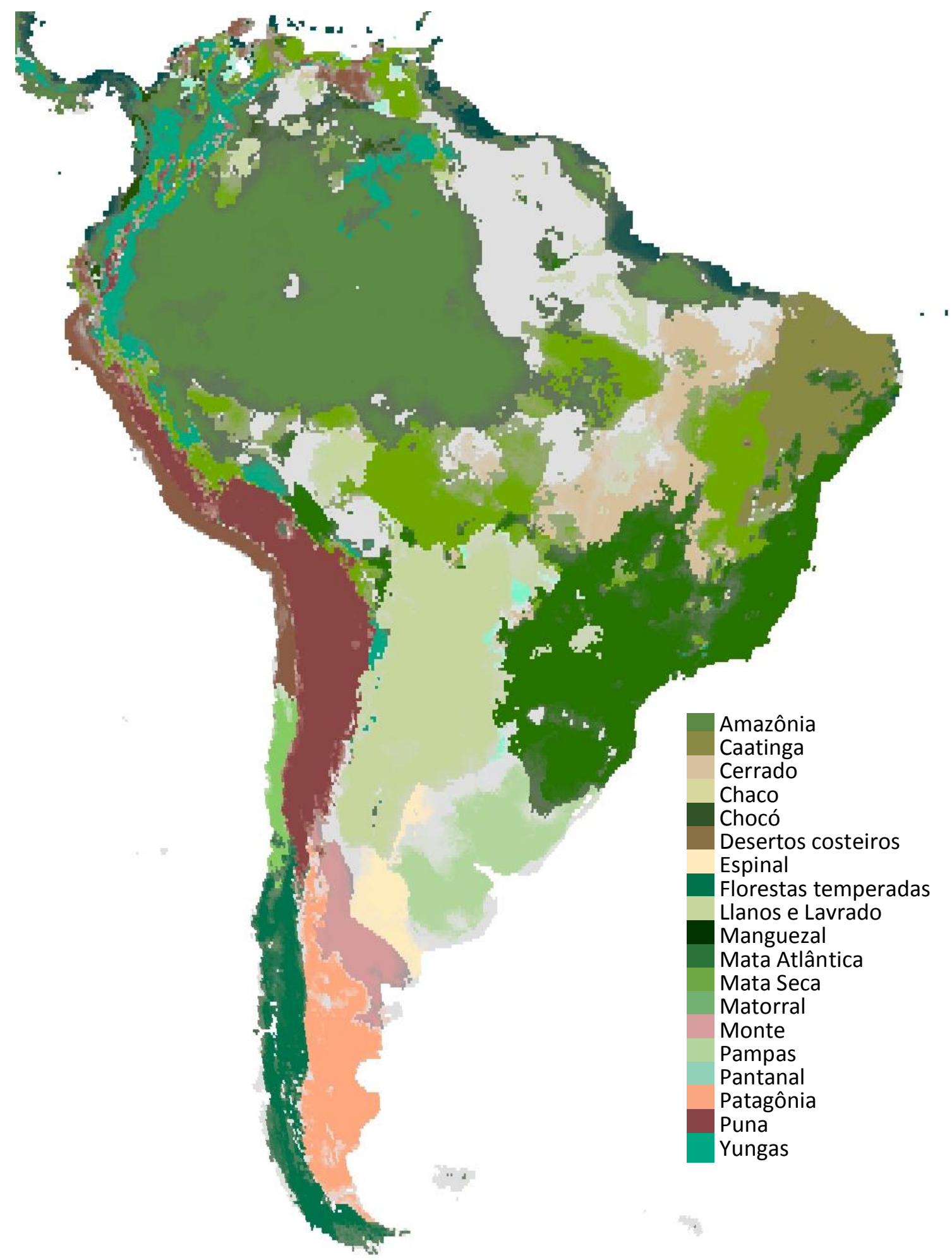

FIGURA 46. Distribuição os biomas segundo modelagem projetada para o Holoceno médio (6 mil anos atrás). 


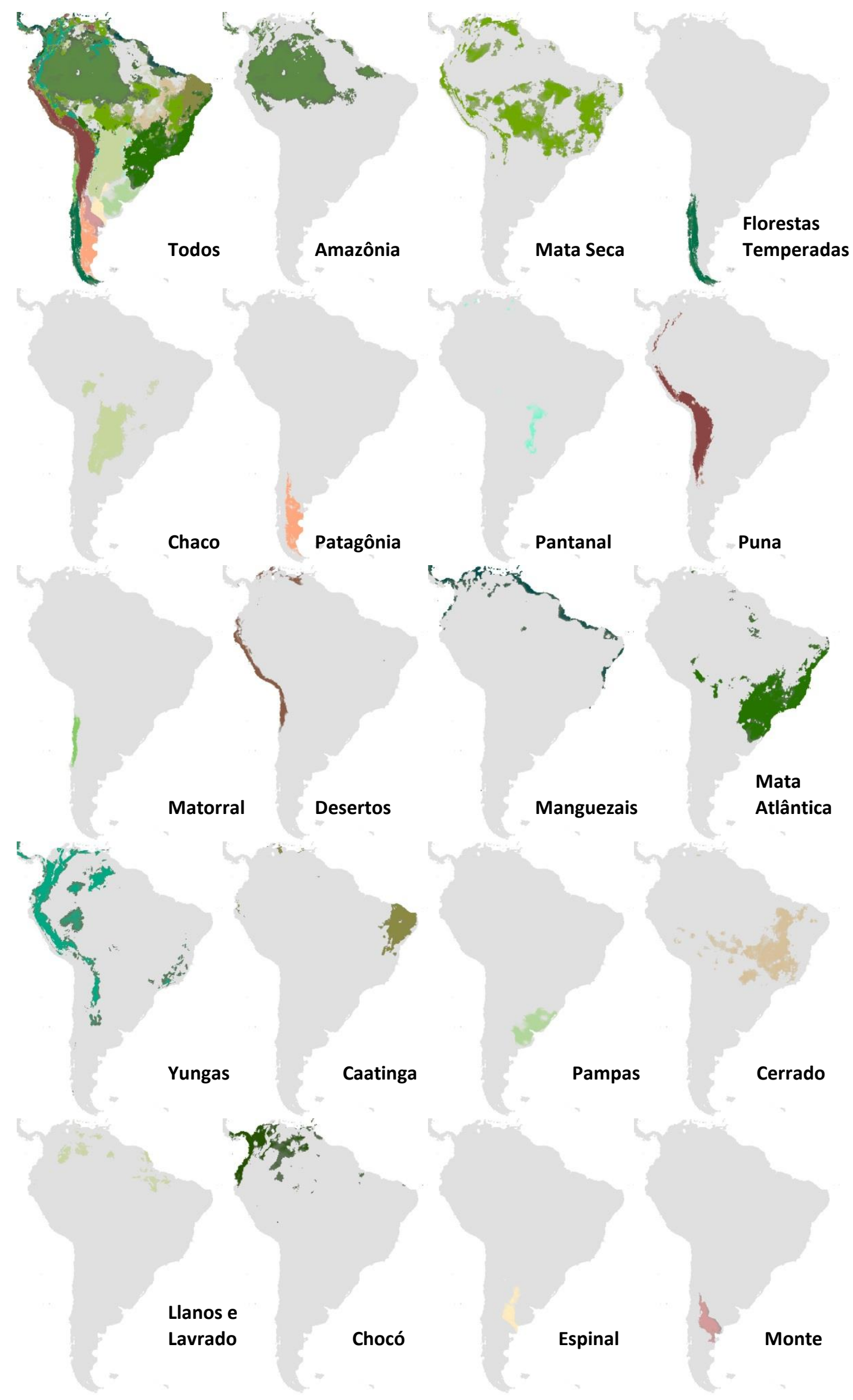

FIGURA 47. Modelagem de cada bioma para o médio Holoceno (6 mil anos atrás). 


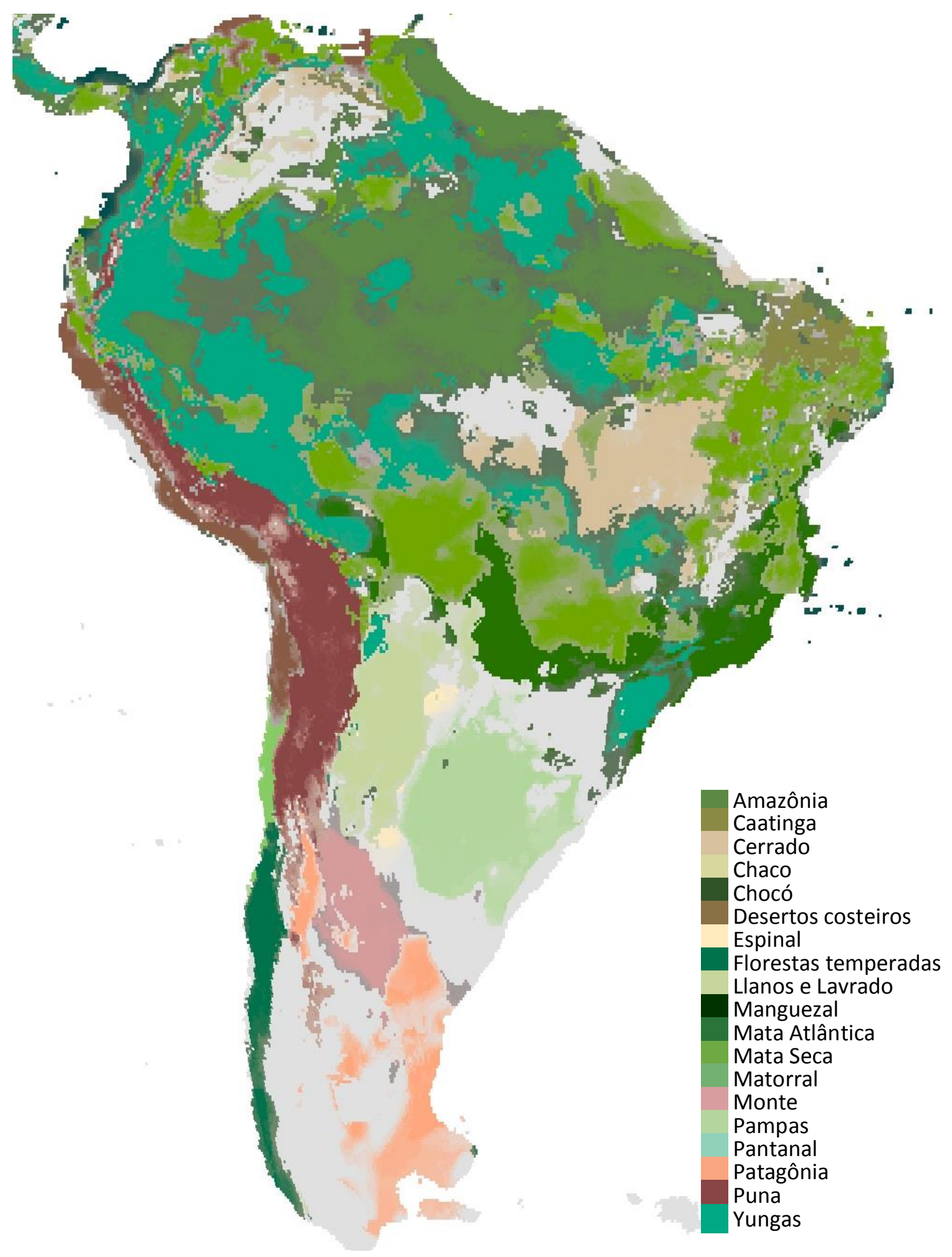

FIGURA 48. Distribuição os biomas segundo modelagem projetada para o Último Máximo Glacial (22 mil anos atrás). 


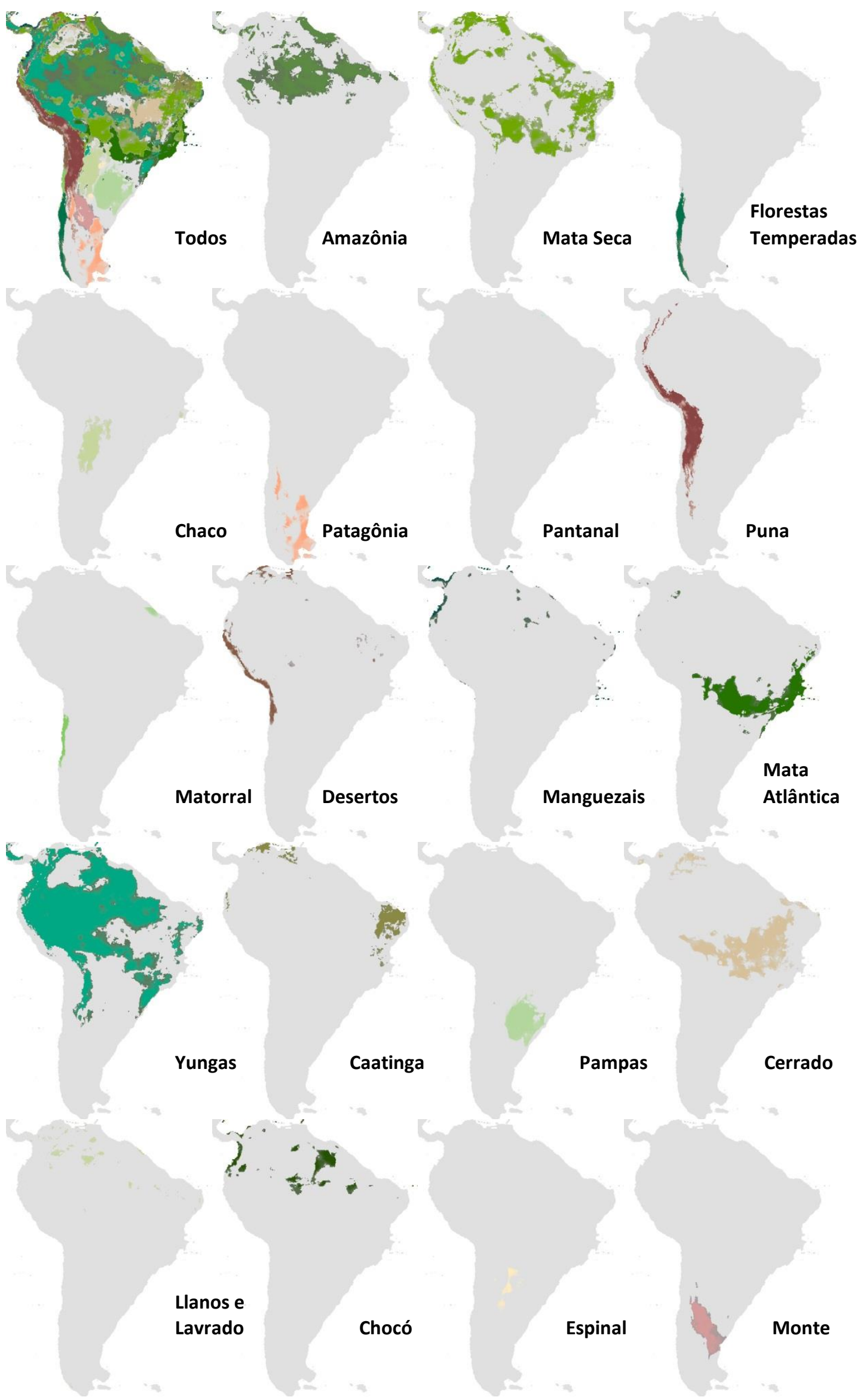

FIGURA 49. Modelagem de cada bioma para o auge do período glacial (22 mil anos atrás). 


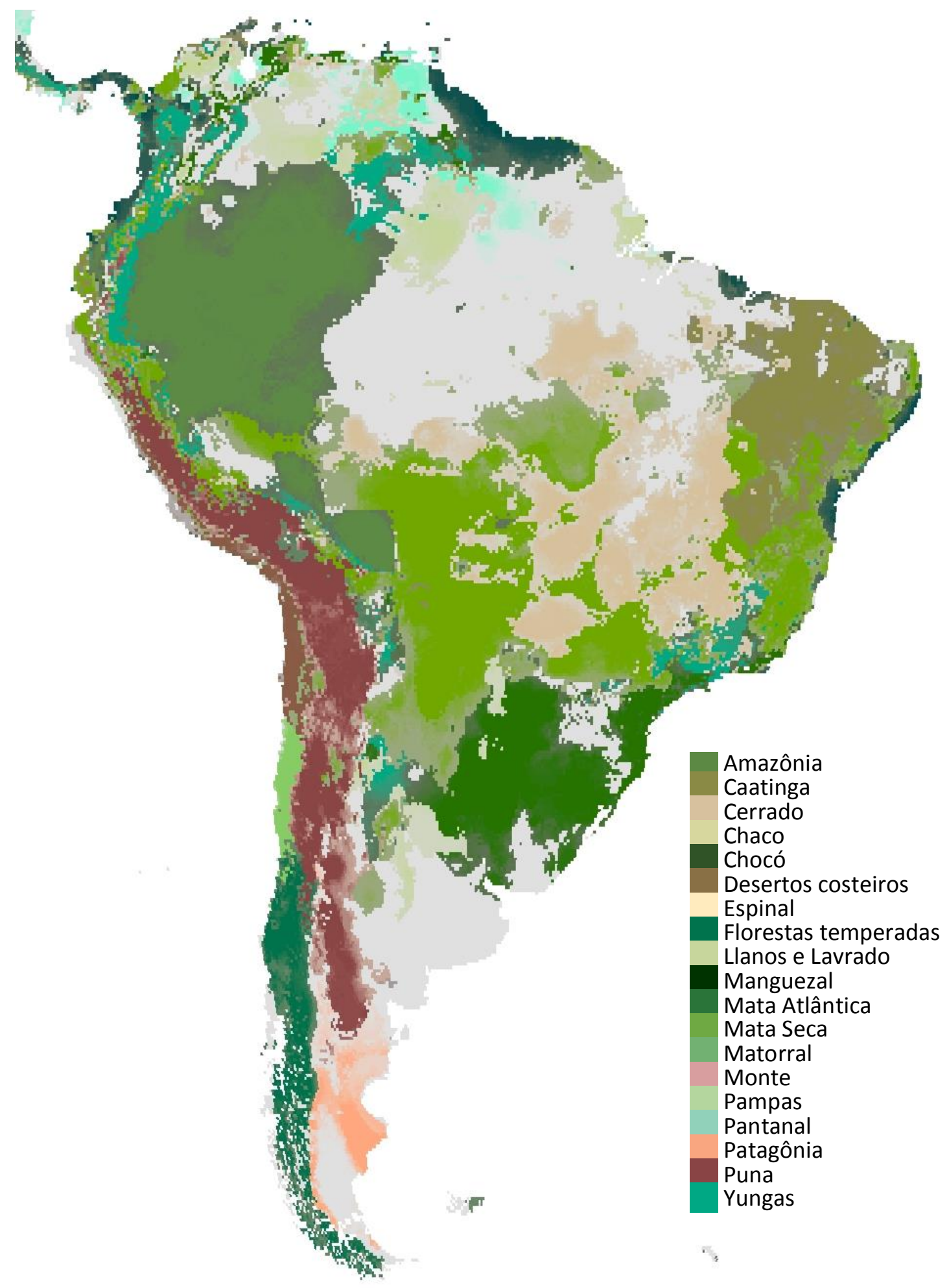

FIGURA 50. Distribuição os biomas segundo modelagem projetada para o auge do último período interglacial (cerca de 120 mil anos atrás). 


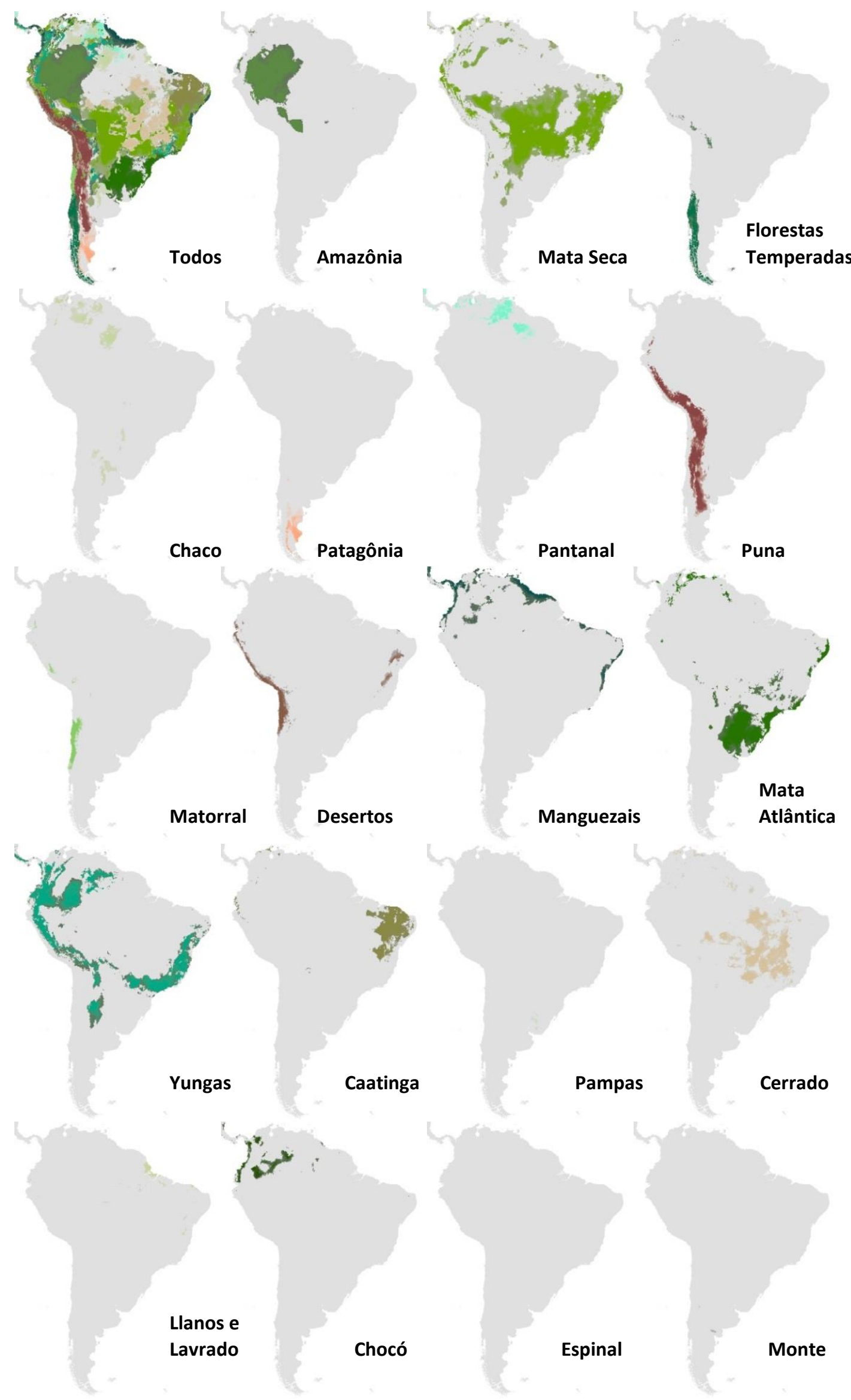

FIGURA 51. Modelagem de cada os biomas para último interglacial (120 mil anos atrás). 


\subsection{DISCUSSÂO}

Mais de uma centena de hipóteses já foram criadas para se tentar explicar por que determinadas áreas são mais ricas que outras (PALMER 1994). Esta questão é tradicionalmente subdividida entre processos que atualmente mantém esta alta riqueza dentro das áreas (processos ecológicos), e naqueles que geram a alta riqueza através do tempo e entre regiões (processos históricos) (MORITZ et al. 2000). Porém a distinção entre estes conjuntos de processos não é tão clara, e atualmente processos históricos têm sido revelados como muito importantes na produção tanto da riqueza regional como da local (RICKLEFS \& SCHLUTER 1993; WILLIAMS \& PEARSON 1997; HUBBELL 2001), assim como a relevância de processos ecológicos na especiação tem sido também frequentemente demonstrada (SCHLUTER 1996; ORR \& SMITH 1998; LU \& BERNATCHEZ 1999). No entanto aparentemente a escala em que a comparação é feita pode fazer muita diferença (WILLIS \& WHITTAKER 2002), e a questão continua sem um processo claro a explique.

Numa escala regional, vemos que o número total de espécies registradas para os répteis não foi tão diferente do encontrado nas áreas de Floresta úmidas, quando comparadas às áreas Abertas e à região Andina (Andes: 1535; Florestas: 1634; Abertas: 1508). Porém estas áreas apresentam extensões distintas (Andes: $3.537 .366 \mathrm{~km}^{2}$; Florestas: $7.902 .440 \mathrm{~km}^{2}$; Abertas: $6.325 .548 \mathrm{~km}^{2}$ ); assim quando a riqueza total é padronizada pela extensão da área (Andes: 0.000434; Florestas: 0.000207; Abertas: 0.000238), uma proporção diferente é observada (Andes: Floresta : Abertas $=2.1: 1: 1.15$ ). Os Andes então apresentam o dobro da densidade de espécies do que as Florestas, que apresentam um valor levemente menor do que o das áreas Abertas. Com relação aos anfíbios a diferença foi mais marcada (Andes: 1753; Florestas: 2020; Abertas: 1221), e proporções semelhantes entre os Andes e as Florestas foram observadas, sendo mais diferentes do que áreas Abertas (Andes: Floresta : Abertas = $1.93: 1$ : $0.75)$.

Porém numa escala local, a riqueza média se mostrou bastante diferente entre as áreas para os répteis [Andes: 53 (0-271); Florestas: 238 (85-308); Abertas: 157 (44-281)], e anfíbios [Andes: 34 (0-239); Floresta: 135 (36-247); Abertas: 66 (10-184)]. Nestes casos as Florestas despontaram com uma riqueza de fato maior que as outras áreas. Assim, uma riqueza regional proporcionalmente menor, associada a uma riqueza local proporcionalmente maior demonstra que as áreas de Florestas, especialmente a Amazônia, são compostas de espécies de ampla distribuição, que se empilham localmente e produzem uma riqueza local alta. Por outro lado as áreas Abertas e os Andes são compostos de um número proporcionalmente mais alto de 
espécies, mas de distribuição mais restrita, cujo empilhamento local produz uma riqueza localmente mais baixa. O que pode ser verificado pela menor diversidade beta (FIGURAS 31 e 37), e menor dissimilaridade (FIGURAS 36 e 42) entre as áreas correspondentes à Amazônia, e maiores nos Andes e nas áreas Abertas, assim como observado para outros grupos (MELO et al. 2009).

O que então possibilita uma co-ocorrência tão ampla de espécies nas áreas de floresta? Muitos estudos sobre animais e plantas vêm encontrando uma forte relação entre a variação na riqueza local e a observada nas condições ambientais, como temperatura, precipitação e produtividade primaria (CURRIE 1991; RAHBEK \& GRAVES 2001; HAWKINS et al. 2003; CURRIE et al. 2004; FIELD et al. 2009). De fato, neste estudo os modelos explicaram boa parte da variação observada na riqueza local de anfíbios e répteis (mais de $82 \%$ ), sugerindo uma forte relação com as condições ambientais atuais. Por exemplo, áreas mais de baixada, com temperatura e precipitação mais estável, e alta heterogeneidade estrutural apresentaram uma maior riqueza local. Estes ambientes quentes e úmidos, como a Floresta Amazônica, apresentam boas oportunidades térmicas e hídricas, tanto para répteis e anfíbios, já que por serem ectotérmicos, temperaturas mais altas auxiliam no seu metabolismo (DUELLMAN \& TRUEB 1994; DEVITT et al. 2013; POUGH et al. 2015). Além disso, anfíbios apresentam uma grande dependência de água, ainda que em forma de umidade, tanto para a respiração cutânea como para a reprodução (DUELLMAN \& TRUEB 1994; DEVITT et al. 2013; POUGH et al. 2015). Isto fica claro nas distribuições de riqueza local de anfíbios, apresentando valores bem baixos nas áreas Abertas (média de 66; variando entre 10-184), e nos Andes (34; 0-239), quando comparada às áreas de Floresta (135; 36-247) (FIGURA 14). Porém répteis que em sua maioria não são tão dependentes de água, mas sim de temperatura, especialmente os lagartos (PIANKA \& VITT 2003; VITT et al. 2013; POUGH et al. 2015), são mais ricos localmente nas áreas abertas (Abertas: 157, 44-281; Andes: 53, 0-271; Florestas: 238, 85-308) do que os anfíbios. Porém se a dependência de ambientes quentes fosse único fator limitante para os répteis, eles poderiam apresentar também altos valores de riqueza local ao longo de outras áreas quentes como o Cerrado e a Caatinga.

Porém outros estudos têm encontrado relações entre a variação nos valores de riqueza local com outros tipos de fatores, como heterogeneidade ambiental (GUEGAN et al. 1998; STEIN et al. 2014), área da superfície (ROSENZWEIG 1995), história regional e evolutiva (RICKLEFS 2004) e uma combinação da história evolutiva e clima (RAHBEK \& GRAVES 2001). Valores de diversidade ou heterogeneidade ambiental (GUEGAN et al. 1998; RAHBEK et al. 2007) dificilmente são baseados em uma medida empírica de dados, sendo geralmente 
construídas sobre índices de vegetação calculados a partir de imagens de satélites (MOURA et al. 2016). Tal procedimento provavelmente enviesa as estimativas, levando ambientes originalmente bastante heterogêneos estruturalmente a serem categorizados como homogêneos por conta do amplo desmatamento. Dessa forma decidiu-se neste estudo calcular-se uma variável que funcionaria como uma estimativa de heterogeneidade ambiental. Esta foi baseada nos elementos básicos de um ambiente natural que poderiam ser potencialmente ocupados pelos animais em questão (e.g. árvores, solo, água e subsolo). Nas análises essa variável (STR), se mostrou bastante importante nas escolhas dos modelos, sempre presente nos melhores modelos para as medidas de riqueza, com o primeiro modelo que sem STR geralmente apresentando um valor de $\triangle \mathrm{AICc}$ muito alto.

No caso dos répteis, as espécies arborícolas e aquáticas apresentaram maior riqueza local nas áreas de Floresta e uma baixa riqueza local nas áreas Abertas, mostrando uma forte relação com a estrutura do ambiente. Assim a Amazônia, que apresenta a maior heterogeneidade estrutural, com uma alta riqueza de espécies de árvores (PITMAN et al. 2001), e grande quantidade de água disponível (COUTINHO 2016) é a mais rica nestes grupos também. O que pode ser testado empiricamente já que praticamente em qualquer ponto da floresta Amazônica é possível se encontrar cerca de 10 espécies de lagartos estritamente arborícolas, umas quatro espécies aquáticas e diversas espécies terrestres. Porém em florestas estruturalmente semelhantes da Mata Atlântica, se encontram no máximo 4 espécies de lagartos estritamente arborícolas, nenhum aquático, e alguns terrestres. A ausência de espécies aquáticas é esperada já que a abundância de água disponível no habitat é bem menor na Mata Atlantica do que na Amazônia (COUTINHO 2016). Porém espécies semiaquáticas poderiam ocorrer, como Neusticurus e Potamites que na Amazônia ocupam pequenos riachos na floresta (AVILA-PIRES 1995). Na Mata Atlântica também a disponibilidade de árvores contrasta com a baixa quantidade de espécies arborícolas as ocupando. $\mathrm{O}$ que por outro lado pode ser consequência da relação com altas temperaturas mais estáveis, já que mesmo sendo estruturalmente bastante heterogênea a Mata Atlântica atinge temperaturas mais baixas e instáveis do que a Amazônia, especialmente em sua porção centro-sul (FIGURA 4). Enquanto espécies terrestres apesar de atingirem seus valores máximos também em áreas de floresta apresentaram uma distribuição de valores contínuos e relativamente altos através das áreas da região do Cerrado (FIGURA 7).

No caso dos anfíbios tanto as espécies arborícolas como as terrestres apresentaram comunidades muito mais ricas nas áreas florestais (FIGURA 15). Então por que, diferentemente dos répteis, as espécies terrestres de anfíbios são pobres nas áreas abertas? 
Possivelmente pela relação de dependência com a água (DUELLMAN \& TRUEB 1994; DEVITT et al. 2013; POUGH et al. 2015), já que a disponibilidade de água é bem menor nas áreas Abertas do que nas áreas de Floresta (FIGURA 3). Isso deve impor restrições à colonização e diversificação nas áreas Abertas, resultando em maiores taxas extinção do que áreas de Floresta (MORITZ et al. 2000; PYRON \& WIENS 2013). Ainda que exista uma fauna de anfíbios adaptada à vida em regiões como o Cerrado (VALDUjo et al. 2012; VALDUjo et al. 2013), Caatinga (RODRIGUES 2003), e Chaco (NORMAN \& NAYLOR 1994; ÁLVAREZ et al. 2009), ou mesmo ao longo dos Andes (DUELLMAN 1999), estes ocorrem em sua maioria próximos a corpos d'água, ou apresentam hábitos de vida crípticos com reprodução explosiva nos momentos de chuva (DUELLMAN \& TRUEB 1994).

Em termos de endemismo os valores foram maiores em regiões montanhosas como observados em outros estudos (HUGHES \& EASTWOOD 2006; ROSAUER \& JETZ 2015). No entanto diferentemente de alguns trabalhos (FJELDSÅ et al. 1999; SANDEL et al. 2011), a relação entre o nível de endemismo e o clima atual foi relativamente fraca (inferior a 25\%). Isso sugere que outros processos, como fatores históricos, possivelmente estejam atuando nestes casos. Como por exemplo, isolamento geográfico, que é um mecanismo de grande importância na geração e manutenção de linhagens restritas (ROSAUER \& JETZ 2015). A região Andina foi a que apresentou o maior nível de endemismos, maior diversidade beta, e maior quantidade de agrupamentos de táxons, demonstrando que sua fauna é composta quase que estritamente por linhagens de distribuição bastante restrita (por exemplo diversas linhagens de Enyalioides, Liolaemus, Atractus, Telmatobius e Pristimantis) (APÊNDICE 3). Esta região foi a que potencialmente sofreu as maiores alterações geográficas, especialmente em altitude, devido à orogênese da cordilheira (GARZIONE et al. 2008; HOORN et al. 2010; INSEL et al. 2010, 2012), o que pode ter contribuído para o isolamento das linhagens. Por outro lado, baixa diversidade beta, baixa dissimilaridade e baixo endemismo foram observados ao longo da região Amazônica, assim como encontrado para outros grupos (CONDIT et al. 2002; MELO et al. 2009). De fato a região Amazônica é uma das áreas que apresenta uma fauna bastante coesa, sempre se agrupando independentemente do nível de corte ou grupo taxonômico (e.g. répteis ou anfíbios), com exceção das Matas de babaçu do extremo leste da Amazônia para anfíbios (FIGURA 36 e 42).

No entanto diversos grupos de aves apresentam distribuições restritas por rios na Amazônia, de maneira que avifaunas muito distintas são encontradas em cada interflúvio (WALLACE 1854; CRACRAFT 1985; HAYES \& SEWLAL 2004; RIBAS et al. 2012). Algumas espécies de répteis parecem apresentar um padrão semelhante (AVILA-PIRES 1995), porém 

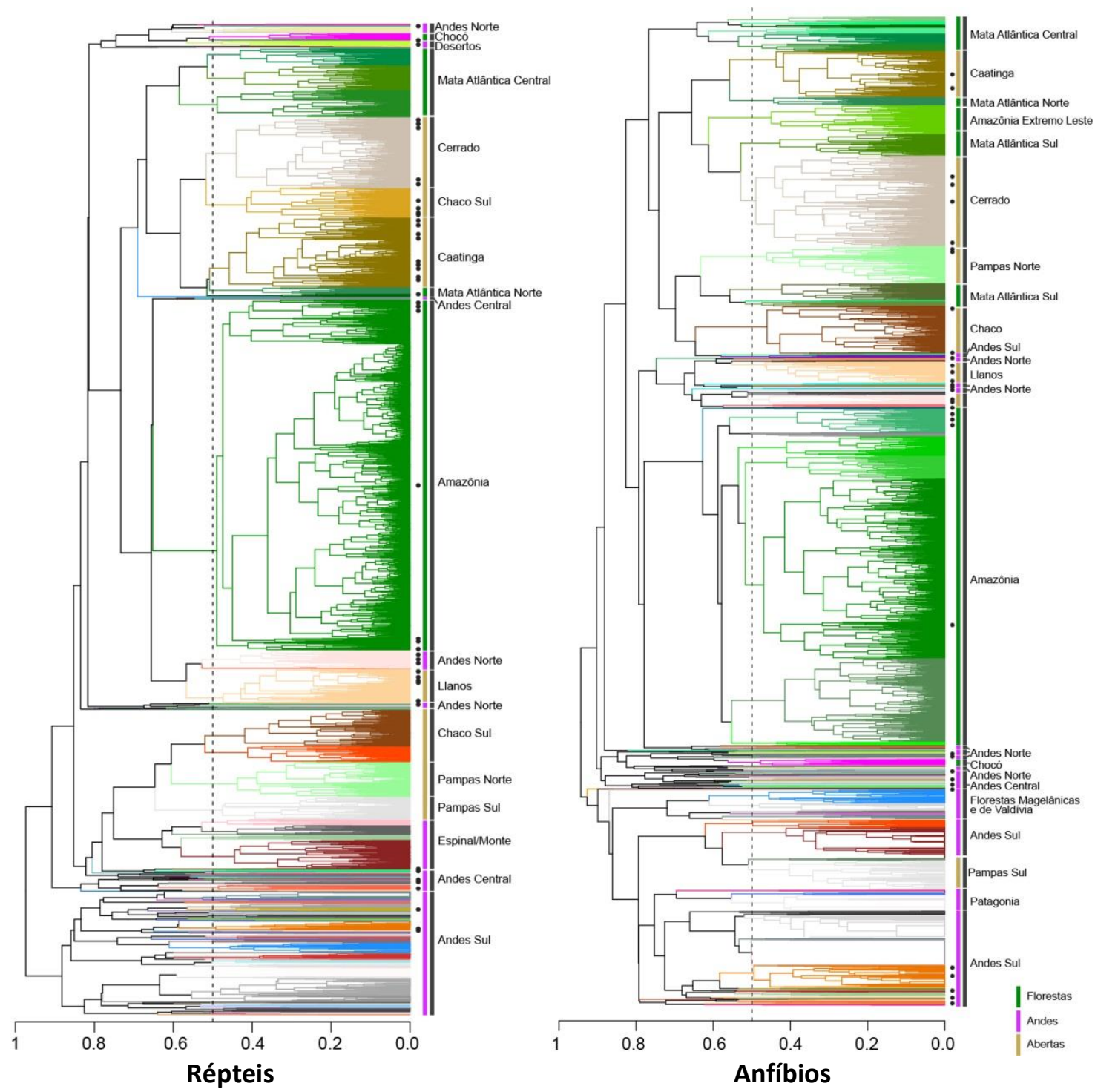

FIGURA 52. Dendrograma de dissimilaridade dividido pelo nível de corte de 0.5 de dissimilaridade, apresentando e os nomes das áreas correspondentes aproximadamente aos biomas. Pontos indicam áreas de Mata Seca; cada ponto pode indicar mais de um terminal.

considerando-se toda a fauna de répteis e anfíbios atualmente conhecida para a Amazônia, nenhum padrão semelhante foi observado. As quebras faunísticas mais evidentes observadas seguem mais um padrão leste/oeste, como já observado apara algumas linhagens de répteis (DAL VECHIO 2015; PRATES et al. 2016; SOUZA 2016).

Diferentemente, outras áreas de Florestas, como a Mata Atlântica, foram subdivididas em agrupamentos menores com maior similaridade faunística com áreas como o Cerrado e a Caatinga do que entre si (FIGURA 52). A porção mais norte da Mata Atlântica, apresenta uma maior similaridade com a Caatinga, do que com a Mata Atlântica Central e Sul, tanto para répteis e como para anfíbios, enquanto partes da Mata Atlântica do Sul se assemelham mais ao Cerrado e outras aos Pampas Norte, enquanto os Pampas do Sul apresentam uma fauna 
mais similar à encontrada nos Andes do Sul, em termos de composição de anfíbios. Para os répteis tanto os Pampas do norte como do sul se mostraram com uma fauna mais similar à do Chaco (FIGURA 52). O mesmo acontece com os Andes, cujas localidades apresentam alta dissimilaridade entre si, e em muitos casos compartilham alguns elementos faunísticos com áreas de Floresta ou com as áreas Abertas (FIGURA 52). Áreas de Mata Secas (incluindo a Caatinga) já tiveram suas composições florísticas avaliadas de maneira semelhante (BANDA-R et al. 2016). Contudo, com a exceção da Caatinga, áreas de Mata Seca não foram recuperadas aqui com parte de um mesmo agrupamento, estando distribuídas ao longo de diversos biomas, apresentando maior similaridade faunística com estes do que com outras áreas de Matas Secas (FIGURA 52).

Embora existam diversas linhagens compartilhadas entre a Amazônia e a Mata Atlântica, (e.g. espécies de Dactyloa, Diploglossus fasciatus, espécies de Allophryne, espécies do complexo Hypsiboas semilineata, espécies de Chironius, Bothrops bilinatus) (APÊNDICE 3) a dissimilaridade entre estes biomas se mostrou bastante alta. Essa falta de coesão nas faunas entre as áreas de um mesmo tipo de ambiente sugere histórias de colonização e diversificação distintas, de maneira que considerar a Mata Atlântica e a Amazônia como parte de um mesmo bioma (OLSON et al. 2001; MORRONE 2006), ou mesmo a região Andina como uma única unidade biogeográfica (KUSCHEL 1969; SICK 1969; RIVAS-MARTINEZ \& TOVAR 1983; MORRONE 2006,2011), pode mascarar diversos processos biológicos e evolutivos independentes, onde escalas diferentes podem resultar em agrupamentos distintos (FIGURA 36 e 42) (MORRONE 2011,2014,2015).

Em ambientes temperados na Europa, as flutuações climáticas do quaternário tiveram grande influência na diversidade de anfíbios e répteis (ARAUJO et al. 2008). Para a América do Sul a paleomodelagem de cada bioma individualmente demonstrou que em certos períodos determinadas áreas apresentavam condições climáticas que poderiam sustentar mais de um tipo de bioma (FIGURAS 46-51). Diversos pontos das áreas Abertas apresentaram climas potencialmente capazes de sustentar uma vegetação de Mata Atlântica, Mata Seca, Yungas e Cerrado durante o Último Máximo Glacial. Dessa maneira, as condições edáficas devem ter sido o fator decisivo para o estabelecimento de um determinado ambiente nessas regiões, como acontece em diversas porções do Brasil central onde florestas estacionais e savanas ocorrem lado a lado em solos distintos, mas sob um mesmo clima (OLIVEIRA-FILHO \& RATTER 2002).

Sobre este mesmo período muita discussão tem sido feita sobre a região Amazônica ter sofrido uma fragmentação, sendo ocupada por uma vegetação savânica (PENNINGTON et al. 2004). Porém segundo os modelos calculados aqui a bacia amazônica apresentava climas, 
semelhante ao típico apresentado pela Amazônia atual, em sua porção mais central, e um clima mais frio, que se assemelha ao observado atualmente na região do Yungas, mais amplamente distribuído pela bacia Amazônica; enquanto algumas manchas de clima de Mata Seca podiam ser encontradas espalhadas pela região (FIGURA 53). Estas informações sugerem a ocorrência de um ambiente florestal mais seco e frio ocupando a maior parte da bacia Amazônica, conectando-se pelo sul do Cerrado com as florestas costeiras da Mata Atlântica, ao invés de uma invasão de vegetação savânica como já foi proposto (WÜSTER et al. 2005; INGENLOFF \& PETERSON 2015). Já durante os períodos mais quentes, como o Holoceno Médio e o último Interglacial, certas áreas apresentaram condições climáticas não encontradas em nenhum outro bioma atualmente existente na América do Sul, como foi o caso da região leste da Amazônia, sendo esta região uma das mais instáveis da paisagem Sul Americana durante este intervalo de 120 mil anos (FIGURA 54).

Por outro lado, a porção oeste da Amazônia, em contato com as encostas dos Andes, se manteve mais estável, e justamente esta porção atualmente comporta as áreas mais ricas em anfíbios na Amazônia. Evidências têm indicado que boa parte da diversidade de anfíbios encontrada na Amazônia atualmente é derivada principalmente de linhagens Andinas que colonizaram as áreas baixas (SANTOS et al. 2009). Assim uma porção oeste estável recebendo linhagens que ali se diversificam, e uma porção leste instável, que durante períodos mais quentes perde a cobertura de florestas úmidas, pode ter provocado esta distribuição diferencial de riqueza de anfíbios dentro da Amazônia. No entanto é difícil de averiguar qual clima estaria presente na Amazônia leste durante estes períodos pra se poder afirmar que eram ambientes inóspitos a anfíbios. Neste Último período interglacial o clima da Mata Atlântica potencialmente se encontrava em uma região mais ao sul do que observada atualmente, enquanto boa parte de sua extensão atual era ocupada por climas frios e secos, capazes de comportar ambientes como Mata Secas e Yungas. Esta fragmentação já foi relatada por paleomodelos e dados genéticos (CARNAVAL et al. 2009) durante o Pleistoceno. Assim dentre todos os biomas, poucos foram os que se mantiveram estáveis ao longo destes 120 mil anos, como as regiões de mais altitude dos Andes, atualmente ocupada principalmente por uma vegetação de Puna (FIGURA 54). Contudo os paleomodelos calculados aqui remetem aos climas extremos dos últimos 120 mil anos (FIGURA 53), enquanto que para diversos grupos, tanto na América do Sul, como em outros lugares do mundo, novas evidências apontam para momentos anteriores ao Pleistoceno como o período onde a maior parte das linhagens atuais surgiu e se diversificou (BUSH 1994; JARAMILLO et al. 2006; WAHLBERG \& FREITAS 2007; BECK 2008; KOHN \& FREMD 2008; RULL 2008; POTTER \& SZATMARI 2009; FINARELLI \& 


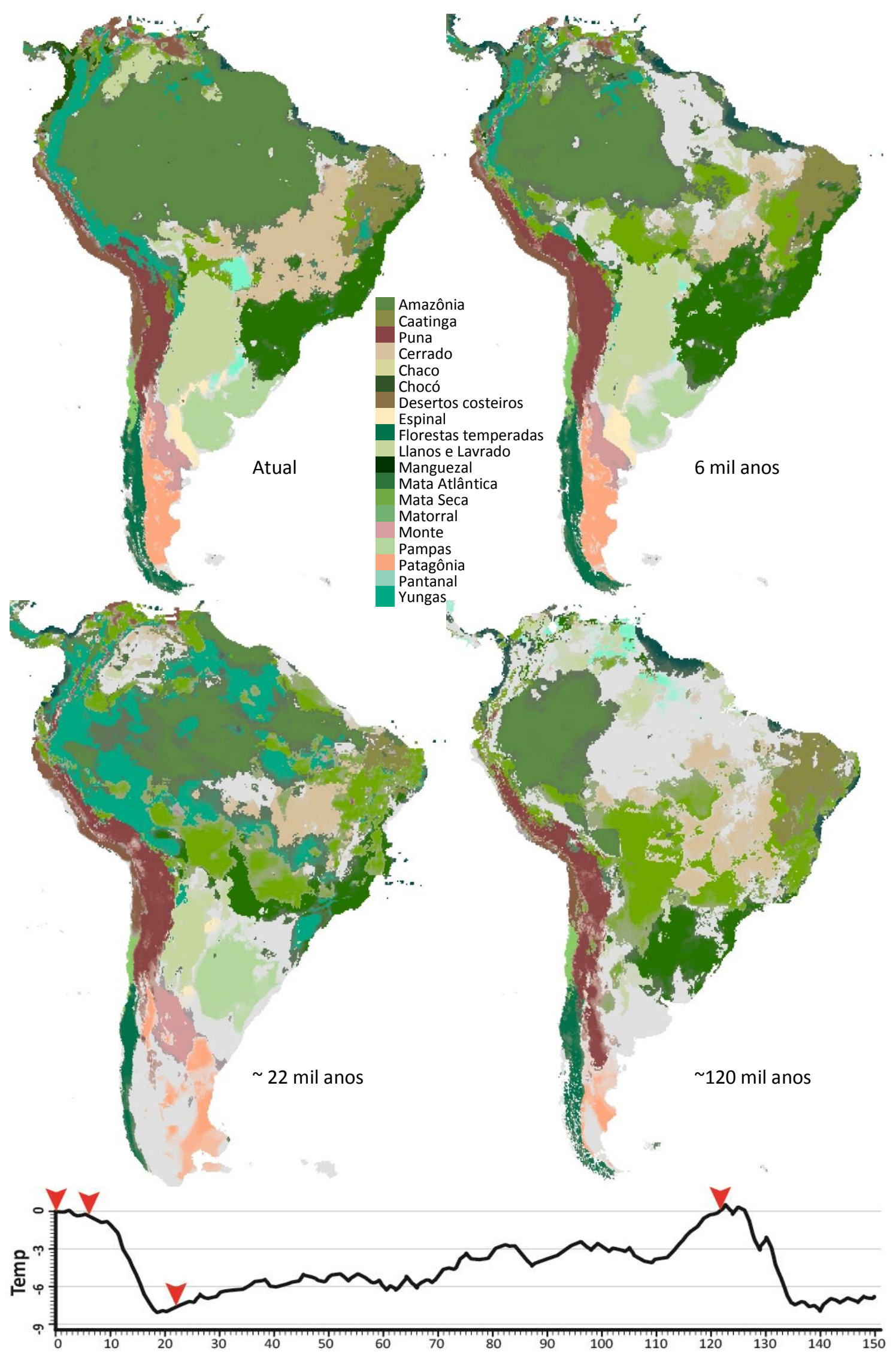

FIGURA 53. Modelagem de cada os biomas para o período atual, Holoceno médio ( 6 mil anos), auge do último período glacial (20 mil anos), e auge do último período interglacial (120 mil anos atrás). Gráfico de temperatura modificado de PETIT et al. (1999). 
BADGLEY 2010; RONCAL et al. 2011; HEIBL \& RENNER 2012). No entanto ciclos climáticos têm ocorrido com uma certa regularidade ao longo da história da Terra (TIWARI 1987; HERBERT et al. 2016; NIE et al. 2017), e estas mudanças na paisagem Sul América ao longo dos últimos 120 mil anos representam uma dinâmica que deve ter se repetido diversas vezes ao longo dos últimos milhões de anos.
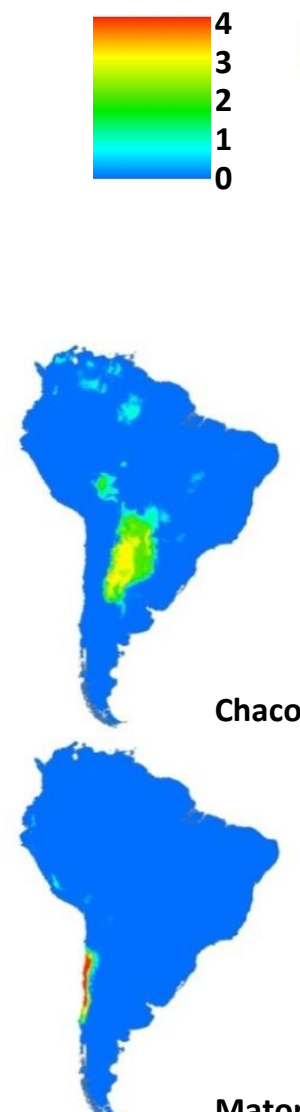

Matorral
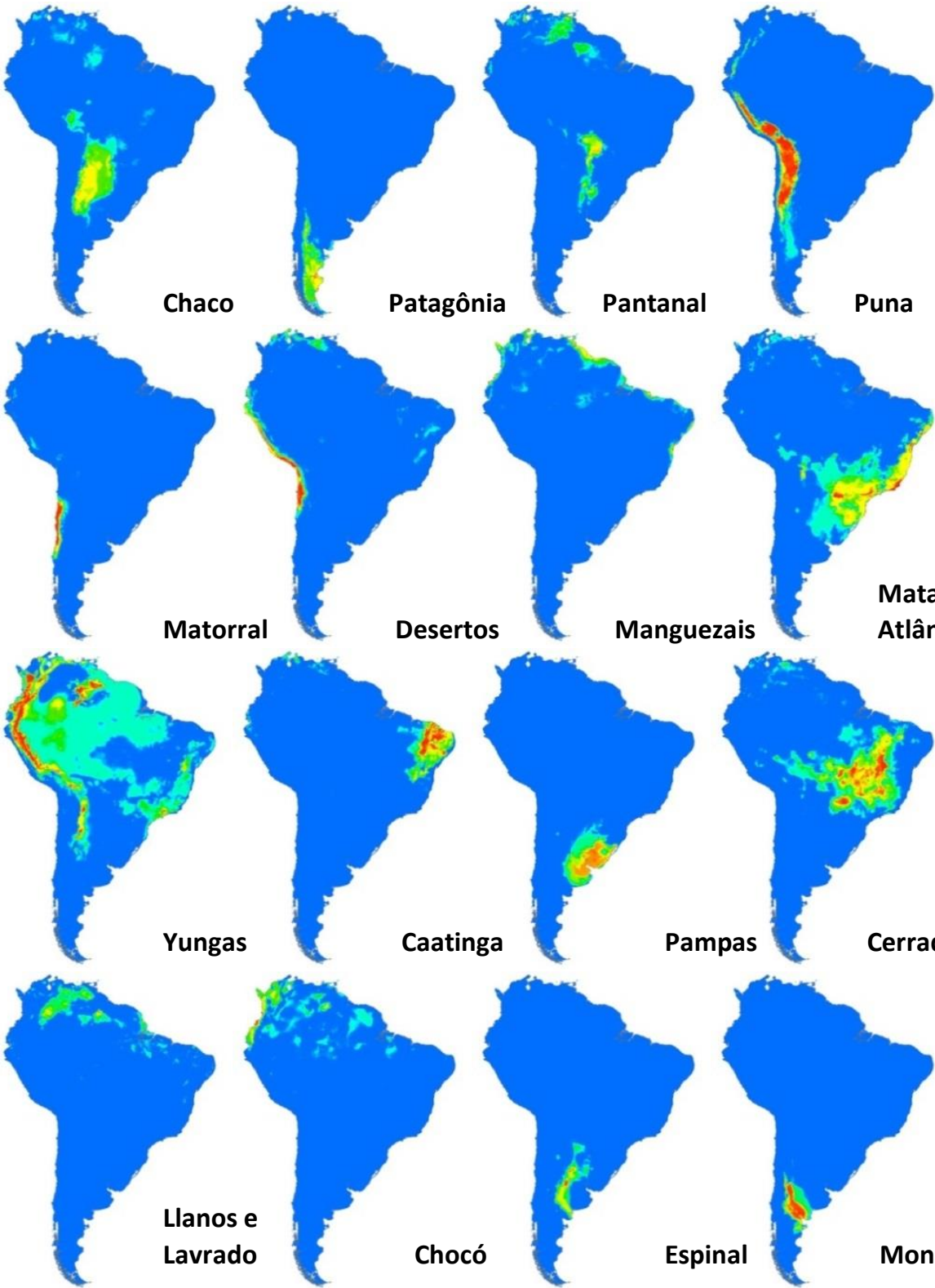

Espinal

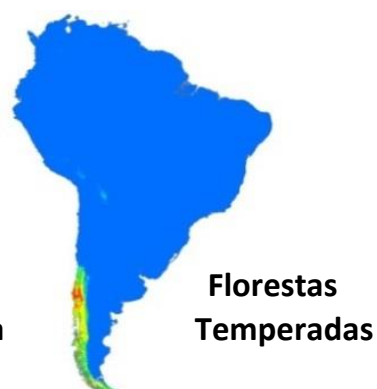

Florestas

Atlântica
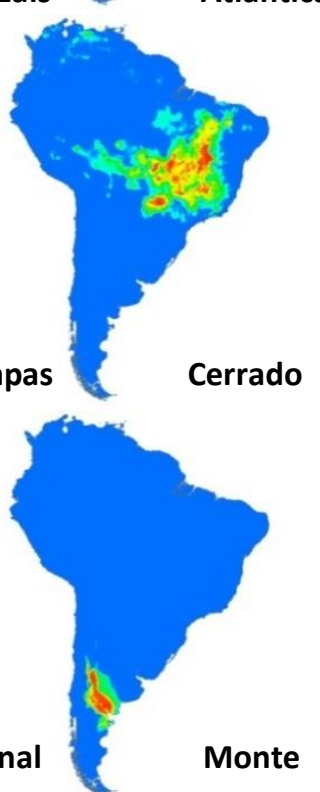

FIGURA 54. Frequência dos modelos entre os quatro períodos modelados (presente, Holoceno, auge do glacial e último interglacial), para cada bioma. 


\section{REFERÊNCIAS}

AKAIKE, H. (1974) New Look at Statistical-Model Identification. leee Transactions on Automatic Control, 19, 716-723.

ÁlVAREZ, B.B., GARCíA, J.A.R., CÉPEDEZ, J.A., HERNANDO, A., ZARACHO, V., CALAMANTE, C.C. \& AGUIRRE, R.H. (2009) Herpetofauna, provinces of Chaco and Formosa, Chaco Oriental region, north-eastern Argentina. Check List, 5, 74-82.

AMARO, R.C., RODRIGUES, M.T., YONENAGA-YASSUDA, Y. \& CARNAVAL, A.C. (2012) Demographic processes in the montane Atlantic rainforest: Molecular and cytogenetic evidence from the endemic frog Proceratophrys boiei. Molecular Phylogenetics and Evolution, 62, 880-888.

ARISTOTÉLĒS. (1952) Meteorologica - with a an english transaltion by H.D.P. Lee, M.A. William Henemann Ltd, London, 433 pp.

ARAÚJO, M.B., NOGUÉS-BRAVO, D., DINIZ-FILHO, J.A.F., HAYWOOD, A.M., VALDES, P.J. \& RAHBEK, C. (2008) Quaternary climate changes explain diversity among reptiles and amphibians. Ecography, 31, 8-15.

AVILA-PIRES, T.C.S. (1995) Lizards of Brazilian Amazonia (Reptilia: Squamata). Zoologische Mededelingen, 299, 1-706.

AZEVEDO, J.A.R., VALDUJO, P.H. \& DE C. NOGUEIRA, C. (2016) Biogeography of anurans and squamates in the Cerrado hotspot: coincident endemism patterns in the richest and most impacted savanna on the globe. Journal of Biogeography, n/a-n/a.

BADGLEY, C. \& FOX, D.L. (2000) Ecological biogeography of North American mammals: species density and ecological structure in relation to environmental gradients. Journal of Biogeography, 27, 1437-1467.

BANDA-R, K., DELGADO-SALINAS, A., DEXTER, K.G., LINARES-PALOMINO, R., OLIVEIRA-FILHO, A., PRADO, D., PULLAN, M., QUINTANA, C., RIINA, R., RODRÍGUEZ M, G.M., WEINTRITT, J., ACEVEDO-RODRÍGUEZ, P., ADARVE, J., ÁlVAREZ, E., ARANGUREN B, A., ARTEAGA, J.C., AYMARD, G., CASTAÑo, A., CEBAllos-MAGO, N., COGollo, Á., CUADROS, H., DELGADO, F., DEVIA, W., DUEÑAS, H., FAJARDO, L., FERNÁNDEZ, Á., FERNÁNDEZ, M.Á., FRANKLIN, J., FREID, E.H., GALETTI, L.A., GONTO, R., GONZÁLEZ-M, R., GRAVESON, R., HELMER, E.H., IDÁRRAGA, Á., LÓPEZ, R., MARCANO-VEGA, H., MARTíNEZ, O.G., MATURO, H.M., MCDONALD, M., MCLAREN, K., MELO, O., MIJARES, F., MOGNI, V., MOLINA, D., MORENO, N.D.P., NASSAR, J.M., NEVES, D.M., OAKLEY, L.J., OATHAM, M., OLVERA-LUNA, A.R., PEZZINI, F.F., DOMINGUEZ, O.J.R., RÍOS, M.E., RIVERA, O., RODRÍGUEZ, N., ROJAS, A., SÄRKINEN, T., SÁNCHEZ, R., SMITH, M., VARGAS, C., VILLANUEVA, B. \& PENNINGTON, R.T. (2016) Plant diversity patterns in neotropical dry forests and their conservation implications. Science, 353, 1383.

BATALHA, H., CABANNE, G.S. \& MIYAKI, C.Y. (2012) Phylogeography of an Atlantic forest passerine reveals demographic stability through the last glacial maximum. Molecular Phylogenetics and Evolution, 65, 892-902.

BEARD, J.S., CHAPMAN, A.R. \& GIOIA, P. (2000) Species richness and endemism in the Western Australian flora. Journal of Biogeography, 27, 1257-1268. 
BECK, R.M.D. (2008) A dated phylogeny of marsupials using a molecular supermatrix and multiple fossil constraints. Journal of Mammalogy, 89, 175-189.

BOOTH, G.D., NICCOLUCCI, M.J. \& SCHUSTER, E.G. (1994) Identifying Proxy Sets in Multiple Linear-Regression - an Aid to Better Coefficient Interpretation. Usda Forest Service Intermountain Research Station Research Paper, 1-13.

BOWERMAN, B.L. \& O'CONNELL, R. (2000) Linear Statistical Models: An Applied Approach. Duxbury Press, $1024 \mathrm{pp}$.

BREGOVIĆ, P. \& ZAGMAJSTER, M. (2016) Understanding hotspots within a global hotspot identifying the drivers of regional species richness patterns in terrestrial subterranean habitats. Insect Conservation and Diversity, 9, 268-281.

BROWN, J.H. (2014) Why are there so many species in the tropics? Journal of Biogeography, $41,8-22$.

BUFFON, G.L.L.C.D. (1761) Historie Naturelle générale et particulière avec la description du Cabinet du Roy. Vol. 9. L'Imprimeire Royale, Paris,pp.

BURNHAM, K.P. \& ANDERSON, D.R. (2002) Model selection and múltimodel inference: A practical information-theoretic approach. Spring-Verlag, New York,pp.

BUSH, M.B. (1994) Amazonian Speciation: A Necessarily Complex Model. Journal of Biogeography, 21, 5-17.

CARNAVAL, A.C. \& MORITZ, C. (2008) Historical climate modelling predicts patterns of current biodiversity in the Brazilian Atlantic forest. Journal of Biogeography, 35, 1187-1201.

CARNAVAL, A.C., HICKERSON, M.J., HADDAD, C.F.B., RODRIGUES, M.T. \& MORITZ, C. (2009) Stability predicts genetic diversity in the Brazilian Atlantic forest hotspot. Science, 323,

CARNAVAL, A.C.O.Q. \& BATES, J.M. (2007) Amphibian DNA shows marked genetic structure and tracks Pleistocene climate change in northeastern Brazil. Evolution, 61, 2942-2957.

CASAGRANDA, D. \& GROSSO, M.L. (2013) Areas of Endemism: Methodological and Applied Biogeographic Contributions from South America. In: SILVA-OPPS, M. (Ed.) Current Progress in Biological Research. InTech3-18.

COLLI, G.R., BASTOS, R.P. \& ARAUJO, A.F. (2002) The character and dynamics of the cerrado herpetofauna. In: OLIVEIRA, P.S. \& MARQUIS, R.J. (Eds.) The cerrados of Brazil: ecology and natural history of a neotropical savanna. Columbia University Press, New York, pp. 223-241.

CONDIT, R., PITMAN, N., LEIGH, E.G., CHAVE, J., TERBORGH, J., FOSTER, R.B., NÚÑEZ, P., AGUILAR, S., VALENCIA, R., VILLA, G., MULLER-LANDAU, H.C., LOSOS, E. \& HUBBELL, S.P. (2002) Beta-Diversity in Tropical Forest Trees. Science, 295, 666.

COUTINHO, L.M. (2016) Biomas brasileiros. Ofinina de Textos, São Paulo, 128 pp.

COX, C.B. \& MOORE, P.D. (2010) Biogeography - An Ecological and Evolutionary Approach. John Wiley \& Sons, Hoboken, NJ, USA, $498 \mathrm{pp}$.

CRACRAFT, J. (1985) Historical biogeography and patterns of differentiation within the South American avifauna: areas of endemism. Ornithological Monographs, 49-84.

CRISP, M.D., LAFFAN, S., LINDER, H.P. \& MONRO, A. (2001) Endemism in the Australian flora. Journal of Biogeography, 28, 183-198.

CURRIE, D.J. (1991) Energy and Large-Scale Patterns of Animal- and Plant-Species Richness. The American Naturalist, 137, 27-49.

CURRIE, D.J., MITTELBACH, G.G., CORNELL, H.V., FIELD, R., GUEGAN, J.F., HAWKINS, B.A., KAUFMAN, D.M., KERR, J.T., OBERDORFF, T., O'BRIEN, E. \& TURNER, J.R.G. (2004) 
Predictions and tests of climate-based hypotheses of broad-scale variation in taxonomic richness. Ecology Letters, 7, 1121-1134.

CVETKOVIC, D., TOMASEVIC, N., FICETOLA, G.F., CRNOBRNJA-ISAILOVIC, J. \& MIAUD, C. (2009) Bergmann's rule in amphibians: combining demographic and ecological parameters to explain body size variation among populations in the common toad Bufo bufo. Journal of Zoological Systematics and Evolutionary Research, 47, 171-180.

DAL VECHIO, F. (2015) Revisão sistemática de Bothrops bilineatus (Serpentes: Viperidae) com base em caracteres moleculares e morfológicos. PhD. Departamento de Zoologia, Universidade de São Paulo, São Paulo, 147 pp.

DASILVA, J.M.C. \& OREN, D.C. (1996) Application of parsimony analysis of endemicity in Amazonian biogeography: An example with primates. Biological Journal of the Linnean Society, 59, 427-437.

DELONG, E.R., DELONG, D.M. \& CLARKE-PEARSON, D.L. (1988) Comparing the Areas under Two or More Correlated Receiver Operating Characteristic Curves: A Nonparametric Approach. Biometrics, 44, 837-845.

DEVITT, T.J., DEVITT, S.E.C., HOLLINGSWORTH, B.D., MCGUIRE, J.A. \& MORITZ, C. (2013) Montane refugia predict population genetic structure in the Large-blotched Ensatina salamander. Molecular Ecology, 22, 1650-1665.

DINIZ-FILHO, J.A.F., BASTOS, R.P., RANGEL, T.F.L.V.B., BINI, L.M., CARVALHO, P. \& SILVA, R.J. (2005) Macroecological correlates and spatial patterns of anuran description dates in the Brazilian Cerrado. Global Ecology and Biogeography, 14, 469-477.

DINIZ-FILHO, J.A.F., BINI, L.M. \& HAWKINS, B.A. (2003) Spatial autocorrelation and red herrings in geographical ecology. Global Ecology and Biogeography, 12, 53-64.

DINIZ-FILHO, J.A.F., NABOUT, J.C., TELLES, M.P.D., SOARES, T.N. \& RANGEL, T.F.L.V.B. (2009) A review of techniques for spatial modeling in geographical, conservation and landscape genetics. Genetics and Molecular Biology, 32, 203-211.

DINIZ-FILHO, J.A.F., RANGEL, T.F.L.V.B. \& BINI, L.M. (2008) Model selection and information theory in geographical ecology. Global Ecology and Biogeography, 17, 479-488.

DONY, J.G. \& DENHOLM, I. (1985) Some Quantitative Methods of Assessing the Conservation Value of Ecologically Similar Sites. Journal of Applied Ecology, 22, 229-238.

DUELLMAN, W.E. \& TRUEB, L. (1994) Biology of Amphibian. The Johns Hopkins University Press, Baltimore, $670 \mathrm{pp}$.

DUELLMAN, W.E. (1999) Patterns of Distribution of Amphibians: A Global Perspective. Johns Hopkins University Press, 633 pp.

ESRI. (2011) ArcGIS Desktop: Release 10. Environmental Systems Research Institute, Redlands, CA

FERNANDES, A.M., WINK, M. \& ALEIXO, A. (2012) Phylogeography of the chestnut-tailed antbird (Myrmeciza hemimelaena) clarifies the role of rivers in Amazonian biogeography. Journal of Biogeography, 39, 1524-1535.

FERRARI, A., PALADINI, A., SCHWERTNER, C.F. \& GRAZIA, J. (2010) Endemism analysis of Neotropical Pentatomidae (Hemiptera, Heteroptera). Iheringia Serie Zoologia, 100, 449462.

FIELD, R., HAWKINS, B.A., CORNELL, H.V., CURRIE, D.J., DINIZ-FILHO, J.A.F., GUEGAN, J.-F., KAUFMAN, D.M., KERR, J.T., MITTELBACH, G.G., OBERDORFF, T., O'BRIEN, E.M. \& 
TURNER, J.R.G. (2009) Spatial species-richness gradients across scales: a meta-analysis. Journal of Biogeography, 36, 132-147.

FINARELLI, J.A. \& BADGLEY, C. (2010) Diversity dynamics of Miocene mammals in relation to the history of tectonism and climate. Proceedings of the Royal Society B: Biological Sciences,

FJELDSÅ, J., LAMBIN, E. \& MERTENS, B. (1999) Correlation between Endemism and Local Ecoclimatic Stability Documented by Comparing Andean Bird Distributions and Remotely Sensed Land Surface Data. Ecography, 22, 63-78.

FORTIN, M.J. \& DALE, M.R.T. (2005) Spatial Analysis: A Guide for Ecologists. Cambridge University Press, Cambridge, New York, Melbourne, Madrid, Cape Town, Singapore, São Paulo, 365 pp.

FROST, D.R. (2016) Amphibian Species of the World: an Online Reference. v. 6.0. American Museum of Natural History, New York, USA. Available from: http://research.amnh.org/herpetology/amphibia/

GARZIONE, C.N., HOKE, G.D., LIBARKIN, J.C., WITHERS, S., MACFADDEN, B., EILER, J., GHOSH, P. \& MULCH, A. (2008) Rise of the Andes. Science, 320, 1304-1307.

GASTON, K.J. (2000) Global patterns in biodiversity. Nature, 405, 220-227.

GEHRING, P.S., PABIJAN, M., RANDRIANIRINA, J.E., GLAW, F. \& VENCES, M. (2012) The influence of riverine barriers on phylogeographic patterns of Malagasy reed frogs (Heterixalus). Molecular Phylogenetics and Evolution, 64, 618-632.

GLOR, R.E., VITT, L.J. \& LARSON, A. (2001) A molecular phylogenetic analysis of diversification in Amazonian Anolis lizards. Molecular Ecology, 10, 2661-2668.

GONZÁLEZ-MAYA, J.F., VÍQUEZ-R, L.R., ARIAS-ALZATE, A., BELANT, J.L. \& CEBALLOS, G. (2016) Spatial patterns of species richness and functional diversity in Costa Rican terrestrial mammals: implications for conservation. Diversity and Distributions, 22, 43-56.

GOOGLE. (2017) Google Earth v.7.1.8.3036

GRAHAM, A. (2011) A natural history of the New World: the ecology and evolution of plants in the Americas. The University of Chicago Press, Chicago, $387 \mathrm{pp}$.

GRAHAM, C.H., RON, S.R., SANTOS, J.C., SCHNEIDER, C.J. \& MORITZ, C. (2004) Integrating phylogenetics and environmental niche models to explore speciation mechanisms in dendrobatid frogs. Evolution, 58, 1781-1793.

GUEDES, T.B., NOGUEIRA, C. \& MARQUES, O.A.V. (2014a) Diversity, natural history, and geographic distribution of snakes in the Caatinga, Northeastern Brazil. Zootaxa, 3863, 193.

GUEDES, T.B., SAWAYA, R.J. \& NOGUEIRA, C.D. (2014b) Biogeography, vicariance and conservation of snakes of the neglected and endangered Caatinga region, north-eastern Brazil. Journal of Biogeography, 41, 919-931.

GUEGAN, J.-F., LEK, S. \& OBERDORFF, T. (1998) Energy availability and habitat heterogeneity predict global riverine fish diversity. Nature, 391, 382-384.

HAFFER, J. \& PRANCE, G.T. (2001) Climatic forcing of evolution in Amazonia during the Cenozoic: On the refuge theory of biotic differentiation. Amazoniana, 16, 579-607.

HAFFER, J. (1969) Speciation in Amazonian forest birds. Science, 165, 131-137.

HAFFER, J. (1974) Avian speciation in tropical South América. Nuttall Ornitological Club, Cambridge, $398 \mathrm{pp}$. 
HAFFER, J. (1992) On the 'river effect' in some forest birds of southern Amazonia. Boletim do Museu Paraense Emilio Goeldi Serie Zoologia, 8, 217-245.

HAFFER, J. (1997) Alternative models of vertebrate speciation in Amazonia: an overview. Biodiversity and Conservation, 6, 451-176.

HAWKINS, B.A. (2012) Eight (and a half) deadly sins of spatial analysis. Journal of Biogeography, 39, 1-9.

HAWKINS, B.A., PORTER, E.E. \& DINIZ, J.A.F. (2003) Productivity and history as predictors of the latitudinal diversity gradient of terrestrial birds. Ecology, 84, 1608-1623.

HAYES, F.E. \& SEWLAL, J.-A.N. (2004) The Amazon River as a dispersal barrier to passerine birds: effects of river width, habitat and taxonomy. Journal of Biogeography, 31, 18091818.

HEIBL, C. \& RENNER, S.S. (2012) Distribution Models and a Dated Phylogeny for Chilean Oxalis Species Reveal Occupation of New Habitats by Different Lineages, not Rapid Adaptive Radiation. Systematic Biology, 61, 823-834.

HERBERT, T.D., LAWRENCE, K.T., TZANOVA, A., PETERSON, L.C., CABALLERO-GILL, R. \& KELLY, C.S. (2016) Late Miocene global cooling and the rise of modern ecosystems. Nature Geosci, 9, 843-847.

hIJMANS, R.J., CAMERON, S.E., PARRA, J.L., JONES, P.G. \& JARVIS, A. (2005) Very high resolution interpolated climate surfaces for global land areas. International Journal of Climatology, 25, 1965-1978.

HIJMANS, R.J., GUARINO, L., CRUZ, M. \& ROJAS, E. (2001) Computer tools for spatial analysis of plant genetic resources data: 1 DIVA-GIS. Plant Genetic Resources Newsletter, 2001, 15-19.

HOORN, C., WESSELINGH, F.P., TER STEEGE, H., BERMUDEZ, M.A., MORA, A., SEVINK, J., SANMARTIN, I., SANCHEZ-MESEGUER, A., ANDERSON, C.L., FIGUEIREDO, J.P., JARAMILLO, C., RIFF, D., NEGRI, F.R., HOOGHIEMSTRA, H., LUNDBERG, J., STADLER, T., SARKINEN, T. \& ANTONELLI, A. (2010) Amazonia Through Time: Andean Uplift, Climate Change, Landscape Evolution, and Biodiversity. Science, 330, 927-931.

HUBBELL, S.P. (2001) The Unified Theory of Biodiversity and Biogeography. Princeton University Press, Princeton 375 pp.

HUGALL, A., MORITZ, C., MOUSSALLI, A. \& STANISIC, J. (2002) Reconciling paleodistribution models and comparative phylogeography in the Wet Tropics rainforest land snail Gnarosophia bellendenkerensis (Brazier 1875). Proceedings of the National Academy of Sciences of the United States of America, 99, 6112-6117.

HUGGETT, R.J. (2004) Fundamentals of Biogeography. Routledge - Taylor \&Francis Group, London and New York, $439 \mathrm{pp}$.

HUGHES, C. \& EASTWOOD, R. (2006) Island radiation on a continental scale: Exceptional rates of plant diversification after uplift of the Andes. Proceedings of the National Academy of Sciences of the United States of America, 103, 10334-10339.

HURVICH, C.M. \& TSAI, C.-L. (1989) Regression and time series model selection in small samples. Biometrika, 76, 297-307.

INGENLOFF, K. \& PETERSON, A.T. (2015) Trans-Amazon dispersal potential for Crotalus durissus during Pleistocene climate events. Biota Neotropica, 15, 
INSEL, N., POULSEN, C.J. \& EHLERS, T.A. (2010) Influence of the Andes Mountains on South American moisture transport, convection, and precipitation. Climate Dynamics, 35, 1477-1492.

INSEL, N., POULSEN, C.J., EHLERS, T.A. \& STURM, C. (2012) Response of meteoric delta $\delta^{18} O$ to surface uplift - Implications for Cenozoic Andean Plateau growth. Earth and Planetary Science Letters, 317, 262-272.

IUCN. (2017) The IUCN Red List of Threatened Species 2017. IUCN. Available from: http://www.iucnredlist.org

JACCARD, P. (1902) Lois de distribution florale. Bulletin de la Societe Vaudoise des Sciences Naturelles, 38, 67-130.

JACCARD, P. (1912) The distribution of the flora in the alpine zone. New Phytologist, 11, 3750.

JARAMILlO, C., RUEDA, M.J. \& MORA, G. (2006) Cenozoic Plant Diversity in the Neotropics. Science, 311, 1893.

JOHNSTON, J.W. (1976) Similarity Indices I: What Do They Measure? Pacific Northwest Laboratories, Richland, $136 \mathrm{pp}$.

KAPS, M. \& LAMBERSON, W.R. (2004) Biostatistics for Animal Science. CABI Publishing, Oxfordshire e Cambridge, $459 \mathrm{pp}$.

KOHN, M.J. \& FREMD, T.J. (2008) Miocene tectonics and climate forcing of biodiversity, western United States. Geology, 36, 783-786.

KUSCHEL, G. (1969) Biogeography and Ecology of South American Coleoptera. In: FITTKAU, E.J., ILLIES, J., KLINGE, H. \& SCHWABE, G.H. (Eds.) Biogeography and Ecology in South America. Dr. W. Junk B. V. Publishers, La Haya, pp. 624-658.

LANDE, R. (1996) Statistics and Partitioning of Species Diversity, and Similarity among Multiple Communities. Oikos, 76, 5-13.

LAWING, A.M. \& POLLY, P.D. (2011) Pleistocene Climate, Phylogeny, and Climate Envelope Models: An Integrative Approach to Better Understand Species' Response to Climate Change. PLOS ONE, 6,

LEITE, Y.L.R., COSTA, L.P., LOSS, A.C., ROCHA, R.G., BATALHA, H., BASTOS, A.C., QUARESMA, V.S., FAGUNDES, V., PARESQUE, R., PASSAMANI, M. \& PARDINI, R. (2016) Neotropical forest expansion during the last glacial period challenges refuge hypothesis. Proceedings of the National Academy of Sciences of the United States of America, 113, 1008-1013.

LI, G.Q., XU, G.H., GUO, K. \& DU, S. (2014) Mapping the Global Potential Geographical Distribution of Black Locust (Robinia Pseudoacacia L.) Using Herbarium Data and a Maximum Entropy Model. Forests, 5, 2773-2792.

LOMOLINO, M.V., RIDDLE, B.R. \& BROWN, J.H. (2006) Biogeography. Sinauer Associates, Inc., Sunderland, MA, $845 \mathrm{pp}$.

LU, G. \& BERNATCHEZ, L. (1999) Correlated trophic specialization and genetic divergence in sympatric lake whitefish ecotypes (Coregonus clupeaformis): Support for the ecological speciation hypothesis. Evolution, 53, 1491-1505.

MAGURRAN, A.E. (1988) Ecological diversity and its measurements. Croom Helm Ltd., London, 1-192 pp.

MAGURRAN, A.E. (2004) Measuring Biological Diversity. Blackwell Publishing, Oxford, 264 pp. 
MARTINS, F.D.M. (2011) Historical biogeography of the Brazilian Atlantic forest and the Carnaval-Moritz model of Pleistocene refugia: what do phylogeographical studies tell us? Biological Journal of the Linnean Society, 104, 499-509.

MELO, A.S., RANGEL, T.F.L.V.B. \& DINIZ, J.A.F. (2009) Environmental drivers of beta-diversity patterns in New-World birds and mammals. Ecography, 32, 226-236.

MITTERMEIER, R.A., MITTERMEIER, C.G., GIL, P.R. \& PILGRIM, J. (2002) Wilderness: Earth's Last Wild Places. Conservation International, Washington, $576 \mathrm{pp}$.

MONTGOMERY, D.C., PECK, E.A. \& VINING, G.G. (2012) Introduction to Linear Regression Wiley, Hoboken, NJ, $672 \mathrm{pp}$.

MORITZ, C., PATTON, J.L., SCHNEIDER, C.J. \& SMITH, T.B. (2000) Diversification of rainforest faunas: An integrated molecular approach. Annual Review of Ecology and Systematics, $31,533-563$.

MORRONE, J.J. (2006) Biogeographic areas and transition zones of Latin America and the Caribbean islands based on panbiogeographic and cladistic analyses of the entomofauna. Annual Review of Entomology, 51, 467-494.

MORRONE, J.J. (2009) Evolutionary Biogeography: an integrative approach with case studies. Columbia University Press, Chichester, NY, 1-301 pp.

MORRONE, J.J. (2011) América do Sul e a geografia da vida: comparação de algumas propostas de regionalização. In: CARVALHO, C.J.B. \& ALMEIDA, E.A.B. (Eds.) Biogeografia da Amrérica do Sul - Padrões \& Processos. Roca, São Paulo, pp. 14-40.

MORRONE, J.J. (2014) Biogeographical regionalisation of the Neotropical region. Zootaxa, $3782,1-110$.

MORRONE, J.J. (2015) Biogeographical regionalisation of the Andean region. Zootaxa, 3936, 207-236.

MOURA, M.R., VILLALOBOS, F., COSTA, G.C. \& GARCIA, P.C.A. (2016) Disentangling the Role of Climate, Topography and Vegetation in Species Richness Gradients. PLOS ONE, 11, e0152468.

MYERS, N., MITTERMEIER, R.A., MITTERMEIER, C.G., DA FONSECA, G.A.B. \& KENT, J. (2000) Biodiversity hotspots for conservation priorities. Nature, 403, 853-858.

NIE, J., GARZIONE, C., SU, Q., LIU, Q., ZHANG, R., HESLOP, D., NECULA, C., ZHANG, S., SONG, Y. \& LUO, Z. (2017) Dominant 100,000-year precipitation cyclicity in a late Miocene lake from northeast Tibet. Science Advances, 3 ,

NOGUEIRA, C., COLLI, G.R. \& MARTINS, M. (2009) Local richness and distribution of the lizard fauna in natural habitat mosaics of the Brazilian Cerrado. Austral Ecology, 34, 83-96.

NOGUEIRA, C., RIBEIRO, S., COSTA, G.C. \& COLLI, G. (2011) Vicariance and endemism in a Neotropical savanna hotspot: distribution patterns of Cerrado squamate reptiles. Journal of Biogeography, 38, 1907-1922.

NORMAN, D.R. \& NAYLOR, L. (1994) Amphibians and reptiles of the Paráguayan Chaco. Autor, University of Texas, $281 \mathrm{pp}$.

NUNES, P.M.S., FOUQUET, A., CURCIO, F.F., KOK, P.J.R. \& RODRIGUES, M.T. (2012) Cryptic species in Iphisa elegans Gray, 1851 (Squamata: Gymnophthalmidae) revealed by hemipenial morphology and molecular data. Zoological Journal of the Linnean Society, 166, 361-376.

O'BRIEN, R.M. (2007) A Caution Regarding Rules of Thumb for Variance Inflation Factors. Quality \& Quantity, 41, 673-690. 
OLIVEIRA, U., BRESCOVIT, A.D. \& SANTOS, A.J. (2015) Delimiting Areas of Endemism through Kernel Interpolation. PLOS ONE, 10,

OLIVEIRA-FILHO, A.T. \& FONTES, M.A.L. (2000) Patterns of floristic differentiation among Atlantic forests in southeastern Brazil and the influence of climate. Biotropica, 32, 793810.

OLIVEIRA-FILHO, A.T. \& RATTER, J.A. (2002) Vegetation Physiognomies and Woody Flora of the Cerrado Biome. In: OLIVEIRA, P.S. \& MARQUIS, R.J. (Eds.) The Cerrados of Brazil Ecology and Natural Hystory of a Neotropical Savanna. Columbia University Press, New York, pp. 91-120.

OLSON, D.M., DINERSTEIN, E., WIKRAMANAYAKE, E.D., BURGUESS, N.D., POWELL, G.V.N., UNDERWOOD, E.C., D'AMICO, J.A., STRAND, J.C., LOUCKS, C.J., ALLNUTT, T.F., RICKETTS, T.H., KURA, Y., LAMOREUX, J.F., WETTENGEL, W.W., HEDAO, P. \& KASSEM, K.R. (2001) Terrestrial Ecoregions of the World: A New Map of Life on Earth. Bioscience, 51, 933-938.

ORR, M.R. \& SMITH, T.B. (1998) Ecology and speciation. Trends in Ecology \& Evolution, 13, 502-506.

OTTO-BLIESNER, B.L., MARSHALL, S.J., OVERPECK, J.T., MILLER, G.H. \& HU, A. (2006) Simulating Arctic Climate Warmth and Icefield Retreat in the Last Interglaciation. Science, 311, 1751.

PALMER, M.W. (1994) Variation in Species Richness: Towards a Unification of Hypotheses. Folia Geobotanica \& Phytotaxonomica, 29, 511-530.

PASSONI, J.C., BENOZZATI, M.L. \& RODRIGUES, M.T. (2008) Phylogeny, species limits, and biogeography of the Brazilian lizards of the genus Eurolophosaurus (Squamata : Tropiduridae) as inferred from mitochondrial DNA sequences. Molecular Phylogenetics and Evolution, 46, 403-414.

PEARSON, R.G. (2010) Species' distribution modeling for conservation educators and practitioners. Lessons in conservation, 3 ,

PELleGRINO, K.C.M., RODRIGUES, M.I., WAITE, A.N., MORANDO, M., YASSUDA, Y.Y. \& SITES, J.W. (2005) Phylogeography and species limits in the Gymnodactylus darwinii complex (Gekkonidae, Squamata): genetic structure coincides with river systems in the Brazilian Atlantic Forest. Biological Journal of the Linnean Society, 85, 13-26.

PENNINGTON, R.T., LAVIN, M., PRADO, D.E., PENDRY, C.A., PELL, S.K. \& BUTTERWORTH, C.A. (2004) Historical climate change and speciation: neotropical seasonally dry forest plants show patterns of both Tertiary and Quaternary diversification. Philosophical Transactions of the Royal Society of London. Series B, Biological Sciences, 359, 515-537.

PETIT, J.R., JOUZEL, J., RAYNAUD, D., BARKOV, N.I., BARNOLA, J.M., BASILE, I., BENDER, M., ChAPpellaZ, J., DAVIS, M., Delaygue, G., DELMOTTE, M., KOTLYAKOV, V.M., LEGRAND, M., LIPENKOV, V.Y., LORIUS, C., PEPIN, L., RITZ, C., SALTZMAN, E. \& STIEVENARD, M. (1999) Climate and atmospheric history of the past 420,000 years from the Vostok ice core, Antarctica. Nature, 399, 429-436.

PHILLIPS, S.J. \& DUDíK, M. (2008) Modeling of species distributions with MaxEnt: new extensions and a comprehensive evaluation. Ecography, 31, 161-175.

PHILLIPS, S.J., ANDERSON, R.P. \& SCHAPIRE, R.E. (2006) Maximum entropy modeling of species geographic distributions. Ecological Modelling, 190, 231-259. 
PIANKA, E.R. \& VITT, L.J. (2003) Lizards: windows to the evolution of diversity. University of California Press, Berkley, 333 pp.

PITMAN, N.C.A., TERBORGH, J.W., SILMAN, M.R., NÚÑEZ V, P., NEILL, D.A., CERÓN, C.E., PALACIOS, W.A. \& AULESTIA, M. (2001) Dominance and Distribution of Tree Species in Upper Amazonian Terra Firme Forests. Ecology, 82, 2101-2117.

POSADAS, P. \& ORTIZ-JAUREGUIZAR, E. (2011) Evolução da Regiao Andina da Amarica do Sul. In: CARVALHO, C.J.B. \& ALMEIDA, E.A.B. (Eds.) Biogeografia da América do Sul - Padrões \& Processos. Roca, São Paulo, pp. 173-189.

POTTER, P.E. \& SZATMARI, P. (2009) Global Miocene tectonics and the modern world. EarthScience Reviews, 96, 279-295.

POUGH, F.H., ANDREWS, R.M., CRUMP, M.L., SAVITZKY, A.H., WELLS, K.D. \& BRANDLEY, M.C. (2015) Herpetology. Sinauer Sunderland, $591 \mathrm{pp}$.

PRADO, J.R., BRENNAND, P.G.G., GODOY, L.P., LIBARDI, G.S., ABREU, E.F., ROTH, P.R.O., CHIQUITO, E.A. \& PERCEQUILLO, A.R. (2015) Species richness and areas of endemism of oryzomyine rodents (Cricetidae, Sigmodontinae) in South America: an NDM/VNDM approach. Journal of Biogeography, 42, 540-551.

PRATES, I., RODRIGUES, M.T., MELO-SAMPAIO, P.R. \& CARNAVAL, A.C. (2015) Phylogenetic relationships of Amazonian anole lizards (Dactyloa): taxonomic implications, new insights about phenotypic evolution and the timing of diversification. Molecular Phylogenetics and Evolution, 82, 258-268.

PRATES, I., XUE, A.T., BROWN, J.L., ALVARADO-SERRANO, D.F., RODRIGUES, M.T., HICKERSON, M.J. \& CARNAVAL, A.C. (2016) Inferring responses to climate dynamics from historical demography in neotropical forest lizards. Proceedings of the National Academy of Sciences, 113, 7978-7985.

PYRON, R.A. \& WIENS, J.J. (2013) Large-scale phylogenetic analyses reveal the causes of high tropical amphibian diversity. Proceedings of the Royal Society B-Biological Sciences, 280, 1-10.

RAHBEK, C. \& GRAVES, G.R. (2001) Multiscale assessment of patterns of avian species richness. Proceedings of the National Academy of Sciences of the United States of America, 98, 4534-4539.

RAHBEK, C., GOTELLI, N.J., COLWELL, R.K., ENTSMINGER, G.L., RANGEL, T.F.L.V.B. \& GRAVES, G.R. (2007) Predicting continental-scale patterns of bird species richness with spatially explicit models. Proceedings of the Royal Society B: Biological Sciences, 274, 165-174.

RANGEL, T.F., DINIZ, J.A.F. \& BINI, L.M. (2010) SAM: a comprehensive application for Spatial Analysis in Macroecology. Ecography, 33, 46-50.

RANGEL, T.F.L.V.B., DINIZ-FILHO, J.A.F. \& BINI, L.M. (2006) Towards an integrated computational tool for spatial analysis in macroecology and biogeography. Global Ecology and Biogeography, 15, 321-327.

RAXWORTHY, C.J., MARTINEZ-MEYER, E., HORNING, N., NUSSBAUM, R.A., SCHNEIDER, G.E., ORTEGA-HUERTA, M.A. \& PETERSON, A.T. (2003) Predicting distributions of known and unknown reptile species in Madagascar. Nature, 426, 837-841.

RECODER, R.S., WERNECK, F.D., TEIXEIRA JR, M., COLLI, G.R., SITES JR, J.W. \& RODRIGUES, M.T. (2014) Geographic variation and systematic review of the lizard genus Vanzosaura (Squamata, Gymnophthalmidae), with the description of a new species. Zoological Journal of the Linnean Society, 171, 206-225. 
REDFORD, K.H., TABER, A. \& SIMONETTI, J.A. (1990) There is more to biodiversity than tropical rainforests. Conservation Biology, 4, 328-330.

RIBAS, C.C., ALEIXO, A., NOGUEIRA, A.C.R., MIYAKI, C.Y. \& CRACRAFT, J. (2012) A palaeobiogeographic model for biotic diversification within Amazonia over the past three million years. Proceedings of the Royal Society of London B Biological Sciences, 279, 681-689.

RIBAS, C.C., GABAN-LIMA, R., MIYAKI, C.Y. \& CRACRAFT, J. (2005) Historical biogeography and diversification within the Neotropical parrot genus Pionopsitta (Aves: Psittacidae). Journal of Biogeography, 32, 1409-1427.

RICKLEFS, R.E. \& SCHLUTER, D. (1993) Species Diversity in Ecological Communities: Historical and Geographical Perspectives. University of Chicago Press, Chicago e London, 414 pp.

RICKLEFS, R.E. (2004) A comprehensive framework for global patterns in biodiversity. Ecology Letters, 7, 1-15.

RIVAS-MARTINEZ, S. \& TOVAR, O. (1983) Sintesis biogeografica de los Andes. Collectanea Botanica (Barcelona), 14, 515-521.

RODRIGUES, M.T. (2003) Herpetofauna da Caatinga. In: LEAL, I.R., TABARELLI, M. \& SILVA, J.M.C. (Eds.) Ecologia e Conservaçao da Caatinga. Universidade Federal de Pernambuco, Recife, pp. 181-236.

ROHLF, F.J. (1963) Classification of Aedes by Numerical Taxonomic Methods (Diptera: Culicidae). Annals of the Entomological Society of America, 56, 798-804.

RONCAL, J., BLACH-OVERGAARD, A., BORCHSENIUS, F., BALSLEV, H. \& SVENNING, J.C. (2011) A Dated Phylogeny Complements Macroecological Analysis to Explain the Diversity Patterns in Geonoma (Arecaceae). Biotropica, 43, 324-334.

ROSAUER, D.F. \& JETZ, W. (2015) Phylogenetic endemism in terrestrial mammals. Global Ecology and Biogeography, 24, 168-179.

ROSENZWEIG, M.L. (1995) Species diversity in space and time. Cambridge University Press, Cambridge,pp.

RSTUDIO. (2016) RStudio: Integrated Development for R. RStudio, Inc., Boston, MA

RULL, V. (2008) Speciation timing and neotropical biodiversity: the Tertiary-Quaternary debate in the light of molecular phylogenetic evidence. Molecular Ecology, 17, 27222729.

SÁNCHEZ-AZOFEIFA, G.A., KALACSKA, M., QUESADA, M., CALVO-ALVARADO, J.C., NASSAR, J.M. \& RODRÍGUEZ, J.P. (2005) Need for Integrated Research for Sustainable Future in Tropical Dry Forest. Conservation Biology, 19, 285-286.

SANDEL, B., ARGE, L., DALSGAARD, B., DAVIES, R.G., GASTON, K.J., SUTHERLAND, W.J. \& SVENNING, J.C. (2011) The Influence of Late Quaternary Climate-Change Velocity on Species Endemism. Science, 334, 660-664.

SANTOS, J.C., COLOMA, L.A., SUMMERS, K., CALDWELL, J.P., REE, R. \& CANNATELLA, D.C. (2009) Amazonian amphibian diversity is primarily derived from late Miocene Andean lineages. PLoS Biology, 7,

SANTOS, R.M., OLIVEIRA, A.T., EISENLOHR, P.V., QUEIROZ, L.P., CARDOSO, D.B.O.S. \& RODAL, M.J.N. (2012) Identity and relationships of the Arboreal Caatinga among other floristic units of seasonally dry tropical forests (SDTFs) of north-eastern and Central Brazil. Ecology and Evolution, 2, 409-428. 
SCHAEFER, S. (2011) The Andes - Riding the Tectonic Uplift. In: ALBERT, J.S. \& REIS, R.E. (Eds.) Historical Biogeography of Neotropical Freshwater Fishes. University of California Press, Berkley, pp. 259-278.

SCHLUTER, D. (1996) Ecological Causes of Adaptive Radiation. The American Naturalist, 148, S40-S64.

SICK, W.D. (1969) Geographical substance. Monographiae Biologicae, 19, 449-474.

SIEDCHLAG, A.C., BENOZZATI, M.L., PASSONI, J.C. \& RODRIGUES, M.T. (2010) Genetic structure, phylogeny, and biogeography of Brazilian eyelid-less lizards of genera Calyptommatus and Nothobachia (Squamata, Gymnophthalmidae) as inferred from mitochondrial DNA sequences. Molecular Phylogenetics and Evolution, 56, 622-630.

SILVA, J.M.C., SOUSA, M.C. \& CASTELLETTI, C.H.M. (2004) Areas of endemism for passerine birds in the Atlantic forest, South America. Global Ecology and Biogeography, 13, 85-92.

SLATYER, C., ROSAUER, D. \& LEMCKERT, F. (2007) An assessment of endemism and species richness patterns in the Australian Anura. Journal of Biogeography, 34, 583-596.

SNEATH, P.H.A. \& SOKAL, R.R. (1973) Numerical taxonomy - The principles and practice of numerical classification. W.H.Freeman, São Francisco, 573 pp.

SOBRAL-SOUZA, T., LIMA-RIBEIRO, M.S. \& SOLFERINI, V.N. (2015) Biogeography of Neotropical Rainforests: past connections between Amazon and Atlantic Forest detected by ecological niche modeling. Evolutionary Ecology, 29, 643-655.

SOUZA, S.M. (2016) Moléculas, morfologia e geologia: uma abordagem multidisciplinar para entender a história evolutiva de lagartos do gênero Loxopholis (Squamata: Gymnophthalmidae) no norte da América do Sul. Doutorado. Departamento de Zoologia, Universidade de São Paulo, São Paulo, 184 pp.

SOUZA, S.M., RODRIGUES, M.T. \& COHN-HAFT, M. (2013) Are Amazonia Rivers Biogeographic Barriers for Lizards? A Study on the Geographic Variation of the Spectacled Lizard Leposoma osvaldoi Avila-Pires (Squamata, Gymnophthalmidae). Journal of Herpetology, 47, 511-519.

STEIN, A., GERSTNER, K. \& KREFT, H. (2014) Environmental heterogeneity as a universal driver of species richness across taxa, biomes and spatial scales. Ecology Letters, 17, 866-880.

SZUMIK, C., AAGESEN, L., CASAGRANDA, D., ARZAMENDIA, V., BALDO, D., CLAPS, L.E., CUEZZO, F., GOMEZ, J.M.D., DI GIACOMO, A., GIRAUDO, A., GOLOBOFF, P., GRAMAJO, C., KOPUCHIAN, C., KRETZSCHMAR, S., LIZARRALDE, M., MOLINA, A., MOLleRACH, M., NAVARRO, F., NOMDEDEU, S., PANIZZA, A., PEREYRA, V.V., SANDOVAL, M., SCROCCHI, G. \& ZULOAGA, F.O. (2012) Detecting areas of endemism with a taxonomically diverse data set: plants, mammals, reptiles, amphibians, birds, and insects from Argentina. Cladistics, 28, 317-329.

SZUMIK, C.A. \& GOLOBOFF, P.A. (2004) Areas of Endemism: An Improved Optimality Criterion. Systematic Biology, 53, 968-977.

SZUMIK, C.A., CUEZZO, F., GOLOBOFF, P.A. \& CHALUP, A.E. (2002) An Optimality Criterion to Determine Areas of Endemism. Systematic Biology, 51, 806-816.

TEIXEIRA JR, M., PRATES, I., SILVA-MARTINS, N.S., STRÜSSMANN, C. \& RODRIGUES, M.T. (2015) Molecular data reveal spatial and temporal patterns of diversification and a cryptic new species of lowland Stenocercus Duméril \& Bibron, 1837 (Squamata: Tropiduridae). Molecular Phylogenetics and Evolution, 94, 410-423. 
TERRIBILE, L.C., OLALLA-TÁRRAGA, M.Á., MORALES-CASTILLA, I., RUEDA, M., VIDANES, R.M., RODRÍGUEZ, M.Á. \& DINIZ-FILHO, J.A.F. (2008) Global richness patterns of venomous snakes reveal contrasting influences of ecology and history in two different clades. Oecologia, 159, 617-626.

TIWARI, R.K. (1987) Higher-order eccentricity cycles of the middle and late Miocene climatic variations. Nature, 327, 219-221.

TUOMISTO, H. (2010a) A consistent terminology for quantifying species diversity? Yes, it does exist. Oecologia, 164, 853-860.

TUOMISTO, H. (2010b) A diversity of beta diversities: straightening up a concept gone awry. Part 1. Defining beta diversity as a function of alpha and gamma diversity. Ecography, 33, 2-22.

TUOMISTO, H., RUOKOLAINEN, K. \& YLI-HALLA, M. (2003) Dispersal, Environment, and Floristic Variation of Western Amazonian Forests. Science, 299, 241.

UETZ, P. \& HOŠEK, J. (2016) The Reptile Database. Available from: http://www.reptiledatabase.org (30.vii.2016).

VALDUJO, P.H., CARNAVAL, A.C.O.Q. \& GRAHAM, C.H. (2013) Environmental correlates of anuran beta diversity in the Brazilian Cerrado. Ecography, 36, 708-717.

VALDUJO, P.H., SILVANO, D.L., COLLI, G.R. \& MARTINS, M. (2012) Anuran Species Composition and Distribution Patterns in Brazilian Cerrado, a Neotropical Hotspot. South American Journal of Herpetology, 7, 63-78.

VANZOLINI, P.E. (1963) Problemas faunísticos do cerrado. In: FERRI, M.G. (Ed.) II Simpósio sobre o Cerrado. EDUSP, São Paulo, pp. 305-321.

VANZOLINI, P.E. (1981) A quase-historical approach to the natural history of the differentiation of reptiles in tropical geographic isolates. Papéis Avulsos de Zoologia, 34, 189-204.

VANZOLINI, P.E. (1994) Brazilian reptiles in open and closed formations: Evolutionary implications. Anais da Academia Brasileira de Ciencias, 66, 173-176.

VASCONCELOS, T.S., PRADO, V.H.M., DA SILVA, F.R. \& HADDAD, C.F.B. (2014) Biogeographic Distribution Patterns and Their Correlates in the Diverse Frog Fauna of the Atlantic Forest Hotspot. PLOS ONE, 9,

VEECH, J.A., SUMMERVILLE, K.S., CRIST, T.O. \& GERING, J.C. (2002) The additive partitioning of species diversity: recent revival of an old idea. Oikos, 99, 3-9.

VITT, L.J. \& CALDWELL, J.P. (2014) Herpetology. Academic Press, San Diego, 734 pp.

WAHLBERG, N. \& FREITAS, A.V.L. (2007) Colonization of and radiation in South America by butterflies in the subtribe Phyciodina (Lepidoptera : Nymphalidae). Molecular Phylogenetics and Evolution, 44, 1257-1272.

WALLACE, A.R. (1854) On the Monkeys of the Amazon. Annals and Magazine of Natural History, 14, 451-454.

WALLACE, A.R. (1876) The geographical distribution of animals. With a study of the relations of living and extinct faunas as elucidating the past changes of the earth's surface. Vol. 1. Harper and Brothers, New York, 503 pp.

WERNECK, F.P., COSTA, G.C., COLLI, G.R., PRADO, D.E. \& SITES JR, J.W. (2010) Revisiting the historical distribution of Seasonally Dry Tropical Forests: new insights based on paleodistribution modelling and palynological evidence. Global Ecology and Biogeography, 20, 272-288. 
WERNECK, F.P., GAMBLE, T., COLLI, G., RODRIGUES, M.T. \& SITES JR, J.W. (2012) Deep diversification and long-term persistence in the South American 'Dry Diagonal': Itegrating continent-wide phylogeography and distribution modeling of geckos. Evolution, 1-21.

WHITTAKER, R.H. (1960) Vegetation of the Siskiyou Mountains, Oregon and California. Ecological Monographs, 30, 280-338.

WHITTAKER, R.H. (1960) Vegetation of the Siskiyou Mountains, Oregon and California. Ecological Monographs, 30, 280-338.

WHITTAKER, R.H. (1972) Evolution and Measurement of Species Diversity. Taxon, 21, 213-251.

WILLIAMS, E.E. \& VANZOLINI, P.E. (1980) Notes and biogeographic comments on anoles from Brasil. Papéis Avulsos de Zoologia, 34, 99-108.

WILLIAMS, P.H., HUMPHRIES, C.J. \& GASTON, K.J. (1994) Centres of Seed-Plant Diversity: The Family Way. Proceedings of the Royal Society of London. Series B: Biological Sciences, 256, 67.

WILLIAMS, S.E. \& PEARSON, R.G. (1997) Historical rainforest contractions, localized extinctions and patterns of vertebrate endemism in the rainforests of Australia's wet tropics. Proceedings of the Royal Society B: Biological Sciences, 264, 709-716.

WILLIS, K.J. \& WHITTAKER, R.J. (2002) Species diversity - Scale matters. Science, 295, 12451248.

WÜSTER, W., FERGUSON, J.E., QUIJADA-MASCARENAS, J.A., POOK, C.E., SALOMAO, M.D. \& THORPE, R.S. (2005) Tracing an invasion: landbridges, refugia, and the phylogeography of the Neotropical rattlesnake (Serpentes: Viperidae: Crotalus durissus). Molecular Ecology, 14, 1095-1108.

ZUUR, A.F., IENO, E.N. \& ELPHICK, C.S. (2010) A protocol for data exploration to avoid common statistical problems. Methods in Ecology and Evolution, 1, 3-14. 


\section{CAPITULO 2 - Quão bom é o esforço de amostragem na América do Sul?}

\section{ABSTRACT}

The fact that species are not homogeneously distributed over earth's surface and that some areas have more species than others, have already been perceived for many centuries, however the knowledge on species distribution is still superficial. Recently there has been a huge improvement on both sampling techniques and geographical cover. Nonetheless, how much effort is needed to fully uncover species richness from a given area is still unknown. Here the knowledge on how good is the sampling effort for lizards across South America is addressed. For that, sampling efficiency was calculated (the difference between observed richness and estimated richness), as well as the geographical coverage of sampling points (the area occupied by areas without sampling points). These values combined indicated areas with the lowest sampling effort at the Amazon Forest, with larger empty areas, especially at the interfluves, while the areas along rivers' shores present the highest effort. With the exception of some areas across Cerrado, practically all remaining continental South America presents relatively high sampling effort. The effort was positively related to the level of human influence: the easier the access to an area, the better sampled it is. This effect is clear in the Amazon, where the effort is concentrated at rivers' shores, as rivers are the main transportation routes at that region.

\section{RESUMO}

O fato de que espécies não se distribuem homogeneamente pela superfície da terra e consequentemente determinadas áreas apresentam mais espécies que outras, foi percebido já há muitos séculos, porém o conhecimento sobre a distribuição das espécies ainda é bastante superficial. Desde então houve uma grande melhora tantos nas técnicas de amostragem, como na cobertura geográfica destas. Porém a informação sobre se o esforço de amostragem realizado em cada área já é suficiente, ainda é desconhecido. Neste estudo buscou-se explorar quão bom é o esforço de amostragem da fauna de lagartos da América do Sul. Para isso foram calculados valores de eficiência amostral (a diferença entre a riqueza observada e a riqueza estimada), e a cobertura geográfica dos pontos amostrais (área ocupada por vazios de pontos). A combinação destes valores indicou que as áreas com menor esforço é a região Amazônica, com grandes vazios amostrais, especialmente ao longo dos interflúvios, enquanto ao longo das margens dos rios estão áreas melhor amostradas. Com a exceção de algumas áreas ao longo do Cerrado praticamente todo o resto do continente apresenta valores de esforço razoavelmente altos. $O$ esforço foi positivamente relacionado ao nível de influência humana, sendo claro o efeito do acesso no quão bem uma área é amostrada. Isso fica claro na Amazônia, onde o esforço está concentrado às margens dos rios que são as principais vias de transporte naquela região. 


\subsection{INTRODUÇÃO}

Desde o início da história da biologia já era percebido que a biota não se apresenta homogeneamente distribuída pelo espaço (ARISTOTÉLĒS 1952). Porém naquela época esta observação se baseou em um ainda pouco expressivo conhecimento biológico. No entanto a ampla coleção de espécimes da fauna e flora iniciada nos séculos 17 e 18, permitiu uma compreensão mais avançada dos padrões de ocorrência das espécies (LOMOLINO et al. 2006). Estes padrões eram inicialmente atribuídos à criação divina, de maneira que os primeiros naturalistas acreditavam estar apenas catalogando e tentando compreender os mistérios da criação. Linnaeus acreditava que para melhor entender a palavra do criador dever-se-ia entender o mundo natural, e para isso criou seu sistema de classificação (LINNAEUS 1758; LOMOLINO et al. 2006). Porém, como ele mesmo percebeu, explicar como espécies imutáveis ocupavam tantas áreas diferentes da terra era uma tarefa difícil. Isso o levou a criar a hipótese de que toda a vida fora criada em uma montanha alta, acomodando cada forma de vida em seu devido tipo de habitat, e que após o dilúvio teriam se dispersado e ocupado os diferentes habitats pelo mundo (LINNAEUS 1781).

Buffon percebeu que sob esta hipótese espécies típicas de certos ambientes teriam que atravessar amplas áreas inóspitas para chegar ao seu habitat típico e coloniza-lo. Criou então uma explicação onde a vida fora criada na Europa, quando a temperatura era mais igualmente distribuída pelo planeta. A partir daí as diferentes formas teriam se dispersado, diferenciandose ao longo da migração, e por isso as biotas observadas hoje em cada continente apresentam composições completamente diferentes (BUFFON 1761). Dessa forma, áreas com condições ambientais semelhantes em diferentes lugares do mundo, apresentariam uma composição diferente. Uma ideia que ficou conhecida como a lei de Buffon (BUFFON 1761; LOMOLINO et al. 2006).

Conforme grandes expedições exploravam os pontos mais longínquos do planeta, aumentava-se o número de espécimes conhecidos e isto permitia ampliar e discutir essas ideias. Forster, depois de acompanhar uma das viagens de circum-navegação do Capitão Cook, apresentou a primeira visão mais sistemática, notando que a lei de Buffon se aplicava também a plantas e a todas as regiões do mundo (FORSTER 1778). Descreveu assim a relação entre floras regionais e condições ambientais em que ocorrem, e como a composição da fauna muda em associação com a flora (FORSTER 1778).

A partir de então outros naturalistas começaram a analisar áreas mais restritas do globo, como as províncias florísticas da Europa, por Willdenow (WILLDENOW 1803), lançando a 
teoria de que a flora fora criada em diversos pontos elevados, e que conforme o diluvio recuava as plantas se dispersavam pra baixo formando as regiões florísticas do mundo. Humboldt estendeu a lei de Buffon e percebeu que a zonação florística de Forster podia ser observada num escala local onde há variação altitudinal (HUMBOLDT 1805).

Assim, no começo do século 19 como grandes explorações já haviam sido feitas, e uma maior quantidade de espécimes haviam sido depositados em museus da Europa, o trabalho de Buffon já havia sido retrabalhado e expandido. Neste momento já estava bem estabelecida a ideia de que o número de espécies e a composição da biota tende a diminuir quando nos afastamos do Equador ou subimos para o alto das montanhas (LOMOLINO et al. 2006).

A América do Sul então passou a atrair a atenção de diversos naturalistas europeus, como o próprio Humboldt, e muitos outros que iniciaram longas expedições por seus domínios (GOODMAN 1992; VANZOLINI 1996), possibilitando questionamentos mais aprofundados a respeito de sua biota. Por exemplo, Azara tentara entender a relação entre a composição de mamíferos da América do Sul e a de outros continentes (AZARA 1809), e Wallace, que não apenas produziu o primeiro mapa detalhado da divisão biótica do mundo, baseado nos mapas de Sclater (SCLATER 1858), e em suas próprias observações (WALLACE 1876a,b), como percebeu que áreas distintas ao longo da Amazônia, as vezes separadas por apenas um rio, apresentavam faunas bastante diferentes (WALLACE 1854). Ainda Spix e Martius, que atravessaram diversos biomas brasileiros (SPIX \& MARTIUS 1824) coletando exemplares da fauna e flora, perceberam também uma grande distinção entre os diversos ambientes aqui observados, propondo uma classificação para categorizar os mesmos (MARTIUS 1840-1906). Além destes, muito outros naturalistas (VANZOLINI 1996) preencheram os museus de história natural da Europa, iniciando eles mesmos os estudos, ou criando as bases para análises futuras.

Todos estes trabalhos têm levado a um fato hoje indubitável: a vida não se distribui aleatoriamente pela superfície do planeta. Assim algumas áreas apresentam uma composição de espécies particularmente rica, tal como os ambientes de florestas tropicais, que apesar de ocuparem cerca de $7 \%$ da superfície do planeta, comportam cerca de $60 \%$ das espécies (LAURANCE 1999; DIRZO \& RAVEN 2003). A percepção desta grande riqueza nas florestas tropicais tem atraído à atenção tanto de pesquisadores como de conservacionistas, que, por um lado, têm feito destas áreas seu foco prioritário para pesquisa e ações de conservação, deixando, por outro lado, áreas tais como ambientes secos e abertos, com seu conteúdo 
biótico virtualmente desconhecido por muito tempo (REDFORD et al. 1990; SÁNCHEZAZOFEIFA et al. 2005).

Isto é particularmente alarmante nos dias de hoje, já que estamos vivenciando uma destruição de ambientes naturais em uma larga escala, com populações de peixes, aves, mamíferos e anfíbios tendo declinado $58 \%$ nos últimos 40 anos (WWF 2016). Algumas áreas, tais com a Mata Atlântica, que comporta cerca de $5 \%$ das espécies de vertebrados e plantas do mundo (SCARANO 2014), está agora restrita a menos de $12 \%$ de sua cobertura original (RIBEIRO et al. 2009). A fim de se desacelerar ou mesmo interromper esta destruição, a riqueza de algumas áreas combinada com o grau de antropização tem levado à criação de listas de áreas prioritárias para conservação (MYERS et al. 2000).

No entanto desde as observações simples feitas por Aristóteles até esta percepção mais recente de que algumas áreas são prioritárias à conservação, o principal fator que tem tornado tudo isso possível é o simples registro das espécies onde elas ocorrem. O que pode parecer bastante trivial e óbvio, mas qualquer inferência biogeográfica, qualquer análise macroecológica, ou definição de áreas para conservação só vão ter algum sentido depois de que tenha sido feito um esforço bastante abrangente para se registrar o máximo possível de espécies ao longo das áreas. Sua ausência pode levar a ideias possivelmente errôneas, gerando consequências potencialmente perigosas para algumas áreas, como aconteceu com as áreas do Cerrado, da Caatinga e do Chaco. Nesses biomas a vegetação dominante é composta por ambientais secos e abertos (OLSON et al. 2001), e têm sido estudadas em mais profundidade por não mais do que 50 anos, levando pesquisadores a acreditar que se tratavam de ambientes pobres, com baixo nível de endemismo, e com uma fauna homogeneamente distribuída por sua extensão (VANZOLINI 1963,1976; VITT 1991; VANZOLINI 2003). Porém um interesse recente por estas áreas tem revelado que muito provavelmente tais afirmações eram apenas resultado de amostragem insuficiente, e estes ambientes tem se mostrado como centros muito importantes de endemismo e que seu conteúdo biótico é bem mais diversificado do que anteriormente se acreditava (COLLI et al. 2002; RODRIGUES 2003; NOGUEIRA 2006), levando o Cerrado a ser incluído como uma das, 25 áreas prioritárias para conservação no mundo (MYERS et al. 2000).

Esta ausência de informações necessárias para se discutir padrões biológicos é um fenômeno tão conspícuo e intrínseco aos de dados geográficos que termos já foram cunhados para se referir a eles (HORTA et al. 2015), com a falta de conhecimento sobre a distribuição das espécies recebendo o termo de Wallacean shortfall (LOMOLINO 2004). Contudo, em 
algumas áreas ao longo da diagonal aberta, a amostragem tem melhorado localmente, porém sua cobertura geográfica ainda está longe de ser satisfatória (RODRIGUES 2003). O mesmo pode ser considerado verdade para até os ambientes mais bem amostrados na América do Sul, como a própria Mata Atlântica que vem sendo explorada desde o início da colonização Europeia, e ainda assim continua revelando diversas novas descobertas. Mais de 1100 espécies de plantas foram descritas entre 1990 e 2006 (SCARANO 2014), assim como um grande número de espécies de anfíbios nos últimos anos (CLEMENTE-CARVALHO et al. 2012; GAREY et al. 2012; LOURENÇO-DE-MORAES et al. 2012; NUNES et al. 2012; SANTANA et al. 2012; SILVA \& OUVERNAY 2012; TEIXEIRA JR et al. 2012; BARATA et al. 2013; CARAMASCHI et al. 2013; DIAS et al. 2013; BRUSCHI et al. 2014; CONDEZ et al. 2014a; CONDEZ et al. 2014b; LOURENÇO-DE-MORAES et al. 2014; MÂNGIA et al. 2014; PONTES et al. 2014; TONINI et al. 2014a; TONINI et al. 2014b; BORNSCHEIN et al. 2015; FERREIRA et al. 2015; HEPP et al. 2015; PIE \& RIBEIRO 2015; RIBEIRO et al. 2015; SA et al. 2015; SANTANA et al. 2015; CONDEZ et al. 2016; MARCIANO-JR et al. 2017).

Porém o tamanho do esforço amostral necessário para se atingir um conhecimento biológico minimamente robusto sobre uma determinada área ainda é desconhecido. E assim técnicas vêm sendo recentemente desenvolvidas para tentar se contornar essa ausência de informações. Dentre estas estão estimadores de riqueza (COLWELL 2013), modelagem de distribuição potencial (PETERSON et al. 2011, 2012), e outras técnicas baseadas nos pontos de ocorrência (SCHULMAN et al. 2007; RUETE 2015; STROPP et al. 2016) e riqueza estimada nas amostras, combinadas com dados climáticos (MORA et al. 2008; BALLESTEROS-MEJIA et al. 2013). Estas nos ajudam a deduzir o quão longe ainda estamos de se obter o conhecimento mínimo necessário sobre cada área.

Lagartos têm sido considerados organismos modelo (PIANKA \& VITT 2003), apresentando metabolismo ectotérmico, dependente de condições ambientais para atingir sua melhor temperatura de funcionamento (VITT \& CALDWELL 2014; POUGH et al. 2015). São também conspícuos onde ocorrem, fazendo deles um alvo muito interessante para se avaliar o tamanho do esforço amostral. Dessa forma este estudo tem por objetivo quantificar o esforço de amostragem realizado ao longo de toda a América do Sul, relacionando-se tais valores ao nível de ocupação humana e revelando quais áreas deveriam ser o foco de amostragens futuras. 


\subsection{MATERIAL E MÉTODOS}

\subsubsection{Definição da área}

A área definida para as análises inclui toda a região continental da América do Sul e as ilhas próximas que estão representadas nas quadrículas que cobrem toda a região continental. As quadrículas apresentam $0.5^{\circ} \times 0.5^{\circ}$ de extensão, ocupando uma área desde $12.5^{\circ} \mathrm{N} \mathrm{e} 34.5^{\circ} \mathrm{W}$ até $56.0^{\circ} \mathrm{S}$ e $81.5^{\circ} \mathrm{W}$ (FIGURA 2). Para as comparações entre as áreas, as Eco-regiões (sensu OLSON et al. 2001) foram divididas em três grandes áreas: 1) região Andina, 2) Florestas Úmidas; e 3) áreas Abertas/Secas (FIGURA 2).

Duas características são fundamentais ao se avaliar esforço amostral: efetividade da amostragem local (e.g. quão bem a amostragem representa a riqueza local) e a cobertura geográfica das amostras (e.g. quais são os espaços sub-amostrados). Assim duas abordagens foram realizadas: (1) uma que se baseia na diferença entre a riqueza observada e a riqueza potencial (efetividade amostral) (MORA et al. 2008; BALLESTEROS-MEJIA et al. 2013), e outra (2) que se baseia na distribuição das amostras, demonstrando áreas onde a densidade de amostras é maior e menor (cobertura geográfica) (SCHULMAN et al. 2007).

\subsubsection{Efetividade amostral}

Basicamente três tipos de mapas vêm sendo feitos atualmente para se mapear espécies e consequentemente valores como riqueza e endemismo, os quais são: (1) mapas pontuais com registros de ocorrência das espécies, (2) mapas poligonais desenhados por especialistas, e (3) modelos de nicho/distribuição potencial das espécies (RUETE, 2015).

Assim aqui se calculou uma riqueza potencial, a qual foi comparada à riqueza observada. O cálculo da riqueza potencial baseou-se em três estimativas de riqueza: (1) modelagem de riqueza, a partir os pontos que ocorrência, da riqueza observada, de estimadores de riqueza, e interpolação de valores; (2) estimativas resultantes de regressão múltipla de valores de riqueza calculados a partir de somatório de polígonos de distribuição de espécies, e variáveis ambientais, e; (3) modelagem individual de espécies, que foram sobrepostas e somadas. Os valores resultante das três abordagens foram combinados em um valor médio que foi considerado a riqueza potencial.

\subsubsection{Modelagem de riqueza}

A modelagem de riqueza foi realizada através do seguinte protocolo: estimação de riqueza através de estimadores; escolha de variáveis que melhor explicam a riqueza estimada; 
e uso dessas variáveis para interpolar a riqueza estimada e produzir uma superfície continua por toda a América do Sul.

Para a estimativa de riqueza foram reunidos pontos de ocorrência disponíveis em cerca de 1120 publicações, complementados por bases de dados eletrônicas (APÊNDICE 1). Os registros publicados variaram entre material examinado em revisões taxonômicas, listas de espécies e notas de distribuição. No caso de registros em que a informação referente às coordenadas geográficas estava disponível, estas foram usadas. No entanto a maioria continha apenas nomes de localidades, como nomes de cidades (e.g. "São Paulo"), pontos geográficos específicos (e.g. "Alto da Serra de Cubatão"), ou descrições de áreas (e.g. "20 km a leste da junção da rodovia nacional 40 e provincial 22 "), e as coordenadas foram então recuperadas através de buscas online (tierra.tutiempo.net, www.google.com) ou estimadas usando programas de sistema de informação geográfica (e.g. ArcGIS v.10.0 e Google Earth v.7.1.8) (ESRI 2011; GOOGLE 2017). Em muitos casos a única informação geográfica disponível eram pontos de ocorrência em mapas, que foram então geo-referenciados usando programas de sistema de informação geográfica (e.g. ArcGIS v.10.0 e Google Earth v.7.1.8) (ESRI 2011; GOOGLE 2017), e os registros usados na construção das distribuições.

Um potencial problema em registros de espécies é a incerteza quanto à correta identificação dos exemplares. Assim, os registos publicados foram utilizados em sua maioria sem alteração, pois foram considerados como tendo sido "verificados" pelo menos pelo especialista que o publicou. Porém espécimes disponíveis em coleções herpetológicas, tendo seus registros disponíveis em base de dados eletrônicas, frequentemente não são devidamente avaliados e sua identificação é potencialmente duvidosa. Assim os registros provenientes destas bases de dados foram considerados "não verificados", e não foram utilizados em sua totalidade. Foram considerados como "duvidosos" quando muito distantes dos pontos "verificados", ou fora de seus habitats naturais (e.g. espécies típicas da floresta Amazônica, com registros "não verificados" na região Andina), e assim descartados.

Com base nestes registros de ocorrência foram desenhados polígonos que representam as distribuições de cada espécie, utilizando-se os programas ArcGIS v.10.0 e Google Earth v.7.1.8 (ESRI 2011; GOOGLE 2017), considerando relevo, vegetação, hidrografia e altitude, para se definir as bordas dos polígonos.

Para o cálculo dos estimadores de riqueza foram escolhidas apenas quadrículas com no mínimo 25 registros (BALLESTEROS-MEJIA et al. 2013). Nestas quadrículas foram calculados os diversos estimadores de riqueza: Chao 1 (CHAO 1984), que estima o número de táxons baseado no número de táxons raros em cada amostra, 


$$
S_{\text {Chao } 1}=S_{o b s}+\frac{F_{1}^{2}}{2\left(F_{2}+1\right)}-\frac{F_{1} F_{2}}{2\left(F_{2}+1\right)^{2}}
$$

onde $S_{o b s}$ é a riqueza observada, $F_{i}$ é a frequência de táxons que tem um número $i$ de observações; Chao 2 (CHAO 1987), que é um estimador baseado na incidência, levando em consideração o número de observações em cada área,

$$
S_{\text {Chao } 2}=S_{o b s}+\frac{Q_{1}^{2}}{2 Q_{2}}
$$

onde $S_{o b s}$ é a riqueza observada, $Q_{i}$ é o número de táxons que ocorrem em um número $i$ de localidades; Jacknife 1 (BURNHAM \& OVERTON 1978; HELTSHE \& FORRESTER 1983), que também é um estimador de primeira ordem baseado na incidência, leva em consideração o número de amostras em cada área

$$
S_{\text {Jack } 1}=S_{o b s}+Q_{1}\left(\frac{m-1}{m}\right)
$$

e Jacknife 2 (SMITH \& VAN BELLE 1984), que é um estimador de segunda ordem, também baseado na incidência, e também leva em consideração o número de amostras em cada área,

$$
S_{\text {Jack } 2}=S_{\text {obs }}+\left[\frac{Q_{1}(2 m-3)}{m}-\frac{Q_{2}(m-2)^{2}}{m(m-1)}\right]
$$

onde $S_{o b s}$ é a riqueza total observada em todas as amostras, $Q_{i}$ é o número de táxons que ocorrem em um número $i$ de localidades, e $m$ o número total de amostras. Micheles-Mertens (RAAIJMAKERS 1987), que é um estimador calculado através de re-amostragens aleatórias e ajuste de uma modelo assintótico,

$$
S(n)=\frac{S_{m m} n}{B+n}
$$

onde $S_{m m}$ e $B$ são constantes ajustadas, e $n$ é o número de amostras, dessa forma considerando que os valores de $X$ e $Y$ da curva podem ser calculados assim $X_{i}=\frac{S(n)}{n} \mathrm{e}$ $Y_{i}=S(n)$, então o estimador Micheles-Mertens busca calcular $S_{m m}$ e $B$ da seguinte forma

$$
\hat{B}=\frac{\bar{X} s_{y y}-\bar{Y} S_{x y}}{\bar{Y} S_{x x}-\bar{X} S_{x y}} \text { e } \hat{S}_{m m}=\dot{Y}+\hat{B} \bar{X} ;
$$

e; por último Chao \& Lee (CHAO \& LEE ; CHAO et al. 1993), que é um estimador baseado na cobertura da abundância (Abundance Coverage-based Estimator: ACE), de maneira que se $S_{\text {obs }}=S_{\text {rara }}+S_{\text {abund }}$, e $C_{\text {ace }}=1-\frac{F_{1}}{N_{\text {rara }}}$, onde $N_{\text {rara }}=\sum_{i=1}^{10} i F_{1}$ sendo $F_{1}$ a frequência de espécies representadas por apenas uma observação, então

$$
S_{\text {obs }}=S_{\text {abund }}+\frac{S_{\text {rara }}}{C_{\text {ace }}}+\frac{F_{1}}{C_{\text {ace }}} \gamma_{\text {ace }}^{2}
$$

onde a estimativa do coeficiente de variação da frequência das categorias espécies $\left(F_{i}\right)$ é 


$$
\gamma_{\text {ace }}^{2}=\max \left[\frac{S_{\text {rara }}}{C_{\text {ace }}} \frac{\sum_{i=1}^{10} i(i-1) F_{1}}{\left(N_{\text {rara }}\right)\left(N_{\text {rara }}-1\right)}-1,0\right]
$$

Nos estimadores baseados em incidência cada quadrícula foi subdivida em 9 áreas para se fazer os cálculos (HIJMANS et al. 2012). Todos os estimadores foram calculados pelo programa DIVA-GIS v.7.5.0.0 (HIJMANS et al. 2001), e a média entre eles foi calculada e usada como riqueza estimada pelo programa ArcGIS v.10.0 (ESRI 2011).

Para cada quadrícula onde a riqueza foi estimada, foram extraídos diversas variáveis ambientais. Estas incluíram altitude (ALT) e as 19 variáveis bio-climáticas disponíveis pelo WorldClim (www.worldclim.org) (HIJMANS et al. 2005) (BIO1: Temperatura média anual, BIO2: Amplitude média diária, BIO3: Isotermalidade (BIO2/BIO7) (* 100), BIO4: Sazonalidade na temperatura (desvio padrão*100), BIO5: Máxima temperatura do mês mais quente, BIO6: Máxima temperatura do mês mais frio, BIO7: Amplitude anual na temperatura (BIO5-BIO6), BI08: Temperatura média do trimestre mais úmido, BI09: Temperatura média do trimestre mais seco, BIO10: Temperatura média do trimestre mais quente, BI011: Temperatura média do trimestre mais frio, BI012: Precipitação anual, BI013: Precipitação do mês mais úmido, BI014: Precipitação do mês mais seco, BI015: Sazonalidade na precipitação, BIO16: Precipitação do trimestre mais úmido, BIO17: Precipitação do trimestre mais seco, BIO18: Precipitação do trimestre mais quente, BIO19: Precipitação do trimestre mais frio) (HIJMANS et al. 2005). Juntamente com três variáveis relacionadas à características do solo à $0 \mathrm{~cm}$ da superfície (SAND: porcentagem de areia, CLAY: porcentagem de cascalho, SILT: porcentagem de silte) (www.soilgrids.org). E uma variável de estrutura do ambiente calculada com base nos dados disponíveis sobre cada Eco-região. Onde foi estimada a disponibilidade de quatros elementos estruturadores do ambiente: (1) árvores, (2) solo, (3) água, e (4) subsolo. Assim áreas onde arvores estão disponíveis em abundância, como florestas ombrófilas, receberam o valor de 1 para "árvores", enquanto áreas onde árvores são menos comuns, como florestas estacionais, receberam 0.75 , áreas de savanas 0.5 , restingas 0.25 , e áreas campestres 0.0 mesmo principio foi aplicado aos outros elementos, como por exemplo subsolo, onde áreas rochosas recebem 0 , e áreas arenosas recebem 1 ; ou solo, onde áreas alagadas periodicamente recebem 0.5 ou rochosas 1 . Os valores de cada elemento tiveram sua média calculada por Eco-região (FIGURA 3; TABELA 1). A média foi então utilizada como um índice de estrutura ambiental (STR), e incluído como mais uma camada nas análises (FIGURA 4). Todas encaixadas na mesma resolução de $0.5^{\circ} \times 0.5^{\circ}$ graus das quadrículas. 
Com base nesses dados, inicialmente foi calculada uma regressão linear múltipla, incluindo a riqueza estimada (como variável resposta), e todas as ambientais (como explanatórias), para se remover as variáveis que apresentam o fator de inflação de variância (Variance Inflation Factor: VIF) mais alto (BADGLEY \& FOX 2000). O VIF é uma função da correlação parcial entre cada variável, assim quando o VIF é alto para uma variável, isso significa que esta é altamente correlacionada com uma ou mais variáveis (MONTGOMERY et al. 2012). Porém se decidir o quão alto um valor de VIF para indicar alta correlação ainda é discutível, e nenhuma regra clara existe, com trabalhos variando desde 20 a 2 (BOWERMAN \& O'CONNELL 2000; OLIVEIRA-FILHO \& FONTES 2000; KAPS \& LAMBERSON 2004; O'BRIEN 2007; CVETKOVIC et al. 2009; MELO et al. 2009; ZUUR et al. 2010; SANTOS et al. 2012; VASCONCELOS et al. 2014; BREGOVIĆ \& ZAGMAJSTER 2016; GONZÁLEZ-MAYA et al. 2016), sendo 3 ou 10 os valores mais comunmente usados. Aqui optou-se por uma abordagem mais restritiva, utilizando-se um valor de corte de 3. Foi realizado um procedimento iterativo onde todas as variáveis oram incluídas, e a com maior VIF foi removida, e a analise repetida, e próxima variável a apresentar o VIF mais alto também foi removida, e o procedimento foi repetido até todas a variáveis apresentaram VIF menor que 3 (BOOTH et al. 1994; BADGLEY \& FOX 2000; MELO et al. 2009).

Dados espaciais em geral apresentam uma grande auto-correlação de valores (e.g. áreas mais próximas tendem a apresentar valores mais parecidos, e áreas mais distantes tendem a apresentar valores mais distintos), o que apesar de ser uma característica intrínseca aos dados, isso pode afetar o resultado de análises estatísticas que realizadas sobre estes dados (DINIZFILHO et al. 2003; DINIZ-FILHO et al. 2009; HAWKINS 2012). Assim para se realizar a escolha da melhor combinação de variáveis que explica a variável medida (e.g. escolha do modelo adequado mínimo) é necessário se minimizar o efeito da auto-correlação espacial das variáveis Este procedimento pode ser feito seguindo-se o protocolo proposto por DINIZ-FILHO et al. (2008), onde mais uma variável é incluída para se remover o efeito da auto-correlação. Esta variável é definida pelo termo auto-regressivo $\rho \mathbf{W}_{\gamma}$ onde $\mathbf{W}$ é a matriz de conectividade, $\gamma$ é a variável medida (e.g. riqueza, endemismo ou diversidade beta), $\rho$ é o coeficiente autoregressivo.

A matriz de conectividade foi calculada pelo critério de distância, sendo esta o valor até o qual ainda há auto-correlação positiva nos resíduos após a regressão ter removido o efeito das variáveis explanatórias, como definido pelo indicie I de Moran (MORAN 1950),

$$
I=\frac{n}{S_{0}} \frac{\sum_{i=1}^{n} \sum_{j=1}^{n} w_{i j} z_{i} z_{j}}{\sum_{i=1}^{n} z_{i}^{2}}
$$


onde $z_{i}$ é o desvio entre o valor de uma localidade $i$ e a média $\left(x_{i}-\bar{X}\right), w_{i, j}$ é a matriz de pesos espaciais entre $i$ e $j, n$ é o numero total de localidades, e $S_{0}$ é o agregado das matrizes espaciais $\left(S_{0}=\sum_{i=1}^{n} \sum_{j=1}^{n} w_{i j}\right)$. Os valores resultantes variam entre -1 e 1 , com valores mais próximos de -1 indicando auto-correlação negativa, e valores próximos de 1 auto-correlação positiva, e próximos de 0 indicam valores aleatórios (ISHIZAWA \& STEVENS 2007; TU \& XIA 2008).

Na seleção de modelos então foram incluídas todas as variáveis explanatórias com VIF menor que 3, como variáveis "flutuantes" e mais o resultado do modelo auto-regressivo como variável "fixa" (e.g. presente em todos os modelos), a escolha do melhor modelo foi realizada através do critério de informação de Akaike corrigido (AICC) (HURVICH \& TSAI 1989; BURNHAM \& ANDERSON 2002)

$$
\mathrm{AICc}=\mathrm{AIC}+\frac{2 k(k+1)}{n-k-1}
$$

onde $n$ representa o tamanho da amostra, $k$ o número de parâmetros, e AIC a medida do critério de informação de Akaike (AKAIKE 1974), definido como

$$
\mathrm{AIC}=n \log \left(\frac{\sum \hat{\epsilon}_{i}^{2}}{n}\right)+2 k
$$

onde $n$ representa o número de observações, e $\hat{\epsilon}$ é resíduo estimado de um modelo em particular (AKAIKE 1974; BURNHAM \& ANDERSON 2002). Com o valor de AIC para cada modelo $i$ foi calculado o $\Delta_{i}$, o qual é a diferença entre $\mathrm{AIC}_{i}$ e o $\mathrm{AIC}$ mínimo calculado, com valores de $\triangle \mathrm{AIC}$ menores que 2 indicando modelos tão adequados quando o que apresenta $\mathrm{o}$ mínimo AIC (BURNHAM \& ANDERSON 2002; DINIZ-FILHO et al 2008). Embora este valor seja arbitrário, o $\Delta_{i}$ pode ser usaso para calcular o peso de Akaike para cada modelo $\left(w_{i}\right)$, que indica qual modelo é o melhor modelo explanatório, definido como

$$
w_{i}=\frac{\exp \left(-1 / 2 \Delta_{i}\right)}{\sum_{i}\left[\exp \left(-1 / 2 \Delta_{i}\right)\right]}
$$

onde $\exp \left(-1 / 2 \Delta_{i}\right)$ aproxima a verossimilhança do modelo. O cálculo das regressões iniciais, o cálculo do modelo auto-regressivo e a seleção de modelos foram realizadas no programa SAM v.4.0 (RANGEL et al. 2010).

Para a produção da superfície continua de riqueza foi utilizada a riqueza estimada, cujos valores foram interpolados através de uma interpolação do tipo CoKriging. Em uma interpolação kriging a auto correlação na variável de interesse (a ser interpolada) é usada para se estimar os valores nas áreas onde estes estão ausentes. Isso também é realizado dentro de uma interpolação CoKriging, porém nesta interpolação outras variáveis, cujos valores estão presentes nas áreas onde a variável de interesse está ausente, são incluídas também, e assim a 
correlação cruzada ente as variáveis é utilizada para se estimar uma superfície continua de valores (GOOVAERTS 1998; ROCHA et al. 2012; ESRI 2013; YAMAMOTO \& LANDIM 2013; PARDO-IGÚZQUIZA et al. 2015). Dessa forma a auto-correlação dentro de cada variável é usada na construção de um semivariograma, assim como a covariância entre cada par de variáveis é usada para se calcular a função covariante. Ambas (semivariograma e função covariante) quantificam a predição de que áreas mais próximas tendem a ter valores mais parecidos do que áreas que estão mais longe. Assim uma curva de semivariograma é ajustada através da formula:

$$
\gamma\left(s_{i}, s_{j}\right)=\frac{1}{2} \operatorname{var}\left(Z\left(s_{i}\right)-Z\left(s_{j}\right)\right)
$$

onde $\gamma$ é o valor da curva do semivariograma, var a variância, e $s_{i}$ e $s_{j}$ cada grupo (neste caso pares) de localidades, assim se duas localidades estão próximas a diferença entre elas $\left(Z\left(s_{i}\right)-Z\left(s_{j}\right)\right.$ ) deve ser pequena, e quando se distanciam a diferença tende a aumentar. De maneira inversa, a covariação entre as variáveis, é uma versão padronizada da correlação, seguindo a fórmula:

$$
C\left(s_{i}, s_{j}\right)=\operatorname{cov}\left(Z\left(s_{i}\right), Z\left(s_{j}\right)\right)
$$

onde $C$ é a função covariante e $\operatorname{cov}$ a covariância, assim se duas localidades estão próximas sua correlação (e covariância) vai ser alta, e conforme se distanciam a covariância deve diminuir, tendendo a zero (ESRI 2013). A curva estimada pelos semi-variogramas e funções covariantes foram usadas para se calcular uma estimativa de valores por toda a América do Sul. A validação cruzada calculada para se avaliar a qualidade do modelo, onde cada ponto é removido iterativamente e a interpolação calculada em sua ausência, e seu valor real comparado com o estimado.

\subsubsection{Riqueza estimada pela regressão múltipla}

Com base nos mesmos registros de ocorrência levantados como descrito no tópico 2.2.2.1. Modelagem de Riqueza, foram desenhados polígonos que representam as distribuições de cada espécie, utilizando-se os programas ArcGIS v.10.0 e Google Earth v.7.1.8 (ESRI 2011; GOOGLE 2017), considerando relevo, vegetação, hidrografia e altitude, para se definir as bordas dos polígonos. Para espécies conhecidas apenas por um único ponto, o polígono não se estendeu muito além da localidade. Em casos onde não havia nenhuma barreira evidente ou mudança de relevo, altitude e vegetação por muitos quilômetros, as bordas do polígono foram desenhadas baseando-se no conhecimento disponível para espécies e/ou linhagens aparentadas, e/ou com ecologias semelhantes. Quando a localidade se 
posicionava em uma área relativamente isolada (e.g. ilha, topo de montanha), o polígono seguiu o contorno do relevo, altitude e vegetação similares ao do ponto.

Em muitos casos as espécies eram compostas por subespécies (e.g. subespécies de Uracentron azureum) (AVILA-PIRES 1995) ou linhagens geograficamente distintas (e.g. Phyllopezus pollicaris) (WERNECK et al. 2010), nestes casos as subespécies ou linhagens foram utilizadas como espécies plenas nas análises. Nos casos em que existem evidencias de linhagens distintas, mas cujas extensões geográficas são desconhecidas, as linhagens não foram analisadas separadamente (e.g. Iphisa elegans) (NUNES et al. 2012).

Para se calcular a riqueza foi somado o número de espécies que intersectam com cada quadrícula, produzindo uma medida de riqueza local. Com base nesses valores e nas variáveis ambientais foi calculada uma regressão linear múltipla incluindo a riqueza como variável resposta, e todas as ambientais como explanatórias (ALT, BIO1, BIO2, BIO3, BIO4, BIO5, BIO6, $\mathrm{BIO}, \mathrm{BIO}, \mathrm{BIO9}, \mathrm{BIO} 10, \mathrm{BIO} 11, \mathrm{BIO} 12, \mathrm{BIO} 13, \mathrm{BIO} 14, \mathrm{BIO} 15, \mathrm{BIO} 16, \mathrm{BIO} 17, \mathrm{BIO} 18, \mathrm{BIO} 19$, SAND, CLAY, SILT, STR). Foram removidas iterativamente as variáveis com VIF maior que 3 , para se evitar multicolinearidade, utilizando-se as mesmas variáveis e procedimento para se evitar multicolinearidade descrito no tópico anterior (2.2.2.1. Modelagem de riqueza). Como resultado da regressão, foram produzidos valores estimados e resíduos, e os estimados foram usados como uma estimativa de riqueza. Estes cálculos foram realizados no programa SAM v.4.0 (RANGEL et al. 2010),

\subsubsection{Modelagem individual de espécies}

Pela sobreposição dos polígonos, descritos no tópico 2 .2.2.2. Riqueza estimada pela regressão múltipla, pelas quadrículas, cada quadrícula que intersecta com cada polígono teve seu centroide convertido em ponto, e estes pontos usados na modelam de cada espécies (FIGURA 55).

Para a modelagem foi usado o algoritmo de máxima entropia, através do programa MaxEnt v. 3.3.3k (PHILLIPS \& DUDÍK 2008), com o máximo de iterações elevado a 5000, e um corte de mínimo de $10 \%$ dos pontos, com as outras configurações deixadas no padrão do programa. Os modelos resultantes foram editados manualmente para remover áreas sobreprevistas (e.g. espécies típicas de uma região sendo modeladas em outras áreas) (FIGURA 56). Os modelos finais foram somados e produziram uma riqueza estimada baseada na modelagem individual. 


\subsubsection{Cobertura geográfica da amostragem}

Para se acessar a cobertura geográfica das amostragens foram utilizados os registros de ocorrência das espécies, e calculada uma rede de polígonos de Thiessen, onde polígonos são ajustados a cada ponto amostral, com seus lados posicionados a meio caminho entre cada par de pontos (FORTIN \& DALE 2005). A ideia é que regiões onde há grande concentração de pontos amostrais apresentarão polígonos de área pequena, enquanto regiões onde os pontos estão bem esparsos, apresentarão polígonos de área grande, assim a área de cada polígono foi então calculada, no programa ArcGIS v.10.0 (ESRI 2011), utilizando-se de uma projeção sinusoidal.

A

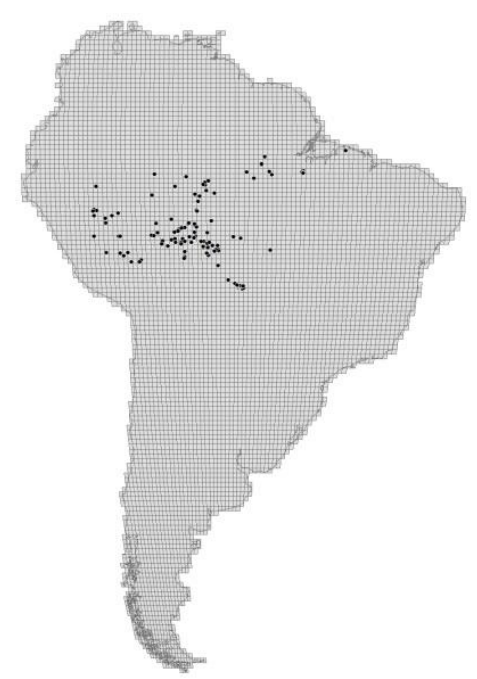

D

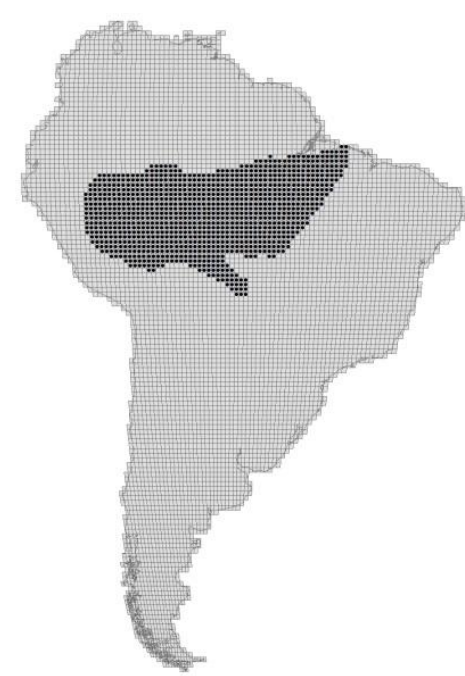

B

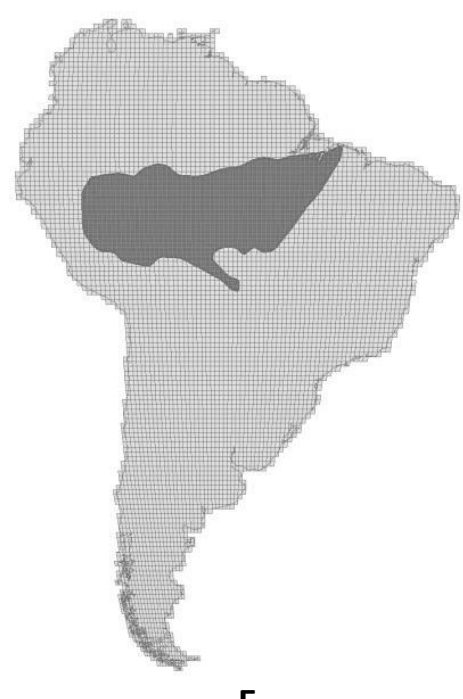

E
C

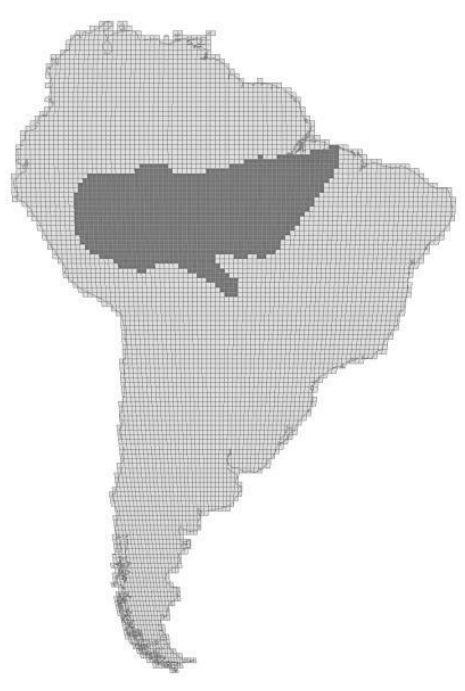

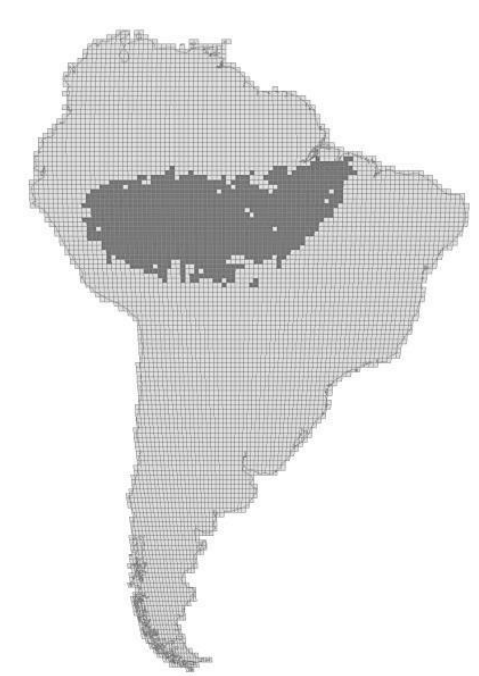

FIGURA 55. Exemplo do processo realizado para modelagem. A) pontos de ocorrência de uma espécie; B) polígono ajustado aos pontos; C) polígono transferido para a grade; D) quadrículas transferidas para pontos; E) modelagem do MaxEnt para estes pontos após o corte. 


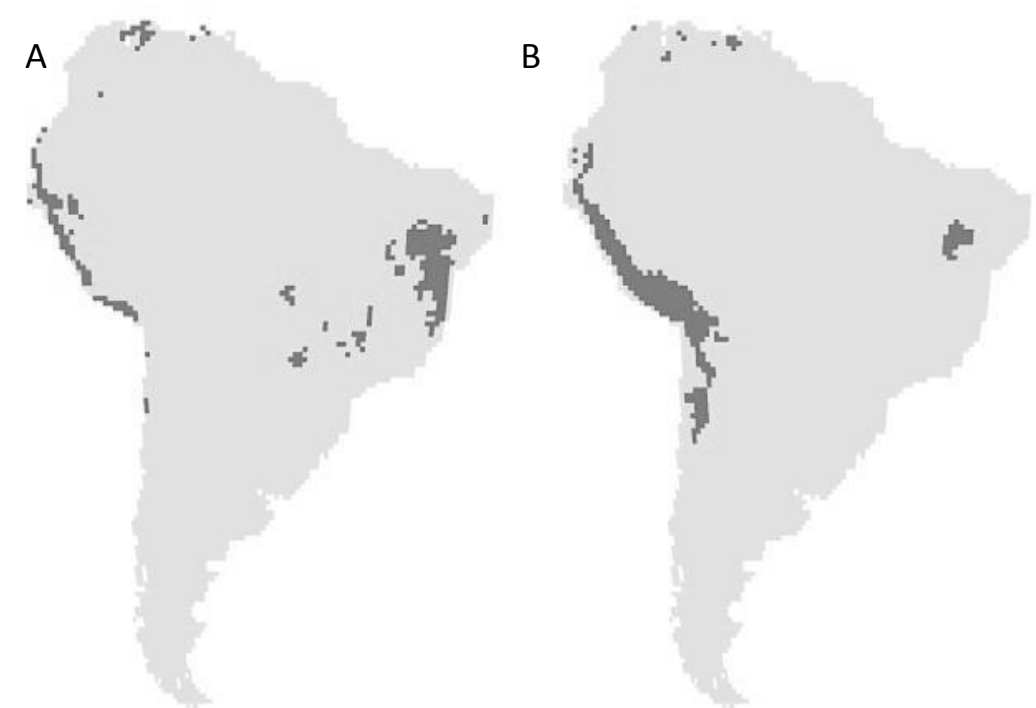

FIGURA 56. Exemplos de espécies típicas da Caatinga sendo preditas nos Andes (A), e espécies dos Andes sendo preditas para Caatinga (B).

\subsubsection{Esforço}

Para se combinar os dados referentes à efetividade amostral e cobertura geográfica da amostragem em uma única avaliação de distribuição de esforço amostral, ambos os dados foram interpolados pelo método do "vizinho natural" para se produzir uma distribuição contínua e suave, e os dados foram padronizados para valores de 0 a 1 , e a média entre eles calculada, no programa ArcGIS v.10.0 (ESRI 2011). Para se avaliar o efeito da ocupação humana no esforço observado, foi calculada correlação entre o esforço e o Índice de Influência Humana v.2. (WCS \& CIESIN 2005). Para se eliminar o efeito da auto-correlação foi utilizado o método de Dutilleul para diminuir o número de graus de liberdade (DUTILLEUL 1993), como implementado pelo programa SAM v.4.0 (RANGEL et al. 2010).

\subsection{RESULTADOS}

\subsubsection{Efetividade amostral}

\subsubsection{Modelagem de riqueza}

Os registros de 1204 espécies (APÊNDICE 4), totalizaram 53049 observações (FIGURA 57) distribuídos por 26537 localidades, ocupando 4199 quadrículas das 6147 que cobrem o continente Sul Americano. O número médio de registros por quadrícula foi de 13 (variando entre 1 e 331). Nas áreas Abertas número médio de registros foi de 9 (1-183), nos Andes 13 (1-331), e nas Florestas 16 (1-317), o número médio de espécies observadas $\left(S_{\text {obs }}\right)$ por quadrícula foi 7 (1-54). Nas áreas Abertas foi 6 (1-43), nos Andes 6 (1-42) e nas áreas de Floresta 9 (1-54) (FIGURA 58). Após a remoção das quadrículas com menos de 25 observações 
restaram 509 quadrículas com 28293 observações, e 998 espécies, com riqueza local variando entre 2 e 54 espécies por quadrícula (FIGURA 59).

Os estimadores de riqueza baseados nas quadrículas com 25 ou mais observações difeririam nos valores máximos estimados (Chao 1: 2-207; Chao 2: 2-22; Chao e Lee: 1-406; Jacknife 1: 2-73; Jacknife 2: 2-99; Michaelis-Menten: 0-1123) (FIGURA 60). A média entre eles foi calculada, porém nove quadrículas apesentaram valores exageradamente altos quando comparados aos demais, estimando mais de 300 de lagartos para cada quadrícula, sendo assim removidos, restando 500 quadrículas, produzindo a riqueza estimada $\left(S_{\text {est }}\right)$. A regressão da $S_{\text {est }}$ (variável resposta) pelas variáveis ambientais (variáveis explanatórias) (FIGURA 62) ( $n=500$,

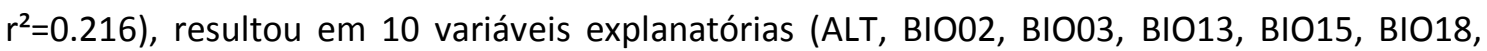
CLAY, SAND, SILT, STR) (FIGURA 61) com VIF < 3 (TABELA 26).

TABELA 26. Resultados da análise de regressão múltipla para $S_{\text {est }}$, como variável resposta, e 10 variáveis explanatórias; $n=500, r^{2}=0.216$. Coef.: coeficiente de regressão; Coef. Pad.: Coeficiente padronizado. ALT: altitude, BIO2: Amplitude média diária, BIO3: Isotermalidade (BIO2/BIO7) (* 100), BIO13: Precipitação do mês mais úmido, BIO15: Sazonalidade na precipitação, BIO18: Precipitação do trimestre mais quente, CLAY: porcentagem de cascalho no solo, SAND: porcentagem de areia no solo, SILT: porcentagem de silte no solo, STR: índice de estrutura ambiental.

\begin{tabular}{lccc}
\hline Variável & VIF & Coef. & Coef. Pad. \\
\hline Constante & 0.00 & -6.099 & 0.00 \\
ALT & 1.923 & -0.004 & -0.229 \\
BIO02 & 1.924 & 0.137 & 0.190 \\
BIO03 & 1.883 & 0.196 & 0.162 \\
BIO13 & 2.783 & 0.012 & 0.102 \\
BIO15 & 1.389 & -0.015 & -0.028 \\
BIO18 & 1.581 & 0.004 & 0.081 \\
CLAY & 1.300 & 0.008 & 0.004 \\
SAND & 1.391 & -0.022 & -0.018 \\
SILT & 1.391 & -0.014 & -0.007 \\
STR & 2.394 & 12.247 & 0.182 \\
\hline
\end{tabular}




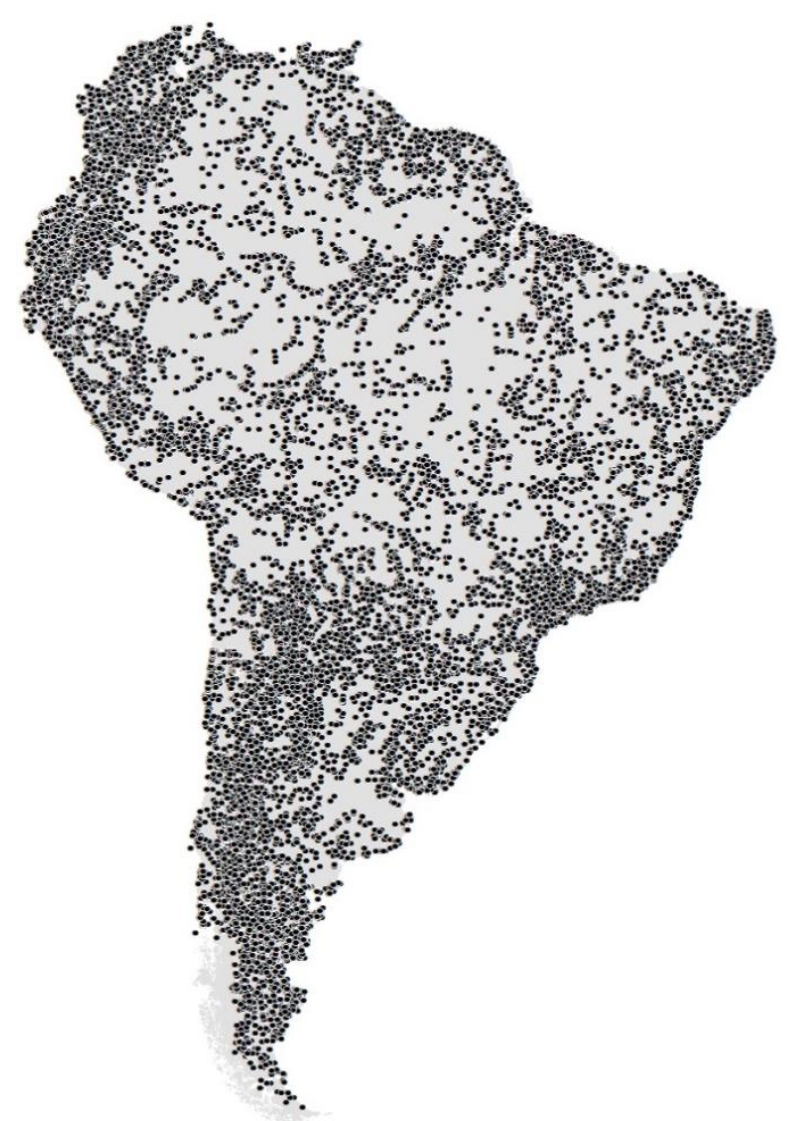

FIGURA 57. Cerca de 53 mil observações referentes cerca de 26 mil localidades e às 1204 espécies de lagartos utilizadas neste estudo (APÊNDICE 4).
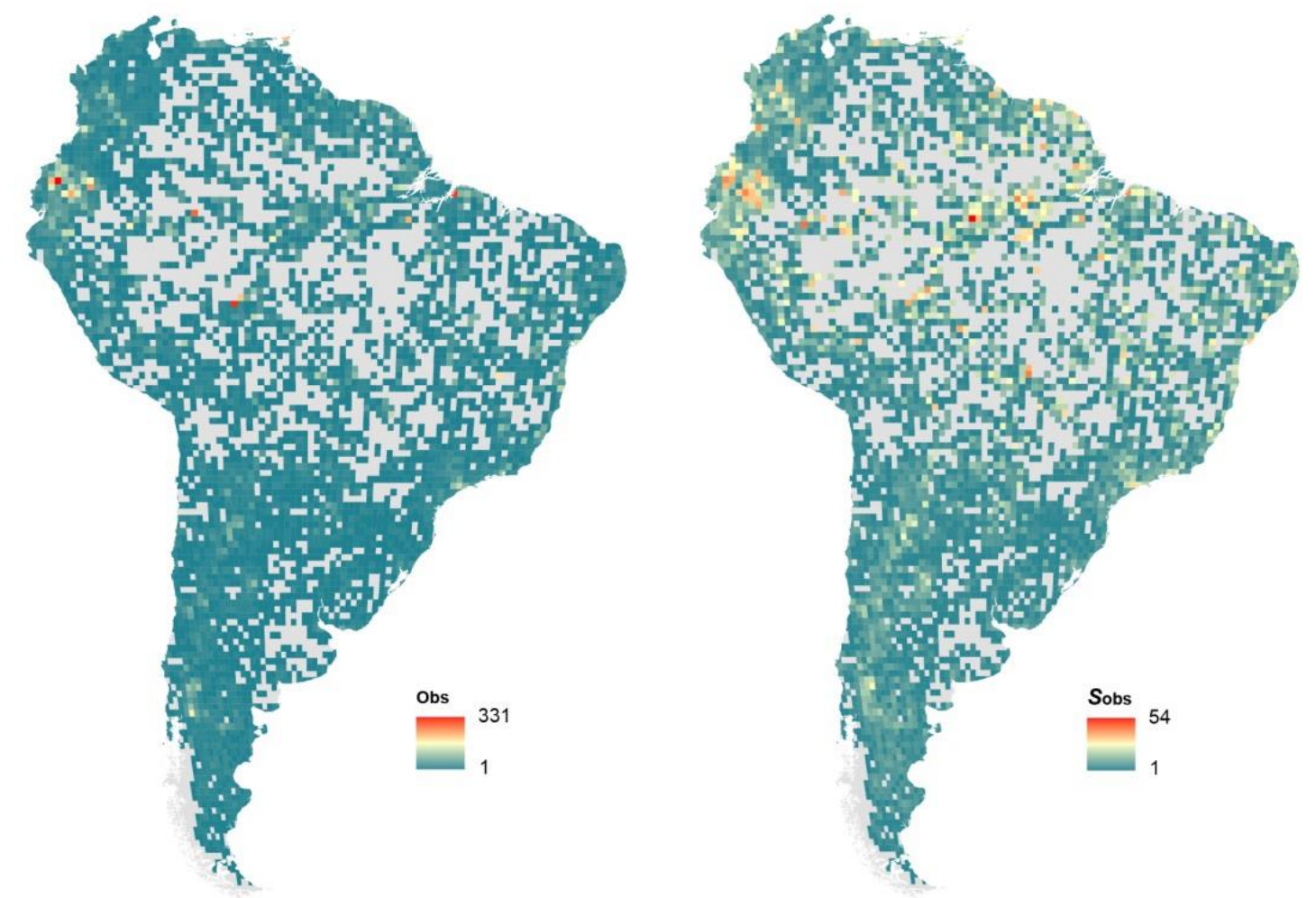

FIGURA 58. Número de registros de espécies de lagartos (esquerda), e o número de espécies observadas $\left(S_{\text {obs }}\right)$ por quadrícula, baseada nos registros individuais (direita). 

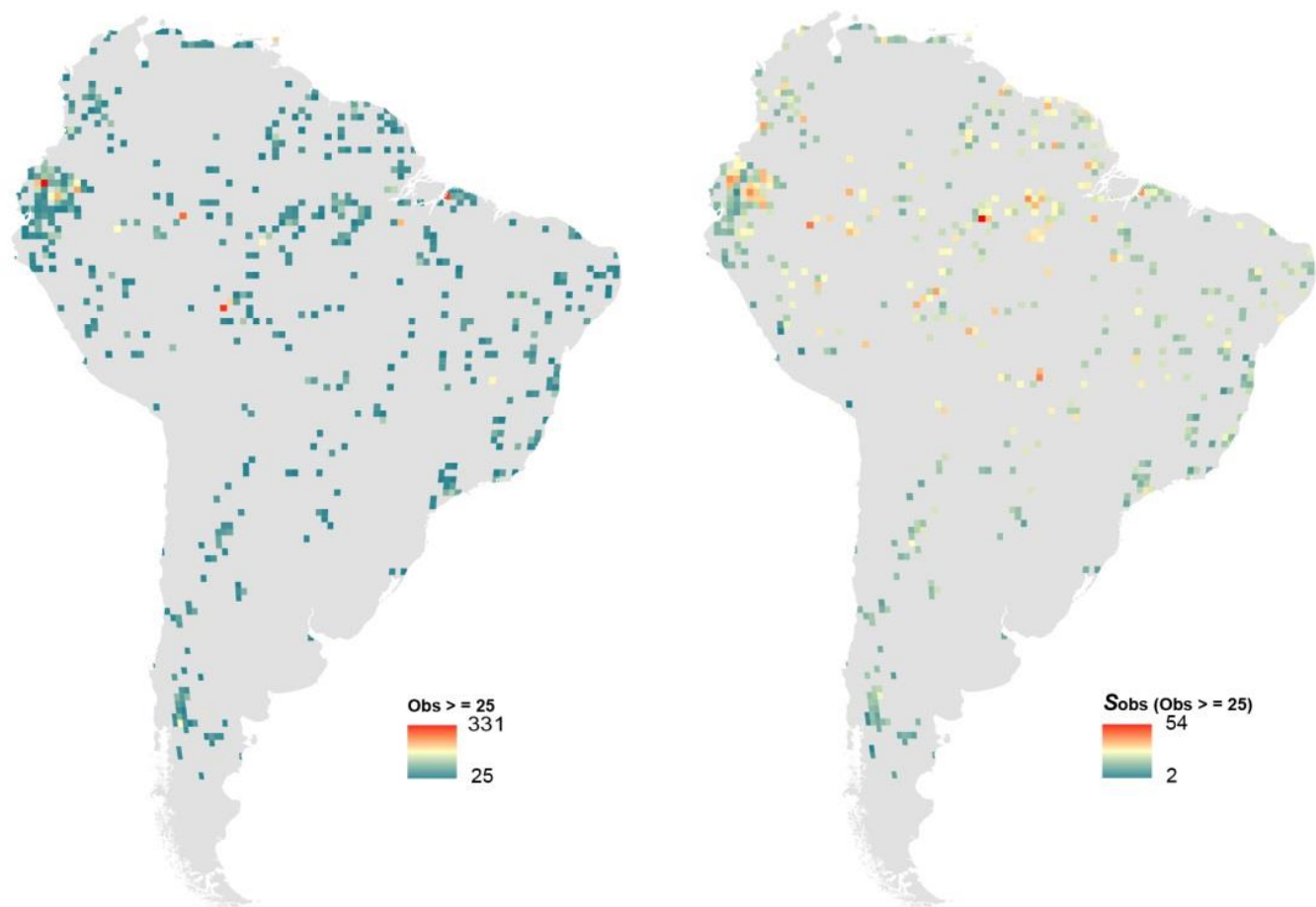

FIGURA 59. Número de registros de espécies de lagartos (esquerda), e o número de espécies observadas $\left(S_{\text {obs }}\right)$ por quadrícula, baseada nos registros individuais (direita), nas quadriculas com no mínimo 25 registros.
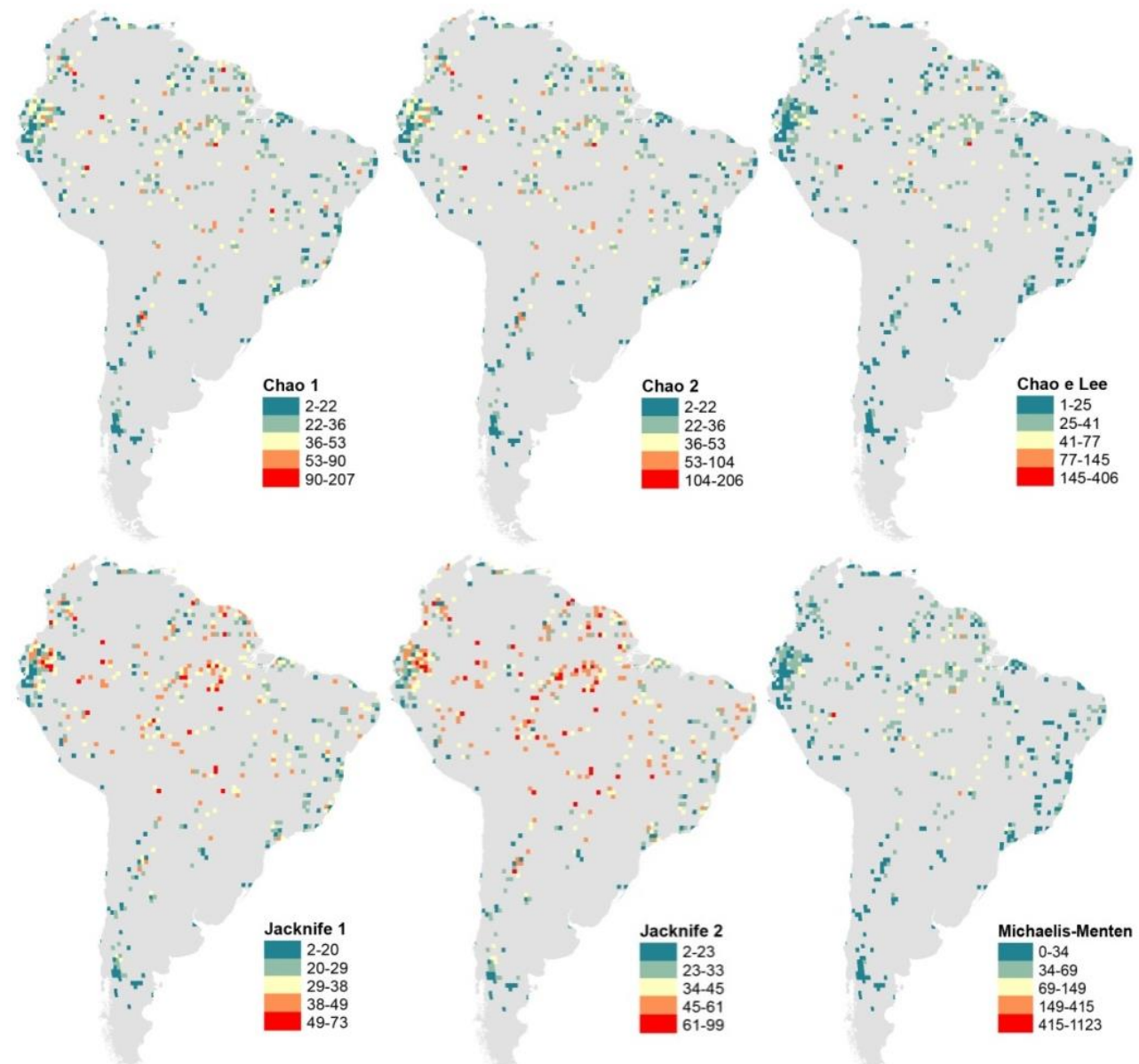

FIGURA 60. Estimadores de riqueza e seus valores baseados nos registros feitos dentro das quadrículas com 25 ou mais registros. 
O correlograma dividido em 18 classes de distância indica que mesmo após a extração dos resíduos, a $S_{\text {est }}$ ainda é positivamente auto-correlacionada até cerca de $956 \mathrm{~km}$ de distância, segundo o índice I de Moran, tornando-se negativamente auto-correlacionada, até cerca de $1457 \mathrm{~km}$, e novamente negativamente auto-correlacionada a $1897 \mathrm{~km}$, até cerca de $3755 \mathrm{~km}$, passando novamente a valores positivo (FIGURA 64).
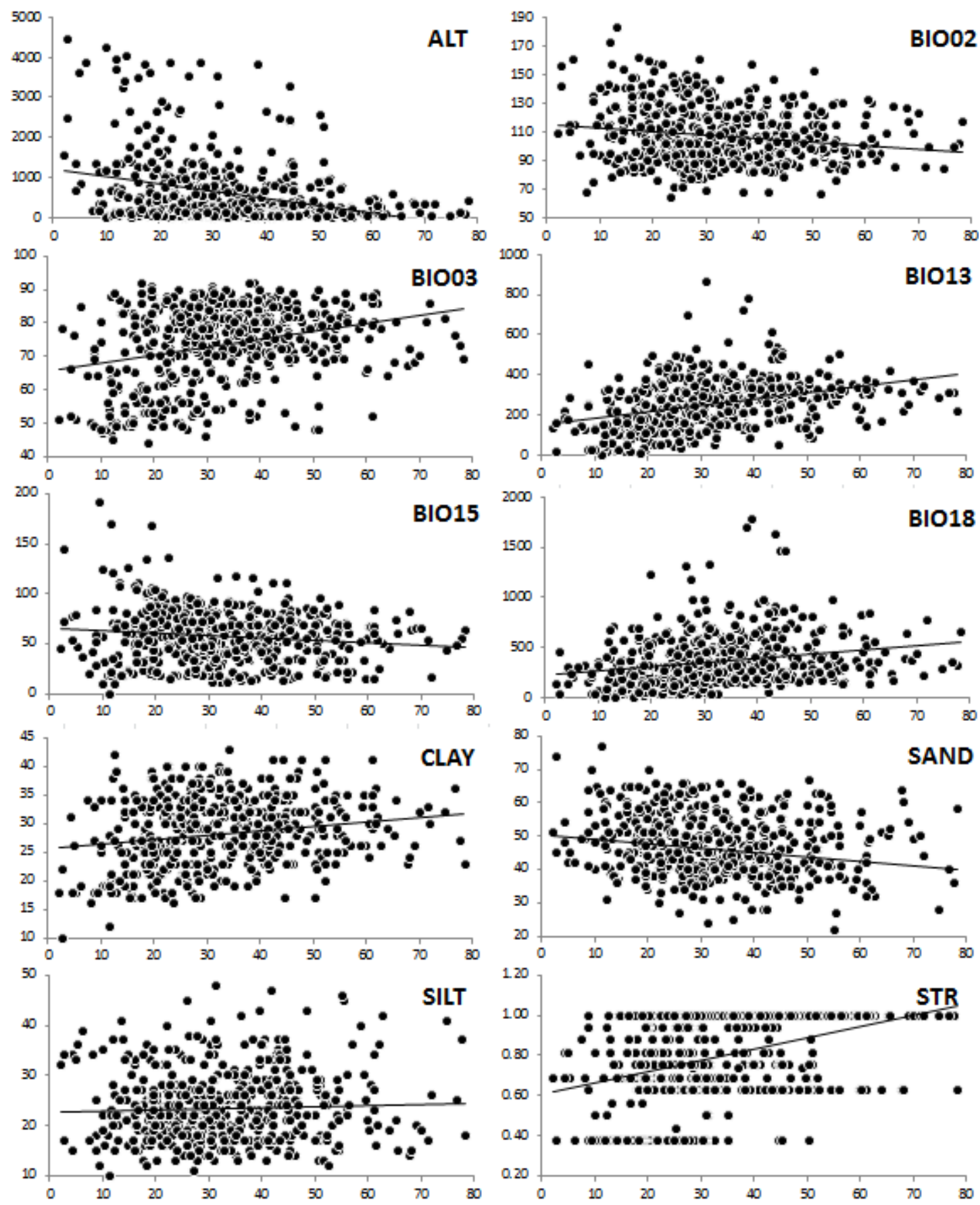

FIGURA 61. Resultados da análise de regressão múltipla para $S_{\text {est, }}$ como variável resposta, e 10 variáveis explanatórias. ALT: altitude, BIO2: Amplitude média diária, BIO3: Isotermalidade (BIO2/BIO7) (* 100), BIO13: Precipitação do mês mais úmido, BIO15: Sazonalidade na precipitação, BIO18: Precipitação do trimestre mais quente, CLAY: porcentagem de cascalho no solo, SAND: porcentagem de areia no solo; SILT: porcentagem de silte no solo, STR: índice de estrutura ambiental. 
A matriz de conectividade, baseada no critério de distância, neste caso a menor distância $\left(956 \mathrm{~km}\right.$ ) calculou 17338 conexões entre as áreas com valores disponíveis de $S_{\text {est }}$, apresentando uma distância mínima de 41.25 km, média de 565.525 km, máxima de 955.91, e desvio padrão de 256.722 (FIGURA 65).

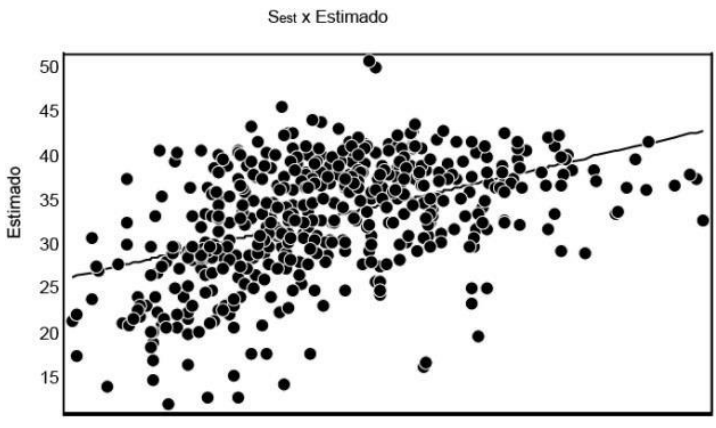

Sest

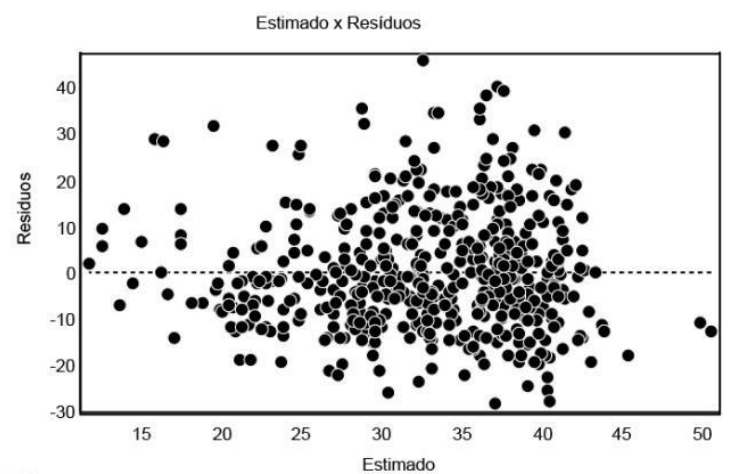

FIGURA 62. Resultados da análise de regressão múltipla para riqueza estimada de lagartos $\left(S_{\text {est }}\right)$, como variável resposta, e 10 variáveis explanatórias.
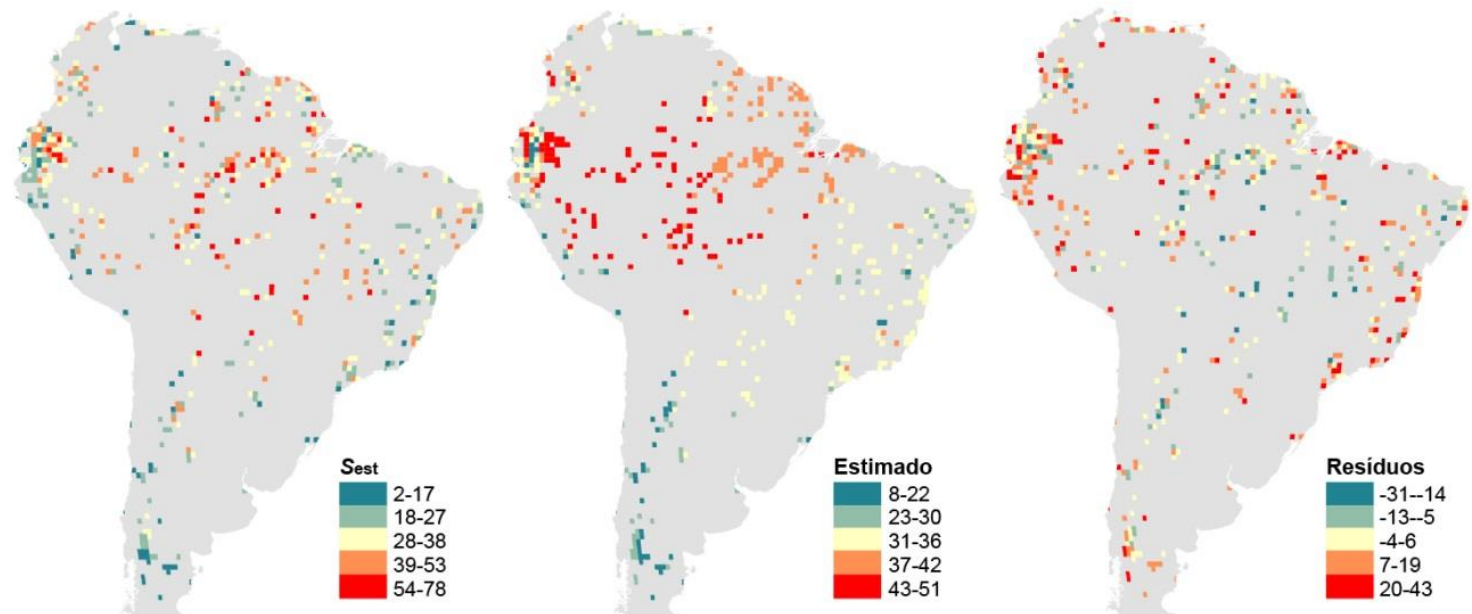

FIGURA 63. Mapas mostrando valores médios de riqueza estimada de lagartos $\left(S_{\text {est }}\right)$ calculados pelos estimadores de riqueza (esquerda), valores estimados na análise de regressão da $S_{\text {est }}$ pelas variáveis ambientais (meio), e seus resíduos (direita). 


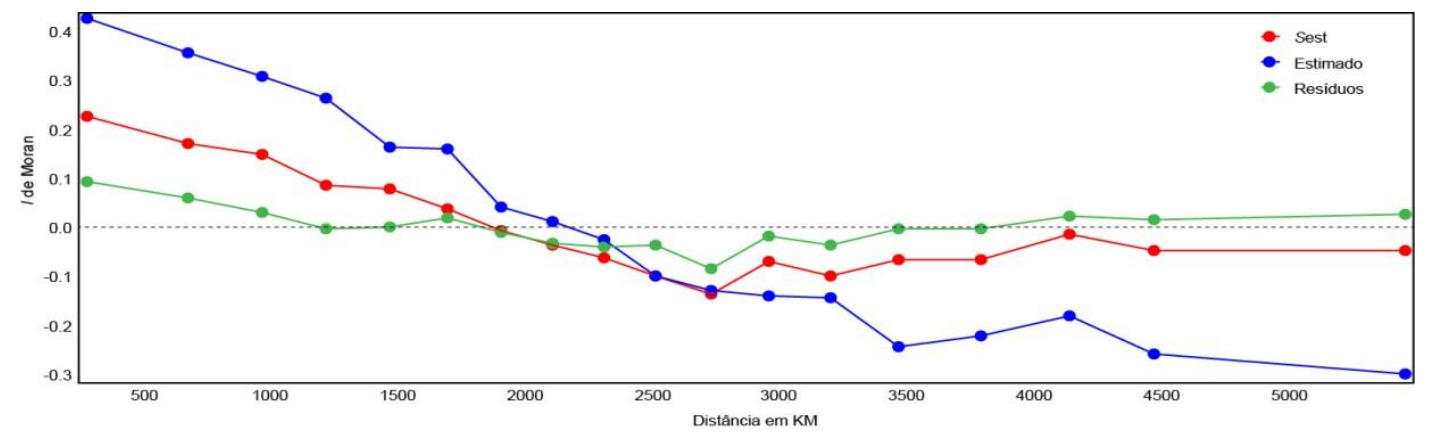

FIGURA 64. Correlograma do I de Moran para a riqueza estimada de lagartos $\left(S_{\text {est }}\right)$, para os valores estimados e os resíduos da regressão da $S_{\text {est }}$ pelas variáveis ambientais.

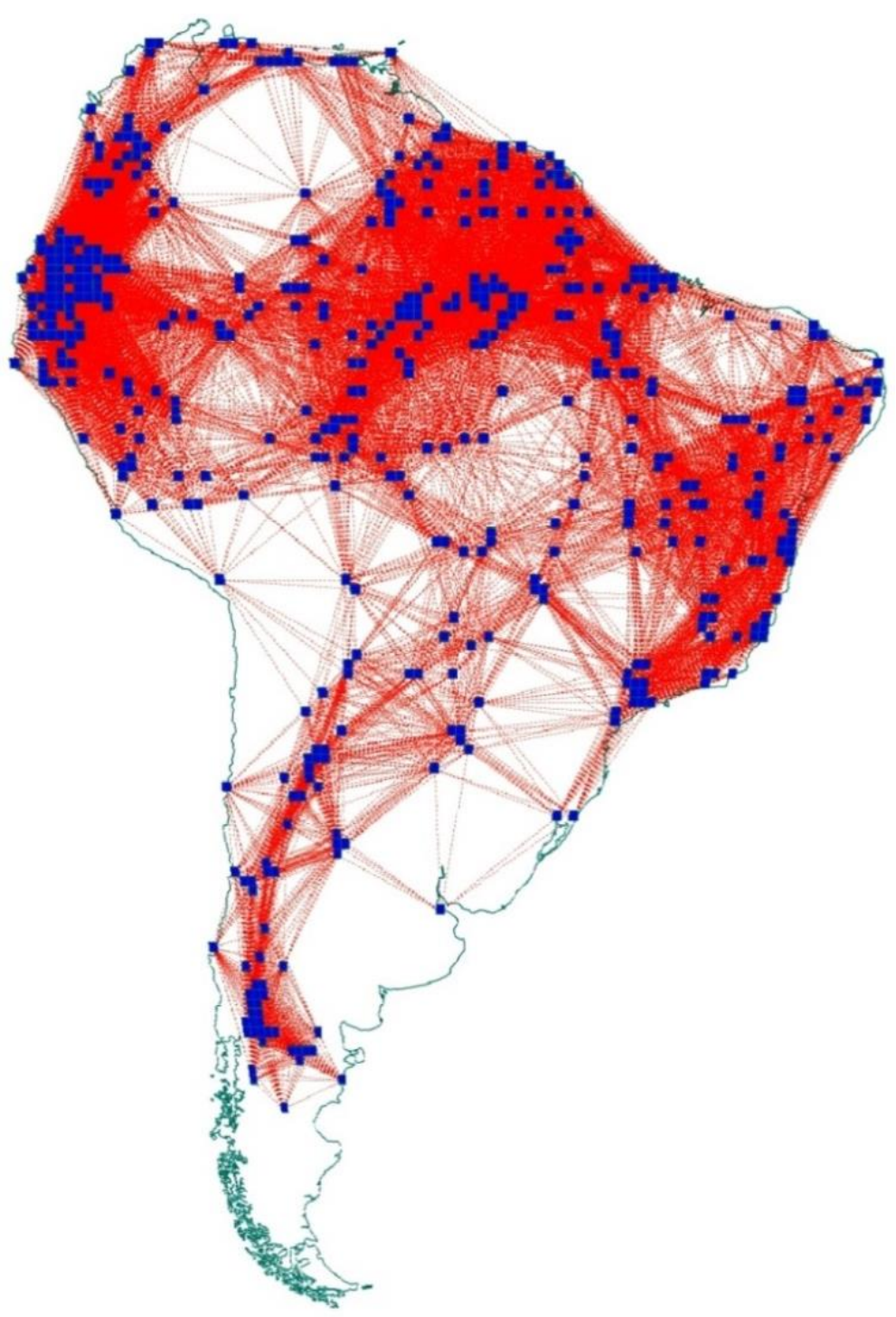

FIGURA 65. Mapa representando a matriz de conectividade entre as quadrículas onde foram calculadas as riquezas estimadas de lagartos $\left(S_{\text {est }}\right)$. A matriz de conectividade foi calculada com base na menor distância $(956 \mathrm{~km})$ do correlograma do / de Moran sobre os resíduos da regressão da $S_{\text {est }}$ e das variáveis ambientais. Quadrados azuis: quadrículas onde $S_{\text {est }}$ foi calculada; Linhas vermelhas tracejadas: conexões. 
O modelo auto-regressivo baseado na riqueza estimada $\left(S_{\text {est }}\right)$, como variável resposta, e nas ambientais (ALT, BIO02, BIO03, BIO13, BIO15, BIO18, CLAY, SAND, SILT e STR), como variáveis explanatórias, e na matriz de conectividade, foi calculado $\left(n=500, r^{2}=0.146, \rho=\right.$ 0.992) (TABELA 27; FIGURAS 66 e 67), e incluído como uma variável fixa (MAR $\mathbf{R}_{\text {SEST }}$ ), presente em todos os modelos na seleção de modelos.

$\mathrm{O}$ procedimento de seleção de modelos aplicado à riqueza estimada de lagartos $\left(S_{\text {est }}\right)$, como variável resposta, tendo as variáveis ambientais (ALT, BIO02, BIO03, BIO13, BIO15, BIO18, CLAY, SAND, SILT e STR) como variáveis explanatórias, testou 1023 modelos. Cinco apresentaram $\triangle \mathrm{AICC}$ menor que 2 , explicando cerca de $36 \%$ da variação observada. $A$ probabilidade de que o modelo com menor AICc para $S_{\text {est }}$ seja o melhor modelo de $13 \%$ (TABELA 28; FIGURA 68), e o modelo com a melhor combinação de variáveis inclui ALT, BIO02, BIO03, BIO18, STR (TABELA 29). O modelo auto-regressivo apresentou o maior coeficiente de regressão, e os valores dos coeficientes de cada variável diminuíram em magnitude, variando entre -0.212 e 0.206 , e foram positivamente correlacionados a $\mathrm{BIO02}, \mathrm{BIO03}, \mathrm{BIO} 13$, $\mathrm{BIO} 18$ e STR, e negativamente a ALT, com maiores valores relacionados à ALT, BIO02 e STR foram então escolhidas para a interpolação CoKriging.

TABELA 27. Resultados do cálculo do modelo auto-regressivo para $S_{\text {est, }}$ como variável resposta, e 10 variáveis explanatórias, usando a matriz de conectividade baseada em distância. Coef.: coeficiente de regressão; Coef. Pad.: coeficiente padronizado. ALT: altitude, BIO2: Amplitude média diária, BIO3: Isotermalidade (BIO2/BIO7) (* 100), BIO13: Precipitação do mês mais úmido, BIO15: Sazonalidade na precipitação, BIO18: Precipitação do trimestre mais quente, CLAY: porcentagem de cascalho no solo, SAND: porcentagem de areia no solo, SILT: porcentagem de silte no solo, STR: índice de estrutura ambiental.

\begin{tabular}{lcc}
\hline Variável & Coef. & Coef. Pad. \\
\hline Constant & 1.805 & 0.000 \\
ALT & $<0.001$ & -0.028 \\
BIO02 & 0.006 & 0.116 \\
BIO03 & -0.021 & -0.253 \\
BIO13 & $<0.001$ & -0.086 \\
BIO15 & -0.005 & -0.131 \\
BIO18 & $<0.001$ & 0.173 \\
CLAY & $<0.001$ & 0.002 \\
SAND & -0.004 & -0.049 \\
SILT & -0.006 & -0.047 \\
STR & -0.395 & -0.085 \\
\hline
\end{tabular}


TABELA 28. Resultado do procedimento de seleção de modelos lineares $\left(r^{2}\right)$, organizados pelo Critério de Informação de Akaike (AICC) e peso de Akaike $\left(w_{i}\right)$. Foram avaliados 1023 modelos, aqui são mostrados apenas os que apresentam $\triangle \mathrm{AICc}$ menores que 2.

\begin{tabular}{lcccc}
\hline Variáveis & $\mathbf{r}^{\mathbf{2}}$ & AICc & DAICc & AICc wi \\
\hline ALT, BIO02, BIO03, BIO13, BIO18, STR & 0.362 & 3876.133 & 0.000 & 0.129 \\
ALT, BIO02, BIO03, BIO13, BIO15, BIO18, STR & 0.363 & 3876.997 & 0.864 & 0.084 \\
ALT, BIO02, BIO03, BIO13, BIO15, STR & 0.361 & 3877.076 & 0.942 & 0.080 \\
ALT, BIO02, BIO03, BIO13, STR & 0.357 & 3877.583 & 1.450 & 0.062 \\
ALT, BIO02, BIO03, BIO13, BIO18, SILT, STR & 0.362 & 3878.001 & 1.868 & 0.051 \\
\hline
\end{tabular}
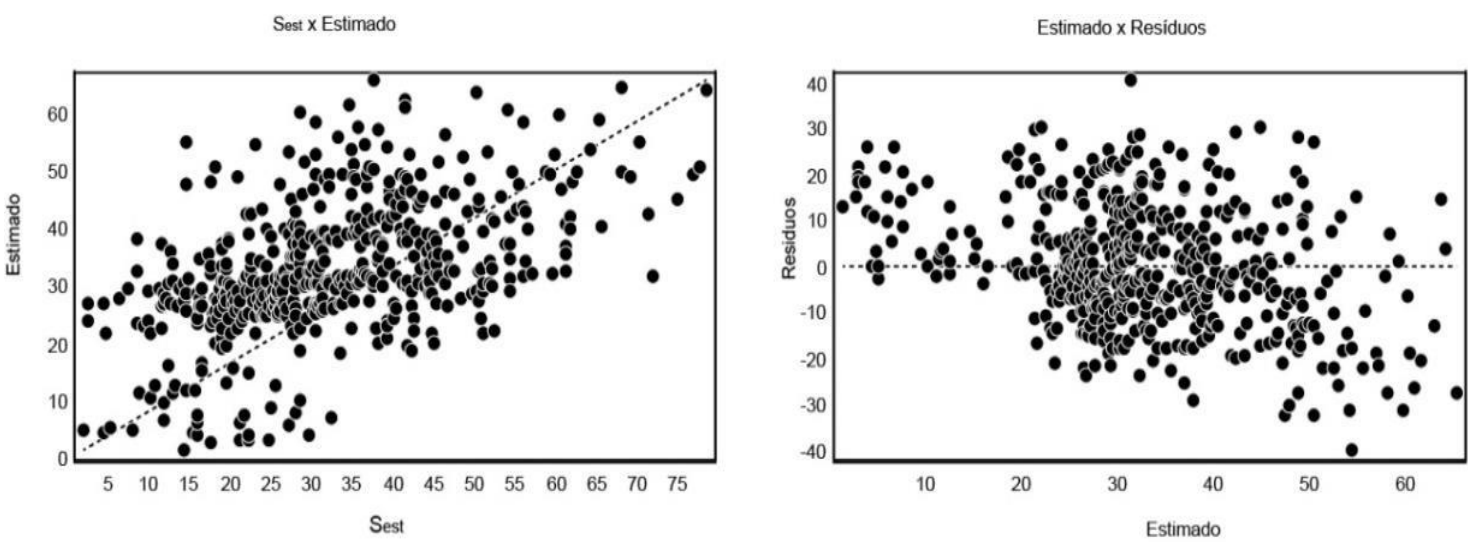

FIGURA 66. Resultados o cálculo do modelo auto-regressivo para riqueza estimada de lagartos $\left(S_{\text {est }}\right)$, como variável resposta, e 10 variáveis explanatórias ambientais.

TABELA 29. Parâmetros calculados para o melhor modelo de acordo com o Critério de informação de Akaike (AICC) tendo $S_{\text {est }}$ como variável resposta e as 10 variáveis ambientais. Coef.: coeficiente de regressão; Coef. Pad.: Coeficiente padronizado. ALT: altitude, BIO2: Amplitude média diária, BIO3: Isotermalidade (BIO2/BIO7) (* 100), BIO13: Precipitação do mês mais úmido, BIO18: Precipitação do trimestre mais quente, STR: índice de estrutura ambiental.

\begin{tabular}{lcc}
\hline Variável & Coef. & Coef. Pad \\
\hline Constant & -8.891 & 0.000 \\
ALT & -0.004 & -0.212 \\
BIO02 & 0.137 & 0.191 \\
BIO03 & 0.165 & 0.136 \\
BIO13 & 0.020 & 0.177 \\
BIO18 & 0.004 & 0.079 \\
STR & 13.842 & 0.206 \\
MAR & 0.321 & 0.388 \\
\hline
\end{tabular}



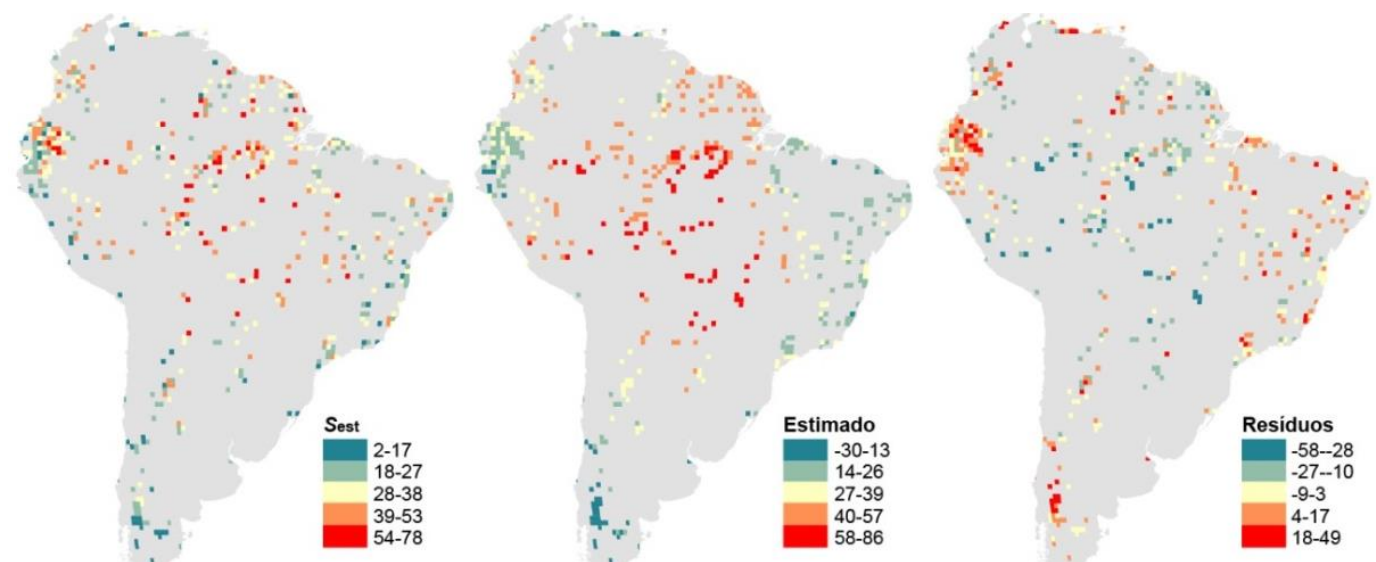

FIGURA 67. Mapas mostrando valores médios de riqueza $\left(S_{\text {est }}\right)$ calculados pelos estimadores de riqueza (esquerda), valores estimados no modelo auto-regressivo da $S_{\text {est }}$ pelas variáveis ambientais (meio), e seus resíduos (direita).

Sest $\times$ Estimado

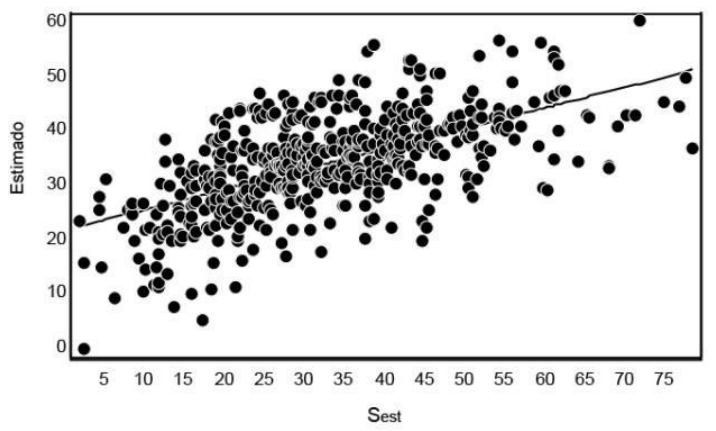

Estimado $x$ Residuos

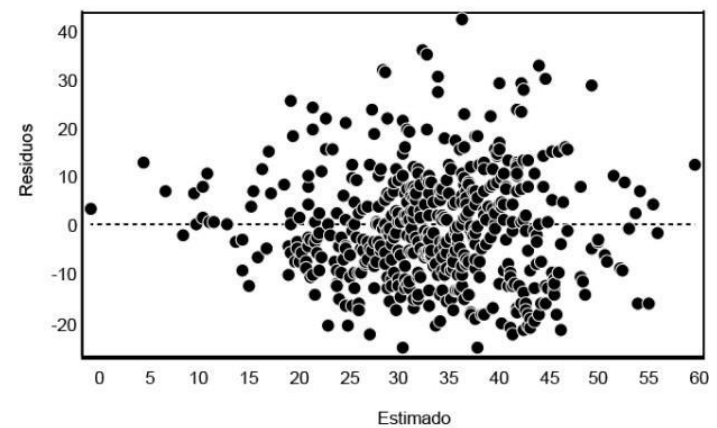

FIGURA 68. Resultados da seleção de modelo, tendo $S_{\text {est }}$ como variável resposta, e 10 variáveis explanatórias (ALT, BIO02, BIO03, BIO13, BIO15, BIO18, CLAY, SAND, SILT, STR) e os resíduos do modelo auto-regressivo (MAR SEST $_{\text {). }}$

$\mathrm{Na}$ interpolação CoKriging da riqueza estimada de lagartos $\left(S_{\text {est }}\right)$ usando as variáveis ambientais ALT, BIO02 e STR, foi calculado um modelo estável (parâmetro=1.328, maior amplitude=21.339) baseado nos semi-variogramas e funções covariântes (FIGURA 69). A validação cruzada mostrou que os valores modelados diferem dos valores observados, com valores observados mais altos tendendo a serem modelados com valores mais baixos, e valores observados mais baixos tendendo a serem modelados com valores mais altos (FIGURA 70). Isso produziu uma superfície contínua de riqueza $\left(S_{\bmod }\right)$ com média de 34 (2-58). A média da região Andina foi de 23 (2-45), das Florestas 41 (18-58) e das áreas Abertas 33 (12-53) (FIGURA 71). 


\section{Semi-variogramas}
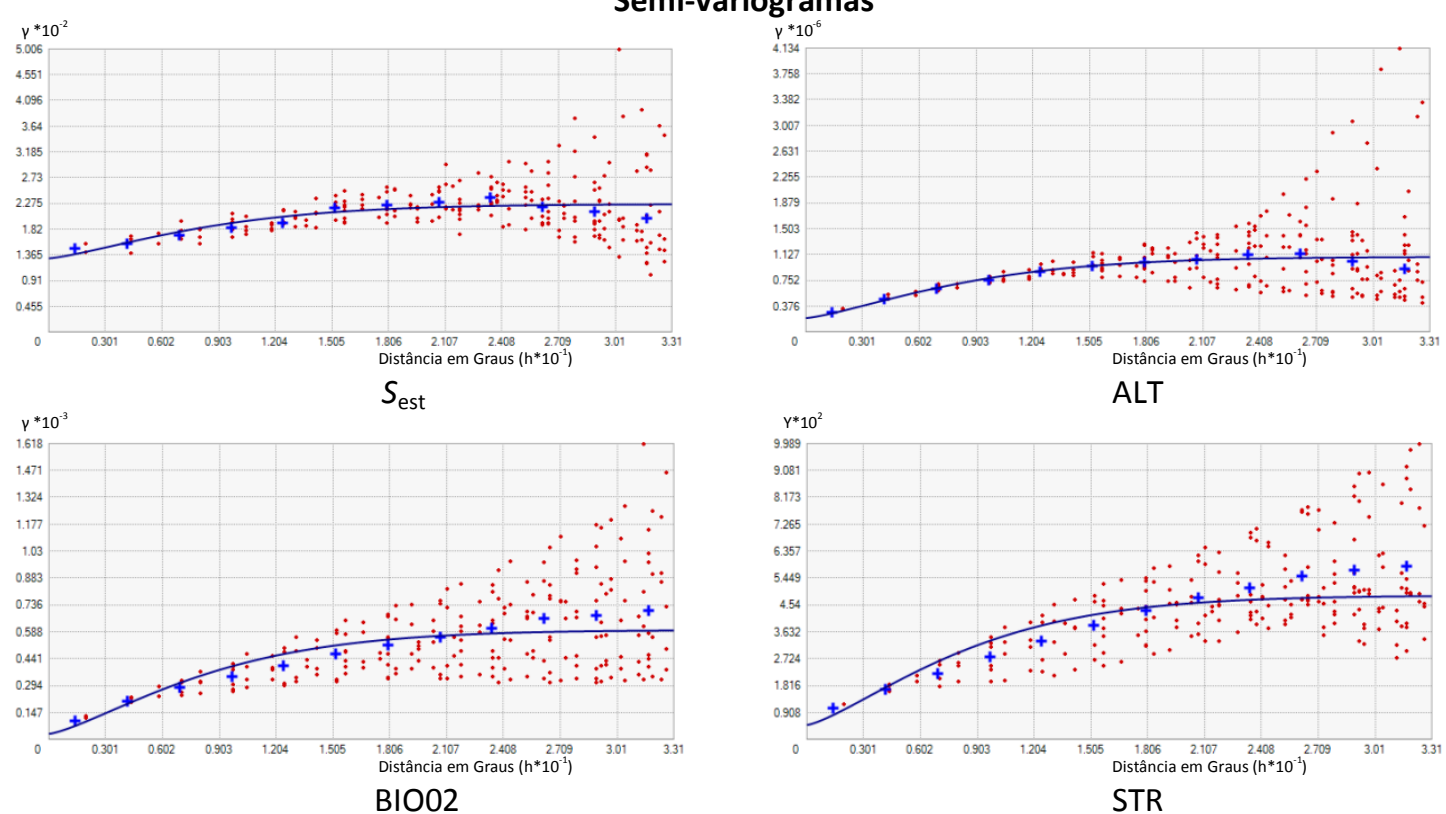

\section{Funções Covariantes}
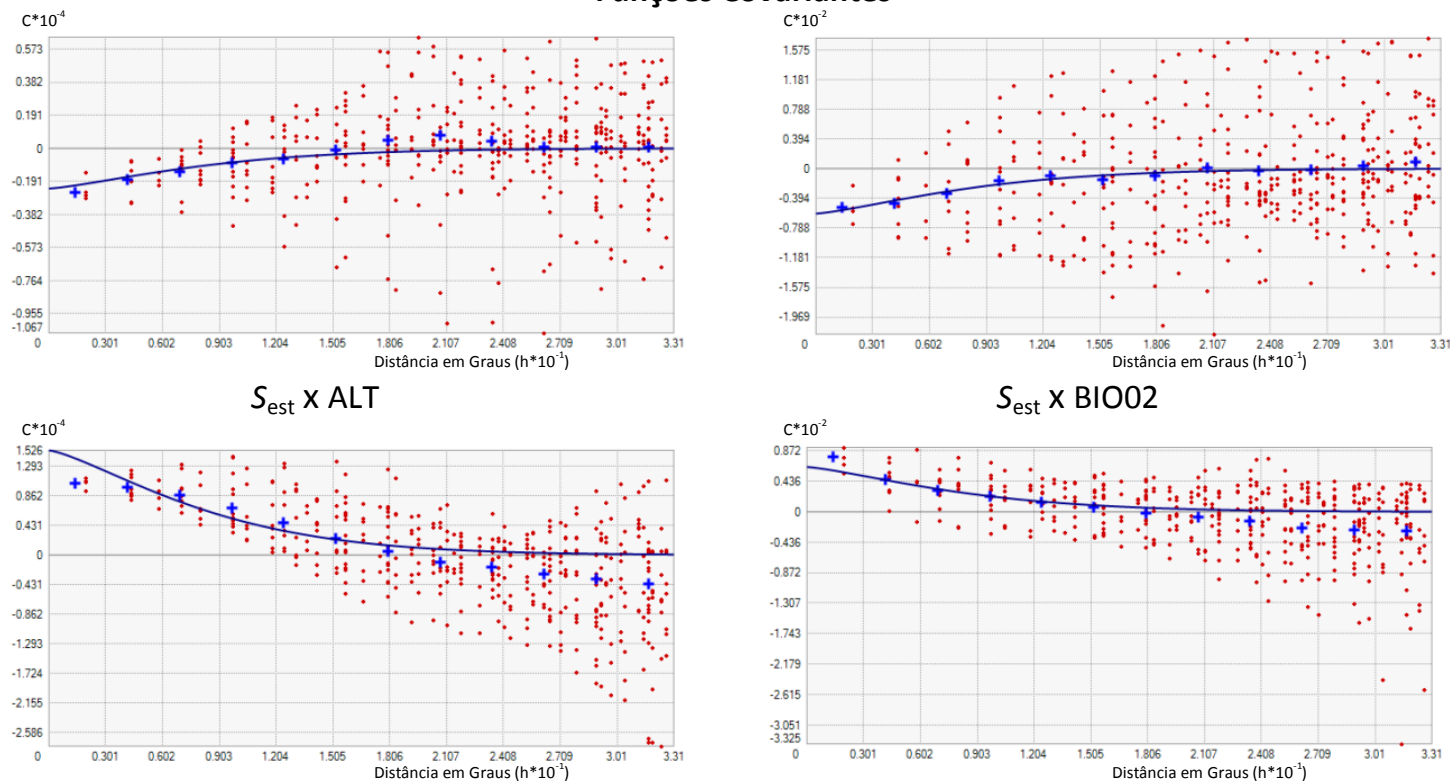

$S_{\text {est }} \times$ STR
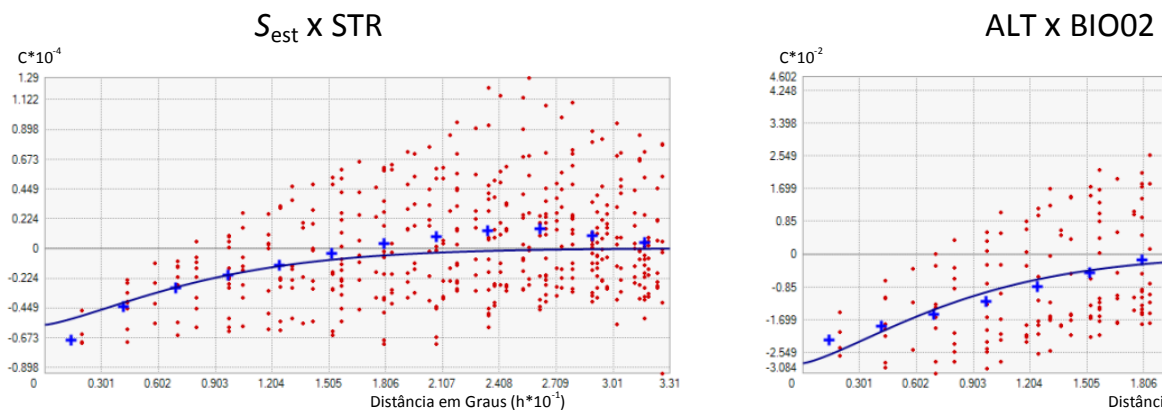

ALT $\times$ STR

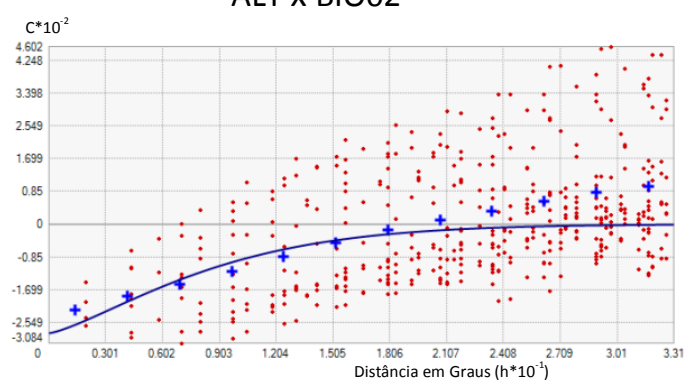

$\mathrm{BIO02} \times \mathrm{STR}$

FIGURA 69. Semivariogramas $(\mathrm{Y})$ da $S_{\text {est }}, A L T, B I O 02, S T R$, e funções covariantes (C) calculadas entre elas; $\bullet=$ pares, $+=$ média, $-=$ modelo. 


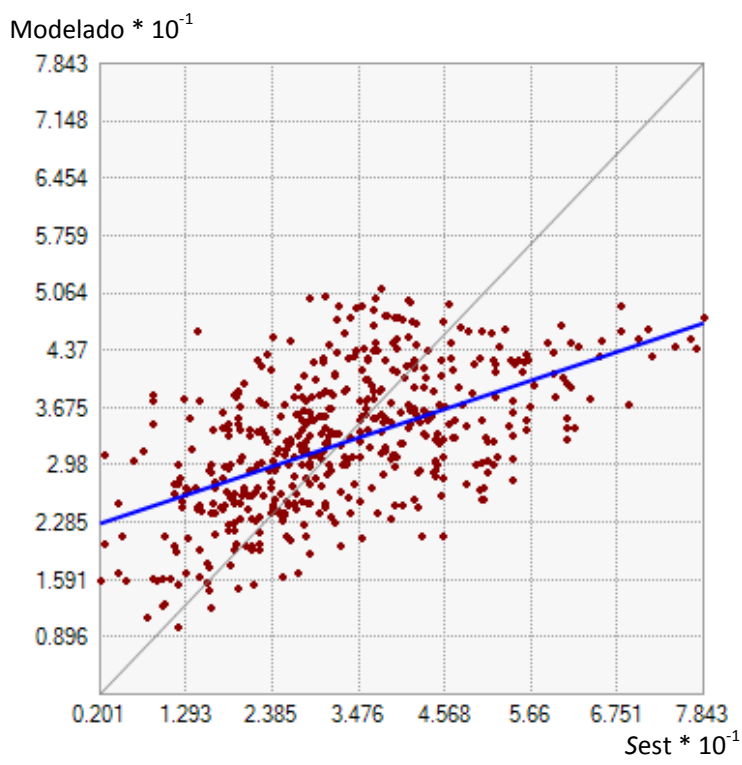

FIGURA 70. Validação cruzada da interpolação CoKriging sobre a riqueza estimada de lagartos $\left(S_{\text {est }}\right)$.

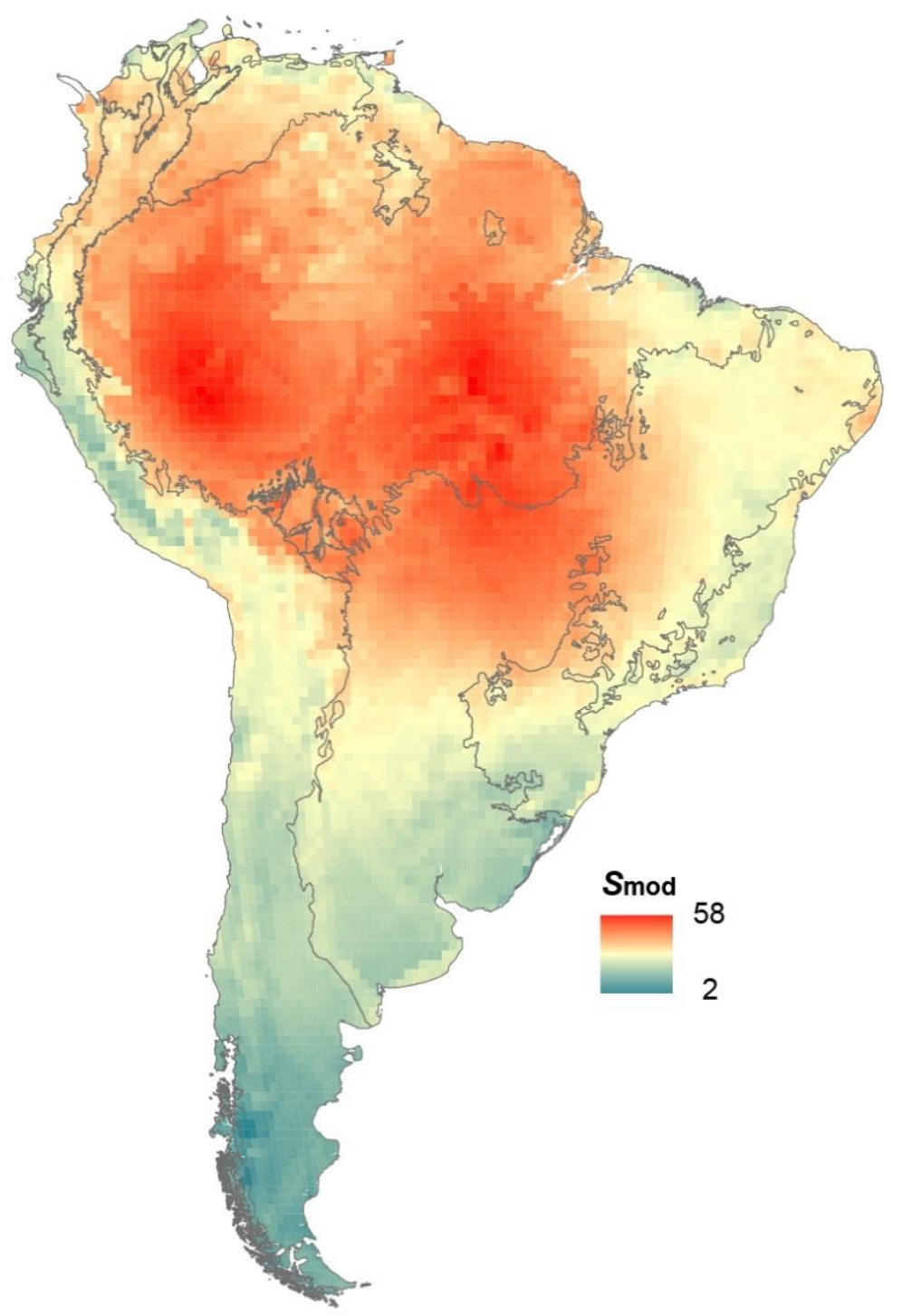

FIGURA 71. Riqueza modelada $\left(S_{\text {mod }}\right)$ pela interpolação da riqueza estimada (Sest), e das variáveis ambientais (STR, ALT, BIO02). 


\subsubsection{Riqueza estimada pela regressão múltipla}

A riqueza de lagartos baseada em polígonos $\left(S_{\text {pol }}\right)$ totalizou 1204 espécies, com riqueza local média de 28 (variando entre 0 e 59), nas áreas Abertas foi de 26 (9-49), nas áreas de Floresta 37 (11-59), e na região Andina 15 (0-56). A média dos valores estimados pela regressão $\left(S_{\text {reg }}\right)$ foi de $28(-3-48)$, nas áreas de Floresta foi de 37 (18-48), nas áreas Abertas 25 (9-40), e na região Andina 16 (-2-42). Os resíduos mostram uma riqueza não contemplada pela estimativa na região do Cerrado e nos Andes do Sul (FIGURA 72). A regressão das variáveis ambientais (variáveis explanatórias) e pela $S_{\text {pol }}$ (variável resposta) (FIGURA 73), ( $n=6147, r^{2}=0.621$ ) se utilizou das 10 variáveis explanatórias (ALT, BIO02, BIO03, BIO15, BIO18, BIO19, CLAY, SAND, SILT, STR) com VIF < 3 (TABELA 30).
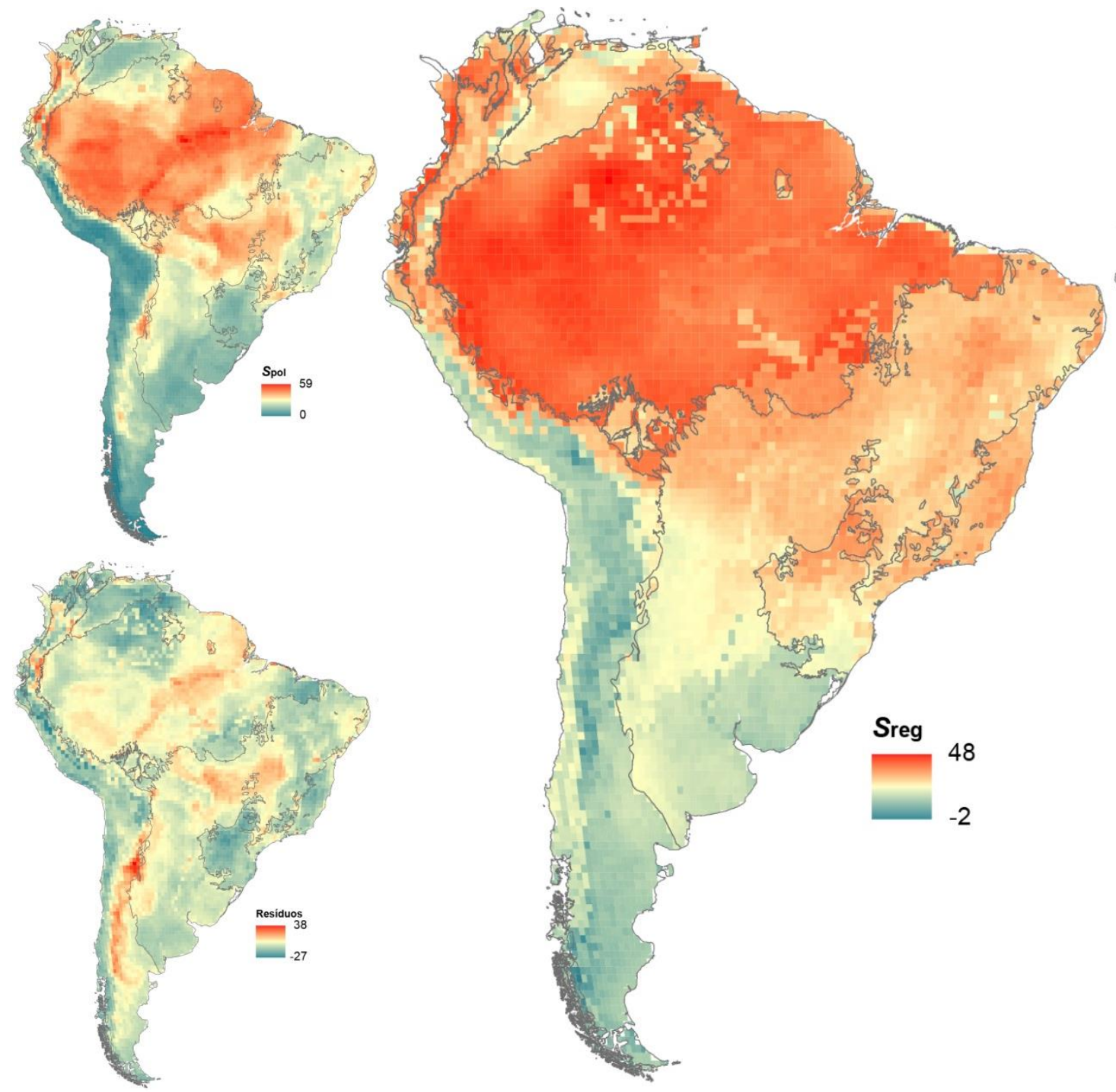

FIGURA 72. Distribuição de riqueza de lagartos baseada em polígonos $\left(S_{\text {pol }}\right)$, estimada pela regressão $\left(S_{\text {reg }}\right)$, e os resíduos da regressão (Resíduos). 

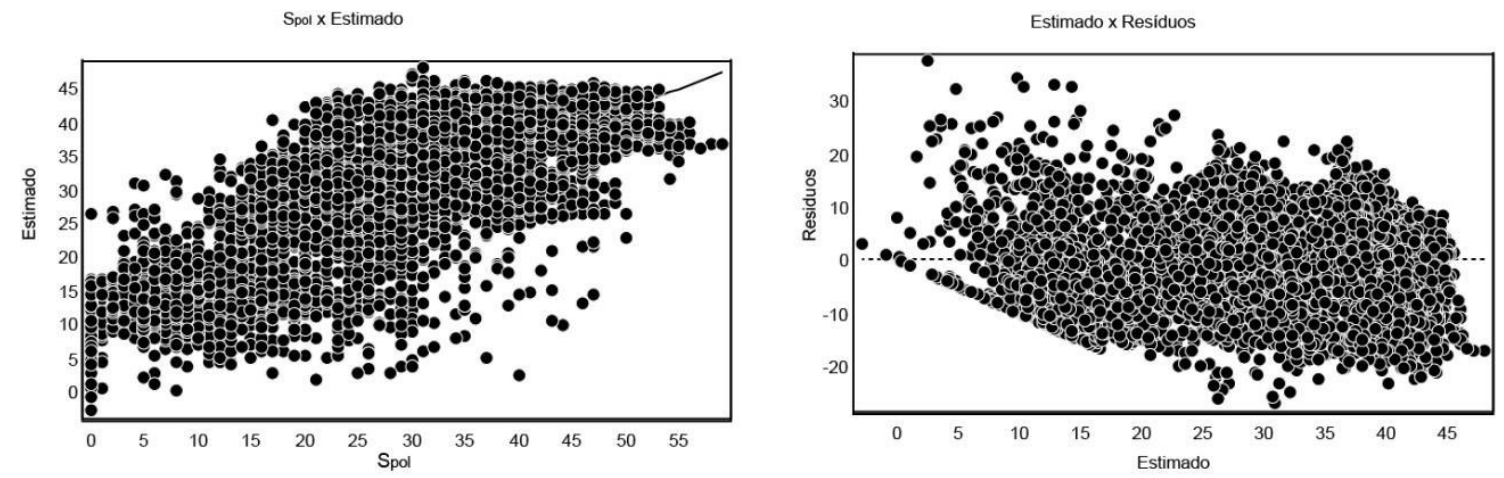

FIGURA 73. Resultados da análise de regressão múltipla para $S_{\text {est, }}$ como variável resposta, e 10 variáveis explanatórias.

TABELA 30. Resultados da análise de regressão múltipla para $S_{\text {pol, }}$ como variável resposta, e 10 variáveis explanatórias; $n=6147$, $r^{2}=0.621$.

\begin{tabular}{lccc}
\hline Variável & VIF & Coef. & Coef. Pad. \\
\hline Constante & 0.000 & -29.988 & 0.000 \\
ALT & 1.781 & -0.003 & -0.218 \\
BIO02 & 2.233 & 0.060 & 0.103 \\
BIO03 & 2.536 & 0.401 & 0.396 \\
BIO15 & 1.704 & -0.003 & -0.006 \\
BIO18 & 1.472 & 0.005 & 0.074 \\
BIO19 & 1.970 & -0.003 & -0.095 \\
CLAY & 1.311 & -0.017 & -0.010 \\
SAND & 1.408 & 0.113 & 0.100 \\
SILT & 1.283 & -0.018 & -0.011 \\
STR & 2.739 & 29.134 & 0.481 \\
\hline
\end{tabular}

O correlograma dividido em 25 classes de distância indica que mesmo após a extração dos resíduos a $S_{\text {est }}$ ainda é positivamente auto-correlacionada até cerca de $842 \mathrm{~km}$ de distância, segundo o índice I de Moran, tornando-se negativamente auto-correlacionada até cerca de $3113 \mathrm{~km}$, e novamente positivamente auto-correlacionada a partir de $3296 \mathrm{~km}$ (FIGURA. 74).

\subsubsection{Modelagem individual de espécies}

Os modelos referentes às 1204 espécies de lagartos gerados pelo MaxEnt no geral apresentaram altos valores de AUC (APÊNDICE 5). A média da a soma dos modelos $\left(S_{\max }\right)$ foi de 30 (0-86). Na região Andina a média foi de 22 (0-86), nas Florestas foi de 37 (8-66), e nas áreas Abertas 27 (0-54) (FIGURA 75). 


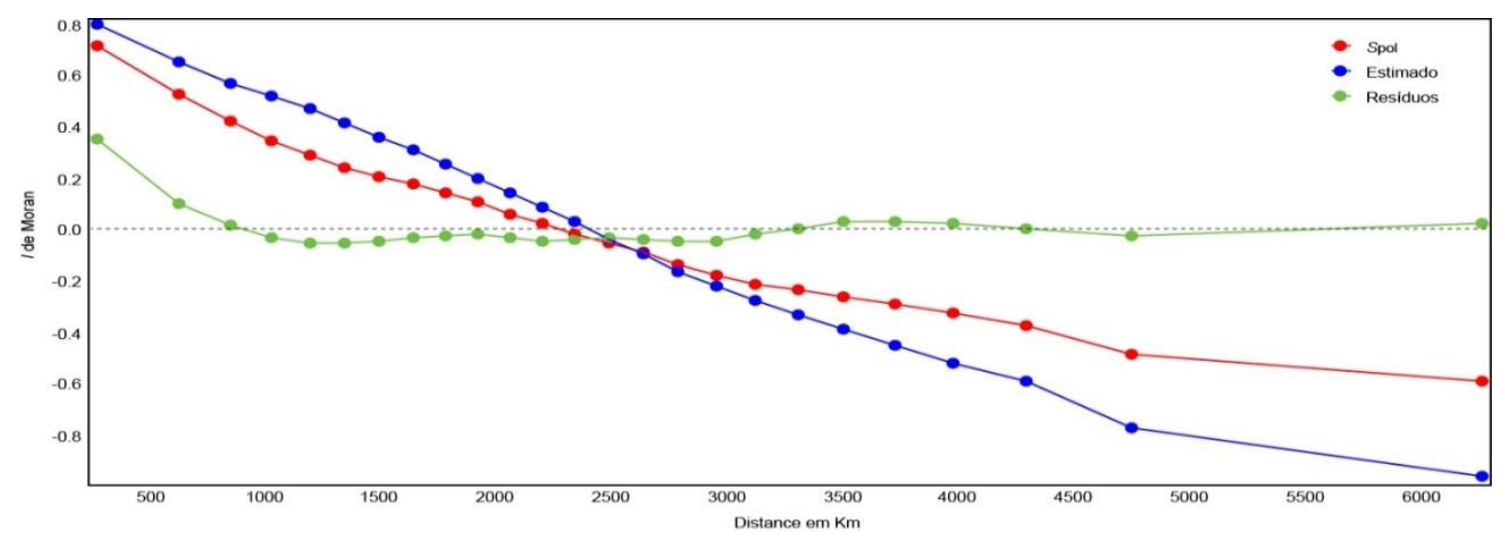

FIGURA 74. Correlograma do I de Moran para a $S_{\text {est }}$ e para os valores estimados e os resíduos da regressão da $S_{\text {est }}$ pelas variáveis ambientais.

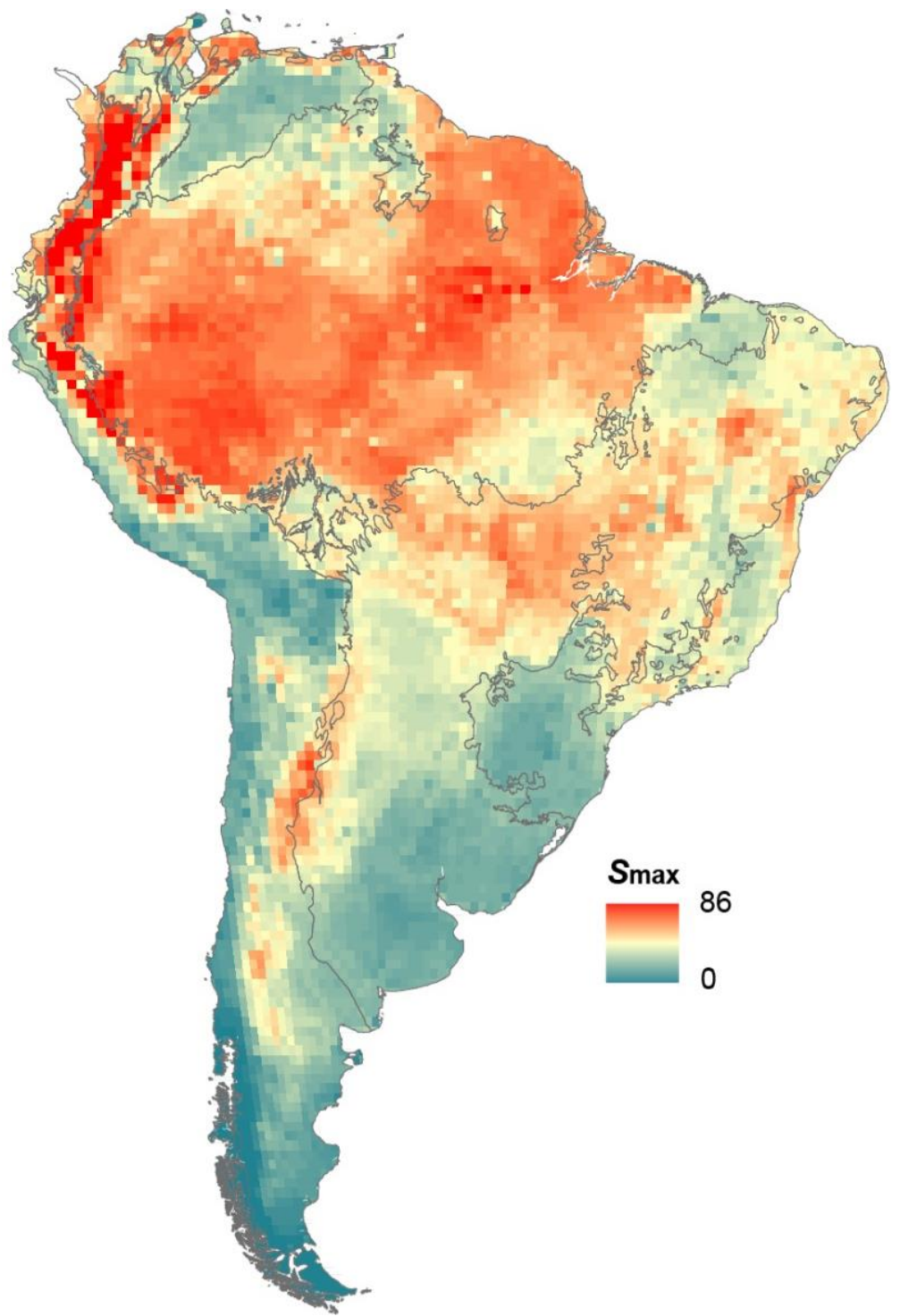

FIGURA 75. Riqueza estimada calculada pela soma dos modelos individuais produzidos pelo MaxEnt $\left(S_{\max }\right)$ para cada espécie. 


\subsubsection{Média das riquezas}

A média entre os valores de riqueza estimados pela modelagem da riqueza $\left(S_{\bmod }\right)$, pela regressão entre a $S_{\text {pol }}$ e as variáveis ambientais $\left(S_{\text {reg }}\right)$, e pela soma dos modelos individuais produzidos pelo MaxEnt $\left(S_{\max }\right)$, resultou em um mapa final de riqueza potencial $\left(S_{\text {pot }}\right)$. A média dos valores foi de 46 (0-78). Nas áreas Abertas a média foi de 42 (17-65), nas Florestas 58 (2675), e nos Andes 30 (0-78) (FIGURA 76).
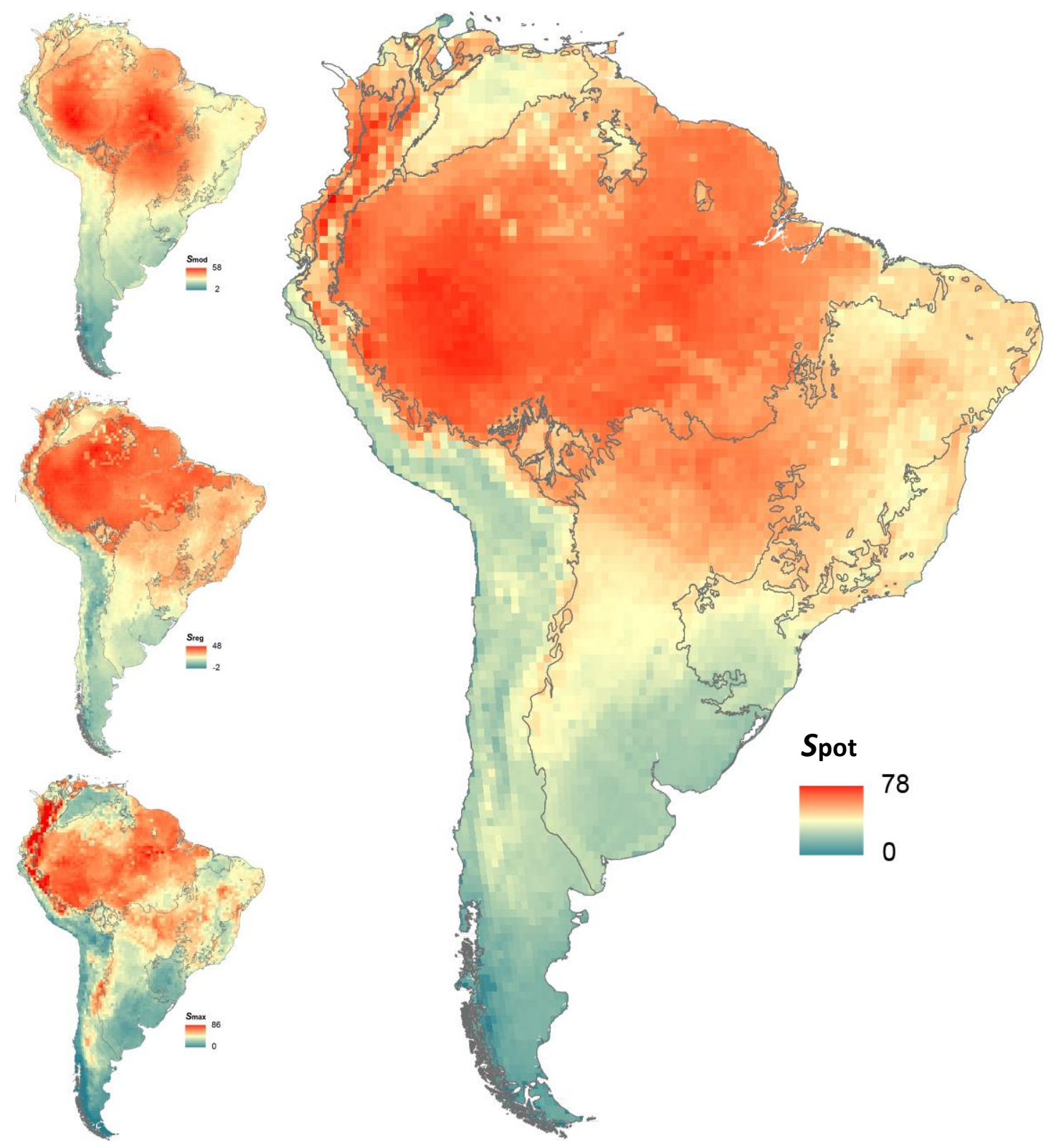

FIGURA 76. Riqueza estimada segundo modelagem de riqueza $\left(S_{\text {mod }}\right)$, baseada nas variáveis ambientais, estimada na regressão entre $S_{\text {pol }}$ e as variáveis ambientais $\left(S_{\text {reg }}\right)$, e calculada pela soma dos modelos individuais produzidos pelo MaxEnt $\left(S_{\max }\right)$, e a média entre elas, produzindo uma riqueza potencial ( $\left.S_{\text {pot }}\right)$. 
A subtração da riqueza potencial $\left(S_{\text {pot }}\right)$ pela riqueza observada $\left(S_{\text {obs }}\right)$ revela um número médio de espécies faltantes de 42 (0-75). Nas áreas Floresta a média foi de 53 (8-75), nas áreas Abertas 38 (10-64), e na região Andina 26 (0-68) (FIGURA 77).
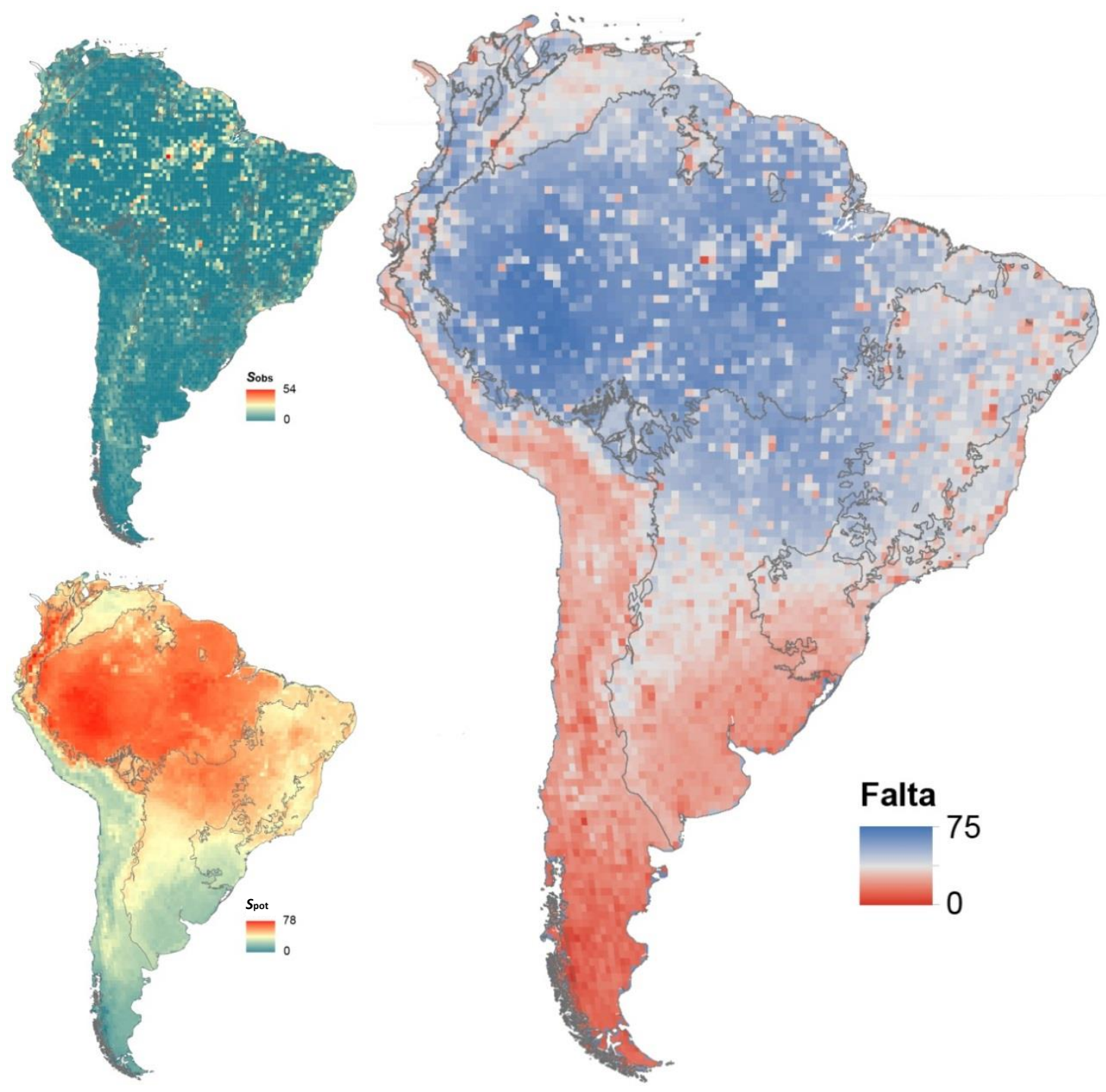

FIGURA 77. Riqueza observada $\left(S_{\text {obs }}\right)$, calculada pelo somatório das espécies registradas nos pontos amostrais, e riqueza potencial $\left(S_{\text {pot }}\right)$ calculada pela média das riquezas estimadas, e a diferença encontrada entre estes valores mostrando quantas espécies ainda faltam ser registradas (falta).

\subsubsection{Cobertura geográfica da amostragem}

A média da área os polígonos de Thiessen referentes às 26537 localidades foi de 3859 $\mathrm{km}^{2}\left(0-32841 \mathrm{~km}^{2}\right)$. Nas áreas Abertas foi de $3287 \mathrm{~km}^{2}\left(0-20333 \mathrm{~km}^{2}\right)$, nos Andes $2780 \mathrm{~km}^{2}(0-$ $\left.32841 \mathrm{~km}^{2}\right)$, e nas Florestas $4894 \mathrm{~km}^{2}\left(0-31474 \mathrm{~km}^{2}\right.$ ) (FIGURA 78).

\subsubsection{Esforço}

As espécies faltantes e a área dos polígonos por localidade foram padronizadas entre $0 \mathrm{e}$ 1 (FIGURA 79), com valores próximos de 1 indicando melhor eficiência amostral, ou melhor 


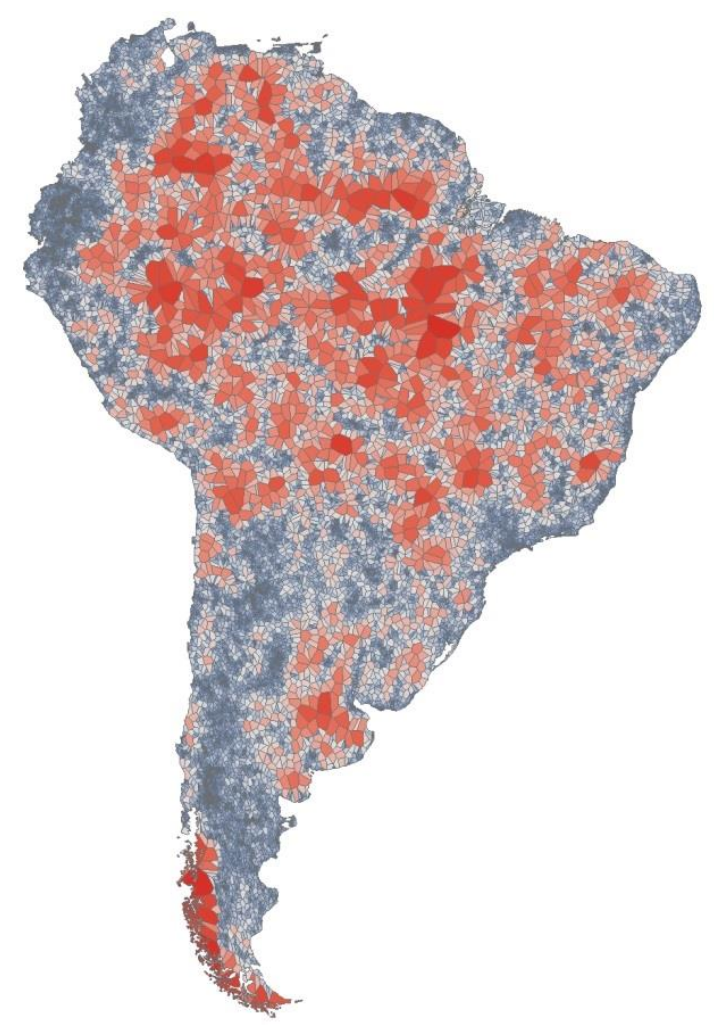

FIGURA 78. Polígonos de Thiessen, calculados com base nas localidades amostradas. Variação na cor entre azul e vermelho refere-se à variação na área de cada polígono de menor para maior respectivamente.
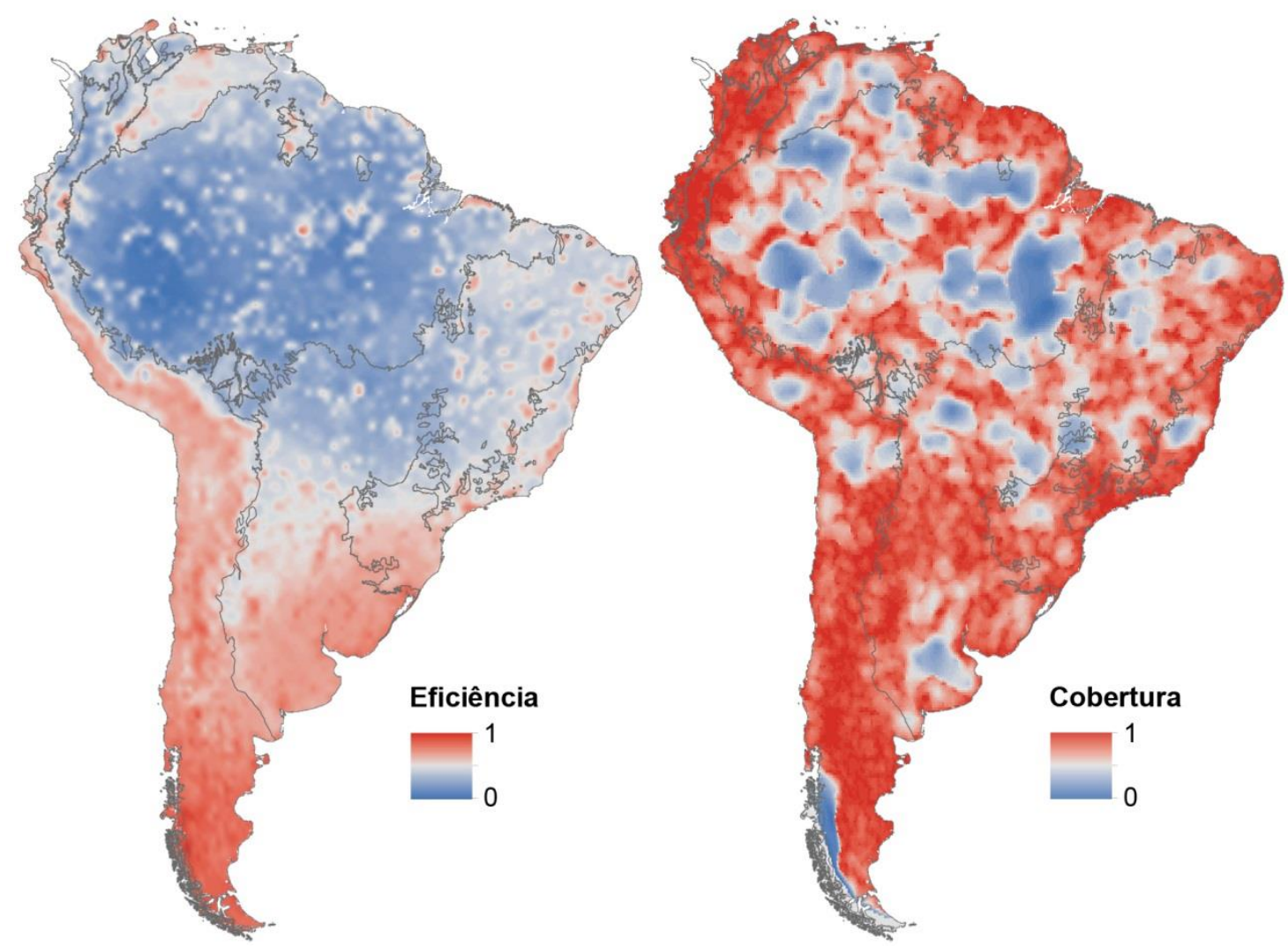

FIGURA 79. Eficiência amostral, calculada pela comparação entre a riqueza observada ( $S_{\text {obs }}$ ) e a potencial $\left(S_{\text {pot }}\right)$, e cobertura geográfica das amostragens, calculada pela área de polígonos de Thiessen ajustados às localidades amostradas. 
cobertura geográfica, respectivamente, e a média entre estes valores foi calculada e considerada a medida do esforço. O esforço médio na América do Sul foi de 0.66 (0.16-0.92) (FIGURA 80), com cerca de $14 \%$ da sua superfície com esforço menor que 0.5. Na região Andina o esforço médio foi de 0.75 (0.53-0.92), sendo que $0 \%$ de sua área apresenta um esforço menor que 0.5; nas Florestas a média foi de $0.56(0.16-0.89)$, sendo que $31 \%$ de sua área apresenta um esforço menor que 0.5, 34\% da Amazônia, 1\% da Mata Atlântica, e 0\% do Chocó apresentam esforço menor que 0.5; as áreas Abertas apresentaram um esforço médio de 0.69 (0.36-0.92), com 3\% de sua área apresentando um esforço menor que 0.5 , e cada bioma um de seus biomas não ultrapassando $8 \%$ de área com esforço menor que 0.5 (FIGURA 81 e 82). A correlação entre o nível de esforço e o Índice de Influência Humana corrigida para auto-correlação (FIGURA 83) ainda mostrou valores significativos ( $r=0.37 ; \mathrm{GL}_{\text {corrigido }}=29.057$; $\left.F_{\text {corrigido }}=4.615 ; P_{\text {corrigido }}=0.04\right)$ (FIGURA 84).
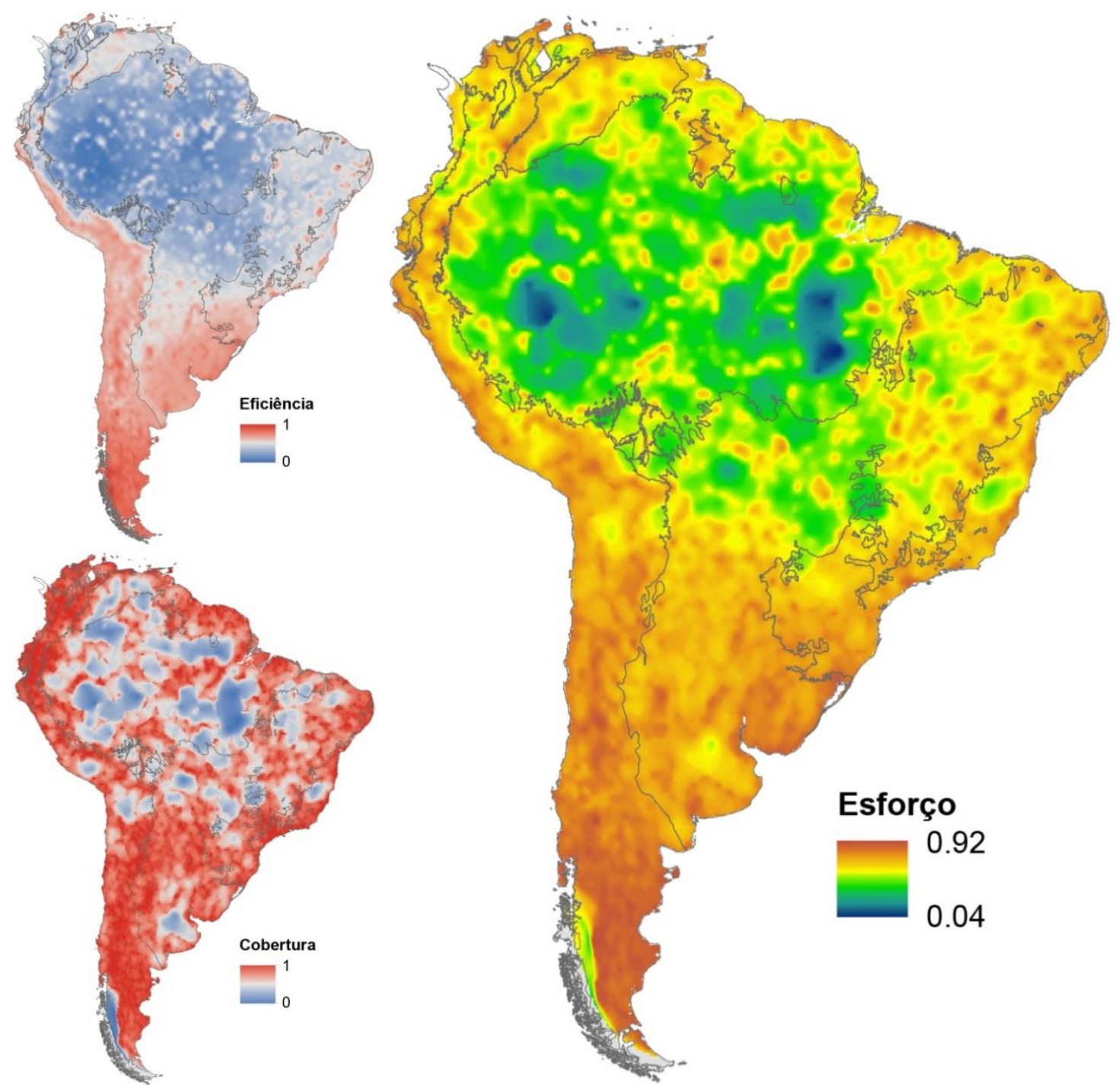

FIGURA 80. Eficiência amostral, calculada pela comparação entre a riqueza observada e a potencial, e cobertura geográfica das amostragens, calculada pela área ajustada de polígonos de Thiessen às localidades amostradas, e a média entre elas caracterizando o esforço. 

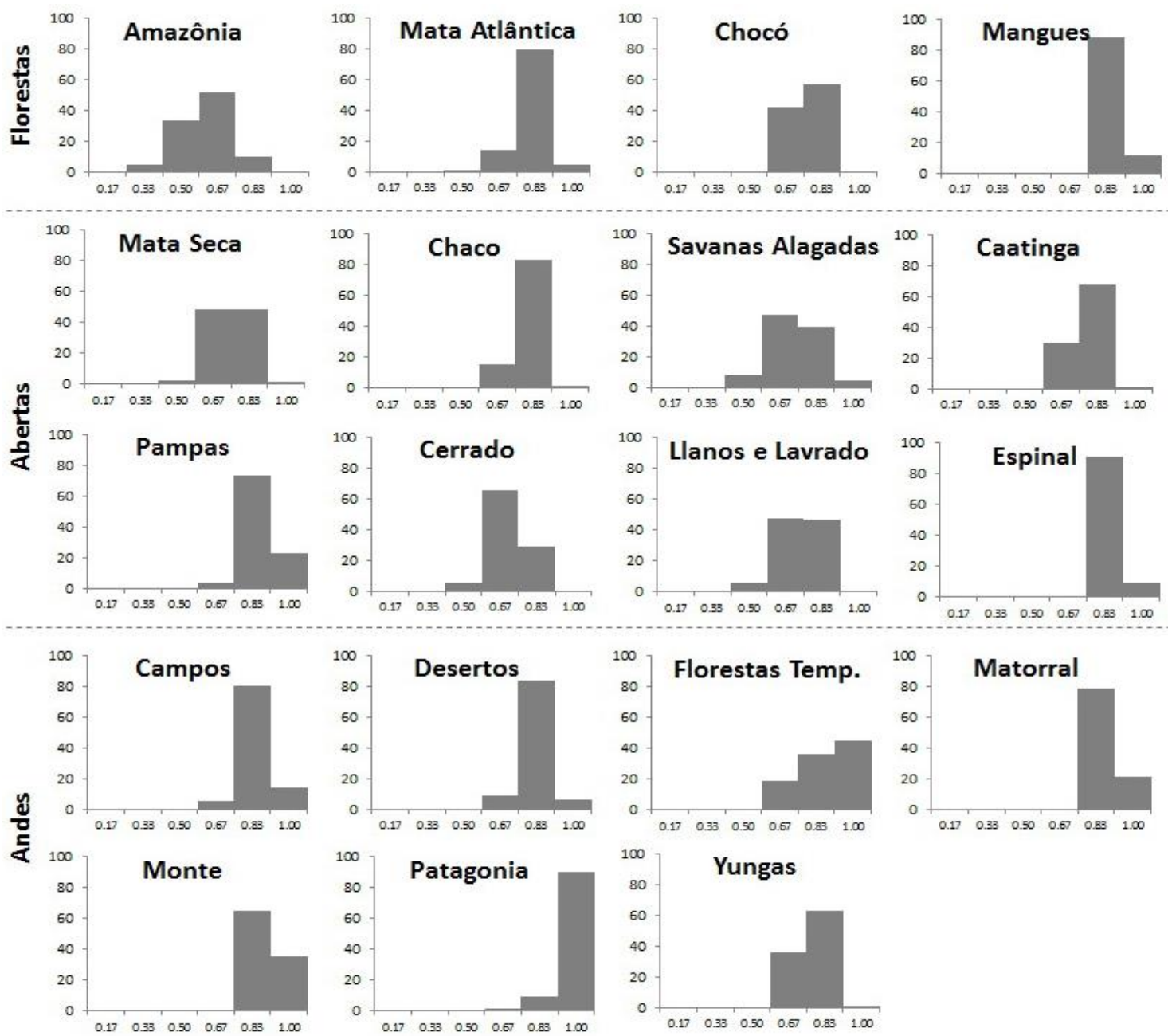

FIGURA 81. Histogramas de frequência de valores de esforço para cada bioma, separados pelas grandes áreas utilizadas aqui.

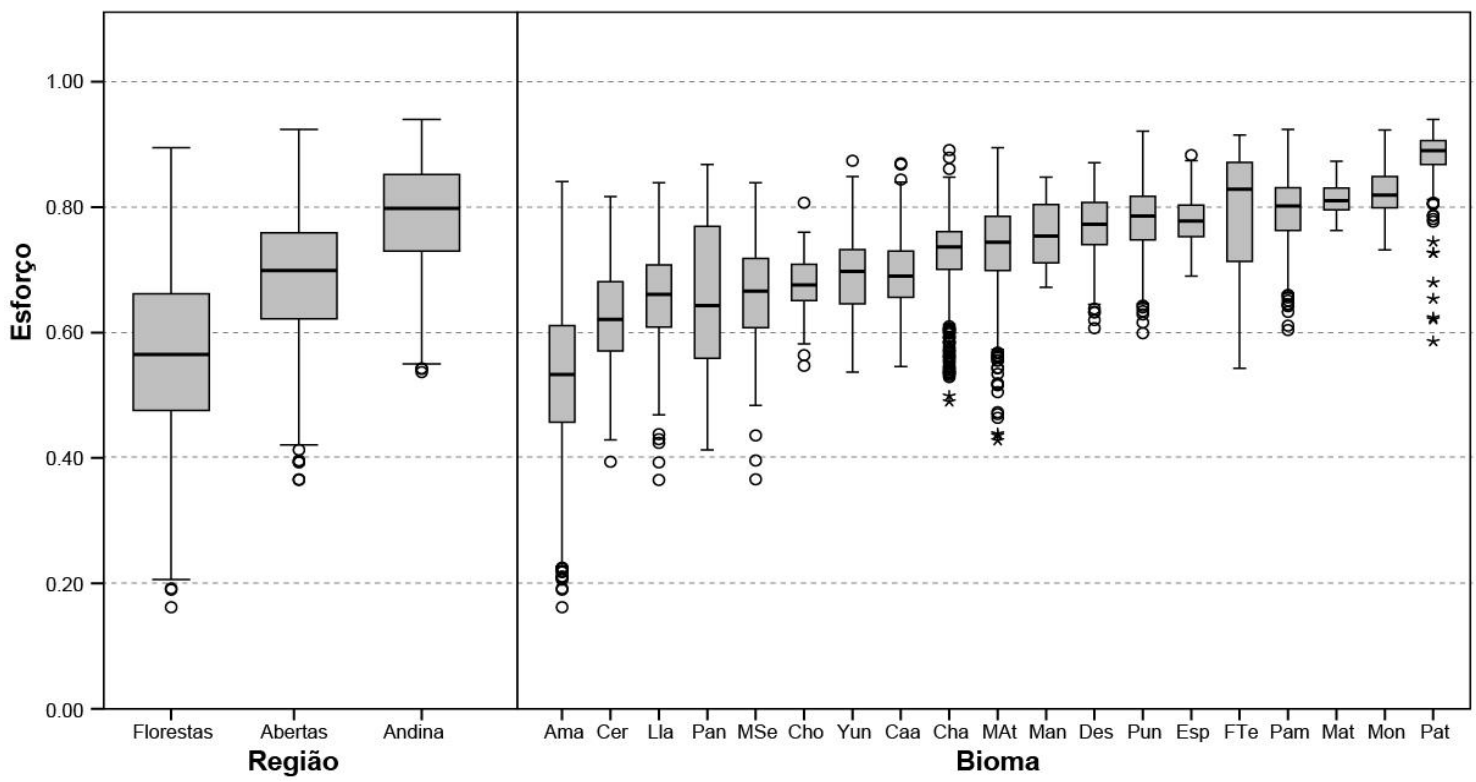

FIGURA 82. Boxplots mostrando a distribuição de valores de esforço para as regiões e para cada Bioma individualmente. Ama: Amazônia; Caa: Caatinga; Cer: Cerrado; Cha: Chaco; Cho: Chocó; Des: Desertos; Esp: Espinal; FTe: Florestas Temperadas; Lla: Llanos; Man: Mangues; MAt: Mata Atlântica; Mat: Matorral; Mon: Monte; MSe: Mata Seca; Pam: Pampas; Pan: Pantanal; Pat: Patagônia; Pun: Puna; Yun: Yungas. 


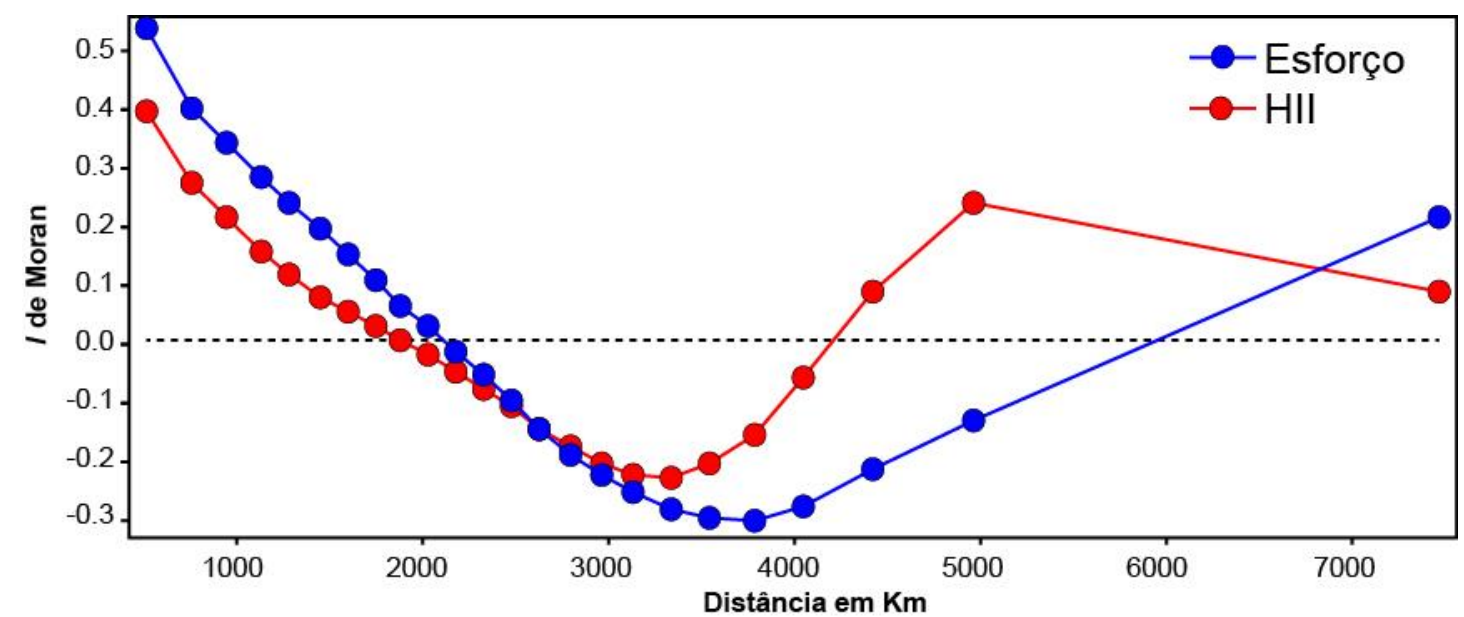

FIGURA 83. Correlograma mostrando o índice I de Moran, para os valores de esforço amostral de lagartos na América do Sul, e o Índice de Influência Humana (HII)

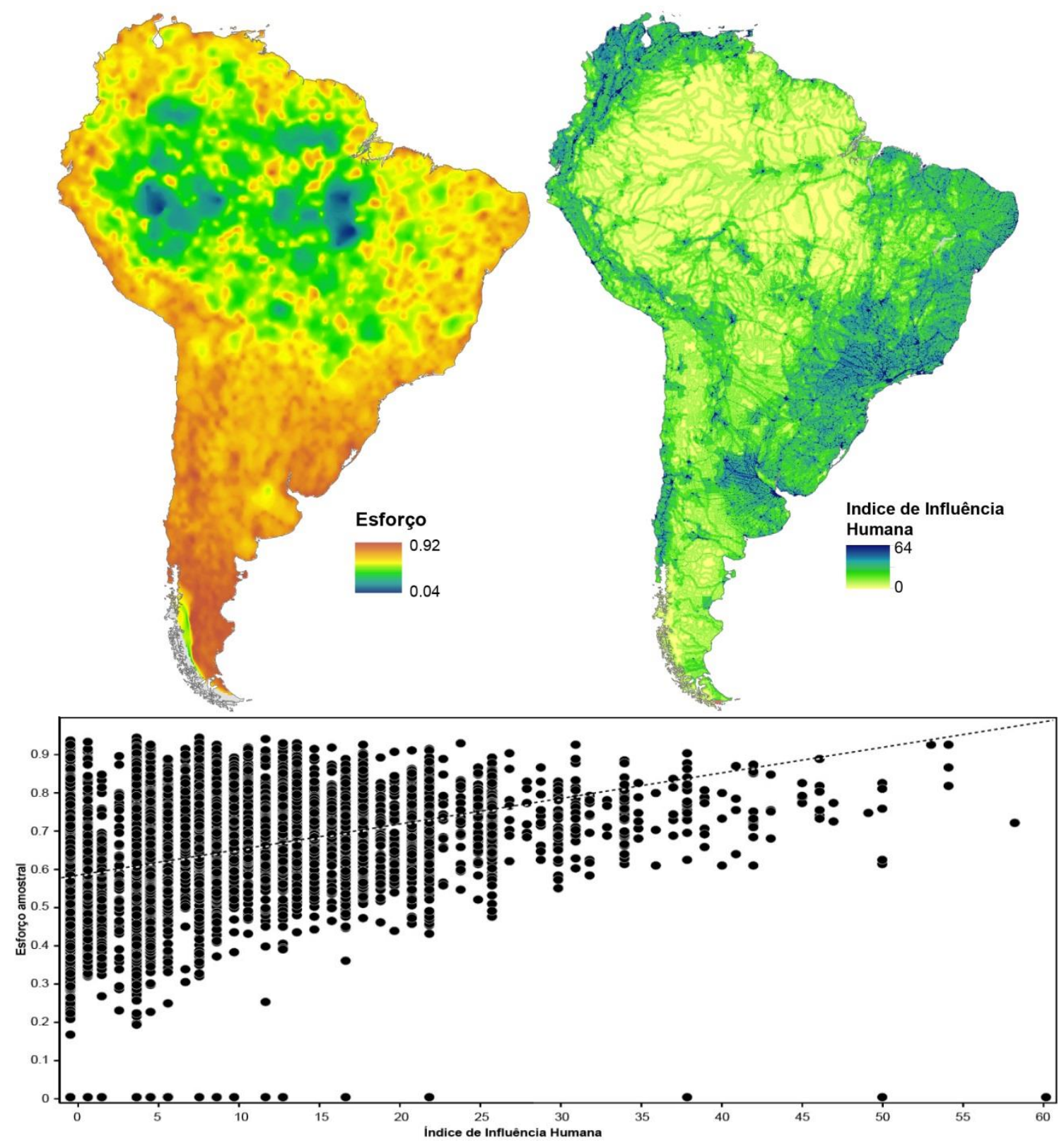

FIGURA 84. Esforço amostral e Índice de Influência Humana, e sua correlação ( $r=0.37 ; \mathrm{GL}_{\text {corrigido }}=$ 29.057; $\left.F_{\text {corrigido }}=4.615 ; P_{\text {corrigido }}=0.04\right)$. 


\subsection{DISCUSSÃO}

A eficiência amostral não se mostrou igualmente distribuída pela superfície da América do Sul, assim como a cobertura das amostragens apresentaram muitas lacunas (FIGURA 80). Uma tendência já observada para algumas áreas Abertas, onde a combinação de eficiência amostral e cobertura geográfica das amostragens, ainda são insuficientes (RODRIGUES 2003). A combinação destes valores por toda a superfície da América do Sul revelou um esforço ainda bastante inexpressivo em muitas áreas, sendo especialmente baixo em muitas regiões da Amazônia (FIGURA 80). Esta foi recuperada pelas estimativas de riqueza (estimado pela regressão da riqueza calculada por polígonos e as variáveis ambientais, a estimada pela modelagem individual de cada espécies, e a estimada pela modelagem da riqueza observada), como a mais rica em espécies (FIGURA 76). Esse baixo esforço amostral na região Amazônica também já foi observado para outros grupos (KRESS et al. 1998; SCHULMAN et al. 2007; SILMAN 2007), indicando que ainda que estas áreas venham sendo amostradas há séculos (SPIX \& MARTIUS 1824; BATES 1863b,a; WALLACE 1876a,b) os dados ainda estão bastante incompletos.

Isso pode ser explicado pelo fato de que para se realizar uma amostragem de espécies, diversos fatores devem ser levados em consideração, como a metodologia, o equipamento, a equipe e, talvez o mais relevante, o acesso ao local que se deseja amostrar. Em termos de metodologia e equipamentos, atualmente são utilizados em coletas passivas diversos tipos de armadilhas, como armadilhas de queda, de funil, de cola, e em coletas ativas a própria coleta manual, estilingues, borrachas ou armas de fogo (FITZGERALD 2012). Isto representa uma grande melhoria nos métodos, quando comparados aos naturalistas (WIED 1820,1821; SPIX \& MARTIUS 1824; WALLACE 1889), que dependiam principalmente de coletas manuais, e armas de fogo. Quanto ao transporte e acessos houve um enorme avanço, já que hoje os pesquisadores têm à sua disposição diversos meios de transporte como automóveis, barcos, aviões, helicópteros, assim como um sistema viário muito mais abrangente. Este fato resulta em uma capacidade exploratória muito mais poderosa quando comparada aos recursos disponíveis àqueles naturalistas, que dependiam geralmente de pequenos barcos e animais de tração, e em diversos casos, escravos (WIED 1820,1821; SPIX \& MARTIUS 1824; WALLACE 1889).

Esta maior facilidade de locomoção atual é em parte resultado, e em parte consequência, do próprio avanço da ocupação humana, o que torna áreas ocupadas mais acessíveis, já que para se utilizar meios de transportes como automóveis, aviões ou 
helicópteros, é necessária uma certa infraestrutura capaz de acomoda-los. Assim é de se esperar que um maior esforço amostral tenha sido realizado em áreas onde a ocupação humana, e consequentemente o acesso, são maiores, resultando em uma abrangência geográfica e eficiência amostral, e até mesmo no foco taxonômico das amostragens, sendo geralmente enviesados pela proximidade de grandes centros urbanos e centros de pesquisa (PALMER et al. 2002; BOAKES et al. 2010; BECK et al. 2012; JETZ et al. 2012; YANG et al. 2014; MEYER et al. 2015). Seguindo este padrão o mesmo foi observado no caso dos lagartos, onde a magnitude do esforço amostral está positivamente relacionada ao nível de ocupação humana (FIGURA 84).

Enquanto na maior parte do continente Sul Americano estradas permitem acesso relativamente fácil a diversas áreas, na região Amazônica, ainda que venha sendo explorada a cerca de 500 anos (MEIRELLES-FILHO 2009,2011), o acesso ainda se faz de maneira bastante semelhante à utilizada pelos primeiros exploradores (HEMMING 2009; MEIRELLES-FILHO 2009; SOUZA 2009), onde as principais vias de transporte ainda são os rios, e os meios de transportes são os barcos. O acesso terrestre às áreas ao logo da Amazônia geralmente se seguem à abertura de uma estrada inicial partindo de algum centro urbano, seguido pelo desmatamento da região, e tornando outras áreas acessíveis pra a instalação de mais estradas (FERREIRA et al. 2005). Contudo grande parte das matas próximas às margens dos rios, onde se localizam estes centros urbanos, são periodicamente inundadas (e.g. várzeas, em áreas de rios de água branca, e igapós, em áreas de rios de água preta), algumas vezes se estendendo por muitos quilômetros de distância da margem do rio, ocupando até cerca de $30 \%$ da bacia Amazônica (JUNK et al. 2011; COUTINHO 2016), enquanto outras áreas, mais frequentemente em interflúvios, são compostas de terra firme (áreas que não alagam). Estas áreas de terra firme são justamente os lugares onde estradas potencialmente poderiam ser instaladas de maneira mais eficiente. Porém atualmente as áreas mais acessíveis ainda são as próximas aos rios, concentrando as amostragens a alguns quilômetros de distância a partir das margens, principalmente nos rios Solimões, Amazonas, Tapajós, Madeira, Purus, Negro e Branco (FIGURA 85).

Diversos estudos contribuíram para o conhecimento na distribuição pontual de lagartos na Amazônia, desde muitos anos atrás (CUNHA 1958,1970; HOOGMOED 1973; CUNHA \& NASCIMENTO 1978; CUNHA 1981; NASCIMENTO et al. 1987,1988; CUNHA \& NASCIMENTO 1993; MEIRELLES-FILHO 2009,2011), até mais recentemente, quando dados referentes a grandes coleções herpetológicas foram incluídos (AVILA-PIRES 1995; RIBEIRO-JR 2015b,a; RIBEIRO-JR \& AMARAL 2016). Atualmente uma fonte improvável de dados biológicos vendo os 
grandes empreendimentos (e.g. usinas hidroelétricas), que apesar de causarem grandes impactos sociais e ambientais (JUNK \& MELLO 1990; FEARNSIDE 2015), de certa forma vêm também melhorando o esforço amostral nestas áreas, permitindo a descoberta de diversas espécies (SIMÕES et al. 2010; SIMOES et al. 2013; TEIXEIRA JR et al. 2013; LIMA et al. 2014; TEIXEIRA JR et al. 2014). Toda esta amostragem tem resultado em um grande esforço próximo à cidades e usinas hidroelétricas: como Manaus, Santa Isabel e UHE Balbina no estado do Amazonas; Porto Walter e Serra do Divisor no estado do Acre; Belém, Oriximiná, Itaituba, Altamira, Santarém e UHEs Tucuruí e Belo Monte no estado do Pará; Pimenta Bueno, Vilhena e Porto Velho com as UHEs Jirau, Santo Antônio e Samuel no estado de Rondônia; Macapá, Calçoene, Serra do Navio e Laranjal do Jari no Amapá; quase toda a região do lavrado, especialmente próximo à Ilha de Maracá, no estado de Roraima; regiões de diversos tepuis na Venezuela; Leticia na Colombia; Iquitos, Orellana e Puerto Maldonado no Perú; Cayenne na Guiana Francesa; Sipaliwini e Paramaribo no Suriname; e Georgetown e Bartica na Guiana. Além destes ainda existem diversos outros pontos onde o esforço mais baixo, mas ainda assim relativamente alto (FIGURA 85). Por outro lado, a dificuldade em se acessar áreas longe das margens dos rios resultou em grandes áreas com esforço bastante baixo: como as regiões de interflúvio Juruá-Amazonas, Purus-Juruá, Tapajós-Madeira, Tapajós-Xingú, Amazonas-Caquetá, Vichada-Uaupés, região do médio e alto rio Uatumã, Nhamumdá, Trombetas e Paru do Leste, e diversas outras áreas onde o esforço foi maior que estas, mas ainda relativamente baixo (FIGURA 85).

Diferentemente da Floresta Amazônica, as áreas Abertas apresentam uma malha viária bastante desenvolvida, permitindo acesso relativamente fácil a quase toda a sua extensão. Porém por muitos anos essa região foi considerada como pobre em biodiversidade, com baixos níveis de endemismos e uma fauna homogeneamente distribuía por sua extensão (VANZOLINI 1963,1976; VITT 1991; VANZOLINI 2003). Ao longo desta região algumas áreas já são ocupadas há muito tempo, apresentarem um crescimento populacional bastante baixo, como a Caatinga (SAMPAIO \& BATISTA 2004), outras, no entanto, como o Cerrado, foram ocupadas em larga escala apenas recentemente, de maneira que até a década de 1950 sua área de cerca de 2 milhões de $\mathrm{km}^{2}$ era ocupada por uma população estimada de 1.7 milhões de habitantes, atingindo 3 milhões em 1960, e 18 milhões em 2000 (KLINK \& MOREIRA 2002). Este avanço na ocupação recente ajudou a despertar apenas recentemente um maior interesse pela sua biodiversidade (ANDRADE-LIMA 1981; SAMPAIO 1995; RODRIGUES 2003; CARMIGNOTTO 2004; NOGUEIRA 2006; SILVA \& OREN 2010). Resultando em diversos pontos com alto esforço amostral: como a região do Jalapão, Estreito e Palmas no estado do Tocantins; Chapada 
Diamantina e Dunas do rio São Francisco no estado da Bahia; Serra da Capivara e Confusões no estado do Piauí; Cariri no estado da Paraíba; Serra da Mesa e Parque Nacional de Emas no estado de Goiás; Brasília no Distrito Federal; Chapada dos Parecis e dos Guimarães no estado do Mato Grosso; assim como amplas áreas ao longo de toda a porção sul das áreas abertas ao longo do Chaco, Pampas e Espinal (FIGURA 85). Contudo algumas áreas continuam com esforço amostral bastante baixo, com a região do Chaco Boliviano, a porção mais norte do Mato Grosso do Sul, sudeste do Mato Grosso, e oeste de Goiás. É sendo difícil avaliar os motivos da falta de amostragens nestas regiões ainda que bastante acessíveis. Este baixo esforço amostral poderia ser resultado do interesse biológico apenas recente, combinado com o fato de que a maior parte destas áreas atualmente não apresentarem mais paisagens naturais, sendo em sua maioria substituídas por plantações de soja, e pastagens a para gado

(KLINK \& MOREIRA 2002; MACHADO et al. 2004).

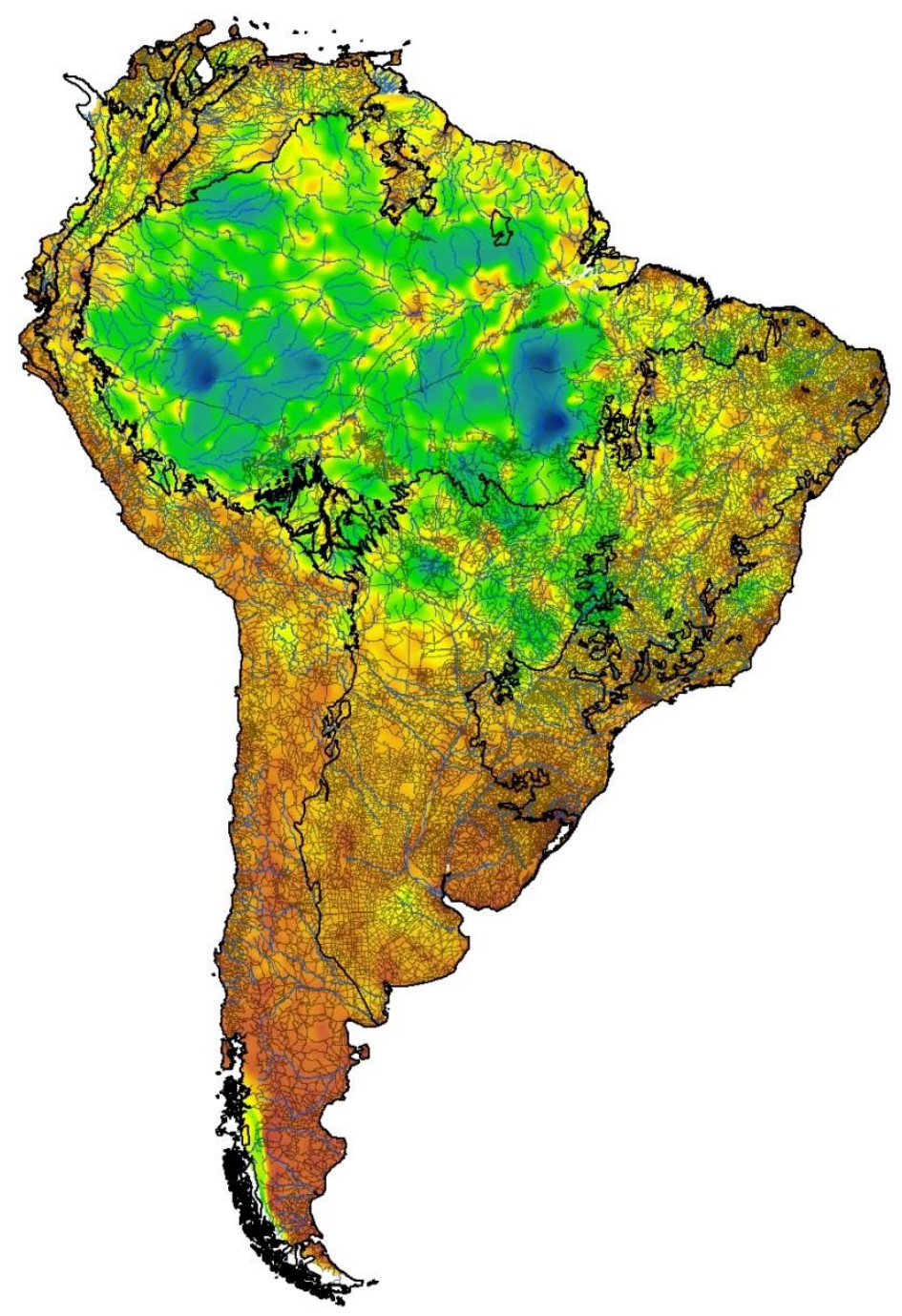

FIGURA 85. Mapa da América do sul mostrando a malha viária (linhas cinza) e os rios (linhas azuis), sobrepostos aos valores de esforço separado pelas grandes áreas Florestais, Abertas e Andinas. 
A região Andina, e assim como as áreas Abertas, apresenta uma extensa malha viária especialmente em sua porção sul que permite um aceso relativamente fácil a grande parte de suas áreas (FIGURA 85), apresentando um esforço amostral relativamente alto (FIGURA 84). Contudo isto não significa que o esforço já foi suficiente para se amostrar totalmente a fauna de lagartos desta região. $\mathrm{O}$ grande número de descrições de espécies nestas áreas nos últimos anos por si só já demonstra que as descobertas devem continuar, porém eles indicam que relativamente a regiões como a Amazônia, o esforço despendido nessas áreas é certamente maior (HEREDIA et al. 2013; ABDALA et al. 2014; ESQUERRE et al. 2014; MINOLI et al. 2014; QUINTEROS et al. 2014; ABDALA et al. 2015; DEMANGEL et al. 2015; ESCOBAR-HUERTA et al. 2015; TRONCOSO-PALACIOS et al. 2015; ABDALA et al. 2016; TRONCOSO-PALACIOS et al. 2016).

Assim a resposta sobre quão bom é o esforço de amostragem ao longo da América do Sul, depende da área em foco. Em algumas regiões o esforço parece ser razoavelmente bom, enquanto em outras áreas ainda está muito longe do mínimo necessário. Sendo esta distribuição de valores possivelmente resultado de um viés que está presente na maioria dos dados geográficos, como para outros grupos taxonômicos (KRESS et al. 1998; SCHULMAN et al. 2007), ainda que muito esforço já tenha sido feito para se tentar medir ou reduzir o efeito desse viés (PRENDERGAST et al. 1993; SCHULMAN et al. 2007; SYFERT et al. 2013; STOLAR \& NIELSEN 2015). Porém quando lacunas de informação na distribuição de dados biológicos são observadas, deve-se tentar identificar as causas dessa completude diferencial nos levantamentos e, para diversos grupos, esse viés parece ser frequentemente causado pela proximidade com grandes centros urbanos (MEYER et al. 2015), o que parece ser o mesmo caso para os lagartos. De maneira que tendo os dados de amostragem em mãos, é relativamente fácil de averiguar quais áreas são as que apresentam o menor esforço, e inferir quais as causas desses baixos valores, porém tendo em vista que o acesso às áreas parece ser o fator mais relevante, é difícil se propor atitudes que possam alterar esse quadro. Em área como as do Cerrado onde o esforço foi baixo é possível se tentar incentivar mais amostragens, ainda que em fragmentos de vegetação nativa, que de alguma forma produzam um mínimo de informações necessárias para se melhorar o conhecimento biológico destas áreas. Porém em áreas como as da Amazônia, onde o esforço foi mais baixo, o acesso ainda é um grande impedimento, e assim infelizmente enquanto a ocupação humana em larga escala não atingir tais áreas, e consequentemente ameaçar sua preservação com amplos desmatamentos, possivelmente dificilmente seu conteúdo biótico vai ser revelado. 


\section{REFERÊNCIAS}

ABDALA, C.S., BALDO, D., JUÁREZ, R.A. \& ESPINOZA, R.E. (2016) The First Parthenogenetic Pleurodont Iguanian: A New All-female Liolaemus (Squamata: Liolaemidae) from Western Argentina. Copeia, 104, 487-497.

ABdAlA, C.S., PROCOPIO, D.E., Stellatelli, O.A., TRAVAinI, A., RODRIgUeZ, A. \& MONACHESI, M.R.R. (2014) New Patagonian species of Liolaemus (Iguania: Liolaemidae) and novelty in the lepidosis of the southernmost lizard of the world: Liolaemus magellanicus. Zootaxa, 3866, 526-542.

ABDALA, C.S., QUINTEROS, A.S. \& SEMHAN, R.V. (2015) A New Species of Liolaemus of the Liolaemus alticolor-bibronii Group (Iguania: Liolaemidae) from Mendoza, Argentina. South American Journal of Herpetology, 10, 104-115.

AKAIKE, H. (1974) New Look at Statistical-Model Identification. leee Transactions on Automatic Control, 19, 716-723.

ANDRADE-LIMA, D. (1981) The Caatingas Dominium. Revista Brasileira de Botânica, 149-153.

ARISTOTÉLĒS. (1952) Meteorologica - with a an english transaltion by H.D.P. Lee, M.A. William Henemann Ltd, London, $433 \mathrm{pp}$.

AVILA-PIRES, T.C.S. (1995) Lizards of Brazilian Amazonia (Reptilia: Squamata). Zoologische Mededelingen, 299, 1-706.

AVILA-PIRES, T.C.S. (1995) Lizards of Brazilian Amazonia (Reptilia: Squamata). Zoologische Mededelingen, 299, 1-706.

AZARA, F. (1809) Voyages dans l'Amérique Méridionale. Vol. 1. Dentu, Paris, 389 pp.

BADGLEY, C. \& FOX, D.L. (2000) Ecological biogeography of North American mammals: species density and ecological structure in relation to environmental gradients. Journal of Biogeography, 27, 1437-1467.

BALLESTEROS-MEJIA, L., KITCHING, I.J., JETZ, W., NAGEL, P. \& BECK, J. (2013) Mapping the biodiversity of tropical insects: species richness and inventory completeness of African sphingid moths. Global Ecology and Biogeography, 22, 586-595.

BARATA, I.M., SANTOS, M.T.T., LEITE, F.S.F. \& GARCIA, P.C.A. (2013) A new species of Crossodactylodes (Anura: Leptodactylidae) from Minas Gerais, Brazil: first record of genus within the Espinhaço Mountain Range. Zootaxa, 3731, 552-560.

BATES, H.W. (1863a) The naturalist on the River Amazons, A record of adventures, habits of animals, sketches of Brazilian and Indian life and aspects of nature under the Equator during eleven years of travel. Vol. 1. John Murray, London,pp.

BATES, H.W. (1863b) The naturalist on the River Amazons, A record of adventures, habits of animals, sketches of Brazilian and Indian life and aspects of nature under the Equator during eleven years of travel. Vol. 2. John Murray, London, $423 \mathrm{pp}$.

BECK, J., BALLESTEROS-MEJIA, L., BUCHMANN, C.M., DENGLER, J., FRITZ, S.A., GRUBER, B., HOF, C., JANSEN, F., KNAPP, S., KREFT, H., SCHNEIDER, A.-K., WINTER, M. \& DORMANN, C.F. (2012) What's on the horizon for macroecology? Ecography, 35, 673683.

BOAKES, E.H., MCGOWAN, P.J.K., FULLER, R.A., DING, C.-Q., CLARK, N.E., O'CONNOR, K. \& MACE, G.M. (2010) Distorted Views of Biodiversity: Spatial and Temporal Bias in Species Occurrence Data. PLoS Biology, 8, 
BOOTH, G.D., NICCOLUCCI, M.J. \& SCHUSTER, E.G. (1994) Identifying Proxy Sets in Multiple Linear-Regression - an Aid to Better Coefficient Interpretation. Usda Forest Service Intermountain Research Station Research Paper, 1-13.

BORNSCHEIN, M.R., FIRKOWSKI, C.R., BALDO, D., RIBEIRO, L.F., BELMONTE-LOPES, R., CORREA, L., MORATO, S.A.A. \& PIE, M.R. (2015) Three New Species of PhytotelmBreeding Melanophryniscus from the Atlantic Rainforest of Southern Brazil (Anura: Bufonidae). PLOS ONE, 10,

BOWERMAN, B.L. \& O'CONNELL, R. (2000) Linear Statistical Models: An Applied Approach. Duxbury Press, $1024 \mathrm{pp}$.

BREGOVIĆ, P. \& ZAGMAJSTER, M. (2016) Understanding hotspots within a global hotspot identifying the drivers of regional species richness patterns in terrestrial subterranean habitats. Insect Conservation and Diversity, 9, 268-281.

BRUSCHI, D.P., LUCAS, E.M., GARCIA, P.C.A. \& RECCO-PIMENTEL, S.M. (2014) Molecular and Morphological Evidence Reveals a New Species in the Phyllomedusa hypochondrialis Group (Hylidae, Phyllomedusinae) from the Atlantic Forest of the Highlands of Southern Brazil. PLOS ONE, 9,

BUFFON, G.L.L.C.D. (1761) Historie Naturelle générale et particulière avec la description du Cabinet du Roy. Vol. 9. L'Imprimeire Royale, Paris,pp.

BURNHAM, K.P. \& ANDERSON, D.R. (2002) Model selection and múltimodel inference: A practical information-theoretic approach. Spring-Verlag, New York,pp.

BURNHAM, K.P. \& OVERTON, W.S. (1978) Estimation of the Size of a Closed Population when Capture Probabilities vary Among Animals. Biometrika, 65, 625-633.

CARAMASCHI, U., ORRICO, V.G.D., FAIVOVICH, J., DIAS, I.R. \& SOLE, M. (2013) A new species of Allophryne (Anura: Allophrynidae) from the Atlantic Rain Forest biome of eastern Brazil. Herpetologica, 69, 480-491.

CARMIGNOTTO, A.P. (2004) Pequenos mamíferos terrestres do bioma Cerrado: padräes faunísticos locais e regionais. Doutorado. Instituto de Biociências da Universidade de São Paulo, Departamento de Zoologia1-404 pp.

CHAO, A. \& LEE, S.M. (1992) Estimating the Number of Classes Via Sample Coverage. Journal of the American Statistical Association, 87, 210-217.

CHAO, A. (1984) Nonparametric-estimation of the number of classes in a population. Scandinavian Journal of Statistics, 11, 265-270.

CHAO, A. (1987) Estimating the Population-Size for Capture Recapture Data with Unequal Catchability. Biometrics, 43, 783-791.

CHAO, A., MA, M.C. \& YANG, M.C.K. (1993) Stopping Rules and Estimation for Recapture Debugging with Unequal Failure Rates. Biometrika, 80, 193-201.

CLEMENTE-CARVALHO, R.B.G., GIARETTA, A.A., CONDEZ, T.H., HADDAD, C.F.B. \& DOS REIS, S.F. (2012) A New Species of Miniaturized Toadlet, Genus Brachycephalus (Anura: Brachycephalidae), from the Atlantic Forest of Southeastern Brazil. Herpetologica, 68, 365-374.

COLLI, G.R., BASTOS, R.P. \& ARAUJO, A.F. (2002) The character and dynamics of the cerrado herpetofauna. In: OLIVEIRA, P.S. \& MARQUIS, R.J. (Eds.) The cerrados of Brazil: ecology and natural history of a neotropical savanna. Columbia University Press, New York, pp. 223-241. 
COLWELL, R.K. (2013) EstimateS: Statistical estimation of species richness and shared species from samples, Department of Ecology \& Evolutionary Biology, University of Connecticut, Storrs, USA

CONDEZ, T.H., CLEMENTE-CARVALHO, R.B.G., HADDAD, C.F.B. \& DOS REIS, S.F. (2014a) A New Species of Brachycephalus (Anura: Brachycephalidae) from the Highlands of the Atlantic Forest, Southeastern Brazil. Herpetologica, 70, 89-99.

CONDEZ, T.H., CLEMENTE-CARVALHO, R.B.G., HADDAD, C.F.B. \& REIS, S.F. (2014b) A New Species of Brachycephalus (Anura: Brachycephalidae) from the Highlands of the Atlantic Forest, Southeastern Brazil. Herpetologica, 70, 89-99.

CONDEZ, T.H., MONTEIRO, J.P.D., COMITTI, E.J., GARCIA, P.C.D., AMARAL, I.B. \& HADDAD, C.F.B. (2016) A new species of flea-toad (Anura: Brachycephalidae) from southern Atlantic Forest, Brazil. Zootaxa, 4083, 40-56.

COUTINHO, L.M. (2016) Biomas brasileiros. Ofinina de Textos, São Paulo, 128 pp.

CUNHA, O.R. \& NASCIMENTO, F.P. (1978) Ofidios da Amazônia 10 - as cobras da regiao leste do Para. Museu Paraense Emilio Goeldi Publicacoes Avulsas, 31, 1-218.

CUNHA, O.R. \& NASCIMENTO, F.P. (1993) Ofídios da Amazonia. As cobras da Região Leste do Para. Boletim do Museu Paraense Emilio Goeldi - Nova Serie - Zoologia, 9, 1-191.

CUNHA, O.R. (1958) I. Lacertilios da Amazônia. Sobre a ocorrência do gênero Bachia Gray, 1845, na Amazônia Brasileira (Lacertilia, Teiide). Boletim do Museu paraense Emílio Goeldi, nova série Zoologia, 10-12.

CUNHA, O.R. (1970) Lacertílios da Amazônia. IV - Um novo Gênero e Espécie de Lagarto do Território Federal do Amapá (Lacertilia - Teiidae). Boletim do Museu Paraense Emílio Goeldi, série Zoologia, 1970, 1-8.

CUNHA, O.R. (1981) Lacertílios da Amazonia. VIII - Sobre Ophryoessoides tricristatus Duméril, 1851, com redescrição da espécie e notas sobre ecologia e distribuição da região leste do Pará (Lacertilia, Iguanidae). Boletim do Museu Paraense Emilio Goeldi Serie Zoologia, 108, 1-23.

CVETKOVIC, D., TOMASEVIC, N., FICETOLA, G.F., CRNOBRNJA-ISAILOVIC, J. \& MIAUD, C. (2009) Bergmann's rule in amphibians: combining demographic and ecological parameters to explain body size variation among populations in the common toad Bufo bufo. Journal of Zoological Systematics and Evolutionary Research, 47, 171-180.

Demangel, D., SEPÚlVedA, C., JARA, M., PINCHEIRA-DONOSO, D. \& NúÑEZ, H. (2015) Liolaemus omorfi, a new lizard sapecies from the Andes of Northern Chile (Sauria, Liolaemidae). Boletín del Museo Nacional de História Natural, 64, 139-155.

DIAS, P.H.D.S., AMARO, R.C., CARVALHO-E-SILVA, A.M.P.T.D. \& RODRIGUES, M.T. (2013) Two new species of Proceratophrys Miranda-Ribeiro, 1920 (Anura; Odontophrynidae) from the Atlantic forest, with taxonomic remarks on the genus. Zootaxa, 3682, 277-304.

DINIZ-FILHO, J.A.F., BINI, L.M. \& HAWKINS, B.A. (2003) Spatial autocorrelation and red herrings in geographical ecology. Global Ecology and Biogeography, 12, 53-64.

DINIZ-FILHO, J.A.F., NABOUT, J.C., TELLES, M.P.D., SOARES, T.N. \& RANGEL, T.F.L.V.B. (2009) A review of techniques for spatial modeling in geographical, conservation and landscape genetics. Genetics and Molecular Biology, 32, 203-211.

DINIZ-FILHO, J.A.F., RANGEL, T.F.L.V.B. \& BINI, L.M. (2008) Model selection and information theory in geographical ecology. Global Ecology and Biogeography, 17, 479-488. 
DIRZO, R. \& RAVEN, P.H. (2003) Global state of biodiversity and loss. Annual Review of Environment and Resources, 28, 137-167.

DUTILLEUL, P. (1993) Modifying the t Test for Assessing the Correlation Between Two Spatial Processes. Biometrics, 49, 305-314.

ESCOBAR-HUERTA, G., SANTIBÁÑEZ-TORO, J. \& ORTIZ, J.C. (2015) Liolaemus lonquimayensis (Squamata: Liolaemidae), a new lizard species for Chile without precloacal pores. Gayana (Concepción), 79, 94-101.

ESQUERRE, D., TRONCOSO-PALACIOS, J., GARIN, C.F. \& NUNEZ, H. (2014) The missing leopard lizard: Liolaemus ubaghsi sp nov., a new species of the leopardinus clade (Reptilia: Squamata: Liolaemidae) from the Andes of the O'Higgins Region in Chile. Zootaxa, 3815, 507-525.

ESRI (2011) ArcGIS Desktop: Release 10. Environmental Systems Research Institute, Redlands, CA

ESRI (2013) Geostatistical Analyst. ArcGIS Desktop Help 10. Environmental Systems Research Institute. Available from: http://help.arcgis.com/en/arcgisdesktop/10.0/help/index.html

FEARNSIDE, P.M. (2015) Hidrelétricas na Amazônia: impactos ambientais e sociais na tomada de decisões sobre grandes obras. Editora do INPA, Manaus, 296 pp.

FERREIRA, L.V., VENTICINQUE, E. \& ALMEIDA, S. (2005) O desmatamento na Amazônia e a importância das áreas protegidas. Estudos Avançados, 19, 157-166.

FERREIRA, R.B., FAIVOVICH, J., BEARD, K.H. \& POMBAL, J.P., JR. (2015) The First Bromeligenous Species of Dendropsophus (Anura: Hylidae) from Brazil's Atlantic Forest. PLOS ONE, 10, e0142893.

FITZGERALD, L.A. (2012) Finding and Capturing Reptiles. In: MCDIARMID, R., FOSTER, M.S., GUYER, C., GIBBONS, J.W. \& CHERNOFF, N. (Eds.) Reptile Biodiversity - Standard methods for inventory and monitoring. University of California Press, Berkeley, Los Angeles, London, pp. 77-88.

FORSTER, J.R. (1778) Observations made during a voyage round the world on physical geography, natural history, and ethic philosophy. G. Robinson, London,pp.

FORTIN, M.J. \& DALE, M.R.T. (2005) Spatial Analysis: A Guide for Ecologists. Cambridge University Press, Cambridge, New York, Melbourne, Madrid, Cape Town, Singapore, São Paulo, 365 pp.

GAREY, M.V., LIMA, A.M.X., HARTMANN, M.T. \& HADDAD, C.F.B. (2012) A New Species of Miniaturized Toadlet, Genus Brachycephalus (Anura: Brachycephalidae), from Southern Brazil. Herpetologica, 68, 266-271.

GONZÁLEZ-MAYA, J.F., VÍQUEZ-R, L.R., ARIAS-ALZATE, A., BELANT, J.L. \& CEBALLOS, G. (2016) Spatial patterns of species richness and functional diversity in Costa Rican terrestrial mammals: implications for conservation. Diversity and Distributions, 22, 43-56.

GOODMAN, E.J. (1992) The Explorers of South America. University of Oklahoma press, Oklahoma, $416 \mathrm{pp}$.

GOOGLE (2017) Google Earth v.7.1.8.3036

GOOVAERTS, P. (1998) Ordinary CoKriging revisited. Mathematical Geology, 30, 21-42.

HAWKINS, B.A. (2012) Eight (and a half) deadly sins of spatial analysis. Journal of Biogeography, 39, 1-9. 
HELTSHE, J.F. \& FORRESTER, N.E. (1983) Estimating Species Richness Using the Jackknife Procedure. Biometrics, 39, 1-11.

HEMMING, J. (2009) Tree of Rivers - The Story of the Amazon. Thames \& Hudson, New York, $368 \mathrm{pp}$.

HEPP, F., DE CARVALHO-E-SILVA, S.P., DE CARVALHO-E-SILVA, A.M.P.T. \& FOLLY, M. (2015) A fifth species of the genus Euparkerella (Griffths, 1959), the advertisement calls of $E$. robusta Izecksohn, 1988 and E. tridactyla Izecksohn, 1988, and a key for the Euparkerella species (Anura: Brachycephaloidea: Craugastoridae). Zootaxa, 3973, 251270.

HEREDIA, V.J., ROBLES, C. \& HALLOY, M. (2013) A new species of Liolaemus from the darwinii group (Iguania: Liolaemidae), Tucuman province, Argentina. Zootaxa, 3681, 524-538.

hIJMANS, R.J., CAMERON, S.E., PARRA, J.L., JONES, P.G. \& JARVIS, A. (2005) Very high resolution interpolated climate surfaces for global land areas. International Journal of Climatology, 25, 1965-1978.

HIJMANS, R.J., GUARINO, F. \& MATHUR, P. (2012) DIVA-GIS Version 7.5 Manual. Available from: http://www.diva-gis.org/

HIJMANS, R.J., GUARINO, L., CRUZ, M. \& ROJAS, E. (2001) Computer tools for spatial analysis of plant genetic resources data: 1 DIVA-GIS. Plant Genetic Resources Newsletter, 2001, 15-19.

HOOGMOED, M.S. (1973) Notes on the herpetofauna of Surinam 4. The lizards and amphisbaenians of Surinam. Biogeographica, 4, 1-419.

HORTAL, J., BELLO, F., DINIZ-FILHO, J.A.F., LEWINSOHN, T.M., LOBO, J.M. \& LADLE, R.J. (2015) Seven Shortfalls that Beset Large-Scale Knowledge of Biodiversity. Annual Review of Ecology, Evolution, and Systematics, 46, 523-549.

HUMBOLDT, A.V. (1805) Essai sur la géographie des plantes: accompagné d'un tableau physique des régions équinoxiales, fondé sur des mesures exécutées, depuis le dixième degré de latitude boréale jusqu'au dixième degré de latitude australe, pendant les années 1799, 1800, 1801, 1802 et 1803. Levrault, Schoell, Paris, 155 pp.

HURVICH, C.M. \& TSAI, C.-L. (1989) Regression and time series model selection in small samples. Biometrika, 76, 297-307.

ISHIZAWA, H. \& STEVENS, G. (2007) Non-English language neighborhoods in Chicago, Illinois: 2000. Social Science Research, 36, 1042-1064.

JETZ, W., MCPHERSON, J.M. \& GURALNICK, R.P. (2012) Integrating biodiversity distribution knowledge: toward a global map of life. Trends in Ecology \& Evolution, 27, 151-159.

JUNK, W.J. \& MELLO, J.A.S.N.D. (1990) Impactos ecológicos das represas hidrelétricas na bacia amazônica brasileira. Estudos Avançados, 4, 126-143.

JUNK, W.J., PIEDADE, M.T.F., SCHÖNGART, J., COHN-HAFT, M., ADENEY, J.M. \& WITTMANN, F. (2011) A Classification of Major Naturally-Occurring Amazonian Lowland Wetlands. Wetlands, 31, 623-640.

KAPS, M. \& LAMBERSON, W.R. (2004) Biostatistics for Animal Science. CABI Publishing, Oxfordshire e Cambridge, $459 \mathrm{pp}$.

KLINK, C.A. \& MOREIRA, A.G. (2002) Past and Current Human Occupation, and Land Use. In: OLIVEIRA, P.S. \& MARQUIS, R.J. (Eds.) The Cerrados of Brazil - Ecology and Natural Hystory pf a Neotropical Savanna. Columbia University Press, New York, pp. 69-90. 
KRESS, W.J., HEYER, W.R., ACEVEDO, P., CODDINGTON, J., COLE, D., ERWIN, T.L., MEGGERS, B.J., POGUE, M., THORINGTON, R.W., VARI, R.P., WEITZMAN, M.J. \& WEITZMAN, S.H. (1998) Amazonian biodiversity: assessing conservation priorities with taxonomic data. Biodiversity and Conservation, 7, 1577-1587.

LAURANCE, W.F. (1999) Reflections on the tropical deforestation crisis. Biological Conservation, 91, 109-117.

LIMA, A.P., SIMÕES, P.I. \& KAEFER, I.L. (2014) A new species of Allobates (Anura: Aromobatidae) from the Tapajós River basin, Pará State, Brazil. Zootaxa, 3889, 355387.

LINNAEUS, C. (1758) Systema naturæ per regna tria naturæ, secundum classes, ordines, genera, species, cum characteribus, differentiis, synonymis, locis. Tomus I. Editio Decima, Reformata. Laurentii Salvii, Holmiæ, 824 pp.

LINNAEUS, C. (1781) On the increase of the habitable earth. In: Select Disertations from the Amœenitates Academicæ, a supplement to Mr. Stillingesleet's tracts relating to Natural Histoty. Vol. I. G. Robinson, London, pp. 71-127.

LOMOLINO, M.V., RIDDLE, B.R. \& BROWN, J.H. (2006) Biogeography. Sinauer Associates, Inc., Sunderland, MA, $845 \mathrm{pp}$.

LOURENÇO-DE-MORAES, R., FERREIRA, R.B., FOUQUET, A. \& BASTOS, R.P. (2014) A new diminutive frog species of Adelophryne (Amphibia: Anura: Eleutherodactylidae) from the Atlantic Forest, southeastern Brazil. Zootaxa, 3846, 348-359.

LOURENÇO-DE-MORAES, R., SOLÉ, M. \& TOLEDO, L.F. (2012) A new species of Adelophryne Hoogmoed and Lescure 1984 (Amphibia: Anura: Eleutherodactylidae) from the Atlantic rainforest of southern Bahia, Brazil. Zootaxa, 59-68.

MACHADO, R.B., RAMOS NETO, M.B., PEREIRA, P., CALDAS, E., GONÇALVEZ, D., SANTOS, N., TABOR, K. \& STEININGER, M. (2004) Estimativas de perda da Área do Cerrado Brasileiro. Conservation International do Brasil, Brasilia, 23 pp.

MÂNGIA, S., SANTANA, D.J., CRUZ, C.A.G. \& FEIO, R.N. (2014) Taxonomic review of Proceratophrys melanopogon (Miranda-Ribeiro, 1926) with description of four new species (Amphibia, Anura, Odontophrynidae). Boletim do Museu Nacional, Nova Série Zoologia, 1-36.

MARCIANO-JR, E., LANTYER-SILVA, A.S.F. \& SOLÉ, M. (2017) A new species of Phyllodytes Wagler, 1830 (Anura, Hylidae) from the Atlantic Forest of southern Bahia, Brazil. Zootaxa, 4238, 135-142.

MARTIUS, K.F.P.V. (1840-1906) Tabulae physiognomicae. Brasiliae regiones iconibus expressas descripsit deque vegetatione illius terrae uberius. . In: MARTIUS, K.F.P.V., EICHLER, A.W. \& URBAN, I. (Eds.) Flora brasiliensis sive, Enumeratio plantarum in Brasilia hactenus detectarum quas cura musei caes. reg. palat. vindobonensis suis aliorumque botanicorum studiis descriptas et methodo naturali digestas sub auspiciis Ferdinandi I. Austriae Imperatoris et Ludovici I. Bavarie Regis. Vol 1. Part. 1. R. Oldenbourg in comm., Monachii \& Lipsiae, pp. 1-110+59.

MEIRELLES-FILHO, J. (2009) Grandes Expedições à Amazônia Brasileira 1500-1930. Metalivros, São Paulo, 244 pp.

MEIRELLES-FILHO, J. (2011) Grandes Expedições à Amazônia Brasileira Século XX. Metalivros, São Paulo, 252 pp. 
MELO, A.S., RANGEL, T.F.L.V.B. \& DINIZ, J.A.F. (2009) Environmental drivers of beta-diversity patterns in New-World birds and mammals. Ecography, 32, 226-236.

MEYER, C., KREFT, H., GURALNICK, R. \& JETZ, W. (2015) Global priorities for an effective information basis of biodiversity distributions. Nature Communications, 6, 8221.

MINOLI, I., MORANDO, M. \& AVILA, L.J. (2014) Integrative taxonomy in the Liolaemus fitzingerii complex (Squamata: Liolaemini) based on morphological analyses and niche modeling. Zootaxa, 3856, 501-528.

MONTGOMERY, D.C., PECK, E.A. \& VINING, G.G. (2012) Introduction to Linear Regression Wiley, Hoboken, NJ, 672 pp.

MORA, C., TITTENSOR, D.P. \& MYERS, R.A. (2008) The completeness of taxonomic inventories for describing the global diversity and distribution of marine fishes. Proceedings of the Royal Society B-Biological Sciences, 275, 149-155.

MORAN, P.A.P. (1950) Notes on Continuous Stochastic Phenomena. Biometrika, 37, 17-23.

MYERS, N., MITTERMEIER, R.A., MITTERMEIER, C.G., DA FONSECA, G.A.B. \& KENT, J. (2000) Biodiversity hotspots for conservation priorities. Nature, 403, 853-858.

NASCIMENTO, F.P., AVILA-PIRES, T.C.S. \& CUNHA, O.R. (1987) Os Répteis da área de Carajás, Pará, Brasil (Squamata). II. Boletim do Museu Paraense Emílio Goeldi, série Zoologia, 3, 33-65.

NASCIMENTO, F.P., AVILA-PIRES, T.C.S. \& CUNHA, O.R. (1988) Répteis Squamata de Rondônia e Mato Grosso coletados através do programa Polonoroeste. Boletim do Museu Paraense Emilio Goeldi - Nova Serie - Zoologia, 4, 21-66.

NOGUEIRA, C. (2006) Diversidade e Padrões de Distribuição da Fauna de Lagartos do Cerrado. Doutorado. Instituto de Biociências da Universidade de São Paulo, Departamento de Ecologia, São Paulo, 295 pp.

NUNES, I., KWET, A. \& POMBAL, J.P. (2012) Taxonomic Revision of the Scinax alter Species Complex (Anura: Hylidae). Copeia, 2012, 554-569.

NUNES, P.M.S., FOUQUET, A., CURCIO, F.F., KOK, P.J.R. \& RODRIGUES, M.T. (2012) Cryptic species in Iphisa elegans Gray, 1851 (Squamata: Gymnophthalmidae) revealed by hemipenial morphology and molecular data. Zoological Journal of the Linnean Society, 166, 361-376.

O'BRIEN, R.M. (2007) A Caution Regarding Rules of Thumb for Variance Inflation Factors. Quality \& Quantity, 41, 673-690.

OLIVEIRA-FILHO, A.T. \& FONTES, M.A.L. (2000) Patterns of floristic differentiation among Atlantic forests in southeastern Brazil and the influence of climate. Biotropica, 32, 793810.

OLSON, D.M., DINERSTEIN, E., WIKRAMANAYAKE, E.D., BURGUESS, N.D., POWELL, G.V.N., UNDERWOOD, E.C., D'AMICO, J.A., STRAND, J.C., LOUCKS, C.J., ALLNUTT, T.F., RICKETTS, T.H., KURA, Y., LAMOREUX, J.F., WETTENGEL, W.W., HEDAO, P. \& KASSEM, K.R. (2001) Terrestrial Ecoregions of the World: A New Map of Life on Earth. Bioscience, 51, 933-938.

PALMER, M.W., EARLS, P.G., HOAGLAND, B.W., WHITE, P.S. \& WOHLGEMUTH, T. (2002) Quantitative tools for perfecting species lists. Environmetrics, 13, 121-137.

PARDO-IGÚZQUIZA, E., CHICA-OLMO, M., LUQUE-ESPINAR, J.A. \& RODRÍGUEZ-GALIANO, V. (2015) Compositional CoKriging for mapping the probability risk of groundwater contamination by nitrates. Science of the Total Environment, 532, 162-175. 
Peterson, A.T., SOBERON, J., PEARSON, R.G., ANDERSON, R.P., MARTíneZ-MEYeR, E., NAKAMURA, M. \& ARAÚJO, M.B. (2011) Ecological niches and geographic distributions. Princeton University Press, Princeton, $314 \mathrm{pp}$.

PETERSON, A.T. \& SOBERÓN, J. (2012) Integrating fundamental concepts of ecology, biogeography, and sampling into effective ecological niche modeling and species distribution modeling. Plant Biosystems - An International Journal Dealing with all Aspects of Plant Biology, 146, 789-796.

PHILLIPS, S.J. \& DUDÍK, M. (2008) Modeling of species distributions with MaxEnt: new extensions and a comprehensive evaluation. Ecography, 31, 161-175.

PIANKA, E.R. \& VITT, L.J. (2003) Lizards: windows to the evolution of diversity. University of California Press, Berkley, 333 pp.

PIE, M.R. \& RIBEIRO, L.F. (2015) A new species of Brachycephalus (Anura: Brachycephalidae) from the Quiriri mountain range of southern Brazil. PeerJ, 3, 1-9.

PONTES, R., CARAMASCHI, U. \& POMBAL, J.P. (2014) A Remarkable New Glass Frog (Centrolenidae: Vitreorana) from the Northeast Atlantic Forest, Brazil. Herpetologica, 70, 298-308.

POUGH, F.H., ANDREWS, R.M., CRUMP, M.L., SAVITZKY, A.H., WELLS, K.D. \& BRANDLEY, M.C. (2015) Herpetology. Sinauer Sunderland, $591 \mathrm{pp}$.

PRENDERGAST, J.R., WOOD, S.N., LAWTON, J.H. \& EVERSHAM, B.C. (1993) Correcting for variation in recording effort in analyses of diversity hotspots. Biodiversity Letters, 1 , 39-53.

QUINTEROS, A.S., VALLADARES, P., SEMHAM, R., ACOSTA, J.L., BARRIONUEVO, S. \& ABDALA, C.S. (2014) A New Species of Liolaemus (Iguania: Liolaemidae) of the alticolor-bibronii Group from Northern Chile. South American Journal of Herpetology, 9, 20-29.

RAAIJMAKERS, J.G.W. (1987) Statistical-Analysis of the Michaelis-Menten Equation. Biometrics, 43, 793-803.

RANGEL, T.F., DINIZ, J.A.F. \& BINI, L.M. (2010) SAM: a comprehensive application for Spatial Analysis in Macroecology. Ecography, 33, 46-50.

REDFORD, K.H., TABER, A. \& SIMONETTI, J.A. (1990) There is more to biodiversity than tropical rainforests. Conservation Biology, 4, 328-330.

RIBEIRO, L.F., BORNCHEIN, M.R., BELMONTE-LOPES, R., FIRKOWSKI, C.R., MORATO, S.A.A. \& PIE, M.R. (2015) Seven new microendemic species of Brachycephalus (Anura: Brachycephalidae) fromsouthern Brazil. PeerJ, 1-35.

RIBEIRO, M.C., METZGER, J.P., MARTENSEN, A.C., PONZONI, F.J. \& HIROTA, M.M. (2009) The Brazilian Atlantic Forest: How much is left, and how is the remaining forest distributed? Implications for conservation. Biological Conservation, 142, 1141-1153.

RIBEIRO-JR, M. \& AMARAL, S. (2016) Diversity, distribution, and conservation of lizards (Reptilia: Squamata) in the Brazilian Amazonia. Neotropical Biodiversity, 2, 195-421.

RIBEIRO-JR, M.A. (2015a) Catalogue of distribution of lizards (Reptilia: Squamata) from the Brazilian Amazonia. I. Dactyloidae, Hoplocercidae, Iguanidae, Leiosauridae, Polychrotidae, Tropiduridae. Zootaxa, 3983, 1-110.

RIBEIRO-JR, M.A. (2015b) Catalogue of distribution of lizards (Reptilia: Squamata) from the Brazilian Amazonia. II. Gekkonidae, Phyllodactylidae, Sphaerodactylidae. Zootaxa, 3981, 1-55. 
ROCHA, M.M., YAMAMOTO, J.K., WATANABE, J. \& FONSECA, P.P. (2012) Studying the influence of a secondary variable in Collocated CoKriging estimates. Anais da Academia Brasileira de Ciencias, 84, 335-346.

RODRIGUES, M.T. (2003) Herpetofauna da Caatinga. In: LEAL, I.R., TABARELLI, M. \& SILVA, J.M.C. (Eds.) Ecologia e Conservaçao da Caatinga. Universidade Federal de Pernambuco, Recife, pp. 181-236.

RODRIGUES, M.T. (2003) Herpetofauna da Caatinga. In: LEAL, I.R., TABARELLI, M. \& SILVA, J.M.C. (Eds.) Ecologia e Conservaçao da Caatinga. Universidade Federal de Pernambuco, Recife, pp. 181-236.

RUETE, A. (2015) Displaying bias in sampling effort of data accessed from biodiversity databases using ignorance maps. Biodiversity Data Journal, e5361.

SA, F.P., CANEDO, C., LYRA, M.L. \& HADDAD, C.F.B. (2015) A new species of Hylodes (Anura, Hylodidae) and its secretive underwater breeding behavior. Herpetologica, 71, 58-71.

SAMPAIO, E.V.S.B. (1995) Overview of the Brazilian caatinga. In: MEDINA, E., MOONEY, H.A. \& BULLOCK, S.H. (Eds.) Seasonally Dry Tropical Forests. Cambridge University Press, Cambridge, pp. 35-63.

SAMPAIO, Y. \& BATISTA, J.E.M. (2004) Desenvolvimento regional e pressões antrópicas no bioma Caatinga. In: SAMPAIO, Y. \& BATISTA, J.E.M. (Eds.) Biodiversidade da Caatinga: áreas e ações prioritárias para a conservação. Ministério do Meio Ambiente, Brasília, pp. 311-324.

SÁNCHEZ-AZOFEIFA, G.A., KALACSKA, M., QUESADA, M., CALVO-ALVARADO, J.C., NASSAR, J.M. \& RODRÍGUEZ, J.P. (2005) Need for Integrated Research for Sustainable Future in Tropical Dry Forest. Conservation Biology, 19, 285-286.

SANTANA, D.J., BARROS, A.B., PONTES, R. \& FEIO, R.N. (2015) A New Species of Glassfrog Genus Vitreorana (Anura, Centrolenidae) from the Cerrado Domain, Southeastern Brazil. Herpetologica, 71, 289-298.

SANTANA, D.J., DA FONSECA, E.M., NEVES, M.D. \& DE CARVALHO, R.M.H. (2012) A new species of Adelophryne (Anura: Eleutherodactylidae) from the Atlantic Forest, southeastern Brazil. Salamandra, 48, 187-192.

SANTOS, R.M., OLIVEIRA, A.T., EISENLOHR, P.V., QUEIROZ, L.P., CARDOSO, D.B.O.S. \& RODAL, M.J.N. (2012) Identity and relationships of the Arboreal Caatinga among other floristic units of seasonally dry tropical forests (SDTFs) of north-eastern and Central Brazil. Ecology and Evolution, 2, 409-428.

SCARANO, F.R. (2014) Mata Atlântica - Uma história do futuro. Conservação Internacional, Rio de Janeiro, $272 \mathrm{pp}$.

SCHULMAN, L., TOIVONEN, T. \& RUOKOLAINEN, K. (2007) Analysing botanical collecting effort in Amazonia and correcting for it in species range estimation. Journal of Biogeography, 34, 1388-1399.

SCLATER, P.L. (1858) On the general Geographical Distribution of the Members of the Class Aves. Journal of the Proceedings of the Linnean Society of London, 2, 130-136.

SILMAN, M.R. (2007) Plant species diversity in Amazonian forests. In: Tropical Rainforest Responses to Climatic Change. Springer Berlin Heidelberg, Berlin, Heidelberg, pp. 269294. 
SILVA, H.R. \& OUVERNAY, D. (2012) A new species of stream-dwelling frog of the genus Cycloramphus (Anura, Cycloramphidae) from the State of Rio de Janeiro, Brazil. Zootaxa, 49-60.

SILVA, J.M.C. \& OREN, D.C. (2010) Geographic variation and conservation of the Moustached Woodcreeper Xiphocolaptes falcirostris, an endemic and threatened species of northeastern Brazil. Bird Conservation International, 7, 263-274.

SIMÕES, P.I., LIMA, A.P. \& FARIAS, I.P. (2010) The description of a cryptic species related to the pan-Amazonian frog Allobates femoralis (Boulenger 1883) (Anura: Aromobatidae). Zootaxa, 2406, 1-28.

SIMOES, P.I., STURARO, M.J., PELOSO, P.L.V. \& LIMA, A.P. (2013) A new diminutive species of Allobates Zimmermann and Zimmermann, 1988 (Anura, Aromobatidae) from the northwestern Rio Madeira-Rio Tapajos interfluve, Amazonas, Brazil. Zootaxa, 3609, 251-273.

SMITH, E.P. \& VAN BELLE, G. (1984) Nonparametric-Estimation of Species Richness. Biometrics, 40, 119-129.

SOUZA, M. (2009) História da Amazonia. Editora Valer, Manaus,pp.

SPIX, J.B.V. \& MARTIUS, K.F.P.V. (1824) Travels in Brazil in the years 1817-1820 undertaken by command of his majesty the King of Bavaria. Vol. I-II. Longman, Hurst, Rees, Orme, Brown and Green, London, 298 pp.

STOLAR, J. \& NIELSEN, S.E. (2015) Accounting for spatially biased sampling effort in presenceonly species distribution modelling. Diversity and Distributions, 21, 595-608.

SYFERT, M.M., SMITH, M.J. \& COOMES, D.A. (2013) The Effects of Sampling Bias and Model Complexity on the Predictive Performance of MaxEnt Species Distribution Models. PLOS ONE, 8,

TEIXEIRA JR, M., DAL VECHIO, F., MOLLO-NETO, A. \& RODRIGUES, M.T. (2014) A New TwoPored Amphisbaena Linnaeus, 1758, from Western Amazonia, Brazil (Amphisbaenia: Reptilia). South American Journal of Herpetology, 9, 62-74.

TEIXEIRA JR, M., DAL VECHIO, F., NUNES, P.M.S., MOLLO-NETO, A., LOBO, L.M., STORTI, L.F., GAIGA, R.A.J., DIAS, P.H.F. \& RODRIGUES, M.T. (2013) A new species of Bachia Gray, 1845 (Squamata: Gymnophthalmidae) from the western Brazilian Amazonia. Zootaxa, 3636, 401-420.

TEIXEIRA JR, M., DAL VECHIO, F., RECODER, R.S., CARNAVAL, A.C., STRANGAS, M., DAMASCENO, R., SENA, M.A. \& RODRIGUES, M.T. (2012) Two new species of marsupial tree-frogs genus Gastrotheca Fitzinger, 1843 (Anura, Hemiphractidae) from the Brazilian Atlantic Forest. Zootaxa, 3437, 1-23.

TONINI, J.F.R., FORLANI, M.C. \& DE SA, R.O. (2014a) A new species of Chiasmocleis (Microhylidae, Gastrophryninae) from the Atlantic Forest of Espirito Santo State, Brazil. ZooKeys, 109-132.

TONINI, J.F.R., FORLANI, M.C. \& DE SÁ, R.O. (2014b) A new species of Chiasmocleis (Microhylidae, Gastrophryninae) from the Atlantic Forest of Espírito Santo State, Brazil. ZooKeys, 109-132.

TRONCOSO-PALACIOS, J., DIAZ, H.A., ESQUERRE, D. \& URRA, F.A. (2015) Two new species of the Liolaemus elongatus-kriegi complex (Iguania, Liolaemidae) from Andean highlands of southern Chile. ZooKeys, 83-109. 
TRONCOSO-PALACIOS, J., ELORZA, A.A., PUAS, G.I. \& ALFARO-PARDO, E. (2016) A new species of Liolaemus related to L. nigroviridis from the Andean highlands of Central Chile (Iguania, Liolaemidae). ZooKeys, 555, 91-114.

TU, J. \& XIA, Z.-G. (2008) Examining spatially varying relationships between land use and water quality using geographically weighted regression I: Model design and evaluation. Science of the Total Environment, 407, 358-378.

VANZOLINI, P.E. (1963) Problemas faunísticos do cerrado. In: FERRI, M.G. (Ed.) II Simpósio sobre o Cerrado. EDUSP, São Paulo, pp. 305-321.

VANZOLINI, P.E. (1976) On the lizards of a Cerrado-Caatinga contact: evolutionary and zoogeographical implications (Sauria). Papéis Avulsos de Zoologia, 29, 111-119.

VANZOLINI, P.E. (1996) A contribuição zoológica dos primeiros naturalistas viajantes do Brasil. Revista USP, 30, 190-238.

VANZOLINI, P.E. (2003) A contribution to the ecogeography of the Brasilian cerrados. Biologia Geral e Experimental, 4, 3-10.

VASCONCELOS, T.S., PRADO, V.H.M., DA SILVA, F.R. \& HADDAD, C.F.B. (2014) Biogeographic Distribution Patterns and Their Correlates in the Diverse Frog Fauna of the Atlantic Forest Hotspot. PLOS ONE, 9,

VITT, L.J. \& CALDWELL, J.P. (2014) Herpetology. Academic Press, San Diego, 734 pp.

VITT, L.J. (1991) An Introduction to the Ecology of Cerrado Lizards. Journal of Herpetology, 25, 79-90.

WALLACE, A.R. (1854) On the Monkeys of the Amazon. Annals and Magazine of Natural History, 14, 451-454.

WALLACE, A.R. (1876a) The geographical distribution of animals. With a study of the relations of living and extinct faunas as elucidating the past changes of the earth's surface. Vol. 1. Harper and Brothers, New York, 503 pp.

WALLACE, A.R. (1876b) The geographical distribution of animals. With a study of the relations of living and extinct faunas as elucidating the past changes of the earth's surface. Vol. 2. Harper and Brothers, New York, $607 \mathrm{pp}$.

WALLACE, A.R. (1889) A narrative of travels on the Amazon and Rio Negro, with an account of the native tribes, and observations on the climate, geology, and natural history of the Amazon valley. Ward, Lock and Co., London, New York \& Mellbourne, 363 pp.

WCS \& CIESIN (2005) Last of the Wild Project, Version 2, 2005 (LWP-2): Global Human Influence Index (HII) Dataset (Geographic). WCS, W.C.S.-. \& UNIVERSITY, C.F.I.E.S.I.N.C.-C. (eds.). NASA Socioeconomic Data and Applications Center (SEDAC), Palisades, NY

WERNECK, F.P., COSTA, G.C., COLLI, G.R., PRADO, D.E. \& SITES JR, J.W. (2010) Revisiting the historical distribution of Seasonally Dry Tropical Forests: new insights based on paleodistribution modelling and palynological evidence. Global Ecology and Biogeography, 20, 272-288.

WIED, M.A.P. (1820) Reise nach Brasilien in den Jahrem 1815 bis 1817 - Vol. 1. Heinrich Ludwig Brönner, Frankfurt, 380 pp.

WIED, M.A.P. (1821) Reise nach Brasilien in den Jahrem 1815 bis 1817 - Vol. 2. Heinrich Ludwig Brönner, Frankfurt, $345 \mathrm{pp}$.

WILLDENOW, K.L. (1803) Nomenclator botanicus sistens plantas omnes in Caroli a Linné Speciebus plantarum. Typis lo. Christ. Hendelii, Halae Magdeb,pp.

WWF (2016) Living Planet Report 2016 - Risk and resilience in a new era. WWF International, Gland, Switzerland, $144 \mathrm{pp}$. 
YAMAMOTO, J.K. \& LANDIM, P.M.B. (2013) Geoestatística: conceitos e aplicações. Oficina de Textos, São Paulo, 215 pp.

YANG, W., MA, K. \& KREFT, H. (2014) Environmental and socio-economic factors shaping the geography of floristic collections in China. Global Ecology and Biogeography, 23, 12841292.

ZUUR, A.F., IENO, E.N. \& ELPHICK, C.S. (2010) A protocol for data exploration to avoid common statistical problems. Methods in Ecology and Evolution, 1, 3-14. 


\section{DISCUSSÃO GERAL}

Historicamente as áreas de florestas tropicais têm atraído a atenção tanto de pesquisadores como conservacionistas (REDFORD et al. 1990; SÁNCHEZ-AZOFEIFA et al. 2005), o que tem ajudado a estabelecer a ideia de que estas áreas apresentam uma riqueza muito alta quando comparadas a ambientes mais secos (RAHBEK \& GRAVES 2001; MUTKE \& BARTHLOTT 2005; PYRON \& WIENS 2013; BENNIE et al. 2014). As florestas tropicais abrigam mais de $60 \%$ de todas as espécies conhecidas no mundo, cobrindo apenas $7 \%$ da superfície da do planeta (LAURANCE 1999; DIRZO \& RAVEN 2003), e muitas hipóteses tem sido criadas para se entender essa disparidade de riquezas (PALMER 1994). Recentemente novos avanços em macroecologia, biogeografia, e na análise de dados moleculares (SLATYER et al. 2007; LOWENBERG-NETO et al. 2008; TERRIBILE et al. 2008; FIELD et al. 2009; PYRON \& WIENS 2013; CARNAVAL et al. 2014), tem permitido se abordar este assunto com ferramentas estatísticas, filogenéticas, e climáticas (HIJMANS et al. 2005; DINIZ-FILHO et al. 2008; DINIZFILHO et al. 2009; ROSAUER et al. 2009; RANGEL et al. 2010). Estes trabalhos têm encontrado forte relação entre certas características climáticas e altas riquezas, semelhante ao observado aqui, com altas riquezas de répteis e anfíbios em áreas de baixada, com temperatura e precipitação mais estáveis e alta heterogeneidade estrutural (CAPÍTULO 1). Em se tratando de répteis e anfíbios, uma forte relação com condições climáticas são esperadas, já que répteis apresentam uma certa dependência de altas temperaturas para que seu metabolismo funcione apropriadamente, especialmente os lagartos (VITT et al. 2013; POUGH et al. 2015). Enquanto que anfíbios apresentam uma grande dependência de água, tanto para respiração como reprodução (DUELLMAN \& TRUEB 1994; DEVITT et al. 2013; POUGH et al. 2015). No entanto dados relacionados a endemismos e diversidade beta foram menos relacionados com as condições climáticas atuais (CAPÍTULO 1), como observado em outros grupos (MELO et al. 2009; NOGUEIRA et al. 2010). Isso sugere uma relação mais forte com outras variáveis, como fatores históricos, que definiram a paisagem ao longo do tempo levando as espécies ao isolamento (ROSAUER \& JETZ 2015), e produzindo altos valores de endemismo e diversidade beta, em locais onde barreiras físicas são mais comuns, como nas áreas montanhosas da região Andina.

Porém esta tendência a se concentrar estudos e ações de conservação nas áreas de floresta tropicais por apresentarem maior riqueza (REDFORD et al. 1990; SÁNCHEZ-AZOFEIFA et al. 2005; BOAKES et al. 2010), deixaram de lado outras áreas supostamente mais pobres, como as áreas Abertas e Secas (REDFORD et al. 1990; SÁNCHEZ-AZOFEIFA et al. 2005), que tiveram sua fauna categorizada como pobre, com baixos níveis de endemismo e 
homogeneamente distribuída pela sua extensão (VANZOLINI 1963,1976; VITT ; VANZOLINI 2003). Contudo recentemente esta ideia tem sido questionada e o viés causado pela maior concentração de pesquisa nas áreas de floresta, em detrimento às áreas abertas, parece ter sido a causa dessa visão mais simplista.

No entanto ainda que se tenha sido argumentado de que essa riqueza maior nas regiões de florestas tropicais tenha enviesado tanto os esforço de pesquisa como de conservação (REDFORD et al. 1990; SÁNCHEZ-AZOFEIFA et al. 2005), os dados referentes aos lagartos (CAPIÍTULO 2), e plantas (SCHULMAN et al. 2007), e potencialmente a muitos outros grupos de taxonômicos, mostram um cenário um tanto diferente, onde justamente a Floresta Amazônica é a área com o menor esforço amostral da América do Sul (CAPITULO 2). O que, considerando-se todos os aspectos que envolvem amostragens de espécies, faz bastante sentido. Já que ainda que as técnicas de coletas atuais envolvam uma grande quantidade de métodos (FITZGERALD 2012), na Amazônia os meios de locomoção, e consequentemente os acessos às áreas, continuam praticamente os mesmos que estavam disponíveis aos naturalistas do século 19 (SPIX \& MARTIUS 1824; BATES 1863b,a; WALLACE 1876a,b). Isso resulta em amostragens sendo feitas apenas alguns poucos quilômetros floresta adentro, a partir das margens dos rios. Enquanto o resto da América do Sul atualmente apresenta uma malha viária que oferece acesso relativamente fácil a praticamente todas as suas áreas (FIGURA 85).

Este viés produz uma grande riqueza ao longo dos rios, e especialmente próximo a centros urbanos na Amazônia, deixando muitos interflúvios mal amostrados (FIGURA 85). Esta amostragem desigual tem como consequência, além de resultados óbvios como padrões de riqueza observados potencialmente errôneos, como também contribui para que registros históricos e atuais de espécies sejam geralmente utilizados para traçar mudanças na biodiversidade, assim como a descoberta de populações anteriormente não amostradas pode levar à ilusão de que as distribuições estão expandindo (BOAKES et al. 2010). No entanto diversas técnicas e protocolos vêm sendo desenvolvidos e utilizados para se lidar com esse viés e lacunas nos dados, estimando-se os valores ausentes (BECK \& KITCHING 2007; MORA et al. 2008; TITTENSOR et al. 2010). Porém tais técnicas são apenas estimativas matemáticas baseadas em modelos (MORA et al. 2008; BALLESTEROS-MEJIA et al. 2013), de maneira que a informação verdadeira sobre a ocorrência das espécies ainda não está disponível para muitas regiões (CAPITULO 2; KRESS et al. 1998; SCHULMAN et al. 2007). Este conhecimento incompleto da ocorrência das espécies, especialmente em áreas como as Florestas tropicais, que apresentam um número muito elevado de espécies, impede um levantamento mais 
preciso dos padrões de riqueza (BALLESTEROS-MEJIA et al. 2013), uma identificação mais acurada de áreas prioritárias para a conservação (LOMOLINO 2004), e consequentemente compromete os resultados de qualquer avaliação biogeográfica, ou macroecologica.

Destruição e degradação ambiental são as principais causas da perda de biodiversidade (HARRISON et al. 1982; WILCOVE et al. 1998), o que combinado com a velocidade das mudanças climáticas (LOARIE et al. 2009), assim como a escassez de recursos disponíveis para frear estas ameaças, criam a necessidade de se escolher áreas que teriam uma prioridade a serem conservadas (MARGULES \& PRESSEY 2000; MARGULES et al. 2002; WILSON et al. 2006; MEYER et al. 2015). A criação de áreas protegidas é a maneira mais eficiente de se manter populações viáveis (BRUNER et al. 2001; PERES 2005). Estas áreas são definidas como prioritárias com base na sua importância biológica, e o nível de ameaça ao qual está exposta (MYERS et al. 2000; BROOKS et al. 2004; FUNK \& FA 2010; MURDOCH et al. 2010; BECK et al. 2011). Por exemplo a Mata Atlântica, que é sempre reconhecida como prioridade para conservação em qualquer atributos biológico em que ela é avaliada (MYERS et al. 2000; BROOKS et al. 2002 2005; BROOKS et al. 2004; CEBALLOS \& EHRLICH 2006; GJERDE et al. 2007; HURLBERT \& JETZ 2007). Mas para se medir essa “importância biológica” de uma determinada área deve-se ter uma boa compreensão dos atributos biológicos da mesma, sendo a sua composição de espécies o dado mínimo necessário.

Assim a compilação de dados de ocorrência (GBIF 2016; SPECIESLINK 2016), e a consequente criação de mapas (IUCN 2017), muitas vezes combinados com dados ambientais (HIJMANS et al. 2005) sobre amplas áreas tem melhorado nosso conhecimento sobre questões de fundamental importância a respeito dos padrões de diversidade apresentados pelas espécies, com consequências tanto biogeográficas como conservacionistas (CURRIE et al. 2004; KREFT \& JETZ 2007; ELITH \& LEATHWICK 2009; FIELD et al. 2009; ELITH et al. 2010; FRANKLIN 2010; PETERSON et al. 2011; JETZ \& FINE 2012; JETZ et al. 2012; PETERSON \& SOBERÓN 2012; FRANKLIN 2013; NAIMI \& ARAUJO 2016; STROPP et al. 2016). Os dados disponíveis pela IUCN (IUCN 2017) são um bom exemplo de como bases de dados modernas tem sido utilizadas em muitos estudos (EKEN et al. 2004; STUART et al. 2008; MELO et al. 2009; WIENS et al. 2011; PYRON \& WIENS 2013; RUEDA et al. 2013; DUELLMAN et al. 2016), e ao mesmo tempo de como a grande falta de dados básicos de ocorrência de espécies podem levar a problemas em se delimitar suas distribuições. Os dados referentes a anfíbios utilizados neste estudo (CAPÍTULO 1) foram inicialmente extraídos dos dados disponíveis na IUCN, e das 2813 espécies utilizadas nas análises, 482 estavam ausentes das bases de dados da IUCN, 74 não apresentavam dados publicados com informação suficiente para se avaliar a qualidade do 
polígono, 271 pareciam estar de acordo com os dados publicados e 1985 tiveram que ser corrigidas de alguma forma, em sua maioria pelo polígono abranger áreas irreais com relação a distribuição do animal. Por exemplo, muitas espécies conhecidas de apenas um ponto tinham um polígono que não abrangia o ponto de ocorrência da espécie; em espécies de distribuição ampla o contorno do polígono abrangia áreas onde a espécies não ocorre, ou não incluía áreas onde ela ocorre, muitas vezes representando contornos políticos de estados ou países (FIGURA 86).
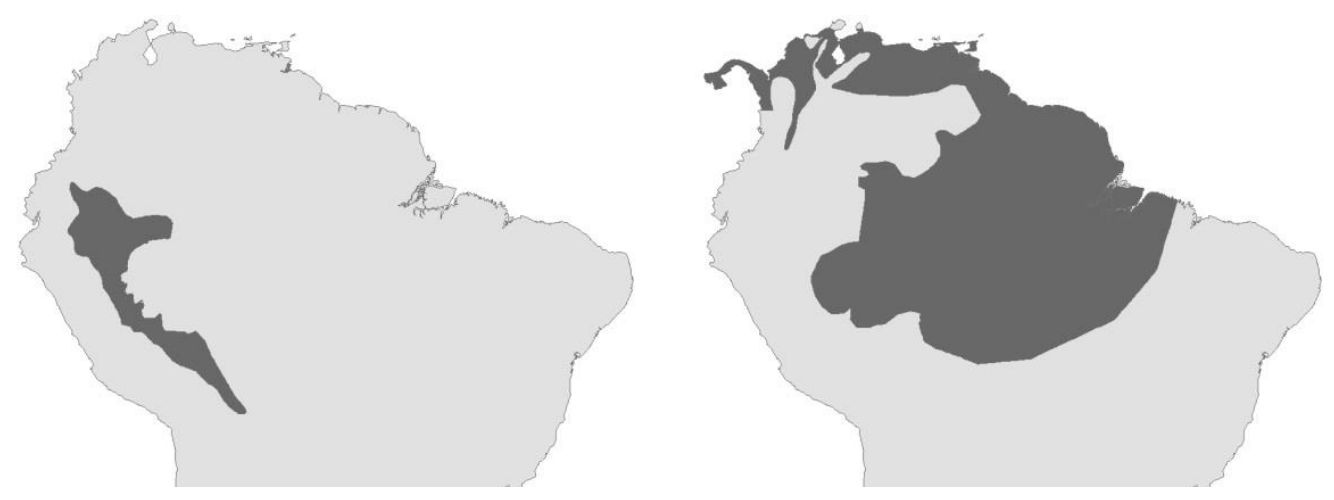

FIGURA 86. Polígonos representando a distribuição de Chiasmocleis ventrimaculada (esquerda) e Dendropsophus microcephalus (direita), como disponíveis pela IUCN.

Erros como estes não são apenas resultado da falta de informação do especialista que o desenhou, mas sim de falta de informação disponível sobre as espécies. A "disponibilidade" dos dados pode ser outra fonte de potenciais problemas, pois dados de ocorrências disponíveis na literatura podem diferir bastante dos dados disponíveis em coleções de museus (BOAKES et al. 2010). Assim considerando que potencialmente todos os dados geográficos de ocorrência de espécies apresentam muitas lacunas e vieses, quaisquer interpretações de padrões produzidos por eles devem ser avaliados com cautela, o que mostra que técnicas matemáticas sofisticadas não necessariamente vão produzir um melhor entendimento dos dados (GARCIA-ROSELLO et al. 2015), enquanto os dados não apresentarem um número de registros maior e uma cobertura geográfica mais abrangente.

\section{REFERÊNCIAS}

BALLESTEROS-MEJIA, L., KITCHING, I.J., JETZ, W., NAGEL, P. \& BECK, J. (2013) Mapping the biodiversity of tropical insects: species richness and inventory completeness of African sphingid moths. Global Ecology and Biogeography, 22, 586-595. 
BATES, H.W. (1863a) The naturalist on the River Amazons, A record of adventures, habits of animals, sketches of Brazilian and Indian life and aspects of nature under the Equator during eleven years of travel. Vol. 1. John Murray, London,pp.

BATES, H.W. (1863b) The naturalist on the River Amazons, A record of adventures, habits of animals, sketches of Brazilian and Indian life and aspects of nature under the Equator during eleven years of travel. Vol. 2. John Murray, London, $423 \mathrm{pp}$.

BECK, J. \& KITCHING, I.J. (2007) Estimating regional species richness of tropical insects from museum data: a comparison of a geography-based and sample-based methods. Journal of Applied Ecology, 44, 672-681.

BECK, J., SCHWANGHART, W., KHEN, C.V. \& HOLLOWAY, J.D. (2011) Predicting geometrid moth diversity in the Heart of Borneo. Insect Conservation and Diversity, 4, 173-183.

BENNIE, J.J., DUFFY, J.P., INGER, R. \& GASTON, K.J. (2014) Biogeography of time partitioning in mammals. Proceedings of the National Academy of Sciences of the United States of America, 111, 13727-13732.

BOAKES, E.H., MCGOWAN, P.J.K., FULLER, R.A., CHANG-QING, D., CLARK, N.E., O'CONNOR, K. \& MACE, G.M. (2010) Distorted Views of Biodiversity: Spatial and Temporal Bias in Species Occurrence Data. PLoS Biology, 8, e1000385.

BROOKS, T., DA FONSECA, G.A.B. \& RODRIGUES, A.S.L. (2004) Species, data, and conservation planning. Conservation Biology, 18, 1682-1688.

BROOKS, T.M., MITTERMEIER, R.A., MITTERMEIER, C.G., DA FONSECA, G.A.B., RYLANDS, A.B., KONSTANT, W.R., FLICK, P., PILGRIM, J., OLDFIELD, S., MAGIN, G. \& HILTONTAYLOR, C. (2002) Habitat Loss and Extinction in the Hotspots of Biodiversity. Conservation Biology, 16, 909-923.

BRUNER, A.G., GULLISON, R.E., RICE, R.E. \& DA FONSECA, G.A.B. (2001) Effectiveness of Parks in Protecting Tropical Biodiversity. Science, 291, 125.

CARNAVAL, A.C., WALTARI, E., RODRIGUES, M.T., ROSAUER, D., VANDERWAL, J., DAMASCENO, R., PRATES, I., STRANGAS, M., SPANOS, Z., RIVERA, D., PIE, M.R., FIRKOWSKI, C.R., BORNSCHEIN, M.R., RIBEIRO, L.F. \& MORITZ, C. (2014) Prediction of phylogeographic endemism in an environmentally complex biome. Proceedings of the Royal Society B-Biological Sciences, 281, 1-8.

CEBALLOS, G. \& EHRLICH, P.R. (2006) Global mammal distributions, biodiversity hotspots, and conservation. Proceedings of the National Academy of Sciences, 103, 19374-19379.

CURRIE, D.J., MITTELBACH, G.G., CORNELL, H.V., FIELD, R., GUEGAN, J.F., HAWKINS, B.A., KAUFMAN, D.M., KERR, J.T., OBERDORFF, T., O'BRIEN, E. \& TURNER, J.R.G. (2004) Predictions and tests of climate-based hypotheses of broad-scale variation in taxonomic richness. Ecology Letters, 7, 1121-1134.

DEVITT, T.J., DEVITT, S.E.C., HOLLINGSWORTH, B.D., MCGUIRE, J.A. \& MORITZ, C. (2013) Montane refugia predict population genetic structure in the Large-blotched Ensatina salamander. Molecular Ecology, 22, 1650-1665.

DINIZ-FILHO, J.A.F., NABOUT, J.C., TELLES, M.P.D., SOARES, T.N. \& RANGEL, T.F.L.V.B. (2009) A review of techniques for spatial modeling in geographical, conservation and landscape genetics. Genetics and Molecular Biology, 32, 203-211.

DINIZ-FILHO, J.A.F., RANGEL, T.F.L.V.B. \& BINI, L.M. (2008) Model selection and information theory in geographical ecology. Global Ecology and Biogeography, 17, 479-488. 
DIRZO, R. \& RAVEN, P.H. (2003) Global state of biodiversity and loss. Annual Review of Environment and Resources, 28, 137-167.

DUELLMAN, W.E. \& TRUEB, L. (1994) Biology of Amphibian. The Johns Hopkins University Press, Baltimore, $670 \mathrm{pp}$.

DUellMAN, W.E., MARION, A.B. \& HeDgeS, S.B. (2016) Phylogenetics, classification, and biogeography of the treefrogs (Amphibia: Anura: Arboranae). Zootaxa, 4104, 1-109.

EKEN, G., BENNUN, L., BROOKS, T.M., DARWALL, W., FISHPOOL, L.D.C., FOSTER, M., KNOX, D., LANGHAMmER, P., MATIKU, P., RADFORD, E., SALAMAN, P., SECHREST, W., SMITH, M.L., SPECTOR, S. \& TORDOFF, A. (2004) Key Biodiversity Areas as Site Conservation Targets. Bioscience, 54, 1110-1118.

ELITH, J., KEARNEY, M. \& PHILLIPS, S. (2010) The art of modelling range-shifting species. Methods in Ecology and Evolution, 1, 330-342.

ELITH, J. \& LEATHWICK, J.R. (2009) Species Distribution Models: Ecological Explanation and Prediction Across Space and Time. Annual Review of Ecology Evolution and Systematics, 40, 677-697.

FIELD, R., HAWKINS, B.A., CORNELL, H.V., CURRIE, D.J., DINIZ-FILHO, J.A.F., GUEGAN, J.-F., KAUFMAN, D.M., KERR, J.T., MITTELBACH, G.G., OBERDORFF, T., O'BRIEN, E.M. \& TURNER, J.R.G. (2009) Spatial species-richness gradients across scales: a metaanalysis. Journal of Biogeography, 36, 132-147.

FITZGERALD, L.A. (2012) Finding and Capturing Reptiles. In: MCDIARMID, R., FOSTER, M.S., GUYER, C., GIBBONS, J.W. \& CHERNOFF, N. (Eds.) Reptile Biodiversity - Standard methods for inventory and monitoring. University of California Press, Berkeley, Los Angeles, London, pp. 77-88.

FRANKLIN, J. (2010) Moving beyond static species distribution models in support of conservation biogeography. Diversity and Distributions, 16, 321-330.

FRANKLIN, J. (2013) Species distribution models in conservation biogeography: developments and challenges. Diversity and Distributions, 19, 1217-1223.

FUNK, S.M. \& FA, J.E. (2010) Ecoregion Prioritization Suggests an Armoury Not a Silver Bullet for Conservation Planning. PLOS ONE, 5, e8923.

GARCIA-ROSELLO, E., GUISANDE, C., MANJARRES-HERNANDEZ, A., GONZALEZ-DACOSTA, J., HEINE, J., PELAYO-VILLAMIL, P., GONZALEZ-VILAS, L., VARI, R.P., VAAMONDE, A., GRANADO-LORENCIO, C. \& LOBO, J.M. (2015) Can we derive macroecological patterns from primary Global Biodiversity Information Facility data? Global Ecology and Biogeography, 24, 335-347.

GBIF (2016) Global Biodiversity Information Facility - Data Portal. Global Biodiversity Information Facility. Available from: http://data.gbif.org/ (2 July 2016).

GJERDE, I., SAETERSDAL, M. \& BLOM, H.H. (2007) Complementary Hotspot Inventory - A method for identification of important areas for biodiversity at the forest stand level. Biological Conservation, 137, 549-557.

HARRISON, J., MILLER, K. \& MCNEELY, J. (1982) The World Coverage of Protected Areas: Development Goals and Environmental Needs. Ambio, 11, 238-245.

HIJMANS, R.J., CAMERON, S.E., PARRA, J.L., JONES, P.G. \& JARVIS, A. (2005) Very high resolution interpolated climate surfaces for global land areas. International Journal of Climatology, 25, 1965-1978. 
HURLBERT, A.H. \& JETZ, W. (2007) Species richness, hotspots, and the scale dependence of range maps in ecology and conservation. Proceedings of the National Academy of Sciences, 104, 13384-13389.

IUCN (2017) The IUCN Red List of Threatened Species 2017. IUCN. Available from: http://www.iucnredlist.org

JETZ, W. \& FINE, P.V.A. (2012) Global Gradients in Vertebrate Diversity Predicted by Historical Area-Productivity Dynamics and Contemporary Environment. PLoS Biology, 10,

JETZ, W., MCPHERSON, J.M. \& GURALNICK, R.P. (2012) Integrating biodiversity distribution knowledge: toward a global map of life. Trends in Ecology \& Evolution, 27, 151-159.

KREFT, H. \& JETZ, W. (2007) Global patterns and determinants of vascular plant diversity. Proceedings of the National Academy of Sciences of the United States of America, 104, 5925-5930.

KRESS, W.J., HEYER, W.R., ACEVEDO, P., CODDINGTON, J., COLE, D., ERWIN, T.L., MEGGERS, B.J., POGUE, M., THORINGTON, R.W., VARI, R.P., WEITZMAN, M.J. \& WEITZMAN, S.H. (1998) Amazonian biodiversity: assessing conservation priorities with taxonomic data. Biodiversity and Conservation, 7, 1577-1587.

LAURANCE, W.F. (1999) Reflections on the tropical deforestation crisis. Biological Conservation, 91, 109-117.

LOARIE, S.R., DUFFY, P.B., HAMILTON, H., ASNER, G.P., FIELD, C.B. \& ACKERLY, D.D. (2009) The velocity of climate change. Nature, 462, 1052-1055.

LOMOLINO, M.V. (2004) Conservation biogeography - Introduction. In: LOMOLINO, M.V. \& HEANEY, L.R. (Eds.) Frontiers of Biogeography - New Directions in the Geography of Nature. Sinauer, Sunderland, pp. 293-296.

LOWENBERG-NETO, P., DE CARVALHO, C.J.B. \& DINIZ-FILHO, J.A.F. (2008) Spatial congruence between biotic history and species richness of Muscidae (Diptera, Insecta) in the Andean and Neotropical regions. Journal of Zoological Systematics and Evolutionary Research, 46, 374-380.

MARGULES, C.R. \& PRESSEY, R.L. (2000) Systematic conservation planning. Nature, 405, 243253.

MARGULES, C.R., PRESSEY, R.L. \& WILLIAMS, P.H. (2002) Representing biodiversity: Data and procedures for identifying priority areas for conservation. Journal of Biosciences, 27, 309-326.

MELO, A.S., RANGEL, T.F.L.V.B. \& DINIZ, J.A.F. (2009) Environmental drivers of beta-diversity patterns in New-World birds and mammals. Ecography, 32, 226-236.

MEYER, C., KREFT, H., GURALNICK, R. \& JETZ, W. (2015) Global priorities for an effective information basis of biodiversity distributions. Nature Communications, 6, 8221.

MORA, C., TITTENSOR, D.P. \& MYERS, R.A. (2008) The completeness of taxonomic inventories for describing the global diversity and distribution of marine fishes. Proceedings of the Royal Society B-Biological Sciences, 275, 149-155.

MURDOCH, W., BODE, M., HOEKSTRA, J., KAREIVA, P., POLASKY, S., POSSINGHAM, H.P. \& WILSON, K.A. (2010) Trade-Offs in Identifying Global Conservation Priority Areas. In: Trade-Offs in Conservation. Wiley-Blackwell, Oxford, pp. 35-55.

MUTKE, J. \& BARTHLOTT, W. (2005) Patterns of vascular plant diversity at continental to global scales. Biologiske Skrifter, 55, 521-531. 
MYERS, N., MITTERMEIER, R.A., MITTERMEIER, C.G., DA FONSECA, G.A.B. \& KENT, J. (2000) Biodiversity hotspots for conservation priorities. Nature, 403, 853-858.

NAIMI, B. \& ARAUJO, M.B. (2016) sdm: a reproducible and extensible R platform for species distribution modelling. Ecography, 39, 368-375.

NOGUEIRA, C., COLLI, G.R., COSTA, G.C. \& MACHADO, R.B. (2010) Diversidade de répteis Squamata e evolução do conhecimento faunístico no Cerrado. In: DINIZ, I.R., MARINHO-FILHO, J., MACHADO, R.B. \& CAVALCANTI, R.B. (Eds.) Cerrado: conhecimento científico quantitativo como subsídio para ações de conservação. Thesaurus, Brasília, pp. 329-372.

PALMER, M.W. (1994) Variation in Species Richness: Towards a Unification of Hypotheses. Folia Geobotanica \& Phytotaxonomica, 29, 511-530.

PERES, C.A. (2005) Why We Need Megareserves in Amazonia. Conservation Biology, 19, 728 733.

PETERSON, A.T. \& SOBERÓN, J. (2012) Integrating fundamental concepts of ecology, biogeography, and sampling into effective ecological niche modeling and species distribution modeling. Plant Biosystems - An International Journal Dealing with all Aspects of Plant Biology, 146, 789-796.

PETERSON, A.T., SOBERON, J., PEARSON, R.G., ANDERSON, R.P., MARTínEZ-MEYER, E., NAKAMURA, M. \& ARAÚJO, M.B. (2011) Ecological niches and geographic distributions. Princeton University Press, Princeton, $314 \mathrm{pp}$.

POUGH, F.H., ANDREWS, R.M., CRUMP, M.L., SAVITZKY, A.H., WELLS, K.D. \& BRANDLEY, M.C. (2015) Herpetology. Sinauer Sunderland, $591 \mathrm{pp}$.

PYRON, R.A. \& WIENS, J.J. (2013) Large-scale phylogenetic analyses reveal the causes of high tropical amphibian diversity. Proceedings of the Royal Society B-Biological Sciences, 280, 1-10.

RAHBEK, C. \& GRAVES, G.R. (2001) Multiscale assessment of patterns of avian species richness. Proceedings of the National Academy of Sciences of the United States of America, 98, 4534-4539.

RANGEL, T.F., DINIZ, J.A.F. \& BINI, L.M. (2010) SAM: a comprehensive application for Spatial Analysis in Macroecology. Ecography, 33, 46-50.

REDFORD, K.H., TABER, A. \& SIMONETTI, J.A. (1990) There is more to biodiversity than tropical rainforests. Conservation Biology, 4, 328-330.

ROSAUER, D., LAFFAN, S.W., CRISP, M.D., DONNELLAN, S.C. \& COOK, L.G. (2009) Phylogenetic endemism: a new approach for identifying geographical concentrations of evolutionary history. Molecular Ecology, 18, 4061-4072.

ROSAUER, D.F. \& JETZ, W. (2015) Phylogenetic endemism in terrestrial mammals. Global Ecology and Biogeography, 24, 168-179.

RUEDA, M., RODRÍGUEZ, M.Á. \& HAWKINS, B.A. (2013) Identifying global zoogeographical regions: lessons from Wallace. Journal of Biogeography, 40, 2215-2225.

SÁNCHEZ-AZOFEIFA, G.A., KALACSKA, M., QUESADA, M., CALVO-ALVARADO, J.C., NASSAR, J.M. \& RODRÍGUEZ, J.P. (2005) Need for Integrated Research for Sustainable Future in Tropical Dry Forest. Conservation Biology, 19, 285-286.

SCHULMAN, L., TOIVONEN, T. \& RUOKOLAINEN, K. (2007) Analysing botanical collecting effort in Amazonia and correcting for it in species range estimation. Journal of Biogeography, 34, 1388-1399. 
SLATYER, C., ROSAUER, D. \& LEMCKERT, F. (2007) An assessment of endemism and species richness patterns in the Australian Anura. Journal of Biogeography, 34, 583-596.

SPECIESLINK. (2016) Rede SpeciesLink. Centro de Referência em Informação Ambiental (CRIA), Fundação de Amparo à Pesquisa do Estado de São Paulo (FAPESP). Available from: http://www.splink.org.br/ (26 March 2016).

SPIX, J.B.V. \& MARTIUS, K.F.P.V. (1824) Travels in Brazil in the years 1817-1820 undertaken by command of his majesty the King of Bavaria. Vol. I-II. Longman, Hurst, Rees, Orme, Brown and Green, London, $298 \mathrm{pp}$.

STROPP, J., LADLE, R.J., M. MALHADO, A.C., HORTAL, J., GAFFURI, J., H. TEMPERLEY, W., OLAV SKФIEN, J. \& MAYAUX, P. (2016) Mapping ignorance: 300 years of collecting flowering plants in Africa. Global Ecology and Biogeography, 25, 1085-1096.

STUART, S.N., HOFFMANN, M., CHANSON, J.S., COX, N.A., BERRIDGE, R.J., RAMANI, P. \& YOUNG, B.E. (2008) Threatened Amphibians of the World. Lynx Edicions, IUCN, Conservation International, Barcelona, Gland, Arlington, 758 pp.

TERRIBILE, L.C., OLALLA-TÁRRAGA, M.Á., MORALES-CASTILLA, I., RUEDA, M., VIDANES, R.M., RODRÍGUEZ, M.Á. \& DINIZ-FILHO, J.A.F. (2008) Global richness patterns of venomous snakes reveal contrasting influences of ecology and history in two different clades. Oecologia, 159, 617-626.

TITTENSOR, D.P., MORA, C., JETZ, W., LOTZE, H.K., RICARD, D., BERGHE, E.V. \& WORM, B. (2010) Global patterns and predictors of marine biodiversity across taxa. Nature, 466, 1098-1101.

VANZOLINI, P.E. (1963) Problemas faunísticos do cerrado. In: FERRI, M.G. (Ed.) /l Simpósio sobre o Cerrado. EDUSP, São Paulo, pp. 305-321.

VANZOLINI, P.E. (1976) On the lizards of a Cerrado-Caatinga contact: evolutionary and zoogeographical implications (Sauria). Papéis Avulsos de Zoologia, 29, 111-119.

VANZOLINI, P.E. (2003) A contribution to the ecogeography of the Brasilian cerrados. Biologia Geral e Experimental, 4, 3-10.

VITT, L.J. (1991) An Introduction to the Ecology of Cerrado Lizards. Journal of Herpetology, 25, 79-90.

WALLACE, A.R. (1876a) The geographical distribution of animals. With a study of the relations of living and extinct faunas as elucidating the past changes of the earth's surface. Vol. 1. Harper and Brothers, New York, 503 pp.

WALLACE, A.R. (1876b) The geographical distribution of animals. With a study of the relations of living and extinct faunas as elucidating the past changes of the earth's surface. Vol. 2. Harper and Brothers, New York, 607 pp.

WIENS, J.J., PYRON, R.A. \& MOEN, D.C. (2011) Phylogenetic origins of local-scale diversity patterns and causes of Amazonian megadiversity. Ecology Letters, 14,

WILCOVE, D.S., ROTHSTEIN, D., DUBOW, J., PHILLIPS, A. \& LOSOS, E. (1998) Quantifying Threats to Imperiled Species in the United StatesAssessing the relative importance of habitat destruction, alien species, pollution, overexploitation, and disease. Bioscience, 48, 607-615.

WILSON, K.A., MCBRIDE, M.F., BODE, M. \& POSSINGHAM, H.P. (2006) Prioritizing global conservation efforts. Nature, 440, 337-340. 


\title{
RESUMO GERAL
}

\begin{abstract}
Our knowledge on species distribution has advanced since the first observations made centuries ago. Recently the improvement on techniques and geographical coverage of samplings activities has improved significantly our knowledge on distribution patterns. This advance has allowed several analyses to be done, and macroecological patterns to emerge, such as the one observed ibn here with reptile and amphibian richness presenting a strong relationship with environmental conditions, with higher values at lower areas, with more stable precipitation and temperature, an higher environmental structure, while endemism and beta diversity have a weaker signal. However the knowledge on species distribution is not homogeneously distributed across all regions, being especially low at the Amazon, which is precisely the area that harbors the highest richness values, being concentrated at the rivers' shores, suggesting that the values we have today may be far underestimated, and thus any inference using them should be interpreted with caution.
\end{abstract}

\section{RESUMO}

O nosso conhecimento sobre a distribuição das espécies vem avançando desde as primeiras observações feitas séculos atrás. Recentemente uma melhoria nos métodos e na cobertura geográfica das amostragens tem melhorado significativamente nosso conhecimento sobre padrões de distribuição. $O$ que tem permito diversos tipos de análises, revelando padrões macroecológicos com os observados aqui onde riqueza de répteis e anfíbios apresenta uma forte relação com o ambiente, sendo maiores em aras mais baixas, com temperatura e precipitação estáveis e maior estrutura no ambiente, enquanto que para endemismo e diversidade beta a relação é mais fraca. Porém este conhecimento sobre a distribuição das espécies não está homogeneamente distribuído por todas as regiões, sendo especialmente baixo na região Amazônica, que é justamente a região que abriga a maior riqueza local de espécies, estando concentrado ao longo das margens dos rios. Isto que pode indicar que os valores que temos disponíveis ainda são subestimados, e que quaisquer inferências sobre estes valores devem ser interpretados com cautela. 


\title{
APÊNDICES
}

\section{APÊNDICE 1 - Referências}

\author{
Referências para a distribuição das espécies.
}

ABDALA, C.S. (2007) Phylogeny of the boulengeri group (Iguania : Liolaemidae, Liolaemus) based on morphologica and molecular characters. Zootaxa, 1-84.

ABDALA, C.S., BALDO, D., JUÁREZ, R.A. \& ESPINOZA, R.E. (2016) The First Parthenogenetic Pleurodont Iguanian: $A$ New All-female Liolaemus (Squamata: Liolaemidae) from Western Argentina. Copeia, 104, 487-497.

ABDALA, C.S., GOMEZ, J.M.D. \& HEREDIA, V.I.J. (2012a) From the far reaches of Patagonia: new phylogenetic analyse and description of two new species of the Liolaemus fitzingerii clade (Iguania: Liolaemidae). Zootaxa, 34-60.

ABDALA, C.S. \& HEREDIA, V.I.J. (2013) Taxonomía y filogenia de un grupo de lagartos amenazados: el grupo de Liolaemus anomalus (Iguania: Liolaemidae). Cuadernos de Herpetologia, 27, 109-153.

ABDALA, C.S. \& LOBO, F. (2006) Description of a new patagonian lizard species of the Liolaemus silvanae group (Iguania: Liolaemidae). South American Journal of Herpetology, 1, 1-8.

ABDALA, C.S., PAZ, M.M. \& SEMHAN, R.V. (2013) Nuevo Liolaemus (Iguania: Liolaemidae) con novedoso carácter morfológico, de la frontera entre Argentina y Chile. Revisto de Biologia Tropical, 61, 1563-1584.

ABDALA, C.S., PROCOPIO, D.E., STELLATELLI, O.A., TRAVAINI, A., RODRIGUEZ, A. \& MONACHESI, M.R.R. (2014) New Patagonian species of Liolaemus (Iguania: Liolaemidae) and novelty in the lepidosis of the southernmost lizard of the world: Liolaemus magellanicus. Zootaxa, 3866, 526-542.

ABDALA, C.S., QUINTEROS, A.S. \& ESPINOZA, R.E. (2008) Two New Species of Liolaemus (Iguania: Liolaemidae) from the Puna of Northwestern Argentina. Herpetologica, 64, 458471.

ABDALA, C.S., QUINTEROS, A.S., SCROCCHI, G.J. \& STAZZONELLI, J.C. (2010) Three new species of the Liolaemus elongatus group (Iguania: Liolaemidae) from Argentina. Cuadernos de Herpetologia, 24, 99-109.

ABDALA, C.S., QUINTEROS, A.S. \& SEMHAN, R.V. (2015) A New Species of Liolaemus of the Liolaemus alticolor-bibroni Group (Iguania: Liolaemidae) from Mendoza, Argentina. South American Journal of Herpetology, 10, 104-115.

ABDALA, C.S. \& QUINTEROS, S. (2007) Liolaemus hermannunezi Pincheira-Donoso et al., 2007 (Iguania hermannunezi Pincheira-Donoso et al., 2007
Liolaemidae). Cuadernos de Herpetologia, 21, 119.

ABDALA, C.S., SEMHAN, R.V., AZOCAR, D.L.M., BONINO, M., PAZ, M.M. \& CRUZ, F. (2012b) Taxonomic study and morphology based phylogeny of the patagonic clade Liolaemus melanops group (Iguania: Liolaemidae), with the description of three new taxa. Zootaxa, 1-32.

ABDALA, V. \& LAVILLA, E.O. (1993) Homonota fasciata (Duméril y Bibron, 1836), Nombre Válido para Homonota pasteuri Wermuth, 1965 y Homonota horrida (Burmeiter, 1861) (Sauria: Gekkonidae). Acta Zoologica Lilloana, 42 1861) (Sauri.

ABDALA, V., MANZANO, A.S., NIETO, L. \& DIOGO, R. (2009) Comparative myology of Leiosauridae (Squamata) and its bearing on their phylogenetic relationships. Belgian Journal of Zoology, 139, 109-123.

ABEGG, A.D., ORTIZ, F.R., ROCHA, B. \& CONDEZ, T.H. (2015) A new record for Brachycephalus nodoterga (Amphibia, Anura, Brachycephalidae) in the state of São Paulo, Brazil. Check List, 11, 1-3.

ABRANTES, S.H. (2008) Revisão dos lagartos Cercosaura do grupo argulus (Reptilia: Squamata: Gymnophthalmidae). MSc Dissertation. Zoology, Museu Paraense Emílio Goeldi, Belém, PA, $73 \mathrm{pp}$

ABREU, M.L.S., FROTA, J.G. \& YUKI, R.N. (2002) Tropidurus hispidus. Geographic Distribution. Herpetological Review, 33,66 .

ACEVEDO, A.A., LAMPO, M. \& CIPRIANI, R. (2016) The cane or marine toad, Rhinella marina (Anura, Bufonidae): two genetically and morphologically distinct species. Zootaxa, 4103, 13 .

ACEVEDO, A.A., WAKE, D.B., MARQUEZ, R., SILVA, K., FRANCO, R. \& AMEZQUITA, A. (2013) Two new species of salamanders, genus Bolitoglossa (Amphibia: Plethodontidae), from the Eastern Colombian Andes. Zootaxa, 3609, 69-84.

ACIOLI, E.C.S. \& TOLEDO, L.F. (2008) Amphibia, Anura, Hylidae, Hypsiboas beckeri: filling gap and description of its advertisement call. Check List, 4, 182-184.

ACOSTA-GALVIS, A.R. \& GUTIÉRREZ-LAMUS, D.L. (2012) A new species of salamander (Bolitoglossa: Plethodontidae) from the Cordillera Oriental of the Colombian Andes. Papéis Avulsos de Zoologia, 52, 18
ACOSTA, J.A. \& BLANCO, G. (2001) Homonota andicola. Herpetological Review, 32, 120

ACOSTA, J.C. \& GOMEZ, P. (2000) Tupinambis rufescens (red tegu). Herpetological Review, 31, 185.

ACOSTA, J.C., MURUA, F. \& ORTIZ, G. (1996) Liolaemus olongasta (NCN). Herpetological Review, 27, 32.

AGUAYO, R. \& QUINTEROS-MUÑOZ, O. (2008) Leposoma percarinatum (Müller, 1923) (Sauria: Gymnophthalmidae). Cuadernos de Herpetologia, 22, 53.

AgUAYO, R., VALDIVIA, F. \& RIVERA, D.S. (2009) Liolaemus puna Lobo y Espinoza, 2004 (Squamata: Liolaemidae). Cuadernos de Herpetologia, 23, 61.

AGUIAR-DE-DOMENICO, E. (2008) Herpetofauna do Mosaico de Ucs de Jacupiranga. MSc. Instituto de Biociências da Universidade de São Paulo, São Paulo, SP199 pp.

AGUILAR-KIRIGIN, A.J. (2012) Primer registro de Plica plica (Linnaeus, 1758) para el departamento de La Paz, Bolivia. Comentarios sobre la extensión de la distribución geográfica para Plica umbra Linnaeus 1758), (Squamata: Tropiduridae). Cuadernos de Herpetologia, 26, 1-3.

AGUILAR-KIRIGIN, A.J., APARICIO, J. \& RÍOS, J.N. (2013) Ampliación de la distribución geográfica de Liolaemus variegatus Laurent 1984 (Iguania: Liolaemidae) en Bolivia. Cuadernos de Herpetologia, 27, 1-3.

AGUILAR, C., CATENAZZI, A., VENEGAS, P.J. \& SIU-TING, K. (2012) Morphological variation of Telmatobius atahualpa (Anura: Telmatobiidae) with comments on its phylogenetic relationships and synapomorphies for the genus. Phyllomedusa, 11, 37-49.

AGUILAR, C., WOOD, P.L., CUSI, J.C., GUZMAN, A., HUARI, F, LUNDBERG, M., MORTENSEN, E., RAMIREZ, C., ROBLES, D. SUAREZ, J., TICONA, A., VARGAS, V.J., VENEGAS, P.J. \& SITES, J.W. (2013) Integrative taxonomy and preliminary assessment of species limits in the Liolaemus walker complex (Squamata, Liolaemidae) with descriptions of three new species from Peru. ZooKeys, 47-91.

AGUIRRE-PENAFIEL, V., TORRES-CARVAJAL, O., NUNES, P.M.S., PECK, M.R. \& MADDOCK, S.T. (2014) A new species of Riama Gray, 1858 (Squamata: Gymnophthalmidae) from the Tropical Andes. Zootaxa, 3866, 246-260.

AGUIRRE, R.H. \& CESPEDEZ, J.A. (2001) Vanzosaura rubricauda. Herpetological Review, 32, 121.

AIRALDI, K., BALDO, D. \& LAVILLA, E.O. (2009) Amphibia, Anura, Bufonidae, Melanophryniscus devincenzii: first record for Paraguay and geographic distribution map. Check List, 5, 377-379.

ALBERTIM, K.M., ANDRADE, E.V.E., MELO, I.V.C. \& DE MOURA, G.J.B. (2010) Anurans and lizards associated to bromeliads in Atlantic Rainforest fragment in Pernambuco State, Northeastern Brazil. Sitientibus Serie Ciencias Biologicas, 10, 289-298.

ALBUQUeRQUE, N.R.D. \& MCDIARMID, R.W. (2010) Redescription of Leptophis cupreus (Cope) (Serpentes, Colubridae), a rare south American Colubrine Snake. Papéis Avulsos de Zoologia, 50, 375-384.

ALLEN, L., VON MAY, R., ORTEGA, J.V., BURDEKIN, O. \& WHITWORTH, A. (2014) A preliminary geographic distribution map of Elachistocleis muiraquitan Nunes de Almeida \& Toledo, 2012 (Amphibia: Anura: Microhylidae). Check List, 10, 388-391.

ALMEIDA-GOMES, M. \& ROCHA, C.F.D. (2014) Diversity and Distribution of Lizards in Fragmented Atlantic Forest Landscape in Southeastern Brazil. Journal of Herpetology, $48,423-429$

ALMEIDA-GOMES, M., SIQUEIRA, C.C., BORGES-JÚNIOR, V.N.T., VRCIBRADIC, D., FUSINATTO, L.A. \& ROCHA, C.F.D. (2014) Herpetofauna of the Reserva Ecológica de Guapiaçu (REGUA) and its surrounding areas, in the state of Rio de (REGUA) and its surrounding areas, in the

ALMEIDA-GOMES, M., VRCIBRADIC, D., SIQUEIRA, C.C. KIEFER, M.C., KLAION, T., MEIDA-SANTOS, P., NASCIMENTO, D., ARIANI, C.V., BORGES, V.N.T., FREITAS, R.F., VAN SLUYS, M. \& ROCHA, C.F.D. (2008) Herpetofaun of an Atlantic rainforest area (Morro São João) in Rio de Janeiro State, Brazil. Anais da Academia Brasileira de Ciencias, 80, 291-300.

ALMEIDA, A.D.P., GASPARINI, J.L. \& PELOSO, P.L.V. (2011) Frogs of the state of Espirito Santo, southeastern Brazil The need for looking at the 'coldspots'. Check List, 7, 542-560.

ALMEIDA, P.C., FEITOSA, D.T., PASSOS, P. \& PRUDENTE, A.L.C. (2014) Morphological variation and taxonomy of Atractus latifrons (Gunther, 1868) (Serpentes: Dipsadidae). Zootaxa 3860, 64-80.

ALMEIDA, R.P.S., ANDRADE, H., CARAMASCHI, U. \& DIAS, E.J.R. (2015) Xenohyla eugenioi Caramaschi, 1998
(Amphibia: Anura: Hylidae): geographic distribution and new record from the state of Sergipe, northeastern Brazil. Check List, 11, 1-3.

ALMEIDA, S.C., MAFFEI, F., ROLIM, D.C., UBAID, F.K. \& JIM, J. (2008a) Amphibia, Anura, Hylidae, Sphaenorhynchus caramaschii: distribution extension in state of São Paulo, Brazil. Check List, 4, 439-441

ALMEIDA, W.O., SANTANA, G.G., VIERA, W.L.S., WANDERLEY, I.C., FREIRE, E.M.X. \& VASCONCELLOS, A. (2008b) Pentastomid, Raillietiella mottae Almeida, Freire and Lopes, 2008 , infecting lizards in an area of caatinga, northeast, Brazil. Brazilian Journal of Biology, 68, 427-431.

ALMENDÁRIZ, A. (1987) Contribucion al conocimiento de la herpetofauna centroriental Ecuatoriana. Politécnica, Biología, 12, 78-133.

ALMENDÁRIZ, A., BRITO, J., BATALLAS, D. \& RON, S. (2014a) Una especie nueva de rana arbórea del género Hyloscirtus (Amphibia: Anura: Hylidae) de la Cordillera del Cóndor. Papéis Avulsos de Zoologia, 54, 33-49.

ALMENDÁRIZ, A. \& ORCÉS, G. (2004) Distribución de alguna especies de la Herpetofauna de los pisos: Altoandino, Temperado y Subtropical. Politécnica, Biología, 25, 97-150.

ALMENDÁRIZ, A., SIMMONS, J.E., BRITO, J. \& VACAGUERRERO, J. (2014b) Overview of the herpetofauna of the unexplored Cordillera del Cóndor of Ecuador. Amphibian and Reptile Conservation, 8, 45-64.

ALMENDÁRIZ C, A., RON, S.R. \& BRITO M, J. (2012) Una especie nueva de rana venenosa de altura del género Excidobates (Dendrobatoidea: Dendrobatidae) de la Cordillera del Cóndor. Papéis Avulsos de Zoologia, 52, 387399.

ALTAMIRANO-BENAVIDES, M., ZAHER, H., LOBO, L., GRAZZIOTIN, F.G., NUNES, P.M.S. \& RODRIGUES, M.T. (2013) A new species of lizard genus Potamites from Ecuador (Squamata, Gymnophthalmidae). Zootaxa, 3717 345-358

ALVARES, D.J. (2011) Modelagem de distribuição geográfica dos répteis ameaçados de extinção no sul do Brasil e análise de áreas prioritarias para conservação. Bacharel. Dapartamento de Zoologia, Universidade Federal do Rio Grando do Sul, Porto Alegre, RS, $59 \mathrm{pp}$.

ALVAREZ, B.B. (1996) Phyllopezus pollicaris przewalskyi ALVAREZ, B.B. (1996) Phyllopezus pollicaris
(Brazilian gecko). Herpetological Review, 27, 211.

ALVAREZ, B.B. (2000) Anisolepis grilli. Herpetological Review, 31, 253.

AlvAREZ, B.B., CEI, J.M. \& SCOLARO, J.A. (1994) A new subspecies of Tropidurus spinulosus (Cope 1862) from the subtropical wet mesic Paraguayan region (Reptilia Squamata Tropiduridae). Tropical Zoology, 7, 161-179.

ÁlVAREZ, B.B., GARCíA, J.A.R., CÉPEDEZ, J.A., HERNANDO, A. ZARACHO, V., CALAMANTE, C.C. \& AGUIRRE, R.H. (2009) Herpetofauna, provinces of Chaco and Formosa, Chaco Oriental region, north-eastern Argentina. Check List, 5, 74-

ALVAREZ, B.B. \& LIONS, M.L. (1996) Liolaemus wiegmann (NCN). Herpetological Review, 27, 32

ALVAREZ, L.G. \& SARAVIA, A.M. (2007) Coleodactylus amazonicus. Herpetological Review, 38, 483

ALVES-PINTO, H.N., VERDADE, V.K. \& RODRIGUES, M.T. (2014) Morphometric variation of Pipa pipa (Linnaeus, 1758) (Anura: Pipidae) with notes on diet and gonad development. Herpetology Notes, 7, 347-353.

ALVES, A.C.R. \& POTSCH DE CARVALHO E SILVA, S. (1999) Descrição da larva de Scinax similis (Cochran) com notas comparativas sobre o grupo "ruber" no sudeste do Brasil (Amphibia, Anura, Hylidae). Revista Brasileira de Zoologia 16, 507-512.

ALVES, A.C.R., SAWAYA, R.J., REIS, S.F. \& HADDAD, C.F.B. (2009) New Species of Brachycephalus (Anura: Brachycephalidae) from the Atlantic Rain Forest in São Paulo State, Southeastern Brazil. Journal of Herpetology, 43, 212-219.

ALVES, M. \& FABIAN-BEURMANN, M. (1974) Sobre ocorrenencia de Homonota uruguayensis (Vaz-Ferreira \& Sierra de Soriano, 1961) no estado do Rio Grande do Sul Brasil. (Lacertilia Gekkonidae). Iheringia, 45, 50-54.

ALZATE, E. (2014) Micrurus camilae. Herpetological Review, 45, 285-286.

ALZATE, E. (2016) Hyalinobatrachium aureoguttatum Herpetological Review, 47, 247 .

AMARAL, A. (1932) Estudos Sobre Lacertilios Neotropicos Novos generos e especies de largartos do Brasil. Memorias do Instituto Butantan, 7, 51-74.

AMARAL, I.B., LANDGREF FILHO, P., SOUZA, F.L \& UETANABARO, M. (2012) Melanophryniscus klappenbachi 
(Klappenbach's Red-bellied Toad). Herpetological Review, 43, 98

AMEZQUITA, A., MARQUEZ, R., MEDINA, R., MEJIA-VARGAS, D., KAHN, T.R., SUAREZ, G. \& MAZARIEGOS, L. (2013) A new species of Andean poison frog, Andinobates (Anura: Dendrobatidae), from the northwestern Andes of Colombia. Zootaxa, 3620, 163-178.

AMORIM, D.M., ROBERTO, I.J. \& ÁVILA, R.W. (2014) Distribution extension of Amphisbaena ibijara Rodrigues, Andrade \& Lima, 2003 (Squamata: Amphisbaenidae). Herpetology Notes, 7, 451-452.

ANAYA-ROJAS, J.M., SERRANO-CARDOZO, V.H. \& RAMÍREZPINILLA, M.P. (2010) Diet, microhabitat use, and therma preferences of Ptychoglossus bicolor (Squamata: Gymnophthalmidae) in an organic coffee shade plantation in Colombia. Papéis Avulsos de Zoologia, 50, 159-166.

ANDERSSON, L.G. (1918) New lizards from South America. Collected by Nils Holmgren and A Roman. Arkiv för Zoologi, $11,1-9$.

ANDRADE, E.B., LIMA, T.G.P., ARAÚJO, K.D.C., LEITE, J.R.S.A \& WEBER, L.N. (2016a) Sympatric occurrence of two species of Pseudopaludicola (Anura: Leptodactylidae) and first record of Pseudopaludicola jaredi Andrade, Magalhães, Nunes-de-Almeida, Veiga-Menoncello, Santana, Garda, Loebmann, Recco-Pimentel, Giaretta \&amp; Toledo, 2016 in the state of Maranhão, northeastern Brazil. Check List, $12,1-6$.

ANDRADE, F.C. \& CARVALHO, T.R. (2013) A new species of Pseudopaludicola Miranda-Ribeiro (Leiuperinae: Leptodactylidae: Anura) from the Cerrado of southeastern Brazil. Zootaxa, 3608, 9

ANDRADE, G.V., GOMES, J.O., FREIRE, P.C. \& CRUZ, L.D. (2004) Hemidactylus agrius. Herpetological Review, 35, 287. ANDRADE, I.S., BARROS, L.C.D.S, OLIVEIRA, A.F.D.S, JUNCÁ, F.A. \& MAGALHÃES, F.M. (2015a) Distribution extension of seudopaludicola pocoto Magalhães, Loebmann, Kokubum, Haddad \& Garda, 2014 (Anura: Leptodactylidae: Leiuperinae) in state of Minas Gerais, Brazil. Herpetology Notes, 8, 227-229.

ANDRADE, M.J.M., JORGE, J.S., MEIRA-RIBEIRO, M., SALES, R.F.D. \& FREIRE, E.M.X. (2015b) Hatchling size of Dryadosaura nordestina (Squamata: Gymnophtalmidae) in Atlantic Forest remnants of Northeastern Brazil. Bioto Amazônia, 5, 132-133.

ANDRADE, M.S., RAMALHO, W.P., DE CARVALHO, T.R. \& MACIEL, N.M. (2016b) The first record of Pseudopaludicol atragula Pansonato, Mudrek, Veiga-Menoncello, RossaFeres, Martins \& Strüssmann, 2014 (Anura: Leptodactylidae) in the state of Goiás, central Brazil. Check List, 12, 1-5.

ANGANOY-CRIOLLO, M. (2012) A new species of Allobates (Anura, Dendrobatidae) from the western flank of the Serrania de Perija, Colombia. Zootaxa, 49-62.

ANGANOY-CRIOLLO, M. (2013) Tadpoles of the High-Andean Hyloxalus subpunctatus (Anura: Dendrobatidae) with description of larval variation and species distinction by larval morphology. Papéis Avulsos de Zoologia, 53, 211-224.

ANGARITA-SIERRA, T (2014) Hemipenial Morphology in the Semifossorial Snakes of the Genus Ninia and a New Specie from Trinidad, West Indies (Serpentes: Dipsadidae). South American Journal of Herpetology, 9, 114-130.

ANGARITA-SIERRA, T.G. (2009) Variación geográfica de Ninia atrata en Colombia (Colubridae: Dipsadinae). Papéis Avulsos de Zoologia, 49, 277-288.

ANJOS, A.C.B., PEREIRA, E.N., PIMENTEL, G., LIMA, C.J.S. BEZERRA, P.E.S. \& SANTOS, E.M. (2015) Vocalização do lagarto da Caatinga, Phyllopezus periosus (Phyllodactylidae), p. 210. In: 70 Congresso Brasileiro de Herpetologia HERPETOLOGIA, S.B.D. (ed.). Sociedade Brasileira de Herpetologia, Gramado

ANJOS, L.A., BEZERRA, C.H., PASSOS, D.C., ZANCHI, D. \& GALDINO, C.A.B. (2011) Helminth fauna of two geck lizards, Hemidactylus agrius and Lygodactylus kluge (Gekkonidade), from caatinga biome, Northeastern Brazil. Neotropical Helminthology, 5, 285-290.

ANNUNZIATA, B.B., CASTRO, I.S., FONTENELE, W.M. \& CISNE, D. (2009) Physalaemus kroyeri (Kroyer's dwarf frog). Herpetological Review, 40, 362

ANNUNZIATA, B.B., FONTENELE, W.M., CASTRO, I.S. GURGEL, R.F. \& NASCIMENTO, K.A. (2007) Amphibia, Anura, Hylidae, Dendropsophus rubicundulus: distribution extension. Check List, 3, 242-243.

ANTUNES, A.P., FAIVOVICH, J. \& HADDAD, C.F.B. (2008) A new species of Hypsiboas from the Atlantic forest of southeastern Brazil (Amphibia: Anura: Hylidae). Copeia 2008, 179-190.

ARAÚJO-NETO, J.V., TIBURCIO, I.C.S., GALDINO, J.Y.A., GONÇALVES, U. \& SILVA, S.T. (2012) Polychrus marmoratus (Green Lizard). Herpetological Review, 43, 103-104.

ARAÚJO-NETO, J.V., TIBURCIO, I.C.S. \& TORQUATO, S. (2014) Stenolepis ridley (Pernambuco Teiid). Herpetological Review, 45, 464.

ARAUJO-NETO, J.V.D., SILVA, B.V.D.M., GALDINO, J.Y.A., DO NASCIMENTO, F.A.C. \& USBOA, B.S. (2012) New records and geographic distribution map of Dendropsophus haddadi (Bastos and Pombal, 1996) (Anura: Hylidae) with comment on color patterns. Check List, 8, 248-250.
ARAUJO-VIEIRA, K., BRANDAO, R.A. \& FARIA, D.C.D. (2015a) A new species of Rock-Dwelling Scinax Wagler (Anura: Hylidae) from Chapada dos Veadeiros, Central Brazil. Zootaxa, 3915, 52-66.

ARAUJO-VIEIRA, K., LACERDA, J.V.A., PEZZUTI, T.L., LEITE, F.S.F., DE ASSIS, C.L. \& CRUZ, C.A.G. (2015b) A new specie of Hatchet-faced Treefrog Sphaenorhynchus Tschud (Anura: Hylidae) from Quadrilátero Ferrífero, Minas Gerais, southeastern Brazil. Zootaxa, 4059, 96-114.

ARAUJO, C.D., CONDEZ, T.H., BOVO, R.P., CENTENO, F.D. \& LUIE, A.M. (2010) Amphibians and reptiles of the Parque Estadual Turistico do Alto Ribeira (PETAR), SP: an Atlantic Forest remnant of Southeastern Brazil. Biota Neotropica $10,257-274$

ARAUJO, J.S, SOUZA, M.B, FARIAS, T.D.A, SILVA, D.P. VENANCIO, N.M., MACIEL, J.M.L. \& MELO-SAMPAIO, P.R. (2012) Liophis dorsocorallinus Esqueda, Natera, La Marca and Ilija-Fistar, 2007 (Squamata: Dipsadidae): Distribution extension in southwestern Amazonia, state of Acre, Brazil. Check List, 8, 518-519.

ARGOLO, A.J.S. (1998) Simophis rhinostoma. Herpetological Review, 29, 179.

ARGOLO, A.J.S. (2001) Oxyrhopus clathratus. Herpetological Review, 32, 61 .

ARIAS, F., CARVALHO, C.M., RODRIGUES, M.T. \& ZAHER, H. (2011a) Two new species of Cnemidophorus (Squamata: Teiidae) of the $C$. ocellifer group, from Bahia, Brazil. Zootaxa, 3022, 1-21.

ARIAS, F., DE CARVALHO, C.M., RODRIGUES, M.T. \& ZAHER, H. (2011b) Two new species of Cnemidophorus (Squamata: Teiidae) from the Caatinga, Northwest Brazil. Zootaxa, 3754.

ARIAS, F. \& LOBO, F. (2007) Kentropyx lagartija (NCN). Diet. Herpetological Review, 38, 78

ARIAS, F.J., BARRIOS, F. \& PALAVECINO, A. (2013) Rang extension and geographic distribution of the poorly known species, Contomastix leachei Peracca, 1897 (Squamata: Teiidae). Check List, 9, 844-846.

ARIAS, F.J., CARVALHO, C.M., ZAHER, H. \& RODRIGUES, M.T. (2014a) A New Species of Ameivula (Squamata, Teiidae) from Southern Espinhaço Mountain Range, Brazil. Copeia 95-105.

ARIAS, F.J., TEIXEIRA JR, M., RECODER, R.S., CARVALHO, C.M ZAHER, H. \& RODRIGUES, M.T. (2014b) Whiptail lizards in South America: a new Ameivula (Squamata, Teiidae) from Planalto dos Gerais, Eastern Brazilian Cerrado. AmphibiaReptilia, 35, 227-242.

ARREDONDO, J.C. (2011) Revisão taxonômica do complexo Philodryas olfersii (Lichestein 1823) (Serpentes: Dipsadidae). MSc. Museu de Zoologia, Universidade de São Paulo, São Paulo, $269 \mathrm{pp}$

ARREDONDO, J.C. (2013) A new species of gymnophthalmid lizard of the genus Anadia (Gymnophthalmidae: Cercosaurinae) from Northern Andes of Colombia. Amphibia-Reptilia, 34, 173-184.

ARREDONDO, J.C. \& SANCHEZ-PACHECO, S.J. (2010) New Endemic Species of Riama (Squamata: Gymnophthalmidae) from Northern Colombia. Journal of Herpetology, 44, 610-

ARROYO, S.B. (2007) New frog (Brachycephalidae: Eleutherodactylus) from the Western Flank of the Cordillera Oriental of Colombia. Zootaxa, 1389, 61-68.

ARRUDA, J.L.S., ARRUDA, D.A. \& CECHIN, S.Z. (2008) Reptilia, Squamata, Tropiduridae, Tropidurus torquatus: distribution extension. Check List, 4, 269-271.

ARRUDA, L.A.G., CARVALHO, M.A. \& KAWASHITA-RIBEIRO, R.A. (2015) New records of the Amazon banded snake Rhinobothryum lentiginosum (Serpentes: Colubridae) from Mato Grosso State, Brazil, with natural history notes. Salamandra, 51, 199-205.

ARTEAGA-NAVARRO, A.F., BUSTAMANTE, M.R. \& GUAYASAMIN, J.M. (2013) The Amphibians and Reptiles of Mindo. Life in the Cloudforest. Serie de Publicaciones Cientificas, Universidad Tecnológica Indoamérica, 1-257.

ARTEAGA, A., PYRON, R.A., PEÑAFIEL, N., ROMEROBARRETO, P., CULEBRAS, J., BUSTAMANTE, L., YÁNEZ MUÑOZ, M.H. \& GUAYASAMIN, J.M. (2016) Comparative Phylogeography Reveals Cryptic Diversity and Repeated Patterns of Cladogenesis for Amphibians and Reptiles in Northwestern Ecuador. PLOS ONE, 11, e0151746.

ARZABE, C., SKUK, G., SANTANA, G.G., DELFIM, F.R., LIMA Y.C.C. \& ABRANTES, S.H.F. (2005) Herpetofauna da área de Curimataú, Paraíba. In: ARAÚJO, F.S., RODAL, M.J.N. \& BARBOSA, M.R.V. (Eds.) Análise das variaçäes da biodiversidade do Bioma Caatinga: suporte a estratégias regionias de conservação. Ministério do Meio Ambiente, Brasília, pp. 265-280.

ARZABE, C., XAVIER DE CARVALHO, C. \& GOES COSTA, M.A. (1998) Anuran assemblages in Crasto Forest ponds (Sergipe State, Brazil): comparative structure and calling activity patterns. Herpetological Journal, 8, 111-113.

ARZAMENDIA, V. (2016) New southern record of Erythrolamprus reginae (Linnaeus, 1758) (Serpentes: Dipsadidae), a vulnerable species in Argentina. Check List 12 ,

ASSIS, C.L., SANTANA, D.J., SILVA, F.A., QUINTELA, F.M. \& FEIO, R.N. (2013) A new and possibly critically endangere species of casque-headed tree frog Aparasphenodon
Miranda-Ribeiro, 1920 (Anura, Hylidae) from southeastern Brazil. Zootaxa, 3716, 583-591.

ASTROZA, M.R.G. \& GONZÁLEZ, M.F. (2013) Liolaemus stolzmanni (Steindachner, 1891) (Squamata: Liolaemidae): Distribution update. Check List, 9, 1067-1069.

ATKINSON, K., SMITH, P., SARVARY, J. \& MATTHEWS, A. (2017) New and noteworthy snake species records (Colubridae and Dipsadidae) for the Reserva Natural Laguna Blanca, eastern Paraguay. Check List, 13, 1-5.

AÚN, L. \& MARTORI, R. (1996) Características de la biología de Cnemidophorus serranus y Cnemidophorus lacertoides. Cuadernos de Herpetologia, 9, 95-99.

AVILA-PIRES, T.C.S. (2001) A new species of Lepidoblepharis (Reptilia: Squamata: Gekkonidae) from Ecuador, with redescription of Lepidoblepharis grandis Miyata, 1985. Occasional Papers Sam Noble Oklahoma Museum of Natural History, 11, 1-11.

AVILA-PIRES, T.C.S. \& HOOGMOED, M. (2000) On two new species of Pseudogonatodes Ruthven, 1915 (Reptilia: Squamata: Gekkonidae), with remarks on the distribution of some other sphaerodactyl lizards. Zoologische Mededelingen, 73, 209-223.

AVILA-PIRES, T.C.S., HOOGMOED, M.S. \& ROCHA, W.A. (2010) Notes on the Vertebrates of northern Pará, Brazil: forgotten part of the Guianan Region, I. Herpetofauna. Boletim do Museu Paraense Emilio Goeldi Ciencias Naturais, 5, 13-112.

AVILA-PIRES, T.C.S. \& VITT, L.J. (1998) A new species of Neusticurus (Reptilia: Gymnophthalmidae) from the Rio Jurua, Acre, Brazil. Herpetologica, 54, 235-245.

AVILA, L.J. (1995a) Mabuya frenata (Sauria: Scincidae) en la Provincia de Córdoba. Cuadernos de Herpetologia, 9, 59.

AVILA, L.J. (1995b) Teius suquiensis: ampliacion de su distribucion geografica y primera cita para la provincia de Santa Fe. Cuadernos de Herpetologia, 9, 57-58

AVILA, L.J. (1998) Vanzosaura rubricauda. Herpetological Review, 29, 52

AVILA, L.J. (2002) Geographic Distribution of Lizards of the Genus Teius (Squamata: Teiidae: Teiinae) in Southern South America. Biogeographica, 78, 15-33.

AVILA, L.J. (2003) A new species of Liolaemus (Squamata

Liolaemidae) from northeastern Argentina and southern Paraguay. Herpetologica, 59, 283-292.

AVILA, L.J., FRUTOS, N., MORANDO, M., PEREZ, C.H.F. \& KOZYKARISKI, M. (2006) Reptilia, Iguania, Liolaemini, Liolaemus petrophilus and Liolaemus pictus: distribution extension, filling gaps, new records. Check List, 2, 65-69.

AVILA, L.J. \& MARTORI, R.A. (1991) A unisexual species of Teius Merrem 1820 (Sauria Teiidae) from central Argentina Tropical Zoology, 4, 193-201.

AVILA, L.J., MEDINA, C.D., PEREZ, C.H.F., SITES, J.W. \& MORANDO, M. (2015) Molecular phylogenetic relationships of the lizard clade Liolaemus elongatus (Iguania: Liolaemini) with the description of a new species from an isolated volcanic peak in northern Patagonia. Zootaxa, 3947, 67-84.

AVILA, L.J., MORANDO, M. \& PEREZ, C.H.F. (2003) New records and natural history notes for Pristidactylus nigroiugulus Cei, Scolaro \& Videla, 2001 from Rio Negro and Chubut provinces, Argentina. Herpetozoa, 16, 83-86.

AVILA, L.J., MORANDO, M., PEREZ, D.R. \& SITES, J.W. (2010a) A new species of the Liolaemus elongatus clade (Reptilia: Iguania: Liolaemini) from Cordillera del Viento northwestern Patagonia, Neuquen, Argentina. Zootaxa, 2842.

AVILA, L.J., PEREZ, C.H.F., MEDINA, C.D., SITES, J.W. \& MORANDO, M. (2012a) A new species of lizard of the Liolaemus elongatus clade (Reptilia: Iguania: Liolaemini) from Curi Leuvu River Valley, northern Patagonia, Neuquen Argentina. Zootaxa, 37-52.

AILA, L.J., PEREZ, C.H.F., MINOLI, I. \& MORANDO, M. (2012b) A new species of Homonota (Reptilia: Squamata: Gekkota: Phyllodactylidae) from the Ventania mountain range, Southeastern Pampas, Buenos Aires Province, Argentina. Zootaxa, 3431, 19-36.

AVILA, LJ PEREZ C.H.F. MINOLU, I \& MORANDO M. (2014) A new lizard of the Phymaturus genus (Squamata: Liolaemidae) from Sierra Grande, northeastern Patagonia Argentina. Zootaxa, 3793, 99-118.

AVILA, L.J., PEREZ, C.H.F., MORANDO, M. \& SITES, J.W. (2010b) A new species of Liolaemus (Reptilia: Squamata) from southwestern Rio Negro province, northern Patagonia, Argentina. Zootaxa, 47-59.

AVILA, L.J., PEREZ, C.H.F., PEREZ, D.R. \& MORANDO, M (2007) Reptilia, Squamata, Liolaemidae, Phymaturus verdugo : Distribution extension, new provincial records, filling gaps, and geographic distribution map. Check List, 3 250-252.

AILA, L.J., PEREZ, C.H.F., PEREZ, D.R. \& MORANDO, M. (2011) Two new mountain lizard species of the Phymaturus genus (Squamata: Iguania) from northwestern Patagonia, Argentina. Zootaxa, 2924, 1-21.

ÁVILA, R.W. \& KAWASHITA-RIBEIRO, R.A. (2011) Herpetofauna of São João da Barra Hydroelectric Plant, state of Mato Grosso, Brazil. Check List, 7, 750-755.

ÁVILA, R.W., PANSONATO, A. \& STRÜSSMANN, C. (2010) A new species of the Rhinella margaritifera group (Anura: Bufonidae) from Brazilian Pantanal. Zootaxa, 57-68. 
Ávila, R.W., PANSONATO, A. \& STRÜSSMANN, C. (2012) A New Species of Proceratophrys (Anura: Cycloramphidae) from Midwestern Brazil. Journal of Herpetology, 46, 466472.

AYALA-VARELA, F., POE, S., CARVAJAL-CAMPOS, A., GRAY, L, DAVIS, J. \& ALMENDARIZ, A. (2011) Anolis soinii Poe and Yanez-Miranda, 2008 (Squamata: Iguanidae: Polychrotinae): Distribution extension, first records for Ecuador and notes on geographic variation. Check List, 7, 629-631.

AYALA-VARELA, F., VELASCO, J.A., CALDERON-ESPINOSA, M. ARTEAGA, A.F., SAGREDO, Y. \& VALVERDE, S. (2014a) First records of Anolis ventrimaculatus Boulenger, 1911 (Squamata: Iguanidae) in Ecuador. Amphibian and Reptile Conservation, 8, 136-140.

AYALA-VARELA, F.P. \& TORRES-CARVAJAL, O. (2010) A new species of dactyloid anole (Iguanidae, Polychrotinae, Anolis) from the southeastern slopes of the Andes of Ecuador ZooKeys, 59-73.

AYALA-VARELA, F.P., TROYA-RODRíGUEZ, D., TALERORODRÍGUEZ, X. \& TORRES-CARVAJAL, O. (2014b) A new Andean anole species of the Dactyloa clade (Squamata: Iguanidae) from western Ecuador. Amphibian and Reptile Conservation, 8, 8-24.

AYALA-VARELA, F.P. \& VELASCO, J.A. (2010) A new species of dactyloid anole (SQUAMATA: IGUANIDAE) from the western Andes of Ecuador. Zootaxa, 46-56.

AYALA, S., HARRIS, D. \& WILLIAMS, E.E. (1983) New or problematic Anolis from Colombia. I. Anolis calimae, new species, from the cloud forest of western Colombia. Breviora, 1-11.

AYALA, S.C. (1986) Saurios de Colombia: lista actualizada, y distribucion de ejemplares colombianos em los museos. Caldasia, 15, 555-575.

AYALA, S.C. \& CASTRO, F. (1983) Dos nuevos gecos (Sauria: Gekkonidae, Sphaerodactylinae) para Colombia: Lepdiblepharis xanthistigma (Noble) y descripcion de una nueva especie. Caldasia, 13, 743-753.

AYALA, S.C. \& HARRIS, D.M. (1984) A new microteiid lizard (Alopoglossus) from the Pacific rainforest of Columbia. Herpetologica, 40, 154-158.

AYALA, S.C. \& SERNA, M.A. (1986) Una nueva especie de Lepidoblepharis (Sauria, Gekkonidae) de la Cordillera Central de Colombia. Caldasia, 15, 649-654.

AYALA, S.C. \& WILLIAMS, E.E. (1988) New or problematic Anolis from Colombia. VI. Two fuscoauratoid anoles from the Pacific lowlands, A. maculiventris Boulenger, 1898 and A. medemi, a new species from Gorgona Island. Breviora, 490, 1-16.

AYARZAGÜENA, J. \& SEÑARIS, J.C. (1994) Dos nuevas especies de Hyla (Anura; Hylidae) para las cumbres tepuyanas de Estado Amazonas, Venezuela. Memoria de la Sociedad de Ciencias Naturales La Salle, 53, 127-146.

AYERBE-GONZÁLEZ, S., ARRIETA-GUEVARA, F.M., CHANTRÈORTìz, C.A., CORAL-PLAZA, E.R. \& GUERRERO-VARGAS, J.A. (2007) Catálogo de los Reptiles presentes en las Colecciones de Referencia y Exhibición del Museo de Historia Natural de la Universidad del Cauca. Taller Editorial Universidad del Cauca, Popayán, $84 \mathrm{pp}$

AZEVEDO-RAMOS, C. \& MOUTINHO, P.R.S. (1994) Amphisbaenians (Reptilia, Amphisbaenidae) in Nests of Atto sexdens (Hymenoptera, Formicidae) in Eastern Amazonia, Brazil. Entomological News, 105, 183-184.

BAENA, J.A.P., ESCOBAR, E.M.M., DELGADO, S.M.G. \& CORREA, M.R. (2006) Anfibios e reptiles del Valle de Aburrá. Editorial Zuluaga Ltda, Medelin, $92 \mathrm{pp}$.

BAÊTA, D., GIASSON, L.O.M., POMBAL, J.P. \& HADDAD, C.F.B. (2016) Review of the Rare Genus Phrynomedusa MirandaRibeiro, 1923 (Anura: Phyllomedusidae) With Description of a New Species. Herpetological Monographs, 30, 49-78.

BAILEY, J.R. \& THOMAS, R.A. (2006) A revision of the Sout American snake genus Thamnodynastes Wagler, 1830 (Serpentes: Colubridae, Tachymenini). II. Three new species from northern South America, with further descriptions of Thamnodynastes gambotensis Perez-Santos and Moreno and Thamnodynastes ramonriveroi Manzanilla and Sanchez. Memoria de la Fundación La Salle de Ciencias Naturales, 66, 7-27.

BAILEY, J.R., THOMAS, R.A. \& DA SILVA, N.J., JR. (2005) A revision of the South American snake genus Thamnodynastes Wagler, 1830 (Serpentes, Colubridae, Tachymenini). I. Two new species of Thamnodynastes from Central Brazil and adjacent areas, with a redefinition of and neotype designation for Thamnodynastes pallidus (Linnaeus, 1758). Phyllomedusa, 4, 83-101.

BALDISSERA JR, F.A., CARAMASCHI, U. \& HADDAD, C.F. (2004) Review of the Bufo crucifer species group, with descriptions of two new related species (Amphibia, Anura, Bufonidae). Arquivos do Museu Nacional, 62, 255-282.

BALDO, D. \& BASSO, N.G. (2004) A New Species of Melanophryniscus (Anura: Bufonidae), with Comments on the Species of the Genus Reported for Misiones, Northeastern Argentina. Journal of Herpetology, 38, 393403.

BALDO, D., BORTEIRO, C., KOLENC, F., ROSSET, S., PRIGIONI, C. \& MARTINEZ DEBAT, C. (2012) The taxonomic status of Melanophryniscus orejasmirandai Prigioni \& Langone, 1987 "1986" (Anura: Bufonidae). Zootaxa, 3235, 45-61.
BALESTRIN, R.L. (2007) História natural e ecologia de uma assembléia de Squamata no Escudo Sul-Rio-Grandense, $p$. 176. In: 3 o Congresso Brasileiro de Herpetologia. HERPETOLOGIA, S.B.D. (ed.), Belém

BARATA, I.M., SANTOS, M.T.T. LEITE, F.S.F. \& GARCIA, P.C.A. (2013) A new species of Crossodactylodes (Anura: Leptodactylidae) from Minas Gerais, Brazil: first record of genus within the Espinhaço Mountain Range. Zootaxa, 3731, 552-560.

BARBO, F.E., GASPARINI, J.L., ALMEIDA, A.P., ZAHER, H. GRAZZIOTIN, F.G., GUSMAO, R.B., FERRARINI, J.M.G. \& SAWAYA, R.J. (2016) Another new and threatened species of lancehead genus Bothrops (Serpentes, Viperidae) from Ilha dos Franceses, Southeastern Brazil. Zootaxa, 4097, 511-529.

BARBO, F.E., GRAZZIOTIN, F.G., SAZIMA, I., MARTINS, M. \& SAWAYA, R.J. (2012) A new and threatened insular species of lancehead from southeastern Brazil. Herpetologica, 68, 418-429.

BARBOUR, T. (1921) Some reptiles from Old Providence Island. Proceedings of the New England Zoölogical Club, 8, 81-85. BARBOUR, T. (1932) New Anoles. Proceedings of the New England Zoölogical Club, 12, 97-102.

BARRASSO, D.A., ALCALDE, L., BLOTTO, B.L. \& BASSO, N.G (2016) Description of the tadpole of Alsodes neuquensis Cei, 1976 and comparison with the sibling species A. gargola Gallardo, 1970 (Amphibia, Anura, Alsodidae). Herpetological Journal, 26, 21-31.

BARRETO-LIMA, A.F. (2009) Gastric suction as an alternative method in studies of lizard diets: tests in two species of Enyalius (Squamata). Studies on Neotropical Fauna and Environment, 44, 23-29.

BARRETO, D.S., VALADÃO, R.M., CASTRO, C.P., FERREIRA, V.L. \& STRÜSSMANN, C. (2012) New locality records, geographical distribution, and morphological variation in Cercosaura parkeri (Ruibal, 1952) (Squamata:
Gymnophthalmidae) from western Brazil. Check List, 8, 1365-1369.

BARRETO, L. \& ARZABE, C. (2005) Barycholos ternetzi (Chimbo frog). Herpetological Review, 36, 198.

BARRETO, L., RIBEIRO, L.E.S. \& NASCIMENTO, M.C. (2011) Caracterização da herpetofauna em áreas da Amazônia do Maranhão. In: MARTINS, M.B. \& OLIVEIRA, T.G. (Eds.) Amazônia Maranhense: Diversidade e Conservação. MPEG Belém, pp. 203-220.

BARRETO, L.N., ARZABE, C. \& LIMA, Y.C.C. (2007) Herpetofauna da região de Balsas. In: BARRETO, L.N. (Ed.) Cerrado Norte do Brasil. USEB, Pelotas, pp. 213-229.

BARRIO-AMORós, C. (2009) Distribución y aspectos de historia natural de las ranas lémur (Hylidae: Phyllomedusinae) en Venezuela. Memoria de la Fundación La Salle de Ciencias Naturales, 2009, 19-46.

BARRIO-AMOROS, C.L. (2006) Hyalinobatrachium ibama Herpetological Review, 37, 238

BARRIO-AMOROS, C.L. \& BREWER-CARIAS, C. (2008) Herpetological results of the 2002 expedition to Sarisarinama, a tepui in Venezuelan Guayana, with the Sescription of five new species. Zootaxa, 1942, 1-68.

BARRIO-AMOROS, C.L. \& CHACON-ORTIZ, A. (2004) Scinax wandae (NCN). Herpetological Review, 35, 185.

BARRIO-AMORÓS, C.L. \& FUENTES, O. (2003) A New Species of Stefania (Anura: Hylidae: Hemiphractinae) from the
summit of Cerro Autana, Estado Amazonas, Venezuela. Herpetologica, 59, 504-512.

BARRIO-AMORÓS, C.L., GUAYASAMIN, J.M. \& HEDGES, S.B. (2012) A new minute Andean Pristimantis (Anura: Strabomantidae) from Venezuela. Phyllomedusa, 11, 83-93. BARRIO-AMORÓS, C.L., HEINICKE, M.P. \& HEDGES, S.B. (2013) A new tuberculated Pristimantis (Anura, Terrarana, Strabomantidae) from the Venezuelan Andes, redescription of Pristimantis pleurostriatus, and variation within Pristimantis vanadisae. Zootaxa, 3647, 43-62.

BARRIO-AMOROS, C.L. \& KAISER, H. (2008) Distribution of Strabomantis biporcatus (Terrarana: Strabomantidae) in northern Venezuela, with comments on its phenotypic northern Venezuela, with comments
variation. Salamandra, 44, 248-254.

BARRIO-AMORÓS, C.L., MESA, J., BREWER-CARÍAS, C. \& MCDIARMID, R.W. (2010a) A new Pristimantis (Anura, Terrarana, Strabomantidae) from Churi-tepui in the Chimanta massif, Venezuelan Guayana. Zootaxa, 35-44.

BARRIO-AMORÓS, C.L. \& NEIRA, D.R. (2004) Hyla joannae. Herpetological Review, 35, 404

BARRIO-AMORÓS, C.L., ORELLANA, A. \& CHACÓN, A. (2004) A new species of Scinax (Anura : Hylidae) from the Andes of Venezuela. Journal of Herpetology, 38, 105-112.

BARRIO-AMORÓS, C.L., RIVERO, R. \& SANTOS, J.C. (2011) A new striking dendrobatid frog (Dendrobatidae: Aromobatinae, Aromobates) from the Venezuelan Andes. Zootaxa, 39-52.

BARRIO-AMORÓS, C.L. \& SANTOS, J.C. (2009) Description of a new Allobates (Anura, Dendrobatidae) from the eastern Andean piedmont, Venezuela. Phyllomedusa, 8, 16

BARRIO-AMORÓS, C.L. \& SANTOS, J.C. (2012) A phylogeny for Aromobates (Anura: Dendrobatidae) with description of three new species from the Andes of Venezuela, taxonomic comments on Aromobates saltuensis, A. inflexus, and note on the conservation status of the genus. Zootaxa, 1-31.
BARRIO-AMOROS, C.L., SANTOS, J.C. \& JOVANOVIC, O. (2010) A new dendrobatid frog (Anura: Dendrobatidae: Anomaloglossus) from the Orinoquian rainforest, southern Venezuela. Zootaxa, 37-50

BARRIO-AMORÓS, C.L., SANTOS, J.C. \& MOLINA, C.R. (2010b) An addition to the diversity of dendrobatid frogs in Venezuela: description of three new collared frogs (Anura: Dendrobatidae: Mannophryne). Phyllomedusa, 9, 3-35.

BARRIO, A. (1965) La subespecies de Hyla pulchella Dumeril y Bibron (Anura, Hylidae). Physis, 25, 115-128.

BARRIO AMOROS, C.L. (1998) Sistematica y biogeografia de los anfíbios (Amphibia) de Venezuela. Acta Biologica Venezuelica, 18, 1-93.

BARRIO, C.L. \& FUENTES, O. (2003) Scinax wandae Herpetological Review, 34, 163.

BARRIONUEVO, J.S. \& BALDO, D. (2009) A new species of Telmatobius (Anura, Ceratophryidae) from Northern Jujuy Province, Argentina. Zootaxa, 2030, 1-20.

BARROS, T.R., ESQUEDA, L.F., MIJARES-URRUTIA, A., LA MARCA, E. \& NICHOLSON, K.E. (2007) The anoline "lost link" rediscovered: variation and distribution of Anolis annectens Williams 1974 (Squamata Polychrotidae). Tropical Zoology, 20, 41-53.

BARROS, T.R., WILLIAMS, E.E. \& VILORIA, A. (1996) The genus Phenacosaurus (Squamata: Iguania) in western Venezuela: Phenacosaurus tetarii, new species, Phenacosaurus euskalerriari, new species, and Phenacosaurus nicefor Dunn, 1944. Breviora, 504, 1-30.

BARTH, A., SOLE, M. \& COSTA, M.A. (2009) Chromosome Polymorphism in Phyllomedusa rohdei Populations (Anura: Hylidae). Journal of Herpetology, 43, 676-679.

BASTOS, R.P., SIGNORELLI, L., NOMURA, F. \& MORAIS, A.R. (2015) Geographical distribution extension and notes on vocalisations of Ischnocnema penaxavantinho Giaretta Toffoli \& Oliveira, 2007 (Anura: Brachycephalidae) Herpetological Bulletin, 132, 22-24.

BATALLAS R., D. \& BRITO M., J. (2014) Nueva especie de rana del género Pristimantis del grupo lacrimosus (Amphibia: Craugastoridae) del Parque Nacional Sangay, Ecuador. Papéis Avulsos de Zoologia, 54, 51-62.

BATISTA, A., HERTZ, A., KOEHLER, G., MEBERT, K. \& VESELY, M. (2014) Morphological variation and phylogeography of frogs related to Pristimantis caryophyllaceus (Anura: Terrarana: Craugastoridae) in Panama. Salamandra, 50 155-171.

BATISTA, V.G. \& BASTOS, R.P. (2014) Anurans from a CerradoAtlantic Forest ecotone in Campos Gerais region, southern Brazil. Check List, 10, 574-582.

BÉDA, A.F. (2004) Redescrição de Cercosaura schreibersi albostrigata (Griffin, 1917) (Sauria, Gymnnophthalmidae, Cercosaurinae). Msc. PUCRSpp.

BEEBE, W. (1944a) Field notes on the lizards of Kartabo, British Guiana, and Caripito, Venezuela. Part 1. Gekkonidae Zoologica, 29, 145-160

BEEBE, W. (1944b) Field notes on the lizards of Kartabo, British Guiana, and Caripito, Venezuela. Part 2. Iguanidae. Zoologica, 29, 195-216

BENAVIDES, E., BAUM, R., SNELL, H.M., SNELL, H.L. \& SITES, J.W. (2009) Island Biogeography of Galapagos Lava Lizards (Tropiduridae: Microlophus): Species Diversity and Colonization of the Archipelago. Evolution, 63, 1606-1626.

BENÍCIO, R.A. \& FONSECA, M.G. (2014) Tupinambis teguixin Linnaeus, 1758 (Squamata: Teiidae). First record for the state of Piauí, northeastern Brazil. Cuadernos de Herpetologia, 28, 45-46.

BENICIO, R.A., SILVA, G.R. \& FONSECA, M.G. (2011) Amphibia, Anura, Hylidae, Sphaenorhynchus lacteus (Daudin, 1800): first record of the genus and species for the State of Piaui, Brazil. Check List, 7, 196-197.

BERGMANN, P.J. \& RUSSELL, A.P. (2007) Systematics and biogeography of the widespread Neotropical gekkonid genus Thecadactylus (Squamata), with the description of a new cryptic species. Zoological Journal of the Linnean Society, 149, 339-370.

BERNARDE, P.S., MACHADO, R.A. \& TURCI, L.C.B. (2011) Herpetofauna da área do Igarapé Esperança na Reserva Extrativista Riozinho da Liberdade, Acre - Brasil. Biota Neotropica, 11, 117-144.

BERNARDE, P.S., MIRANDA, D.B., DE ALBUQUERQUE, S. \& TURCI, L.C.B. (2010) Amphibia, Anura, Hemiphractidae, Hemiphractus helioi Sheil and Mendelson, 2001: distribution extension in the state of Acre and second record for Brazil. Check List, 6, 491-492.

BERNARDO, P.H., GUERRA-FUENTES, R.A., MATIAZZI, W. \& ZAHER, H. (2012) Checklist of Amphibians and Reptiles of Reserva Biológica do Tapirapé, Pará, Brazil. Check List, 8 , 839-846.

BERNARDO, P.H., JUNQUEIRA, A.F.B. \& MARTINS, I.A. (2011) A new geographic distribution record of the rare lizard Colobodactylus dalcyanus Vanzolini and Ramos, 1977 (Squamata, Gymnophthalmidae, Heterodactylini). Herpetology Notes, 4, 327-329.

BERNARDO, P.H. \& PIRES, M.R. (2006) Ophiodes striatus (glass SERARDO, P.H. \& PIRES, M.R. (2006) Ophiodes striatus (glass
snake). Reproduction. Herpetological Review, 37, 469-470. BERNECK, B.V.M., GIARETTA, A.A., BRANDÃO, R.A., CRUZ, C.A.G. \& HADDAD, C.F.B. (2017) The first species of Aplastodiscus endemic to the Brazilian Cerrado (Anura, Hylidae). ZooKeys, 642, 115-130. 
BERNECK, B.V.M., TARGINO, M. \& GARCIA, P.C.D. (2013) Rediscovery and re-description of Ischnocnema nigriventris (Lutz, 1925) (Anura: Terrarana: Brachycephalidae). Zootaxa, 3694, 131-142.

BÉRNILS, R.S., MOURA-LEITE, J. \& MORATO, S.A.A. (2004) Répteis. In: MIKICH, S.B. \& BÉRNILS, R.S. (Eds.) Livro Vermelho da Fauna Ameaçada no Estado do Paraná. Instituto Ambiental do Paraná, Curitiba, pp. 497-535.

BERTHOLD, A.A. (1846) Über verschiedene neue oder selten Reptilien aus Neu-Granada und Crustaceen aus China. Abhandlungen der Königlichen Gesellschaft der Wissenschaften zu Göttingen, 3, 3-32.

BERTOLOTTO, C.E.V. (2006) Enyalius (Leiosauridae, Squamata): o que os dados moleculares e cromossômicos revelam sobre esse gênero de lagartos endêmico do Brasil. Departamento de Genética e Biologia Evolutiva, Instituto de Biociências da Universidade de São Paulo1-129 pp.

BerTolotTo, C.E.V., CRISTINA, K., PELlegRINO, M. RODRIGUES, M.T. \& YONENAGA-YASSUDA, Y. (2002) Comparative cytogenetics and supernumerary chromosomes in the Brazilian lizard genus Enyalius (Squamata, Polychrotidae). Hereditas, 136, 51-57.

BERTOLOTTO, C.E.V., RODRIGUES, M.T. \& YONENAGA YASSUDA, Y. (2001) Banding patterns, multiple sex chromosome system and localization of telomeric (TTAGGG)( $n$ ) sequences by FISH on two species of Polychrus (Squamata, Polychrotidae). Caryologia, 54, 217-226.

BERTOLUCI, J., CANELAS, M.A.S., EISEMBERG, C.C., PALMUTI, C.F.D.S. \& MONTINGELLI, G.G. (2009) Herpetofauna of Estação Ambiental de Peti, an Atlantic Rainforest fragment of Minas Gerais State, southeastern Brazil. Biota of Minas Gerais Stat.

BITAR, Y.O.C., SILVA, K.R.A., SILVA FILHO, H.F. \& PINHEIRO, L.C. (2015) Amphibia, Anura, Hylidae, Cruziohyla craspedopus (Funkhouser, 1957): distribution extension an first record from the state of Para, Brazil. Check List, 11, 13.

BLOTTO, B.L., NUNEZ, J.J., BASSO, N.G., UBEDA, C.A., WHEELER, W.C. \& FAIVOVICH, J. (2013) Phylogenetic relationships of a Patagonian frog radiation, the Alsodes + Eupsophus clade (Anura: Alsodidae), with comments on the supposed paraphyly of Eupsophus. Cladistics, 29, 113-131.

BOANO, G., MAZZOTTI, S. \& SINDACO, R. (2008) A new peculiar frog species of the genus Pristimantis from Yanachaga-Chemillén National Park, Peru. Zootaxa, 51-57.

BOCOURT, M.F. (1870) Description de quelques sauriens nouveaux originaires de l'Amérique méridionale. Nouvelles archives du Museum d'Histoire Naturelle de Paris, 6, 11-18.

BOERIS, J. FERRO, J.M. KRAUCZUK, E. \& BALDO, D. (2010) Amphibia, Anura, Bufonidae, Melanophryniscus devincenzii
(ats. J., FERRO, J.M., KRAUCZUK, E. \& BALDO, D. (2010) Amphibia, Anura, Bufonidae, Melanophryniscus devincenzii
Klappenbach, 1968: first record for Corrientes province, Argentina. Check List, 6, 395-396.

BOETTGER, O. (1876) Über eine neue Eidechse aus Brasilien. Berichte über die Senckenbergische naturforschende Gesellschaft, 1876, 140-143.

BOGERT, C.M. (1968) The variations and affinities of the dwarf boas of the genus Ungaliophis. American Museum Novitates, 1968, 1-26.

BolivaR-G, W., GIRALDO, A. \& MENDEZ, J. (2011) Amphibia, Anura, Strabomantidae, Pristimantis palmeri Boulenger, 1912: distribution extension for the central Cordillera, Colombia. Check List, 7, 9-10.

BONATTI, J., ZANELLA, N., HARTMANN, F.S. \& KRAUSE, L. (2004) Composição e sazonalidade de uma comunidade de lagartos na região do planalto médio, norte do Estado do Rio Grande do Sul. In: 1o Congresso Brasileiro de Herpetologia. HERPETOLOGIA, S.B.D. (ed.), Curitiba

BOOS, J.O. \& QUESNEL, V.C. (1971) Notes on Kentropyx striatus in Trinidad, West Indies. Herpetologica, 27, 477481.

BORGES-LEITE, M.J., MOTA RODRIGUES, J.F. \& BORGESNOJOSA, D.M. (2014) Herpetofauna of a coastal region of northeastern Brazil. Herpetology Notes, 7, 405-413.

BORGES-MARTINS, M. (1998) Revisão taxonômica sistemática filogenética do gênero Ophiodes Wagler, 1828 (Sauria, Anguidae, Diploglossinae). Doutorado. Pontifícia (Sauria, Anguidae, Diploglossinae). Doutorado. Pontifícia
Universidade Católica do Rio Grande do Sul, Poro Alegre, 1Universidad $239 \mathrm{pp}$.

BORGES-NOJOSA, D.M. \& CARAMASCHI, U. (2003) Composição e Análise Comparativa da Diversidade e das Afinidades Biogeográficas dos Lagartos e Anfisbenídeos (Squamata) dos Brejos Nordestinos. In: LEAL, I., SILVA, L.M.C. \& TABARELLI, M. (Eds.) Ecologia e Conservação da Caatinga. UFPE, Recife, pp. 463-512.

BORGES-NOJOSA, D.M., CARAMASCHI, U. \& RODRIGUES, M.T. (2016) A new species of lizard Placosoma Tschudi, 1847 (Squamata: Gymnophthalmidae) from the relictual forest mountains of the State of Ceará, Brazil. 2016, 4169, 160-170.

BORGES-NOJOSA, D.M. \& CASCON, P. (2005) Herpetofauna da área Reserva da Serra das Almas, Ceará. In: ARAÚJO, F.S., RODAL, M.J.N. \& BARBOSA, M.R.V. (Eds.) Análise das RODAL, M.J.N. \& Bäes da Biodiversidade do Bioma Caatinga. Ministério
Varion Variaçäes da Biodiversidade do Bioma Ca
do Meio Ambiente, Brasília, pp. 244-258.

BORNSCHEIN, M.R., FIRKOWSKI, C.R., BALDO, D., RIBEIRO, L.F., BELMONTE-LOPES, R., CORREA, L., MORATO, S.A.A. \&
PIE, M.R. (2015) Three New Species of Phytotelm-Breeding
Melanophryniscus from the Atlantic Rainforest of Southern Brazil (Anura: Bufonidae). PLOS ONE, 10,

BORTEIRO, C., KOLENC, F., TEDROS, M. \& GUTIERREZ, F. (2005) Melanophryniscus pachyrhynus. Herpetological Review, 36, 199-200

BORTEIRO, C., NIETO, C. \& KOLENC, F. (2007) Amphibia, Anura, Hylidae, Scinax aromothyella: Distribution extension and habitat. Check List, 3, 98-99.

BOULENGER, G.A. (1885a) Catalogue of the lizards in the British Museum. Volume II. Iguanidæ, Xenosauridx, Zonuridæ, Anguidæ, Anniellidæ, Helodermatidæ, Varanidæ, Xantusiidæ, Teiidæ, Amphisbaenidæ. Taylor \& Francis, London, $497 \mathrm{pp}$.

BOULENGER, G.A. (1885b) Catalogue of the lizards in the British Museum. Volume. I., Geckonidæ, Eublepharidæ, Uroplatidæ, Pygopodidæ, Agamidæ. Taylor \& Francis, London, $436 \mathrm{pp}$.

BOULENGER, G.A. (1887) Catalogue of the lizards in the British Museum. Volume III. Lacertidæ Gerrhosauridæ, Scincidæ, Anelytropidæ, Dibamidæ, Chamaeleontidæ. Taylor \& Francis, London, $575 \mathrm{pp}$.

BOULENGER, G.A. (1888) On some reptiles and batrachians from Iguarasse, Pernambuco. Annals and Magazine of Natural History. 6th Series, 2, 40-43.

BOULENGER, G.A. (1891) Description of a new Iguanoid lizard of the genus Anisolepis. Annali del Museo Civico di Storia Naturale di Genova, 10, 909

BOULENGER, G.A. (1894a) List of reptiles and batachian collected by Dr. T. Bohls near Asuncion, Paraguay. Annals and Magazine of Natural History, 6, 342-348.

BOULENGER, G.A. (1894b) Second report on additions to the lizard collections in the Natural History Museum Proceedings of the Zoological Society of London, 1894, 722 736

BOULENGER, G.A. (1896a) Catalogue of the Snakes in the British Museum (Natural History). Vol. iii, containing the Colubridae (Opixthoglyphae and Proteroglyphae), Amblycephalidae, and Viperidae. xiv \& 727 pp. pp.

BOULENGER, G.A. (1896b) Descriptions of new batrachians in the British Museum. Annals and Magazine of Natural History, 17, 401-406.

BOULENGER, G.A. (1898) A list of reptiles and batrachians collected by the late Professor L. Balzan in Bolivia. Annali del Museo Civico di Storia Naturale di Genova, 19, 128-133. BOULENGER, G.A. (1900) Reptiles and Batrachians. In LANKESTER, E.R. (Ed.) Report on a Collection made by Messrs F. V. McConnell and J. J. Quelch at Mount Roraima in British Guiana. Transactions of the Linnean Society of London53-56.

BOULENGER, G.A. (1902a) Descriptions of new Batrachians and Reptiles from North-Western Ecuador. Annals of Natural History, 7, 51-57.

BOULENGER, G.A. (1902b) Descriptions of new Batrachians and Reptiles from the Andes of Peru and Bolivia. Annals of Natural History, 10, 394-402.

BOULENGER, G.A. (1902c) List of the Fishes, Batrachians and Reptiles collected by the late Mr P. O. Simons in the Provinces of Mendoza and Cordova, Argentina. Annals and Magazine of Natural History, 7, 336-339.

BOULENGER, G.A. (1903) Descriptions of new Lizards in the Collection of the British Museum. Annals and Magazine of Natural History, 12, 429-435.

BOULENGER, G.A. (1908a) Descriptions of new batrachians and reptiles discovered by Mr. M. G. Palmer in South western Colombia. Annals and Magazine of Natural History, 515-522.

BOULENGER, G.A. (1908b) Descriptions of new SouthAmerican reptiles. Annals and Magazine of Natural History, 1,111-115.

BOULENGER, G.A. (1911) Descriptions of new reptiles from the Andes of South America, preserved in the Britis Museum. Annals \& Magazine of Natural History, 7, 19-25. BOULENGER, G.A. (1912) Descriptions of new reptiles from the Andes of South America, preserved in the British Museum. Annals and Magazine of Natural History, 8, 420424.

BOULENGER, G.A. (1913) Descriptions of new Lizards in the collection of the British Museum. Annals and Magazine of Natural History, 12, 563-566.

BOUR, R. \& ZAHER, H. (2005) A new species of Mesoclemmys, from the open formations of northeastern Brazil (Chelonii, Chelidae). Papéis Avulsos de Zoologia, 45, 295-311.

BOURGEOIS, P.-A. (2010) Amphibia, Anura, Cycloramphidae, Macrogenioglottus alipioi Carvalho, 1946: distribution extension, state of Alagoas, northeastern Brazil. Check List, 6, 187-188.

BOURKE, J., BUSSE, K. \& BOEHME, W. (2012) Searching for a lost frog (Rhinoderma rufum): identification of the mos promising areas for future surveys and possible reasons of its enigmatic decline. North-Western Journal of Zoology, 8 99-106.

BRAGA, L.R.A., BRANDAO, R.A. \& COLLI, G.R. (2010) Amphibia, Anura, Hylidae, Hypsiboas buriti (Caramaschi and Cruz, 1999): distribution update and map. Check List, 6, 232-233.

BRAME, A.H., JR. \& WAKE, D.B. (1972) New species of salamanders (genus Bolitoglossa) from Colombia, Ecuado and Panamá. Contributions in Science, 1-34.
BRAME, A.H. \& WAKE, D.B. (1963) The salamanders of South America. Contr Sci Nat Hist Mus, Los Angeles County, 69, BRANDÃO, R.A., DE MAGALHAES, R.F., GARDA, A.A. CAMPOS, L.A., SEBBEN, A. \& MACIEL, N.M. (2012) A new species of Bokermannohyla (Anura: Hylidae) from highlands species of Bokermannohyla (Anu

BRASILEIRO, C.A. \& HADDAD, C.F.B. (2015) A New Species of Physalaemus from Central Brazil (Anura: Leptodactylidae). Herpetologica, 71, 280-288.

BRAVO-VALENCIA, L. \& RIVERA-CORREA, M. (2011) A new species of harlequin frog (Bufonidae: Atelopus) with an unusual behavior from Andes of Colombia. Zootaxa, 57-67.

BRCKO, I.C., HOOGMOED, M.S. \& NECKEL-OLIVEIRA, S. (2013) Taxonomy and distribution of the salamander genus Bolitoglossa Duméril, Bibron \& Duméril, 1854 (Amphibia, Caudata, Plethodontidae) in Brazilian Amazonia. Zootaxa 3686, 401-431.

BREITMAN, M.F., MINOLI, I., AVILA, L.J., MEDINA, C.D., SITES JR, J.W. \& MORANDO, M. (2014) Lagartijas de la provincia de Santa Cruz, Argentina: distribución geográfica, diversidad genética y estado de conservación. Cuadernos de Herpetologia, 28, 83-110.

BREITMAN, M.F., MORANDO, M. \& AVILA, L.J. (2013) Pas and present taxonomy of the Liolaemus lineomaculatus section (Liolaemidae): is the morphological arrangement hypothesis valid? Zoological Journal of the Linnean Society 168, 612-668.

BREITMAN, M.F., PARRA, M., PEREZ, C.H.F. \& SITES, J.W. (2011a) Two new species of lizards from the Liolaemus lineomaculatus section (Squamata: Iguania: Liolaemidae) from southern Patagonia. Zootaxa, 1-28.

BREITMAN, M.F., PEREZ, C.H.F., PARRA, M., MORANDO, M SITES, J.W. \& AVILA, L.J. (2011b) New species of lizard from the magellanicus clade of the Liolaemus lineomaculatus section (Squamata: Iguania: Liolaemidae) from southern Patagonia. Zootaxa, 32-48.

BRIGUERA, V., TAMBURINI, D., KUFNER, M., GAVIER, G. GIRAUDO, L., TORRES, R. \& BECHARA, V. (2006) Herpetofauna en relictos de Bosque Chaqueño de la región de Mar Chiquita. Cuadernos de Herpetologia, 20, 25-31.

BRITO M, J., OJALA-BARBOUR, R., BATALLAS R, D. \& ALMENDÁRIZ C, A. (2016) A New Species of Pristimantis (Amphibia: Strabomantidae) from the Cloud Forest of Sangay National Park, Ecuador. Journal of Herpetology, 50 337-344

BRITO M, J. \& POZO-ZAMORA, G. (2013) Una nueva especie de rana terrestre del género Pristimantis (Amphibia: Craugastoridae), de la Cordillera de Kutukú, Ecuador. Papéis Avulsos de Zoologia, 53, 315-325.

BRITO M., J., BATALLAS R., D. \& VELALCÁZAR, D. (2014) Nueva especie de rana terrestre del género Pristimantis (Amphibia: Craugastoridae), meseta de la Dordillera de Cóndor. Papéis Avulsos de Zoologia, 54, 435-466.

BRITO, M.S., BARBOSA, L.F.S., PEREIRA, L.C., NICOLA, P.A. \& RIBEIRO, L.B. (2012) Range extension, new state record and geographic distribution map of Acratosaura mentalis (Amaral, 1933) (Squamata: Gymnophthalmidae). Check List, $8,172-174$.

BROUARD, J.P. \& SMITH, P. (2014) Reserva Natural Laguna Blanca, Departamento San Pedro, Paraguay - Lizards, Amphisbaenids and Blind Snakes of Laguna Blanca Chicago $2 \mathrm{pp}$

BROWN, J.L. \& TWOMEY, E. (2009) Complicated histories: three new species of poison frogs of the genus Ameerega (Anura: Dendrobatidae) from north-central Peru. Zootaxa, $1-38$.

BROWN, J.L., TWOMEY, E., AMEZQUITA, A., DE SOUZA, M.B. CALDWELL, J.P., LOTTERS, $S$, VON MAY, $R$, MELOSAMPaio, P.R., MEJIA-VARGas, D., PEREZ-PENA, P., PEPPER, M., POELMAN, E.H., SANCHEZ-RODRIGUEZ, M. \& SUMMERS, K. (2011) A taxonomic revision of the Neotropical poison frog genus Ranitomeya (Amphibia: Dendrobatidae). Zootaxa, 1-120.

BRUSCHI, D.P., LUCAS, E.M., GARCIA, P.C.A. \& RECCO PIMENTEL, S.M. (2014) Molecular and Morphologica Evidence Reveals a New Species in the Phyllomedusa hypochondrialis Group (Hylidae, Phyllomedusinae) from the Atlantic Forest of the Highlands of Southern Brazil. PLOS ONE, 9 ,

BRUSQUETTI, F., BALDO, D. \& MOTTE, M. (2007) Amphibia Anura, Bufonidae, Melanophryniscus krauczuki: geographic distribution map and first record for Paraguay. Check List, 3 , 141-142.

BRUSQUETTI, F., JANSEN, M., BARRIO-AMORÓS, C., SEGALLA, M. \& HADDAD, C.F.B. (2014) Taxonomic review of Scinax fuscomarginatus (Lutz, 1925) and related species (Anura; Hylidae). Zoological Journal of the Linnean Society, 171 783-821.

BRUSQUETTI, F. \& LAVILLA, E.O. (2006) Lista comentada de los anfíbios de Paraguay. Cuadernos de Herpetologia, 20, 379.

BUARQUE JR., D.V. \& MOURA, G.J.B. (2011) Anurofauna da cidade de Barreiros, remanescente de Mata Atlântica Nordeste do Brasil - Pernambuco. In: MOURA, G.J.B SANTOS, E.M., OLIVEIRA, M.A.B. \& CABRAL, M.C.C. (Eds.) Herpetofauna de Pernambuco. IBAMA, Brasília, pp. 149162 . 
BUITRAgo-gonZaLEZ, W., HERNAN LOPEZ-GUZMAN, J. \& VARGAS-SALINAS, F. (2016) Niceforonia adenobrachia Ardila-Robayo, Ruiz-Carranza \& Barrera-Rodriguez, 1996 (Amphibia: Anura: Craugastoridae): extension of geographical distribution in the Central Andes of Colombia. Check List, 12, 1845.

BUJES, C.S. (1998) Padroes de atividade de Teius oculatus (Sauria, Teiidae) na Reserva Biologica do Lami, Estado do Rio Grande do Sul - Brasil. Cuadernos de Herpetologia, 12, $13-21$

BUJES, C.S. \& VERRASTRO, L. (2008) Annual activity of the lizard Liolaemus occipitalis (Squamata, Liolaemidae) in the coastal sand dunes of southern Brazil. Iheringia, Série Zoologia, 98, 156-160.

BÜRGER, O. (1907) Estudo sobre reptiles Chilenos - Sobre algunos lagartos nuevos clasificados $\mathrm{i}$ descritos doctor $\mathrm{E}$. Werner de Viena. Memorias Cientificas $i$ Literarias, 121 149-155.

BURMEISTER, C.V. (1888) Algunas Noticias sobre la Fauna de la Patagonia. Anales del Museo Nacional de Buenos Aires, 3 , 237-252.

BURT, C.E. (1935) A new lizard from the Dutch Leeward Islands (Cnemidophorus murinus ruthveni). Occasional Papers of the Museum of Zoology, University of Michigan, 1-3.

BURT, C.E. \& BURT, M.D. (1931) South American Lizards in the Collection of the American Museum of Natural History. Bulletin of the American Museum of Natural History, 61 227-395.

BUSTAMANTE, M.R. \& MENDELSON, J.R. (2008) A new frog species (Strabomantidae: Pristimantis) from the High Andes of Southeastern Ecuador. Zootaxa, 49-59.

CABAllero GINI, A., BUENO VILLAFAÑE, D., ROMERO NARDELLI, L. \& LAVILLA, E.O. (2014) Elachistocleis haroi Pereyra, Akmentins, Laufer \& Vaira, 2013 (Anura: Microhylidae) en Paraguay. Boletín del Museo Nacional de Historia Natural del Paraguay, 18, 98-103.

CABRAL, H. \& CACCIALI, P. (2015) A New Species of Phalotris (Serpentes: Dipsadidae) from the Paraguayan Chaco. Herpetologica, 71, 72-77.

CABRERA, M.R. (2002) New records for Ameiva ameiva (L., 1758) (Squamata, Teiidae) in Argentina. Cuadernos de Herpetologia, 16, 169-170.

CABRERA, M.R. (2012) A new species of Cnemidophorus (Squamata, Teiidae) from the South American Chaco. The Herpetological Journal, 22, 123-131.

CABRERA, M.R. \& MONGUILLOT, J.C. (2007) Reptilia, Squamata, Teiidae, Teius suquiensis: New evidence of recent expansion of this parthenogenetic lizard? Check List, 3, 180-184.

CACCIALI, P., AVILA, I. \& BAUER, F. (2007) A new species of Homonota (Squamata, Gekkonidae) from Paraguay, with key to the genus. Phyllomedusa, 6, 137-146.

CACCIALI, P., ESPINOLA, D., VINALES, S.C., GAUTO ESPINOLA I. \& CABRAL, H. (2011) Squamata, Serpentes, Micrurus silviae Di-Bernardo, Borges-Martins and Silva, 2007: Presence confirmation in Paraguay. Check List, 7, 809-810.

CACCIALI, P. \& MOTTE, M. (2009) Nuevos registros de Hemidactylus mabouia (Sauria: Gekkonidae) en Paraguay. Cuadernos de Herpetologia, 23, 41-44.

CACCIALI, P. \& SCOTT, N.J. (2015) Key to the Ophiode (Squamata: Sauria: Diploglossidae) of Paraguay with the description of a new species. Zootaxa, 3980, 42-50.

CACCIALI, P., SCOTT, N.J., GUENTHER, R., SAWAYA, R.J., BRUSQUETTI, F. \& BAUER, F. (2009) Taxonomic Status of the False Coral Snake Genus Simophis (Peters, 1860) (Serpentes: Colubridae: Colubrinae) from Paraguay and Brazil. Journal of Herpetology, 43, 698-703.

CACCIALI, P., SCOTT, N.J., ORTíZ, A.L.A., FITZGERALD, L.A. \& SMITH, P. (2016) The Reptiles of Paraguay: Literature, Distribution, and an Annotated Taxonomic Checklist. Special Publication of the Museum of Southwestern Biology $1-373$.

CADLE, J.E. (1989) A New Species of Coniophanes (Serpentes, Colubridae) from Northwestern Peru. Herpetologica, 45 411-424.

CADLE, J.E. (1991) Systematics of Lizards of the Genus Stenocercus (Iguania, Tropiduridae) from Northern Peru New Species and Comments on Relationships and Distribution Patterns. Proceedings of the Academy of Natural Sciences of Philadelphia, 143, 1-96.

CADLE, J.E. (1998) New species of lizards, genus Stenocercus (Iguania: Tropiduridae) from western Ecuador and Peru. Bulletin of the Museum of Comparative Zoology, 155, 257297.$$
297 .
$$

CADLE, J.E. (2007) The Snake Genus Sibynomorphus (Colubridae: Dipsadinae: Dipsadini) In Peru And Ecuador, With Comments On The Systematics Of Dipsadini. Bulleti of the Museum of Comparative Zoology, 158, 183-283.

CADLE, J.E. (2012) Systematics of the neotropical snak Dendrophidion percarinatum (Serpentes: Colubridae), with descriptions of two new species from western Colombia and ecuador and supplementary data on $D$. brunneum. Bulletin of the Museum of Comparative Zoology, 160, 259Bulle

CADLE, J.E. \& CHUNA M, P. (1995) A new lizard of the genus Macropholidus (Teiidae) from a relictual humid forest of northwestern Peru, and notes on Macropholidus ruthven Noble. Breviora, 501, 1-39.
CADLE, J.E. \& SAVAGE, J.M. (2012) Systematics of the Dendrophidion nuchale complex (Serpentes: Colubridae) with the description of a new species from Central America. Zootaxa, 1-50.

CAJADE, R., ETCHEPARE, E.G., FALCIONE, C., BARRASSO, D.A. \& ALVAREZ, B.B. (2013a) A new species of Homonota (Reptilia: Squamata: Gekkota: Phyllodactylidae) endemic to the hills of Paraje Tres Cerros, Corrientes Province, Argentina. Zootaxa, 3709, 162-176.

CAJADE, R., MARANGONI, F. \& GANGENOVA, E. (2013b) Age, body size and growth pattern of Argenteohyla siemersi pederseni (Anura: Hylidae) in northeastern Argentina. Journal of Natural History, 47, 237-251.

CALCAÑO, D. \& BARRIO-AMORÓS, C.L. (2003a) Dipsas variegata (NCN). Herpetological Review, 34, 388.

CALCAÑO, D. \& BARRIO-AMORÓS, C.L. (2003b) Pseustes shropshirei (NCN). Herpetological Review, 34, 389-390.

CALDART, V.M., IOP, S., DE SA, F.P., DA ROCHA, M.C. STEINDORFF DE ARRUDA, J.L., DOS SANTOS, T.G. \& CECHIN, S.Z. (2013) New records of Crossodactylus schmidti Gallardo, 1961 (Anura: Hylodidae) for the state of Rio Grande do Sul, Brazil, with data on morphometry and an updated geographic distribution map. Check List, 9, 15521555.

CALDAS, F.L.S., COSTA, T.B., LARANJEIRAS, D.O., MESQUITA, D.O. \& GARDA, A.A. (2016) Herpetofauna of protected areas in the Caatinga V: Seridó Ecological Station (Rio Grande do Norte, Brazil). Check List, 12, 1-14.

CALDAS, F.L.S., DE-CARVALHO, C.B., SANTANA, D.O., SANTOS, R.A., SILVA, B.D. \& FARIA, R.G. (2010) Amphibia, Anura, Leiuperidae, Physalaemus cicada Bokermann, 1966: first records for the state of Sergipe. Check List, 6, 427-428.

CALDERÓN-ESPINOSA, M.L. \& FORERO, A.B. (2011) Morphological Diversification in Solitary Endemic Anoles: Anolis concolor and Anolis pinchoti from San Andrés and Providence Islands, Colombia. South American Journal of Herpetology, 6, 205-210.

CALDERÓN-ESPINOSA, M.L. \& MEDINA-RANGEL, G.F. (2016) A new Lepidoblepharis lizard (Squamata: Sphaerodactylidae) from the Colombian Guyana shield. Zootaxa, 4067, 215232

CALDERON, M. \& JOFRE, M. (2011) Hypsiboas pulchellus (Montevideo treefrog, Ranita del Zarzal). Herpetological Review, 42, 385.

CALDWELL, J.P. \& MYERS, C.W. (1990) A new poison frog from Amazonian Brazil, with further revision of the quinquevittatus group of Dendrobates. American Museum Novitates, 1-21.

CAMACHO, A. \& ROCHA, P.L.B. (2010) Passive Restoration in Biodiversity Hotspots: Consequences for an Atlantic Rainforest Lizard Taxocene. Biotropica, 42, 379-387.

CAMARDELLI, M., MATOS, M.A. \& MARCIANO-JR., E. (2013) Leposoma puk. Geographic Ditribution. Herpetological Review, 44, 273-274.

CAMERA, B.F. \& KRINSKI, D. (2014) Distribution extension and geographic distribution map of the Brazil-nut poison dart frog Adelphobates castaneoticus (Caldwell \& Myers, 1990) (Anura: Dendrobatidae): New record for southwestern Pará State, Brazil. Check List, 10, 244-245.

CAMINER, M. \& RON, S. (2014) Systematics of treefrogs of the Hypsiboas calcaratus and Hypsiboas fasciatus specie complex (Anura, Hylidae) with the description of four new species. ZooKeys, 370, 1-68.

CAMPBELL, J.A. \& LAMAR, W.W. (2004) The venomous reptiles of the Western Hemisphere. Cornell University Press, Ithaca, 1-870 pp.

CAMPOS, K.T. \& VILLAFUERTE, L.B. (2014) Río Madre de Dios, Departamento de Madre de Dios, Perú - Herpetofauna común de Manu Wildlife Center Chicago, 5 pp.

CAMPOS, V.A., ODA, F.H., CUSTÓDIO, R.J., KOPPE, V.C. \& DARTORA, A. (2011) First state record and distribution extension of Tupinambis duseni Lönnberg, 1910 (Squamata: Sauria: Teiidae) from Mato Grosso state, central Brazil. Herpetology Notes, 4, 1-3.

CAMURUGI, F., LIMA, T.M., MERCÊS, E.A. \& JUNCÁ, F.A. (2010) Anurans of the Reserva Ecológica da Michelin Municipality of Igrapiúna, State of Bahia, Brazil. Biota Neotropica, 10, 305-312.

CANDIDO, C.E.R., BRANADAP, R.A., FREITAS, M.A.D., COELHO, W.D.A. \& FELBERG, E.L. (2012) Amphibia, Anura, Hylidae, Scinax camposseabrai (Bokermann, 1968): geographic distribution and map. Check List, 8, 272-273.

CANEDO, C., DIXO, M. \& POMBAL, J.P., JR. (2004) A new species of Chiasmocleis Mehely, 1904 (Anura, Microhylidae) from the Atlantic Rainforest of Bahia, Brazil. Herpetologica $60,495-501$

CANEDO, C. \& HADDAD, C.F.B. (2012) Phylogenetic relationships within anuran clade Terrarana, with emphasis on the placement of Brazilian Atlantic rainforest frogs genus Ischnocnema (Anura: Brachycephalidae). Molecular Phylogenetics and Evolution, 65, 610-620.

CANEDO, C. \& PIMENTA, B.V.S. (2010) New species of Ischnocnema (Anura, Brachycephalidae) from the Atlantic rainforest of the state of Espírito Santo, Brazil. South American Journal of Herpetology, 5, 199-206.

CANEDO, C., PIMENTA, B.V.S., LEITE, F.S.F. \& CARAMASCHI, U. (2010) New Species of Ischnocnema (Anura:
Brachycephalidae) from the State of Minas Gerais,

Southeastern Brazil, with Comments on the I. verrucosa Species Series. Copeia, 2010, 629-634.

CANEDO, C. \& POMBAL, J.P. (2007) Two new species of torrent frog of the genus Hylodes (Anura, Hylodidae) with nuptial thumb tubercles. Herpetologica, 63, 224-235.

CANEDO, C., TARGINO, M., LEITE, F.S.F. \& HADDAD, C.F.B. (2012) A New Species Of Ischnocnema (Anura) From The São Francisco Basin Karst Region, Brazil. Herpetologica, 68 393-400

CANELAS, M.A.S. \& BERTOLUCI, J. (2007) Anurans of the Serra do Caraça, southeastern Brazil: species composition and phenological patterns of calling activity. Iheringia, Série Zoologia, 97, 21-26.

CANNATELLA, D.C. (1980a) A review of the Phyllomedusa buckleyi group (Anura: Hylidae). Occasional Papers of the Museum of Natural History University of Kansas, 87, 1-40.

CANNATELLA, D.C. (1980b) Two new species of Centrolenella

from Bolivia (Anura: Centrolenidae). Proceedings of the Biological Society of Washington, 93, 714-724.

CANO, P.D., BALL, H.A., CAERPINETTO, M.F. \& PEÑA, G.D. (2015) Reptile checklist of Río Pilcomayo National Park, Formosa, Argentina. Check List, 11, 1-13.

CAORSI, V.Z., COLOMBO, P., FREIRE, M.D., AMARAL, I.B. ZANK, C., BORGES-MARTINS, M. \& GRANT, T. (2014) Natural history, coloration pattern and conservation statu of the threatened South Brazilian red bellied toad, Melanophryniscus macrogranulosus Braun, 1973 (Anura, Bufonidae). Herpetology Notes, 7, 585-598.

CAPPELLARI, L.H., BALESTRIN, R.L. \& BEUREN, E.C. (2001) Anisolepis grilli. Herpetological Review, 32, 192.

CARAM, J., LUNA-DIAS, C., GOMES, M.D.R. \& DE CARVALHO E-SILVA, S.P. (2011) Distribution extension of Scinax hiemalis (Haddad and Pombal, 1987) and new state record from Rio de Janeiro, southeastern Brazil (Amphibia: Anura: Hylidae). Herpetology Notes, 4, 153-154.

CARAMASCHI, U. (2006) Redefinição do grupo de Phyllomedusa hypochondrialis, com redescrição de $P$. megacephala (Miranda-Ribeiro, 1926), revalidação de $P$. azurea Cope, 1862 e descrição de uma nova espécie (Amphibia, Anura, Hylidae). Arquivos do Museu Nacional, 64, 159-179.

CARAMASCHI, U. (2010) Notes on the taxonomic status of Elachistocleis ovalis (Schneider, 1799) and description of five new species of Elachistocleis Parker, 1927 (Amphibia, Anura, Microhylidae). Boletim do Museu Nacional, Nova Série - Zoologia, 527, 1-30.

CARAMASCHI, U., ALMEIDA, A.D. \& GASPARINI, J.L. (2009a) Description of two new species of Sphaenorhynchus (Anura Hylidae) from the State of Espírito Santo, Southeastern Brazil. Zootaxa, 34-46.

CARAMASCHI, U. \& CRUZ, C.A.G. (2013) A New Species of the Hypsiboas polytaenius Clade from Southeastern Brazi (Anura: Hylidae). South American Journal of Herpetology, 8 121-126.

CARAMASCHI, U., CRUZ, C.A.G. \& NASCIMENTO, L.B. (2009b) A new species of Hypsiboas of the $H$. polytaenius clade from southeastern Brazil (Anura: Hylidae). South American Journal of Herpetology, 4, 210-216.

CARAMASCHI, U., CRUZ, C.A.G. \& SEGALLA, M.V. (2010) A New Species of Hypsiboas of the H. polytaenius Clade from the State of Paraná, Southern Brazil (Anura: Hylidae). South American Journal of Herpetology, 5, 169-174.

CARAMASCHI, U. \& CRUZ, C.A.G.D. (1998) Taxonomic notes on Pseudis fusca Garman and P. bolbodactyla A. Lutz, with description of a new correlated species (Anura, Pseudidae). Revista Brasileira de Zoologia, 15, 929-944.

CARAMASCHI, U. \& DE NIEMEYER, H. (2005) Stefania tamacuarina. Herpetological Review, 36, 77 .

CARAMASCHI, U., FEIO, R.N. \& SAO-PEDRO, V.A. (2008) A new species of Leptodactylus fitzinger (Anura,
Leptodactylidae) from Serra do Brigadeiro, State of Minas Gerais, Southeastern Brazil. Zootaxa, 44-54.

CARAMASCHI, U. \& GONCALVES DA CRUZ, C.A. (1997) Redescription of Chiasmocleis albopunctata (Boettger) and description of a new species of Chiasmocleis (Anura: Microhylidae). Herpetologica, 53, 259-268.

CARAMASCHI, U., LULA SALLES, R.D.O. \& GONCALVES CRUZ, C.A. (2012) A new species of Stereocyclops Cope (Anura, Microhylidae) from Southeastern Brazil. Zootaxa, 3583, 8388

CARAMASCHI, U. \& NAPOLI, M.F. (2012) Taxonomic revision of the Odontophrynus cultripes species group, with description of a new related species (Anura, Cycloramphidae). Zootaxa, 3155, 1-20.

CARAMASCHI, U., NUNES, I., NASCIMENTO, L.B. \& CARVALHO, R.R. (2013a) The type locality of Scinax dollo (Werner, 1903) (Anura, Hylidae). Zootaxa, 3691, 299-300. CARAMASCHI, U., ORRICO, V.G.D., FAIVOVICH, J., DIAS, I.R. \& SOLE, M. (2013b) A new species of Allophryne (Anura: Allophrynidae) from the Atlantic Rain Forest biome of eastern Brazil. Herpetologica, 69, 480-491.

CARAMASCHI, U. \& PEIXOTO, O.L. (2004) A new species of Phyllodytes (Anura : Hylidae) from the State of Sergipe, northeastern Brazil. Amphibia-Reptilia, 25, 1-7.

CARAMASCHI, U., PEIXOTO, O.L. \& RODRIGUES, M.T. (2004a) Revalidation and redescription of Phyllodytes wucherer (Peters, 1873) (Amphibia, Anura, Hylidae). Arquivos do 
CARAMASCHI, U., PIMENTA, B.V.S. \& FEIO, R.N. (2004b) A new species of the group of Hyla geographica Spix, 1824 from the Atlantic rain forest, Brazil (Amphibia, Anura, Hylidae). Boletim do Museu Nacional, Nova Série - Zoologia, 518, 1-14.

CARDOSO DA SILVA, M.C. (2009) Sistemática do gênero Phyllodytes Wagler, 1830 (Anura, Hylidae). Doutorado. Zoologia, Universidade Federal do Rio de Janeiro, Rio de Janeiro, $159 \mathrm{pp}$.

CARLO, A.B. \& ROZE, J.A. (2005) Lizards of the Genus Anolis (Reptilia: Polychrotidae) from Sierra Nevada de Santa Marta, Colombia, with Description of two New Species. Novedades Colombianas Nueva Epoca, 8, 9-26.

CARRASCO, P.A., VENEGAS, P.J. \& VALENCIA, J.H. (2016) First confirmed records of the endangered Andean pitviper Bothrops lojanus Parker, 1930 (Viperidae: Crotalinae) from Peru. Herpetology Notes, 9, 297-301.

CARREIRA, S. \& BALETTA, S. (2004) Stenocercus azureus (NCN). Reproduction. Herpetological Review, 35, 270

CARREIRA, S., MENEGHEL, M. \& ACHAVAL, F. (2005) Reptiles de Uruguay. DIRAC Facultad de Ciencias, Universidad de la República, Montevideo, $639 \mathrm{pp}$.

CARRILLO DE ESPINOZA, N. (1983) List of Peruvian Anolis with distributional data (Sauria: Iguanidae). In: RHODIN, A.G.J. \& MIYATA, K. (Eds.) Advances in Herpetology and Evolutionary Biology. Mus. Comp. Zool., Cambridge, pp. 406-411.

CARVAJAL-COGOLLO, J.E. \& BERNAL-GONZALEZ, V.A. (2011) Anolis euskalerriari. Herpetological Review, 42, 111.

CARVAJAL-COGOLLO, J.E., BERNAL-GONZALEZ, V.A. \& NONZOQUE-LÓPEZ, N. (2011) Anadia ocellata (Ocellated Anadia). Herpetological Review, 42, 390.

CARVALHO-E-SILVA, A.M.P.T., MONGIN, M.M., IZECKSOHN, E. \& CARVALHO-E-SILVA, S.P. (2010) A new species of Dendrophryniscus Jiménez-de-la-Espada from the Parque Nacional da Serra dos Órgãos, Teresópolis, state of Rio de Janeiro, Brazil (Amphibia, Anura, Bufonidae). Zootaxa 2632, 46-52.

CARVALHO-E-SILVA, A.M.P.T., SILVA, G.R. \& CARVALHO-ESILVA, S. (2008) Anurans at Rio das Pedras Reserve, Mangaratiba, RJ, Brazil. Biota Neotropica, 8, 199-209.

CARVALHO-E-SILVA, A.M.P.T., SILVA, G.R. \& CARVALHO-ESILVA, S.P. (2009) A new species of Phasmahyla Cruz, 1990 from the Atlantic Forest in the state of Rio de Janeiro, Brazil (Amphibia, Hylidae, Phyllomedusinae). Zootaxa, 15-26.

CARVALHO-JR, R.R., CANELAS, M.A.S. \& NASCIMENTO, L.B. (2004) Caracterização da herpetofauna da área de Influência do AHE Aimorés, bacia do rio Doce, Minas Gerais. In: 10 Congresso Brasileiro de Herpetologia. HERPETOLOGIA, S.B.D. (ed.). Sociedade Brasileira de HERPETOLOGIA, S.B.D.
Herpetologia, Curitiba

CARVALHO, A.L.G. (2016) Three new species of the Tropidurus spinulosus group (Squamata: Tropiduridae) from Eastern Paraguay. American Museum Novitates, 2016, 1-44.

CARVAlHo, A.L.G., ARAUJO, A.F.B. \& SILVA, H.R. (2007a) Lagartos da Marambaia, um remanescente insular de Restinga e Floresta Atlântica no Estado do Rio de Janeiro, Brasil. Biota Neotropica, 7, 1-6.

Carvalho, A.L.G., SeNA, M.A., Peloso, P.L., MACHADO, F.A., MONTESINOS, R., SILVA, H.R., CAMPBELL, G. \& RODRIGUES, M.T. (2016a) A new Tropidurus (Tropiduridae) from the semiarid Brazilian Caatinga: evidence for conflicting signal between mitochondrial and nuclear loci affecting the phylogenetic reconstruction of South American collared lizards. American Museum Novitates, 2016, 1-66.

CARVALHO, A.L.G., SILVA, H.R., ARAUJO, A.F.B., VES-SILVA, R. \& SILVA-LEITE, R.R. (2007b) Feeding ecology of Tropidurus torquatus (Wied) (Squamata,Tropiduridae) in two areas with different degrees of conservation in Marambaia Island, Rio de Janeiro, Southeastern Brazil. Revista Brasileira de Zoologia, 24, 222-227.

CARVALHO, C.B., SANTOS, R.A., ROCHA, S.M., CALDAS, F.L.S., FREITAS, E.B., SILVA, B.D., SANTANA, D.O. \& FARIA, R.G (2012a) Gymnodactylus geckoides (Naked-Toed Gecko): Predation. Herpetological Bulletin, 41-43.

CARVALHO, C.M. (1997) Uma nova espécie de Microteiideo do gênero Gymnophthalmus do estado de Roraima, Brasil (Sauria, Gymnophthalmidae). Papéis Avulsos de Zoologia, 40, 161-174.

CARVALHO, C.M.D., VILAR, J.C. \& OLIVEIRA, F.F. (2005) Répteis e Anfíbios. In: CARVALHO, C.M.D. \& VILAR, J.C. (Eds.) Parque Nacional Serra de Itabaiana - Levantamento da Biota. IBAMA, Biologia Geral e Experimental - UFS, Aracaju, pp. 39-61.

CARVALHO, R.R., JR., KLEINSORGE, J.M.D. \& FUSINATTO, L.A. (2010a) Amphibia, Anura, Cycloramphidae, Odontophrynus moratoi Jim and Caramaschi, 1980: filling gaps. Discovery of a new population in the state of São Paulo, southeastern Brazil. Check List, 6, 36-37.

CARVALHO, T.R., GIARETTA, A.A. \& MAGRINI, L. (2012b) A new species of the Bokermannohyla circumdata group (Anura: Hylidae) from southeastern Brazil, with bioacoustic data on seven species of the genus. Zootaxa, 37-55.

CARVALHO, T.R., GIARETTA, A.A., TEIXEIRA, B.F.D. \& MARTINS, L.B. (2013) New bioacoustic and distributional data on Bokermannohyla sapiranga Brandão et al., 2012 (Anura: Hylidae): revisiting its diagnosis in comparison with
B. pseudopseudis (Miranda-Ribeiro, 1937). Zootaxa, 3746, 383-392.

CARVALHO, T.R., MARTINS, L.B. \& GIARETTA, A.A. (2015a) The complex vocalization of Scinax cardosoi (Anura: Hylidae), with comments on advertisement calls in the $S$. Hylidae), with comments on advertisem
ruber Clade. Phyllomedusa, 14, 127-137.

CARVALHO, T.R., MARTINS, L.B. \& GIARETTA, A.A. (2016b) A new account for the endangered Cerrado Rocket Frog Allobates goianus (Bokermann, 1975) (Anura: Aromobatidae), with comments on taxonomy and conservation. Acta Herpetologica, 11, 21-30.

CARVALHO, T.R., MARTINS, L.B., TEIXEIRA, B.F.D., GODINHO, L.B. \& GIARETTA, A.A. (2015b) Intraspecific variation in acoustic traits and body size, and new distributional records for Pseudopaludicola giarettai carvalho, 2012 (Anura, Leptodactylidae, Leiuperinae): implications for its
congeneric diagnosis. Papéis Avulsos de Zoologia, 55, 245cong.

CARVALHO, V.T., BONORA, L., VOGT, R.C. \& AVILA-PIRES, T.C.S. (2006) Bachia pyburni. Herpetological Review, 37 240.

CARVALHO, V.T., MACCULLOCH, R.D., BONORA, L. \& VOGT, R.C. (2010b) New Species of Stefania (Anura: Cryptobatrachidae) from Northern Amazonas, Brazil. Journal of Herpetology, 44, 229-235.

CASSIMIRO, J. \& RODRIGUES, M.T. (2009) A new species of lizard genus Gymnodactylus Spix, 1825 (Squamata: Gekkota: Phyllodactylidae) from Serra do Sincorá, 2005. Zootaxa, 38-52.

CASSIMIRO, J., SILVA, V.X. \& BERTOLUCI, J. (2006) Anolis punctatus (Lagartixa Verda da Amazônia; Amazon Green Anole). Geographic Distribution. Herpetological Review, 37 105-106.

CASSIMIRO, J., VERDADE, V.K. \& RODRIGUES, M.T. (2008) A large and enigmatic new eleutherodactyline frog (Anura, Strabomantidae) from Serra do Sincora, Espinhaco range, northeastern Brazil. Zootaxa, 59-68.

CASSINI, C.S., CRUZ, C.A.G. \& CARAMASCHI, U. (2010) Taxonomic review of Physalaemus olfersii (Lichtenstein \& Martens, 2856) with revalidation of Physalaemus lateristriga (Steindachner, 1864) and description of two new related species (Anura: Leiuperidae). Zootaxa, 1-33.

CASTAÑO-MORA, O.V., CÁRDENAS-A., G., HERNÁNDEZ-R., E. \& CASTRO-H., F. (2004) Reptiles en el Chocó Biogeográfico. In: RANGEL, O. (Ed.) Colombia Diversidad Biótica IV, EI Chocó Biogeográfico / Costa Pacífica. . Universidad Nacional de Colombia-UNIBIBLOS, Conservación Internacional, Bogotá, pp. 597-631.

CASTRILLON, M.I. \& STRÜSSMANN, C. (1998) A new species of Bachia and the occurrence of $B$. dorbignyi (Duméril and Bibron) in southwestern Mato Grosso, Brazil (Sauria, Gymnophthalmidae). Revista Brasileira de Zoologia, 15, 567-581.

CASTRO-HERRERA, F., BolívAR-GARCía, W. \& HERRERAMONTES, M.I. (2007) Guía de los anfibios y reptiles del Bosque de Yotoco, Valle del Cauca - Colombia. Imprenta Bosque de Yotoco, Valle del Cauca - Colombital del Valle del Cauca, Cali, 70 pp.

CASTRO-MELLO, C. (2000) A new species of Amphisbaena from central Brasil (Squamata: Amphisbaenidae). Papéis Avulsos de Zoologia, 41, 243-246.

CASTRO, F. \& AYALA, S.C. (1982) Nueva especie de (Sauria: Iguanidae) lagarto collarejo de la zona sur Andina de Colombia. Caldasia, 13, 473-478.

CASTRO, S.A., JIMENEZ, J.E. \& JAKSIC, F.M. (1991) Diet of the Racerunner Callopistes palluma in North-Central Chile. Journal of Herpetology, 25, 127-129.

CASTROVIEJO-FISHER, S., GUAYASAMIN, J.M. \& KOK, P.J.R. (2009a) Species status of Centrolene lema Duellman and Senaris, 2003 (Amphibia: Centrolenidae) revealed by Integrative Taxonomy. Zootaxa, 16-28.

CASTROVIEJO-FISHER, S., MORAVEC, J., APARICIO, J., GUERRERO-REINHARD, M. \& CALDERON, G. (2011) DNA taxonomy reveals two new species records of Hyalinobatrachium (Anura: Centrolenidae) for Bolivia. Zootaxa, 64-68.

CASTROVIEJO-FISHER, S., PADIAL, J.M., CHAPARRO, J.C. AGUAYO, R. \& DE LA RIVA, I. (2009b) A new species of Hyalinobatrachium (Anura: Centrolenidae) from the Amazonian slopes of the central Andes, with comments on the diversity of the genus in the area. Zootaxa, 24-44.

CASTROVIEJO-FISHER, S., PEREZ-PENA, P.E., PADIAL, J.M. \& GUAYASAMIN, J.M. (2012) A Second Species of the Family Allophrynidae (Amphibia: Anura). American Museum Novitates, 1-17.

CATENAZZI, A. \& TTITo, A. (2016) A new species of Psychrophrynella (Amphibia, Anura, Craugastoridae) from the humid montane forests of Cusco, eastern slopes of the Peruvian Andes. PeerJ, 4, e1807.

CATENAZZI, A., VARGAS GARCIA, V. \& LEHR, E. (2015a) A new species of Telmatobius (Amphibia, Anura, Telmatobiidae) from the Pacific slopes of the Andes, Peru. ZooKeys, 480, 81-95.

CATENAZZI, A., VARGAS, V. \& LEHR, E. (2015b) A new species of Telmatobius (Amphibia, Anura, Telmatobiidae) from the Pacific slopes of the Andes, Peru. ZooKeys, 480, 81-95. CATENAZZI, A., VON MAY, R., LEHR, E., GAGLIARDI-URRUTIA,
G. \& GUAYASAMIN, J.M. (2012) A new, high-elevation glassfrog (Anura: Centrolenidae) from Manu National Park, southern Peru. Zootaxa, 3388, 56-68.

CEI, J.M. (1962) Mapa preliminar de la distribucion continental de las "sibling species" del grupo ocellatus (genero Leptodactylus). Revista de la Sociedad Argentina de Biologia, 38, 258-265.

CEI, J.M. (1974) Two New Species of Ctenoblepharis (Reptilia, Iguanidae) from the Arid Environments of the Central Argentina (Mendoza Province). Journal of Herpetology, 8 $71-75$

CEI, J.M. (1982) A new species of Tropidurus (Sauria, Iguanidae) from the arid chacoan and western regions of Argentina. Occasional Papers of the Museum of Natural History University of Kansas, 1-10.

CEI, J.M. (1986) Reptiles del centro, centro-oeste y sur de lo Argentina - Herpetofauna de las zonas áridas y semiáridas. Museo Riogionale di Scienze Naturali Torino, Torino, 537 $\mathrm{pp}$.

CEI, J.M. (1993) Reptiles del noroeste, nordeste y este de la Argentina - Herpetofauna de las selvas subtropicales, Puna y Pampas. Museo Regionale di Scienze Naturali, Torino, 949 ypamp.

CEI, J.M. \& ORTIZ, J.C. (1983) Descripcion de una nueva especie de lagarto Liolaemus coeruleus $\mathrm{n}$. sp. para Argentina (Sauria, Iguanidae). Boletin de la Sociedad de Biología de Concepción, 54, 35-41.

CEI, J.M. \& PÉFAUR, J.E. (1982) Una nueva especie de Liolaemus (Iguanidae: Squamata): Su sistemática, ecología y distribución. Zoología Neotropical: Actas VIII Congreso Latinoamericano de Zoología, 2, 573-586.

CEI, J.M., SCOLARO, J.A. \& VIDELA, F. (2001) The present status of Argentinean polychrotid species of the genus Pristidactylus and description of its southernmost taxon as a new species. Journal of Herpetology, 35, 597-605.

CEI, J.M. \& VIDELA, F. (2002) A new species of Liolaemus lacking precloacal pores in males from the Andean southeastern mountains of Mendoza Province, Argentina. (Liolaemidae, Iguania, Lacertilia, Reptilia). Museo Regionale di Scienze Naturali Bollettino (Turin), 20, 275-290.

CESPEDEZ, J.A. (2000) Natural history of Pedersen's frog Argenteohyla siemersi pederseni (Anura: Hylidae), and larval description. Boletin de la Asociacion Herpetologica Espanola, 11, 75-80.

CÉSPEDEZ, J.A. (1996) Primera cita de Physalaemus riograndensis Milstead, 1960, para la provincia de Formosa y comentarios sobre su distribución actual (Anura: Leptodactylidae). Cuadernos de Herpetologia, 10, 75-76.

CÉSPEDEZ, J.A. (2008) Una nueva especie de Melanophryniscus Gallardo, 1961 de Argentina (Amphibia: Melanophryniscus Gallardo, 1961 de
Anura: Bufonidae). Facena, 24, 35-48.

CÉSPEDEZ, J.A. \& MOTTE, M. (2007) Una nueva especie de Melanophryniscus Gallardo, 1961 de Paraguay (Amphibia: Anura: Bufonidae). Facena, 23, 29-40.

CHALKIDIS, H.D.M. \& DI-BERNARDO, M. (2004) Amphisbaena darwinii trachura (worm lizard). Albinism. Herpetologica Review, 35, 165.

CHAPARRO, J.C., MOTTA, A.P., GUTIERREZ, R.C. \& PADIAL, J.M. (2012) A new species of Pristimantis (Anura: Strabomantidae) from Andean cloud forests of northern Peru. Zootaxa, 39-48.

CHAPARRO, J.C., PADIAL, J.M., GUTIERREZ, R.C. \& DE LA RIVA, I. (2015) A new species of Andean frog of the genus Bryophryne from southern Peru (Anura: Craugastoridae) and its phylogenetic position, with notes on the diversity of the genus. Zootaxa, 3994, 94-108.

CHARRIER, A., CORREA, C., CASTRO, C. \& MENDEZ, M.A. (2015) A new species of Alsodes (Anura: Alsodidae) from Altos de Cantillana, central Chile. Zootaxa, 3915, 540-550.

CHÁVEZ-ARRIBASPLATA, J.C., DURAN, V. \& CHÁVEZ, G. (2015) Reptilia, Squamata, Gymnophthalmidae, Potamites erythrocularis Chávez \& Catenazzi, 2014: Distribution extension Herpetology Notes, 8, 625-628.

CHÁVEZ, G. (2012) Tachymenis affinis Boulenger, 1896 (Squamata: Colubridae): distribution extension in Perú. Herpetotrópicos, 7, 31-33.

CHÁVEZ, G. \& CATENAZZI, A. (2014) A new Andean lizard of the genus Potamites (Sauria, Gymnophthalmidae) from Manu National Park, southeastern Peru. Zootaxa, 3774, 4556.

CHÁVEZ, G. \& CATENAZZI, A. (2016) A new species of frog of the genus Pristimantis from Tingo María National Park Huánuco Department, central Peru (Anura, Craugastoridae). ZooKeys, 610, 113-130.

CHÁVEZ, G., SANTA-CRUZ, R., RODRIGUEZ, D. \& LEHR, E. (2015) Two new species of frogs of the genus Phrynopus (Anura: Terrarana: Craugastoridae) from the Peruvian Andes. Amphibian and Reptile Conservation, 9, 15-25.

CHÁVEZ, G., SIU-TING, K., DURAN, V. \& VENEGAS, P.J. (2011) Two new species of Andean gymnophthalmid lizards of the genus Euspondylus (Reptilia, Squamata) from central and southern Peru. ZooKeys, 1-17.

CHAVEZ, G. \& VASQUEZ, D. (2012) A new species of Andean semiaquatic lizard of the genus Potamites (Sauria, Gymnophtalmidae) from southern Peru. ZooKeys, 31-43.

CHÁVEZ, G., VÁSQUEZ, D. \& ECHEVARRíA, L.Y. (2013) Amphibia, Anura, Bufonidae, Rhinella manu Chaparro Pramuk and Gluesenkamp, 2007; Rhinella tacana Padial Reichle, Mcdiarmid and de la Riva, 2006: Distribution 
extension and country record from southern Peru. Check List, 9, 840-843.

CICCHI, P.J., SERAFIM, H., SENA, M.A., CENTENO, F.D.C. \& JIM, J. (2009) Herpetofauna em uma área de Floresta Atlântica na llha Anchieta, município de Ubatuba, sudeste do Brasil. Biota Neotropica, 9, 1-12.

CINTRA, C.E.D., SILVA, H.L.R. \& SILVA JR, N.J. (2009a) Herpetofauna, Santa Edwiges I and II hydroelectric powe plants, state of Goiás, Brazil. Check List, 5, 570-576.

CINTRA, C.E.D., SILVA, H.L.R., SILVA JR., N.J., GARCIA, P.C.A. \& ZAHER, H. (2009b) A new species of Trachycephalus (Amphibia, Anura, Hylidae) from the State of Goiás, Brazil. Zootaxa, 58-68.

CINTRA, C.E.D., SILVA, H.L.R. \& SILVA JUNIOR, N.J. (2013) New state record of Vitreorana eurygnatha (Lutz 1925) (Anura: Centrolenidae) in Brazil. Herpetology Notes, 6, 587590.

CISNEROS-HEREDIA, D.F. (2003) Herpetofauna de la Estación de Biodiversidad Tiputini, Amazonía Ecuatoriana: Ecología de una comunidad taxonómicamente diversa con comentarios sobre metodologías de inventario. In: DE LA TORRE, S. \& RECK, G. (Eds.) Ecología y Ambiente en el Ecuador: Memorias del I Congreso de Ecología y Ambiente, Ecuador país megadiverso. Universidad San Francisco de Quito, Quito, pp. 1-21.

CISNEROS-HEREDIA, D.F. (2006a) La Herpetofauna de la Estación de Biodiversidad Tiputini, Ecuador - Diversidad Ecología de los Anfíbios \& Reptiles de una Comunidad Taxonómicamente Diversa. Colegio de Ciencias Biológicas y Ambientales de lá Universidad San Francisco de Quito, Quito, LOR1-143 pp.

CISNEROS-HEREDIA, D.F. (2006b) Reptilia, Colubridae, Helicops angulatus and Helicops leopardinus: distribution extension, new country record. Check List, 2, 36-37.

CISNEROS-HEREDIA, D.F. (2007) A new species of glassfrog of the genus Centrolene from the foothills of Cordillera Oriental of Ecuador (Anura: Centrolenidae). Herpetozoa, 20, 27-34.

CISNEROS-HEREDIA, D.F. (2008) Reptilia, Squamata, Leptotyphlopidae, Leptotyphlops, Ecuador: re-evaluation of the species cited for the country. 2008, 4, 1-4.

CISNEROS-HEREDIA, D.F. (2009) Amphibia, Anura, Centrolenidae, Chimerella mariaelenae (Cisneros-Heredia and McDiarmid, 2006), Rulyrana flavopunctata (Lynch and Duellman, 1973), Teratohyla pulverata (Peters, 1873), and Teratohyla spinosa (Taylor, 1949): historical records, distribution extension and new provincial record in Ecuador. Check List, 5, 912-916.

CISNEROS-HEREDIA, D.F., ARMIJOS-OJEDA, D. \& VALAREZO, K. (2009) First country record of Pristimantis metabates (Duellman and Pramuk) and distribution extension of Pristimantis skydmainos (Flores and Rodriguez) in eastern Ecuador (Amphibia, Anura, Strabomantidae). Herpetology Notes, 2, 185-188.

CISNEROS-HEREDIA, D.F. \& GLUESENKAMP, A.G. (2010) A new Andean Toad of the genus Osornophryne (Amphibia: Anura: Bufonidae) from northwestern Ecuador, with taxonomic remarks on the genus. Avances en Ciencias $e$ Ingenierias, Section B, 2, B64-B673.

CISNEROS-HEREDIA, D.F. \& MCDIARMID, R.W. (2005) Amphibia, Centrolenidae, Centrolene peristictum Centrolene prosoblepon, Cochranella cochranae, Cochranella midas, Cochranella resplendens, Cochranella spinosa, Hyalinobatrachium munozorum: range extension and new provincial records. Check List, 1, 18-22.

CISNEROS-HEREDIA, D.F. \& MCDIARMID, R.W. (2006a) A new species of the genus Centrolene (Amphibia: Anura: Centrolenidae) from Ecuador with comments on the taxonomy and biogeography of Glassfrogs. Zootaxa, 1244, 1-32.

CISNEROS-HEREDIA, D.F. \& MCDIARMID, R.W. (2006b) Primer registro de Hyalinobatrachium ruedai (Amphibia: Centrolenidae) en Ecuador, con notas sobre otras especies congenericas. Herpetotrópicos, 3, 21-28.

CISNEROS-HEREDIA, D.F. \& MCDIARMID, R.W. (2006c) Review of the taxonomy and conservation status of the Ecuadorian Glassfrog Centrolenella puyoensis Flores \& McDiarmid (Amphibia: Anura: Centrolenidae). Zootaxa, 21-31.

CISNEROS-HEREDIA, D.F. \& MCDIARMID, R.W. (2007) Revision of the characters of Centrolenidae (Amphibia: Anura: Athesphatanura), with comments on its taxonomy and the description of new taxa of glassfrogs. Zootaxa, 1572, 1-82.

CISNEROS-HEREDIA, D.F. \& MORALES-MITE, M.A. (2008) A new species of glassfrog from the elfin forests of the Cordillera del Condor, southeastern Ecuador. (Anura: Centrolenidae). Herpetozoa, 21, 49-56.

CISNEROS-HEREDIA, D.F., VENEGAS, P.J., RADA, M. \& SCHULTE, R. (2008) A new species of glassfrog (Anura: Centrolenidae) from the Foothill Andean Forests of Ecuador and Peru. Herpetologica, 64, 341-353.

CISNEROS-HEREDIA, D.F. \& YÁNEZ-MUÑOZ, M.H. (2010) A new poison frog of the genus Epipedobates (Dendrobatoidea: Dendrobatidae) from the north-western Andes of Ecuador. Avances en Ciencias e Ingenierias, Section B, 2, B83-B86.

CLEMENTE-CARVALHO, R.B.G., GIARETTA, A.A., CONDEZ, T.H., HADDAD, C.F.B. \& DOS REIS, S.F. (2012) A New
(Anura: Brachycephalidae), from the Atlantic Forest of Southeastern Brazil. Herpetologica, 68, 365-374.

COLE, C.J. \& DESSAUER, H.C. (1993) Unisexual and Bisexual Whiptail Lizards of the Cnemidophorus lemniscatus Complex (Squamata: Teiidae) of the Guiana Region, South America, with Descriptions of New Species. American Museum Novitates, 1993, 1-30.

COLE, C.J., DESSAUER, H.C., TOWNSEND, C.R. \& ARNOLD, M.G. (1990) Unisexual lizards of the genus Gymnophthalmus (Reptilia: Teiidae) in the Neotropics: genetics, origin, and systematics. American Museum Novitates, 1990, 1-29.

COLE, C.J. \& KOK, P.J.R. (2006) A New Species of Gekkonid Lizard (Sphaerodactylinae: Gonatodes) from Guyana, South America. American Museum Novitates, 2006, 1-13.

COLE, C.J., TOWNSEND, C.R., REYNOLDS, R.P., MACCULLOCH R.D. \& LATHROP, A. (2013) Amphibians and reptiles of Guyana, South America: illustrated keys, annotated species
accounts, and a biogeographic synopsis. Proceedings of the Biological Society of Washington, 125, 317-620.

COLINA, M., ARRIETA, D. \& CARREIRA, S. (2012) Ophiodes intermedius Boulenger, 1894 (Squamata: Anguidae) Uruguay distribution extension with conservation comments. Check List, 8, 896-897.

COLLI, G.R., BASTOS, R.P. \& ARAUJO, A.F. (2002) The character and dynamics of the cerrado herpetofauna. In: OLIVEIRA, P.S. \& MARQUIS, R.J. (Eds.) The cerrados of Brazil: ecology and natural history of a neotropical sava

COLLI, G.R., CALDWELL, J.P., COSTA, G.C., GAINSBURY, A.M., GARDA, A.A., MESQUITA, D.O., FILHO, C.M., SOARES, A.H., SILVA, V.N., VALDUJO, P.H., VIEIRA, G.H., VITT, L.J., WERNECK, F.P., WIEDERHECKER, H.C. \& ZATZ, M.G (2003a) A new species of Cnemidophorus (Squamata, Teiidae) from the Cerrado biome in Central Brazil. Occasional Papers Sam Noble Oklahoma Museum of Natural History, 14, 1-14.

COLLI, G.R., COSTA, G.C., GARDA, A.A., KOPP, K.A, MESQUITA, D.O., PERES, A.K., VALDUJO, P.H., VIEIRA, G.H.C. \& WIEDERHECKER, H.C. (2003b) A critically G.H.C. \& WIangered new species of Cnemidophorus (Squamata,
endang Teiidae) from a Cerrado enclave in southwestern Amazonia, Brazil. Herpetologica, 59, 76-88.

COLLI, G.R., GIUGLIANO, L.G., MESQUITA, D.O. \& FRANÇA F.G.R. (2009) A New Species Of Cnemidophorus From The Jalapão Region, In The Central Brazilian Cerrado. Herpetologica, 65, 311-327.

COLLI, G.R., HOOGMOED, M.S., CANNATELLA, D.C. CASSIMIRO, J., GOMES, J.O., GHELLERE, J.M., NUNES, P.M.S., PELLEGRINO, K.C.M., SALERNO, P., SOUZA, S.M. \& RODRIGUES, M.T. (2015) Description and phylogenetic relationships of a new genus and two new species of lizards from Brazilian Amazonia, with nomenclatural comments on the taxonomy of Gymnophthalmidae (Reptilia: Squamata). Zootaxa, 4000, 401-427.

COLLI, G.R., MESQUITA, D.O., RODRIGUES, P.V.V. \& KITAYAMA, K. (2003c) Ecology of the gecko Gymnodactylus geckoides amarali in a neotropical Savanna. Journal of Herpetology, 37, 694-706

COLLI, G.R., PERES, A.K. \& DA CUNHA, H.J. (1998) A new species of Tupinambis (Squamata : Teiidae) from central Brazil, with an analysis of morphological and genetic variation in the genus. Herpetologica, 54, 477-492.

COLOMA, L.A. (1995) Ecuadorian frogs of the genus Colostethus (Anura: Dendrobatidae). University of Kansas Natural History Museum Miscellaneous Publication, 87, 172.

COLOMA, L.A., CARVAJAL-ENDARA, S., DUENAS, J.F., PAREDES-RECALDE, A., MORALES-MITE, M., ALMEIDAREINOSO, D., TAPIA, E.E., HUTTER, C.R., TORAL, E. \& GUAYASAMIN, J.M. (2012) Molecular phylogenetics of stream treefrogs of the Hyloscirtus larinopygion group (Anura: Hylidae), and description of two new species from Ecuador. Zootaxa, 1-78.

COLOMA, LA., DUELIMAN, W.E., ANA, A.C., RON, S.R., TERAN-VALDEZ, A. \& GUAYASAMIN, J.M. (2010) Five new (extinct?) species of Atelopus (Anura: Bufonidae) from Andean Colombia, Ecuador, and Peru. Zootaxa, 1-54.

COLOMA, L.A., LOTTERS, S., DUELLMAN, W.E. \& MIRANDA LEIVA, A. (2007) A taxonomic revision of Atelopus pachydermus, and description of two new (extinct?) species of Atelopus from Ecuador (Anura: Bufonidae). Zootaxa, 1 32.

COLOMA, L.A., LOTTERS, S. \& SALAS, A.W. (2000) Taxonomy of the Atelopus ignescens complex (Anura : Bufonidae) Designation of a neotype of Atelopus ignescens and recognition of Atelopus exiguus. Herpetologica, 56, 303324

COLOMBO, P., ZANK, C., COSTA SCHMIDT, L.E., GONCALVES, G. \& REPPOLD MARINHO, J. (2007) Anura, Bufonidae, Melanophryniscus simplex: distribution extension. Check List, 3, 305-307.

CONDEZ, T.H., CLEMENTE-CARVALHO, R.B.G., HADDAD, C.F.B. \& DOS REIS, S.F. (2014) A New Species of Brachycephalus (Anura: Brachycephalidae) from the Highlands of the Atlantic Forest, Southeastern Brazil. Herpetologica, 70, 8999.
CONDEZ, T.H., MONTEIRO, J.P.D., COMITTI, E.J., GARCIA, P.C.D., AMARAL, I.B. \& HADDAD, C.F.B. (2016) A new species of flea-toad (Anura: Brachycephalidae) from southern Atlantic Forest, Brazil. Zootaxa, 4083, 40-56.

CONDEZ, T.H., SAWAYA, R.J. \& DIXO, M. (2009) Herpetofaun dos remanescentes de Mata Atlântica da região de Tapiraí e Piedade, SP, sudeste do Brasil. Biota Neotropica, 9, 1-30.

CONTE, C.E., GAREY, M.V., LINGNAU, R., DA SILVA, M.X. ARMSTRONG, C. \& HARTMANN, M.T. (2009) Amphibia, Anura, Limnomedusa macroglossa, Dendropsophus anceps, $D$. berthalutzae, $D$. seniculus, Scinax littoralis: new state records, distribution extension and filling gaps. Check List, 5, 202-209.

CONTE, C.E., LINGNAU, R. \& KWET, A. (2005) Description of the advertisement call of Hyla ehrhardti Mueller, 1924 and new distribution records (Anura: Hylidae). Salamandra, 41, 147-151.

CONTE, C.E. \& MACHADO, R.A. (2005) Riqueza de espécie distribuiição espacial e temporal em comunidades de anuros (Amphibia, Anura) em uma localidade de Tijucas do Sul, Paraná, Brasil. Revista Brasileira de Zoologia, 22, 940948 .

COPE, E.D. (1862) Contributions to Neotropical Saurology. Proceedings of the Academy of Natural Sciences of Philadelphia, 14, 176-188.

COPE, E.D. (1864) Contributions to the herpetology of tropica America. Proceedings of the Academy of Natural Sciences of Philadelphia, 16, 166-181.

COPE, E.D. (1868) An examination of the Reptilia and Batrachia obtained by the Orton Expedition to Ecuador and the Upper Amazon, with notes on other species. Proceedings of the Academy of Natural Sciences of Philadelphia, 20, 96-119.

COPE, E.D. (1876) Report on the Reptiles brought by Professo James Orton from the middle and upper Amazon and western Peru. Journal of the Academy of Natural Sciences of Philadelphia, 2, 159-183.

COPE, E.D. (1899) Contributions to the herpetology of New Granada and Argentina, with descriptions of new forms. The Philadelphia Museums Scientifc Bulletin, 1-19.

CORDEIRO, A.C., BATISTELLA, A.M., PEREIRA, O.S., GORDO, M. \& VOGT, R.C. (2009) Colostethus caeruleodactylus. Herpetological Review, 40, 233

CORREA, C., CISTERNAS, J., VELASQUEZ, N., LOBOS, G. \& SAN MARTIN-ORDENES, J. (2014) Distribution extension, new records and historical occurrence of Batrachyla taeniat Notes, 7, 703-706.

CORTEZ, C., REICHLE, S., DE LA RIVA, I. \& KÖHLER, J. (2004) Rhinella quechua. The IUCN Red List of Threatened Species, $1-8$

COSTA-CAMPOS, C.E., DE CARVALHO, T.R. \& FREIRE, E.M.X (2016) First record of Pseudopaludicola boliviana Parker 1927 (Anura, Leptodactylidae, Leiuperinae) in the Brazilian state of Amapá, with comments on its advertisement call and distribution. Check List, 12,

COSTA-CAMPOS, C.E., GAMA, S.L., GALENO, E.O., SILVA SILVA, D.W., GAYA CORREA, K.J., ALMEIDA, D.P. \& SANTIAGO, A.G. (2014) New record and distribution map of Hypsiboas lanciformis (Cope, 1871) (Amphibia, Anura, Hylidae) in Eastern Amazonia, Brazil. Check List, 10, 960-
961.

COSTA-CAMPOS, C.E. \& XAVIER FREIRE, E.M. (2015) Distribution extension and geographic distribution map of Elachistocleis helianneae (Anura: Microhylidae): new record for state of Amapa, Eastern Amazon. Check List, 11, 1747.

COSTA, C.H., SÃO PEDRO, V.A., PERES, A.K. \& FEIO, R.N. (2008) Reptilia, Squamata, Teiidae, Tupinambis longilineus: distribution extension. Check List, 4, 267-268.

COSTA, G.C., MESQUITA, D.O. \& FRANÇA, F.G.R. (2005) Crocodilurus amazonicus (Jacarerana). Diet. Herpetological Review, 36, 174-175.

COSTA, G.C., NOGUEIRA, C., MACHADO, R.B. \& COLLI, G.R (2010a) Sampling bias and the use of ecological niche modeling in conservation planning: a field evaluation in a biodiversity hotspot. Biodiversity and Conservation, 19 883-899.

COSTA, H.C. (2011) Strobilurus torquatus. Herpetological Review, $42,570$.

COSTA, H.C. \& BÉRNILS, R.S. (2014) Répteis brasileiros: Lista de espécies. Herpetologia Brasileira, 3, 74-84.

COSTA, H.C. \& FEIO, R.N. (2011) Enyalius bibroni (NCN) Herpetological Review, 42, 240.

COSTA, H.C., FERNANDES, V.D., RODRIGUES, A.C. \& FEIO, R.N. (2009a) Lizards and amphisbaenians, municipality of Viçosa, State of Minas Gerais, southeastern Brazil. Check List, 5 , 732-745

COSTA, H.C., MOURA, M.R. \& FEIO, R.N. (2013) Taxonomic revision of Drymoluber Amaral, 1930 (Serpentes: Colubridae). Zootaxa, 3716, 349-394.

COSTA, H.C., PINTO, R.R. \& SANTANA, D.J. (2009b) Reptilia Leptotyphlopidae, Leptotyphlops salgueiroi Amaral, 1954: distribution extension and geographic variation. Check List, distribution

COSTA, H.C., RESENDE, F.C., TEIXEIRA JR, M., DAL VECHIO, F. \& CLEMENTE, C.A. (2015) A new Amphisbaena (Squamata: Amphisbaenidae) from southern Espinhaço Range, 
southeastern Brazil. Anais da Academia Brasileira de Ciencias, 87, 891-901.

COSTA, H.C., SANTANA, D.J., LEAL, F., KOROIVA, R. \& GARCIA P.C.A. (2016) A New Species of Helicops (Serpentes: Dipsadidae: Hydropsini) from Southeastern Brazil. Herpetologica, 72, 157-166

COSTA, J.C.L., MANZANI, P.R., BRITO, M.P.L. \& MACIEL, A.O. (2010b) Tropidurus hispidus (Calango). Prey. Herpetological Review, 41

COUTO-FERREIRA, D., TINÔCO, M.S., OLIVEIRA, M.L.T., BROWNE-RIBEIRO, H.C., FAZOLATO, C.P., SILVA, R.M BARRETO, G.S. \& DIAS, M.A. (2011) Restinga lizards (Reptilia: Squamata) at the Imbassaí Preserve on the northern coast of Bahia, Brazil. Journal of Threatened Taxa $3,1990-2000$.

CRESPO, S. \& KOCH, C. (2015) Notes on natural history and distribution of Callopistes flavipunctatus (Squamata: Teiidae) in northwestern Peru. Salamandra, 51, 57-60.

CRUZ, C.A.G. \& CARAMASCHI, U. (1998) Definição, compisição e distribuição geográfica do grupo de Hyla polytaenia Cope, 1870 (Amphibia, Anura, Hylidae). Boletim do Museu Nacional. Nova Serie, Zoologia, 392, 1-19.

CRUZ, C.A.G., CARAMASCHI, U. \& IZECKSOHN, E. (1997) The genus Chiasmocleis Mehely, 1904 (Anura, Microhylidae) in the Atlantic Rain Forest of Brazil, with description of three new species. Alytes, 15, 49-71.

CRUZ, C.A.G., CARAMASCHI, U. \& NAPOLI, M.F. (2007a) A new species of Chiasmocleis (Anura, Microhylidae) from the Atlantic rain forest of northeastern Bahia, Brazil. South American Journal of Herpetology, 2, 47-52.

CRUZ, C.A.G., FEIO, R.N. \& NASCIMENTO, L.B. (2008a) A new species of Phasmahyla Cruz, 1990 (Anura : Hylidae) from the Atlantic Rain Forest of the States of Minas Gerais and Bahia, Brazil. Amphibia-Reptilia, 29, 311-318.

CRUZ, C.A.G. \& FUSINATTO, L.A. (2008) A new species of Dendrophryniscus, Jiménez de la Espada, 1871 (Amphibia, Anura, Bufonidae) from the atlantic rain forest of Rio Grande do Sul, Brazil. South American Journal of Herpetology, 3, 22-26.

CRUZ, C.A.G., NAPOLI, M.F. \& FONSECA, P.M. (2008b) A new species of Phasmahyla Cruz, 1990 (Anura: Hylidae) from the State of Bahia, Brazil. South American Journal of Herpetology, 3, 187-195.

CRUZ, C.A.G., NASCIMENTO, L.B. \& FEIO, R.N. (2007b) A new species of the genus Physalaemus Fitzinger, 1826 (Anura, leiuperidae) from southeastern Brazil. Amphibia-Reptilia, $28,457-465$

CRUZ, C.A.G. \& PEIXOTO, O. (1985a) Especies verdes de Hyla: o complexo "Albofrenata" (Amphibia, Anura, Hylidae) Arquivos da Universidade Federal Rural do Rio de Janeiro, 8 $59-70$

CRUZ, C.A.G. \& PEIXOTO, O.L. (1985b) Especies verdes de Hyla: o complexo albosignata (Amphibia, Anura, Hylidae). Arquivos de Universidade Federal Rural do Rio de Janeiro, 7 31-47.

CRUZ, C.G. \& CARAMASCHI, U. (2003) Taxonomic status of Melanophryniscus stelzneri dorsalis (Mertens, 1933) and Melanophryniscus stelzneri fulvoguttatus (Mertens, 1937) (Amphibia, Anura, Bufonidae). Boletim do Museu Nacional Rio de Janeiro Zoologia, 500, 1-11.

CRUZ, F.B. (1994) Actividad reproductiva en Vanzosaura rubricauda (Sauria Teiidae) del Chaco Occidental en Argentina. Cuadernos de Herpetologia, 8, 112-118.

CRUZ, F.B., SCROCCHI, G.J. \& LAVILLA, E.O. (1994) Phyllopezus pollicaris przewalskyi (ututo macho). Herpetological Review, $25,161$.

CUEVAS, C. (2013a) Análisis taxonómico de Alsodes nodosus (Duméril \& Bibron, 1841) (Amphibia, Neobatrachia): antecedentes morfológicos y moleculares. Universidad Austral de Chile, Valdivia, $126 \mathrm{pp}$.

CUEVAS, C.C. (2010) A new species of Telmatobufo (Schmidt 1852) (Anura, Calyptocephalellidae) from a remnant of the Maulino Forest, central Chile. Gayana, 74, 102-112.

CUEVAS, C.C. (2013b) The identity of the Chilean frog Alsodes laevis (Philippi 1902) (Cycloramphidae): Synonymy and generic partitioning of the type series. Herpetological Journal, 23, 145-152.

CUEVAS, C.C. \& FORMAS, J.R. (2002) Telmatobius philippii, una nueva especie de rana acuática de Ollagüe, norte de Chile (Leptodactylidae). Revista Chilena de Historia Natural, $75,245-258$

CUEVAS P, C.C. \& CIFUENTES P, S.L. (2010) Amphibia, Anura, Ceratophryidae, Batrachyla leptopus Bell, 1843: new records updating and geographic distribution map, Chile. Check List, 6, 633-636.

CUNHA-BARROS, M., VAN SLUYS, M., VRCIBRADIC, D. GALDINO, C.A.B., HATANO, F.H. \& ROCHA, C.F.D. (2003) Patterns of infestation by chigger mites in four diurnal lizar pecies from a restinga habitat (Jurubatiba) of Southeaster Brazil em um ambiente de restinga (Jurubatiba) no Sudeste do Brasil. Brazilian Journal of Biology, 63, 393-399.

CUNHA, O.R. (1970) Lacertílios da Amazônia. IV - Um novo Gênero e Espécie de Lagarto do Território Federal do Amapá (Lacertilia - Teiidae). Boletim do Museu Paraense Emílio Goeldi, série Zoologia, 1970, 1-8.

CUNHA, O.R. (1981) Lacertílios da Amazonia. VIII - Sobre Ophryoessoides tricristatus Duméril, 1851, com redescrição da espécie e notas sobre ecologia e distribuição da região leste do Pará (Lacertilia, Iguanidae). Boletim do Museu Paraense Emilio Goeldi Serie Zoologia, 108, 1-23.

CUNHA, O.R. \& NASCIMENTO, F.P. (1978) Ofidios da Amazônia 10 - as cobras da regiao leste do Para. Museu Paraense Emilio Goeldi Publicacoes Avulsas, 31, 1-218.

CURCIO, F.F., NUNES, P.M.S., ARGOLO, A.J.S., SKUK, G. \& RODRIGUES, M.T. (2012) Taxonomy of the South American Dwarf Boas of the Genus Tropidophis Bibron, 1840, With the Description of Two New Species from the Atlantic Forest (Serpentes: Tropidophiidae). Herpetological Monograph, 26, 80-121.

CURCIO, F.F., SALES NUNES, P.M., HARVEY, M.B. \& RODRIGUES, M.T. (2011) Redescription of Apostolepis longicaudata (Eerpentes: $\mathrm{X}$ ) with comments on its hemipenial morphology and natural history. Herpetologica, 67, 318-331.

CURCIO, F.F., SANCHEZ-PACHECO, S.J., MUESES-CISNEROS, J.J. \& RODRIGUES, M.T. (2009) Notes on distribution, variation and characterization of Erythrolamprus pseudocorallus Roze, 1959 (Serpentes: Colubridae) with the first records from Colombia. Zootaxa, 33-42.

CURCIO, F.F., SCALI, S. \& RODRIGUES, M.T. (2015) Taxonomic Status of Erythrolamprus bizona Jan (1863) (Serpentes, Xenodontinae): Assembling a Puzzle with Many Missing Pieces. Herpetological Monographs, 29, 40-64.

CUSI, J.C., BARBOZA, A.C., VREDENBURG, V. \& VON MAY, R (2015) A new locality, range extension and record of Batrachochytrium dendrobatidis in the endangered terrestrial breeding frog Pristimantis katoptroides Flores, 1988 (Anura: Craugastoridae) in Peru. Check List, 11, 1608.

D'ANGIOLELLA, A.B. DIAS, E.J.D \& LIRA-DA-SILVA, R.M. (2007) Comunidades de Lagartos em Fragmentos de Mata Atlântica de Salvador, Bahia, Brasil, p. 90-91. In: 39 Congresso Brasileiro de Herpetologia. HERPETOLOGIA S.B.D. (ed.). Sociedade Brasileira de Herpetologia, Belém

D'ANGIOLELLA, A.B., GAMBLE, T., AVILA-PIRES, T.C.S., COLL

G.R., NOONAN, B.P. \& VITT, L.J. (2011) Anolis chrysolepis Dumeril and Bibron, 1837 (Squamata: Iguanidae), Revisited: Molecular Phylogeny and Taxonomy of the Anolis chrysolepis Species Group. Bulletin of the Museum of Comparative Zoology, 160, 35-63.

D'ASSUNÇÃO, M.M., BARROS-FILHO, D.S.B., ARAÚJO, A.S. \& MOURA, G.J.B. (2012) Anolis ortonii. Herpetological Review, 43, 101

DA SILVA, H.R. \& ALVES-SILVA, R. (2008) New coastal and insular species of the bromeligenous Scinax perpusillus group, from the State of Rio de Janeiro, Brazil (Anura, Hylidae). Zootaxa, 34-44.

DAL VECHIO, F. RECODER, R.S., RODRIGUES, M.T. \& ZAHER, H. (2013) The herpetofauna of the Estação Ecológica de Uruçuí-Una, state of Piauí, Brazil. Papéis Avulsos de Zoologia, 53, 225-243.

DAL VECHIO, F., TEIXEIRA JR, M., MOLLO-NETO, A. \& RODRIGUES, M.T. (2015a) On the snake Siphlophis worontzowi (Prado, 1940): notes on its distribution, diet and morphological data. Check List, 11, 1-5.

DAL VECHIO, F., TEIXEIRA JR., M., RECODER, R.S RODRIGUES, M.T. \& ZAHER, H. (2016) The herpetofauna of Parque Nacional da Serra das Confusões, state of Piaui, Brazil, with a regional species list from an ecotonal area of Cerrado and Caatinga. Biota Neotropica, 16

DAL VECHIO, F., TEIXEIRA JUNIOR, M., RECODER, R.D.S., DE SENA, M.A., SOUZA, S.M. \& RODRIGUES, M.T. (2015b) Distribution extension and revised map of Erythrolamprus pygmaeus (Cope, 1868) (Serpentes: Dipsadidae). Check List, 11,1719

DAUDIN, F.M. (1802) Histoire Naturelle, Générale et Particulière des Reptiles; ouvrage faisant suit à l'Histoire naturell générale et particulière, composée par Leclerc de Buffon; et rédigee par C.S. Sonnini, membre de plusieurs sociétés savantes. Tome II. F. Dufart, Paris, $432 \mathrm{pp}$.

DE-CARVALHO, C.B., CALDAS, F.L.S., SANTANA, D.O. NORONHA, N.V., FREITAS, E.B., FARIA, R.G. \& SANTOS, R.A. (2010) Reptilia, Squamata, Gymnophthalmidae, Acratosaura mentalis (Amaral 1933): Distribution extension Acratosaura mentalis (Amaral 1933): Distribution extens
and geographic distribution map. Check List, 6, 434-436.

DE LA RIVA, I. (2002) Taxonomy and distribution of the south American toad Bufo poeppigii Tschudi, 1845 (Amphibia, Anura, Bufonidae). Graellsia, 58, 49-57.

DE LA RIVA, I. (2005) Bolivian frogs of the genus Telmatobius: synopsis, taxonomic comments, and description of a new species. Monografias de Herpetologia, 7, 65-101.

DE LA RIVA, I. (2007) Bolivian frogs of the genus Phrynopus, with the description of twelve new species (Anura: Brachycephalidae). Herpetological Monographs, 21, 241-

DE LA RIVA, I. \& BURROWES, P.A. (2014) A new species o Psychrophrynella (Anura: Craugastoridae) from the Cordillera Real, Department La Paz, Bolivia. Zootaxa, 3887, 459-470.

DE LA RIVA, I., CASTROVIEJO-FISHER, S., CHAPARRO, J.C., BOISTEL, R. \& PADIAL, J.M. (2011) A new species of Atelopus (Anura: Bufonidae) from the Amazonian slopes of Atelopus (Anura: Bufonidae) from the Amazonian slopes of DE LA RIVA, I. \& KOHLER, J. (1998) A new minute leptodactylid frog, genus Phyllonastes, from humid montane forests of Bolivia. Journal of Herpetology, 32, 325-329.
DE LA RIVA, I., KÖHLER, J., LÖTTERS, S. \& REICHLE, S. (2000) Ten years of research on Bolivian amphibians: updated checklist, distribution, taxonomic problems, literature and iconography. Revista Espanola de Herpetologia, 14, 19-164.

DE LA RIVA, I., TRUEB, L. \& DUELLMAN, W.E. (2012) A new species of Telmatobius (Aanura: Telmatobiidae) from montane forests of southern Peru, with a review of osteological features of the genus. South American Journa of Herpetology, 7, 91-109.

DE LEMA, T. (1994) Lista comentada dos répteis ocorrentes no Rio Grande do Sul, Brasil. Comunicacoes do Museu de Ciencias da PUCRS Serie Zoologia, 7, 41-150.

DE SÁ, R.O., GRANT, T., CAMARGO, A., HEYER, W.R., PONSSA, M.L. \& STANLEY, E. (2014) Systematics of the Neotropica Genus Leptodactylus Fitzinger, 1826 (Anura: Leptodactylidae): Phylogeny, the Relevance of Nonmolecular Evidence, and Species Accounts. South American Journal of Herpetology, 9, S1-S128.

DEIQUES, C.H., STAHNKE, L.F., REINKE, M. \& SCHMITT, P. (2007) Guia ilustrado - Anfíbios e répteis da Parque Nacional de Aparados da Serra, Rio Grande do Sul-Santo Catarina. USEB, Pelotas, RS, $117 \mathrm{pp}$

DELATORRE, M., VASCONCELOS, T.S., CUNHA, N.L., MARTINS, F.I., ODA, F.H., AOKI, C. \& LANDGREF-FILHO, P. (2014) Implementing new northernmost records to modelling the distribution of Hypsiboas caingua (Anura: Hylidae) in South America. Brazilian Journal of Biology, 74, 854-860.

DELFIM, F.R. \& FREIRE, E.M.X. (2007) Os lagarto gimnoftalmídeos (Squamata: Gymnophthalmidae) do Carin Paraibano e do Seridó do Rio Grande do Norte, nordeste do Brasil: consideraçäes acerca da distribuição geográfica e ecologia. Oecologia Brasiliensis, 11, 365-382.

DELFIM, F.R., GONÇALVES, E.M. \& SILVA, S.T. (2006) Squamata, Gymnophthalmidae, Psilophthalmus paeminosus: distribution extension, new state record. Check List, 2, 89-92.

DELFIM, F.R., MESQUITA, D.O., FERNANDES-FERREIRA, H. \& CAVALCANTI, L.B.D.Q. (2011) Procellosaurinus erythrocercus Rodrigues, 1991 (Squamata: Gymnophthalmidae): Distribution extension. Check List, 7 856-858

DeMANGel, D., SEPÚlVedA, C., JARA, M., PINCHEIRADONOSO, D. \& NÚNEEZ, H. (2015) Liolaemus omorfi, a new lizard sapecies from the Andes of Northern Chile (Sauria, Liolaemidae). Boletín del Museo Nacional de Historia Natural, 64, 139-155.

DEWYNTER, M. \& SURUGUE, N. (2012) First record of Amapasaurus tetradactylus Cunha, 1970 (Squamata: Gymnophthalmidae) in French Guiana. Check List, 8, 815816.

DI-BERNARDO, A.E., BORGES-MARTINS, M. \& OLIVEIRA, R.B. (2003) Répteis. In: FONTANA, C.S., BENCKE, G.A. \& REIS, R.E. (Eds.) Livro vermelho da fauna ameaçada de extinção no Rio Grande do Sul. EDIPUCRS, Porto Alegre, pp. 165-188. DI-BERNARDO, M., BORGES-MARTINS, M. \& DA SILVA, N.J. (2007) A new species of coralsnake (Micrurus: Elapidae) from southern Brazil. Zootaxa, 1-26.

DI PIETRO, D.O., NENDA, S.J. \& GÓMEZ, S.E. (2016) Phyllodryas trilineata. Herpetological Review, 47, 428-429. DIAS, E.J.D., ROCHA, C.F.D. \& VRCIBRADIC, D. (2002) New Cnemidophorus (Squamata : Teiidae) from Bahia State northeastern Brazil. Copeia, 1070-1077.

DIAS, E.J.R. \& ROCHA, C.F.D. (2013) Ecpleopus gaudichaudi Duméril and Bibron, 1839 (Squamata: Gymnophthalmidae) and Psychosaura agmosticha (Rodrigues, 2000) (Squamata: Scincidae): Distribution extension and new records from Atlantic Forest in Bahia state, Brazil. Check List, 9, 607-609. DIAS, I.R., MEDEIROS, T.T., NOVA, M.F.V. \& SOLE, M. (2014) Amphibians of Serra Bonita, southern Bahia: a new hotpoint within Brazil's Atlantic Forest hotspot. ZooKeys, 105-130

IAS, P.H.D.S., AMARO, R.C., CARVALHO-E-SILVA, A.M.P.T.D. \& RODRIGUES, M.T. (2013) Two new species of Proceratophrys Miranda-Ribeiro, 1920 (Anura; Odontophrynidae) from the Atlantic forest, with taxonomic Odontophrynidae) from the Atlantic forest, with
remarks on the genus. Zootaxa, 3682, 277-304.

DÍAZ-AYALA, R.F., GUTIÉRREZ-CÁRDENAS, P.D.A., VÁSQUEZCORREA, A.M. \& CAICEDO-PORTILLA, J.R. (2015) New records of Diploglossus monotropis (Kuhl, 1820) (Squamata: Anguidae) from Urabá and Magdalena River valley, Colombia, with an updated geographic distribution map. Check List, 11, 1-7.

DIAZ-LAMEIRO, A.M., KAISER, H. \& POWELL, R. (2008) Pristimantis shrevei (Schwartz) St. Vincent frog. Catalogue of American Amphibians and Reptiles, 844, 1-4.

DíAZ-PÁEZ, H., ALVEAL, N., CISTERNAS-MEDINA, I. \& ORTIZ, J.C. (2015) New distribution records of Chaltenobatrachus grandisonae (Anura: Batrachylidae) in Patagonia, Chile. Check List, 11, 1-3.

DIRKSEN, L. \& DE LA RIVA, I. (1999) The lizards and amphisbaenians of Bolivia (Reptilia, Squamata): checklist, localities, and bibliography. Graellsia, 55, 199-215.

DIRKSEN, L. \& HENDERSON, R.W. (2002) Eunectes DIRKSEN, L. \& HENDERSON, R.W. (2002) Eunectes
deschauenseei Dunn and Conant: de Schauensee's anaconda. Catalogue of American Amphibians and Reptiles, $1-3$

DIXO, M. (2001) Efeito da Fragmentação da floresta sobre comunidade de sapos e lagartos de serrapilheira no sul da 
Bahia. Dissertation. Instituto de Biociências da Universidade de São Paulo1-77 pp.

DIXO, M. \& VERDADE, V.K. (2006) Leaf litter herpetofauna of the Reserva Florestal de Morro Grande, Cotia (SP). Bioto Neotropica, 6, 1-20.

DIXO, M.B.O. (2005) Diversidade de sapos e lagartos de serrapilheira numa paisagem fragmentada do Planalto Atlântico de São Paulo. PhD. Departamento de Ecologia, Universidade de São Paulo, São paulo, $180 \mathrm{pp}$.

DIXON, J.R. (1973) A systematic review of the teiid lizards, genus Bachia with remarks on Heterodactylus and Anotosaura. Miscellaneous Publications of the Museum of Natural History of the University of Kansas, 57, 1-47.

DIXON, J.R. (1974a) Systematic review of the lizard genus Anotosaura (Teiidae). Herpetologica, 30, 13-18

DIXON, J.R. (1974b) Systematic review of the microteiid genus Iphisa. Herpetologica, 30, 133-139.

DIXON, J.R. (1983) Taxonomic status of the South American snakes Liophis miliaris, L. amazonicus, L. chrysostomus, L. mossoroensis and L. purpurans (Colubridae: Serpentes). Copeia, 1983, 791-802.

DIXON, J.R. (1989) A key and checklist to the Neotropical snake genus Liophis with country lists and maps. Smithsonian Herpetological Information Service, 1-28.

DIXON, J.R. (2000) Ecuadorian, Peruvian and Bolivian snakes of the Liophis taeniurus complex with descriptions of two new species. Copeia, 2000, 482-490.

DIXON, J.R. \& HENDRICKS, F.S. (1979) The wormsnake (Family Typhlopidae) of the Neotropics, exclusive of the Antilles. Zoologische Verhandelingen, 1-39.

DIXON, J.R. \& HUEY, R.B. (1970) Systematics of the lizards of the Gekkonid genus Phyllodactylus on mainland South America. Los Angeles County Museum Contributions in Science, 1-78.

DIXON, J.R. \& KOFRON, C.P. (1983) The Central and South American anomalepid snakes of the genus Liotyphlops. Amphibia-Reptilia, 4, 241-264.

DIXON, J.R. \& LAMAR, W.W. (1981) A New Species of Microteid Lizard (Genus Neusticurus) from Colombia. Journal of Herpetology, 15, 309-314.

DIXON, J.R. \& SOINI, P. (1986) The reptiles of the Upper Amazon basin, lquitos region, Peru. I. Lizards and amphisbaenians. II. Crocodilians turtles and snakes. Milwaukee Public Museum, Milwaukee $154 \mathrm{pp}$

DIXON, J.R., WIEST JR., J.A. \& CEI, J.M. (1993) Revision of the Neotropical snake genus Chironius Fitzinger (Serpentes, Colubridae). Museo Regionale di Scienze Natural Monografie, 13, 1-280.

DIXON, J.R. \& WRIGHT, J.W. (1975) A review of the lizards of the iguanid genus Tropidurus in Peru. Natural History Museum of Los Angeles County Contribution in Science, 139.

DOAN, T.M. (2003a) A new phylogenetic classification for the gymnophthalmid genera Cercosaura, Pantodactylus and Prionodactylus (Reptilia : Squamata). Zoological Journal of the Linnean Society, 137, 101-115.

DOAN, T.M. (2003b) A south-to-north biogeographic hypothesis for Andean speciation: evidence from the lizard genus Proctoporus (Reptilia, Gymnophthalmidae). Journal of Biogeography, 30, 361-374.

DOAN, T.M. \& ADAMS, G. (2015) A novel species of Euspondylus (Squamata: Gymnophthalmidae) from the Andes Mountains of central Peru. Zootaxa, 4033, 129-136.

DOAN, T.M. \& CASTOE, T.A. (2005) Phylogenetic taxonomy of the Cercosaurini (Squamata : Gymnophthalmidae), with new genera for species of Neusticurus and Proctoporus. Zoological Journal of the Linnean Society, 143, 405-416.

DOAN, T.M. \& CUSI, J.C. (2014) Geographic distribution of Cercosaura vertebralis O'Shaughnessy, 1879 (Reptilia: Squamata: Gymnophthalmidae) and the status of Cercosaura ampuedai (Lancini, 1968). Check List, 10, 11951200.

DOAN, T.M. \& LAMAR, W.W. (2012) A new montane species of Cercosaura (Squamata: Gymnophthalmidae) from Colombia, with notes on the distribution of the genus. Zootaxa, 44-54.

DOAN, T.M., NOWACKI, A.M. \& ROBERTS, P.A. (2012) Dendrobates leucomelas Steindachner Yellow Banded Poison Dart Frog, Bumblebee Poison Dart Frog, Sapito Minero. Catalogue of American Amphibians and Reptiles, 886, 1-6.

DOAN, T.M. \& SCHARGEL, W.E. (2003) Bridging the gap in Proctoporus distribution: a new species (Squamata: Gymnophthalmidae) from the Andes of Venezuela. Herpetologica, 59, 68-75.

DOMINGOS CINTRA, C.E., RODRIGUES DA SILVA, H.L. \& DA SILVA JUNIOR, N.J. (2014) First record of Lithodytes lineatus (Schneider, 1799) (Anura: Leptodactylidae) in the state of Tocantins, ecotone zone Amazon-Cerrado biomes, with notes on its natural history. Herpetology Notes, 7, 179184

DOMINGOS, F.M.C.B. (2009) Variação geográfica na morfologia de Gymnodactylus amarali (Squamata, morfologia de Gymnodactylus amarali (Squamata,
Gekkonidae). Doutorado. Instituto de Ciências Biológicas da Gekkonidae). Doutorado. Instituto de Ciências
Universidade de Brasília, Brasília, DF1-95 pp.

DONNELLY, M.A., MCDIARMID, R.W. \& MYERS, C.W. (1992) A New Lizard of the Genus Arthrosaura (Teiidae) from
Southern Venezuela. Proceedings of the Biological Society of Washington, 105, 821-833.

DONNELLY, M.A. \& MYERS, C.W. (1991) Herpetological Results of the 1990 Venezuelan Expedition to the Summit of Cerro Guaiquinima with New Tepui Reptiles. American Museum Novitates, 1991, 1-54

DONNELLY, M.A. \& WAKE, M.H. (2013) A New Microcaecilia (Amphibia: Gymnophiona) from Guyana with Comments on Epicrionops niger. Copeia, 2, 223-231.

DONOSO-BARROS, R. (1961) Three new lizards of the genus Liolaemus from the highest Andes of Chile and Argentina. Copeia, No. 4, 387-391.

DONOSO-BARROS, R. (1966a) Dos nuevos Gonatodes de Venezuela. Publicación Ocasional, Museo Nacional de Historia Natural, 1-32.

DONOSO-BARROS, R. (1966b) Reptiles de Chile. Universidad de Chile, Santiado, 458+cxlvi pp.

DONOSO-BARROS, R. (1968) The lizards of Venezuela (checklist and Key). Caribbean Journal of Science, 8, 105122.

DONOSO-BARROS, R. (1974) Nuevos reptiles y anfíbios de Chile. Boletin de la Sociedad de Biología de Concepción, 48 , 217-229.

DORADO-RODRIGUES, T.F., STRÜSSMANN, C. \& UIMA F.A.N.S. (2013) Reptilia, Squamata, Amphisbaenidae, Amphisbaena brasiliana (Gray, 1865): range extension. Herpetology Notes, 6, 331-333.

DORIGO, T.A., MAIA-CARNEIRO, T., ALMEIDA-GOMES, M., SIQUEIRA, C.C., VRCIBRADIC, D.A.C., VAN SLUYS, M. \& ROCHA, C.F.D. (2014) Diet and helminths of Enyalius brasiliensis (Lacertilia, Iguania, Leiosauridae) in an Atlantic brasiliensis (Lacertilia, Iguania, Leiosauridae) in an Atlantic of Biology, 74, 199-204.

RUMMOND, L.D.O., LUCENA, V.D.D. \& PIRES, M.R.S. (2007) Registro de queratofagia de exemplar de Enyalius ihering em cativeiro, p. 268. In: 3 o Congresso Brasileiro de Herpetologia. HERPETOLOGIA, S.B.D. (ed.). Sociedade Brasileira de Herpetologia, Belém

DRUMMOND, L.O., CRUZ, A.J.R., COSTA, H.C. \& BRAGA, C.A.C. (2014) New records of the teiid lizards Kentropyx paulensis (Boettger, 1893) and Tupinambis duseni Lönnberg, 1910 (Squamata: Teiidae) from the state of Minas Gerais, southeastern Brazil. Check List, 10, 15491554 .

DUELLMAN, W.E. (1958) A monographic study of the colubrid snake genus Leptodeira. Bulletin of the American Museum of Natural History, 114, 1-152.

DUELLMAN, W.E. (1968a) Smilisca phaeota. Catalogue of American Amphibians and Reptiles, $61,1-2$.

DUELLMAN, W.E. (1968b) Smilisca sila. Catalogue of American Amphibians and Reptiles, 63, 1-2.

DUELLMAN, W.E. (1970) The Hylid frogs of Middle America. Monograph of the Museum of Natural History University of Kansas, 1-753.

DUELLMAN, W.E. (1972a) A review of the neotropical frogs of the Hyla bogotensis group. Occasional Papers of the Museum of Natural History University of Kansas, 1-31.

DUELLMAN, W.E. (1972b) South American frogs of the Hyla rostrata group (Amphibia, Anura, Hylidae). Zoologische Mededelingen, 47, 177-192.

DUELLMAN, W.E. (1973) Descriptions of new lizards from the upper Amazon Basin. Herpetologica, 228-231.

DUELLMAN, W.E. (1974) A reassessment of the taxonomic status of some neotropical hylid frogs. Occasional Papers Mus Nat Hist Univ Kans, No. 27, 1-27.

DUELLMAN, W.E. (1978) The Biology of An Equatorial Herpeto Fauna in Amazonian Ecuador. Miscellaneous Publications of the Museum of Natural History of the University of Kansas, $1-352$

DUELLMAN, W.E. (1980) The identity of Centrolenella grandisonae Cochran and Goin (Anura: Centrolenidae). Transactions of the Kansas Academy of Science, 83, 26-32.

DUELLMAN, W.E. (1987) Lizards in an Amazonian Rain Fores Community: Resource Utilization and Abundance. National Geographic Research, 3, 489-500.

DUELLMAN, W.E. (1989) New species of hylid frogs from the Andes of Columbia and Venezuela. Occasional Papers of the Museum of Natural History University of Kansas, 1-12.

DUELLMAN, W.E. (1997) Amphibians of La Escalera Region, Southeastern Venezuela: Taxonomy, Ecology, and Biogeography. Scientific Papers Natural History Museum the University of Kansas, 1-52.

DUELLMAN, W.E. (2004) Frogs of the genus Colostethus (Anura: Dendrobatidae) in the Andes of northern Peru. Scientific Papers Natural History Museum the University of Kansas, 1-49.

DUELLMAN, W.E. (2005) Cuzco Amazónico - The lives of amphibians and reptiles in an Amazonian rainforest. Cornel University Press, Ithaca \& London, $433 \mathrm{pp}$.

DUELLMAN, W.E. (2015) Marsupial Frogs: Gastrotheca \& allied genera. Johns Hopkins Universtity Press, Baltimore, $407 \mathrm{pp}$.

DUELLMAN, W.E., DE LA RIVA, I. \& WILD, E.R. (1997) Frogs of the Hyla armata and Hyla pulchella groups in the Andes of South America, with definitions and analyses of phylogenetic relationships of Andean groups of Hyla. Scientific Papers Natural History Museum University of Kansas, 3, 1-41.
DUELLMAN, W.E. \& LEHR, E. (2007) Frogs of the genus Eleutherodactylus (Leptodactylidae) in the Cordiller Occidental in Peru with descriptions of three new species. Scientific Papers Natural History Museum the University of Kansas, 39, 1-13.

DUELLMAN, W.E. \& MENDELSON, J.R. (1995) Amphibians and reptiles from northern Departamento Loreto, Peru: Taxonomy and biogeography. University of Kansas Science Bulletin, 55, 329-376.

DUELLMAN, W.E. \& PRAMUK, J.B. (1999) Frogs of the genus Eleutherodactylus (Anura: Leptodactylidae) in the Andes of northern Peru. Scientific Papers Natural History Museum the University of Kansas, 13, 1-78.

DUELLMAN, W.E. \& SALAS, A.W. (1991) Annotated checklis of the amphibians and reptiles of Cuzco Amazonico, Peru. Occasional Papers of the Museum of Natural History, University of Kansas, 143, 1-13.

DUELLMAN, W.E. \& TOFT, C.A. (1979) Anurans from Serranía de Sira, Amazonian Perú: Taxonomy and Biogeography. Herpetologica, 35, 60-70.

DUELLMAN, W.E. \& TRUEB, L. (1983) Frogs of the Hyla columbiana group: taxonomy and phylogenetic relationships. In: Advances in herpetology and evolutionary biology. Essays in honor of Ernest E. Williams. Museum of Comparative Zoology, Cambridge, Massachusetts33-51.

DUELLMAN, W.E. \& VENEGAS, P.J. (2016) Diversity of marsupial frogs (Anura:Hemiphractidae: Gastrotheca) in the northern Cordillera Central, Peru, with the descriptions of two new species. Phyllomedusa, 15, 103-117.

DUELLMAN, W.E. \& WIENS, J.J. (1993) Hylid frogs of the genus Scinax Wagler, 1830, in Amazonian Ecuador and Peru. Occasional Papers of the Museum of Natural History University of Kansas, 1-57.

DUMÉRIL, A.M.C. (1851) Catalogue méthodique de la collection des reptiles du Muséum d'Histoire Naturelle de Paris. Gide et Baudry/Roret, Paris, $224 \mathrm{pp}$.

DUMÉRIL, A.M.C. \& BIBRON, G. (1837) Erpétologie Générale ou Histoire Naturelle Complete des Reptiles. Vol. 4. Encyclopédique Roret, Paris, $570 \mathrm{pp}$.

DUMÉRIL, A.M.C. \& BIBRON, G. (1839) Erpétologie Générale on Histoire Naturelle Complète des Reptiles. Vol. 5. Roret/Fain et Thunot, Paris, $871 \mathrm{pp}$.

DUNN, E.R. (1935) The snakes of the genus Ninia. Proceeding of the National Academy of Sciences of the United States of America, 21, 9-12.

DUNN, E.R. (1936) Notes on American Mabuyas. Proceedings of the Academy of Natural Sciences of Philadelphia, 87, 533-557.

DUNN, E.R. (1939) Mainland Forms of the Snake Genus Tretanorhinus. Copeia Ann Arbor, 1939, 212-217.

DUNN, E.R. (1943) New Race of Ameiva Festiva from Colombia. Notulae Naturae of The Academy of Natura Sciences of Philadelphia, 1-2.

DUNN, E.R. (1944) The lizard genus Phenacosaurus. Caldasia $11,57-62$

DUNN, E.R. \& SAXE JR, L.H. (1950) Results of the Catherwood Chaplin West Indies Expedition, 1948. Part V. Amphibian andReptiles of San Andrés and Providencia. Proceedings of the Academy of Natural Sciences of Philadelphia, 102, 141165

ECHEVARRÍA, L.Y. (2014) Distribution extension of the endemic lizard Macropholidus huancabambae (Reeder, 1996) (Squamata: Gymnophthalmidae). Herpetology Notes, 7, 167-168.

ECHEVARRÍA, L.Y., BARBOZA, A.C. \& VENEGAS, P.J. (2015) A new species of montane gymnophthalmid lizard, genus Cercosaura (Squamata: Gymnophthalmidae), from the Amazon slope of northern Peru. Amphibian and Reptile Conservation, 9, 34-44.

CHEVARRía, L.Y. \& VENEGAS, P.J. (2015) A new elusive species of Petracola (Squamata: Gymnophthalmidae) from the Utcubamba basin in the Andes of northern Peru. Amphibian and Reptile Conservation, 9, 26-33.

ECHTERNACHT, A.C. (1970) Taxonomic and ecological notes on some middle and south American lizards of the genus Ameiva (Teiidae). Breviora, 1-9.

EISEMBERG, C.C., CASSIMIRO, J. \& BERTOLUCI, J. (2004) Notes on the diet of the rare gymnophthalmid Lizard Ecpleopus gaudichaudii from southeastern Brazil. Herpetological Review, 35, 336-337.

ELGUETA, E., REID, S., PLISCOFF, P., MÉNDEZ, M.A., NÚNEZ, J. \& SMITH-RAMíREZ, C. (2006) Catastro de vertebrados terrestres $\mathrm{y}$ análisis en seis habitats presentes en la Reserva Nacional Futaleufu, provincia de Palena, X Región, Chile. Gayana, 70, 195-205.

ENTIAUSPE-NETO, O.M. \& ABEGG, A.D. (2013) New record and distribution extension of Atractus paraguayensis Werner, 1924 (Serpentes: Dipsadidae). Check List, 9, 104105.

ENTIAUSPE-NETO, O.M., LEMA, T. \& BECONI, H.E.C. (2014) Apostolepis intermedia Koslowsky, 1898 (Serpentes: Xenodontinae: Elapomorphini): First records for Paraguay. Check List, 10, 600-601.

ESCOBAR-HUERTA, G., SANTIBÁÑEZ-TORO, J. \& ORTIZ, J.C. (2015) Liolaemus lonquimayensis (Squamata: Liolaemidae), a new lizard species for Chile without precloacal pores. Gayana (Concepción), 79, 94-101. 
ESPINOSA, A.P.O. (2014) Herpetofauna de la Reserva Nacional Lago Jeinimeni, Región de Aysén, Chile Instituto de Ciencias Marinas y Limnológicas, Facultad de Ciencias Forestales y Recursos Naturales, Universidad Austral de Chile34 pp.

ESPINOZA, R.E. \& LOBO, F. (2003) Two New Species of Liolaemus Lizards from Northwestern Argentina: Speciation within the Northern Subclade of the elongatus Group (Iguania: Liolaemidae). Herpetologica, 59, 89-105.

ESQUEDA, L., LA MARCA, E. \& PRADERIO, M.J. (2010) Una nueva especie del lagarto Altotepuyano del género Riolama (Squata: Gymnophthalmidae) del cerro marahuaca, Estado Amazonas, Venezuela. Herpetotrópicos, 1, 11-17.

ESQUEDA, L.F. (2004) Una nueva especie de Gonatodes (Squamata: Gekkonidae) proveniente del piedemonte cisandino de Venezuela. Herpetotrópicos, 1, 32-39.

ESQUEDA, L.F. (2005) Un nuevo Leposoma (Squamata: Gymnophthalmidae) de la reserva forestal de Caparo, Estado Barinas, Venezuela. Herpetotrópicos, 2, 33-42.

ESQUEDA, L.F., NATERA, M., LA MARCA, E. \& ILIJA-FISTAR, M (2005) Nueva especie de serpiente (Reptilia: Colubridae: Liophis) de un Bosque tropical relictual en el estado Barinas, Venezuela. Herpetotrópicos, 2, 95-103.

ESQUERRE, D., NUNEZ, H. \& SCOLARO, J.A. (2013) Liolaemus carlosgarini and Liolaemus riodamas (Squamata: Liolaemidae), two new species of lizards lacking precloacal pores, from Andean areas of central Chile. Zootaxa, 3619, 428-452.

ESQUERRE, D., TRONCOSO-PALACIOS, J., GARIN, C.F. \& NUNEZ, H. (2014) The missing leopard lizard: Liolaemus ubaghsi sp nov., a new species of the leopardinus clade (Reptilia: Squamata: Liolaemidae) from the Andes of the (Reptilia: Squamata: Liolaemidae) from the Andes
O'Higgins Region in Chile. Zootaxa, 3815, 507-525.

ETCHEPARE, E.G., INGARAMO, M.D.R., FALCIONE, C., AGUIRRE, R.H. \& BARRIOS, C.E. (2011) Homonota fasciato Duméril y Bibron, 1839 (Reptilia, Squamata Phyllodactylidae). Primer registro para la provincia de Corrientes (República Argentina). Cuadernos de Herpetologia, 25, 21-22.

ETHERIDGE, R. (2000) A Review of Lizards of the Liolaemus wiegmannii Group (Squamata, Iguania, Tropiduridae), and a History of Morphological Change in the Sand-Dwelling Species. Herpetological Monographs, 14, 293-352.

ETHERIDGE, R. \& CHRISTIE, M.I. (2003) Two new species of the lizard genus Liolaemus (Squamata: Liolaemidae) from northern Patagonia, with comments on Liolaemus rothi. Journal of Herpetology, 37, 325-341.

ETHERIDGE, R. \& WILLIAMS, E.E. (1991) A Review of the South American Lizard Genera Urostrophus and Anisolepis (Squamata: Iguania: Polychridae). Bulletin of the Museum of Comparative Zoology, 152, 317-359.

ETHERIDGE, R.W., E E. (1985) Notes on Pristidactylus (Squamata: Iguanidae). Breviora, 1-18.

EVERS, P.R., JR., SILVEIRA, A.L. \& SANTOS LIMA FILHO, D. (2006) Amphisbaena dubia. Herpetological Review, 37, 240 EVERSOLE, C.B., POWELL, R., LIZARRO, D. \& CHOLIMA BRAVO, R. (2016) Erythrolamprus dorsocorallinus (Esqueda, Natera, La Marca \& Ilija-Fistar, 2005) (Squamata: Dipsadidae): range extension, new country record, and comments on color pattern. Check List, 12,

FAIVOVICH, J. (2005) A new species of Scinax (Anura: Hylidae) from Misiones, Argentina. Herpetologica, 61, 69-77.

FAIVOVICH, J., LUGLI, L., CALIJORNE LOURENCO, A.C. \& HADDAD, C.F.B. (2009) A new species of the Bokermannohyla martinsi group from central Bahia, Brazil with comments on Bokermannohyla (Anura: Hylidae). Herpetologica, 65, 303-310.

FAIVOVICH, J., NICOLI, L., BLOTTO, B.L., PEREYRA, M.O., BALDO, D., BARRIONUEVO, J.S., FABREZI, M., WILD, E.R. \& HADDAD, C.F.B. (2014) Big, Bad, and Beautiful: Phylogenetic Relationships of the Horned Frogs (Anura: Ceratophryidae). South American Journal of Herpetology, 9 , 207-227

FALCÃo, A.C.G.P. \& HERNÁNDEZ, M.I.M. (2007) Lagartos de restinga no Nordeste brasileiro: análise da fauna de áreas conservadas e reflorestadas. Anais do VIII Congresso de Ecologia do Brasil, 23 a 28 de Setembro de 2007, Caxambu, Ecologia

FARIA, R.G. (2006) Estudo da interação entre Tropidurus oreadicus e Tropidurus itambere (Iguanidae: Tropiduridae), em áreas de cerrado rupestre do Brasil Central: um abordagem comparativa e experimental. PhD. Departamento de Zoologia, Universidade de Brasilia, Brasilia, pp.

FARINA, J.M., SEPULVEDA, M., REYNA, M.V., WALLEM, K.P. \& OSSA-ZAZZALI, P.G. (2008) Geographical variation in the use of intertidal rocky shores by the lizard Microlophus atacamensis in relation to changes in terrestria productivity along the Atacama Desert coast. Journal of Animal Ecology, 77, 458-468.

FAUSTO FILHO, J. (1988) Aspectos bioecológicos do açude Santo Anastácio do Campus do Pici da Universidade Federal do Ceará. Revista Ciencia Agronomica, 19, 79-84.

FAVERO, E.R., VEIGA-MENONCELLO, A.C.P., ROSSA-FERES, D.C., STRUSSMANN, C., GIARETTA, A.A., ANDRADE, G.V COLOMBO, P. \& RECCO-PIMENTEL, S.M. (2011) Intrageneric Karyotypic Variation in Pseudopaludicola (Anura: Leiuperidae) and Its Taxonomic Relatedness. Zoological Studies, 50, 826-836.
FEDERICO, L. (2000) Cnemidophorus lacertoides. Herpetological Review, 31, 52

FEIO, R.N. \& CARAMASCHI, U. (2002) Contribuição ao conhecimento da herpetofauna do nordeste do estado de Minas Gerais, Brasil. Phyllomedusa, 1, 105-111.

FEIO, R.N., NAPOLI, M.F. \& CARAMASCHI, U. (2006) Consideraçäes taxonômicas sobre Thoropa milliaris (Spix, 1824), com a revalidação e redescrição de Thoropa taophora (Miranda-Ribeiro, 1923) (Amphibia, Anura, Leptodactylidae). Arquivos do Museu Nacional, 64, 41-60.

FEIO, R.N., SANTOS, P.S., CASSINI, C.S., DAYRELL, J.S. \& DE OLIVEIRA, E.F. (2008) Amphibian diversity in the Serra do Brigadeiro State Park, Minas Gerais, Brazil. MG Biota, 1, 132.

FEITOSA, D.T., DA SILVA, N.J., PIRES, M.G., ZAHER, H. \& PRUDENTE, A.L.D. (2015) A new species of monadal coral snake of the genus Micrurus (Serpentes, Elapidae) from western Amazon. Zootaxa, 3974, 538-554.

FELTRIM, A.C. (2002) Sexual dimorphism in Cnemidophorus lacertoides (Squamata, Teiidae) from Southern South America. Phyllomedusa, 1, 75-80.

FELTRIM, A.C. \& LEMA, T. (2000) Uma Nova Espécie de Cnemidophprus Wagler, 1830 do Estado do Rio Grande do Sul, Brasil (Sauria, Teiidae). Biociências, 8, 103-114.

ENOLIO, D.B., MENDELSON, J.R., III \& LAMAR, W.W. (2012) A New Diagnosis and Description of Variation among Adult Rhinella ceratophrys (Boulenger) (Amphibia: Bufonidae), with Notes on Ecology and Distribution. South American Journal of Herpetology, 7, 9-15.

FERMIN, G., GARCIA-GUTIERREZ, J., ESCALONA, M., MORA, A. \& DIAZ, A. (2012) Molecular taxonomic reassessment of the Cloud Forest's Bolitoglossa salamanders (Caudata: Plethodontidae) from Cordillera de Merida (Merida state, Venezuela). Zootaxa, 47-56

FERNANDES, D.S., GERMANO, V.J., FERNANDES, R. \& FRANCO, F.L. (2002) Taxonomic status and geographic distribution of the lowland species of the Liophis cobella group with comments on the species from the Venezuelan tepuis (Serpentes, Colubridae). Boletim do Museu Nacional Rio de Janeiro Zoologia, 481, 1-14.

FERNANDES, D.S. \& HAMDAN, B. (2014) A new species of Chironius Fitzinger, 1826 from the state of Bahia, Northeastern Brazil (Serpentes: Colubridae). Zootaxa, 3881, 563-575.

FERNANDES, D.S., MARQUES, O.A.V. \& ARGOLO, A.J.S. (2010) A new species of Dipsas Laurenti from the Atlantic Forest of Brazil (Serpentes: Dipsadidae). Zootaxa, 57-66.

FERRAO, M., DE FRAGA, R., SIMOES, P.I. \& LIMA, A.P. (2014) On the poorly sampled Amazonian frogs genus Hydrolaetare (Anura: Leptodactylidae): geographic ranges and species identification. Salamandra, 50, 77-84.

FERRAREZZI, H. (1993a) Nota sobre o genero Phalotris com revisao do grupo nasutus e descricao de tres novas especies (Serpentes, Colubridae, Xenodontinae). Memorias do Instituto Butantan, 55, 21-38.

FERRAREZZI, H. (1993b) Sistemática Filogenética de Elapomorphus, Phalotris e Apostolepis (Serpentes: Colubridae: Xenodontinae). Mestrado. Instituto de Biociências da Universidade de São Paulon, São Paulo, SP, 1-277 pp.

ERRAREZZI, H., BARBo, F.E. \& ALBUQUERQUE, C.E. (2005a) Phylogenetic relationships of a new species of Apostolepis from Brazilian Cerrado with notes on the assimilis group (Serpentes: Colubridae: Xenodontinae: Elapomorphini). Papéis Avulsos de Zoologia, 45, 215-229.

FERRAREZZI, H., CALLEFFO, M.E.V., CASTELLAR, T.M. \& DE LAURO, M. (2005b) Phalotris reticulatus. Herpetological Review, 36, 470 .

ERRAREZZI, H. \& FREIRE, E.M.X. (2001) New species of Bothrops Wagler, 1824 from the Atlantic Forest of northeastern Brazil (Serpentes, Viperidae, Crotalinae).
Boletim do Museu Nacional Rio de Janeiro Zoologia, 440, 110.

FERRARO, D.P. \& CASAGRANDA, M.D. (2009) Geographic distribution of the genus Pleurodema in Argentina (Anura: Leiuperidae). Zootaxa, 2024, 33-55.

FERREIRA, L.V., PEREIRA, J.L.G., AVILA-PIRES, T.C.S., CHAVES, P.P., CUNHA, D.A. \& FURTADO, C.S. (2009) Primeira ocorrência de Tupinambis quadrilineatus Manzani \& Abe, 1997 (Squamata: Teiidae) no bioma Amazônia. Boletim do Museu Paraense Emilio Goeldi Ciencias Naturais, 4, 355361.

FERREIRA, R.B., FAIVOVICH, J., BEARD, K.H. \& POMBAL, J.P., JR. (2015) The First Bromeligenous Species of Dendropsophus (Anura: Hylidae) from Brazil's Atlantic Forest. PLOS ONE, 10, e0142893.

FerREIRA, V.L. \& AVILA, R.W. (2009) Reptilia, Squamata, Serpentes, Dipsadidae, Sibynomorphus lavillai Scrocchi, Porto and Rey 1993: new country record and geographic distribution map. Check List, 5, 773-775.

FERREIRA, V.L., PETRONI, D.M. \& CACERAS, N.C. (2005) Bachia bresslaui (Bresslau's bachia). Herpetological Review, 36,78

FIALHO, R.F., ROCHA, C.F.D. \& VRCIBRADIC, D. (2000) Feeding ecology of Tropidurus torquatus: Ontogenetic shift in plant consumption and seasonal trends in diet. Journal of Herpetology, 34, 325-330.
FITZGERALD, L.A., COOK, J.A. \& AQUINO, A. (1999a) Molecular phylogenetics and conservation of Tupinambis (Sauria: Teiidae). Copeia, 1999, 894-905.

FITZGeRALD, L.A., CRUZ, F.B. \& PEROTTI, G. (1999b) Phenology of a lizard assemblage in the dry Chaco of Argentina. Journal of Herpetology, 33, 526-535.

FOLLECO-FERNÁNDEZ, A.J. (2010) Taxononía del complejo Bothrops asper (Serpentes: Viperidae) en el sudoeste de Colombia. Revalidación de la espécie Bothrops rhombeatus (García 1896) y descripción de una nueva especie. Revista Novedades Colombienas, 10, 33-70.

FOLLY, M., HEPP, F., CARVALHO-E-SILVA, S.P. \& DUELLMAN, W.E. (2014a) Taxonomic status and redescription of Flectonotus ulei (Anura: Hemiphractidae), with a key for the species of Fritziana. Zoologia, 31, 393-399.

FOLLY, M., KIRCHMEYER, J., GOMES, M.D.R., HEPP, F., RUGGERI, J., LUNA-DIAS, C., BEZERRA, A.M., AMARAL, L.C. \& CARVALHO-E-SILVA, S.P. (2014b) Amphibians from the Centro Marista São José das Paineiras, in Mendes, and surrounding municipalities, State of Rio de Janeiro, Brazil. Herpetology Notes, 7, 489-499.

FONSECA, E., TINOCO, M.S., MARQUES, R., BROWNERIBEIRO, H.C. \& FAZOLATO, C.P. (2012) Strobilurus torquatus (Amazon Lava Lizard). Herpetological Review, 43, 446.

ONTE, L.F.M. \& VOLKMER, G. (2013) Scinax squalirostris (Striped Snouted Treefrog), Scinax aromothyella. Morbid embrace. Herpetological Review, 44, 300-301.

FORLANI, M.C. (2010) Morfologia do gênero Chiasmocleis Méhely, 1904 (Anura, Microhylidae, Gastrophryninae), e suas implicações filogenéticas. Mestrado. Instituto de Biociências, Universidade de São Paulo, São Paulo, 138 pp. Biociências, Universidade de São Paulo, São Paulo, 138 pp.
FORLANI, M.C., BERNARDO, P.H., HADDAD, C.F.B. \& ZAHER H. (2010) Herpetofauna of the Carlos Botelho State Park,
ORLANI, M.C., BERNARDO, P.H., HADDAD, C.F.B. \& ZAHER, São Paulo State, Brazil. Biota Neotropica, 10, 265-308.

FORLANI, M.C., BERNARDO, P.H. \& ZAHER, H. (2012) Amphibia, Anura, Hylidae, Phyllomedusa tarsius Cope 1868: Distribution extension, new country record and geographic distribution map. Check List, 8, 155-157.

FORLANI, M.C., MIRA MENDES, C.V., DIAS, I.R., RUAS, D.S., TONINI, J.F.R. \& SA, R.O. (2013) The Advertisement Calls and Distribution of Two Sympatric Species of Chiasmocleis (Mehely 1904) (Anura, Microhylidae, Gastrophryninae) from the Atlantic Forest. South American Journal of Herpetology, 8, 46-51

FORMAS, J.R., BENAVIDES, E. \& CUEVAS, C. (2003) A new species of Telmatobius (Anura: Leptodactylidae) from Rio Vilama, northern Chile, and the redescription of $T$. halli Noble. Herpetologica, 59, 253-270.

FORTI, L.R., MARTINS, F.A.M. \& BERTOLUCI, J. (2012) Advertisement call and geographical variation in call features of Dendropsophus berthalutzae (Anura: Hylidae) from the Atlantic Rainforest of southeastern Brazil. Zootaxa, 3310, 66-68.

FOUQUET, A., BLOTTO, B.L., MARONNA, M.M., VERDADE, V.K., JUNCA, F.A., DE SÁ, R. \& RODRIGUES, M.T. (2013a) Unexpected phylogenetic positions of the genera Rupiran and Crossodactylodes reveal insights into the biogeography and reproductive evolution of leptodactylid frogs. Molecular Phylogenetics and Evolution, 67, 445-457.

OUQUET, A., CASSINI, C.S., HADDAD, C.F.B., PECH, N. \& RODRIGUES, M.T. (2014) Species delimitation, patterns of diversification and historical biogeography of the Neotropical frog genus Adenomera (Anura, Leptodactylidae). Journal of Biogeography, 41, 855-870.

FOUQUET, A., COURTOIS, E.A., BAUDAIN, D., LIMA, J.D SOUZA, S.M., NOONAN, B.P. \& RODRIGUES, M.T. (2015a) The trans-riverine genetic structure of 28 Amazonian frog species is dependent on life history. Journal of Tropical Ecology, 31, 361-373.

FUQUET, A., LOEBMANN, D., CASTROVIEJO-FISHER, S. PADIAL, J.M., ORRICO, V.G.D., LYRA, M.L., ROBERTO, I.J, KOK, P.J.R., HADDAD, C.F.B. \& RODRIGUES, M.T. (2012a) From Amazonia to the Atlantic forest: Molecular phylogeny of Phyzelaphryninae frogs reveals unexpected diversity and a striking biogeographic pattern emphasizing conservation challenges. Molecular Phylogenetics and Evolution, 65, 547561

OUQUET, A., MARTINEZ, Q., ZEIDLER, L., COURTOIS, E.A GAUCHER, P., BLANC, M., LIMA, J.D., SOUZA, S.M., RODRIGUES, M.T. \& KOK, P.J.R. (2016) Cryptic diversity in the Hypsiboas semilineatus species group (Amphibia Anura) with the description of a new species from the eastern Guiana Shield. Zootaxa, 4084, 104.

FOUQUET, A., NOONAN, B.P., BLANC, M. \& ORRICO, V.G.D. (2011) Phylogenetic position of Dendropsophus gaucher (Lescure and Marty 2000) highlights the need for an in depth investigation of the phylogenetic relationships of Dendropsophus (Anura: Hylidae). Zootaxa, 3035, 59-67.

FOUQUET, A., NOONAN, B.P., RODRIGUES, M.T., PECH, N., GILLES, A. \& GEMMEL, N.J. (2012b) Multiple Quaternary Refugia in the Eastern Guiana Shield Revealed by Comparative Phylogeography of 12 Frog Species. Systematic Biology, 61, 461-489.

FOUQUET, A., ORRICO, V.G.D., ERNST, R., BLANC, M. MARTINEZ, Q., VACHER, J.-P., RODRIGUES, M.T. OUBOTER, P., JAIRAM, R. \& RON, S. (2015b) A new Dendropsophus Fitzinger, 1843 (Anura: Hylidae) of the 
parviceps group from the lowlands of the Guiana Shield. Zootaxa, 4052, 39-64.

FOUQUET, A., PINEAU, K., RODRIGUES, M.T., MAILlES, J., SCHNEIDER, J.B., ERNST, R. \& DEWYNTER, M. (2013b) Endemic or exotic: the phylogenetic position of the Martinique Volcano Frog (Anura: Dendrobatidae) sheds light on its origin and challenges current conservation strategies. Systematics and Biodiversity, 2013, 1-15.

FOUQUET, A., RECODER, R., TEIXEIRA JR, M., CASSIMIRO, J., AMARO, R.C., CAMACHO, A., DAMASCENO, R., CARNAVAL, A.C., MORITZ, C. \& RODRIGUES, M.T. (2012c) Molecula phylogeny and morphometric analyses reveal deep divergence between Amazonia and Atlantic Forest species of Dendrophryniscus. Molecular Phylogenetics and Evolution, 62, 826-838.

FOUQUET, A., SOUZA, S.M., NUNES, P.M.S., KOK, P.J.R., CURCIO, F.F., CARVALHO, C.M., GRANT, T. \& RODRIGUES, M.T. (2015c) Two new endangered species of Anomaloglossus (Anura: Aromobatidae) from Roraima State, northern Brazil. Zootaxa, 3926, 191-210.

FOUQUET, A., VACHER, J.-P., KADOSOE, V., JAIRAM, R. \& OUBOTER, P. (2015d) Checklist of the Amphibians of the Sipaliwini area, Suriname. Herpetology Notes, 8, 63-68.

FRAGA, R., FERRÃO, M. \& CARVALHO, V.T. (2014) Geographic range extension of the Toad Leaf Frog Phyllomedus atelopoides Duellman, Cadle and Cannatella, 1988 (Anura, Hylidae). Herpetology Notes, 7, 203-205.

FRANÇA, D.P.F., FREITAS, M.A., BERNARDE, P.S. \& UHLIG V.M. (2013) Erythrolamprus oligolepis (Boulenger, 1905) (Serpentes: Dipsadidae): First record for the state of Acre, Brazil. Check List, 9, 668-669.

FRANCISCO, B.C.S., PINTO, R.R. \& FERNANDES, D.S. (2012) Taxonomy of Epictia munoai (Orejas-Miranda, 1961) (Squamata: Serpentes: Leptotyphlopidae). Zootaxa, 42-52.

FANCO, F.L., DE CARVALHo CINTRA, L.A. \& DE LEMA, T. (2006) A new species of Calamodontophis Amaral, 1963 (Serpentes, Colubridae, Xenodontinae) from southern Brazil. South American Journal of Herpetology, 1, 218-226.

FRANCO, F.L., FERNANDES, D.S. \& BENTIM, B.M. (2007) A new species of Hydrodynastes Fitzinger, 1843 from centra Brazil (Serpentes: Colubridae: Xenodontinae). Zootaxa, $57-$ 65

FANCO, F.L. \& FERREIRA, T.G. (2002) Description of a new species of Thamnodynastes Wagler, 1830 (Serpentes, Colubridae) from northeastern Brazil, with comments on the genus. Phyllomedusa, 1, 57-74.

FRANCO, F.L. \& FERREIRA, T.G. (2003) Occurrence of Thamnodynastes strigatus (Serpentes, Colubridae) in the Escudo das Guianas, Para and Roraima states, Brazil. Phyllomedusa, 2, 117-119.

FRANCO, F.L., FERREIRA, T.G., MARQUES, O.A.V. \& SAZIMA, I. (2003) A new species of hood-displaying Thamnodynastes Serpentes: Colubridae) from the Atlantic forest in southeast Brazil. Zootaxa, 334, 1-7.

FRANCO, F.L., SALOMAO, E.L., BORGES-MARTINS, M., DIBERNARDO, M., MENEGHEL, M.D. \& CARREIRA, S. (2001) New records of Calamodontophis paucidens (Serpentes, Colubridae, Xenodontinae) from Brazil and Uruguay. Cuadernos de Herpetologia, 14, 155-159.

RANZ, I. \& MELLO, M.H. (2015) Fritziana aff. fissilis (MirandaRibeiro, 1920) ( Anura, Hemiphractidae): the first hemiphractid for the state of Rio Grande do Sul, southern Brazil. Check List, 11, 1594.

FREIRE, E.M.X. (1996) Estudo ecológico e zoogeográfico sobre a fauna de lagartos (Sauria) das dunas de Natal, Rio Grande do Norte e da restinga de Ponta de Campina, Cabedelo, Paraíba, Brasil. Revista Brasileira de Zoologia, 13, 903-921.

FREIRE, E.M.X. (1998a) Geographical differentiation in Gymnodactylus darwinii (Gray, 1845) (Sauria, Gekkonidae) Papéis Avulsos de Zoologia, 40, 311-322.

FREIRE, E.M.X. (1998b) Sibon nebulata. Herpetological Review, 29, 178.

FREIRE, E.M.X. (1999) New species of Coleodactylus Parker, 1926 of the dunes of Natal, Rio Grande do Norte, Brazil, with notes on its relationships and sexual dichromatism in the genus (Squamata, Gekkonidae). Boletim do Museu Nacional, Nova Série - Zoologia, 399, 1-14.

FREIRE, E.M.X., CARAMASCHI, U. \& GONCALVES, U. (2010) A new species of Dendrophidion (Serpentes: Colubridae) from the Atlantic Rain Forest of Northeastern Brazil. Zootaxa, 62-68

FREIRE, E.M.X., FEIO, R.N. \& POMBAL, J.P. (2000) Phyllopezus periosus. Herpetological Review, 31,54

FREIRE, E.M.X., JORGE, J.S. \& RIBEIRO, L.B. (2012) First recor of Colobosaura modesta (Reinhardt and Lütken, 1862) (Squamata: Gymnophthalmidae) to the Cariri region, state of Ceará, Brazil, with a map of its geographical distribution. Check List, 8, 970-972.

FREIRE, E.M.X., JORGE, J.S., SALES, R.F.D., RIBEIRO, M.M., ANDRADE, M.J.M. \& SOUSA, P.A.G. (2013) New record and geographic distribution map of Alexandresaurus camacan Rodrigues, Pellegrino, Dixo, Verdade, Pavan, Argôlo and Sites Jr., 2007 (Squamata: Gymnophthalmidae) in Sites Jr., 2007 (Squamata: Gymnop
northeastern Brazil. Check List, 9, 783-784.

FREIRE, E.M.X., SKUK, G.O.S., KOLODIUK, M.F., RIBEIRO, L.B. MAGGI, B.S., RODRIGUES, L.S., VIEIRA, W.L.S. \& FALCÃO A.C.G.P. (2009) Répteis Squamata das Caatingas do Serido do Rio Grande do Norte e do Cariri da Paraiba: sintese do conhecimento atual e perspectivas. In: FREIRE, E.M.X. (Ed.) Recursos natura is das caatingas: uma visao multidisciplinar. EDUFRN, Natal, RN, $\mathrm{pp}$.

FREIRE, M.D., COLOMBO, P., ZANK, C. \& MODKOWSKI, S.P. (2016) Southermost records of the anurans, Chiasmocleis leucosticta (Boulenger, 1888) (Microhylidae) and Dendropsophus werneri (Cochran, 1952) (Hylidae), in the Atlantic forest, Brazil. Herpetology Notes, 9, 149-155.

REITAS, J.L. (2011a) Evolução da Forma do Corpo em lagarto do Gênero Bachia Gray. 1845 (Squamata, Universidade de Brasília, Universidade de Brasília, Brasília, Brasil, $50 \mathrm{pp}$.

FREITAS, J.L., STRÜSSMANN, C., CARVALHO, M.A. KAWASHITA-RIBEIRO, R.A. \& MOTT, T. (2011a) A new species of Bachia Gray, 1845 (Squamata: Gymnophthalmidae) from the Cerrado of Midwestern Brazil. Zootaxa, 2737, 61-68.

FREITAS, M.A. (2011b) Anfibios do Nordeste Brasileiro. Mata Atlântica - Caatinga - Cerrado - Zona Costeira - Amazônia. (produced by the author), $86 \mathrm{pp}$

FREITAS, M.A., ALMEIDA, B.A., ALMEIDA, M.S.M.A., DANIN, T.S. \& MOURA, G.J.B. (2014a) Rediscovery and first record of Sibynomorphus mikanii septentrionalis (Cunha, Nascimento \& Hoge, 1980), (Squamata; Serpentes) for the state of Pará. 2014, 10, 1246-1248.

REITAS, M.A., DIAS, I.R., FARIAS, T., OLIVEIRA E SOUSA, $S$. VIEIRA, R.S., BARBOSA DE MOURA, G.J. \& UHLIG, V. (2014b) First record of Ctenophryne geayi Mocquard, 1904 (Amphibia: Anura) for the state of Maranhão, Brazil. Check List, 10, 585-587.

FREITAS, M.A., FAGUNDES DE FRANCA, D.P. \& VERISSIMO, D.

(2011b) Distribution extension of Uracentron flavicep (Guichenot, 1855) (Reptilia: Squamata): Second record fo the state of Acre, Brazil. Check List, 7, 823-824.

REITAS, M.A., FARIAS, T., OLIVEIRA E SOUSA, S., VIEIRA, R.S. BARBOSA DE MOURA, G.J. \& DIAS, I.R. (2014c) First record of Lithodytes lineatus (Schneider, 1799) (Anura: Leptodactylidae) in northeastern Brazil. Check List, 10, 615617.

REITAS, M.A., FARIAS, T., SOUSA, S.O., VIEIRA, R.S., MOURA, G.J.B.D. \& UHLIG, V. (2014d) First record of Phyllomedus vaillantii Boulenger, 1882 (Amphibia: Anura) for the state of Maranhao, Brazil. Herpetology Notes, 7, 457-459.

REITAS, M.A., FRANÇA, D.P.F. \& LIMA, T.O. (2011c) Stenocercus quinarius. Geographic Distribution. Herpetological Review, 42, 391-392.

FREITAS, M.A., FRANÇA, D.P.F. \& VERÍSSIMO, D. (2011d) First record of Cercosaura eigenmanni (Griffin, 1917) (Squamata: Gymnophthalmidae) for the state of Acre, Brazil. Check List 7, 516

FREITAS, M.A., LIMA, T.D.O. \& FAGUNDES DE FRANCA, D.P. (2011e) Trachycephalus mambaiensis. Herpetological Review, 42, 387.

FREITAS, M.A., LIMA, T.O. \& FRANÇA, D.P.F. (2011f) Tupinambis quadrilineatus. Geographic Distribution. Herpetological Review, 42, 392

FREITAS, M.A., MACHADO, D.C., VENÂNCIO, N.M., FRANÇA, D.P.F. \& VERÍSSIMO, D. (2013a) First record for Brazil of the Odd Anole lizard, Anolis dissimilis Williams, 1965 (Squamata: Polychrotidae) with notes on coloration Herpetology Notes, 6, 383-385.

FREITAS, M.A. \& MOISÉS, L.E. (2009) Anotosaura vanzolinia Geographic Distribution. Herpetological Review, 40

FREITAS, M.A. \& MOURA, G.J.B. (2013) Tupinambis quadrilineatus. Geographic Distribution. Herpetological Review, 44, 274.

FREITAS, M.A. \& SILVA, T.F.S. (2007) A Herpetofauna das Caatingas e Áreas de Altitude do Nordeste Brasileiro. USEB, Salvador, $380 \mathrm{pp}$.

FREITAS, M.A., SILVA, T.F.S. \& MORAES, E.P. (2007) Alexandresaurus camacan. Herpetological Review, 38, 481.

FREITAS, M.A., SOUSA, S.O., VIEIRA, R.S., FARIAS, T. \& MOURA, G.J.B. (2013b) First record of Cercosaura argulus (Peters, 1863) (Squamata: Gymnophthalmidae) for the (Peters, 1863) (Squamata: Gymnophthalmidae)

FREITAS, M.A., VERÍSSIMO, D., ALBUQUERQUE, S. \& LIMA T.D.O. (2012) Distribution extension for the lizard Enyalius lechii (Boulenger, 1885) (Squamata: Leiosauridae): Third record for the state of Rondônia, Brazil. Herpetology Notes, 5, 33-34.

FRITTS, T.H. (1972) New species of Lizard of the genus Stenocercus from Perú (Sauria: Iguanidae). Occasional Papers of the Museum of Natural History University of Kansas, 1-21.

FITTS, T.H. (1974) A multivariate and evolutionary analysis of the andean iguanid lizards of the genus Stenocercus. San Diego Society of Natural History Memoires, 7, 1-89.

RITTS, T.H., ALMENDARIZ, A. \& SAMEC, S. (2002) A new species of Echinosaura (Gymnophthalmidae) from Ecuador and Colombia with comments on other members of the genus and Teuchocercus keyi. Journal of Herpetology, 36, 349-355.

FROST, D.R. (2016) Amphibian Species of the World: an Online Reference. v. 6.0. American Museum of Natural History, $\begin{array}{lccc}\text { New York, USA. Available from: } & \\ \text { http://research.amnh.org/herpetology/amphibia/ } & \end{array}$
FROST, D.R., CRAFTS, H.M., FITZGERALD, L.A. \& TITUS, T.A (1998) Geographic variation, species recognition, and molecular evolution of cytochrome oxidase 1 in the Tropidurus spinulosus complex (Iguania: Tropiduridae). Copeia, 839-851.

FROTA, JG (2005) Nova espécie de Helicops Wagler, 1830 (Serpentes, Colubridae) do rio Tapajos, Amazonia, Brasil. Phyllomedusa, 4, 61-68.

UENMAYOR, G.R., MANZANILLA, J., RIVERO, R. \& LA MARCA, E. (2002) Lepidoblepharis sanctaemartae (Ruthven, 1916), a lizard new the the Venezuelan fauna. Herpetozoa, 15, 92-94.

FUENMAYOR, G.R. \& MOLINA, C.R. (2001) Coleodactylus septentrionalis (Pigmy gecko). Herpetological Review, 32,

UENMAYOR, G.R. \& MOLINA R, C.R. (1998) Pseustes shropshirei. Herpetological Review, 29, 178.

UNK, W.C., ANGULO, A., CALDWELL, J.P., RYAN, M.J. \& CANNATELLA, D.C. (2008) Comparison of morphology and calls of two cryptic species of Physalaemus (Anura: Leiuperidae). Herpetologica, 64, 290-304.

FUSINATTO, L.A., ALEXANDRINO, J., HADDAD, C.F.B., BRUNES, T.O., ROCHA, C.F.D. \& SEQUEIRA, F. (2013) Cryptic genetic diversity is paramount in small-bodied amphibians of the genus Euparkerella (Anura: Craugastoridae) endemic to the Brazilian Atlantic Forest. PLOS ONE, 8,

GAIARSA, M.P. (2010) Definindo prioridades de conservação em grupos monofiléticos: um estudo de caso com uma linhagem de serpentes neotropicais. Dissertation. Instituto de Biociências da Universidade de São Paulo, São Paulo, SP72 pp.

AINSBURY, A.M. \& COLLI, G.R. (2003) Lizard assemblages from natural cerrado enclaves in southwestern Amazonia: The role of stochastic extinctions and isolation. Biotropica $35,503-519$.

GALDINO, C.A. \& VAN SLUYS, M. (2004) Tropidurus torquatus (Collared Lizard, Calango) saurophagy. Herpetological Review, 35, 173.

GALDINO, J.Y.A., GONÇALVES, U., MATIAS, G. \& TORQUATO, S. (2015) Amphisbaena lumbricalis Vanzolini, 1996 (Squamata: Amphisbaenidae): Distribution extension and map. Boletim do Museu de Biologia Mello Leitao, 37, 293 29.

GALLAGHER, D.S. \& DIXON, J.R. (1992) Taxonomic revision of the South American lizard genus Kentropyx Spix (Sauria, Teiidae). Museo Regionale di Scienze Naturali Bollettino (Turino), 10, 125-171.

GALLARDO, J. (1964) Los generos Urostrophus D. et B. Cupriguanus gen. nov. (Sauria, Iguanidae) y sus especies. Neotropica, 10, 125-136.

GALLARDO, J.M. (1966) 'Liolaemus lentus' nov. sp. (Iguanidae) de la pampa y algunas observaciones sobre los saurios de dicha provincia Argentina y del oeste de Buenos Aires. Neotropica, 12, 15-29.

GALLEGO, F. (1999) Vanzosaura rubricauda. Herpetologica Review, 30, 234-235.

GALLY, M., SILVA, A.S.F.L. \& ZINA, J. (2012) Death feigning in Physalaemus kroyeri (Reinhardt and Luetken, 1862) (Anura, Leiuperidae). Herpetology Notes, 5, 133-135.

GANS, C. (1962a) Notes on Amphisbaenids (Amphisbaenia, Reptilia). 5. A Redefinition and a Bibliography of Amphisbaena alba Linné. American Museum Novitates, 1962, 1-32.

GANS, C. (1962b) Redefinition and Description of the Brasilian Reptiles Amphisbaena silvestrii Boulenger and $A$. neglecto Dunn and Piatt. Copeia, 1962, 164-170.

GANS, C. (1963a) Notes on amphisbaenids (Amphisbaenia, Reptilia). 7. Redescription and redefinition of Amphisbaena mitchelli Procter and Amphisbaena slevini Schmidt from the Middle and Lower Amazon, Brazil. American Museum Novitates, 1963, 1-22.

GANS, C. (1963b) Notes on Amphisbaenids (Amphisbaenia, Reptilia). 8 A Redescription of Amphisbaena stejnegeri and the Description of a New Species of Amphisbaena from British Guiana. American Museum Novitates, 1963, 1-18.

GANS, C. (1963c) Notes on amphisbaenids (Amphisbaenia Reptilia). 10. Redescription and redefinition of Amphisbaena pericensis Noble from the mountains of northwestern Peru. Breviora, 189, 1-15.

GANS, C. (1964a) Amphisbaena mitchelli Procter recorded from Belem, Para, Brazil. Herpetologica, 20, 192-194.

GANS, C. (1964b) New records of Amphisbaena silvestrii Boulenger, and the description of a new two-pored species from the Northern Chaco. Copeia, 1964, 553-561.

GANS, C. (1964c) Notes on amphisbaenid 15. The South American species of Amphisbaena with a vertically keeled tail (Reptilia, Amphisbaenidae). Senckenbergiana Biologica 45, 387-416.

GANS, C. (1964d) Redescription of Amphisbaena dubia Muller (Amphisbaenia : Reptilia). Breviora, 205, 1-11.

GANS, C. (1965a) Notes on Amphisbaenids (Amphisbaenia, Reptilia). 17 A Redescription and Discussion of Amphisbaena angustifrons Cope and Amphisbaena camura Cope of Southern South America. American Museum Novitates, 1965, 1-32.

GANS, C. (1965b) On Amphisbaena heathi Schmidt and A. carvalhoi, new species, small forms from the northeast of 
Brazil (Amphisbaenia: Reptilia). Proceedings of the California Academy of Sciences, 31, 613-630.

GANS, C. (1965c) Redescription of Amphisbaena pretre Dumeril and Bibron and A. leucocephala Peters, with a discussion of their relation and synonymy (Amphisbaenia: Reptilia). American Midland Naturalist, 74, 387-407.

GANS, C. (1966a) Redescription of Amphisbaena mertensi Strauch, with Comments on Its Geographic Variation an Synonymy (Amphisbaenia: Reptilia). Copeia, 1966, 534-548.

GANS, C. (1966b) Studies on Amphisbaenids (Amphisbaenia, Reptilia). 3. The small species from southern South America commonly identified as Amphisbaena darwini. Bulletin of the American Museum of Natural History, 134, 185-260.

GANS, C. (1967a) A new record of Amphisbaena leeseri from Mato Grosso. Herpetologica, 23, 247-248.

GANS, C. (1967b) Redescription of Amphisbaena slater Boulenger, with Comments on Its Range Extension into Bolivia. Herpetologica, 23, 223-227.

GANS, C. (1971a) Comments on the types and some othe interesting amphisbaenians in the collection of the Leningrad Zoological Institute. Smithsonian Hepetological Information Service, 25, 1-2.

GANS, C. (1971b) Redescription of Three Monotypic Genera of Amphisbaenians From South America: Aulura Barbour, Bronia Gray, and Mesobaena Mertens. American Museum Novitates, 1971, 1-32.

GANS, C. (1971c) Studies on Amphisbaenians (Amphisbaenia Reptilia) 4. A Review of the Amphisbaenid Genus Leposternon. Bulletin of the American Museum of Natura History, 144, 379-464.

GANS, C. (1987) Studies on Amphisbaenians (Reptilia). 7. The Small Round-headed Species (Cynisca) from Western Africa. American Museum Novitates, 1987, 1-84.

GANS, C. \& AMDUR, M.A. (1966) Redescription of Amphisbaena vermicularis Wagler, with comments on its range and synonymy (Amphisbaenia: Reptilia). Proceedings of the California Academy of Sciences, 33, 69-90.

GANS, C., BAUER, A.M. \& GÜNTHER, R. (1997) An annotated type catalogue of the amphisbaenians (Reptilia: Squamata: Amphisbaenia) in the Zoological Museum, Berlin. Mitteilungen aus dem Zoologischen Museum in Berlin, 73 $41-50$.

GANS, C. \& DIEFENBACH, C.O.C. (1972) Description and Geographical Variation of the South America Amphisbaena angustifrons: the Southernmost Amphisbaenian in the World (Reptilia, Amphisbaenia). American Museum Novitates, 1972, 1-20.

GANS, C. \& MATHERS, S. (1977) Amphisbaena medemi, An Interesting New Species from Colombia (Amphisbaenia Reptilia), with a Key to the Amphisbaenians of the Americas. Fieldiana Zoology, 72, 21-26.

GANS, C. \& RHODES, C. (1964) Notes on Amphisbaenids (Amphisbaenia, Reptilia). 13 A Systematic Review of Anop Bell, 1833. American Museum Novitates, 1964, 1-26.

GARCIA-GUTIERREZ, J., ESCALONA, M., MORA, A., DE PASCUAL, A.D. \& FERMIN, G. (2013) A new species of salamander (Caudata: Plethodontidae, Bolitoglossa) from Sierra Nevada de Merida, Venezuela. Zootaxa, 3620, 179191.

GARCÍA-PÉREZ, J.E. (1995) Una nueva espécie del complejo de Ameiva bifrontata (Sauria: Teiidae) del bolson arido d Lagunillas, Cordillera de Merida, Venezuela. Revista Unellez de Ciencia y Tecnología, 13, 127-144.

GARCIA-PÉREZ, J.E. \& YUSTIZ, E.E. (1995) Una nueva especie de Proctoporus (Sauria: Gymnophthalmidae) de los Andes de Venezuela. Revista de Ecologia LatinoAmericana, 4, 1-5.

GARCIA, P., SEGALLA, M.V. \& BALDO, D. (2008a) Vitreorana uranoscopa. The IUCN Red List of Threatened Species, 1-8.

GARCIA, P.C.A., PEIXOTO, O.L. \& HADDAD, C.F.B. (2008b) A new species of Hypsiboas (Anura: Hylidae) from the Atlantic orest of Santa Catarina, southern Brazil, with comments on its conservation status. South American Journal of Herpetology, 3, 27-35.

GARCIA, P.C.D.A., BERNECK, B.V.M. \& ROCHA DA COSTA, C.O. (2009) A new species of Paratelmatobius (Amphibia, Anura, Leptodactylidae) from Atlantic rain forest of southeastern

Brazil. South American Journal of Herpetology, 4, 217-224.
GARDA, A.A., COSTA, T.B., SANTOS-SILVA, C., MESQUITA D.O., FARIA, R.G., CONCEIÇÃO, B.M., SILVA, I.R.S FERREIRA, A.S., ROCHA, S.M., PALMEIRA, C.N.S RODRIGUES, R., FERRARI, S.F. \& TORQUATO, S. (2013) Herpetofauna of protected areas in the Caatinga I: Raso da Catarina Ecological Station (Bahia, Brazil). Check List, 9, 405-414.

GAREY, M.V., LIMA, A.M.X., HARTMANN, M.T. \& HADDAD, C.F.B. (2012) A New Species of Miniaturized Toadlet, Genus Brachycephalus (Anura: Brachycephalidae), from Southern Brazil. Herpetologica, 68, 266-271.

GAREY, M.V., PROVETE, D.B., MARTINS, I.A., HADDAD, C.F.B. \& ROSSA-FERES, D.C. (2014) Anurans from the Serra da Bocaina National Park and surrounding buffer area, southeastern Brazil. Check List, 10, 308-316.

GARMAN, S. (1887) On the West Indian Teiids in the Museum of Comparative Zoology. Bulletin of the Essex Institute, 19, $1-12$.

GASC, J.P. (1977) Liste commenteé de lezards captures en Amazonie colombienne. Bulletin de la Societe Zoologique de France, 102, 267-276.
GASCON, C. (1996) Amphibian Litter Fauna and River Barriers in Flooded and Non-Flooded Amazonian Rain Forest. Biotropica, 28, 136-140.

GASPARINI, J.L., KOSKI, D.A. \& PELOSO, P.L.V. (2010) Reptilia, Squamata, Leiosauridae, Urostrophus vautieri Duméril and Bribon, 1837: Distribution extension, new state record, and geographic distribution map. Check List, 6, 432-433.

GASPARINI, J.L., PELOSO, P.L. \& ALMEIDA, A.P. (2007) A herpetofauna da APA de Setiba, município de Guarapari, Espírito Santo, Brasil, p. 3-4. In: 3o Congresso Brasileiro de Herpetologia. HERPETOLOGIA, S.B.D. (ed.). Sociedade Brasileira de Herpetologia, Belém

GBIF. (2016) Global Biodiversity Information Facility - Data Portal. Global Biodiversity Information Facility. Available from: http://data.gbif.org/ (2 July 2016).

GeHARA, M., CANEDO, C., HADDAD, C.F.B. \& VENCES, M (2013) From widespread to microendemic: molecular and acoustic analyses show that Ischnocnema guenther (Amphibia: Brachycephalidae) is endemic to Rio de Janeiro, Brazil. Conservation Genetics, 14, 973-982.

GEHARA, M., CRAWFORD, A.J., ORRICO, V.G.D., RODRIGUEZ, A., LOTTERS, S., FOUQUET, A., BARRIENTOS, L.S., B., LOTTERS, S., FOUQTI, F., DE LA RIVA, I., ERNST, R., URRUTIA, G.G., GLAW, F., GUAYASAMIN, J.M., HOLTING, M., JANSEN, M. KOK, P.J.R., KWET, A., LINGNAU, R., LYRA, M., MORAVEC, KOK, P.J.R., KWET, A., LINGNAU, R., LYRA, M., MORAVEC,
J., POMBAL, J.P., ROJAS-RUNJAIC, F.J.M., SCHULZE, A., J., POMBAL, J.P., ROJAS-RUNJAIC, F.J.M., SCHULZE, A.,
SENARIS, J.C., SOLE, M., RODRIGUES, M.T., TWOMEY, E, HADDAD, C.F.B., VENCES, M. \& KÖHLER, J. (2014) High Levels of Diversity Uncovered in a Widespread Nominal Taxon: Continental Phylogeography of the Neotropical Tree Frog Dendropsophus minutus. PLOS ONE, 9, 1-12.

GHIZONI-JR, I.R., KUNZ, T.S., CHEREM, J.J. \& BÉRNILS, R.S. (2009) Registros notáveis de répteis de áreas abertas naturais do planalto e litoral do Estado de Santa Catarina sul do Brasil. Biotemas, 22, 129-141.

GIARETTA, A.A. (1996) Tropidurus torquatus (NCN). Home range. Herpetological Review, 27, 80-81.

GIARETTA, A.A., TOFFOLI, D. \& OLIVEIRA, L.E. (2007) A new species of Ischnocnema (Anura: Eleutherodactylinae) from open areas of the Cerrado Biome in southeastern Brazil. Zootaxa, 53-51.

GIASSON, L.O.M., KUNZ, T.S. \& GHIZONI-JR, I.R. (2011) Amphibia, Anura, Bufonidae, Melanophryniscus spectabilis Caramaschi and Cruz, 2002: Distribution extension and geographic distribution map. Check List, 7, 641-644.

GIMENES, C.R. \& GALLEGO, F. (1999) Teius suquiensis (lagartija verde). Herpetological Review, 30, 234.

GIRAUDO, A.R. \& SCROCCHI, G.J. (1998) A new species of Apostolepis (Serpentes: Colubridae) and comments on the genus in Argentina. Herpetologica, 54, 470-476

GIUGLIANO, L.G., CONTEL, E.P.B. \& COLLI, G.R. (2006) Genetic variability and phylogenetic relationships of Cnemidophorus parecis (Squamata, Teiidae) from Cerrado isolates in southwestern Amazo

GODOY, F.D. \& DA SILVA, V.A.A. (2004) Levantamento preliminar de lagartos no Parque do Bacaba, Nova Xavantina - MT. In: 10 Congresso Brasileiro de Herpetologia. HERPETOLOGIA, S.B.D. (ed.). Sociedade Brasileira de HERPETOLOGIA, S.B.
Herpetologia, Curitiba

OELDI, E.A. (1898) Die Eier von 13 brasilianischen Reptilien nebst Bemerkungen über Lebens- und Fortpflanzungsweis letzterer. Beobachtungen aus den Jahren 1884-1897. Zoologische Jahrbücher, Abteilung für Systematik, Geographie und Biologie der Tiere, 10, 640-676.

GOELDI, E.A. (1902) Lagartos do Brazil VII Lacertilios Boletim do Museu Paraense de História Natural e Etnografia, 3 499-560.

Gogliath, M., RIBEIRO, L.B. \& FREIRE, E.M.X. (2010a) Acratosaura mentalis (NCN). Herpetological Review, 41, 105-06.

GOGLIATH, M., RIBEIRO, L.B. \& FREIRE, E.M.X. (2010b) Anotosaura vanzolinia. Geographic Distribution. Herpetological Review, 41, 243.

GOGLIATH, M., RIBEIRO, L.B. \& FREIRE, E.M.X. (2010c) Reptilia, Squamata, Leiosauridae, Enyalius bibroni Boulenger, 1885: Distribution extension and geographic distribution map. Check List, 6, 652-653.

OICOECHEA, N., PADIAL, J.M., CHAPAR, J.C., CASTROVIEJOFISHER, S. \& DE LA RIV, I. (2013) A taxonomic revision of Proctoporus bolivianus Werner (Squamata:
Gymnophthalmidae) with the description of three new species and resurrection of Proctoporus lacertus Stejneger. American Museum Novitates, 2013, 1-32.

GOLDBERG, S.R. (2010) Note on the reproductive cycle of Cope's ameiva, Ameiva bifrontata (Squamata: Teiidae) from Peru. Bulletin of the Chicago Herpetological Society, 45, 125-126.

GOLDBERG, S.R., BURSEY, C.R., VITT, L.J. \& ARREOLA, J. (2012) Iphisa elegans (Glossy Shade Lizard). Endoparasites. Herpetological Review, 43, 647-649.

GOMES, J.O. \& MACIEL, A.O. (2012) A new species of Amphisbaena Linnaeus (Squamata, Amphisbaenidae) from the state of Maranhão, northern Brazilian Cerrado. Zootaxa, 3572, 43-54.

GOMES, J.O., MACIEL, A.O., COSTA, J.C.L. \& ANDRADE, G.V. (2009) Diet Composition in Two Sympatric Amphisbaenian from the Brazilian Cerrado. Journal of Herpetology, 43, 377384

GOMES, M.D.R. \& PEIXOTO, O.L. (2009) Dendropsophus marmoratus. Herpetological Review, 40, 445.

GómEZ, A.C. (2013) Anfibios Y algunos Reptiles del Parque Nacional Del Agua Carmen De Apicalá- Tolima, Colombia The Field Museum, Chicago, $2 \mathrm{pp}$.

GóMEZ, J.M.D. (2007) Reptilia, Iguania, Liolaeminae Liolaemus, Puna, Prepuna, and mountain ranges, Northwestern Argentina. Check List, 3, 105-118.

GOMIDES, S.C. \& SOUSA, B.M. (2013) Enyalius brasiliensis. Death-Feigning. Herpetological Review, 44, 141-142.

GONÇALVES, U., BRITO, P.S., GALDINO, J.Y. \& TORQUATO, S. (2012a) Squamata, Gymnophthalmidae, Anotosaura vanzolinia Dixon, 1974: New records and geographic distribution map. Check List, 8, 632-633.

ONÇALVES, U., TORQUATUS, S., SKUK, G. \& SENA, G.A.B. (2012b) A new species of Coleodactylus Parker, 1926 (Squamata: Sphaerodactylidae) from the Atlantic Forest of northeast Brazil. Zootaxa, 3204, 20-30.

GONZALES, L., LOTTERS, S. \& REICHLE, S. (1999) On the dendrobatid frogs from Bolivia: rediscovery of Epipedobates bolivianus (Boulenger, 1902), first record of Colostethus brunneus (Cope, 1887) and comments on other species (Anura: Dendrobatidae). Herpetozoa, 12, 179-186. GONZÁLEZ-CARCACÍA, J.A., ROMERO, V.P. \& RIVAS, G. (2012) Phimophis guianensis (Troschel's Pampas Snake). Diet Herpetological Review, 43, 496-497.

GONZÁLEZ-MARÍN, A. \& HERNANDO, A. (2013) Notes on the postcranial osteology of the sand lizard Liolaemus azarai (Squamata: Liolaemidae). Phyllomedusa, 12, 135-141.

GONZALEZ, R.C., DA COSTA PRUDENTE, A.L. \& FRANCO, F.L

(2014a) Morphological variation of Gomesophis brasiliensis and Ptychophis flavovirgatus (Serpentes, Dipsadidae, Xenodontinae). Salamandra, 50, 85-98.

GONZALEZ, R.C., SILVA-SOARES, T., DE CASTRO, T.M. \& BERNILS, R.S. (2014b) Review of the geographic distribution of Micrurus decoratus (Jan, 1858) (Serpentes: Elapidae). Phyllomedusa, 13, 29-39.

GONZALEZ SPONGA, M.A. \& GANS, C. (1971) Amphisbaen gracilis Strauch Rediscovered (Amphisbaenia: Reptilia). Copeia, 589-+.

ORDO, M., TOLEDO, L.F., SUÁREZ, P., KAWASHITA-RIBEIRO, R.A., ÁVILA, R.W., MORAIS, D.H. \& NUNES, I. (2013) A New Species of Milk Frog of the Genus Trachycephalus tschudi (Anura, Hylidae) from the Amazonian Rainforest. Herpetologica, 69, 466-479.

GORZULA, S. \& SENARIS, J.C. (1998) Contribution to the herpetofauna of the Venezuelan Guayana 1. A data base. Scientia Guaianae, 8, i-xviii, 1-269.

GORZULA, S.J. (1985) Geographic distribution. Amphisbaena gracilis (Morrona). Herpetological Review, 16, 83.

GOWER, D.J., WILKINSON, M., SHERRATT, E. \& KOK, P.J.R. (2010) A new species of Rhinatrema Dumeril \& Bibron
(Amphibia: Gymnophiona: Rhinatrematidae) from Guyana. Zootaxa, 47-60.

GRABOSKI, R., PEREIRA, G.A., DA SILVA, A.A.A., PRUDENTE, A.L.D. \& ZAHER, H. (2015) A new species of Amerotyphlops from Northeastern Brazil, with comments on distribution of related species. Zootaxa, 3920, 443-452.

RAHAM, C.H., RON, S.R., SANTOS, J.C., SCHNEIDER, C.J. \& MORITZ, C. (2004) Integrating phylogenetics and environmental niche models to explore speciation mechanisms in dendrobatid frogs. Evolution, 58, 17811793.

GRANDA-RODRIGUEZ, H.D., SABOYA-ACOSTA, L.P. PORTILLO-MOZO, A.D. \& RENJIFO, J.M. (2014) Rang extension of dendrobatid frog Colostethus ruthveni Kaplan, 1997 (Anura: Dendrobatidae) in the Sierra Nevada de Santa Marta, Colombia. Check List, 10, 674-676.

GRANT, C. (1958) A New Gymnophthalmus (Reptilia, Teidae) From Barbados, B.W.I. Herpetologica, 14, 227-228.

GRANT, T. (2004) On the identities of Colostethus inguinalis (Cope, 1868) and C. panamensis (Dunn, 1933), with comments on C. latinasus (Cope, 1863) (Anura: comments on C. latinasus (Cope, 1863) (Anura:
Dendrobatidae). American Museum Novitates, 3444, 1-24.

GRANT, T., ACOSTA, A. \& RADA, M. (2007) A name for the species of Allobates (Anura: Dendrobatoidea: Aromobatidae) from the Magdalena Valley of Colombia. Copeia, 2007, 844-854

GRANT, T. \& ARDILA-ROBAYO, M.C. (2002) A New Species of Colostethus (Anura: Dendrobatidae) from the Eastern Slopes of the Cordillera Oriental of Colombia. Herpetologica, 58, 252-260.

GRANT, T. \& BOLIVAR, W. (2014) A New Species of Semiarboreal Toad with a Salamander-Like Ear (Anura: Bufonidae: Rhinella). Herpetologica, 70, 198-210.

GRANT, T. \& MYERS, C.W. (2013) Review of the Frog Genus Silverstoneia, with, Descriptions of Five New Species from the Colombian Chocó (Dendrobatidae: Colostethinae). American Museum Novitates, 2013, 1-58.

GRAVENHORST, J.L.C.C. (1838) Beiträge zur genaueren Kenntniss einiger Eidechsengattungen. Nova acta physicomedica Academiae Caesareae Leopoldino-Carolinae Naturae Curiosum, 18, 712-784.

GRAY, J.E. (1851) Description of a new genus and family of cyclosaurian lizards from Para. Proceedings of the Zoological Society of London, 1851, 38-39. 
GREENE, H.W. (1977) Lizards of the genus Uracentron (Iguanidae)

GRIFFIN, L.E. (1917) A list of South American lizards of the Carnegie Museum, with descriptions of four new species. Annal of Carnegie Museum, 11, 304-320.

GUARNIZO, C.E., ESCALLON, C., CANNATELLA, D. \& AMEZQUITA, A. (2012) Congruence between acoustic traits and genealogical history reveals a new species of Dendropsophus (anura: hylidae) in the high Andes of Colombia. Herpetologica, 68, 523-540.

GUARNIZO, C.E., PAZ, A., MUNOZ-ORTIZ, A., FLECHAS, S.V., MENDEZ-NARVAEZ, J. \& CRAWFORD, A.J. (2015) DNA Barcoding Survey of Anurans across the Eastern Cordillera of Colombia and the Impact of the Andes on Cryptic Diversity. PLOS ONE, 10,

GUAYASAMIN, J.M., ALMEIDA-REINOSO, D. \& NOGALES SORNOSA, F. (2004) Two New Species of Frogs (Leptodactylidae: Eleutherodactylus) from the High Andes of Northern Ecuador. Herpetological Monographs, 18, 127141

GUAYASAMIN, J.M. \& ARTEAGA, A.F. (2013) A new species of the Pristimantis orestes group (Amphibia: Strabomantidae) from the high Andes of Ecuador, Reserva Mazar. Zootaxa, 3616, 345-356.

GUAYASAMIN, J.M., CISNEROS-HEREDIA, D.F., YANEZMUNOZ, M. \& BUSTAMANTE, M. (2006) Amphibi Centrolenidae, Centrolene ilex, Centrolene litorale, Centrolene medemi, Cochranella albomaculata, Cochranella ametarsia: range extensions and new country records. Check List, 2, 24-26.

GUAYASAMIN, J.M. \& FUNK, W.C. (2009) The amphibian community at Yanayacu Biological Station, Ecuador, with comparison of vertical microhabitat use among Pristimantis species and the description of a new species of the Pristimantis myersi group. Zootaxa, 41-66.

GUAYASAMIN, J.M., KRYNAK, T., KRYNAK, K., CULEBRAS, J. \& HUTTER, C.R. (2015a) Phenotypic plasticity raises question for taxonomically important traits: a remarkable new Andean rainfrog (Pristimantis) with the ability to change

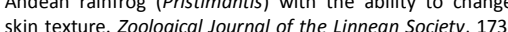
skin texture.

GUAYASAMIN, J.M., RIVERA-CORREA, M., ARTEAGA, A. CULEBRAS, J., BUSTAMANTE, L., PYRON, R.A., PEÑAFIEL, N., MOROCHZ, C. \& HUTTER, C.R. (2015b) Molecula phylogeny of stream treefrogs (Hylidae: Hyloscirtus bogotensis Group), with a new species from the Andes of Ecuador. Neotropical Biodiversity, 1, 2-21.

GUERREIRO, A., BALDONI, J.C. \& BRIGADA, A.M. (2005) Herpetofauna de Sierra de Las Quijadas ( San Luis, Argentina). Guyana, 69, 6-9.

GUERREIRO, A.C., CRUZ BALDONI, J., BRIGADA, A.M. \& CABRERA, M.R. (1998) Ampliacion de la distribucion de Teius oculatus y $T$. suquiensis (Sauria: Teiidae) en la provincia de San Luis (Republica Argentina). Cuadernos de Herpetologia, 12, 51.

GUERRERO, A.C. \& RODRIGUES, M.T. (2007) Dryadosaura nordestina (Briba Cabeçuda). Geographic Distribution. Herpetological Review, 38, 218

GUERRERO, M., VENEGAS, P.J., GAGLIARDI, G., SUAREZ, A. TOYAMA, R., CONTRERAS, V.H. \& RUIZ, J. (2011) Centro de Investigaciones Jenaro Herrera - Loreto, Perú - Anfibios y Reptiles. Chicago, $10 \mathrm{pp}$.

GUICHENOT, A. (1855) Reptiles. In: CASTELNAU, F.L.L. (Ed.) Animaux Nouveaux ou Rares Recueillis Pendant L'expédition dans les Parties Centrales de L Amérioue du Sud, de Rio de Janeiro a Lima et de Lima au Pará. Exécutée par Ordre du Gouvernement Français Pendant les Années 1843 à 1847, sous la direction de F. de castelnau. Chez P. Bertrand, Paris, pp. 1-95.

GUIMARKES, T.C., FIGUEIREDO, G.B. \& SALMITO, W.E. (2007) Tupinambis quadrilineatus. Herpetological Review, 38, 353354

GUTIERREZ-C, P.D. \& RIVERA-CORREA, M. (2007) Cochranella punctulata Ruiz-Carranza \& Lynch, 1995 - new record from the department of Antioquia (Colombia), with comments on the conservation status. Herpetozoa, 20, 75-77.

GUTIÉRREZ-C., P.D. \& DAZA-R., J.M. (2006) Reptilia, Squamata, Gekkonidae, Lepidoblepharis williamsi distribution extension. Check List, 2, 59-60.

GUTIERREZ, D.R. \& ALVAREZ, L.G. (2009) Pristimantis ashkapara (NCN). Herpetological Review, 40, 109.

GUZMAN, J.A. \& DIAZ-PAEZ, H. (2011) Hylorina sylvatica (Emerald Forest Frog). Herpetological Review, 42, 237.

HADDAD, C.F.B., ALVES, A.C.R., CLEMENTE-CARVALHO, R.B.G \& DOS REIS, S.F. (2010) A New Species of Brachycephalus from the Atlantic Rain Forest in São Paulo State, Southeastern Brazil (Amphibia: Anura: Brachycephalidae). Copeia, 410-420.

HALLOWELL, M.D. (1856) Notes on the Reptiles in the collection of the Academy of Natural Sciences of Philadelphia. Proceedings of the Academy of Natural Sciences of Philadelphia, 8, 221-238.

HAMDAN, B. \& FERNANDES, D.S. (2015) Taxonomic revision of Chironius flavolineatus (Jan, 1863) with description of a new species (Serpentes: Colubridae). Zootaxa, 4012, 97119 .
HAMDAN, B., SILVA, N.J.J. \& SILVA, H.L.R. (2013) Redescription of Phalotris labiomaculatus (Serpentes, Dipsadidae, Elapomorphini), with notes on the taxonom boundaries within the nasutus group. Zootaxa, 3693, 7 .

HARO, J., SFERCO, G. \& ARCANDO, U. (2000) Nueva localidad para Tupinambis rufescens (Günther, 1871) en la provincia de Córdoba (Argentina). Cuadernos de Herpetologia, 14, 79. HARRIS, D.M. (1982) The Sphaerodactylus (Sauria: Gekkonidae) of South America. Occasional Papers of the Museum of Zoology University of Michigan, 1-32.

HARRIS, D.M. (1994) Review of the teiid lizard genus Ptychoglossus. Herpetological Monographs, 8, 226-275.

HARRIS, D.M. \& AYALA, S.C. (1987) A new Anadia (Sauria: Teiidae) from Colombia and restoration of Anadic pamplonensis Dunn to species status. Herpetologica, 43 182-190.

HARTMANN, M.T. \& HARTMANN, P.A. (2002) Hyla giesler (Giesler's treefrog). Herpetological Review, 33, 220-22

HARVEY, M.B., AGUAYO, R. \& MIRALLES, A. (2008) Redescription and biogeography of Mabuya cochabambae Dunn with comments on Bolivian congeners (Lacertilia Scincidae). Zootaxa, 43-56.

HARVEY, M.B. ALMENDARIZ, A., BRITO, J. \& BATALLAS, D. (2013) A new species of Noblella (Anura: Craugastoridae) from the Amazonian Slopes of the Ecuadorian Andes with Comments on Noblella lochites (Lynch). Zootaxa, 3635, 114

HARVEY, M.B. \& GUTBERLET, R.L. (1998) Lizards of the genus Tropidurus (Iguania : Tropiduridae) from the Serrania de Huanchaca, Bolivia: New species, natural history, and a key to the genus. Herpetologica, 54, 493-520.

HARVEY, M.B. \& NOONAN, B.P. (2005) Bolivian glass frogs (Anura: Centrolenidae) with a description of a new species from Amazonia. Proceedings of the Biological Society of Washington, 118, 428-441.

HARVEY, M.B., RIVAS, G.A. \& MANZANILLA, J. (2004) Redescription of Stenocercus erythrogaster (Hallowell). Copeia, 940-944.

HARVEY, M.B. \& SHEEHY, C.M. (2005) A new species of Ischnocnema (Anura: Leptodactylidae) from La Paz, Bolivia. Herpetologica, 61, 268-275.

HARVEY, M.B. \& SMITH, E.N. (1993) A new species of aquatic Bufo (Anura: Bufonidae) from cloud forests in the Serrania de Siberia, Bolivia. Proceedings of the Biological Society of Washington, 106, 442-449.

HARVEY, M.B., UGUETO, G.N. \& GUTBERLET, R.L. (2012) Review of Teiid Morphology with a Revised Taxonomy and Phylogeny of the Teiidae (Lepidosauria: Squamata). Zootaxa, 1-156.

HATANO, F.H., VRCIBRADIC, D., GALDINO, C.A.B., CUNHABARROS, M., ROCHA, C.F.D. \& VAN SLUYS, M. (2001) Thermal ecology and activity patterns of the lizard community of the restinga of Jurubatiba, Macae, RJ. Revisto Brasileira de Biologia, 61, 287-294.

HEDGES, S.B. \& CONN, C.E. (2012) A new skink fauna from Caribbean islands (Squamata, Mabuyidae, Mabuyinae). Zootaxa, 3288, 1-244.

HEINICKE, M.P., DUELLMAN, W.E., TRUEB, L., MEANS, D.B. MACCULLOCH, R.D. \& HEDGES, S.B. (2009) A new frog family (Anura: Terrarana) from South America and an expanded direct-developing clade revealed by molecula phylogeny. Zootaxa, 1-35.

HELLMICH, W. (1950) Die Eidechsen der Ausbeute Schröde (Gattung Liolaemus, Iguan.) (Beiträge zur Kenntnis de Herpetofauna Chiles XIII.). Veröffentlichungen der Zoologischen Staatssammlung München, 1, 129-194.

HELIMICH, W. (1960) Die Sauria des Gran Chaco und seine Randgebiete. Bayerische Akademie der Wissenschaften Mathematisch-Naturwissenschaftliche Klasse, No. 101, 1131

HENDERSON, R.W. (1997) A Taxonomic Review of the Corallus hortulanus Complex of Neotropical Tree Boas. Caribbean Journal of Science, 33, 198-221.

HENDERSON, R.W. \& POWELL, R. (2009) The state of natural history: a perspective from the literature on West Indian herpetology. Herpetological Review, 40, 273-275.

HENLE, K. \& EHRL, A. (1991) Zur Reptilienfauna Perus nebst Beschreibung eines neuen Anolis (Iguanidae) und zweie neuer Schlangen (Colubridae). Bonner Zoologische Beitraege, 42, 143-180.

HEPP, F., DE CARVALHO-E-SILVA, S.P., DE CARVALHO-E-SILVA, A.M.P.T. \& FOLLY, M. (2015) A fifth species of the genus Euparkerella (Griffths, 1959), the advertisement calls of $E$. robusta Izecksohn, 1988 and E. tridactyla Izecksohn, 1988, and a key for the Euparkerella species (Anura: Brachycephaloidea: Craugastoridae). Zootaxa, 3973, 251270.

HEREDIA, V.J., ROBLES, C. \& HALLOY, M. (2013) A new specie of Liolaemus from the darwinii group (Iguania: (iolaemidae), Tucuman province, Argentina. Zootaxa, 3681, 524-538.

HERNÁNDEZ-RUZ, J.E., MASCARENHAS, B.E. \& MIRANDA, R. (2008) Caracterização preliminar da herpetofauna das (2008) Caracterização preliminar da herpetofauna das Boletim do Laboratório de Hidrobiologia, 21, 25-30.

HERNANDEZ CORDOBA, O.D., CARDONA BOTERO, V.E. \& CASTRO HERRERA, F. (2014) Amphibia, Anura, Bufonidae Atelopus eusebianus (Rivero \& Granados-Diaz, 1993):
Distribution extension for Valle del Cauca, Colombia. Check List, 10, 682-683.

HEYER, M.M., HEYER, W.R. \& DE SÁ, R.O. (2012) Leptodactylus pentadactylus. Catalogue of American Amphibians and Reptiles, 887, 887.1-887.48.

HEYER, R. (1983a) Variation and Systematics of Frogs of the Genus Cycloramphus (Amphibia, Leptodactylidae). Arquivos de Zoologia, 30, 235-339.

HEYER, W. (2005) Variation and taxonomic clarification of the large species of the Leptodactylus pentadactylus species group (Amphibia: Leptodactylidae) from Middle America, northern South America, and Amazonia. Arquivos de Zoologia, 37, 269-348.

HEYER, W.R. (1969) Studies on the genus Lepodactylus (Amphibia, Leptodactylidae). 3. A redefinition of the genus Leptodactylus and a description of a new genus of Leptodactylid frogs. Contributions in Science, 155, 1-14.

HEYER, W.R. (1977) Taxonomic notes on frogs from teh Madeira and Purus Rivers, Brasil. Papéis Avulsos de Zoologia, 31, 141-162.

HEYER, W.R. (1983b) Clarification of the names Rana mystacea Spix, 1824, Leptodactylus amazonicus Heyer, 1978 and a description of a new species, Leptodactylus spixi (Amphibia: Leptodactylidae). Proceedings of the Biological Society of Washington, 96, 270-272.

HEYER, W.R. (1983c) Notes on the frog genus Cycloramphus (Amphibia: Leptodactylidae), with descriptions of two new species. Proceedings of the Biological Society of Washington, 96, 548-559.

HEYER, W.R. (1984) Variation, systematics, and zoogeography of Eleutherodactylus guentheri and closely related specie (Amhibia: Anura: Leptodactylidae). Smithsonian Contributions to Zoology, 402, 1-42.

HEYER, W.R. \& HEYER, M.M. (2006) Leptodactylus knudsen Heyer: Knudsen's thin-toed frog. Catalogue of American Amphibians and Reptiles, 807, 1-12.

HEYER, W.R., RAND, A.S., CRUZ, C.A.G.D., PEIXOTO, O.L. \& NELSON, C.E. (1990) Frogs of Boracéia. Arquivos de Zoologia, 31, 231-410.

HEYER, W.R. \& THOMPSON, A.S. (2000) Leptodactylus rugosus Noble. Catalogue of American Amphibians and Reptiles, 708, 708.1-708.5.

HILLIS, D.M. \& DE SA, R. (1988) Phylogeny and taxonomy of the Rana palmipes group (Salientia: Ranidae). Herpetological Monographs, 1-26.

HOOGMOED, M. (1985a) Notes on the Herpetofauna of Suriname : X. Coleodactylus septentrionalis Vanzolini, a Lizard new for the Surinamese Fauna (Sauria: Gekkonidae). Zoologische Mededelingen, 59, 229-238.

HOOGMOED, M. (2013) Rediscovery of the rare tree frog Hyla inframaculata Boulenger, 1882 (Anura: Hylidae), in Amazonian Brazil with notes on variation and distribution and its generic allocation. Amphibia-Reptilia, 34, 421-432. HOOGMOED, M.S. (1973) Notes on the herpetofauna of Surinam 4. The lizards and amphisbaenians of Surinam. Biogeographica, 4, 1-419.

HOOGMOED, M.S. (1977) On a new species of Leptotyphlops from Surinam, with notes on the other Surinam species of the genus (Leptotyphlopidae, Serpentes). - Notes on the herpetofauna of Surinam. Zoologische Meded Leiden, 51 99-123.

HOOGMOED, M.S. (1980) Revision of the genus Atractus in Surinam, with the ressurection of two species (Colubridae, Reptilia). Zoologische Verhandelingen, 1-47.

HOOGMOED, M.S. (1985b) Xenodon werneri Eiselt, a poorly known snake from Guiana, with notes on Waglerophis merremii (Wagler) (Reptilia: Serpentes: Colubridae). Notes on the herpetofauna of Surinam IX. Zoologische Mededelingen, 59, 79-88

HOOGMOED, M.S. (1990) Resurrection of Hyla wavrini Parke (Amphibia: Anura: Hylidae), a gladiator frog from northern South America. Zoologische Mededelingen, 64, 71-93.

HOOGMOED, M.S. (1997) Rediscovery of a forgotten snake in an unexpected place and remarks on a small herpetologica collection from southeastern Brazil. Zoologische collection from sou

HOOGMOED, M.S. \& AVILA-PIRES, T.C.S. (1991a) Annotated Checklist of the Herpetofauna of Petit Saut Sinnamary River French Guiana. Zoologische Mededelingen, 65, 53-88.

HOOGMOED, M.S. \& AVILA-PIRES, T.C.S. (1991b) A new species of small Amphisbaena (Reptilia: Amphisbaenia: Amphisbaenidae) from western Amazonian Brazil. Boletim do Museu Paraense Emilio Goeldi Serie Zoologia, 7, 77-94. HOOGMOED, M.S. \& AVILA-PIRES, T.C. (1992) Studies on the species of the South American lizard genus Arthrosaura Boulenger (Reptilia: Sauria: Teiidae), with the resurrection of two species. Zoologische Mededelingen, 66, 453-484.

HOOGMOED, M.S. \& AVILA-PIRES, T.C.S. (2012) Inventory of color polymorphism in populations of Dendrobates galactonotus (Anura: Dendrobatidae), a poison fros endemic to Brazil. Phyllomedusa, 11, 95-115.

HOOGMOED, M.S., COLE, C.J. \& AYARZAGUENA, J. (1992) A new cryptic species of lizard (Sauria: Teiidae: Gymnophthalmus) from Venezuela. Zoologische Mededelingen, 66, 1-18.

HOOGMOED, M.S. \& DIXON, J.R. (1977) A new species of Bachia (Teiidae, Sauria) from Estado Bolivar, Venezuela, 
with notes on the zoogeography of the genus. Zoologische Mededelingen, 51, 25-31.

HOOGMOED, M.S. \& LESCURE, J. (1975) An Annotated Checklist of the Lizards of French Guiana Mainly Based on 2 Recent Collections. Zoologische Mededelingen, 49, 141171

HOOGMOED, M.S., LYNCH, J.D. \& LESCURE, J. (1977) A neW species of Eleutherodactylus from Guiana (Leptodactylidae, Anura). Zoologische Meded Leiden, 51, 33-41,illust.

HOOGMOED, M.S., PINTO, R.R., DA ROCHA, W.A. \& PEREIRA E.G. (2009) A New Species of Mesobaena Mertens, 1925 (Squamata: Amphisbaenidae) from Brazilian Guiana, with Key to the Amphisbaenidae of the Guianan Region. Herpetologica, 65, 436-448.

HUERTA, G.E. \& ORTIZ, J.C. (2011) Liolaemus cristian (Cristian's Lizard). Herpetological Review, 42, 569.

HUTTER, C.R. \& GUAYASAMIN, J.M. (2012) A new crypti species of glassfrog (Centrolenidae: Nymphargus) from Reserva Las Gralarias, Ecuador. Zootaxa, 1-21.

HUTTER, C.R. \& GUAYASAMIN, J.M. (2015) Cryptic diversity concealed in the Andean cloud forests: two new species of rainfrogs (Pristimantis) uncovered by molecular and bioacoustic data. Neotropical Biodiversity, 1, 36-59.

IAP. (2002) Plano de manejo do Parque Estadual do Cerrado. Instituto Ambiental do Paraná, Curitiba,PR, 1-459 pp.

BARRA-VIDAL, H. (2005) Nueva especie de lagartija de altiplano de Chile, Liolaemus lopezi sp. n. (Reptilia, Tropiduridae, Liolaeminae). Boletin de la Sociedad de Biología de Concepción, 76-77, 7-13.

ICOCHEA, J., QUISPITUPAC, E., PORTILLA, A. \& PONCE, E. (2001) Assessment of Amphibians and Reptiles of the Lowe Urubamba Region, Peru. In: ALONSO, A., DALLMEIER, F. \& CAMPBELL, P. (Eds.) Urubamba: The Biodiversity of a Peruvian Rainforest. Smithsonian Institution, Washington pp. 129-142.

IHERING, R.V. (1898) Contributions to the Herpetology of Sao Paulo, Brazil: I. Proceedings of the Academy of Natural Sciences of Philadelphia, 50, 101-109.

ILHA, P. \& DIXO, M. (2010) Anurans and Lizards, Rio Preto da Eva, Amazonas, Brazil. Check List, 6, 17-21.

INFANTE-RIVERO, E.E., ROJAS-RUNJAIC, F.JM. \& BARRIOAMOROS, C.L. (2008) Un nuevo Cryptobatrachus Ruthven, 1916 (Anura: Cryptobatrachidae) de la vertiente venezolan de la sierra de Perijá. Memoria de la Fundación La Salle de Ciencias Naturales, 68, 45-63.

IPCBBB. (2006) Mapping the Occurrence, Distribution and Conservation Status of Endemic and Threatened Reptiles in Bahian Restingas, p. 1-11. Instituto de Pesquisas Conservação da Biodiversidade dos Biomas Brasileiros Instituto Biomas, Rio de Janeiro, RJ

IVERSON, J.B. (1992) A Revised Checklist with Distribution Maps of the Turtles of the World. Privetly printed, Richmond, $363 \mathrm{pp}$.

IZECKSOHN, E., CARVALHO-E-SILVA, S.P. \& PEIXOTO, O.L (2009) Sobre Gastrotheca fissipes (Boulenger, 1888), com descrição de uma nova espécie (Amphibia, Anura, Amphignathodontidae). Arquivos do Museu Nacional, 67, 81-91.

JACKSON, J.F. (1978) Differentiation in the Genera Enyalius and Strobilurus Iguanidae Implications for Pleistocen Climatic Changes in Eastern Brazil. Arquivos de Zoologia, 30 1-79.

JADIN, R.C., BURBRINK, F.T., RIVAS, G.A., VITT, L.J., BARRIOAMORÓS, C.L. \& GURALNICK, R.P. (2014) Finding arboreal snakes in an evolutionary tree: phylogenetic placement and systematic revision of the Neotropical birdsnakes. Journal of Zoological Systematics and Evolutionary Research, 52, of Zoologica 264 .

JAIRAM, R. \& JAIRAM-DOERGA, S. (2015) First record of mapasaurus tetradactylus Cunha, 1970 (Squamata: Gymnopthalmidae) in Suriname. Check List, 11, 1-4.

JANSEN, M., BLOCH, R., SCHULZE, A. \& PFENNINGER, M (2011) Integrative inventory of Bolivia's lowland anuran reveals hidden diversity. Zoologica Scripta, 40, 567-583.

JANSEN, M., GONZALES ALVAREZ, L. \& KÖHLER, G. (2009) Description of a new species of Xenopholis (Serpentes: Colubridae) from the Cerrado of Bolivia, with comments on Xenopholis scalaris in Bolivia. Zootaxa, 2222, 31-45.

JANSEN, M. \& KÖHLER, G. (2008) A new species of Phalotris from the eastern lowlands of Bolivia (Reptilia, Squamata, Colubridae). Senckenbergiana Biologica, 88, 103-110.

JANSEN, M. \& KÖHLER, J. (2010) Reptilia, Squamata, Amphisbaenidae, Amphisbaena cegei Montero, 1997, and Reptilia, Squamata, Teiidae, Tupinambis rufescens (Günther, 1871): vertical range extension. Check List, 6 503-504.

JARAMILLO-MARTINEZ, A.F., VALENCIA-Z, A., CARDONA, V.E. CASTRO-HERRERA, F. \& CISNEROS-HEREDIA, D.F. (2015) Range extension of Cochranella mache Guayasamin an Bonaccorso, 2004 (Anura: Centrolenidae) with comments on the distribution of $C$. euknemos (Savage and Starrett, 1967) in Colombia. Herpetology Notes, 8, 161-163.

JAVIER AVILA, L., FRUTOS, N., PEREZ, C.H.F. \& MORANDO, M. (2007) Reptilia, Iguania, Liolaemidae, Liolaemus somuncurae: distribution extension. Check List, 3, 11-13.

JORGE, J.S. \& FREIRE, E.M.X. (2010) Mabuya agmosticha Herpetological Review, 41, 512-513.
JOYEUX, J.C. \& GASPARINI, J.L. (2006) Tropidurus torquatus (Brazilian Collared Lizard). Mortality. Herpetological Review, 37,475

JULIANO, R.F., BASTOS, R.P. \& MOTTA, J.A.D. (2002a) Tropidurus torquatus (calango). Diet. Herpetological Review, 33, 54-55.

JULIANO, R.F., BASTOS, R.P., RUA LOPEZ, M. \& MOTTA, J.A.D.

(2002b) Mabuya bistriata (NCN) diet. Herpetological Review, 33, 52-53.

JUNCÁ, F.A. (2005) Anfíbios e Répteis. In: JUNCÁ, F.A. \& FUNCH, L. (Eds.) Biodiversidade e Conservação da Chapada Diamantina. Ministério do Meio Ambiente, Brasília, DF, pp. 339-376.

JUNCÁ, F.A., NAPOLI, M.F., NUNES, I., MERCES, E.A. \& ABREU, R.O. (2015) A New Species of the Scinax ruber Clade (Anura, Hylidae) from the Espinhaco Range, Northeastern Brazil. Herpetologica, 71, 299-309.

UNGFER, K.-H., FAIVOVICH, J., PADIAL, J.M., CASTROVIEJO FISHER, S., LYRA, M.M., BERNECK, B.V.M., IGLESIAS, P.P. KOK, P.J.R., MACCULLOCH, R.D., RODRIGUES, M.T., VERDADE, V.K., TORRES GASTELLO, C.P., CARLOS CHAPARRO, J., VALDUJO, P.H., REICHLE, S., MORAVEC, J., GVOZDIK, V., GAGLIARDI-URRUTIA, G., ERNST, R., DE LA RIVA, I., MEANS, D.B., LIMA, A.P., CELSA SENARIS, J., WHEELER, W.C. \& HADDAD, C.F.B. (2013) Systematics of WHEELER, W.C. \& HADDAD, C.F.B. (2013) Systematics of
spiny-backed treefrogs (Hylidae: Osteocephalus): an spiny-backed treefrogs (Hylidae: Osteocephalus): Amazonian puzzle. Zoologica Scripta, 42, 351-380.

JUNGFER, K.H. (2010) The taxonomic status of some spinybacked treefrogs, genus

JUNGFER, K.H., REICHLE, S. \& PISKUREK, O. (2010) Description of a new cryptic southwestern Amazonian species of leafgluing treefrog, genus Dendropsophus (Amphibia: Anura: gluing treefrog, genus Dendropsophy
Hylidae). Salamandra, 46, 204-213.

UNQUEIRA, A.F.B., MARTINS, I.A., GOMES, F.B.R. \& ZAHER, H.E. (2007) Inventário da herpetofauna na região de Cristina, Serra da Mantiqueira, Minas Gerais, p. 186-187. In: 3o Congresso Brasileiro de Herpetologia. HERPETOLOGIA, S.B.D. (ed.). Sociedade Brasileira de Herpetologia, Belém

KACOLIRIS, F.P. BERKUNSKY, I. \& WILLIAMS, J. (2006) Herpetofauna of the Argentinean Impenetrable Great Chaco. Phyllomedusa, 5, 149-157.

AEFER, Í.L., SIMÕES, P.I. \& LIMA, A.P. (2012) First record of Allobates nidicola (Anura: Dendrobatoidea) from the state of Rondônia, southwestern Amazonia, Brazil. Salamandra, 48, 122-124.

KAISER, H., BARRIO-AMOROS, C.L., RIVAS, G.A., STEINLEIN, C \& SCHMID, M. (2015) Five new species of Pristimantis (Anura: Strabomantidae) from the coastal cloud forest of the Peninsula de Paria, Venezuela. Journal of Threatened Taxa, 7, 7047-7088.

KaSAHARA, S., PELLEGRINO, K.C.M., RODRIGUES, M.T. \& YNENAGA-YASSUDA, Y. (1996) Comparative cytogenetic studies of eleven species of the Tropidurus torquatus group (Sauria, Tropiduridae), with banding patterns. Hereditas, $125,37-46$

KAWASHITA-RIBEIRO, R.A., ARRUDA, L.A.G., CARVALHO, M.A., SILVA, A.F., SILVA, J.P., AVILA, R.W., MORAIS, D.H. \& MOTT, T. (2011) Leposoma osvaldoi Avila-Pires, 1995 (Squamata: Gymnophthalmidae): New records and distribution map in the state of Mato Grosso, Brazil. Check List, 7, 852-853.

KAWASHITA-RIBEIRO, R.A. \& AVILA, R.W. (2008) Reptilia, Squamata, Polychrus spp.: New record, range extensions, and distribution map in the state of Mato Grosso, Brazil. Check List, 4, 362-365.

KAWASHITA-RIBEIRO, R.A., ÁVILA, R.W. \& MORAIS, D.H.

(2013) A New Snake of the Genus Helicops Wagler, 1830 (Dipsadidae, Xenodontinae) from Brazil. Herpetologica, 69 80-90.

KIEFER, M.C. (1998) Anotosaura brachylepis (NCN). Predation. Herpetological Review, 29, 41

KIEFER, M.C., VAN SLUYS, M. \& ROCHA, C.F.D. (2008) Clutch and egg size of the tropical lizard Tropidurus torquatus (Tropiduridae) along its geographic range in coastal eastern Brazil. Canadian Journal of Zoology-Revue Canadienne De Zoologie, 86, 1376-1388.

KIZIRIAN, D.A. (1996) A review of Ecuadorian Proctoporus (Squamata: Gymnophthalmidae) with descriptions of nine new species. Herpetological Monographs, 10, 85-155.

KIZIRIAN, D.A. \& MCDIARMID, R.W. (1998) A new species of Bachia (Squamata : Gymnophthalmidae) with plesiomorphic limb morphology. Herpetologica, 54, 245253.

KLUGE, A.G. (1964) A Revision of the South American Gekkonid Lizard Genus Homonota Gray. American Museum Novitates, 1964, 1-42.

KLUGE, A.G. (1969) The evolution and geographical origin of the New World Hemidactylus mabouia-brookii complex (Gekkonidae, Sauria). Miscellaneous Publications Museum of Zoology University of Michigan, 138, 1-78.

KOCH, C. \& BERAUN, A.M. (2011) Squamata, Phyllodactylidae Phyllodactylus thompsoni Venegas, Townsend, Koch and Bohme, 2008 and Phyllodactylus delsolari Venegas, Townsend, Koch and Bohme, 2008: latitudinal and altitudinal distribution extension and geographic distribution map. Check List, 7, 272-275.
KOCH, C., VENEGAS, P.J. \& BOEHME, W. (2006) A remarkable discovery: description of a big-growing new gecko (Squamata: Gekkonidae : Phyllopezus) from northwestern Peru. Salamandra, 42, 145-150.

KOCH, C., VENEGAS, P.J. \& BOHME, W. (2015) Three new endemic species of Epictia Gray, 1845 (Serpentes: Leptotyphlopidae) from the dry forest of northwestern Peru. Zootaxa, 3964, 228-244.

KOCH, C., VENEGAS, P.J., GARCIA-BRAVO, A. \& BOHME, W (2011) A new bush anole (Iguanidae, Polychrotinae, Polychrus) from the upper Maranon basin, Peru, with redescription of Polychrus peruvianus (Noble, 1924) and additional information on $P$. gutturosus Berthold, 1845. ZooKeys, 79-106.

KOCH, C., VENEGAS, P.J., ROEDDER, D., FLECKS, M. \& BOEHME, W. (2013) Two new endemic species of Ameivo (Squamata: Teiidae) from the dry forest of northwestern Peru and additional information on Ameiva concolo Ruthven, 1924. Zootaxa, 3745, 263-295.

KOFRON, C.P. (1988) The Central and South American blindsnakes of the genus Anomalepis. Amphibia-Reptilia, 9, 7-13.

KÖHLER, G. (2010) A revision of the Central American specie related to Anolis pentaprion with the resurrection of $A$ beckeri and the description of a new species (Squamata: Polychrotidae). Zootaxa, 2354, 1-18.

KÖHLER, G., BATISTA, A., VESELY, M., PONCE, M., CARRIZO A. \& LOTZKAT, S. (2012a) Evidence for the recognition of two species of Anolis formerly referred to as $A$. tropidogaster (Squamata: Dactyloidae). Zootaxa, 1-23.

KÖHLER, G., BOHME, W. \& SCHMITZ, A. (2004) A new specie of Echinosaura (Squamata: Gymnophthalmidae) from Ecuador. Journal of Herpetology, 38, 52-60.

ÖHLER, G., DIETHERT, H.H. \& VESELÝ, M. (2012b) A Contribution to the Knowledge of the Lizard Genus Alopoglossus (Squamata: Gymnophthalmidae). Herpetological Monographs, 26, 173-188.

KÖHLER, G. \& KIECKBUSCH, M. (2014) Two new species of Atractus from Colombia (Reptilia, Squamata, Dipsadidae). Zootaxa, 3872, 291-300.

KÖHLER, G. \& LEHR, E. (2004) Comments on Euspondylus and Proctoporus (Squamata: Gymnophthalmidae) from Peru, with the description of three new species and a key to the Peruvian species. Herpetologica, 60, 501-518.

KöHLER, G. \& LEHR, E. (2015) Two new species of lizards of the genus Stenocercus (Iguania, Tropiduridae) from centra Peru. Zootaxa, 3956, 413-427.

KÖHLER, J., JUNGFER, K.-H. \& REICHLE, S. (2005) Another New Species of Small Hyla (Anura, Hylidae) from Amazonian SubAndean Forest of Western Bolivia. Journal of Herpetology, 39, 43-50

KOHLER, J., KOSCINSKI, D., PADIAL, J.M., CHAPARRO, J.C., HANDFORD, P., LOUGHEED, S.C. \& DE LA RIVA, I. (2010) Systematics of Andean gladiator frogs of the Hypsiboa pulchellus species group (Anura, Hylidae). Zoologica Scripta 39, 572-590.

KOK, P. \& FUENMAYOR, G.R. (2008) Typhlophis ayarzaguenai Senaris, 1998 is a junior synonym of Typhlophis squamosus (Schlegel, 1839). Amphibia-Reptilia, 29, 555-558.

KK, P.J. (2008) A new highland species of Arthrosaura Boulenger, 1885 (Squamata: Gymnophthalmidae) from Maringma tepui on the border of Guyana and Brazil. Zootaxa, 1909, 1-15.

OK, P.J.R. (2005) A new genus and species of gymnophthalmid lizard (Squamata: Gymnophthalmidae) from Kaieteur National Park, Guyana. Bulletin de I'Institut Royal des Sciences Naturelles de Belgique Biologie, 75, 3545.

KOK, P.J.R. (2009a) Lizard in the clouds: a new highland genus and species of Gymnophthalmidae (Reptilia: Squamata) from Maringma tepui, western Guyana. Zootaxa, 53-67.

KOK, P.J.R. (2009b) A new species of Oreophrynella (Anura: Bufonidae) from the Pantepui region of Guyana, with notes on O. macconnelli Boulenger, 1900. Zootaxa, 35-49.

KOK, P.J.R. (2010) A new species of Chironius Fitzinger, 1826 (Squamata: Colubridae) from the Pantepui region, northeastern South America. Zootaxa, 31-44.

KOK, P.J.R. (2011) A new species of the genus Gonatodes Fitzinger, 1843 (Reptilia: Sphaerodactylidae) from centra Guyana, northern South America. Zootaxa, 1-12.

KOK, P.J.R. (2013) Two new charismatic Pristimantis species (Anura: Craugastoridae) from the tepuis of "The Lost World" (Pantepui region, South America). European Journal of Taxonomy, 60, 1-24.

KOK, P.J.R. (2015) A new species of the Pantepui endemic genus Riolama (Squamata: Gymnophthalmidae) from the summit of Murisipán-tepui, with the erection of a new gymnophthalmid subfamily. Zoological Journal of the Linnean Society, 2015, 500-518.

KOK, P.J.R. \& CASTROVIEJO-FISHER, S. (2008) Glassfrog (Anura : Centrolenidae) of Kaieteur National Park, Guyana, with notes on the distribution and taxonomy of some species of the family in the Guiana Shield. Zootaxa, 25-53.

KOK, P.J.R., MACCULLOCH, R.D., GAUCHER, P., POELMAN, E.H., BOURNE, G.R., LATHROP, A. \& LENGLET, G.L. (2006) A new species of Colostethus (Anura, Dendrobatidae) from French Guiana with a redescription of Colostethus beebei (Noble, 1923) from its type locality. Phyllomedusa, 5, 43-66. 
KOK, P.J.R., MACCULLOCH, R.D., LATHROP, A., WILLAERT, B. \& BOSSUYT, F. (2010) A new species of Anomaloglossus (Anura: Aromobatidae) from the Pakaraima Mountains of Guyana. Zootaxa, 18-32.

KOK, P.J.R., MACCULLOCH, R.D., MEANS, D.B., ROELANTS, K. VAN BOCXLAER, I. \& BOSSUYT, F. (2012) Low genetic diversity in tepui summit vertebrates. Current Biology, 22 R589-R590.

KOK, P.J.R., RATZ, S., TEGELAAR, M., AUBRET, F. \& MEANS, D.B. (2015) Out of taxonomic limbo: a name for the species of Tepuihyla (Anura: Hylidae) from the Chimantá Massif, Pantepui region, northern South America. Salamandra, 51, 283-314.

KOK, P.J.R. \& RIVAS, G.A. (2011) A new species of Anadia (Reptilia, Squamata) from the Venezuelan 'Lost World', northern South America. European Journal of Taxonomy, 3 $1-18$.

KOK, P.J.R., RUSSO, V.G., RATZ, S. \& AUBRET, F. (2016) On the distribution and conservation of two "Lost World" tepui summit endemic frogs, Stefania ginesi Rivero, 1968 and $S$. satelles Señaris, Ayarzagüena, and Gorzula, 1997. Amphibian and Reptile Conservation, 10, 5-12.

KOK, P.J.R, WILLAERT, B. \& MEANS, D.B. (2013) A New Diagnosis and Description of Anomaloglossus roraima (La Marca, 1998) (Anura: Aromobatidae: Anomaloglossinae), with Description of its Tadpole and Call. South American Journal of Herpetology, 8, 29-45.

KOLENC, F., BORTEIRO, C., BALDO, D., FERRARO, D.P. \& PRIGIONI, C. (2009) The tadpoles and advertisement calls of Pleurodema bibroni Tschudi and Pleurodema kriegi (Mueller), with notes on their geographic distribution and conservation status (Amphibia, Anura, Leiuperidae). Zootaxa, 1969, 1-35.

KOLENC, F., BORTEIRO, C., TEDROS, M. \& PRIGIONI, C. (2007) The tadpole of Scinax aromothyella (Anura: Hylidae) from Uruguay. Studies on Neotropical Fauna and Environment, 42, 175-180.

KOLODIUK, M.F., RIBEIRO, L.B. \& FREIRE, E.M.X. (2009) The effects of seasonality on the foraging behavior of Tropidurus hispidus and Tropidurus semitaeniatus (Squamata, Tropiduridae) living in sympatry in the Caatinga of northeastern Brazil. Zoologia, 26, 581-585.

KORNACKER, P.M. (2001) Anolis auratus (grass anole). Herpetological Review, 32, 117-118.

KRETZSCHMAR, S. (2006) Revisión histórica y redescripción de Leptotyphlops albipunctus (Serpentes: Leptotyphlopidae). Cuadernos de Herpetologia, 19, 43-56.

KUNZ, T.S. \& BORGES-MARTINS, M. (2013) A new microendemic species of Tropidurus (Squamata: Tropiduridae) from southern Brazil and revalidation of Tropidurus catalanensis Gudynas \& Skuk, 1983. Zootaxa, 3681, 413-439.

KUNZ, T.S. \& GHIZONI-JR, I.R. (2011) Amphibia, Anura, Cycloramphidae, Odontophrynus maisuma Rosset, 2008: Distribution extension and geographic distribution map. Check List, 7, 131-132.

KUNZ, T.S., GHIZONI-JR, I.R. \& GIASSON, L.O.M. (2011a) Novos registros de répteis para as áreas abertas naturais do planalto e do litoral sul de Santa Catarina, Brasil. Biotemas, 24, 59-68.

KUNZ, T.S., GHIZONI-JR, I.R. \& GRAIPEL, M.E. (2011b) Reptilia, quamata, Gymnophthalmidae, Ecpleopus gaudichaud Dumeril and Bibron, 1839: distribution extension in the state of Santa Catarina, Brazil. Check List, 7, 11-12.

LA MARCA, E. (1985) Systematics and Ecological Observations on the Neotropical Frogs Hyla jahni and Hyla platydactyla. Journal of Herpetology, 19, 227-237.

LA MARCA, E. (2004a) Descripción de dos nuevos anfíbios e piedemonte Andino de Venezuela. Herpetotrópicos, 1, 1-9.

A MARCA, E. (2004b) Revisión Taxonómica del Colosthetus del norte de Venezuela confundido durante largo tiempo con C. brunneus. Herpetotrópicos, 1, 40-50.

LA MARCA, E. \& GARCIA-PEREZ, J.E. (1990) A new species of high Andean Anadia (Sauria: Teiidae) from Paramo el Riecito, Estado Trujillo, Venezuela. Herpetologica, 46, 275282.

LA MARCA, E. \& LóPEZ, L.M.O. (2011) Rediscovery of the types of Colostethus meridensis, with description of a related new species and redescription of Aromobates mayorgai (Amphibia: Anura: Dendrobatidae). Herpetotrópicos, 7, 55-74.

LACERDA, J.V.A., FERREIRA, R.B., DE SOUZA, G.A., DA SILVA, H.R. \& FEIO, R.N. (2015) On the diagnosis and conservation of the poorly known bromeligenous Scinax arduous Peixoto, 2002 (Amphibia; Anura; Hylidae). Zootaxa, 4021, 401-417.

2002 (Amphibia; Anura; Hylidae). Zootaxa, $4021,401-417$. species of the bromeligenous Scinax perpusillus group (Anura; Hylidae) from Serra do Brigadeiro, State of Minas Gerais, Southeastern Brazil. Zootaxa, 31-42.

Lajmanovích, R.C., Peltzer, P.P., ATtAdemo, A.M CABAGNA, M.C., JUNGES, C.M. \& BASSO, A. (2012) Amphibia, Anura, Hylidae, Argenteohyla siemersi pedersen (Williams and Bosso, 1994) first record and some hematological data in Santa Fe Province, Argentina. Check List, 8, 790-791.

LAMAR, W.W. (1985) A New Lepidoblepharis (Sauria: Gekkonidae) from the North Coast of Colombia. Herpetologica, 41, 128-132.
LAMAS, M. \& ZARACHO, V. (2006) Tropidurus torquatus (Brown Lizard). Endoparasites. Herpetological Review, 37, $474-475$

LAMBOROT, M. \& ORTIZ, J.C. (1990) Liolaemus pseudolemniscatus, una nueva especie de lagarto del Norte Chico de Chile (Sauria: Tropiduridae). Gayana Zoologia, 54 $135-142$

LANDAURO, C.Z., GARCIA-BRAVO, A. \& VENEGAS, P.J. (2015) An endemic new species of Ameiva (Squamata: Teiidae) from an isolated dry forest in southern Peru. Zootaxa, 3946, 387-400

LANDGREF FILHO, P., GODOI, M.N. \& SOUZA, F.L. (2012) Dendropsophus sanborni (Sanborn's treefrog). Herpetological Review, 43, 97

LANGONE, J.A., ESPINOSA, B.M. \& RODRÍGUEZ-MAZZINI, R. (2000) Nuevos registros y observaciones sobre Anisolepis undulatus (Wiegmann, 1834) (Squamata: Polychrotidae) en Uruguay. Cuadernos de Herpetologia, 14, 83-84.

LANGONE, J.A., LAVILLA, E.O., DE SA, R.O. \& CARDOZO, D. (2015) Comments on the type locality, type series, and geographic distribution of Pseudopaludicola falcipes (Hensel, 1867) (Amphibia Anura) Zootaxa, 4058, 145-150 LANGSTROTH P.R. (2011) On the species identities of complex Liolaemus fauna from the Altiplano and Atacama Desert: insights on Liolaemus stolzmanni, L. reichei, L. jamesi pachecoi, and L. poconchilensis (Squamata: Liolaemidae). Zootaxa, 20-32.

LANGSTROTH, R.P. (2005) Adiciones probables y confirmadas para la saurofauna Boliviana. Kempffiana, 1, 101-128.

LANGSTROTH, R.P. (2006) Notas sobre Anolis meridionalis Boetteger, 1885 (Squamata: Iguania: Polychrotidae) en Bolivia y commentarios sobre Anolis steinbachi. Kempffiana, 2, 154-172.

ANTYER-SILVA, A.S.F., MATOS, M.A., GOGLIATH, M. MARCIANO-JR, E. \& NICOLA, P.A. (2016) New records of Pseudopaludicola pocoto Magalhães, Loebmann, Kokubum, Haddad \& Garda, 2014 (Amphibia: Anura: Leptodactylidae) in the Caatinga Biome, Brazil. Check List, 12,

LARREAL, J.T., RIVAS, G.A., PORTILLO-QUINTERO, C. \& BARROS, T.R. (2012) Squamata reptiles of a fragment of tropical dry forest in northwestern Venezuela (Lake Maracaibo region). Check List, 8, 1220-1224.

LASPIUR, A., ACOSTA, J.C. \& ABDALA, C.S. (2007) A new species of Leiosaurus (Iguania : Leiosauridae) from centralwestern Argentina. Zootaxa, 47-57.

LAUFER, G., PINEIRO-GUERRA, J.M., PEREIRA-GARBERO, R. BARRENECHE, J.M. \& FERRERO, R. (2009) Distribution extension of Scinax aromothyella (Anura, Hylidae). Biota Neotropica, 9, 275-277.

LAURENT, R.F. (1982) Description de trois espèces nouvelle du genre Liolaemus (Sauria, Iguanidae). Spixiana, 5, 139147.

LAURENT, R.F. (1984) Tres especies nuevas del genero Liolaemus (Reptilia, Iguanidae). Acta Zoologica Lilloana, 37 273-294.

LAURENT, R.F. \& LAVILLA, E.O. (1986) Redescripción de Telmatobius hauthali Koslowsky (Anura: leptodactylidae) y descripción de una nueva especie del mismo género. Cuadernos de Herpetologia, 2, 1-24.

LAZELL, J.D. (1969) The genus Phenacosaurus (Sauria: Iguanidae.). Breviora, 1-24

EÃO, A.T. \& COCHRAN, D.M. (1952) Revalidation and redescription of Bufo ocellatus Gunther, 1858 (Anura: Bufonidae). Memorias do Instituto Butantan, 24, 271-280.

LEHR, E. (2002) Amphibien und Reptilen in Peru. Natur und Tier Verlag, Münster, $208 \mathrm{pp}$

LEHR, E. (2005) A new species of the Eleutherodactylus nigrovittatus Group (Anura: Leptodactylidae) from Andean Peru. Herpetologica, 61, 199-208.

EHR, E. (2006) Taxonomic status of some species of Peruvian Phrynopus (Anura: Leptodactylidae), with the description of a new species from the Andes of Southern Peru. Herpetologica, 62, 331-347.

LEHR, E., AGUILAR, C. \& DUELLMAN, W.E. (2004) A striking new species of Eleutherodactylus from andean peru (Anura Leptodactylidae). Herpetologica, 60, 275-280.

EHR, E. \& CATENAZZI, A. (2009) Three New Species of Bryophryne (Anura: Strabomantidae) from the Region of Cusco, Peru. South American Journal of Herpetology, 4, 125 138

LEHR, E. \& CATENAZZI, A. (2010) Two New Species of Bryophryne (Anura: Strabomantidae) from High Elevations in Southern Peru (Region of Cusco). Herpetologica, 66, 308319.

LEHR, E., CATENAZZI, A. \& RODRIGUEZ, D. (2009) A new species of Pristimantis (Anura: Strabomantidae) from the Amazonian lowlands of northern Peru (Region Loreto and San Martin). Zootaxa, 30-40.

LEHR, E. \& COLOMA, L.A. (2008) A Minute New Ecuadorian Andean Frog (Anura: Strabomantidae, Pristimantis). Herpetologica, 64, 354-367.

LEHR, E., FAIVOVICH, J. \& JUNGFER, K.H. (2010a) A new andean species of the Hypsiboas pulchellus group: adults, calls, and phylogenetic relationships. Herpetologica, 66 296-307.

LEHR, E., GREGORY, C. \& CATENAZZI, A. (2013) A new specie of Pristimantis (Amphibia: Anura: Strabomantidae) from the Rio Abiseo National Park, Peru. Zootaxa, 3731, 201-211.
LEHR, E., KOEHLER, G. \& PONCE, E. (2000) A new species of Phrynopus from Peru (Amphibia, Anura, Leptodactylidae). Senckenbergiana Biologica, 80, 205-212.

LEHR, E., LOETTERS, S. \& LUNDBERG, M. (2008) A new species of Atelopus (Anura: Bufonidae) from the Cordillera Oriental of Central Peru. Herpetologica, 64, 368-378.

LEHR, E., LUNDBERG, M., AGUILAR, C. \& VON MAY, R. (2006) New species of Eleutherodactylus (Anura: Leptodactylidae) from the eastern Andes of central Peru with comments on central Peruvian Eleutherodactylus. Herpetological Monographs, 20, 105-128.

LEHR, E., LUNDBERG, M. \& AGUILAR, U. (2005a) Three new species of Phrynopus from central Peru (Amphibia : Anura : Leptodactylidae). Copeia, 479-491.

LEHR, E., MORAVEC, J. \& URRUTIA, L.A.G.G. (2010b) A new species of Pristimantis (Anura: Strabomantidae) from the Amazonian lowlands of northern Peru. Salamandra, 46, 197-203.

LEHR, E. \& ORÓz, A. (2012) Two new species of Phrynopus (Anura: Strabomantidae) from the Cordillera de Carpish in central Peru (Departamento de Huanuco). Zootaxa, 53-63.

EEHR, E., PRAMUK, J.B., HEDGES, S.B. \& CORDOVA, J.H. (2007) A new species of arboreal Rhinella (Anura Bufonidae) from Yanachaga-Chemillen National Park in central Peru. Zootaxa, 1-14.

LEHR, E., PRAMUK, J.B. \& LUNDBERG, M. (2005b) A new species of Bufo (Anura: Bufonidae) from Andean Peru. Herpetologica, 61, 308-318.

LEHR, E. \& VON MAY, R. (2004) Stenocercus fimbriatus (NCN). Herpetological Review, 35, 188-189.

EITE, F.S.F. (2012) Taxonomia, biogeografia e conservação dos anfíbios da Serra do Espinhaço. Doutorado. Ecologia Conservação e Manejo da Vida Silvestre, Universidade Federal de Minas Gerais, Belo Horizonte, $101 \mathrm{pp}$.

EITE, F.S.F., PEZZUTI, T.L. \& GARCIA, P.C.D. (2012) A New Species of the Bokermannohyla pseudopseudis Group from the Espinhaço Range, Central Bahia, Brazil (Anura: Hylidae). Herpetologica, 68, 401-409.

LEITE, F.S.F., PEZZUTI, T.L. \& VIANA, P.L. (2006) Amphibia, Bokermannohyla nanuzae, Scinax curicica, Leptodactylus camaquara, Physalaemus evangelistai, and Proceratophrys cururu: distribution extensions. Check List, 2, 5 .

EMA, T. (2002) Os répteis do Rio Grande do Sul: atuais fósseis - biogeografia e ofidismo. Editora da PUCRS, Porto Alegre, RS, $485 \mathrm{pp}$.

A. T. \& ALBUQUERQUE, N.R. (2010) The identity of Apostolepis pymi and placement of $A$. quinquelineata in the synonymy of $A$. nigrolineata (Serpentes, Xenodontinae). Biota Neotropica, 10, 343-346.

EEMA, T. \& DEIQUES, C.H. (2010) Description of a new genus for allocation of Elapomorpus lepidus and the status of Elapomorphus wuchereri (Serpentes: Dipsadidae: Xenodontinae: Elapomorphini). Neotropical Biology and Conservation, 5, 113-119

LEMA, T.D., D'AGOSTINI, F.M. \& CAPPELLARI, L.H. (2005) Nova espécie de Phalotris, redescrição de $P$. tricolor e osteologia craniana (Serpentes, Elapomorphinae). Iheringia, 95, 65-78.

LEMOS, F.G. \& KOKBUM, M.N.C. (2004) Tropidurus torquatus (calango). Saurophagy. Herpetological Review, 35, 270-271. LESCURE, J. (1981) Contribution à l'étude des Amphibiens de Guyane française. VIII. Validation d' Atelopus spumarius Cope, 1871, et désignation d'un néotype. Description d' Atelopus spumarius barbotini nov. ssp. Données éthoécologiques et biogéographiques sur les Atelopus du groupe flavescens (Anoures, Bufonidés). Bulletin $d u$ Museum National d'Histoire Naturelle, $4 \underline{\underline{a}}$ série, section $A$ 1981, 893-910.

LESCURE, J. \& GASC, J.P. (1986) Partage de l'espace forestie par les amphibiens et les reptiles en Amazonie du nord ouest. Caldasia, 15, 707-723.

LEYNAUD, G.C., CABRERA, M.R. \& CARRASCO, P. (2005) A survey of the southernmost representatives of the tricolor species group, genus Phalotris (Serpentes, Colubridae). Phyllomedusa, 4, 103-110.

LEYTON, G.M.R. \& DONOSO, D.P. (2005) Fauna del altiplano desierto de Atacama: vertebrados de la provincia de EI Loa. Phrynosaura Ediciones, Calama, $395 \mathrm{pp}$.

ICHTENSTEIN, H. \& VON MARTENS, E. (1856) Nomenclato reptilium et amphibiorum Musei Zoologici Berolinensis. Namenverzeichniss der in der zoologischen Sammlung der Königlichen Universität zu Berlin aufgestellten Arten von Reptilien und Amphibien nach ihren Ordnungen, Familien und Gattungen. Königliche Akademie der Wissenschaften Berlin, $48 \mathrm{pp}$.

LEB, C.S. (1988) Systematic Status of the Neotropical Snakes Dendrophidion dendrophis and D. nuchalis (Colubridae). Herpetologica, 44, 162-175.

LIEB, C.S. (1991) Dendrophidion nuchale (W. Peters). Blacknaped forest racer. Catalogue of American Amphibians and Reptiles, 1-2.

LIEB, C.S. (1996) Dendrophidion percarinatum (Cope) Brown Forest Racer. Catalogue of American Amphibians and Reptiles, 1-2.

LIMA, A.C. \& PIMENTA, F.E. (2008) Reptilia, Squamata, Teiidae, Tupinambis longilineus: distribution extension. Check List, 4, 240-243. 
LIMA, A.P. \& CALDWELL, J.P. (2001) A new Amazonian species of Colostethus with sky blue digits. Herpetologica, 57, 180189.

LIMA, A.P., CALDWELL, J.P., BIAVATI, G. \& MONTANARIN, A. (2010) A new species of Allobates (Anura: Aromobatidae) (2010) A new species of Allobates (Anura: Aromobatidae)
from Paleovarzea Forest in Amazonas, Brazil. Zootaxa, 1-17. from Paleovarzea Forest in Amazonas, Brazil. Zootaxa, 1-17.
LIMA, A.P., SIMOES, P.I. \& KAEFER, I.L. (2015) A new species of Allobates (Anura: Aromobatidae) from Parque Nacional da Amazonia, Pará State, Brazil. Zootaxa, 3980, 501-525.

LIMA, A.P., SIMÕES, P.I. \& KAEFER, I.L. (2014a) A new species of Allobates (Anura: Aromobatidae) from the Tapajós River basin, Pará State, Brazil. Zootaxa, 3889, 355-387.

LIMA, F.A.N.D.E., GASPARINI, J.L., ALMEIDA, A.D., VITAL, M.V.C. \& MOTT, T. (2014b) Sexual dimorphism in Amphisbaena nigricauda (Reptilia, Squamata, Amphisbaenidae) from Southeastern Brazil. Iheringia Serie Zoologia, 104, 299-307.

LIMA, J.D. (2008) A herpetofauna do Parque Nacional do Montanhas do Tumucumaque, Amapá, Brasil, Expedições a V. In: BERNARD, E. (Ed.) Inventários Biológicos Rápidos no Parque Nacional Montanhas do Tumucumaque, Amapá, Brasil. RAP Bulletin of Biological Assessment 48. Conservation International, Arlington, pp. 38-50.

LIMA, J.O., ANDRADE, H., SILVA, T.L. \& DIAS, E.J.R. (2016) Enyalius bibronii. Herpetological Review, 47, 422-423.

LIMA, T.M. \& JUNCÁ, F.A. (2008) A herpetofauna de serapilheira da Reserva Ecológica da Michelin, Ituberá, Bahia, Brasil. Sitientibus Serie Ciencias Biologicas, 8, 316-

LINARES, A.M., DE OLIVEIRA BATEMARQUE, M.H., DE MELLO H.E.S. \& NASCIMENTO, L.B. (2011) Amphibia, Anura, H.E.S. \& NASCIMENTO, L.B. (2011) Amphibia, Anura,
Hylidae, Scinax cardosoi (Carvalho-e-Silva and Peixoto, 1991): Distribution extension. Check List, 7, 397-399.

OBO, F., ABDALA, C. \& VALDECANTOS, S. (2010) Taxonomic studies of the genus Phymaturus (Iguania: Liolaemidae): description of four new species. South American Journal of Herpetology, 5, 102-126.

OBO, F., ESPINOZA, R.E., SANABRIA, E.A. \& QUIROGA, L.B. (2012) A New Phymaturus (Iguania: Liolaemidae) from the Southern Extreme of the Argentine Puna. Copeia, 2012, 1222.

LOBO, F., LASPIUR, A. \& CARLOS ACOSTA, J. (2013) Description of new andean species of the genus Phymaturus (Iguania: Liolaemidae) from Northwestern Argentina. Zootaxa, 3683, 117-132.

LOBO, F. \& NENDA, S.J. (2015) Discovery of two new species of Phymaturus (Iguania: Liolaemidae) from Patagonia, Argentina, and occurrence of melanism in the patagonicus group. Cuadernos de Herpetologia, 29, 5-25.

OBO, F. \& QUINTEROS, S. (2005) A morphology-base phylogeny of Phymaturus (Iguania: Liolaemidae) with the description of four new species from Argentina. Papéis Avulsos de Zoologia, 45, 143-177.

LOBO, F., QUINTEROS, S. \& DIAZ GOMEZ, J.M. (2007) Description of a new species of the Liolaemus alticolor group (Iguania: Liolaemidae) from Cuzco, Peru. Herpetologica, 63, 537-543.

LOBOS, G.A., HERNÁNDEZ, H.J., MÉNDEZ, M.A., CATTAN A, P., DINIZ-FILHO, J.A.F. \& GALLARDO G., C.E. (2010) Atlas de biodiversidad de anfibios y reptiles de la Región Metropolitana de Chile - Una herramienta para la gestión de los recursos naturales Centro de Estudios para la Vida Silvestre, Chile, $73 \mathrm{pp}$

LOEBMANN, D. \& HADDAD, C.F.B. (2010) Amphibians and reptiles from a highly diverse area of the Caatinga domain: composition and conservation implications. Biota Neotropica, 10, 227-256.

LÓPEZ-PERILLA, Y.R., MEDINA-RANGEL, G.F. \& ROJASMURCIA, L.E. (2014) Bachia guianensis (Guyana Bachia). Geographyc Distribution. Herpetological Review, 45, 282.

LóPEZ-ROJAS, J.J. (2009) Anfibios y Reptilies de la Reserva Florestal Santa Cruz, Mazán, Loreto - Perú. Chicago, 14 pp.

LÓPEZ-ROJAS, J.J., RAMALHO, W.P., SUSÇUARANA, M.S. \& SOUZA, M.B. (2013) Three new records of Pristimantis (Amphibia: Anura: Craugastoridae) for Brazil and comment of the advertisement call of Pristimantis orcus. Check List, 9, 1548-1551.

LóPEZ, C.A. \& KUBISCH, E. (2008) Relevamiento in situ de la herpetofauna del Refugio Privado de Vida Silvestre Yacutinga, Provincia de Misiones (Argentina). APRONA Boletín Científico, 40, 1-12.

LóPEZ, C.R., PINTO, D.M. \& RODRÍGUEZ, A.E. (2012) Reptiles de la Reserva Tanimboca, Amazonas - Colombia. The Field Museum, Chicago, $9 \mathrm{pp}$.

LÓPEZ, C.R., PINTO, D.M. \& RODRÍGUEZ, A.E. (2013) Anfíbios $y$ Reptiles de la Reserva Natural Palmarí, Amazonas - Brasil. The Field Museum, Chicago, $19 \mathrm{pp}$.

LOTTERS, S. \& DE LA RIVA, I. (1998) Redescription of Atelopus tricolor boulenger from southeastern Peru and adjacen Bolivia, with comments on related forms. Journal of Herpetology, 32, 481-488.

LÖTTERS, S., HASS, A., SCHICK, S. \& BÖHME, W. (2002a) On the systematics of the harlequin frogs (Amphibia: Bufonidae: Atelopus) from Amazonia. I: Description of a new species from the Cordillera Azul, Peru Salamandra, 38 95-104.

LÖTTERS, S., HASS, A., SCHICK, S. \& BÖHME, W. (2002b) On the systematics of the harlequin frogs (Amphibia: Bufonidae: Atelopus) from Amazonia. II: Redescription of
Atelopus pulcher (Boulenger, 1882) from the eastern Andean versant in Peru. Salamandra, 38, 165-184.

LÖTTERS, S., SCHMITZ, A. \& REICHLE, S. (2005) A new cryptic species of poison frog from the Bolivian Yungas (Anura: Dendrobatidae: Epipedobates). Herpetozoa, 18, 115-124.

OTTERS, S. SCHMITZ, A, REICHLE, S, RODDER, D. \& QUENNET, V. (2009) Another case of cryptic diversity in poison frogs (Dendrobatidae: Ameerega) - description of new species from Bolivia. Zootaxa, 20-30.

OTZKAT, S., BATISTA, A., VARGAS, J., HERTZ, A. \& KÖHLER, G. (2012) Reptilia, Squamata, Gymnophthalmidae, Potamites apodemus (Uzzell, 1966): Distribution extension and first records from Panama. Check List, 8, 302-306.

LOURENCCO-DE-MORAES, R., FERREIRA, R.B., FOUQUET, A. \& BASTOS, R.P. (2014) A new diminutive frog species of Adelophryne (Amphibia: Anura: Eleutherodactylidae) from the Atlantic Forest, southeastern Brazil. Zootaxa, 3846, 348-359.

OURENÇO-DE-MORAES, R., SOLÉ, M. \& TOLEDO, L.F. (2012) A new species of Adelophryne Hoogmoed and Lescure 1984 (Amphibia: Anura: Eleutherodactylidae) from the Atlantic rainforest of southern Bahia, Brazil. Zootaxa, 59-68.

LOURENÇO, A.C.C., CARVALHO, A.L.G., BAETA, D., PEZZUTI, T.L. \& LEITE, F.S.F. (2013) A new species of the Scinax catharinae group (Anura, Hylidae) from Serra da Canastra, southwestern state of Minas Gerais, Brazil. Zootaxa, 3613, 573-588.

LOURENÇO, A.C.C., LUNA, M.C. \& JR, J.P. (2014) A new species of the Scinax catharinae Group (Anura: Hylidae) from Northeastern Brazil. Zootaxa, 3889, 259-276.

LOURENCO, A.C.C., NASCIMENTO, L.B. \& PIRES, M.R.S. (2009)

A New Species of the Scinax catharinae Species Group (Anura: Hylidae) from Minas Gerais, Southeastern Brazil. Herpetologica, 65, 468-479.

OURENÇO, L.B., TARGUETA, C.P., NASCIMENTO, J., GARCIA P.C.A., ANDRADE, G.V., HADDAD, C.F.B. \& RECCOPIMENTEL, S.M. (2015) Phylogeny of frogs from the genus Physalaemus (Anura, Leptodactylidae) inferred from mitochondrial and nuclear gene sequences. Molecula Phylogenetics and Evolution, 92, 204-216.

UCAS, E.M. \& GARCIA, P.C.A. (2011) Amphibia, Anura, Hylidae Rafinesque, 1815 and Hylodidae Günther, 1858 distribution extension and new records for Santa Catarina, southern Brazil. Check List, 7, 13-16.

UUAN, L., VENEGAS, P.J. \& ECHEVARRíA, L.Y. (2014) Cochranella nola Harvey, 1996 (Amphibia, Anura, Centrolenidae): First country record from Peru. Herpetology Notes, 7, 607-608.

IUNA-DIAS, C., BRAGA, J.P. \& CARVALHO-E-SILVA, S.P. (2007) Scinax ranki (NCN). Herpetological Review, 38, 478.

UNA-DIAS, C., CARVALHO-E-SILVA, S.P. \& CARVALHO-ESILVA, A.M.P.T. (2009) Amphibia, Anura, Hylidae, Scinax trapicheiroi: distribution extension. Check List, 5, 251-253.

UUTZ, B. (1958) Anfíbios novos e raros das Serras Costeiras do Brasil. Eleutherodactylus venancioi n.sp., E. hoehnei n.sp., Holoaden bradei n.sp. e H. luederwaldti Mir. Rib., 1920. Memorias do Instituto Oswaldo Cruz, 56, 372-389.

LYNCH, J.D. (1969) Taxonomic Notes on Ecuadorian Frogs (Leptodactylidae: Eleutherodactylus). Herpetologica, 25 262-274

YNCH, J.D. (1975a) The identity of the frog Eleutherodactylus conspicillatus (Gunther), with descriptions of two related species from northwestern South America (Amphibia, Leptodactylidae). Contributions Sci Los Angeles, No. 272, 1 19.

LYNCH, J.D. (1976) Three New Leptodactylid Frogs (Genus Eleutherodactylus) from the Andean Slopes of Colombia and Ecuador. Herpetologica, 32, 310-317.

YNCH, J.D. (1979) Leptodactylid frogs of the genus Eleutherodactylus from the Andes of southern Ecuador. Miscellaneous Publications of the Museum of Natural History of the University of Kansas, 1-62.

YYNCH, J.D. (1980a) Systematic Status and Distribution of Some Poorly Known Frogs of the Genus Eleutherodactylus from the Chocoan Lowlands of South-America. Herpetologica, 36, 175-189.

YNCH, J.D. (1980b) A taxonomic and distributional synopsis of the Amazonian frogs of the genus Eleutherodactylus. American Museum Novitates, 1980, 1-24.

YYNCH, J.D. (1981) Leptodactylid frogs of the genus Eleutherodactylus in the Andes of northern Ecuador and adjacent Colombia. University of Kansas Natural History Museum Miscellaneous Publication, 1-46.

YYNCH, J.D. (1989) A review of the leptodactylid frogs of the genus Pseudopaludicola in northern South America. Copeia 1989, 577-588

LYNCH, J.D. (1990) A new large species of streamside Eleutherodactylus from western Colombia (Amphibia: Leptodactylidae). Herpetologica, 46, 135-142.

LYNCH, J.D. (1992) Two New Species of Eleutherodactylus from Southwestern Colombia and the Proposal of a New Species Group (Amphibia: Leptodactylidae). Journal of Herpetology, 26, 53-59.

YNCH, J.D. (1993) A new centrolenid frog from the Andes of western Colombia. Revista de la Academia Colombiana de Ciencias Exactas Fisicas y Naturales, 18, 567-569.
LYNCH, J.D. (1996a) Eleutherodactylus erythropleura. Catalogue of American Amphibians and Reptiles, 623, 1-3. LYNCH, J.D. (1996b) New frog (Eleutherodactylus: Leptodactylidae) from the Andes of eastern Colombia, part of a remarkable pattern of distribution. Copeia, 1996, 103 108 .

YNCH, J.D. (1996c) New frogs of the genus Eleutherodactylus (family Leptodactylidae) from the San Antonio region of the Colombian Cordillera Occidental. Revista de la Academia Colombiana de Ciencias Exactas Fisicas y Naturales, 20, 331 345.

YNCH, J.D. (1997) Intrageneric relationships of mainland Eleutherodactylus 2. A review of the Eleutherodactylus sulcatus group. Revista de la Academia Colombiana de Ciencias Exactas Fisicas y Naturales, 21, 353-372.

YYNCH, J.D. (1998) New species of Eleutherodactylus from the Cordillera Occidental of western Columbia with a synopsis of the distributions of species in western Columbia. Revisto de la Academia Colombiana de Ciencias Exactas Fisicas Naturales, 22, 117-148.

YNCH, J.D. (2000) A new species of frog, genus Eleutherodactylus (Leptodactylidae), from the Sabana de Bogota. Revista de la Academia Colombiana de Ciencias Exactas Fisicas y Naturales, 24, 435-439.

LYNCH, J.D. (2006) The amphibian fauna in the Villavicencio region of eastern Colombia. Caldasia, 28, 135-155.

LYNCH, J.D. (2008a) Osteocephalus planiceps Cope (Amphibia: Hylidae): its distribution in Colombia and significance. Revista de la Academia Colombiana de Ciencias Exactas Fisicas y Naturales, 32, 87-91.

YNCH, J.D. (2008b) A taxonomic revision of frogs of the genus Cryptobatrachus (Anura: Hemiphractidae). Zootaxa, 28-68. LYNCH, J.D. \& ARDILA-ROBAYO, M.C. (1993a) Eleutherodactylus anatipes Lynch and Myers. Catalogue of American Amphibians and Reptiles, 558, 1-2.

YYNCH, J.D. \& ARDILA-ROBAYO, M.C. (1993b) Eleutherodactylus anomalus (Boulenger). Catalogue of American Amphibians and Reptiles, 559, 1-2.

YYNCH, J.D. \& ARDILA-ROBAYO, M.C. (1993C) Eleutherodactylus zygodactylus Lynch and Myers. Catalogue of American Amphibians and Reptiles, 560, 1-2.

LYNCH, J.D. \& ARDILA-ROBAYO, M.C. (1999) The Eleutherodactylus of the taeniatus complex in western Colombia: taxonomy and distribution. Revista de la Academia Colombiana de Ciencias Exactas fisicas Naturales, 23, 615-624.

LYNCH, J.D. \& DUELLMAN, W.E. (1973) A review of the centrolenid frogs of Ecuador, with descriptions of new species. Occasional Papers Mus Nat Hist Univ Kans, 1-66. YNCH, J.D. \& DUELLMAN, W.E. (1980) The Eleutherodactylus of the Amazonian slopes of the Ecuadorian Andes (Anura: Leptodactylidae). University of Kansas Natural History Museum Miscellaneous Publication, 1-86.

LYNCH, J.D. \& DUELLMAN, W.E. (1997) Frogs of the genus Eleutherodactylus (Leptodactylidae) in Western Ecuador: Systematics, Ecology, and Biogoegraphy. The University of Kansas Natural History Museum Special Publication, 23, 1236

YNCH, J.D. \& LESCURE, J. (1980) A collection of eleutherodactyline frogs from northeastern Amazonian Peru with the description of two new species (Amphibia, Salientia, Leptodactylidae). Bulletin du Museum National $d^{\prime}$ Histoire Naturelle Section A Zoologie Biologie et Ecologie Animales, 2, 303-316.

LYNCH, J.D. \& MYERS, C.W. (1983) Frogs of the fitzinger group of Eleutherodactylus in eastern Panama and Chocoan South America (Leptodactylidae). Bulletin of the American Museum of Natural History, 175, 481-568.

YNCH, J.D. \& SUÁREZ-MAYORGA, Á.M. (2004) Anfíbios en e Chocó biogeográfico. In: RANGEL-CHURIO, J.O. (Ed.) Colombia Diversidad Biotic IV: EI Chocó biogeográfico/Costa Pacifica. Universidad Nacional de Colombia - Instituto de Ciencias Naturales, Conservación Internacional Colombia, Bogotá, pp. 633-667.

YNCH, J.D. \& VARGAS RAMIREZ, M.A. (2000) Preliminary list of frog species of the Departmento del Guainia, Colombia. Revista de la Academia Colombiana de Ciencias Exactas Fisicas y Naturales, 24, 579-589.

YNCH, R.L., KOHN, S., AYALA-VARELA, F.P., HAMILTON, P.S \& RON, S.R. (2014a) Rediscovery of Andinophryne olalla Hoogmoed, 1985 (Anura, Bufonidae), an enigmatic and endangered Andean

IYNCH, R.L., MAYNARD, P.S.H. \& BURKART, D. (2014b) Anfibios de la Reserva Jama-Coaque, Manabi, Ecuador. Chicago, $4 \mathrm{pp}$

YNCH, T.D. (1975b) A review of the broad-headed eleutherodactyline frogs of South America (Leptodactylidae). Occasional Papers Mus Nat Hist Univ Kans, No. 38, 1-46.

LYRA, M.L., HADDAD, C.F.B. \& DE AZEREDO-ESPIN, A.M.L. (2017) Meeting the challenge of DNA barcoding Neotropical amphibians: polymerase chain reaction optimization and new COI primers. Molecular Ecology Resources, n/a-n/a.

MACCULLOCH, R.D. \& LATHROP, A. (2001) A new species of Arthrosaura (Sauria : Teiidae) from the highlands of Guyana. Caribbean Journal of Science, 37, 174-181. 
MACCULLOCH, R.D. \& LATHROP, A. (2002) Exceptional diversity of Stefania (Anura : Hylidae) on Mount Ayanganna, Guyana: Three new species and new distribution records. Herpetologica, 58, 327-346.

MACCULLOCH, R.D. \& LATHROP, A. (2006a) Stefania ackawaio Rana Stefania Ackawaio. Catalogue of American Amphibians and Reptiles, 824, 1-2.

MACCULLOCH, R.D. \& LATHROP, A. (2006b) Stefania ayangannae MacCulloch and Lathrop, Ayanganna Stefania; Rana Stefania de Ayanganna. Catalogue of American Amphibians and Reptiles, 825, 1-2.

MACCULLOCH, R.D. \& LATHROP, A. (2006c) Stefania coxi MacCulloch and Lathrop Cox's Stefania; Rana Stefania de Cox. Catalogue of American Amphibians and Reptiles, 826, $1-2$.

MACCULLOCH, R.D. \& LATHROP, A. (2006d) Stefania evansi (Boulenger) Evans' Stefania; Rana Stefania guayanesa. Catalogue of American Amphibians and Reptiles, 1-3.

MACCULLOCH, R.D. \& LATHROP, A. (2006e) Stefania roraimae Duellman and Hoogmoed Roraima Stefania; Rana Stefania de Roraima. Catalogue of American Amphibians and Reptiles, 828, 1-2.

MACCULLOCH, R.D. \& LATHROP, A. (2006f) Stefania woodleyi Rivero Woodley's Stefania; Rana Stefania de Woodley. Catalogue of American Amphibians and Reptiles, 829, 1-2.

MACCULLOCH, R.D., LATHROP, A. \& KHAN, S.Z. (2006) Exceptional diversity of Stefania (Anura, Cryptobatrachidae) II: Six species from Mount Wokomung, Guyana. Phyllomedusa, 5, 31-41.

MACCULLOCH, R.D., LATHROP, A., KOK, P.J.R., MINTER, L.R., KHAN, S.Z. \& BARRIO-AMOROS, C.L. (2008) A new species of Adelophryne (Anura: Eleutherodactylidae) from Guyana, with additional data on A. gutturosa. Zootaxa, 1884, 36-50.

MACCULLOCH, R.D., LATHROP, A., REYNOLDS, R.P., CELSA SENARIS, J. \& SCHNEIDER, G.E. (2007) Herpetofauna of Mount Roraima, Guiana Shield region, northeastern South America. Herpetological Review, 38, 24-30.

MACCULLOCH, R.D. \& REYNOLDS, R.P. (2012) Amphibians and reptiles from Paramakatoi and Kato, Guyana. Check List, 8 , 207-210.

MACCULLOCH, R.D. \& REYNOLDS, R.P. (2013) Baseline Inventory of Amphibians and Reptiles in the Vicinity of Kurupukari, Guyana. Check List, 9, 1378-1382.

MACEDO, L.C., BERNARDE, P.S. \& ABE, A.S. (2008) Lagartos (Squamata: Lacertilia) em áreas de floresta e de pastagem em Espigão do Oeste, Rondônia, sudoeste da Amazônia Brasil. Biota Neotropica, 8, 133-139.

MACHADO, M. \& LIPINSKI, V.M. (2014) Predation event on tadpole of Scinax aromothyella (Anura: Hylidae) by the fishing spider Thaumasia velox (Araneae: Pisauridae) in a rainforest of southern Brazil. Herpetology Notes, 7, 517 518.

MACIEL, A.O., GOMES, J.O., COSTA, J.C.L. \& ANDRADE, G.V. (2006) Caecilia gracilis. Herpetological Review, 37, 104

MACIEL, A.O. \& HOOGMOED, M.S. (2011) Taxonomy and distribution of caecilian amphibians (Gymnophiona) of Brazilian Amazonia, with a key to their identification. Zootaxa, 1-53.

MACIEL, A.O. \& HOOGMOED, M.S. (2013) A new species of Microcaecilia (Amphibia: Gymnophiona: Siphonopidae) from the Guianan region of Brazil. Zootaxa, 3693, 387-394.

MACIEL, A.O., MOTT, T. \& HOOGMOED, M.S. (2009a) A second species of Brasilotyphlus (Amphibia: Gymnophiona: Caeciliidae) from Brazilian Amazonia. Zootaxa, 19-27.

MACIEL, A.O., SANTANA, D.J., SILVA, E.T. \& FEIO, R.N. (2009b) Amphibia, Gymnophiona, Caeciliidae, Siphonops hardy Boulenger, 1888: distribution extension, new state record Boulenger, 1888: distribution extension, new st
and notes on meristic data. Check List, 5, 919-921.

MACIEL, A.O., SILVA, B.V.M., NASCIMENTO, F.A.C., BORGES NOJOSA, D.M. \& LIMA, D.C. (2013) First records of Chthonerpeton arii Cascon and Lima-Verde, 1994 (Amphibia: Gymnophiona: Typhlonectidae) out of the type locality. Check List, 9, 818-819.

MACIEL, D.B. \& NUNES, I. (2010) A new species of four-eyed frog genus Pleurodema Tschudi, 1838 (Anura: Leiuperidae) from the rock meadows of Espinhaço range, Brazil. Zootaxa, 53-61.

MACIEL, N.M., VAZ-SILVA, W., OLIVEIRA, R.M. \& PADIAL, J.M. (2012) A new species of Pristimantis (Anura: Strabomantidae) from the Brazilian Cerrado. Zootaxa, 3265, 43-56

MAGALHÃES, F.M., LARANJEIRAS, D.O., COSTA, T.B., JUNCÁ F.A., MESQUITA, D.O., RÖHR, D.L., SILVA, W.P., VIEIRA, G.H.C. \& GARDA, A.A. (2015) Herpetofauna of protected areas in the Caatinga IV: Chapada Diamantina National Park, Bahia, Brazil. Herpetology Notes, 8, 243-261.

MAIA, A.R. (2002a) Kentropyx altamazonica (Chocha whiptail). Herpetological Review, 33, 225

MAIA, A.R. (2002b) Kentropyx pelviceps (bronzy forest whiptail). Herpetological Review, 33, 225.

MALAGOLI, L.R., CONDEZ, T.H. \& HADDAD, C.F.B. (2012) Arcovomer passarellii Carvalho, 1954 (Amphibia: Anura: Microhylidae): distribution extension in São Paulo state, Brazil and geographic distribution map. Check List, 8, 505506

MALAMBO-L, C. \& MARIN-V, A. (2006) Eletherodactylus medemi (NCN). Herpetological Review, 37, 487 .
MAMANI, L., GOICOECHEA, N. \& CHAPARRO, J.C. (2015) A new species of Andean lizard Proctoporus (Squamata: Gymnophthalmidae) from montane forest of the Historic Sanctuary of Machu Picchu, Peru. Amphibian and Reptile Conservation, 9, A1-A11.

MANEYRO, R., NAYA, D.E. \& BALDO, D. (2008) A new species

of Melanophryniscus (Anura, Bufonidae) from Uruguay. heringia. Série Zoologia, 98, 189-192.

MÂNGIA, S., SANTANA, D.J., CRUZ, C.A.G. \& FEIO, R.N. (2014) Taxonomic review of Proceratophrys melanopogon (Miranda-Ribeiro, 1926) with description of four new species (Amphibia, Anura, Odontophrynidae). Boletim do Museu Nacional, Nova Série - Zoologia, 1-36.

MANGIA, S., TEIXEIRA DA SILVA, E., SANT'ANNA, A.C. \& SANTANA, D.J. (2011) Amphibia, Anura, Brachycephalidae, Ischnocnema oea (Heyer, 1984): distribution extension new state record and geographic distribution map. Check List, 7, 164-165.

MANTILLA, J.C. \& CASTAÑO, J.H. (2015) Distribution extension and ecology notes of endemic lizard Stenocercus bolivarensis Castro \& Ayala, 1982 (Squamata: Tropiduridae). Herpetology Notes, 8, 575-577.

MANZAMILLA, J., RIVERO, R. \& NATRA, M. (1997) Kentropix striata (Striped Kentropyx). Herpetological Review, 28, 50. MANZANI, P.R. \& ABE, A.S. (1990) A new species of Tapinurus from the caatinga of Piaui, northeastern Brazil (Squamata: Tropiduridae). Herpetologica, 46, 462-467.

MANZANILLA, J., CORNIELES, R. \& FERNANDEZ-BADILLO, A. (1998) Ameiva bifrontata. Herpetological Review, 29, 109110.

MARAGNO, F.P., RIBEIRO, M.M. \& RIBEIRO, L.B. (2015) Coleodactylus meridionalis (Meridian Gecko). Herpetological Review, 46, 383.

MARÇAL, A.S., GOMES, I.B.S.R. \& CORAGEM, J.T. (2011) UHE Santon Antônio: Guia das Espécies de Fauna Resgatadas. Scriba, São Paulo, $227 \mathrm{pp}$

MARKEZICH, A.L., COLE, C.J. \& DESSAUER, H.C. (1997) The blue and green whiptail lizards (Squamata: Teiidae: Cnemidophorus) of the Peninsula de Paraguana, Venezuela: systematics, ecology, descriptions of two new taxa, and systematics, ecology, descriptions of two new taxa, and
relationships to whiptails of the Guianas. American Museum Novitates, 1997, 1-60.

MARKEZICH, A.L. \& DIXON, J.R. (1979) A New South American Species of Snake and Comments on the Genus Umbrivaga. Copeia, 1979, 698-701.

MARKEZICH, A.L. \& TAPHORN, D.C. (1994) A New Lepidoblepharis (Squamata, Gekkonidae) from the Paraguana Peninsula, Venezuela, with Comments on Its Conservation Status. Herpetologica, 50, 7-14.

MARQUES, O.A.V. \& SAZIMA, I. (2004) História natural do répteis da Estação Ecologica Juréia-Itatins. In: MARQUES, O.A.V. \& DULEBA, W. (Eds.) Estação Ecológica Juréia-ltatins, Ambiente Físico, Flora e Fauna. Editora Holos, Ribeirão Preto, pp. 257-277.

MARQUEZ, R., CORREDOR, G., GALVIS, C., GOEZ, D. \& AMEZQUITA, A. (2012) Range extension of the critically endangered true poison-dart frog, Phyllobates terribilis (Anura: Dendrobatidae), in western Colombia. Acto Herpetologica, 7, 341-345

MARTINAZZO, L.B., NASSO, N.G. \& UBEDA, C.A. (2011) Atelognathus reverberii. Herpetological Review, 42, 236.

MARTINEZ, L.E., AVILA, L.J., PEREZ, C.H.F., PEREZ, D.R., SITES, J.W., JR. \& MORANDO, M. (2011) A new species of Liolaemus (Squamata, Iguania, Liolaemini) endemic to the Auca Mahuida volcano, northwestern Patagonia, Argentina. Zootaxa, 31-46.

MARTINS, I.A., ALMEIDA, S.C., JIM, J., CRUZ, E.F.S. \& CARDANA, B.R. (2004) Hyla cruzi. Herpetological Review, $35,281-282$

MARTINS, I.A. \& HADDAD, C.F.B. (2010) A new species of Ischnocnema from highlands of the Atlantic Forest, Southeastern Brazil (Terrarana, Brachycephalidae). Zootaxa, 2010, 55-65.

MARTINS, I.A. \& ZAHER, H. (2013) A new species of the highland frog genus Holoaden (Amphibia, Strabomantidae) from cloud forests of southeastern Brazil. Zootaxa, 3599, 178-188.

MARTINS, L.A. \& DE LEMA, T. (2015) Elapomorphin (Serpentes, Xenodontinae) do Brasil sudoeste. Neotropica Biology and Conservation, 10, 93-102.

MARTINS, L.B., SILVA, W.R. \& GIARETTA, A.A. (2009) Distribution and calls of two South American frogs (Anura). Salamandra, 45, 106-109.

MARTINS, M. (1991) The Lizards of Balbina, Central Amazonia, Brazil - A Qualitative-Analysis of Resource Utilization. Studies on Neotropical Fauna and Environment, 26, 179190.

MARTINS, M. (2006) Life in the Water: Ecology of the Jacarerana Lizard, Crocodilurus amazonicus. The Herpetological Journal, 16, 171-177.

MARTINS, M. \& OLIVEIRA, M.E. (1993) The snakes of the genus Atractus Wagler (Reptilia: Squamata: Colubridae) from the Manaus region, central Amazonia, Brazil. from the Manaus region, central Amazonide
Zoologische Mededelingen (Leiden), 67, 21-40.

MARTORI, R.A. \& AUN, L. (1993) Reproductive cycle of the parthenogenetic lizard Teius suquiensis. Amphibia-Reptilia $14,389-393$.
MARX, H. (1960) A new iguanid lizard of the genus Ctenoblepharis. Fieldiana Zoology, 39, 407-409.

MASSARY, J.C., HOOGMOED, M.S. \& BLANC, M. (2000) Comments on the type specimen of Dracaena guianensis Daudin, 1801 (Reptilia: Sauria: Teiidae), and rediscovery of the species in French Guiana. Zoologische Mededelingen, $74,167-180$

MATAVELLI, R., CAMPOS, A.M., SILVA, G.R. \& ANDRADE, G.V. (2014) First record of Rhinella ocellata (Gunther, 1858) (Bufonidae) for the state of Maranhão, northeastern Brazil. Check List, 10, 432-433.

MATOS, L.D. (2011) Revisão taxonômica das espécies de Cycloramphus do grupo eleutherodactylus Heyer 1983 (Anura, Cycloramphidae). Mestrado. Zoologia, Universidade de São Paulo, São Paulo, 121 pp.

MATOS, M.A., CAMARDELLI, M. \& MARCIANO-JR., E. (2013) Alexandresaurus camacan (Alexandre's Lizard, Calanguinho do Alexandre). Geographyc Distribution. Herpetological Review, 44, 273.

MATTEDI, C. \& PONTES, R. (2014) Range extension and upated distribution of Hypsiboas pardalis (Spix, 1824) (Anura, Hylidae). Herpetology Notes, 7, 791-795.

MAUSFELD, P., SCHMITZ, A., BOHME, W., MISOF, B. VRCIBRADIC, D. \& ROCHA, C.F.D. (2002) Phylogenetic affinities of Mabuya atlantica Schmidt, 1945, endemic to the Atlantic Ocean archipelago of Fernando de Noronh (Brazil): Necessity of partitioning the genus Mabuya Fitzinger, 1826 (Scincidae : Lygosominae). Zoologische Anzeiger, 241, 281-293.

MCCRACKEN, S.F. \& FORSTNER, M.R.J. (2014) Herpetofaunal community of a high canopy tank bromeliad (Aechmed zebrina) in the Yasuní Biosphere Reserve of Amazonian Ecuador, with comments on the use of "arboreal" in the herpetological literature. Amphibian and Reptile Conservation, 8, 65-75.

MCCRANIE, J.R. (2004) Enuliophis McCranie and Villa. Catalogue of American Amphibians and Reptiles, 1-3.

MCCRANIE, J.R. \& CASTANEDA, F.E. (2006) A new species of hylid frog from Northwestern Honduras. Herpetologica, 62 318-323.

MCCRANIE, J.R. \& HEDGES, S.B. (2016) Molecular phylogen and taxonomy of the Epictia goudotii Species complex (Serpentes: Leptotyphlopidae: Epictinae) in Middle America and northern South America. PeerJ, 4, e1551.

MCCRYSTAL, H.K. \& DIXON, J.R. (1987) A New Species of Cnemidophorus (Sauria, Teiidae) from the Llanos of Colombia and Venezuela. Journal of Herpetology, 21, 245254

MCDIARMID, R.W. \& DONNELLY, M.A. (2005) The herpetofauna of the Guayana Highlands: amphibians and reptiles of the Lost World. In: DONNELLY, M.A., CROTHER, B.I., GUYER, C., WAKE, M.H. \& WHITE, M.E. (Eds.) Ecology and evolution in the tropics: a herpetological perspective. University of Chicago Press, Chicago \& London, pp. 461560.

MCDIARMID, R.W. \& FOSTER, M.S. (1987) Additions to the reptile fauna of Paraguay with notes on a small herpetological collection from Amambay. Studies on Neotropical Fauna and Environment, 22, 1-9.

MECHLER, B. (1968) Les Geckonidés de la Colombie. Revue Suisse de Zoologie, 75, 305-371.

MEDEL, R.G., MARQUET, P.A. \& JAKSIĆ, F.M. (1988) Microhabitat shifts of lizards under different contexts of sympatry: a case study with South American Liolaemus. Oecologia, 76, 567-569.

MEDEM, F. (1968) El desarrollo de la herpetologia en Colombia. Revista de la Academia Colombiana de Ciencias Exactas, Fisicas y Naturales, 13, 1-51.

MEDEM, F. (1983) Los Crocodylia de Sur America. Volumen II. Universidad Nacional de Colombia y Fondo Colombiano de Investigaciones Clentificas y proyectos Especiales "Fracisco Jose de Caldas", Bogota, $270 \mathrm{pp}$.

MEDINA-MUELLER, M. \& CHAVEZ, G. (2007) Ameerega planipaleae: color pattern variation and its relevance to Ameerega taxonomy (Amphibia: Dendrobatidae). Herpetotrópicos, 4, 64.

MEDINA-MÜLLER, M. (2007) Epipedobates macero (Manu poison frog). Herpetological Review, 38, 214.

MEDINA-RANGEL, G.F. (2011) Diversidad alfa y beta de comunidad de reptiles en el complejo cenagoso de Zapatosa, Colombia Revista de Biologia Tropical, 59, 935368.

MEDINA-RANGEL, G.F. \& CALDERÓN, M.L. (2013) Bachia guianensis (Guyana Bachia). Geographyc Distribution. Herpetological Review, 44, 474

MEDINA, C.D., AVILA, L.J., SITES, J.W. \& MORANDO, M. (2014) Multilocus phylogeography of the Patagonian lizard complex Liolaemus kriegi (Iguania: Liolaemini). Biologica Journal of the Linnean Society, 113, 256-269.

MEILINK, W.R.M., CLEGG, J.R., MAYERL, C.J., PINTO, J.S. GRASSO, D., STEGEN, G., SEGAL, M. \& KOK, P.J.R. (2013) Confirmation of the presence of the sphaerodactylid lizard Gonatodes vittatus in Guyana, and an indication of reproductively active population in Georgetown. Salamandra, 49, 59-62.

MELLA, J.E. (2005) Guía de Campo Reptiles de Chile: Zona Central Ediciones del Centro de Ecología Aplicada Ltda, Chile, $147 \mathrm{pp}$. 
MELO-SAMPAIO, P.R. \& DE SOUZA, M.B. (2015) New and noteworthy distributional records of treefrogs (Anura) from southwestern Amazonia. Check List, 11, 1681.

Melo-SAMPaio, P.R., DE SOUZA, M.B. \& Peloso, P.L.V. (2013a) A new, riparian, species of Allobates Zimmermann and Zimmermann, 1988 (Anura: Aromobatidae) from southwestern Amazonia. Zootaxa, 3716, 336-348.

MELo-SAMPAIO, P.R., MELO, B.L.A.S., SILVA, A., MACIEL, M.L., NOGUEIRA, M., ARRUDA, S.M., LIMA, L., SILVA, J.C. \& MATOS, L. (2013b) Anolis dissimils. Geographic Distribution. Herpetological Review, 44, 473.

MELO-SAMPAIO, P.R., MENEGHELLI, D., MENDES VENANCIO, N., SILVA, T.R.B., SUENDEL, U., MESSIAS, M. \& BARBOSA DE SOUZA, M. (2012) Amphibia, Anura, Hylidae, Hypsiboas microderma (Pyburn, 1977): First record for the state of Rondonia and new record for the state of Acre, southwestern Amazonia, Brazil. Check List, 8, 147-148.

MELO, A.C.B., LIMA-ARAUJO, F., AGUIAR, F.C. \& PASSO, D.C. (2015) Herpetofauna da Caatinga de Groaíras, Ceará, Nordeste do Brasil, p. 286. In: 70 Congresso Brasileiro de Herpetologia. HERPETOLOGIA, S.B.D. (ed.). Siociedade Brasileira de Herpetologia, Gramado

MENDELSON, J.R., III, MULCAHY, D.G., WILLIAMS, T.S. \& SITES, J.W., JR. (2011) A phylogeny and evolutionary natural history of mesoamerican toads (Anura: Bufonidae: Incilius) based on morphology, life history, and molecular data. Zootaxa, 3138, 1-34.

MENDES-PINTO, T.J. \& SOUZA, S.M. (2011) Preliminary assessment of amphibians and reptiles from Florest Nacional do Trairão, with a new snake record for the Para state, Brazilian Amazon. Salamandra, 47, 199-206.

MENDEZ-NARVAEZ, J., BOLIVAR-G, W. \& CASTRO-HERRERA F. (2010) Amphibia, Anura, Strabomantidae, Pristimantis permixtus Lynch, Ruiz-Carranza, and Ardila-Robayo, 1994 distribution extension, Valle del Cauca, Colombia. Chec List, 6, 499-500

MENDEZ-NARVAEZ, J., ORTIZ-NAVIA, J.O. \& BOLIVAR-G, W. (2014) Hypsiboas pugnax Schmidt, 1857 and Scinax ruber Laurenti, 1768 (Amphibia: Anura): Distribution extension in the Rio Cauca Valley, Colombia. Check List, 10, 409-410.

MENESES-PELAYO, E, ECHAVARRÍA-RENTERÍA, J.D., BAYONASERRANO, J.D., CAICEDO-PORTILLA, J.R. \& RENGIFOMOSQUERA, J.T. (2016) New records and an update of the distribution of Sibon annulatus (Colubridae: Dipsadinae: Dipsadini) for Colombia. 2016, 12, 1-5.

MENEZES, L., CANEDO, C., BATALHA, H., GARDA, A.A. GEHARA, M. \& NAPOLI, M.F. (2016) Multilocus Phylogeography of the Treefrog Scinax eurydice (Anura, Hylidae) Reveals a Plio-Pleistocene Diversification in the Atlantic Forest. PLOS ONE, 11,

MENEZES, V.A. \& ROCHA, C.F.D. (2013) Geographic distribution, population densities, and issues on conservation of whiptail lizards in restinga habitats alon the eastern coast of Brazil. North-Western Journal of Zoology, 9, 337-344.

MENEZES, V.A., ROCHA, C.F.D. \& DUTRA, G.F. (2000) Termoregulação no lagarto partenogenetico Cnemidophorus nativo (Teiidae) em uma área de restinga do Nordeste do Brasil. Revista de Etologia, 2, 103-109.

MERIGGIO, V., VELOSO, A., YOUNG, S. \& NUNEZ, H. (2004) Atelognathus jeinimenensis $\mathrm{n}$. sp. de Leptodactylidae para el sur de Chile. Boletin del Museo Nacional de Historia Natural Chile, 53, 99-123.

MERINO-VITERI, A., COLOMA, L.A. \& ALMENDARIZ, A. (2005) Los Telmatobius de los Andes de Ecuador y su disminución poblacional. Monografias de Herpetologia, 7, 9-37.

MESQUITA, D.O., PERES, A.K., JR., VIEIRA, G.H.C. \& COLLI, G.R. (2000) Mabuya guaporicola (calango-liso). Natural history. Herpetological Review, 31, 240-241.

MEZA-JOYA, F.L. (2016) First records of two rain frogs, genus Pristimantis (Anura, Craugastoridae), for Colombia. Check List, 12, 1-6.

MIJARES-URRUTIA, A. \& ARENDS, A. (2001) A new toad of the Bufo margaritifer complex (Amphibia: Bufonidae) from Northwestern Venezuela. Herpetologica, 57, 523-531.

MIJARES-URRUTIA, A., CELSA SEÑARIS, J. \& ARENDS, A (2000) Taxonomía de algunos microtéidos (Squamata) de Venezuela: variación y distribución geográfica de Euspondylus acutirostris y descripción de un nuevo Euspondylus del nordeste de Venezuela. Revista de Biologia Tropical, 48, 671-680.

MINOLI, I., MORANDO, M. \& AVILA, L.J. (2014) Integrative taxonomy in the Liolaemus fitzingerii complex (Squamata: Liolaemini) based on morphological analyses and niche modeling. Zootaxa, 3856, 501-528.

MINOLI, I., MORANDO, M. \& AVILA, L.J. (2015) Reptiles of Chubut province, Argentina: richness, diversity, conservation status and geographic distribution maps. ZooKeys, 103-126.

MIRALLES, A. (2006) A new species of Mabuya (Reptilia, Squamata, Scincidae) from the Caribbean island of San Andres, with a new interpretation of nuchal scales: A character of taxonomic importance. The Herpetological Journal, 16, 1-7.

MIRALleS, A. \& CARRANZA, S. (2009) Systematics and biogeography of the Neotropical genus Mabuya, with special emphasis on the Amazonian skink Mabuya nigropunctata (Reptilia, Scincidae). Molecular Phylogenetics and Evolution, 85, 857-869.

MIRALLES, A., CHAPARRO, J.C. \& HARVEY, M.B. (2009a) Three re and enigmatic South American skinks. Zootaxa, 47-68. MIRALLES, A FUENMAYOR, G.R \& BARRIO-AMOROS, C.L. (2005a) Taxonomy of the genus Mabuya (Reptilia Squamata, Scincidae) in Venezuela. Zoosystema, 27, 825837.

MIRALLES, A., FUENMAYOR, G.R., BONILLO, C., SCHARGEL, W.E., BARROS, T., GARCíA-PEREZ, J.E. \& BARRIO-AMORÓS, C.L. (2009b) Molecular systematics of Caribbean skinks of the genus Mabuya (Reptilia, Scincidae), with descriptions of two new species from Venezuela. Zoological Journal of the Linnean Society, 156, 598-616.

MIRALLES, A., RIVAS, G. \& SCHARGEL, W.E. (2005b) A new species of Mabuya (Squamata, Scincidae) from the Venezuelan Andes. Zootaxa, 1-1

MIRANDA, B.H.V. \& FERNANDES, D.S. (2012) Morphologica Variation of Sordellina punctata (Peters, 1880) with Notes on the Phylogenetic Position of the Genus within the Family Dipsadidae (Serpentes). International Journal of Zoology 2012, 1-10.

MISSASSI, A.F.R., COSTA, J.C.L. \& PRUDENTE, A.L.C. (2015) Range extension of the Chocoan blunt-headed vine snake: Imantodes chocoensis (Serpentes: Dipsadidae) in northwestern Colombia. Salamandra, 51, 269-272.

MIYATA, K. (1985) A new Lepidoblepharis from the pacific slope of Ecuadorian Andes (Sauria: Gekkonidae). Herpetologica, 41, 121-127.

MOLINA, C. (2001a) Bachia flavescens. Herpetological Review, $32,275$.

MOLINA, C. (2001b) Bachia guianensis. Herpetological Review, 32, 275.

MOLINA, C. (2001c) Cercosaura ocellata ocellata (Black-striped shade lizard). Herpetological Review, 32, 275.

MOLINA, C. (2001d) Pseudogonatodes guianensis. Herpetological Review, 32, 193.

MOLINA, C., LA MARCA, E. \& SENARIS, C. (2003) Anolis ortoni (NCN). Herpetological Review, 34, 383.

MOLINA, C., SENARIS, J.C. \& AYARZAGUENA, J. (2002) Contribution to the knowledge of the taxonomy, distribution, and natural history of Leposoma hexalepis (Reptilia : Gymnophthalmidae) in Venezuela. Herpetologica, 58, 485-491.

MOLINA, C., SEÑARIS, J.C. \& RIVAS, G. (2004) Los reptiles de Delta del Orinoco, Venezuela. Memoria de la Fundación LO Salle de Ciencias Naturales, 159-160, 235-264.

MOLINA, F.B., MACHADO, F.A. \& ZAHER, H. (2012) Taxonomic validity of Mesoclemmys heliostemma (McCord, JosephOuni \& Lamar, 2001) (Testudines, Chelidae) inferred from morphological analysis. Zootaxa, 63-77.

MOLLO-NETO, A. \& TEIXEIRA JR, M. (2012) Checklist of the genus Aparasphenodon Miranda-Ribeiro, 1920 (Anura: Hylidae), distribution map, and new record from São Paulo state, Brazil. Check List, 8, 1303-1307.

MONGUILLOT, J.C., CABRERA, M.R., ACOSTA, J.C. \& VILLAVICENCIO, J. (2006) A new species of Liolaemus (Reptilia: Iguanidae) from San Guillermo National Park, western Argentina. Zootaxa, 1361, 33-43.

MONTERO, R. (1996) Lista de las localidades de los Amphisbaenidae de la Republica Argentina. Cuadernos de Herpetologia, 10, 25-45.

MONTERO, R. (2001) Amphisbaena cegei. Catalogue of American Amphibians and Reptiles, 1-3.

MONTERO, R. \& CÉSPEDEZ, J. (2002) New two-pored Amphisbaena (Squamata: Amphisbaenidae) from Amphisbaena (Squamata: Amph
Argentina. Copeia, 2002, 792-797.

MONTERO, R., FERNADEZ SAFADEZ, I. \& GONZALES ALVAREZ, L. (1997) A new species of Amphisbaena from Bolivia. Journal of Herpetology, 31, 218-220.

MONTERO, R., SCROCCHI, G., MONTAÑO, M.E. \& FERNÁNDEZ, I.M. (1995) Nuevas citas de saurios, anfisbenidos y ofidios para Bolivia. Cuadernos de Herpetologia, 9, 7-13.

MONTEZUMA, M.F. \& MUESES-CISNEROS, J.J. (2009) Amphibia, Anura, Hylidae, Hyloscirtus tigrinus: distribution extension, first department record, Cauca and Huila, Colombia. Check List, 5, 243-245.

MONTINGELLI, G.G. (2009) Revisão taxonômica do gênero Mastigodryas Amaral, 1934 (Serpentes: Colubridae). Vol. III. PhD. Instituto de Biociências, Universidade de São Paulo, São Paulo, $495 \mathrm{pp}$

MONTINGELLI, G.G. \& ZAHER, H. (2011) New Species of Mastigodryas Amaral, 1934 from Brazilian Amazonia and Guyana (Serpentes: Colubridae). Journal of Herpetology, 45 , 111-119.

MORAES, L.F.P. (2008) Diversidade beta em comunidades de agartos em duas ecorregiões distintas na Amazonia. Master. INPA/UFAM, Manaus, $31 \mathrm{pp}$

MORAIS, A.R., BASTOS, R.P., VIEIRA, R. \& SIGNORELLI, L. (2012) Herpetofauna da Floresta Nacional de Silvânia, um remanescente de Cerrado no Brasil Central. Neotropical Biology and Conservation, 7, 114-121.

MORAIS, A.R., SIGNORELLI, L., VIEIRA, R.R.S. \& BASTOS, R.P. (2010) Reptilia, Squamata, Tropiduridae, Stenocercus sinesaccus Torres-Carvajal, 2005: Distribution extension Check List, 6, 155-156.
MORAIS, C.J.S., BARRETO-LIMA, A.F., DANTAS, P.T., DOMINGOS, F.M.C.B., LEDO, R.M.D., PANTOJA, D.L., SOUSA, H.C. \& COLL, G.R. (2014) First records of Tropidurus callathelys and $T$. chromatops (Reptilia: Squamata: Tropiduridae) in Brazil. Check List, 10, 1213-1217.

MORALES, V.R. (2002) Sistematica y biogeografía del grupo trilineatus (Amphibia, Anura, Dendrobatidae, Colostethus) con descripción de once nuevas especies. Publicaciones de la Asociación de Amigos de Doñana, 13, 1-59.

MORALES, V.R. (2007) Una especie nueva de Eleutherodactylus (Amphibia: Anura: Brachycephalidae) de la Amazonía central del Perú. Biotempo, 7, 5-11.

MORALES, V.R. \& ICOCHEA, J. (2000) Review of the type material of Eleutherodactylus mendax and a new record of Eleutherodactylus bromeliaceus from Peru. Journal of Herpetology, 34, 158-160.

MORANDO, M., MEDINA, C.D., AVILAPEREZ, C.H.F., BUXTON, A. \& SITES JR, J.W. (2014) Molecular phylogeny of the New World gecko genus Homonota (Squamata: Phyllodactylidae). Zoologica Scripta, 43, 249-260.

MORANDO, M., OLAVE, M., AVILA, L.J., BAKER, E. \& SITES, J.W. (2015) Molecular Phylogeny of the Lizard Clade Leiosaurae Endemic to Southern South America. Herpetologica, 71, 322-331.

MORATO, S.A.A. (2005) Serpentes da região Atlântica do estado do Paraná, Brasil. PhD. Setor de Ciências Biológicas, Universidade Federal do Paraná, Curitiba, $165 \mathrm{pp}$

MORATO, S.A.A., CALIXTO, P.O., MENDES, L.R.L.P. \& GOMES, R. (2014) Guia fotográfico de identificação da herpetofauna da Floresta Nacional de Saracá-Taquera, Estado do Pará STCP Engenharia de Projetos Ltda., Porto Trombetas: MRN - Mineração Rio do Norte S.A., Curitiba, 213 pp.

MORATO, S.A.A., LIMA, A.M.X., STAUT, D.C.P., FARIA, R.G., SOUZA-ALVES, J.P., GOUVEIA, S.F., SCUPINO, M.R.C., GOMES, R. \& DA SILVA, M.J. (2011) Amphibians and Reptiles of the Refúgio de Vida Silvestre Mata do Junco municipality of Capela, state of Sergipe, northeastern Brazil. Check List, 7, 756-762.

MORATO, S.A.A., VAN DER MEER, P.M., BORNSCHEIN, M.R. CAPELA, D.J.V., ULANDOWSKI, L.K.M.A. \& ZAMPIER, A.C. (2015) Range extension for Tupinambis quadrilineatus Manzani and Abe, 1997 (Squamata: Teiidae), with notes on habitats and aquatic behavior. Herpetology Notes, 8, 571 573.

MORAVEC, J., APARICIO, J., GUERRERO-REINHARD, M. CALDERON, G., JUNGFER, K.H. \& GVOZDIK, V. (2009) A new species of Osteocephalus (Anura: Hylidae) from Amazonian Bolivia: first evidence of tree frog breeding in fruit capsules of the Brazil nut tree. Zootaxa, 37-54.

MORAVEC, J., LEHR, E., CUSI, J.C., CORDOVA, J.H. \& GVOZDIK, V. (2014) A new species of the Rhinella margaritifera species group (Anura, Bufonidae) from the montane forest of the Selva Central, Peru. ZooKeys, 35-56.

MORAVEC, J., LEHR, E., PEÑA, P.E.P., LOPEZ, J.J., URRUTIA G.G. \& TUANAMA, I.A. (2010) A new green, arboreal species of Pristimantis (Anura, Strabomantidae) from Amazonian Peru. Vertebrate Zoology, 60, 225-232.

MORENO, L. \& GUTIERREZ, R. (2008) Ampliación de la distribución Physalaemus biligonigerus (Cope, 1860) (Anura: Leiuperidae) en la provincia de San Luis Argentina. Cuadernos de Herpetologia, 22, 49-50.

MORENO, R., MORENO, J., ORTIZ, J.C., VICTORIANO, P. \& TORRES-PÉREZ, F. (2002) Herpetofauna del Parque Nacional Llanos de Challe (III Region, Chile). Gayana, 66, 710.

MORETTI, R. (2009) Revisão taxonômica do gênero Coleodactylus Parker, 1926 (Squamata: Sphaerodactylidae). Tese de Doutorado. Departamento de Zoologia Universidade de São Paulo, São Paulo, 268 pp.

MOROTI, M.T., PEDROZO, M., MACHADO, I.F. \& SANTANA D.J. (2016) Distribution extension of Chiasmocleis mantiqueira Cruz, Feio and Cassini, 2007 (Amphibia, Anura, Microhylidae) in state of São Paulo. Herpetology Notes, 9, 229-231.

MOTT, T., CARVALHO NETO, C.D.S. \& CARVALHO FILHO K.D.S. (2011a) Amphisbaena miringoera Vanzolini, 1971 (Squamata: Amphisbaenidae): New state record. Check List, 7, 594-595.

MOTT, T., CORREIA, L.L., ALMEIDA, J.P.A., LISBOA, B.S. \& GUARNIERI, M.C. (2016) On the distribution of Siphonops paulensis Boettger, 1892 (Gymnophiona: Siphonopidae): four new Brazilian state records. Check List, 12, 1-5.

MOTT, T., MORAIS, D.H. \& KAWASHITA-RIBEIRO, R.A. (2008a) Reptilia, Squamata, Amphisbaenidae, Anops bilabialatus: distribution extension, meristic data, and conservation. Check List, 4, 146-150.

MOTT, T., MOURA, M.R., MACIEL, A.O. \& FEIO, R.N. (2011b) Morphological variation and geographical distribution of Luetkenotyphlus brasiliensis (Gymnophiona: Siphonopidae). Phyllomedusa, 10, 153-163.

MOTT, T., RODRIGUES, M.T., DE FREITAS, M.A. \& SILVA, T.F.S (2008b) New species of Amphisbaena with a nonautotomic and dorsally tuberculate blunt tail from state of Bahia Brazil (Squamata, Amphisbaenidae). Journal of Herpetology, $42,172-175$.

MOTT, T., RODRIGUES, M.T. \& SANTOS, E.M. (2009) A new Amphisbaena with chevron-shaped anterior body annul 
from state of Pernambuco: Brazil (Squamata: Amphisbaenidae). Zootaxa, 2165, 52-58.

MOTTA, A.P., CASTROVIEJO-FISHER, S., VENEGAS, P.J. ORRICO, V.G.D. \& PADIAL, J.M. (2012) A new species of the Dendropsophus parviceps group from the western Amazon Basin (Amphibia: Anura: Hylidae). Zootaxa, 3249, 18-30.

MOTTA, A.P., CHAPARRO, J.C., POMBAL, J.J.P. GUAYASAMIN, J.M., DE LA RIVA, I. \& PADIAL, J.M. (2016) Molecular Phylogenetics and Taxonomy of the Andea Genus Lynchius Hedges, Duellman, and Heinicke 2008 (Anura: Craugastoridae). Herpetological Monographs, 30, 119-142.

MOTTA, A.P., PIRANI, R.M., DA SILVA, E.T., SANTANA, D.J. MANGIA, S. \& FEIO, R.N. (2010) New record and distribution extension of Zachaenus carvalhoi Izecksohn 1983 (Anura, Cycloramphidae) in south-eastern Brazil. Herpetology Notes, 3, 85-86.

MOURA-LEITE, J.C., MORATO, S.A.A. \& BERNILS, R.S. (1996) New Records of Reptiles from the State of Paraná, Brazil. Herpetological Review, 27, 216-217.

MOURA, G.J.B., ANDRADE, E.V.E. \& FREIRE, E.M.X. (2010a) Amphibia, Anura, Microhylidae, Stereocyclops incrassatus Cope, 1870: distribution extension. Check List, 6, 71-72.

MOURA, G.J.B., FREIRE, E.M.X., SANTOS, E.M., MORAIS, Z.M.B.M., LINS, E.A.M., ANDRADE, E.V.E. \& FERREIRA J.D.C. (2011) Distribuição geográfica e caracterização ecológica dos répteis do estado de Pernambuco. In: MOURA, G.J.B., SANTOS, E.M., OLIVEIRA, M.A.B. \& CABRAL, M.C.C. (Eds.) Herpetofauna de Pernambuco. MMA/IBAMA, Brasilia, pp. 229-290.

MOURA, M.R., COSTA, H.C. \& PIRANI, R.M. (2013) Rediscovery of Phalotris concolor (Serpentes: Dipsadidae: Elapomorphini). Zoologia, 30, 430-436.

MOURA, M.R., DAYRELL, J.S. \& SÃO-PEDRO, V.D.A. (2010b) Reptilia, Gymnophthalmidae, Micrablepharus maximilian (Reinhardt and Lutken, 1861): distribution extension, new state record and geographic distribution map. Check List, 6 , 419-426.

MOURA, M.R. \& FEIO, R.N. (2010) Amphibia, Anura, Hylidae, Bokermannohyla sazimai (Cardoso and Andrade, 1982): Distribution extension and geographic distribution map. Check List, 6, 439-441.

MUESES-CISNEROS, J.J. (2003) El género Osornophryne (Amphibia: Bufonidae) en Colombia. Caldasia, 25, 419-427.

MUESES-CISNEROS, J.J. (2005a) The amphibian fauna of the Valle de Sibundoy, Putumayo-Colombia. Caldasia, 27, 229242

MUESES-CISNEROS, J.J. (2005b) The amphibian fauna of the Valle de Sibundoy, Putumayo-Colombia.

Fauna anfibia del Valle de Sibundoy, Putumayo-Colombia. Caldasia, 27, 229-242.

MUESES-CISNEROS, J.J. (2007) Fauna Anura asociada a um sistema de Charcos dentro de bosque em el kilometro 11 carretera Leticia-Tarapacá. Caldasia, 29, 385-395.

MUESES-CISNEROS, J.J. (2008) Rhaebo haematiticus (Cope 1862): un complejo de especies. Con redescripcion de Rhaebo hypomelas (Boulenger 1913) y descripcion de una nueva especie. Herpetotrópicos, 5, 29-47.

MUESES-CISNEROS, J.J. \& ANGANOY-CRIOLLO, M.A. (2008) Una nueva especie del grupo Hyloscirtus larinopygio (Amphibia: Anura: Hylidae) del suroccidente de Colombia. Papéis Avulsos de Zoologia, 48, 129-138.

MUESES-CISNEROS, J.J., CEPEDA-QUILINDO, B. \& MORENOQUINTERO, V. (2008) Una nueva especie de Epipedobates (Anura: Dendrobatidae) del suroccidente de Colombia. Papéis Avulsos de Zoologia, 48, 1-10.

MUESES-CISNEROS, J.J., CISNEROS-HEREDIA, D.F. \& MCDIARMID, R.W. (2012) A new Amazonian species of Rhaebo (Anura: Bufonidae) with comments on Rhaebo glaberrimus (Gunther, 1869) and Rhaebo guttatus (Schneider, 1799). Zootaxa, 22-40.

MUESES-CISNEROS, J.J. \& MORENO-QUINTERO, V. (2011) Amphibian fauna of Reserva Natural Biotopo Selva Humeda, Barbacoas, Narino, Colombia.

FAUNA ANFIBIA DE LA RESERVA NATURAL BIOTOPO SELVA HUMEDA, BARBACOAS, NARINO, COLOMBIA. Herpetotrópicos, 7, 39-54.

MULLER, L. (1912) Zoologische Ergebnisse einer Reise in das Mundungsgebiet des Amazonas herausgegeben von Lorenz Muller. I. Allgemeine Bemerkungen uber Fauna und Flora des bereisten Gebietes. Abhandlungen der Königlich Bayerischen Akademie der Wissenschaften. MathematischPhysikalische Klasse, 26, 1-42.

MÜLLER, L. (1923) Neue oder seltene Reptilien und Batrachier der Zoologischen Sammlung des bayrischen Staates. Zoologischer Anzeiger, 57, 145-156.

MÜLLER, L. \& HELLMICH, W. (1932) Beiträge zur Kenntnis de Herpetofauna Chiles. II. Neue Liolaemus - Arten und Rassen aus den Hochanden Chiles. Zoologische Anzeiger, 97, 307329.
MÜLLER, L. \& HELLMICH, W. (1933) Beiträge zur Kenntnis der Herpetofauna Chiles. VII. Der Rassenkreis der Liolaemus nigromaculatus. Zoologische Anzeiger, 103, 128-142.

MUNIZ, S.L.S., MOURA, C.C.M., VEGA, S.F., COUTO, A.A SILVA, J.S., SANTOS, E.M. \& MOURA, G.J.B. (2013) Leptophis ahaetulla (Swordsnake). Diet. Herpetological Review, 44, 154.

MUNIZ, S.L.S., VEGA, E.S.F., CHAVES, L.S., MOURA, C.C.M., SANTOS, E.M. \& MOURA, G.J.B. (2012) Colobosaura modesta. Herpetological Review, 43, 444-445.

MUÑOZ-ARCOS, R., GUERRERO-CUPACÁN, J.A. \& CEPEDAQUILINDO, B. (2016) First record of Pristimantis crucifer Boulenger, 1899 (Anura: Craugastoridae) from Colombia, Nariño Department. Check List, 12, 1-4.

MUÑOZ-SARAVIA, A., RIVAS-TORRICO, L.R., GONZALES, L. \& QUISPE, J. (2009) Reptilia, Serpentes, Elapidae, Micrurus serranus: distribution extension. Check List, 5, 510-512.

MURPHY, J.C. \& JOWERS, M.J. (2013) Treerunners, cryptic lizards of the Plica plica group (Squamata, Sauria, Tropiduridae) of northern South America. ZooKeys, 49-77.

MURTA-FONSECA, R.A., FRANCO, F.L. \& FERNANDES, D.S (2016) Taxonomic status and morphological variation of Hydrodynastes bicinctus (Hermann, 1804) (Serpentes: Dipsadidae). Zootaxa, 4007, 19

MYERS, C.W. (1973) A new genus for Andean snakes related to Lygophis boursieri and a new species (Colubridae). American Museum Novitates, 1973, 1-37.

MYERS, C.W. (1974) The systematics of Rhadinaea (Colubridae), a genus of New World snakes. Bulletin of the American Museum of Natural History, 153, 1-262.

MYERS, C.W. (2011) A New Genus and New Tribe for Enicognathus melanauchen Jan, 1863, a Neglected South American Snake (Colubridae: Xenodontinae), with Taxonomic Notes on Some Dipsadinae. American Museum Novitates, 1-33.

MYERS, C.W. \& CADLE, J.E. (1994) A new genus for South American snakes related to Rhadinaea obtusa Cope (Colubridae) and resurrection of Taeniophallus Cope for the "Rhadinaea" brevirostris group. American Museum Novitates, 1994, 1-33.

MYERS, C.W. \& DONNELLY, M.A. (1996) A new herpetofaun from Cerro Yavi, Venezuela: first results of the Robert G. Goelet American Museum-TERRAMAR Expedition to the northwestern Tepuis. American Museum Novitates, 1996 $1-56$.

MYERS, C.W. \& DONNELLY, M.A. (1997) A tepui herpetofauna on a granitic mountain (Tamacuari) in the borderland between Venezuela and Brazil: report from the Phipps Tapirapeco Expedition. American Museum Novitates, 1997 T-71.

MYERS, C.W. \& DONNELLY, M.A. (2001) Herpetofauna of the Yutaje-Corocoro massif, Venezuela: Second report from The Robert G. Goelet American Museum-terramar expedition to the northwestern tepuis. Bulletin of the American Museum of Natural History, 1-85.

MYERS, C.W. \& DONNELLY, M.A. (2008) The summit herpetofauna of Auyantepui, Venezuela: report from the Robert G. Goelet American Museum - TERRAMAR Expedition. Bulletin of the American Museum of Natural History, 1-147.

MYERS, C.W., FUENMAYOR, G.R. \& JADIN, R.C. (2009) New Species of Lizards from Auyantepui and La Escalera in th Venezuelan Guayana, with Notes on "Microteiid" Hernipenes (Squamata: Gymnophthalmidae). American Museum Novitates, 2009, 1-31.

MYERS, C.W. \& GRANT, T. (2009) Anomaloglossus confusus, a new ecuadorian frog formerly masquerading a "Colostethus" chocoensis (Dendrobatoidea: Aromobatidae). American Museum Novitates, 2009, 1-12.

MYERS, C.W. \& MCDOWELL, S.B. (2014) New Taxa and Cryptic Species of Neotropical Snakes (Xenodontinae), with Commentary on Hemipenes as Generic and Specific Characters. Bulletin of the American Museum of Natural History, 1-112.

MYERS, C.W., RODRIGUEZ, L.O. \& ICOCHEA, J. (1998) Epipedobates simulans, a new cryptic species of poison fro from southeastern Peru, with notes on E. macero and $E$. petersi (Dendrobatidae). American Museum Novitates, 1998, 1-20.

MYERS, C.W. \& SCHARGEL, W.E. (2006) Morphological extremes - two new snakes of the genus Atractus from northwestern South America (Colubridae: Dipsadinae). American Museum Novitates, 3532, 1-13.

MYERS, G.S. \& CARVALHO, A.L. (1945) A strange new leafnosed lizard of the genus Anolis from Amazonia. Boletim do Museu Nacional, 43, 1-14.

NAPOLI, M.F. (2000) Taxonomia, variação morfológica e distribuição geográfica das espécies do grupo de Hyla circumdata (Cope, 1870) (Amphibia, Anura, Hylidae) Doutorado. Zoologia, Universidade Federal do Rio de Janeiro, Rio de Janeiro, $208 \mathrm{pp}$

NAPOLI, M.F. \& CARAMASCHI, U. (2004) Two new species of the Hyla circumdata group from Serra do Mar and Serra da Mantiqueira, Southeastern Brazil, with description of the advertisement call of Hyla ibitipoca (Anura, Hylidae). Copeia, 2004, 534-545.

NAPOLI, M.F., CARAMASCHI, U., CRUZ, C.A.G. \& DIAS, I.R. (2011) A new species of flea-toad, genus Brachycephalus
Fitzinger (Amphibia: Anura: Brachycephalidae), from the Atlantic rainforest of southern Bahia, Brazil. Zootaxa, 2739, 33-40.

NAPOLI, M.F., JUNCA, F.A., CRUZ, D. \& ABREU, R.O. (2010) Amphibia, Anura, Strabomatidae, Strabomantis aramunh Cassimiro, Verdade and Rodriguez, 2008: distribution extension with notes on natural history, color patterns, and morphometric data. Check List, 6, 275-279.

NAPOLI, M.F. \& PIMENTA, B.V.S. (2009) A New Species of the Bokermannohyla circumdata Group (Anura: Hylidae) from the Coastal Forests of Bahia, Northeastern Brazil. Copeia 2009, 674-683.

NARVAES, P. \& RODRIGUES, M.T. (2009) Taxonomic revision of Rhinella granulosa species group (Amphibia, Anura, Bufonidae), with a description of a new species. Arquivos de Zoologia, 40, 1-73.

NASCIMENTO, F.P., AVILA-PIRES, T.C.S. \& CUNHA, O.R. (1987) Os Répteis da área de Carajás, Pará, Brasil (Squamata). II. Boletim do Museu Paraense Emílio Goeldi, série Zoologia, 3 33-65.

NASCIMENTO, L.B., PIMENTA, B.V.S., CRUZ, C.A.G. \& CARAMASCHI, U. (2006) Taxonomic status of Gomphobates marmoratus Rheinhardt and Luetken, 1862 "1861" and Eupemphix fuscomaculatus Steindachner, 1864 (Amphibia, Anura, Leptdactylidae). South American Journal of Herpetology, 1, 166-174.

NASCIMENTO, V. \& SANTOS, E.M. (2016) Dendrophdion atlantica. Herpetological Review, 47, 261.

NAVARRETE, L.F., RODRIGUEZ-ACOSTA, A., CONTRERAS, Y. \& BRICENO, J.M. (2005) Stenorrhina degenhardtii ocellata Jan, 1876 in Venezuela. Herpetozoa, 18, 89-91.

NAVARRETE, M.J., VENEGAS, P.J. \& RON, S.R. (2016) Two new species of frogs of the genus Pristimantis from Llanganates National Park in Ecuador with comments on the regional diversity of Ecuadorian Pristimantis (Anura Craugastoridae). ZooKeys, 593, 139-162.

NELSON, C.E. \& LESCURE, J. (1975) The taxonomy and distribution of Myersiella and Synapturanus (Anura: Microhylidae). Herpetologica, 31, 389-397.

NETA, A.F.S., FERREIRA, A.J.G., OLIVEIRA, H.F., SILVA, M.C. \& ÁVILA, R.W. (2014) Phyllopezus periosus - Geographic Distribution. Herpetological Review, 45, 661.

NETO, C.S.C. \& PACHECO, B.G. (2007) Dieta, morfometria razão sexual de Polychrus acutirostris (Spix, 1825) (Squamata: Polychrotidae), sob pressão da eliminação de habitats pelo enchimento do reservatório da UHE Irapé no Rio Jequitinhonha, Nordeste de Minas Gerais, p. 113. In: 39 Congresso Brasileiro de Herpetologia. HERPETOLOGIA, S.B.D. (ed.). Sociedade Brasileira de Herpetologia, Belém

S.B.D. (ed.). Sociedade Brasileira de Herpetologia, Belem
N.D.O., PEREIRA, E.A., FERREIRA ROCHA, L.C. VASQUES, J.B. \& SANTOS, P.D.S. (2014) Distribution extension of Scinax constrictus Lima, Bastos \& Giaretta, 2004 (Amphibia, Hylidae): new state record in the Brazilian Cerrado. Herpetology Notes, 7, 745-74

NEVES, M.O., ASSIS, C.L., NEVES, C.P., SANTOS, P.S. \& FEIO, R.N. (2016) Amphibia, Anura, Hylidae, Scinax cosenzai Lacerda, Peixoto \& Feio, 2012: New records and geographic distribution map. Herpetology Notes, 9, 197-199.

NOBLE, G.K. (1920) Some new lizards from northwestern Peru. Annals of the New York Academy of Sciences, 29, 133-139.

NOBLE, G.K. (1923) A New Gekkonid Lizard and a new Brachycephalid Frog from Colombia. American Museum Novitates, 1923, 1-3.

NOGUEIRA-COSTA, P., OLIVEIRA AGUIAR, F.V., SILVA, G.R., AFONSO, M.C., BARBOSA BALDINE, J.T. \& VENANCIO, M.F. (2013) Reptilia, Squamata, Amphisbaenidae, Amphisbaen fuliginosa wiedi Vanzolini, 1951: Distribution extension. Check List, 9, 167-168.

NOGUEIRA, C. (2006) Diversidade e Padrões de Distribuição da Fauna de Lagartos do Cerrado. Doutorado. Instituto de Biociências da Universidade de São Paulo, Departamento de Ecologia, São Paulo, 295 pp.

NOGUEIRA, C., BARBO, F.E. \& FERRAREZZI, H. (2012) Redescription of Apostolepis albicollaris Lema, 2002, with a key for the species groups of the genus Apostolepis (Serpentes: Dipsadidae: Elapomorphini). South American Journal of Herpetology, 7, 213-225.

NOGUEIRA, C. \& RODRIGUES, M.T. (2006) The genus Stenocercus (Squamata: Tropiduridae) in extra-Amazonian Brazil, with the description of two new species. South American Journal of Herpetology, 1, 149-166.

NOONAN, B.P. \& GAUCHER, P. (2005) Phylogeography and demography of Guianan harlequin toads (Atelopus) diversification within a refuge. Molecular Ecology, 14, 3017-3031.

NORONHA-OLIVEIRA, M.V., BRITO-DE-CARVALHO, C. \& FARIA, R.G. (2010) Dryadosaura nordestina (NCN) Herpetological Review, 41, 512 .

NORONHA-OLIVEIRA, M.V., CARVALHO, C.B., FREITAS, E.B. \& FARIA, R.G. (2012) Cercosaura ocellata (Ocellated Tegu). Herpetological Review, 43, 617-618.

NOVAES-E-FAGUNDES, G., FREITAS, J.L., CARDOSO, M.C.S., BARBOSA, T. \& ZINA, J. (2016) Leptodactylus caatingae. Herpetological Review, 47, 419-420.

NOVELLI, I.A., LUCAS, P.S. \& SANTOS, R.C. (2011) Reptilia, Squamata, Gymnophthalmidae, Heterodactylus imbricatus Spix, 1825: Filling gaps in the state of Minas Gerais. Check List, 7, 30-31. 
NUNES, I., CARVALHAO, R.R., JR. \& PEREIRA, E.G. (2010) A new species of Scinax Wagler (Anura: Hylidae) from Cerrado of Brazil. Zootaxa, 2514, 24-34.

NUNES, I., KWET, A. \& POMBAL, J.P. (2012a) Taxonomic Revision of the Scinax alter Species Complex (Anura: Hylidae). Copeia, 2012, 554-569.

NUNES, I, LOEBMANN, D. CRUZ, CA.G. \& HADDAD, C.F.B. (2015) Advertisement call, colour variation, natural history, and geographic distribution of Proceratophrys caramaschil (Anura: Odontophrynidae). Salamandra, 51, 103-110.

NUNES, I. \& POMBAL, J.P. (2010) A new Scinax Wagler (Amphibia, Anura, Hylidae) from the Atlantic Rain Forest remains of southern State of Bahia, North-eastern Brazil. Amphibia-Reptilia, 31, 347-353.

NUNES, I., SUÁREZ, P., GORDO, M. \& POMBAL JR, J.P. (2013) A Second Species of Trachycephalus Tschudi (Anura: Hylidae) with a Single Vocal Sac from the Brazilian Amazon. Copeia, 634-640.

NUNES, P.M.S., FOUQUET, A., CURCIO, F.F., KOK, P.J.R. \& RODRIGUES, M.T. (2012b) Cryptic species in Iphisa elegan Gray, 1851 (Squamata: Gymnophthalmidae) revealed by hemipenial morphology and molecular data. Zoological Journal of the Linnean Society, 166, 361-376.

NÚÑEZ, H. (1992) Geographical data of Chilean Lizards and Snakes in the Museo Nacional de Historia Natural Santiago, Chile. Smithsonian Herpetological Information Service, 29.

NÚÑEZ, H. (2007) Liolaemus frassinettii, nueva especie de lagartija para los Altos de Cantillana, región Metropolitan (Reptilia: Sauria). Boletín del Museo Nacional de Historia Natural, 56, 81-87.

NÚÑEZ, H. \& LABRA, M.A. (1985) Liolaemus curis, a new lizard from the Los Andes Range, central Chile. Copeia, 1985, 556-

NúÑEZ, H., NAVARRO, J., GARIN, C., PINCHEIRA-DONOSO, D. \& MERIGGIO, V. (2003) Phrynosaura manueli Phrynosaura torresi, nuevas especies de lagartijas para el Norte de Chile (Squamata: Sauria). Boletin del Museo Nacional de Historia Natural Chile, 52, 67-88.

NÚÑEZ, H., NAVARRO, J. \& LOYOLA, J. (1991) Liolaemus maldonadae y Liolaemus cristiani, dos especies nuevas de lagartijas para Chile (Reptilia, Squamata). Museo Nacional de Historia Natural Boletin, 79-88.

NÚÑEZ, H., NAVARRO, J. \& VELOSO, A. (2000) Liolaemus foxi, una nueva especie de lagarto para el norte de Chil Squamata: Reptilia: Sauria). Boletin del Museo Nacional de Historia Natural Chile, 49, 117-130.

NÚÑEZ, H. \& PINCHEIRA-DONOSO, D. (2006) Liolaemus confusus, una nueva especie de lagartija de la Cordillera de la Costa de Chile central (Sauria, Liolaeminae): evidencia fenetica y citogenetica. Boletin del Museo Nacional de Historia Natural Chile, 75-86.

NÚÑEZ, H., PINCHEIRA-DONOSO, D. \& GARÍN, C. (2004) Liolaemus hajeki, nueva especie de Lagartijade Chile (Squamata, Sauria). Boletín del Museo Nacional de Historia Natural, 85-97.

NÚÑEZ, H. \& SCOLARO, J.A. (2009) Liolaemus (Donosolaemus) chacabucoense, nueva especie de lagartija para la region de Aisen, Chile (Reptilia, Sauria). Boletin del Museo Nacional de Historia Natural Chile, 58, 67-74.

NÚÑEZ, H. \& TORRES-MURA, J.C. (2014) Liolaemus kolengh (Sauria: Liolaemidae), in Lago Jeinimeni National Reserve, new lizard for Chile Boletín del Museo Nacional de Historia Natural, 63, 43-50.

NÚÑEZ, H., TORRES-MURA, J.C. \& YAÑEZ, J. (2012) NeW localities for Chilean lizards in Nothern Northern Area of Chile. Boletin del Museo Nacional de Historia Natural Chile, Chile. Boletin

NÚÑEZ, H., VELOSO, A., ESPEJO, P., VELOSO, C., CORTÉS, A. \& ARAYA, S. (2010) Nuevas especies de Phymaturus (Grupo "palluma") para la zona cordillerana central de Chile (Reptilia, Sauria, Liolaemidae). Boletín del Museo Nacional de Historia Natural, 59, 41-74.

NÚÑEZ, H. \& YÁÑEZ, J. (1983) Ctenoblepharis audituvelatus new species, a lizard from northern Chile (Reptilia Iguanidae). Copeia, 1983, 454-457.

NUNEZ, J.J., RABANAL, F.E. \& FORMAS, J.R. (2012) Description of a new species of Eupsophus (Amphibia: Neobatrachia) from the Valdivian Coastal range, Southern Chile: an integrative taxonomic approach. Zootaxa, 3305, 53-68.

NÚÑEZ, K. (2011) Melanophryniscus devincenzii. Herpetological Review, 42, 107

NUSSBAUM, R.A. \& WILKINSON, M. (1987) Two new specie of Chthonerpeton (Amphibia: Gymnophiona: Typhlonectidae) from Brazil. Occasional Papers of the Museum of Zoology University of Michigan, 1-15.

O'SHAUGHNESSY, A.W.E. (1881) An account of the collection of lizards made by Mr. Buckley in Ecuador, and now in the British Museum, with descritions of the new species. Proceedings of the Zoological Society of London, 1881, 227245

OCAMPO, M., AGUILAR-KIRIGIN, A. \& QUINTEROS, S. (2012) A new species of Liolaemus (Iguania: Liolaemidae) of the alticolor group from La Paz, Bolivia. Herpetologica, 68, 410-

OCAMPO, M., APARICIO, J. \& WALLACE, R. (2017) Southernmost record for the leaflitter frog Pristimantis ockendeni (Boulenger, 1912) (Anura: Craugastoridae). Check List, 13, 1-3.
OFTEDAL, O.T. (1974) A revision of the genus Anadia (Sauria, Teiidae). Arquivos zool S Paulo, 25, 203-265.

OHMER, M.E., ROBERTSON, J.M. \& ZAMUDIO, K.R. (2009) Discordance in body size, colour pattern, and advertisement call across genetically distinct populations in a Neotropical anuran (Dendropsophus ebraccatus). Biological Journal of the Linnean Society, 97, 298-313.

OLIVEIRA, A.K.C.D., OLIVEIRA, I.S., HARTMANN, M.T., SILVA N.R. \& TOLEDO, L.F. (2011) Amphibia, Anura, Brachycephalidae, Brachycephalus hermogenesi (Giarett and Sawaya, 1998): new species record in the state of Parana, southern Brazil and geographic distribution map. Check List, 7, 17-18.

OLIVEIRA, B.H.S. \& PESSANHA, A.L.M. (2013) Microhabitat use and diet of Anotosaura vanzolinia (Squamata: Gymnophthalmidae) in a Caatinga area, Brazil. Bioto Neotropica, 13, 193-198.

OLIVEIRA, C.N. \& MOURA, G.J.B. (2013) Cercosaura ocellat Wagler, 1830 (Lacertilia, Gymnophthalmidae): distribution extension of Northeastern Brazil. Biota Neotropica, 13, 387-389.

OLIVEIRA, D.P. (2015) Distribuição e Diversidade Filogenética de Lagartos da Amazônia Brasileira. PhD. Genética, Conservação e Biologia Evolutiva, Instituto Nacional de Pesquisas da Amazônia, Manaus, 230 pp.

OLIVEIRA, D.P., SOUZA, S.M., FRAZÃO, L., ALMEIDA, A.P. \& HRBEK, T. (2014) Lizards from central Jatapú River Amazonas, Brazil. Check List, 10, 46-53.

OLIVEIRA, E.F., TOLLEDO, J. \& FEIO, R.N. (2009) Amphibia, Anura, Physalaemus rupestris Caramaschi, Carcerelli and Feio, 1991: distribution extension and geographic Feio, 1991: distribution extension

OLIVEIRA, F.A. CINTRA, C.E.D., FONSECA, M.P.S. \& SILVA, H.L.R. (2007) Répteis do inventário faunístico do Parque Ecológico Altamiro de Moura Pacheco e Parque dos Ipês, estado de Goiás, p. 276. In: 3o Congresso Brasileiro de Herpetologia. HERPETOLOGIA, S.B.D. (ed.), Belém

OLIVEIRA, J.C.F., COCO, L., PAGOTTO, R.V., PRALON, E., VRCIBRADIC, D., POMBAL JR, J.P. \& ROCHA, C.F.D. (2012a) Amphibia, Anura, Brachycephalus didactylus (Izecksohn 1971) and Zachaenus parvulus (Girard, 1853): distribution extension. Check List, 8, 242-244.

OLIVEIRA, U., COSTA, C.S., MENEGHELLI, D. \& MESSIAS, M.R. (2012b) Amphibia, Anura, Centrolenidae, Cochranell denocheira Harvey and Noonan, 2005: Distribution and geographic extension in the state of Rondonia, Brazil. Check List, 8, 145-146.

ORMEÑO, J., CORTÉS, A. \& ZEPEDA, M. (2008) Fauna De Reptiles Y Mamíferos Sector Quebradas El Arrayán: Centro De Cultivo De Abalones - Ocean Matters S. A., p. 1-24. In: Fauna Proyecto Centro de cultivo de abalones, La Serena Chile

ORRICO, V.G.D. (2010) Amphibia, Anura, Brachycephalidae, schnocnema verrucosa Reinhardt and Luetken, 1862: distribution extension to northeastern Brazil. Check List, 6 246-247.

ORRICO, V.G.D., PELOSO, P.L.V., STURARO, M.J., DA SILVA, H.F., NECKEL-OLIVEIRA, S., GORDO, M., FAIVOVICH, J. \& HADDAD, C.F.B. (2014) A new "Bat-Voiced" species of Dendropsophus Fitzinger, 1843 (Anura, Hylidae) from the Amazon Basin, Brazil. Zootaxa, 3881, 341-361.

ORTEGA-ANDRADE, H.M. (2006) Reptilia, Squamata, Gymnophthalmidae, Echinosaura horrida: distribution extension and new geographic distribution map for Ecuador. Check List, 2, 1-3.

ORTEGA-ANDRADE, H.M. (2009) Amphibia, Anura, Eleutherodactylidae, Adelophryne adiastola Hoogmoed and Lescure, 1984: first countries records and distribution extension from Ecuador and Brazil. Check List, 5, 139-143.

RTEGA-ANDRADE, H.M., ROJAS-SOTO, O.R., VALENCIA, J.H ESPINOSA DE LOS MONTEROS, A., MORRONE, J.J., RON, S.R. \& CANNATELLA, D.C. (2015) Insights from Integrative Systematics Reveal Cryptic Diversity in Pristimantis Frog (Anura: Craugastoridae) from the Upper Amazon Basin. PLOSONE, 10, 1-43.

ORTEGA-ANDPADE, H.M. \& RON, S.R. (2013) A new species of small tree frog, genus Dendropsophus (Anura: Hylidae) from the eastern Amazon lowlands of Ecuador. Zootaxa, 3652, $163-178$.

ORTEGA-ANDRADE, H.M. \& VALENCIA, J.H. (2010) Firs country records of Pristimantis luscombei (Duellman and Mendelson) and Syncope tridactyla (Duellman and Mendelson) in eastern lowlands of Ecuador (Amphibia: Anura: Strabomantidae, Microhylidae). Herpetology Notes, 3, 251-256.

ORTEGA-ANDRADE, H.M. \& VALENCIA, J.H. (2012) A new species of the Pristimantis frater group (Anura: Strabomantidae) from the eastern evergreen lowland forests of Ecuador. Herpetologica, 68, 244-255.

ORTEGA-ANDRADE, H.M. \& VENEGAS, P.J. (2014) A new synonym for Pristimantis luscombei (Duellman and Mendelson 1995) and the description of a new species of Pristimantis from the upper Amazon basin (Amphibia: Craugastoridae). Zootaxa, 3895, 31-57.

ORTIZ, J.C. (1980) Revisión taxonómica del género Tropidurus en Chile. In: Actas de la Primera Reunión Iberoamericana de Zoología de Vertebrados. Ediciones del Ministerio de
ORTIZ, J.C. \& VIDAL, M. (2001) Microlophus theresioides. Herpetological Review, 32, 120.

OSPINA-SARRIA, J.J., ANDRES VELASQUEZ-TRUJILLO, D. \& BOLIVAR-G, W. (2015a) First records of the two poorly known Terrarana frogs Pristimantis esmeraldas (Guayasamin, 2004) and Strabomantis necerus (Lynch, 1975) (Amphibia: Anura: Craugastoridae) for Colombia. Herpetology Notes, 8, 27-30.

OSPINA-SARRIA, J.J., ANGARITA-SIERRA, T. \& PEDROZABANDA, R. (2015b) A New Species of Craugastor (Anura: Craugastoridae) from the Magdalena River Valley, Colombia, with Evaluation of the Characters used to Identify Species of the Craugastor fitzingeri Group. South American Journal of Herpetology, 10, 165-177.

OSPINA-SARRIA, J.J., BOLIVAR-G, W. \& MENDEZ-NARVAEZ, J. (2010) Amphibia, Anura, Centrolenidae, Espadaran callistomma (Guayasamin and Trueb, 2007): first country records from Colombia. Check List, 6, 244-245.

OSPINA-SARRIA, J.J., MENDEZ-NARVAEZ, J., BURBANO YANDI, C. \& BOLIVAR-G, W. (2011) A new species of Pristimantis (Amphibia: Craugastoridae) with cranial crests from the Colombian Andes. Zootaxa, 37-48.

PADIAL, J.M., CASTROVIEJO-FISHER, S. \& DE LA RIVA, I. (2009a) The phylogenetic relationships of Yunganastes revisited (Anura: Terrarana). Molecular Phylogenetics and Evolution, 52, 911-915.

PADIAL, J.M., CHAPARRO, J.C., CASTROVIEJO-FISHER, S. GUAYASAMIN, J.M., LEHR, E., DELGADO, A.J., VAIRA, M. TEIXEIRA JR, M., AGUAY, R. \& DE LA RIVA, I. (2012) A revision of species diversity in the Neotropical genus Oreobates (Anura: Strabomantidae), with the description of three new species from the Amazonian slopes of the Andes. American Museum Novitates, 2012, 1-55.

PADIAL, J.M., CHAPARRO, J.C., KÖHLER, J. \& DE LA RIVA, I. (2009b) Rediscovery, resurrection and redescription of Rhinella leptoscelis (Boulenger, 1912) (Anura: Bufonidae). Zootaxa, 2115, 56-64.

PADIAL, J.M. \& DE LA RIVA, I. (2009) Integrative taxonomy reveals cryptic Amazonian species of Pristimantis (Anura: Strabomantidae). Zoological Journal of the Linnean Society, 155, 97-122.

PADIAL, J.M., GAGLIARDI-URRUTIA, G., CHAPARRO, J.C. \& GUTIERREZ, R.C. (2016) A New Species of the Pristimantis Conspicillatus Group from the Peruvian Amazon (Anura: Craugastoridae). Annals of Carnegie Museum, 83, 207-218.

PADIAL, J.M., GONZALES, L. \& DE LA RIVA, I. (2005a) A new species of the Eleutherodactylus discoidalis group (Anura: Leptodactylidae) from Andean humid montane forests of Bolivia. Herpetologica, 61, 318-325.

PADIAL, J.M., GONZALES, L., REICHLE, S., AGUAYO, R. \& DE LA RIVA, I. (2004) First records of five species of the genus Eleutherodactylus Dumeril and Bibron, 1841 (Anura, Leptodactylidae) for Bolivia. Graellsia, 60, 167-174.

PADIAL, J.M., REICHLE, S. \& DE LA RIVA, I. (2005b) New species of Ischnocnema (Anura: Leptodactylidae) from the Andes of Bolivia. Journal of Herpetology, 39, 186-191.

PAEZ-MOSCOSO, D.J., GUAYASAMIN, J.M. \& YANEZ-MUNOZ, M. (2011) A new species of Andean toad (Bufonidae, Osornophryne) discovered using molecular and morphological data, with a taxonomic key for the genus. ZooKeys, 108, 73-97.

PAEZ-VACAS, M.I., COLOMA, L.A. \& SANTOS, J.C. (2010) Systematics of the Hyloxalus bocagei complex (Anura: Dendrobatidae), description of two new cryptic species, and recognition of $H$. maculosus. Zootaxa, 1-75.

PALMEIRA, C.N.S., GONCALVES, U. \& PAZ, V.N. (2011) Physalaemus albifrons Spix, 1824 (Anura: Leiuperidae) Distribution and geographic extension. Check List, 7, 839840.

PANSONATO, A., AVILA, R.W., KAWASHITA-RIBEIRO, R.A. \& MORAIS, D.H. (2011) Advertisement call and new distribution records of Hypsiboas leucocheilus (Anura: Hylidae). Salamandra, 47, 55-58.

PANSONATO, A., MORAIS, D.H., AVILA, R.W., KAWASHITA RIBEIRO, R.A., STRUSSMANN, C. \& MARTINS, I.A. (2012) new species of Pseudopaludicola Miranda-Ribeiro, 1926 (Anura: Leiuperidae) from the state of Mato Grosso, Brazil, with comments on the geographic distribution of Pseudopaludicola canga Giaretta \& Kokubum, 2003. Zootaxa, 3523, 49-58.

PANSONATO, A., VEIGA-MENONCELLO, A.C.P., MUDREK, J.R. JANSEN, M., RECCO-PIMENTEL, S.M., MARTINS, I.A. \& STRÜSSMANN, C. (2016) Two New Species of Pseudopaludicola (Anura: Leptodactylidae: Leiuperinae) from Eastern Bolivia and Western Brazil. Herpetologica, 72 235-255.

PANTOJA, D.L., COLLI, G.R., LIMA, E.C., COSTA, B.M., ESTEVES, T.L. \& BORGES, I.S. (2007) Estrutura da taxocenose de lagartos em áreas de cerrado sensu stricto sob diferentes regimes de queima no Brasil Central, p. 145 In: 3o Congresso Brasileiro de Herpetologia. In: 30 Congresso Brasileiro de Herpetologia.
HERPETOLOGIA, S.B.D. (ed.). Sociedade Brasileira de Herpetologia, Belém

ANTOJA, D.L. \& DE FRAGA, R. (2012) Herpetofauna of the Reserva Extrativista do Rio Gregorio, Jurua Basin, southwes Amazonia, Brazil. Check List, 8, 360-374. 
PAOLILLO O, A. (1985) Tretioscincus agilis. Herpetological Review, 16, 31-32.

PARKER, H.W. (1926) The Neotropical Lizards of the Gener Lepidoblepharis, Pseudogonatodos, Lathrogecko, and Sphaerodactylus, with the description of a new genus. Annals and Magazine of Natural History, 17, 291-301.

PARKER, H.W. (1935) The Frogs, Lizards, and Snakes of British Guiana. Proceedings of the Zoological Society of London, 105, 505-530

PASSONI, J.C., BENOZZATI, M.L. \& RODRIGUES, M.T. (2008) Phylogeny, species limits, and biogeography of the Brazilia lizards of the genus Eurolophosaurus (Squamata : Tropiduridae) as inferred from mitochondrial DNA sequences. Molecular Phylogenetics and Evolution, 46, 403414.

PASSOS, D.C. \& BORGES-NOJOSA, D.M. (2011) Morphometry of Hemidactylus agrius (Squamata: Gekkonidae) hatchling from a semi-arid area in northeastern Brazil. Herpetology Notes, 4,

PASSOS, D.C., LIMA-ARAUJO, F., MELO, A.C.B. \& BORGESNOJOSA, D.M. (2013a) New state record and distribution extension of the golden tegu Tupinambis teguixin (Linnaeus, 1758) (Squamata: Teiidae) to the Caating (Linnaeus, 1758) (Squamata: Teiidae) to the Catin
biome, northeastern Brazil. Check List, 9, 1524-1526.

PASSOS, D.C., LIMA, D.C. \& BORGES-NOJOSA, D.M. (2011) A new species of Tropidurus (Squamata, Tropiduridae) of the semitaeniatus group from a semiarid area in Northeastern Brazil. Zootaxa, 2930, 60-68.

PASSOS, D.C. \& MESQUITA, P.C.M.D. (2012) Gymnodactylus geckoides. Defensive Behavior. Herpetological Review, 43, 487.

PASSOS, P., AGUAYO, R. \& SCROCCHI, G. (2009a) Rediscovery of the rare Atractus bocki, with assessment of the taxonomic status of Atractus canedii (Serpentes: Colubridae: Dipsadinae). Journal of Herpetology, 43, 710715.

PASSOS, P., ARREDONDO, J.C., FERNANDES, R. \& LYNCH, J.D. (2009b) Three new Atractus (Serpentes: Dipsadidae) from the Andes of Colombia. Copeia, 2009, 425-436.

PASSOS, P., CARAMASCHI, U. \& PINTO, R. (2006) Redescription of Leptotyphlops koppesi Amaral, 1954, and description of a new species of the Leptotyphlops dulcis group from Central Brazil (Serpentes: Leptotyphlopidae). Amphibia-Reptilia, 27, 347-357.

PASSOS, P., ECHEVARRIA, L.Y. \& VENEGAS, P.J. (2013b) Morphological Variation of Atractus carrioni (Serpentes: Dipsadidae). South American Journal of Herpetology, 8, 109-120.

PASSOS, P. \& FERNANDES, R. (2008a) A new species of the colubrid snake genus Atractus (Reptilia: Serpentes) from the central Amazon of Brazil. Zootaxa, 59-66.

PASSOS, P. \& FERNANDES, R. (2008b) Revision of The Epicrates cenchria Complex (Serpentes: Boidae). Herpetological Monographs, 22, 1-30.

PASSOS, P., FERNANDES, R., BERNILS, R.S. \& DE MOURALEITE, J.C. (2010) Taxonomic revision of the Brazilian Atlantic Forest Atractus (Reptilia: Serpentes: Dipsadidae). Zootaxa, 3-63.

PASSOS, P., FERNANDES, R. \& ZANella, N. (2005) A new species of Atractus (Serpentes: Colubridae) from southern Brazil. Herpetologica, 61, 209-218.

PASSOS, P., FUENMAYOR, G.R. \& BARRIO-AMOROS, C. (2009c) Description of two new species from Venezuela in the highly diverse dipsadine genus Atractus (Serpentes: Colubridae). Amphibia-Reptilia, 30, 233-243.

PASSOS, P. \& LYNCH, J.D. (2010) Revision of Atractus (Serpentes: Dipsadidae) from Middle and Upper Magdalena drainage of Colombia. Herpetological Monographs, 24, 149-173.

PASSOS, P., LYNCH, J.D. \& FERNANDES, R. (2008) Taxonomic status of Atractus sanctaemartae and Atractus nebularis, and description of a new Atractus from the Atlantic coast of Colombia. Herpetological Journal, 18, 175-186.

PASSOS, P., MARTINS, A. \& PINTO-COELHO, D. (2016a) Population Morphological Variation and Natural History of Atractus potschi (Serpentes: Dipsadidae) in Northeastern Brazil. South American Journal of Herpetology, 11, 188-211.

PASSOS, P., MUESES-CISNEROS, J., LYNCH, J.D. \& FERNANDES, R. (2009d) Pacific lowland snakes of the genus Atractus (Serpentes: Dipsadidae), with description of thre new species. Zootaxa, 2293, 1-34.

PASSOS, P., PRUDENTE, A.L.C. \& LYNCH, J.D. (2016b) Redescription of Atractus punctiventris and Description of Two New Atractus (Serpentes: Dipsadidae) from Brazilian Amazonia. Herpetological Monographs, 30, 1-20.

PASSOS, P., RAMOS, L. \& PEREIRA, D.N. (2012) Distribution natural history, and morphology of the rare snake, Caaeteboia amarali (Serpentes: Dipsadidae). Salamandra 48, 51-57.

PASSOS, P., TEIXEIRA JR, M., RECODER, R.S., SENA, M.A., DAL VECHIO, F., PINTO, H.B.A., MENDONÇA, S.H.S.T., CASSIMIRO, J. \& RODRIGUES, M.T. (2013c) A new species of Atractus (Serpentes: Dipsadidae) from Serra do Cipó, Espinhaço Range, Southeastern Brazil, with proposition of a new species group to the genus. Papéis Avulsos de Zoologia, 53, 75-85.

PAVAN, D. (2007) Assembléias de répteis e anfíbios do Cerrado ao longo da bacia do rio Tocantins e o impacto do aproveitamento hidreletrico da regiáo na sua conservação. PhD. Departamento de Zoologia, Insituto de Biociências, Universidade de São Paulo, São Paulo, 405 pp.

PAVAN, D. \& DIXO, M. (2004) A herpetofauna da área de influência do reservatório da Usina Hidrelétrica Luís Eduardo Magalhães, Palmas, TO. Humanitas, 4/6, 13-30. PECCININI-SEALE, D., ROCHA, C.F.D., ALMEIDA, T.M.B. ARAúJO, A.F.B. \& DE SENA, M.A. (2004) Cytogenetics of the Brazilian whiptail lizard Cnemidophorus littoralis (Teiidae) from a restinga area (Barra de Maricá) in Southeastern Brazil de Maricá no Sudeste do Brasil. Brazilian Journal of Biology, 64, 661-667.

PEDRO, V.D.A.S., FREITAS, M.A.D., OLIVEIRA, E.F.D VENÂNCIO, N.M. \& ZANOTTI, A.P. (2016) Geographical distribution of Ninia hudsoni (Serpentes: Dipsadidae) with new occurrence records. Oecologia Australis, 20, 537-542.

EEDROSA, I.M.M.C., COSTA, T.B., FARIA, R.G., FRANÇA, F.G.R., LARANJEIRAS, D.O., OLIVEIRA, T.C.S.P., PALMEIRA, C.N.S., TORQUATO, S., MOTT, T., VIEIRA, G.H.C. \& GARDA A.A. (2014) Herpetofauna of protected areas in the Caatinga III: The Catimbau National Park, Pernambuco, Brazil. Biota Neotropica, 14, 1-12.

PEIXOTO, M.A.A. LACERDA, JV.A. GUIMARÃES, C.S TEIXEIRA, B., SILVA, E.T. \& FEIO, R.N. (2013) Amphibia, Anura, Microhylidae, Myersiella microps (Duméril and Bibron, 1841): New records and geographic distribution map. Check List, 9, 847-848.

PELEGRIN, N. (2007) Presence of a polydactylous Tropidurus etheridgei (Squamata: Iguanidae: Tropidurinae) in the dry chaco of Cordoba Province, Argentina. Cuadernos de Herpetologia, 21, 115-116.

PELLEGRIN, N. \& LEYNAUD, G.C. (2006) Reptile fauna of the Chancani Reserve (Arid Chaco, Argentina): species list and conservation status. Herpetozoa, 19, 85-86.

PELLEGRINO, K.C.M., BERTOLOTTO, C.E.V., RODRIGUES, M.T. \& YONENAGA-YASSUDA, Y. (1999) Banding patterns, heteromorphic sex chromosomes and Ag-stained NORs after pachytene stage in the meiosis of the Brazilian lizard Uroshophus vautieri (Squamata, Polychrotidae). Caryologia 52, 21-26.

PELLEGRINO, K.C.M., KASAHARA, S., RODRIGUES, M.T. \& YONENAGA-YASSUDA, Y. (1997) Pericentric inversion events in karyotypic distinction of Brazilian lizards of genus Phyllopezus (Squamata, Gekkonidae) detected by chromosomal banding patterns. Hereditas, 127, 255-262.

PELLEGRINO, K.C.M., RODRIGUES, M.T. \& YONENAGAYASSUDA, Y. (2003) Triploid Karyotype of Leposoma percarinatum (Squamata, Gymnophthalmidae). Journal of percarinatum (Squamata,

PELLEGRINO, K.C.M., RODRIGUES, M.T., YONENAGAYASSUDA, Y. \& SITES, J.W. (2001) A molecular perspective on the evolution of microteiid lizards (Squamata, Gymnophthalmidae), and a new classification for the family. Biological Journal of the Linnean Society, 74, 315338.

PELOSO, P.L. \& AVILA-PIRES, T.C.S. (2010) Morphological Variation in Ptychoglossus brevifrontalis Boulenger, 1912 and the Status of Ptychoglossus nicefori (Loveridge, 1929) (Squamata, Gymnophthalmidae). Herpetologica, 66, 357372.

PELOSO, P.L.V., FAIVOVICH, J., GRANT, T., GASPARINI, J.L. \& HADDAD, C.F.B. (2012) An extraordinary new species of Melanophryniscus (Anura, Bufonidae) from southeastern Brazil. American Museum Novitates, 3762, 1-31.

PELOSO, P.L.V., PELLEGRINO, K.C.M., RODRIGUES, M.T. \& AVILA-PIRES, T.C.S. (2011) Description and Phylogenetic Relationships of a New Genus and Species of Lizard (Squamata, Gymnophthalmidae) from the Amazonian Rainforest of Northern Brazil. American Museum Novitates, 2011, 1-24.

PELOSO, P.L.V. \& STURARO, M.J. (2008) A new species of narrow-mouthed frog of the genus Chiasmocleis Mehely 1904 (Anura, Microhylidae) from the Amazonian rainforest of Brazil. Zootaxa, 1947, 39-52.

PELOSO, P.L.V., STURARO, M.J., FORLANI, M.C., GAUCHER, P. MOTTA, A.P. \& WHEELER, W.C. (2014) Phylogeny, Taxonomic Revision, and Character Evolution of the Genera Chiasmocleis and Syncope (Anura, Microhylidae) in Amazonia, with Descriptions of Three New Species. Bulletin of the American Museum of Natural History, 4-U17.

PERACCA, M.G. (1896) Descrizione di un nuovo genere e $d i$ una nuova specie di Teiidae raccolta nel Darien dal dott $\mathrm{E}$ Festa. Bollettino dei Musei di Zoologia e di Anatomia Comparata Torino, 11, 1-4.

PERACCA, M.G. (1897) Viaggio del Dr. Enrico Festa nell'Ecuador e regioni vicine. VI. Rettili. Bollettino dei muse di zoologia ed anatomia comparata della $R$. Università d Torino, 12, 1-20.

PERACCA, M.G. (1904) Viaggio del Dr Enrico Festa nell Ecuado e regioni vicine. Bollettino dei Musei di Zoologia e di Anatomia Comparata Torino, 19, 1-41.

PERDOMO-CASTILLO, I.V. \& MUESES-CISNEROS, J.J. (2014) Ampliación del ámbito de distribución geográfica de Hypsiboas nympha (Amphibia: Anura: Hylidae) en Colombia. Herpetotrópicos, 10, 33-35.

PEREIRA, E.A., NEVES, M.O., HOTE, P.S., SANTANA, D.J. \& FEIO, R.N. (2016) Anurans of the municipality of Barão de
Monte Alto, state of Minas Gerais, southeastern Brazil. Check List, 12, 1977.

PEREIRA, E.N., TELES, M.J.L. \& SANTOS, E.M. (2015) Herpetofauna em remanescente de Caatinga no Sertão de Pernambuco, Brasil. Boletim do Museu de Biologia Mello Leitao, 37, 37-51.

PÉRES JR, A.K. (2003) Sistemática e Conservação de Lagartos do Gênero Tupinambis (Squamata, Teiidae). Doutorado. Departamento de Zoologia, Universidade de Brasília1-193 $\mathrm{pp}$.

PÉRES JR, A.K. \& COLLI, G.R. (2004) The taxonomic status of Tupinambis rufescens and T. duseni (Squamata: Teiidae), with a redescription of the two species. Occasional Papers Sam Noble Oklahoma Museum of Natural History, 15, 1-12. PEREYRA, L.C., AKMENTINS, M.S., LAUFER, G. \& VAIRA, M (2013) A new species of Elachistocleis (Anura: Microhylidae) from north-western Argentina. Zootaxa, 3694, 525-544.

PEREYRA, M.O., BORTEIRO, C., BALDO, D., KOLENC, F. \& CONTE, C.E. (2012) Advertisement call of the closely related species Scinax aromothyella Faivovich 2005 and S. berthae (Barrio 1962), with comments on the complex calls in the $S$. catharinae group. Herpetological Journal, 22, 133-137.

PEREYRA, M.O., CARDOZO, D.E, BALDO, J. \& BALDO, D. (2014) Description and phylogenetic position of a new species of Oreobates (Anura: Craugastoridae) from northwestern Argentina. Herpetologica, 70, 211-227.

PEREZ-PENA, P.E., CHAVEZ, G., TWOMEY, E. \& BROWN, J.L. (2010) Two new species of Ranitomeya (Anura: Dendrobatidae) from eastern Amazonian Peru. Zootaxa 2349, 1-23.

PÉREZ, C.H.F. \& ÁVILA, L.J. (2011) First record of Liolaemus lentus Gallardo, 1966 (Squamata, Iguania, Liolaemini) in Río Negro province, Argentina. Herpetology Notes, 4, 191-193. PEREZ, C.H.F., FRUTOS, N., KOZYKARISKI, M.L., MORANDO, M., PEREZ, D.R. \& AVILA, L.J. (2011) Lizards of Rio Negro Province, northern Patagonia, Argentina. Check List, 7, 202219.

PEREZ, C.H.F. \& GRASSINI, C.M. (2001) Cnemidophoru lacertoides. Herpetological Review, 32, 275.

PEREZ, E.P.D. \& MORALES, R.M.C. (2011) Aspectos de Ecología de Stenocercus santander en un bosque húmedo montano bajo de los Andes Orientales de Colombia. Herpetotrópicos, 6, 17-24.

PÉREZ, G.A.T. (2015) Diversidad de los reptiles de la Orinoquía Colombiana: análisis de los patrones de distribución relaciones ambientales. MSc. Instituto de Ciencias Naturales, Inuversidad Nacional de Colombia, Bogotá, 130

pp.
PEREZ, R., RIBEIRO, S. \& BORGES-MARTINS, M. (2012) Reappraisal of the taxonomic status of Amphisbaen prunicolor (Cope 1885) and Amphisbaena albocingulato Boettger 1885 (Amphisbaenia: Amphisbaenidae). Zootaxa 3550, 1-25.

PEREZ, R. \& RIBEIRO, S.L.B. (2008) Reptilia, Squamata, Amphisbaenidae, Leposternon spp.: distribution extension new state record, and geographic distribution map. Check List, 4, 291-294.

PÉREZ Z., J., ECHEVARRíA, L.Y., ÁlvAREZ, S.C., VERA, A., ALARCón, J.G. \& ANDíA, M. (2012) Ecología trófica de la lagartija Stenocercus modestus (Squamata: Tropiduridae) en una zona urbana, Lima, Perú. Revista Peruana de Biología, 19, 323-326.

PÉREZ Z., J., RAMÍREZ, C. \& BALTA, K. (2013) A new record o Phyllodactylus sentosus (Dixon \& Huey, 1970) (Squamata: Phyllodactylidae) for the coastal desert of Peru. Cuadernos de Herpetologia, 27, 171-171.

PERINI, F.A. \& BUTTI, M. (2008) Ecpleopus gaudichaudil (NCN). Reproduction. Herpetological Review, 39, 222

PETERS, J.A. (1960) The snakes of the subfamily Dipsadinae. Miscellaneous Publications Museum of Zoology University of Michigan, No. 114, 1-224.

PETERS, J.A. (1964) The lizard genus Ameiva in Ecuador. Bulletin of the Southern California Academy of Sciences, 63 113-127.

PETERS, J.A. (1973) The frog genus Atelopus in Ecuado (Anura: Bufonidae). Smithsonian Contributions to Zoology, No. $145,1-49$.

PETERS, J.A. \& ORCES-V, G. (1956) A third leaf-nosed species of the lizard genus Anolis from South America. Breviora, 1 8

PETERS, W. (1863a) Über Cercosaura und die mit diese Gattung verwandten Eidechsen aus Südamerika. Abhandlungen der Königlichen Akademie der Wissenschaften zu Berlin, 1862, 165-225.

PETERS, W.C.H. (1863b) Über einige neue Arten der SaurierGattung Anolis. Monatsberichte der Königlich preussischen Akademie der Wissenschaften zu Berlin, 1863, 135-149.

PETERS, W.C.H. (1873) Über eine neue Art von Cnemidophorus. Sitzungsberichte der Gesellschaft Naturforschender Freunde zu Berlin, 1873, 76-77.

PHILIPPI, R.A. (1860) Reise durch die Wüste Atacama, auf Befehl der chilenischen Regierung im Sommer 1853-1854. Eduard Anton, Halle, $192 \mathrm{pp}$.

PIE, M.R. \& RIBEIRO, L.F. (2015) A new species of Brachycephalus (Anura: Brachycephalidae) from the Quirir mountain range of southern Brazil. PeerJ, 3, 1-9.

PIMENTA, B.V.S. \& CARAMASCHI, U. (2007) New species of toad, genus Frostius Cannatella, 1986, from the Atlantic 
RainNew species of toad, genus Frostius Cannatella, 1986, from the Atlantic rain forest of Bahia, Brazil (Amphibia, Anura, Bufonidae). Zootaxa, 61-68.

PIMENTA, B.V.S., CARAMASCHI, U. \& CRUZ, C.A.G. (2015) Synonymy of Crossodactylus bokermanni Caramaschi \& Sazima, 1985 with Crossodactylus trachystomus (Reinhardt \& Lutken, 1862) and description of a new species from Minas Gerais, Brazil (Anura: Hylodidae). Zootaxa, 3955, 6582.

PIMENTA, B.V.S., CRUZ, C.A.G. \& CARAMASCHI, U. (2014) Taxonomic Review of the species complex of Crossodactylus dispar A. Lutz, 1925 (Anura, Hylodidae). Arquivos de Zoologia, 45, 1-33.

PIMENTA, B.V.S., FAIVOVICH, J. \& POMBAL, J.P. (2007a) On the identity of Hyla strigilata Spix, 1824 (Anura: Hylidae): redescription and neotype designation for a "ghost" taxon. Zootaxa, 1441, 35-49.

PIMENTA, B.V.S., NAPOLI, M.F. \& HADDAD, C.F.B. (2009) A new species of casque-headed tree frog, genus Aparasphenodon Miranda-Ribeiro (Amphibia: Anura: Hylidae), from the Atlantic Rainforest of southern Bahia, Brazil. Zootaxa, 2009, 46-54.

PIMENTA, B.V.S., NUNES, I. \& CRUZ, C.A.G. (2007b) Notes on the poorly known phyllomedusine frog Hylomantis aspera Peters, 1872 (Anura, Hylidae). South American Journal of Herpetology, 2, 206-214.

PIMENTA, B.V.S., WACHLEVSKI, M. \& GONCALVES CRUZ, C.A. (2008) Morphological and acoustical variation, geographic distribution, and conservation status of the spinythumb frog Crossodactylus bokermanni Caramaschi and Sazima, 1985 (Anura, Hylodidae). Journal of Herpetology, 42, 4811985.
492.

PINCHEIRA-DONOSO, D. (2006) Los geckos de Chile (Scleroglossa, Gekkonidae, Gekkoninae). Parte II. Biogeografía y cambios ontogenéticos en el patrón de coloración de Phyllodactylus gerrhopygus. Puede la evidencia sostener la presencia de Phyllodactylus inaequalis en Chile? Multequina, 15, 37-48.

PINCHEIRA-DONOSO, D. \& NÚÑEZ, H. (2003) Liolaemus robertoi, una nueva especie de los Andes del Norte de Chile perteneciente al grupo ruibali (Iguania: Tropiduridae: Liolaeminae). Multequina, 12, 1-15.

PINCHEIRA-DONOSO, D. \& NÚÑEZ, H. (2005) Las especies Chilenas del Género Liolaemus Weigmann, 1834 (Iguana: Tropiduridae: Liolaeminae) Taxonomía, Sistemática y Evolución. Publicación Ocasional del Museo Nacional de Historia Natural Chile, 7-486.

PINCHEIRA-DONOSO, D. \& NÚÑEZ, H. (2007) Conspecificity of Liolaemus isabelae Navarro \& Núñez, 1993 and Liolaemus nigroventrolateralis Ortiz, 1994 (Iguania: Tropiduridae: Liolaeminae) from Northern Chile. The Herpetological Journal, 17, 65-67.

PINHEIRO, P.D.P., PEZZUTI, T.L., LEITE, F.S.F., GARCIA, P.C.A., HADDAD, C.F.B. \& FAIVOVICH, J. (2016) A New Species of the Hypsiboas pulchellus Group from the Serra da Mantiqueira, Southeastern Brazil (Amphibia: Anura: Hylidae). Herpetologica, 72, 256-270.

PINNA, P.H., MENDONÇA, A.F., BOCCHIGLIERI, A. \& FERNANDES, D.S. (2010) A new two-pored Amphisbaeno Linnaeus from the endangered Brazilian Cerrado biome (Squamata: Amphisbaenidae). Zootaxa, 2569, 44-54.

PINNA, P.H., MENDONÇA, A.F., BOCCHIGLIERI, A. \& FERNANDES, D.S. (2014) A New Species of Amphisbaena Linnaeus, 1758 from a Cerrado Region in Bahia, Northeastern Brazil (Squamata: Amphisbaenidae) Herpetologica, 70, 339-349.

PINTO, G.S. (1999) Leposoma osvaldoi. Herpetological Review, 30,52 .

PINTO, M.G. \& ARAUJO, A.B. (2000) Mabuya frenata. Herpetological Review, 31, 53

PINTO, M.G.M. \& QUATMAN, W.E. (2005) Ptychoglossus brevifrontalis (Boulenger's large-scaled lizard). Herpetological Review, 36, 202

PINTO, R.R. \& CURCIO, F.F. (2011) On the generic identity of Siagonodon brasiliensis, with the description of a new leptotyphlopid from Central Brazil (Serpentes: Leptotyphlopidae). Copeia, 53-63.

PINTO, R.R. \& FERNANDES, R. (2012) A New Blind Snake Species of the Genus Tricheilostoma from Espinhaco Range, Brazil and Taxonomic Status of Rena dimidiata (Jan, 1861) (Serpentes: Epictinae: Leptotyphlopidae). Copeia, 37-48.

PINTO, R.R., PASSOS, P., PORTILLA, J.R.C., ARREDONDO, J.C. \& FERNANDES, R. (2010) Taxonomy of the Threadsnakes of the tribe Epictini (Squamata: Serpentes: Leptotyphlopidae) in Colombia. Zootaxa, 1-28.

POE, S., LATELLA, I., AYALA-VARELA, F., YANEZ-MIRANDA, C. \& TORRES-CARVAJAL, O. (2015) A New Species of Phenacosaur Anolis (Squamata; Iguanidae) from Peru and a Comprehensive Phylogeny of Dactyloa-clade Anolis Based on New DNA Sequences and Morphology. Copeia, 103, 639-650.

POE, S., VELASCO, J.A., MIYATA, K. \& WILLIAMS, E.E. (2009) Descriptions of two nomen nudum species of Anolis lizard from northwestern South America. Breviora, 1-16.

POE, S. \& YANEZ-MIRANDA, C. (2007) A new species of Phenacosaur Anolis from Peru. Herpetologica, 63, 219-223.
POE, S. \& YANEZ-MIRANDA, C. (2008) Another new species of green Anolis (Squamata : Iguania) from the eastern Andes of Peru. Journal of Herpetology, 42, 564-571.

POE, S., YANEZ-MIRANDA, C. \& LEHR, E. (2008) Notes on variation in Anolis boettgeri Boulenger 1911, assessment of the status of Anolis albimaculatus Henle and Ehrl 1991, and description of a new species of Anolis (Squamata : Iguania) similar to Anolis boettgeri. Journal of Herpetology, 42, 251259

POMBAL, J.P., JR. (2010) A posição taxonômica das "variedades" de Brachycephalus ephippium (Spix, 1824) descritas por Miranda-Ribeiro, 1920 (Amphibia, Anura, Brachycephalidae). Boletim do Museu Nacional Rio de Janeiro Zoologia, 526, 1-12.

POMBAL, J.P., JR. \& HADDAD, C.F.B. (1992) Espécies de Phyllomedusa do grupo burmeisteri do Brasil oriental, com descrição de uma espécie nova (Amphibia, Hylidae). Revista Brasileira de Biologia, 52, 217-229.

POMBAL, J.P., JR., HADDAD, C.F.B. \& CRUZ, C.A.G. (2003) New species of Phrynohyas from Atlantic rain forest of southeastern Brazil (Anura, Hylidae). Copeia, 2003, 379383.

POMBAL, J.P., JR. \& IZECKSOHN, E. (2011) Uma nova espécie de Brachycephalus (Anura, Brachycephalidae) do estado do Rio de Janeiro. Papéis Avulsos de Zoologia, 51, 443-451.

POMBAL JR, J.P., CARVALHO JR, R.R., CANELAS, M.A.S. \& BASTOS, R.P. (2010) A new Scinax of the S. catharina species group from Central Brazil (Amphibia: Anura: Hylidae). Zoologia, 27, 795-802.

POMBAL JR, J.P. \& CRUZ, C.A.G. (1999) Redescrição de Eleutherodactylus bolbodactylus (A. Lutz, 1925) e a posição taxonômica de E. gehrti (Miranda-Ribeiro, 1926) (Anura Leptodactylidae). Boletim do Museu Nacional. Nova Serie, Zoologia, 404, 1-10.

POMBAL JR, J.P. \& HADDAD, C.F.B. (1999) Frogs of the genus Paratelmatobius (Anura : Leptodactylidae) with descriptions of two new species. Copeia, 1999, 1014-1026. POMBAL JR, J.P., MENEZES, V.A., FONTES, A.F., NUNES, I. ROCHA, C.F.D. \& VAN SLUYS, M. (2012) A second species of the Casque-headed frog genus Corythomantis (Anura: Hylidae) from Northeastern Brazil, the distribution of $C$. greeningi, and comments on the genus. Boletim do Museu Nacional, 1-14.

POMBAL JR, J.P., SIQUEIRA, C.C., DORIGO, T.A., VRCIBRADIC, D. \& ROCHA, C.F.D. (2008) A third species of the rare frog genus Holoaden (Terrarana, Strabomantidae) from a montane rainforest area of southeastern Brazil. Zootaxa 1938, 61-68

POMBAL JR., J.P. (1999) Oviposição e desenvolvimento de Brachycephalus ephippium (Spix) (Anura, Brachycephalidae). Revista Brasileira de Zoologia, 16, 967976.

PONSSA, M.L., JOWERS, M.J. \& DESA, R.O. (2010) Osteology, natural history notes, and phylogenetic relationships of the poorly known Caribbean frog Leptodactylus nesiotus (Anura, Leptodactylidae). Zootaxa, 1-25.

PONSSA, M.L. \& LAVILLA, E. (2005) Hyla nana (dwarf treefrog). Herpetological Review, 36, 199.

PONTES, R., CARAMASCHI, U. \& POMBAL, J.P. (2014) A Remarkable New Glass Frog (Centrolenidae: Vitreorana) from the Northeast Atlantic Forest, Brazil. Herpetologica 70, 298-308

PONTES, R. \& MATTEDI, C. (2013) An unexpected record o Teratohyla midas (Lynch and Duellman, 1973) for Brazil reveals the presence of glassfrogs in the Brazilian northern lowlands (Anura: Centrolenidae). Check List, 9, 1590-1591.

PONTES, R., MATTEDI, C. \& BAETA, D. (2013) Vocal repertory of Scinax littoreus (Anura: Hylidae) with comments on the advertisement call of the Scinax perpusillus species group. Zoologia, 30, 363-370.

POWELL, R. \& LINDSAY, K. (1999) Gymnophthalmus underwoodi. Herpetological Review, 30, 110

POWELL, R.L., EVERSOLE, C.B., CROCKER, A.V., LIZARRO, D. \& BRAVO, R.C. (2016) Xenopholis werdingorum, Jansen, Álvarez \& Köhler, 2009 (Squamata: Dipsadidae): range extension with comments on distribution. Check List, 12, 13.

PREGILL, G.K. \& BERRIAN, J.E. (1984) Type specimens of amphibians and reptiles in the San Diego Natural Histor Museum. Transactions of the San Diego Society of Natural History, 20, 151-164.

PRIGIONI, C., BORTEIRO, C. \& KOLENC, F. (2011) Amphibia and Reptilia, Quebrada de los Cuervos, Departamento de Treinta y Tres, Uruguay. Check List, 7, 763-767.

PRIGIONI, C., BORTEIRO, C., TEDROS, M. \& KOLENC, F. (2005) Scinax aromothyella. Herpetological Review, 36, 464.

PROCTER, J.B. (1921) On a small Collection of Reptiles and Batrachians made by Mr. Goodfellow in E. Bolivia (1918-19) Annals and Magazine of Natural History, 9, 189-192.

PROCTER, J.B. (1923) On New and Rare Reptiles from South America. Proceedings of the Zoological Society of London, 1923, 1061-1068.

PRODEAGRO. (1998) Distribuição das espécies de lagartos Lista sistemática dos répteis e anfibios de Mato Grosso. Núcleo Interdiciplinar de Estudos Faunísticos, UFMT, Cuiabá, MT. Available from:
PROTAZIO, A.D.S., CAVALCANTI, L.B.Q., MESQUITA, D.O. \& PROTAZIO, A.S. (2011) Scinax auratus (Golden Tree Frog). Herpetological Review, 42, 108.

PRUDENTE, A.L.C., MAGALHÃES, F., MENKS, A. \& SARMENTO, J.F.M. (2013) Checklist of Lizards of the Juruti, state of Pará, Brazil. Check List, 9, 42-50.

PRUDENTE, A.L.C. \& PASSOS, P. (2008) New species of Atractus Wagler, 1828 (Serpentes: Dipsadinae) from Guyana Plateau in northern Brazil. Journal of Herpetology, 42, 723-732.

PRUDENTE, A.L.C. \& PASSOS, P. (2010) New cryptic species of Atractus (Serpentes: Dipsadidae) from Brazilian Amazonia. Copeia, 2010, 397-404.

PRUDENTE, A.L.D.C., DA SILVA, M.A.A., DA ROCHA, W.A. \& FRANCO, F.L. (2008) Morphological variation in Xenoxybelis boulengeri (Procter, 1923) (Serpentes, Xenodontinae, Philodryadini). Zootaxa, 1743, 53-6

PUGLIESE, A., POMBAL, J.P. \& SAZIMA, I. (2004) A new species of Scinax (Anura : Hylidae) from rocky montane fields of the Serra do Cipó, Southeastern Brazil. Zootaxa, 115.

PUORTO, G. \& FERRAREZZI, H. (1993) Uma nova espécie de Phalotris Cope, 1862, com comentários sobre o grupo bilineatus (Serpentes: Colubridae: Xenodontinae) Memorias do Instituto Butantan, 55, 39-46.

PYBURN, W.F. (1975) A new species of microhylid frog of the genus Synapturanus from southeastern Colombia. Herpetologica, 31, 439-443.

PYBURN, W.F. (1977) A New Hylid Frog (Amphibia, Anura, Hylidae) from the Vaupés River of Colombia with Comments on Related Species. Journal of Herpetology, 11 405-410.

PYBURN, W.F. (1981) A new poison-dart frog (Anura: Dendrobatidae) from the forest of southeastern Colombia Proceedings of the Biological Society of Washington, 94, 67 75.

PYRON, R.A., ARTEAGA, A., ECHEVARRÍA, L.Y. \& TORRES CARVAJAL, O. (2016) A revision and key for the tribe Diaphorolepidini (Serpentes: Dipsadidae) and checklist for the genus Synophis. Zootaxa, 4171, 293-320.

PYRON, R.A., GUAYASAMIN, J.M., PENAFIEL, N BUSTAMANTE, L. \& ARTEAGA, A. (2015) Systematics of Nothopsini (Serpentes, Dipsadidae), with a new species of Synophis from the Pacific Andean slopes of southwestern Ecuador. ZooKeys, 109-147.

QUEIROZ, A.N. \& LEMA, T. (1996) Novo registro de Colobosaura mentalis Amaral, 1933, (Sauria; Teiidae) para o nordeste do Brasil. Biociências, 4, 97-90.

QUEZADA, C.L.C., AYERZA, M.S., CONSTANT, P.I., COLLADO, G. \& MENDEZ, M.A. (2008) Amphibia, Anura, Cycloramphidae, Alsodes montanus: new record and geographic distribution map. Check List, 4, 467-471.

QUINTERO-ANGEL, A. \& CARR, J.L. (2010) Lepidoblepharis xanthostigma (Orange-tailed Gecko). Predation. Herpetological Review, 41, 80.

QUINTEROS, A.S. (2012) Taxonomy of the Liolaemus alticolorbibronii Group (Iguania: Liolaemidae), with Descriptions of Two New Species. Herpetologica, 68, 100-120.

QUINTEROS, A.S., VALLADARES, P., SEMHAM, R., ACOSTA, J.L., BARRIONUEVO, S. \& ABDALA, C.S. (2014) A New Species of Liolaemus (Iguania: Liolaemidae) of the alticolor bibronii Group from Northern Chile. South American Journa of Herpetology, 9, 20-29.

RABANAL, F.E. (2010) Amphibia, Anura, Ceratophryidae, Batrachyla nibaldoi Formas, 1997: latitudinal extension in patagonia, southern Chile, and distributional range actualization. Check List, 6, 287-288.

RABANAL, F.E. \& MORENO-PUIG, V. (2014) New distribution records of the critically endangered frog Telmatobufo bullocki Schmidt, 1952 (Anura: Calyptocephalellidae) in southern Chile. Check List, 10, 428-431.

RABANAL, F.E. \& NUNEZ, J.J. (2012) Discovery of a new population of the critically endangered frog Insuetophrynus acarpicus Barrio, 1970 (Anura: Cycloramphidae): latitudina and altitudinal extension in the Valdivian Coastal Range, and altitudinal extension in the Vald

RADA, M. \& GUAYASAMIN, J.M. (2008) Redescripcion de Cochranella megista (Rivero, 1985) y ampliacion de la distribucion de nueve ranas de cristal (Anura: Centrolenidae) en Colombia. Papéis Avulsos de Zoologia 48, 89-101.

RADDI, G. (1823) Continuazione della descrizione dei Rettili Brasiliani. Accademia Nazionale dei Quaranta, Memorie delle Società Italiana Scienze, 19, 58-73.

RAMALHO, W.P., JORGE, R.F. \& FRANÇA, D.P.F.D. (2007) Estrutura preliminar da populacional e distribuição espacia dos réptes do Parque Ecológico Altamiro de Moura Pacheco, p. 149-150. In: 3o Congresso Brasileiro de Herpetologia. HERPETOLOGIA, S.B.D. (ed.). Sociedade Brasileira de Herpetologia, Belém

RAMOS, L.D.O. \& SILVEIRA, A.L. (2011) New records and distribution map of Ecpleopus gaudichaudii (Reptilia, Squamata, Gymnophthalmidae) in southeastern Brazil. Herpetology Notes, 4, 173-176.

REBOUÇAS-SPIEKER, R. (1981a) Sobre uma nova espécie de Mabuya da Amazônia Brasileira (Sauria, Scincidae) Papéis Avulsos de Zoologia, 34, 161-163. 

REBOUÇAS-SPIEKER, R. (1981b) Sobre uma nova espécie de
Mabuya do Nordeste do Brasil (Sauria, Scincidae). Papéis Avulsos de Zoologia, 34, 121-123.

REBOUCAS-SPIEKER, R. \& VANZOLINI, P.E. (1990) Mabuya carvalhoi, espécie nova do estado de Roraima, Brasil (Sauria, Scincidae). Revista Brasileira de Biologia, 50, 377386.

RECODER, R.S. \& NOGUEIRA, C. (2007) Composição e diversidade de répteis na região sul do Parque Nacional Grande Sertão Veredas, Brasil Central. Biota Neotropica, 7 , 267-278.

RECODER, R.S., TEIXEIRA JR, M., CAMACHO, A., NUNES, P.M.S., MOTT, T., VALDUJO, P.H., GHELLERE, J.M.B., NOGUEIRA, C. \& RODRIGUES, M.T. (2011) Répteis da NOGUEIRA, C. \& RODRIGUES, M.T. (2011) Répteis da
Estação Ecológica Serra Geral do Tocantins, Brasil Central. Biota Neotropica, 11, 1-19.

RECODER, R.S., WERNECK, F.D., TEIXEIRA JR, M., COLLI, G.R., SITES JR, J.W. \& RODRIGUES, M.T. (2014) Geographic variation and systematic review of the lizard genus Vanzosaura (Squamata, Gymnophthalmidae), with the description of a new species. Zoological Journal of the Linnean Society, 171, 206-225.

REEDER, T.W. (1996) A new species of Pholidobolus (squamata: Gymnophthalmidae) from the Huancabamb depression of northern Peru. Herpetologica, 52, 282-289.

REINHARDT, J.T. \& LÜTKEN, C.F. (1862) Bidrag til Kundskab om Brasiliens Padder og Krybdyr. Videnskabelige meddelelser fra den Naturhistoriske forening i Kjöbenhavn, 3, 143-242.

REYES-PUIG, J.P., REYES-PUIG, C., PEREZ, M.B. \& YÁNEZMUÑOZ, M.H. (2015) Dos nuevas especies de ranas Pristimantis (Craugastoridae) de la cordillera de los Sacha Llanganatis, vertiente oriental de los Andes de Ecuador. Avances en Ciencias e Ingenierías, Section B, 7, 61-74.

REYES-PUIG, J.P., REYES-PUIG, C., RÁMíREZ-JARAMILLO, S. PÉREZ-L., M.B. \& YÁNEZ-MUÑOZ, M.H. (2014) Tres nuevas especies de ranas terrestres Pristimantis (Anura: Craugastoridae) de la cuenca alta del Río Pastaza, Ecuador. Avances en Ciencias e Ingenierías, Section B, 6, 51-62.

REYES-PUIG, M.M. REYES-PUIG, J.P. \& YÁNEZ-MUÑOZ, M.H. (2013) Ranas terrestres del género Pristimantis (Anura: Craugastoridae) de la Reserva Ecológica Río Zúñag, Tungurahua, Ecuador: Lista anotada y descripción de una especie nueva. Avances en Ciencias e Ingenierías, Section $B$ 5, B5-B13.

RIBEIRO-JR, M.A. (2015a) Catalogue of distribution of lizards (Reptilia: Squamata) from the Brazilian Amazonia. I. Dactyloidae, Hoplocercidae, Iguanidae, Leiosauridae, Dactyloidae, Hoplocercidae, Iguanidae, Leios,

RIBEIRO-JR, M.A. (2015b) Catalogue of distribution of lizards (Reptilia: Squamata) from the Brazilian Amazonia. II. Gekkonidae, Phyllodactylidae, Sphaerodactylidae. Zootaxa 3981, 1-55.

RIBEIRO-JR, M.A., SILVA, M.B. \& LIMA, J.D. (2016) A New Species of Bachia Gray 1845 (Squamata: Gymnophthalmidae) from the Eastern Guiana Shield. Herpetologica, 72, 148-156.

RIBEIRO-JÚNIOR, M.A. \& AMARAL, S. (2016) Catalogue of distribution of lizards (Reptilia: Squamata) from the Brazilian Amazonia. III. Anguidae, Scincidae, Teiidae. 2016, 4205, 401-430.

RIBEIRO, L.B., BRITO, M.D.S., SILVA BARBOSA, L.F., MACHADO PEREIRA, L.C. \& NICOLA, P.A. (2012) Tropidurus cocorobensis Rodrigues, 1987 (Squamata, Tropiduridae): new record and geographic distribution map in new record and geographic distribution map in
northeastern Brazil. Cuadernos de Herpetologia, 26, 63-65.

RIBEIRO, L.B., GOGLIATH, M., RODRIGUES, R.G., BARRETO, R.M.F. \& FREIRE, E.M.X. (2013) Two new records of Coleodactylus meridionalis (Boulenger, 1888) (Squamata, Sphaerodactylidae) in north-eastern Brazil, including a map and comments regarding its geographical distribution Herpetology Notes, 6, 23-27.

RIBEIRO, L.B. \& SOUSA, B.M. (2006) Urostrophus vautieri (NCN). Skin shedding. Herpetological Review, 37, 348.

RIBEIRO, L.F., BORNCHEIN, M.R., BELMONTE-LOPES, R., FIRKOWSKI, C.R., MORATO, S.A.A. \& PIE, M.R. (2015) Seven new microendemic species of Brachycephalus (Anura: Brachycephalidae) fromsouthern Brazil. PeerJ, 135

RIBEIRO, R.S., EGITO, G.T.B.T. \& HADDAD, C.F.B. (2005) Chave de identificação: anfíbios anuros da vertente de Jundiaí da Serra do Japi, Estado de São Paulo. Biota Neotropica, 5, 1Sera.

RIBEIRO, S., CASTRO-MELLO, C. \& NOGUEIRA, C. (2009a) New Species of Anops Bell, 1833 (Squamata, Amphisbaenia) from Jalapão Region in the Brazilian Cerrado. Journal of Herpetology, 43, 21-28.

RIBEIRO, S., GOMES, J.O., SILVA, H.L.R.D., CINTRA, C.E.D. \& SILVA, N.J.D.J. (2016) A new two-pored species of Amphisbaena (Squamata, Amphisbaenidae) from the Brazilian Cerrado, with a key to the two-pored species of Amphisbaena Zootaxa, 4147, 124-142.

RIBEIRO, S., NOGUEIRA, C., CINTRA, C.E.D., SILVA JR, N.J. \& ZAHER, H. (2011) Description of a New Pored Leposternon (Squamata, Amphisbaenidae) from the Brazilian Cerrado. South American Journal of Herpetology, 6, 177-188.
RIBEIRO, S., VAZ-SILVA, W. \& SANTOS JR, A.P. (2008a) NeW pored Leposternon (Squamata, Amphisbaenia) from Brazilian Cerrado. Zootaxa, 1930, 18-38.

RIBEIRO, S.C., FERREIRA, F.S., BRITO, S.V., SANTANA, G.G. VIERA, W.L.S., ALVES, R.R.N. \& ALMEIDA, W.O. (2008b) The squamata fauna of the Chapada do Araripe, Northeastern Brazil. Cadernos de Cultura e Ciência, 1, 6776.

RIBEIRO, S.C., ROBERTO, I.J., SALES, D.L. \& ALMEIDA, W.o (2009b) Distribution extension of Stenocercus squarrosus Nogueira and Rodrigues, 2006 (Reptilia, Squamata, Tropiduridae) in Northeastern Brazil. Biotemas, 22, 165167.

RIGHI, A.F., NASCIMENTO, L.B. \& GALDINO, C.A.B. (2012) Seasonal Reproduction in the Rock Gecko Phyllopezus pollicaris from a Rock Field Habitat in Southeastern Brazil. Journal of Herpetology, 46, 632-636.

RINCÓN, A.A.A., PALLARES, R.F. \& PÉREZ, K.L.S. (2014) Nuevos registros de especies del género Pristimantis (Anura: Craugastoridae) para el nororiente de Colombia. Revista Biodiversidad Neotropical, 4, 162-169.

Ríos ALVEAR, G. \& REYES-PUIG, C. (2016) Reptilia, Sauria, Sphaerodactylidae, Lepidoblepharis conolepis Avila-Pires, 2001: distribution extension in northern Ecuador. Check List, 12, 1-3.

RIVAS, F. \& ROJAS-RUNJAIC, F.J. (2006) Coleodactylus septentrionalis (pygmy gecko). Herpetological Review, 37 106.

RIVAS, G., SCHARGEL, W.E. \& MEIK, J.M. (2005) A new species of Riama (Squamata: Gymnophthalmidae), endemic to the Península de Paria, Venezuela. Herpetologica, 61, 461-468.

IVAS, G A \& FREITAS S, M. (2015) Discovery of the Critically Endangered Golden Tree Frog, Phytotriades auratus (Boulenger, 1917), in Eastern Venezuela, with Comments on its Distribution, Conservation, and Biogeography. Herpetological Review, 46, 153-157.

RIVAS, G.A., NUNES, P.M.S., DIXON, J.R., SCHARGEL, W.E., CAICEDO, J.R., BARROS, T.R., CAMARGO, E.G. \& BARRIOAMOROS, C.L. (2012) Taxonomy, Hemipenial Morphology, and Natural History of Two Poorly Known Species of Anadia (Gymnophthalmidae) from Northern South America. Journal of Herpetology, 46, 33-40.

RIVAS, G.A. \& SCHARGEL, W.E. (2008) Gecko on the rocks: an enigmatic new species of Gonatodes (Sphaerodactylidae) from Inselbergs of the Venezuelan Guayana. Zootaxa, 3950.

RIVAS, G.A., UGUETO, G.N., SCHARGEL, W.E., BARROS, T.R., VELOZO, P. \& ESTHER SANCHEZ, L. (2013) A Distinctive New Species of Gonatodes (Squamata: Sphaerodactylidae) from Isla La Blanquilla, Venezuela, with Remarks on the Distribution of Some Other Caribbean Sphaerodactylid Lizards. South American Journal of Herpetology, 8, 5-18.

RIVERA-CORREA, M. (2010) Amphibia, Centrolenidae Centrolene antioquiense (Noble, 1920): new records and geographical distribution in Colombia. Check List, 6, 220221.

RIVERA-CORREA, M., DUARTE-CUBIDES, F., RUEDAALMONACID, J.V. \& DAZA, J.M. (2013) A new red-eyed treefrog of Agalychnis (Anura: Hylidae: Phyllomedusinae) from middle Magdalena River valley of Colombia with comments on its phylogenetic position. Zootaxa, 3636, 85100.

RIVERA-CORREA, M. \& FAIVOVICH, J. (2013) A New Species of Hyloscirtus (Anura: Hylidae) from Colombia, with a Rediagnosis of Hyloscirtus larinopygion (Duellman, 1973). Herpetologica, 69, 298-313.

RIVERA-CORREA, M., GARCIA-BURNEO, K. \& GRANT, T. (2016a) A new red-eyed of stream treefrog of Hyloscirtus (Anura: Hylidae) from Peru, with comments on the taxonomy of the genus. Zootaxa, 4061, 29-

RIVERA-CORREA, M. \& GUTIERREZ-CARDENAS, P.D.A. (2012) A new highland species of treefrog of the Dendropsophus columbianus group (Anura: Hylidae) from the Andes of Colombia. Zootaxa, 3486, 50-62.

RIVERA-CORREA, M., LAMADRID-FERIS, F. \& CRAWFORD, ANDREW J. (2016b) A new small golden frog of the genus Pristimantis (Anura: Craugastoridae) from an Andean cloud forest of Colombia. Amphibia-Reptilia, 37, 153-166.

RIVERA-CORREA, M. \& ORRICO, V.G.D. (2013) Description and phylogenetic relationships of a new species of treefrog of the Dendropsophus leucophyllatus group (Anura: Hylidae) from the Amazon basin of Colombia and with an exceptional color pattern. Zootaxa, 3686, 447-460.

RIVERO-BLANCO, C. \& SCHARGEL, W.E. (2012) A strikingly polychromatic new species of Gonatodes (Squamata: Sphaerodactylidae) from northern Venezuela. Zootaxa $3518,66-78$

RIVERO, J.A. (1968) A New Species of Elosia (Amphibia, Salientia) from Mt. Duida, Venezuela. American Museum Novitates, 1968, 1-10.

RIVERO, J.A. (1982) Los Eleutherodactylus (Amphibia, Salientia) de los Andes venezolanos. 2. Especies Subparameras. Memoria de la Sociedad de Ciencias Naturales La Salle, 118, 57-132.

ROBERTO, I.J. \& ALBANO, C. (2012) Aspects of the clutch size and oviposition period of Leposoma baturitensis (Squamata: Gymnophthalmidae). Herpetology Notes, 5 445-446.
ROBERTO, I.J., BRITO, L. \& THOMÉ, M.T.C. (2014a) A New Species of Rhinella (Anura: Bufonidae) from Northeastern Brazil. South American Journal of Herpetology, 9, 190-199. ROBERTO, I.J., BRITO, L.B.M. \& ÁVILA, R.W. (2014b) A new six-pored Amphisbaena (Squamata: Amphisbaenidae) from the coastal zone of northeast Brazil. Zootaxa, 3753, 167176

ROBERTO, I.J. \& BRITO, P.T.P. (2004a) Lista preliminar da herpetofauna encontrada no Açude do Castanhão - Nova Jaguaribara - Ceará. In: 1ํ Congresso Brasileiro de Herpetologia. HERPETOLOGIA, S.B.D. (ed.). Sociedade Brasileira de Herpetologia, Curitiba

ROBERTO, I.J. \& BRITO, P.T.P. (2004b) Phyllopezus periosus. Herpetological Review, 35, 409

ROBERTO, I.J., CARDOZO, D. \& AVILA, R.W. (2013) A new species of Pseudopaludicola (Anura, Leiuperidae) from western Piauí State, Northeast Brazil. Zootaxa, 3636, 348360.

ROBERTO, I.J., PINTO, T., MENEZES, B.F., BRITO, L. \& RIBEIRO, S.C. (2012) Mabuya arajara (Arajara Mabuya). Herpetological Review, 43, 618

ROBERTO, I.J., RIBEIRO, S.C., BEZERRA, L. \& CARNEIRO, P.B.D.M. (2011) Amphibia, Anura, Hylidae, Trachycephalus atlas Bokermann, 1966: distribution extension and geographic distribution map. Check List, 7, 326-327.

ROCHA, C.F.D. (1998) Composição e organização d comunidade de répteis da área de Mata Atlântica da região de Linhares, Espírito Santo. Anais do VIII Seminário Regiona de Ecologia, 8, 869-881.

ROCHA, C.F.D., ARAUJO, A.F.B., VRCIBRADIC, D. \& DA COSTA E.M.M. (2000) New Cnemidophorus (Squamata; Teiidae) from coastal Rio de Janeiro State, southeastern Brazil. Copeia, 501-509.

OCHA, C.F.D., MENEZES, V.A., BeRGallo, H.G. \& DUTRA, G.F. (1999) Cnemidophorus nativo (Brazilian whiptail). Herpetological Review, 30, 109

ROCHA, C.F.D., SIQUEIRA, C.C. \& ARLANI, C. (2009) The endemic and threatened lizard Liolaemus lutzae (Squamata: Liolaemidae): current geographic distribution and areas of occurrence with estimated population densities. Zoologia 26, 454-460.

ROCHA, C.F.D. \& VAN SLUYS, M. (2006) New records of reptiles from Ilha Grande Island in Rio de Janeiro State, Brazil. Herpetological Review, 37, 112-114.

ROCHA, C.F.D. \& VRCIBRADIC, D. (2003) Nematode assemblages of some insular anda continental lizard hosts of the genus Mabuya Fitzinger (Reptilia, Scincidae) along the eastern Brazilian coast. Revista Brasileira de Zoologia 20, 755-759.

ROCHA JR, J.C. \& MENTA GIASSON, L.O. (2014) Hypsiboa caingua Carrizo, 1990 (Anura: Hylidae): First record for the State of Santa Catarina, Brazil. Check List, 10, 583-584.

ROCHA, P.C., PEZZUTTI, T.L. \& GARCIA, P.C.A. (2016) Advertisement call of Leptodactylus viridis (Anura: Leptodactylidae) from Minas Gerais, Brazil. Salamandra, 52, 342-344.

ROCHA, W.A., LIMA, C.J.S., CAVALCANTE, V.H.G. RODRIGUES, F.S. \& SANTOS, M.P.D. (2004) Levantamento dos Lagartos, Crocodilianos e Quelônios do Parque Naciona de Sete Cidades, estado do Piauí, Brasil. In: 1 o Congresso Brasileiro de Herpetologia. HERPETOLOGIA, S.B.D. (ed.) Sociedade Brasileira de Herpetologia, Curitiba

RÖDDER, D. \& JUNGFER, K.-H. (2008) A new Pristimantis (Anura, Strabomantidae) from Yuraní-tepui, Venezuela. Zootaxa, 1814, 58-68.

RÖDDER, D. \& SCHLÜTER, A. (2009) Pristimantis minutulus Duellman \& Hedges, 2007 (Anura: Strabomantidae): geographic range extension and colour polymorphism. Salamandra, 45, 53-56.

RODDER, D. \& SCHMITZ, A. (2009) Two new Pristimantis (Anura, Strabomantidae) belonging to the myersi group from the Andean slopes of Ecuador. Revue Suisse de Zoologie, 116, 275-288

RODRIGUES, D.J., NORONHA, J.C., LIMA, M.M. \& ROSA, A.C. (2011) Amphibia, Anura, Hylidae, Phyllomedusa boliviana Boulenger, 1902 and Phyllomedusa camba De la Riva, 2000 Distribution extension in central Brazil. Check List, 7, $397-$ 399

RODRIGUES, F.S., PRUDENTE, A.L.C., BEZERRA, K.C. \& CAVALCANTE, V.H.G. (2007a) Inventário de lagartos anfisbênias (Reptilia, Squamata) em uma área de transição Cerrado-Caatinga no município de Castelo do Piauí, Piauí, Brasil, p. 187. In: 3o Congresso Brasileiro de Herpetologia. HERPETOLOGIA, S.B.D. (ed.). Sociedade Brasileira de Herpetologia, Belém

RODRIGUES, K.C., DELFIM, F.R., CASTRO, C.S.S.P., FRANÇA, F.G.R., LEITE FILHO, E., MESQUITA, D.O., OLIVEIRA, F.A., SANTOS, A.C.A., FERRARI, S.F. \& VALENÇA-MONTENEGRO, M.M. (2013) Strobilurus torquatus Wiegmann, 1834 (Squamata: Tropiduridae): New records from the Brazilian state of Paraíba and a geographic distribution map. Check List, 9, 614-617.

RODRIGUES, M.T. (1980) Descriçao de uma nova espécie de Gonatodes da Amazônia (Sauria, Gekkonidae). Papéis Avulsos de Zoologia, 33, 309-314.

RODRIGUES, M.T. (1984a) Nothobachia ablephara: Novo Gênero e Espécie do Nordeste do Brasil (Sauri, Teiidae). Papéis Avulsos de Zoologia, 35, 361-366. 
RODRIGUES, M.T. (1984b) Uma nova espécie brasileira de Tropidurus com crista dorsal (Sauria, Iguanidae). Papéis Avulsos de Zoologia, 35, 169-175.

RODRIGUES, M.T. (1986a) Um novo Tropidurus com crista dorsal do Brasil com comentarios sôbre suas relaçäes, distribuição e origem (Sauria; Iguanida). Papéis Avulsos de Zoologia, 36, 171-179.

RODRIGUES, M.T. (1986b) Uma nova Espécie do Gênero Phyllopezus de cabaceiras: Paraiba: Brasil; Com comentários sobre a Fauna de lagartos da Área (Sauria Gekkonidae). Papéis Avulsos de Zoologia, 36, 237-250.

RODRIGUES, M.T. (1987) Sistemática, Ecologia e Zoogeografia dos Tropidurus do Grupo torquatus ao Sul do Rio Amazonas (Sauria, Iguanidae). Arquivos de Zoologia, 31, 105-230.

RODRIGUES, M.T. (1988a) Distribution of lizards of the genus Tropidurus in Brazil (Sauria, Iguanidae). In: VANZOLINI, P. \& HEYER, W. (Eds.) Proceedings of a Workshop on Neotropical Distribution Patterns. Academia Brasileira de Ciências, Rio de Janeiro, pp. 305-315.

RODRIGUES, M.T. (1988b) A new anole of the punctatus group from central Amazonia (Sauria, Iguanidae). Papéis Avulsos de Zoologia, 36, 333-336.

RODRIGUES, M.T. (1991a) Herpetofauna das dunas interiores do rio São Francisco: Bahia: Brasil. 1. Introdução à área e descrição de um novo gênero de microteiideos (Calyptommatus) com notas sobre sua ecologia, distribuição e especiação (Sauria, Teiidae). Papéis Avulsos de Zoologia, 37, 285-320.

RODRIGUES, M.T. (1991b) Herpetofauna das dunas interiore do rio São Francisco: Bahia: Brasil. 2. Psilophthalmus: um novo gênero de microteiideos sem pálpebra (Sauria: novo gênero de microteiideos sem pálpebr
Teiidae). Papéis Avulsos de Zoologia, 37, 321-327.

RODRIGUES, M.T. (1991c) Herpetofauna das dunas interiores do rio São Francisco: Bahia: Brasil. 3. Procellosaurinus: um novo gênero de microteiideo sem palpebra, com a redefinição do gênero Gymnophthalmus (Sauria: Teiidae). Papéis Avulsos de Zoologia, 37, 329-342.

RODRIGUES, M.T. (1991d) Herpetofauna das dunas interiores do rio São Francisco: Bahia: Brasil. 4. Uma nova espécie de Typhlops (Ophidia, Typhlopidae). Papéis Avulsos de Zoologia, 37, 343-346.

RODRIGUES, M.T. (1992) Nota sobre o compartamento copulatorio de Anolis fuscoauratus (Sauria, Iguanidade). Boletim de Zoologia, 12, 27-29.

RODRIGUES, M.T. (1996a) Lizards, snakes, and amphisbaenians from the quaternary sand dunes of the middle Rio São Francisco, Bahia, Brazil. Journal of Herpetology, 30, 513-523.

RODRIGUES, M.T. (1996b) A new species of lizard, genus Micrablepharus (Squamata: Gymnophthalmidae), from Brazil. Herpetologica, 52, 535-541.

RODRIGUES, M.T. (1997) A new species of Leposoma (Squamata: Gymnophthalmidae) from the Atlantic forest of Brazil. Herpetologica, 53, 383-389.

RODRIGUES, M.T. (2000) A new species of Mabuya (Squamata: Scincidae) from the semiarid Caatingas of northeastern Brazil. Papéis Avulsos de Zoologia, 41, 313328.

RODRIGUES, M.T. (2002) Herpetofauna of the quaternary sand dunes of the middle Rio São Francisco, Bahia, Brazil. 8 . Amphisbaena arda sp. nov., a fuliginosa-like checkered patterned Amphisbaena (Squamata, Amphisbaenidae). Phyllomedusa, 1, 51-56.

RODRIGUES, M.T. (2003) Herpetofauna da Caatinga. In: LEAL, I.R., TABARELLI, M. \& SILVA, J.M.C. (Eds.) Ecologia e Conservaçao da Caatinga. Universidade Federal de Conservaçao da Caatinga. Uni
Pernambuco, Recife, pp. 181-236.

RODRIGUES, M.T., ANDRADE, G.V. \& LIMA, J.D. (2003) A new species of Amphisbaena (Squamata, Amphisbaenidae) from state of Maranhão, Brazil. Phyllomedusa, 2, 21-26.

RODRIGUES, M.T. \& AVILA-PIRES, T.C.S. (2005) New lizard of the genus Leposoma (Squamata, Gymnophthalmidae) from the lower Rio Negro, Amazonas, Brazil. Journal of Herpetology, 39, 541-546.

RODRIGUES, M.T. \& BORGES, D.M. (1997) A new species of Leposoma (Squamata: Gymnophthalmidae) from a relictual forest in semiarid northeastern Brazil. Herpetologica, 53, 16

RODRIGUES, M.T., CASSIMIRO, J., DE FREITAS, M.A. \& SILVA, T.F.S. (2009a) A new microteiid lizard of the genus Acratosaura (Squamata: Gymnophthalmidae) from Serra do Sincora, State of Bahia, Brazil. Zootaxa, 17-29.

RODRIGUES, M.T., CASSIMIRO, J., PAVAN, D., CURCIO, F.F., VERDADE, V.K. \& PELLEGRINO, K.C.M. (2009b) A New Genus of Microteiid Lizard from the Caparaó Mountains, Southeastern Brazil, with a Discussion of Relationship among Gymnophthalminae (Squamata). American Museum Novitates, 2009, 1-27.

RODRIGUES, M.T., DIXO, M. \& ACCACIO, G.M. (2002a) A large sample of Leposoma (Squamata, Gymnopthalmidae) from the Atlantic Forests of Bahia, the status of Leposoma annectans Ruibal, 1952, and notes on conservatoin. Papéis Avulsos de Zoologia, 45, 103-117.

RODRIGUES, M.T., DIXO, M., PAVAN, D. \& VERDADE, V.K. (2002b) A new species of Leposoma (Squamata, Gymnophthalmidae) from the remnant Atlantic Forests of the state of Bahia, Brazil. Papéis Avulsos de Zoologia, 42, 335-350.
RODRIGUES, M.T., FREIRE, E.M.X., PELLEGRINO, K.C.M. \& SITES, J.W. (2005) Phylogenetic relationships of a new genus and species of microteiid lizard from the Atlantic forest of north-eastern Brazil (Squamata, Gymnophthalmidae). Zoological Journal of the Linnean Society, 144, 543-557.

RODRIGUES, M.T., FREITAS, M.A. \& SILVA, T.F.S. (2009c) New Species of Earless Lizard Genus Heterodactylus (Squamata: Gymnophthalmidae) from the Highlands of Chapada Diamantina, State of Bahia, Brazil. Journal of Herpetology 43, 605-611

RODRIGUES, M.T., FREITAS, M.A., SILVA, T.F.S. \& BERTOLOTTO, C.E.V. (2006) A new species of lizard genus Enyalius (Squamata, Leiosauridae) from the highlands of Chapada Diamantina, state of Bahia, Brazil, with a key to species. Phyllomedusa, 5, 11-24.

RODRIGUES, M.T., KASAHARA, S. \& YONENAGA-YASSUDA, Y (1988) Tropidurus psammonastes: Una nova especie do grupo torquatus com notas sobre seu cariótipo distribuição (Sauria, Iguanidae). Papéis Avulsos de Zoologia 36, 307-313.

RODRIGUES, M.T., PELLEGRINO, H.C.M., DIXO, M., VERDADE, V.K., PAVAN, D., ARGOLO, A.J.S. \& SITES, J.W. (2007b) A new genus of microteiid lizard from the Atlantic forests of state of Bahia, Brazil, with a new generic name for Colobosaura rnentalis, and a discussion of relationships

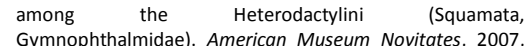
$1-27$.

RODRIGUES, M.T. \& SANTOS, E.M. (2008) A new genus and species of eyelid-less and limb reduced gymnophthalmid lizard from northeastern Brazil (Squamata Gymnophthalmidae). Zootaxa, 1873, 50-60.

RIIGUES, M.T., SILVA, V.X., SKUK, G.O.S. \& PAVAN, D. (2002c) New specimens of Anolis phyllorhinus (Squamata Polychrotidae): the first female of the species and of proboscid anoles. Papéis Avulsos de Zoologia, 42, 363-380. RODRIGUES, M.T., YONENAGAYASSUDA, Y. \& KASAHARA, S. (1989) Notes on the Ecology and Karyotypic Description of Strobilurus torquatus (Sauria, Iguanidae). Revista Brasileira de Genetica, 12, 747-759.

RODRIGUES, M.T., ZAHER, H. \& CURCIO, F.F. (2001) A new species of lizard, genus Calyptommatus, from the caatingas of the state of Piauí, northeastern Brazil (Squamata, Gymnophthalmidae). Papéis Avulsos de Zoologia, 41, 529546

RODRIGUEZ, L. \& MYERS, C.W. (1993) A new poison frog from Manu National Park, southeastern Peru (Dendrobatidae, Epipedobates). American Museum Novitates, 1993, 1-15. RODRIGUEZ, L.B. \& CADLE, J.E. (1990) A preliminary overview of the herpetofauna of Cocha Cashu, Manu National Park, Peru. In: GENTRY, A.H. (Ed.) Four Neotropical rainforests. Yale University Press, New Haven \& London410-425.

RODRIGUEZ, L.O. \& DUELLMAN, W.E. (1994) Guide to the frogs of the Iquitos region, Amazonian Peru. University of Kansas Museum of Natural History Special Publication, 22, ivi, 1-80.

RODRIGUEZ, P.P., QUESADA-MOSQUERA, K. \& MOSQUERA J.T.R. (2013a) Nuevo registro y ampliación de distribución geográfica para Agalychnis psilopygion (Anura: Hylidae: Phyllomedusinae) en el Chocó Biogeográfico de Colombia. Revista Biodiversidad Neotropical, 3, 123-126.

RODRIGUEZ, P.P., RENGIFO-MOSQUERA, J.T. \& ECHAVARRÍARENTERIA, J.D. (2013b) Primer reporte de Dendropsophus bogerti (Anura: Hylidae: Hylinae) en el departamento del Chocó, Colombia. Revista Biodiversidad Neotropical, 3, $127-$ 130

ROJAS-MORALES, J.A., ARIAS-MONSALVE, H.F. \& GONZÁLEZDURÁN, G.A. (2014) Anfíbios y reptiles de la región centrosur del departamento de Caldas, Colombia. Biota Colombiana, 15, 73-93.

ROJAS-RUNJAIC, F.J.M., BARRIO-AMOROS, C.L., MOLINA R, C., SENARIS, J.C. \& FEDON, I.C. (2008) Amphibia, Anura, Hylidae, Scarthyla vigilans: range extensions and new state records from Delta Amacuro and Miranda states, records from Delta Amacuro
Venezuela. Check List, 4, 301-303

ROJAS-RUNJAIC, F.J.M., CASTROVIEJO-FISHER, S. \& BARRIOAMORós, C. (2013) First record of the Amazonian tiny tree toad Amazophrynella minuta (Melin, 1941) (Anura: Bufonidae), for Venezuela. Check List, 9, 1122-1123.

ROJAS-RUNJAIC, F.J.M., DELGADO C., J.A. \& GUAYASAMIN, J.M. (2014) A new rainfrog of the Pristimantis myersi Group (Amphibia, Craugastoridae) from Volcán Pichincha, Ecuador. Zootaxa, 3780, 36-50.

ROJAS-RUNJAIC, F.J.M., FERRER, A., FUENMAYOR, G.A.R. \& MONTERO, Z.A. (2006) Tropidurus hispidus (thornytail lizard). Saurophagy. Herpetological Review, 37, 474

ROJAS-RUNJAIC, F.J.M. \& GUAYASAMIN, J.M. (2015) First record of the rain frog Pristimantis myersi (Goin \& Cochran, 1963) (Anura, Craugastoridae) for Ecuador. Check List, 11 1542.

ROJAS-RUNJAIC, F.J.M., INFANTE-RIVERO, E.E. \& BARRIOAMOROS, C.L. (2011) A new frog of the genus Aromobates (Anura, Dendrobatidae) from Sierra de Períja, Venezuela. Zootaxa, 37-50.

ROJAS-RUNJAIC, F.J.M., INFANTE-RIVERO, E.E. \& CABELLO, P. (2012) New records and distribution extensions of centrolenid frogs for Venezuela. Check List, 8, 819-825.
ROJAS-RUNJAIC, F.J.M., INFANTE-RIVERO, E.E., CABELLO, P. \& VELOZO, P. (2010a) A new non-sexually dichromatic species of the genus Gonatodes (Sauria: Sphaerodactylidae) from Sierra de Perija, Venezuela. Zootaxa, 2671, 1-16.

ROJAS-RUNJAIC, F.J.M., INFANTE-RIVERO, E.E., SENARIS, J.C. \& CABELLO, P. (2010b) Amphibia, Anura, Centrolenidae, Centrolene daidaleum (Ruiz-Carranza and Lynch, 1991): first record for Venezuela, new altitudinal record, and distribution map. Check List, 6, 460-462.

ROJAS-RUNJAIC, F.J.M. \& INFANTE RIVERO, E.E. (2006) Bachio heteropa lineata (worm lizard). Herpetological Review, 37, 106.

ROJAS-RUNJAIC, F.J.M. \& RIVERO, E.E.I. (2009) Redescripción de Gonatodes petersi Donoso-Barros, 1967 (Squamata: Gekkonidae), un tuqueque endémico de la vertiente venezolana de la sierra de Perijá. Memoria de la Fundación La Salle de Ciencias Naturales, 170, 81-98.

ROJAS-RUNJAIC, F.J.M., RIVERO, E.E.I., BARRIO-AMOROS, C.L. \& BLANCO, T.R.B. (2007) New Distributional Records of Amphibians and Reptiles from Estado Zulia in the Maracaibo Basin, Venezuela. Herpetological Review, 38, 235-237.

ROJAS, F. \& INFANTE, E. (2005) Bachia heteropa lineata (NCN). Herpetological Review, 36, 336

OJAS, R.R., CARVALHO, V.T., ÁVILA, R.W., FARIAS, I.P. GORDO, M. \& HRBEK, T. (2015) Two new species of Amazophrynella (Amphibia: Anura: Bufonidae) from Loreto, Peru. Zootaxa, 3946, 79-103.

ROJAS, R.R., CHAPARRO, J., CARVALHO, V., AVILA, R., FARIAS, I., HRBEK, T. \& GORDO, M. (2016) Uncovering the diversity in the Amazophrynella minuta complex: integrative taxonomy reveals a new species of Amazophrynella (Anura, Bufonidae) from southern Peru. ZooKeys, 563, 43-71.

ON, S.R., CANNATELLA, D.C. \& COLOMA, L.A. (2004) Two new species of Physalaemus (Anura: Leptodactylidae) from western Ecuador. Herpetologica, 60, 261-275.

RON, S.R., COLOMA, L.A. \& CANNATELLA, D.C. (2005) A new, cryptic species of Physalaemus (Anura: Leptodactylidae) from western Ecuador with comments on the call structure of the P. pustulosus species group. Herpetologica, 61, 178198

RON, S.R., FRENKEL, C., COLOMA, L.A., FÉLIX-NOVOA, C. QUIGUANGO-UBILLÚS, A. \& VARELA-JARAMILLO, A. (2014) Atelopus exiguus. Museo de Zoología, Pontificia Universidad Católica del Ecuador. Available from http://zoologia.puce.edu.ec/vertebrados/anfíbios/FichaEsp ecie.aspx?ld=1147

RON, S.R., MUESES-CISNEROS, J.J., GUTIÉRREZ-CÁRDENAS, P.D.A., ROJAS-RIVERA, A., LYNCH, R.L., ROCHA, C.F.D. \& GALARZA, G. (2015) Systematics of the endangered toad genus Andinophryne (Anura: Bufonidae): phylogenetic position and synonymy under the genus Rhaebo. Zootaxa 3947, 347-366.

RON, S.R., READ, M. \& PAZMIÑO-ARMIJOS, G. (2012) Dendropsophus gryllatus. Museo de Zoología, Pontificia Universidad Católica del Ecuador. Available from: http://zoologia.puce.edu.ec/vertebrados/anfíbios/FichaEsp ecie.aspx?ld=1287

RON, S.R., TORAL, E., RIVERA, M. \& TERAN-VALDEZ, A. (2010) A new species of Engystomops (Anura: Leiuperidae) from southwestern Ecuador. Zootaxa, 25-49.

RON, S.R., VENEGAS, P.J., MAURICIO ORTEGA-ANDRADE, H. GAGLIARDI-URRUTIA, G. \& SALERNO, P.E. (2016) Systematics of Ecnomiohyla tuberculosa with the description of a new species and comments on the taxonomy of Trachycephalus typhonius (Anura, Hylidae). ZooKeys, 630, 115-154.

RÖSLER, H. \& GLAW, F. (2010) Morphologische Variation und Taxonomie von Hemidactylus brookii Gray, 1845 und Hemidactylus angulatus Hallowell, 1854 sowie phänotypisch ähnlicher Taxa. Spixiana, 33, 139-160

ROSSET, S.D. (2008) New species of Odontophrynus Reinhard and Lutken 1862 (Anura : Neobatrachia) from Brazil and Uruguay. Journal of Herpetology, 42, 134-144.

ROSSET, S.D., FERRARO, D.P. ALCALDE, L. \& BASSO, N.G. (2007) A revision of Odontophrynus barrioi (Anura: Neobatrachia): morphology, osteology, vocalizations, and geographic distribution. South American Journal of Herpetology, 2, 97-106.

ROSSMAN, D.A. (1976) Revision of the South American colubrid snakes of the Helicops pastazae complex Occasional Papers of the Museum of Zoology Louisiana State University, 1-15.

ROSSMAN, D.A. (2010) Morphological variation in the striped water snake Helicops trivittatus (Gray, 1849) (Reptilia: Serpentes: Xenodontidae) of eastern Amazonia. Boletim do Museu Paraense Emilio Goeldi Ciencias Naturais, 5, 271278.

ROZE, J.A. (1953) The Rassenkreis Coluber (Masticophis) mentovarius (Dumeril, Bibron et Dumeril), 1854. Herpetologica, 9, 113-120.

ROZE, J.A. (1958) Los reptiles del Chimantá Tepui (Estado Bolivar, Venezuela) colectados por la expedición botanica del Chicago Natural History Museum. Acta Biologica Venezuelica, 2, 299-314.

ROZE, J.A. (1959) Taxonomic notes on a collection of Venezuelan reptiles in the American Museum of Natura History. American Museum Novitates, 1-14. 
ROZE, J.A. (1969) Una nueva coral falsa del genero Scaphiodontophis (Serpentes: Colubridae) de Colombia. Caldasia, 10, 355-363.

RUANE, S., BRYSON, R.W., PYRON, R.A. \& BURBRINK, F.T. (2014) Coalescent Species Delimitation in Milksnakes (Genus Lampropeltis) and Impacts on Phylogenetic Comparative Analyses. Systematic Biology, 63, 231-250.

RUBIO-ROCHA, L.C., ALZATE, E. \& JIMENEZ, C. (2012) Lepidodactylus lugubris (Mouring Gecko). Herpetological Review, 43, 306.

RUEDA-ALMONACID, J.V. \& CAICEDO, J.R. (2004) Una especie nueva de Anadia (Reptilia: Sauria: Gymnophthalmidae) para el noroccidente de la Cordillera Oriental de Colombia. Revista de la Academia Colombiana de Ciencias Exactas Fisicas y Naturales, 28, 281-284.

RUEDA-ALMONACID, J.V., LYNCH, J.D. \& AMÉZQUITA, A. (2004) Libro Rojo de los Anfíbios de Colombia. Conservation Internetional; Universidad Nacional de Colombia; Ministerio de Ambiente, vivencia y Desarollo Territorial, Bogotá, 384 $\mathrm{pp}$.

RUEDA-SOLANO, L.A., GONZALES, A. \& VARGAS-SALINAS, F. (2016) Pseudis paradoxa (Linnaeus, 1758): Northward extension of the known distribution range in Colombia. Herpetozoa, 28, 192-193.

RUEDA-SOLANO, L.A. \& VARGAS-SALINAS, F. (2014) Cryptobatrachus boulengeri (Boulenger's backpack frog) latitudinal and altitudinal range extension. Herpetotrópicos, 10, 51-52.

RUEDA, J.V. \& WILLIAMS, E.E. (1986) Una nueva espécie de saurio para la Cordillera Oriental de Colombia (Sauria; Iguanidae). Caldasia, 15, 511-524.

RUIBAL, R. (1952) Revisionary studies of some South American teiidae. Bulletin of the Museum of Comparative Zoology, 106, 477-529.

RUIZ-C, P.M. \& LYNCH, J.D. (1982) Dos nuevas especies de Hyla (Amphibia: Anura) de Colombia, con aportes al conocimiento de Hyla bogotensis. Caldasia, 13, 647-671.

RUIZ-CARRANZA, P.M. \& LYNCH, J.D. (1996) Ranas Centrolenidae de Colombia 9. Dos nuevas especies del suroeste de Colombia. Lozania, 68, 1-11.

RUIZ-CARRANZA, P.M. \& LYNCH, J.D. (1998) Ranas Centrolenidae de Colombia XI. Nuevas especies de ranas cristal del genero Hyalinobatrachium. Revista de la Academia Colombiana de Ciencias Exactas fisicas y Naturales, 22, 571-586.

RUTHVEN, A.G. (1916a) Description of a new genus and species of lizard from British Guiana. Occasional Papers of the Museum of Zoology University of Michigan, 1916, 1-4.

RUTHVEN, A.G. (1916b) A new genus and species of lizard from Colombia, with remarks on the genus Prom Colombia, with remarks on the genus Zoology University of Michigan, 1916, 1-4.

RUTHVEN, A.G. (1922) The Amphibians and Reptiles of the Sierra Nevada de Santa Marta, Colombia. Miscellaneous Publications Museum of Zoology University of Michigan, 169.

RUTHVEN, A.G. (1923) The reptiles of the Dutch Leeward Islands. Occasional Papers of the Museum of Zoology, University of Michigan, 1-10.

RUTHVEN, A.G. (1924a) Description of a new lizard of the genus Alopoglossus. Occasional Papers of the Museum of Zoology, University of Michigan, 1-4.

RUTHVEN, A.G. (1924b) The subspecies of Ameiva bifrontata. Occasional Papers of the Museum of Zoology University of Michigan, 155, 1-6.

RUTHVEN, A.G. \& GAIGE, H.T. (1924) A new Leposoma from Panama. Occasional Papers of the Museum of Zoology, University of Michigan, 1-4.

SA, F.P., CANEDO, C., LYRA, M.L. \& HADDAD, C.F.B. (2015) A new species of Hylodes (Anura, Hylodidae) and its secretive underwater breeding behavior. Herpetologica, 71, 58-71

SAITO, E.N., KUNZ, T.S. \& AMBROZIO-ASSIS, A. (2016) Firs record of Rhinella achavali (Maneyro, Arrieta \& de Sá, 2004) in the state of Santa Catarina, southern Brazil (Anura: Bufonidae). Check List, 12, 1887.

SALAZAR-VALENZUELA, D., MARTINS, A., AMADOR-OYOLA, L. \& TORRES-CARVAJAL, O. (2014) A new species and country record of threadsnakes (Serpentes: Leptotyphlopidae: Epictinae) from northern Ecuador. Amphibian and Reptile Conservation, 8, e89, 107-120.

SALES, R.F.D., DE ANDRADE, M.J.M., JORGE, J.D., KOLODIUK, M.F., RIBEIRO, M.M. \& FREIRE, E.M.X. (2015a) Geographic distribution model for Mabuya agmosticha (Squamata: Scincidae) in northeastern Brazil. Zoologia, 32, 71-76.

SALES, R.F.D., JORGE, J.S., MEIRA-RIBEIRO, M. \& FREIRE, E.M.X. (2014) New record of Cercosaura ocellata Wagler, 1830 (Squamata, Gymnophthalmidae) in northeastern Brazil, with a distribution map for the species in South America. Check List, 10, 1531-1534.

SALES, R.F.D., LISBOA, C.M.C.A. \& FREIRE, E.M.X. (2009) Répteis squamata de remanescentes florestais do Campus da Universidade Federal do Rio Grande do Norte, Natal-RN, Brasil. Cuadernos de Herpetologia, 23, 77-88.

SALES, R.F.D., RIBEIRO, L.B. \& FREIRE, E.M.X. (2015b) New record and update on the geographic distribution of Enyalius bilineatus Duméril \& Bibron, 1837 (Squamata: Leiosauridae) in Brazil. Check List, 11, 1-5.
SALLES, R.D.O.L. \& SILVA-SOARES, T. (2010) Répteis do município de Duque de Caxias, Baixada Fluminense, Rio de Janeiro, Sudeste do Brasil. Biotemas, 23, 135-144.

SALLES, R.O.L., WEBER, L.N. \& SILVA-SOARES, T. (2009) Amphibia, Anura, Parque Natural Municipal da Taquara, municipality of Duque de Caxias, state of Rio de Janeiro, southeastern Brazil. Check List, 5, 840-854.

SANAIOTTI, T.M. (2013) Allobates caeruleodactylus. Herpetological Review, 44, 620

SÁNCHEZ-PACHECO, S.J., AGUIRRE-PENAFIEL, V. \& TORRESCARVAJAL, O. (2012) Lizards of the genus Riama (Squamata: Gymnophthalmidae): the diversity in southern ecuador revisited. South American Journal of Herpetology 7, 259-275.

SANCHEZ-PACHECO, S.J., KIZIRIAN, D.A. \& NUNES, P.M.S (2011) A New Species of Riama from Ecuador Previously Referred to as Riama hyposticta (Boulenger, 1902) (Squamata: Gymnophthalmidae). American Museum Novitates, 2011, 1-16

SANCHEZ, D.A. (2010) Larval development and synapomorphies for species groups of Hyloscirtus Paters, 1882 (Anura: Hylidae: Cophomantini). Copeia, 2010, 351363.

SANTA-CRUZ, R., DELGADO, A.J., SALAS, C.Y. \& VON MAY, R. (2016) New distributional records of the Amazon River Frog Lithobates palmipes (Spix, 1824) in Peru. Amphibian and Reptile Conservation, 10, 17-20.

SANTANA, D.J., BARROS, A.B., PONTES, R. \& FEIO, R.N. (2015a) A New Species of Glassfrog Genus Vitreorana (Anura, Centrolenidae) from the Cerrado Domain, Southeastern Brazil. Herpetologica, 71, 289-298.

SANTANA, D.J., COSTA, H.C., DRUMMOND, L.O., FERREIRA, P.L. \& FEIO, R.N. (2009) Amphibia, Anura, Hylidae, Scinax auratus: Distribution extension, new state records, and distribution map. Check List, 5, 246-248.

SANTANA, D.J., DA FONSECA, E.M., NEVES, M.D. \& DE CARVALHO, R.M.H. (2012) A new species of Adelophryne (Anura: Eleutherodactylidae) from the Atlantic Forest, southeastern Brazil. Salamandra, 48, 187-192.

SANTANA, D.J., GAIGA, R., STORTI, L.F., SANTOS, T.G. \& DIXO, M. (2010a) New state record and distribution map of Rhinella cerradensis (Anura, Bufonidae) in the Cerrado biome, Brazil. Herpetology Notes, 3, 55-56.

SANTANA, D.J., MANGIA, S., SILVEIRA-FILHO, R.R., BARROS, L.C.D., ANDRADE, I., NAPOLI, M.F., JUNCA, F. \& GARDA, A.A. (2015b) Anurans from the Middle Jaguaribe River Region, Ceará State, Northeastern Brazil. Biota Neotropica 15 ,

SANTANA, D.J., SÃO PEDRO, V.A., BERNARDE, P.S. \& FEIO, R.N. (2010b) Description of the advertisement call and
sent sexual dimorphism of Proceratophrys concavitympanum Giaretta, Bernarde \& Kokubum, 2000. Papéis Avulsos de Zoologia, 50, 167-174.

ANTANA, D.J., SÃO PEDRO, V.A., HOTE, P.S., ROBERTI, H.M., SANT'ANNA, A.C., FIGUEIREDO-DE-ANDRADE, C.A. \& FEIO, R.N. (2010c) Anurans in the region of the High Muriae River, state of Minas Gerais, Brazil. Herpetology Notes, 3, 110.

SANTANA, D.O., ALMEIDA, R.P.S., CALDAS, F.L.S., DIAS, E.J.R. \& FARIA, R.G. (2016) New records of Trachycephalus mesophaeus (Hensel, 1867) (Anura: Hylidae) from Atlantic Forest in Sergipe state, Brazil. Herpetology Notes, 9, 255260

SANTANA, D.O., FRANCO, S.D.C., ROCHA, S.M., DE FREITAS, E.B., DE-CARVALHO, C.B. \& FARIA, R.G. (2014) First record of Pipa carvalhoi (Miranda-Ribeiro, 1937) (Anura: Pipidae) in the state of Sergipe, northeastern Brazil. Check List, 10, in the state

SANTANA, G.G., VIEIRA, W.L.S., PEREIRA-FILHO, G.A., DELFIM, F.R., LIMA, Y.C.C. \& VIEIRA, K.S. (2008) Herpetofauna em um fragmento de Floresta Atlântica no Estado da Paraíba, Região Nordeste do Brasil. Biotemas, 21 75-84.

SANTO, M.M., AVILA, R.W. \& KAWASHITA-RIBEIRO, R.A. (2011) Checklist of the amphibians and reptiles in Nobres municipality, Mato Grosso state, central Brazil. Herpetology Notes, 4, 455-461.

ANTOS-COSTA, M.C., AVILA-PIRES, T.C.S., PRUDENTE, A.L.C. \& SANTOS, R.M. (2004) Composição, riqueza e abundância de lagartos e anfisbenas (Reptilia: Squamata) coletados em armadilhas de interceptação e queda, floresta de terra firme, Pará. In: 1o Congresso Brasileiro de Herpetologia. HERPETOLOGIA, S.B.D. (ed.). Sociedade Brasileira de Herpetologia, Curitiba

SANTOS-JR, A.P. (2009) Revisão taxonômica do grupo de Taeniophallus occipitalis e o relacionamento filogenético da tribo Echinantherini (Serpentes, Dipsadidae, Xenodontinae). PhD. Faculdade de Biociências, Pontifica Universidade Católica do Rio Grande do Sul, Porto Alegre, $247 \mathrm{pp}$.

SANTOS-JR, A.P.D., FROTA, J.G.D. \& RIBEIRO, F.R.V. (2007) Reptilia, Squamata, Polychrotidae, Anolis nitens tandai distribution extension, new state record, and geographic distribution map. Check List, 3, 9-10.

SANTOS-SILVA, C.R., DE-CARVALHO, C.B. \& FERRARI, S.F. (2012) Amphibia, Anura, Hylidae, Dendropsophus novais (Bokermann, 1968) distribution extension and geographic distribution map. Check List, 8, 499-500.
SANTOS, E.M., NASCIMENTO, V., PEREIRA, E.N. \& AMORIM, F.O. (2016) Physalaemus caete. Herpetological Review, 47 249.

SANTOS, F.J.M., LUZ, V.L.F., PEKA, A.P., FALEIRO JR, S.G. \& PIRES, R.A.P. (2008a) Relação dos Squamata (Reptilia) da área de Proteção Ambiental Meandros do Rio Araguaia, Brasil. Estudos, 35, 401-404.

SANTOS, F.J.M., PEÑA, A.P. \& LUZ, V.L.F. (2008b) Considerações Biogeográficas sobre a Herpetofauna do Submédio e da Foz do Rio São Francisco, Brasil. Estudos, 35 59-78

SANTOS JR, A.P., ABREU, M.L.S. \& FROTA, J.G. (2002) Tropidurus oreadicus. Herpetological Review, 3,66 .

SANTOS, P.S., SILVA, E.T., FELHBERG, B.H.B., SANTOS, M.T.T. \& GARCIA, P.C.A. (2011) Amphibia, Anura, Hylodidae, Megaelosia apuana Pombal, Prado and Canedo, 2003 Distribution extension, new state record and geographic distribution map. Check List, 7, 394-396.

SANTOS, R.C., LUCAS, P.S., SOUSA, B.M. \& NOVELLI, I.A. (2009) Reptilia, Squamata, Leiosauridae, Urostrophus vautieri: Distribution extension and geographic distribution map. Check List, 5, 533-536.

SANTOS, R.M.L., BERTOLOTTO, C.E.V., PELLEGRINO, K.C.M. RODRIGUES, M.T. \& YONENAGA-YASSUDA, Y. (2003) Chromosomal studies on sphaerodactyl lizards of genera Gonatodes and Coleodactylus (Squamata, Gekkonidae) using differential staining and fragile sites analyses. Cytogenetic and Genome Research, 103, 128-134.

SANTOS, R.M.L., RODRIGUES, M.T., YONENAGA-YASSUDA, Y. \& PELLEGRINO, K.C.M. (2008c) Differential staining and microchromosomal variation in karyotypes of four Brazilian species of Tupinambinae lizards (Squamata : Teiidae). Genetica, 134, 261-266.

SANTOS, S.P., IBANEZ, R. \& RON, S.R. (2015) Systematics of the Rhinella margaritifera complex (Anura, Bufonidae) from western Ecuador and Panama with insights in the biogeography of Rhinella alata. ZooKeys, 501, 109-145.

SÃO-PEDRO, V.D.A. \& FEIO, R.N. (2011) Anuran species composition from Serra do Ouro Branco, southernmos Espinhaco Mountain Range, state of Minas Gerais, Brazil. Check List, 7, 671-680.

SAVAGE, J.M. \& CROTHER, B.I. (1989) The Status of Pliocercus and Urotheca (Serpentes, Colubridae), with a Review of Included Species of Coral Snake Mimics. Zoological Journal of the Linnean Society, 95, 335-362.

SAVAGE, J.M. \& MYERS, C.W. (2002) Frogs of the Eleutherodactylus biporcatus group (Leptodactylidae) of Central America and northern South America, including rediscovered, resurrected, and new taxa. American Museum Novitates, 3357, 1-48.

SAVAGE, J.M. \& WATLING, J.I. (2008) Not so rare snakes: a revision of the Geophis sieboldi group (Colubridae: Dipsadinae) in lower Central America and Colombia. Zoological Journal of the Linnean Society, 153, 561-599.

SAWAYA, R.J. \& HADDAD, C.F.B. (2006) Amphibia, Anura, Stereocyclops parkeri: distribution extension, new state record, geographic distribution map. Check List, 2, 74-76.

SAWAYA, R.J., VASCONCELOS, C.H. \& NUNES, R. (1999) Placosoma glabellum (NCN). Reproduction. Herpetological Review, 30, 167.

SAZIMA, I. \& HADDAD, C.F.B. (1992) Répteis da Serra do Japi: Notas sobre história natural. In: MORELLATO, L.P.C. (Ed.) História natural da Serra do Japi: Ecologia e preservação de uma área florestal no sudeste do Brasil. UNICAMP \& FAPESP, Campinas, SP, pp. 212-236.

SAZIMA, I. \& LEONEL, C. (2001) Répteis. In: Fundação Florestal Intervales. Fundação para Conservação e Produção Florestal do Estado de São Paulo, São Paulo, SP, pp. 147157

SCHARGEL, W.E., FUENMAYOR, G.R., BARROS, T.R., PEFAUR, J.E. \& NAVARRETE, L.F. (2007) A new aquatic snak (Colubridae: Pseudoeryx) from the Lake Maracaibo Basin northwestern Venezuela: a relic of the past course of the Orinoco River. Herpetologica, 63, 236-244.

SCHARGEL, W.E., GARCIA-PEREZ, J.E. \& SMITH, E.N. (2002) A new species of Bolitoglossa (Caudata: Plethodontidae) from the Cordillera de Merida, Venezuela. Proceedings of the Biological Society of Washington, 115, 534-542.

SHARGEL, W.E., LAMAR, W.W., PASSOS, P., VALENCIA, J.H. CISNEROS-HEREDIA, D.F. \& CAMPBELL, J.A. (2013) A new giant Atractus (Serpentes: Dipsadidae) from Ecuador, with notes on some other large Amazonian congeners. Zootaxa, 3721, 455-474.

SCHARGEL, W.E., RIVAS, G.A., MAKOWSKY, R., SEÑARIS, J.C. NATERA, M.A., BARROS, T.R., MOLINA, C.R. \& BARRIOAMOROS, C.L. (2010) Phylogenetic systematics of the genus Gonatodes (Squamata: Sphaerodactylidae) in the Guayan region, with description of a new species from Venezuela. Systematics and Biodiversity, 8, 321-339.

SCHETTINO CANELAS, M.A. \& FILOGONIO, R. (2010) Physalaemus aguirrei (Linhares dwarf frog). Herpetological Review, 41, 376

SCHLÜTER, A. \& RÖDDER, D. (2006) Three new frogs of the genus Eleutherodactylus (Amphibia, Leptodactylidae) from Guaiquinima Table Mountain, Bolivar, Venezuela. Herpetotrópicos, 3, 88-99. 
SCHMIDT, K. \& INGER, R. (1951) Amphibians and reptiles of the Hopkins-Branner Expedition to Brazil. Fieldiana, Zoology, 31, 439-465.

SCHMIDT, K.P. (1936) Notes on Brazilian Amphisbaenians. Herpetologica, 1, 28-32.

SCHMIDT, K.P. (1957) Notes on lizards of the genus Dicrodon. Fieldiana Zoology, 39, 65-71.

SCHMIDT, K.P. \& WALKER, W.F. (1943) Snakes of the Peruvian coastal region, by Karl P. Schmidt and Warren F. Walker. Chicago,pp.

SCHULTE, J.A., VALLADARES, J.P. \& LARSON, A. (2003) Phylogenetic relationships within Iguanidae inferred using molecular and morphological data and a phylogenetic taxonomy of iguanian lizards. Herpetologica, 59, 399-419.

SCOLARO, J.A. \& CEI, J.M. (2003) Una excepcional nueva especie de Phymaturus de la precordillera de Chubut, Argentina (Liolaemidae, Iguania, Lacertilia, Reptilia) Facena, 19, 157-163.

SCOLARO, J.A., DE LA CRUZ, F.M. \& IBARGUENGOYTIA, N.R. (2012) A new species of Phymaturus of the patagonicus clade (Squamata, Liolaemidae) from isolated plateau of southwestern Rio Negro Province, Argentina. Zootaxa, 1730.

SCOLARO, J.A., JARA, M. \& PINCHEIRA-DONOSO, D. (2013) The sexual signals of speciation? A new sexually dimorphic Phymaturus species of the patagonicus clade from Patagonia Argentina. Zootaxa, 3722, 317-332

SCOLARO, J.A. \& PINCHEIRA-DONOSO, D. (2010) Lizards at the end of the world: two new species of Phymaturus of the patagonicus clade (Squamata, Liolaemidae) revealed in southern Patagonia of Argentina. Zootaxa, 2393, 17-32.

SCOLARO, J.A. \& TAPPARI, O.F. (2009) Una Nueva Especie de Género Phymaturus del "Grupo Patagonicus" en los Afloramientos Rocosos del Sudoeste de la Provincia de Río Negro, Patagonia Argentina Naturalia patagónica, 4, 80-93.

SCOTT, N.J. \& CACCIALI, P. (2011) Reptilia, Squamata, Teiidae,

Dracaena paraguayensis Amaral, 1950: In Paraguay, Dracaena sí, Crocodilurus no. Check List, 7, 52.

SENA, M.A. (2015) Filogenia e evolução dos Tropidurus do grupo torquatus (Squamata: Tropiduridae). PhD. Zoology, Universidade de São Paulo, São Paulo, 205 pp.

SETZ, E.Z.F. \& KAMIMURA, K.H. (2006) Lista de vertebrados da bacia hidrografica do ribeirão das Anhumas. In: TORRES, R.B., COSTA, M.C., NOGUEIRA, F.P. \& PEREZ-FILHO, A. (Eds.) Recuperação ambiental, participação e poder público: uma experiência em Campinas. Relatório de Pesquisa - Projeto Anhumas. Instituto Agronômico, Governo do Estado de São Paulo200-206.

SHEIL, C.A. \& MENDELSON, J.R. (2001) A new species of Hemiphractus (Anura: Hylidae: Hemiphractinae), and redescription of $H$. johnsoni. Herpetologica, 57, 189-202.

SHEIL, C.A., MENDELSON, J.R. \& SILVA, H.R. (2001) Phylogenetic Relationships of the Species of Neotropica Horned Frogs, Genus Hemiphractus (Anura: Hylidae: Hemiphractinae), Based on Evidence from Morphology. Herpetologica, 57, 203-214.

SILVA-JR, M.F., SOARES FILHO, J.A.R. \& SILVA, M.O. (2008) Fauna de répteis da fazenda Santa Rita, município de Alto Alegre dos Parecis, Rondônia. Ciência \& Consciência, 1

SILVA-SOARES, T., HEPP, F., COSTA, P.N., DE LUNA-DIAS, C. GOMES, M.D.R., CARVALHO E SILVA, S.P. \& DE CARVALHO E SILVA, A.M.P.T. (2010) Anuran Amphibians from RPPN Campo Escoteiro Geraldo Hugo Nunes, Guapimirim Municipality, Rio de Janeiro, Southeastern Brazil. Biota Neotropica, 10, 225-233.

SILVA, A.M.P.T.D.E., DA SILVA, G.R. \& SILVA, S.P.D.E. (2009) A new species of Phasmahyla Cruz, 1990 from the Atlantic Forest in the state of Rio de Janeiro, Brazil (Amphibia, Hylidae, Phyllomedusinae). Zootaxa, 15-26.

SILVA, A.O. \& MOURA, G.J.B. (2013) New record and geographic distribution map of Enyalius bibronii Boulenge 1885 (Squamata: Leiosauridae). Check List, 9, 666-667.

SILVA, C.M. (2006) Filogeografia e diferenciação morfológica das populações de Liolaemus occipitalis Boulenger, 1885 (Iguania: Liolaemidae) ao longo de seu domínio geográfico. pp.

SILVA, D.F.N.D. \& FERREIRA, A. (2007) Comportamento de corte e cópula de Tropidurus torquatus no Cerrado, Mato Grosso, Brasil, p. 84-85. In: 30 Congresso Brasileiro de Herpetologia,. HERPETOLOGIA, S.B.D. (ed.). Sociedade Brasileira de Herpetologia, Belém

SILVA, D.J. (2005) Efeitos da fragmentação sobre a comunidade de lagartos em áreas de floresta estaciona semidecidual submontana no sudoeste de Mato Grosso, Brasil. Thesis. Instituto Nacional de Pesquisas da Amazônia, Manaus, $107 \mathrm{pp}$.

SILVA, E.T., FERREIRA, P.L., SILVA SANTOS, P. \& NEVES FEIO, R. (2011a) Amphibia, Hylidae, Dendropsophus anceps (A. Lutz, 1929) and Itapotihyla langsdorffii (Dumeril and Bibron, 1841): new records for the state of Minas Gerais, Brazil. Check List, 7, 128-130.

SILVA, F.R., PRADO, V.H.M. \& ROSSA-FERES, D.D.C. (2010) Amphibia, Anura, Hylidae, Dendropsophus melanargyreus (Cope, 1887): distribution extension, new state record and geographic distribution map. Check List, 6, 402-404.

SILVA, G.R., BRITO VIEIRA, J. \& ALVES, M.R. (2011b) Amphibia, Anura, Hylidae, Dendropsophus rubicundulus
(Reinhardt and Lutken, 1862): Distribution extension in northeastern Brazil. Check List, 7, 843-844.

SILVA, G.R., LUNA-DIAS, C. \& CARVALHO E SILVA, S.P. (2013a) Amphibia, Anura, Hylidae, Sphaenorhynchus prasinus Bokermann, 1973: First record of the genus and species for the State of Alagoas, Brazil. Check List, 9, 1519-1520.

SILVA, H.R. \& BENMAMAN, P. (2008) Uma nova espécie de Hylodes Fitzinger da Serra da Mantiqueira, Minas Gerais, Brasil (Anura: Hylodidae). Revista Brasileira de Zoologia, 25 89-99.

SILVA, H.R., CARVALHO, A.L.G. \& BITTENCOURT-SILVA, G.B. (2008) Frogs of Marambaia: a naturally isolated Restinga and Atlantic forest remnant of southeastern Brazil. Biota Neotropica, 8, 167-174.

SILVA, H.R. \& OUVERNAY, D. (2012) A new species of streamdwelling frog of the genus Cycloramphus (Anura, Cycloramphidae) from the State of Rio de Janeiro, Brazil. Zootaxa, 49-60.

SILVA JR, N.J., CINTRA, C.E.D., SILVA, H.L.R., COSTA, M.C. SOUZA, C.A., PACHÊCO JR, A.A. \& GONÇALVEZ, F.A. (2009) Herpetofauna, Ponte de Pedra Hydroelectric Power Plant, states of Mato Grosso and Mato Grosso do Sul, Brazil. Check List, 5, 518-525.

SILVA JR, N.J., SILVA, H.L.R., RIBEIRO, R.S., SOUZA, I. \& SOUZA, C.D.A. (2005a) Uma nova espécie do gênero Atractus Wagler, 1928 (Colubridae: Dipsadinae) do Cerrado do Brasil central. Papéis Avulsos de Zoologia, 45, 33-39.

SILVA JR, N.J., SILVA, H.L.R., RODRIGUES, M.T., VALLE, N.C. COSTA, M.C., CASTRO, S.P., LINDER, E.T., JOHANSSON, C. \& SITES JR, J.W. (2005b) A fauna de vertebrados do vale do Alto Rio Tocantins em áreas de usinas hidreletricas. Estudos, 32, 57-101.

SILVA JR., N.J., HAMDAN, B., TONIAL, I., JR., SILVA, H.L.R.D. \& CINTRA, C.E.D. (2012) Hydrodynastes melanogigas Franco, Fernandes and Bentim, 2007 (Squamata: Serpentes: Colubridae): range extension and new state record. Check List, 8, 813-814.

SILVA, M.B. \& AVILA-PIRES, T.C.S. (2013) The genus Cnemidophorus (Squamata: Teiidae) in State of Piauí, northeastern Brazil, with description of a new species. Zootaxa, 3681, 455-477.

SILVA, M.B., LIMA-FILHO, G.R., CRONENBERGER, A.A., CARVALHO, L.S., MANZANI, P.R. \& VIEIRA, J.B. (2013b) Description of the hemipenial morphology of Tupinambis quadrilineatus Manzani and Abe, 1997 (Squamata, Teiidae) and new records from Piauí, Brazil. ZooKeys, 361, 61-72.

SILVA, M.B., ROCHA, W.A. \& PARANHOS, J.D.N. (2007a) Herpetofauna da Fazenda Varjota, estado do Maranhão, Brasil, p. 168-169. In: 30 Congresso Brasileiro de Herpetologia. HERPETOLOGIA, S.B.D. (ed.). Sociedade Brasileira de Herpetologia, Belém

SILVA, M.B., RODRIGUES, v. \& ROCHA, W.A. (2007b) Colobosauroides cearensis. Herpetological Review, 38, 351. SILVA, M.B., RODRIGUES, V. \& ROCHA, W.A. (2007c) Gonatodes humeralis. Herpetological Review, 38, 351.

SILVA, M.C., OLIVEIRA, D.B., OLIVEIRA, H.F., ROBERTO, I.J., MORAIS, D.H., BRITO, S.V. \& AVILA, R.W. (2013c) Geographic distribution of Physalaemus cicada Bokermann 1966 (Anura: Leiuperidae) in Northeastern Brazil. Check List, 9, 1119-1121.

SILVA, M.C., OLIVEIRA, R.H., MORAIS, D.H., KAWASHITARIBEIRO, R.A., BRITO, E.S. \& ÁVILA, R.W. (2015) Amphibians and reptiles of a Cerrado area in Primavera do Leste Municipality, Mato Grosso State, Central Brazil. Salamandra, 51, 187-194.

SILVA, M.O. \& CARDOSO, M.W. (2004) Anfíbios anuros répteis mortos por atropelamento num trecho asfaltado da PR-340, rodovia Antonina-Guaraqueçaba. In: 10 Congresso Brasileiro de Herpetologia. HERPETOLOGIA, S.B.D. (ed.) Sociedade Brasileira de Herpetologia, Curitiba

SILVA, S.T. \& SILVA, U.G. (2004) Composição e ecologia dos répteis Squamata da Reserva Biológica Guaribas, Mamanguape, Paraíba, Brasil. In: 10 Congresso Brasileiro de Herpetologia. HERPETOLOGIA, S.B.D. (ed.). Sociedade Brasileira de Herpetologia, Curitiba

SILVA, U.G. (2008) Diversidade de espécies e ecologia da comunidade de lagartos de um fragmento de Mata Atlântica no Nordeste do Brasil. Doutorado. Universidade Federal do Rio Grande do Norte, Natal, RN1-90 pp.

SILVA, V.X. \& RIBEIRO-JR, M.A. (2004) Levantamento de lagartos do Parque Municipal Manoel Pedro Rodrigues, Alfenas - MG. In: 10 Congresso Brasileiro de Herpetologia. HERPETOLOGIA, S.B.D. (ed.). Sociedade Brasileira de Herpetologia, Curitiba

SILVANO, D.L. \& PIMENTA, B.V.S. (2003) Diversidade Distribuição de Anfíbios na Mata Atlântica do Sul da Bahia. In: PRADO, P.I., LANDAU, E.C., MOURA, R.T., PINTO, L.P.S FONSECA, G.A.B. \& ALGER, K. (Eds.) Corredor de Biodiversidade na Mata Atlântica do Sul da Bahia. ISEB/CI/CABS/UFMG/UNICAMP, Ilhéus,BA, pp. 1-22.

SILVEIRA, A.L. (2009) Reptilia, Squamata, Teiidae, Tupinambis quadrilineatus: Distribution extension and geographic distribution map. Check List, 5, 442-445.

SILVEIRA, A.L., RIBEIRO COSTA, E. \& SALLES, L.M. (2004a) Lystrophis nattereri. Herpetological Review, 35, 412. SILVEIRA, F.L., DUTRA, F.A. \& CHEFFE, M.M. (2004b) Herpetofauna do Cerro das Almas, Capão do Leão, RS. In: 19
Congresso Brasileiro de Herpetologia. HERPETOLOGIA S.B.D. (ed.). Sociedade Brasileira de Herpetologia, Curitiba SILVEIRA, J.M, MIRANDA, C.B. \& AZEVEDO-RAMOS, C. (1998) Neusticurus ecpleopus. Herpetological Review, 29, 51.

SILVERSTONE, P.A. (1975) A revision of the poison - arrow frogs of the genus Dendrobates Wagler. Science Bulletin of the Natural History Museum of Los Angeles County, 1-55.

SIMÕES, P.I. (2007) Colostethus caeruleodactylus (blue-toed rocket frog). Herpetological Review, 38, 473

SIMÕES, P.I. (2016) A new species of nurse-frog (Aromobatidae, Allobates) from the Madeira River basin with a small geographic range. Zootaxa, 4083, 501-525.

SIMÕES, P.I., KAEFER, I.L., GOMES, F.B.R. \& LIMA, A.P. (2012) Distribution extension of Hyalinobatrachium cappellei (van Lidth de Jeude, 1904) (Anura: Centrolenidae) across Central Amazonia. Check List, 8, 636-637.

IMÕES, P.I., KAEFER, I.L. \& LIMA, A.P. (2011) The first record of the rare microhylid Altigius alios Wild, 1995 in Brazil. Herpetology Notes, 4, 141-142.

SIMÕES, P.I., LIMA, A.P. \& FARIAS, I.P. (2010) The description of a cryptic species related to the pan-Amazonian fros Allobates femoralis (Boulenger 1883) (Anura: Aromobatidae). Zootaxa, 2406, 1-28.

SIMOES, P.I., STURARO, M.J., PELOSO, P.L.V. \& LIMA, A.P. (2013) A new diminutive species of Allobates Zimmermann and Zimmermann, 1988 (Anura, Aromobatidae) from the northwestern Rio Madeira-Rio Tapajos interfluve, Amazonas, Brazil. Zootaxa, 3609, 251-273.

SINSCH, U., SALAS, A.W. \& CANALES, V. (1995) Reassessmen of central Peruvian Telmatobiinae (genera Batrachophrynus and Telmatobius). 1. Morphometry and classification. Alytes (Paris), 13, 14-44.

SKUK, G.O.S. (1999) Revisão dos lagartos do complexo Ameiva ameiva (Squamata: Teiidae). Doutorado. Departamento de Zoologia, Instituto de Biociências, Universidade de São Paulopp.

SMITH, H.M., MARTIN, R.L. \& SWAIN, T.A. (1977) A new genus and two new species of South American geckos (Reptilia: Lacertilia). Papéis Avulsos de Zoologia, 30, 195213.

SMITH, P., CACCIALI, P., ATKINSON, K., KÄLLBERG, A. \& PHEASEY, H. (2011) Nuevos registros de Gymnophthalmidae (Reptilia: Sauria) en la Reserva Natural Laguna Blanca, Departamento San Pedro, Paraguay y una clave para las especies Paraguayas. Nótulas Faunisticas, 2011, 1-6.

SOARES, M. \& CARAMASCHI, U. (1998) A new species of Colobosauroides Cunha, Lima-Verde \& Lima, 1991 from the state of Bahia, Brazil (Squamata, Sauria, Gymnophthalmidae). Boletim do Museu Nacional, Nova Série - Zoologia, 388, 1-8.

SOBRINHO, P.M.M., SANTOS, E.G.S., MELO, V.L., SANTOS, E.M. \& MOURA, G.J.B. (2016) First Record of Macrogenioglottus alipioi Carvalho, 1964 (Amphibia: Anura) for the state of Pernambuco, Brazil. Herpetology Notes, 9 103-104.

SOTO-AZAT, C., VALENZUELA-SÁNCHEZ, A., COLlen, B. ROWCLIFFE, J.M., VELOSO, A. \& CUNNINGHAM, A.A. (2013) The Population Decline and Extinction of Darwin's Frogs. PLOS ONE, 8, e66957.

SOUSA, B.M., CRUZ, C.A.G., CARVALHO, R.M.H. \& SILVA, M.N. (2000) Description of the shedding skin process in Enyalius perditus Jackson (Reptilia, Sauria, Polychrotidae). Revista Brasileira de Zoologia, 17, 225-228.

SOUSA, B.M. \& DA CRUZ, C.A.G. (2000) Echinanthera affinis (NCN). Diet. Herpetological Review, 31, 178.

SOUSA, B.M., RESGALLA DO NASCIMENTO, A.E., GOMIDES, S.C., VARELA RIOS, C.H., HUDSON, A.D.A. \& NOVELLI, I.A. (2010) Reptiles in fragments of Cerrado and Atlantic Forest at the Campo das Vertentes, Minas Gerais State, Southeastern Brazil. Biota Neotropica, 10, 129-138.

SOUSA, J.C., CORRÊA, J.G., FRANÇA, P.F., COSTA-CAMPOS, C.E., LIMA, J.R.F. \& LIMA, J.D. (2016) Scarthyla goinorum. Herpetological Review, 47, 421.

SOUSA, P.A.G. \& FREIRE, E.M.X. (2008) Kentropyx calcarata. Herpetological Review, 39, 238.

SOUZA FILHO, G.A. (2011) Urostrophus vautieri Dumeril and Bibron, 1837 (Reptilia: Squamata: Sauria: Leiosauridae): Distribution extension, Parana, Brazil. Check List, 7, 876877.

SOUZA FILHO, G.A. (2013) Cnemidophorus vacariensis Feltrim and Lema, 2000 (Squamata: Teiidae): A new record for the state of Paraná, southern Brazil. Check List, 9, 1564-1566.

SOUZA FILHO, G.A., PLOMBON, L.L. \& CAPELA, D.J.V. (2015) Reptiles of the Complexo Energético Fundão-Santa Clara, central-south region of Paraná state, southern Brazil. Check List, 11, 1-6.

SOUZA FILHO, G.A. \& VERRASTRO, L. (2012) Reptiles of the Parque Estadual de Itapuã, state of Rio Grande do Sul, southern Brazil. Check List, 8, 847-851.

SOUZA, F.L., UETANABARO, M., LANDGREF FILHO, P., PIATTI,

L. \& PRADO, C.P.A. (2010) Herpetofauna, municipality of Porto Murtinho, Chaco region, state of Mato Grosso do Sul, Brazil. Check List, 6, 470-475.

SOUZA, I.F., SILVA, W.V. \& DA SILVA JUNIOR, N.J. (2002) Tropidurus torquatus (calango). Herpetological Review, 33 149 
SPECIESLINK. (2016) Rede SpeciesLink. Centro de Referência em Informação Ambiental (CRIA), Fundação de Amparo Pesquisa do Estado de São Paulo (FAPESP). Available from: http://www.splink.org.br/ (26 March 2016).

SPIX J.B.V. (1825) Animalia nova, sive, Species novae lacertarum quas in itinere per Brasliliam annis MDCCCXVIIMDCCCXX jussu et auspiciis Maximilani Josephi I. Bavaria regis. Typis Francisci Seraphici Hübschmanni, Monachii, 26 pp.

STEINBACH-PADILHA, G.C. (2008) A new species of Melanophryniscus (Anura, Bufonidae) from the Campos Gerais region of southern Brazil. Phyllomedusa, 7, 99-108.

STEINDACHNER, F. (1867) Reise der österreichischen Fregatte Novara um die Erde in den Jahren 1857, 1858, 1859 unter den Bafehlen des Commodore B. von Wüllerstorf-Urbair. Zologischer Theil. 1. Amphibien. Kaiserlich-Königlichen Hofund Staatsdruckerei, Wien, $70 \mathrm{pp}$

STEINDACHNER, F. (1891) Über neue und seltene Lacertiden aus den herpetologischen Sammlungen des k. k. naturhistorischen Hofmuseums. Annalen

STEJNEGER, L. (1909) Batrachians and Reptiles, Part II. In SCOTT, W.B. (Ed.) Reports of the Princeton University Expeditions to Patagonia, 1896-1899, Vol 3, Part 1. Princeton University, Stuugart, pp. 211-224.

STETSON, R.E. (1999) Hyla sanborni Schmidt, 1944 (Anura, Hylidae). Primera cita para las provincias de Chaco Formosa, Argentina. Cuadernos de Herpetologia, 13, 103.

STETSON, R.E., BENITEZ, P. \& PIVIDORI, N. (1996) Ampliacion de la distribucion geografica de Hyla sanborni Schmidt 1944 (Anura: Hylidae). Primera cita para la provincia de 1944 (Anura: Hylidae). Primera cita para la provir

STEVAUX, M.N. (2002) A new species of Bufo Laurenti (Anura, Bufonidae) from northeastern Brazil. Revista Brasileira de Zoologia, 19, 235-242.

STRAHM, M.H. \& SCHWARTZ, A. (1977) Osteoderms in the Anguid Lizard Subfamily Diploglossinae and Their Taxonomic Importance. Biotropica, 9, 58-72.

STRAUCH, A. (1881) Bemerkungen über die Eidechsenfamilie der Amphisbaeniden. Mélanges biologiques tirés du Bulletin physico-mathématique de l'Académie impériale des sciences de Saint-Pétersbourg, 11, 355-479.

STRÜSSMANN, C. \& CARVALHO, M.A. (1998) New herpetological records for the state of Mato Grosso, western Brazil. Herpetological Review, 29, 183-185.

STRÜSSMANN, C. \& CARVALHO, M.A. (2001) Two new species of Cercolophia Vanzolini, 1992 from the state of Mato Grosso, western Brazil (Reptilia, Amphisbaenia, Amphisbaenidae). Museo Regionale di Scienze Natural Bollettino, 18, 487-505.

STRÜSSMANN, C. \& MOTT, T. (2009) Sympatric mphisbaenids from Manso Dam region, Mato Grosso tate, Western Brazil, with the description of a new two pored species of Amphisbaena (Squamata, Amphisbaenidae). Studies on Neotropical Fauna and Environment, 44, 37-46.

STURARO, M.J. \& AVILA-PIRES, T.C.S. (2011) Taxonomic revision of the geckos of the Gonatodes concinnatus complex (Squamata: Sphaerodactylidae), with description of two new species. Zootaxa, 2869, 1-36.

STURARO, M.J. \& PELOSO, P.L.V. (2014) A new species of Scinax Wagler, 1830 (Anura: Hylidae) from the middle Amazon River basin, Brazil. Papéis Avulsos de Zoologia, 54 $9-23$.

SUAREZ, A.P.M.S., ZAHER, H., KLACZKO, J., NUNES, P.M.S., MASIERO, R.L. \& MATIAZZI, W. (2005) Herpetofauna d Estação Ecológica de Bananal, Serra da Bocaina, BananalSP. In: 2o Congresso Brasileiro de Herpetologia. HERPETOLOGIA, S.B.D. (ed.). Sociedade Brasileira de Herpetologia, Belo Horizonte

SUGAI, J.L.M.M., FAGGIONI, G.P., PIATTI, L., LEMOS, A.A SOUZA, F.L. \& PRADO, C.P.A. (2013) Lepidobatrachus asper Budgett,1899 (Amphibia: Anura: Ceratophryidae): New country record, distribution map and natural history notes. Check List, 9, 133-135.

SUGAI, J.L.M.M., SOUZA, F.L., LANDGREF FILHO, P. \& SCZESNY-MORAES, E.A. (2014) Rhinella scitula (Caramasch \& Niemeyer, 2003) (Amphibia: Anura: Bufonidae): New distribution records. Check List, 10, 694-696.

SULLIVAN, J. (2016) Dendropsophus haraldschultzi - Manylined Treefrog. WildHerps. Available from: http://www.wildherps.com/species/D.haraldschultzi.html

SZÉKELY, P., ARMIJOS-OJEDA, D., ORDÓÑEZ-DELGADO, L., SZÉKELY, D. \& COGĂLNICEANU, D. (2016a) Amphibia Anura, Bufonidae, Rhaebo ecuadorensis Mueses-Cisneros, Cisneros-Heredia \& McDiarmid, 2012, and Anura, Hylidae, Phyllomedusa tarsius (Cope, 1868): range extensions an first records for Zamora-Chinchipe province, Ecuador. Check List, 12, 1-5.

SZÉKELY, P., COGĂLNICEANU, D., SZÉKELY, D., PAEZ, N. \& RON, S. (2016b) A new species of Pristimantis from southern Ecuador (Anura, Craugastoridae). ZooKeys, 606, 77-97.

TARGINO, M. \& CARVALHO-E-SILVA, S.P. (2008) Redescrição de Ischnocnema holti (Amphibia: Anura: Brachycephalidae). Revista Brasileira de Zoologia, 25, 716-723.

ARGINO, M., COSTA, P.N. \& CARVALHO-E-SILVA, S.P. (2009) Two New Species of the Ischnocnema lactea Species Serie from Itatiaia Highlands, Southeastern Brazil (Amphibia, Anura, Brachycephalidae). South American Journal of Herpetology, 4, 139-150.

TARGINO, M. \& POMBAL, J.P., JR. (2011) Redescription and variation of Hyophryne histrio Carvalho, 1954, an enigmatic microhylid frog from the Atlantic Rainforest of Brazil. Amphibia-Reptilia, 32, 465-475.

TAUCCE, P.P.G., LEITE, F.S.F., SANTOS, P.S., FEIO, R.N. \& GARCIA, P.C.A. (2012) The advertisement call, color patterns and distribution of Ischnocnema izecksohni Caramaschi and Kisteumacher, 1989) (Anura, Brachycephalidae). Papeis Avulsos de Zoologia (Sao Paulo), $52,112-120$

TAYLOR, E.H. (1968) The Caecilians of the World: A Taxonomic Review. University of Kansas Press, Lawrence, 848 pp. TAYLOR, E.H. (1973) A caecilian miscellany. Kansas University Science Bulletin, 50, 187-231.

TAYLOR, E.H. \& PETERS, J.A. (1974) The Caecilians of Ecuador. University of Kansas Science Bulletin, 50, 333-346.

TEDESCO, M.E. (1998) Una nueva especie de Pantodactylus (Squamata, Gymnophthalmaidae) de la provincia de Corrientes, República Argentina. Facena, 14, 53-62.

TEDESCO, M.E. \& AGUIRRE, R.H. (1998) Cercosaura ocellata petersi Ruibal, 1952 (Squamata, Gymnophthalmidae). Nuevo registro para la lacertofauna de la Republica Argentina. Cuadernos de Herpetologia, 12, 53.

EIXEIRA, A.A.M., ROBERTO, I.J., OLIVEIRA, H.F., SOUSA, J.G.G., FREITAS, F.R.V. \& ÁVILA, R.W. (2013) Phloem sap feeding in Lygodactylus klugei (Squamata: Gekkonidae) in northeastern Brazil. Herpetology Notes, 6, 545-547.

TEIXEIRA, B.F.V. \& GIARETTA, A.A. (2015) Setting a fundament for taxonomy: advertisement calls from the type localities of three species of the Dendropsophus rubicundulus group (Anura: Hylidae). Salamandra, 51, 137-146.

TEIXEIRA JR, M., AMARO, R.C., RECODER, R.S., DAL VECHIO, F. \& RODRIGUES, M.T. (2012a) A new dwarf species of Proceratophrys Miranda-Ribeiro, 1920 (Anura, Cycloramphidae) from the highlands of Chapada Diamantina, Bahia, Brazil. Zootaxa, 3551, 25-42.

TEIXEIRA JR, M., AMARO, R.C., RECODER, R.S., DE SENA, M.A. \& RODRIGUES, M.T. (2012b) A relict new species of Oreobates (Anura, Strabomantidae) from the Seasonally Dry Tropical Forests of Minas Gerais, Brazil, and its implication to the biogeography of the genus and that of South American Dry Forests. Zootaxa, 3158, 37-52.

TEIXEIRA JR, M., DAL VECHIO, F., MOLLO-NETO, A. \& RODRIGUES, M.T. (2014) A New Two-Pored Amphisbaena Linnaeus, 1758, from Western Amazonia, Brazi (Amphisbaenia: Reptilia). South American Journal of Herpetology, 9, 62-74.

TEIXEIRA JR, M., DAL VECHIO, F., NUNES, P.M.S., MOLLONETO, A., LOBO, L.M., STORTI, L.F., GAIGA, R.A.J., DIAS, P.H.F. \& RODRIGUES, M.T. (2013a) A new species of Bachio Gray, 1845 (Squamata: Gymnophthalmidae) from the western Brazilian Amazonia. Zootaxa, 3636, 401-420.

TEIXEIRA JR, M., DAL VECHIO, F., RECODER, R.S., CARNAVAL, A.C., STRANGAS, M., DAMASCENO, R., SENA, M.A. \& RODRIGUES, M.T. (2012c) Two new species of marsupia tree-frogs genus Gastrotheca Fitzinger, 1843 (Anura, Hemiphractidae) from the Brazilian Atlantic Forest. Zootaxa, 3437, 1-23.

TEIXEIRA JR, M., PRATES, I., SILVA-MARTINS, N.S STRÜSSMANN, C. \& RODRIGUES, M.T. (2015) Molecular data reveal spatial and temporal patterns of diversification and a cryptic new species of lowland Stenocercus Duméril \& Bibron, 1837 (Squamata: Tropiduridae). Molecular Phylogenetics and Evolution, 94, 410-423.

TEIXEIRA JR, M., RECODER, R.S., AMARO, R.C., DAMASCENO, R.P., CASSIMIRO, J. \& RODRIGUES, M.T. (2013b) A new Crossodactylodes Cochran, 1938 (Anura: Leptodactylidae: Paratelmatobiinae) from the highlands of the Atlantic Forests of southern Bahia, Brazil. Zootaxa, 3702, 459-472.

TEIXEIRA JR, M., RECODER, R.S., CAMACHO, A., SENA, M.A., NAVAS, C.A. \& RODRIGUES, M.T. (2013c) A new species of Bachia Gray, 1845 (Squamata: Gymnophthalmidae) from the Eastern Brazilian Cerrado, and data on its ecology, physiology and behavior. Zootaxa, 3616, 173-189.

TEIXEIRA, R.L. (2001) Comunidade de lagartos da restinga de Guriri, São Mateus-ES sudeste do Brasil. Atlantica, 23, 7784.

TEIXEIRA, R.L. \& GIOVANELLI, M. (1999) Ecology of Tropidurus torquatus (Sauria: Tropiduridae) of a sandy coastal plain of Guriri, São Mateus, ES, southeastern Brazil. Revisto Brasileira de Biologia, 59, 11-18.

TERÁN-VALDEZ, A. \& GUAYASAMIN, J.M. (2010) The smalles terrestrial vertebrate of Ecuador: A new frog of the genus Pristimantis (Amphibia: Strabomantidae) from the Cordillera del Cóndor. Zootaxa, 53-68.

TEST, F.H., SEXTON, O.J. \& HEATWOLE, H.A.R.O. (1966) Reptiles of Rancho Grande and vicinity, Estado Aragua, Venezuela. Miscellaneous Publications of the Museum of Zoology, University of Michigan, 128, 1-63.

THOMAS, R.A. (1976) A revision of the South American colubrid snake genus Philodryas Wagler, 1830. PhD Thesis. Graduate College of Texas A \& M University378 pp. THOMAS, R.A., BERNILS, R.S., MOURA-LEITE, J.C. \& MORATO, S.A.A. (2006) Redescription of Ditaxodon taeniatus (Hensel, elationships, and distribution. South American Journal of Herpetology, 1, 94-101.

THOMASSEN, H., COSTA, H.C., SILVEIRA, A.L., GARCIA, P.C.A \& BÉRNILS, R.S. (2015) First records of the snake Siphlophis leucocephalus (Günther, 1863) in Minas Gerais, Brazil, and a review of the geographic distribution of $S$. Iongicaudatus (Andersson, 1901) (Squamata: Dipsadidae). Check List, 11 1-10.

THOMÉ, M.T.C. (2006) Diversidade de anuros e lagartos em fisionomias de Cerrado na região de Itirapina, Sudeste do Brasil. Mestrado. Instituto de Biociências da Universidade de São Paulo, São Paulo, SP1-60 pp.

THOMÉ, M.T.C. SEQUEIRA, F., BRUSQUETTI, F., CARSTENS, B., HADDAD, C.F.B., RODRIGUES, M.T. \& ALEXANDRINO, J. (2016) Recurrent connections between Amazon and Atlantic forests shaped diversity in Caatinga four-eyed frogs. Journal of Biogeography, n/a-n/a.

THOMÉ, M.T.C., ZAMUDIO, K.R., GIOVANELLI, J.G.R. HADDAD, C.F.B., BALDISSERA JR, F.A. \& ALEXANDRINO, J. (2010) Phylogeography of endemic toads and post-Pliocen persistence of the Brazilian Atlantic Forest. Molecula Phylogenetics and Evolution, 55, 1018-1031.

THOMÉ, M.T.C., ZAMUDIO, K.R., HADDAD, C.F.B. \& ALEXANDRINO, J. (2012) Delimiting genetic units in Neotropical toads under incomplete lineage sorting and hybridization. BMC Evolutionary Biology, 12,

TIBURCIO, I.C.S., LISBOA, B.S. \& ARAUJA-VIEIRA, K. (2016) Xenopholis undulatus. Herpetological Review, 47, 266.

TINÔCO, M.S., RIBEIRO, H.C.B. \& DIAS, M.A. (2010) The Bahian Sand Dunes Whiptail Lizard Cnemidophorus abaetensis Dias, Rocha \& Vrcibradic 2002 (Reptilia, Scleroglossa, Teiidae), geographic distribution and habitat use in Bahia, Brazil. Herpetological Bulletin, 2010, 19-24.

TOLEDO, L.F., SIQUEIRA, S., DUARTE, T.C., VEIGA MENONCELLO, A.C.P., RECCO-PIMENTEL, S.M. \& HADDAD, C.F.B. (2010) Description of a new species of Pseudopaludicola Miranda-Ribeiro, 1926 from the state of São Paulo, Southeastern Brazil (Anura, Leiuperidae). Zootaxa, 2496, 38-48.

TOLLEDO, J OLIVEIRA, E.F., FEIO, R.N. \& WEBER, L.N. (2009) Amphibia, Anura, Leiuperidae, Physalaemus jordanensis Bokermann, 1967: Distribution extension and geographic distribution map. Check List, 5, 422-424.

ONINI, J.F.R., CARÃO, L.M., PINTO, I.S., GASPARINI, J.L. LEITE, Y.L.R. \& COSTA, L.P. (2010) Non-volant tetrapods from Reserva Biológica de Duas Bocas, State of Espírito Santo, Southeastern Brazil. Biota Neotropica, 10, 339-351.

TORRES-CARVAJAL, O. (2004) Stenocercus azureus (NCN). Reproduction. Herpetological Review, 35, 172.

TORRES-CARVAJAL, O. (2005) A new species of Stenocercus (Squamata, Iguania) from central-western Brazil with a key to Brazilian Stenocercus. Phyllomedusa, 4, 123-132.

TORRES-CARVAJAL, O. (2007) A taxonomic revision of South American Stenocercus (Squamata: Iguania) lizards. Herpetological Monographs, 21, 76-178.

TORRES-CARVAJAL, O., CARVAJAL-CAMPOS, A., BARNES, C.W., NICHOLLS, G. \& POZO-ANDRADE, M.J. (2013a) A New Andean Species of Leaf-toed Gecko (Phyllodactylidae: Phyllodactylus) from Ecuador Journal of Herpetology, 47 384-390.

ORRES-CARVAJAL, O., ECHEVARRIA, L.Y., VENEGAS, P.J. CHAVEZ, G. \& CAMPER, J.D. (2015a) Description and phylogeny of three new species of Synophis (Colubridae, Dipsadinae) from the tropical Andes in Ecuador and Peru. ZooKeys, 153-179.

TORRES-CARVAJAL, O., ETHERIDGE, R. \& DE QUEIROZ, K. (2011) A systematic revision of Neotropical lizards in the clade Hoplocercinae (Squamata: Iguania). Zootaxa, 1-44.

ORRES-CARVAJAL, O., GAONA, F.P., ZARAGOZA, C. \& SZÉKELY, P. (2015b) First record of Macropholidus ruthven Noble 1921 (Squamata: Gymnophthalmidae) from Ecuador. Herpetology Notes, 8, 25-26.

TORRES-CARVAJAL, O. \& LOBOS, S.E. (2014) A new species of Alopoglossus lizard (Squamata, Gymnophthalmidae) from the tropical Andes, with a molecular phylogeny of the genus. ZooKeys, 2014, 105-120.

TORRES-CARVAJAL, O, LOBOS, S.E., VENEGAS, P.J., CHÁVEZ, G., AGUIRRE-PEÑAFIEL, V., ZURITA, D. \& ECHEVARRÍA, LY. (2016) Phylogeny and biogeography of the most diverse clade of South American gymnophthalmid lizards (Squamata, Gymnophthalmidae, Cercosaurinae). Molecular Phylogenetics and Evolution, 99, 63-75.

TORRES-CARVAJAL, O. \& MAFLA-ENDARA, P. (2013) Evolutionary history of Andean Pholidobolus and Macropholidus (Squamata: Gymnophthalmidae) lizards. Molecular Phylogenetics and Evolution, 68, 212-217.

ORRES-CARVAJAL, O., SALAZAR-VALENZUELA, D. \& MERINO VITERI, A. (2013b) ReptiliaWebEcuador. Versión 2013.1 Museo de Zoología QCAZ, Pontificia Universidad Católica del Ecuador Museo de Zoología QCAZ, Pontificia Universidad Católica del Ecuador. Available from http://zoologia.puce.edu.ec/Vertebrados/reptiles/reptilesE cuador

TORRES-CARVAJAL, O., SCHULTE, J.A. \& CADLE, J.E. (2006) Phylogenetic relationships of South American lizards of the genus Stenocercus (Squamata : Iguania): A new approach using a general mixture model for gene sequence data. Molecular Phylogenetics and Evolution, 39, 171-185. 
torRes-CARVAJAL, O., Venegas, P.J. \& DE QUEIROZ, K. (2015c) Three new species of woodlizards (Hoplocercinae, Enyalioides) from northwestern South America. Zookeys, 107-132.

TORRES-GASTELLO, C.P., SUAREZ-SEGOVIA, J. \& CISNEROSHEREDIA, D.F. (2007) Cochranella erminea, a new species of Centrolenidae (Amphibia: Anura: Athesphatanura) from Amazonian Peru. Journal of the National Museum Prague Natural History Series, 176, 1-12.

TORRES-PEREZ, F., GOMEZ-LOBO F, D. \& GARIN, C. (2005) Liolaemus nigroviridis (black-green tree iguana). Herpetological Review, 36, 80

TORTATO, M.A. \& CAMPBELL-THOMPSON, E.R. (2006) Ocupação de caixas de nidificação por vertebrados de pequeno porte em área de Floresta Atlântica no sul do Brasil, e sua viabilidade de uso. Biotemas, 19, 67-75.

TRAJANO, E. \& GHIRINGHELLO, A. (1978) Comparação entre as proporções corporais de Iguana $i$. iguana da região das caatingas e da hiléia amazônica(Sauria, Iguanidae). Papéis Avulsos de Zoologia, 32, 107-115.

TREIN, F.L., LIMA, L.P., ULANDOWSKI, L.K.A. \& MORATO, S.A.A. (2014) Pleurodema bibroni Tschudi, 1838 (Anura: Leiuperidae): Distribution extension and first record for the state of Parana, Brazil. Check List, 10, 417-418.

TRONCOSO-PALACIOS, J. (2011) Liolaemus pseudolemniscatus Lamborot and Ortiz, 1990 (Squamata: Liolaemidae) Distribution extension in Central Chile. Check List, 7, 849851.

TRONCOSO-PALACIOS, J. (2013) Revisión del estatus taxonómico de Liolaemus donosoi Ortiz, 1975 (Iguania: Liolaemidae). Boletín del Museo Nacional de Historia Natural, 62, 119-127.

TRONCOSO-PALACIOS, J. (2014) Revision of the geographic distribution of three species of the montanus group of Liolaemus Wiegmann, 1834 (Reptilia: Squamata: Liolaemidae). Check List, 10, 221-229.

TRONCOSO-PALACIOS, J., DIAZ, H.A., ESQUERRE, D. \& URRA, F.A. (2015a) Two new species of the Liolaemus elongatuskriegi complex (Iguania, Liolaemidae) from Andean highlands of southern Chile. ZooKeys, 83-109.

TRONCOSO-PALACIOS, J. \& ESQUERRÉ, D. (2014) A new species of Phymaturus of the P. mallimaccii Group from the Andes of central Chile (Iguania: Liolaemidae) Phyllomedusa, 13, 3-15.

TRONCOSO-PALACIOS, J. \& FERRI-YÁNEZ, F. (2012) Revisión del estatus taxonómico de Liolaemus josephorum Núñez, Schulte \& Garin (Iguania: Liolaemidae). Boletin del Museo Regional de Atacama, 3, 93-101.

TRONCOSO-PALACIOS, J. \& FERRI-YÁNEZ, F. (2013) Liolaemus patriciaiturrae Navarro and Núñez, 1993 (Squamata: Liolaemidae): Distribution extension in northern Chile and geographic distribution map. Check List, 9, 78-80.

TRONCOSO-PALACIOS, J. \& GARIN, C.F. (2013) On the identity of Liolaemus nigromaculatus Wiegmann, 1834 (Iguania, Liolaemidae) and correction of its type locality. ZooKeys, 37-56.

TRONCOSO-PALACIOS, J. \& LOBO, F. (2012) A new species of Phymaturus (Iguania: Liolaemidae) of the palluma group from Central Chile. Cuadernos de Herpetologia, 26, 69-78.

RONCOSO-PALACIOS, J., LOBO, F., ETHERIDGE, R., ACOSTA J.C. \& LASPIUR, A. (2013) The rediscovery of Oplurus bibronii Guichenot, 1848 a valid species of the liolaemid genus Phymaturus (Iguania: Liolaemidae). Zootaxa, 3652, $547-561$

TRONCOSO-PALACIOS, J., SCHULTE II, J.A., MARAMBIOALFARO, Y. \& HIRIART, D. (2015b) Phenotypic Variation Phylogenetic Position and New Distributional Records for the Poorly Known Liolaemus silvai Ortiz, 1989 (Iguania: Iguanidae: Liolaemini). South American Journal of Herpetology, 10, 71-81.

TRUEB, L. (1971) Phylogenetic relationships of certain neotropical toads with the description of a new genus (Anura: Bufonidae). Contr Sci, No. 216, 1-40.

TRUEB, L. \& LeHR, E. (2008) A new species of Phrynopus (Anura, Strabomantidae) from Peru, with comments on the osteology of the genus. Phyllomedusa, 7, 11-24.

TSCHUDI, J.J. (1845) Reptilium conspectus quae in Republica Peruana reperiuntur et pleraque observata vel collecta sun in itinere. Archiv für Naturgeschichte, 11, 150-170.

TTITO, A., LANDAURO, C.Z., VENEGAS, P.J., DE LA RIVA, I. \& CHAPARRO, J.C. (2016) A New Species of Telmatobius Wiegmann, 1834, from the Eastern Cordillera Central of the Andes, Peru. (Anura: Telmatobiidae), with Description of Its Tadpole, and Range Extension of T. mendelsoni De La Riva Et Al., 2012. Annals of Carnegie Museum, 83, 255-268.

TURCI, L.C.B. \& BERNARDE, P.S. (2007) Levantamento herpetofaunistico em um a localidade no municipio de Cacoal, Rondônia, p. 200. In: 3o Congresso Brasileiro de Herpetologia. HERPETOLOGIA, S.B.D. (ed.). Sociedade Brasileira de Herpetologia, Belém

TURCI, L.C.B. \& BERNARDE, P.S. (2008) Levantamento Herpetofaunístico de uma localidade no munícipio de Cacoal, Rondônia-Brasil. Bioikos, 22, 101-108.

TWOMEY, E. \& BROWN, J.L. (2008) A partial revision of the Ameerega hahneli complex (Anura : Dendrobatidae) and new cryptic species from the East-Andean versant of Central Peru. Zootaxa, 49-65.
TWOMEY, E., DELIA, J. \& CASTROVIEJO-FISHER, S. (2014) A review of Northern Peruvian glassfrogs (Centrolenidae) with the description of four new remarkable species. Zootaxa, 3851, 1-87.

ÚBEDA, C.A. (2000) Eupsophus calcaratus (Anura, Leptodactilydae): ampliación de su distribución geográfica hábitats en Argentina. Cuadernos de Herpetologia, 14, 7174.

UETANABARO, M., GUIMARAEES, L.D., BEDA, A.F., LANDGREF FILHO, P., PRADO, C.P.A., BASTOS, R.P. \& AVILA, R.W. (2006) Inventário da herpetofauna do Complexo AporéSucuriú. In: PAGOTTO, T.C.S. \& SOUZA, P.R. (Eds.) Biodiversidade do Complexo Jauru, subsídios ... conservação e manejo do Cerrado. UFMS, Campo Grande, MS, pp. 105e man.

JETANABARO, M., SOUZA, F.L., LANDGREF FILHO, P., BEDA, A.F. \& BRANDÃO, R.A. (2007) Anfíbios e répteis do Parque Nacional da Serra da Bodoquena, Mato Grosso do Sul, Brasil. Biota Neotropica, 7, 279-289.

UETZ, P. \& HOŠEK, J. (2016) The Reptile Database. Available from: http://www.reptile-database.org (30.vii.2016).

UGUETO, G.N., FUENMAYOR, G.R., BARROS, T., SANCHEZ PACHECO, S.J. \& GARCIA-PEREZ, J.E. (2007) A revision of the Venezuelan Anoles I: A new Anolis species from the Andes of Venezuela with the redescription of Anolis jacare Boulenger 1903 (Reptilia : Polychrotidae) and the clarification of the status of Anolis nigropunctatus William 1974. Zootaxa, 1-30.

UGUETO, G.N. \& HARVEY, M.B. (2010) Southern Caribbean Cnemidophorus (Squamata: Teiidae): Description of New Species and Taxonomic Status of $C$. murinus ruthveni Burt. Herpetological Monographs, 24, 111-148.

UGUETO, G.N. \& HARVEY, M.B. (2011) Revision of Ameiva ameiva Linnaeus (Squamata: Teidae) in Venezuela: recognition of four species and status of introduced populations in southern Florida, USA. Herpetological Monographs, 25, 113-170.

UGUETO, G.N., HARVEY, M.B. \& RIVAS, G.A. (2009a) Two New Species of Cnemidophorus (Squamata: Teiidae) from Islands of the Northeastern Coast of Venezuela. Herpetological of the Northeastern Coast

UGUETO, G.N., RIVAS, G., BARROS, T. \& SMITH, E.N. (2009b) A revision of the Venezuelan anoles II: redescription of Anolis squamulatus Peters 1863 and Anolis tigrinus Peters 1863 (Reptilia: Polychrotidae). Caribbean Journal of Science, $45,30-51$.

URGILÉS, V.L., SÁNCHEZ-NIVICELA, J.C., NIEVES, C. \& YÁNEZ MUÑOZ, M.H. (2014) Ranas terrestres en los ecosistemas surandinos de Ecuador I: Dos nuevas especies de Pristimantis (Anura: Craugastoridae) de la ladera oriental. Avances en Ciencias e Ingenierías, Section B, 6, B51-B59.

UZZELL, T. (1966) Teiid lizards of the genus Neusticurus (Reptilia, Sauria). Bulletin of the American Museum of Natural History, 132, 277-328.

UZZELL, T. (1973) A revision of lizards of the genus Prionodactylus, with a new genus for $P$. leucostictus and notes on the genus Euspondylus (Sauria, Teiidae). Postilla 159, 1-67.

UZZELL, T. \& BARRY, J.C. (1971) Leposoma percarinatum, unisexual Species related to L. guianense; and Leposoma ioanna, a new species from the Pacific Coastal Colombia (Sauria, Teiidae). Postilla, 1-39.

UZzELL, T.M. (1959) Teiid lizards of the genus Placosoma. Occasional Papers of the Museum of Zoology, University of Michigan, 606, 1-16.

UZ7ELL, T.M. (1962) Additional notes on teiid lizards of the genus Placosoma. Copeia, 1962, 833-835.

UZZELL, T.M. (1965) Teiid lizards of the genus Echinosaura. Copeia, 1965, 82-89.

UZZELL, T.M. (1969) The status of the genera Ecpleopus, Arthroseps and Aspidolaemus (Sauria, Teiidae). Postilla, No. $135,1-23$.

VALDIVIESO \& TAMSITT, J. (1963) Records and obser vations on Columbian reptiles. Herpetologica, 19, 28-39.

VALDUJO, P.H., CAMACHO, A., RECODER, R.S., TEIXEIRA JR, M., BELOTI GHELLERE, J.M., MOTT, T., SALES NUNES, P.M., NOGUEIRA, C. \& RODRIGUES, M.T. (2011) Anfíbios d Estação Ecológica Serra Geral do Tocantins, região do Jalapão, Estados do Tocantins e Bahia. Biota Neotropica, 11 251-261.

VALDUJO, P.H., NOGUEIRA, C., BAUMGARTEN, L., RODRIGUES, F.H.G., BRANDÃO, R.A., ETEROVIC, A., RAMOS-NETO, M.B. \& MARQUES, O.A.V. (2009) Squamate Reptiles from Parque Nacional das Emas and surroundings, Cerrado of Central Brazil. Check List, 5, 405-417.

VALENCIA, J.H., GARZON T, K. \& BETANCOURT-YEPEZ, R. (2007) First record of the snake Dendrophidion bivittatus (Duméril, Bibron \& Duméril, 1854) and taxonomic remarks on the genus in Ecuador. Herpetozoa, 20, 86-88.

VALENCIA, J.H., PATRICIA BEJARANO-MUNOZ, E. \& YANEZ MUNOZ, M.H. (2013) Una nueva especie de rana Pristimantis verde (Anura: Craugastoridae) de los bosques andinos del distrito metropolitano de Quito, Ecuador. Herpetotrópicos, 9, 25-35.

VALETTI, J.A., OTERO, M.A., GRENAT, P.R., SALAS, N.E. \& MARTINO, A.L. (2013) Currently known geographica distribution of Pleurodema cordobae Valetti, Salas \&
Martino 2009 (Anura: Leptodactylidae: Leiuperinae) in Sierra Grande of Córdoba. Herpetology Notes, 6, 559-561. VALLADARES-FAUNDEZ, P. (2011) Analysis, synthesis and evaluation of the literature of lizards from Atacama Region Chile. Gayana, 75, 81-98

VALLE, M.F., MARQUES, R. \& TINÔCO, M.S. (2016) Filling gap in the disjunct distribution of Rhinoclemmys punctularia (Daudin, 1801) (Testudines: Geoemydidae) and first record from Bahia state, northeast Brazil. Check List, 12, 1-4.

VAN SLUYS, M. (1992) Aspectos da Ecologia do Lagarto Tropidurus itambere (Tropiduridae), em uma área do Sudeste do Brasil. Revista Brasileira de Biologia, 52, $181-$ 185.

VAN SLUYS, M. (1998) Physalaemus aguirrei. Herpetological Review, 29, 49

VAN SLUYS, M., ROCHA, C.F.D., VRCIBRADIC, D. ALEKSANDER, C., GALDINO, B. \& FONTES, A.F. (2004) Diet, activity and microhabitat use of two syntopic Tropidurus species (Lacertilia : Tropiduridae) in Minas Gerais, Brazil. Journal of Herpetology, 38, 606-611.

VANEGAS-GUERRERO, J., BATISTA, A., MEDINA, I. \& VARGASSALINAS, F. (2015a) Tantilla alticola (Boulenger, 1903) (Squamata: Colubridae): filling a geographical distribution gap in western Colombia. Check List, 11, 1555.

VANEGAS-GUERRERO, J., GÓMEZ-HOYOS, D.A., GÓMEZLÓPEZ, C.M. \& LONDOÑO-GUARNIZO, C.A. (2015b) Reptilia, Sauria, Gymnophthalmidae, Anadia rhombifer (Günther, 1859): Distribution extension and first records from Quindío department, Colombia. Check List, 11, 1-3.

VANEGAS-GUERRERO, J., LONDOÑO-GUARNIZO, C.A. \& GÓMEZ-HOYOS, D.A. (2015c) Stenocercus bolivarensis Castro \& Ayala 1982 (Squamata: Tropiduridae): a distribution extension in Quindío (Colombia), three decades after its discovery. Biota Colombiana, 16, 106-109.

VANEGAS-GUERRERO, J., MANTILLA-CASTAÑO, J.C. \& PASSOS, P. (2014) Atractus titanicus Passos, Arredondo, Fernandes \& Lynch, 2009 (Serpentes: Dipsadidae): Filling gaps in its geographical distribution. Check List, 10, 672673.

VANZOLINI, P.E. (1948) Sobre urn novo Pantodactylus do estado de Minas Gerais (Sauria, Teiidae). ( $P$. femoralis, sp. nov.). Papéis Avulsos do Departamento de Zoologia de São Paulo, 8, 337-340.

ANZOLINI, P.E. (1953a) Notas sobre alguns lagartos su Americanos (Sauria, Gekkonidae). Revista Brasileira de Biologia, 13, 73-74

VANZOLINI, P.E. (1953b) On the type locality of some Brazilian reptiles and amphibians collected by $\mathrm{H}$. H. Smith and described by E. D. Cope. Copeia, 1953, 124-125.

VANZOLINI, P.E. (1953c) Sobre a diferenciação geográfica de Gymnodactylus geckoides (Sauria, Gekkonidae). Papéis Avulsos do Departamento de Zoologia, 11, 225-262.

VANZOLINI, P.E. (1953d) Sobre a presença do gênero Lepidoblepharis Brasil (Sauria, Gekkonidae). Papeis Avulso do Departamento de Zoologia Secretaria de Agricultura São Paulo, 11, 263-270.

VANZOLINI, P.E. (1953e) Sobre o gênero Phyllopezus Peters (Sauria, Gekkonidae). Papéis Avulsos do Departamento de Zoologia, 11, 353-369.

ANZOLINI, P.E. (1955a) Contribuições ao conhecimento do lagartos brasileiros da família Amphisbaenidae Gray, 1825 Distribuição geográfica e biometria de Amphisbaena alba L. Arquivos do Museu Nacional, 42, 683-706.

VANZOLINI, P.E. (1955b) Sobre Gonatodes varius (Auguste Duméril), com notas sobre outras espécies do gênero (Sauria, Gekkonidae) Papéis Avulsos de Zoologia, 12, 119132.

VANZOLINI, P.E. (1961a) Bachia: Especies Brasileiras e conceito generico (Sauria: Teiidae). Papéis Avulsos de Zoologia, 14, 193-209.

VANZOLINI, P.E. (1961b) On Ophiognomon trisanale and abendrothii (Sauria, Teiidae). Papéis Avulsos de Zoologia $14,249-254$

VANZOLINI, P.E. (1966) Sobre o segundo exemplar de Bachia bresslaui (Sauria, Teiidae). Papéis Avulsos de Zoologia, 19, 189-192.

VANZOLINI, P.E. (1971) New Amphisbaenidae from Brasi (Sauria). Papéis Avulsos de Zoologia, 24, 191-195.

VANZOLINI, P.E. (1972) Miscellaneous notes on the ecology of some Brazilian lizards (Sauria). Papéis Avulsos de Zoologia 26, 83-115.

VANZOLINI, P.E. (1974) Ecological and geographical distribution of lizards in Pernambuco, Northeastern Brasil (Sauria). Papéis Avulsos de Zoologia, 58, 61-90.

VANZOLINI, P.E. (1978a) Lepidoblepharis in Amazonia (Sauria, Gekkonidae). Papéis Avulsos de Zoologia, 31, 203-211.

VANZOLINI, P.E. (1978b) On South American Hemidactylus (Sauria, Gekkonidae). Papéis Avulsos de Zoologia, 31, 307343.

VANZOLINI, P.E. (1980) Coleodactylus septentrionalis, sp. n., with Notes on the Distribution of the Genus Sauria Gekkonidae. Papéis Avulsos de Zoologia, 34, 1-9.

VANZOLINI, P.E. (1982) A new Gymnodactylus from Minas Gerais, Brasil, with remarks on the genus, on the area and on Montane Endemism in Brasil (Sauria, Gekkonidae) Papéis Avulsos de Zoologia, 34, 403-413.

VANZOLINI, P.E. (1983) Guiano-Brasilian Polychrus: distribution and speciation (Sauria: Iguanidae). Advances in 
herpetology and evolutionary biology: Essays in honor of Ernest E. Williams., 118-131.

VANZOLINI, P.E. (1986) Levantamento Herpetológico da Área do Estado de Rondônia sob a Influência da Rodovia BR-364. CNPq, Brasilia, $50 \mathrm{pp}$

VANZOLINI, P.E. (1991a) Biometry and geographical differentiation of Amphisbaena roberti Gans, 1964 (Reptilia Amphisbaenia). Papéis Avulsos de Zoologia, 37, 363-377.

VANZOLINI, P.E. (1991b) Two further new species of Amphisbaena from the semi-arid Northeast of Brasil (Reptilia, Amphisbaenia). Papéis Avulsos de Zoologia, 37, 347-361.

VANZOLINI, P.E. (1992) Cercolophia, a new genus for the species of Amphisbaenia with a terminal vertical keel on the tail (Reptilia, Amphisbaenia). Papéis Avulsos de Zoologia, 37, 401-412.

VANZOLINI, P.E. (1995a) Neusticurus ocellatus Sinitsin, 1930: valid species of teiid lizard from Bolivia. American Museum Novitates, 1995, 1-7.

VANZOLINI, P.E. (1995b) A new species of Amphisbaena from the state of Mato Grosso, Brasil (Reptilia: Amphisbaenia Amphisbaenidae). Papéis Avulsos de Zoologia, 39, 217-221.

VANZOUIN P.E. (1996) On slender species of Amphisbaena, with the description of a new one from northeastern Brasil (Reptilia, Amphisbaenia). Papéis Avulsos de Zoologia, 39, 293-305.

VANZOLINI, P.E. (1997) The silvestrii species group of Amphisbaena, with the description of two new Brasilia species (Reptilia: Amphisbaenia). Papéis Avulsos de Zoologia, 40, 65-85.

VANZOLINI, P.E. (1999) On Anops (Reptilia: Amphisbaenia: Amphisbaenidae). Papéis Avulsos de Zoologia, 41, 1-37.

VANZOLINI, P.E. (2002) A second note on the geographica differentiation of Amphisbaena fuliginosa L., 1758 (Squamata, Amphisbaenidae), with a consideration of the forest refuge model of speciation. Anais da Academia Brasileira de Ciencias, 74, 609-648.

VANZOLINI, P.E. (2004) On the geographical differentiation of Gymnodactylus geckoides Spix, 1825 (Sauria, Gekkonidae): Speciation in the Brasilian caatingas. Anais da Academia Brasileira de Ciencias, 76, 663-698.

VANZOLINI, P.E. (2005) On Gymnodactylus amarali Barbour, 1925, with the description of a new species (Sauria, Gekkonidae). Anais da Academia Brasileira de Ciencias, 77 595-611.

VANZOLINI, P.E. \& CARVALHO, C.M.D. (1991) Two Sibling and Sympatric Species of Gymnophthalmus in Roraima Brazi Sauria Teiidae. Papéis Avulsos de Zoologia, 37, 173-226.

VANZOLINI, P.E. \& GOMES, N. (1979) On Tropidurus hygomi: redescription, ecological notes, distribution and history (Sauria, Iguanidae). Papéis Avulsos do Departamento de Zoologia, 32, 243-259.

VANZOLINI, P.E. \& RAMOS, A.M.M. (1977) A New Species of Colobodactylus with Notes on the Distribution of A Group of Stranded Microteiid Lizards Sauria Teiidae. Papéis Avulsos de Zoologia, 31, 19-48.

VANZOLINI, P.E. \& REBOUÇAS-SPIEKER, R. (1976) Distribution and Differentiation of Animals Along the Coast and on Continental Islands of the State of São Paulo Brazil Part 3 Reproductive Differences Between and Within Mabuya caissara and Mabuya macrorhyncha Sauria Scincidae. Papéis Avulsos de Zoologia, 29, 95-109.

VANZOLINI, P.E. \& VALENCIA, J. (1965) The genus Dracaena with a brief consideration of macroteiid relationships (Sauria, Teiidae). Arquivos de Zoologia, 13, 7-35.

VANZOLINI, P.E. \& WILLIAMS, E.E. (1962) Jamaican and Hispaniolan Gonatodes and allied forms Bulletin of the Museum of Comparative Zoology, 127, 479-498.

VARELA-JARAMILLO, A. \& PÁEZ-ROSALES, N. (2017) Pristimantis incomptus. Museo de Zoología, Pontifici Universidad Católica del Ecuador. Available from: http://zoologia.puce.edu.ec/vertebrados/anfíbios/FichaEsp ecie. aspx?ld $=1422$

VARELA, R.O. \& BUCHER, E.H. (2002) The Lizard Teius teyou (Squamata: Teiidae) as a Legitimate Seed Disperser in the Dry Chaco Forest of Argentina. Studies on Neotropical Fauna and Environment, 2002, 2

VASCONCELOS, J.P., SOUSA, G.D.L., LEITE, J.R.S.A. \& ANDRADE, E.B. (2014) New record and geographic distribution map of Physalaemus centralis (Anura: Leptodactylidae), in Piauí, northeastern Brazil. Herpetology Notes, 7, 325-327.

VAZ-SILVA, W., GUEDES, A.G., AZEVEDO-SILVA, P.L., GONTIJO, F.F., BARBOSA, R.S., ALOÍSIO, G.R. \& OLIVEIRA, F.C.G. (2007) Herpetofauna, Espora Hydroelectric Power Plant, state of Goiás, Brazil. Check List, 3, 338-345.

VAZ-SILVA, W., MACIEL, N.M., BASTOS, R.P. \& POMBAL JR J.P. (2015) Revealing Two New Species of the Rhinella margaritifera Species Group (Anura, Bufonidae): An Enigmatic Taxonomic Group of Neotropical Toads. Herpetologica, 71, 212-222.

VAZ-SILVA, W., VALDUJO, P.H. \& POMBAL JR, J.P. (2012) New species of the Rhinella crucifer group (Anura, Bufonidae) from the Brazilian Cerrado. Zootaxa, 3265, 57-65.

VELASCO, J.A., GUTIERREZ-CARDENAS, P.D.A. \& QUINTEROANGEL, A. (2010) A new species of Anolis of the aequatorialis group (Squamata: Iguania) from the central
VELASCO, J.A. \& HURTADO-GOMEZ, J.P. (2014) A new green anole lizard of the "Dactyloa" clade (Squamata: Dactyloidae) from the Magdalena river valley of Colombia. Zootaxa, 3785, 201-216.

VENANCIO, N.M., SOUZA, M.B. \& KOKUBUM, M.N.C. (2014) Hyalinobatrachium mondolfii Senari \& Ayarzaguena, 2001 (Anura: Centrolenidae): First record for the state of Acre, Brazil. Check List, 10, 1184-1186.

VENEGAS, P. (2005) Phrynopus carpish. Herpetological Review, $36,76$.

VENEGAS, P.J. \& DUELLMAN, W.E. (2012) Two syntopic new species of the Pristimantis orestes Group (Anura: Strabomantidae) from northwestern Peru. Zootaxa, 47-59. VENEGAS, P.J., DURAN, V. \& GARCIA-BURNEO, K. (2013a) A new species of arboreal iguanid lizard, genus Stenocercus (Squamata: Iguania), from central Peru. Zootaxa, 3609, 291-301.

VENEGAS, P.J., DURAN, V., LANDAURO, C.Z. \& LUJAN, L. (2011) A distinctive new species of wood lizard (Hoplocercinae, Enyalioides) from the Yanachaga Chemillen National Park in central Peru. Zootaxa, 39-48.

VENEGAS, P.J., ECHEVARRÍA, L.Y. \& ALVAREZ, S.C. (2014) new species of spiny-tailed iguanid lizard (Iguania: Stenocercus) from northwestern Peru. Zootaxa, 3753, 4758

VENEGAS, P.J., ECHEVARRIA, L.Y., ALVAREZ, S.C. \& VASQUEZ, D. (2010) Reptilia, Squamata, Iguanidae, Stenocercus humeralis Gunther, 1859: first country record, Peru. Check List, 6, 250-252.

VENEGAS, P.J., ECHEVARRÍA, L.Y., GARCÍA-BURNEO, K. \& $\mathrm{KOCH}, \mathrm{C}$. (2016a) A new species of iguanid lizard, genus Stenocercus (Squamata, Iguania), from the Central Andes in Peru. 2016, 4205, 52-64.

VENEGAS, P.J., ECHEVARRIA, L.Y., LOBOS, S.E., NUNES, P.M.S \& TORRES-CARVAJAL, O. (2016b) A new species of Andean microteiid lizard (Gymnophthalmidae: Cercosaurinae: Pholidobolus) from Peru, with comments on $P$. vertebralis. Amphibian and Reptile Conservation, 10, 21-33.

VENEGAS, P.J. \& GAGLIARDI-URRUTIA, G. (2013) Anfíbios reptiles. In: PITMAN, N., RUELAS INZUNZA, E., VRIESENDORP, C., STOTZ, D.F., WACHTER, T., CAMPO, A. ALVIRA, D., RODRÍGUEZ GRÁNDEZ, B., SMITH, R.C. \& SÁENZ RODRÍGUEZ, A.R. (Eds.) Ere-Campuya-Algodón. Rapid Biological and social Inventories Report 25. Field Museum of Natural History, Chicago, pp. 107-113.

VENEGAS, P.J., TORRES-CARVAJAL, O., DURAN, V. \& DE QUEIROZ, K. (2013b) Two sympatric new species of woodlizards (Hoplocercinae, Enyalioides) from Cordillera Azul National Park in northeastern Peru. ZooKeys, 69-90.

VERA-PÉREZ, L.E. \& ZÚÑIGA-BAOS, J.A. (2015) First record of Urotheca dumerilli (Bibron, 1840) (Squamata: Dipsadidae) in Cauca state, Colombia and notes on natural history. 2015, 11, 1-5.

VERDADE, V.K., CASSIMIRO, J. \& RODRIGUES, M.T. (2009a) Cycloramphus fuliginosus (Tschudi's button frog). Saurophagy. Herpetological Review, 40, 201-202.

VERDADE, V.K. \& RODRIGUES, M.T. (2008) On the Identity of Cycloramphus jordanensis Heyer, 1983 (Anura: Cycloramphidae). Herpetologica, 64, 452-457.

VERDADE, V.K., RODRIGUES, M.T. \& PAVAN, D. (2009b) Anfíbios anuros da região da Estação Biológica do Alto da Serra de Paranapiacaba. In: LOPES, M.I.M.S., KIRIZAWA, M. \& MELO, M.M.R.F. (Eds.) Patrimônio da Reserva Biológica do Alto da Serra de Paranapiacaba: a antiga Estação Biológica do Alto da Serra. Instituto de Botânica, São Paulo, piologica do $579-603$.

VERRASTRO, L., SCHOSSLER, M. \& DA SILVA, C.M. (2006) iolaemus occipitalis (sand lizard). Herpetological Review, 37,495

VERRASTRO, L., VeroneSE, L.B., BUJES, C. \& DIAS FILHO, M.M. (2003) A New Species of Liolaemus From Southern Brazil (Iguania: Tropiduridae). Herpetologica, 59, 105-118.

VETTER, H. (2005) Turtles of the World Vol. 3. Central and South America. Verlag, Frankfurt, $128 \mathrm{pp}$.
S

VIANA, L.A., WINCK, G.R., ALMEIDA-SANTOS, M., DA SILVA TELLES, F.B., GAZETA, G.S. \& DUARTE ROCHA, C.F. (2012) New host records for Amblyomma rotundatum (Acari: Ixodidae) from Grussai restinga, Rio de Janeiro, Brazil. Revista Brasileira De Parasitologia Veterinaria, 21, 319-322. VICTORIANO, P.F., CORONADO, T.M. \& ORTIZ, J.C. (2010) A multivariate analysis of taxonomic limits in Diplolaemus Bell 1843. Gayana, 74, 23-36

VIDAL, M.A. \& ORTIZ, J.C. (2004) Analisis osteologico en do especies de Microlophus (Sauria, Tropiduridae) de la costa Chileno-Peruana. Gayana, 68, 9-19.

VIDAL, M.A., PIZARRO-ARAYA, J., JEREZ, V. \& ORTIZ, J.C. (2011) Daily activity and thermoregulation in predator-prey interaction during the Flowering Desert in Chile. Journal of Arid Environments, 75, 802-808.

VIEIRA, M.I., ALVES, M.L.M. \& FABIAN-BEURMANN, M.E. (1980) Osteologia craniana de Amphisbaena darwin trachura Cape, 1885 (Lacertilia - Amphisbaenidae). Iheringia Serie Zoologia, 107-120.

VIEITAS, C.F. (1995) Analise ambiental das ilhas da regiao de ubatuba (SP), e proposta de manejo para a ilha do ma virado. Mestraso. Instituto de Biociências da Universidade de São Paulo, São Paulo, SP130 pp.

VIÑAS, M. \& DANERI, G. (1991) Pantodactylus screiberssi parkeri Ruibal 1962 (Sauria, Teiidae), para el Noroeste Argentino. Boletín de la Asociación Herpetológica Argentina, 6, 10-11.

VITT, L.J., SARTORIUS, S.S., AVILA-PIRES, T.C.S. \& ESPOSITO, M.C. (2001) Life on the leaf litter: The ecology of Anolis nitens tandai in the Brazilian Amazon. Copeia, 2001, 401 412

VON MAY, R. (2016) New records of the Critically Endangered frog Pristimantis pardalinus (Craugastoridae) in the easter Andean slopes of central Peru. Amphibian and Reptile Conservation, 10, 13-16.

VRCIBRADIC, D., ALMEIDA-GOMES, M., BORGES-JUNIOR, V.N., KIEFER, M.C. \& ROCHA, C.F.D. (2006a) Reptilia, Scincidae, Mabuya frenata: distribution extension. Check List, 2, 57-58.

VRCIBRADIC, D., CUNHA-BARROS, M. \& ROCHA, C.F.D. (2004a) Ecological observations on Mabuya dorsivittata (Squamata; Scincidae) from a high altitude habitat in southeastern Brazil. The Herpetological Journal, 14, 109-112

VRCIBRADIC, D., HATANO, F.H., ROCHA, C.F.D. \& VAN SLUYS, M. (2000) Bogertia lutzae. Herpetological Review, 31, 112. VRCIBRADIC, D. MAUSFELD-LAFDHIYA, P. \& ROCHA, C.F.D. (2006b) Molecular phylogeny of Brazilian Mabuya (Reptilia, Squamata, Scincidae) of the agilis/caissara/heathi complex. The Herpetological Journal, 16, 83-91.

VRCIBRADIC, D. \& MOURA-LEITE, J.C. (2003) Mabuya frenata. Herpetological Review, 34, 166

VRCIBRADIC, D. \& ROCHA, C.F.D. (1996a) Ecological differences in tropical sympatric skinks (Mabuya macrorhyncha and Mabuya agilis) in Southeastern Brazil. Journal of Herpetology, 30, 60-67.

VRCIBRADIC, D. \& ROCHA, C.F.D. (1996b) Mabuya frenat (NCN): Cannibalism. Herpetological Review, 27, 201-202.

VRCIBRADIC, D., ROCHA, C.F.D. \& ARIANI, C.V. (2004b)

Cnemidophorus lacertoides. Herpetological Review, 35, 408.

VRCIBRADIC, D. ROCHA, C.F.D. KIEFER, M.C., HATANO, F.H,

FONTES, A.F., ALMEIDA-GOMES, M., SEQUEIRA, C.C. PONTES, J.A.L., BORGES-JUNIOR, V.N.T., GIL, L.O., KLAION, T., RUBIAO, E.C.N. \& VAN SLUYS, M. (2011) Herpetofauna, Estação Ecológica Estadual do Paraíso, state of Rio de Janeiro, southewastern Brazil. Check List, 7, 745-749.

VRCIBRADIC, D., ROCHA, C.F.D., MENEZES, V.A. \& ARIANI C.V. (2004c) Mabuya dorsivittata. Herpetological Review, 35,409

VRCIBRADIC, D., ROCHA, C.F.D. \& TEIXEIRA, R.L. (2002) Cnemidophorus nativo (NCN). Herpetological Review, 33

VRCIBRADIC, D. \& SOARES, M. (1999) Amphisbaena anaemariae. Herpetological Review, 30, 233.

WAKE, M.H. \& DONNELLY, M.A. (2010) A new lungles caecilian (Amphibia: Gymnophiona) from Guyana. Proceedings of the Royal Society B-Biological Sciences, 277 915-922.

WALDEZ, F., MENIN, M. \& VOGT, R.C. (2013) Diversidade de anfíbios e répteis Squamata na região do baixo rio Purus, Amazônia Central, Brasil. Biota Neotropica, 13, 300-317.

WALDEZ, F. \& VOGT, R.C. (2006) Cercosaura argulus (elegant eyed lizard). Herpetological Review, 37, 493-494.

WALKER, W.F., JR. (1945) A study of the snake Tachymenis peruviana Wiegmarm and its allies. Bulletin of the Museum of Comparative Zoology, 96, 1-55.

WALLER, T., BECCACECI, M.D. \& CARPANETTO, G. (2003) Estudios de Fauna. In: CANZIANI, G., ROSSI, C., LOISELLE, S. \& R., F. (Eds.) Los Esteros del Iberá - Informe del Proyecto "EI Manejo Sustentable de Humedales en el Mercosur". Fundación Vida Silvestre Argentina, Buenos Aires, pp. 161166

WEBER, L.N., SILVA-SOARES, T. \& SALLES, R.D.O.L. (2009) Amphibia, Anura, Hylidae, Hypsiboas secedens: reassessment of type locality coordinates and distribution extension. Check List, 5, 218-221.

WENDT, A. \& LYNCH, R.L. (2016) Diploglossus monotropis. Herpetological Review, 47, 257.

WERNECK, F.D., COLLI, G.R. \& VITT, L.J. (2009a) Determinants of assemblage structure in Neotropical dry forest lizards. Austral Ecology, 34, 97-115.

WERNECK, F.D., GIUGLIANO, L.G., COLLEVATTI, R.G. \& COLLI, G.R. (2009b) Phylogeny, biogeography and evolution of clutch size in South American lizards of the genus Kentropyx (Squamata: Teiidae). Molecular Ecology, 18, 262-278.

WERNECK, F.P. \& COLLI, G.R. (2006) The lizard assemblage from seasonally dry tropical forest enclaves in the Cerrado biome, Brazil, and its association with the Pleistocenic Arc. Journal of Biogeography, 33, 1983-1992.

WERNER, F. (1894) Herpetologische Nova. Zoologische Anzeiger, 17, 410-415.

WERNER, F. (1901) Reptilien und Batrachier aus Peru und Bolivien. Abhandlungen und Berichte des Königl, 9, 1-14.

WERNER, F. (1910) Über neue oder seltene Reptilien de NaturMstorischen Museums in Hamburg. Jahrbuch der Hamburgischen Wissenschaftlichen Anstalten, 27, 1-46.

WERNER, F. (1916) Bemerkungen über einige niedere Wirbeltiere der Anden von Kolumbien mit Beschreibungen neuer Arten. Zoologische Anzeiger, 47, 301-311. 
WIED, M.A.P. (1821) Reise nach Brasilien in den Jahrem 1815 bis 1817 - Vol. 2. Heinrich Ludwig Brönner, Frankfurt, 345 pp.

WIEGMANN, A.F.A. (1834) Herpetologia Mexicana, seu descriptio amphibiorum novae hispaniae, quae itineribus comitis de Sack, Ferdinandi Deppe et Chr. Guil. Schiede im Museum Zoologicum Berolinense Pervenerunt. Pars prima, saurorum species. Lüderitz, Berlin, $54 \mathrm{pp}$.

WIENS, J.J. (1993) Systematics of the leptodactylid frog genus Telmatobius in the Andes of northern Peru. Occasiona Papers of the Museum of Natural History University of Kansas, 162, 1-76.

WILKINSON, M., ANTONIAZZI, M.M. \& JARED, C. (2015) A new species of Microcaecilia Taylor, 1968 (Amphibia: Gymnophiona: Siphonopidae) from Amazonian Brazil. Zootaxa, 3905, 425-431.

WILKINSON, M. \& GOWER, D.J. (2010) A new species of Rhinatrema Dumeril \& Bibron (Amphibia: Gymnophiona: Rhinatrematidae) from Amazonas, Brazil. Zootaxa, 63-68.

WILKINSON, M. \& KOK, P.J.R. (2010) A new species of Microcaecilia (Amphibia: Gymnophiona: Caeciliidae) from Guyana. Zootaxa, 35-40.

WILKINSON, M., SHERRATT, E., STARACE, F. \& GOWER, D.J. (2013) A New Species of Skin-Feeding Caecilian and the First Report of Reproductive Mode in Microcaecilia (Amphibia: Gymnophiona: Siphonopidae). PLOS ONE, 8

WILLIAMS, E.E. (1965) South America Anolis (Sauria, Iguanidae) two new species of the punctatus group. Breviora, 1-15.

WILLIAMS, E.E. (1966) South American Anoles: Anolis biporcatus and Anolis fraseri (Sauria, Iguanidae) compared. Breviora, 1966, 1-14.

WILLIAMS, E.E. (1974a) A case history in retrograde evolution: The onca lineage in anoline lizards. I. Anolis annectens new species, intermediate between the genera Anolis and Tropidodactylus. Breviora, 1-21.

WILLIAMS, E.E. (1974b) South American Anolis: Three new species related to Anolis nigrolineatus and $A$ dissimilis. Breviora, 1-15.

WILLIAMS, E.E. (1975a) South American Anolis: Anolis ibague, new species of the pentaprion group from Colombia. Breviora, 1-10.

WILLIAMS, E.E. (1975b) South American Anolis: Anolis parilis, new species, near A mirus Williams. Breviora, 1-8.

WILLIAMS, E.E. (1975c) South American Anolis: Anolis parilis, new species, near $A$. mirus Williams. Breviora, 1-8.

WILLIAMS, E.E. (1982) Three new species of the Anolis punctatus complex from Amazonian and inter-Audean Colombia, with comments on the eastern members of the punctatus species group. Breviora, 1-38.

WILLIAMS, E.E. (1984a) New or problematic Anolis from Colombia. II. Anolis propinquus, another new species from the cloud forest of western Colombia. Breviora, 1-7.

WILLIAMS, E.E. (1984b) New or problematic Anolis from Colombia. III. Two new semiaquatic anoles from Antioquia and Choco, Colombia. Breviora, 1-22.

WILLIAMS, E.E. (1985) New or problematic Anolis from Colombia. IV. Anolis antioquiae, new species of the Anolis eulaemus subgroup from western Colombia. Breviora, 1-9.

WILLIAMS, E.E. (1988) New or problematic Anolis from Colombia. V. Anolis danieli, a new species of the latifron species group and a reassessment of Anolis appollinaris Boulenger, 1919. Breviora, 1-25.

WILLIAMS, E.E. (1992) New or problematic Anolis from Colombia. VII. Anolis lamari, a new anole from the Cordillera Oriental of Colombia, with a discussion of tigrinus and punctatus species group boundaries. Breviora, 1-24.

WILLIAMS, E.E. \& DUELLMAN, W.E. (1984) Anolis fitchi, a new species of the Anolis aequatorialis group from Ecuador and Colombia. University of Kansas Publications of the Museum of Natural History, 257-266.

WILLIAMS, E.E., ORCES V, G., MATHEUS, J.A. \& BLEIWEISS, R. 1996a) A new giant phenacosaur from Ecuador. Breviora, $1-32$.

WILLIAMS, E.E., PRADERIO, M.J. \& GORZULA, S. (1996b) A Pheracosaur from Chimantá Tepui, Venezuela. Breviora, 116.

WILLIAMS, E.E. \& VANZoLINI, P.E. (1980) Notes and biogeographic comments on anoles from Brasil. Papéis Avulsos de Zoologia, 34, 99-108.

WILLIAMS, J.D. (1997) Liolaemus lineomaculatus (Sauria: Tropiduridae). Primera cita para la Provincia de Chubut, Argentina. Cuadernos de Herpetologia, 11, 87-89.

WILLIAMS, J.D. \& BOSSO, A. (1994) Estado sistemático $y$ distribución geográfica de Argenteohyla siemersi (Mertens, 1937) en la República Argentina (Anura: Hylidae) Cuadernos de Herpetologia, 8, 57-62.

WILSON, L.D. (1974) Drymobius margaritiferus (Schlegel) Central American Speckled Racer. Catalogue of American Amphibians and Reptiles, 1-2.

WILSON, L.D. (1985) Tantilla reticulata Cope. Catalogue of American Amphibians and Reptiles, 1.

WILSON, L.D. (1986) Tantilla alticola (Boulenger). Catalogue of American Amphibians and Reptiles, 1.

WILSON, L.D. (1990a) Tantilla miyatai Wilson and Knight. Catalogue of American Amphibians and Reptiles, 1.
WILSON, L.D. (1990b) Tantilla semicincta (Duméril, Bibron and Duméril). Catalogue of American Amphibians and Reptiles, 1.

WILSON, L.D. (1991) Tantilla petersi Wilson. Catalogue of American Amphibians and Reptiles, 1.

WILSON, L.D. (1992a) Tantilla melanocephala (Linneaus). Catalogue of American Amphibians and Reptiles, 1-3.

WILSON, L.D. (1992b) Tantilla nigra (Boulenger). Catalogue of American Amphibians and Reptiles, 548, 1.

WILSON, L.D. \& MATA-SILVA, V. (2015) A checklist and key to the snakes of the Tantilla clade (Squamata: Colubridae) with comments on taxonomy, distribution, and conservation. Mesoamerican Herpetology, 2, 418-499.

WILSON, L.D. \& MENA, C.E. (1980) Systematics of the melanocephala group of the colubrid snake genus Tantilla. San Diego Society of Natural History Memoirs, 11, 5-58.

WRAY, K. (2015) Dendropsophus haraldschultzi (Harald's Treefrog). Available https://www.flickr.com/photos/kwray/16436782017

YÁNEZ-MUÑOZ, M., PÉREZ-PEÑA, P. \& CISNEROS-HEREDIA, D. (2009) New country records of Hyalinobatrachium iaspidiense (Amphibia, Anura, Centrolenidae) from the Amazonian lowlands of Ecuador and Peru. Herpetology Amazos, 2, 49-52.

YÁNEZ-MUÑOZ, M.H. \& ALTAMIRANO-BENAVIDES, M. (2011) Nueva especie de Sapo Andino del género Osornophryne (Amphibia: Bufonidae) del norte de Ecuador, con notas sobre la diversidad del género en Colombia. Avances en Ciencias e Ingenierias, Section B, 2, B46-B5.

YÁNEZ-MUÑOZ, M.H., BEJARANO-MUÑOZ, P., BRITO-M., J. \& BATALLAS-R, D. (2014a) Ranas terrestres de los Andes Surorientales de Ecuador II: Una nueva especie de Pristimantis verde espinosa de los bosques montanos de Parque Nacional Sangay (Anura: Craugastoridae). Avances en Ciencias e Ingenierías, Section B, 6, B63-B77.

YÁNEZ-MUÑOZ, M.H., CISNEROS-HEREDIA, D.F. \& REYES PUIG, J.P. (2011a) Una nueva especie de rana terrestre Pristimantis (Anura: Terrarana: Strabomantidae) de la cuenca alta del Río Pastaza, Ecuador. Avances en Ciencias e Ingenierías, Section $\mathrm{B}, 2, \mathrm{~B} 28-\mathrm{B} 32$

YÁNEZ-MUÑOZ, M.H., MEZA-RAMOS, P., CISNEROS-HEREDIA D.F. \& REYES-PUIG, J.P. (2011b) Descripción de tres nuevas especies de ranas del género Pristimantis (Anura: Terrarana: Strabomantidae) de los bosques nublados de Distrito Metropolitano de Quito, Ecuador. Avances en Ciencias e Ingenierías, Section B, 2, B16-B27.

YÁNEZ-MUÑOZ, M.H., REYES-PUIG, C., BEJARANO-MUÑOZ, E.P. \& RON, S.R. (2015) Otra nueva especie de rana Pristimantis (Anura: Terrarana) de las estribaciones occidentales del Volcán Pichincha, Ecuador. Avances en Ciencias e Ingenierías, Section B, 7, 52-60.

ÁNEZ-MUÑOZ, M.H., SÁNCHEZ-NIVICELA, J.C. \& REYES PUIG, C. (2016) Tres nuevas especies de ranas terrestres Pristimantis (Anura: Craugastoridae) de la Provincia de E Oro, Ecuador. ACl Avances en Ciencias e Ingenierías, 8, 525.

YÁNEZ-MUÑOZ, M.H., SÁNCHEZ L., J.C., LÓPEZ, K., REA S., E., MEZA-RAMOS, P.A., OYAGATA C., L.A. \& GUERRERO, P. (2014b) Ampliaciones del rango de distribución de algunas especies de anfibios y reptiles en el suroccidente de Ecuador. Avances en Ciencias e Ingenierías, Section B, 6 , B2-B5.

YÁNEZ-MUÑOZ, M.H., TORAL-CONTRERAS, E., MEZA-RAMOS, P.A., REYES-PUIG, J.P., BEJARANO-MUÑOZ, E.P., MUESESCISNEROS, J.J. \& PAUCAR, D. (2012) New country records for five species of Pristimantis Jiménez de la Espada, 1870 from Ecuador. Check List, 8, 286-290.

YÁNEZ-MUÑOZ, M.H., VEINTIMILLA, D.A., SMITH, E.N. ALTAMIRANO-BENAVIDES, M. \& FRANKLIN, C.J. (2010) Descubrimiento de dos poblaciones sobrevivientes de Sapos Arlequín (Amphibia: Bufonidae: Atelopus) en los Andes de Ecuador. Avances en Ciencias e Ingenierías, Section B, 2, 74-77.

YAÑEZ, J.L. \& NÚÑEZ, H. (1983) Liolaemus fabiani, a new species of lizard from northern Chile (Reptilia: Iguanidae). Copeia, 1983, 788-790

YOUNG-DOWNEY, A. \& MORENO, J. (1991) A new species of tropidurine lizard (Squamata: Tropiduridae) from Los Andes of north Chile. Gayana Zoologia, 55, 391-396.

YUKI, R.N., GALATTI, U. \& ROCHA, R.A.T. (1999) Contribuição ao conhecimento da fauna de Squamata de Rondônia, Brasil, com dois novos registros. Boletim do Museu Paraense Emilio Goeldi Serie Zoologia, 15, 181-193.

ZAHER, H., ARREDONDO, J.C., VALENCIA, J.H., ARBELAEZ, E. RODRIGUES, M.T. \& ALTAMIRANO-BENAVIDES, M. (2014) A new Andean species of Philodryas (Dipsadidae, Xenodontinae) from Ecuador. Zootaxa, 3785, 469-480.

ZAHER, H., SCROCCHI, G. \& MASIERO, R. (2008) Rediscovery and redescription of the type of Philodryas laticeps Werner 1900 and the taxonomic status of $\mathrm{P}$. oligolepis Gomes, 1921 (Serpentes, Colubridae). Zootaxa, 1940, 25-40.

ZANELLA, N., MACHADO, L.S. \& BUSIN, C.S. (2012) Hypsiboas curupi. Herpetological Review, 43, 440.

ZANETTE-SILVA, L., FARIAS, D.L. \& GHIZONI-JR, I.R. (2016) New records of Aparasphenodon bokermanni (Pombal, 1993) from Santa Catarina, southern Brazil, and extension of genus range (Anura: Hylidae). Check List, 12, 1-4.
ZANK, C., COLOMBO, P., ADAMS, G., BORBA, D. \& MARTINS M.B. (2013) New country record and geographic distribution map for the San Martin red-bellied toad Melanophryniscus sanmartini Klappenbach, 1968 (Amphibia, Bufonidae). Herpetology Notes, 6, 555-557. (Amphiba, Bufonidae). Herpetology Notes, 6, 555-557.

ZARACHO, V.H. \& ARETA, J.I. (2008) The advertisement call of Argenteohyla siemersi pederseni (Amphibia, Anura, Hylidae), and comments on its taxonomic status. Facena 24, 49-57.

ZERBINI, G.J., COSTA, E.M.M., ARAUJO, A.F.B. \& BRANDÃO, R.A. (1998) Tropidurus strobilurus. Herpetological Review, 29, 111

ZIEGLER, T., BOEHME, W. \& UNGER, J. (2002) First record of Gymnophthalmus rubricauda Boulenger, 1902 for Paraguay, with notes on its morphology, ecology and habitat (Reptilia: Sauria: Gymnophthalmidae). Faunistische Abhandlungen 22, 347-351.

ZIMMERMAN, B.L. \& RODRIGUES, M.T. (1990) Frogs, snakes, and lizards of the INPA-WWF reserves near Manaus, Brazil. In: GENTRY, A.H. (Ed.) Four neotropical rainforests. Yale University Press, London, pp. 426-454.

ZULUAGA-ISAZA, J.C., ROJAS-MORALES, J.A., DÍAZ-AYALA, R.F. \& RAMÍREZ-CASTAÑO, V.A. (2015) Pseustes shropshirei (Shropshire's Puffing Snake). Diet. Herpetological Review, 46,649 


\section{APÊNDICE 2 - Lista de espécies}

Lista de táxons usados nas análises, listados em ordem alfabética para Anfíbios e Répteis. Os valores apresentados após os nomes dos táxons representam valor do índice de endemismo e categorização como terrestre, arborícola, aquático e fossorial, respectivamente.

\section{Anfíbios}

Adelastes, 0.00714, 0, 0, 0, 0; Adelastes hylonomos, 0.00714, 0, 1, 0, 0; Adelophryne, 0.00000, 0, 0, 0, 0; Adelophryne adiastola $0.00000,0,1,0,0 ;$ Adelophryne baturitensis, 0.00021, 0, 1, 0, 0; Adelophryne glandulata, 0.00759, 0, 1, 0, 0; Adelophryne gutturosa, 0.00003 , 0, 1, 0, 0; Adelophryne maranguapensis, 0.02118, 0, 1, 0, 0; Adelophryne meridionalis, 0.00769, 0, 1, 0, 0; Adelophryne mucronatus, 0.00080, 0, 1, 0, 0; Adelophryne pachydactyla, 0.00154, 0, 1, 0, 0; Adelophryne patamona, 0.00040, 0, 1, 0, 0; Adelophryne sp1, 0.00791, 0, 1, 0, 0; Adelophryne sp2, 0.00805, 0, 1, 0, 0; Adelophryne sp3, 0.00968, 0, 1, 0, 0; Adelophryne sp4, 0.00816, 0, 1, 0, 0; Adelophryne sp4, 0.00816, 0, 1, 0, 0; Adelophryne sp4, 0.00816, 0, 1, 0, 0; Adelophryne sp5, 0.00012, 0, 1, 0, 0; Adelophryne sp7, 0.00783, 0, 1, 0, 0; Adelphobates, 0.00000, 0, 0, 0, 0; Adelphobates castaneoticus, 0.00000, 0, 1, 0, 0; Adelphobates galactonotus, 0.00000, 0, 1, 0, 0; Adelphobates quinquevittatus, 0.00000, 0, 1, 0, 0; Adenomera, 0.00000, 0, 0, 0, 0; Adenomera ajurauna, 0.00011, 0, 1, 0, 0; Adenomera andreae, 0.00000, 0, 1, 0, 0; Adenomera araucaria, 0.00008, 0, 1, 0, 0; Adenomera bokermanni, 0.00361, 0, 1, 0, 0; Adenomera coca, 0.01209, 0, 1, 0, 0; Adenomera cotuba, 0.00000, 0, 1, 0, 0; Adenomera diptyx, 0.00000, 0, 1, 0, 0; Adenomera engelsi, 0.00018, 0, 1, 0, 0; Adenomera heyeri, 0.00000, 0, 1, 0, 0; Adenomera hylaedactyla, 0.00000, 0, 1, 0, 0; Adenomera juikitam, 0.00735, 0, 1, 0, 0; Adenomera lutzi, 0.00012, 0, 1, 0, 0; Adenomera marmorata, 0.00003, 0, 1, 0, 0; Adenomera martinezi, 0.00117, 0, 1, 0, 0; Adenomera nana, 0.00022, 0, 1, 0, 0; Adenomera saci, $0.00000,0,1,0,0$; Adenomera simonstuarti, $0.00000,0,1,0,0$; Adenomera $s p \_A, 0.00847,0,1,0,0$; Adenomera $s p \_B, 0.00789,0$, 1, 0, 0; Adenomera sp_C, $0.00001,0,1,0,0$; Adenomera $s p_{-} D, 0.00794,0,1,0,0$; Adenomera $s p_{-} E, 0.00000,0,1,0,0 ;$ Adenomera $s p \_F, 0.00000,0,1$, 0, 0; Adenomera $s p_{-} G, 0.00001,0,1,0,0$; Adenomera $s p_{-} I, 0.00000,0,1$, 0, 0; Adenomera $s p_{-} J, 0.00024,0,1$, 0,0 ; Adenomera $s p_{-} K, 0.00068,0,1,0,0$; Adenomera $s p_{-} L, 0.00084,0,1,0,0$; Adenomera $s p_{-} M, 0.00082,0,1,0,0 ;$ Adenomera $s p \_N, 0.00867,0,1,0,0$; Adenomera $s p \_0,0.01042,0,1,0,0$; Adenomera $s p \_P, 0.00783,0,1,0,0$; Adenomera $s p \_Q, 0.00783,0,1$, 0,0 ; Adenomera $s p_{-} R, 0.00122,0,1,0,0$; Adenomera $s p_{-} S, 0.00005,0,1,0$, 0; Adenomera $s p_{-} T, 0.00803,0,1,0,0 ;$ Adenomera thomei, 0.00001, 0, 1, 0, 0; Agalychnis, 0.00000, 0, 0, 0, 0; Agalychnis buckleyi, 0.00002, 1, 0, 0, 0; Agalychnis callidryas, 0.00000, 1, 0, 0, 0; Agalychnis danieli, 0.00097, 1, 0, 0, 0; Agalychnis hulli, 0.00003, 1, 0, 0, 0; Agalychnis lemur, 0.00003, 1, 0, 0, 0; Agalychnis medinae, 0.00021, 1, 0, 0, 0; Agalychnis psilopygion, 0.00002, 1, 0, 0, 0; Agalychnis spurrelli, 0.00002, 1, 0, 0, 0; Agalychnis terranova, 0.00014, 1, 0, 0, 0; Allobates, 0.00000, 0, 0, 0, 0; Allobates alessandroi, 0.00076, 0, 1, 0, 0; Allobates algorei, 0.00026, 0, 1, 0, 0; Allobates amissibilis, 0.00717, 0, 1, 0, 0; Allobates bacurau, 0.00716, 0, 1, 0, 0; Allobates bromelicola, 0.00255, 0, 1, 0, 0; Allobates brunneus, 0.00000, 0, 1, 0, 0; Allobates caeruleodactylus, 0.00001, 0, 1, 0, 0; Allobates caribe, 0.00496, 0, 1, 0, 0; Allobates cepedai, 0.00395, 0, 1, 0, 0; Allobates conspicuus, 0.00000, 0, 1, 0, 0; Allobates crombiei, 0.00008, 0, 1, 0, 0; Allobates femoralis, $0.00000,0,1,0,0$; Allobates flaviventris, 0.00010, 0, 1, 0, 0; Allobates fratisenescus, 0.00076, 0, 1, 0, 0; Allobates fuscellus, 0.00000, 0, 1, 0, 0; Allobates gasconi, 0.00001, 0, 1, 0, 0; Allobates goianus, 0.00002, 0, 1, 0, 0; Allobates granti, 0.00002, 0, 1, 0, 0; Allobates grillisimilis, 0.00024, 0, 1, 0, 0; Allobates hodli, 0.00005, 0, 1, 0, 0; Allobates humilis, 0.00028, 0, 1, 0, 0; Allobates ignotus, 0.00046, 0, 1, 0, 0; Allobates insperatus, 0.00001, 0, 1, 0, 0; Allobates juanii, 0.00466, 0, 1, 0, 0; Allobates kingsburyi, 0.00029, 0, 1, 0, 0; Allobates magnussoni, 0.00003, 0, 1, 0, 0; Allobates mandelorum, 0.00016, 0, 1, 0, 0; Allobates marchesianus, 0.00000, 0, 1, 0, 0; Allobates masniger, 0.00010, 0, 1, 0, 0; Allobates mcdiarmidi, 0.00003, 0, 1, 0, 0; Allobates melanolaemus, 0.00012, 0, 1, 0, 0; Allobates myersi, $0.00001,0,1,0,0$; Allobates nidicola, 0.00001, 0, 1, 0, 0; Allobates niputidea, 0.00012, 0, 1, 0, 0; Allobates olfersioides, 0.00001, 0, 1, 0, 0; Allobates ornatus, 0.00610, 0, 1, 0, 0; Allobates paleovarzensis, 0.00008, 0, 1, 0, 0; Allobates picachos, 0.00546, 0, 1, 0, 0; Allobates pittieri, 0.00003, 0, 1, 0, 0; Allobates ranoides, 0.00046, 0, 1, 0, 0; Allobates sanmartini, 0.00199, 0, 1, 0, 0; Allobates subfolionidificans, 0.00556, 0, 1, 0, 0; Allobates sumtuosus, 0.00000, 0, 1, 0, 0; Allobates talamancae, 0.00001 , 0, 1, 0, 0; Allobates tapajos, 0.00003, 0, 1, 0, 0; Allobates trilineatus, 0.00000, 0, 1, 0, 0; Allobates undulatus, 0.00076, 0, 1, 0, 0; Allobates vanzolinius, 0.00001, 0, 1, 0, 0; Allobates wayuu, 0.00411, 0, 1, 0, 0; Allobates zaparo, 0.00002, 0, 1, 0, 0; Allophryne, 0.00000 , 0, 0, 0, 0; Allophryne relicta, 0.00737, 1, 0, 0, 0; Allophryne resplendens, 0.00006, 1, 0, 0, 0; Allophryne ruthveni, 0.00000, 1, 0, 0, 0; ALLOPHRYNIDAE, 0.00000, 0, 0, 0, 0; Alsodes, 0.00001, 0, 0, 0, 0; Alsodes australis, 0.00331, 0, 1, 0, 0; Alsodes barrioi, $0.00079,0,1,0,0$; Alsodes cantillanensis, 0.00075, 0, 1, 0, 0; Alsodes coppingeri, 0.00011, 0, 1, 0, 0; Alsodes gargola, 0.00010, 0, 1, 0, 0; Alsodes hugoi, 0.00894, 0, 1, 0, 0; Alsodes igneus, 0.00336, 0, 1, 0, 0; Alsodes kaweshkari, 0.00196, 0, 1, 0, 0; Alsodes montanus, 0.00091, 0, 1, 0, 0; Alsodes monticola, 0.15462, 0, 1, 0, 0; Alsodes neuquensis, 0.00028, 0, 1, 0, 0; Alsodes nodosus, $0.00002,0,1$, 0, 0; Alsodes norae, 0.00567, 0, 1, 0, 0; Alsodes pehuenche, 0.11214, 0, 1, 0, 0; Alsodes tumultuosus, 0.00277, 0, 1, 0, 0 ; Alsodes valdiviensis, 0.00132, 0, 1, 0, 0; Alsodes vanzolinii, 0.00828, 0, 1, 0, 0; Alsodes verrucosus, 0.00003, 0, 1, 0, 0; Alsodes vittatus, 0.00584, 0, 1, 0, 0; ALSODIDAE, 0.00000, 0, 0, 0, 0; Amazophrynella, 0.00000, 0, 0, 0, 0; Amazophrynella amazonicola, 0.00014 , 0, 1, 0, 0; Amazophrynella bokermanni, 0.00000, 0, 1, 0, 0; Amazophrynella javierbustamantei, 0.00002, 0, 1, 0, 0; Amazophrynella matses, 0.00030, 0, 1, 0, 0; Amazophrynella minuta, 0.00001, 0, 1, 0, 0; Amazophrynella vote, 0.00000, 0, 1, 0, 0; Ameerega, 0.00000, 0, 0, 0, 0; Ameerega altamazonica, 0.00001, 1, 1, 0, 0; Ameerega andina, 0.00977, 1, 1, 0, 0; Ameerega bassleri, 0.00005, 1, 1, 0, 0; Ameerega berohoka, 0.00003, 1, 1, 0, 0; Ameerega bilinguis, 0.00001, 1, 1, 0, 0; Ameerega boehmei, $0.00096,1,1,0$, 0; Ameerega boliviana, 0.00008, 1, 1, 0, 0; Ameerega braccata, 0.00001, 1, 1, 0, 0; Ameerega cainarachi, 0.00135, 1, 1, 0, 0; Ameerega erythromos, 0.00022, 1, 1, 0, 0; Ameerega flavopicta, 0.00000, 1, 1, 0, 0; Ameerega hahneli, 0.00000, 1, 1, 0, 0; Ameerega ignipedis, 0.00214, 1, 1, 0, 0; Ameerega ingeri, 0.00072, 1, 1, 0, 0; Ameerega labialis, 0.00785, 1, 1, 0, 0; Ameerega macero, 0.00001, 1, 1, 0, 0; Ameerega parvula, 0.00000, 1, 1, 0, 0; Ameerega pepperi, 0.00053, 1, 1, 0, 0; Ameerega petersi, $0.00001,1,1$, 0, 0; Ameerega picta, 0.00000, 1, 1, 0, 0; Ameerega planipaleae, 0.00451, 1, 1, 0, 0; Ameerega pongoensis, 0.00010 , 1,1 , 0, 0; Ameerega pulchripecta, 0.00014, 1, 1, 0, 0; Ameerega rubriventris, 0.00034, 1, 1, 0, 0; Ameerega silverstonei, 0.00024, 1, 1, 0, 0; Ameerega simulans, 0.00011, 1, 1, 0, 0; Ameerega smaragdina, 0.00180, 1, 1, 0, 0; Ameerega trivittata, 0.00000, 1, 1, 0, 0; 
Ameerega yoshina, 0.00126, 1, 1, 0, 0; Ameerega yungicola, 0.00025, 1, 1, 0, 0; Andinobates, 0.00001, 0, 0, 0, 0; Andinobates abditus, 0.00871, 0, 1, 0, 0; Andinobates altobueyensis, 0.00162, 0, 1, 0, 0; Andinobates bombetes, 0.00050, 0, 1, 0, 0; Andinobates cassidyhornae, 0.00100, 0, 1, 0, 0; Andinobates daleswansoni, 0.00167, 0, 1, 0, 0; Andinobates dorisswansonae, 0.00719, 0, 1, 0, 0; Andinobates fulguritus, 0.00002, 0, 1, 0, 0; Andinobates minutus, 0.00001, 0, 1, 0, 0; Andinobates opisthomelas, 0.00005, 0, 1, 0, 0; Andinobates tolimensis, 0.00163, 0, 1, 0, 0; Andinobates viridis, 0.00020, 0, 1, 0, 0; Andinobates virolinensis, 0.00023, 0, 1, 0, 0; Anomaloglossus, 0.00000, 0, 0, 0, 0; Anomaloglossus apiau, 0.00952, 0, 1, 0, 0; Anomaloglossus atopoglossus, 0.00958, 0, 1, 0, 0; Anomaloglossus ayarzaguenai, 0.00033, 0, 1, 0, 0; Anomaloglossus baeobatrachus, 0.00000, 0, 1, 0, 0; Anomaloglossus beebei, 0.00011, 0, 1, 0, 0; Anomaloglossus breweri, 0.00354, 0, 1, 0, 0; Anomaloglossus confusus, 0.00032, 0, 1, 0, 0; Anomaloglossus degranvillei, 0.00001, 0, 1, 0, 0; Anomaloglossus guanayensis, 0.00089, 0, 1, 0, 0; Anomaloglossus kaiei, 0.00009, 0, 1, 0, 0; Anomaloglossus lacrimosus, 0.00020, 0, 1, 0, 0; Anomaloglossus leopardus, 0.00222, 0, 1, 0, 0; Anomaloglossus megacephalus, 0.00118, 0, 1, 0, 0; Anomaloglossus moffetti, 0.00492, 0, 1, 0, 0; Anomaloglossus murisipanensis, 0.01379, 0, 1, 0, 0; Anomaloglossus parimae, 0.00143, 0, 1, 0, 0; Anomaloglossus parkerae, 0.00116, 0, 1, 0, 0; Anomaloglossus praderioi, 0.00025, 0, 1, 0, 0; Anomaloglossus roraima, 0.00299, 0, 1, 0, 0; Anomaloglossus rufulus, 0.00079, 0, 1, 0, 0; Anomaloglossus shrevei, 0.00250, 0, 1, 0, 0; Anomaloglossus stepheni, 0.00001, 0, 1, 0, 0; Anomaloglossus surinamensis, 0.00766, 0, 1, 0, 0; Anomaloglossus tamacuarensis, 0.00103, 0, 1, 0, 0; Anomaloglossus tepequem, 0.00954, 0, 1, 0, 0; Anomaloglossus tepuyensis, 0.00056, 0, 1, 0, 0; Anomaloglossus triunfo, 0.01291, 0, 1, 0, 0; Anomaloglossus verbeeksnyderorum, 0.01812, 0, 1, 0, 0; Anomaloglossus wothuja, 0.01206, 0, 1, 0, 0; ANURA, 0.00000, 0, 0, 0, 0; Aparasphenodon, 0.00000, 0, 0, 0, 0; Aparasphenodon arapapa, 0.00029, 1, 0, 0, 0; Aparasphenodon bokermanni, 0.00010, 1, 0, 0, 0; Aparasphenodon brunoi, 0.00001, 1, 0, 0, 0; Aparasphenodon pomba, 0.00766, 1, 0, 0, 0; Aparasphenodon venezolanus, 0.00000, 1, 0, 0, 0; Aplastodiscus, 0.00000, 0, 0, 0, 0; Aplastodiscus albofrenatus, 0.00006, 1, 0, 0, 0; Aplastodiscus albosignatus, 0.00002, 1, 0, 0, 0; Aplastodiscus arildae, 0.00002, 1, 0, 0, 0; Aplastodiscus cavicola, 0.00002, 1, 0, 0, 0; Aplastodiscus cochranae, 0.00008, 1, 0, 0, 0; Aplastodiscus ehrhardti, 0.00003, 1, 0, 0, 0; Aplastodiscus eugenioi, 0.00038, 1, 0, 0, 0; Aplastodiscus flumineus, 0.00950, 1, 0, 0, 0; Aplastodiscus ibirapitanga, 0.00001, 1, 0, 0, 0; Aplastodiscus leucopygius, 0.00002, 1, 0, 0, 0; Aplastodiscus lutzorum, 0.00002, 1, 0, 0, 0; Aplastodiscus musicus, 0.00148, 1, 0, 0, 0; Aplastodiscus perviridis, 0.00000, 1, 0, 0, 0; Aplastodiscus sibilatus, 0.00012, 1, 0, 0, 0; Aplastodiscus weygoldti, 0.00003, 1, 0, 0, 0; Arcovomer, 0.00002, 0, 0, 0, 0; Arcovomer passarellii, 0.00002, 0, 1, 0, 0; Argenteohyla, 0.00001, 0, 0, 0, 0; Argenteohyla siemersi, 0.00001, 1, 0, 0, 0; Aromobates, 0.00013, 0, 0, 0, 0; Aromobates alboguttatus, 0.00064, 0, 1, 0, 0; Aromobates cannatellai, 0.00806, 0, 1, 0, 0; Aromobates capurinensis, 0.00575, 0, 1, 0, 0; Aromobates duranti, 0.00251, 0, 1, 0, 0; Aromobates ericksonae, 0.00042, 0, 1, 0, 0; Aromobates haydeeae, 0.00341, 0, 1, 0, 0; Aromobates leopardalis, 0.00357, 0, 1, 0, 0; Aromobates mayorgai, 0.00402, 0, 1, 0, 0; Aromobates meridensis, 0.00396, 0, 1, 0, 0; Aromobates molinarii, 0.00505, 0, 1, 0, 0; Aromobates nocturnus, 0.00536, 0, 1, 0, 0; Aromobates ornatissimus, 0.00809, 0, 1, 0, 0; Aromobates orostoma, 0.00366, 0, 1, 0, 0; Aromobates saltuensis, 0.00059, 0, 1, 0, 0; Aromobates serranus, 0.01527, 0, 1, 0, 0; Aromobates tokuko, 0.00518, 0, 1, 0, 0; Aromobates walterarpi, 0.00362, 0, 1, 0, 0; Aromobates zippeli, 0.00378, 0, 1, 0, 0; AROMOBATIDAE, 0.00000, 0, 0, 0, 0; Atelognathus, 0.00008, 0, 0, 0, 0; Atelognathus ceii, 0.01004 , 0, 1, 0, 0; Atelognathus nitoi, 0.00422, 0, 1, 0, 0; Atelognathus patagonicus, 0.00088, 0, 1, 0, 0; Atelognathus praebasalticus, 0.00018, 0, 1, 0, 0; Atelognathus reverberii, 0.00020, 0, 1, 0, 0; Atelognathus salai, 0.00505, 0, 1, 0, 0; Atelognathus solitarius, 0.00436, 0, 1, 0, 0; Atelopus, 0.00000, 0, 0, 0, 0; Atelopus andinus, 0.00020, 0, 1, 0, 0; Atelopus angelito, 0.00462, 0, 1, 0, 0; Atelopus ardila, 0.00141, 0, 1, 0, 0; Atelopus arsyecue, 0.00172, 0, 1, 0, 0; Atelopus arthuri, 0.00241, 0, 1, 0, 0; Atelopus balios, 0.00262, 0, 1, 0, 0; Atelopus barbotini, 0.00005, 0, 1, 0, 0; Atelopus bomolochos, 0.00009, 0, 1, 0, 0; Atelopus boulengeri, 0.00031, 0, 1, 0, 0; Atelopus carauta, 0.00294, 0, 1, 0, 0; Atelopus carbonerensis, 0.00691, 0, 1, 0, 0; Atelopus carrikeri, 0.00031, 0, 1, 0, 0; Atelopus chocoensis, 0.00290, 0, 1, 0, 0; Atelopus chrysocorallus, 0.00395, 0, 1, 0, 0; Atelopus coynei, 0.00034, 0, 1, 0, 0; Atelopus cruciger, 0.00014, 0, 1, 0, 0; Atelopus dimorphus, 0.00612, 0, 1, 0, 0; Atelopus ebenoides, 0.00075, 0, 1, 0, 0; Atelopus elegans, 0.00003, 0, 1, 0, 0; Atelopus elegans, 0.06970, 0, 1, 0, 0; Atelopus epikeisthos, 0.00101, 0, 1, 0, 0; Atelopus erythropus, 0.00375, 0, 1, 0, 0; Atelopus eusebianus, 0.00022, 0, 1, 0, 0; Atelopus eusebiodiazi, 0.00181, 0, 1, 0, 0; Atelopus exiguus, 0.00064, 0, 1, 0, 0; Atelopus famelicus, 0.00431, 0, 1, 0, 0; Atelopus farci, 0.01003, 0, 1, 0, 0; Atelopus flavescens, 0.00021, 0, 1, 0, 0; Atelopus franciscus, 0.00010, 0, 1, 0, 0; Atelopus galactogaster, 0.01553, 0, 1, 0, 0; Atelopus gigas, 0.00399, 0, 1, 0, 0; Atelopus glyphus, 0.00351, 0, 1, 0, 0; Atelopus guanujo, 0.00299, 0, 1, 0, 0; Atelopus guitarraensis, 0.00116, 0, 1, 0, 0; Atelopus halihelos, 0.00204, 0, 1, 0, 0; Atelopus hoogmoedi, 0.00000, 0, 1, 0, 0; Atelopus ignescens, 0.00010, 0, 1, 0, 0; Atelopus laetissimus, 0.00080, 0, 1, 0, 0; Atelopus loettersi, 0.00008, 0, 1, 0, 0; Atelopus longibrachius, 0.00098, 0, 1, 0, 0; Atelopus longirostris, 0.00020, 0, 1, 0, 0; Atelopus lozanoi, 0.00224, 0, 1, 0, 0; Atelopus lynchi, 0.00427, 0, 1, 0, 0; Atelopus mandingues, 0.00347, 0, 1, 0, 0; Atelopus marinkellei, 0.00045, 0, 1, 0, 0; Atelopus mindoensis, 0.00025, 0, 1, 0, 0; Atelopus minutulus, 0.00549, 0, 1, 0, 0; Atelopus mittermeieri, 0.00731, 0, 1, 0, 0; Atelopus monohernandezii, 0.00986, 0, 1, 0, 0; Atelopus mucubajiensis, 0.01114, 0, 1, 0, 0; Atelopus muisca, 0.00731, 0, 1, 0, 0; Atelopus nahumae, 0.00056, 0, 1, 0, 0; Atelopus nanay, 0.00524, 0, 1, 0, 0; Atelopus nepiozomus, 0.00017, 0, 1, 0, 0; Atelopus nicefori, 0.01102, 0, 1, 0, 0; Atelopus nocturnus, 0.00734, 0, 1, 0, 0; Atelopus onorei, 0.00618, 0, 1, 0, 0; Atelopus orcesi, 0.00589, 0, 1, 0, 0; Atelopus oxapampae, 0.00231, 0, 1, 0, 0; Atelopus oxyrhynchus, 0.00291, 0, 1, 0, 0; Atelopus pachydermus, 0.00008, 0, 1, 0, 0; Atelopus palmatus, 0.00114, 0, 1, 0, 0; Atelopus pastuso, 0.00019, 0, 1, 0, 0; Atelopus patazensis, 0.00353, 0, 1, 0, 0; Atelopus pedimarmoratus, 0.01032, 0, 1, 0, 0; Atelopus peruensis, 0.00004, 0, 1, 0, 0; Atelopus petersi, 0.00014, 0, 1, 0, 0; Atelopus petriruizi, 0.00220, 0, 1, 0, 0; Atelopus pictiventris, 0.00141, 0, 1, 0, 0; Atelopus pinangoi, 0.00466, 0, 1, 0, 0; Atelopus planispina, 0.00031, 0, 1, 0, 0; Atelopus podocarpus, 0.00022, 0, 1, 0, 0; Atelopus pulcher, 0.00011, 0, 1, 0, 0; Atelopus pyrodactylus, 0.00296, 0, 1, 0, 0; Atelopus quimbaya, 0.00411, 0, 1, 0, 0; Atelopus reticulatus, 0.01476, 0, 1, 0, 0; Atelopus sanjosei, 0.00288, 0, 1, 0, 0; Atelopus seminiferus, 0.00044, 0, 1, 0, 0; Atelopus sernai, 0.00132, 0, 1, 0, 0; Atelopus simulatus, 0.00022, 0, 1, 0, 0; Atelopus siranus, 0.00073, 0, 1, 0, 0; Atelopus sonsonensis, 0.00282, 0, 1, 0, 0; Atelopus sorianoi, 0.00549, 0, 1, 0, 0; Atelopus spumarius, 0.00000, 0, 1, 0, 0; Atelopus spurrelli, 0.00004, 0, 1, 0, 0; Atelopus subornatus, 0.00326, 0, 1, 0, 0; Atelopus tamaense, 0.00172, 0, 1, 0, 0; Atelopus tricolor, 0.00002, 0, 1, 0, 0; Atelopus vogli, 0.00101, 0, 1, 0, 0; Atelopus walkeri, 0.00163, 0, 1, 0, 0; Atopophrynus, 0.00596, 0, 0, 0, 0; Atopophrynus syntomopus, 0.00596, 0, 1, 0, 0; Atretochoana, 0.00000, 0, 0, 0, 0; Atretochoana eiselti, 0.00000, 0, 0, 1, 1; Barycholos, 0.00000, 0, 0, 0, 0; Barycholos pulcher, 0.00003, 0, 1, 0, 0; Barycholos ternetzi, 0.00000, 0, 1, 0, 0; Batrachyla, 0.00000, 0, 0, 0, 0; Batrachyla antartandica, 0.00001, 0, 1, 0, 0; Batrachyla fitzroya, 0.01608, 0, 1, 0, 0; Batrachyla leptopus, 0.00001, 0, 1, 0, 
0; Batrachyla nibaldoi, 0.00002, 0, 1, 0, 0; Batrachyla taeniata, 0.00000, 0, 1, 0, 0; BATRACHYLIDAE, 0.00000, 0, 0, 0, 0; Bokermannohyla, 0.00000, 0, 0, 0, 0; Bokermannohyla aff_circumdata, 0.00004, 1, 0, 0, 0; Bokermannohyla ahenea, 0.02169, 1, 0, 0, 0; Bokermannohyla alvarengai, 0.00001, 1, 1, 0, 0; Bokermannohyla astartea, 0.00016, 1, 0, 0, 0; Bokermannohyla capra, $0.00008,1,0,0$, 0; Bokermannohyla caramaschii, 0.00006, 1, 0, 0, 0; Bokermannohyla carvalhoi, 0.00027, 1, 0, 0, 0; Bokermannohyla circumdata, 0.00002, 1, 0, 0, 0; Bokermannohyla claresignata, 0.00025, 1, 0, 0, 0; Bokermannohyla clepsydra, $0.00019,1,0,0,0$; Bokermannohyla diamantina, 0.00052, 1, 1, 0, 0; Bokermannohyla flavopicta, 0.00023, 1, 1, 0, 0; Bokermannohyla gouveai, 0.00218, 1, 0, 0, 0; Bokermannohyla hylax, 0.00001, 1, 0, 0, 0; Bokermannohyla ibitiguara, 0.00584, 1, 0, 0, 0; Bokermannohyla ibitipoca, 0.01547, 1, 0, 0, 0; Bokermannohyla itapoty, 0.00021, 1, 0, 0, 0; Bokermannohyla izecksohni, $0.00115,1,0,0$, 0; Bokermannohyla juiju, 0.00023, 1, 0, 0, 0; Bokermannohyla langei, 0.01170, 1, 0, 0, 0; Bokermannohyla lucianae, 0.00310, 1, 0, 0, 0; Bokermannohyla luctuosa, 0.00005, 1, 0, 0, 0; Bokermannohyla martinsi, 0.00005, 1, 0, 0, 0; Bokermannohyla nanuzae, 0.00008, 1, 1, 0, 0; Bokermannohyla napolii, 0.00756, 1, 0, 0, 0; Bokermannohyla oxente, 0.00004, 1, 0, 0, 0; Bokermannohyla pseudopseudis, 0.00001, 1, 0, 0, 0; Bokermannohyla ravida, 0.00216, 1, 0, 0, 0; Bokermannohyla sagarana, 0.00048, 1, 0, 0, 0; Bokermannohyla sapiranga, 0.00001, 1, 0, 0, 0; Bokermannohyla saxicola, 0.00002, 1, 1, 0, 0; Bokermannohyla sazimai, 0.00003, 1, 0, 0, 0; Bokermannohyla vulcaniae, 0.00896, 1, 0, 0, 0; Bolitoglossa, 0.00000, 0, 0, 0, 0; Bolitoglossa adspersa, $0.00005,1,0,0$, 0; Bolitoglossa altamazonica, 0.00000, 1, 0, 0, 0; Bolitoglossa biseriata, 0.00002, 1, 0, 0, 0; Bolitoglossa borburata, $0.00035,1$, 0, 0, 0; Bolitoglossa caldwellae, 0.00003, 1, 0, 0, 0; Bolitoglossa capitana, 0.00840, 1, 0, 0, 0; Bolitoglossa chica, 0.00015, 1, 0, 0, 0; Bolitoglossa digitigrada, 0.00314, 1, 0, 0, 0; Bolitoglossa equatoriana, 0.00003, 1, 0, 0, 0; Bolitoglossa guaneae, 0.00021 , 1, 0, 0, 0; Bolitoglossa guaramacalensis, 0.00598, 1, 0, 0, 0; Bolitoglossa hiemalis, 0.00583, 1, 0, 0, 0; Bolitoglossa hypacra, 0.00302, 1, 0, 0, 0; Bolitoglossa leandrae, 0.00763, 1, 0, 0, 0; Bolitoglossa lozanoi, 0.00004, 1, 0, 0, 0; Bolitoglossa madeira, 0.00012, 1, 0, 0, 0; Bolitoglossa medemi, 0.00008, 1, 0, 0, 0; Bolitoglossa mucuyensis, 0.00765, 1, 0, 0, 0; Bolitoglossa nicefori, 0.00031, 1, 0, 0, 0; Bolitoglossa orestes, $0.00278,1,0,0,0$; Bolitoglossa palmata, $0.00003,1,0,0,0$; Bolitoglossa pandi, 0.00244, 1, 0, 0, 0; Bolitoglossa paraensis, 0.00001, 1, 0, 0, 0; Bolitoglossa peruviana, 0.00001, 1, 0, 0, 0; Bolitoglossa phalarosoma, 0.00707, 1, 0, 0, 0; Bolitoglossa ramosi, 0.00010, 1, 0, 0, 0; Bolitoglossa savagei, 0.00328, 1, 0, 0, 0; Bolitoglossa silverstonei, 0.00003, 1, 0, 0, 0; Bolitoglossa sima, $0.00019,1$, 0, 0, 0; Bolitoglossa tamaense, 0.00648, 1, 0, 0, 0; Bolitoglossa tapajonica, 0.00001, 1, 0, 0, 0; Bolitoglossa tatamae, $0.00228,1,0,0$, 0; Bolitoglossa vallecula, 0.00010, 1, 0, 0, 0; Bolitoglossa walkeri, 0.00047, 1, 0, 0, 0; BRACHYCEPHALIDAE, 0.00000, 0, 0, 0, 0; Brachycephalus, 0.00001, 0, 0, 0, 0; Brachycephalus alipioi, 0.00037, 0, 1, 0, 0; Brachycephalus atelopoide, 0.00848, 0, 1, 0, 0; Brachycephalus auroguttatus, 0.01347, 0, 1, 0, 0; Brachycephalus boticario, 0.00797, 0, 1, 0, 0; Brachycephalus brunneus, 0.02109, 0, 1, 0, 0; Brachycephalus bufonoides, 0.00718, 0, 1, 0, 0; Brachycephalus crispus, 0.01844, 0, 1, 0, 0; Brachycephalus didactylus, 0.00004, 0, 1, 0, 0; Brachycephalus ephippium, 0.00001, 0, 1, 0, 0; Brachycephalus ferruginus, 0.00859, 0, 1, 0, 0; Brachycephalus fuscolineatus, 0.02066, 0, 1, 0, 0; Brachycephalus garbeanus, 0.00223, 0, 1, 0, 0; Brachycephalus guarani, 0.03906, $0,1,0$, 0; Brachycephalus hermogenesi, 0.00002, 0, 1, 0, 0; Brachycephalus izecksohni, 0.00777, 0, 1, 0, 0; Brachycephalus leopardus, 0.02050, 0, 1, 0, 0; Brachycephalus margaritatus, 0.00193, 0, 1, 0, 0; Brachycephalus mariaeterezae, 0.01202, 0, 1, 0, 0; Brachycephalus nodoterga, 0.00018, 0, 1, 0, 0; Brachycephalus olivaceus, 0.01702, 0, 1, 0, 0; Brachycephalus pernix, 0.00551, 0, 1, 0, 0; Brachycephalus pitanga, 0.00506, 0, 1, 0, 0; Brachycephalus pombali, 0.00393, 0, 1, 0, 0; Brachycephalus pulex, 0.01198, 0, 1, 0, 0; Brachycephalus quiririensis, 0.00753, 0, 1, 0, 0; Brachycephalus sulfuratus, 0.00008, 0, 1, 0, 0; Brachycephalus toby, 0.04281, 0, 1, 0, 0; Brachycephalus tridactylus, 0.02940, 0, 1, 0, 0; Brachycephalus verrucosus, 0.02087, 0, 1, 0, 0; Brachycephalus vertebralis, $0.01287,0$, 1, 0, 0; Brasilotyphlus, 0.00001, 0, 0, 0, 0; Brasilotyphlus braziliensis, 0.00030, 0, 0, 0, 1; Brasilotyphlus guarantanus, 0.00001 , 0, 0, 0, 1; Bryophryne, 0.00043, 0, 0, 0, 0; Bryophryne abramalagae, 0.00977, 0, 1, 0, 0; Bryophryne bakersfield, 0.00838, 0, 1, 0, 0; Bryophryne bustamantei, 0.00121, 0, 1, 0, 0; Bryophryne cophites, 0.00372, 0, 1, 0, 0; Bryophryne flammiventris, 0.00977, 0, 1, 0, 0; Bryophryne gymnotis, 0.00317, 0, 1, 0, 0; Bryophryne hanssaueri, 0.00489, 0, 1, 0, 0; Bryophryne nubilosus, 0.00330, 0, 1, 0, 0; Bryophryne zonalis, 0.00183, 0, 1, 0, 0; BUFONIDAE, 0.00000, 0, 0, 0, 0; Caecilia, 0.00000, 0, 0, 0, 0; Caecilia abitaguae, 0.00027, $0,0,0,1$; Caecilia antioquiaensis, 0.01025, 0, 0, 0, 1; Caecilia attenuata, 0.00326, 0, 0, 0, 1; Caecilia bokermanni, 0.00001, 0, 0, 0, 1; Caecilia caribea, 0.00167, 0, 0, 0, 1; Caecilia corpulenta, 0.01326, 0, 0, 0, 1; Caecilia crassisquama, 0.01134, 0, 0, 0, 1; Caecilia degenerata, 0.00010, 0, 0, 0, 1; Caecilia disossea, 0.00003, 0, 0, 0, 1; Caecilia dunni, 0.00337, 0, 0, 0, 1; Caecilia flavopunctata, $0.00327,0$, 0, 0, 1; Caecilia gracilis, 0.00000, 0, 0, 0, 1; Caecilia guntheri, 0.00003, 0, 0, 0, 1; Caecilia inca, 0.00009, 0, 0, 0, 1; Caecilia isthmica, 0.00001, 0, 0, 0, 1; Caecilia leucocephala, 0.00002, 0, 0, 0, 1; Caecilia marcusi, 0.00000, 0, 0, 0, 1; Caecilia nigricans, $0.00001,0,0,0,1$; Caecilia occidentalis, $0.00012,0,0,0,1$; Caecilia orientalis, 0.00068, 0, 0, 0, 1; Caecilia pachynema, 0.00006, 0, 0, 0, 1; Caecilia perdita, 0.00004, 0, 0, 0, 1; Caecilia pressula, 0.00514, 0, 0, 0, 1; Caecilia subdermalis, 0.00002, 0, 0, 0, 1; Caecilia subnigricans, 0.00000, 0, 0, 0, 1; Caecilia tentaculata, 0.00000, 0, 0, 0, 1; Caecilia tenuissima, 0.00003, 0, 0, 0, 1; Caecilia thompsoni, 0.00005 , 0, 0, 0, 1; CAECILIIDAE, 0.00000, 0, 0, 0, 0; Callimedusa, 0.00000, 0, 0, 0, 0; Callimedusa atelopoides, 0.00000, 1, 0, 0, 0; Callimedusa baltea, 0.00321, 1, 0, 0, 0; Callimedusa duellmani, 0.01343, 1, 0, 0, 0; Callimedusa ecuatoriana, 0.01502, 1, 0, 0, 0; Callimedusa perinesos, 0.00011, 1, 0, 0, 0; Callimedusa tomopterna, 0.00000, 1, 0, 0, 0; Calyptocephalella, 0.00001, 0, 0, 0, 0; Calyptocephalella gayi, 0.00001, 1, 1, 0, 0; CALYPTOCEPHALELLIDAE, 0.00001, 0, 0, 0, 0; CAUDATA, 0.00000, 0, 0, 0, 0; Celsiella, 0.00018, 0, 0, 0, 0; Celsiella revocata, 0.00019, 1, 0, 0, 0; Celsiella vozmedianoi, 0.00759, 1, 0, 0, 0; Centrolene, 0.00000, 0, 0, 0, 0; Centrolene acanthidiocephalum, 0.00187, 1, 0, 0, 0; Centrolene altitudinale, 0.00893, 1, 0, 0, 0; Centrolene antioquiense, 0.00005, 1, 0, 0, 0; Centrolene azulae, 0.00657, 1, 0, 0, 0; Centrolene bacatum, 0.00014, 1, 0, 0, 0; Centrolene ballux, 0.00025, 1, 0, 0, 0; Centrolene buckleyi, 0.00000, 1, 0, 0, 0; Centrolene charapita, 0.00779, 1, 0, 0, 0; Centrolene condor, 0.00585, 1, 0, 0, 0; Centrolene daidaleum, 0.00004, 1, 0, 0, 0; Centrolene geckoideum, 0.00001, 1, 0, 0, 0; Centrolene gemmatum, 0.00198, 1, 0, 0, 0; Centrolene guanacarum, 0.01512, 1, 0, 0, 0; Centrolene heloderma, 0.00006, 1, 0, 0, 0; Centrolene hesperium, 0.00284, 1, 0, 0, 0; Centrolene huilense, 0.00702, 1, 0, 0, 0; Centrolene hybrida, 0.00020, 1, 0, 0, 0; Centrolene lemniscatum, 0.01052, 1, 0, 0, 0; Centrolene lynchi, $0.00005,1,0,0,0$; Centrolene medemi, 0.00003, 1, 0, 0, 0; Centrolene muelleri, 0.00163, 1, 0, 0, 0; Centrolene notostictum, 0.00003, 1, 0, 0, 0; Centrolene paezorum, 0.00950, 1, 0, 0, 0; Centrolene peristictum, 0.00007, 1, 0, 0, 0; Centrolene petrophilum, 0.00309, 1, 0, 0, 0; Centrolene pipilatum, 0.00200, 1, 0, 0, 0; Centrolene quindianum, 0.00009, 1, 0, 0, 0; Centrolene robledoi, 0.00013, 1, 0, 0, 0; Centrolene sabini, 0.00999, 1, 0, 0, 0; Centrolene sanchezi, 0.00192, 1, 0, 0, 0; Centrolene savagei, 0.00024, 1, 0, 0, 0; Centrolene scirtetes, $0.00038,1$, 0, 0, 0; Centrolene solitaria, 0.00630, 1, 0, 0, 0; Centrolene venezuelense, 0.00005, 1, 0, 0, 0; CENTROLENIDAE, 
$0.00000,0,0$, 0, 0; CERATOPHRYIDAE, 0.00000, 0, 0, 0, 0; Ceratophrys, 0.00000, 0, 0, 0, 0; Ceratophrys aurita, 0.00000, 0, 1, 0, 0; Ceratophrys calcarata, $0.00001,0,1,0,0$; Ceratophrys cornuta, 0.00000, 0, 1, 0, 0; Ceratophrys cranwelli, 0.00000, 0, 1, 0, 0; Ceratophrys joazeirensis, 0.00000, 0, 1, 0, 0; Ceratophrys ornata, 0.00000, 0, 1, 0, 0; Ceratophrys stolzmanni, 0.00005, 0, 1, 0, 0; Ceratophrys testudo, 0.00248, 0, 1, 0, 0; CEUTHOMANTIDAE, 0.00068, 0, 0, 0, 0; Ceuthomantis, 0.00068, 0, 0, 0, 0; Ceuthomantis aracamuni, 0.00543, 1, 0, 0, 0; Ceuthomantis cavernibardus, 0.00226, 1, 0, 0, 0; Ceuthomantis duellmani, 0.00139, 1, 0, 0, 0; Ceuthomantis smaragdinus, 0.00751, 1, 0, 0, 0; Chacophrys, 0.00000, 0, 0, 0, 0; Chacophrys pierottii, 0.00000, 0, 1, 0, 0; Chaltenobatrachus, 0.00004, 0, 0, 0, 0; Chaltenobatrachus grandisonae, 0.00004, 0, 1, 0, 0; Chiasmocleis, 0.00000, 0, 0, 0, 0; Chiasmocleis alagoana, 0.00014, 0, 1, 0, 0; Chiasmocleis albopunctata, 0.00000, 0, 1, 0, 0; Chiasmocleis altomontana, 0.00055, 0, 1, 0, 0; Chiasmocleis anatipes, 0.00001, 0, 1, 0, 0; Chiasmocleis antenori, 0.00000, 0, 1, 0, 0; Chiasmocleis atlantica, 0.00005, 0, 1, 0, 0; Chiasmocleis avilapiresae, $0.00000,0,1,0$, 0; Chiasmocleis bassleri, 0.00000, 0, 1, 0, 0; Chiasmocleis capixaba, 0.00013, 0, 1, 0, 0; Chiasmocleis carvalhoi, 0.00001, 0, 1, 0, 0; Chiasmocleis centralis, 0.00003, 0, 1, 0, 0; Chiasmocleis cordeiroi, 0.00005, 0, 1, 0, 0; Chiasmocleis crucis, 0.00009, 0, 1, 0, 0; Chiasmocleis devriesi, 0.00327, 0, 1, 0, 0; Chiasmocleis gnoma, 0.00132, 0, 1, 0, 0; Chiasmocleis haddadi, 0.00004, 0, 1, 0, 0; Chiasmocleis hudsoni, 0.00000, 0, 1, 0, 0; Chiasmocleis lacrimae, 0.00003, 0, 1, 0, 0; Chiasmocleis leucosticta, 0.00001, 0, 1, 0, 0; Chiasmocleis magnova, 0.00003, 0, 1, 0, 0; Chiasmocleis mantiqueira, 0.00002, 0, 1, 0, 0; Chiasmocleis mehelyi, 0.00001, 0, 1, 0, 0; Chiasmocleis migueli, 0.00024, 0, 1, 0, 0; Chiasmocleis papachibe, 0.00005, 0, 1, 0, 0; Chiasmocleis quilombola, 0.00016, 0, 1, 0, 0; Chiasmocleis royi, 0.00000, 0, 1, 0, 0; Chiasmocleis sapiranga, 0.01960, 0, 1, 0, 0; Chiasmocleis schubarti, $0.00001,0,1,0$, 0; Chiasmocleis shudikarensis, 0.00000, 0, 1, 0, 0; Chiasmocleis supercilialba, 0.00001, 0, 1, 0,0 ; Chiasmocleis tridactyla, $0.00001,0,1,0,0$; Chiasmocleis ventrimaculata, 0.00000, 0, 1, 0, 0; Chiasmocleis veracruz, $0.00025,0$, 1, 0, 0; Chimerella, 0.00007, 0, 0, 0, 0; Chimerella corleone, 0.00731, 1, 0, 0, 0; Chimerella mariaelenae, 0.00007, 1, 0, 0, 0; Chthonerpeton, $0.00000,0,0,0,0$; Chthonerpeton arii, $0.00001,0,0,1,1$; Chthonerpeton indistinctum, 0.00000, 0, 0, 1, 1; Chthonerpeton noctinectes, $0.00022,0,0,1,1$; Chthonerpeton onorei, 0.01372, 0, 0, 1, 1; Chthonerpeton perissodus, 0.00958, 0, 0 , 1 , 1 ; Chthonerpeton tremembe, $0.00786,0,0,1,1$; Chthonerpeton viviparum, $0.00187,0,0,1,1$; Cochranella, 0.00000, 0, 0, 0, 0; Cochranella balionota, 0.00008, 1, 0, 0, 0; Cochranella duidaeana, 0.00084, 1, 0, 0, 0; Cochranella erminea, 0.00001, 1, 0, 0, 0; Cochranella euhystrix, 0.00847, 1, 0, 0, 0; Cochranella euknemos, 0.00002, 1, 0, 0, 0; Cochranella geijskesi, 0.00006, 1, 0, 0, 0; Cochranella guayasamini, 0.00008, 1, 0, 0, 0; Cochranella litoralis, 0.00031, 1, 0, 0, 0; Cochranella mache, 0.00002, 1, 0, 0, 0; Cochranella megista, 0.00020, 1, 0, 0, 0; Cochranella nola, 0.00001, 1, 0, 0, 0; Cochranella phryxa, 0.00044, 1, 0, 0, 0; Cochranella ramirezi, 0.00012, 1, 0, 0, 0; Cochranella resplendens, 0.00001, 1, 0, 0, 0; Cochranella riveroi, 0.00775, 1, 0, 0, 0; Cochranella xanthocheridia, 0.00024, 1, 0, 0, 0; Colomascirtus, 0.00001, 0, 0, 0, 0; Colomascirtus antioquia, 0.00024, 1, 0, 0, 0; Colomascirtus armatus, 0.00002, 1, 0, 0, 0; Colomascirtus caucanus, 0.00312, 1, 0, 0, 0; Colomascirtus charazani, 0.00619, 1, 0, 0, 0; Colomascirtus chlorosteus, 0.00677, 1, 0, 0, 0; Colomascirtus condor, 0.00882, 1, 0, 0, 0; Colomascirtus criptico, 0.00394, 1, 0, 0, 0; Colomascirtus larinopygion, 0.00001, 1, 0, 0, 0; Colomascirtus lindae, 0.00019, 1, 0, 0, 0; Colomascirtus pacha, 0.00532, 1, 0, 0, 0; Colomascirtus pantostictus, 0.00204, 1, 0, 0, 0; Colomascirtus princecharlesi, 0.00488, 1, 0, 0, 0; Colomascirtus psarolaimus, 0.00032, 1, 0, 0, 0; Colomascirtus ptychodactylus, 0.00205, 1, 0, 0, 0; Colomascirtus staufferorum, 0.00236, 1, 0, 0, 0; Colomascirtus tapichalaca, 0.01240, 1, 0, 0, 0; Colomascirtus tigrinus, 0.00035, 1, 0, 0, 0; Colostethus, 0.00001, 0, 0, 0, 0; Colostethus agilis, 0.00094, 0, 1, 0, 0; Colostethus alacris, 0.00509, 0, 1, 0, 0; Colostethus argyrogaster, 0.00004, 0, 1, 0, 0; Colostethus brachistriatus, 0.01273, 0, 1, 0, 0; Colostethus dysprosium, 0.00283, 0, 1, 0, 0; Colostethus fraterdanieli, 0.00006, 0, 1, 0, 0; Colostethus fugax, 0.00023, 0, 1, 0, 0; Colostethus furviventris, 0.00168, 0, 1, 0, 0; Colostethus imbricolus, 0.00084, 0, 1, 0, 0; Colostethus inguinalis, 0.00003, 0, 1, 0, 0; Colostethus jacobuspetersi, 0.00010, 0, 1, 0, 0; Colostethus latinasus, 0.00062, 0, 1, 0, 0; Colostethus lynchi, 0.00345, 0, 1, 0, 0; Colostethus mertensi, 0.00033, 0, 1, 0, 0; Colostethus panamansis, 0.00004, 0, 1, 0, 0; Colostethus poecilonotus, 0.00157, 0, 1, 0, 0; Colostethus pratti, 0.00001, 0, 1, 0, 0; Colostethus ramirezi, 0.00465, 0, 1, 0, 0; Colostethus ruthveni, 0.00091, 0, 1, 0, 0; Colostethus thorntoni, 0.00037, 0, 1, 0, 0; Colostethus ucumari, 0.00024, 0, 1, 0, 0; Colostethus yaguara, 0.00469, 0, 1, 0, 0; Corythomantis, $0.00000,0,0,0$, 0; Corythomantis galeata, 0.00157, 1, 1, 0, 0; Corythomantis greeningi, 0.00000, 1, 1, 0, 0; Craugastor, 0.00000, 0, 0, 0, 0; Craugastor crassidigitus, 0.00001, 1, 1, 0, 0; Craugastor fitzingeri, 0.00001, 1, 1, 0, 0; Craugastor longirostris, 0.00001, 1, 1, 0 , 0; Craugastor metriosistus, 0.00002, 1, 1, 0, 0; Craugastor opimus, 0.00001, 1, 1, 0, 0; Craugastor raniformis, 0.00001, 1, 1, 0, 0; CRAUGASTORIDAE, 0.00000, 0, 0, 0, 0; Crossodactylodes, 0.00046, 0, 0, 0, 0; Crossodactylodes bokermanni, 0.00062, 1, 1, 0, 0; Crossodactylodes itambe, 0.01013, 1, 1, 0, 0; Crossodactylodes izecksohni, 0.00268, 1, 1, 0, 0; Crossodactylodes pintoi, 0.01301, 1, 1, 0, 0; Crossodactylodes septentrionalis, 0.01211, 1, 1, 0, 0; Crossodactylus, 0.00000, 0, 0, 0, 0; Crossodactylus aeneus, 0.00035, 0, 1, 1, 0; Crossodactylus boulengeri, 0.00039, 0, 1, 1, 0; Crossodactylus caramaschii, 0.00002, 0, 1, 1, 0; Crossodactylus cyclospinus, 0.00010, 0, 1, 1, 0; Crossodactylus dantei, 0.00324, 0, 1, 1, 0; Crossodactylus dispar, 0.00039, 0, 1, 1, 0; Crossodactylus franciscanus, $0.00098,0,1,1$, 0; Crossodactylus gaudichaudii, 0.00001, 0, 1, 1, 0; Crossodactylus grandis, 0.00025, 0, 1, 1, 0; Crossodactylus lutzorum, 0.00508, 0, 1, 1, 0; Crossodactylus schmidti, 0.00001, 0, 1, 1, 0; Crossodactylus timbuhy, 0.00113, 0, 1, 1, 0; Crossodactylus trachystomus, 0.00003, 0, 1, 1, 0; Crossodactylus werneri, 0.00015, 0, 1, 1, 0; Cruziohyla, 0.00000, 0, 0, 0, 0; Cruziohyla calcarifer, $0.00003,1$, 0, 0, 0; Cruziohyla craspedopus, 0.00000, 1, 0, 0, 0; Cryptobatrachus, 0.00002, 0, 0, 0, 0; Cryptobatrachus boulengeri, $0.00022,0,1,1$, 0; Cryptobatrachus conditus, 0.01323, 0, 1, 1, 0; Cryptobatrachus fuhrmanni, 0.00003, 0, 1, 1, 0; Cryptobatrachus nicefori, 0.01323, 0, 1, 1, 0; Cryptobatrachus pedroruizi, 0.00032, 0, 1, 1, 0; Cryptobatrachus remotus, 0.00032, 0, 1, 1, 0; Cryptobatrachus ruthveni, 0.00748, 0, 1, 1, 0; Ctenophryne, 0.00000, 0, 0, 0, 0; Ctenophryne aequatorialis, 0.00026, 0, 1, 0, 0; Ctenophryne aterrima, 0.00000, 0, 1, 0, 0; Ctenophryne barbatula, 0.00590, 0, 1, 0, 0; Ctenophryne carpish, 0.00009, 0, 1, 0, 0; Ctenophryne geayi, 0.00000, 0, 1, 0, 0; Ctenophryne minor, 0.00174, 0, 1, 0, 0; CYCLORAMPHIDAE, 0.00000, 0, 0, 0, 0; Cycloramphus, 0.00001, 0, 0, 0, 0; Cycloramphus acangatan, 0.00019, 0, 1, 1, 0; Cycloramphus asper, 0.00006, 0, 1, 1, 0; Cycloramphus bandeirensis, 0.00787, 0, 1, 1, 0; Cycloramphus bolitoglossus, 0.00005, 0, 1, 1, 0; Cycloramphus boraceiensis, 0.00012 , 0, 1, 1, 0; Cycloramphus brasiliensis, 0.00020, 0, 1, 1, 0; Cycloramphus carvalhoi, 0.00044, 0, 1, 1, 0; Cycloramphus catarinensis, 0.00079, 0, 1, 1, 0; Cycloramphus cedrensis, 0.00285, 0, 1, 1, 0; Cycloramphus diringshofeni, 0.00012, 0, 1, 1, 0; Cycloramphus dubius, 0.00149, 0, 1, 1, 0; Cycloramphus duseni, 0.00255, 0, 1, 1, 0; Cycloramphus eleutherodactylus, 0.00001, 0, 1, 1, 0; Cycloramphus faustoi, 0.45996, 0, 1, 1, 0; Cycloramphus fuliginosus, 0.00021, 0, 1, 1, 0; Cycloramphus granulosus, 0.00049, 0 , 1, 1, 0; Cycloramphus izecksohni, 0.00004, 0, 1, 1, 0; Cycloramphus juimirim, 0.00560, 0, 1, 1, 0; Cycloramphus lithomimeticus, 
$0.00768,0,1,1,0$; Cycloramphus lutzorum, 0.00007, 0, 1, 1, 0; Cycloramphus migueli, 0.00010, 0, 1, 1, 0; Cycloramphus mirandaribeiroi, $0.00089,0,1,1,0$; Cycloramphus ohausi, 0.00064, 0, 1, 1, 0; Cycloramphus organensis, 0.01728, 0, 1, 1, 0; Cycloramphus rhyakonastes, 0.00048, 0, 1, 1, 0; Cycloramphus semipalmatus, 0.00081, 0, 1, 1, 0; Cycloramphus stejnegeri, 0.00108 , 0, 1, 1, 0; Cycloramphus valae, 0.00025, 0, 1, 1, 0; Dasypops, 0.00006, 0, 0, 0, 0; Dasypops schirchi, 0.00006, 0, 1, 0, 0; Dendrobates, $0.00000,0,0,0$, 0; Dendrobates auratus, 0.00001, 0, 1, 0, 0; Dendrobates leucomelas, 0.00000, 0, 1, 0, 0; Dendrobates nubeculosus, 0.00437, 0, 1, 0, 0; Dendrobates tinctorius, 0.00000, 0, 1, 0, 0; Dendrobates truncatus, 0.00001, 0, 1, 0, 0; DENDROBATIDAE, 0.00000 , 0, 0, 0, 0; Dendrophryniscus, 0.00001, 0, 0, 0, 0; Dendrophryniscus berthalutzae, 0.00004, 1, 1, 0, 0; Dendrophryniscus brevipollicatus, 0.00002, 1, 1, 0, 0; Dendrophryniscus carvalhoi, 0.00009, 1, 1, 0, 0; Dendrophryniscus krausae, 0.00009, 1, 1, 0, 0; Dendrophryniscus leucomystax, 0.00002, 1, 1, 0, 0; Dendrophryniscus oreites, 0.01369, 1, 1, 0, 0; Dendrophryniscus organensis, 0.04068, 1, 1, 0, 0; Dendrophryniscus proboscideus, 0.00003, 1, 1, 0, 0; Dendrophryniscus skuki, 0.03299, 1, 1, 0, 0; Dendrophryniscus stawiarskyi, 0.01763, 1, 1, 0, 0; Dendropsophus, 0.00000, 0, 0, 0, 0; Dendropsophus acreanus, 0.00000, 1, 0, 0, 0; Dendropsophus amicorum, 0.02328, 1, 0, 0, 0; Dendropsophus anataliasiasi, 0.00000, 1, 0, 0, 0; Dendropsophus anceps, 0.00000, 1, 0, 0, 0; Dendropsophus aperomeus, 0.00005, 1, 0, 0, 0; Dendropsophus araguaya, 0.00009, 1, 0, 0, 0; Dendropsophus battersbyi, 0.00066, 1, 0, 0, 0; Dendropsophus berthalutzae, 0.00003, 1, 0, 0, 0; Dendropsophus bifurcus, 0.00000, 1, 0, 0, 0; Dendropsophus bipunctatus, 0.00000, 1, 0, 0, 0; Dendropsophus bogerti, 0.00003, 1, 0, 0, 0; Dendropsophus bokermanni, 0.00000, 1, 0, 0, 0; Dendropsophus branneri, 0.00000, 1, 0, 0, 0; Dendropsophus brevifrons, 0.00000, 1, 0, 0, 0; Dendropsophus bromeliaceus, 0.00446, 1, 0, 0, 0; Dendropsophus cachimbo, 0.00154, 1, 0, 0, 0; Dendropsophus carnifex, 0.00013, 1, 0, 0, 0; Dendropsophus cerradensis, 0.00207, 1, 0, 0, 0; Dendropsophus coffeus, 0.00156, 1, 0, 0, 0; Dendropsophus columbianus, 0.00005, 1, 0, 0, 0; Dendropsophus counani, 0.00000, 1, 0, 0, 0; Dendropsophus cruzi, 0.00000, 1, 0, 0, 0; Dendropsophus decipiens, 0.00000, 1, 0, 0, 0; Dendropsophus delarivai, $0.00001,1,0,0$, 0; Dendropsophus dutrai, 0.00021, 1, 0, 0, 0; Dendropsophus ebraccatus, 0.00000, 1, 0, 0, 0; Dendropsophus elegans, 0.00000, 1, 0, 0, 0; Dendropsophus elianeae, 0.00000, 1, 0, 0, 0; Dendropsophus frosti, 0.00003, 1, 0, 0, 0; Dendropsophus garagoensis, 0.00673, 1, 0, 0, 0; Dendropsophus gaucheri, 0.00000, 1, 0, 0, 0; Dendropsophus giesleri, 0.00000, 1, 0, 0, 0; Dendropsophus gryllatus, 0.00151, 1, 0, 0, 0; Dendropsophus haddadi, 0.00001, 1, 0, 0, 0; Dendropsophus haraldschultzi, 0.00000 , 1, 0, 0, 0; Dendropsophus jimi, 0.00000, 1, 0, 0, 0; Dendropsophus joannae, 0.00000, 1, 0, 0, 0; Dendropsophus juliani, 0.00004, 1, 0, 0, 0; Dendropsophus koechlini, 0.00000, 1, 0, 0, 0; Dendropsophus labialis, 0.00007, 1, 0, 0, 0; Dendropsophus leali, $0.00000,1,0,0,0$; Dendropsophus leucophyllatus, 0.00000, 1, 0, 0, 0; Dendropsophus limai, 0.00866, 1, 0, 0, 0; Dendropsophus luddeckei, 0.00008, 1, 0, 0, 0; Dendropsophus luteoocellatus, 0.00001, 1, 0, 0, 0; Dendropsophus manonegra, 0.00036, 1, 0, 0, 0; Dendropsophus marmoratus, 0.00000, 1, 0, 0, 0; Dendropsophus mathiassoni, 0.00001, 1, 0, 0, 0; Dendropsophus melanargyreus, 0.00000, 1, 0, 0, 0; Dendropsophus meridensis, 0.00030, 1, 0, 0, 0; Dendropsophus meridianus, 0.00008, 1, 0, 0, 0; Dendropsophus microcephalus, 0.00000, 1, 0, 0, 0; Dendropsophus microps, 0.00000, 1, 0, 0, 0; Dendropsophus minimus, 0.00174, 1, 0, 0, 0; Dendropsophus minusculus, 0.00000, 1, 0, 0, 0; Dendropsophus minutus, 0.00000, 1, 0, 0, 0; Dendropsophus miyatai, 0.00000, 1, 0, 0, 0; Dendropsophus nahdereri, 0.00007, 1, 0, 0, 0; Dendropsophus nanus, 0.00000, 1, 0, 0, 0; Dendropsophus norandinus, 0.00452 , 1, 0, 0, 0; Dendropsophus novaisi, 0.00004, 1, 0, 0, 0; Dendropsophus oliveirai, 0.00000, 1, 0, 0, 0; Dendropsophus ozzyi, 0.00006, 1, 0, 0, 0; Dendropsophus padreluna, 0.00721, 1, 0, 0, 0; Dendropsophus parviceps, $0.00000,1,0,0$, 0; Dendropsophus pauiniensis, $0.00000,1,0,0$, 0; Dendropsophus phlebodes, 0.00002, 1, 0, 0, 0; Dendropsophus praestans, 0.00050, 1, 0, 0, 0; Dendropsophus pseudomeridianus, 0.00003, 1, 0, 0, 0; Dendropsophus reichlei, 0.00004, 1, 0, 0, 0; Dendropsophus rhea, 0.00515, 1, 0, 0, 0; Dendropsophus rhodopeplus, 0.00000, 1, 0, 0, 0; Dendropsophus riveroi, 0.00000, 1, 0, 0, 0; Dendropsophus rossalleni, 0.00000, 1, 0, 0, 0; Dendropsophus rubicundulus, 0.00000, 1, 0, 0, 0; Dendropsophus ruschii, 0.00018, 1, 0, 0, 0; Dendropsophus salli, 0.00000, 1, 0, 0, 0; Dendropsophus sanborni, 0.00000, 1, 0, 0, 0; Dendropsophus sarayacuensis, 0.00000, 1, 0, 0, 0; Dendropsophus schubarti, $0.00000,1$, 0, 0, 0; Dendropsophus seniculus, 0.00000, 1, 0, 0, 0; Dendropsophus shiwiarum, 0.00002, 1, 0, 0, 0; Dendropsophus soaresi, 0.00000, 1, 0, 0, 0; Dendropsophus stingi, 0.00193, 1, 0, 0, 0; Dendropsophus studerae, 0.00003, 1, 0, 0, 0; Dendropsophus subocularis, 0.00002, 1, 0, 0, 0; Dendropsophus timbeba, 0.00000, 1, 0, 0, 0; Dendropsophus tintinnabulum, 0.00003, 1, 0, 0, 0; Dendropsophus triangulum, 0.00000, 1, 0, 0, 0; Dendropsophus tritaeniatus, 0.00000, 1, 0, 0, 0; Dendropsophus virolinensis, 0.00038 , 1, 0, 0, 0; Dendropsophus walfordi, 0.00000, 1, 0, 0, 0; Dendropsophus werneri, 0.00002, 1, 0, 0, 0; Dendropsophus xapuriensis, 0.00188, 1, 0, 0, 0; Dendropsophus yaracuyanus, 0.00347, 1, 0, 0, 0; Dermatonotus, 0.00000, 0, 0, 0, 0; Dermatonotus muelleri, 0.00000, 0, 1, 0, 0; DERMOPHIIDAE, 0.00000, 0, 0, 0, 0; Dermophis, 0.00000, 0, 0, 0, 0; Dermophis glandulosus, 0.00003, 0, 0, 0, 1; Dermophis parviceps, 0.00003, 0, 0, 0, 1; Diasporus, 0.00001, 0, 0, 0, 0; Diasporus anthrax, 0.00091, 1, 1, 0, 0; Diasporus gularis, 0.00002, 1, 1, 0, 0; Diasporus quidditus, 0.00001, 1, 1, 0, 0; Diasporus tinker, 0.00002, 1, 1, 0, 0; Dischidodactylus, 0.00074 , 0, 0, 0, 0; Dischidodactylus colonnelloi, 0.00601, 0, 1, 1, 0; Dischidodactylus duidensis, 0.00084, 0, 1, 1, 0; Dryaderces, 0.00000, 0, 0, 0, 0; Dryaderces inframaculata, 0.00005, 1, 0, 0, 0; Dryaderces pearsoni, 0.00002, 1, 0, 0, 0; Dryaderces sp1, 0.00001, 1, 0, 0, 0; Ecnomiohyla, 0.00000, 0, 0, 0, 0; Ecnomiohyla phantasmagoria, 0.00128, 1, 0, 0, 0; Edalorhina, 0.00000, 0, 0, 0, 0; Edalorhina nasuta, 0.00012, 0, 1, 0, 0; Edalorhina perezi, 0.00000, 0, 1, 0, 0; Elachistocleis, 0.00000, 0, 0, 0, 0; Elachistocleis bicolor, 0.00000, 0, 1, 1, 0; Elachistocleis bumbameuboi, 0.00002, 0, 1, 1, 0; Elachistocleis carvalhoi, 0.00001, 0, 1, 1, 0; Elachistocleis cesarii, 0.00000, 0 , 1, 1, 0; Elachistocleis erythrogaster, 0.00077, 0, 1, 1, 0; Elachistocleis haroi, 0.00000, 0, 1, 1, 0; Elachistocleis helianneae, 0.00000, 0, 1, 1, 0; Elachistocleis magnus, 0.00000, 0, 1, 1, 0; Elachistocleis matogrosso, 0.00000, 0, 1, 1, 0; Elachistocleis muiraquitan, 0.00001 , $0,1,1,0$; Elachistocleis ovalis, $0.00000,0,1,1,0$; Elachistocleis panamensis, $0.00001,0,1,1,0$; Elachistocleis pearsei, $0.00001,0,1$, 1, 0; Elachistocleis piauiensis, 0.00000, 0, 1, 1, 0; Elachistocleis skotogaster, 0.00019, 0, 1, 1, 0; Elachistocleis surinamensis, 0.00000 , 0, 1, 1, 0; Elachistocleis surumu, 0.00007, 0, 1, 1, 0; ELEUTHERODACTYLIDAE, 0.00000, 0, 0, 0, 0; Eleutherodactylus bilineatus, $0.00003,0,1$, 0, 0; Eleutherodactylus_gen_nov, 0.00003, 0, 0, 0, 0; Engystomops, $0.00000,0,0,0$, 0; Engystomops coloradorum, 0.00005 , 0, 1, 0, 0; Engystomops freibergi, 0.00000, 0, 1, 0, 0; Engystomops guayaco, 0.00012, 0, 1, 0, 0; Engystomops montubio, $0.00006,0,1$, 0, 0; Engystomops petersi, 0.00000, 0, 1, 0, 0; Engystomops pustulatus, 0.00003, 0, 1, 0, 0; Engystomops pustulosus, $0.00000,0,1$, 0, 0; Engystomops puyango, 0.00031, 0, 1, 0, 0; Engystomops randi, 0.00013, 0, 1, 0, 0; Epicrionops, 0.00000, 0, 0, 0, 0; Epicrionops bicolor, 0.00001, 0, 0, 0, 1; Epicrionops columbianus, 0.00016, 0, 0, 0, 1; Epicrionops marmoratus, 0.00083, 0, 0, 0, 1; Epicrionops niger, 0.00002, 0, 0, 0, 1; Epicrionops parkeri, 0.00017, 0, 0, 0, 1; Epicrionops peruvianus, 0.01074, 0, 0, 0, 1; Epicrionops petersi, 0.00000, 0, 0, 0, 1; Epipedobates, 0.00001, 0, 0, 0, 0; Epipedobates anthonyi, 0.00005, 0, 1, 0, 0; Epipedobates boulengeri, 
$0.00002,0,1,0,0$; Epipedobates darwinwallacei, 0.00040, 0, 1, 0, 0; Epipedobates espinosai, 0.00798, 0, 1, 0, 0; Epipedobates machalilla, 0.00002, 0, 1, 0, 0; Epipedobates narinensis, 0.00356, 0, 1, 0, 0; Epipedobates tricolor, 0.00052, 0, 1, 0, 0; Espadarana, $0.00000,0,0,0,0$; Espadarana andina, 0.00003, 1, 0, 0, 0; Espadarana audax, 0.00002, 1, 0, 0, 0; Espadarana callistomma, 0.00003, 1, 0, 0, 0; Espadarana durrellorum, 0.00018, 1, 0, 0, 0; Espadarana prosoblepon, 0.00000, 1, 0, 0, 0; Euparkerella, 0.00026, 0, 0, 0, 0; Euparkerella aff_brasiliensis_1, 0.00135, 0, 1, 0, 0; Euparkerella aff_brasiliensis_2, $0.00256,0,1,0$, 0; Euparkerella aff_brasiliensis_3, $0.00145,0,1,0,0$; Euparkerella aff_brasiliensis_4, 0.01145, 0, 1, 0, 0; Euparkerella aff_cochranae, 0.00473, 0, 1, 0, 0; Euparkerella cochranae, 0.00123, 0, 1, 0, 0; Euparkerella cryptica, 0.00847, 0, 1, 0, 0; Euparkerella robusta, 0.01321, 0, 1, 0, 0; Euparkerella tridactyla, 0.00105, 0, 1, 0, 0; Eupsophus, 0.00001, 0, 0, 0, 0; Eupsophus altor, 0.00231, 0, 1, 0, 0; Eupsophus calcaratus, 0.00001, 0, 1, 0, 0; Eupsophus contulmoensis, 0.00023, 0, 1, 0, 0; Eupsophus emiliopugini, 0.00002, 0, 1, 0, 0; Eupsophus insularis, 0.02219, 0, 1, 0, 0; Eupsophus migueli, 0.00419, 0, 1, 0, 0; Eupsophus nahuelbutensis, 0.00037, 0, 1, 0, 0; Eupsophus roseus, $0.00005,0,1,0$, 0; Eupsophus septentrionalis, 0.00429, 0, 1, 0, 0; Eupsophus vertebralis, 0.00002, 0, 1, 0, 0; Excidobates, $0.00011,0,0,0$, 0; Excidobates captivus, 0.00011, 1, 1, 0, 0; Excidobates condor, 0.00784, 1, 1, 0, 0; Excidobates mysteriosus, 0.00676, 1, 1, 0, 0; Flectonotus, 0.00002, 0, 0, 0, 0; Flectonotus fitzgeraldi, 0.00038, 1, 0, 0, 0; Flectonotus pygmaeus, 0.00003, 1, 0, 0, 0; Fritziana, 0.00001 , 0, 0, 0, 0; Fritziana fissilis, 0.00001, 1, 0, 0, 0; Fritziana goeldii, 0.00002, 1, 0, 0, 0; Fritziana ohausi, 0.00002 , 1, 0, 0, 0; Fritziana ulei, 0.00018, 1, 0, 0, 0; Frostius, 0.00003, 0, 0, 0, 0; Frostius erythrophthalmus, 0.00007, 0, 1, 0, 0; Frostius pernambucensis, 0.00004, 0, 1, 0, 0; Gastrotheca, 0.00000, 0, 0, 0, 0; Gastrotheca abdita, 0.00667, 1, 0, 0, 0; Gastrotheca aguaruna, 0.00036 , 1, 0, 0, 0; Gastrotheca albolineata, 0.00002, 1, 0, 0, 0; Gastrotheca andaquiensis, 0.00008, 1, 0, 0, 0; Gastrotheca angustifrons, 0.00004, 1, 0, 0, 0; Gastrotheca antomia, 0.00018, 1, 0, 0, 0; Gastrotheca antoniiochoai, 0.00577, 1, 0, 0, 0; Gastrotheca aratia, 0.00034, 1, 0, 0, 0; Gastrotheca argenteovirens, 0.00004, 1, 0, 0, 0; Gastrotheca atympana, 0.00156, 1, 0, 0, 0; Gastrotheca aureomaculata, 0.00065, 1, 0, 0, 0; Gastrotheca bufona, 0.00371, 1, 0, 0, 0; Gastrotheca carinaceps, 0.00389, 1, 0, 0, 0; Gastrotheca christiani, 0.00028, 1, 0, 0, 0; Gastrotheca chrysosticta, 0.00048, 1, 0, 0, 0; Gastrotheca coeruleomaculatus, 0.00172, 1, 0, 0, 0; Gastrotheca cornuta, 0.00001, 1, 0, 0, 0; Gastrotheca dendronastes, 0.00007, 1, 0, 0, 0; Gastrotheca dunni, 0.00017, 1, 0, 0, 0; Gastrotheca dysprosita, 0.00788, 1, 0, 0, 0; Gastrotheca ernestoi, 0.00002, 1, 0, 0, 0; Gastrotheca espeletia, 0.00017, 1, 0, 0, 0; Gastrotheca excubitor, 0.00026, 1, 0, 0, 0; Gastrotheca fissipes, 0.00005, 1, 0, 0, 0; Gastrotheca flamma, 0.00010, 1, 0, 0, 0; Gastrotheca fulvorufa, 0.00009, 1, 0, 0, 0; Gastrotheca galeata, 0.00316, 1, 0, 0, 0; Gastrotheca gracilis, 0.00014, 1, 0, 0, 0; Gastrotheca griswoldi, 0.00008, 1, 0, 0, 0; Gastrotheca guentheri, 0.00006, 1, 0, 0, 0; Gastrotheca helenae, 0.00219, 1, 0, 0, 0; Gastrotheca lateonota, 0.00012, 1, 0, 0, 0; Gastrotheca litonedis, 0.00284, 1, 0, 0, 0; Gastrotheca lojana, 0.00016, 1, 0, 0, 0; Gastrotheca longipes, 0.00001, 1, 0, 0, 0; Gastrotheca marsupiata, 0.00000, 1, 0, 0, 0; Gastrotheca megacephala, 0.00002, 1, 0, 0, 0; Gastrotheca microdiscus, 0.00001, 1, 0, 0, 0; Gastrotheca monticola, 0.00004, 1, 0, 0, 0; Gastrotheca nebulanastes, 0.00040, 1, 0, 0, 0; Gastrotheca nicefori, 0.00001, 1, 0, 0, 0; Gastrotheca ochoai, 0.00012, 1, 0, 0, 0; Gastrotheca oresbios, 0.00196, 1, 0, 0, 0; Gastrotheca orophylax, 0.00030, 1, 0, 0, 0; Gastrotheca ossilaginis, 0.01491, 1, 0, 0, 0; Gastrotheca ovifera, 0.00035, 1, 0, 0, 0; Gastrotheca pacchamama, 0.01789, 1, 0, 0, 0; Gastrotheca pachachacae, 0.01794, 1, 0, 0, 0; Gastrotheca peruana, 0.00002, 1, 0, 0, 0; Gastrotheca phalarosa, 0.00440, 1, 0, 0, 0; Gastrotheca phelloderma, 0.00789, 1, 0, 0, 0; Gastrotheca piperata, 0.00015, 1, 0, 0, 0; Gastrotheca plumbea, 0.00010, 1, 0, 0, 0; Gastrotheca prasina, 0.00815, 1, 0, 0, 0; Gastrotheca pseustes, 0.00004, 1, 0, 0, 0; Gastrotheca psychrophila, 0.00126, 1, 0, 0, 0; Gastrotheca pulchra, 0.00007, 1, 0, 0, 0; Gastrotheca rebeccae, 0.00044, 1, 0, 0, 0; Gastrotheca recava, 0.00003, 1, 0, 0, 0; Gastrotheca riobambae, 0.00013, 1, 0, 0, 0; Gastrotheca ruizi, 0.00434, 1, 0, 0, 0; Gastrotheca sp, 0.00668, 1, 0, 0, 0; Gastrotheca spectabilis, 0.00668, 1, 0, 0, 0; Gastrotheca splendens, 0.00155, 1, 0, 0, 0; Gastrotheca stictopleura, 0.00034, 1, 0, 0, 0; Gastrotheca testudinea, 0.00001, 1, 0, 0, 0; Gastrotheca trachyceps, 0.00398, 1, 0, 0, 0; Gastrotheca walkeri, 0.00017, 1, 0, 0, 0; Gastrotheca weinlandii, 0.00002, 1, 0, 0, 0; Gastrotheca williamsoni, 0.00423, 1, 0, 0, 0; Gastrotheca zeugocystis, 0.00301, 1, 0, 0, 0; Geobatrachus, 0.00208, 0, 0, 0, 0; Geobatrachus walkeri, 0.00208, 0, 1, 0, 0; GYMNOPHIONA, 0.00000, 0, 0, 0, 0; Haddadus, 0.00000, 0, 0, 0, 0; Haddadus aramunha, 0.00026, 0, 1, 0, 0; Haddadus binotatus, 0.00000, 0, 1, 0, 0; Haddadus plicifer, 0.00290, 0, 1, 0, 0; Hamptophryne, 0.00000, 0, 0, 0, 0; Hamptophryne alios, 0.00001, 0, 1, 0, 0; Hamptophryne boliviana, 0.00000, 0, 1, 0, 0; HEMIPHRACTIDAE, 0.00000, 0, 0, 0, 0; Hemiphractus, 0.00000, 0, 0, 0, 0; Hemiphractus bubalus, 0.00001, 1, 1, 0, 0; Hemiphractus fasciatus, 0.00001, 1, 1, 0, 0; Hemiphractus helioi, 0.00000, 1, 1, 0, 0; Hemiphractus johnsoni, 0.00004, 1, 1, 0, 0; Hemiphractus proboscideus, 0.00000, 1, 1, 0, 0; Hemiphractus scutatus, 0.00000, 1, 1, 0, 0; Holoaden, 0.00009, 0, 0, 0, 0; Holoaden bradei, 0.00276, 0, 1, 0, 0; Holoaden luederwaldti, 0.00057, 0, 1, 0, 0; Holoaden pholeter, 0.01038, 0, 1, 0, 0; Holoaden suarezi, 0.00011, 0, 1, 0, 0; Hyalinobatrachium, 0.00000, 0, 0, 0, 0; Hyalinobatrachium anachoretus, 0.00786, 1, 0, 0, 0; Hyalinobatrachium aureoguttatum, 0.00002, 1, 0, 0, 0; Hyalinobatrachium bergeri, 0.00007, 1, 0, 0, 0; Hyalinobatrachium cappellei, 0.00000, 1, 0, 0, 0; Hyalinobatrachium carlesvilai, 0.00001, 1, 0, 0, 0; Hyalinobatrachium chirripoi, 0.00014, 1, 0, 0, 0; Hyalinobatrachium colymbiphyllum, 0.00001, 1, 0, 0, 0; Hyalinobatrachium duranti, 0.00044, 1, 0, 0, 0; Hyalinobatrachium esmeralda, 0.00179, 1, 0, 0, 0; Hyalinobatrachium fleischmanni, 0.00001, 1, 0, 0, 0; Hyalinobatrachium fragile, 0.00015, 1, 0, 0, 0; Hyalinobatrachium guairarepanense, 0.00115, 1, 0, 0, 0; Hyalinobatrachium iaspidiense, 0.00000, 1, 0, 0, 0; Hyalinobatrachium ibama, 0.00005, 1, 0, 0, 0; Hyalinobatrachium kawense, 0.00170, 1, 0, 0, 0; Hyalinobatrachium mesai, 0.00785, 1, 0, 0, 0; Hyalinobatrachium mondolfii, 0.00000, 1, 0, 0, 0; Hyalinobatrachium munozorum, 0.00000, 1, 0, 0, 0; Hyalinobatrachium orientale, 0.00022 , 1, 0, 0, 0; Hyalinobatrachium orocostale, 0.00047, 1, 0, 0, 0; Hyalinobatrachium pallidum, 0.00068, 1, 0, 0, 0; Hyalinobatrachium pellucidum, 0.00001, 1, 0, 0, 0; Hyalinobatrachium ruedai, 0.00001, 1, 0, 0, 0; Hyalinobatrachium tatayoi, 0.00694, 1, 0, 0, 0; Hyalinobatrachium taylori, 0.00000, 1, 0, 0, 0; Hyalinobatrachium tricolor, 0.00382, 1, 0, 0, 0; Hyalinobatrachium valerioi, 0.00001, 1, 0, 0, 0; Hydrolaetare, 0.00000, 0, 0, 0, 0; Hydrolaetare caparu, 0.00000, 0, 1, 1, 0; Hydrolaetare dantasi, $0.00000,0,1,1,0$; Hydrolaetare schmidti, 0.00000, 0, 1, 1, 0; HYLIDAE, 0.00000, 0, 0, 0, 0; Hylodes, 0.00001, 0, 0, 0, 0; Hylodes amnicola, 0.00012, 0, 1, 1, 0; Hylodes asper, 0.00007, 0, 1, 1, 0; Hylodes babax, 0.00005, 0, 1, 1, 0; Hylodes cardosoi, 0.00014, 0, 1, 1, 0; Hylodes charadranaetes, 0.00022, 0, 1, 1, 0; Hylodes dactylocinus, 0.00151, 0, 1, 1, 0; Hylodes fredi, 0.00703, 0, 1, 1, 0; Hylodes glaber, 0.00329, 0, 1, 1, 0; Hylodes heyeri, 0.00005, 0, 1, 1, 0; Hylodes japi, 0.00852, 0, 1, 1, 0; Hylodes lateristrigatus, 0.00008, 0, 1, 1, 0; Hylodes magalhaesi, 0.00065, 0, 1, 1, 0; Hylodes meridionalis, 0.00007, 0, 1, 1, 0; Hylodes mertensi, 0.00256, 0, 1, 1, 0; Hylodes nasus, $0.00018,0,1,1,0$; Hylodes ornatus, $0.00065,0,1,1,0$; Hylodes otavioi, 0.00060, 0, 1, 1, 0; Hylodes perere, 0.00844, 0, 1, 1, 0 ; Hylodes perplicatus, 0.00007, 0, 1, 1, 0; Hylodes phyllodes, 0.00006, 0, 1, 1, 0; Hylodes pipilans, 0.00079, 0, 1, 1, 0; Hylodes regius, 
0.00060, 0, 1, 1, 0; Hylodes sazimai, 0.00005, 0, 1, 1, 0; Hylodes sp1, 0.00064, 0, 1, 1, 0; Hylodes sp2, 0.00065, 0, 1, 1, 0; Hylodes sp3, $0.00065,0,1,1,0$; Hylodes sp4, 0.00064, 0, 1, 1, 0; Hylodes sp5, 0.00065, 0, 1, 1, 0; Hylodes sp6, 0.00010, 0, 1, 1, 0; Hylodes uai, $0.00018,0,1,1,0$; Hylodes vanzolinii, 0.00837, 0, 1, 1, 0; HYLODIDAE, 0.00000, 0, 0, 0, 0; Hylomantis, 0.00003, 0, 0, 0, 0; Hylomantis aspera, 0.00008, 1, 0, 0, 0; Hylomantis granulosa, 0.00005, 1, 0, 0, 0; Hylorina, 0.00001, 0, 0, 0, 0; Hylorina sylvatica, 0.00001, 1, 1, 0, 0; Hyloscirtus, 0.00000, 0, 0, 0, 0; Hyloscirtus albopunctulatus, 0.00000, 0, 0, 0, 0; Hyloscirtus alytolylax, 0.00003, 1, 0, 0, 0; Hyloscirtus bogotensis, 0.00002, 1, 0, 0, 0; Hyloscirtus callipeza, 0.00034, 1, 0, 0, 0; Hyloscirtus colymba, 0.00001, 1, 0, 0, 0; Hyloscirtus denticulentus, 0.00019, 1, 0, 0, 0; Hyloscirtus diabolus, 0.00042, 1, 0, 0, 0; Hyloscirtus estevesi, 0.00791, 1, 0, 0, 0; Hyloscirtus jahni, 0.00012, 1, 0, 0, 0; Hyloscirtus lascinius, 0.00042, 1, 0, 0, 0; Hyloscirtus lynchi, 0.00274, 1, 0, 0, 0; Hyloscirtus mashpi, 0.00625, 1, 0, 0, 0; Hyloscirtus palmeri, 0.00001, 1, 0, 0, 0; Hyloscirtus phyllognathus, 0.00001, 1, 0, 0, 0; Hyloscirtus piceigularis, 0.00008, 1, 0, 0, 0; Hyloscirtus platydactylus, 0.00006, 1, 0, 0, 0; Hyloscirtus sarampiona, 0.00397, 1, 0, 0, 0; Hyloscirtus simmonsi, 0.00028, 1, 0, 0, 0; Hyloscirtus torrenticola, 0.00025, 1, 0, 0, 0; Hyloxalus, 0.00000, 0, 0, 0, 0; Hyloxalus abditaurantius, $0.00005,0,1,0,0$; Hyloxalus aeruginosus, 0.00061, 0, 1, 0, 0; Hyloxalus anthracinus, 0.00008, 0, 1, 0, 0; Hyloxalus awa, 0.00005, 0, 1, 0, 0; Hyloxalus azureiventris, 0.00053, 0, 1, 0, 0; Hyloxalus betancuri, 0.00670, 0, 1, 0, 0; Hyloxalus bocagei, 0.00042, 0, 1, 0, 0; Hyloxalus borjai, 0.00473, 0, 1, 0, 0; Hyloxalus breviquartus, $0.00003,0,1,0,0$; Hyloxalus cevallosi, 0.00018, 0, 1, 0, 0; Hyloxalus chlorocraspedus, 0.10278, 0, 1, 0, 0; Hyloxalus chocoensis, 0.00010, 0, 1, 0, 0; Hyloxalus craspedoceps, 0.01067, 0, 1, 0, 0; Hyloxalus delatorreae, 0.00320, 0, 1, 0, 0; Hyloxalus edwardsi, 0.00197, 0, 1, 0, 0; Hyloxalus elachyhistus, 0.00005, 0, 1, 0, 0; Hyloxalus eleutherodactylus, 0.00377, 0, 1, 0, 0; Hyloxalus exasperatus, 0.00009, 0, 1, 0, 0; Hyloxalus excisus, 0.00369, 0, 1, 0, 0; Hyloxalus faciopunctulatus, 0.00115, 0, 1, 0, 0; Hyloxalus fallax, 0.00039, 0, 1, 0, 0; Hyloxalus fascianigrus, 0.00011, 0, 1, 0, 0; Hyloxalus fuliginosus, 0.00029, 0, 1, 0, 0; Hyloxalus idiomelus, 0.00007, 0, 1, 0, 0; Hyloxalus infraguttatus, 0.00002, 0, 1, 0, 0; Hyloxalus insulatus, 0.00006, 0, 1, 0, 0; Hyloxalus italoi, 0.00005, 0, 1, 0, 0; Hyloxalus lehmanni, 0.00001, 0, 1, 0, 0; Hyloxalus leucophaeus, $0.00188,0$, 1, 0, 0; Hyloxalus littoralis, 0.00020, 0, 1, 0, 0; Hyloxalus maculosus, 0.00063, 0, 1, 0, 0; Hyloxalus maquipucuna, 0.00206, 0, 1, 0, 0; Hyloxalus marmoreoventris, 0.00187, 0, 1, 0, 0; Hyloxalus mittermeieri, 0.00572, 0, 1, 0, 0; Hyloxalus mystax, $0.00834,0,1,0,0$; Hyloxalus nexipus, $0.00003,0,1,0,0$; Hyloxalus parcus, $0.00335,0,1,0,0$; Hyloxalus patitae, 0.00870, 0, 1, 0, 0; Hyloxalus peculiaris, 0.00754, 0, 1, 0, 0; Hyloxalus peruvianus, 0.00040, 0, 1, 0, 0; Hyloxalus pinguis, 0.00611, 0, 1, 0, 0; Hyloxalus pulchellus, 0.00004, 0, 1, 0, 0; Hyloxalus pulcherrimus, 0.00245, 0, 1, 0, 0; Hyloxalus pumilus, 0.00904, 0, 1, 0, 0; Hyloxalus ramosi, 0.00033 , 0, 1, 0, 0; Hyloxalus ruizi, 0.00205, 0, 1, 0, 0; Hyloxalus saltuarius, 0.00232, 0, 1, 0, 0; Hyloxalus sauli, 0.00002, 0, 1, 0, 0; Hyloxalus shuar, 0.00012, 0, 1, 0, 0; Hyloxalus sordidatus, 0.00017, 0, 1, 0, 0; Hyloxalus spilotogaster, 0.00670, 0, 1, 0, 0; Hyloxalus subpunctatus, $0.00004,0,1,0$, 0; Hyloxalus sylvaticus, $0.00127,0,1,0$, 0; Hyloxalus toachi, 0.00023, 0, 1, 0, 0; Hyloxalus utcubambensis, 0.00368, 0, 1, 0, 0; Hyloxalus vergeli, 0.00216, 0, 1, 0, 0; Hyloxalus vertebralis, 0.00011, 0, 1, 0, 0; Hyloxalus whymperi, 0.00314, 0, 1, 0, 0; Hyloxalus yasuni, 0.00003, 0, 1, 0, 0; Hypodactylus, 0.00000, 0, 0, 0, 0; Hypodactylus adercus, 0.00581 , 0, 1, 0, 0; Hypodactylus babax, 0.00008, 0, 1, 0, 0; Hypodactylus brunneus, 0.00271, 0, 1, 0, 0; Hypodactylus dolops, $0.00024,0,1,0$, 0; Hypodactylus elassodiscus, 0.00020, 0, 1, 0, 0; Hypodactylus fallaciosus, 0.00225, 0, 1, 0, 0; Hypodactylus latens, 0.00010 , 0, 1, 0, 0; Hypodactylus lucida, 0.00062, 0, 1, 0, 0; Hypodactylus mantipus, 0.00004, 0, 1, 0, 0; Hypodactylus nigrovittatus, 0.00000, 0, 1, 0, 0; Hypodactylus peraccai, 0.00156, 0, 1, 0, 0; Hypsiboas, 0.00000, 0, 0, 0, 0; Hypsiboas aff fasciatus, 0.00000, 1, 0, 0 , 0; Hypsiboas aff_geographicus, 0.00000, 1, 0, 0, 0; Hypsiboas aff_semilineatus_2, 0.00000, 1, 0, 0, 0; Hypsiboas aff_semilineatus_3, 0.00000, 1, 0, 0, 0; Hypsiboas aff_semilineatus_4, 0.00001, 1, 0, 0, 0; Hypsiboas aff_semilineatus_5, 0.00001, 1, 0, 0, 0; Hypsiboas aguilari, 0.00098, 1, 0, 0, 0; Hypsiboas albomarginatus, 0.00000, 1, 0, 0, 0; Hypsiboas alboniger, 0.00002, 1, 0, 0, 0; Hypsiboas albopunctatus, 0.00000, 1, 0, 0, 0; Hypsiboas alemani, 0.00264, 1, 0, 0, 0; Hypsiboas alfaroi, 0.00005, 1, 0, 0, 0; Hypsiboas almendarizae, 0.00010, 1, 0, 0, 0; Hypsiboas atlanticus, 0.00002, 1, 0, 0, 0; Hypsiboas balzani, 0.00001, 1, 0, 0, 0; Hypsiboas bandeirantes, 0.00011, 1, 0, 0, 0; Hypsiboas beckeri, 0.00843, 1, 0, 0, 0; Hypsiboas benitezi, 0.00003, 1, 0, 0, 0; Hypsiboas bischoffi, 0.00000, 1, 0, 0, 0; Hypsiboas boans, 0.00000, 1, 0, 0, 0; Hypsiboas botumirim, 0.00819, 1, 0, 0, 0; Hypsiboas buriti, 0.00003, 1, 0, 0, 0; Hypsiboas caingua, 0.00000, 1, 0, 0, 0; Hypsiboas caipora, 0.00117, 1, 0, 0, 0; Hypsiboas calcaratus, 0.00000, 1, 0, 0, 0; Hypsiboas callipleura, 0.00011, 1, 0, 0, 0; Hypsiboas cambui, 0.00023, 1, 0, 0, 0; Hypsiboas cinerascens, 0.00000, 1, 0, 0, 0; Hypsiboas cipoensis, 0.00009, 1, 0, 0, 0; Hypsiboas cordobae, 0.00006, 1, 0, 0, 0; Hypsiboas crepitans, 0.00000, 1, 0, 0, 0; Hypsiboas curupi, 0.00002, 1, 0, 0, 0; Hypsiboas cymbalum, 0.00478, 1, 0, 0, 0; Hypsiboas dentei, 0.00001, 1, 0, 0, 0; Hypsiboas diabolicus, 0.00001, 1, 0, 0, 0; Hypsiboas ericae, 0.00072, 1, 0, 0, 0; Hypsiboas exastis, 0.00007, 1, 0, 0, 0; Hypsiboas faber, 0.00000, 1, 0, 0, 0; Hypsiboas fasciatus, 0.00011, 1, 0, 0, 0; Hypsiboas freicanecae, 0.00737, 1, 0, 0, 0; Hypsiboas fuentei, 0.00741, 1, 0, 0, 0; Hypsiboas geographicus, 0.00000, 1, 0, 0, 0; Hypsiboas gladiator, 0.00011, 1, 0, 0, 0; Hypsiboas goianus, 0.00001, 1, 0, 0, 0; Hypsiboas guentheri, 0.00004, 1, 0, 0, 0; Hypsiboas hobbsi, 0.00001, 1, 0, 0, 0; Hypsiboas hutchinsi, 0.00001, 1, 0, 0, 0; Hypsiboas jaguariaivensis, 0.00802, 1, 0, 0, 0; Hypsiboas jimenezi, 0.00244, 1, 0, 0, 0; Hypsiboas joaquini, 0.00012, 1, 0, 0, 0; Hypsiboas lanciformis, 0.00000, 1, 0, 0, 0; Hypsiboas latistriatus, 0.00459, 1, 0, 0, 0; Hypsiboas lemai, 0.00003, 1, 0, 0, 0; Hypsiboas leptolineatus, 0.00001, 1, 0, 0, 0; Hypsiboas leucocheilus, 0.00001, 1, 0, 0, 0; Hypsiboas liliae, 0.00017, 1, 0, 0, 0; Hypsiboas lundii, 0.00000 , 1, 0, 0, 0; Hypsiboas maculateralis, 0.00004, 1, 0, 0, 0; Hypsiboas marginatus, 0.00016, 1, 0, 0, 0; Hypsiboas marianitae, $0.00001,1,0,0$, 0; Hypsiboas melanopleura, 0.00062, 1, 0, 0, 0; Hypsiboas microderma, 0.00000, 1, 0, 0, 0; Hypsiboas multifasciatus, 0.00000, 1, 0, 0, 0; Hypsiboas nympha, 0.00000, 1, 0, 0, 0; Hypsiboas ornatissimus, 0.00000, 1, 0, 0, 0; Hypsiboas palaestes, 0.00011, 1, 0, 0, 0; Hypsiboas paranaiba, 0.00023, 1, 0, 0, 0; Hypsiboas pardalis, 0.00000, 1, 0, 0, 0; Hypsiboas pellucens, 0.00001 , 1, 0, 0, 0; Hypsiboas phaeopleura, 0.00038, 1, 0, 0, 0; Hypsiboas picturatus, 0.00002, 1, 0, 0, 0; Hypsiboas poaju, 0.00053, 1, 0, 0, 0; Hypsiboas polytaenius, 0.00001, 1, 0, 0, 0; Hypsiboas pombali, 0.00001, 1, 0, 0, 0; Hypsiboas prasinus, 0.00000, 1, 0, 0, 0; Hypsiboas pugnax, $0.00000,1,0,0$, 0; Hypsiboas pulchellus, 0.00000, 1, 0, 0, 0; Hypsiboas pulidoi, 0.00082, 1, 0, 0, 0; Hypsiboas punctatus, 0.00000, 1, 0, 0, 0; Hypsiboas raniceps, 0.00000, 1, 0, 0, 0; Hypsiboas rhythmicus, 0.00104, 1, 0, 0, 0; Hypsiboas riojanus, $0.00000,1$, 0, 0, 0; Hypsiboas roraima, 0.00003, 1, 0, 0, 0; Hypsiboas rosenbergi, 0.00001, 1, 0, 0, 0; Hypsiboas rubracylus, 0.00002 , 1, 0, 0, 0; Hypsiboas secedens, 0.00149, 1, 0, 0, 0; Hypsiboas semiguttatus, 0.00015, 1, 0, 0, 0; Hypsiboas semilineatus, 0.00000, 1, 0, 0, 0; Hypsiboas sibleszi, 0.00001, 1, 0, 0, 0; Hypsiboas steinbachi, 0.00818, 1, 0, 0, 0; Hypsiboas stellae, 0.00011, 1, 0, 0, 0; Hypsiboas stenocephalus, 0.00285, 1, 0, 0, 0; Hypsiboas tepuianus, 0.00002, 1, 0, 0, 0; Hypsiboas tetete, 0.00113, 1, 0, 0, 0; Hypsiboas varelae, 0.00018 , 1, 0, 0, 0; Hypsiboas wavrini, 0.00000, 1, 0, 0, 0; Hypsiboas xerophyllus, $0.00000,1$, 0, 0, 0; Ikakogi, 0.00025, 0, 0, 0, 0; 
Ikakogi tayrona, 0.00025, 1, 0, 0, 0; Incilius, 0.00000, 0, 0, 0, 0; Incilius coniferus, 0.00001, 0, 1, 0, 0; Insuetophrynus, 0.00168, 0, 0, 0, 0; Insuetophrynus acarpicus, 0.00168, 0, 0, 0, 0; Ischnocnema, 0.00000, 0, 0, 0, 0; Ischnocnema abdita, 0.00008, 1, 1, 0, 0; Ischnocnema aff_guentheri_1, 0.00002, 1, 1, 0, 0; Ischnocnema aff_guentheri_2, 0.00031, 1, 1, 0, 0; Ischnocnema aff_guentheri_3, $0.00002,1,1,0,0$; Ischnocnema aff_guentheri_4, 0.00003, 1, 1, 0, 0; Ischnocnema aff_holti, 0.00180, 1, 1, 0, 0; Ischnocnema bolbodactyla, 0.00047, 1, 1, 0, 0; Ischnocnema cf_holti_1, 0.00661, 1, 1, 0, 0; Ischnocnema cf_holti_2, 0.00661, 1, 1, 0, 0; Ischnocnema cf_spanios, 0.00024, 1, 1, 0, 0; Ischnocnema concolor, 0.00661, 0, 1, 0, 0; Ischnocnema epipeda, 0.00879, 1, 1, 0, 0; Ischnocnema erythromera, 0.00099, 1, 1, 0, 0; Ischnocnema gehrti, 0.00734, 1, 1, 0, 0; Ischnocnema gualteri, 0.00096, 1, 1, 0, 0; Ischnocnema guentheri, 0.00812, 1, 1, 0, 0; Ischnocnema henselii, 0.00000, 1, 1, 0, 0; Ischnocnema hoehnei, 0.00022, 1, 1, 0, 0; Ischnocnema holti, 0.00661, 1, 1, 0, 0; Ischnocnema izecksohni, 0.00002, 1, 1, 0, 0; Ischnocnema juipoca, 0.00001, 0, 1, 0, 0; Ischnocnema karst, 0.00834, 0, 1, 0, 0; Ischnocnema lactea, 0.00007, 1, 1, 0, 0; Ischnocnema manezinho, 0.00007, 1, 1, 0, 0; Ischnocnema melanopygia, 0.00661, 0, 1, 0, 0; Ischnocnema nasuta, 0.00001, 1, 1, 0, 0; Ischnocnema nigriventris, 0.00102, 1, 1, 0, 0; Ischnocnema octavioi, 0.00007, 0, 1, 0, 0; Ischnocnema oea, 0.00005, 1, 1, 0, 0; Ischnocnema paranaensis, 0.01623, 1, 1, 0, 0; Ischnocnema parva, 0.00000, 0, 1, 0, 0; Ischnocnema penaxavantinho, 0.00001, 0, 1, 0, 0; Ischnocnema pusilla, 0.00075, 0, 1, 0, 0; Ischnocnema randorum, 0.00263, 1, 1, 0, 0; Ischnocnema sambaqui, 0.00065, 0, 1, 0, 0; Ischnocnema sp, 0.00658, 1, 1, 0, 0; Ischnocnema sp_3, 0.00661, 1, 1, 0, 0; Ischnocnema sp_4, 0.00661, 1, 1, 0, 0; Ischnocnema spanios, 0.00014, 1, 1, 0, 0; Ischnocnema surda, 0.00019, 0, 1, 0, 0; Ischnocnema venancioi, 0.00034, 1, 1, 0, 0; Ischnocnema verrucosa, 0.00001, 0, 1, 0, 0; Ischnocnema vizottoi, 0.00848, 0, 1, 0, 0; Itapotihyla, 0.00000, 0, 0, 0, 0; Itapotihyla langsdorffii, 0.00000, 1, 0, 0, 0; Julianus, 0.00000, 0, 0, 0, 0; Julianus pinimus, $0.00094,1$, 0, 0, 0; Julianus uruguayus, $0.00000,1,0,0$, 0; Lepidobatrachus, $0.00000,0,0,0$, 0; Lepidobatrachus asper, 0.00000, 0, 1, 1, 0; Lepidobatrachus laevis, 0.00000, 0, 1, 1, 0; Lepidobatrachus Ilanensis, 0.00000, 0, 1, 1, 0; LEPTODACTYLIDAE, 0.00000, 0, 0, 0, 0; Leptodactylus, 0.00000, 0, 0, 0, 0; Leptodactylus bolivianus, 0.00000, 0, 1, 1, 0; Leptodactylus bufonius, $0.00000,0,1,0$, 0; Leptodactylus caatingae, $0.00000,0,1,0$, 0; Leptodactylus camaquara, 0.00005, 0, 1, 0, 0; Leptodactylus chaquensis, 0.00000, 0, 1, 1, 0; Leptodactylus colombiensis, 0.00000, 0, 1, 0, 0; Leptodactylus cunicularius, 0.00001, 0, 1, 0, 0; Leptodactylus cupreus, 0.00001, 0, 1, 0, 0; Leptodactylus didymus, 0.00000, 0, 1, 0, 0; Leptodactylus diedrus, 0.00000, 0, 1, 0, 0; Leptodactylus discodactylus, 0.00000, 0, 1, 0, 0; Leptodactylus elenae, 0.00000, 0, 1, 0, 0; Leptodactylus flavopictus, 0.00001, 0, 1, 0, 0; Leptodactylus fragilis, 0.00000, 0, 1, 0, 0; Leptodactylus furnarius, 0.00000, 0, 1, 0, 0; Leptodactylus fuscus, 0.00000, 0, 1, 0, 0; Leptodactylus gracilis, $0.00000,0,1,0$, 0; Leptodactylus griseigularis, $0.00001,0,1,0,0$; Leptodactylus guianensis, $0.00000,0,1,0$, 0; Leptodactylus hylodes, 0.00460, 0, 1, 0, 0; Leptodactylus insularum, 0.00000, 0, 1, 0, 0; Leptodactylus jolyi, 0.00001, 0, 1, 0, 0; Leptodactylus knudseni, 0.00000, 0, 1, 0, 0; Leptodactylus labrosus, 0.00001, 0, 1, 0, 0; Leptodactylus labyrinthicus, 0.00000, 0, 1, 0, 0; Leptodactylus laticeps, 0.00000, 0, 1, 0, 0; Leptodactylus latinasus, 0.00000, 0, 1, 0, 0; Leptodactylus latrans, 0.00000, 0, 1, 1, 0; Leptodactylus lauramiriamae, 0.00001, 0, 1, 0, 0; Leptodactylus leptodactyloides, $0.00000,0,1,0$, 0; Leptodactylus lithonaetes, $0.00000,0$, 1, 0, 0; Leptodactylus longirostris, 0.00000, 0, 1, 0, 0; Leptodactylus magistris, 0.00454, 0, 1, 0, 0; Leptodactylus marambaiae, 0.01294, 0, 1, 0, 0; Leptodactylus melanonotus, 0.00002, 0, 1, 0, 0; Leptodactylus myersi, 0.00000, 0, 1, 0, 0; Leptodactylus mystaceus, 0.00000, 0, 1, 0, 0; Leptodactylus mystacinus, 0.00000, 0, 1, 0, 0; Leptodactylus natalensis, 0.00000, 0, 1, 0, 0; Leptodactylus nesiotus, 0.00570, 0, 1, 0, 0; Leptodactylus notoaktites, 0.00001, 0, 1, 0, 0; Leptodactylus oreomantis, 0.00805, 0, 1, 0, 0; Leptodactylus paraensis, $0.00000,0,1,0,0$; Leptodactylus pascoensis, $0.00000,0,1,0$, 0; Leptodactylus pentadactylus, $0.00000,0,1,0$, 0; Leptodactylus peritoaktites, 0.00005, 0, 1, 0, 0; Leptodactylus petersii, 0.00000, 0, 1, 0, 0; Leptodactylus plaumanni, 0.00000, 0, 1, 0, 0; Leptodactylus podicipinus, 0.00000, 0, 1, 0, 0; Leptodactylus poecilochilus, 0.00001, 0, 1, 0, 0; Leptodactylus pustulatus, $0.00000,0,1,0$, 0; Leptodactylus rhodomerus, $0.00003,0,1,0$, 0; Leptodactylus rhodomystax, 0.00000, 0, 1, 0, 0; Leptodactylus rhodonotus, 0.00000, 0, 1, 0, 0; Leptodactylus riveroi, 0.00000, 0, 1, 0, 0; Leptodactylus rugosus, 0.00001, 0, 1, 0, 0; Leptodactylus sabanensis, 0.00020, 0, 1, 0, 0; Leptodactylus savagei, 0.00000, 0, 1, 0, 0; Leptodactylus sertanejo, 0.00000, 0, 1, 0, 0; Leptodactylus spixi, 0.00000, 0, 1, 0, 0; Leptodactylus stenodema, 0.00000, 0, 1, 0, 0; Leptodactylus syphax, 0.00000, 0, 1, 0, 0; Leptodactylus tapiti, $0.00370,0,1$, 0, 0; Leptodactylus troglodytes, $0.00000,0,1,0$, 0; Leptodactylus turimiquensis, 0.00017, 0, 1, 0, 0 ; Leptodactylus validus, $0.00000,0,1,0$, 0; Leptodactylus vastus, $0.00000,0,1,0,0$; Leptodactylus ventrimaculatus, 0.00001, 0, 1, 0 , 0; Leptodactylus viridis, $0.00005,0,1,1,0$; Leptodactylus wagneri, $0.00000,0,1,0,0$; Limnomedusa, 0.00000, 0, 0, 0, 0; Limnomedusa macroglossa, 0.00000, 0, 1, 0, 0; Lithobates, 0.00000, 0, 0, 0, 0; Lithobates bwana, 0.00014, 0, 1, 1, 0; Lithobates palmipes, $0.00000,0,1,1,0$; Lithobates vaillanti, $0.00000,0,1,1,0$; Lithodytes, $0.00000,0,0,0,0$; Lithodytes lineatus, $0.00000,0$, 1, 1, 0; Lithodytes rhodostima, 0.00008, 0, 1, 0, 0; Luetkenotyphlus, 0.00000, 0, 0, 0, 0; Luetkenotyphlus brasiliensis, 0.00000, 0, 0, 0 , 1; Lynchius, 0.00005, 0, 0, 0, 0; Lynchius flavomaculatus, 0.00006, 0, 1, 0, 0; Lynchius nebulanastes, 0.00479, 0, 1, 0, 0; Lynchius oblitus, 0.00479, 0, 1, 0, 0; Lynchius parkeri, 0.00180, 0, 1, 0, 0; Lynchius simmonsi, 0.00048, 0, 1, 0, 0; Lynchius tabaconas, 0.00479, $0,0,0$, 0; Lysapsus, 0.00000, 0, 0, 0, 0; Lysapsus bolivianus, 0.00000, 0, 1, 1, 0; Lysapsus caraya, 0.00000, 0, 1, 1, 0; Lysapsus laevis, 0.00002 , 0, 1, 1, 0; Lysapsus limellum, 0.00000, 0, 1, 1, 0; Macrogenioglottus, 0.00000, 0, 0, 0, 0; Macrogenioglottus alipioi, 0.00000, 0, 1, 0, 0; Mannophryne, 0.00006, 0, 0, 0, 0; Mannophryne caquetio, 0.00721, 0, 1, 0, 0; Mannophryne collaris, 0.00084, 0, 1, 0, 0; Mannophryne cordilleriana, 0.00117, 0, 1, 0, 0; Mannophryne herminae, 0.00038, 0, 1, 0, 0; Mannophryne lamarcai, 0.02010, 0, 1, 0, 0; Mannophryne larandina, 0.00739, 0, 1, 0, 0; Mannophryne leonardoi, 0.00025, 0, 1, 0, 0; Mannophryne neblina, 0.01045, 0, 1, 0, 0; Mannophryne oblitterata, 0.00059, 0, 1, 0, 0; Mannophryne olmonae, 0.00692, 0, 1, 0, 0; Mannophryne orellana, 0.00117, 0, 1, 0, 0; Mannophryne riveroi, 0.00306, 0, 1, 0, 0; Mannophryne speeri, 0.00827, 0, 1, 0, 0; Mannophryne trinitatis, 0.00041, 0, 1, 0, 0; Mannophryne trujillensis, 0.00540, 0, 1, 0, 0; Mannophryne urticans, 0.00293, 0, 1, 0, 0; Mannophryne venezuelensis, 0.00079, 0, 1, 0, 0; Mannophryne vulcano, 0.00393, 0, 1, 0, 0; Mannophryne yustizi, 0.00086, 0, 1, 0, 0; Megaelosia, 0.00003, 0, 0, 0, 0; Megaelosia apuana, 0.00006, 0, 1, 1, 0; Megaelosia bocainensis, 0.00210, 0, 1, 1, 0; Megaelosia boticariana, 0.00679, 0, 1, 1, 0; Megaelosia goeldii, 0.00010, 0, 1, 1, 0; Megaelosia jordanensis, 0.00135, 0, 1, 1, 0; Megaelosia lutzae, 0.00224, 0, 1, 1, 0; Megaelosia massarti, 0.00138, 0, 1, 1, 0; Melanophryniscus, 0.00000, 0, 0, 0, 0; Melanophryniscus admirabilis, 0.00959, 0, 1, 0, 0; Melanophryniscus alipioi, 0.00704, 0, 1, 0, 0; Melanophryniscus atroluteus, 0.00000, 0, 1, 0, 0; Melanophryniscus biancae, 0.00871 , $0,1,0,0$; Melanophryniscus cambaraensis, $0.00041,0,1,0,0$; Melanophryniscus cupreuscapularis, 0.00003, 0, 1, 0, 0; Melanophryniscus devincenzii, 0.00000, 0, 1, 0, 0; Melanophryniscus dorsalis, 0.00012, 0, 1, 0, 0; Melanophryniscus estebani, $0.00010,0,1,0$, 0; Melanophryniscus fulvoguttatus, 0.00001, 0, 1, 0, 0; Melanophryniscus klappenbachi, 0.00000, 0, 1, 0, 0; 
Melanophryniscus krauczuki, 0.00017, 0, 1, 0, 0; Melanophryniscus langonei, 0.00977, 0, 1, 0, 0; Melanophryniscus macrogranulosus, 0.00115, 0, 1, 0, 0; Melanophryniscus milanoi, 0.00166, 0, 1, 0, 0; Melanophryniscus montevidensis, 0.00010, 0, 1, 0, 0; Melanophryniscus moreirae, $0.00157,0,1,0,0 ;$ Melanophryniscus pachyrhynus, $0.00001,0,1,0$, 0; Melanophryniscus paraguayensis, 0.00866, 0, 1, 0, 0; Melanophryniscus peritus, 0.01149, 0, 1, 0, 0; Melanophryniscus rubriventris, 0.00002, 0, 1, 0, 0; Melanophryniscus sanmartini, 0.00001, 0, 1, 0, 0; Melanophryniscus setiba, 0.01758, 0, 1, 0, 0; Melanophryniscus simplex, 0.00029 , $0,1,0,0 ;$ Melanophryniscus spectabilis, $0.00061,0,1,0,0$; Melanophryniscus stelzneri, $0.00002,0,1,0$, 0; Melanophryniscus tumifrons, 0.00001, 0, 1, 0, 0; Melanophryniscus vilavelhensis, 0.00865, 0, 1, 0, 0; Melanophryniscus xanthostomus, 0.00141, 0, 1, 0, 0; Metaphryniscus, 0.00277, 0, 0, 0, 0; Metaphryniscus sosai, 0.00277, 0, 1, 0, 0; Microcaecilia, 0.00000, 0, 0, 0, 0; Microcaecilia albiceps, 0.00002, 0, 0, 0, 1; Microcaecilia butantan, 0.00783, 0, 0, 0, 1; Microcaecilia dermatophaga, 0.00786, 0, 0, 0, 1; Microcaecilia grandis, 0.00785, 0, 0, 0, 1; Microcaecilia iwokramae, 0.00662, 0, 0, 0, 1; Microcaecilia iyob, 0.00787, 0, 0, 0, 1; Microcaecilia marvaleewakeae, 0.00003, 0, 0, 0, 1; Microcaecilia nicefori, 0.00004, 0, 0, 0, 1; Microcaecilia pricei, 0.00006, 0, 0, 0, 1; Microcaecilia rabei, $0.00001,0,0,0,1$; Microcaecilia rochai, $0.00001,0,0,0,1$; Microcaecilia taylori, 0.00000, 0, 0, 0, 1; Microcaecilia trombetas, $0.00783,0,0,0$, 1; Microcaecilia unicolor, 0.00003, 0, 0, 0, 1; MICROHYLIDAE, 0.00000, 0, 0, 0, 0; Mimosiphonops, 0.00692, 0, 0, 0, 0; Mimosiphonops vermiculatus, 0.00692, 0, 0, 0, 1; Minyobates, 0.03021, 0, 0, 0, 0; Minyobates steyermarki, 0.03021, 1, 1, 0, 0; Myersiella, 0.00000, 0, 0, 0, 0; Myersiella microps, 0.00000, 0, 1, 0, 0; Myersiohyla, 0.00069, 0, 0, 0, 0; Myersiohyla aromatica, 0.01382, 1, 0, 0, 0; Myersiohyla chamaeleo, 0.00783, 1, 0, 0, 0; Myersiohyla inparquesi, 0.00226, 1, 0, 0, 0; Myersiohyla kanaima, 0.00426, 1, 0, 0, 0; Myersiohyla loveridgei, 0.00163, 1, 0, 0, 0; Myersiohyla neblinaria, 0.00783, 1, 0, 0, 0; Nannophryne, 0.00000, 0, 0, 0, 0; Nannophryne apolobambica, 0.01461, 0, 1, 0, 0; Nannophryne cophotis, 0.00005, 0, 1, 0, 0; Nannophryne corynetes, 0.01835, 0, 1, 0, 0; Nannophryne variegata, 0.00001, 0, 1, 0, 0; Nectocaecilia, 0.00001, 0, 0, 0, 0; Nectocaecilia petersii, 0.00001, 0, 0, 1, 1; Niceforonia, 0.00030, 0, 0, 0, 0; Niceforonia adenobrachia, 0.00035, 0, 0, 0, 0; Niceforonia columbiana, 0.05729, 0, 1, 0, 0; Niceforonia nana, 0.00211, 0, 1, 0, 0; Noblella, 0.00000, 0, 0, 0, 0; Noblella carrascoicola, 0.00063 , 0, 1, 0, 0; Noblella coloma, 0.00748, 0, 1, 0, 0; Noblella duellmani, 0.00648, 0, 1, 0, 0; Noblella heyeri, 0.00013, 0, 1, 0, 0; Noblella lochites, 0.00015, 0, 1, 0, 0; Noblella lynchi, 0.00314, 0, 1, 0, 0; Noblella madreselva, 0.00225, 0, 1, 0, 0; Noblella myrmecoides, $0.00000,0,1,0,0$; Noblella personina, 0.00783, 0, 1, 0, 0; Noblella peruviana, 0.00805, 0, 1, 0, 0; Noblella pygmaea, 0.00346, 0, 1 , 0 , 0; Noblella ritarasquinae, $0.00066,0,1,0,0 ;$ Nyctimantis, $0.00000,0,0,0,0$; Nyctimantis rugiceps, 0.00000, 1, 0, 0, 0; Nymphargus, 0.00001, 0, 0, 0, 0; Nymphargus anomalus, 0.01497, 1, 0, 0, 0; Nymphargus armatus, 0.00593, 1, 1, 0, 0; Nymphargus bejaranoi, 0.00003, 1, 0, 0, 0; Nymphargus buenaventura, 0.00036, 1, 0, 0, 0; Nymphargus cariticommatus, 0.00150, 1, 0, 0, 0; Nymphargus chami, 0.00032, 1, 0, 0, 0; Nymphargus chancas, 0.00023, 1, 0, 0, 0; Nymphargus cochranae, 0.00006, 1, 0, 0, 0; Nymphargus cristinae, 0.00198, 1, 0, 0, 0; Nymphargus garciae, 0.00014, 1, 0, 0, 0; Nymphargus grandisonae, 0.00003, 1, 0, 0, 0; Nymphargus griffithsi, 0.00009, 1, 0, 0, 0; Nymphargus ignotus, 0.00029, 1, 0, 0, 0; Nymphargus lasgralarias, 0.00782, 1, 0, 0, 0; Nymphargus laurae, 0.00897, 1, 0, 0, 0; Nymphargus luminosus, 0.00168, 1, 0, 0, 0; Nymphargus luteopunctatus, 0.00877, 1, 0, 0, 0; Nymphargus mariae, 0.00126, 1, 0, 0, 0; Nymphargus megacheirus, 0.00037, 1, 0, 0, 0; Nymphargus mixomaculatus, 0.00291, 1, 0, 0, 0; Nymphargus nephelophila, 0.00090, 1, 0, 0, 0; Nymphargus ocellatus, 0.00005, 1, 0, 0, 0; Nymphargus oreonympha, 0.01246, 1, 0, 0, 0; Nymphargus phenax, 0.00895, 1, 0, 0, 0; Nymphargus pluvialis, 0.00186, 1, 0, 0, 0; Nymphargus posadae, 0.00003, 1, 0, 0, 0; Nymphargus prasinus, $0.00028,1,0,0,0$; Nymphargus puyoensis, $0.00027,1,0,0,0$; Nymphargus rosada, 0.00010, 1, 0, 0, 0; Nymphargus ruizi, 0.00068, 1, 0, 0, 0; Nymphargus siren, 0.00021, 1, 0, 0, 0; Nymphargus spilotus, 0.00513, 1, 0, 0, 0; Nymphargus sucre, 0.00784, 1, 0, 0, 0; Nymphargus truebae, 0.00067, 1, 0, 0, 0; Nymphargus vicenteruedai, 0.00456, 1, 0, 0, 0; Nymphargus wileyi, 0.00604, 1, 0, 0, 0; ODONTOPHRYNIDAE, 0.00000, 0, 0, 0, 0; Odontophrynus, 0.00000, 0, 0, 0, 0; Odontophrynus achalensis, $0.00006,0,1,0$, 0; Odontophrynus americanus, 0.00000, 0, 1, 0, 0; Odontophrynus barrioi, 0.00003, 0, 1, 0, 0; Odontophrynus carvalhoi, 0.00000, 0, 1, 0, 0; Odontophrynus cordobae, 0.00002, 0, 1, 0, 0; Odontophrynus cultripes, 0.00000, 0, 1, 0, 0; Odontophrynus lavillai, 0.00000, 0, 1, 0, 0; Odontophrynus maisuma, 0.00003, 0, 1, 0, 0; Odontophrynus monachus, 0.00266, 0, 1, 0, 0; Odontophrynus occidentalis, 0.00000, 0, 1, 0, 0; Odontophrynus salvatori, 0.00001, 0, 1, 0, 0; Oedipina, 0.00000, 0, 0, 0, 0; Oedipina complex, 0.00002, 1, 0, 0, 0; Oedipina parvipes, 0.00003, 1, 0, 0, 0; Ololygon, 0.00000, 0, 0, 0, 0; Ololygon agilis, 0.00009, 1, 0, 0, 0; Ololygon albicans, 0.00007, 1, 0, 0, 0; Ololygon angrensis, 0.00073, 1, 0, 0, 0; Ololygon arduous, 0.00140, 1, 0, 0, 0; Ololygon argyreornata, 0.00001, 1, 0, 0, 0; Ololygon ariadne, 0.00355, 1, 0, 0, 0; Ololygon aromothyella, 0.00000, 1, 0, 0, 0; Ololygon atrata, 0.00162, 1, 0, 0, 0; Ololygon belloni, 0.00090, 1, 0, 0, 0; Ololygon berthae, 0.00000, 1, 0, 0, 0; Ololygon brieni, $0.00003,1,0,0$, 0; Ololygon canastrensis, $0.00006,1,0,0,0$; Ololygon carnevallii, $0.00001,1,0$, 0, 0; Ololygon catharinae, 0.00001 , 1, 0, 0, 0; Ololygon centralis, 0.00001, 1, 0, 0, 0; Ololygon cosenzai, 0.00008, 1, 0, 0, 0; Ololygon flavoguttata, 0.00001, 1, 0, 0, 0; Ololygon heyeri, 0.00059, 1, 0, 0, 0; Ololygon hiemalis, 0.00003, 1, 0, 0, 0; Ololygon humilis, 0.00002, 1, 0, 0, 0; Ololygon insperata, 0.00146, 1, 0, 0, 0; Ololygon jureia, 0.00043, 1, 0, 0, 0; Ololygon kautskyi, 0.01629, 1, 0, 0, 0; Ololygon littoralis, 0.00003, 1, 0, 0, 0; Ololygon littoreus, 0.00019, 1, 0, 0, 0; Ololygon longilinea, 0.00001, 1, 0, 0, 0; Ololygon luizotavioi, 0.00002, 1, 0, 0, 0; Ololygon machadoi, 0.00002, 1, 0, 0, 0; Ololygon melanodactylus, 0.00002, 1, 0, 0, 0; Ololygon melloi, 0.00087, 1, 0, 0, 0; Ololygon muriciensis, 0.00523, 1, 0, 0, 0; Ololygon obtriangulata, 0.00020, 1, 0, 0, 0; Ololygon perpusilla, 0.00002, 1, 0, 0, 0; Ololygon pombali, 0.00267, 1, 0, 0, 0; Ololygon ranki, 0.00010, 1, 0, 0, 0; Ololygon rizibilis, 0.00001, 1, 0, 0, 0; Ololygon skaios, 0.00810, 1, 0, 0, 0; Ololygon skuki, 0.00321, 1, 0, 0, 0; Ololygon strigilata, 0.00004, 1, 0, 0, 0; Ololygon tripui, 0.00011, 1, 0, 0, 0; Ololygon tupinamba, 0.00402, 1, 0, 0, 0; Ololygon v-signata, 0.00009, 1, 0, 0, 0; Oophaga, 0.00000, 0, 0, 0, 0; Oophaga histrionica, 0.00002, 0, 1, 0, 0; Oophaga lehmanni, 0.00031, 0, 1, 0, 0; Oophaga occultator, 0.00796, 0, 1, 0, 0; Oophaga sylvatica, 0.00003, 0, 1, 0, 0; Oreobates, 0.00000, 0, 0, 0, 0; Oreobates amarakaeri, 0.00137, 0, 1, 0, 0; Oreobates ayacucho, 0.00393, 0, 1, 0, 0; Oreobates barituensis, 0.00016, 0, 1, 0, 0; Oreobates berdemenos, 0.00387, 0, 1, 0, 0; Oreobates choristolemma, 0.00134, 0, 1, 0, 0; Oreobates crepitans, 0.00005, 0, 1, 0, 0; Oreobates cruralis, 0.00000, 0, 1, 0, 0; Oreobates discoidalis, 0.00001, 0, 1, 0, 0; Oreobates gemcare, $0.00030,0$, 1, 0, 0; Oreobates granulosus, 0.00032, 0, 1, 0, 0; Oreobates heterodactylus, 0.00673, 0, 1, 0, 0; Oreobates ibischi, 0.00011 , 0, 1, 0, 0; Oreobates lehri, 0.00029, 0, 1, 0, 0; Oreobates lundbergi, 0.00094, 0, 1, 0, 0; Oreobates machiguenga, 0.00802, 0,1 , 0, 0; Oreobates madidi, 0.00143, 0, 1, 0, 0; Oreobates pereger, 0.00062, 0, 1, 0, 0; Oreobates quixensis, 0.00000, 0, 1, 0, 0; Oreobates remotus, 0.00099, 0, 1, 0, 0; Oreobates sanctaecrucis, 0.00013, 0, 1, 0, 0; Oreobates sanderi, 0.00005, 0, 1, 0, 0; Oreobates saxatilis, 0.00002, 0, 1, 0, 0; Oreobates zongoensis, 0.00698, 0, 1, 0, 0; Oreophrynella, 0.00111, 0, 0, 0, 0; Oreophrynella 
cryptica, 0.00155, 0, 1, 0, 0; Oreophrynella dendronastes, 0.03883, 0, 1, 0, 0; Oreophrynella huberi, 0.03538, 0, 1, 0, 0; Oreophrynella macconnelli, 0.01300, 0, 1, 0, 0; Oreophrynella nigra, 0.01890, 0, 1, 0, 0; Oreophrynella quelchii, 0.01876, 0, 1, 0, 0; Oreophrynella seegobini, 0.03912, 0, 1, 0, 0; Oreophrynella vasquezi, 0.02236, 0, 1, 0, 0; Oreophrynella weiassipuensis, 0.61030, 0, 1, 0, 0; Oscaecilia, 0.00000, 0, 0, 0, 0; Oscaecilia bassleri, 0.00000, 0, 0, 0, 1; Oscaecilia equatorialis, 0.00782, 0, 0, 0, 1; Oscaecilia hypereumeces, $0.00203,0,0,0,1$; Oscaecilia koepckeorum, 0.00209, 0, 0, 0, 1; Oscaecilia ochrocephala, 0.00004, 0, 0, 0, 1; Oscaecilia polyzona, 0.00004, 0, 0, 0, 1; Osornophryne, 0.00003, 0, 0, 0, 0; Osornophryne angel, 0.00783, 1, 1, 0, 0; Osornophryne antisana, 0.00112, 1, 1, 0, 0; Osornophryne bufoniformis, 0.00005, 1, 1, 0, 0; Osornophryne cofanorum, 0.01058, 1, 1, 0, 0; Osornophryne guacamayo, 0.00012, 1, 1, 0, 0; Osornophryne occidentalis, 0.00069, 1, 1, 0, 0; Osornophryne percrassa, 0.00054, 1, 1, 0, 0; Osornophryne puruanta, 0.01125, 1, 1, 0, 0; Osornophryne simpsoni, 0.00783, 1, 1, 0, 0; Osornophryne sumacoensis, $0.00385,1,1,0$, 0; Osornophryne talipes, 0.00007, 1, 1, 0, 0; Osteocephalus, 0.00000, 0, 0, 0, 0; Osteocephalus aff_buckleyi, $0.00004,1,0,0,0$; Osteocephalus aff_leprieurii_1, 0.00004, 1, 0, 0, 0; Osteocephalus aff_leprieurii_2, 0.00000, 1, 0, 0, 0; Osteocephalus aff_mutabor, 0.00001, 1, 0, 0, 0; Osteocephalus aff_planiceps, $0.00783,1,0,0$, 0; Osteocephalus aff_taurinus_1, $0.00017,1,0,0,0$; Osteocephalus aff_taurinus_2, 0.00056, 1, 0, 0, 0; Osteocephalus aff_taurinus_3, 0.00001, 1, 0, 0, 0; Osteocephalus aff_taurinus_4, $0.00002,1,0,0,0 ;$ Osteocephalus aff_taurinus_5, 0.00000, 1, 0, 0, 0; Osteocephalus alboguttatus, $0.00002,1,0,0,0$; Osteocephalus buckleyi, 0.00001, 1, 0, 0, 0; Osteocephalus cabrerai, 0.00001, 1, 0, 0, 0; Osteocephalus cannatellai, 0.00001, 1, 0, 0, 0; Osteocephalus carri, 0.00786, 1, 0, 0, 0; Osteocephalus castaneicola, 0.00001, 1, 0, 0, 0; Osteocephalus deridens, $0.00000,1,0,0,0$; Osteocephalus duellmani, 0.00784, 1, 0, 0, 0; Osteocephalus festae, 0.00001, 1, 0, 0, 0; Osteocephalus fuscifacies, 0.00002, 1, 0, 0, 0; Osteocephalus helenae, $0.00000,1,0,0,0$; Osteocephalus heyeri, 0.00020, 1, 0, 0, 0; Osteocephalus leoniae, 0.00003, 1, 0, 0, 0; Osteocephalus leprieurii, 0.00000, 1, 0, 0, 0; Osteocephalus mimeticus, 0.00001, 1, 0, 0, 0 ; Osteocephalus mutabor, 0.00005, 1, 0, 0, 0; Osteocephalus oophagus, 0.00000, 1, 0, 0, 0; Osteocephalus planiceps, 0.00000, 1, 0, 0, 0; Osteocephalus subtilis, 0.00001, 1, 0, 0, 0; Osteocephalus taurinus, 0.00000, 1, 0, 0, 0; Osteocephalus verruciger, 0.00003, 1, 0, 0,0 ; Osteocephalus vilarsi, $0.00783,1,0,0,0$; Osteocephalus yasuni, 0.00000, 1, 0, 0, 0; Otophryne, 0.00000, 0, 0, 0, 0; Otophryne pyburni, 0.00000, 0, 1, 0, 0; Otophryne robusta, 0.00002, 0, 1, 0, 0; Otophryne steyermarki, 0.00003, 0, 1, 0, 0; Paratelmatobius, 0.00062 , 0, 0, 0, 0; Paratelmatobius cardosoi, 0.00109, 1, 1, 0, 0; Paratelmatobius gaigeae, 0.01123, 1, 1, 0, 0; Paratelmatobius lutzii, 0.01221, 1, 1, 0, 0; Paratelmatobius mantiqueira, 0.00973, 1, 1, 0, 0; Paratelmatobius poecilogaster, 0.00075, 1, 1, 0, 0; Paratelmatobius yepiranga, 0.00980, 1, 1, 0, 0; Phasmahyla, 0.00001, 0, 0, 0, 0; Phasmahyla cochranae, 0.00001, 1, 0, 0, 0; Phasmahyla cruzi, 0.01116, 1, 0, 0, 0; Phasmahyla exilis, 0.00026, 1, 0, 0, 0; Phasmahyla guttata, 0.00002, 1, 0, 0, 0; Phasmahyla jandaia, 0.00006, 1, 0, 0, 0; Phasmahyla spectabilis, 0.00060, 1, 0, 0, 0; Phasmahyla timbo, 0.00911, 1, 0, 0, 0; Phrynomedusa, 0.00003, 0, 0, 0, 0; Phrynomedusa appendiculata, 0.00004, 1, 0, 0, 0; Phrynomedusa bokermanni, 0.00574, 1, 0, 0, 0; Phrynomedusa dryade, 0.00015, 1, 0, 0, 0; Phrynomedusa fimbriata, 0.00862, 1, 0, 0, 0; Phrynomedusa marginata, 0.00128, 1, 0, 0, 0; Phrynomedusa vanzolinii, 0.00012, 1, 0, 0, 0; Phrynopus, 0.00012, 0, 0, 0, 0; Phrynopus auriculatus, 0.00137, 0, 1, 0, 0; Phrynopus badius, 0.00795, 0, 1, 0, 0; Phrynopus barthlenae, 0.00151, 0, 1, 0, 0; Phrynopus bracki, 0.00158, 0, 1, 0, 0; Phrynopus bufoides, 0.00328, 0, 1, 0, 0; Phrynopus chaparroi, 0.00799, 0, 1, 0, 0; Phrynopus curator, 0.00795, 0, 1, 0, 0; Phrynopus daemon, 0.00033, 0, 1, 0, 0; Phrynopus dagmarae, 0.00150, 0, 1, 0, 0; Phrynopus heimorum, 0.00113, 0, 1, 0, 0; Phrynopus horstpauli, 0.00336, 0, 1, 0, 0; Phrynopus interstinctus, 0.00794, 0, 1, 0, 0; Phrynopus kauneorum, 0.00212, 0, 1, 0, 0; Phrynopus kotosh, 0.00595, 0, 1, 0, 0; Phrynopus lechriorhynchus, 0.00794, 0, 1, 0, 0; Phrynopus miroslawae, 0.00524, 0, 1, 0, 0; Phrynopus montium, 0.00148, 0, 1, 0, 0; Phrynopus nicoleae, 0.00344, 0, 1, 0, 0; Phrynopus oblivius, 0.00502, 0, 1, 0, 0; Phrynopus paucari, 0.00660, 0, 1, 0, 0; Phrynopus peruanus, 0.00459, 0, 1, 0, 0; Phrynopus pesantesi, 0.00796, 0, 1, 0, 0; Phrynopus tautzorum, 0.00711, 0, 1, 0, 0; Phrynopus thompsoni, 0.01259, 0, 1, 0, 0; Phrynopus tribulosus, 0.00193, 0, 1, 0, 0; Phrynopus valquii, 0.00790, 0, 1, 0, 0; Phrynopus vestigiatus, 0.00794, 0, 1, 0, 0; Phyllobates, 0.00006, 0, 0, 0, 0; Phyllobates aurotaenia, 0.00009, 0, 1, 0, 0; Phyllobates bicolor, $0.00013,0,1,0$, 0; Phyllobates terribilis, 0.00052, 0, 1, 0, 0; Phyllodytes, 0.00000, 0, 0, 0, 0; Phyllodytes acuminatus, 0.00010, 1, 0, 0, 0; Phyllodytes brevirostris, 0.00004, 1, 0, 0, 0; Phyllodytes edelmoi, 0.00023, 1, 0, 0, 0; Phyllodytes gyrinaethes, 0.00012, 1, 0, 0, 0; Phyllodytes kautskyi, 0.00010, 1, 0, 0, 0; Phyllodytes luteolus, 0.00001, 1, 0, 0, 0; Phyllodytes maculosus, 0.00006, 1, 0, 0, 0; Phyllodytes megatympanum, 0.00011, 1, 0, 0, 0; Phyllodytes melanomystax, 0.00002, 1, 0, 0, 0; Phyllodytes punctatus, 0.00028, 1, 0, 0, 0; Phyllodytes tuberculosus, 0.00001, 1, 0, 0, 0; Phyllodytes wuchereri, 0.00002, 1, 0, 0, 0; Phyllomedusa, 0.00000, 0, 0, 0, 0; Phyllomedusa bahiana, 0.00001, 1, 0, 0, 0; Phyllomedusa bicolor, 0.00000, 1, 0, 0, 0; Phyllomedusa boliviana, 0.00000, 1, 0, 0, 0; Phyllomedusa burmeisteri, 0.00000, 1, 0, 0, 0; Phyllomedusa camba, 0.00000, 1, 0, 0, 0; Phyllomedusa coelestis, 0.00000, 1, 0, 0, 0; Phyllomedusa distincta, 0.00001, 1, 0, 0, 0; Phyllomedusa iheringii, 0.00000, 1, 0, 0, 0; Phyllomedusa neildi, 0.00110, 1, 0, 0, 0; Phyllomedusa rohdei, 0.00000, 1, 0, 0, 0; Phyllomedusa rustica, 0.00875, 1, 0, 0, 0; Phyllomedusa sauvagii, 0.00000, 1, 0, 0, 0; Phyllomedusa tarsius, 0.00000, 1, 0, 0, 0; Phyllomedusa tetraploidea, 0.00000, 1, 0, 0, 0; Phyllomedusa trinitatis, 0.00001, 1, 0, 0, 0; Phyllomedusa vaillantii, 0.00000, 1, 0, 0, 0; Phyllomedusa venusta, 0.00001, 1, 0, 0, 0; PHYLLOMEDUSIDAE, 0.00000, 0, 0, 0, 0; Physalaemus, 0.00000, 0, 0, 0, 0; Physalaemus aff_albonotatus, 0.00000, 0, 1, 0, 0; Physalaemus aff_cuvieri, 0.00796, 0, 1, 0, 0; Physalaemus aguirrei, $0.00001,0,1,0,0$; Physalaemus albifrons, $0.00000,0,1,0,0$; Physalaemus albonotatus, 0.00000, 0, 1, 0, 0; Physalaemus angrensis, 0.03342, 0, 1, 0, 0; Physalaemus atim, 0.00288, 0, 1, 0, 0; Physalaemus atlanticus, 0.01253, 0, 1, 0, 0; Physalaemus barrioi, 0.00745, 0, 1, 0, 0; Physalaemus biligonigerus, 0.00000, 0, 1, 0, 0; Physalaemus bokermanni, 0.00058, 0, 1, 0, 0; Physalaemus caete, 0.00006, 0, 1, 0, 0; Physalaemus camacan, 0.00023, 0, 1, 0, 0; Physalaemus centralis, 0.00000, 0, 1, 0, 0; Physalaemus cicada, 0.00000, 0, 1, 0, 0; Physalaemus crombiei, 0.00006, 0, 1, 0, 0; Physalaemus cuvieri, 0.00000, 0, 1, 0, 0; Physalaemus deimaticus, 0.00064, 0, 1, 0, 0; Physalaemus ephippifer, 0.00000, 0, 1, 0, 0; Physalaemus erikae, 0.00010, 0, 1, 0, 0; Physalaemus erythros, $0.00153,0,1,0$, 0; Physalaemus evangelistai, $0.00010,0,1,0$, 0; Physalaemus feioi, 0.00002, 0, 1, 0, 0; Physalaemus fernandezae, 0.00001, 0, 1, 0, 0; Physalaemus fischeri, 0.00000, 0, 1, 0, 0; Physalaemus gracilis, 0.00000, 0, 1, 0, 0; Physalaemus henselii, $0.00000,0,1,0$, 0; Physalaemus insperatus, $0.00372,0,1,0$, 0; Physalaemus irroratus, 0.00263, 0, 1, 0, 0; Physalaemus jordanensis, 0.00005, 0, 1, 0, 0; Physalaemus kroyeri, 0.00000, 0, 1, 0, 0; Physalaemus lateristriga, 0.00003, 0, 1, 0, 0; Physalaemus lisei, 0.00002, 0, 1, 0, 0; Physalaemus maculiventris, 0.00006, 0, 1, 0, 0; Physalaemus marmoratus, 0.00000, 0, 1, 0, 0; Physalaemus maximus, 0.00015, 0, 1, 0, 0; Physalaemus moreirae, 0.00016, 0, 1, 0, 0; Physalaemus nanus, 0.00003, 0, 1, 0, 0; Physalaemus nattereri, 0.00000, 0, 1, 0, 0; Physalaemus obtectus, 0.00005, 0, 1, 0, 0; Physalaemus olfersii, 0.00002, 0, 1, 0, 0; 
Physalaemus orophilus, 0.00004, 0, 1, 0, 0; Physalaemus riograndensis, 0.00000, 0, 1, 0, 0; Physalaemus rupestris, 0.00045, 0, 1, 0, 0 ; Physalaemus santafecinus, 0.00001, 0, 1, 0, 0; Physalaemus signifer, 0.00013, 0, 1, 0, 0; Physalaemus soaresi, 0.00543, 0, 1, 0, 0; Physalaemus spiniger, 0.00004, 0, 1, 0, 0; Phytotriades, 0.00026, 0, 0, 0, 0; Phytotriades auratus, 0.00026, 1, 0, 0, 0; Phyzelaphryne, $0.00000,0,0,0,0$; Phyzelaphryne aff_miriamae, 0.00000, 0, 1, 0, 0; Phyzelaphryne miriamae, 0.00000, 0, 1, 0, 0; Pipa, 0.00000, 0, 0 , 0, 0; Pipa arrabali, 0.00000, 0, 0, 1, 0; Pipa aspera, 0.00001, 0, 0, 1, 0; Pipa carvalhoi, 0.00000, 0, 0, 1, 0; Pipa parva, 0.00001, 0, 0, 1, 0; Pipa pipa, 0.00000, 0, 0, 1, 0; Pipa snethlageae, 0.00000, 0, 0, 1, 0; PIPIDAE, 0.00000, 0, 0, 0, 0; Pithecopus, 0.00000, 0, 0, 0, 0; Pithecopus ayeaye, 0.00001, 1, 0, 0, 0; Pithecopus azureus, 0.00000, 1, 0, 0, 0; Pithecopus centralis, 0.00157, 1, 0, 0, 0; Pithecopus hypochondrialis, $0.00000,1,0,0$, 0; Pithecopus megacephalus, 0.00050, 1, 0, 0, 0; Pithecopus nordestinus, 0.00000, 1, 0, 0, 0; Pithecopus oreades, $0.00001,1,0,0$, 0; Pithecopus palliatus, 0.00000, 1, 0, 0, 0; PLETHODONTIDAE, 0.00000, 0, 0, 0, 0; Pleurodema, 0.00000 , 0, 0, 0, 0; Pleurodema alium, 0.00001, 0, 1, 0, 0; Pleurodema bibroni, 0.00000, 0, 1, 0, 0; Pleurodema borellii, 0.00001, 0, 1, 0, 0; Pleurodema brachyops, 0.00000, 0, 1, 0, 0; Pleurodema bufoninum, 0.00000, 0, 1, 0, 0; Pleurodema cinereum, 0.00000, 0, 1, 0, 0; Pleurodema cordobae, 0.00248, 0, 1, 0, 0; Pleurodema diplolister, 0.00000, 0, 1, 0, 0; Pleurodema guayapae, 0.00000, 0, 1, 0, 0; Pleurodema kriegi, 0.00041, 0, 1, 0, 0; Pleurodema marmoratum, 0.00000, 0, 1, 0, 0; Pleurodema nebulosum, 0.00000, 0, 1, 0, 0; Pleurodema somuncurense, 0.00414, 0, 1, 0, 0; Pleurodema thaul, 0.00000, 0, 1, 0, 0; Pleurodema tucumanum, 0.00000, 0, 1, 0, 0; Potomotyphlus, $0.00000,0,0,0,0$; Potomotyphlus kaupii, $0.00000,0,0,1$, 0; Pristimantis, 0.00000, 0, 0, 0, 0; Pristimantis aaptus, 0.00002 , 1, 1, 0, 0; Pristimantis abakapa, 0.00786, 1, 1, 0, 0; Pristimantis academicus, $0.00000,1,1,0$, 0; Pristimantis acatallelus, $0.00008,1,1,0,0$; Pristimantis acerus, $0.00222,1,1,0,0$; Pristimantis achatinus, $0.00001,1,1,0$, 0; Pristimantis actinolaimus, $0.00471,1,1,0$, 0; Pristimantis actites, 0.00012, 1, 1, 0, 0; Pristimantis acuminatus, $0.00000,1,1,0$, 0; Pristimantis acutirostris, $0.00962,1,1,0$, 0; Pristimantis adiastolus, $0.00072,1,1,0$, 0; Pristimantis aemulatus, 0.00460, 1, 1, 0, 0; Pristimantis affinis, $0.00033,1,1,0$, 0; Pristimantis alalocophus, 0.00031, 1, 1, 0, 0; Pristimantis albericoi, 0.00552, 1, 1, 0, 0; Pristimantis albertus, $0.00251,1,1,0$, 0; Pristimantis allpapuyu, 0.00072, 1, 1, 0, 0; Pristimantis almendariz, 0.00072, 1, 1, 0, 0; Pristimantis altamazonicus, 0.00000, 1, 1, 0, 0; Pristimantis altamnis, 0.00004, 1, 1, 0, 0; Pristimantis ameliae, 0.00792, 1, 1, 0, 0; Pristimantis amydrotus, 0.00214, 1, 1, 0, 0; Pristimantis andinognomus, 0.00008, 1, 1, 0, 0; Pristimantis anemerus, 0.00019, 1, 1, 0, 0; Pristimantis angustilineatus, 0.00092, 1, 1, 0, 0; Pristimantis aniptopalmatus, 0.00255, 1, 1, 0, 0; Pristimantis anolirex, 0.00038, 1, 1, 0, 0; Pristimantis anotis, 0.01331, 1, 1, 0, 0; Pristimantis apiculatus, 0.00025, 1, 1, 0, 0; Pristimantis appendiculatus, 0.00016, 1, 1, 0, 0 ; Pristimantis aquilonaris, $0.00074,1,1,0$, 0; Pristimantis ardalonychus, $0.00013,1,1,0,0$; Pristimantis ardyae, 0.00199, 1, 1, 0, 0; Pristimantis atrabracus, 0.00597, 1, 1, 0, 0; Pristimantis atratus, 0.00007, 1, 1, 0, 0; Pristimantis aurantiguttatus, 0.00021, 1, 1, 0, 0; Pristimantis aureolineatus, 0.00000, 1, 1, 0, 0; Pristimantis aureoventris, $0.00511,1,1,0,0$; Pristimantis auricarens, 0.00193, 1, 1, 0 , 0; Pristimantis avicuporum, 0.00265, 1, 1, 0, 0; Pristimantis avius, 0.00474, 1, 1, 0, 0; Pristimantis bacchus, 0.00252, 1, 1, 0, 0; Pristimantis baiotis, 0.00617, 1, 1, 0, 0; Pristimantis balionotus, 0.00078, 1, 1, 0, 0; Pristimantis bambu, 0.00019, 1, 1, 0, 0; Pristimantis baryecuus, $0.00035,1,1,0$, 0; Pristimantis batrachites, $0.00244,1,1,0$, 0; Pristimantis bearsei, 0.00030, 1, 1, 0, 0; Pristimantis bellae, $0.00074,1,1,0,0$; Pristimantis bellator, $0.00058,1,1,0,0$; Pristimantis bellona, 0.00164, 1, 1, 0, 0; Pristimantis bernali, 0.00167, 1, 1, 0, 0; Pristimantis bicantus, 0.00007, 1, 1, 0, 0; Pristimantis bicolor, 0.00015, 1, 1, 0, 0; Pristimantis bicumulus, $0.00041,1,1,0$, 0; Pristimantis bipunctatus, 0.00002, 1, 1, 0, 0; Pristimantis boconoensis, 0.00394, 1, 1, 0, 0; Pristimantis bogotensis, $0.00025,1,1,0$, 0; Pristimantis boulengeri, $0.00003,1,1,0$, 0; Pristimantis brevicrus, $0.00000,1,1,0,0 ;$ Pristimantis brevifrons, $0.00007,1,1$, 0, 0; Pristimantis briceni, 0.00132, 1, 1, 0, 0; Pristimantis bromeliaceus, $0.00001,1,1,0,0 ;$ Pristimantis buccinator, $0.00001,1,1,0,0$; Pristimantis buckleyi, 0.00002, 1, 1, 0, 0; Pristimantis buenaventura, 0.00031, 1, 1, 0, 0; Pristimantis bustamante, $0.00786,1,1,0$, 0; Pristimantis cabrerai, 0.00015, 1, 1, 0, 0; Pristimantis cacao, 0.00184, 1, 1, 0, 0; Pristimantis caeruleonotus, 0.00096, 1, 1, 0, 0; Pristimantis cajamarcensis, 0.00003, 1, 1, 0, 0; Pristimantis calcaratus, 0.00033, 1, 1, 0, 0; Pristimantis calcarulatus, $0.00012,1,1,0$, 0; Pristimantis cantitans, $0.00137,1,1,0$, 0; Pristimantis capitonis, 0.00077, 1, 1, 0, 0; Pristimantis caprifer, 0.00003, 1, 1, 0, 0; Pristimantis carlosceroni, 0.00782, 1, 1, 0, 0; Pristimantis carlossanchezi, 0.00032, 1, 1, 0, 0; Pristimantis carmelitae, 0.00309, 1, 1, 0, 0; Pristimantis carranguerorum, 0.00081, 1, 1, 0, 0; Pristimantis carvalhoi, 0.00000, 1, 1, 0, 0 ; Pristimantis caryophyllaceus, 0.00002, 1, 1, 0, 0; Pristimantis cedros, 0.00782, 1, 1, 0, 0; Pristimantis celator, 0.00008, 1, 1, 0, 0; Pristimantis ceuthospilus, $0.00019,1,1,0,0$; Pristimantis chalceus, $0.00001,1,1,0,0$; Pristimantis charlottevillensis, 0.01113, 1, 1, 0, 0; Pristimantis chiastonotus, 0.00000, 1, 1, 0, 0; Pristimantis chimu, 0.01129, 1, 1, 0, 0; Pristimantis chloronotus, 0.00009, 1, 1, 0, 0; Pristimantis chrysops, $0.00041,1,1,0$, 0; Pristimantis citriogaster, $0.00003,1,1,0$, 0; Pristimantis colodactylus, 0.00005, 1, 1, 0, 0; Pristimantis colomai, 0.00010, 1, 1, 0, 0; Pristimantis colonensis, 0.00010, 1, 1, 0, 0; Pristimantis colostichos, 0.00269, 1, 1, 0, 0; Pristimantis condor, 0.00002, 1, 1, 0, 0; Pristimantis conservatio, 0.00792, 1, 1, 0, 0; Pristimantis conspicillatus, 0.00000, 1, 1, 0, 0; Pristimantis cordovae, $0.00378,1,1,0$, 0; Pristimantis corniger, 0.00047, 1, 1, 0, 0; Pristimantis coronatus, 0.00551, 1, 1, 0, 0; Pristimantis corrugatus, $0.00022,1,1,0,0$; Pristimantis cosnipatae, $0.00117,1,1,0$, 0; Pristimantis cremnobates, $0.00004,1,1,0$, 0; Pristimantis crenunguis, 0.00005, 1, 1, 0, 0; Pristimantis cristinae, 0.00568, 1, 1, 0, 0; Pristimantis croceoinguinis, 0.00000, 1, 1, 0, 0; Pristimantis crucifer, 0.00008, 1, 1, 0, 0; Pristimantis cruciocularis, 0.00034, 1, 1, 0, 0; Pristimantis cruentus, 0.00409, 1, 1, 0, 0; Pristimantis cryophilius, $0.00010,1,1,0,0$; Pristimantis cryptomelas, $0.00010,1,1,0$, 0; Pristimantis cuentasi, $0.00375,1,1,0,0$; Pristimantis culatensis, 0.00042, 1, 1, 0, 0; Pristimantis cuneirostris, 0.00213, 1, 1, 0, 0; Pristimantis curtipes, 0.00004, 1, 1, 0, 0; Pristimantis danae, $0.00002,1,1,0$, 0; Pristimantis degener, $0.00042,1,1,0,0$; Pristimantis deinops, 0.00030, 1, 1, 0, 0; Pristimantis delicatus, 0.00324, 1, 1, 0, 0; Pristimantis delius, 0.00000, 1, 1, 0, 0; Pristimantis dendrobatoides, 0.00358, 1, 1, 0, 0; Pristimantis devillei, 0.00004, 1, 1, 0, 0; Pristimantis deyi, 0.00790, 1, 1, 0, 0; Pristimantis diadematus, 0.00000, 1, 1, 0, 0; Pristimantis diaphonus, $0.01231,1,1,0$, 0; Pristimantis diogenes, $0.00475,1,1,0$, 0; Pristimantis dissimulatus, $0.00152,1,1,0$, 0; Pristimantis divnae, $0.00057,1,1,0,0$; Pristimantis dorato, $0.00073,1,1,0,0$; Pristimantis dorsopictus, $0.00061,1,1,0$, 0; Pristimantis duellmani, $0.00012,1,1,0,0$; Pristimantis duende, 0.00976, 1, 1, 0, 0; Pristimantis dundeei, 0.00021, 1, 1, 0, 0; Pristimantis elegans, 0.00007, 1, 1, 0, 0; Pristimantis enigmaticus, 0.00001, 1, 1, 0, 0; Pristimantis epacrus, 0.01281, 1, 1, 0, 0; Pristimantis eremitus, 0.00020, 1, 1, 0, 0; Pristimantis eriphus, $0.00008,1,1,0$, 0; Pristimantis ernesti, $0.00837,1,1,0$, 0; Pristimantis erythropleura, 0.00004, 1, 1, 0, 0; Pristimantis esmeraldas, $0.00002,1,1,0$, 0; Pristimantis espedeus, $0.00785,1,1,0$, 0; Pristimantis eugeniae, 0.00026, 1, 1, 0, 0; Pristimantis eurydactylus, 0.00000, 1, 1, 0, 0; Pristimantis exoristus, 0.00003, 1, 1, 0, 0; Pristimantis factiosus, 0.00025, 1, 1, 0, 0; Pristimantis fallax, 0.00039, 1, 1, 0, 0; Pristimantis farisorum, 0.00783, 1, 1, 0, 0; Pristimantis fasciatus, 0.00052, 1, 1, 0, 0; 
Pristimantis fenestratus, $0.00000,1,1,0$, 0; Pristimantis festae, $0.00008,1,1,0$, 0; Pristimantis fetosus, 0.00378, 1, 1, 0, 0; Pristimantis flabellidiscus, $0.00248,1,1,0$, 0; Pristimantis flavobracatus, $0.00320,1,1,0$, 0; Pristimantis floridus, 0.00007, 1, 1, 0, 0; Pristimantis frater, $0.00034,1,1,0$, 0; Pristimantis gagliardoi, 0.00050, 1, 1, 0, 0; Pristimantis gaigei, 0.00001, 1, 1, 0, 0; Pristimantis galdi, 0.00002, 1, 1, 0, 0; Pristimantis ganonotus, 0.00018, 1, 1, 0, 0; Pristimantis geminus, 0.00796, 1, 1, 0, 0; Pristimantis gentryi, $0.00039,1,1,0,0$; Pristimantis ginesi, $0.00118,1,1,0$, 0; Pristimantis gladiator, $0.00010,1,1,0$, 0; Pristimantis glandulosus, $0.00033,1,1,0$, 0; Pristimantis gracilis, 0.00019, 1, 1, 0, 0; Pristimantis grandiceps, $0.00058,1,1,0$, 0; Pristimantis gryllus, 0.00017 , 1, 1, 0, 0; Pristimantis guaiquinimensis, 0.00089, 1, 1, 0, 0; Pristimantis gualacenio, 0.00784, 1, 1, 0, 0; Pristimantis gutturalis, $0.00000,1,1,0,0$; Pristimantis hamiotae, $0.00800,1,1,0$, 0; Pristimantis hampatusami, 0.00054, 1, 1, 0, 0; Pristimantis hectus, $0.00010,1,1,0$, 0; Pristimantis helvolus, 0.00021, 1, 1, 0, 0; Pristimantis hernandezi, 0.00069, 1, 1, 0, 0; Pristimantis hoogmoedi, $0.00803,1,1,0$, 0; Pristimantis huicundo, 0.00084, 1, 1, 0, 0; Pristimantis hybotragus, $0.00032,1,1$, 0, 0; Pristimantis ignicolor, 0.00333 , 1, 1, 0, 0; Pristimantis iiap, 0.00330, 1, 1, 0, 0; Pristimantis illotus, 0.00007, 1, 1, 0, 0; Pristimantis imitatrix, 0.00002, 1, 1, 0, 0; Pristimantis imthurni, 0.00786, 1, 1, 0, 0; Pristimantis incanus, 0.00010, 1, 1, 0, 0; Pristimantis incertus, 0.00850, 1, 1, 0, 0; Pristimantis incomptus, $0.00003,1,1,0$, 0; Pristimantis infraguttatus, $0.00070,1,1,0$, 0; Pristimantis inguinalis, 0.00001, 1, 1, 0, 0; Pristimantis insignitus, 0.00109, 1, 1, 0, 0; Pristimantis inusitatus, 0.00011, 1, 1, 0, 0; Pristimantis ixalus, 0.00727, 1, 1, 0, 0; Pristimantis jabonensis, 0.01122, 1, 1, 0, 0; Pristimantis jaguensis, $0.00787,1,1$, 0, 0; Pristimantis jaimei, 0.00157, 1, 1, 0, 0; Pristimantis jamescameroni, 0.00786, 1, 1, 0, 0; Pristimantis jester, 0.00378, 1, 1, 0, 0; Pristimantis johannesdei, 0.00082, 1, 1, 0, 0; Pristimantis jorgevelosai, 0.00326, 1, 1, 0, 0; Pristimantis juanchoi, 0.00040, 1, 1, 0, 0; Pristimantis jubatus, 0.00623, 1, 1, 0, 0; Pristimantis kareliae, 0.00252, 1, 1, 0, 0; Pristimantis katoptroides, 0.00003, 1, 1, 0, 0; Pristimantis kelephus, 0.00683, 1, 1, 0, 0; Pristimantis kichwarum, 0.00003, 1, 1, 0, 0; Pristimantis kirklandi, 0.00047, 1, 1, 0, 0; Pristimantis koehleri, 0.00008, 1, 1, 0, 0; Pristimantis kuri, $0.00029,1,1,0$, 0; Pristimantis labiosus, 0.00004, 1, 1, 0, 0; Pristimantis lacrimosus, 0.00000, 1, 1, 0, 0; Pristimantis lancinii, $0.00113,1,1,0$, 0; Pristimantis lanthanites, $0.00000,1,1,0$, 0; Pristimantis lasalleorum, 0.00534, 1, 1, 0, 0; Pristimantis lassoalcalai, 0.00684, 1, 1, 0, 0; Pristimantis latericius, $0.00783,1,1,0$, 0; Pristimantis laticlavius, $0.00015,1,1,0,0$; Pristimantis latidiscus, $0.00001,1,1,0$, 0; Pristimantis lemur, $0.00012,1,1,0$, 0; Pristimantis leoni, 0.00006, 1, 1, 0, 0; Pristimantis leptolophus, $0.00035,1,1,0$, 0; Pristimantis leucopus, 0.00108, 1, 1, 0, 0; Pristimantis leucorrhinus, 0.00796, 1, 1, 0, 0; Pristimantis librarius, 0.00002, 1, 1, 0, 0; Pristimantis lichenoides, 0.00323, 1, 1, 0, 0; Pristimantis limoncochensis, 0.00002, 1, 1, 0, 0; Pristimantis lindae, 0.00018, 1, 1, 0, 0; Pristimantis lirellus, 0.00000, 1, 1, 0, 0; Pristimantis lividus, $0.00045,1,1,0$, 0; Pristimantis llanganati, $0.00048,1,1,0$, 0; Pristimantis llojsintuta, 0.00013, 1, 1, 0, 0; Pristimantis longicorpus, 0.00878, 1, 1, 0, 0; Pristimantis loujosti, $0.00783,1,1,0$, 0; Pristimantis loustes, 0.00051, 1, 1, 0, 0; Pristimantis lucasi, 0.00296, 1, 1, 0, 0; Pristimantis lucidosignatus, 0.00782 , 1, 1, 0, 0; Pristimantis luscombei, 0.00000, 1, 1, 0, 0; Pristimantis luteolateralis, 0.00020, 1, 1, 0, 0; Pristimantis lutitus, $0.00041,1,1,0$, 0; Pristimantis lymani, 0.00002, 1, 1, 0, 0; Pristimantis lynchi, 0.00541, 1, 1, 0, 0; Pristimantis lythrodes, 0.00004, 1, 1, 0, 0; Pristimantis maculosus, 0.00042, 1, 1, 0, 0; Pristimantis malkini, 0.00000, 1, 1, 0, 0; Pristimantis marahuaka, 0.00157, 1, 1, 0, 0; Pristimantis marcoreyesi, 0.00186, 1, 1, 0, 0; Pristimantis mariaelenae, 0.00787, 1, 1, 0, 0; Pristimantis marmoratus, 0.00000, 1, 1, 0, 0; Pristimantis mars, 0.00967, 1, 1, 0, 0; Pristimantis martiae, 0.00000, 1, 1, 0, 0; Pristimantis matidiktyo, 0.00002, 1, 1, 0, 0; Pristimantis mazar, 0.00783, 1, 1, 0, 0; Pristimantis medemi, 0.00004, 1, 1, 0, 0; Pristimantis megalops, 0.00031, 1, 1, 0, 0; Pristimantis melanogaster, 0.00034, 1, 1, 0, 0; Pristimantis melanoproctus, 0.00047, 1, 1, 0, 0; Pristimantis memorans, 0.00733, 1, 1, 0, 0; Pristimantis mendax, 0.00001, 1, 1, 0, 0; Pristimantis meridionalis, 0.00976, 1, 1, 0, 0; Pristimantis merostictus, 0.00197, 1, 1, 0, 0; Pristimantis metabates, 0.00010, 1, 1, 0, 0; Pristimantis miktos, 0.00001, 1, 1, 0, 0; Pristimantis mindo, 0.00069, 1, 1, 0, 0; Pristimantis minimus, $0.00436,1,1,0$, 0; Pristimantis minutulus, $0.00014,1,1,0,0$; Pristimantis miyatai, $0.00009,1,1,0,0$; Pristimantis mnionaetes, 0.00256, 1, 1, 0, 0; Pristimantis modipeplus, 0.00067, 1, 1, 0, 0; Pristimantis molybrignus, 0.00036, 1, 1, 0, 0; Pristimantis mondolfii, 0.00042, 1, 1, 0, 0; Pristimantis moro, 0.00005, 1, 1, 0, 0; Pristimantis muchimuk, 0.00786, 1, 1, 0, 0; Pristimantis munozi, 0.00782, 1, 1, 0, 0; Pristimantis muricatus, 0.00009, 1, 1, 0, 0; Pristimantis muscosus, 0.00005, 1, 1, 0, 0; Pristimantis mutabilis, 0.00077, 1, 1, 0, 0; Pristimantis myersi, 0.00007, 1, 1, 0, 0; Pristimantis myops, 0.00052, 1, 1, 0, 0; Pristimantis nebulosus, 0.00809, 1, 1, 0, 0; Pristimantis nephophilus, 0.00004, 1, 1, 0, 0; Pristimantis nervicus, 0.00027, 1, 1, 0, 0; Pristimantis nicefori, $0.00039,1,1,0$, 0; Pristimantis nietoi, $0.00019,1,1,0$, 0; Pristimantis nigrogriseus, 0.00004, 1, 1, 0, 0; Pristimantis nubisilva, 0.00859, 1, 1, 0, 0; Pristimantis nyctophylax, 0.00036, 1, 1, 0, 0; Pristimantis obmutescens, 0.00074, 1, 1, 0, 0; Pristimantis ocellatus, 0.00026, 1, 1, 0, 0; Pristimantis ockendeni, 0.00000, 1, 1, 0, 0; Pristimantis ocreatus, 0.00019, 1, 1, 0, 0; Pristimantis olivaceus, $0.00001,1,1,0$, 0; Pristimantis omeviridis, $0.00002,1,1,0$, 0; Pristimantis onorei, 0.00032, 1, 1, 0, 0; Pristimantis orcesi, 0.00007, 1, 1, 0, 0; Pristimantis orcus, 0.00000, 1, 1, 0, 0; Pristimantis orestes, 0.00030, 1, 1, 0, 0; Pristimantis ornatissimus, $0.00007,1,1$, 0, 0; Pristimantis ornatus, $0.00077,1,1,0$, 0; Pristimantis orpacobates, 0.00026, 1, 1, 0, 0; Pristimantis orphnolaimus, $0.00002,1,1,0$, 0; Pristimantis ortizi, $0.00022,1,1,0$, 0; Pristimantis padiali, 0.00784, 1, 1, 0, 0; Pristimantis padrecarlosi, 0.00023, 1, 1, 0, 0; Pristimantis pahuma, 0.00782, 1, 1, 0, 0; Pristimantis paisa, 0.00011, 1, 1, 0, 0; Pristimantis palmeri, 0.00004, 1, 1, 0, 0; Pristimantis paquishae, 0.00784, 1, 1, 0, 0; Pristimantis paramerus, 0.01341, 1, 1, 0, 0; Pristimantis pardalinus, $0.00643,1,1,0$, 0; Pristimantis parectatus, $0.00085,1,1,0,0$; Pristimantis pariagnomus, 0.00940, 1, 1, 0, 0; Pristimantis parvillus, 0.00002, 1, 1, 0, 0; Pristimantis pastazensis, 0.00261, 1, 1, 0, 0; Pristimantis pataikos, 0.00007, 1, 1, 0, 0; Pristimantis paulodutrai, 0.00002, 1, 1, 0, 0; Pristimantis paululus, 0.00001, 1, 1, 0, 0; Pristimantis pecki, 0.00009, 1, 1, 0, 0; Pristimantis pedimontanus, $0.00011,1,1,0$, 0; Pristimantis penelopus, 0.00016, 1, 1, 0, 0; Pristimantis peraticus, 0.00093, 1, 1, 0, 0; Pristimantis percnopterus, 0.00006, 1, 1, 0, 0; Pristimantis percultus, 0.00463, 1, 1, 0, 0; Pristimantis permixtus, 0.00004, 1, 1, 0, 0; Pristimantis peruvianus, $0.00000,1,1,0$, 0; Pristimantis petersi, 0.00010, 1, 1, 0, 0; Pristimantis petrobardus, 0.00360, 1, 1, 0, 0; Pristimantis phalaroinguinis, $0.00215,1,1,0$, 0; Pristimantis phalarus, $0.01051,1,1,0$, 0; Pristimantis pharangobates, 0.00001, 1, 1, 0, 0; Pristimantis philipi, 0.00760, 1, 1, 0, 0; Pristimantis phoxocephalus, 0.00002, 1, 1, 0, 0; Pristimantis phragmipleuron, 0.00627, 1, 1, 0, 0; Pristimantis piceus, 0.00005, 1, 1, 0, 0; Pristimantis pichincha, 0.00090, 1, 1, 0, 0; Pristimantis pinchaque, 0.00090, 1, 1, 0, 0; Pristimantis pinguis, $0.00020,1,1,0,0$; Pristimantis platychilus, $0.00019,1,1,0,0$; Pristimantis platydactylus, $0.00001,1,1,0,0$; Pristimantis pleurostriatus, $0.00261,1,1,0$, 0; Pristimantis polemistes, $0.01373,1,1,0$, 0; Pristimantis polychrus, 0.00057, 1, 1, 0, 0; Pristimantis prolatus, 0.00005, 1, 1, 0, 0; Pristimantis prometeii, 0.00450, 1, 1, 0, 0; Pristimantis proserpens, 0.00013, 1, 1, 0, 0; Pristimantis pruinatus, $0.00343,1,1,0$, 0; Pristimantis pseudoacuminatus, $0.00001,1,1,0$, 0; Pristimantis pteridophilus, $0.00053,1$, 
1, 0, 0; Pristimantis ptochus, $0.00071,1,1,0,0$; Pristimantis pugnax, $0.00009,1,1,0,0$; Pristimantis pulchridormientes, $0.00752,1$, 1, 0, 0; Pristimantis pulvinatus, $0.00000,1,1,0,0$; Pristimantis punzan, $0.00850,1,1,0,0$; Pristimantis puruscafeum, $0.00850,1,1$, 0,0 ; Pristimantis pycnodermis, 0.00028, 1, 1, 0, 0; Pristimantis pyrrhomerus, $0.00015,1,1,0,0$; Pristimantis quantus, $0.00219,1,1$, 0, 0; Pristimantis quaquaversus, $0.00001,1,1,0,0$; Pristimantis quicato, 0.00784, 1, 1, 0, 0; Pristimantis quinquagesimus, 0.00014 , 1, 1, 0, 0; Pristimantis racemus, 0.00017, 1, 1, 0, 0; Pristimantis ramagii, 0.00001, 1, 1, 0, 0; Pristimantis reclusas, 0.00137, 1, 1, 0, 0; Pristimantis reichlei, $0.00000,1,1,0$, 0; Pristimantis renjiforum, 0.00133, 1, 1, 0, 0; Pristimantis repens, 0.00093, 1, 1, 0, 0; Pristimantis restrepoi, 0.00029, 1, 1, 0, 0; Pristimantis reticulatus, 0.00308, 1, 1, 0, 0; Pristimantis rhabdocnemus, 0.00010, 1, 1, 0, 0; Pristimantis rhabdolaemus, 0.00015, 1, 1, 0, 0; Pristimantis rhigophilus, 0.00464, 1, 1, 0, 0; Pristimantis rhodoplichus, 0.00047, 1, 1, 0, 0; Pristimantis rhodostichus, 0.00004, 1, 1, 0, 0; Pristimantis ridens, $0.00000,1,1,0$, 0; Pristimantis rivasi, 0.00029, 1, 1, 0, 0; Pristimantis riveroi, 0.00319, 1, 1, 0, 0; Pristimantis riveti, 0.00007, 1, 1, 0, 0; Pristimantis romanorum, 0.00107, 1, 1, 0, 0; Pristimantis roni, $0.00783,1,1,0,0$; Pristimantis rosadoi, $0.00005,1,1,0,0$; Pristimantis roseus, $0.00003,1,1,0,0$; Pristimantis royi, 0.00795, 1, 1, 0, 0; Pristimantis rozei, 0.00246, 1, 1, 0, 0; Pristimantis rubicundus, 0.00017, 1, 1, 0, 0; Pristimantis ruedai, $0.00038,1,1,0$, 0; Pristimantis rufioculis, 0.00014, 1, 1, 0, 0; Pristimantis rufoviridis, 0.00247, 1, 1, 0, 0; Pristimantis ruidus, 0.00407 , 1, 1, 0, 0; Pristimantis ruthveni, 0.00488, 1, 1, 0, 0; Pristimantis sacharuna, 0.00090, 1, 1, 0, 0; Pristimantis sagittulus, 0.00796, 1, 1, 0, 0; Pristimantis salaputium, $0.00005,1,1,0$, 0; Pristimantis saltissimus, $0.00518,1,1,0,0$; Pristimantis samaipatae, $0.00009,1,1$, 0,0 ; Pristimantis sanctaemartae, $0.00024,1,1,0$, 0; Pristimantis sanguineus, $0.00026,1,1,0$, 0; Pristimantis sarisarinama, 0.00785 , 1, 1, 0, 0; Pristimantis satagius, 0.00250, 1, 1, 0, 0; Pristimantis savagei, $0.00040,1,1,0,0$; Pristimantis schultei, $0.00003,1,1,0,0$; Pristimantis scitulus, 0.00130, 1, 1, 0, 0; Pristimantis scoloblepharus, 0.00037, 1, 1, 0, 0; Pristimantis scolodiscus, 0.00022, 1, 1, 0, 0; Pristimantis scopaeus, 0.00623, 1, 1, 0, 0; Pristimantis seorsus, 0.00450, 1, 1, 0, 0; Pristimantis serendipitus, 0.00005, 1, 1, 0, 0; Pristimantis signifer, $0.00164,1,1,0$, 0; Pristimantis silverstonei, $0.00093,1,1,0$, 0; Pristimantis simonbolivari, $0.00429,1,1,0,0$; Pristimantis simonsii, $0.00025,1,1,0,0$; Pristimantis simoteriscus, $0.00666,1,1,0$, 0; Pristimantis simoterus, $0.00131,1,1,0,0$; Pristimantis siopelus, $0.00163,1,1,0$, 0; Pristimantis sirnigeli, $0.00060,1,1,0$, 0; Pristimantis skydmainos, 0.00000, 1, 1, 0, 0; Pristimantis sobetes, $0.00028,1,1,0$, 0; Pristimantis spectabilis, $0.01022,1,1,0$, 0; Pristimantis spilogaster, 0.00189, 1, 1, 0, 0; Pristimantis spinosus, $0.00022,1,1,0,0$; Pristimantis stenodiscus, 0.00527, 1, 1, 0, 0; Pristimantis sternothylax, 0.00009, 1, 1, 0, 0; Pristimantis stictoboubonus, 0.00362, 1, 1, 0, 0; Pristimantis stictogaster, $0.00483,1,1,0$, 0; Pristimantis stipa, 0.00787, 1, 1, 0, 0; Pristimantis subsigillatus, 0.00001, 1, 1, 0, 0; Pristimantis suetus, 0.00029, 1, 1, 0, 0; Pristimantis sulculus, 0.00218, 1, 1, 0, 0; Pristimantis supernatis, 0.00012, 1, 1, 0, 0; Pristimantis surdus, 0.00034, 1, 1, 0, 0; Pristimantis susaguae, 0.00031, 1, 1, 0, 0; Pristimantis taciturnus, 0.00451, 1, 1, 0, 0; Pristimantis taeniatus, 0.00001, 1, 1, 0, 0; Pristimantis tamsitti, 0.00014, 1, 1, 0, 0; Pristimantis tantanti, $0.00000,1,1,0$, 0; Pristimantis tanyrhynchus, 0.00238, 1, 1, 0, 0; Pristimantis tayrona, 0.00021, 1, 1, 0, 0; Pristimantis telefericus, 0.00273, 1, 1, 0, 0; Pristimantis tenebrionis, 0.00012, 1, 1, 0, 0; Pristimantis terraebolivaris, 0.00021, 1, 1, 0, 0 ; Pristimantis thectopternus, $0.00004,1,1,0,0$; Pristimantis thyellus, $0.00056,1,1,0$, 0; Pristimantis thymalopsoides, $0.00763,1$, 1, 0, 0; Pristimantis thymelensis, 0.00008, 1, 1, 0, 0; Pristimantis tinajillas, 0.00784, 1, 1, 0, 0; Pristimantis tinguichaca, 0.00763, 1, 1, 0, 0; Pristimantis toftae, 0.00000, 1, 1, 0, 0; Pristimantis torrenticola, 0.00645, 1, 1, 0, 0; Pristimantis trachyblepharis, 0.00000, 1, 1, 0, 0; Pristimantis tribulosus, 0.01010, 1, 1, 0, 0; Pristimantis truebae, 0.00017, 1, 1, 0, 0; Pristimantis tubernasus, 0.00016, 1, 1, 0, 0; Pristimantis tungurahua, $0.00482,1,1,0$, 0; Pristimantis turik, 0.00282, 1, 1, 0, 0; Pristimantis turpinorum, 0.00486, 1, 1, 0, 0; Pristimantis turumiquirensis, 0.00100, 1, 1, 0, 0; Pristimantis uisae, 0.00993, 1, 1, 0, 0; Pristimantis unistrigatus, 0.00004, 1, 1, 0, 0; Pristimantis uranobates, $0.00014,1,1,0$, 0; Pristimantis urichi, 0.00032, 1, 1, 0, 0; Pristimantis vanadise, 0.00095, 1, 1, 0, 0; Pristimantis variabilis, $0.00000,1,1,0$, 0; Pristimantis veletis, $0.00470,1,1,0$, 0; Pristimantis ventrigranulosus, 0.00816, 1, 1, 0, 0; Pristimantis ventriguttatus, $0.01101,1,1,0,0$; Pristimantis ventrimarmoratus, $0.00000,1,1,0,0$; Pristimantis verecundus, 0.00012 , 1, 1, 0, 0; Pristimantis versicolor, $0.00012,1,1,0$, 0; Pristimantis vertebralis, $0.00014,1,1,0$, 0; Pristimantis vicarius, $0.00015,1,1$, 0, 0; Pristimantis vidua, 0.00036, 1, 1, 0, 0; Pristimantis viejas, 0.00009, 1, 1, 0, 0; Pristimantis vilarsi, 0.00000, 1, 1, 0, 0; Pristimantis vilcabambae, $0.00238,1,1,0$, 0; Pristimantis vinhai, $0.00001,1,1,0,0$; Pristimantis viridicans, $0.00070,1,1,0,0$; Pristimantis viridis, 0.00030, 1, 1, 0, 0; Pristimantis wagteri, 0.00228, 1, 1, 0, 0; Pristimantis walkeri, 0.00002, 1, 1, 0, 0; Pristimantis waoranii, $0.00757,1,1,0,0$; Pristimantis wiensi, 0.00164, 1, 1, 0, 0; Pristimantis w-nigrum, 0.00001, 1, 1, 0, 0; Pristimantis xeniolum, 0.00679, 1, 1, 0, 0; Pristimantis xestus, 0.00313, 1, 1, 0, 0; Pristimantis xylochobates, 0.00707, 1, 1, 0, 0; Pristimantis yanezi, 0.00055, 1, 1, 0, 0; Pristimantis yaviensis, 0.00316, 1, 1, 0, 0; Pristimantis yukpa, 0.00025, 1, 1, 0, 0; Pristimantis yumbo, 0.00107, 1, 1, 0, 0; Pristimantis yuruaniensis, 0.00786, 1, 1, 0, 0; Pristimantis yustizi, 0.00008, 1, 1, 0, 0; Pristimantis zeuctotylus, 0.00000, 1, 1, 0, 0; Pristimantis zimmermanae, $0.00000,1,1,0,0$; Pristimantis zoilae, $0.00131,1,1,0$, 0; Pristimantis zophus, 0.00073, 1, 1, 0, 0; Proceratophrys, 0.00000, 0, 0, 0, 0; Proceratophrys appendiculata, 0.00011, 0, 1, 0, 0; Proceratophrys aridus, 0.00788, 0, 1, 0, 0; Proceratophrys avelinoi, 0.00000, 0, 1, 0, 0; Proceratophrys belzebul, 0.00039, 0, 1, 0, 0; Proceratophrys bigibbosa, 0.00001, 0, 1, 0, 0; Proceratophrys boiei, 0.00000, 0, 1, 0, 0; Proceratophrys brauni, 0.00004, 0, 1, 0, 0; Proceratophrys caramaschii, 0.00004, 0, 1, 0, 0; Proceratophrys carranca, 0.00001, 0, 1, 0, 0; Proceratophrys concavitympanum, 0.00000, 0, 1, 0, 0; Proceratophrys cristiceps, 0.00000, 0, 1, 0, 0; Proceratophrys cururu, 0.00019, 0, 1, 0, 0; Proceratophrys gladius, 0.00848, 0, 1, 0, 0; Proceratophrys goyana, $0.00001,0,1,0$, 0; Proceratophrys huntingtoni, 0.00009, 0, 1, 0, 0; Proceratophrys itamari, 0.00105, 0, 1, 0, 0; Proceratophrys izecksohni, 0.00266, 0, 1, 0, 0; Proceratophrys laticeps, 0.00004, 0, 1, 0, 0; Proceratophrys mantiqueira, 0.00003, 0, 1, 0, 0; Proceratophrys melanopogon, 0.00003, 0, 1, 0, 0; Proceratophrys minuta, 0.00078, 0, 1, 0, 0; Proceratophrys moehringi, 0.00018, 0, 1, 0, 0; Proceratophrys moratoi, 0.00000, 0, 1, 0, 0; Proceratophrys palustris, $0.00110,0,1,0,0$; Proceratophrys paviotii, $0.00010,0$, 1, 0, 0; Proceratophrys phyllostomus, 0.00041, 0, 1, 0, 0; Proceratophrys pombali, 0.00071, 0, 1, 0, 0; Proceratophrys redacta, 0.00211 , 0, 1, 0, 0; Proceratophrys renalis, 0.00000, 0, 1, 0, 0; Proceratophrys rondonae, 0.00800, 0, 1, 0, 0; Proceratophrys sanctaritae, 0.00052, 0, 1, 0, 0; Proceratophrys schirchi, 0.00001, 0, 1, 0, 0; Proceratophrys strussmannae, 0.00103, 0, 1, 0, 0; Proceratophrys subguttata, 0.00004, 0, 1, 0, 0; Proceratophrys tupinamba, 0.01027, 0, 1, 0, 0; Proceratophrys vielliardi, 0.00003, 0 , 1, 0, 0; Prostherapis, 0.00325, 0, 0, 0, 0; Prostherapis dunni, 0.00325, 0, 1, 0, 0; Prostherapis dunni, 0.00049, 0, 1, 0, 0; Pseudis, $0.00000,0,0,0$, 0; Pseudis bolbodactyla, 0.00000, 0, 0, 1, 0; Pseudis cardosoi, 0.00002, 0, 0, 1, 0; Pseudis fusca, 0.00001, 0, 0, 1, 0; Pseudis minuta, 0.00000, 0, 0, 1, 0; Pseudis paradoxa, 0.00000, 0, 0, 1, 0; Pseudis platensis, 0.00000, 0, 0, 1, 0; Pseudis tocantins, $0.00000,0,0,1,0 ;$ Pseudopaludicola, 0.00000, 0, 0, 0, 0; Pseudopaludicola ameghini, 0.00405, 0, 1, 1, 0; Pseudopaludicola atragula, 
$0.00003,0,1,1,0$; Pseudopaludicola boliviana, 0.00000, 0, 1, 1, 0; Pseudopaludicola canga, 0.00000, 0, 1, 1, 0; Pseudopaludicola ceratophyes, $0.00000,0,1,1,0$; Pseudopaludicola facureae, 0.00827, 0, 1, 1, 0; Pseudopaludicola falcipes, 0.00000, 0, 1, 1, 0; Pseudopaludicola giarettai, 0.00001, 0, 1, 1, 0; Pseudopaludicola hyleaustralis, 0.00001, 0, 1, 1, 0; Pseudopaludicola ibisoroca, $0.00001,0,1,1,0$; Pseudopaludicola jaredi, 0.00000, 0, 1, 1, 0; Pseudopaludicola llanera, 0.00000, 0, 1, 1, 0; Pseudopaludicola mineira, 0.00008, 0, 1, 1, 0; Pseudopaludicola motorzinho, 0.00000, 0, 1, 1, 0; Pseudopaludicola murundu, 0.00001, 0, 1, 1, 0; Pseudopaludicola mystacalis, 0.00000, 0, 1, 1, 0; Pseudopaludicola parnaiba, 0.00789, 0, 1, 1, 0; Pseudopaludicola pocoto, 0.00000 , $0,1,1,0$; Pseudopaludicola pusilla, 0.00001, 0, 1, 1, 0; Pseudopaludicola saltica, 0.00000, 0, 1, 1, 0; Pseudopaludicola ternetzi, $0.00000,0,1,1$, 0; Psychrophrynella, 0.00005, 0, 0, 0, 0; Psychrophrynella adenopleura, 0.00094, 0, 1, 0, 0; Psychrophrynella ankohuma, 0.00293, 0, 1, 0, 0; Psychrophrynella bagrecito, 0.00010, 0, 1, 0, 0; Psychrophrynella boettgeri, 0.00752, 0, 1, 0, 0; Psychrophrynella chacaltaya, 0.01204, 0, 1, 0, 0; Psychrophrynella chaupi, 0.00124, 0, 1, 0, 0; Psychrophrynella chirihampatu, $0.00750,0,1,0,0$; Psychrophrynella colla, 0.00124, 0, 1, 0, 0; Psychrophrynella condoriri, 0.00272, 0, 1, 0, 0; Psychrophrynella guillei, 0.01911, 0, 1, 0, 0; Psychrophrynella harveyi, 0.00725, 0, 1, 0, 0; Psychrophrynella iani, 0.00619, 0, 1, 0, 0; Psychrophrynella iatamasi, 0.00171, 0, 1, 0, 0; Psychrophrynella illampu, 0.00214, 0, 1, 0, 0; Psychrophrynella illimani, 0.00487, 0, 1, 0, 0; Psychrophrynella kallawaya, 0.00960, 0, 1, 0, 0; Psychrophrynella katantika, 0.00124, 0, 1, 0, 0; Psychrophrynella kempffi, 0.00053 , 0, 1, 0, 0; Psychrophrynella melanocheira, 0.00124, 0, 1, 0, 0; Psychrophrynella pinguis, 0.00852, 0, 1, 0, 0; Psychrophrynella quimsacruzis, 0.00081, 0, 1, 0, 0; Psychrophrynella saltator, 0.01383, 0, 1, 0, 0; Psychrophrynella teqta, 0.00814, 0, 1, 0, 0; Psychrophrynella usurpator, 0.00016, 0, 1, 0, 0; Psychrophrynella wettsteini, 0.00116, 0, 1, 0, 0; RANIDAE, 0.00000, 0, 0, 0, 0; Ranitomeya, 0.00000, 0, 0, 0, 0; Ranitomeya amazonica, 0.00000, 1, 1, 0, 0; Ranitomeya benedicta, 0.00012, 1, 1, 0, 0; Ranitomeya cyanovittata, 0.00144, 1, 1, 0, 0; Ranitomeya defleri, 0.00001, 1, 1, 0, 0; Ranitomeya fantastica, 0.00007, 1, 1, 0, 0; Ranitomeya flavovittata, $0.00010,1,1,0,0$; Ranitomeya imitator, $0.00010,1,1,0,0$; Ranitomeya reticulata, 0.00001, 1, 1, 0, 0; Ranitomeya sirensis, 0.00001, 1, 1, 0, 0; Ranitomeya summersi, 0.00410, 1, 1, 0, 0; Ranitomeya toraro, 0.00000, 1, 1, 0, 0; Ranitomeya uakarii, $0.00000,1,1,0$, 0; Ranitomeya vanzolinii, 0.00001, 1, 1, 0, 0; Ranitomeya variabilis, $0.00000,1,1,0$, 0; Ranitomeya ventrimaculata, $0.00000,1$, 1, 0, 0; Ranitomeya yavaricola, 0.00006, 1, 1, 0, 0; Rhaebo, 0.00000, 0, 0, 0, 0; Rhaebo andinophrynoides, 0.00005, 0, 1, 0, 0; Rhaebo atelopoides, $0.00555,0,1,0,0$; Rhaebo blombergi, 0.00004, 0, 1, 0, 0; Rhaebo caeruleostictus, 0.00003, 0, 1, 0, 0; Rhaebo colomai, $0.00071,0,1,0$, 0; Rhaebo ecuadorensis, 0.00000, 0, 1, 0, 0; Rhaebo glaberrimus, 0.00002, 0, 1, 0, 0; Rhaebo guttatus, $0.00000,0,1$, 0, 0; Rhaebo haematiticus, 0.00000, 0, 1, 0, 0; Rhaebo hypomelas, 0.00005, 0, 1, 0, 0; Rhaebo lynchi, $0.00897,0,1$, 0, 0; Rhaebo nasicus, $0.00002,0,1,0,0$; Rhaebo olallai, $0.00031,0,1,0,0$; Rheobates, 0.00005, 0, 0, 0, 0; Rheobates palmatus, $0.00005,0,1,0$, 0; Rheobates pseudopalmatus, $0.00903,0,1,0$, 0; Rhinatrema, 0.00000, 0, 0, 0, 0; Rhinatrema bivittatum, $0.00000,0,0,0,1$; Rhinatrema ron, 0.00001, 0, 0, 0, 1; Rhinatrema shiv, 0.00786, 0, 0, 0, 1; RHINATREMATIDAE, $0.00000,0,0,0,0 ;$ Rhinella, $0.00000,0,0,0,0 ;$ Rhinella abei, 0.00003, 0, 1, 0, 0; Rhinella achalensis, 0.00004, 0, 1, 0, 0; Rhinella achavali, $0.00000,0,1,0,0$; Rhinella acrolopha, 0.00067, 0, 1, 0, 0; Rhinella acutirostris, 0.00000, 0, 1, 0, 0; Rhinella alata, 0.00001 , $0,1,0,0$; Rhinella amabilis, 0.01383, 0, 1, 0, 0; Rhinella amboroensis, 0.00683, 0, 1, 1, 0; Rhinella arborescandens, 0.00232, 1, 1, 0, 0; Rhinella arenarum, 0.00000, 0, 1, 0, 0; Rhinella arequipensis, 0.00011, 0, 1, 0, 0; Rhinella arunco, 0.00001, 0, 1, 0, 0; Rhinella atacamensis, 0.00004, 0, 1, 0, 0; Rhinella azarai, 0.00001, 0, 1, 0, 0; Rhinella bergi, 0.00000, 0, 1, 0, 0; Rhinella bernardoi, 0.00012 , 0,1 , 0, 0; Rhinella casconi, 0.00155, 0, 1, 0, 0; Rhinella castaneotica, 0.00000, 0, 1, 0, 0; Rhinella ceratophrys, 0.00000, 0, 1, 0, 0; Rhinella cerradensis, $0.00000,0,1,0,0$; Rhinella chavin, $0.00163,0,1,0,0$; Rhinella cristinae, $0.00225,0,1,0,0$; Rhinella crucifer, $0.00000,0,1$, 0, 0; Rhinella dapsilis, 0.00000, 0, 1, 0, 0; Rhinella diptycha, 0.00006, 0, 1, 0, 0; Rhinella dorbignyi, 0.00000, 0, 1, 0, 0; Rhinella fernandezae, 0.00000, 0, 1, 0, 0; Rhinella festae, 0.00004, 0, 1, 0, 0; Rhinella fissipes, 0.00002, 0, 1, 0, 0; Rhinella gallardoi, $0.00066,0,1,0,0 ;$ Rhinella gildae, 0.00786, 0, 1, 0, 0; Rhinella gnustae, $0.00033,0,1,0,0$; Rhinella granulosa, 0.00000, 0, 1, 0, 0; Rhinella henseli, $0.00001,0,1,0,0$; Rhinella hoogmoedi, $0.00001,0,1,0$, 0; Rhinella horribilis, 0.00000, 0, 1, 0, 0; Rhinella humboldti, 0.00000, 0, 1, 0, 0; Rhinella icterica, 0.00000, 0, 1, 0, 0; Rhinella inca, 0.00002, 0, 1, 0, 0; Rhinella inopina, 0.00003, 0, 1, 0, 0; Rhinella iserni, 0.00064, 0, 1, 0, 0; Rhinella jimi, 0.00000, 0, 1, 0, 0; Rhinella justinianoi, 0.00012, 0, 1, 0, 0; Rhinella lescurei, $0.00002,0,1,0,0$; Rhinella limensis, 0.00002, 0, 1, 0, 0; Rhinella lindae, 0.01000, 0, 1, 0, 0; Rhinella macrorhina, 0.00008, 0, 1, 0, 0; Rhinella magnussoni, $0.00015,0,1,0,0$; Rhinella major, 0.00000, 0, 1, 0, 0; Rhinella manu, 0.00005, 1, 1, 0, 0; Rhinella margaritifera, 0.00000, 0, 1, 0, 0; Rhinella marina, 0.00000, 0, 1, 0, 0; Rhinella martyi, 0.00000, 0, 1, 0, 0; Rhinella merianae, $0.00000,0,1,0,0$; Rhinella mirandaribeiroi, $0.00000,0,1,0,0$; Rhinella multiverrucosa, 0.00040, 0, 1, 0, 0; Rhinella nattereri, $0.00006,0,1,0,0 ;$ Rhinella nesiotes, $0.00185,1,1,0,0$; Rhinella nicefori, 0.00065, 0, 1, 0, 0; Rhinella ocellata, 0.00000, 0, 1, 0, 0; Rhinella ornata, 0.00000, 0, 1, 0, 0; Rhinella paraguas, 0.00024, 1, 1, 0, 0; Rhinella paraguayensis, 0.00004, 0, 1, 0, 0; Rhinella poeppigii, 0.00000, 0, 1, 0, 0; Rhinella proboscidea, 0.00000, 0, 1, 0, 0; Rhinella pygmaea, 0.00008, 0, 1, 0, 0; Rhinella quechua, 0.00016 , 0, 1, 0, 0; Rhinella roqueana, 0.00000, 0, 1, 0, 0; Rhinella rostrata, 0.00345, 0, 1, 0, 0; Rhinella rubescens, 0.00000, 0, 1, 0, 0; Rhinella rubropunctata, 0.00002, 0, 1, 0, 0; Rhinella ruizi, 0.00026, 0, 1, 0, 0; Rhinella rumbolli, 0.00020, 0, 1, 0, 0; Rhinella schneideri, 0.00000, 0, 1, 0, 0; Rhinella scitula, 0.00001, 0, 1, 0, 0; Rhinella sclerocephala, 0.00230, 0, 1, 0, 0; Rhinella sebbeni, 0.00816 , 0, 1, 0, 0; Rhinella spinulosa, 0.00000, 0, 1, 0, 0; Rhinella stanlaii, 0.00004, 0, 1, 0, 0; Rhinella sternosignata, 0.00004, 0, 1, 0, 0; Rhinella tacana, 0.00003, 1, 1, 0, 0; Rhinella tenrec, 0.00212, 0, 1, 0, 0; Rhinella vellardi, 0.01045, 0, 1, 0, 0; Rhinella veraguensis, $0.00001,0,1,0,0$; Rhinella veredas, $0.00001,0,1,0,0$; Rhinella yanachaga, $0.00251,0,1,0$, 0 ; Rhinella yunga, 0.00031, 0, 1, 0, 0; Rhinoderma, 0.00001, 0, 0, 0, 0; Rhinoderma darwinii, 0.00001, 0, 1, 0, 0; Rhinoderma rufum, 0.00002, 0, 1, 0, 0; Rulyrana, 0.00001, 0, 0, 0, 0; Rulyrana adiazeta, 0.00009, 1, 0, 0, 0; Rulyrana flavopunctata, 0.00002, 1, 0, 0, 0; Rulyrana mcdiarmidi, 0.00006, 1, 0, 0, 0; Rulyrana saxiscandens, 0.00099, 1, 0, 0, 0; Rulyrana spiculata, 0.00006, 1, 0, 0, 0; Rulyrana susatamai, 0.00019, 1, 0, 0, 0; Rupirana, 0.00004, 0, 0, 0, 0; Rupirana cardosoi, 0.00004, 0, 1, 0, 0; Sachatamia, 0.00000, 0, 0, 0, 0; Sachatamia albomaculata, 0.00001, 1, 0, 0, 0; Sachatamia ilex, 0.00001, 1, 0, 0, 0; Sachatamia orejuela, 0.00007, 1, 0, 0, 0; Sachatamia punctulata, $0.00013,1,0,0$, 0; Scarthyla, $0.00000,0,0,0,0$; Scarthyla goinorum, 0.00000, 1, 0, 0, 0; Scarthyla vigilans, $0.00000,1,0,0,0$; Scinax, 0.00000, 0, 0, 0, 0; Scinax acuminatus, 0.00000, 1, 0, 0, 0; Scinax alter, 0.00001, 1, 0, 0, 0; Scinax auratus, $0.00001,1,0,0$, 0; Scinax baumgardneri, 0.00045, 1, 0, 0, 0; Scinax blairi, 0.00001, 1, 0, 0, 0; Scinax boesemani, 0.00000, 1, 0, 0, 0; Scinax boulengeri, $0.00000,1,0,0$, 0; Scinax cabralensis, $0.00049,1,0,0$, 0; Scinax caldarum, 0.00087, 1, 0, 0, 0; Scinax camposseabrai, 0.00001, 1, 0, 0, 0; Scinax cardosoi, 0.00003, 1, 0, 0, 0; Scinax castroviejoi, 0.00002, 1, 0, 0, 0; Scinax chiquitanus, 
$0.00001,1,0,0$, 0; Scinax constrictus, 0.00000, 1, 0, 0, 0; Scinax cretatus, 0.00002, 1, 0, 0, 0; Scinax crospedospilus, 0.00002, 1, 0, 0, 0 ; Scinax cruentommus, $0.00000,1,0,0$, 0; Scinax curicica, 0.00032, 1, 0, 0, 0; Scinax cuspidatus, 0.00000, 1, 0, 0, 0; Scinax danae, 0.00059, 1, 0, 0, 0; Scinax dolloi, 0.00846, 1, 0, 0, 0; Scinax duartei, 0.00012, 1, 0, 0, 0; Scinax elaeochrous, 0.01629, 1, 0, 0, 0; Scinax eurydice, 0.00000, 1, 0, 0, 0; Scinax exiguus, 0.00009, 1, 0, 0, 0; Scinax funereus, 0.00000, 1, 0, 0, 0; Scinax fuscomarginatus, $0.00000,1,0,0$, 0; Scinax fuscovarius, 0.00000, 1, 0, 0, 0; Scinax garbei, 0.00000, 1, 0, 0, 0; Scinax granulatus, 0.00000, 1, 0, 0, 0; Scinax haddadorum, 0.00813, 1, 0, 0, 0; Scinax hayii, 0.00001, 1, 0, 0, 0; Scinax ictericus, 0.00000, 1, 0, 0, 0; Scinax imbegue, 0.00005, 1, 0, 0, 0; Scinax iquitorum, 0.00000, 1, 0, 0, 0; Scinax jolyi, 0.00791, 1, 0, 0, 0; Scinax juncae, 0.00003, 1, 0, 0, 0; Scinax karenanneae, 0.00003 , 1, 0, 0, 0; Scinax kennedyi, 0.00001, 1, 0, 0, 0; Scinax lindsayi, 0.00001, 1, 0, 0, 0; Scinax madeirae, 0.00000 , 1, 0, 0, 0; Scinax manriquei, 0.00014, 1, 0, 0, 0; Scinax maracaya, 0.00028, 1, 0, 0, 0; Scinax montivagus, 0.00005, 1, 0, 0, 0; Scinax nasicus, 0.00000, 1, 0, 0, 0; Scinax nebulosus, 0.00000, 1, 0, 0, 0; Scinax oreites, 0.00003, 1, 0, 0, 0; Scinax pachycrus, 0.00000, 1, 0, 0, 0; Scinax pedromedinae, $0.00000,1,0,0$, 0; Scinax perereca, 0.00000, 1, 0, 0, 0; Scinax proboscideus, 0.00000, 1, 0, 0, 0; Scinax quinquefasciatus, $0.00001,1,0,0$, 0; Scinax rostratus, $0.00000,1,0,0,0$; Scinax ruber, $0.00000,1,0,0,0$; Scinax rupestris, 0.00807 , 1, 0, 0, 0; Scinax sateremawe, 0.00013, 1, 0, 0, 0; Scinax similis, 0.00004, 1, 0, 0, 0; Scinax squalirostris, 0.00000, 1, 0, 0, 0; Scinax sugillatus, 0.00002, 1, 0, 0, 0; Scinax tigrinus, 0.00002, 1, 0, 0, 0; Scinax trapicheiroi, 0.00008, 1, 0, 0, 0; Scinax tymbamirim, 0.00001, 1, 0, 0, 0; Scinax villasboasi, 0.00791, 1, 0, 0, 0; Scinax wandae, 0.00000, 1, 0, 0, 0; Scinax x-signatus, 0.00000, 1, 0, 0, 0; Scythrophrys, 0.00007, 0, 0, 0, 0; Scythrophrys sawayae, 0.00007, 0, 1, 0, 0; Silverstoneia, 0.00001, 0, 0, 0, 0; Silverstoneia dalyi, $0.00010,0,1,0$, 0; Silverstoneia erasmios, $0.00128,0,1,0$, 0; Silverstoneia gutturalis, $0.00134,0,1,0$, 0; Silverstoneia minima, $0.00079,0,1,0$, 0; Silverstoneia minutissima, $0.00048,0,1,0$, 0; Silverstoneia nubicola, 0.00001, 0, 1, 0, 0; Silverstoneia punctiventris, 0.00068, 0, 1, 0, 0; SIPHONOPIDAE, 0.00000, 0, 0, 0, 0; Siphonops, 0.00000, 0, 0, 0, 0; Siphonops annulatus, 0.00000 , 0, 0, 0, 1; Siphonops hardyi, 0.00001, 0, 0, 0, 1; Siphonops insulanus, 0.00123, 0, 0, 0, 1; Siphonops paulensis, 0.00000, 0, 0, 0, 1; Smilisca, 0.00000, 0, 0, 0, 0; Smilisca phaeota, 0.00000, 1, 0, 0, 0; Smilisca sila, 0.00001, 1, 0, 0, 0; Smilisca sordida, 0.00001, 1, 0, 0, 0; Sphaenorhynchus, 0.00000, 0, 0, 0, 0; Sphaenorhynchus botocudo, 0.00823, 1, 0, 1, 0; Sphaenorhynchus bromelicola, 0.00054, 1, 0,1 , 0; Sphaenorhynchus canga, 0.00833, 1, 0, 1, 0; Sphaenorhynchus caramaschii, 0.00001, 1, 0, 1, 0; Sphaenorhynchus carneus, $0.00000,1,0,1$, 0; Sphaenorhynchus dorisae, 0.00000, 1, 0, 1, 0; Sphaenorhynchus lacteus, 0.00000, 1, 0, 1, 0; Sphaenorhynchus mirim, 0.00180, 1, 0, 1, 0; Sphaenorhynchus orophilus, 0.00003, 1, 0, 1, 0; Sphaenorhynchus palustris, 0.00002, 1, 0, 1, 0; Sphaenorhynchus pauloalvini, 0.00003, 1, 0, 1, 0; Sphaenorhynchus planicola, 0.00003, 1, 0, 1, 0; Sphaenorhynchus prasinus, 0.00001 , 1, 0, 1, 0; Sphaenorhynchus surdus, 0.00001, 1, 0, 1, 0; Stefania, 0.00002, 0, 0, 0, 0; Stefania ackawaio, 0.00124, 1, 1, 0, 0; Stefania ayangannae, $0.00124,1,1,0$, 0; Stefania breweri, 0.00783, 1, 1, 0, 0; Stefania coxi, 0.00124, 1, 1, 0, 0; Stefania evansi, $0.00002,1,1,0$, 0; Stefania ginesi, 0.00057, 1, 1, 0, 0; Stefania goini, 0.00116, 1, 1, 0, 0; Stefania marahuaquensis, 0.00052, 1, 1, 0, 0; Stefania neblinae, $0.00783,1,1,0$, 0; Stefania oculosa, 0.00106, 1, 1, 0, 0; Stefania percristata, 0.00106, 1, 1, 0, 0; Stefania riae, 0.00125 , 1, 1, 0, 0; Stefania riveroi, 0.00584, 1, 1, 0, 0; Stefania roraimae, 0.00010, 1, 1, 0, 0; Stefania satelles, 0.00622, 1, 1, 0, 0; Stefania scalae, $0.00047,1,1,0$, 0; Stefania schuberti, 0.00352, 1, 1, 0, 0; Stefania tamacuarina, 0.00897, 1, 1, 0, 0; Stefania woodleyi, 0.00003, 1, 1, 0, 0; Stereocyclops, 0.00000, 0, 0, 0, 0; Stereocyclops histrio, 0.00003, 0, 1, 0, 0; Stereocyclops incrassatus, $0.00001,0,1$, 0, 0; Stereocyclops palmipes, 0.00028, 0, 1, 0, 0; Stereocyclops parkeri, 0.00005, 0, 1, 0, 0; Strabomantis, 0.00000, 0, 0, 0, 0; Strabomantis anatipes, 0.00009, 0, 1, 0, 0; Strabomantis anomalus, 0.00001, 0, 1, 0, 0; Strabomantis biporcatus, 0.00006, 0, 1, 0, 0; Strabomantis bufoniformis, 0.00002, 0, 1, 0, 0; Strabomantis cadenai, 0.00434, 0, 1, 0, 0; Strabomantis cerastes, $0.00003,0$, 1, 0, 0; Strabomantis cheiroplethus, $0.00020,0,1,0$, 0; Strabomantis cornutus, 0.00003, 0, 1, 0, 0; Strabomantis helonotus, 0.00040 , $0,1,0,0$; Strabomantis ingeri, 0.00001, 0, 1, 0, 0; Strabomantis necerus, 0.00005, 0, 1, 0, 0; Strabomantis necopinus, 0.00006, 0, 1, 0, 0; Strabomantis ruizi, $0.00038,0,1,0$, 0; Strabomantis sulcatus, 0.00000, 0, 1, 0, 0; Strabomantis zygodactylus, 0.00004, 0, 1, 0, 0; Synapturanus, 0.00000, 0, 0, 0, 0; Synapturanus mirandaribeiroi, 0.00000, 0, 1, 0, 1; Synapturanus rabus, 0.00000, 0, 1, 0, 1; Synapturanus salseri, $0.00000,0,1,0$, 1; Tachiramantis, $0.00004,0,0,0$, 0; Tachiramantis douglasi, 0.00014, 1, 1, 0, 0; Tachiramantis lentiginosus, 0.00210, 1, 1, 0, 0; Tachiramantis prolixodiscus, 0.00004, 1, 1, 0, 0; TELMATOBIIDAE, 0.00000, 0, 0, 0, 0; Telmatobius, 0.00000, 0, 0, 0, 0; Telmatobius arequipensis, 0.00041, 0, 1, 1, 0; Telmatobius atacamensis, 0.00389, 0, 1, 1, 0; Telmatobius atahualpai, 0.00016, 0, 1, 1, 0; Telmatobius bolivianus, 0.00011, 0, 1, 1, 0; Telmatobius brachydactylus, 0.00087, 0, 1, 1, 0; Telmatobius brevipes, 0.00017, 0, 1, 1, 0; Telmatobius brevirostris, 0.00030, 0, 1, 1, 0; Telmatobius carrillae, 0.00018, 0, 1, 1, 0; Telmatobius ceiorum, 0.00057, 0, 1, 1, 0; Telmatobius chusmisensis, 0.00509, 0, 1, 1, 0; Telmatobius cirrhacelis, 0.00448, 0, 1, 1, 0; Telmatobius colanensis, 0.00134, 0, 1, 1, 0; Telmatobius contrerasi, 0.00725, 0, 1, 1, 0; Telmatobius culeus, 0.00006, 0, 1, 1, 0; Telmatobius dankoi, 0.00308, 0, 1, 1, 0; Telmatobius degener, 0.00640, 0, 1, 1, 0; Telmatobius edaphonastes, 0.00068, 0, 1, 1, 0; Telmatobius espadai, 0.00011, 0, 1, 1, 0; Telmatobius fronteriensis, 0.00403, 0, 1, 1, 0; Telmatobius gigas, 0.00049, 0, 1, 1, 0; Telmatobius halli, 0.00728, 0, 1, 1, 0; Telmatobius hauthali, 0.00856, 0, 1, 1, 0; Telmatobius hintoni, 0.00002, 0, 1, 1, 0; Telmatobius hockingi, 0.01160, 0, 1, 1, 0; Telmatobius huayra, 0.00008, 0, 1, 1, 0; Telmatobius hypselocephalus, 0.00534, 0, 1, 1, 0; Telmatobius ignavus, 0.00123, 0, 1, 1, 0; Telmatobius intermedius, 0.03014, 0, 1, 1, 0; Telmatobius jelskii, 0.00002, 0, 1, 1, 0; Telmatobius laevis, $0.00938,0,1,1$, 0; Telmatobius laticeps, 0.00268, 0, 1, 1, 0; Telmatobius latirostris, $0.00349,0,1,1$, 0; Telmatobius macrostomus, 0.00095, 0, 1, 1, 0; Telmatobius mantaro, 0.00031, 0, 1, 1, 0; Telmatobius marmoratus, 0.00000, 0, 1, 1, 0; Telmatobius mayoloi, $0.00199,0,1,1,0$; Telmatobius mendelsoni, 0.00005, 0, 1, 1, 0; Telmatobius necopinus, 0.00162, 0, 1, 1, 0; Telmatobius niger, $0.00008,0,1,1$, 0; Telmatobius oxycephalus, 0.00041, 0, 1, 1, 0; Telmatobius pefauri, 0.00957, 0, 1, 1, 0; Telmatobius peruvianus, $0.00010,0,1,1$, 0; Telmatobius philippii, 0.00664, 0, 1, 1, 0; Telmatobius pinguiculus, 0.00799, 0, 1, 1, 0; Telmatobius pisanoi, $0.00016,0,1,1$, 0; Telmatobius platycephalus, 0.00426, 0, 1, 1, 0; Telmatobius punctatus, 0.00067, 0, 1, 1, 0; Telmatobius rimac, $0.00007,0,1,1$, 0; Telmatobius rubigo, $0.00098,0,1,1$, 0; Telmatobius sanborni, $0.00014,0,1,1$, 0; Telmatobius schreiteri, $0.00029,0,1,1$, 0; Telmatobius scrocchii, 0.00032, 0, 1, 1, 0; Telmatobius sibiricus, 0.00029, 0, 1, 1, 0; Telmatobius simonsi, $0.00001,0,1,1$, 0; Telmatobius stephani, 0.00086, 0, 1, 1, 0; Telmatobius thompsoni, 0.00150, 0, 1, 1, 0; Telmatobius timens, $0.00009,0,1,1,0$; Telmatobius truebae, $0.00023,0,1,1,0$; Telmatobius vellardi, $0.00144,0,1,1$, 0; Telmatobius ventriflavum, $0.00805,0,1,1,0$; Telmatobius verrucosus, $0.00020,0,1,1$, 0; Telmatobius vilamensis, $0.00323,0,1,1,0$; Telmatobius yuracare, $0.00015,0,1,1$, 0; Telmatobius zapahuirensis, 0.00956, 0, 1, 1, 0; Telmatobufo, 0.00003, 0, 0, 0, 0; Telmatobufo australis, 0.00007, $0,1,1,0$; Telmatobufo bullocki, 0.00024, 0, 1, 1, 0; Telmatobufo ignotus, 0.00967, 0, 1, 1, 0; Telmatobufo venustus, 0.00006, 0, 1, 1, 
0; Tepuihyla, 0.00000, 0, 0, 0, 0; Tepuihyla aecii, 0.00101, 1, 0, 0, 0; Tepuihyla aff_edelcae, 0.00080, 1, 0, 0, 0; Tepuihyla edelcae, $0.00080,1$, 0, 0, 0; Tepuihyla exophthalma, 0.00004, 1, 0, 0, 0; Tepuihyla luteolabris, 0.00188, 1, 0, 0, 0; Tepuihyla obscura, 0.00074 1, 0, 0, 0; Tepuihyla rodriguezi, 0.00004, 1, 0, 0, 0; Tepuihyla shushupe, 0.00010, 1, 0, 0, 0; Tepuihyla tuberculosa, 0.00000, 1, 0, 0, 0; Tepuihyla warreni, 0.00062, 1, 0, 0, 0; Teratohyla, 0.00000, 0, 0, 0, 0; Teratohyla adenocheira, 0.00000, 1, 0, 0, 0; Teratohyla amelie, 0.00001 , 1, 0, 0, 0; Teratohyla midas, 0.00000, 1, 0, 0, 0; Teratohyla pulverata, 0.00001, 1, 0, 0, 0; Teratohyla spinosa, 0.00001, 1, 0, 0, 0; Thoropa, 0.00000, 0, 0, 0, 0; Thoropa lutzi, 0.00003, 0, 1, 1, 0; Thoropa megatympanum, 0.00004, 0, 1, 1, 0; Thoropa miliaris, 0.00000, 0, 1, 1, 0; Thoropa petropolitana, 0.00137, 0, 1, 1, 0; Thoropa saxatilis, 0.00020, 0, 1, 1, 0; Thoropa taophora, 0.00009, 0, 1, 1, 0; Trachycephalus, 0.00000, 0, 0, 0, 0; Trachycephalus atlas, 0.00000, 1, 0, 0, 0; Trachycephalus coriaceus, 0.00000, 1, 0, 0, 0, Trachycephalus cunauaru, 0.00000, 1, 0, 0, 0; Trachycephalus dibernardoi, 0.00002, 1, 0, 0, 0; Trachycephalus hadroceps, 0.00000, 1, 0, 0, 0; Trachycephalus helioi, 0.00120, 1, 0, 0, 0; Trachycephalus imitatrix, 0.00001, 1, 0, 0, 0; Trachycephalus jordani, 0.00001, 1, 0, 0, 0; Trachycephalus lepidus, 0.00101, 1, 0, 0, 0; Trachycephalus macrotis, 0.00000, 1, 0, 0, 0; Trachycephalus mambaiensis, $0.00001,1,0$, 0, 0; Trachycephalus mesophaeus, 0.00000, 1, 0, 0, 0; Trachycephalus nigromaculatus, 0.00000, 1, 0, 0, 0; Trachycephalus quadrangulum, 0.00002, 1, 0, 0, 0; Trachycephalus resinifictrix, 0.00000, 1, 0, 0, 0; Trachycephalus spilomma, 0.00000 , 1, 0, 0, 0; Trachycephalus typhonius, 0.00000, 1, 0, 0, 0; Truebella, 0.00120, 0, 0, 0, 0; Truebella skoptes, 0.00132, 0, 1, 0, 0; Truebella tothastes, $0.01244,0,1,0$, 0; Typhlonectes, $0.00000,0,0,0$, 0; Typhlonectes compressicauda, 0.00000, 0, 0, 1, 1; Typhlonectes natans, 0.00001, 0, 0, 1, 1; TYPHLONECTIDAE, 0.00000, 0, 0, 0, 0; Vitreorana, 0.00000, 0, 0, 0, 0; Vitreorana antisthenesi, 0.00018, 1, 0, 0, 0; Vitreorana baliomma, 0.00002, 1, 0, 0, 0; Vitreorana castroviejoi, 0.00160, 1, 0, 0, 0; Vitreorana eurygnatha, $0.00000,1,0,0$, 0; Vitreorana franciscana, $0.00007,1,0,0$, 0; Vitreorana gorzulae, 0.00004, 1, 0, 0, 0; Vitreorana helenae, 0.00004, 1, 0, 0, 0; Vitreorana parvula, 0.00146, 1, 0, 0, 0; Vitreorana ritae, 0.00000, 1, 0, 0, 0; Vitreorana uranoscopa $0.00000,1,0,0$, 0; Xenohyla, 0.00002, 0, 0, 0, 0; Xenohyla eugenioi, 0.00002, 1, 0, 0, 0; Xenohyla truncata, 0.00009, 1, 0, 0, 0; Yunganastes, $0.00002,0,0,0$, 0; Yunganastes ashkapara, 0.00012, 0, 1, 0, 0; Yunganastes bisignatus, 0.00021, 0, 1, 0, 0; Yunganastes fraudator, 0.00010, 0, 1, 0, 0; Yunganastes mercedesae, 0.00002, 0, 1, 0, 0; Yunganastes pluvicanorus, 0.00008, 0, 1, 0, 0; Zachaenus, 0.00004, 0, 0, 0, 0; Zachaenus carvalhoi, 0.00007, 0, 1, 0, 0; Zachaenus parvulus, 0.00012, 0, 1, 0, 0.

\section{Répteis}

Acanthochelys, 0.00000, 0, 0, 0, 0; Acanthochelys macrocephala, 0.00000, 1, 0, 1, 0; Acanthochelys pallidipectoris, 0.00000, 1, 0, 1, 0; Acanthochelys radiolata, 0.00000, 1, 0, 1, 0; Acanthochelys spixii, 0.00000, 1, 0, 1, 0; Acratosaura, 0.00000, 0, 0, 0, 0; Acratosaura mentalis, 0.00000, 1, 0, 0, 0; Acratosaura spinosa, 0.00125, 1, 0, 0, 0; Adercosaurus, 0.00138, 0, 0, 0, 0; Adercosaurus vixadnexus, 0.00138 , 1, 0, 0, 0; Alexandresaurus, 0.00003, 0, 0, 0, 0; Alexandresaurus camacan, 0.00003, 1, 0, 0, 0; ALLIGATORIDAE, 0.00000, 0, 0, 0, 0; Alopoglossus, 0.00000, 0, 0, 0, 0; Alopoglossus angulatus, 0.00000, 1, 0, 0, 0; Alopoglossus atriventris, 0.00000, 1, 0, 0, 0; Alopoglossus buckleyi, 0.00001, 1, 0, 0, 0; Alopoglossus copii, 0.00002, 1, 0, 0, 0; Alopoglossus festae, 0.00001, 1, 0, 0, 0; Alopoglossus lehmanni, 0.00089, 1, 0, 0, 0; Alopoglossus viridiceps, 0.00109, 1, 0, 0, 0; Amapasaurus, 0.00000, 0, 0, 0, 0; Amapasaurus tetradactylus, 0.00000, 1, 0, 0, 0; Ameiva, 0.00000, 0, 0, 0, 0; Ameiva aff jacuba, 0.00027, 1, 0, 0, 0; Ameiva aggerecusans, 0.00046, 1, 0, 0, 0; Ameiva ameiva ameiva, 0.00000, 1, 0, 0, 0; Ameiva ameiva tobagana, 0.00018, 1, 0, 0, 0; Ameiva atrigularis, 0.00003, 1, 0, 0, 0; Ameiva bifrontata, 0.00000, 1, 0, 0, 0; Ameiva concolor, 0.00011, 1, 0, 0, 0; Ameiva jacuba, 0.00004, 1, 0, 0, 0; Ameiva nodam, 0.00025, 1, 0, 0, 0; Ameiva pantherina, 0.00443, 1, 0, 0, 0; Ameiva parecis, 0.00003, 1, 0, 0, 0; Ameiva praesignis, 0.00000, 1, 0, 0, 0; Ameiva provitaae, 0.00025, 1, 0, 0, 0; Ameiva reticulata, 0.00023, 1, 0, 0, 0; Ameivula, 0.00000, 0, 0, 0, 0; Ameivula abalosi, 0.00000, 1, 0, 0, 0; Ameivula cipoensis, 0.00038, 1, 0, 0, 0; Ameivula confusioniba, 0.00057, 1, 0, 0, 0; Ameivula jalapensis, 0.00010, 1, 0, 0, 0; Ameivula mumbuca, 0.00017, 1, 0, 0, 0; Ameivula nativo, 0.00003, 1, 0, 0, 0; Ameivula nigrigula, 0.00004, 1, 0, 0, 0; Ameivula ocellifera, 0.00000, 1, 0, 0, 0; Ameivula pyrrhogularis, 0.00001, 1, 0, 0, 0; Ameivula xacriaba, 0.00002, 1, 0, 0, 0; Amerotyphlops, 0.00000, 0, 0, 0, 0; Amerotyphlops amoipira, 0.00001, 0, 0, 0, 1; Amerotyphlops arenensis, $0.00000,0,0,0,1$; Amerotyphlops brongersmianus, 0.00000, 0, 0, 0, 1; Amerotyphlops lehneri, 0.00012, 0, 0, 0, 1; Amerotyphlops minuisquamus, 0.00000, 0, 0, 0, 1; Amerotyphlops paucisquamus, 0.00000, 0, 0, 0, 1; Amerotyphlops reticulatus, 0.00000, 0, 0, 0, 1 ; Amerotyphlops trinitatus, 0.00022, 0, 0, 0, 1; Amerotyphlops yonenagae, 0.00002, 0, 0, 0, 1; Amnesteophis, 0.00030, 0, 0, 0, 0; Amnesteophis melanauchen, 0.00030, 1, 0, 0, 0; Amphisbaena, 0.00000, 0, 0, 0, 0; Amphisbaena absaberi, 0.00009, 0, 0, 0, 1; Amphisbaena acrobeles, 0.00008, 0, 0, 0, 1; Amphisbaena alba, 0.00000, 0, 0, 0, 1; Amphisbaena albocingulata, 0.00001, 0, 0, 0, 1; Amphisbaena anaemariae, 0.00000, 0, 0, 0, 1; Amphisbaena angustifrons, 0.00000, 0, 0, 0, 1; Amphisbaena anomala, 0.00000, 0, 0, 0, 1; Amphisbaena arda, 0.00016, 0, 0, 0, 1; Amphisbaena arenaria, 0.00035, 0, 0, 0, 1; Amphisbaena bahiana, 0.00026, 0, 0, 0, 1; Amphisbaena bedai, 0.00003, 0, 0, 0, 1; Amphisbaena bilabialatus, 0.00001, 0, 0, 0, 1; Amphisbaena bolivica, 0.00000, 0, 0, 0, 1; Amphisbaena borellii, 0.00000, 0, 0, 0, 1; Amphisbaena brasiliana, 0.00000, 0, 0, 0, 1; Amphisbaena brevis, 0.00002, 0, 0, 0, 1; Amphisbaena caiari, 0.00001, 0, 0, 0, 1; Amphisbaena camura, 0.00000, 0, 0, 0, 1; Amphisbaena carli, 0.00001, 0, 0, 0, 1; Amphisbaena carvalhoi, 0.00003, 0, 0, 0, 1; Amphisbaena cegei, 0.00001, 0, 0, 0, 1; Amphisbaena cerradensis, 0.00011, 0, 0, 0, 1; Amphisbaena crisae, 0.00003, 0, 0, 0, 1; Amphisbaena cuiabana, 0.00001, 0, 0, 0, 1; Amphisbaena cunhai, 0.00001, 0, 0, 0, 1; Amphisbaena darwinii, 0.00000, 0, 0, 0, 1; Amphisbaena dubia, 0.00000, 0, 0, 0, 1; Amphisbaena filiformis, 0.00023, 0, 0, 0, 1; Amphisbaena frontalis, 0.00000, 0, 0, 0, 1; Amphisbaena fuliginosa, 0.00000, 0, 0, 0, 1; Amphisbaena gracilis, 0.00002, 0, 0, 0, 1; Amphisbaena hastata, 0.00003, 0, 0, 0, 1; Amphisbaena heathi, 0.00001, 0, 0, 0, 1; Amphisbaena heterozonata, 0.00000, 0, 0, 0, 1; Amphisbaena hogei, 0.00001, 0, 0, 0, 1; Amphisbaena ignatiana, 0.00026, 0, 0, 0, 1; Amphisbaena infraorbitale, 0.00000, 0, 0, 0, 1; Amphisbaena kingii, 0.00000, 0, 0, 0, 1; Amphisbaena kisteumacheri, 0.00001, 0, 0, 0, 1; Amphisbaena kraoh, 0.00001, 0, 0, 0, 1; Amphisbaena leeseri, 0.00000, 0, 0, 0, 1; Amphisbaena leucocephala, 0.00004, 0, 0, 0, 1; Amphisbaena litoralis, 0.00006, 0, 0, 0, 1; Amphisbaena lumbricalis, 0.00002, 0, 0, 0, 1; Amphisbaena maximus, 0.00006, 0, 0, 0, 1; Amphisbaena medemi, 0.00010, 0, 0, 0, 1; Amphisbaena mensae, 0.00000, 0, 0, 0, 1; Amphisbaena mertensii, 0.00000, 0, 0, 0, 1; Amphisbaena metallurga, 0.00052, 0, 0, 0, 1; Amphisbaena microcephalum, 0.00000, 0, 0, 0, 1; Amphisbaena miringoera, 0.00000, 0, 0, 0, 1; Amphisbaena mitchelli, 0.00000, 0, 0, 0, 1; Amphisbaena munoai, 0.00000, 0, 0, 0, 1; Amphisbaena myersi, 0.00002, 0, 0, 0, 1; Amphisbaena neglecta, 0.00000, 0, 0, 0, 1; Amphisbaena nigricauda, 0.00003, 0, 0, 0, 1; Amphisbaena occidentalis, 0.00001, 0, 0, 0, 1; Amphisbaena octostegum, 0.00007, 
$0,0,0,1$; Amphisbaena pericensis, 0.00017, 0, 0, 0, 1; Amphisbaena persephone, 0.00002, 0, 0, 0, 1; Amphisbaena plumbea, 0.00000 , 0, 0, 0, 1; Amphisbaena polygrammica, 0.00058, 0, 0, 0, 1; Amphisbaena polystegum, 0.00000, 0, 0, 0, 1; Amphisbaena pretrei, 0.00000, 0, 0, 0, 1; Amphisbaena prunicolor, 0.00000, 0, 0, 0, 1; Amphisbaena roberti, 0.00000, 0, 0, 0, 1; Amphisbaena rozei, 0.00009, 0, 0, 0, 1; Amphisbaena sanctaritae, 0.00004, 0, 0, 0, 1; Amphisbaena scutigerum, 0.00024, 0, 0, 0, 1; Amphisbaena silvestrii, 0.00000, 0, 0, 0, 1; Amphisbaena slateri, 0.00001, 0, 0, 0, 1; Amphisbaena slevini, 0.00006, 0, 0, 0, 1; Amphisbaena spurrelli, 0.00002, 0, 0, 0, 1; Amphisbaena steindachneri, 0.00000, 0, 0, 0, 1; Amphisbaena supernumeraria, 0.00005, 0, 0, 0, 1; Amphisbaena talisiae, 0.00004, 0, 0, 0, 1; Amphisbaena townsendi, 0.00004, 0, 0, 0, 1; Amphisbaena trachura, 0.00000, 0, 0, 0, 1 ; Amphisbaena tragorrhectes, 0.00003, 0, 0, 0, 1; Amphisbaena uroxena, 0.00053, 0, 0, 0, 1; Amphisbaena vanzolini, 0.00000, 0, 0, 0, 1; Amphisbaena vermicularis, 0.00000, 0, 0, 0, 1; Amphisbaena wuchereri, 0.00003, 0, 0, 0, 1; AMPHISBAENIDAE, 0.00000, 0, 0, 0, 0; Anadia, 0.00000, 0, 0, 0, 0; Anadia altaserrania, 0.00023, 1, 0, 0, 0; Anadia antioquensis, 0.00022, 1, 0, 0, 0; Anadia bitaeniata, 0.00087, 1, 0, 0, 0; Anadia blakei, 0.00036, 1, 0, 0, 0; Anadia bogotensis, 0.00004, 1, 0, 0, 0; Anadia brevifrontalis, 0.00165, 1, 0, 0, 0; Anadia bumanguesa, 0.00358, 1, 0, 0, 0; Anadia escalerae, 0.00655, 1, 0, 0, 0; Anadia hobarti, 0.00989, 1, 0, 0, 0; Anadia marmorata, 0.00025, 1, 0, 0, 0; Anadia mcdiarmidi, 0.00668, 1, 0, 0, 0; Anadia ocellata, 0.00005, 1, 0, 0, 0; Anadia pamplonensis, 0.00079, 1, 0, 0, 0; Anadia pariaensis, 0.00143, 1, 0, 0, 0; Anadia petersi, 0.00113, 1, 0, 0, 0; Anadia pulchella, 0.00019, 1, 0, 0, 0; Anadia rhombifera, 0.00000, 1, 0, 0, 0; Anadia sp, 0.00058, 1, 0, 0, 0; Anadia steyeri, 0.00003, 1, 0, 0, 0; Anadia vittata, 0.00019, 1, 0, 0, 0; ANILIIDAE, 0.00000, 0, 0, 0, 0; Anilius, 0.00000, 0, 0, 0, 0; Anilius scytale, 0.00000, 1, 0, 0, 0; Anisolepis, 0.00000, 0, 0, 0, 0; Anisolepis grilli, 0.00000, 1, 1, 0, 0; Anisolepis longicauda, 0.00001, 1, 1, 0, 0; Anisolepis undulatus, 0.00001, 1, 1, 0, 0; ANOMALEPIDIDAE, 0.00000, 0, 0, 0, 0; Anomalepis, 0.00000, 0, 0, 0, 0; Anomalepis aspinosus, 0.00020, 0, 0, 0, 1; Anomalepis colombia, 0.00186, 0, 0, 0, 1; Anomalepis flavapices, 0.00006, 0, 0, 0, 1; Anomalepis mexicanus, 0.00002, 0, 0, 0, 1; Anotosaura, 0.00001 , 0, 0, 0, 0; Anotosaura collaris, 0.00506, 1, 0, 0, 1; Anotosaura vanzolinia, 0.00001, 1, 0, 0, 1; Apostolepis, 0.00000, 0, 0, 0, 0 ; Apostolepis albicollaris, 0.00000, 1, 0, 0, 1; Apostolepis ambiniger, 0.00000, 1, 0, 0, 1; Apostolepis ammodites, 0.00000, 1, 0, 0, 1; Apostolepis arenaria, 0.00044, 1, 0, 0, 1; Apostolepis assimilis, 0.00000, 1, 0, 0, 1; Apostolepis borellii, 0.00026, 1, 0, 0, 1; Apostolepis breviceps, $0.00004,1$, 0, 0, 1; Apostolepis cearensis, 0.00000, 1, 0, 0, 1; Apostolepis cerradoensis, 0.00019, 1, 0, 0, 1; Apostolepis christineae, 0.00055, 1, 0, 0, 1; Apostolepis dimidiata, 0.00000, 1, 0, 0, 1; Apostolepis dorbignyi, 0.00004, 1, 0, 0, 1; Apostolepis flavotorquata, 0.00000, 1, 0, 0, 1; Apostolepis gaboi, 0.00013, 1, 0, 0, 1; Apostolepis goiasensis, 0.00000, 1, 0, 0, 1; Apostolepis intermedia, 0.00001, 1, 0, 0, 1; Apostolepis lineata, 0.00038, 1, 0, 0, 1; Apostolepis longicaudata, 0.00002, 1, 0, 0, 1; Apostolepis multicincta, 0.00004, 1, 0, 0, 1; Apostolepis nelsonjorgei, 0.00000, 1, 0, 0, 1; Apostolepis niceforoi, 0.00003, 1, 0, 0, 1; Apostolepis nigrolineata, 0.00000, 1, 0, 0, 1; Apostolepis nigroterminata, 0.00000, 1, 0, 0, 1; Apostolepis phillipsae, 0.00012, 1, 0, 0, 1 ; Apostolepis polylepis, 0.00006, 1, 0, 0, 1; Apostolepis quinquelineata, 0.00000, 1, 0, 0, 1; Apostolepis quirogai, 0.00005, 1, 0, 0, 1; Apostolepis serrana, 0.00118, 1, 0, 0, 1; Apostolepis striata, 0.00005, 1, 0, 0, 1; Apostolepis tenuis, 0.00013, 1, 0, 0, 1; Apostolepis tertulianobeui, 0.00008, 1, 0, 0, 1; Apostolepis vittata, 0.00001, 1, 0, 0, 1; Arthrosaura, 0.00000, 0, 0, 0, 0; Arthrosaura guianensis, 0.00049, 1, 0, 0, 0; Arthrosaura hoogmoedi, 0.00289, 1, 0, 0, 0; Arthrosaura kockii, 0.00000, 1, 0, 0, 0; Arthrosaura montigena, $0.00037,1$, 0, 0, 0; Arthrosaura reticulata, 0.00000, 1, 0, 0, 0; Arthrosaura synaptolepis, 0.00030, 1, 0, 0, 0; Arthrosaura testigensis, 0.00136, 1, 0, 0, 0; Arthrosaura tyleri, 0.00017, 1, 0, 0, 0; Arthrosaura versteegii, 0.00000, 1, 0, 0, 0; Atractus, 0.00000, 0, 0, 0, 0; Atractus acheronius, 0.00030, 1, 0, 0, 1; Atractus albuquerquei, 0.00000, 1, 0, 0, 1; Atractus alphonsehogei, 0.00000, 1, 0, 0, 1; Atractus altagratiae, 0.00010, 1, 0, 0, 1; Atractus alytogrammus, 0.00300, 1, 0, 0, 1; Atractus apophis, 0.00061, 1, 0, 0, 1; Atractus arangoi, 0.00032, 1, 0, 0, 1; Atractus atratus, 0.00033, 1, 0, 0, 1; Atractus attenuates, 0.00026, 1, 0, 0, 1; Atractus avernus, 0.00041 , 1, 0, 0, 1; Atractus ayeush, 0.00026, 1, 0, 0, 1; Atractus badius, 0.00000, 1, 0, 0, 1; Atractus balzani, 0.00012, 1, 0, 0, 1; Atractus biseriatus, 0.00481, 1, 0, 0, 1; Atractus bocki, 0.00001, 1, 0, 0, 1; Atractus bocourti, 0.00001, 1, 0, 0, 1; Atractus boettgeri, 0.00026, 1, 0, 0, 1; Atractus boimirim, 0.00000, 1, 0, 0, 1; Atractus boulengerii, 0.00027, 1, 0, 0, 1; Atractus caete, 0.00019, 1, 0, 0, 1; Atractus careolepis, 0.00134, 1, 0, 0, 1; Atractus carrioni, 0.00054, 1, 0, 0, 1; Atractus caxiuana, 0.00003, 1, 0, 0, 1; Atractus charitoae, $0.00005,1,0,0,1$; Atractus chthonius, 0.00013, 1, 0, 0, 1 ; Atractus clarki, 0.00001, 1, 0, 0, 1; Atractus collaris, 0.00000, 1, 0, 0, 1; Atractus crassicaudatus, 0.00002, 1, 0, 0, 1; Atractus duboisi, 0.00022, 1, 0, 0, 1; Atractus duidensis, 0.00134, 1, 0, 0, 1; Atractus dunni, 0.00005, 1, 0, 0, 1; Atractus echidna, 0.00042, 1, 0, 0, 1; Atractus ecuadorensis, 0.00074, 1, 0, 0, 1; Atractus edioi, $0.00098,1$, 0, 0, 1; Atractus elaps, 0.00000, 1, 0, 0, 1; Atractus emersoni, 0.00006, 1, 0, 0, 1; Atractus emigdioi, 0.00025, 1, 0, 0, 1; Atractus emmeli, 0.00000, 1, 0, 0, 1; Atractus eriki, 0.00005, 1, 0, 0, 1; Atractus erythromelas, 0.00018, 1, 0, 0, 1; Atractus favae, 0.00002, 1, 0, 0, 1; Atractus flammigerus, 0.00000, 1, 0, 0, 1; Atractus franciscopaivai, 0.00006, 1, 0, 0, 1; Atractus francoi, 0.00007, 1, 0, 0, 1; Atractus gaigeae, 0.00002, 1, 0, 0, 1; Atractus gigas, 0.00065, 1, 0, 0, 1; Atractus guentheri, 0.00006, 1, 0, 0, 1; Atractus heliobelluomini, 0.00006, 1, 0, 0, 1; Atractus hoogmoedi, 0.00004, 1, 0, 0, 1; Atractus indistinctus, 0.00054, 1, 0, 0, 1; Atractus insipidus, 0.00192, 1, 0, 0, 1; Atractus iridescens, 0.00003, 1, 0, 0, 1; Atractus lancinii, 0.00011, 1, 0, 0, 1; Atractus lasallei, 0.00008, 1, 0, 0, 1; Atractus latifrons, 0.00000, 1, 0, 0, 1; Atractus lehmanni, 0.00007, 1, 0, 0, 1; Atractus limitaneus, 0.00001, 1, 0, 0, 1; Atractus loveridgei, 0.00025, 1, 0, 0, 1; Atractus macondo, 0.00037, 1, 0, 0, 1; Atractus maculatus, 0.00008, 1, 0, 0, 1; Atractus major, 0.00000, 1, 0, 0, 1; Atractus manizalesensis, 0.00036, 1, 0, 0, 1; Atractus mariselae, 0.00025, 1, 0, 0, 1; Atractus matthewi, $0.00013,1,0,0,1$; Atractus melanogaster, 0.00008, 1, 0, 0, 1; Atractus melas, 0.00005, 1, 0, 0, 1; Atractus meridensis, 0.00019, 1, 0, 0, 1; Atractus micheleae, 0.00010, 1, 0, 0, 1; Atractus microrhynchus, 0.00012, 1, 0, 0, 1; Atractus mijaresi, 0.00012, 1, 0, 0, 1; Atractus modestus, 0.00004, 1, 0, 0, 1; Atractus multicinctus, 0.00026, 1, 0, 0, 1; Atractus multidentatus, 0.00012, 1, 0, 0, 1; Atractus nasutus, 0.00076, 1, 0, 0, 1; Atractus natans, 0.00000, 1, 0, 0, 1; Atractus nicefori, 0.00033, 1, 0, 0, 1; Atractus nigricaudus, 0.00016, $1,0,0,1$; Atractus nigriventris, 0.00016, 1, 0, 0, 1; Atractus obesus, 0.00035, 1, 0, 0, 1; Atractus obtusirostris, 0.00004, 1, 0, 0, 1; Atractus occidentalis, 0.00188, 1, 0, 0, 1; Atractus occipitoalbus, 0.00003, 1, 0, 0, 1; Atractus ochrosetrus, 0.00011, 1, 0, 0, 1; Atractus oculotemporalis, 0.00016, 1, 0, 0, 1; Atractus orcesi, 0.00004, 1, 0, 0, 1; Atractus paisa, 0.00020, 1, 0, 0, 1; Atractus pamplonensis, 0.00008, 1, 0, 0, 1; Atractus pantostictus, 0.00000, 1, 0, 0, 1; Atractus paraguayensis, 0.00000, 1, 0, 0, 1; Atractus paravertebralis, 0.00012, 1, 0, 0, 1; Atractus paucidens, 0.00027, 1, 0, 0, 1; Atractus pauciscutatus, 0.00735, 1, 0, 0, 1; Atractus poeppigi, 0.00000, 1, 0, 0, 1; Atractus potschi, 0.00001, 1, 0, 0, 1; Atractus punctiventris, 0.00022, 1, 0, 0, 1; Atractus reticulatus, $0.00000,1,0,0,1$; Atractus riveroi, 0.00011, 1, 0, 0, 1; Atractus ronnie, 0.00001, 1, 0, 0, 1; Atractus roulei, 0.00005, 1, 0, 0, 1; Atractus sanctaemartae, 0.00012, 1, 0, 0, 1; Atractus sanguineus, 0.00014, 1, 0, 0, 1; Atractus savagei, 0.00153, 1, 0, 0, 1; Atractus 
schach, $0.00000,1,0,0,1$; Atractus serranus, 0.00007, 1, 0, 0, 1; Atractus snethlageae, 0.00000, 1, 0, 0, 1; Atractus spinalis, $0.00102,1,0,0$, 1; Atractus steyermarki, 0.00004, 1, 0, 0, 1; Atractus surucucu, 0.00045, 1, 0, 0, 1; Atractus taeniatus, 0.00000, 1, 0 , 0,1 ; Atractus tamaensis, 0.00019, 1, 0, 0, 1; Atractus tamessari, 0.00007, 1, 0, 0, 1; Atractus taphorni, 0.00012, 1, 0, 0, 1; Atractus tartarus, $0.00000,1,0,0,1$; Atractus thalesdelemai, 0.00002, 1, 0, 0, 1; Atractus titanicus, 0.00010, 1, 0, 0, 1; Atractus torquatus, $0.00000,1,0,0,1$; Atractus touzeti, $0.00018,1,0,0,1$; Atractus trihedrurus, 0.00003, 1, 0, 0, 1; Atractus trilineatus, 0.00001, 1, 0, 0 , 1; Atractus trivittatus, 0.00009, 1, 0, 0, 1; Atractus turikensis, 0.00022, 1, 0, 0, 1; Atractus typhon, 0.00014, 1, 0, 0, 1; Atractus univittatus, 0.00002, 1, 0, 0, 1; Atractus variegatus, 0.00016, 1, 0, 0, 1; Atractus ventrimaculatus, 0.00012, 1, 0, 0, 1; Atractus vertebralis, $0.00074,1,0,0,1$; Atractus vertebrolineatus, $0.00027,1,0,0,1$; Atractus vittatus, $0.00012,1,0,0,1$; Atractus wagleri, $0.00005,1,0,0,1$; Atractus werneri, 0.00006, 1, 0, 0, 1; Atractus zebrinus, 0.00000, 1, 0, 0, 1; Atractus zidoki, 0.00000, 1, 0, 0, 1; Aurivela, 0.00000, 0, 0, 0, 0; Aurivela longicauda, 0.00000, 1, 0, 0, 0; Aurivela tergolaevigata, 0.00003, 1, 0, 0, 0; Bachia, 0.00000, 0 , 0, 0, 0; Bachia barbouri, 0.00049, 1, 0, 0, 1; Bachia bicolor, 0.00001, 1, 0, 0, 1; Bachia bresslaui, 0.00000, 1, 0, 0, 1; Bachia cacerensis, 0.00108, 1, 0, 0, 1; Bachia didactyla, 0.00003, 1, 0, 0, 1; Bachia dorbignyi, 0.00000, 1, 0, 0, 1; Bachia flavescens, 0.00000 , 1, 0, 0, 1; Bachia geralista, 0.00002, 0, 0, 0, 1; Bachia guianensis, 0.00000, 1, 0, 0, 1; Bachia heteropa alleni, 0.00093, 1, 0, 0, 1; Bachia heteropa heteropa, 0.00009, 1, 0, 0, 1; Bachia heteropa lineata, 0.00001, 1, 0, 0, 1; Bachia heteropa marcelae, 0.00004, 1, 0, 0,1 ; Bachia heteropa trinitatis, 0.00002, 1, 0, 0, 1; Bachia huallagana, 0.00007, 1, 0, 0, 1; Bachia intermedia, 0.00042, 1, 0, 0, 1; Bachia micromela, 0.00088, 1, 0, 0, 1; Bachia oxyrhina, 0.00101, 0, 0, 0, 1; Bachia pallidiceps, 0.00002, 1, 0, 0, 1; Bachia panoplia, 0.00002 , 1, 0, 0, 1; Bachia peruana, 0.00001, 1, 0, 0, 1; Bachia psamophila, 0.00875, 0, 0, 0, 1; Bachia pyburni, 0.00019, 1, 0, 0, 1; Bachia scaea, 0.00000, 1, 0, 0, 1; Bachia scolecoides, 0.00000, 1, 0, 0, 1; Bachia talpa, 0.00005, 1, 0, 0, 1; Bachia trisanale abendrothii, $0.00000,1,0,0,1$; Bachia trisanale trisanale, $0.00000,1,0,0,1$; Bachia vermiformis, 0.00001, 1, 0, 0, 1; Basiliscus, 0.00000 , 0, 0, 0, 0; Basiliscus basiliscus barbouri, 0.00001, 1, 1, 0, 0; Basiliscus basiliscus basiliscus, 0.00000, 1, 1, 0, 0; Basiliscus galeritus, 0.00000, 1, 1, 0, 0; Boa, 0.00000, 0, 0, 0, 0; Boa constrictor, 0.00000, 1, 0, 0, 0; BOIDAE, 0.00000, 0, 0, 0, 0; Boiruna, 0.00000, 0, 0, 0, 0; Boiruna maculata, 0.00000, 1, 0, 0, 0; Boiruna sertaneja, 0.00000, 1, 0, 0, 0; Bothriechis, 0.00000, 0, 0, 0, 0; Bothriechis schlegelii, 0.00000, 1, 1, 0, 0; Bothrocophias, 0.00000, 0, 0, 0, 0; Bothrocophias andianus, 0.00001, 1, 0, 0, 0; Bothrocophias campbelli, 0.00008, 1, 0, 0, 0; Bothrocophias colombianus, 0.00023, 1, 0, 0, 0; Bothrocophias hyoprora, 0.00000, 1, 0, 0, 0; Bothrocophias microphthalmus, 0.00000, 1, 0, 0, 0; Bothrocophias myersi, 0.00003, 1, 0, 0, 0; Bothrops, 0.00000, 0, 0, 0, 0; Bothrops alcatraz, 0.45345, 1, 0, 0, 0; Bothrops alternatus, 0.00000, 1, 0, 0, 0; Bothrops ammodytoides, 0.00000, 1, 0, 0, 0; Bothrops andianus, 0.00002, 1, 0, 0, 0; Bothrops asper, 0.00000, 1, 0, 0, 0; Bothrops atrox, 0.00000, 1, 0, 0, 0; Bothrops ayerbei, 0.00013, 1, 0, 0, 0; Bothrops barnetti, 0.00002, 1, 0, 0, 0; Bothrops bilineata, 0.00000, 1, 1, 0, 0; Bothrops brazili, 0.00000, 1, 0, 0, 0; Bothrops chloromelas, 0.00001, 1, 0, 0, 0; Bothrops cotiara, 0.00000, 1, 0, 0, 0; Bothrops diporus, 0.00000, 1, 0, 0, 0; Bothrops erythromelas, $0.00000,1$, 0, 0, 0; Bothrops fonsecai, 0.00006, 1, 0, 0, 0; Bothrops insularis, 1.51523, 1, 0, 0, 0; Bothrops isabelae, 0.00001, 1, 0, 0, 0; Bothrops itapetiningae, 0.00000, 1, 0, 0, 0; Bothrops jararaca, 0.00000, 1, 0, 0, 0; Bothrops jararacussu, 0.00000, 1, 0, 0, 0; Bothrops jonathani, 0.00002, 1, 0, 0, 0; Bothrops leucurus, 0.00000, 1, 0, 0, 0; Bothrops lojanus, 0.00007, 1, 0, 0, 0; Bothrops lutzi, $0.00000,1$, 0, 0, 0; Bothrops marajoensis, 0.00001, 1, 0, 0, 0; Bothrops marmoratus, 0.00000, 1, 0, 0, 0; Bothrops matogrossensis, 0.00000, 1, 0, 0, 0; Bothrops medusa, 0.00015, 1, 0, 0, 0; Bothrops moojeni, 0.00000, 1, 0, 0, 0; Bothrops muriciensis, 0.00011, 1, 0, 0, 0; Bothrops neuwiedi, 0.00000, 1, 0, 0, 0; Bothrops oligolepis, 0.00001, 1, 0, 0, 0; Bothrops osbornei, 0.00008, 1, 0, 0, 0; Bothrops otavioi, 0.38074, 1, 0, 0, 0; Bothrops pauloensis, 0.00000, 1, 0, 0, 0; Bothrops pictus, 0.00001, 1, 0, 0, 0; Bothrops pirajai, 0.00009, 1, 0, 0, 0; Bothrops pubescens, 0.00000, 1, 0, 0, 0; Bothrops pulchra, 0.00000, 1, 0, 0, 0; Bothrops punctatus, 0.00001, 1, 0, 0, 0; Bothrops rhombeatus, $0.00003,1,0,0$, 0; Bothrops sanctaecrucis, 0.00002, 1, 0, 0, 0; Bothrops sazimai, 5.98901, 1, 0, 0, 0; Bothrops taeniata, 0.00000, 1, 1, 0, 0; Bothrops venezuelensis, 0.00002, 1, 0, 0, 0; Caaeteboia, 0.00000, 0, 0, 0, 0; Caaeteboia amarali, $0.00000,1$, 0, 0, 0; Caiman, 0.00000, 0, 0, 0, 0; Caiman crocodilus, 0.00000, 1, 0, 1, 0; Caiman latirostris, 0.00000, 1, 0, 1, 0; Caiman yacare, 0.00000, 1, 0, 1, 0; Calamodontophis, 0.00001, 0, 0, 0, 0; Calamodontophis paucidens, 0.00001, 1, 0, 0, 0; Calamodontophis ronaldoi, 0.00003, 1, 0, 0, 0; Callopistes, 0.00001, 0, 0, 0, 0; Callopistes flavipunctatus, 0.00001, 1, 0, 0, 0; Callopistes maculatus, 0.00001 , 1, 0, 0, 0; Calyptommatus, 0.00006, 0, 0, 0, 0; Calyptommatus confusionibus, 0.00026, 0, 0, 0, 1; Calyptommatus leiolepis, $0.00008,0,0,0,1$; Calyptommatus nicterus, 0.00219, 0, 0, 0, 1; Calyptommatus sinebrachiatus, 0.00219, 0, 0, 0, 1; Caparaonia, 0.00337, 0, 0, 0, 0; Caparaonia itaiquara, 0.00337, 1, 0, 0, 0; Cercophis, 0.00007, 0, 0, 0, 0; Cercophis auratus, 0.00007, 0, 1, 0, 0; Cercosaura, 0.00000, 0, 0, 0, 0; Cercosaura argulus, 0.00000, 1, 0, 0, 0; Cercosaura bassleri, 0.00000, 1, 0, 0, 0; Cercosaura doanae, 0.00079 , 1, 0, 0, 0; Cercosaura eigenmanni, 0.00000, 1, 0, 0, 0; Cercosaura hypnoides, 0.00075, 1, 0, 0, 0; Cercosaura manicata boliviana, 0.00001, 1, 0, 0, 0; Cercosaura manicata manicata, 0.00000, 1, 0, 0, 0; Cercosaura nigroventris, 0.00142, 1, 0, 0, 0; Cercosaura ocellata ocellata, 0.00000, 1, 0, 0, 0; Cercosaura ocellata petersi, 0.00000, 1, 0, 0, 0; Cercosaura oshaughnessyi, 0.00000 , 1, 0, 0, 0; Cercosaura parkeri, 0.00000, 1, 0, 0, 0; Cercosaura phelpsorum, 0.00006, 1, 0, 0, 0; Cercosaura quadrilineata, 0.00000, 1, 0, 0, 0; Cercosaura schreibersii albostrigatus, 0.00000, 1, 0, 0, 0; Cercosaura schreibersii schreibersii, 0.00000, 1, 0, 0, 0; Cercosaura sp 1, 0.00000, 1, 0, 0, 0; Cercosaura sp 2, 0.00000, 1, 0, 0, 0; Cercosaura steyeri, 0.00033, 1, 0, 0, 0; Chatogekko, 0.00000, 0, 0, 0, 0; Chatogekko amazonicus, 0.00000, 1, 0, 0, 0; CHELIDAE, 0.00000, 0, 0, 0, 0; Chelonoidis, 0.00000, 0, 0, 0, 0; Chelonoidis carbonarius, $0.00000,1,0,0$, 0; Chelonoidis chilensis, 0.00000, 1, 0, 0, 0; Chelonoidis denticulatus, $0.00000,1,0,0,0$; Chelus, 0.00000, 0, 0, 0, 0; Chelus fimbriata, 0.00000, 0, 0, 1, 0; Chelydra, 0.00000, 0, 0, 0, 0; Chelydra acutirostris, 0.00000, 0, 0, 1, 0; CHELYDRIDAE, 0.00000, 0, 0, 0, 0; Chironius, 0.00000, 0, 0, 0, 0; Chironius bicarinatus, 0.00000, 1, 1, 0, 0; Chironius brazili, 0.00000, 1, 1, 0, 0; Chironius carinatus, $0.00000,1,1,0$, 0; Chironius challenger, 0.00003, 1, 1, 0, 0; Chironius diamantina, 0.00004, 1, 1, 0, 0; Chironius exoletus, $0.00000,1,1,0$, 0; Chironius flavolineatus, 0.00000, 1, 1, 0, 0; Chironius flavopictus, 0.00000, 1, 1, 0, 0; Chironius foveatus, 0.00000 , 1, 1, 0, 0; Chironius fuscus, 0.00000, 1, 1, 0, 0; Chironius grandisquamus, 0.00000, 1, 1, 0, 0; Chironius laevicollis, 0.00000, 1, 1, 0, 0; Chironius laurenti, 0.00000, 1, 1, 0, 0; Chironius leucometapus, 0.00002, 1, 1, 0, 0; Chironius maculoventris, 0.00000, 1, 1, 0, 0; Chironius monticola, 0.00000, 1, 1, 0, 0; Chironius multiventris, 0.00000, 1, 1, 0, 0; Chironius quadricarinatus, 0.00000, 1, 1, 0, 0; Chironius scurrulus, $0.00000,1,1,0,0$; Chironius septentrionalis, 0.00002, 1, 1, 0, 0; Chironius spixii, 0.00000, 1, 1, 0, 0; Clelia, 0.00000, 0, 0, 0, 0; Clelia clelia, 0.00000, 1, 0, 0, 0; Clelia equatoriana, 0.00000, 1, 0, 0, 0; Clelia hussami, 0.00004, 1, 0, 0, 0; Clelia langeri, 0.00001, 1, 0, 0, 0; Clelia plumbea, 0.00000, 1, 0, 0, 0; Clelia scytalina, 0.00001, 1, 0, 0, 0; Cnemidophorus, 0.00000, 0, 0, 0, 0 ; Cnemidophorus arenivagus, 0.00006, 1, 0, 0, 0; Cnemidophorus cryptus, 0.00000, 1, 0, 0, 0; Cnemidophorus flavissimus, 0.00137 , 
1, 0, 0, 0; Cnemidophorus gaigei, 0.00046, 1, 0, 0, 0; Cnemidophorus gramivagus, 0.00000, 1, 0, 0, 0; Cnemidophorus lemniscatus, $0.00000,1,0,0$, 0; Cnemidophorus murinus, 0.00104, 1, 0, 0, 0; Cnemidophorus nigricolor, 0.00678, 1, 0, 0, 0; Cnemidophorus pseudolemniscatus, 0.00002, 1, 0, 0, 0; Cnemidophorus rostralis, 0.00634, 1, 0, 0, 0; Cnemidophorus senectus, 0.00117, 1, 0, 0, 0; Cnemidophorus splendidus, 0.00040, 1, 0, 0, 0; Coleodactylus, 0.00000, 0, 0, 0, 0; Coleodactylus brachystoma, 0.00000, 1, 0, 0, 0; Coleodactylus elizae, 0.00119, 1, 0, 0, 0; Coleodactylus meridionalis, 0.00000, 1, 0, 0, 0; Coleodactylus natalensis, 0.00159, 1, 0, 0, 0; Coleodactylus septentrionalis, 0.00001, 1, 0, 0, 0; Colobodactylus, 0.00001, 0, 0, 0, 0; Colobodactylus dalcyanus, 0.00108, 1, 0, 0, 0; Colobodactylus taunayi, 0.00001, 1, 0, 0, 0; Colobosaura, 0.00000, 0, 0, 0, 0; Colobosaura kraepelini, 0.00425, 1, 0, 0, 0; Colobosaura modesta, 0.00000, 1, 0, 0, 0; Colobosauroides, 0.00002, 0, 0, 0, 0; Colobosauroides carvalhoi, 0.00032, 1, 0, 0, 0; Colobosauroides cearensis, 0.00002, 1, 0, 0, 0; Coluber, 0.00000, 0, 0, 0, 0; Coluber mentovarius centralis, 0.00000, 1, 1, 0, 0; Coluber mentovarius mentovarius, 0.00000, 1, 1, 0, 0; Coluber mentovarius striolatus, 0.00000, 1, 1, 0, 0; Coluber mentovarius suborbitalis, 0.00001, 1, 1, 0,0 ; Coluber mentovarius variolosus, $0.00000,1,1,0,0$; COLUBRIDAE, $0.00000,0,0,0,0$; Coniophanes, 0.00000, 0, 0, 0, 0; Coniophanes dromiciformis, 0.00023, 1, 0, 0, 0; Coniophanes fissidens, 0.00000, 1, 0, 0, 0; Coniophanes longinquus, 0.00010, 1, 0, 0, 0; Contomastix, 0.00000, 0, 0, 0, 0; Contomastix lacertoides, 0.00000, 1, 0, 0, 0; Contomastix leachei, 0.00003, 1, 0, 0, 0; Contomastix serrana, 0.00002, 1, 0, 0, 0; Contomastix vacariensis, 0.00006, 1, 0, 0, 0; Contomastix vittata, 0.00212, 1, 0, 0, 0; Corallus, 0.00000, 0, 0, 0, 0; Corallus annulatus, 0.00000, 0, 1, 0, 0; Corallus batesii, 0.00000, 0, 1, 0, 0; Corallus blombergi, 0.00002 , $0,1,0,0$; Corallus caninus, $0.00000,0,1,0,0$; Corallus cropanii, $0.00035,1,0,0,0$; Corallus hortulanus, 0.00000, 0, 1, 0, 0; Corallus ruschenbergerii, 0.00000, 0, 1, 0, 0; Coronelaps, 0.00000, 0, 0, 0, 0; Coronelaps lepidus, 0.00000, 1, 0, 0, 1; Corytophanes, 0.00000 , 0, 0, 0, 0; Corytophanes cristatus, 0.00000, 1, 1, 0, 0; CORYTOPHANIDAE, 0.00000, 0, 0, 0, 0; Crocodilurus, 0.00000, 0, 0, 0, 0; Crocodilurus amazonicus, 0.00000, 0, 0, 1, 0; CROCODYLIA, 0.00000, 0, 0, 0, 0; CROCODYLIDAE, 0.00000, 0, 0, 0, 0; Crocodylus, $0.00000,0,0$, 0, 0; Crocodylus acutus, 0.00000, 1, 0, 1, 0; Crocodylus intermedius, 0.00000, 1, 0, 1, 0; Crotalus, 0.00000, 0, 0, 0, 0; Crotalus durissus, 0.00000, 1, 0, 0, 0; Ctenoblepharys, 0.00008, 0, 0, 0, 0; Ctenoblepharys adspersa, 0.00008, 1, 1, 0, 0; Dactyloa, 0.00000, 0, 0, 0, 0; Dactyloa aequatorialis, 0.00004, 0, 1, 0, 0; Dactyloa anatoloros, 0.00018, 0, 1, 0, 0; Dactyloa anchicayae, 0.00001 , 0, 1, 0, 0; Dactyloa anoriensis, 0.00017, 0, 1, 0, 0; Dactyloa antioquiae, 0.00039, 0, 1, 0, 0; Dactyloa apollinaris, 0.00008, 0, 1, 0, 0; Dactyloa bellipeniculus, 0.00079, 0, 1, 0, 0; Dactyloa boettgeri, 0.00001, 0, 1, 0, 0; Dactyloa calimae, 0.00016, 0, 1, 0, 0; Dactyloa caquetae, 0.00578, 0, 1, 0, 0; Dactyloa carlostoddi, 0.00069, 0, 1, 0, 0; Dactyloa chloris, 0.00001, 0, 1, 0, 0; Dactyloa cuscoensis, 0.00179, 0, 1, 0, 0; Dactyloa danieli, 0.00012, 0, 1, 0, 0; Dactyloa deltae, 0.00011, 0, 1, 0, 0; Dactyloa dissimilis, 0.00001 , 0, 1, 0, 0; Dactyloa eulaema, 0.00002, 0, 1, 0, 0; Dactyloa euskalerriari, 0.00023, 0, 1, 0, 0; Dactyloa fasciata, 0.00002, 0, 1, 0, 0; Dactyloa festae, 0.00001, 0, 1, 0, 0; Dactyloa fitchi, 0.00004, 0, 1, 0, 0; Dactyloa fraseri, 0.00001, 0, 1, 0, 0; Dactyloa frenata, 0.00001 , 0, 1, 0, 0; Dactyloa gemmosa, 0.00005, 0, 1, 0, 0; Dactyloa gorgonae, 0.04227, 0, 1, 0, 0; Dactyloa heteroderma, 0.00001, 0, 1, 0, 0; Dactyloa huilae, 0.00004, 0, 1, 0, 0; Dactyloa inderenae, 0.00084, 0, 1, 0, 0; Dactyloa jacare, 0.00002, 0, 1, 0, 0; Dactyloa laevis, 0.00239, 0, 1, 0, 0; Dactyloa lamari, 0.00420, 0, 1, 0, 0; Dactyloa latifrons, 0.00001, 0, 1, 0, 0; Dactyloa limon, 0.00007, 0, 1, 0, 0; Dactyloa maculigula, 0.00007, 0, 1, 0, 0; Dactyloa megalopitheca, 0.00052, 0, 1, 0, 0; Dactyloa menta, 0.00087, 0, 1, 0, 0; Dactyloa mira, 0.00005, 0, 1, 0, 0; Dactyloa nasofrontalis, 0.00436, 0, 1, 0, 0; Dactyloa neblininus, 0.00163, 0, 1, 0, 0; Dactyloa nicefori, 0.00003, 0, 1, 0, 0; Dactyloa nigrolineata, 0.00028, 0, 1, 0, 0; Dactyloa orcesi, 0.00012, 0, 1, 0, 0; Dactyloa otongae, 0.00052 , 0, 1, 0, 0; Dactyloa paravertebralis, 0.00148, 0, 1, 0, 0; Dactyloa parilis, 0.00012, 0, 1, 0, 0; Dactyloa peraccae, $0.00001,0$, 1, 0, 0; Dactyloa peruensis, 0.00426, 0, 1, 0, 0; Dactyloa phyllorhina, 0.00000, 0, 1, 0, 0; Dactyloa podocarpus, 0.00016, 0, 1, 0, 0; Dactyloa poei, 0.00022, 0, 1, 0, 0; Dactyloa princeps, 0.00002, 0, 1, 0, 0; Dactyloa proboscis, 0.00045, 0, 1, 0, 0; Dactyloa propinqua, 0.00219, 0, 1, 0, 0; Dactyloa pseudotigrina, 0.00294, 0, 1, 0, 0; Dactyloa punctata, 0.00000, 0, 1, 0, 0; Dactyloa purpurescens, 0.00001, 0, 1, 0, 0; Dactyloa richardii, 0.00396, 0, 1, 0, 0; Dactyloa ruizii, 0.00006, 0, 1, 0, 0; Dactyloa santamartae, 0.00199, 0, 1, 0, 0; Dactyloa soinii, 0.00004, 0, 1, 0, 0; Dactyloa solitaria, 0.00061, 0, 1, 0, 0; Dactyloa squamulata, 0.00013, 0, 1, 0, 0; Dactyloa tetarii, 0.00111, 0, 1, 0, 0; Dactyloa tigrina, 0.00010, 0, 1, 0, 0; Dactyloa transversalis, 0.00000, 0, 1, 0, 0; Dactyloa trinitatis, 0.00144, 0, 1, 0, 0; Dactyloa umbrivaga, 0.00486, 0, 1, 0, 0; Dactyloa vanzolinii, 0.00133, 0, 1, 0, 0; Dactyloa vaupesiana, 0.00002, 0, 1, 0, 0; Dactyloa ventrimaculata, 0.00003, 0, 1, 0, 0; Dactyloa williamsmittermeierorum, 0.00046, 0, 1, 0, 0; DACTYLOIDAE, 0.00000, 0, 0, 0, 0; Dendrophidion, 0.00000, 0, 0, 0, 0; Dendrophidion atlantica, 0.00008, 1, 1, 0, 0; Dendrophidion bivittatus, 0.00001, 1, 1, 0, 0; Dendrophidion boshelli, 0.00012, 1, 1, 0, 0; Dendrophidion brunneum, 0.00002, 1, 1, 0, 0; Dendrophidion clarkii, 0.00000, 1, 1, 0, 0; Dendrophidion dendrophis, 0.00000, 1, 1, 0, 0; Dendrophidion graciliverpa, 0.00001, 1, 1, 0, 0; Dendrophidion nuchale, 0.00000 , 1, 1, 0, 0; Dendrophidion percarinatum, 0.00000, 1, 1, 0, 0; Dendrophidion prolixum, 0.00002, 1, 1, 0, 0; Diaphorolepis, 0.00001, 0, 0, 0, 0; Diaphorolepis wagneri, 0.00001, 1, 1, 0, 0; Dicrodon, 0.00001, 0, 0, 0, 0; Dicrodon guttulatum, 0.00001, 1, 0, 0, 0; Dicrodon heterolepis, 0.00002, 1, 0, 0, 0; Dicrodon holmbergi, 0.00014, 1, 0, 0, 0; DIPLOGLOSSIDAE, 0.00000, 0, 0, 0, 0; Diploglossus, 0.00000 , 0, 0, 0, 0; Diploglossus fasciatus, 0.00000, 1, 0, 0, 0; Diploglossus lessonae, 0.00000, 1, 0, 0, 0; Diploglossus monotropis, 0.00000, 1 , 0, 0, 0; Diplolaemus, 0.00000, 0, 0, 0, 0; Diplolaemus bibronii, 0.00000, 1, 1, 0, 0; Diplolaemus darwinii, 0.00000, 1, 1, 0, 0; Diplolaemus leopardinus, 0.00001, 1, 1, 0, 0; Diplolaemus sexcinctus, 0.00000, 1, 1, 0, 0; DIPSADIDAE, 0.00000, 0, 0, 0, 0; Dipsas, 0.00000, 0, 0, 0, 0; Dipsas albifrons, 0.00000, 0, 1, 0, 0; Dipsas alternans, 0.00000, 0, 1, 0, 0; Dipsas andiana, 0.00007, 0, 1, 0, 0; Dipsas baliomelas, 0.00037, 0, 1, 0, 0; Dipsas bucephala bucephala, 0.00000, 0, 1, 0, 0; Dipsas bucephala cisticeps, 0.00000, 0, 1, 0, 0; Dipsas catesbyi, 0.00000, 0, 1, 0, 0; Dipsas chaparensis, 0.00007, 0, 1, 0, 0; Dipsas copei, 0.00000, 0, 1, 0, 0; Dipsas elegans, 0.00003 , 0, 1, 0, 0; Dipsas ellipsifera, 0.00006, 0, 1, 0, 0; Dipsas gracilis, 0.00004, 0, 1, 0, 0; Dipsas incerta, 0.00001, 0, 1, 0, 0; Dipsas indica, 0.00000, 0, 1, 0, 0; Dipsas neivai, 0.00000, 0, 1, 0, 0; Dipsas oreas, 0.00004, 0, 1, 0, 0; Dipsas pakaraima, 0.00011, 0, 1, 0, 0; Dipsas pavonina, 0.00000, 0, 1, 0, 0; Dipsas peruana, 0.00000, 0, 1, 0, 0; Dipsas praeornata, 0.00009, 0, 1, 0, 0; Dipsas pratti, 0.00006, 0, 1, 0, 0; Dipsas sanctijoannis, 0.00002, 0, 1, 0, 0; Dipsas sazimai, 0.00001, 0, 1, 0, 0; Dipsas schunkii, 0.00001, 0, 1, 0, 0; Dipsas temporalis, 0.00001, 0, 1, 0, 0; Dipsas variegata, $0.00000,0,1,0,0$; Dipsas vermiculata, 0.00001, 0, 1, 0, 0; Dipsas viguieri, 0.00006, 0, 1, 0, 0; Ditaxodon, 0.00000, 0, 0, 0, 0; Ditaxodon taeniatus, 0.00000, 1, 0, 0, 0; Dracaena, 0.00000, 0, 0, 0, 0; Dracaena guianensis, 0.00000, 1, 0, 1, 0; Dracaena paraguayensis, 0.00000, 1, 0, 1, 0; Drepanoides, 0.00000, 0, 0, 0, 0; Drepanoides anomalus, $0.00000,1$, 0, 0, 0; Dryadosaura, 0.00002, 0, 0, 0, 0; Dryadosaura nordestina, 0.00002, 1, 0, 0, 0; Drymarchon, 0.00000, 0, 0, 0, 0; Drymarchon caudomaculatus, 0.00003, 1, 0, 0, 0; Drymarchon corais, 0.00000, 1, 0, 0, 0; Drymarchon margaritae, 0.00136, 1, 0, 0, 0; Drymarchon melanurus, 0.00000, 1, 0, 0, 0; Drymobius, 0.00000, 0, 0, 0, 0; Drymobius margaritiferus, 0.00000, 1, 1, 0, 0; 
Drymobius rhombifer, $0.00000,1,1,0$, 0; Drymoluber, $0.00000,0,0,0$, 0; Drymoluber apurimacensis, 0.00004, 1, 1, 0, 0; Drymoluber brazili, $0.00000,1,1,0,0$; Drymoluber dichrous, $0.00000,1,1,0$, 0; Echinanthera, 0.00000, 0, 0, 0, 0; Echinanthera amoena, 0.00000, 1, 0, 0, 0; Echinanthera cephalomaculata, 0.00009, 1, 0, 0, 0; Echinanthera cephalostriata, 0.00000, 1, 0, 0, 0; Echinanthera cyanopleura, 0.00000, 1, 0, 0, 0; Echinanthera melanostigma, 0.00001, 1, 0, 0, 0; Echinanthera undulata, 0.00000, 1, 0,0 , 0; Echinosaura, 0.00001, 0, 0, 0, 0; Echinosaura brachycephala, 0.00030, 1, 0, 0, 0; Echinosaura horrida, 0.00002, 1, 0, 0, 0; Echinosaura keyi, 0.00009, 1, 0, 0, 0; Echinosaura orcesi, 0.00006, 1, 0, 0, 0; Echinosaura palmeri, 0.00001, 1, 0, 0, 0; Echinosaura sulcarostrum, 0.00345, 1, 0, 0, 0; Ecpleopus, 0.00000, 0, 0, 0, 0; Ecpleopus gaudichaudii, 0.00000, 1, 0, 0, 0; ELAPIDAE, 0.00000, 0, 0, 0, 0; Elapomorphus, 0.00000, 0, 0, 0, 0; Elapomorphus quinquelineatus, 0.00000, 1, 0, 0, 1; Elapomorphus wuchereri, 0.00001, 1, 0, 0, 1; Emmochliophis, 0.00015, 0, 0, 0, 0; Emmochliophis fugleri, 0.00026, 1, 0, 0, 0; Emmochliophis miops, 0.00034, 1, 0, 0, 0; EMYDIDAE, 0.00000, 0, 0, 0, 0; Enuliophis, 0.00000, 0, 0, 0, 0; Enuliophis sclateri, 0.00000, 1, 0, 0, 0; Enyalioides, 0.00000, 0, 0, 0, 0; Enyalioides altotambo, 0.00075, 1, 1, 0, 0; Enyalioides anisolepis, 0.00028, 1, 1, 0, 0; Enyalioides azulae, 0.00097, 1, 1, 0, 0; Enyalioides binzayedi, 0.00077, 1, 1, 0, 0; Enyalioides cofanorum, 0.00000, 1, 1, 0, 0; Enyalioides heterolepis, 0.00001, 1, 1, 0, 0; Enyalioides laticeps, $0.00000,1,1,0,0$; Enyalioides microlepis, $0.00001,1,1,0,0$; Enyalioides oshaughnessyi, 0.00001, 1, 1, 0, 0; Enyalioides palpebralis, 0.00000, 1, 1, 0, 0; Enyalioides praestabilis, $0.00001,1,1,0$, 0; Enyalioides rubrigularis, 0.00015, 1, 1, 0, 0; Enyalioides rudolfarndti, 0.00131, 1, 1, 0, 0; Enyalioides sophiarothschildae, 0.00091, 1, 1, 0, 0; Enyalioides touzeti, 0.00021, 1, 1, 0, 0; Enyalius, 0.00000, 0, 0, 0, 0; Enyalius bibronii, 0.00000, 1, 1, 0, 0; Enyalius bilineatus, 0.00001, 1, 1, 0, 0; Enyalius boulengeri, $0.00004,1,1,0$, 0; Enyalius brasiliensis, 0.00004, 1, 1, 0, 0; Enyalius catenatus, 0.00001, 1, 1, 0, 0; Enyalius erythroceneus, 0.00061 , 1, 1, 0, 0; Enyalius iheringii, 0.00000, 1, 1, 0, 0; Enyalius leechii, 0.00000, 1, 1, 0, 0; Enyalius perditus, 0.00000, 1, 1, 0, 0; Enyalius pictus, 0.00001, 1, 1, 0, 0; Epicrates, 0.00000, 0, 0, 0, 0; Epicrates alvarezi, 0.00000, 1, 0, 0, 0; Epicrates assisi, 0.00000, 1, 0, 0, 0; Epicrates cenchria, $0.00000,1,0,0$, 0; Epicrates crassus, $0.00000,1,0,0,0$; Epicrates maurus, $0.00000,1,0,0,0 ;$ Epictia, 0.00000, 0 , 0, 0, 0; Epictia albipuncta, 0.00000, 0, 0, 0, 1; Epictia alfredschmidti, 0.00034, 0, 0, 0, 1; Epictia antoniogarciai, 0.00036, 0, 0, 0, 1; Epictia australis, $0.00000,0,0,0,1$; Epictia borapeliotes, 0.00000, 0, 0, 0, 1; Epictia clinorostris, 0.00009, 0, 0, 0, 1; Epictia collaris, 0.00002 , 0, 0, 0, 1; Epictia diaplocia, 0.00000, 0, 0, 0, 1; Epictia goudotii, 0.00005, 0, 0, 0, 1; Epictia melanurus, 0.01141, 0, 0, 0, 1; Epictia munoai, 0.00000, 0, 0, 0, 1; Epictia peruviana, 0.00014, 0, 0, 0, 1; Epictia rubrolineata, 0.00024, 0, 0, 0, 1; Epictia rufidorsa, $0.00006,0,0,0,1$; Epictia septemlineata, 0.00334, 0, 0, 0, 1; Epictia signata, 0.00001, 0, 0, 0, 1; Epictia striatula, 0.00001, 0, 0, 0, 1; Epictia subcrotilla, $0.00001,0,0,0,1$; Epictia teaguei, $0.00029,0,0,0,1$; Epictia tenella, $0.00000,0,0,0,1$; Epictia tesselata, 0.00025 , 0, 0, 0, 1; Epictia tricolor, 0.00005, 0, 0, 0, 1; Epictia undecimstriata, 0.00011, 0, 0, 0, 1; Epictia vanwallachi, 0.00099, 0, 0, 0,1 ; Epictia vellardi, $0.00000,0,0,0,1$; Epictia venegasi, $0.00131,0,0,0,1$; Epictia vonmayi, $0.00131,0,0,0,1 ;$ Erythrolamprus, $0.00000,0,0,0,0$; Erythrolamprus aesculapii, 0.00000, 1, 0, 0, 0; Erythrolamprus albertguentheri, 0.00000, 1, 0, 0, 0; Erythrolamprus almadensis, 0.00000, 1, 0, 0, 0; Erythrolamprus andinus, 0.00083, 1, 0, 0, 0; Erythrolamprus atraventer, 0.00008, 1, 0, 0, 0; Erythrolamprus bizona, 0.00000, 1, 0, 0, 0; Erythrolamprus breviceps, $0.00000,1,0,0$, 0; Erythrolamprus carajasensis, $0.00008,1,0,0$, 0; Erythrolamprus ceii, 0.00001, 1, 0, 0, 0; Erythrolamprus cobellus, 0.00001, 1, 0, 0, 0; Erythrolamprus dorsocorallinus, 0.00000, 1, 0, 0, 0; Erythrolamprus epinephelus albiventris, 0.00002, 1, 0, 0, 0; Erythrolamprus epinephelus bimaculatus, 0.00001, 1, 0, 0, 0; Erythrolamprus epinephelus epinephelus, 0.00000, 1, 0, 0, 0; Erythrolamprus epinephelus fraseri, $0.00001,1,0,0$, 0; Erythrolamprus epinephelus juvenalis, 0.00003, 1, 0, 0, 0; Erythrolamprus epinephelus kogiorum, 0.00006, 1, 0, 0, 0; Erythrolamprus epinephelus laemonae, 0.00001, 1, 0, 0, 0; Erythrolamprus epinephelus opisthotaenia, 0.00008, 1, 0, 0, 0; Erythrolamprus epinephelus pseudocobellus, 0.00002, 1, 0, 0, 0; Erythrolamprus festae, 0.00001, 1, 0, 0, 0; Erythrolamprus frenatus, $0.00000,1,0,0,0$; Erythrolamprus guentheri, $0.00000,1,0,0,0$; Erythrolamprus ingeri, $0.00082,1,0,0,0$; Erythrolamprus jaegeri, $0.00000,1,0,0$, 0; Erythrolamprus janaleeae, 0.00001, 1, 0, 0, 0; Erythrolamprus longiventris, 0.00000, 1, 0, 0, 0; Erythrolamprus maryellenae, 0.00000, 1, 0, 0, 0; Erythrolamprus melanotus, 0.00000, 1, 0, 0, 0; Erythrolamprus mertensi, 0.00043, 1, 0, 0, 0; Erythrolamprus miliaris amazonicus, $0.00000,1,0,1,0$; Erythrolamprus miliaris chrysostomus, $0.00000,1,0,1,0 ;$ Erythrolamprus miliaris merremi, $0.00000,1,0,1$, 0; Erythrolamprus miliaris miliaris, 0.00000, 1, 0, 1, 0; Erythrolamprus miliaris orinus, $0.00000,1$, 0, 1, 0; Erythrolamprus mimus, 0.00000, 1, 0, 0, 0; Erythrolamprus mossoroensis, 0.00000, 1, 0, 0, 0; Erythrolamprus oligolepis, 0.00000 , 1, 0, 0, 0; Erythrolamprus poecilogyrus, 0.00000, 1, 0, 0, 0; Erythrolamprus problematicus, 0.00065, 1, 0, 0, 0; Erythrolamprus pseudocorallus, 0.00001, 1, 0, 0, 0; Erythrolamprus pyburni, 0.00008, 1, 0, 0, 0; Erythrolamprus pygmaeus, 0.00000 , 1, 0, 0, 0; Erythrolamprus reginae, 0.00000, 1, 0, 0, 0; Erythrolamprus sagittifer, 0.00000, 1, 0, 0, 0; Erythrolamprus semiaureus, $0.00000,1,0,0$, 0; Erythrolamprus subocularis, 0.00017, 1, 0, 0, 0; Erythrolamprus taeniogaster, 0.00000, 1, 0, 0, 0; Erythrolamprus taeniurus, 0.00000, 1, 0, 0, 0; Erythrolamprus torrenicola, 0.00082, 1, 0, 0, 0; Erythrolamprus trebbaui, 0.00008, 1, 0, 0, 0; Erythrolamprus typhlus brachyurus, 0.00000, 1, 0, 0, 0; Erythrolamprus typhlus elaeoides, $0.00000,1,0,0,0$; Erythrolamprus typhlus typhlus, 0.00000, 1, 0, 0, 0; Erythrolamprus viridis, 0.00000, 1, 0, 0, 0; Erythrolamprus vitti, 0.00010, 1, 0, 0, 0; Erythrolamprus williamsi, 0.00004, 1, 0, 0, 0; Erythrolamprus zweifeli, 0.00006, 1, 0, 0, 0; Eunectes, 0.00000, 0, 0, 0, 0; Eunectes beniensis, 0.00000 , 1, 0, 1, 0; Eunectes deschauenseei, 0.00000, 1, 0, 0, 0; Eunectes murinus, 0.00000, 1, 0, 1, 0; Eunectes notaeus, 0.00000, 1, 0, 1, 0; Eurolophosaurus, 0.00003, 0, 0, 0, 0; Eurolophosaurus amathites, 0.00026, 1, 0, 0, 0; Eurolophosaurus divaricatus, 0.00009, 1, 0, 0, 0; Eurolophosaurus nanuzae, 0.00005, 1, 0, 0, 0; Euspondylus, 0.00000, 0, 0, 0, 0; Euspondylus acutirostris, 0.00016, 1, 0, 0, 0; Euspondylus auyanensis, 0.00149, 1, 0, 0, 0; Euspondylus caideni, 0.00013, 1, 0, 0, 0; Euspondylus guentheri, 0.00002, 1, 0, 0, 0; Euspondylus josyi, 0.00042, 1, 0, 0, 0; Euspondylus maculatus, $0.00001,1,0,0,0$; Euspondylus monsfumus, 0.00108, 1, 0, 0, 0; Euspondylus nellycarrillae, 0.00138, 1, 0, 0, 0; Euspondylus paxcorpus, 0.00369, 1, 0, 0, 0; Euspondylus simonsii, 0.00001, 1, 0, 0, 0; Eutrachelophis, 0.00000, 0, 0, 0, 0; Eutrachelophis bassleri, 0.00000, 1, 0, 0, 0; Eutrachelophis steinbachi, 0.00004, 1, 0, 0, 0; Garthia, 0.00003, 0, 0, 0, 0; Garthia gaudichaudii, 0.00003, 1, 0, 0, 0; Garthia penai, 0.00015, 1, 0, 0, 0; GEKKONIDAE, 0.00000, 0, 0, 0, 0; Gelanesaurus, 0.00001, 0, 0, 0, 0; Gelanesaurus cochranae, 0.00001, 1, 0, 1, 0; Gelanesaurus flavogularis, 0.00032, 1, 0, 1, 0; GEOEMYDIDAE, 0.00000, 0, 0, 0, 0; Geophis, 0.00000, 0, 0, 0, 0; Geophis betaniensis, 0.00064, 1, 0, 0, 0; Geophis nigroalbus, 0.00013 , 1, 0, 0, 0; Glaucomastix, 0.00003, 0, 0, 0, 0; Glaucomastix abaetensis, 0.00031, 1, 0, 0, 0; Glaucomastix cyanura, 0.00017, 1, 0, 0, 0; Glaucomastix littoralis, 0.00037, 1, 0, 0, 0; Glaucomastix venetacauda, 0.00004, 1, 0, 0, 0; Gomesophis, 0.00000, 0, 0, 0, 0; Gomesophis brasiliensis, 0.00000, 1, 0, 0, 0; Gonatodes, 0.00000, 0, 0, 0, 0; Gonatodes albogularis, 0.00000, 0, 1, 0, 0; Gonatodes alexandermendesi, $0.00001,0,1,0$, 0; Gonatodes annularis, 0.00000, 0, 1, 0, 0; Gonatodes astralis, 0.00013, 0, 1, 0, 0; Gonatodes 
atricucullaris, 0.00008, 0, 1, 0, 0; Gonatodes caudiscutatus, 0.00001, 0, 1, 0, 0; Gonatodes ceciliae, 0.00041, 0, 1, 0, 0; Gonatodes concinnatus, $0.00000,0,1,0$, 0; Gonatodes eladioi, 0.00000, 0, 1, 0, 0; Gonatodes falconensis, 0.00007, 0, 1, 0, 0; Gonatodes hasemani, $0.00000,0,1,0,0$; Gonatodes humeralis, 0.00000, 0, 1, 0, 0; Gonatodes infernalis, 0.00813, 0, 1, 0, 0; Gonatodes lichenosus, 0.00190, 0, 1, 0, 0; Gonatodes ligiae, 0.00016, 0, 1, 0, 0; Gonatodes nascimentoi, 0.00001, 0, 1, 0, 0; Gonatodes ocellatus, $0.00044,0,1,0$, 0; Gonatodes petersi, 0.00022, 0, 1, 0, 0; Gonatodes purpurogularis, 0.00287, 0, 1, 0, 0; Gonatodes riveroi, 0.00001, 0, 1, 0, 0; Gonatodes rozei, 0.00012, 0, 1, 0, 0; Gonatodes seigliei, 0.00198, 0, 1, 0, 0; Gonatodes taniae, 0.00045, 0, 1, 0, 0; Gonatodes tapajonicus, 0.00006, 0, 1, 0, 0; Gonatodes timidus, 0.00284, 0, 1, 0, 0; Gonatodes vittatus, 0.00001, 0, 1, 0, 0; Gymnodactylus, 0.00000, 0, 0, 0, 0; Gymnodactylus amarali, 0.00000, 1, 0, 0, 0; Gymnodactylus darwinii, 0.00000, 1, 1, 0, 0; Gymnodactylus geckoides, 0.00000, 1, 0, 0, 0; Gymnodactylus guttulatus, 0.00122, 1, 0, 0, 0; Gymnodactylus vanzolinii, 0.00220, 1, 0, 0, 0; GYMNOPHTHALMIDAE, 0.00000, 0, 0, 0, 0; Gymnophthalmus, 0.00000, 0, 0, 0, 0; Gymnophthalmus cryptus, 0.00265, 1, 0, 0, 0; Gymnophthalmus leucomystax, 0.00003, 1, 0, 0, 0; Gymnophthalmus lineatus, 0.00025, 1, 0, 0, 0; Gymnophthalmus speciosus, 0.00000 , 1, 0, 0, 0; Gymnophthalmus underwoodi, 0.00000, 1, 0, 0, 0; Gymnophthalmus vanzoi, 0.00001, 1, 0, 0, 0; Helicops, 0.00000, 0, 0, 0, 0; Helicops angulatus, 0.00000, 0, 0, 1, 0; Helicops apiaka, 0.00001, 0, 0, 1, 0; Helicops carinicaudus, 0.00000, 0, 0, 1, 0; Helicops danieli, 0.00001, 0, 0, 1, 0; Helicops gomesi, 0.00000, 0, 0, 1, 0; Helicops hagmanni, 0.00000, 0, 0, 1, 0; Helicops infrataeniatus, 0.00000, 0, 0, 1, 0; Helicops leopardinus, 0.00000, 0, 0, 1, 0; Helicops modestus, 0.00000, 0, 0, 1, 0; Helicops nentur, 0.00001, 0, 0, 1, 0; Helicops pastazae, 0.00000, 0, 0, 1, 0; Helicops petersi, 0.00005, 0, 0, 1, 0; Helicops polylepis, 0.00000, 0, 0, 1, 0; Helicops scalaris, 0.00003, 0, 0, 1, 0; Helicops tapajonicus, 0.00002, 0, 0, 1, 0; Helicops trivittatus, 0.00000, 0, 0, 1, 0; Helicops yacu, 0.00002 , 0, 0, 1, 0; Helminthophis, 0.00001, 0, 0, 0, 0; Helminthophis flavoterminatus, 0.00011, 0, 0, 0, 1; Helminthophis praeocularis, 0.00002, 0, 0, 0, 1; Hemidactylus, 0.00000, 0, 0, 0, 0; Hemidactylus agrius, 0.00000, 1, 0, 0, 0; Hemidactylus brasilianus, 0.00000, 1, 0, 0, 0; Hemidactylus palaichthus, 0.00000, 1, 0, 0, 0; Heterodactylus, 0.00000, 0, 0, 0, 0; Heterodactylus imbricatus, 0.00000, 1, 0, 0, 0; Heterodactylus lundii, 0.00007, 1, 0, 0, 0; Heterodactylus septentrionalis, 0.00324, 1, 0, 0, 0; Holcosus, 0.00000, 0, 0, 0, 0; Holcosus anomalus, 0.00004, 1, 0, 0, 0; Holcosus bridgesii, 0.00001, 1, 0, 0, 0; Holcosus festivus edwardsii, 0.00001, 1, 0, 0, 0; Holcosus festivus festivus, 0.00001, 1, 0, 0, 0; Holcosus festivus occidentalis, 0.00003, 1, 0, 0, 0; Holcosus leptophrys, 0.00002, 1, 0, 0, 0; Holcosus niceforoi, 0.00009, 1, 0, 0, 0; Holcosus septemlineatus, 0.00001, 1, 0, 0, 0; Homonota, 0.00000, 0, 0, 0, 0; Homonota andicola, 0.00001, 1, 0, 0, 0; Homonota borellii, 0.00000, 1, 0, 0, 0; Homonota darwinii, 0.00000 , 1, 0, 0, 0; Homonota fasciata, 0.00000, 1, 0, 0, 0; Homonota rupicola, 0.00076, 1, 0, 0, 0; Homonota taragui, 0.00030, 1, 0, 0, 0; Homonota underwoodi, 0.00000, 1, 0, 0, 0; Homonota uruguayensis, 0.00001, 1, 0, 0, 0; Homonota whitii, 0.00001, 1, 0, 0, 0; Homonota williamsii, 0.00006, 1, 0, 0, 0; HOPLOCERCIDAE, 0.00000, 0, 0, 0, 0; Hoplocercus, 0.00000, 0, 0, 0, 0; Hoplocercus spinosus, 0.00000, 1, 0, 0, 0; Hydrodynastes, 0.00000, 0, 0, 0, 0; Hydrodynastes bicinctus, 0.00000, 1, 0, 1, 0; Hydrodynastes gigas, $0.00000,1,0,1,0$; Hydrodynastes melanogigas, 0.00003, 1, 0, 1, 0; Hydromedusa, 0.00000, 0, 0, 0, 0; Hydromedusa maximiliani, $0.00000,1$, 0, 1, 0; Hydromedusa tectifera, 0.00000, 1, 0, 1, 0; Hydrops, 0.00000, 0, 0, 0, 0; Hydrops caesurus, 0.00000, 0, 0, 1, 0; Hydrops martii, $0.00000,0,0,1,0$; Hydrops triangularis, 0.00000, 0, 0, 1, 0; Iguana, 0.00000, 0, 0, 0, 0; Iguana iguana, 0.00000, 1, 1, 0, 0; IGUANIDAE, 0.00000, 0, 0, 0, 0; Imantodes, 0.00000, 0, 0, 0, 0; Imantodes cenchoa, 0.00000, 0, 1, 0, 0; Imantodes chocoensis, $0.00001,0,1,0$, 0; Imantodes gemmistratus, $0.00000,0,1,0$, 0; Imantodes guane, $0.00013,0,1$, 0, 0; Imantodes inornatus, $0.00000,0,1,0$, 0; Imantodes lentiferus, $0.00000,0,1,0,0 ;$ Iphisa, 0.00000, 0, 0, 0, 0; Iphisa elegans elegans, 0.00000, 1, 0, 0, 0; Iphisa elegans soinii, 0.00000, 1, 0, 0, 0; Kaieteurosaurus, 0.00965, 0, 0, 0, 0; Kaieteurosaurus hindsi, 0.00965, 1, 0, 0, 0; Kentropyx, $0.00000,0$, 0, 0, 0; Kentropyx altamazonica, 0.00000, 1, 0, 0, 0; Kentropyx borckiana, 0.00000, 1, 0, 0, 0; Kentropyx calcarata, 0.00000 , 1, 0, 0, 0; Kentropyx lagartija, 0.00001, 1, 0, 0, 0; Kentropyx paulensis, 0.00000, 1, 0, 0, 0; Kentropyx pelviceps, 0.00000, 1, 0, 0, 0; Kentropyx striata, 0.00000, 1, 0, 0, 0; Kentropyx vanzoi, 0.00000, 1, 0, 0, 0; Kentropyx viridistriga, 0.00000, 1, 0, 0, 0; KINOSTERNIDAE, 0.00000, 0, 0, 0, 0; Kinosternon, 0.00000, 0, 0, 0, 0; Kinosternon dunni, 0.00008, 1, 0, 1, 0; Kinosternon leucostomum leucostomum, 0.00000, 1, 0, 1, 0; Kinosternon leucostomum postinguinale, $0.00000,1,0,1,0$; Kinosternon scorpioides scorpioides, 0.00000, 1, 0, 1, 0; Kinosternon scorpioides serei, 0.00000, 1, 0, 1, 0; Lachesis, 0.00000, 0, 0, 0, 0; Lachesis acrochorda, $0.00000,1,0,0$, 0; Lachesis muta, 0.00000, 1, 0, 0, 0; Lampropeltis, 0.00000, 0, 0, 0, 0; Lampropeltis micropholis, 0.00000, 1, 0, 0, 0; LEIOSAURIDAE, $0.00000,0,0,0$, 0; Leiosaurus, 0.00000, 0, 0, 0, 0; Leiosaurus bellii, 0.00000, 1, 1, 0, 0; Leiosaurus catamarcensis, 0.00001 , 1, 1, 0, 0; Leiosaurus jaguaris, 0.00002, 1, 1, 0, 0; Leiosaurus paronae, 0.00000, 1, 1, 0, 0; Lepidoblepharis, 0.00000, 0, 0, 0, 0; Lepidoblepharis buchwaldi, 0.00001, 1, 0, 0, 0; Lepidoblepharis colombianus, $0.00002,1,0$, 0, 0; Lepidoblepharis conolepis, $0.00018,1,0,0$, 0; Lepidoblepharis duolepis, 0.00006, 1, 0, 0, 0; Lepidoblepharis festae, $0.00002,1,0,0$, 0; Lepidoblepharis grandis, 0.00010 , 1, 0, 0, 0; Lepidoblepharis heyerorum, 0.00000, 1, 0, 0, 0; Lepidoblepharis hoogmoedi, 0.00000, 1, 0, 0, 0; Lepidoblepharis intermedius, $0.00001,1,0,0$, 0; Lepidoblepharis microlepis, 0.00006, 1, 0, 0, 0; Lepidoblepharis miyatai, 0.00115, 1, 0, 0, 0; Lepidoblepharis montecanoensis, 0.00274, 1, 0, 0, 0; Lepidoblepharis nukak, 0.00217, 1, 0, 0, 0; Lepidoblepharis peraccae, 0.00003 , $1,0,0,0$; Lepidoblepharis ruthveni, $0.00008,1,0,0,0$; Lepidoblepharis sanctaemartae, $0.00001,1,0,0$, 0; Lepidoblepharis williamsi, 0.00010, 1, 0, 0, 0; Leposoma, 0.00001, 0, 0, 0, 0; Leposoma annectans, 0.00003, 1, 0, 0, 0; Leposoma baturitensis, 0.00017, 1, 0, 0, 0; Leposoma nanodactylus, 0.00089, 1, 0, 0, 0; Leposoma puk, 0.00022, 1, 0, 0, 0; Leposoma scincoides, 0.00001, 1, 0, 0, 0; Leposoma sinepollex, 0.00038, 1, 0, 0, 0; Leptodeira, 0.00000, 0, 0, 0, 0; Leptodeira annulata, 0.00000, 1, 1, 0, 0; Leptodeira bakeri, $0.00037,1,1,0$, 0; Leptodeira septentrionalis, 0.00000, 1, 1, 0, 0; Leptophis, 0.00000, 0, 0, 0, 0; Leptophis ahaetulla ahaetulla, $0.00000,1,1,0$, 0; Leptophis ahaetulla bocourti, 0.00002, 1, 1, 0, 0; Leptophis ahaetulla bolivianus, 0.00000, 1, 1, 0, 0; Leptophis ahaetulla chocoensis, $0.00003,1,1,0$, 0; Leptophis ahaetulla liocercus, 0.00000, 1, 1, 0, 0; Leptophis ahaetulla marginatus, 0.00000 , 1, 1, 0, 0; Leptophis ahaetulla nigromarginatus, $0.00000,1,1,0$, 0; Leptophis ahaetulla occidentalis, 0.00000, 1, 1, 0, 0; Leptophis ahaetulla prestans, $0.00000,1,1,0$, 0; Leptophis coeruleodorsus, $0.00000,1,1,0$, 0; Leptophis cupreus, 0.00000, 1, 1, 0, 0; Leptophis depressirostris, 0.00000, 1, 1, 0, 0; Leptophis haileyi, 0.00290, 1, 1, 0, 0; Leptophis riveti, 0.00001, 1, 1, 0, 0; Leptophis stimsoni, 0.00289, 1, 1, 0, 0; LEPTOTYPHLOPIDAE, 0.00000, 0, 0, 0, 0; Lioheterophis, 0.00033, 0, 0, 0, 0; Lioheterophis iheringi, 0.00033 , 1, 0, 0, 0; LIOLAEMIDAE, 0.00000, 0, 0, 0, 0; Liolaemus, 0.00000, 0, 0, 0, 0; Liolaemus abaucan, 0.00025, 1, 0, 0, 0; Liolaemus abdalai, $0.00015,1,0,0,0$; Liolaemus acostai, $0.00018,1,0,0$, 0; Liolaemus albiceps, 0.00025, 1, 0, 0, 0; Liolaemus alticolor, 0.00001, 1, 0, 0, 0; Liolaemus andinus, 0.00001, 1, 0, 0, 0; Liolaemus annectens, 0.00066, 1, 0, 0, 0; Liolaemus anomalus, $0.00002,1,0,0$, 0; Liolaemus antumalguen, $0.00062,1,0,0$, 0; Liolaemus aparicioi, $0.00041,1,0,0$, 0; Liolaemus arambarensis, 
$0.00047,1,0$, 0, 0; Liolaemus araucaniensis, 0.00003, 1, 0, 0, 0; Liolaemus archeforus, $0.00008,1,0,0,0$; Liolaemus atacamensis, $0.00003,1,0,0$, 0; Liolaemus audituvelatus, 0.00005, 1, 0, 0, 0; Liolaemus austromendocinus, 0.00001, 1, 0, 0, 0; Liolaemus avilae, 0.00025 , 1, 0, 0, 0; Liolaemus azarai, 0.00006, 1, 0, 0, 0; Liolaemus baguali, 0.00011, 1, 0, 0, 0; Liolaemus bellii, 0.00001, 1, 0, 0, 0; Liolaemus bibronii, 0.00000, 1, 0, 0, 0; Liolaemus bitaeniatus, 0.00001, 1, 0, 0, 0; Liolaemus boulengeri, 0.00000, 1, 0, 0, 0; Liolaemus buergeri, $0.00001,1,0,0$, 0; Liolaemus burmeisteri, $0.00044,1,0,0$, 0; Liolaemus calchaqui, 0.00018, 1, 0, 0, 0; Liolaemus camarones, 0.00065 , 1, 0, 0, 0; Liolaemus canqueli, 0.00004, 1, 0, 0, 0; Liolaemus caparensis, 0.00069, 1, 0, 0, 0; Liolaemus capillitas, 0.00005 , 1, 0, 0, 0; Liolaemus carlosgarini, 0.00103, 1, 0, 0, 0; Liolaemus casamiquelai, 0.00002, 1, 0, 0, 0; Liolaemus cazianae, $0.00012,1,0,0$, 0; Liolaemus chacabucoense, $0.00118,1,0,0$, 0; Liolaemus chacoensis, $0.00000,1,0,0$, 0; Liolaemus chaltin, $0.00004,1$, 0, 0, 0; Liolaemus chavin, 0.00016, 1, 0, 0, 0; Liolaemus chehuachekenk, 0.00002, 1, 0, 0, 0; Liolaemus chiliensis, 0.00001, 1, 0, 0, 0; Liolaemus chillanensis, 0.00004, 1, 0, 0, 0; Liolaemus chlorostictus, 0.00007, 1, 0, 0, 0; Liolaemus choique, 0.00087, 1, 0, 0, 0 ; Liolaemus chungara, $0.00021,1,0,0$, 0; Liolaemus cinereus, $0.00055,1,0,0$, 0; Liolaemus coeruleus, 0.00006, 1, 0, 0, 0; Liolaemus confusus, $0.00269,1,0,0,0$; Liolaemus constanzae, 0.00002, 1, 0, 0, 0; Liolaemus crandalli, 0.00040, 1, 0, 0, 0; Liolaemus cranwelli, 0.00067, 1, 0, 0, 0; Liolaemus crepuscularis, 0.00042, 1, 0, 0, 0; Liolaemus cristiani, 0.00005, 1, 0, 0, 0; Liolaemus curicensis, 0.00009, 1, 0, 0, 0; Liolaemus curis, 0.00085, 1, 0, 0, 0; Liolaemus cuyanus, 0.00001, 1, 0, 0, 0; Liolaemus cuyumhue, 0.00078 , 1, 0, 0, 0; Liolaemus cyaneinotatus, 0.00028, 1, 0, 0, 0; Liolaemus cyanogaster, 0.00001, 1, 0, 0, 0; Liolaemus darwinii, 0.00000, 1, 0, 0, 0; Liolaemus diaguita, 0.00356, 1, 0, 0, 0; Liolaemus dicktracyi, 0.00019, 1, 0, 0, 0; Liolaemus disjunctus, 0.00442, 1, 0, 0, 0; Liolaemus ditadai, 0.00002, 1, 0, 0, 0; Liolaemus donosobarrosi, $0.00003,1,0,0,0$; Liolaemus dorbignyi, 0.00001, 1, 0, 0, 0; Liolaemus duellmani, 0.00103, 1, 0, 0, 0; Liolaemus dumerili, 0.00120, 1, 0, 0, 0; Liolaemus eleodori, 0.00004, 1, 0, 0, 0; Liolaemus elongatus, $0.00000,1,0,0$, 0; Liolaemus erguetae, $0.00044,1,0,0$, 0; Liolaemus erroneus, 0.00256, 1, 0, 0, 0; Liolaemus escarchadosi, $0.00001,1,0,0$, 0; Liolaemus espinozai, 0.00006, 1, 0, 0, 0; Liolaemus etheridgei, 0.00050, 1, 0, 0, 0; Liolaemus exploratorum, $0.00115,1$, 0, 0, 0; Liolaemus fabiani, 0.00012, 1, 0, 0, 0; Liolaemus famatinae, 0.00010, 1, 0, 0, 0; Liolaemus filiorum, 0.00115 , 1, 0, 0, 0; Liolaemus fittkaui, 0.00121, 1, 0, 0, 0; Liolaemus fitzgeraldi, 0.00004, 1, 0, 0, 0; Liolaemus fitzingerii, 0.00000, 1, 0, 0, 0; Liolaemus flavipiceus, 0.00086, 1, 0, 0, 0; Liolaemus forsteri, 0.00270, 1, 0, 0, 0; Liolaemus foxi, 0.00034, 1, 0, 0, 0; Liolaemus frassinettii, 0.00122, 1, 0, 0, 0; Liolaemus fuscus, 0.00002, 1, 0, 0, 0; Liolaemus gallardoi, 0.00003, 1, 0, 0, 0; Liolaemus goetschi, 0.00003 , 1, 0, 0, 0; Liolaemus gracielae, 0.00014, 1, 0, 0, 0; Liolaemus gracilis, 0.00000, 1, 0, 0, 0; Liolaemus gravenhorstii, 0.00001, 1, 0, 0, 0; Liolaemus griseus, 0.00026, 1, 0, 0, 0; Liolaemus grosseorum, 0.00001, 1, 0, 0, 0; Liolaemus gununakuna, 0.00003, 1, 0, 0, 0; Liolaemus hajeki, 0.00007, 1, 0, 0, 0; Liolaemus halonastes, 0.00068, 1, 0, 0, 0; Liolaemus hatcheri, 0.00002, 1, 0, 0, 0; Liolaemus heliodermis, 0.00036, 1, 0, 0, 0; Liolaemus hellmichi, 0.00109, 1, 0, 0, 0; Liolaemus hermannunezi, 0.00159, 1, 0, 0, 0; Liolaemus huacahuasicus, 0.00004, 1, 0, 0, 0; Liolaemus huayra, 0.00047, 1, 0, 0, 0; Liolaemus inacayali, 0.00001, 1, 0, 0, 0; Liolaemus incaicus, 0.00009, 1, 0, 0, 0; Liolaemus insolitus, 0.00022, 1, 0, 0, 0; Liolaemus irregularis, 0.00007, 1, 0, 0, 0; Liolaemus isabelae, 0.00018, 1, 0, 0, 0; Liolaemus jamesi, 0.00002, 1, 0, 0, 0; Liolaemus josei, 0.00002, 1, 0, 0, 0; Liolaemus juanortizi, 0.00022, 1, 0, 0, 0; Liolaemus kingii, 0.00000, 1, 0, 0, 0; Liolaemus kolengh, 0.00003, 1, 0, 0, 0; Liolaemus koslowskyi, 0.00002, 1, 0, 0, 0; Liolaemus kriegi, 0.00001, 1, 0, 0, 0; Liolaemus kuhlmanni, 0.00003, 1, 0, 0, 0; Liolaemus laurenti, 0.00006, 1, 0, 0, 0; Liolaemus lavillai, 0.00010, 1, 0, 0, 0; Liolaemus lemniscatus, $0.00001,1,0,0,0$; Liolaemus lentus, 0.00002, 1, 0, 0, 0; Liolaemus leopardinus, 0.00016, 1, 0, 0, 0; Liolaemus lineomaculatus, 0.00000, 1, 0, 0, 0; Liolaemus loboi, 0.00004, 1, 0, 0, 0; Liolaemus lonquimayensis, 0.00059, 1, 0, 0, 0; Liolaemus lopezi, 0.00146, 1, 0, 0, 0; Liolaemus lorenzmuelleri, 0.00104, 1, 0, 0, 0; Liolaemus lutzae, 0.00043, 1, 0, 0, 0; Liolaemus magellanicus, 0.00002, 1, 0, 0, 0; Liolaemus maldonadae, 0.00056, 1, 0, 0, 0; Liolaemus manueli, 0.00012, 1, 0, 0, 0; Liolaemus mapuche, $0.00009,1,0$, 0, 0; Liolaemus martorii, 0.00002, 1, 0, 0, 0; Liolaemus melaniceps, 0.00119, 1, 0, 0, 0; Liolaemus melanogaster, 0.00008, 1, 0, 0, 0; Liolaemus melanopleurus, 0.00094, 1, 0, 0, 0; Liolaemus melanops, 0.00000, 1, 0, 0, 0; Liolaemus millcayac, 0.00004, 1, 0, 0, 0; Liolaemus molinai, 0.00009, 1, 0, 0, 0; Liolaemus montanezi, 0.00069, 1, 0, 0, 0; Liolaemus montanus, 0.00018 , 1, 0, 0, 0; Liolaemus monticola, 0.00001, 1, 0, 0, 0; Liolaemus moradoensis, 0.00056, 1, 0, 0, 0; Liolaemus morandae, $0.00003,1,0,0$, 0; Liolaemus morenoi, 0.00007, 1, 0, 0, 0; Liolaemus multicolor, 0.00002, 1, 0, 0, 0; Liolaemus multiformis, 0.00000, 1, 0, 0, 0; Liolaemus multimaculatus, 0.00001, 1, 0, 0, 0; Liolaemus neuquensis, $0.00005,1,0,0$, 0; Liolaemus nigriceps, $0.00001,1$, 0, 0, 0; Liolaemus nigromaculatus, 0.00001, 1, 0, 0, 0; Liolaemus nigroviridis, 0.00002, 1, 0, 0, 0; Liolaemus nitidus, 0.00001, 1, 0, 0 , 0; Liolaemus occipitalis, 0.00006, 1, 0, 0, 0; Liolaemus olongasta, 0.00002, 1, 0, 0, 0; Liolaemus omorfi, 0.00005, 1, 0, 0, 0; Liolaemus orientalis, $0.00000,1$, 0, 0, 0; Liolaemus orko, 0.00021, 1, 0, 0, 0; Liolaemus ornatus, $0.00000,1,0,0$, 0; Liolaemus ortizi, 0.00003, 1, 0, 0, 0; Liolaemus pacha, 0.00053, 1, 0, 0, 0; Liolaemus pachacutec, 0.00004, 1, 0, 0, 0; Liolaemus pachecoi, 0.00005, 1, 0, 0, 0; Liolaemus pagaburoi, 0.00002, 1, 0, 0, 0; Liolaemus pantherinus, $0.00001,1,0,0$, 0; Liolaemus parthenos, 0.00076, 1, 0, 0, 0; Liolaemus parvus, $0.00001,1,0,0$, 0; Liolaemus patriciaiturrae, $0.00005,1,0,0,0$; Liolaemus paulinae, 0.00007, 1, 0, 0, 0; Liolaemus petrophilus, $0.00000,1,0,0$, 0; Liolaemus pictus, 0.00000, 1, 0, 0, 0; Liolaemus pipanaco, 0.00006, 1, 0, 0, 0; Liolaemus platei, 0.00003, 1, 0, 0, 0; Liolaemus pleopholis, 0.00015, 1, 0, 0, 0; Liolaemus poconchilensis, 0.00006, 1, 0, 0, 0; Liolaemus poecilochromus, $0.00001,1,0,0$, 0; Liolaemus polystictus, $0.00014,1,0,0$, 0; Liolaemus porosus, 0.00016, 1, 0, 0, 0; Liolaemus pseudoanomalus, $0.00001,1,0,0$, 0; Liolaemus pseudolemniscatus, $0.00008,1,0,0$, 0; Liolaemus puelche, 0.00013, 1, 0, 0, 0; Liolaemus pulcherrimus, $0.00021,1,0,0,0$; Liolaemus puna, $0.00000,1,0,0$, 0; Liolaemus punmahuida, 0.00020, 1, 0, 0, 0; Liolaemus puritamensis, 0.00002, 1, 0, 0, 0; Liolaemus purul, $0.00004,1,0,0$, 0; Liolaemus pyriphlogos, 0.00018, 1, 0, 0, 0; Liolaemus quilmes, 0.00001, 1, 0, 0, 0; Liolaemus rabinoi, 0.00030, 1, 0, 0, 0; Liolaemus ramirezae, 0.00003, 1, 0, 0, 0; Liolaemus ramonensis, $0.00015,1,0,0$, 0; Liolaemus riodamas, $0.00035,1,0,0$, 0; Liolaemus riojanus, $0.00003,1,0$, 0, 0; Liolaemus robertmertensi, $0.00001,1,0,0$, 0; Liolaemus robertoi, $0.00006,1,0,0$, 0; Liolaemus robustus, 0.00022, 1, 0, 0, 0; Liolaemus rosenmanni, 0.00003, 1, 0, 0, 0; Liolaemus rothi, 0.00001, 1, 0, 0, 0; Liolaemus ruibali, $0.00001,1,0,0$, 0; Liolaemus sagei, 0.00002 , 1, 0, 0, 0; Liolaemus salinicola, 0.00002, 1, 0, 0, 0; Liolaemus sanjuanensis, 0.00022, 1, 0, 0, 0; Liolaemus sarmientoi, 0.00001, 1, 0, 0, 0; Liolaemus saxatilis, 0.00002, 1, 0, 0, 0; Liolaemus scapularis, 0.00002, 1, 0, 0, 0; Liolaemus schmidti, 0.00001, 1, 0, 0, 0; Liolaemus schroederi, 0.00001, 1, 0, 0, 0; Liolaemus scolaroi, 0.00002, 1, 0, 0, 0; Liolaemus scorialis, 0.00005, 1, 0, 0, 0; Liolaemus scrocchii, 0.00002 , 1, 0, 0, 0; Liolaemus senguer, $0.00003,1,0,0$, 0; Liolaemus septentrionalis, $0.00024,1,0$, 0, 0; Liolaemus shehuen, $0.00014,1$, 0, 0, 0; Liolaemus shitan, 0.00010, 1, 0, 0, 0; Liolaemus signifer, 0.00000, 1, 0, 0, 0; Liolaemus silvai, 0.00018, 1, 0, 0, 0; Liolaemus silvanae, $0.00014,1,0,0$, 0; Liolaemus sitesi, $0.00020,1,0,0$, 0; Liolaemus smaug, 0.00007, 1, 0, 0, 0; Liolaemus 
somuncurae, $0.00003,1,0,0,0$; Liolaemus $s p$ b, 0.00005, 1, 0, 0, 0; Liolaemus $s p c, 0.00014,1,0,0,0$; Liolaemus $s p d, 0.00010,1,0$, 0 , 0; Liolaemus stolzmanni, 0.00001, 1, 0, 0, 0; Liolaemus tacnae, 0.00003, 1, 0, 0, 0; Liolaemus talampaya, 0.00017, 1, 0, 0, 0; Liolaemus tandiliensis, $0.00007,1,0,0,0$; Liolaemus tari, 0.00009, 1, 0, 0, 0; Liolaemus tehuelche, 0.00005, 1, 0, 0, 0; Liolaemus telsen, 0.00003, 1, 0, 0, 0; Liolaemus tenuis, 0.00001, 1, 0, 0, 0; Liolaemus thermarum, 0.00028, 1, 0, 0, 0; Liolaemus thomasi, 0.00029 , 1, 0, 0, 0; Liolaemus torresi, 0.00038, 1, 0, 0, 0; Liolaemus tregenzai, 0.00008, 1, 0, 0, 0; Liolaemus tristis, 0.00006, 1, 0, 0, 0; Liolaemus tromen, 0.00016, 1, 0, 0, 0; Liolaemus tulkas, 0.00016, 1, 0, 0, 0; Liolaemus ubaghsi, 0.00029, 1, 0, 0, 0; Liolaemus umbrifer, 0.00003, 1, 0, 0, 0; Liolaemus uniformis, 0.00127, 1, 0, 0, 0; Liolaemus uptoni, 0.00009, 1, 0, 0, 0; Liolaemus uspallatensis, $0.00005,1,0,0$, 0; Liolaemus valdesianus, $0.00012,1,0,0$, 0; Liolaemus vallecurensis, $0.00012,1,0$, 0, 0; Liolaemus variegatus, 0.00001 , 1, 0, 0, 0; Liolaemus velosoi, 0.00010, 1, 0, 0, 0; Liolaemus vulcanus, 0.00004, 1, 0, 0, 0; Liolaemus walkeri, 0.00001, 1, 0, 0 , 0 ; Liolaemus wari, 0.00005, 1, 0, 0, 0; Liolaemus wiegmannii, 0.00000, 1, 0, 0, 0; Liolaemus williamsi, 0.00028, 1, 0, 0, 0; Liolaemus xanthoviridis, $0.00002,1$, 0, 0, 0; Liolaemus yalguaraz, 0.00004, 1, 0, 0, 0; Liolaemus yanalcu, 0.00032, 1, 0, 0, 0; Liolaemus yatel, $0.00043,1,0,0$, 0; Liolaemus zabalai, 0.00006, 1, 0, 0, 0; Liolaemus zapallarensis, 0.00005, 1, 0, 0, 0; Liolaemus zullyae, 0.00004, 1 , 0, 0, 0; Liotyphlops, $0.00000,0,0,0$, 0; Liotyphlops albirostris, 0.00000, 0, 0, 0, 1; Liotyphlops anops, 0.00087, 0, 0, 0, 1; Liotyphlops argaleus, 0.00005, 0, 0, 0, 1; Liotyphlops beui, 0.00000, 0, 0, 0, 1; Liotyphlops caissara, 0.00301, 0, 0, 0, 1; Liotyphlops haadi, 0.00013 , 0, 0, 0, 1; Liotyphlops schubarti, 0.00002, 0, 0, 0, 1; Liotyphlops ternetzi, 0.00000, 0, 0, 0, 1; Liotyphlops trefauti, 0.00015, 0, 0, 0, 1; Liotyphlops wilderi, 0.00001, 0, 0, 0, 1; Loxopholis, 0.00000, 0, 0, 0, 0; Loxopholis caparensis, 0.00036, 1, 0, 0, 0; Loxopholis ferreirai, 0.00086, 1, 0, 0, 0; Loxopholis guianense, 0.00000, 1, 0, 0, 0; Loxopholis hexalepis, 0.00018, 1, 0, 0, 0; Loxopholis ioanna, 0.00195 , 1, 0, 0, 0; Loxopholis osvaldoi, 0.00000, 1, 0, 0, 0; Loxopholis parietale, 0.00000, 1, 0, 0, 0; Loxopholis percarinatum, 0.00000 , 1, 0, 0, 0; Loxopholis rugiceps, 0.00000, 1, 0, 0, 0; Loxopholis snethlageae, 0.00000, 1, 0, 0, 0; Loxopholis southi, 0.00001, 1, 0,0 , 0; Lygodactylus, 0.00000, 0, 0, 0, 0; Lygodactylus klugei, 0.00000, 0, 1, 0, 0; Lygodactylus wetzeli, 0.00000, 0, 1, 0, 0; Lygophis, $0.00000,0,0$, 0, 0; Lygophis anomalus, 0.00000, 1, 0, 0, 0; Lygophis dilepis, 0.00000, 1, 0, 0, 0; Lygophis elegantissimus, 0.00007, 1, 0, 0, 0; Lygophis flavifrenatus, 0.00000, 1, 0, 0, 0; Lygophis lineatus, 0.00000, 1, 0, 0, 0; Lygophis meridionalis, 0.00000, 1, 0, 0, 0; Lygophis paucidens, $0.00000,1$, 0, 0, 0; Lygophis vanzolinii, 0.00004, 1, 0, 0, 0; Mabuya, 0.00000, 0, 0, 0, 0; Mabuya agilis, 0.00001 , 1, 0, 0, 0; Mabuya agmosticha, 0.00000, 1, 0, 0, 0; Mabuya altamazonica, 0.00000, 1, 0, 0, 0; Mabuya arajara, 0.00010, 1, 0, 0, 0; Mabuya aurae, 0.00005, 1, 0, 0, 0; Mabuya aurulae, 0.00342, 1, 0, 0, 0; Mabuya bistriata, 0.00000, 1, 0, 0, 0; Mabuya caissara, 0.00071 , 1, 0, 0, 0; Mabuya carvalhoi, 0.00001, 1, 0, 0, 0; Mabuya cochabambae, 0.00007, 1, 0, 0, 0; Mabuya croizati, 0.00006, 1, 0, 0, 0; Mabuya dorsivittata, 0.00000, 1, 0, 0, 0; Mabuya falconensis, 0.00002, 1, 0, 0, 0; Mabuya frenata, 0.00000, 1, 0, 0, 0; Mabuya guaporicola, 0.00000, 1, 0, 0, 0; Mabuya heathi, 0.00000, 1, 0, 0, 0; Mabuya macrorhyncha, 0.00001, 1, 0, 0, 0; Mabuya margaritae, 0.00097, 1, 0, 0, 0; Mabuya meridensis, 0.00006, 1, 0, 0, 0; Mabuya nebulosylvestris, 0.00005, 1, 0, 0, 0; Mabuya nigropalmata, 0.00000 , 1, 0, 0, 0; Mabuya nigropunctata, 0.00000, 1, 0, 0, 0; Mabuya sp I, 0.00003, 1, 0, 0, 0; Mabuya sp II, 0.00051, 1, 0, 0, 0; Mabuya sp III, 0.00029, 1, 0, 0, 0; Mabuya sp IV, 0.00000, 1, 0, 0, 0; Mabuya spilonota, 0.00387, 1, 0, 0, 0; Mabuya unimarginata, 0.00000, 1, 0, 0, 0; Mabuya zuliae, 0.00002, 1, 0, 0, 0; Macropholidus, 0.00004, 0, 0, 0, 0; Macropholidus annectens, 0.00013, 1, 0, 0, 0; Macropholidus ataktolepis, 0.00309, 1, 0, 0, 0; Macropholidus huancabambae, 0.00061, 1, 0, 0, 0; Macropholidus ruthveni, 0.00007, 1, 0, 0, 0; Marinusaurus, 0.00159, 0, 0, 0, 0; Marinusaurus curupira, 0.00159, 1, 0, 0, 0; Mastigodryas, 0.00000, 0, 0, 0, 0; Mastigodryas amarali, 0.00000, 1, 0, 0, 0; Mastigodryas bifossatus, 0.00000, 1, 0, 0, 0; Mastigodryas boddaerti, 0.00000, 1, 0, 0, 0; Mastigodryas danieli, 0.00003, 1, 1, 0, 0; Mastigodryas dunni, 0.00410, 1, 0, 0, 0; Mastigodryas heathii, 0.00001, 1, 1, 0, 0; Mastigodryas moratoi, 0.00000, 1, 1, 0, 0; Mastigodryas pleei, 0.00000, 1, 0, 0, 0; Mastigodryas pulchriceps, 0.00002, 1, 1, 0, 0; Mastigodryas reticulatus, 0.00006, 1, 1, 0, 0; Mastigodryas ruthiveni, 0.00001, 1, 0, 0, 0; Mastigodryas sp, 0.00001, 1, 1, 0, 0; Mastigodryas sp1, 0.00000, 1, 1, 0, 0; Medopheos, 0.00001, 0, 0, 0, 0; Medopheos edracanthus, 0.00001, 1, 0, 0, 0; Melanosuchus, 0.00000, 0, 0, 0, 0; Melanosuchus niger, 0.00000, 1, 0, 1, 0; Mesobaena, 0.00001, 0, 0, 0, 0; Mesobaena huebneri, 0.00001, 0, 0, 0, 1; Mesobaena rhachicephala, 0.00006, 0, 0, 0, 1; Mesoclemmys, 0.00000, 0, 0, 0, 0; Mesoclemmys dahli, 0.00057, 1, 0, 1, 0; Mesoclemmys gibba, 0.00000, 1, 0, 1, 0; "Mesoclemmys heliostemma; Mesoclemmys heliostemma", 0.00000, 1, 0, 1, 0; Mesoclemmys hogei, 0.00003, 1, 0, 1, 0; Mesoclemmys nasuta, 0.00001, 1, 0, 1, 0; "Mesoclemmys perplexa; Mesoclemmys heliostemma", 0.00012, 1, 0, 1, 0; Mesoclemmys raniceps, 0.00000, 1, 0, 1, 0; Mesoclemmys tuberculata, 0.00000, 1, 0, 1, 0; Mesoclemmys vanderhaegei, 0.00000, 1, 0, 1, 0; Mesoclemmys zuliae, 0.00009, 1, 0, 1, 0; Micrablepharus, 0.00000, 0, 0, 0, 0; Micrablepharus atticolus, 0.00000, 1, 0, 0, 0; Micrablepharus maximiliani, 0.00000, 1, 0, 0, 0; Microlophus, 0.00000, 0, 0, 0, 0; Microlophus atacamensis, 0.00005, 1, 0, 0, 0; Microlophus habelii, 0.00004, 1, 0, 0, 0; Microlophus heterolepis, 0.00015, 1, 0, 0, 0; Microlophus koepckeorum, 0.00002, 1, 0, 0, 0; Microlophus occipitalis, 0.00001, 1, 0, 0, 0; Microlophus peruvianus, 0.00000, 1, 0, 0, 0; Microlophus quadrivittatus, 0.00003, 1, 0, 0, 0; Microlophus tarapacensis, 0.00002, 1, 0, 0, 0; Microlophus theresiae, 0.00015, 1, 0, 0, 0; Microlophus theresioides, 0.00002, 1, 0, 0, 0; Microlophus thoracicus icae, 0.00006, 1, 0, 0, 0; Microlophus thoracicus talarae, 0.00027, 1, 0, 0, 0; Microlophus thoracicus thoracicus, 0.00003, 1, 0, 0, 0; Microlophus tigris, 0.00001, 1, 0, 0, 0; Microlophus yanezi, 0.00166, 1, 0, 0, 0; Micrurus, 0.00000, 0, 0, 0, 0; Micrurus albicinctus, 0.00000, 1, 0, 0, 0; Micrurus altirostris, $0.00000,1,0,0,0$; Micrurus ancoralis ancoralis, 0.00004, 1, 0, 0, 0; Micrurus ancoralis jani, 0.00001, 1, 0, 0, 0; Micrurus annellatus, $0.00000,1$, 0, 0, 0; Micrurus averyi, 0.00000, 1, 0, 0, 0; Micrurus baliocoryphus, 0.00000, 1, 0, 0, 0; Micrurus bocourti, 0.00001, 1, 0, 0, 0; Micrurus brasiliensis, 0.00000, 1, 0, 0, 0; Micrurus camilae, 0.00031, 1, 0, 0, 0; Micrurus catamayensis, 0.00006, 1, 0, 0, 0; Micrurus circinalis, 0.00004, 1, 0, 0, 0; Micrurus clarki, 0.00002, 1, 0, 0, 0; Micrurus collaris breviventris, 0.00001, 1, 0, 0, 0; Micrurus collaris collaris, 0.00000, 1, 0, 0, 0; Micrurus coralinus, 0.00000, 1, 0, 0, 0; Micrurus decoratus, 0.00000, 1, 0, 0, 0; Micrurus diana, 0.00000, 1, 0, 0, 0; Micrurus dissoleucus dissoleucus, 0.00000, 1, 0, 0, 0; Micrurus dissoleucus dunni, 0.00005, 1, 0, 0, 0; Micrurus dissoleucus melanogenys, 0.00009, 1, 0, 0, 0; Micrurus dissoleucus nigrirostris, 0.00002, 1, 0, 0, 0; Micrurus dumerilii antioquiensis, 0.00002 , 1, 0, 0, 0; Micrurus dumerilii carinicauda, 0.00003, 1, 0, 0, 0; Micrurus dumerilii colombianus, 0.00005, 1, 0, 0, 0; Micrurus dumerilii dumerilii, $0.00008,1$, 0, 0, 0; Micrurus dumerilii transandinus, 0.00001, 1, 0, 0, 0; Micrurus dumerilii venezuelensis, 0.00002 , 1, 0, 0, 0; Micrurus filiformis, 0.00000, 1, 0, 0, 0; Micrurus frontalis, 0.00000, 1, 0, 0, 0; Micrurus hemprichii hemprichii, $0.00000,1,0,0,0$; Micrurus hemprichii ortoni, 0.00000, 1, 0, 0, 0; Micrurus ibiboboca, 0.00000, 1, 0, 0, 0; Micrurus isozonus, $0.00000,1,0,0$, 0; Micrurus langsdorffi, 0.00000, 1, 0, 0, 0; Micrurus lemniscatus carvalhoi, 0.00000, 1, 0, 0, 0; Micrurus lemniscatus diutius, 0.00000, 1, 0, 0, 0; Micrurus lemniscatus helleri, 0.00000, 1, 0, 0, 0; Micrurus lemniscatus lemniscatus, 0.00000, 1, 0, 0, 0; 
Micrurus margaritiferus, 0.00013, 1, 0, 0, 0; Micrurus medemi, 0.00001, 1, 0, 0, 0; Micrurus meridensis, 0.00018, 1, 0, 0, 0; Micrurus mertensi, 0.00001, 1, 0, 0, 0; Micrurus mipartitus anomalus, 0.00001, 1, 0, 0, 0; Micrurus mipartitus decussatus, 0.00001, 1, 0, 0, 0; Micrurus mipartitus mipartitus, 0.00001, 1, 0, 0, 0; Micrurus mipartitus popayanensis, $0.00021,1,0,0$, 0; Micrurus mipartitus rozei, 0.00002 , 1, 0, 0, 0; Micrurus multifasciatus, 0.00003, 1, 0, 0, 0; Micrurus multiscutatus, 0.00011, 1, 0, 0, 0; Micrurus narduccii melanotus, $0.00000,1$, 0, 0, 0; Micrurus narduccii narduccii, 0.00009, 1, 0, 0, 0; Micrurus nattereri, 0.00000, 1, 0, 0, 0; Micrurus nigrocinctus, $0.00000,1,0,0$, 0; Micrurus obscurus, $0.00000,1,0,0,0 ;$ Micrurus oligoanellatus, 0.00018, 1, 0, 0, 0; Micrurus ornatissimus, $0.00001,1,0,0$, 0; Micrurus pacaraimae, 0.00016, 1, 0, 0, 0; Micrurus paraensis, 0.00000, 1, 0, 0, 0; Micrurus peruvianus, $0.00009,1,0,0,0$; Micrurus petersi, 0.00017, 1, 0, 0, 0; Micrurus potyguara, 0.00011, 1, 0, 0, 0; Micrurus psyches, $0.00000,1,0,0$, 0; Micrurus putumayensis, 0.00000, 1, 0, 0, 0; Micrurus pyrrhocryptus, 0.00000, 1, 0, 0, 0; Micrurus remotus, $0.00000,1,0$, 0, 0; Micrurus renjifoi, 0.00010, 1, 0, 0, 0; Micrurus sangilensis, 0.00005, 1, 0, 0, 0; Micrurus santamartensis, 0.00028, 1, 0, 0, 0; Micrurus scutiventris, 0.00000, 1, 0, 0, 0; Micrurus serranus, 0.00004, 1, 0, 0, 0; Micrurus silviae, 0.00000, 1, 0, 0, 0; Micrurus spixii martiusi, $0.00000,1$, 0, 0, 0; Micrurus spixii spixii, 0.00000, 1, 0, 0, 0; Micrurus spurrelli, 0.00011, 1, 0, 0, 0; Micrurus steindachneri, 0.00001, 1, 0, 0, 0; Micrurus surinamensis, 0.00000, 1, 0, 0, 0; Micrurus tikuna, 0.00003, 1, 0, 0, 0; Micrurus tschudii, 0.00001 , 1, 0, 0, 0; Morunasaurus, 0.00001, 0, 0, 0, 0; Morunasaurus annularis, 0.00001, 1, 1, 0, 0; Morunasaurus groi, $0.00002,1$, 1, 0, 0; Morunasaurus peruvianus, $0.00033,1,1,0,0$; Mussurana, $0.00000,0,0,0,0$; Mussurana bicolor, 0.00000, 1, 0, 0, 0; Mussurana montana, 0.00006, 1, 0, 0, 0; Mussurana quimi, 0.00000, 1, 0, 0, 0; Neusticurus, 0.00000, 0, 0, 0, 0; Neusticurus bicarinatus, 0.00000, 1, 0, 1, 0; Neusticurus medemi, 0.00002, 1, 0, 1, 0; Neusticurus racenisi, 0.00001, 1, 0, 1, 0; Neusticurus rudis, $0.00000,1,0,1,0 ;$ Neusticurus tatei, 0.00023, 1, 0, 1, 0; Ninia, 0.00000, 0, 0, 0, 0; Ninia atrata, 0.00000, 1, 0, 0, 0; Ninia franciscoi, 0.00021 , 1, 0, 0, 0; Ninia hudsoni, 0.00000, 1, 0, 0, 0; Norops, 0.00000, 0, 0, 0, 0; Norops annectens, 0.00002, 0, 1, 0, 0; Norops antonii, 0.00001, 0, 1, 0, 0; Norops auratus, 0.00000, 0, 1, 0, 0; Norops binotatus, 0.00002, 0, 1, 0, 0; Norops biporcatus, 0.00000, 0 , 1, 0, 0; Norops bitectus, 0.00002, 0, 1, 0, 0; Norops bombiceps, 0.00000, 0, 1, 0, 0; Norops brasiliensis, 0.00000, 0, 1, 0, 0; Norops chrysolepis, 0.00000, 0, 1, 0, 0; Norops fuscoauratus fuscoauratus, 0.00000, 0, 1, 0, 0; Norops fuscoauratus kugleri, 0.00008, 0, 1, 0, 0 ; Norops gaigei, 0.00001, 0, 1, 0, 0; Norops gracilipes, 0.00001, 0, 1, 0, 0; Norops granuliceps, 0.00001, 0, 1, 0, 0; Norops ibague, 0.00066 , 0, 1, 0, 0; Norops lemniscatus, 0.00102, 0, 1, 0, 0; Norops lynchi, 0.00005, 0, 1, 0, 0; Norops lyra, 0.00001, 0, 1, 0, 0; Norops macrolepis, 0.00089, 0, 1, 0, 0; Norops maculiventris, 0.00000, 0, 1, 0, 0; Norops mariarum, 0.00022, 0, 1, 0, 0; Norops medemi, 0.04227, 0, 1, 0, 0; Norops meridionalis, 0.00000, 1, 1, 0, 0; Norops notopholis, 0.00015, 0, 1, 0, 0; Norops onca, 0.00002, 0, 1, 0, 0; Norops ortonii, $0.00000,0,1,0$, 0; Norops pentaprion, $0.00355,0,1,0,0$; Norops planiceps, $0.00000,0,1,0$, 0; Norops radulinus, 0.00712 , 0, 1, 0, 0; Norops rivalis, 0.00003, 0, 1, 0, 0; Norops scapularis, 0.00009, 0, 1, 0, 0; Norops scypheus, 0.00000, 0, 1, 0, 0; Norops sulcifrons, $0.00395,0,1,0,0$; Norops tandai, 0.00000, 0, 1, 0, 0; Norops tolimensis, 0.00015, 0, 1, 0, 0; Norops trachyderma, $0.00000,0$, 1, 0, 0; Norops tropidogaster, $0.00000,0,1,0,0$; Norops vicarius, $0.00013,0,1,0$, 0; Norops vittigerus, 0.00001, 0, 1, 0, 0; Nothobachia, 0.00009, 0, 0, 0, 0; Nothobachia ablephara, 0.00009, 0, 0, 0, 1; Nothopsis, 0.00000, 0, 0, 0, 0; Nothopsis rugosus, $0.00000,1$, 0, 0, 0; Ophiodes, 0.00000, 0, 0, 0, 0; Ophiodes fragilis, 0.00000, 1, 0, 0, 0; Ophiodes intermedius, 0.00000, 1, 0, 0, 0; Ophiodes luciae, 0.00089, 1, 0, 0, 0; Ophiodes sp 1, 0.00000, 1, 0, 0, 0; Ophiodes sp 2, 0.00000, 1, 0, 0, 0; Ophiodes sp 3, 0.00000, 1, 0, 0, 0; Ophiodes striatus, 0.00000, 1, 0, 0, 0; Ophiodes vertebralis, 0.00000, 1, 0, 0, 0; Oxybelis, 0.00000, 0, 0, 0, 0; Oxybelis aeneus, $0.00000,1,1,0,0$; Oxybelis brevirostris, 0.00000, 1, 1, 0, 0; Oxybelis fulgidus, 0.00000, 1, 1, 0, 0; Oxyrhopus, 0.00000, 0, 0, 0, 0; Oxyrhopus clathratus, 0.00000, 1, 0, 0, 0; Oxyrhopus doliatus, 0.00028, 1, 0, 0, 0; Oxyrhopus erdisii, 0.00013, 1, 0, 0, 0; Oxyrhopus fitzingeri, 0.00002, 1, 0, 0, 0; Oxyrhopus formosus, 0.00008, 1, 0, 0, 0; Oxyrhopus guibei, 0.00000, 1, 0, 0, 0; Oxyrhopus leucomelas, $0.00001,1,0,0,0$; Oxyrhopus marcapatae, 0.00105, 1, 0, 0, 0; Oxyrhopus melanogenys, 0.00000, 1, 0, 0, 0; Oxyrhopus occipitalis, 0.00000, 1, 0, 0, 0; Oxyrhopus petolarius, 0.00000, 1, 0, 0, 0; Oxyrhopus rhombifer, 0.00000, 1, 0, 0, 0; Oxyrhopus trigeminus, $0.00000,1,0,0,0$; Oxyrhopus vanidicus, 0.00000, 1, 0, 0, 0; Paleosuchus, 0.00000, 0, 0, 0, 0; Paleosuchus palpebrosus, 0.00000, 1, 0, 1, 0; Paleosuchus trigonatus, 0.00000, 1, 0, 1, 0; Pantepuisaurus, 0.00200, 0, 0, 0, 0; Pantepuisaurus rodriguesi, 0.00200, 1, 0, 0, 0; Paraphimophis, 0.00000, 0, 0, 0, 0; Paraphimophis rusticus, 0.00000, 1, 0, 0, 0; Peltocephalus, 0.00000, 0, 0, 0, 0; Peltocephalus dumerilianus, 0.00000, 1, 0, 1, 0; Petracola, 0.00008, 0, 0, 0, 0; Petracola angustisoma, 0.00491, 1, 0, 0, 0; Petracola labioocularis, 0.00076 , 1, 0, 0, 0; Petracola ventrimaculatus, 0.00009, 1, 0, 0, 0; Phalotris, 0.00000, 0, 0, 0, 0; Phalotris bilineatus, 0.00000, 0, 0, 0, 1; Phalotris concolor, 0.00001, 0, 0, 0, 1; Phalotris cuyanus, 0.00001, 0, 0, 0, 1; Phalotris labiomaculatus, 0.00001, 0, 0, 0, 1; Phalotris lativittatus, $0.00001,0,0,0,1$; Phalotris lemniscatus, $0.00000,0,0,0,1$; Phalotris matogrossensis, 0.00000, 0, 0, 0, 1; Phalotris mertensi, $0.00000,0,0,0,1$; Phalotris multipunctatus, $0.00000,0,0,0,1$; Phalotris nasutus, $0.00000,1,0,0,1 ;$ Phalotris nigrilatus, 0.00002, 0, 0, 0, 1; Phalotris normanscotti, 0.00007, 0, 0, 0, 1; Phalotris reticulatus, 0.00001, 0, 0, 0, 1; Phalotris sansebastiani, 0.00028, 0, 0, 0, 1; Phalotris tricolor, 0.00000, 0, 0, 0, 1; Philodryas, 0.00000, 0, 0, 0, 0; Philodryas aestivus aestivus, $0.00000,1,0,0$, 0; Philodryas aestivus levisquamus, $0.00002,1,0,0$, 0; Philodryas aestivus subcarinatus, 0.00000, 1, 0, 0, 0; Philodryas agassizii, 0.00000, 1, 0, 0, 0; Philodryas amaru, 0.00009, 1, 0, 0, 0; Philodryas argentea, 0.00000, 1, 1, 0, 0; Philodryas arnaldoi, 0.00002, 1, 0, 0, 0; Philodryas baroni, 0.00000, 1, 0, 0, 0; Philodryas boliviana, 0.00004, 1, 0, 0, 0; Philodryas chamissonis, $0.00001,1,0,0$, 0; Philodryas cordata, 0.00045, 1, 0, 0, 0; Philodryas erlandi, 0.00000, 1, 0, 0, 0; Philodryas georgeboulengeri, 0.00000, 1, 1, 0, 0; Philodryas laticeps, 0.00000, 1, 0, 0, 0; Philodryas latirostris, 0.00000, 1, 0, 0, 0; Philodryas livida, 0.00000, 1, 0, 0, 0; Philodryas mattogrossensis, 0.00000, 1, 0, 0, 0; Philodryas nattereri, 0.00000, 1, 0, 0, 0; Philodryas olfersii, 0.00000, 1, 1, 0, 0; Philodryas patagoniensis, 0.00000, 1, 0, 0, 0; Philodryas psammophideus andensis, $0.00001,1,0,0$, 0; Philodryas psammophideus lativittatus, 0.00001, 1, 0, 0, 0; Philodryas psammophideus psammophideus, 0.00000, 1, 0, 0, 0; Philodryas simonsii, 0.00000, 1, 0, 0, 0; Philodryas tachymenoides, 0.00006, 1, 0, 0, 0; Philodryas trilineata, $0.00000,1$, 0, 0, 0; Philodryas varia, 0.00000, 1, 0, 0, 0; Philodryas viridissimus, $0.00000,1,0,0$, 0; Phimophis, $0.00000,0,0,0$, 0; Phimophis guerini, 0.00000, 1, 0, 0, 1; Phimophis guianensis, 0.00000, 1, 0, 0, 1; Phimophis vittatus, 0.00000, 1, 0, 0, 1; Pholidobolus, 0.00000, 0, 0, 0, 0; Pholidobolus affinis, 0.00014 , 1, 0, 0, 0; Pholidobolus anomalus, 0.00160, 1, 0, 0, 0; Pholidobolus dicrus, 0.00014, 1, 0, 0, 0; Pholidobolus hillisi, 0.00125, 1, 0, 0, 0; Pholidobolus macbrydei, 0.00004, 1, 0, 0, 0; Pholidobolus montium, 0.00018, 1, 0, 0, 0; Pholidobolus prefrontalis, 0.00033, 1, 0, 0, 0; Pholidobolus ulisesi, 0.00003, 1, 0, 0, 0; Pholidobolus vertebralis, 0.00001, 1, 0, 0, 0; Phrynonax, 0.00000, 0, 0, 0, 0; Phrynonax poecilonotus, 0.00000, 1, 1, 0, 0; Phrynonax polylepis, 0.00000, 1, 1, 0, 0; Phrynonax sexcarinatus, 0.00000, 1, 1, 0, 0; Phrynonax shropshirei, 0.00000, 1, 1, 0, 0; Phrynops, 0.00000, 0, 0, 0, 0; Phrynops geoffroanus, 0.00000, 1, 0, 1, 0; Phrynops hilarii, 0.00000, 1, 
0, 1, 0; "Phrynops tuberosus; Mesoclemmys heliostemma", 0.00000, 1, 0, 1, 0; Phrynops williamsi, 0.00000, 1, 0, 1, 0; PHYLLODACTYLIDAE, $0.00000,0,0,0$, 0; Phyllodactylus, 0.00000, 0, 0, 0, 0; Phyllodactylus angustidigitus, 0.00029, 1, 0, 0, 0; Phyllodactylus clinatus, 0.00008, 1, 0, 0, 0; Phyllodactylus delsolari, 0.00031, 1, 0, 0, 0; Phyllodactylus dixoni, 0.00026, 1, 0, 0, 0; Phyllodactylus gerrhopygus, 0.00001, 1, 0, 0, 0; Phyllodactylus heterurus, 0.00061, 1, 0, 0, 0; Phyllodactylus inaequalis, 0.00002, 1, 0, 0, 0; Phyllodactylus interandinus, 0.00039, 1, 0, 0, 0; Phyllodactylus johnwrighti, 0.00037, 1, 0, 0, 0; Phyllodactylus kofordi, 0.00002 , 1, 0, 0, 0; Phyllodactylus leoni, 0.00145, 1, 0, 0, 0; Phyllodactylus lepidopygus, 0.00003, 1, 0, 0, 0; Phyllodactylus microphyllus, 0.00002, 1, 0, 0, 0; Phyllodactylus pulcher, 0.00010, 1, 0, 0, 0; Phyllodactylus pumilus, 0.00007, 1, 0, 0, 0; Phyllodactylus reissii, 0.00001, 1, 0, 0, 0; Phyllodactylus rutteni, 0.00698, 1, 0, 0, 0; Phyllodactylus sentosus, 0.00199, 1, 0, 0, 0; Phyllodactylus thompsoni, 0.00040, 1, 0, 0, 0; Phyllodactylus ventralis, 0.00001, 1, 0, 0, 0; Phyllopezus, 0.00000, 0, 0, 0, 0; Phyllopezus lutzae, 0.00002, 1, 1, 0, 0; Phyllopezus maranjonensis, 0.00054, 1, 0, 0, 0; Phyllopezus periosus, 0.00001, 1, 1, 0, 0; Phyllopezus sp1, 0.00085, 1, 0, 0, 0; Phyllopezus sp10, 0.00444, 1, 0, 0, 0; Phyllopezus sp11, 0.00010, 1, 0, 0, 0; Phyllopezus sp12, $0.00149,1$, 0, 0, 0; Phyllopezus sp13, 0.00000, 1, 1, 0, 0; Phyllopezus sp14, 0.00000, 1, 1, 0, 0; Phyllopezus sp2, 0.00392, 1, 0, 0, 0; Phyllopezus sp3, 0.00243, 1, 0, 0, 0; Phyllopezus sp4, 0.00034, 1, 0, 0, 0; Phyllopezus sp5, 0.00199, 1, 0, 0, 0; Phyllopezus sp6, 0.00007, 1, 1, 0, 0; Phyllopezus sp7, 0.00197, 1, 0, 0, 0; Phyllopezus sp8, 0.00043, 1, 0, 0, 0; Phyllopezus sp9, 0.00001, 1, 0, 0, 0; Phymaturus, 0.00000, 0, 0, 0, 0; Phymaturus aguanegra, 0.00088, 1, 0, 0, 0; Phymaturus aguedae, 0.00090, 1, 0, 0, 0; Phymaturus alicahuense, 0.00033, 1, 0, 0, 0; Phymaturus antofagastensis, 0.00006, 1, 0, 0, 0; Phymaturus cacivioi, 0.00459, 1, 0, 0, 0; Phymaturus calcogaster, 0.00010, 1, 0, 0, 0; Phymaturus camilae, 0.00006, 1, 0, 0, 0; Phymaturus castillensis, 0.00052, 1, 0, 0, 0; Phymaturus ceii, 0.00008, 1, 0, 0, 0; Phymaturus damasense, 0.00085, 1, 0, 0, 0; Phymaturus darwini, 0.00059, 1, 0, 0, 0; Phymaturus delheyi, 0.00275, 1, 0, 0, 0; Phymaturus denotatus, 0.00060, 1, 0, 0, 0; Phymaturus desuetus, 0.00029, 1, 0, 0, 0; Phymaturus dorsimaculatus, 0.00056, 1, 0, 0, 0; Phymaturus etheridgei, 0.00022, 1, 0, 0, 0; Phymaturus excelsus, 0.00169, 1, 0, 0, 0; Phymaturus extrilidus, 0.00093, 1, 0, 0, 0; Phymaturus felixi, 0.00054, 1, 0, 0, 0; Phymaturus indistinctus, 0.00043, 1, 0, 0, 0; Phymaturus laurenti, 0.00003, 1, 0, 0, 0; Phymaturus mallimaccii, 0.00010, 1, 0, 0, 0; Phymaturus manuelae, 0.00084, 1, 0, 0, 0; Phymaturus maulense, $0.00013,1,0,0,0$; Phymaturus nevadoi, $0.00013,1,0,0$, 0; Phymaturus palluma, 0.00001, 1, 0, 0, 0; Phymaturus patagonicus, 0.00000, 1, 0, 0, 0; Phymaturus payuniae, 0.00025, 1, 0, 0, 0; Phymaturus punae, 0.00004, 1, 0, 0, 0; Phymaturus querque, 0.00023, 1, 0, 0, 0; Phymaturus roigorum, 0.00010, 1, 0, 0, 0; Phymaturus sinervoi, 0.00100, 1, 0, 0, 0; Phymaturus sitesi, 0.00127, 1, 0, 0, 0; Phymaturus somuncurensis, 0.00001, 1, 0, 0, 0; Phymaturus spectabilis, 0.00005, 1, 0, 0, 0; Phymaturus spurcus, 0.00013, 1, 0, 0, 0; Phymaturus tenebrosus, 0.00018, 1, 0, 0, 0; Phymaturus tromen, 0.00268, 1, 0, 0, 0; Phymaturus verdugo, 0.00013, 1, 0, 0, 0; Phymaturus videlai, 0.00053, 1, 0, 0, 0; Phymaturus vociferator, 0.00088, 1, 0, 0, 0; Phymaturus williamsi, 0.00074, 1, 0, 0, 0; Phymaturus yachanana, 0.00055, 1, 0, 0, 0; Phymaturus zapalensis, 0.00002, 1, 0, 0, 0; Placosoma, 0.00001, 0, 0, 0, 0; Placosoma champsonotus, 0.00002, 1, 0, 0, 0; Placosoma cipoense, 0.00045, 1, 0, 0, 0; Placosoma cordylinum, 0.00010, 1, 0, 0, 0; Placosoma glabellum, 0.00001, 1, 0, 0, 0; Placosoma limaverdorum, 0.00048, 1, 0, 0, 0; Platemys, $0.00000,0,0,0$, 0; Platemys platycephala, 0.00000, 1, 0, 1, 0; Plesiodipsas, 0.00005, 0, 0, 0, 0; Plesiodipsas perijanensis, 0.00005, 1, 0, 0, 0; Plica, 0.00000, 0, 0, 0, 0; Plica caribeana, 0.00003, 0, 1, 0, 0; Plica kathleenae, 0.00141, 0, 1, 0, 0; Plica lumaria, 0.00057, 0, 1, 0, 0; Plica medemi, 0.00240, 0, 1, 0, 0; Plica pansticta, 0.00092, 0, 1, 0, 0; Plica plica, 0.00000, 0, 1, 0, 0; Plica rayi, 0.00032, 0, 1, 0, 0; Plica umbra ochrocollaris, 0.00000, 0, 1, 0, 0; Plica umbra umbra, 0.00000, 0, 1, 0, 0; Pliocercus, 0.00000, 0, 0, 0, 0; Pliocercus euryzonus, 0.00000, 1, 0, 0, 0; PODOCNEMIDIDAE, 0.00000, 0, 0, 0, 0; Podocnemis, 0.00000, 0, 0, 0, 0; Podocnemis erythrocephala, $0.00000,1,0,1,0$; Podocnemis expansa, 0.00000, 1, 0, 1, 0; Podocnemis lewyana, 0.00001, 1, 0, 1, 0; Podocnemis sextuberculata, $0.00000,1,0,1$, 0; Podocnemis unifilis, 0.00000, 1, 0, 1, 0; Podocnemis vogli, 0.00000, 1, 0, 1, 0; POLYCHROTIDAE, 0.00000, 0, 0, 0 , 0; Polychrus, 0.00000, 0, 0, 0, 0; Polychrus acutirostris, 0.00000, 1, 1, 0, 0; Polychrus femoralis, 0.00002, 1, 1, 0, 0; Polychrus gutturosus, 0.00000, 1, 1, 0, 0; Polychrus jacquelinae, 0.00147, 1, 1, 0, 0; Polychrus liogaster, 0.00000, 1, 1, 0, 0; Polychrus marmoratus, 0.00000, 1, 1, 0, 0; Polychrus peruvianus, 0.00015, 1, 1, 0, 0; Porthidium, 0.00000, 0, 0, 0, 0; Porthidium arcosae, 0.00006 , 1, 0, 0, 0; Porthidium lansbergii hutmanni, 0.00117, 1, 0, 0, 0; Porthidium lansbergii lansbergii, 0.00000, 1, 0, 0, 0; Porthidium lansbergii rozei, 0.00001, 1, 0, 0, 0; Porthidium nasutum, 0.00000, 1, 0, 0, 0; Potamites, 0.00000, 0, 0, 0, 0; Potamites ecpleopus, $0.00000,1,0$, 1, 0; Potamites erythrocularis, 0.00014, 1, 0, 1, 0; Potamites juruazensis, 0.00002, 1, 0, 1, 0; Potamites montanicola, 0.00024, 1, 0, 1, 0; Potamites ocellatus, $0.00010,1,0,1,0$; Potamites strangulatus, 0.00002, 1, 0, 1, 0; Potamites trachodus, 0.00002, 1, 0, 1, 0; Pristidactylus, 0.00000, 0, 0, 0, 0; Pristidactylus achalensis, 0.00003, 1, 1, 0, 0; Pristidactylus alvaroi, $0.00014,1,1,0$, 0; Pristidactylus araucanus, 0.00003, 1, 1, 0, 0; Pristidactylus casuhatiensis, 0.00030, 1, 1, 0, 0; Pristidactylus fasciatus, $0.00000,1,1,0$, 0; Pristidactylus nigroiugulus, $0.00000,1,1,0$, 0; Pristidactylus scapulatus, 0.00000, 1, 1, 0, 0; Pristidactylus torquatus, 0.00001, 1, 1, 0, 0; Pristidactylus valeriae, 0.00008, 1, 1, 0, 0; Pristidactylus volcanensis, 0.00027, 1, 1, 0, 0; Procellosaurinus, $0.00001,0,0,0,0$; Procellosaurinus erythrocercus, $0.00001,1,0,0,1$; Procellosaurinus tetradactylus, $0.00720,1$, 0, 0, 1; Proctoporus, 0.00000, 0, 0, 0, 0; Proctoporus bolivianus, 0.00001, 1, 0, 0, 0; Proctoporus carabaya, 0.00018, 1, 0, 0, 0; Proctoporus cephalolineatus, 0.00040, 1, 0, 0, 0; Proctoporus chasqui, 0.00094, 1, 0, 0, 0; Proctoporus guentheri, 0.00001, 1, 0, 0, 0; Proctoporus iridescens, 0.00095, 1, 0, 0, 0; Proctoporus kiziriani, 0.00032, 1, 0, 0, 0; Proctoporus lacertus, 0.00007, 1, 0, 0, 0; Proctoporus laudahnae, 0.00143, 1, 0, 0, 0; Proctoporus machupicchu, 0.01028, 1, 0, 0, 0; Proctoporus oreades, 0.00298, 1, 0, 0, 0; Proctoporus pachyurus, 0.00032, 1, 0, 0, 0; Proctoporus rahmi, 0.00006, 1, 0, 0, 0; Proctoporus spinalis, 0.00004, 1, 0, 0, 0; Proctoporus sucullucu, 0.00006, 1, 0, 0, 0; Proctoporus unsaacae, 0.00158, 1, 0, 0, 0; Proctoporus xestus, 0.00001, 1, 0, 0, 0; Pseudalsophis, 0.00000, 0, 0, 0, 0; Pseudalsophis elegans, 0.00000, 1, 0, 0, 0; Pseudoboa, 0.00000, 0, 0, 0, 0; Pseudoboa coronata, 0.00000, 1, 0, 0, 0; Pseudoboa haasi, 0.00000, 1, 0, 0, 0; Pseudoboa martinsi, 0.00000, 1, 0, 0, 0; Pseudoboa neuwiedii, 0.00000, 1, 0, 0, 0; Pseudoboa nigra, 0.00000, 1, 0, 0, 0; Pseudoboa serrana, 0.00004, 1, 0, 0, 0; Pseudoeryx, 0.00000, 0, 0, 0, 0; Pseudoeryx plicatilis, 0.00000, 0, 0, 1, 0; Pseudoeryx relictualis, 0.00011, 0, 0, 1, 0; Pseudogonatodes, 0.00000, 0, 0, 0, 0; Pseudogonatodes barbouri, 0.00021, 1, 0, 0, 0; Pseudogonatodes furvus, 0.00056, 1, 0, 0, 0; Pseudogonatodes gasconi, 0.00808, 1, 0, 0, 0; Pseudogonatodes guianensis, 0.00000, 1, 0, 0, 0; Pseudogonatodes lunulatus, 0.00001, 1, 0, 0, 0; Pseudogonatodes manessi, 0.00021 , 1, 0, 0, 0; Pseudogonatodes peruvianus, 0.00067, 1, 0, 0, 0; Pseudotomodon, 0.00000, 0, 0, 0, 0; Pseudotomodon trigonatus, 0.00000, 1, 0, 0, 0; Psilophthalmus, 0.00001, 0, 0, 0, 0; Psilophthalmus paeminosus, 0.00002, 1, 0, 0, 1; Psomophis, $0.00000,0,0,0$, 0; Psomophis genimaculatus, 0.00000, 1, 0, 0, 0; Psomophis joberti, 0.00000, 1, 0, 0, 0; Psomophis obtusus, 
$0.00000,1$, 0, 0, 0; Ptychoglossus, 0.00000, 0, 0, 0, 0; Ptychoglossus bicolor, 0.00008, 1, 0, 0, 0; Ptychoglossus brevifrontalis, $0.00000,1$, 0, 0, 0; Ptychoglossus danieli, 0.00132, 1, 0, 0, 0; Ptychoglossus eurylepis, $0.00035,1,0,0,0$; Ptychoglossus festae, $0.00001,1,0$, 0, 0; Ptychoglossus gorgonae, 0.00002, 1, 0, 0, 0; Ptychoglossus grandisquamatus, 0.00103, 1, 0, 0, 0; Ptychoglossus kugleri, 0.00073, 1, 0, 0, 0; Ptychoglossus nicefori, 0.00004, 1, 0, 0, 0; Ptychoglossus plicatus, 0.00001, 1, 0, 0, 0; Ptychoglossus romaleos, $0.00300,1,0,0$, 0; Ptychoglossus stenolepis, $0.00017,1,0,0,0 ;$ Ptychoglossus vallensis, $0.00018,1,0,0,0 ;$ Ptychophis, $0.00000,0,0,0$, 0; Ptychophis flavovirgatus, $0.00000,0,0,1,0$; Rena, 0.00000, 0, 0, 0, 0; Rena affinis, 0.00008, 0, 0, 0, 1; Rhachidelus, 0.00000, 0, 0, 0, 0; Rhachidelus brazili, 0.00000, 1, 1, 0, 0; Rhachisaurus, 0.00005, 0, 0, 0, 0; Rhachisaurus brachylepis, 0.00005 , 1, 0, 0, 0; Rhadinaea, 0.00000, 0, 0, 0, 0; Rhadinaea decorata, 0.00000, 1, 0, 0, 0; Rhinemys, 0.00000, 0, 0, 0, 0; Rhinemys rufipes, $0.00000,1,0,1$, 0; Rhinobothryum, 0.00000, 0, 0, 0, 0; Rhinobothryum bovallii, 0.00000, 1, 1, 0, 0; Rhinobothryum lentiginosum, $0.00000,1,1,0$, 0; Rhinoclemmys, $0.00000,0,0,0,0$; Rhinoclemmys annulata, 0.00000, 1, 0, 1, 0; Rhinoclemmys diademata, $0.00003,1,0,1$, 0; Rhinoclemmys melanosterna, 0.00001, 1, 0, 1, 0; Rhinoclemmys nasuta, 0.00001, 1, 0, 1, 0; Rhinoclemmys punctularia flammigera, 0.00003, 1, 0, 1, 0; Rhinoclemmys punctularia punctularia, 0.00000, 1, 0, 1, 0; Riama, 0.00001, 0, 0, 0, 0; Riama achlyens, 0.00023, 1, 0, 0, 0; Riama afrania, 0.00295, 1, 0, 0, 0; Riama anatoloros, 0.00004, 1, 0, 0, 0; Riama aurea, 0.00093, 1, 0, 0, 0; Riama balneator, 0.00211, 1, 0, 0, 0; Riama cashcaensis, 0.00120, 1, 0, 0, 0; Riama colomaromani, 0.00226, 1, 0, 0, 0; Riama columbiana, 0.00017, 1, 0, 0, 0; Riama crypta, 0.00440, 1, 0, 0, 0; Riama hyposticta, 0.00009, 1, 0, 0, 0; Riama inanis, 0.00055, 1, 0, 0, 0; Riama kiziriani, 0.00105, 1, 0, 0, 0; Riama labionis, 0.00065, 1, 0, 0, 0; Riama laevis, 0.00030, 1, 0, 0, 0; Riama luctuosa, 0.00051, 1, 0, 0, 0; Riama meleagris, 0.00079, 1, 0, 0, 0; Riama oculata, 0.00023, 1, 0, 0, 0; Riama orcesi, 0.00047, 1, 0, 0, 0; Riama petrorum, 0.00069, 1, 0, 0, 0; Riama raneyi, 0.00018, 1, 0, 0, 0; Riama rhodogaster, 0.00067, 1, 0, 0, 0; Riama shrevei, 0.00088, 1, 0, 0, 0; Riama simotera, 0.00015, 1, 0, 0, 0; Riama stellae, 0.00507, 1, 0, 0, 0; Riama stigmatoral, 0.00051 , 1, 0, 0, 0; Riama striata, 0.00005, 1, 0, 0, 0; Riama unicolor, 0.00008, 1, 0, 0, 0; Riama vespertina, 0.00014, 1, 0, 0, 0; Riama vieta, 0.00096, 1, 0, 0, 0; Riama yumborum, 0.00260, 1, 0, 0, 0; Riolama, 0.00015, 0, 0, 0, 0; Riolama inopinata, 0.00057, 1, 0, 0, 0; Riolama leucosticta, 0.00047, 1, 0, 0, 0; Riolama luridiventris, 0.00069, 1, 0, 0, 0; Riolama sp 1, 0.00100, 1, 0, 0, 0; Riolama sp 2, 0.00145 , 1, 0, 0, 0; Riolama uzzelli, 0.00078, 1, 0, 0, 0; Rodriguesophis, 0.00000, 0, 0, 0, 0; Rodriguesophis chui, 0.00014, 1, 0, 0, 1; Rodriguesophis iglesiasi, 0.00000, 1, 0, 0, 1; Rodriguesophis scriptorcibatus, 0.00008, 1, 0, 0, 1; Rondonops, 0.00000, 0, 0, 0, 0; Rondonops biscutatus, 0.00000, 1, 0, 0, 0; Rondonops xanthomystax, 0.00002, 1, 0, 0, 0; Salvator, 0.00000, 0, 0, 0, 0; Salvator duseni, 0.00000, 1, 0, 0, 0; Salvator merianae, 0.00000, 1, 0, 0, 0; Salvator rufescens, 0.00000, 1, 0, 0, 0; Saphenophis, 0.00001, 0, 0, 0, 0; Saphenophis antioquiensis, 0.00021, 1, 0, 0, 0; Saphenophis atahuallpae, 0.00021, 1, 0, 0, 0; Saphenophis boursieri, 0.00001, 1, 0, 0, 0; Saphenophis sneiderni, 0.00046, 1, 0, 0, 0; Saphenophis tristriatus, 0.00043, 1, 0, 0, 0; Scaphiodontophis, 0.00000, 0, 0, 0, 0; Scaphiodontophis annulatus, $0.00000,1,0,0,0$; Scaphiodontophis venustissimus, $0.00000,1,0,0,0 ;$ SCINCIDAE, 0.00000, 0, 0, 0, 0; Scriptosaura, 0.00052, 0, 0, 0, 0; Scriptosaura catimbau, 0.00052, 0, 0, 0, 1; Siagonodon, 0.00000, 0, 0, 0, 0; Siagonodon acutirostris, $0.00003,0,0,0,1$; Siagonodon borrichianus, $0.00000,0,0,0,1$; Siagonodon cupinensis, $0.00000,0,0$, 0, 1; Siagonodon septemstriatus, $0.00000,0,0,0,1$; Siagonodon unguirostris, $0.00001,0,0,0,1$; Sibon, $0.00000,0,0,0,0$; Sibon annulatus, 0.00000 , 1, 1, 0, 0; Sibon dunni, 0.00836, 1, 1, 0, 0; Sibon nebulatus, 0.00000, 1, 1, 0, 0; Sibynomorphus, 0.00000, 0, 0, 0, 0; Sibynomorphus lavillai, $0.00000,1,1,0$, 0; Sibynomorphus mikanii, 0.00000, 1, 1, 0, 0; Sibynomorphus neuwiedi, 0.00000, 1, 1, 0, 0; Sibynomorphus oligozonatus, 0.00007, 1, 1, 0, 0; Sibynomorphus oneilli, 0.00004, 1, 1, 0, 0; Sibynomorphus petersi, 0.00002, 1, 1, 0, 0; Sibynomorphus turgidus, 0.00000, 1, 1, 0, 0; Sibynomorphus vagrans, 0.00017, 1, 1, 0, 0; Sibynomorphus vagus, 0.00018, 1, 1, 0, 0; Sibynomorphus ventrimaculatus, 0.00000, 1, 1, 0, 0; Sibynomorphus williamsi, 0.00005, 1, 1, 0, 0; SIBYNOPHIIDAE, 0.00002, 0, 0, 0, 0; Simophis, 0.00000, 0, 0, 0, 0; Simophis rhinostoma, 0.00000, 1, 0, 0, 0; Siphlophis, 0.00000, 0, 0, 0, 0; Siphlophis ayauma, 0.00021, 1, 1, 0, 0; Siphlophis cervinus, 0.00000, 1, 1, 0, 0; Siphlophis compressus, $0.00000,1,1,0$, 0; Siphlophis leucocephalus, 0.00002, 1, 1, 0 , 0; Siphlophis longicaudatus, $0.00000,1,1,0$, 0; Siphlophis pulcher, $0.00001,1,1,0$, 0; Siphlophis worontzowi, 0.00000, 1, 1, 0, 0; Sordellina, 0.00001, 0, 0, 0, 0; Sordellina punctata, 0.00001, 0, 0, 1, 0; SPHAERODACTYLIDAE, 0.00000, 0, 0, 0, 0; Sphaerodactylus, 0.00000 , 0, 0, 0, 0; Sphaerodactylus heliconiae, 0.00124, 1, 0, 0, 0; Sphaerodactylus lineolatus, 0.00001, 1, 0, 0, 0; Sphaerodactylus molei, 0.00002, 1, 0, 0, 0; Sphaerodactylus scapularis, 0.00093, 1, 0, 0, 0; Spilotes, 0.00000, 0, 0, 0, 0; Spilotes pullatus, 0.00000, 1, 1, 0, 0; Spilotes sulphureus, 0.00000, 1, 1, 0, 0; SQUAMATA, 0.00000, 0, 0, 0, 0; Stenocercus, $0.00000,0,0,0$, 0; Stenocercus aculeatus, $0.00004,1$, 0, 0, 0; Stenocercus albolineatus, 0.00000, 1, 0, 0, 0; Stenocercus amydrorhytus, 0.00129, 1, 0, 0, 0; Stenocercus angel, $0.00027,1,0,0$, 0; Stenocercus angulifer, 0.00004, 1, 0, 0, 0; Stenocercus apurimacus, 0.00008, 1, 0, 0, 0; Stenocercus arndti, $0.00125,1,0,0$, 0; Stenocercus azureus, 0.00000, 1, 0, 0, 0; Stenocercus boettgeri, 0.00007, 1, 0, 0, 0; Stenocercus bolivarensis, $0.00011,1,0,0$, 0; Stenocercus cadlei, 0.00021, 1, 0, 0, 0; Stenocercus caducus, 0.00000, 1, 0, 0, 0; Stenocercus carrioni, 0.00014, 1, 0, 0, 0; Stenocercus chinchaoensis, 0.00139, 1, 0, 0, 0; Stenocercus chlorostictus, $0.00031,1,0,0$, 0; Stenocercus chota, $0.00067,1$, 0, 0, 0; Stenocercus chrysopygus, 0.00006, 1, 0, 0, 0; Stenocercus crassicaudatus, $0.00013,1,0,0$, 0; Stenocercus cupreus, 0.00030 , 1, 0, 0, 0; Stenocercus doellojuradoi, 0.00000, 1, 0, 0, 0; Stenocercus dumerilii, 0.00000, 1, 0, 0, 0; Stenocercus empetrus, $0.00014,1$, 0, 0, 0; Stenocercus erythrogaster, 0.00001, 1, 0, 0, 0; Stenocercus eunetopsis, 0.00746, 1, 0, 0, 0; Stenocercus festae, 0.00012, 1, 0, 0, 0; Stenocercus fimbriatus, 0.00000, 1, 0, 0, 0; Stenocercus formosus, 0.00059, 1, 0, 0, 0; Stenocercus frittsi, 0.00027, 1, 0, 0, 0; Stenocercus guentheri, 0.00005, 1, 0, 0, 0; Stenocercus haenschi, 0.00113, 1, 0, 0, 0; Stenocercus huancabambae, 0.00014, 1, 0, 0, 0; Stenocercus humeralis, 0.00011, 1, 0, 0, 0; Stenocercus imitator, 0.00024, 1, 0, 0, 0; Stenocercus iridescens, 0.00001, 1, 0, 0, 0; Stenocercus ivitus, $0.00189,1,0,0$, 0; Stenocercus johaberfellneri, 0.00150, 1, 0, 0, 0; Stenocercus lache, 0.00022, 1, 0, 0, 0; Stenocercus latebrosus, 0.00020, 1, 0, 0, 0; Stenocercus limitaris, 0.00011, 1, 0, 0, 0; Stenocercus marmoratus, 0.00001, 1, 0, 0, 0; Stenocercus melanopygus, 0.00014, 1, 0, 0, 0; Stenocercus modestus, 0.00041, 1, 0, 0, 0; Stenocercus nigromaculatus, 0.00050, 1, 0, 0, 0; Stenocercus nubicola, 0.00266, 1, 0, 0, 0; Stenocercus ochoai, 0.00022, 1, 0, 0, 0; Stenocercus omari, 0.00026, 1, 0, 0, 0; Stenocercus orientalis, $0.00026,1,0,0$, 0; Stenocercus ornatissimus, $0.00003,1,0,0$, 0; Stenocercus ornatus, 0.00013, 1, 0, 0, 0; Stenocercus pectinatus, 0.00000, 1, 0, 0, 0; Stenocercus percultus, 0.00021, 1, 0, 0, 0; Stenocercus praeornatus, 0.00317, 1, 0, 0, 0; Stenocercus prionotus, $0.00000,1,0,0$, 0; Stenocercus puyango, $0.00008,1,0,0$, 0; Stenocercus quinarius, 0.00001, 1, 0, 0, 0; Stenocercus rhodomelas, $0.00015,1,0,0$, 0; Stenocercus roseiventris, $0.00000,1,0,0$, 0; Stenocercus santander, 0.00016, 1, 0, 0, 0; Stenocercus scapularis, 0.00001, 1, 0, 0, 0; Stenocercus simonsii, 0.00038, 1, 0, 0, 0; Stenocercus sinesaccus, 0.00000, 1, 0, 0, 0; Stenocercus squarrosus, $0.00002,1,0,0,0$; Stenocercus stigmosus, $0.00035,1,0,0$, 0; Stenocercus torquatus, $0.00011,1,0,0,0$; 
Stenocercus trachycephalus, $0.00002,1,0,0$, 0; Stenocercus tricristatus, $0.00030,1,0,0$, 0; Stenocercus variabilis, 0.00090, 1, 0, 0 , 0 ; Stenocercus varius, $0.00013,1,0,0$, 0; Stenolepis, 0.00006, 0, 0, 0, 0; Stenolepis ridleyi, 0.00006, 1, 0, 0, 0; Stenorrhina, 0.00000 , 0, 0, 0, 0; Stenorrhina degenhardtii, 0.00000, 1, 0, 0, 0; Strobilurus, 0.00000, 0, 0, 0, 0; Strobilurus torquatus, 0.00000, 0, 1, 0, 0; Synophis, 0.00001, 0, 0, 0, 0; Synophis bicolor, 0.00011, 1, 1, 0, 0; Synophis bogerti, 0.00008, 1, 1, 0, 0; Synophis calamitus, 0.00004, $1,1,0,0$; Synophis insulomontanus, 0.00002, 1, 1, 0, 0; Synophis lasallei, 0.00001, 1, 1, 0, 0; Synophis niceforomariae, 0.00011, 1, 1, 0, 0; Synophis plectovertebralis, 0.00059, 1, 1, 0, 0; Synophis zaheri, 0.00022, 1, 1, 0, 0; Synophis zamora, 0.00007, 1, 1, 0, 0; Tachymenis, 0.00000, 0, 0, 0, 0; Tachymenis affinis, 0.00002, 1, 0, 0, 0; Tachymenis attenuata attenuata, 0.00010, 1, 0, 0, 0; Tachymenis attenuata boliviana, 0.00008, 1, 0, 0, 0; Tachymenis chilensis, 0.00001, 1, 0, 0, 0; Tachymenis elongata, 0.00030, 1, 0, 0, 0; Tachymenis peruviana, $0.00043,1,0,0$, 0; Tachymenis tarmensis, $0.00000,1,0,0,0$; Taeniophallus, 0.00000, 0, 0, 0, 0; Taeniophallus affinis, 0.00000, 1, 0, 0, 0; Taeniophallus bilineatus, 0.00000, 1, 0, 0, 0; Taeniophallus brevirostris, 0.00000, 1, 0, 0, 0; Taeniophallus imaculado, 0.00000, 1, 0, 0, 0; Taeniophallus maculado, 0.00000, 1, 0, 0, 0; Taeniophallus miolepis, 0.00000, 1, 0, 0, 0 ; Taeniophallus nebularis, $0.00033,1,0,0,0$; Taeniophallus nicagus, $0.00000,1,0,0,0$; Taeniophallus occipitalis, 0.00000, 1, 0, 0, 0 ; Taeniophallus persimilis, $0.00001,1,0,0$, 0; Taeniophallus poecilopogon, $0.00000,1,0,0$, 0; Taeniophallus quadriocellatus, $0.00000,1,0,0$, 0; Taeniophallus sp2, 0.00000, 1, 0, 0, 0; Tantilla, 0.00000, 0, 0, 0, 0; Tantilla alticola, 0.00000, 1, 0, 0, 0; Tantilla andinista, 0.00012, 1, 0, 0, 0; Tantilla boipiranga, 0.00069, 1, 0, 0, 0; Tantilla capistrata, 0.00003, 1, 0, 0, 0; Tantilla melanocephala, $0.00000,1,0,0$, 0; Tantilla miyatai, 0.00013, 1, 0, 0, 0; Tantilla nigra, 0.00012, 1, 0, 0, 0; Tantilla petersi, 0.00010, 1, 0, 0, 0; Tantilla reticulata, 0.00001, 1, 0, 0, 0; Tantilla semicincta, 0.00001, 1, 0, 0, 0; Tantilla supracincta, 0.00000, 1, 0, 0, 0; TEIIDAE, 0.00000, 0, 0, 0, 0; Teius, 0.00000, 0, 0, 0, 0; Teius oculatus, $0.00000,1,0,0,0$; Teius suquiensis, $0.00001,1,0,0,0$; Teius teyou, 0.00000, 1, 0, 0, 0; TESTUDINES, 0.00000, 0, 0, 0, 0; TESTUDINIDAE, 0.00000, 0, 0, 0, 0; Thamnodynastes, $0.00000,0,0,0$, 0; Thamnodynastes almae, $0.00011,1,0,1$, 0; Thamnodynastes ceibae, 0.00020, 1, 0, 1, 0; Thamnodynastes chaquensis, 0.00000, 1, 0, 1, 0; Thamnodynastes chimanta, 0.00116, 1, 0, 1, 0; Thamnodynastes corocoroensis, $0.00755,1,0,1$, 0; Thamnodynastes dixoni, 0.00000, 1, 0, 1, 0; Thamnodynastes duida, 0.00061, 1, 0, 1, 0; Thamnodynastes gambotensis, 0.00002, 1, 0, 1, 0; Thamnodynastes hypoconia, 0.00000 , 1, 0, 1, 0; Thamnodynastes lanei, 0.00000, 1, 0, 1, 0; Thamnodynastes longicaudus, $0.00002,1,0$, 1, 0; Thamnodynastes marahuaquensis, 0.00236, 1, 0, 1, 0; Thamnodynastes pallidus, 0.00000, 1, 0, 1, 0; Thamnodynastes paraguanae, 0.00004, 1, 0, 1, 0; Thamnodynastes ramonriveroi, 0.00000, 1, 0, 1, 0; Thamnodynastes rutilus, 0.00000, 1, 0, 1, 0; Thamnodynastes sertanejo, 0.00000 , 1, 0, 1, 0; Thamnodynastes strigatus, 0.00000, 1, 0, 1, 0; Thamnodynastes yavi, 0.00911, 1, 0, 1, 0; Thecadactylus, 0.00000, 0, 0, 0, 0; Thecadactylus rapicauda, 0.00000, 0, 1, 0, 0; Thecadactylus solimoensis, 0.00000, 0, 1, 0, 0; Tomodon, 0.00000, 0, 0, 0, 0; Tomodon dorsatus, 0.00000, 1, 0, 0, 0; Tomodon ocellatus, 0.00000, 1, 0, 0, 0; Tomodon orestes, $0.00004,1,0,0,0 ;$ Trachemys, 0.00000, 0, 0 , 0 , 0; Trachemys adiutrix, $0.00007,1,0,1,0$; Trachemys callirostris callirostris, $0.00001,1,0,1,0$; Trachemys callirostris chichiriviche, 0.00033, 1, 0, 1, 0; Trachemys dorbigni, 0.00000, 1, 0, 1, 0; "Trachemys venusta; Mesoclemmys heliostemma", 0.00000, 1, 0, 1, 0; Trachyboa, 0.00001, 0, 0, 0, 0; Trachyboa boulengeri, 0.00001, 1, 1, 0, 0; Trachyboa gularis, 0.00014, 1, 1, 0, 0; Tretanorhinus, $0.00000,0,0,0,0$; Tretanorhinus equatoriana, 0.00009, 1, 0, 1, 0; Tretanorhinus taeniatus, 0.00002, 1, 0, 1, 0; Tretioscincus, $0.00000,0,0,0,0$; Tretioscincus agilis, 0.00000, 1, 0, 0, 0; Tretioscincus bifasciatus, $0.00000,1,0,0,0$; Tretioscincus oriximinensis, 0.00000 , 1, 0, 0, 0; Trilepida, 0.00000, 0, 0, 0, 0; Trilepida anthracina, 0.00007, 0, 0, 0, 1; Trilepida brasiliensis, 0.00000, 0, 0, 0, 1; Trilepida brevissima, 0.00072, 0, 0, 0, 1; Trilepida dimidiata, $0.00000,0,0,0,1 ;$ Trilepida dugandi, 0.00025, 0, 0, 0, 1; Trilepida fuliginosa, 0.00001, 0, 0, 0, 1; Trilepida guayaquilensis, 0.00010,0,0,0, 1; Trilepida jani, 0.00006, 0, 0, 0, 1; Trilepida joshuai, 0.00002 , 0, 0, 0, 1; Trilepida koppesi, 0.00000, 0, 0, 0, 1; Trilepida macrolepis, 0.00000, 0, 0, 0, 1; Trilepida nicefori, 0.00012, 0, 0, 0, 1; Trilepida pastusa, 0.00096, 0, 0, 0, 1; Trilepida salgueiroi, $0.00000,0,0,0,1$; Tropidodryas, $0.00000,0,0,0,0$; Tropidodryas serra, 0.00000, 0, 1, 0, 0; Tropidodryas striaticeps, 0.00000, 0, 1, 0, 0; TROPIDOPHIIDAE, 0.00000, 0, 0, 0, 0; Tropidophis, 0.00000, 0, 0, 0, 0; Tropidophis grapiuna, 0.00006, 0, 1, 0, 0; Tropidophis paucisquamis, 0.00001, 0, 1, 0, 0; Tropidophis preciosus, 0.00007, 0, 1, 0, 0; Tropidophis taczanowskyi, 0.00001, 0, 1, 0, 0; TROPIDURIDAE, 0.00000, 0, 0, 0, 0; Tropidurus, 0.00000, 0, 0, 0, 0; Tropidurus arenarius, $0.00004,1,1,0$, 0; Tropidurus bogerti, $0.00040,1,1,0,0$; Tropidurus callathelys, 0.00009, 1, 1, 0, 0; Tropidurus catalanensis, 0.00000, 1, 1, 0, 0; Tropidurus chromatops, 0.00006, 1, 1, 0, 0; Tropidurus cocorobensis, 0.00001, 1, 1, 0, 0; Tropidurus erythrocephalus, $0.00007,1,1,0$, 0; Tropidurus etheridgei, $0.00000,1,1,0$, 0; Tropidurus guarani, 0.00024, 1, 1, 0, 0; Tropidurus helenae, 0.00039, 1, 1, 0, 0; Tropidurus hispidus, 0.00000, 1, 1, 0, 0; Tropidurus hygomi, 0.00004, 1, 1, 0, 0; Tropidurus imbituba, $0.00001,1,1,0,0$; Tropidurus insulanus, 0.00003, 1, 1, 0, 0; Tropidurus itambere, $0.00000,1,1,0$, 0; Tropidurus jaguaribanus, $0.00004,1,1,0$, 0; Tropidurus lagunablanca, 0.00418, 1, 1, 0, 0; Tropidurus melanopleurus melanopleurus, 0.00001, 1, 1, 0, 0; Tropidurus melanopleurus pictus, 0.00002, 1, 1, 0, 0; Tropidurus montanus, 0.00002, 1, 1, 0, 0; Tropidurus mucujensis, 0.00023, 1, 1, 0, 0; Tropidurus oreadicus, 0.00000, 1, 1, 0, 0; Tropidurus pinima, 0.00013, 1, 1, 0, 0; Tropidurus psammonastes, 0.00017, 1, 1, 0, 0; Tropidurus semitaeniatus sp1, 0.00065, 1, 1, 0, 0; Tropidurus semitaeniatus sp2, 0.00008, 1, 1, 0, 0; Tropidurus semitaeniatus sp3, $0.00001,1,1$, 0, 0; Tropidurus semitaeniatus sp4, 0.00001, 1, 1, 0, 0; Tropidurus semitaeniatus sp5, 0.00000, 1, 1, 0, 0; Tropidurus semitaeniatus sp6, 0.00071, 1, 1, 0, 0; Tropidurus semitaeniatus sp7, 0.00017, 1, 1, 0, 0; Tropidurus sertanejo, 0.00015, 1, 1, 0, 0; Tropidurus spinulosus, 0.00000, 1, 1, 0, 0; Tropidurus tarara, 0.00001, 1, 1, 0, 0; Tropidurus teyumirim, 0.00049, 1, 1, 0, 0; Tropidurus torquatus, 0.00000, 1, 1, 0, 0; Tropidurus xanthochilus, 0.00030, 1, 1, 0, 0; Tupinambis, 0.00000, 0, 0, 0, 0; Tupinambis cryptus, 0.00000, 1, 0, 0, 0; Tupinambis cuzcoensis, 0.00000, 1, 0, 0, 0; Tupinambis longilineus, 0.00000, 1, 0, 0, 0; Tupinambis quadrilineatus, $0.00000,1,0,0,0$; Tupinambis $s p, 0.00000,1,0,0,0$; Tupinambis teguixin, $0.00000,1,0,0,0$; Tupinambis zuliensis, 0.00001 , 1, 0, 0, 0; Typhlophis, 0.00000, 0, 0, 0, 0; Typhlophis squamosus, 0.00000, 0, 0, 0, 1; TYPHLOPIDAE, 0.00000, 0, 0, 0, 0; Ungaliophis, 0.00000, 0, 0, 0, 0; Ungaliophis panamensis, 0.00001, 0, 1, 0, 0; Uracentron, 0.00000, 0, 0, 0, 0; Uracentron azureum azureum, 0.00000, 0, 1, 0, 0; Uracentron azureum guentheri, 0.00000, 0, 1, 0, 0; Uracentron azureum werneri, 0.00000, 0, 1, 0, 0; Uracentron flaviceps, $0.00000,0,1,0$, 0; Uranoscodon, $0.00000,0,0,0$, 0; Uranoscodon superciliosus, 0.00000, 0, 1, 1, 0; Uromacerina, 0.00000, 0, 0, 0, 0; Uromacerina ricardinii, 0.00000, 0, 1, 0, 0; Urostrophus, $0.00000,0,0,0$, 0; Urostrophus gallardoi, $0.00000,1,1,0$, 0; Urostrophus vautieri, 0.00000, 1, 1, 0, 0; Urotheca, 0.00000, 0, 0, 0, 0; Urotheca decipiens, 0.00001, 1, 0, 0, 0; Urotheca dumerilli, 0.00002, 1, 0, 0, 0; Urotheca fulviceps, 0.00000, 1, 0, 0, 0; Urotheca lateristriga, 0.00000, 1, 0, 0, 0; Urotheca multilineata, $0.00005,1,0,0$, 0; Vanzosaura, 0.00000, 0, 0, 0, 0; Vanzosaura multiscutata, 0.00000, 1, 0, 0, 1; Vanzosaura rubricauda, 0.00000, 1, 0, 0, 1; Vanzosaura savanicola, 0.00001, 1, 0, 0, 1; VIPERIDAE, 0.00000, 0, 0, 0, 0; Xenodon, 0.00000, 0, 0, 0, 
0 ; Xenodon dorbignyi, 0.00000, 1, 0, 0, 0; Xenodon guentheri, 0.00001, 1, 0, 0, 0; Xenodon histricus, 0.00000, 1, 0, 0, 0; Xenodon matogrossensis, $0.00001,1,0,0,0$; Xenodon merremii, $0.00000,1,0,0$, 0; Xenodon nattereri, $0.00000,1,0,0,0 ;$ Xenodon neuwiedii, $0.00000,1,0,0,0$; Xenodon pulcher, $0.00000,1,0,0$, 0; Xenodon rabdocephalus, 0.00000, 1, 0, 0, 0; Xenodon semicinctus, 0.00000, 1, 0, 0, 0; Xenodon severus, 0.00000, 1, 0, 0, 0; Xenodon werneri, 0.00001, 1, 0, 0, 0; Xenopholis, 0.00000, 0, 0, 0,0 ; Xenopholis scalaris, $0.00000,1,0,0,0$; Xenopholis undulatus, $0.00000,1,0,0,0$; Xenopholis werdingorum, $0.00000,1,0,0,0$. 


\section{APÊNDICE 3 - Mapas}

Polígonos representando a distribuição geográfica das espécies de Anfíbios e Répteis utilizados nas análises.

\section{Anfíbios}

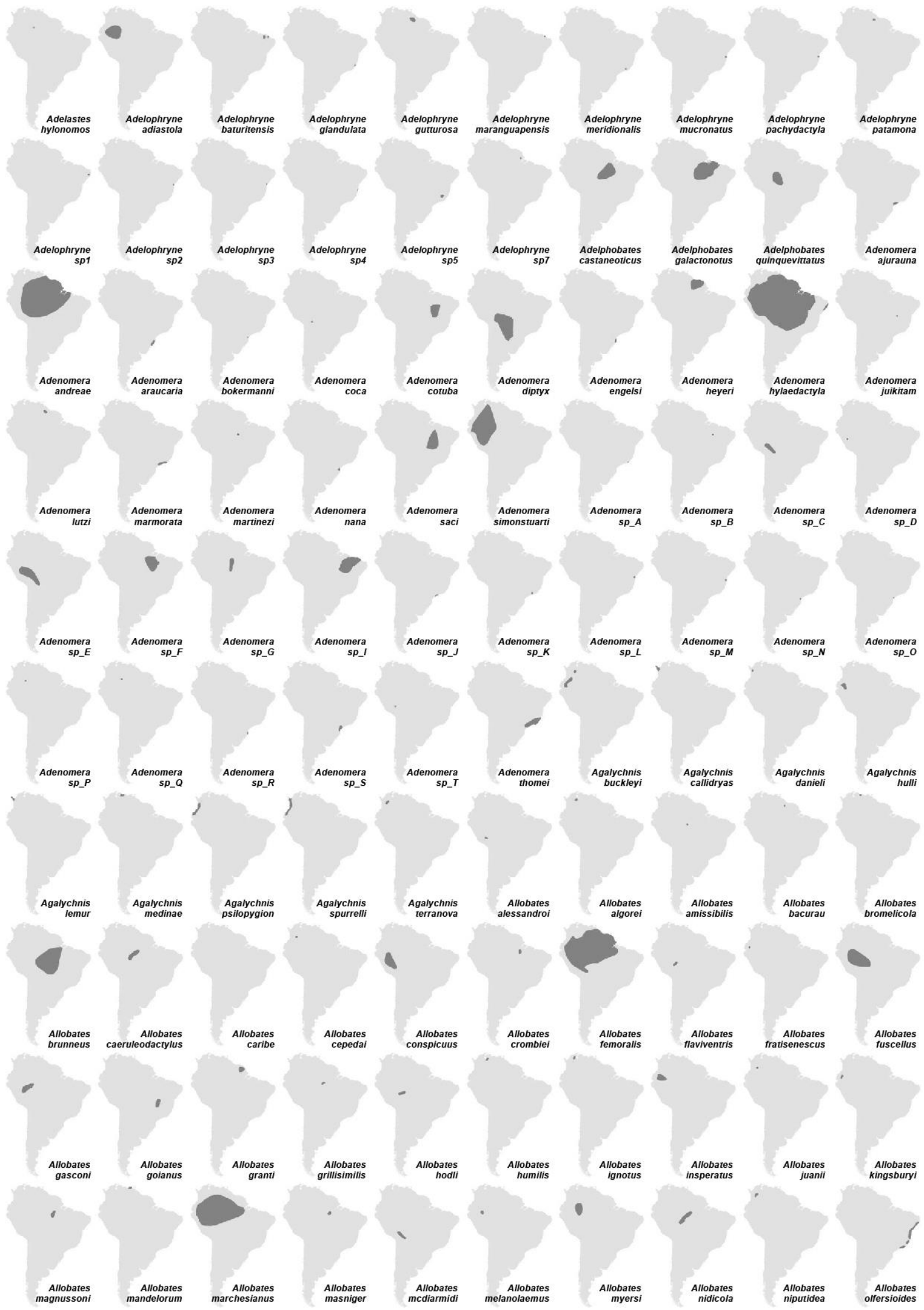




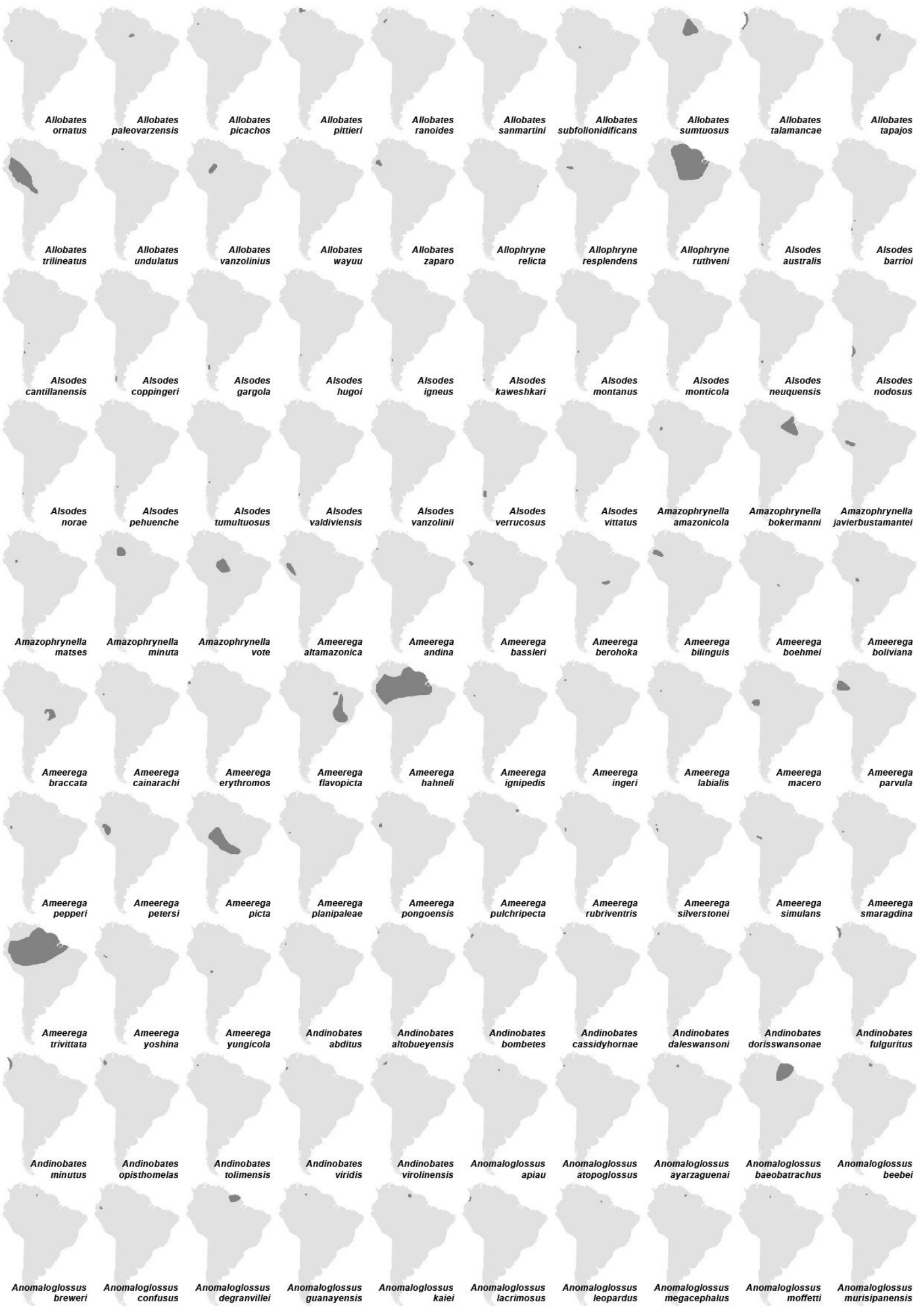




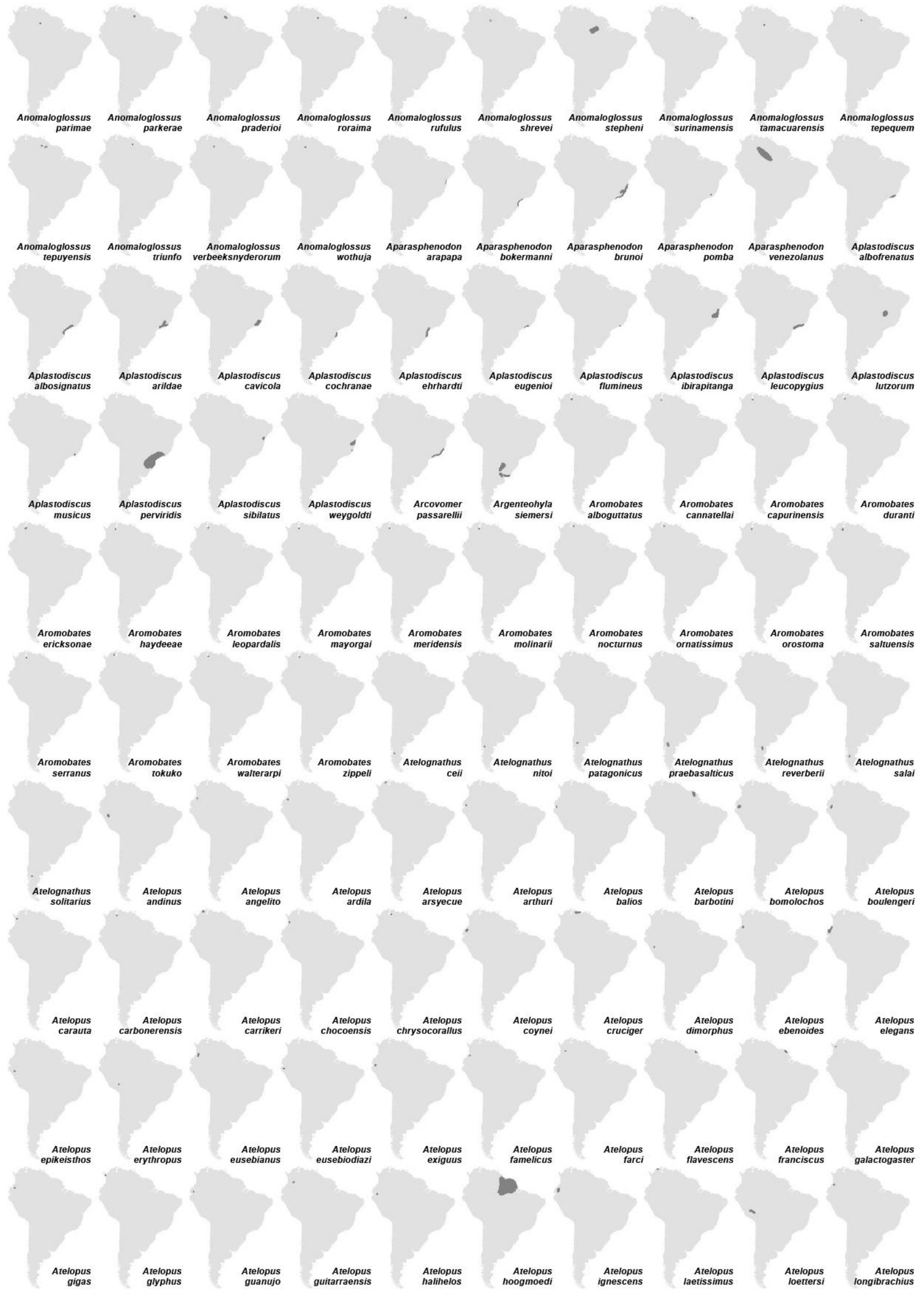




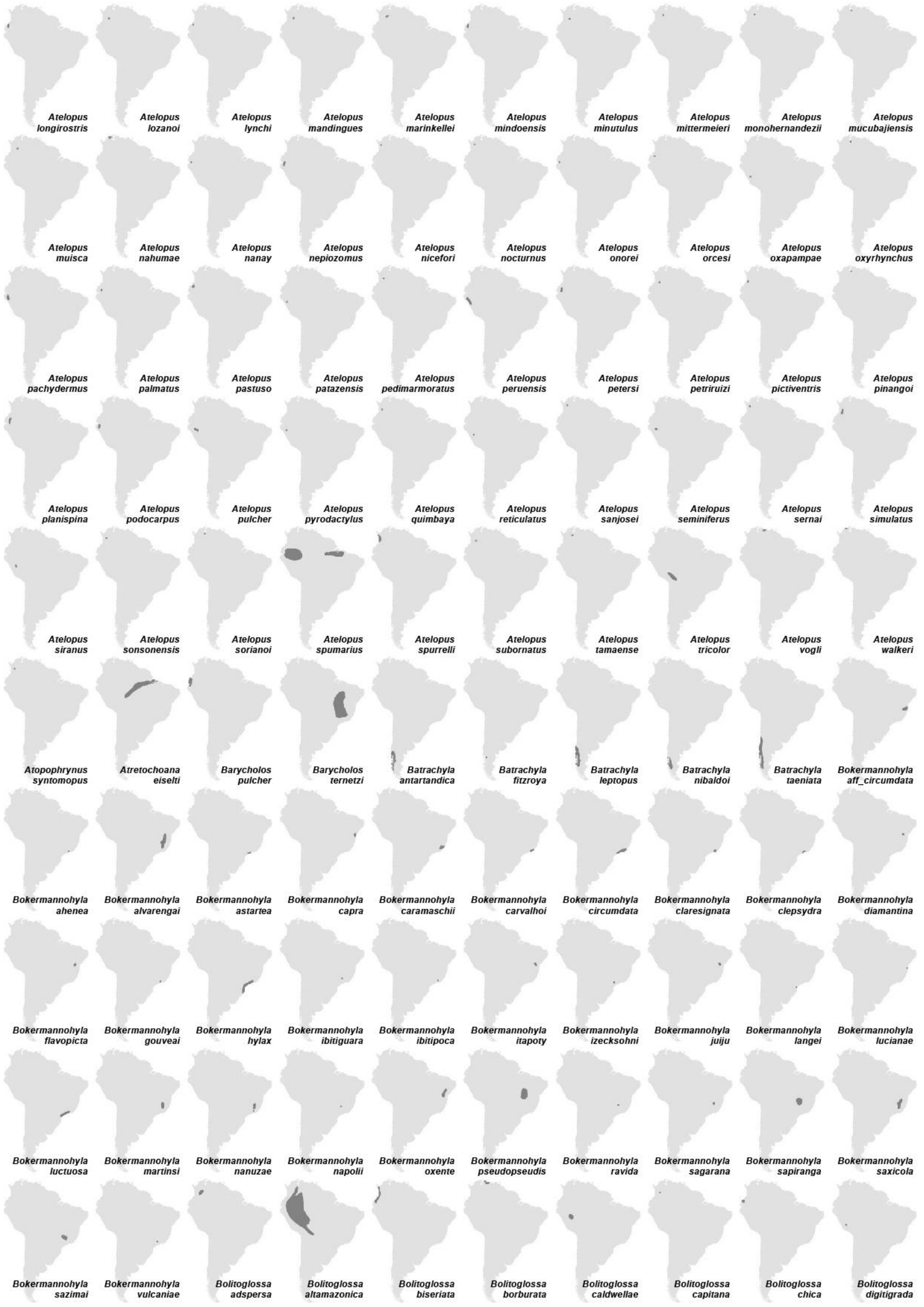




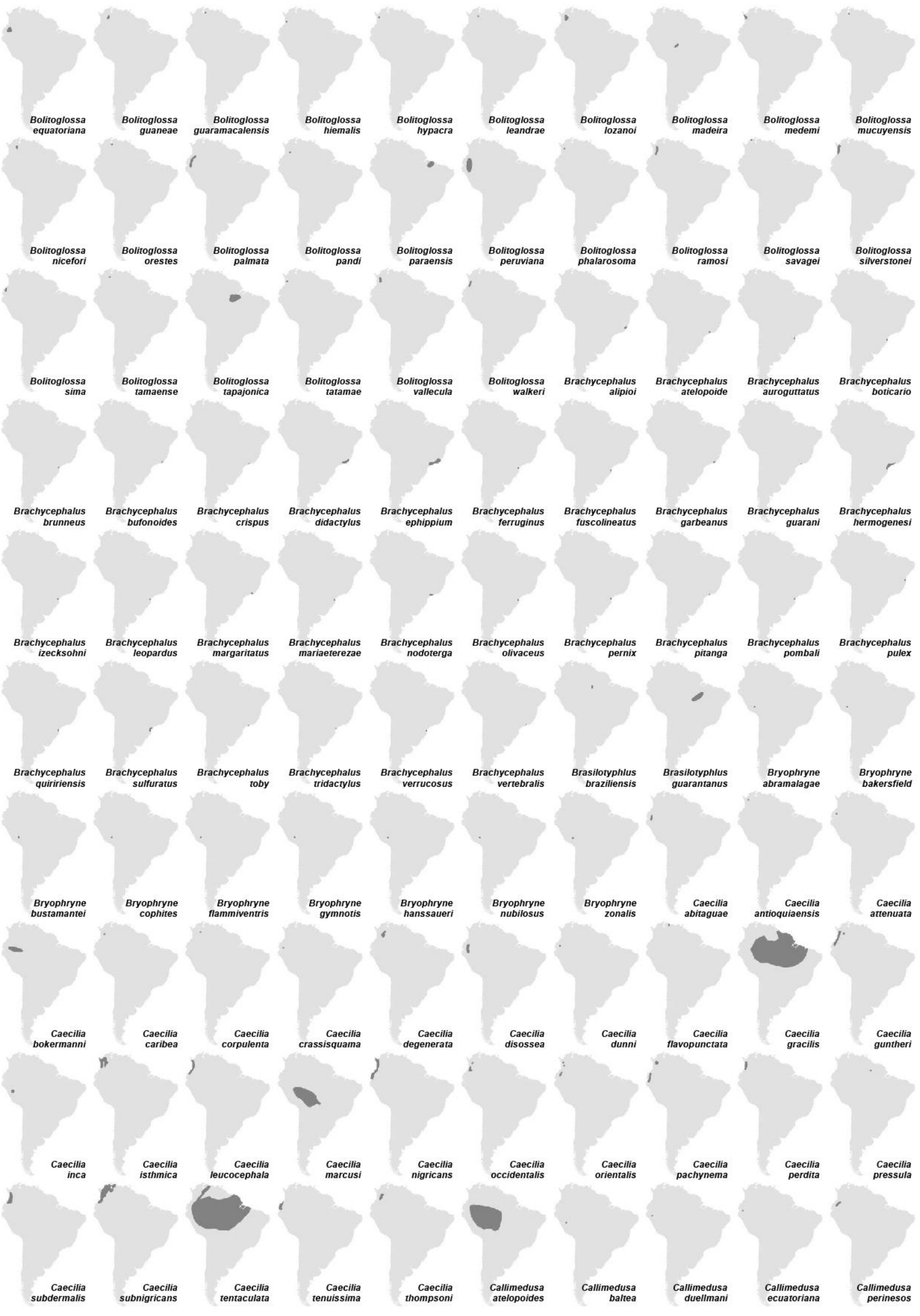




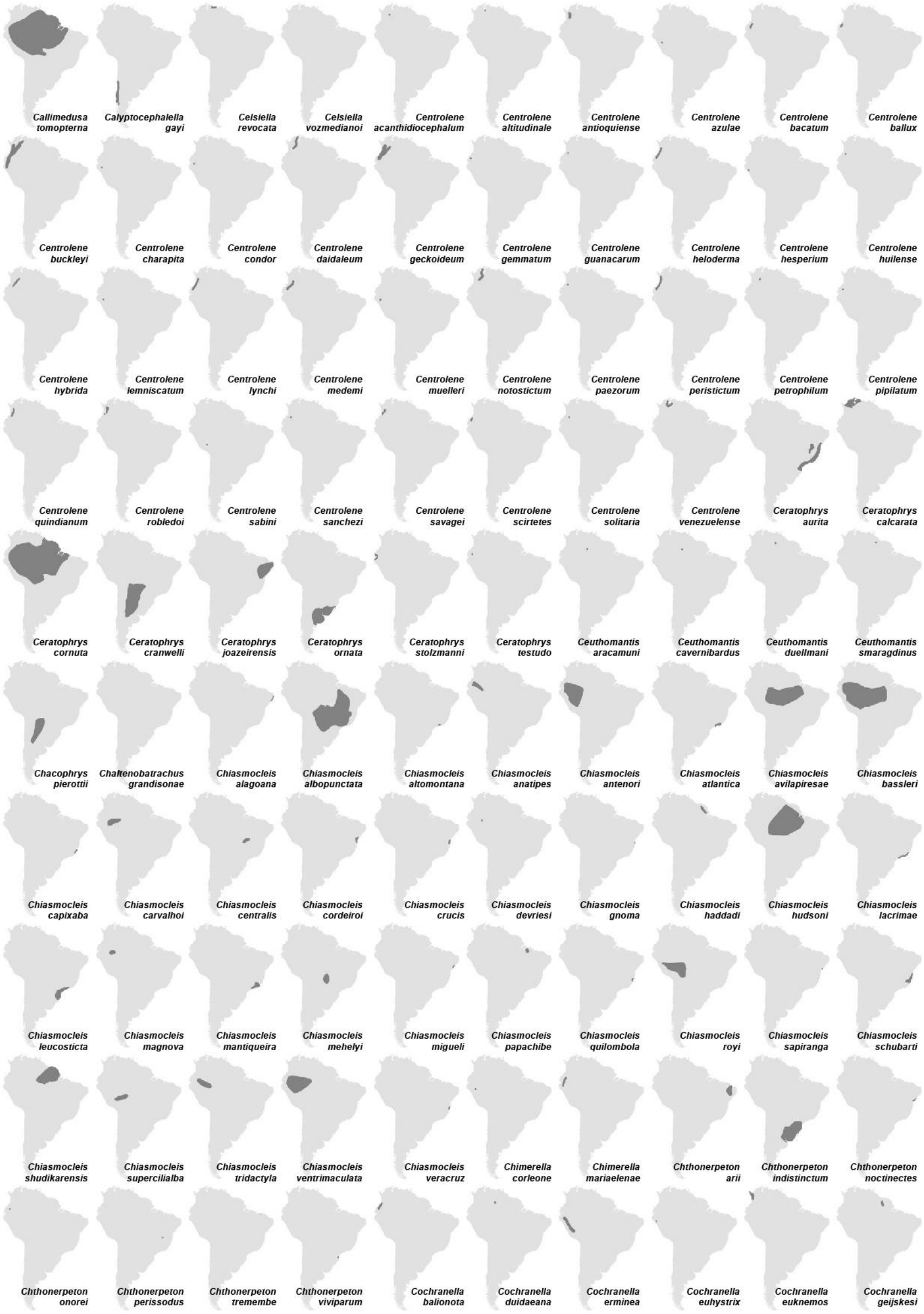




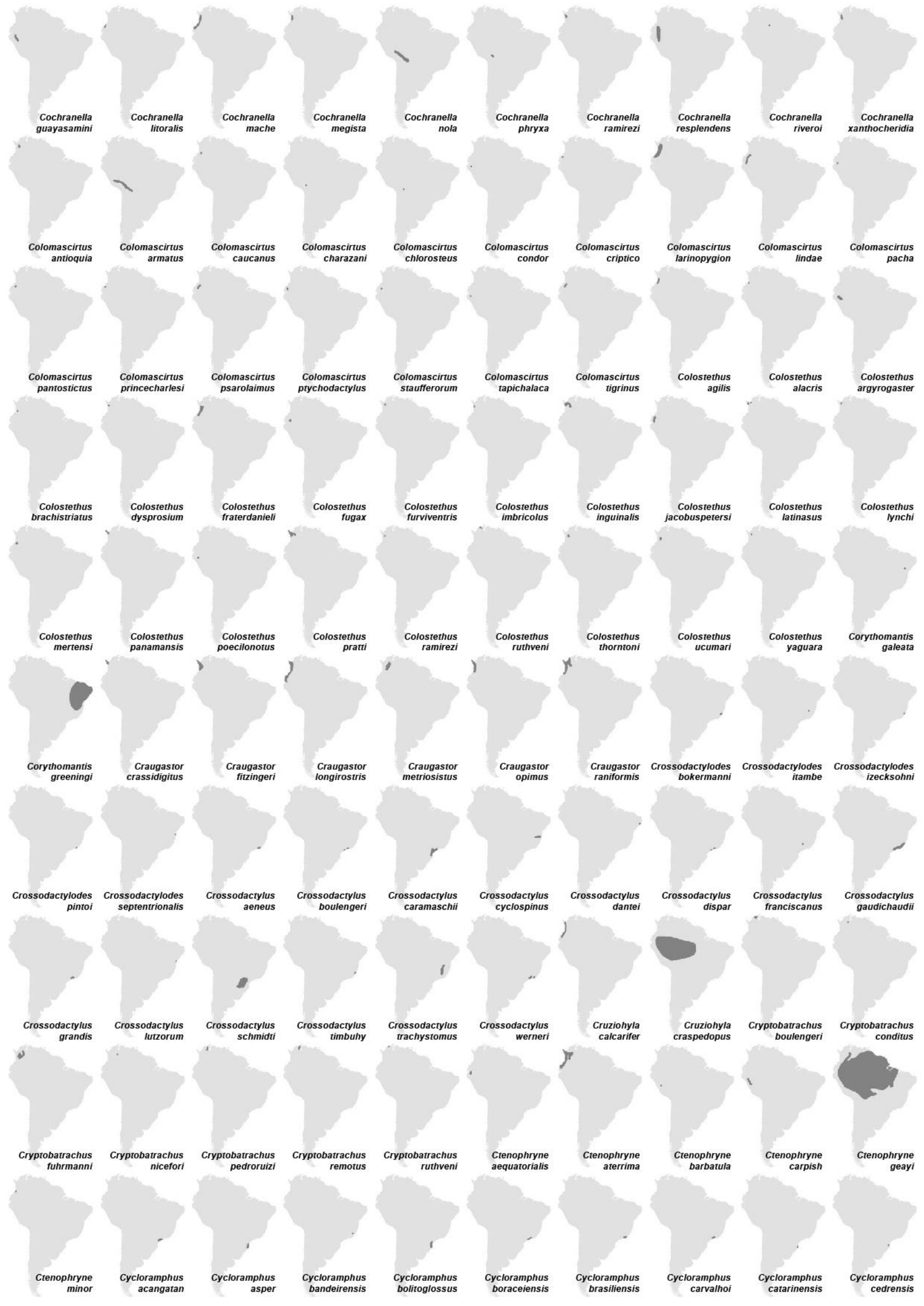




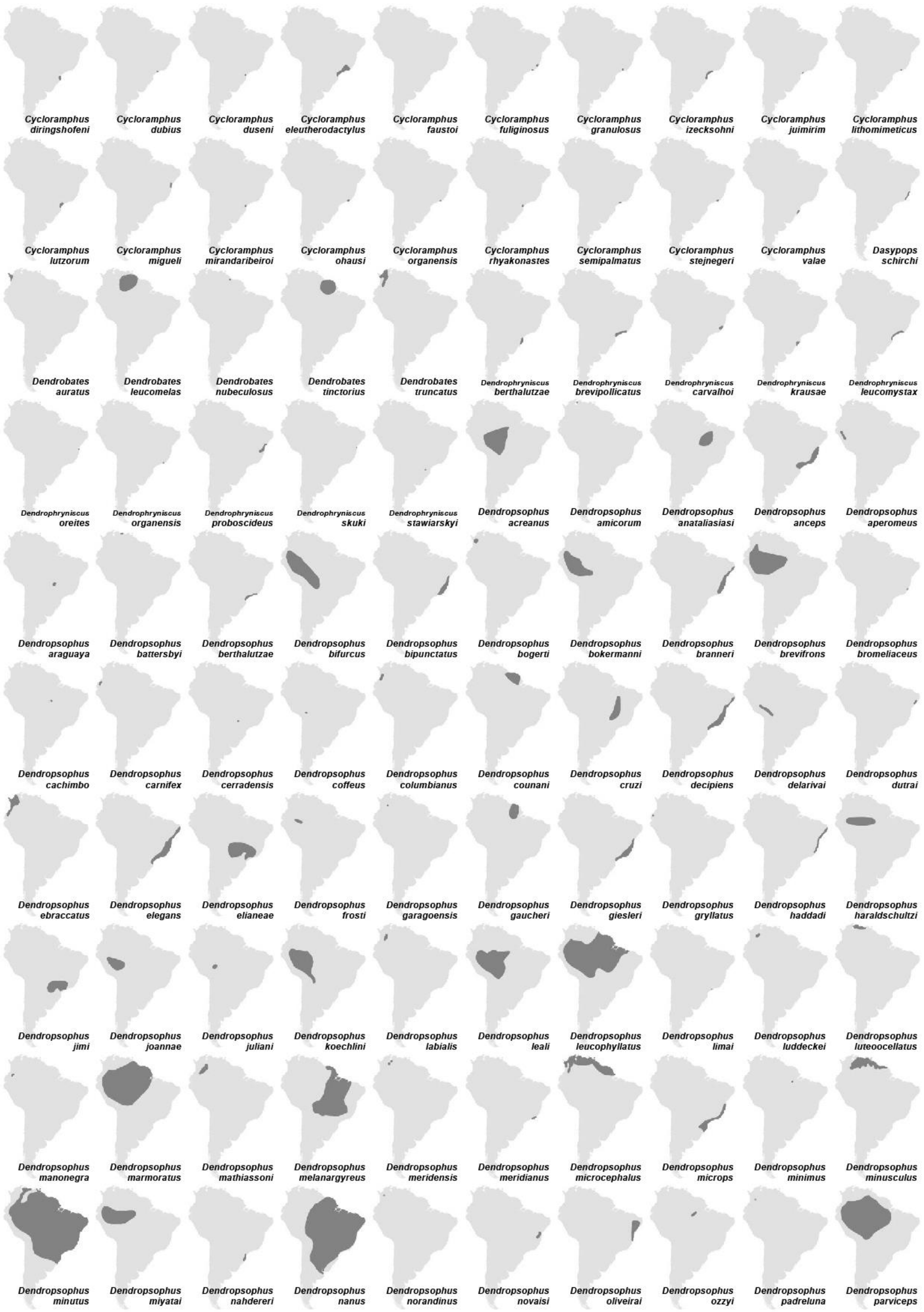




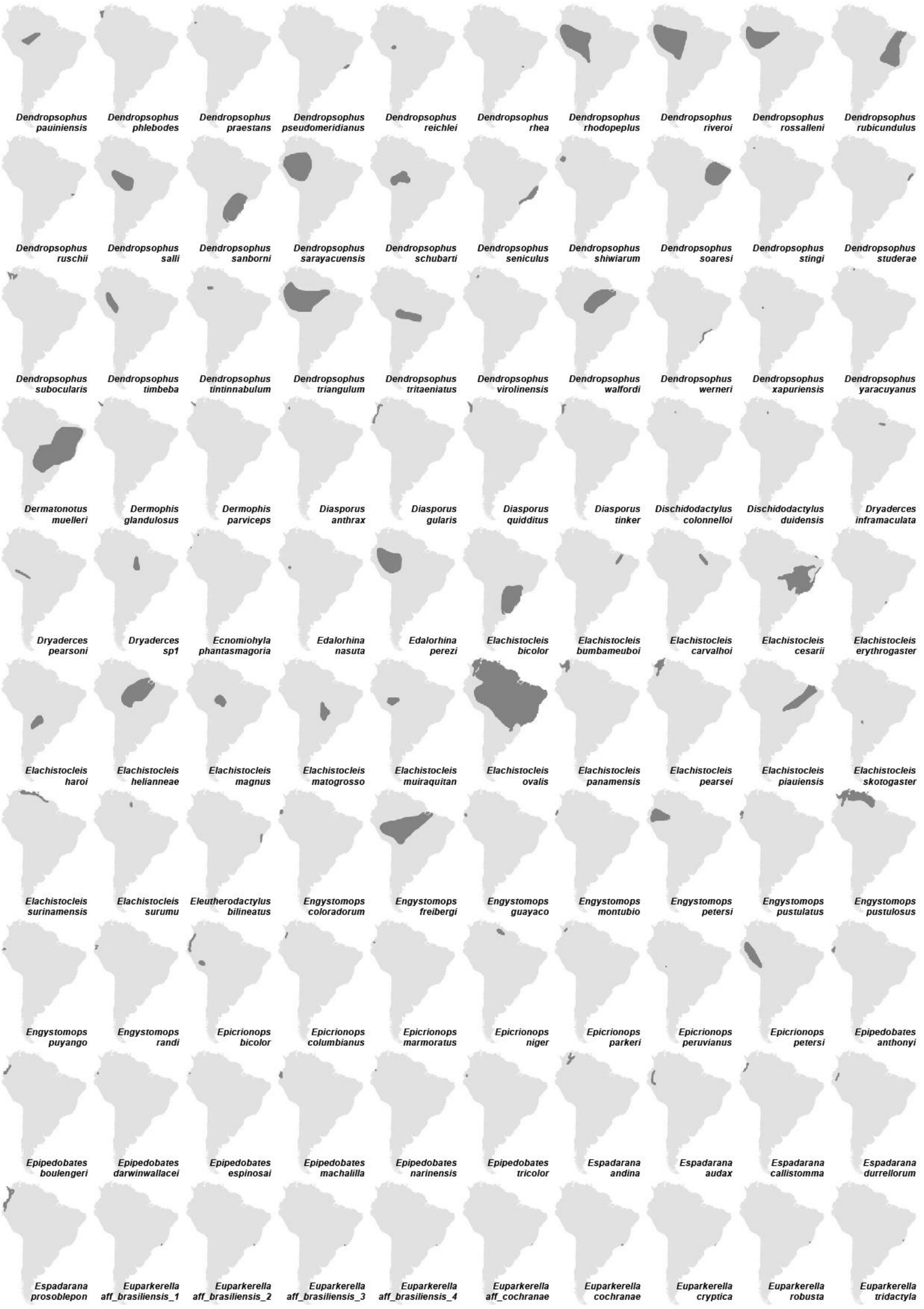




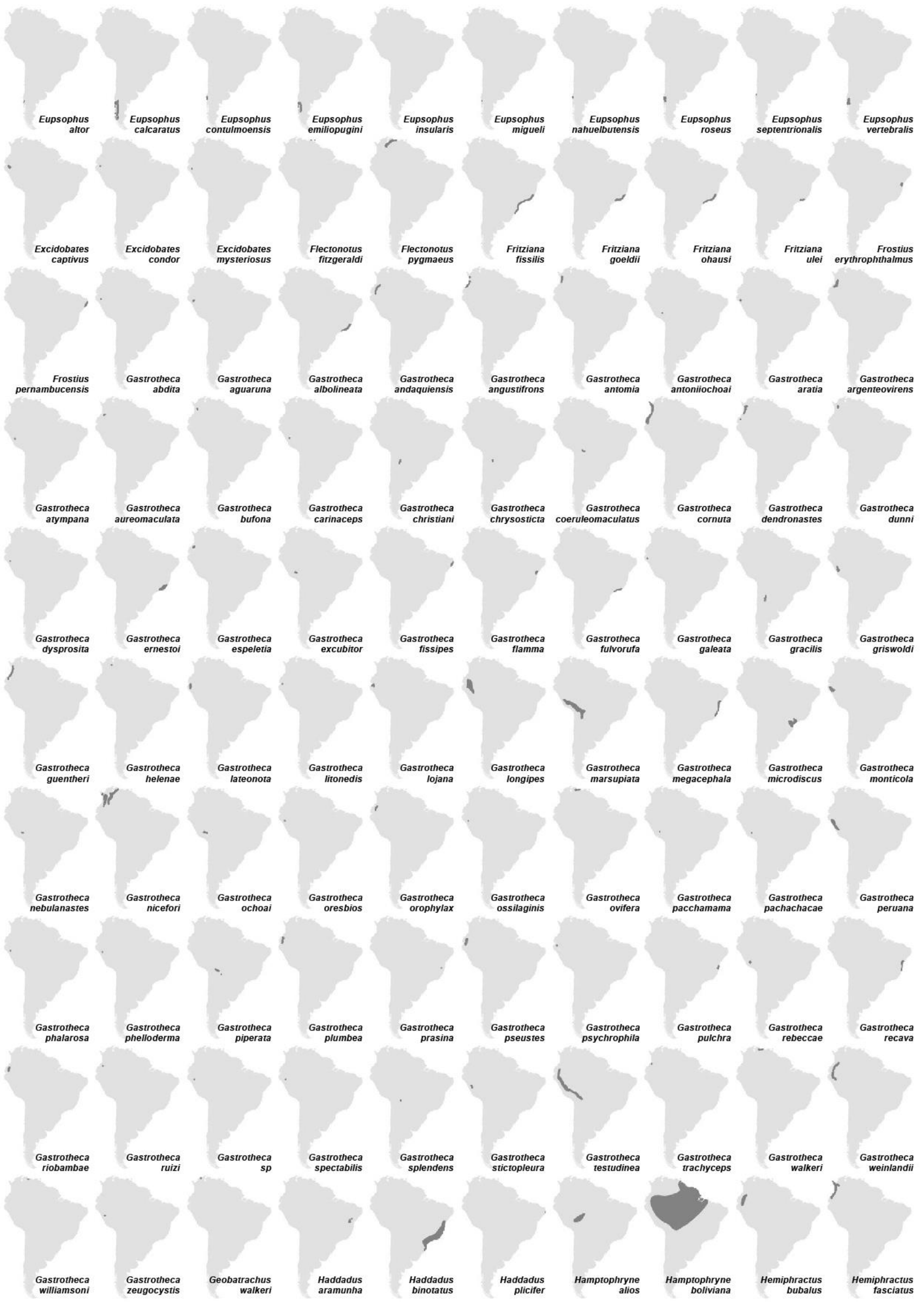




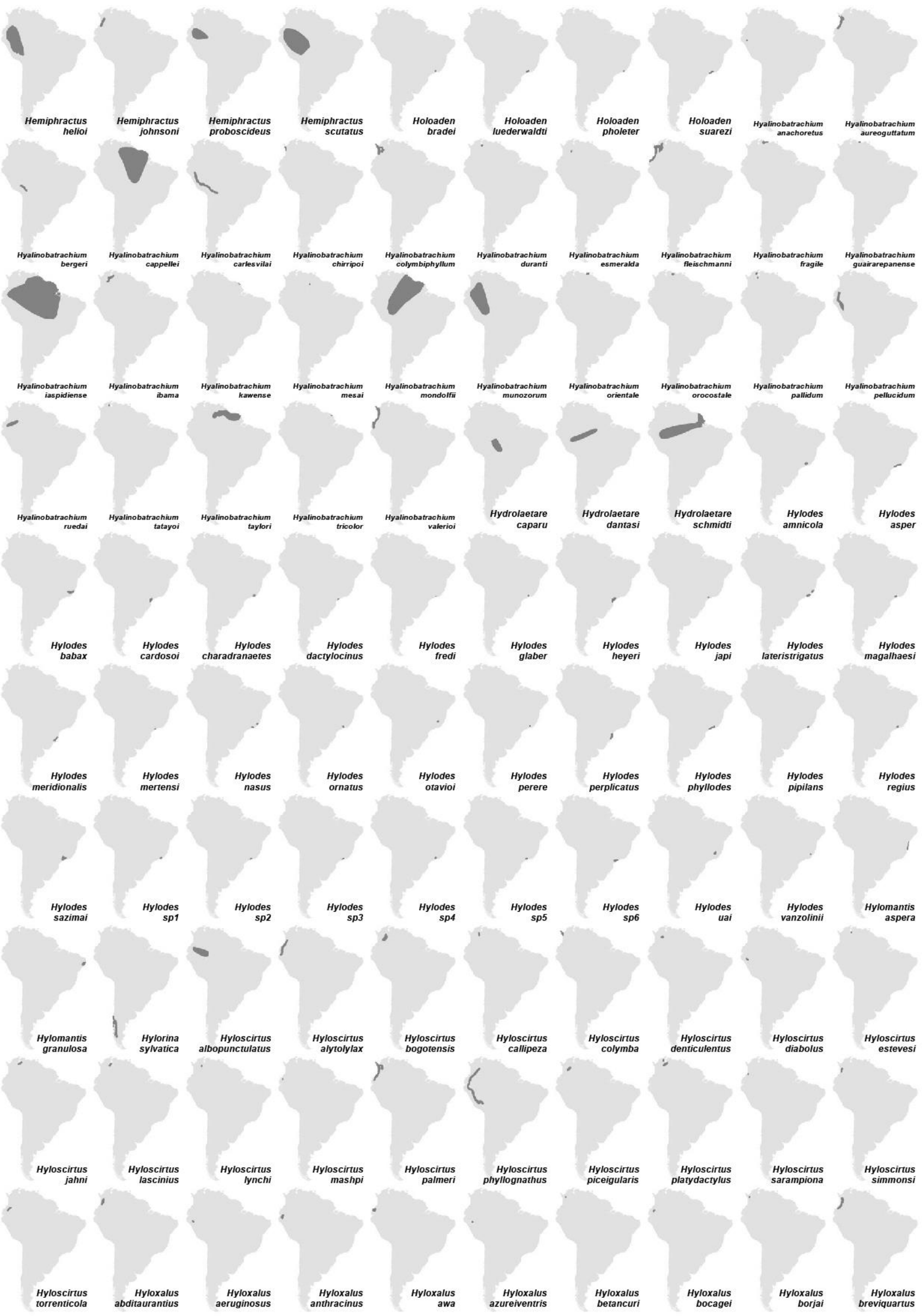




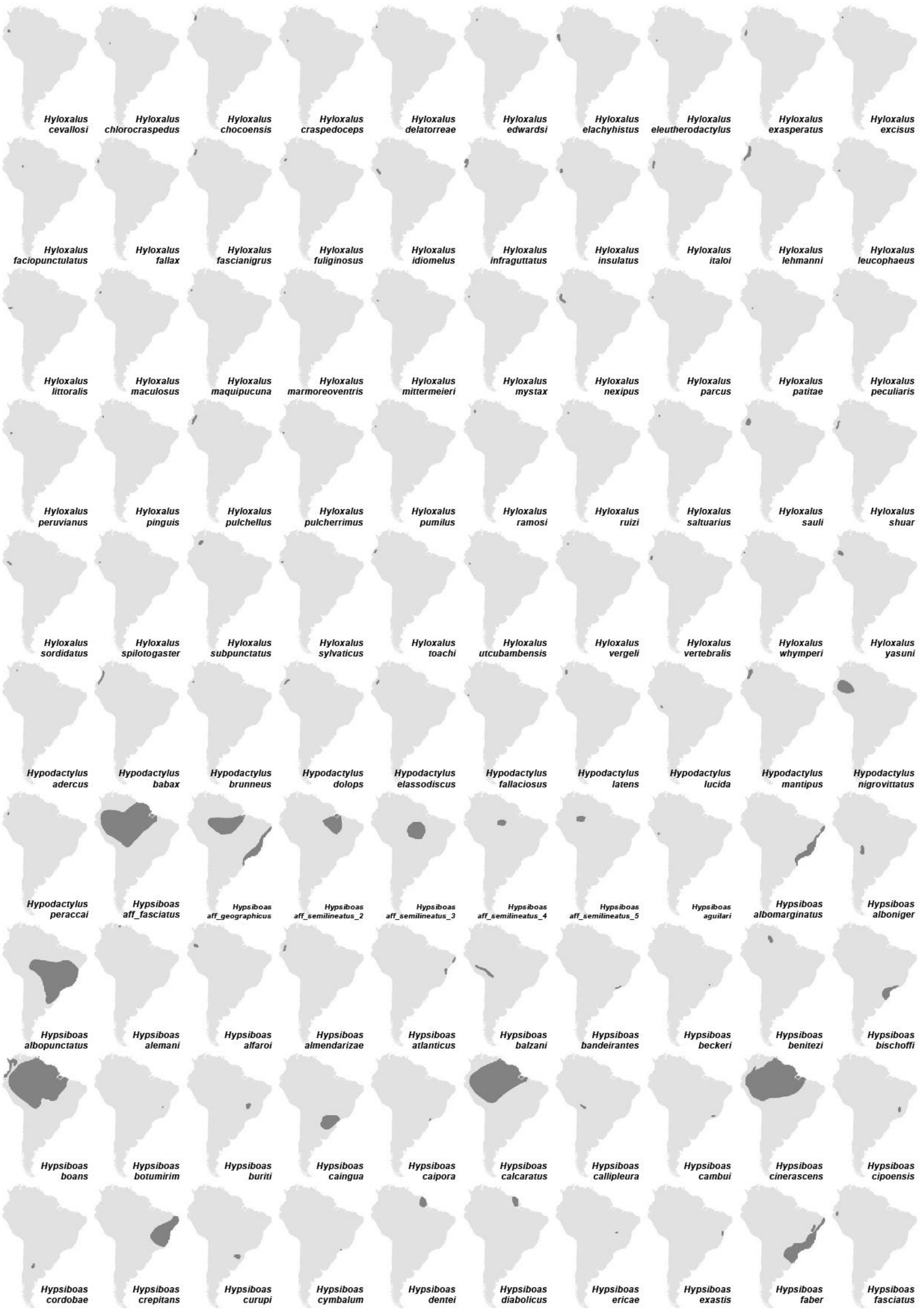




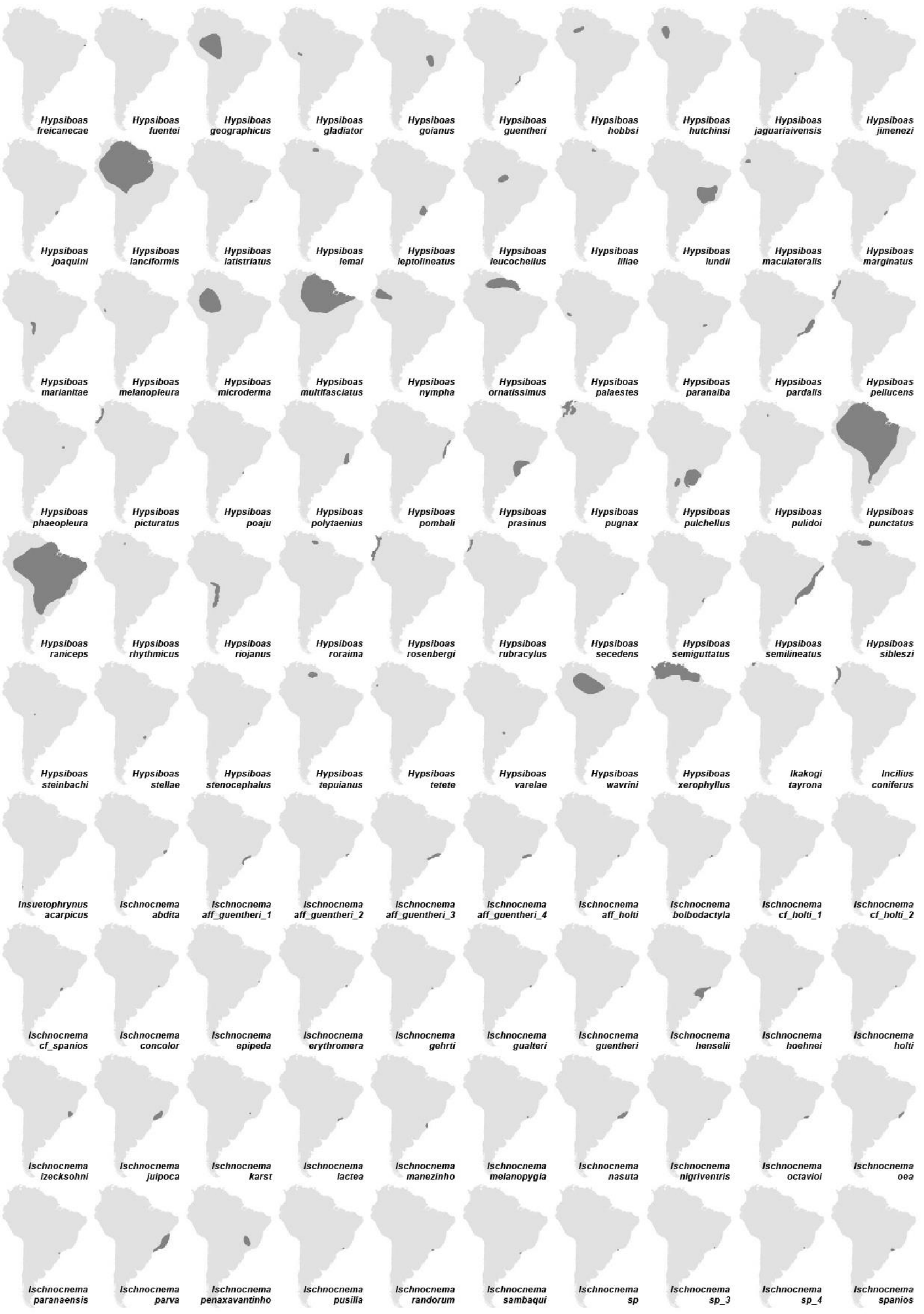




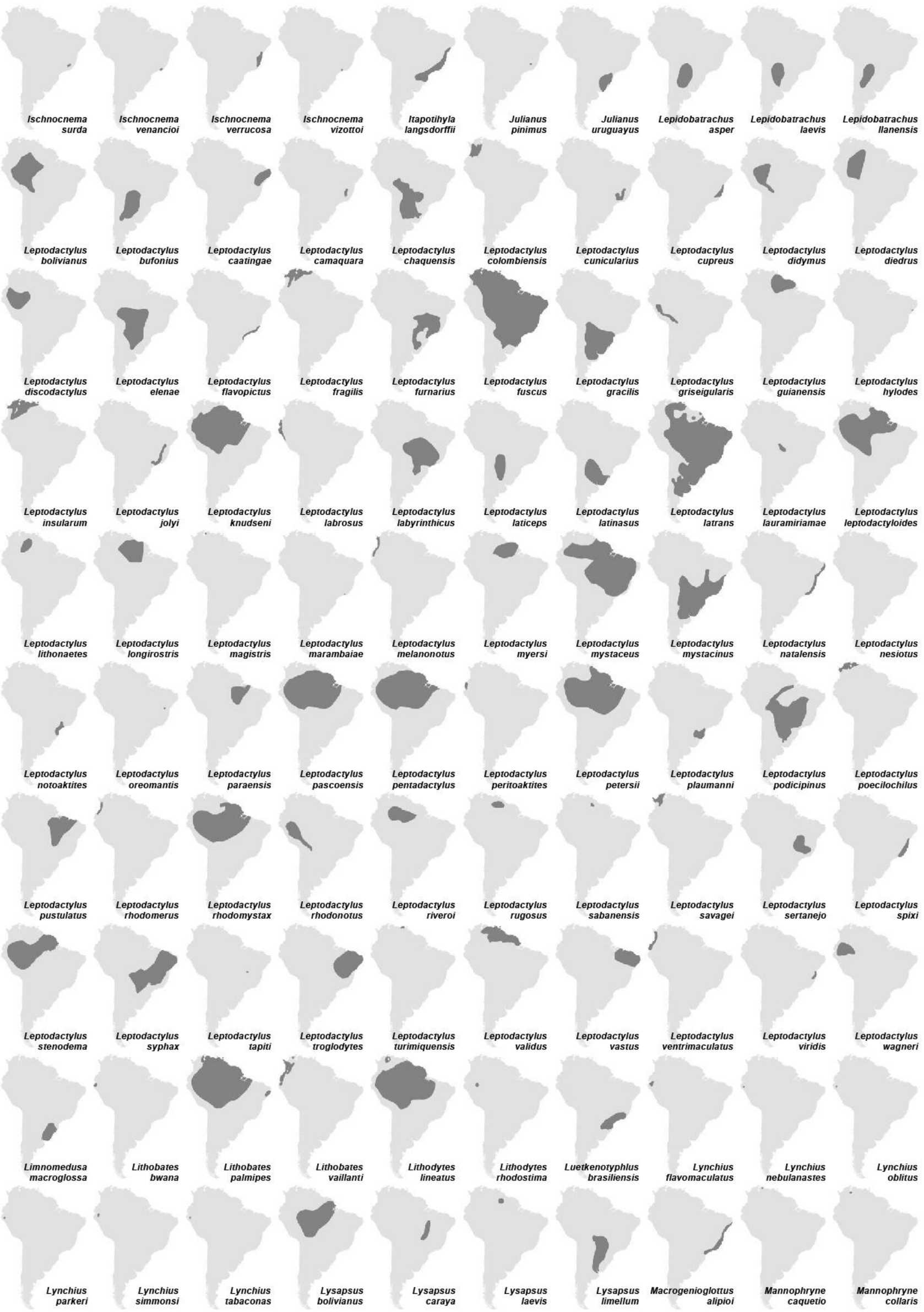




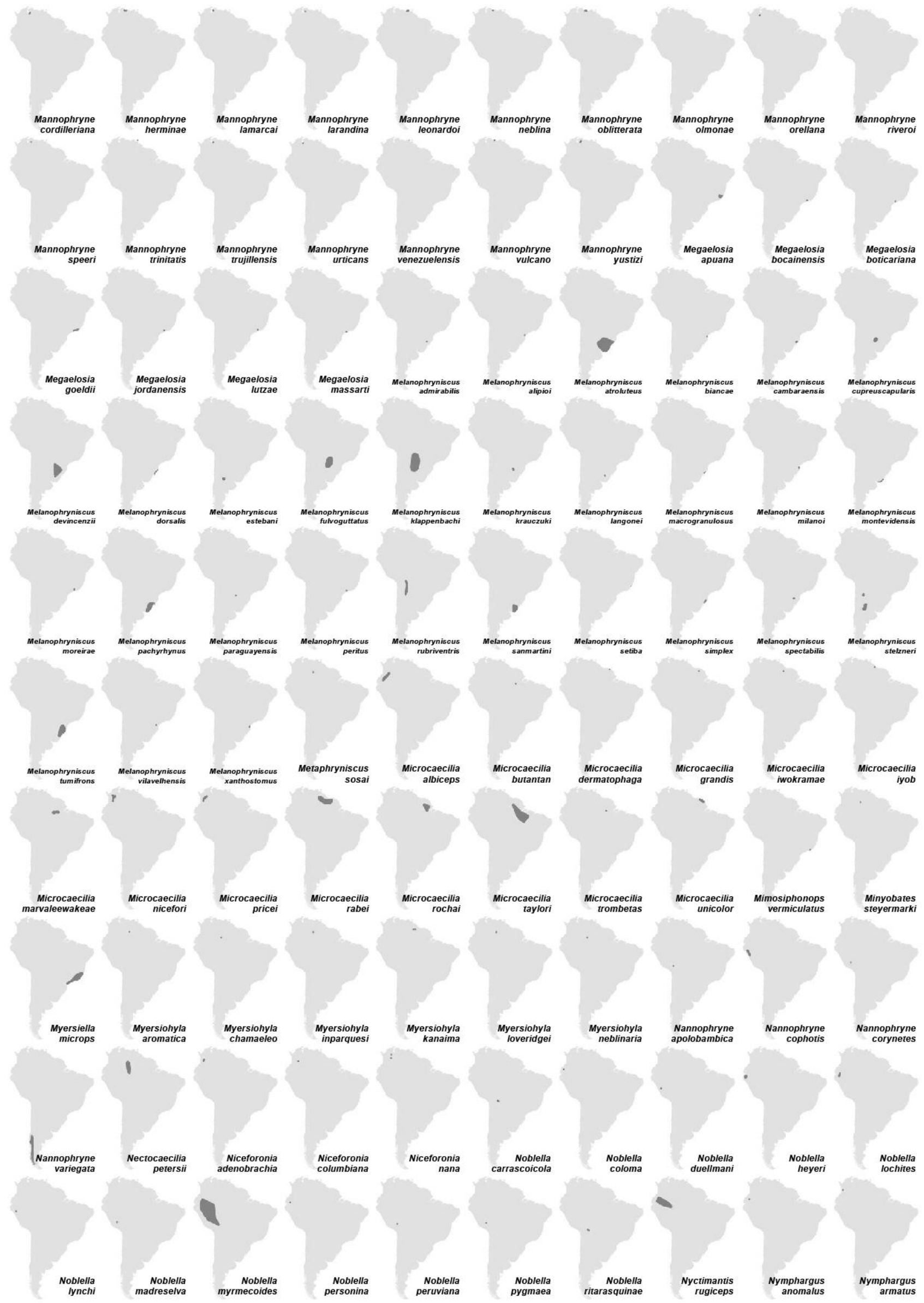




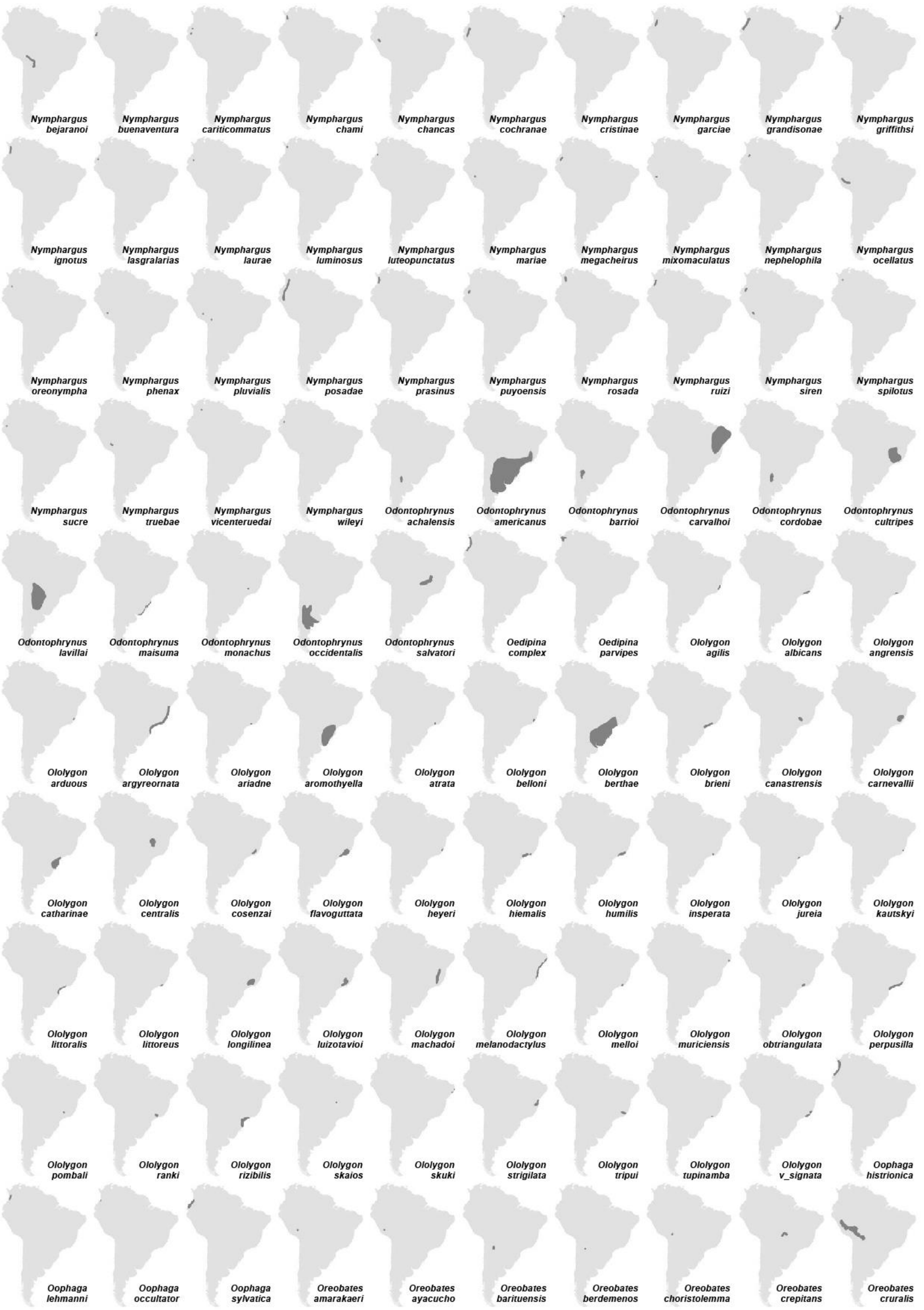




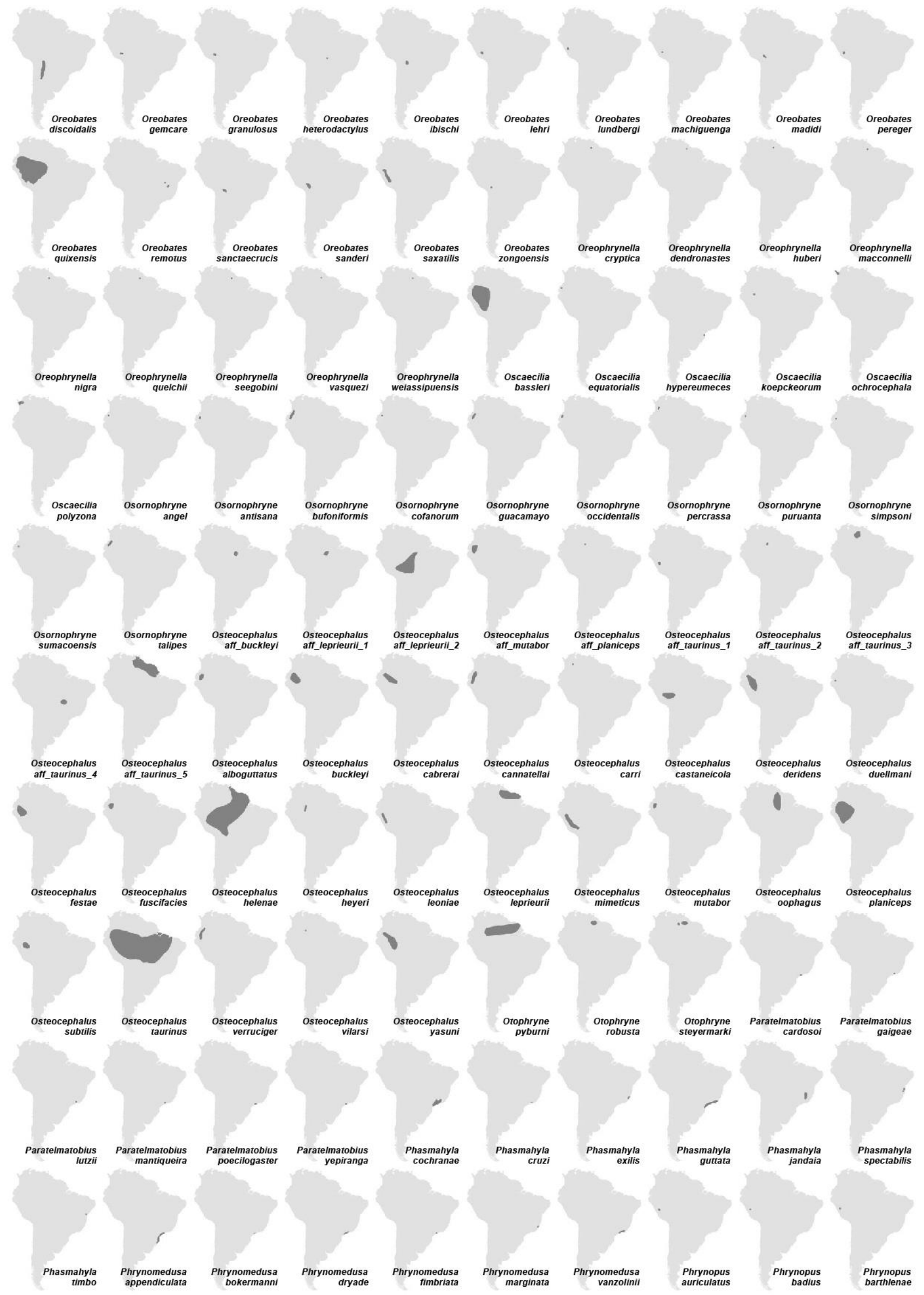




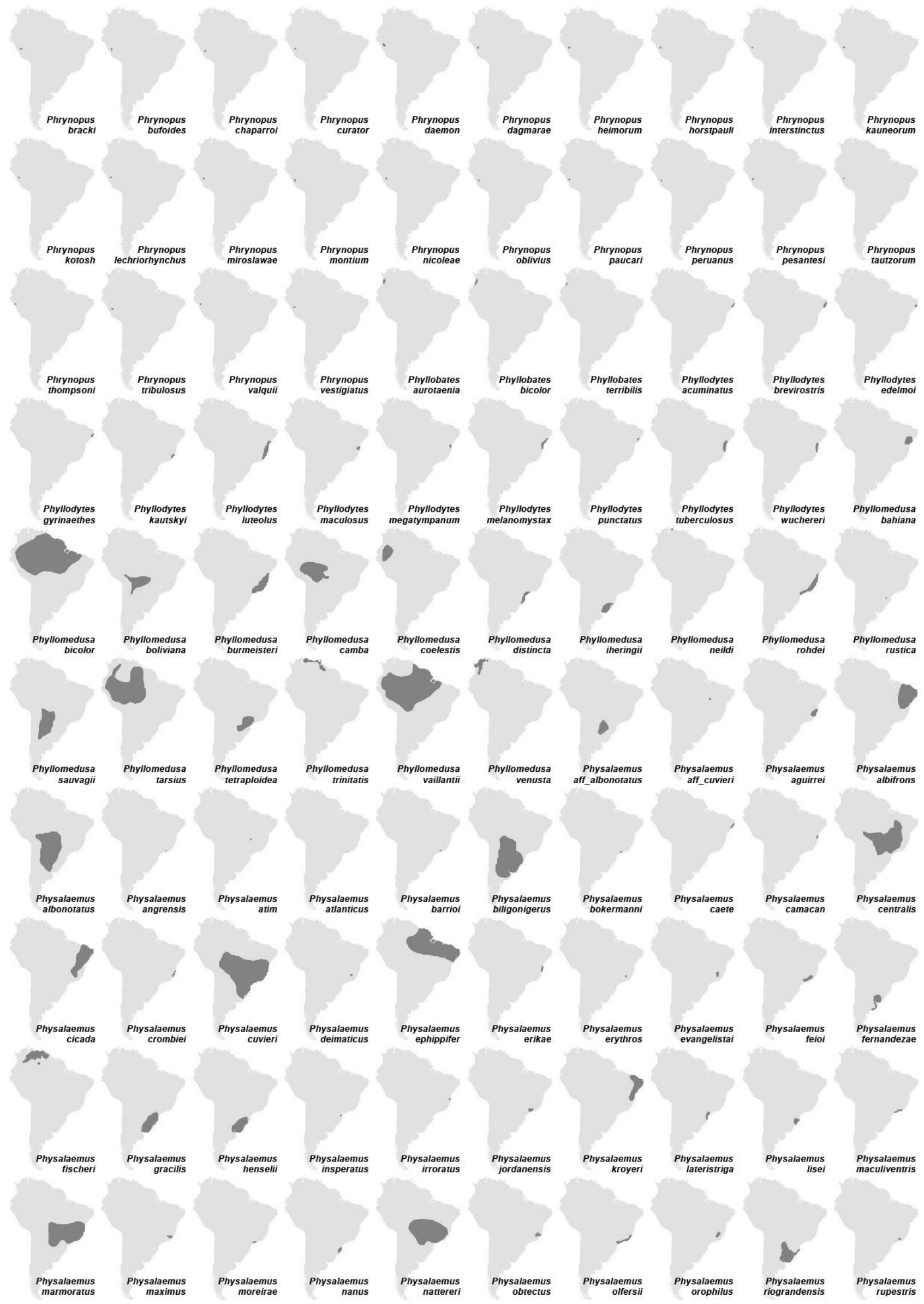




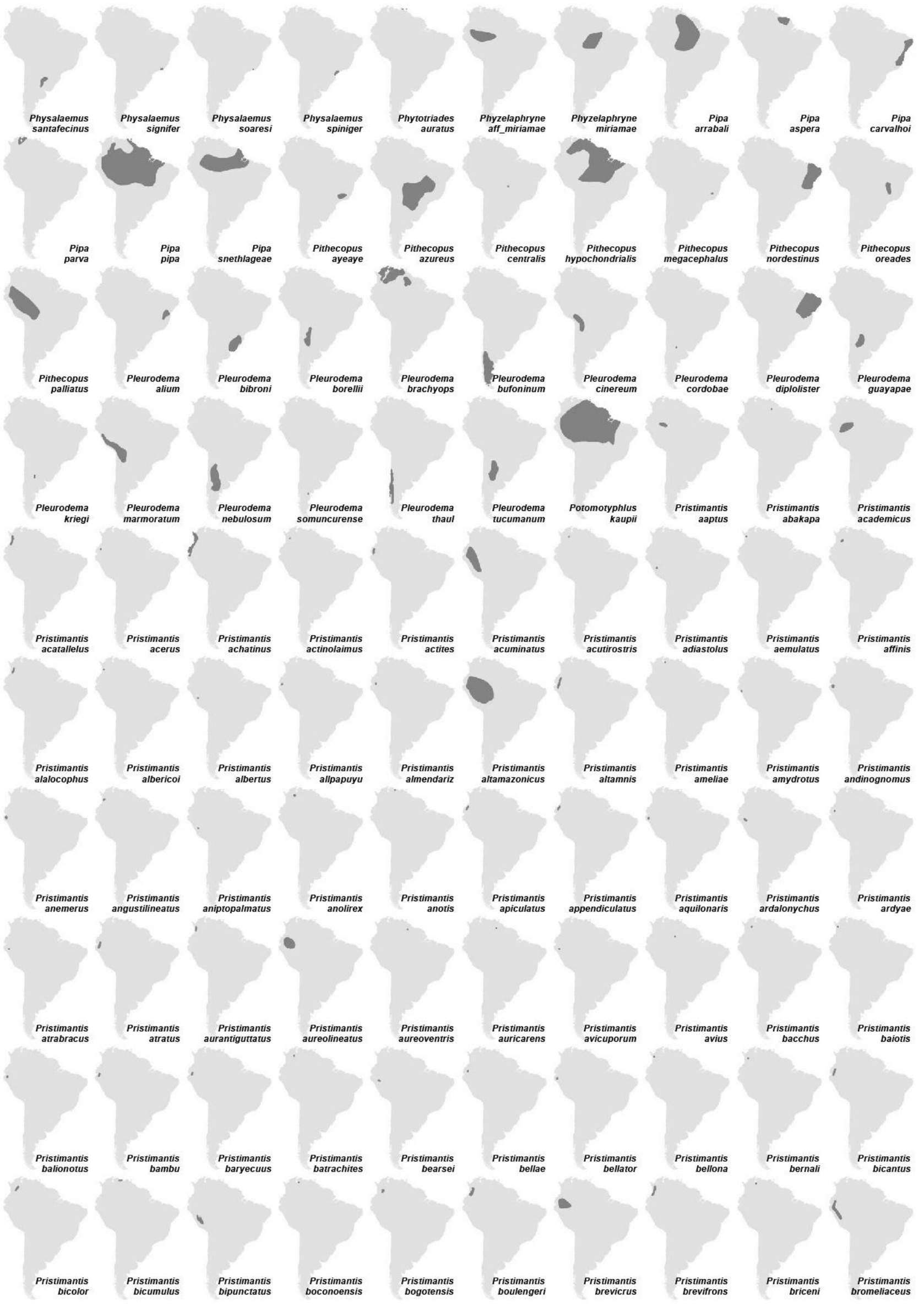




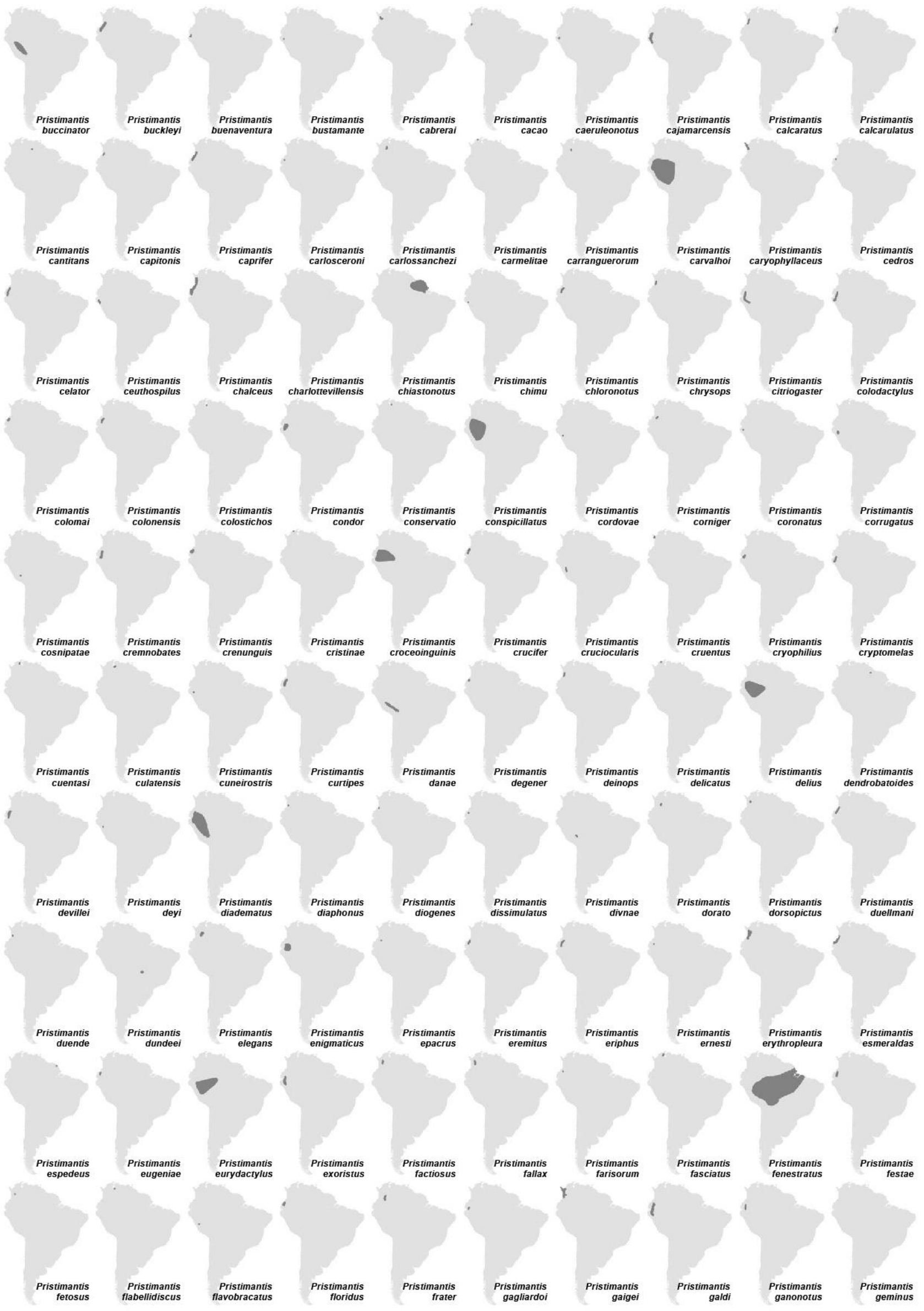




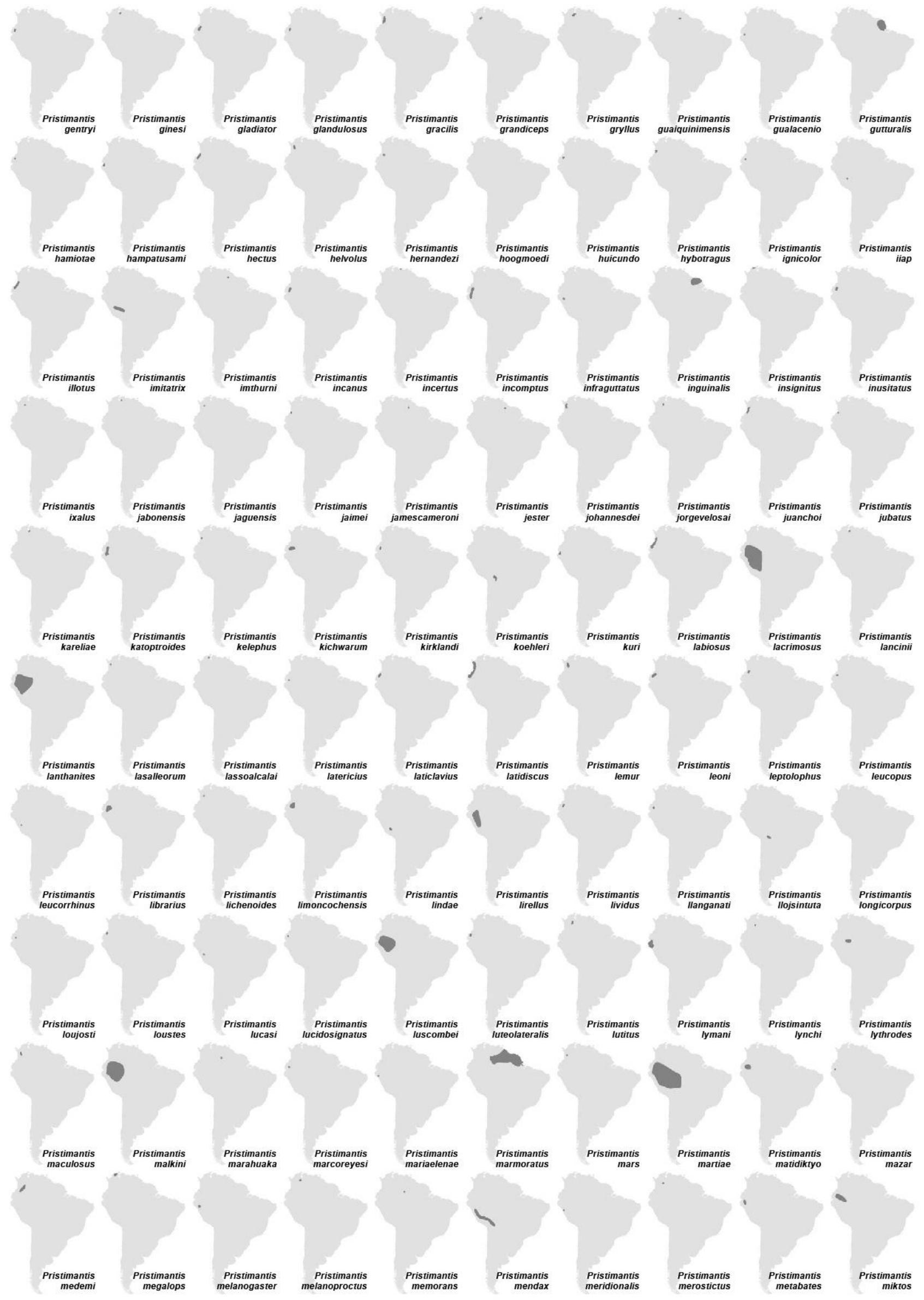




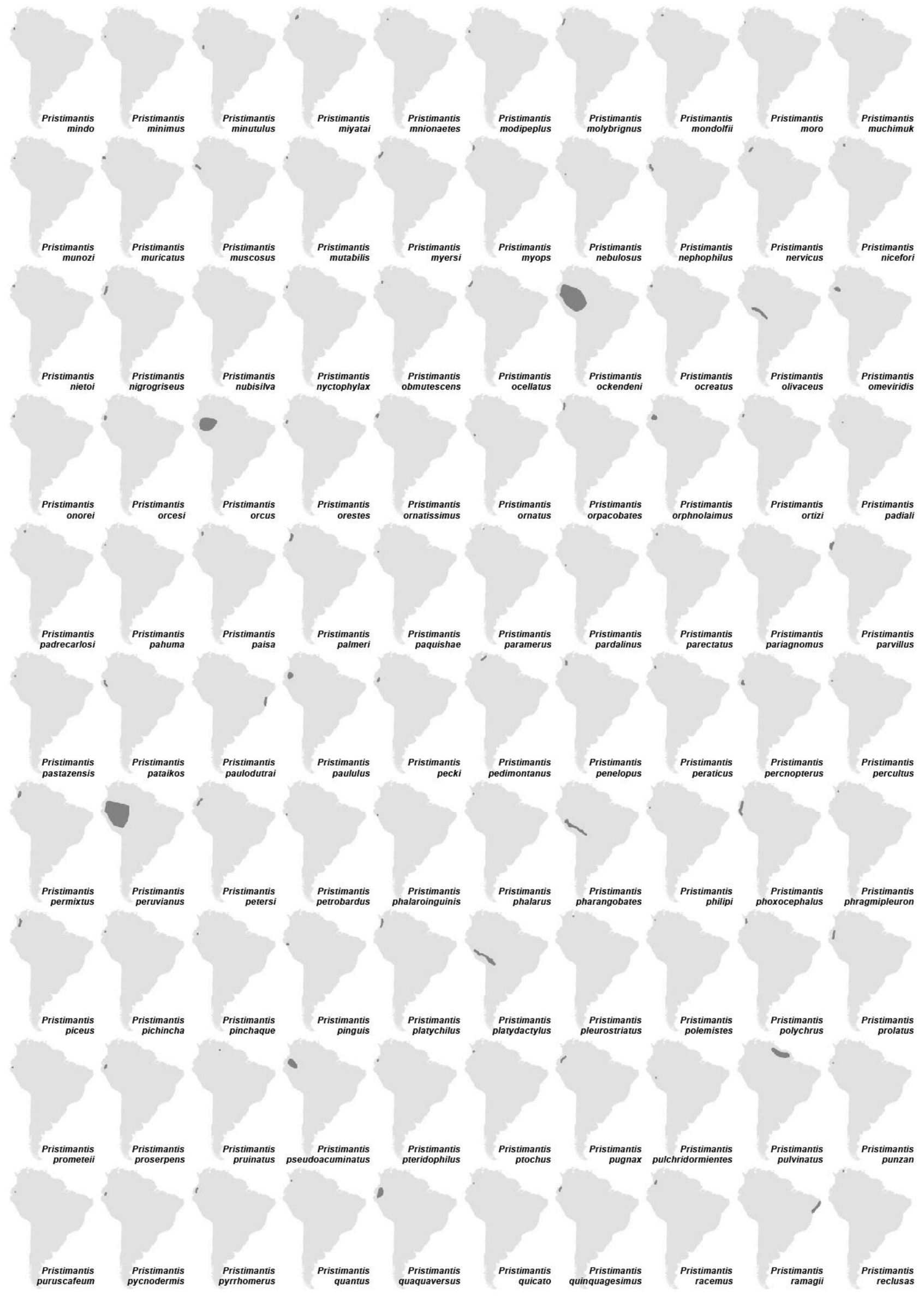




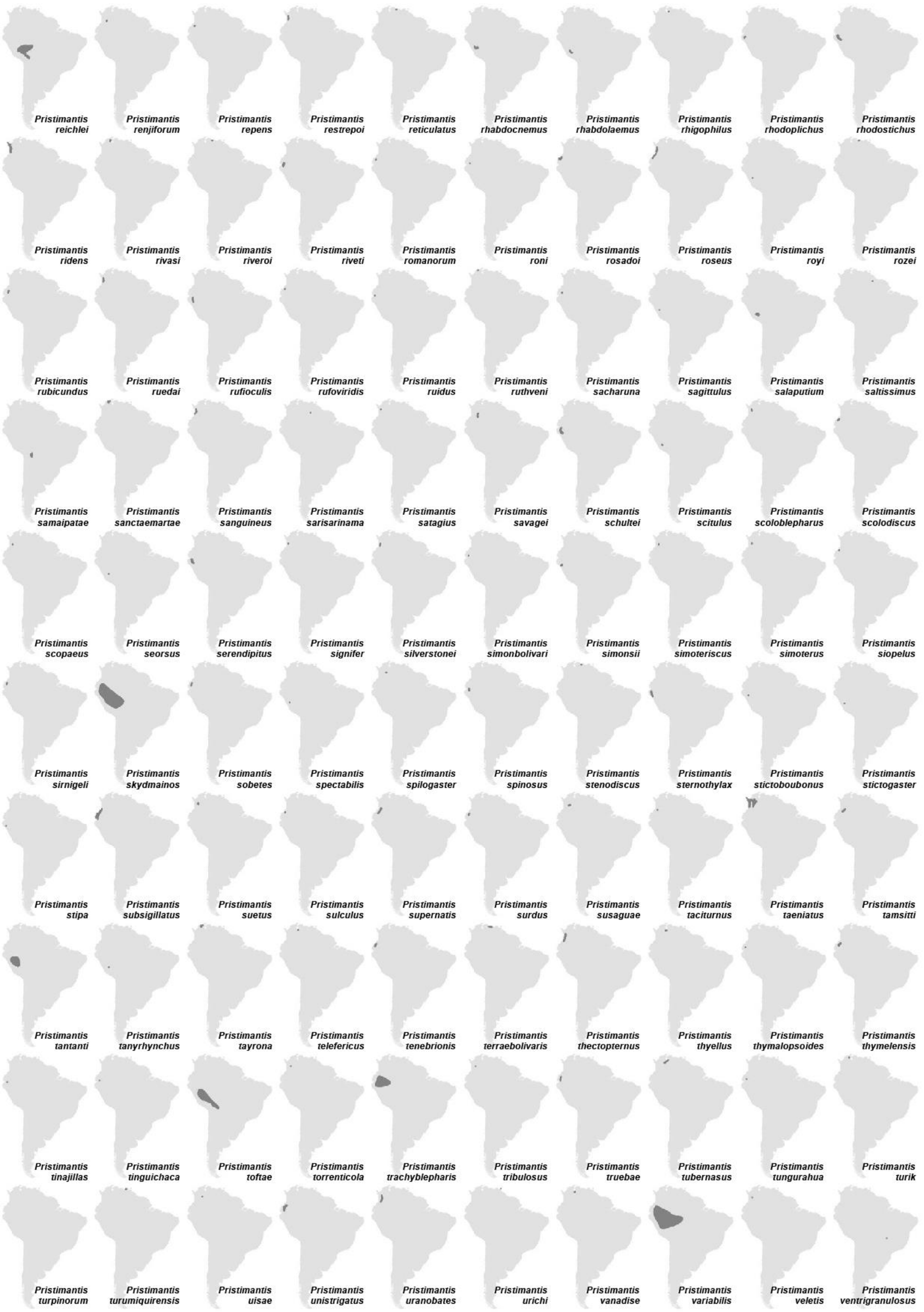




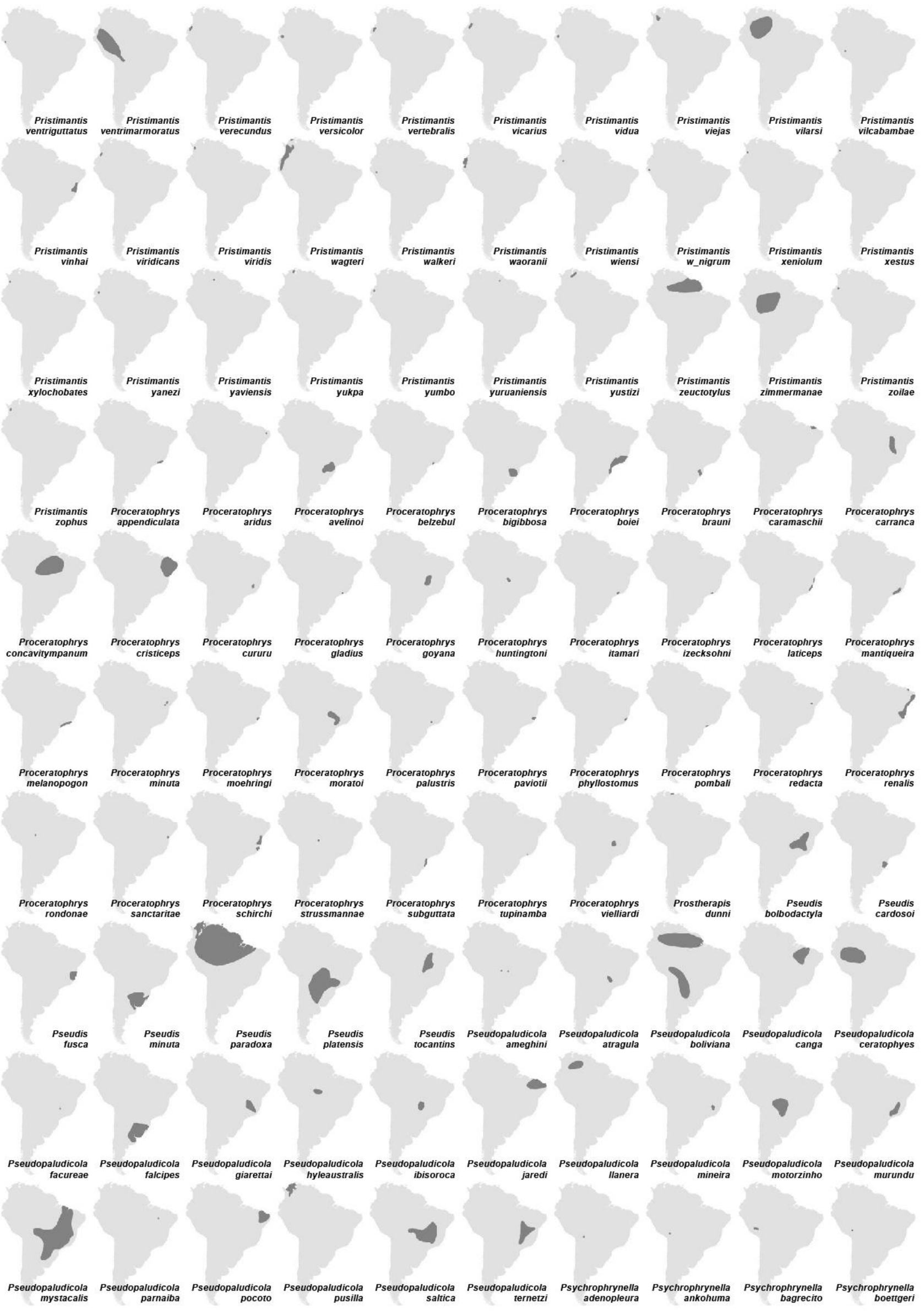




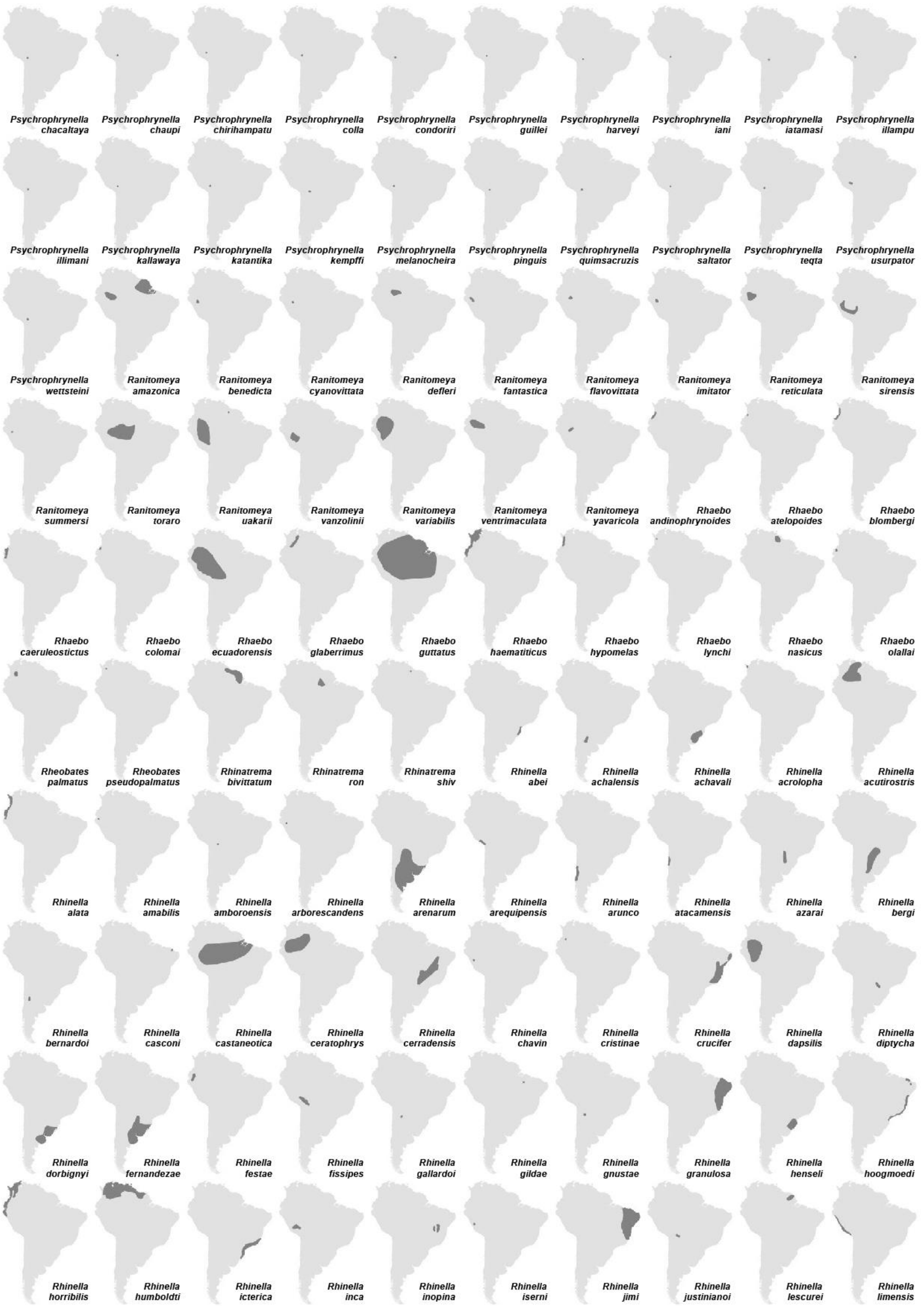




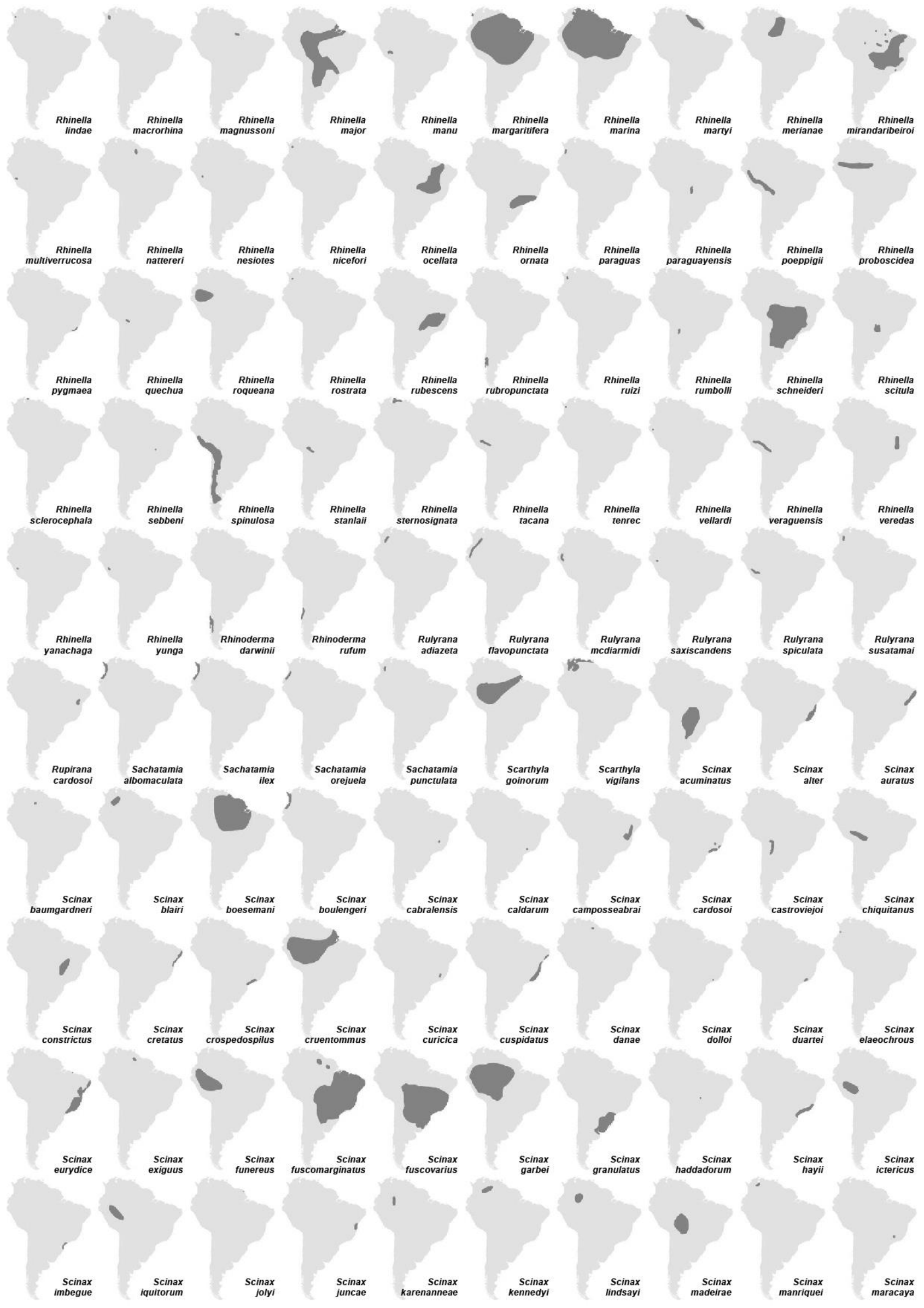




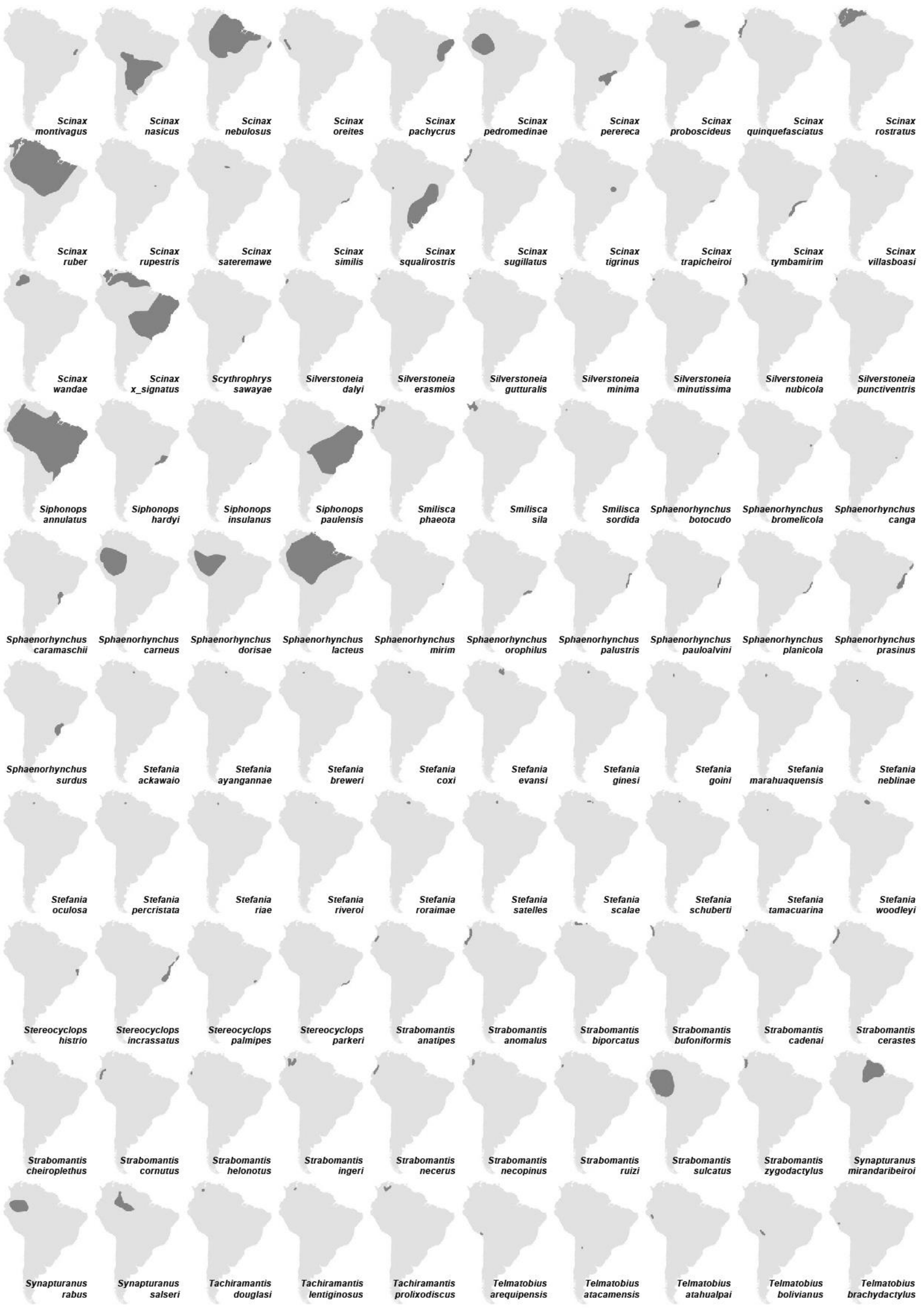




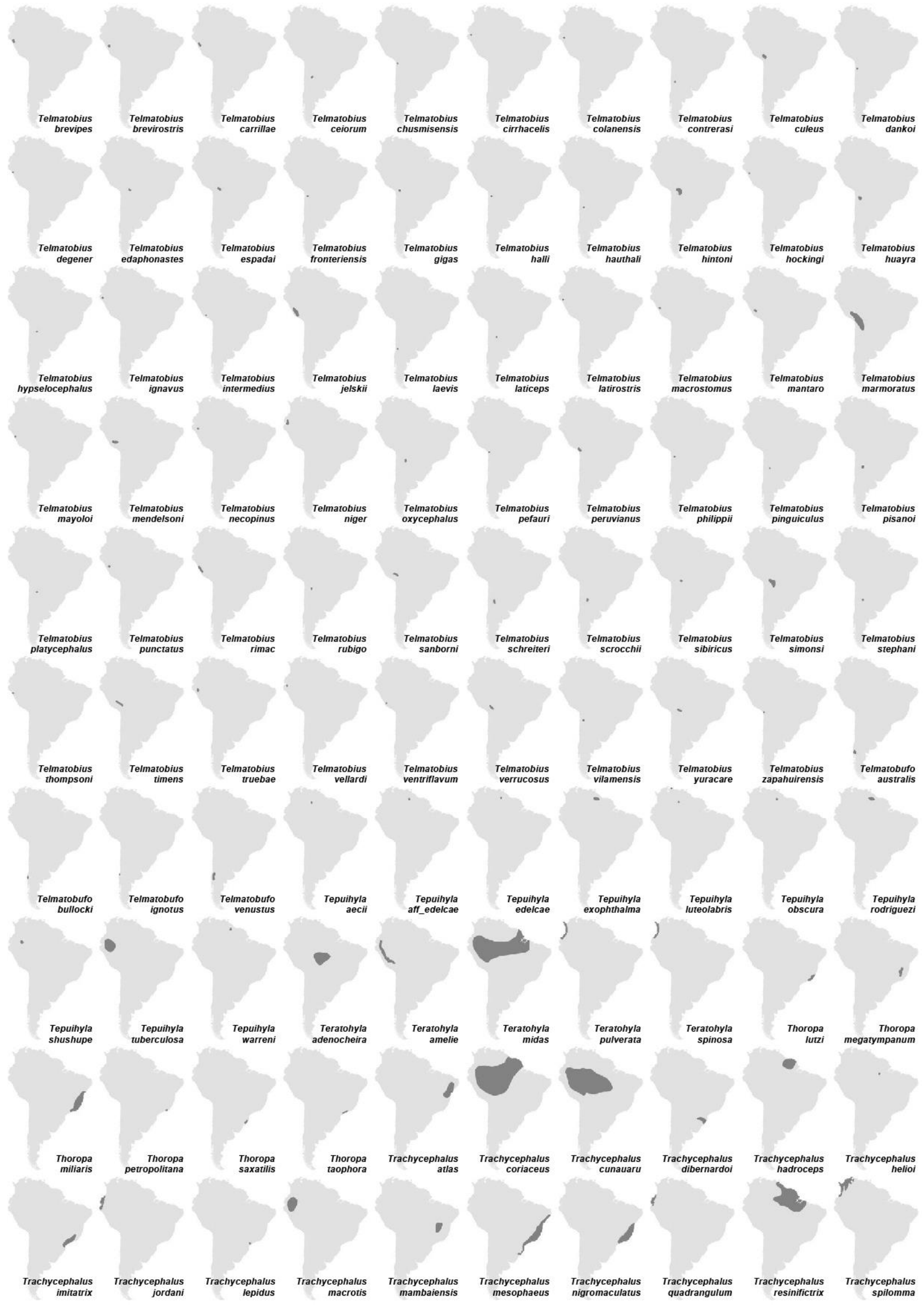




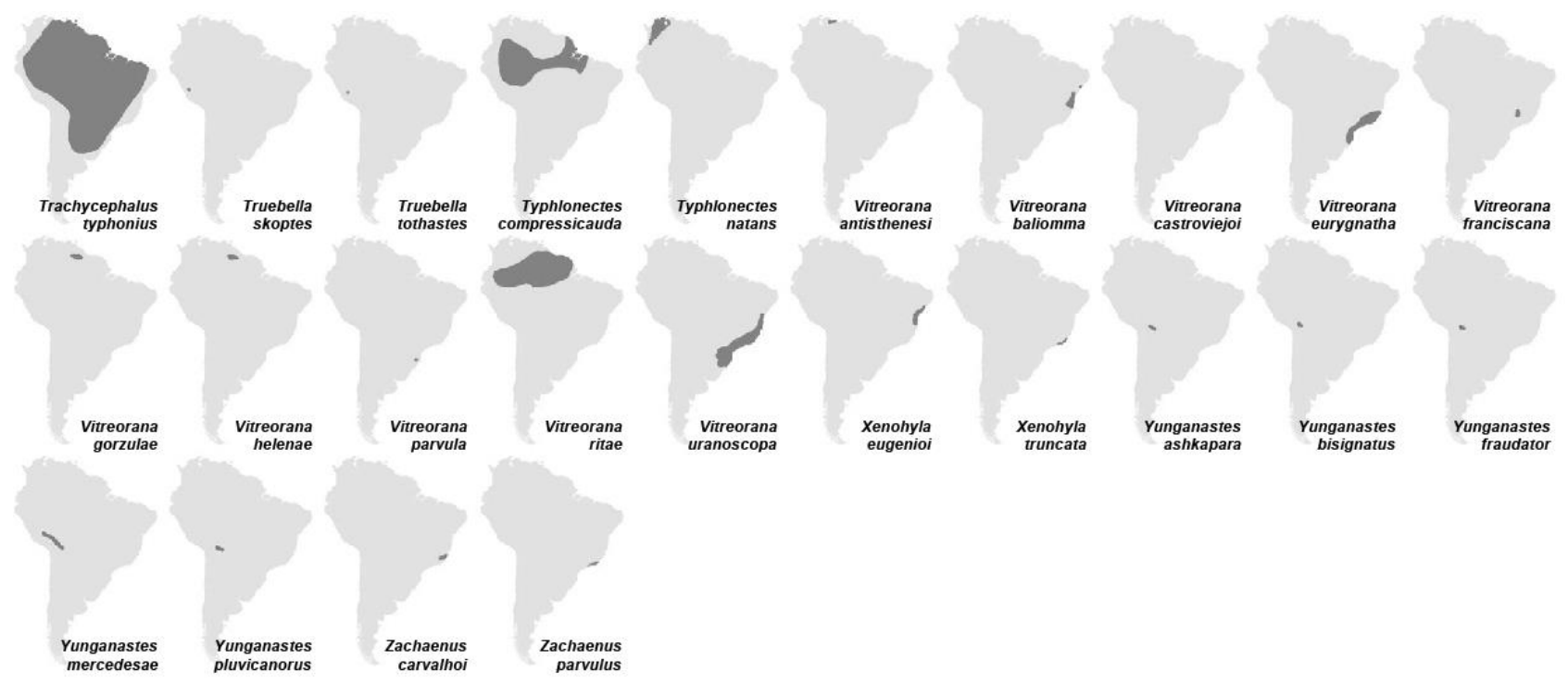




\section{Répteis}

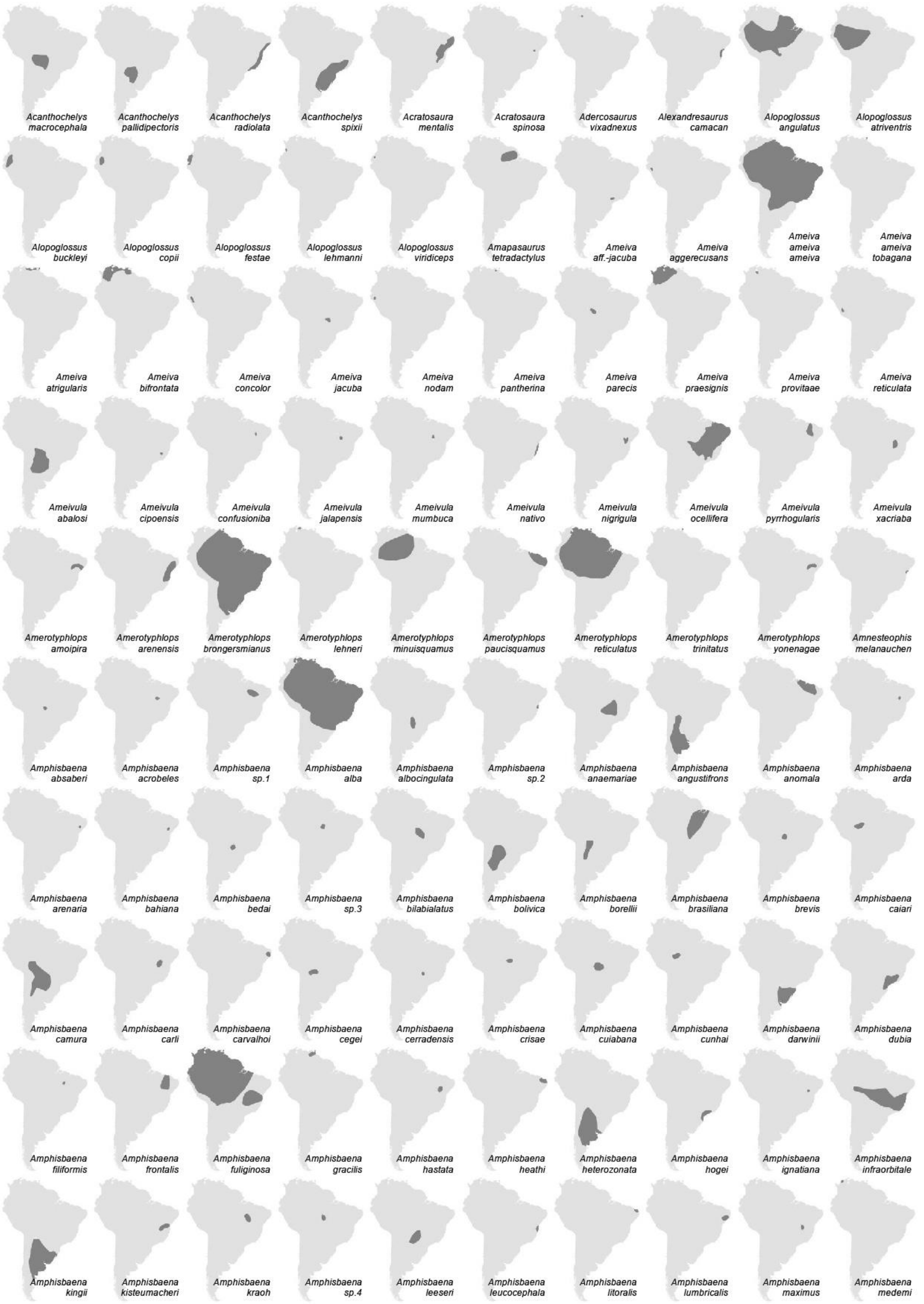




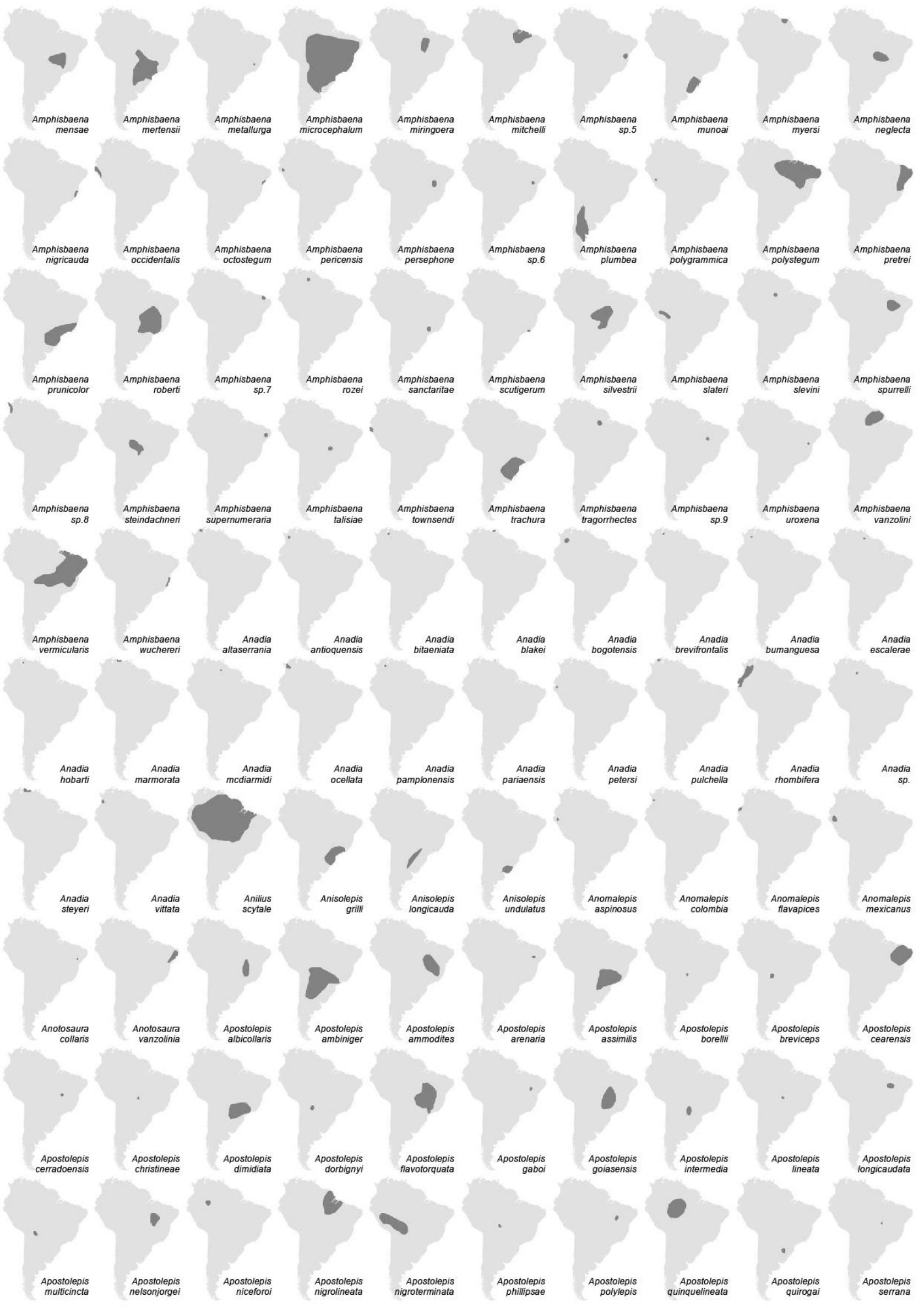




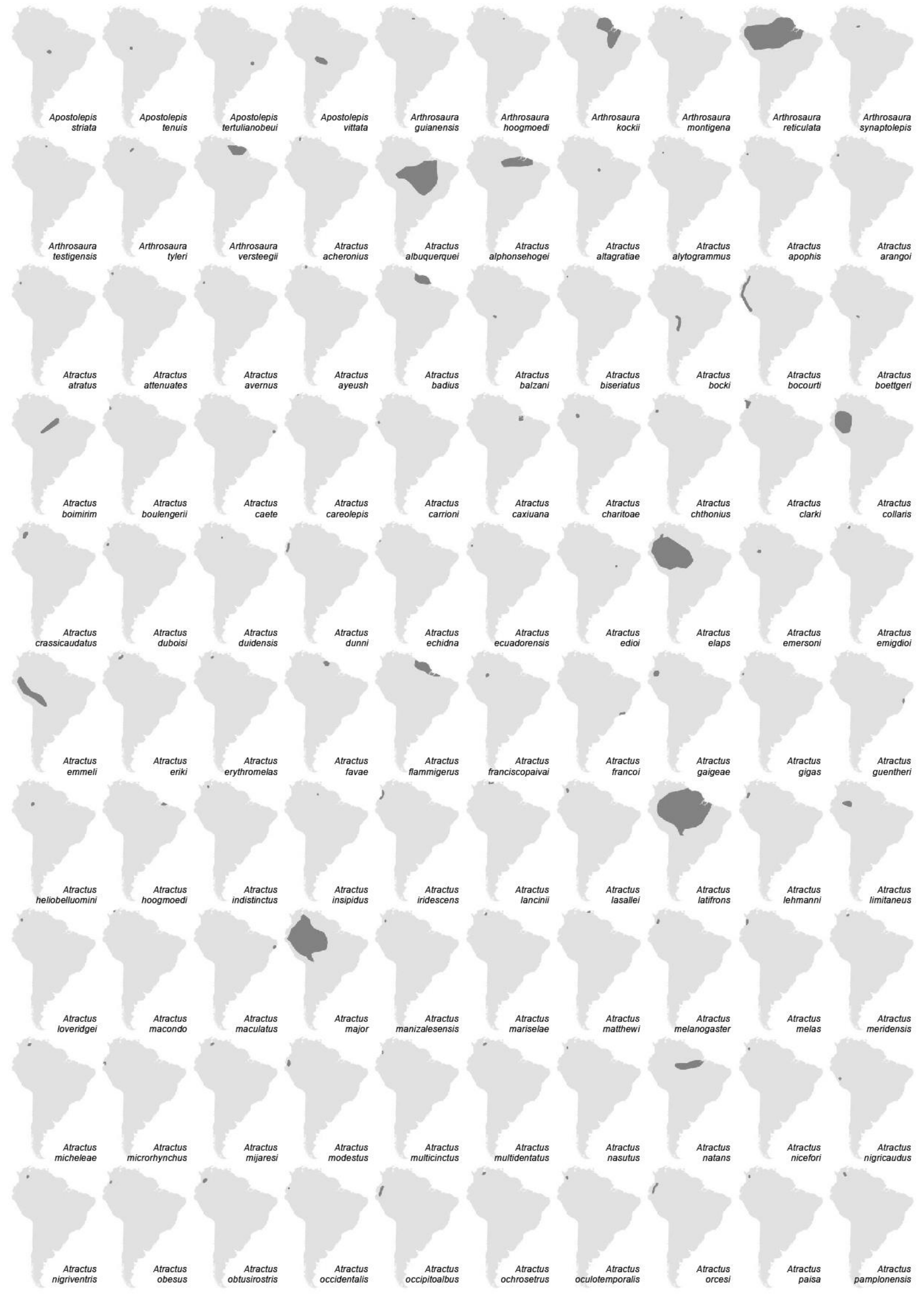




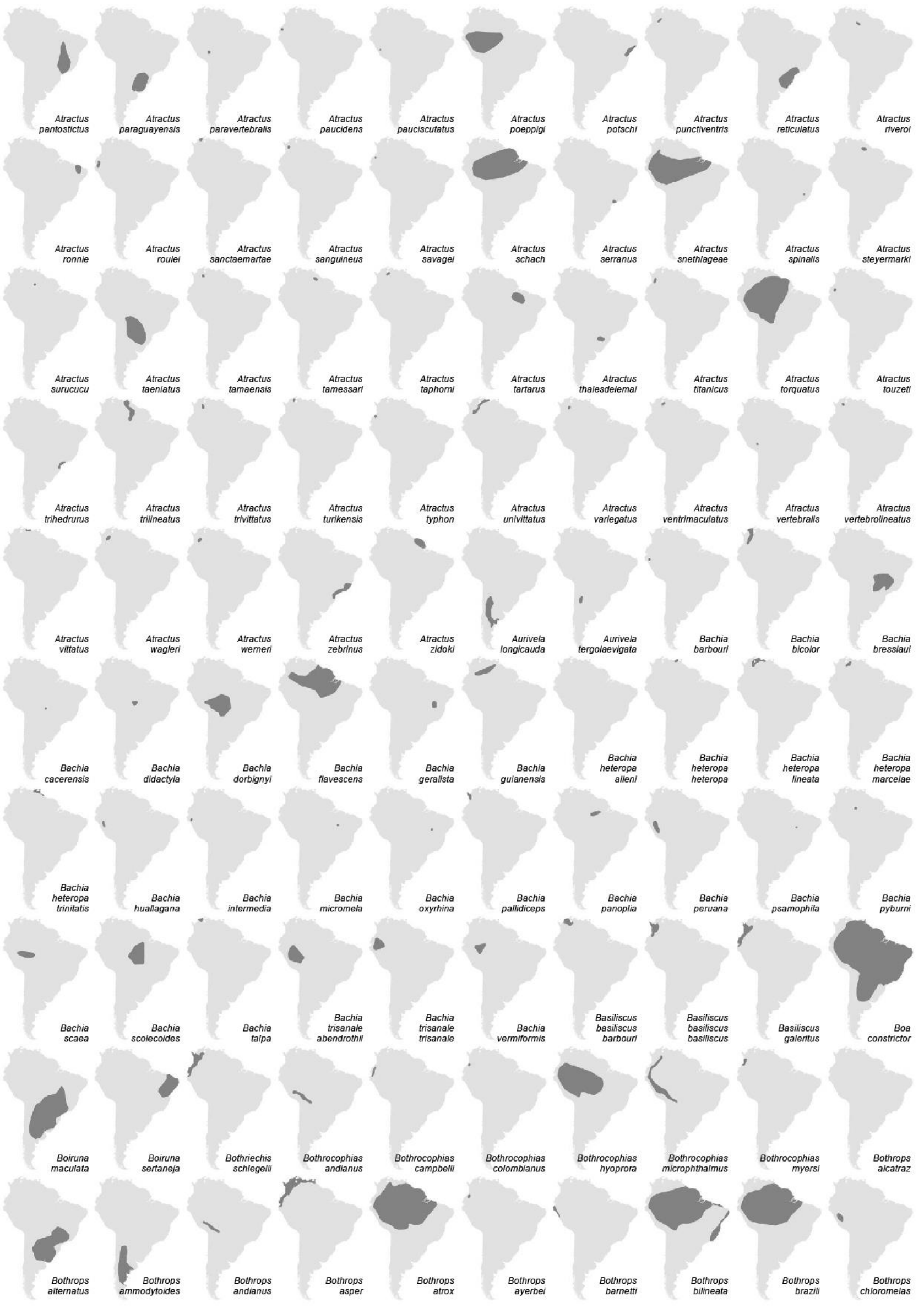




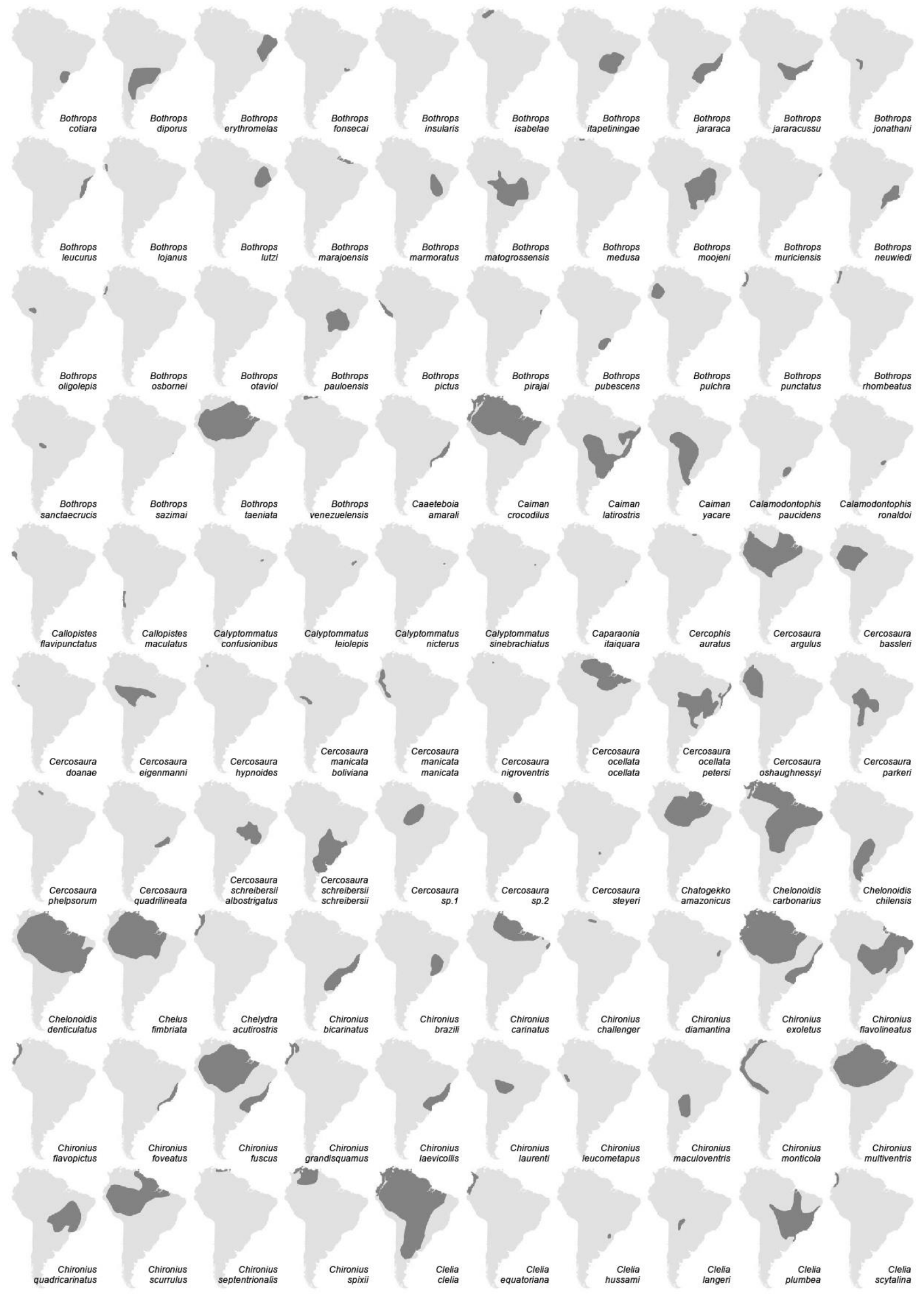




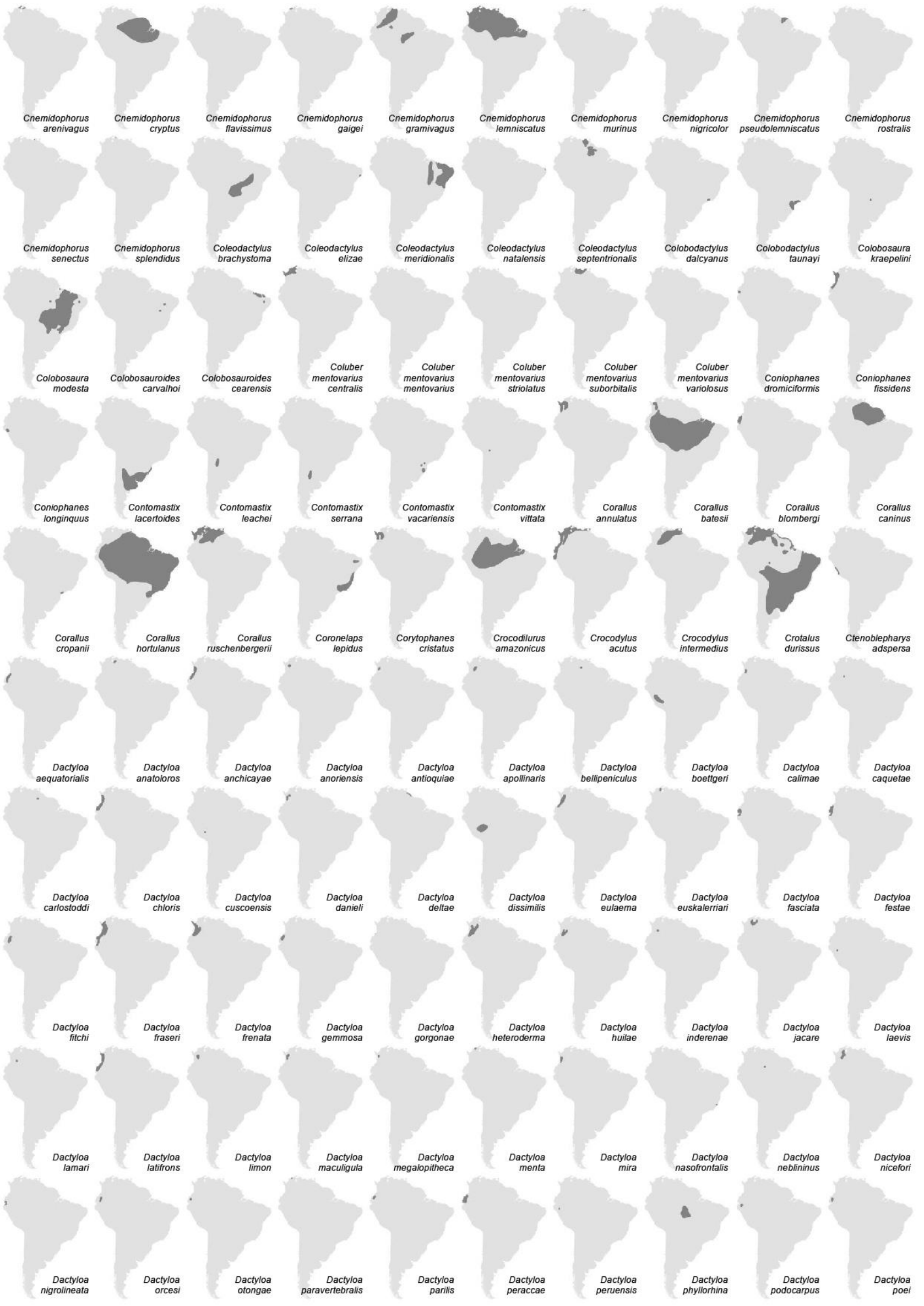




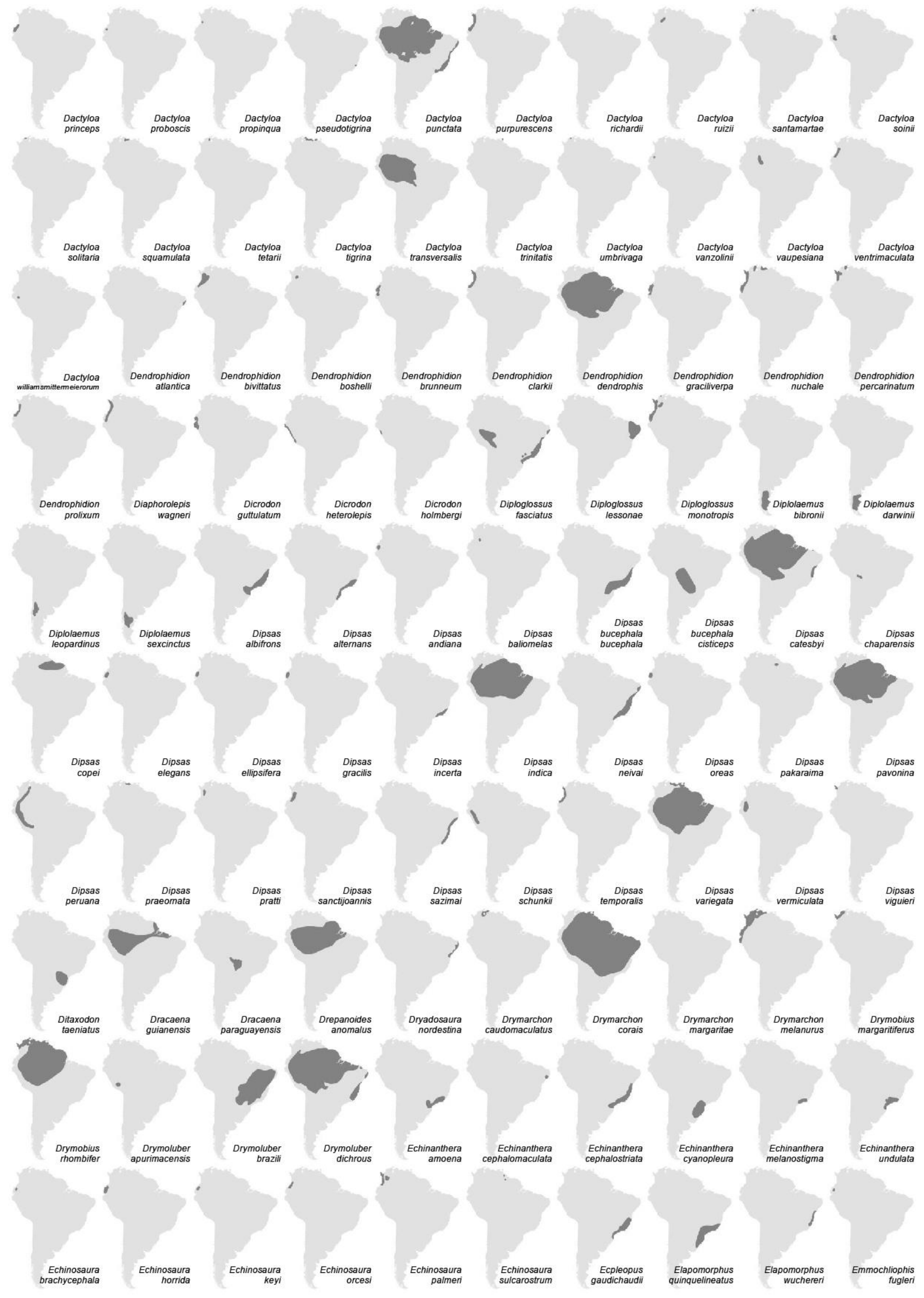




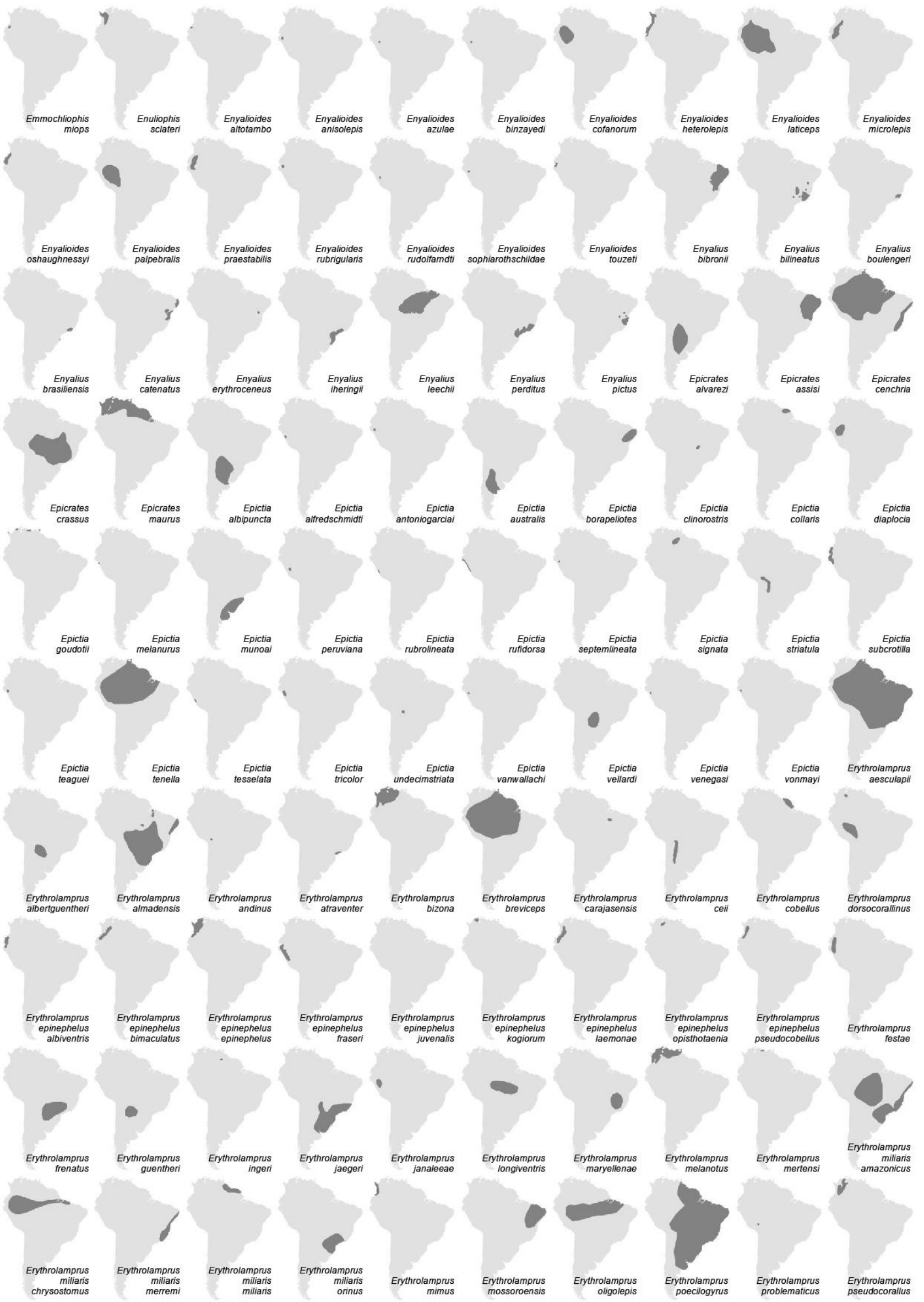




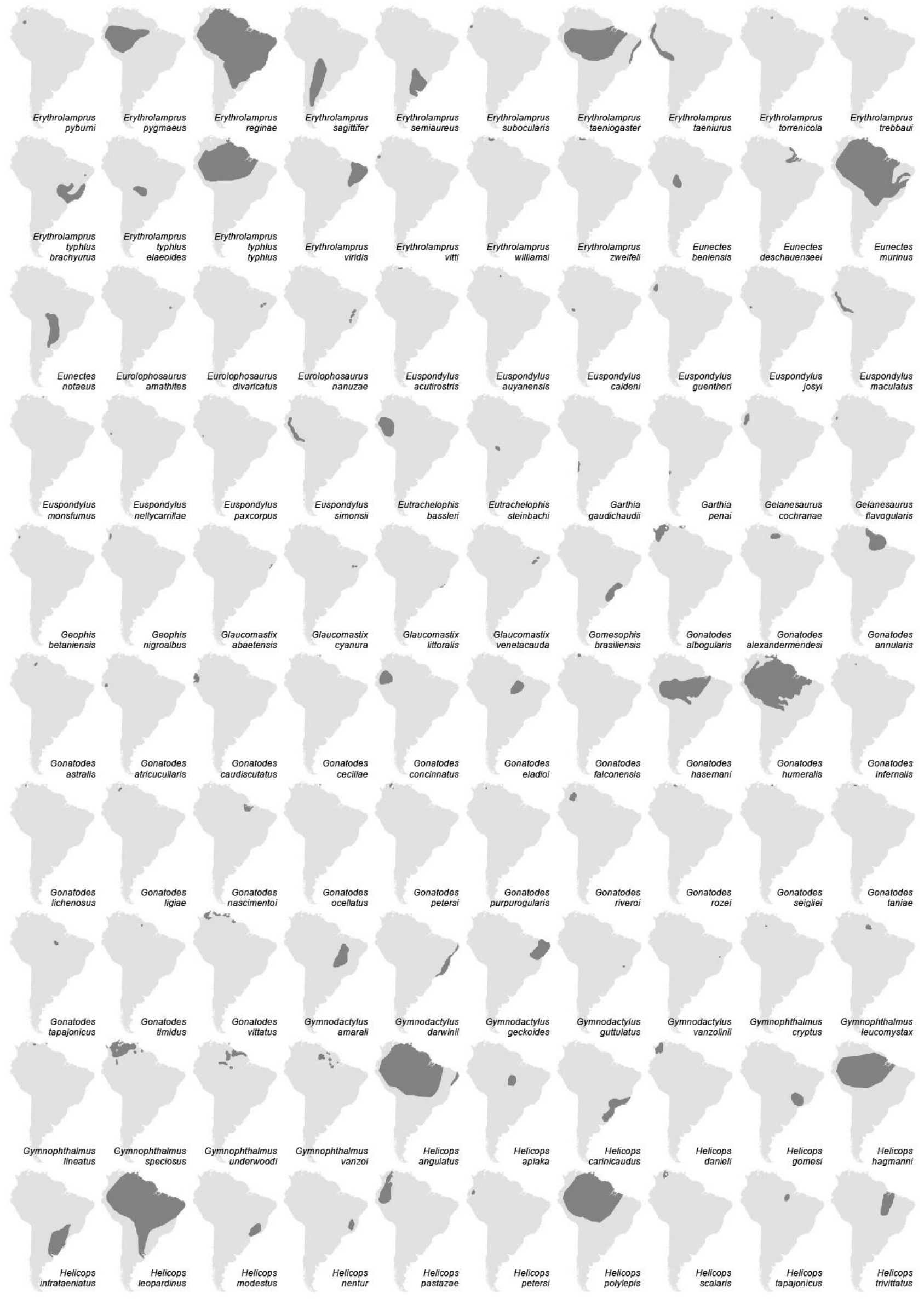




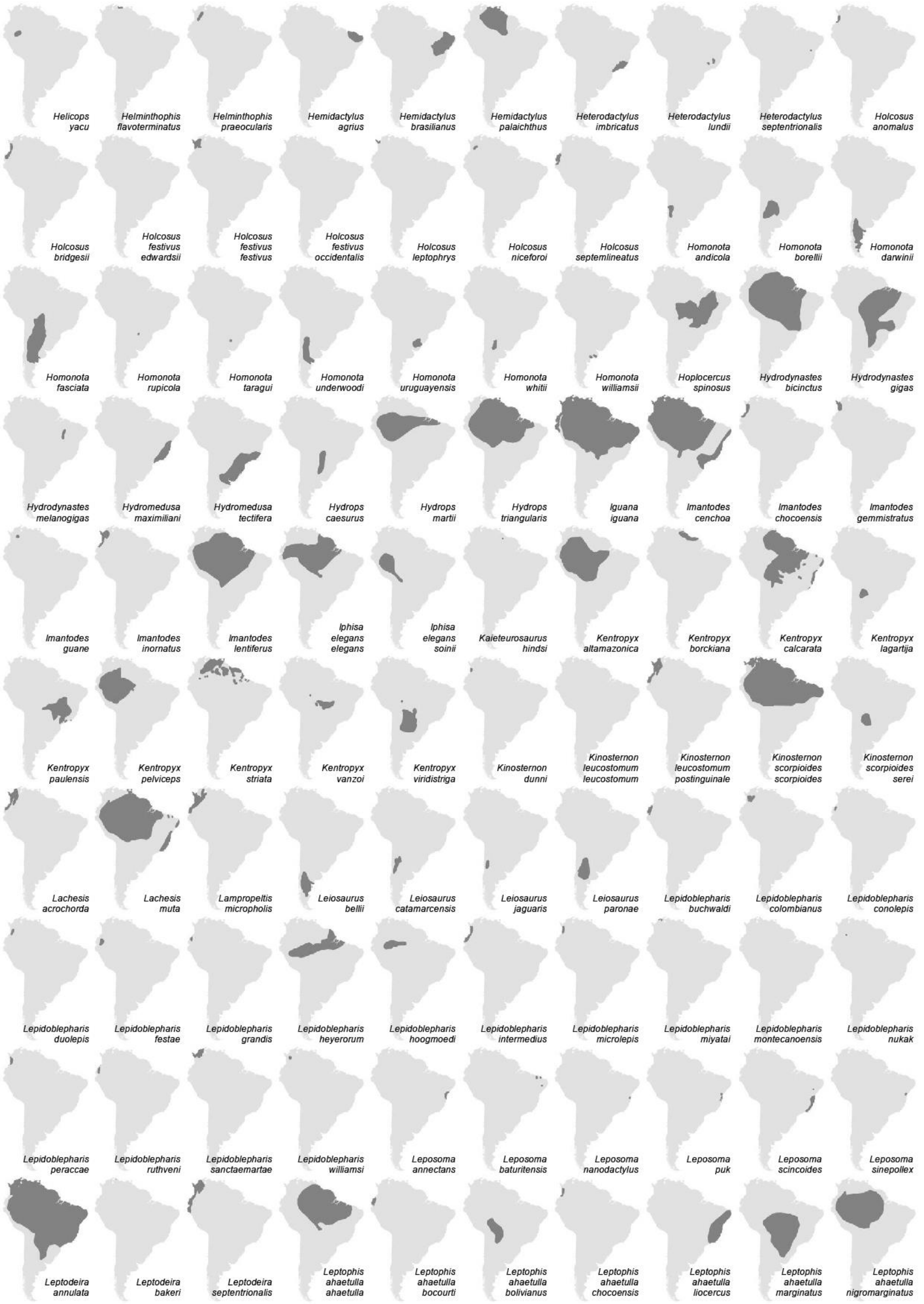




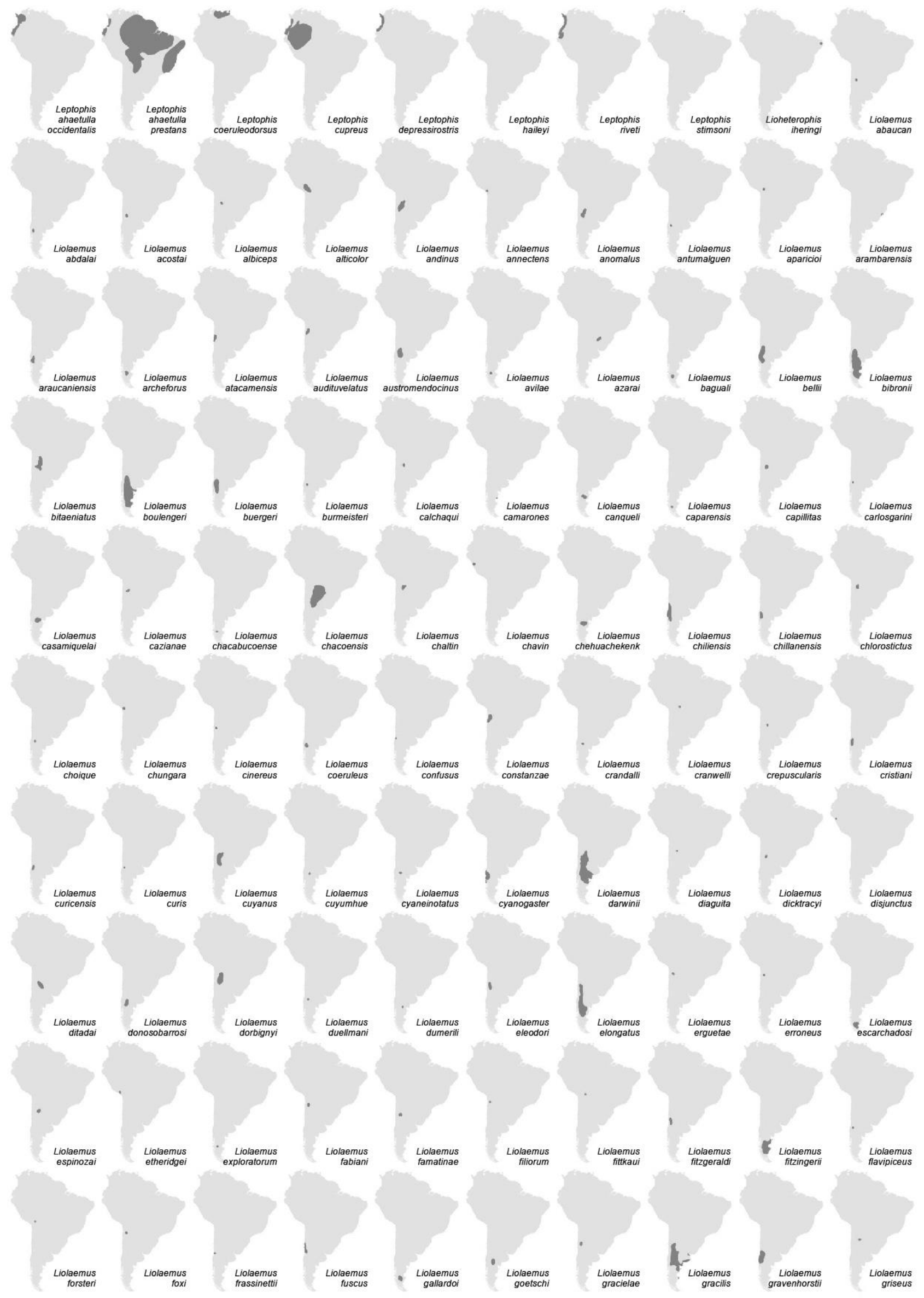




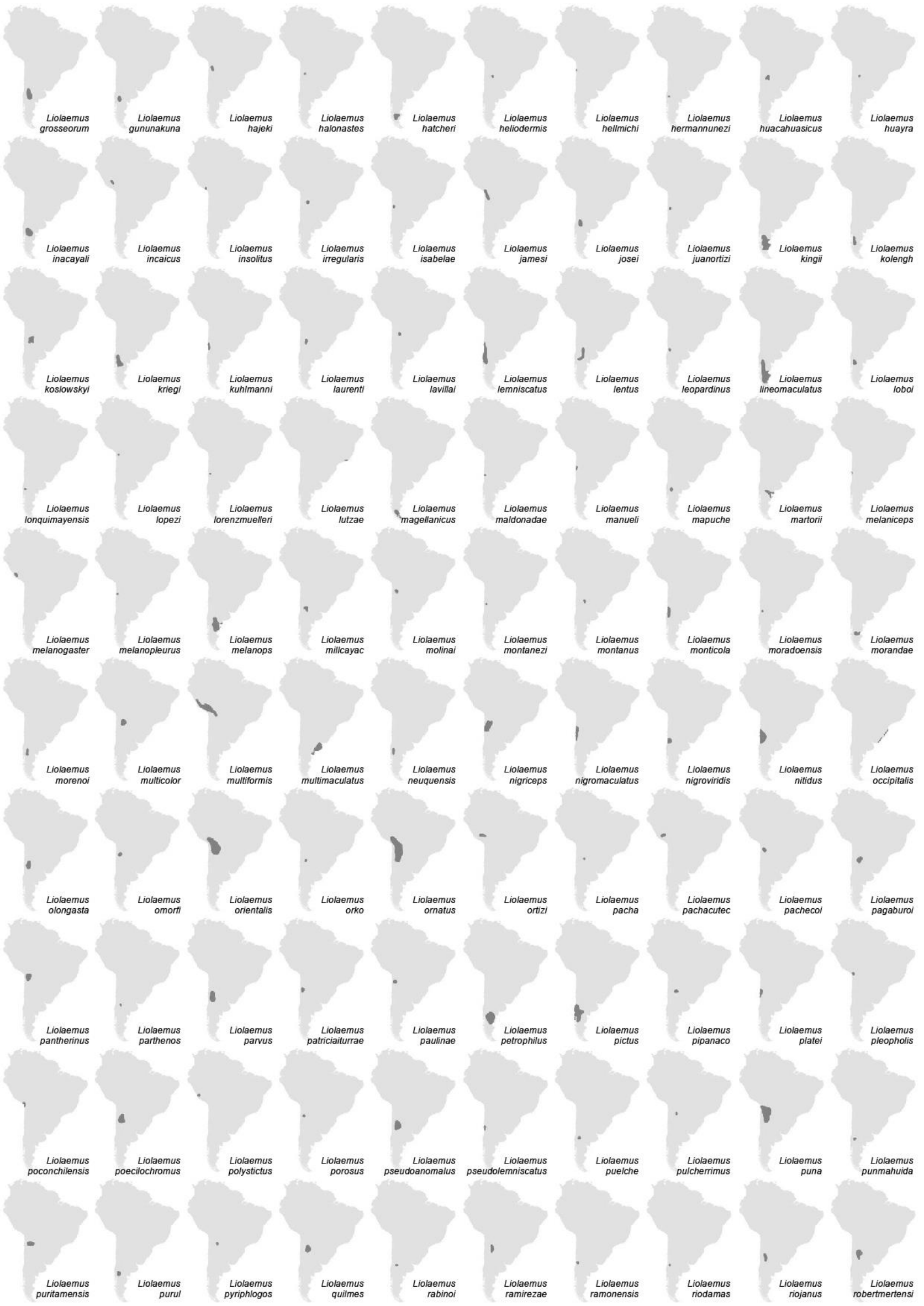




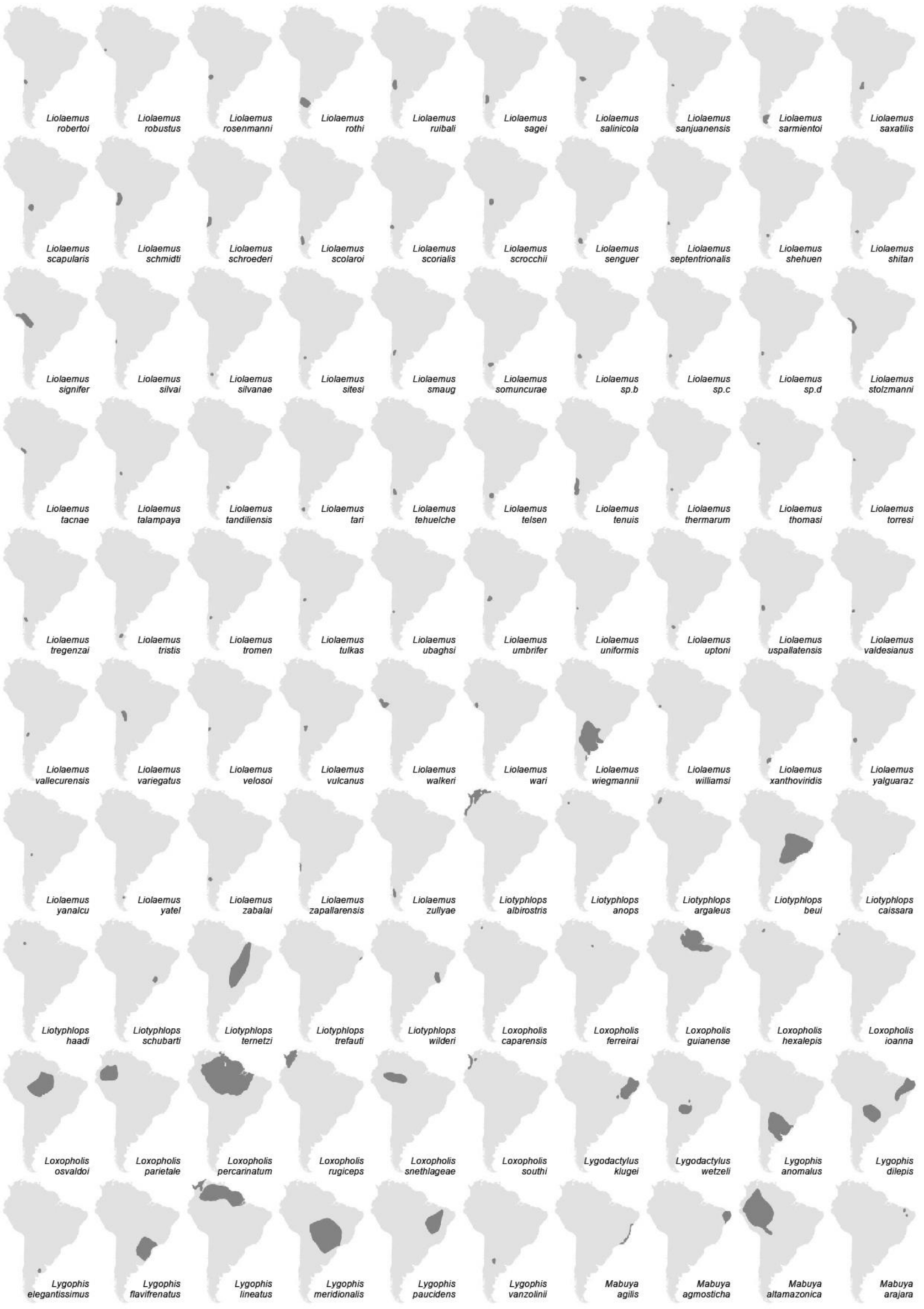




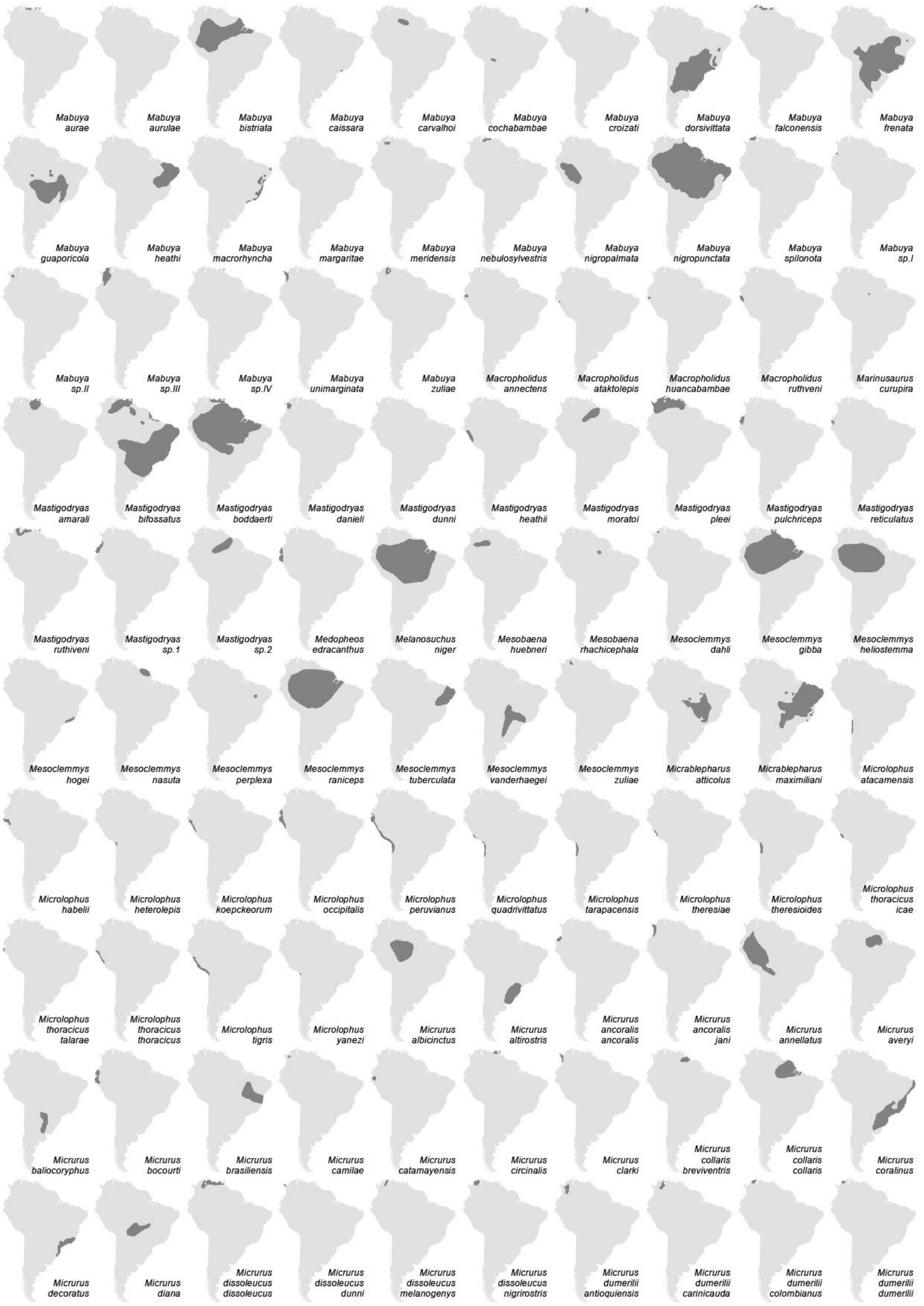




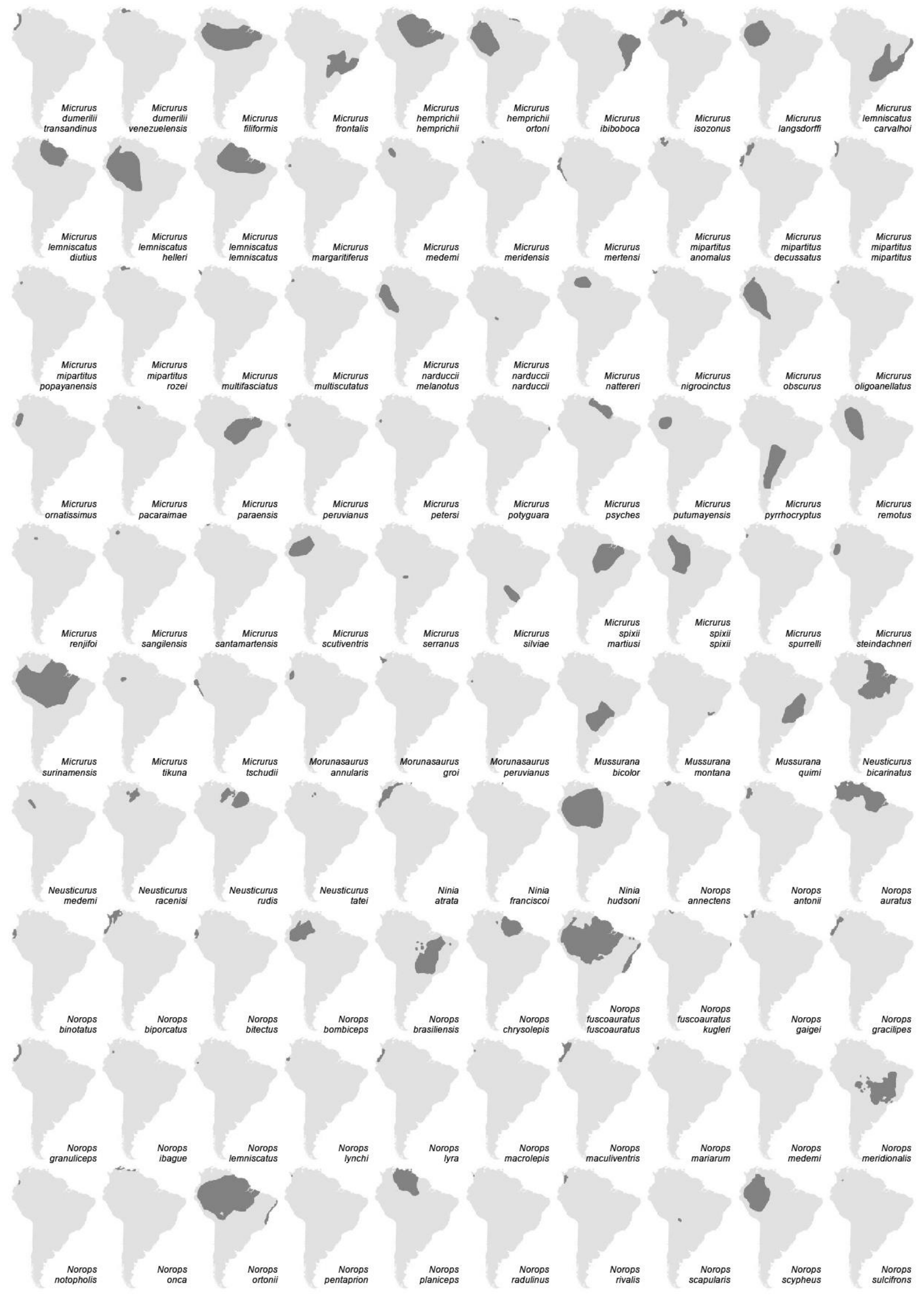




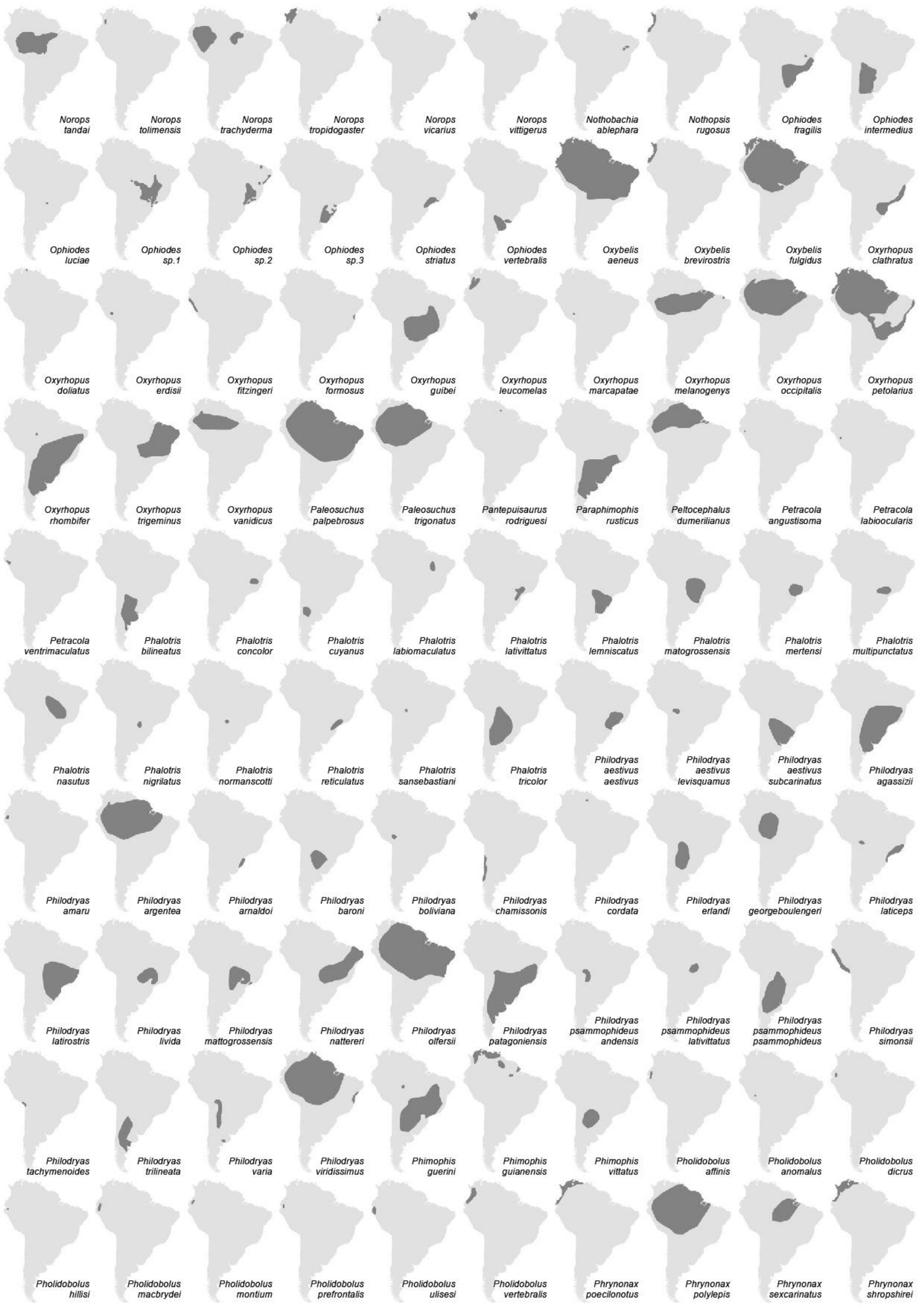




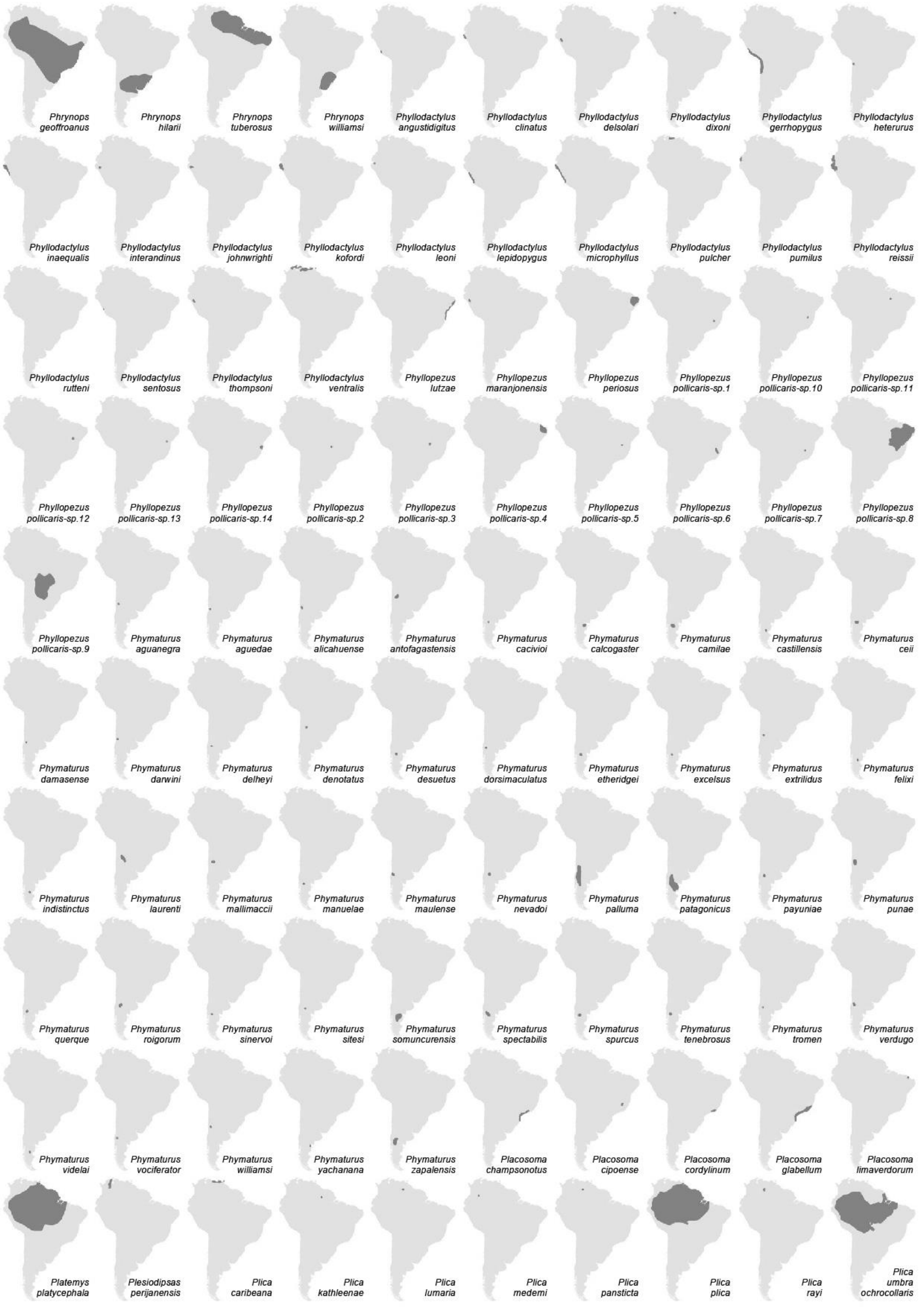




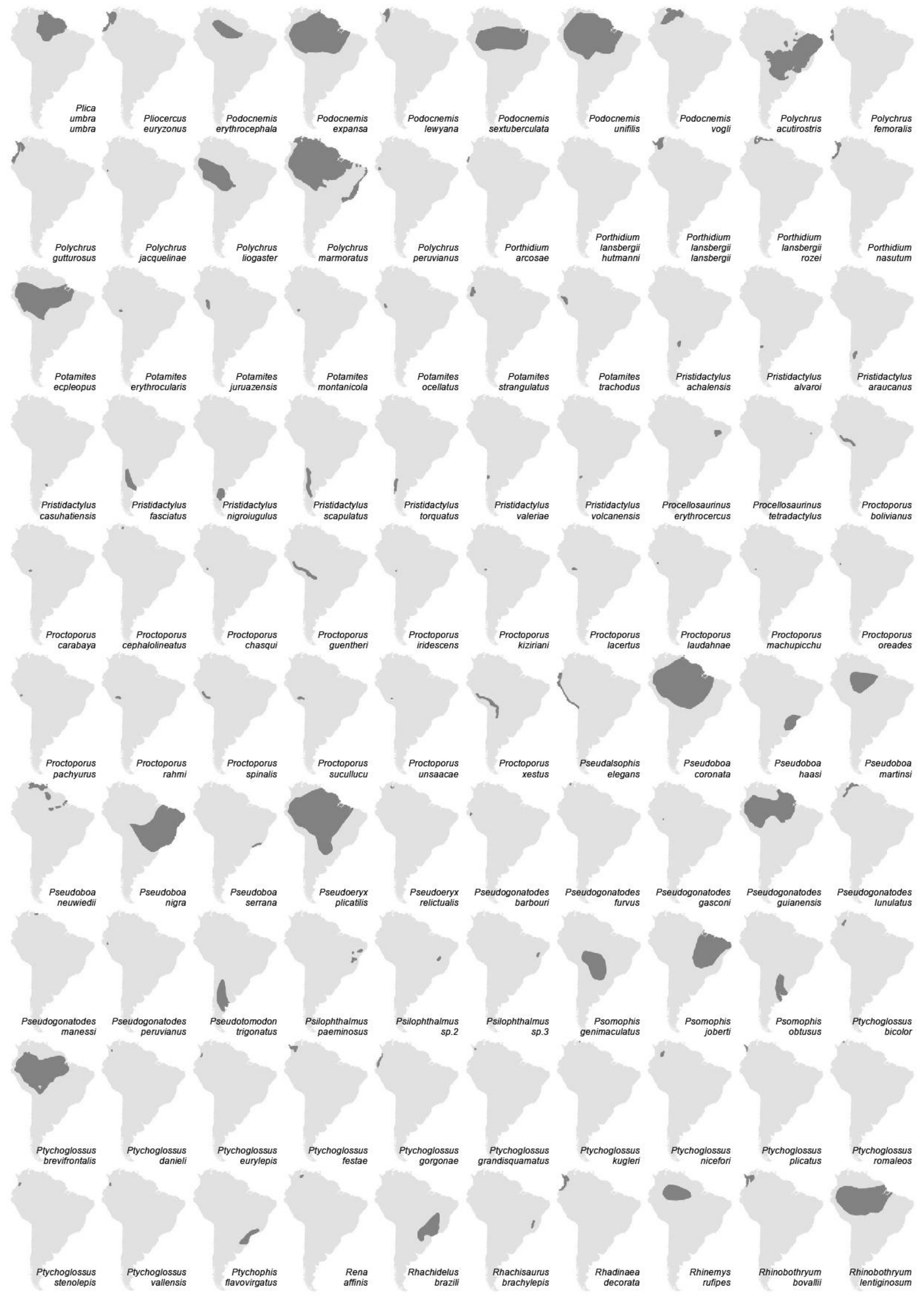




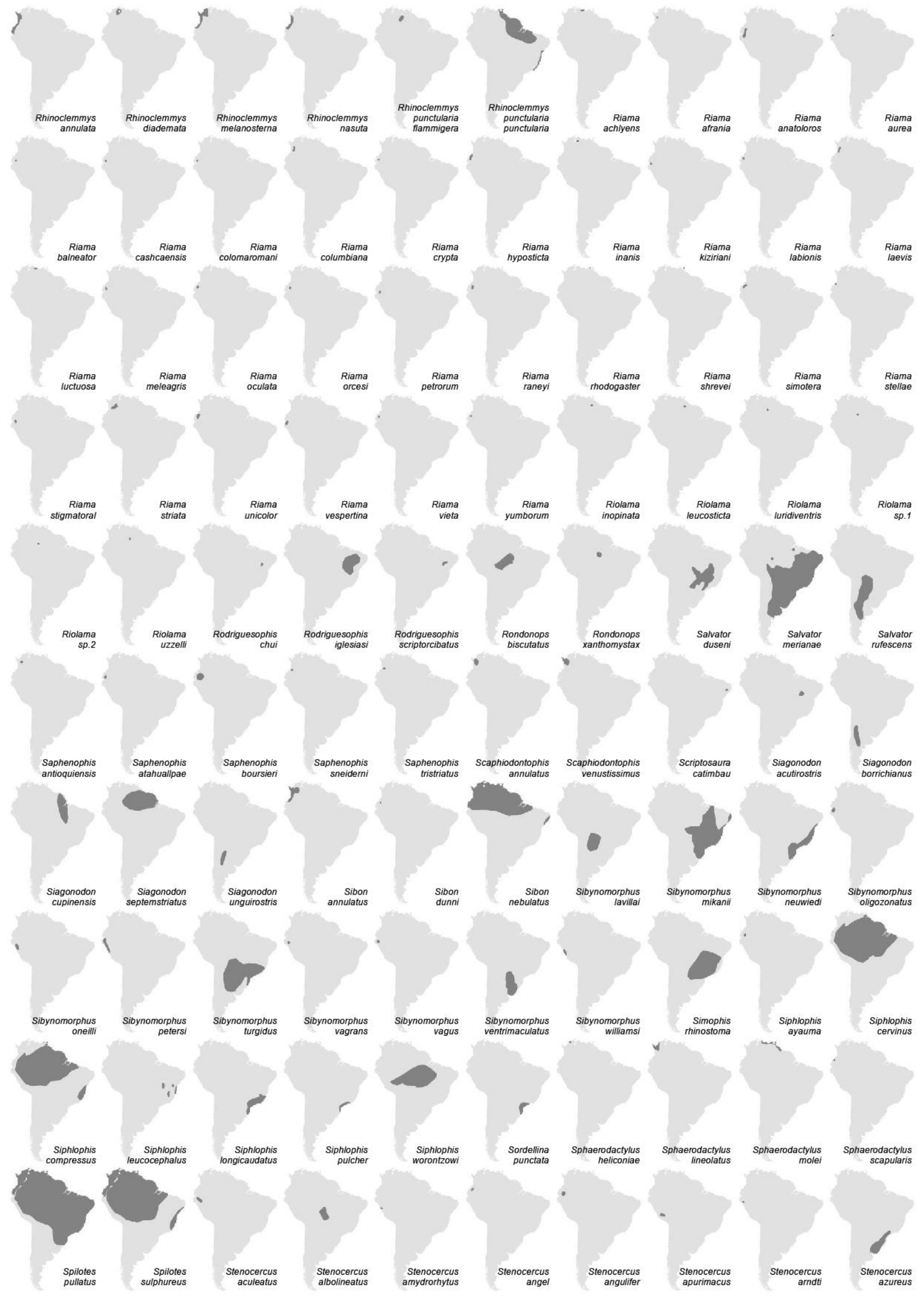




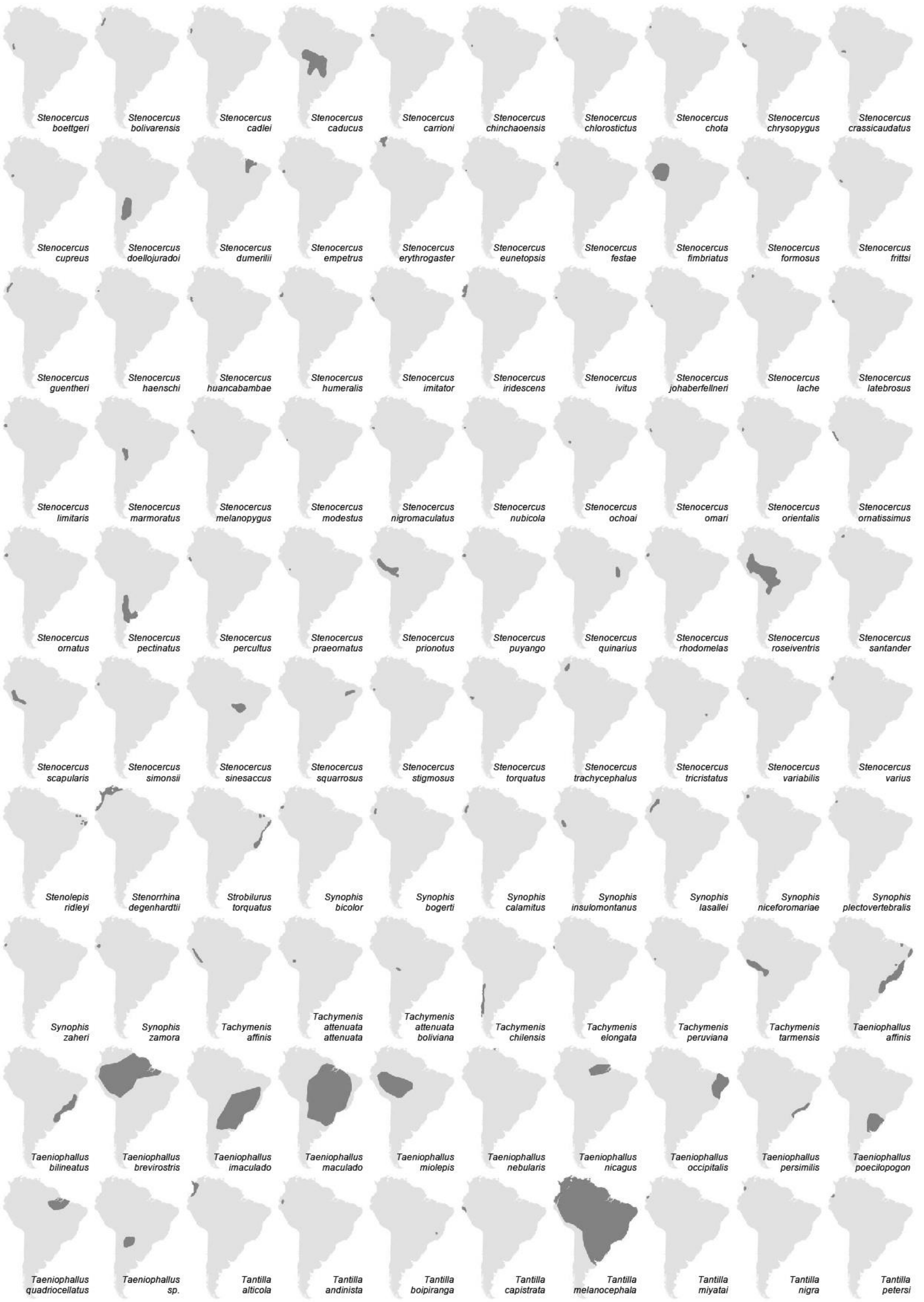




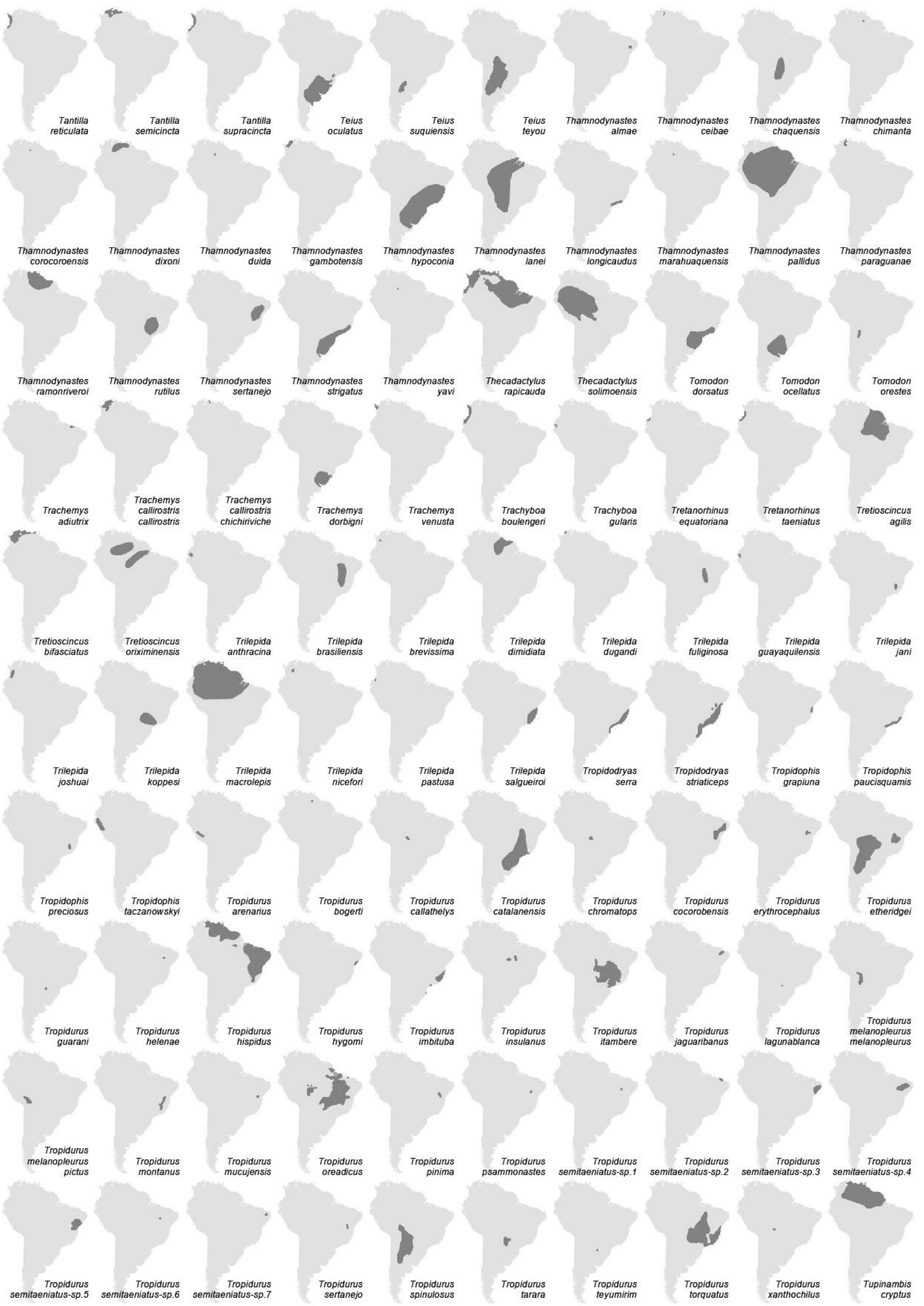




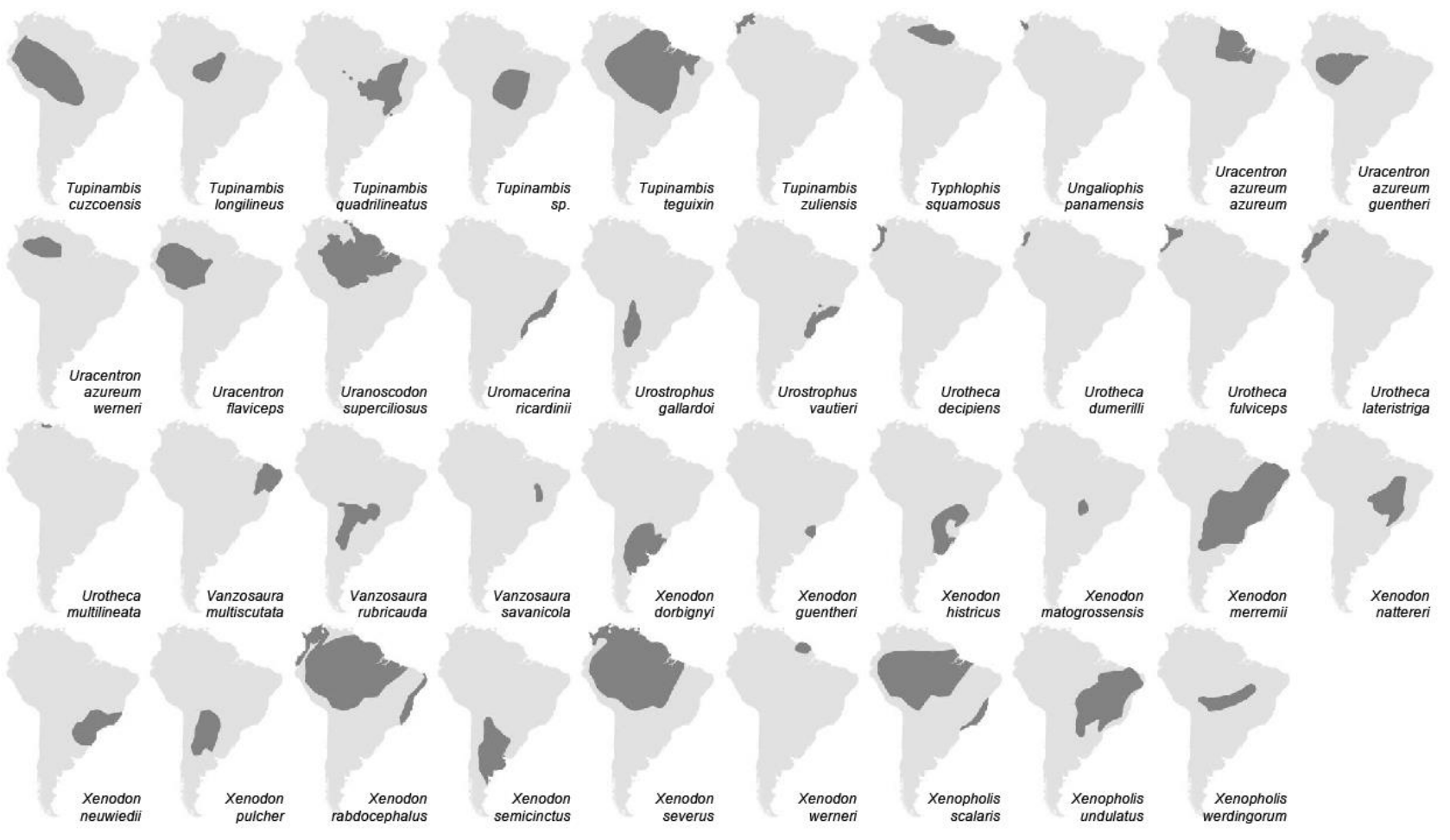




\title{
APÊNDICE 4 - Lista de lagartos
}

\author{
Lista de espécies de lagartos utilizados na análise, em ordem alfabética de nome.
}

Acratosaura mentalis, A. spinosa, Adercosaurus vixadnexus, Alexandresaurus camacan, Alopoglossus angulatus, A. atriventris, A. buckleyi, A. copii, A. festae, A. lehmanni, A. viridiceps, Amapasaurus tetradactylus, Ameiva aff_jacuba, A. aggerecusans, A. ameiva ameiva, , A. a. tobagana, , A. atrigularis, A. bifrontata, A. concolor, A. jacuba, A. nodam, A. pantherina, A. parecis, A. praesignis, A. provitaae, A. reticulata, Ameivula abalosi, A. cipoensis, A. confusioniba, A. jalapensis, A. mumbuca, A. nativo, A. nigrigula, A. ocellifera, A. pyrrhogularis, A. xacriaba, Amphisbaena absaberi, A. acrobeles, A. alba, A. albocingulata, A. anaemariae, A. angustifrons, A. anomala, A. arda, A. arenaria, A. bahiana, A. bedai, A. bilabialatus, A. bolivica, A. borellii, A. brasiliana, $A$. brevis, $A$. caiari, A. camura, A. carli, A. carvalhoi, A. cegei, A. cerradensis, A. crisae, A. cuiabana, A. cunhai, A. darwinii, A. dubia, A. filiformis, A. frontalis, A. fuliginosa, A. gracilis, A. hastata, A. heathi, A. heterozonata, A. hogei, A. ignatiana, A. infraorbitale, A. kingii, A. kisteumacheri, A. kraoh, A. leeseri, A. leucocephala, A. litoralis, A. lumbricalis, A. maximus, A. medemi, A. mensae, A. mertensii, $A$. metallurga, A. microcephalum, A. miringoera, A. mitchelli, A. munoai, A. myersi, A. neglecta, A. nigricauda, A. occidentalis, A. octostegum, A. pericensis, A. persephone, A. plumbea, A. polygrammica, A. polystegum, A. pretrei, A. prunicolor, A. roberti, A. rozei, A. sanctaritae, A. scutigerum, A. silvestrii, A. slateri, A. slevini, A. spurrelli, A. steindachneri, A. supernumeraria, A. talisiae, A. townsendi, A. trachura, A. tragorrhectes, A. uroxena, A. vanzolini, A. vermicularis, A. wuchereri, Anadia altaserrania, A. antioquensis, A. bitaeniata, A. blakei, A. bogotensis, A. brevifrontalis, A. bumanguesa, A. escalerae, A. hobarti, A. marmorata, A. mcdiarmidi, A. ocellata, A. pamplonensis, A. petersi, A. pulchella, A. rhombifera, A. sp, A. steyeri, A. vittata, Anisolepis grilli, A. longicauda, A. undulatus, Anotosaura collaris, A. vanzolinia, Arthrosaura guianensis, A. hoogmoedi, A. kockii, A. montigena, A. reticulata, A. synaptolepis, A. testigensis, A. tyleri, A. versteegii, Aurivela longicauda, A. tergolaevigata, Bachia barbouri, $B$. bicolor, B. bresslaui, B. cacerensis, B. didactyla, B. dorbignyi, B. flavescens, B. geralista, B. guianensis, B. heteropa heteropa, , B. $h$. lineata, , B. h. marcelae, , B. h. trinitatis, , B. huallagana, B. intermedia, B. micromela, B. oxyrhina, B. pallidiceps, B. panoplia, B. peruana, B. psamophila, B. pyburni, B. scaea, B. scolecoides, B. talpa, B. trisanale abendrothii, , B. t. trisanale, , B. vermiformis, Basiliscus basiliscus barbouri, , B. b. basiliscus, , B. galeritus, Callopistes flavipunctatus, C. maculatus, Calyptommatus confusionibus, C. leiolepis, C. nicterus, C. sinebrachiatus, Caparaonia itaiquara, Cercosaura argulus, C. bassleri, C. doanae, C. eigenmanni, C. hypnoides, C. manicata boliviana, , C. m. manicata, , C. nigroventris, C. ocellata ocellata, , C. o. petersi, , C. oshaughnessyi, C. parkeri, C. phelpsorum, C. quadrilineata, C. schreibersii albostrigatus, , C. s. schreibersii, , C. sp 1, C. sp 2, C. steyeri, Chatogekko amazonicus, Cnemidophorus arenivagus, C. cryptus, C. flavissimus, C. gaigei, C. gramivagus, C. lemniscatus, C. murinus, $C$. pseudolemniscatus, $C$. senectus, C. sp lendidus, Coleodactylus brachystoma, C. elizae, C. meridionalis, C. septentrionalis, Colobodactylus dalcyanus, C. taunayi, Colobosaura kraepelini, C. modesta, Colobosauroides carvalhoi, C. cearensis, Contomastix lacertoides, C. leachei, C. serrana, C. vacariensis, C. vittata, Corytophanes cristatus, Crocodilurus amazonicus, Ctenoblepharys adspersa, Dactyloa aequatorialis, $D$. anatoloros, $D$. anchicayae, $D$. anoriensis, $D$. antioquiae, $D$. apollinaris, $D$. bellipeniculus, $D$. boettgeri, $D$. calimae, $D$. caquetae, $D$. carlostoddi, $D$. chloris, $D$. cuscoensis, D. danieli, D. deltae, D. dissimilis, D. eulaema, D. euskalerriari, $D$. fasciata, $D$. festae, $D$. fitchi, $D$. fraseri, $D$. frenata, $D$. gemmosa, $D$. gorgonae, $D$. heteroderma, $D$. huilae, $D$. inderenae, $D$. jacare, $D$. laevis, $D$. lamari, $D$. latifrons, $D$. limon, $D$. maculigula, D. megalopitheca, $D$. menta, $D$. mira, $D$. nasofrontalis, $D$. neblininus, $D$. nicefori, $D$. nigrolineata, $D$. orcesi, $D$. otongae, D. paravertebralis, D. parilis, D. peraccae, D. peruensis, D. phyllorhina, D. podocarpus, $D$. poei, $D$. princeps, $D$. proboscis, D. propinqua, D. pseudotigrina, D. punctata, D. purpurescens, D. ruizii, D. santamartae, D. soinii, D. solitaria, $D$. squamulata, $D$. tetarii, $D$. tigrina, $D$. transversalis, $D$. trinitatis, $D$. umbrivaga, $D$. vanzolinii, $D$. vaupesiana, $D$. ventrimaculata, $D$. williamsmittermeierorum, Dicrodon guttulatum, D. heterolepis, D. holmbergi, Diploglossus fasciatus, D. lessonae, D. monotropis, Diplolaemus bibronii, D. darwinii, D. leopardinus, D. sexcinctus, Dracaena guianensis, D. paraguayensis, Dryadosaura nordestina, Echinosaura brachycephala, E. horrida, E. keyi, E. orcesi, E. palmeri, E. sulcarostrum, Ecpleopus gaudichaudii, Enyalioides altotambo, E. anisolepis, E. azulae, E. binzayedi, E. cofanorum, E. heterolepis, E. laticeps, E. microlepis, E. oshaughnessyi, E. palpebralis, E. praestabilis, E. rubrigularis, E. rudolfarndti, E. sophiarothschildae, E. touzeti, Enyalius bibronii, E. bilineatus, E. boulengeri, E. brasiliensis, E. catenatus, E. erythroceneus, E. iheringii, E. leechii, E. perditus, E. pictus, Eurolophosaurus amathites, E. divaricatus, E. nanuzae, Euspondylus acutirostris, E. auyanensis, E. caideni, E. guentheri, E. josyi, E. maculatus, E. monsfumus, E. nellycarrillae, E. paxcorpus, E. simonsii, Garthia gaudichaudii, G. penai, Gelanesaurus cochranae, G. flavogularis, Glaucomastix abaetensis, G. cyanura, G. littoralis, G. venetacauda, Gonatodes albogularis, G. alexandermendesi, G. annularis, G. astralis, G. atricucullaris, G. caudiscutatus, G. ceciliae, G. concinnatus, G. eladioi, G. falconensis, G. hasemani, G. humeralis, G. infernalis, G. lichenosus, G. ligiae, G. nascimentoi, G. ocellatus, G. petersi, G. purpurogularis, G. riveroi, G. rozei, G. seigliei, G. taniae, G. tapajonicus, G. timidus, G. vittatus, Gymnodactylus amarali, G. darwinii, G. geckoides, G. guttulatus, G. vanzolinii, Gymnophthalmus cryptus, G. leucomystax, G. lineatus, G. sp eciosus, G. underwoodi, G. vanzoi, Hemidactylus agrius, H. brasilianus, H. palaichthus, Heterodactylus imbricatus, $H$. lundii, $H$. septentrionalis, Holcosus anomalus, $H$. bridgesii, $H$. festivus festivus, , $H$. leptophrys, $H$. niceforoi, $H$. septemlineatus, Homonota andicola, $\mathrm{H}$. borellii, $\mathrm{H}$. darwinii, $\mathrm{H}$. fasciata, $\mathrm{H}$. rupicola, $\mathrm{H}$. taragui, $\mathrm{H}$. underwoodi, $\mathrm{H}$. uruguayensis, $\mathrm{H}$. whitii, $\mathrm{H}$. williamsii, Hoplocercus sp inosus, Iguana iguana, Iphisa elegans elegans, , I. e. soinii, , Kaieteurosaurus hindsi, Kentropyx altamazonica, K. borckiana, K. calcarata, K. lagartija, K. paulensis, K. pelviceps, K. striata, K. vanzoi, K. viridistriga, Leiosaurus bellii, L. catamarcensis, L. jaguaris, L. paronae, Lepidoblepharis buchwaldi, L. colombianus, L. conolepis, L. duolepis, L. festae, L. grandis, L. heyerorum, L. hoogmoedi, L. intermedius, L. microlepis, L. miyatai, L. montecanoensis, L. nukak, L. peraccae, L. ruthveni, L. sanctaemartae, L. williamsi, Leposoma annectans, L. baturitensis, L. nanodactylus, L. puk, L. scincoides, L. sinepollex, Liolaemus abaucan, L. abdalai, L. acostai, L. albiceps, L. alticolor, L. andinus, L. annectens, L. anomalus, L. antumalguen, L. aparicioi, L. arambarensis, L. araucaniensis, L. archeforus, L. atacamensis, L. audituvelatus, L. austromendocinus, L. avilae, L. azarai, L. baguali, L. bellii, L. bibronii, L. bitaeniatus, L. boulengeri, L. buergeri, L. burmeisteri, L. calchaqui, L. camarones, L. canqueli, L. caparensis, L. capillitas, L. carlosgarini, L. casamiquelai, L. cazianae, L. chacabucoense, L. chacoensis, L. chaltin, L. chavin, L. chehuachekenk, L. chiliensis, L. chillanensis, L. chlorostictus, L. choique, L. chungara, L. cinereus, L. coeruleus, L. confusus, L. constanzae, L. crandalli, L. cranwelli, L. crepuscularis, L. cristiani, L. curicensis, L. curis, L. cuyanus, L. cuyumhue, L. cyaneinotatus, L. cyanogaster, L. darwinii, L. 
diaguita, L. dicktracyi, L. disjunctus, L. ditadai, L. donosobarrosi, L. dorbignyi, L. duellmani, L. dumerili, L. eleodori, L. elongatus, L. erguetae, L. erroneus, L. escarchadosi, L. espinozai, L. etheridgei, L. exploratorum, L. fabiani, L. famatinae, L. filiorum, L. fittkaui, L. fitzgeraldi, L. fitzingerii, L. flavipiceus, L. forsteri, L. foxi, L. frassinettii, L. fuscus, L. gallardoi, L. goetschi, L. gracielae, L. gracilis, L. gravenhorstii, L. griseus, L. grosseorum, L. gununakuna, L. hajeki, L. halonastes, L. hatcheri, L. heliodermis, L. hellmichi, L. hermannunezi, L. huacahuasicus, L. huayra, L. inacayali, L. incaicus, L. insolitus, L. irregularis, L. isabelae, L. jamesi, L. josei, L. juanortizi, L. kingii, L. kolengh, L. koslowskyi, L. kriegi, L. kuhlmanni, L. laurenti, L. lavillai, L. lemniscatus, L. lentus, L. leopardinus, L. lineomaculatus, L. Ioboi, L. Ionquimayensis, L. lopezi, L. lorenzmuelleri, L. lutzae, L. magellanicus, L. maldonadae, L. manueli, L. mapuche, L. martorii, L. melaniceps, L. melanogaster, L. melanopleurus, L. melanops, L. millcayac, L. molinai, L. montanezi, $L$. montanus, L. monticola, L. moradoensis, L. morandae, L. morenoi, L. multicolor, L. multiformis, L. multimaculatus, L. neuquensis, L. nigriceps, L. nigromaculatus, L. nigroviridis, L. nitidus, L. occipitalis, L. olongasta, L. omorfi, L. orientalis, L. orko, L. ornatus, L. ortizi, L. pacha, L. pachacutec, L. pachecoi, L. pagaburoi, L. pantherinus, L. parthenos, L. parvus, L. patriciaiturrae, L. paulinae, L. petrophilus, L. pictus, L. pipanaco, L. platei, L. pleopholis, L. poconchilensis, L. poecilochromus, L. polystictus, L. porosus, L. pseudoanomalus, L. pseudolemniscatus, L. puelche, L. pulcherrimus, L. puna, L. punmahuida, L. puritamensis, L. purul, L. pyriphlogos, L. quilmes, L. rabinoi, L. ramirezae, L. ramonensis, L. riodamas, L. riojanus, L. robertmertensi, L. robertoi, L. robustus, $L$. rosenmanni, L. rothi, L. ruibali, L. sagei, L. salinicola, L. sanjuanensis, L. sarmientoi, L. saxatilis, L. scapularis, $L$. schmidti, $L$. schroederi, L. scolaroi, L. scorialis, L. scrocchii, L. senguer, L. septentrionalis, L. shehuen, L. shitan, L. signifer, L. silvai, L. silvanae, L. sitesi, L. smaug, L. somuncurae, L. sp b, L. sp c, L. sp d, L. stolzmanni, L. tacnae, L. talampaya, L. tandiliensis, L. tari, L. tehuelche, L. telsen, L. tenuis, L. thermarum, L. thomasi, L. torresi, L. tregenzai, L. tristis, L. tromen, L. tulkas, L. ubaghsi, L. umbrifer, L. uniformis, L. uptoni, L. uspallatensis, L. valdesianus, L. vallecurensis, L. variegatus, L. velosoi, L. vulcanus, L. walkeri, L. wari, L. wiegmannii, $L$. williamsi, L. xanthoviridis, L. yalguaraz, L. yanalcu, L. yatel, L. zabalai, L. zapallarensis, L. zullyae, Loxopholis caparensis, L. ferreirai, L. guianense, L. hexalepis, L. ioanna, L. osvaldoi, L. parietale, L. percarinatum, L. rugiceps, L. snethlageae, L. southi, Lygodactylus klugei, L. wetzeli, Mabuya agilis, M. agmosticha, M. altamazonica, M. arajara, M. aurae, M. bistriata, M. caissara, M. carvalhoi, M. cochabambae, M. croizati, M. dorsivittata, M. falconensis, M. frenata, M. guaporicola, M. heathi, M. macrorhyncha, M. margaritae, $M$. meridensis, $M$. nebulosylvestris, $M$. nigropalmata, $M$. nigropunctata, $M$. spilonota, $M . \mathrm{sp} 1, M$. sp 2, M. sp 3, $M$. sp 4, M. unimarginata, M. zuliae, Macropholidus annectens, M. ataktolepis, M. huancabambae, M. ruthveni, Marinusaurus curupira, Medopheos edracanthus, Mesobaena huebneri, M. rhachicephala, Micrablepharus atticolus, M. maximiliani, Microlophus atacamensis, M. habelii, M. heterolepis, M. koepckeorum, M. occipitalis, M. peruvianus, M. quadrivittatus, $M$. tarapacensis, $M$. theresiae, M. theresioides, M. thoracicus icae, , M. t. talarae, , M. t. thoracicus, , M. tigris, M. yanezi, Morunasaurus annularis, M. groi, M. peruvianus, Neusticurus bicarinatus, N. medemi, N. racenisi, N. rudis, N. tatei, Norops annectens, N. antonii, N. auratus, N. binotatus, N. biporcatus, N. bitectus, N. bombiceps, N. brasiliensis, N. chrysolepis, N. fuscoauratus fuscoauratus, , N. $f . k u g l e r i, ~, N$. gaigei, N. gracilipes, N. granuliceps, N. ibague, N. lemniscatus, N. lynchi, N. lyra, N. macrolepis, N. maculiventris, N. mariarum, N. medemi, N. meridionalis, N. notopholis, N. onca, N. ortonii, N. pentaprion, N. planiceps, N. radulinus, N. rivalis, N. scapularis, $N$. scypheus, N. sulcifrons, N. tandai, N. tolimensis, N. trachyderma, N. tropidogaster, N. vicarius, N. vittigerus, Nothobachia ablephara,

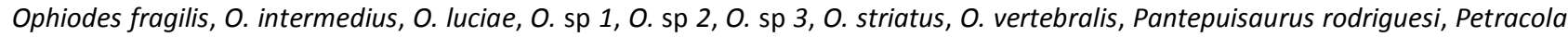
angustisoma, P. labioocularis, $P$. ventrimaculatus, Pholidobolus affinis, P. anomalus, $P$. dicrus, $P$. hillisi, P. macbrydei, $P$. montium, $P$. prefrontalis, P. ulisesi, P. vertebralis, Phyllodactylus angustidigitus, P. clinatus, P. delsolari, P. dixoni, P. gerrhopygus, P. heterurus, $P$. inaequalis, P. interandinus, P. johnwrighti, P. kofordi, P. leoni, P. lepidopygus, P. microphyllus, P. pulcher, P. pumilus, P. reissii, P. sentosus, $P$. thompsoni, $P$. ventralis, Phyllopezus lutzae, P. maranjonensis, P. periosus, P. pollicaris $1, P$. pollicaris $2, P$. pollicaris $3, P$. pollicaris 4, P. pollicaris 5, P. pollicaris 6, P. pollicaris 7, P. pollicaris 8, P. pollicaris 9, P. pollicaris 10, P. pollicaris 11, P. pollicaris 12, P. pollicaris 13, P. pollicaris 14, Phymaturus aguanegra, P. aguedae, P. alicahuense, P. antofagastensis, P. cacivioi, P. calcogaster, $P$. camilae, P. castillensis, P. ceii, P. damasense, P. darwini, P. delheyi, P. denotatus, $P$. desuetus, $P$. dorsimaculatus, $P$. etheridgei, $P$. excelsus, P. extrilidus, P. felixi, P. indistinctus, P. laurenti, P. mallimaccii, P. manuelae, P. maulense, P. nevadoi, $P$. palluma, $P$. patagonicus, P. payuniae, P. punae, $P$. querque, $P$. roigorum, $P$. sinervoi, $P$. sitesi, $P$. somuncurensis, $P$. spectabilis, $P$. spurcus, $P$. tenebrosus, $P$. tromen, $P$. verdugo, P. videlai, $P$. vociferator, $P$. williamsi, $P$. yachanana, $P$. zapalensis, Placosoma champsonotus, $P$. cipoense, P. cordylinum, P. glabellum, P. limaverdorum, Plica caribeana, P. kathleenae, P. lumaria, P. medemi, P. pansticta, P. plica, P. rayi, $P$. umbra ochrocollaris, , P. u. umbra, , Polychrus acutirostris, P. femoralis, $P$. gutturosus, $P$. jacquelinae, $P$. liogaster, $P$. marmoratus, $P$. peruvianus, Potamites ecpleopus, $P$. erythrocularis, $P$. juruazensis, $P$. montanicola, $P$. ocellatus, $P$. strangulatus, $P$. trachodus, Pristidactylus achalensis, P. alvaroi, P. araucanus, P. casuhatiensis, P. fasciatus, $P$. nigroiugulus, $P$. scapulatus, $P$. torquatus, $P$. valeriae, $P$. volcanensis, Procellosaurinus erythrocercus, $P$. tetradactylus, Proctoporus bolivianus, $P$. carabaya, $P$. cephalolineatus, P. chasqui, P. guentheri, P. iridescens, P. kiziriani, P. lacertus, P. laudahnae, P. machupicchu, P. oreades, P. pachyurus, P. rahmi, P. spinalis, P. sucullucu, P. unsaacae, P. xestus, Pseudogonatodes barbouri, P. furvus, P. gasconi, P. guianensis, P. lunulatus, P. manessi, P. peruvianus, Psilophthalmus paeminosus, Ptychoglossus bicolor, P. brevifrontalis, P. danieli, P. eurylepis, $P$. festae, $P$. gorgonae, $P$. grandisquamatus, $P$. kugleri, $P$. nicefori, $P$. plicatus, $P$. romaleos, $P$. stenolepis, $P$. vallensis, Rhachisaurus brachylepis, Riama achlyens, $R$. afrania, $R$. anatoloros, $R$. aurea, $R$. balneator, $R$. cashcaensis, $R$. colomaromani, $R$. columbiana, $R$. crypta, $R$. hyposticta, $R$. inanis, $R$. kiziriani, $R$. labionis, $R$. laevis, $R$. luctuosa, $R$. meleagris, $R$. oculata, $R$. orcesi, $R$. petrorum, $R$. raneyi, $R$. rhodogaster, $R$. shrevei, $R$. simotera, $R$. stellae, $R$. stigmatoral, $R$. striata, $R$. unicolor, $R$. vespertina, $R$. vieta, $R$. yumborum, Riolama inopinata, $R$. leucosticta, $R$. luridiventris, $R$. $\operatorname{sp~} 1, R . \operatorname{sp} 2, R$. uzzelli, Rondonops biscutatus, $R$. xanthomystax, Salvator duseni, S. merianae, S. rufescens, Scriptosaura catimbau, Sphaerodactylus heliconiae, S. lineolatus, S. molei, S. scapularis, Stenocercus aculeatus, S. albolineatus, S. amydrorhytus, S. angel, S. angulifer, S. apurimacus, S. arndti, S. azureus, S. boettgeri, S. bolivarensis, S. cadlei, S. caducus, S. carrioni, S. chinchaoensis, S. chlorostictus, S. chota, S. chrysopygus, S. crassicaudatus, S. cupreus, S. doellojuradoi, S. dumerilii, S. empetrus, S. erythrogaster, S. eunetopsis, S. festae, S. fimbriatus, S. formosus, S. frittsi, S. guentheri, S. haenschi, S. huancabambae, S. humeralis, S. imitator, S. iridescens, S. ivitus, S. johaberfellneri, S. lache, S. latebrosus, S. limitaris, S. marmoratus, S. melanopygus, S. modestus, S. nigromaculatus, S. nubicola, S. ochoai, S. omari, S. orientalis, S. ornatissimus, S. ornatus, S. pectinatus, S. percultus, S. praeornatus, S. prionotus, S. puyango, S. quinarius, S. rhodomelas, S. roseiventris, S. santander, S. scapularis, S. simonsii, S. sinesaccus, S. squarrosus, S. stigmosus, S. torquatus, S. trachycephalus, S. tricristatus, S. 
variabilis, S. varius, Stenolepis ridleyi, Strobilurus torquatus, Teius oculatus, T. suquiensis, T. teyou, Thecadactylus rapicauda, $T$. solimoensis, Tretioscincus agilis, T. bifasciatus, T. oriximinensis, Tropidurus arenarius, T. bogerti, T. callathelys, T. catalanensis, $T$. chromatops, T. cocorobensis, T. erythrocephalus, T. etheridgei, T. guarani, T. helenae, T. hispidus, T. hygomi, T. imbituba, T. insulanus, T. itambere, T. jaguaribanus, T. lagunablanca, T. melanopleurus melanopleurus, , T. m. pictus, , T. montanus, T. mucujensis, T. oreadicus, T. pinima, T. psammonastes, $T$. semitaeniatus sp 1, , T. semitaeniatus sp $2,, T$. semitaeniatus sp 3, , $T$. semitaeniatus sp 4, , T. semitaeniatus sp 5, , T. semitaeniatus sp 6, , T. semitaeniatus sp 7, , T. sertanejo, $T$. sp inulosus, $T$. tarara, $T$. teyumirim, $T$. torquatus, $T$. xanthochilus, Tupinambis cryptus, $T$. cuzcoensis, $T$. longilineus, $T$. quadrilineatus, $T$. sp, $T$. teguixin, $T$. zuliensis, Uracentron azureum azureum, , U. a. guentheri, , U. a. werneri, , U. flaviceps, Uranoscodon superciliosus, Urostrophus gallardoi, U. vautieri, Vanzosaura multiscutata, V. rubricauda, V. savanicola. 


\section{APÊNDICE 5 - Modelos}

\section{Modelos individuais de cada espécie}

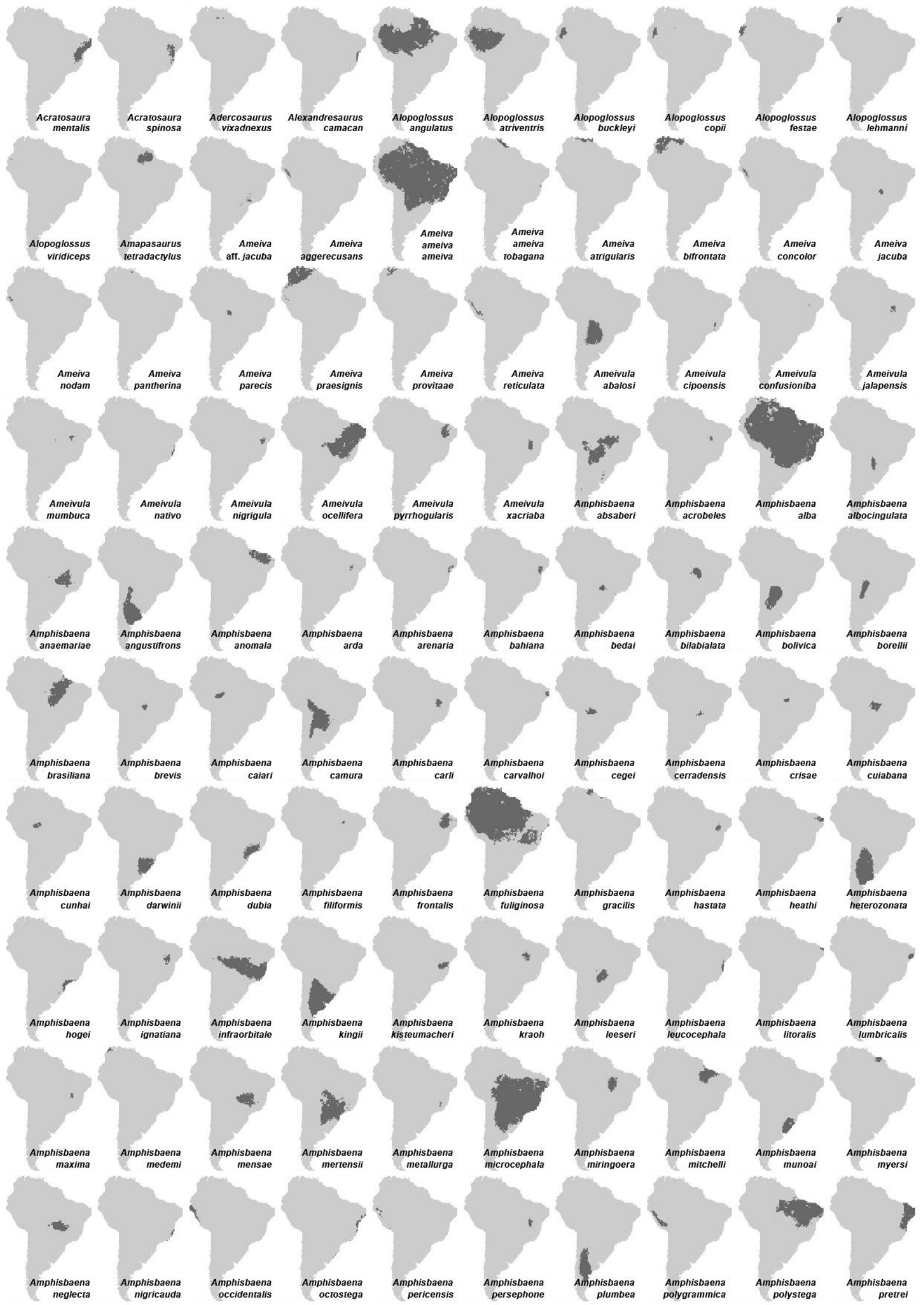




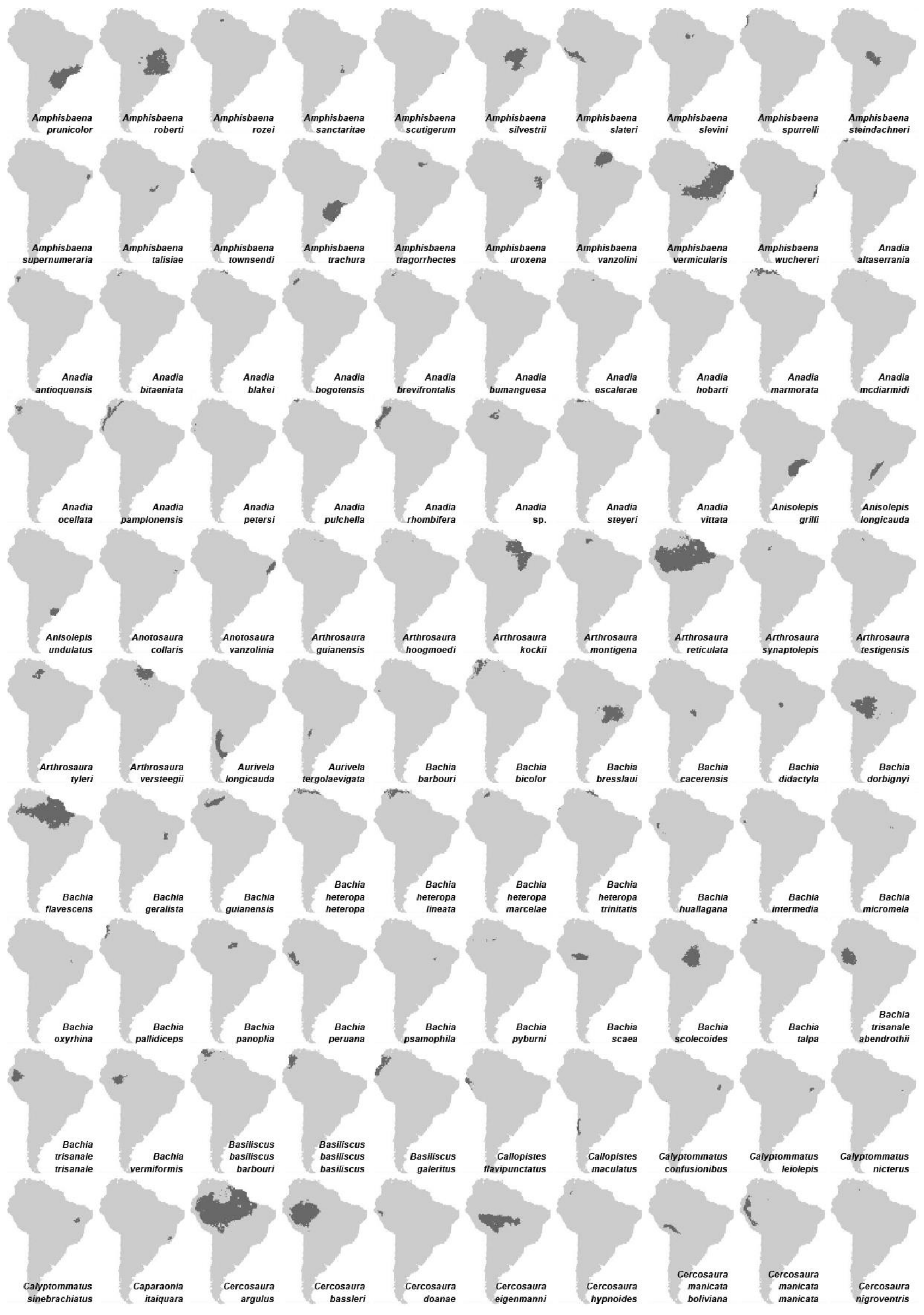




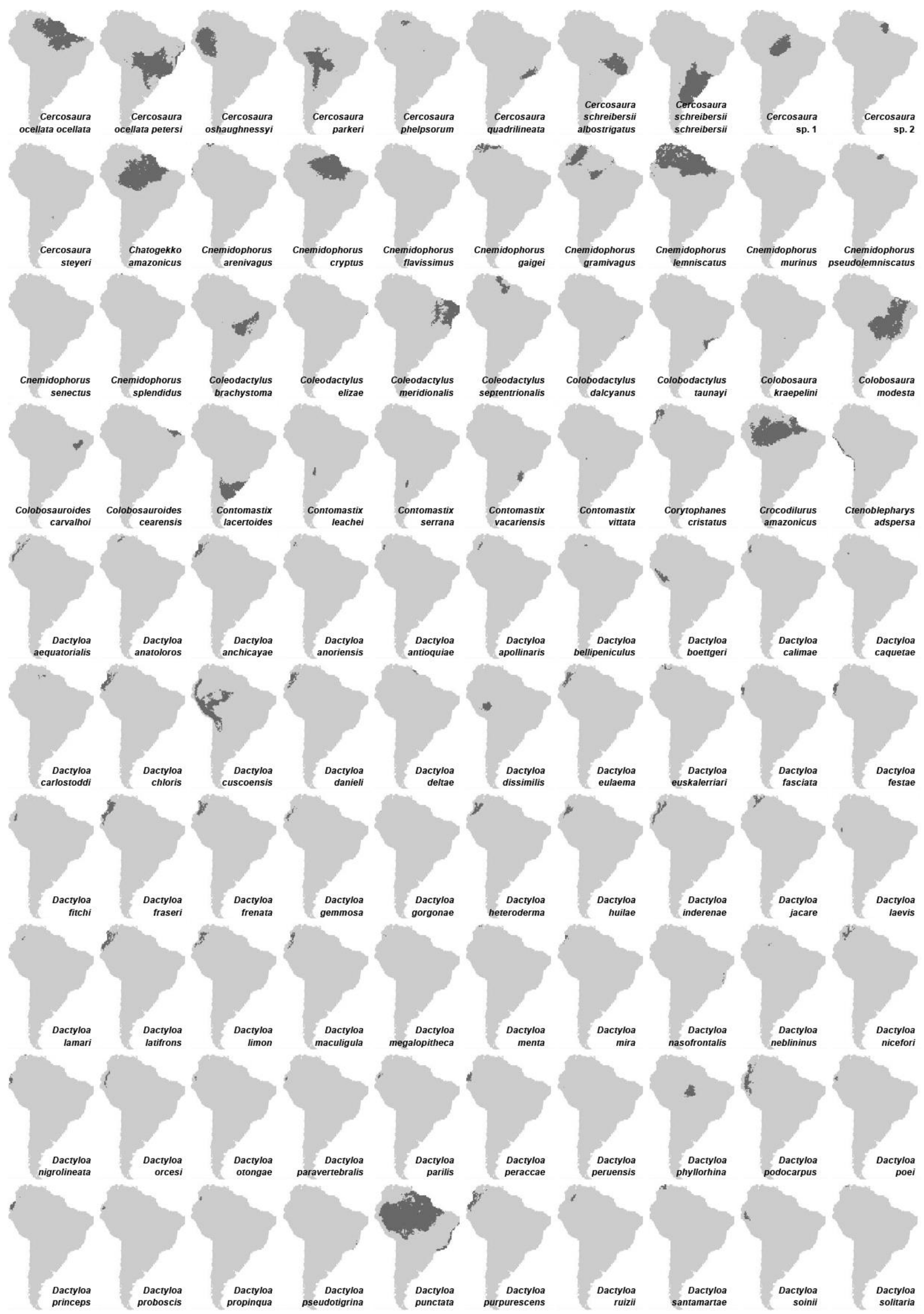




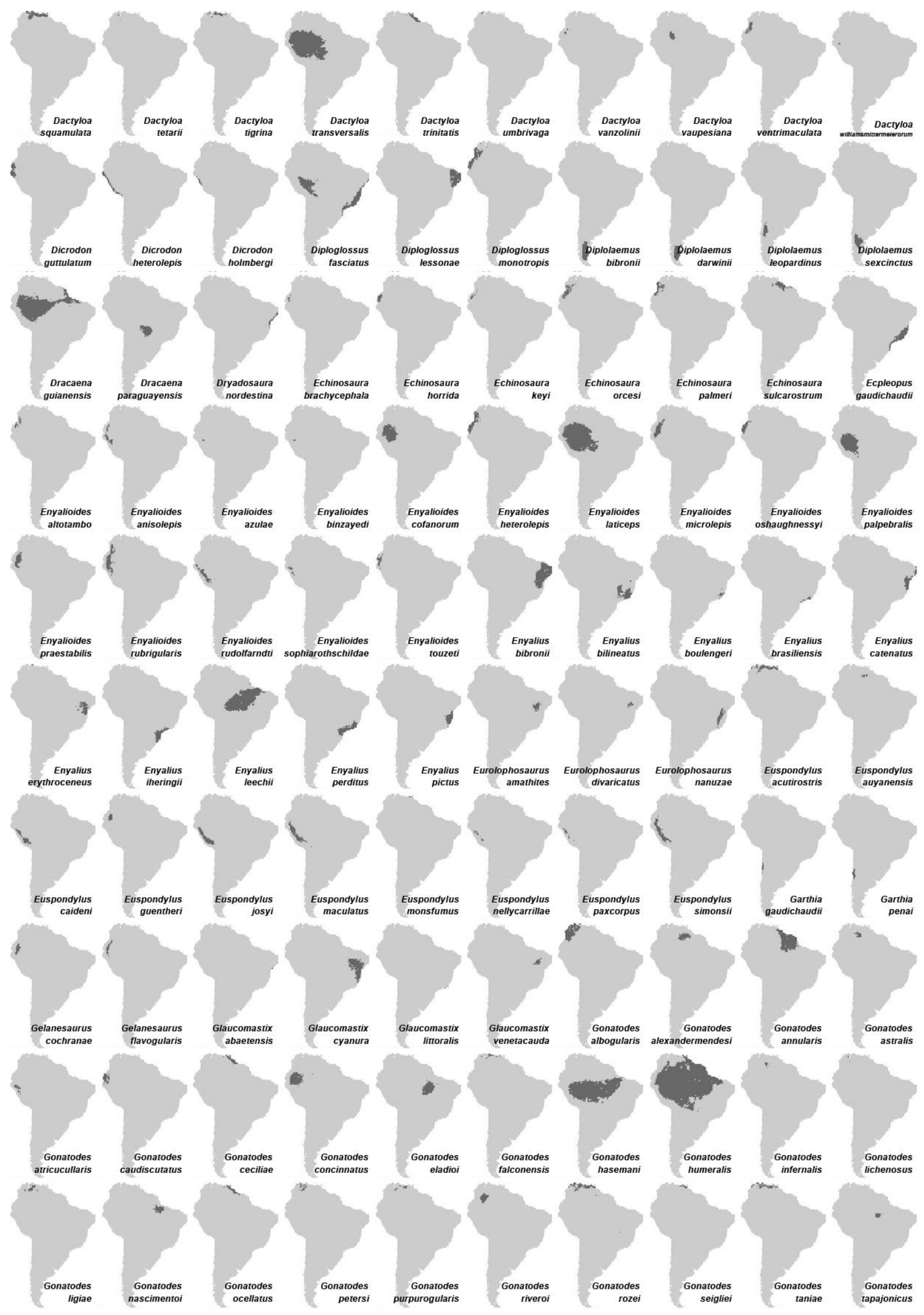




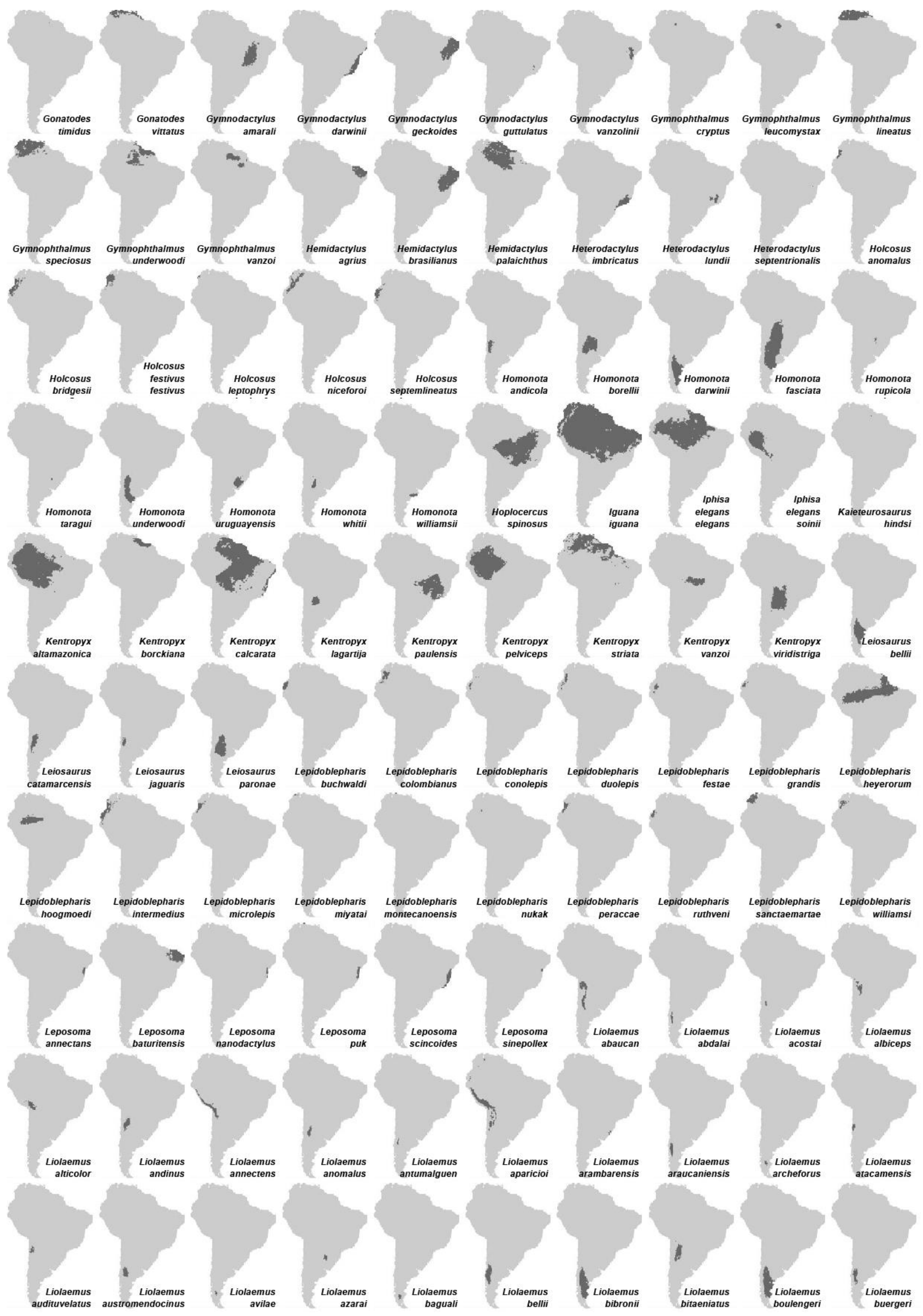




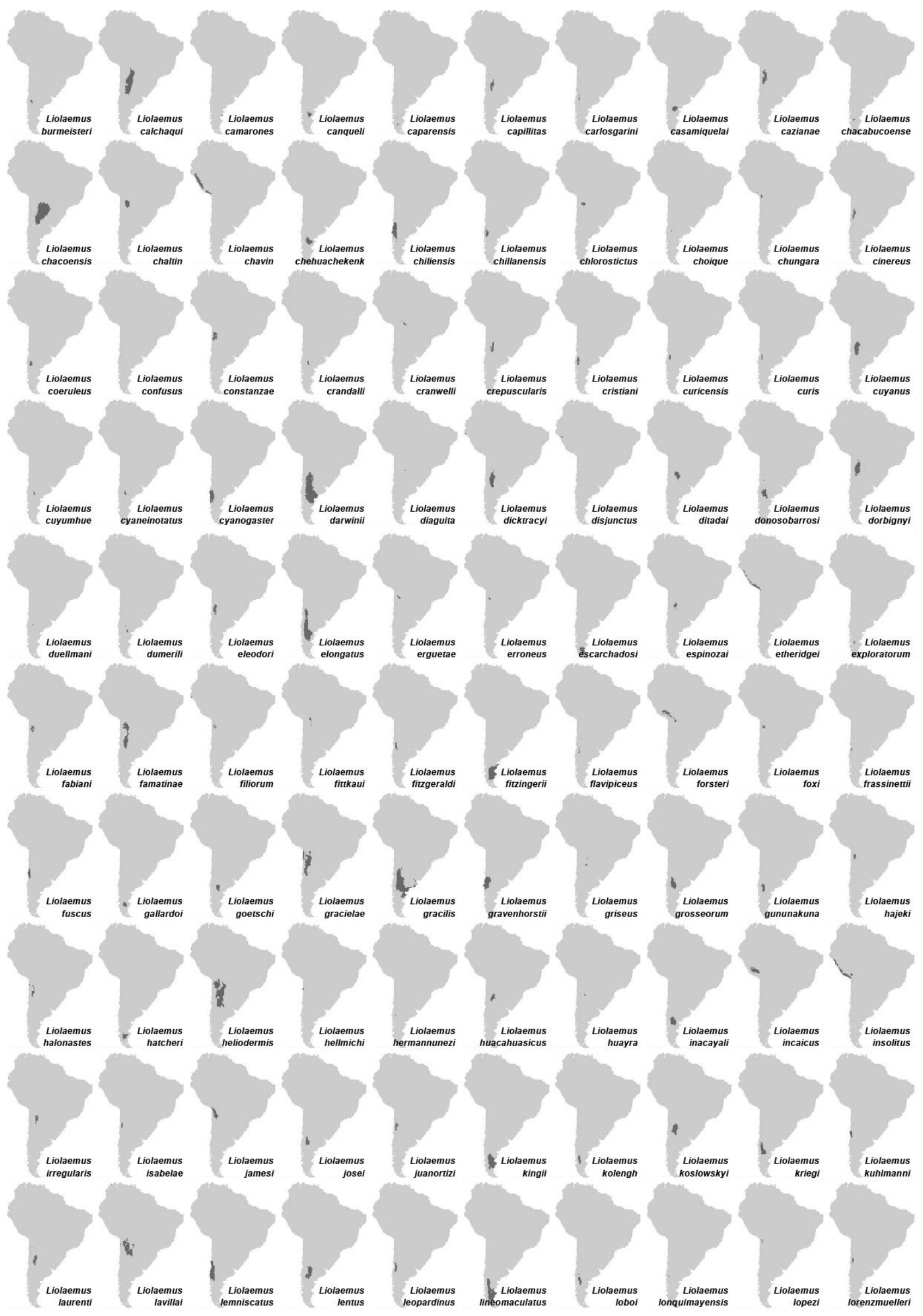




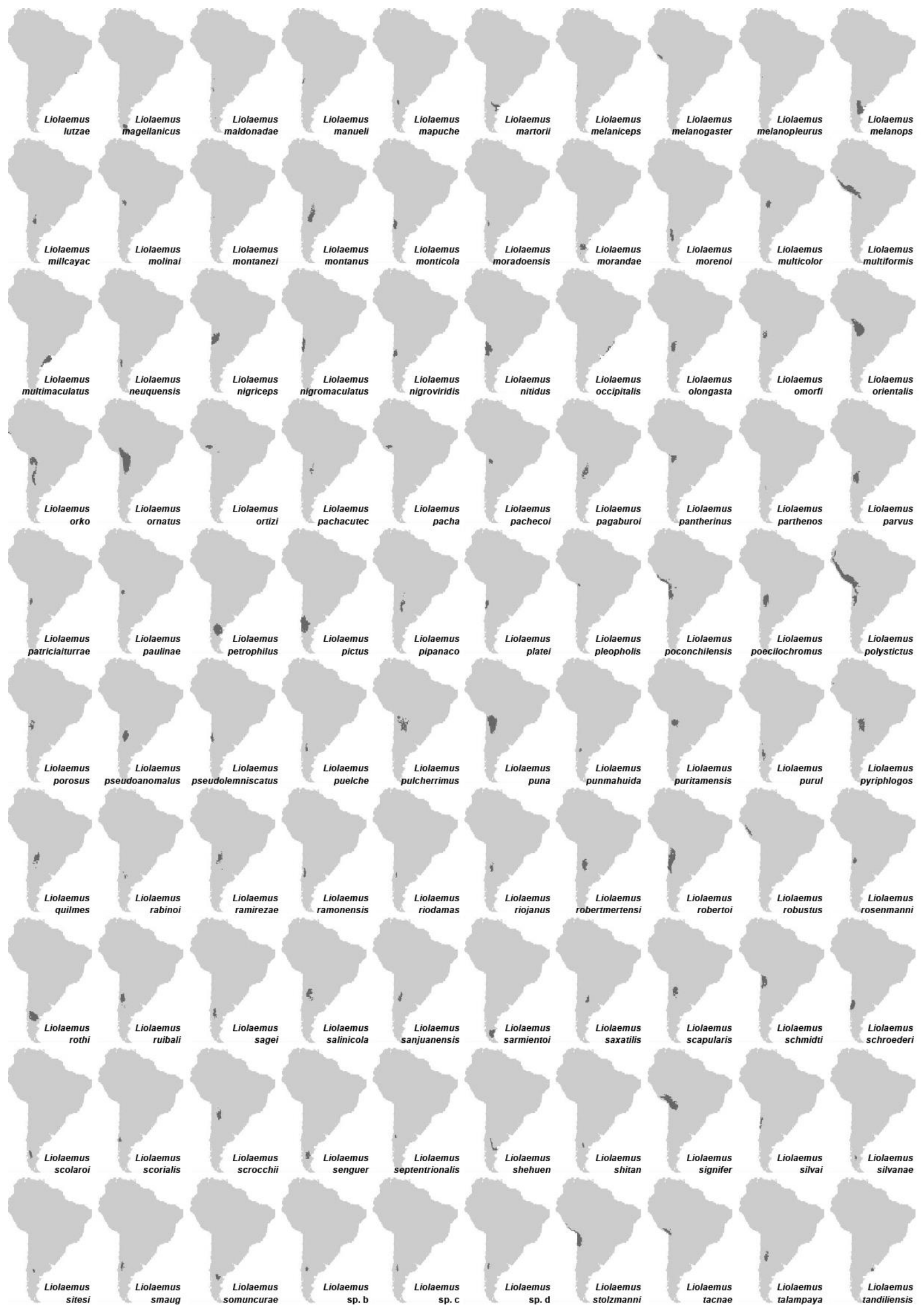




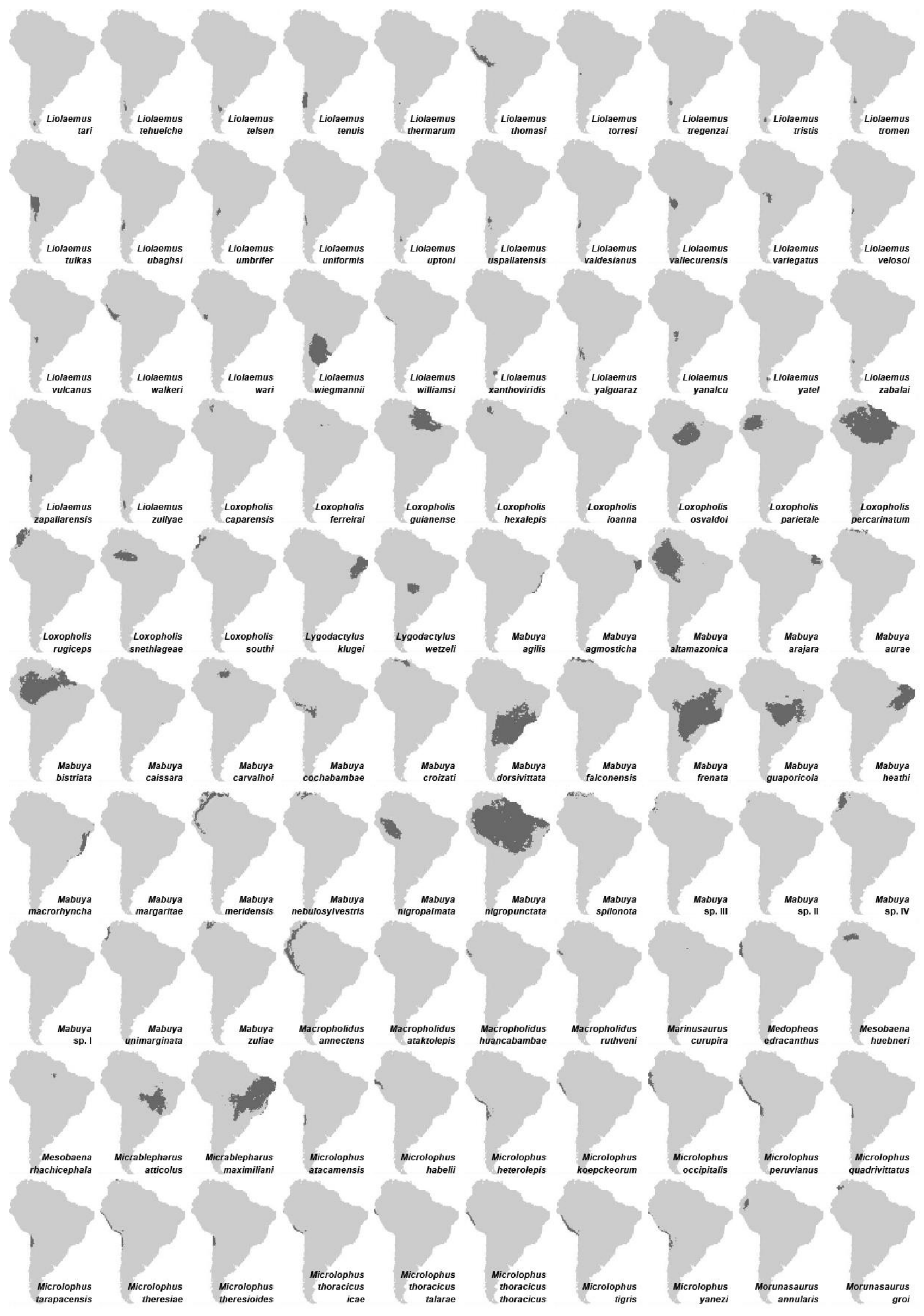




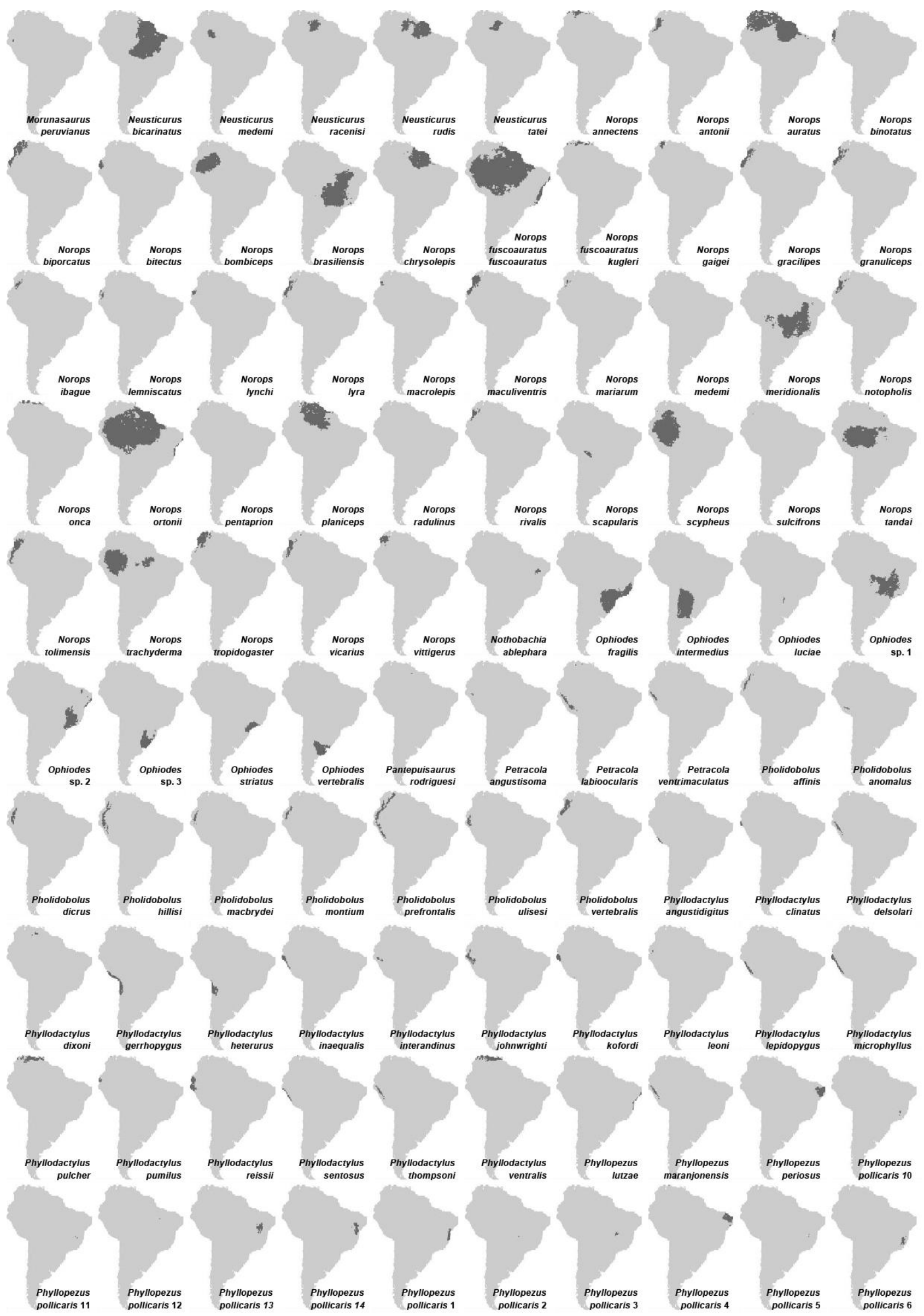




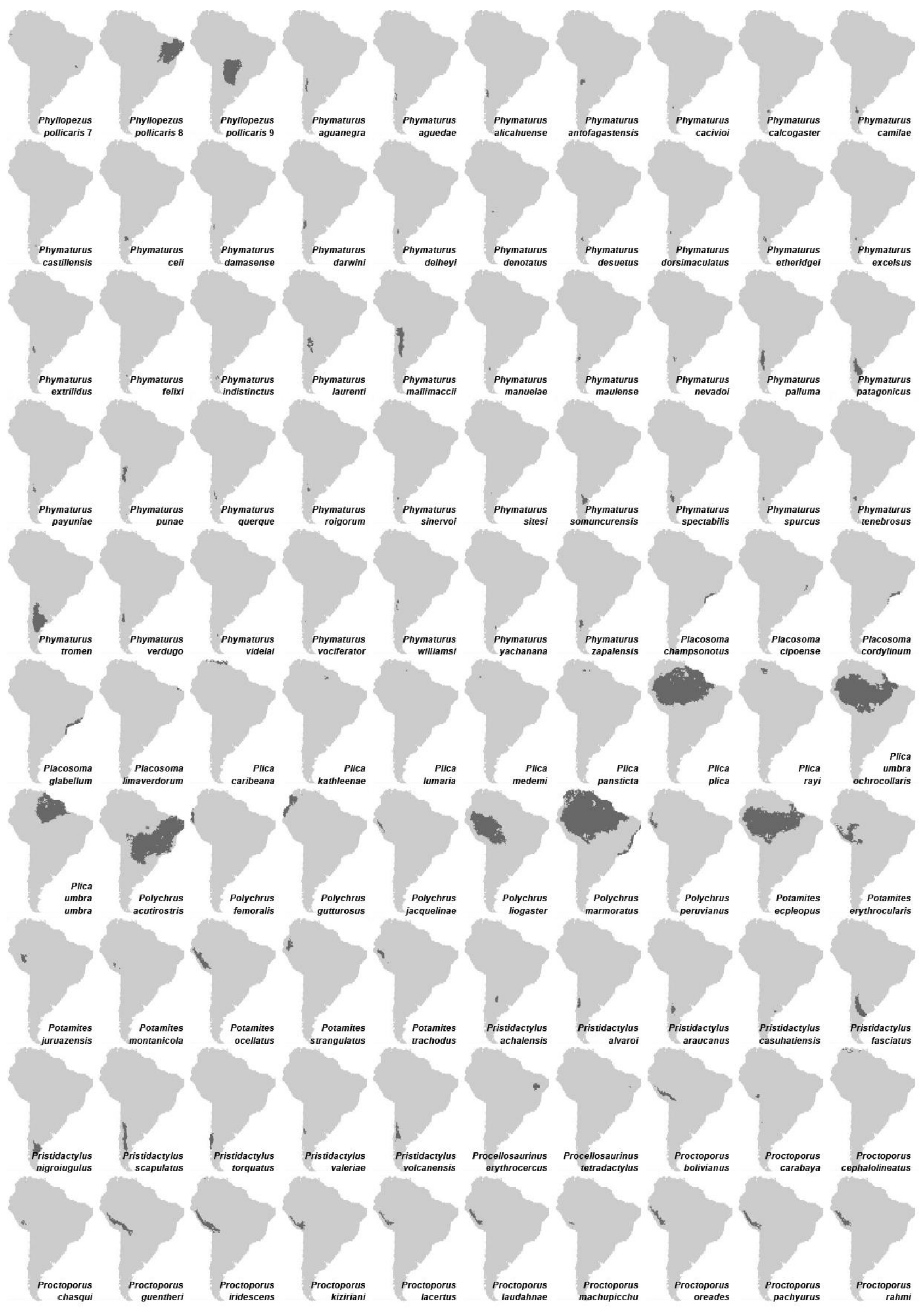




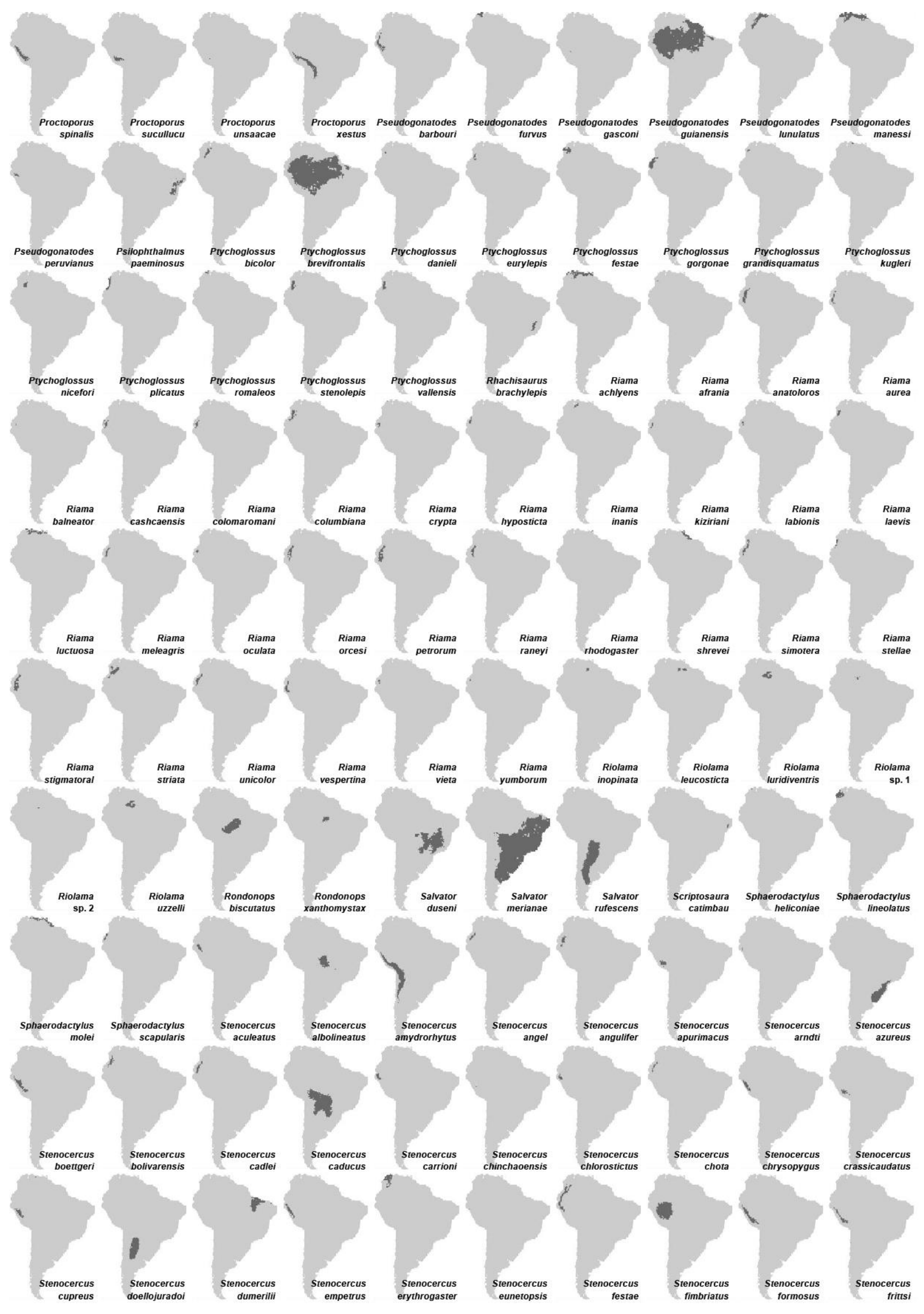




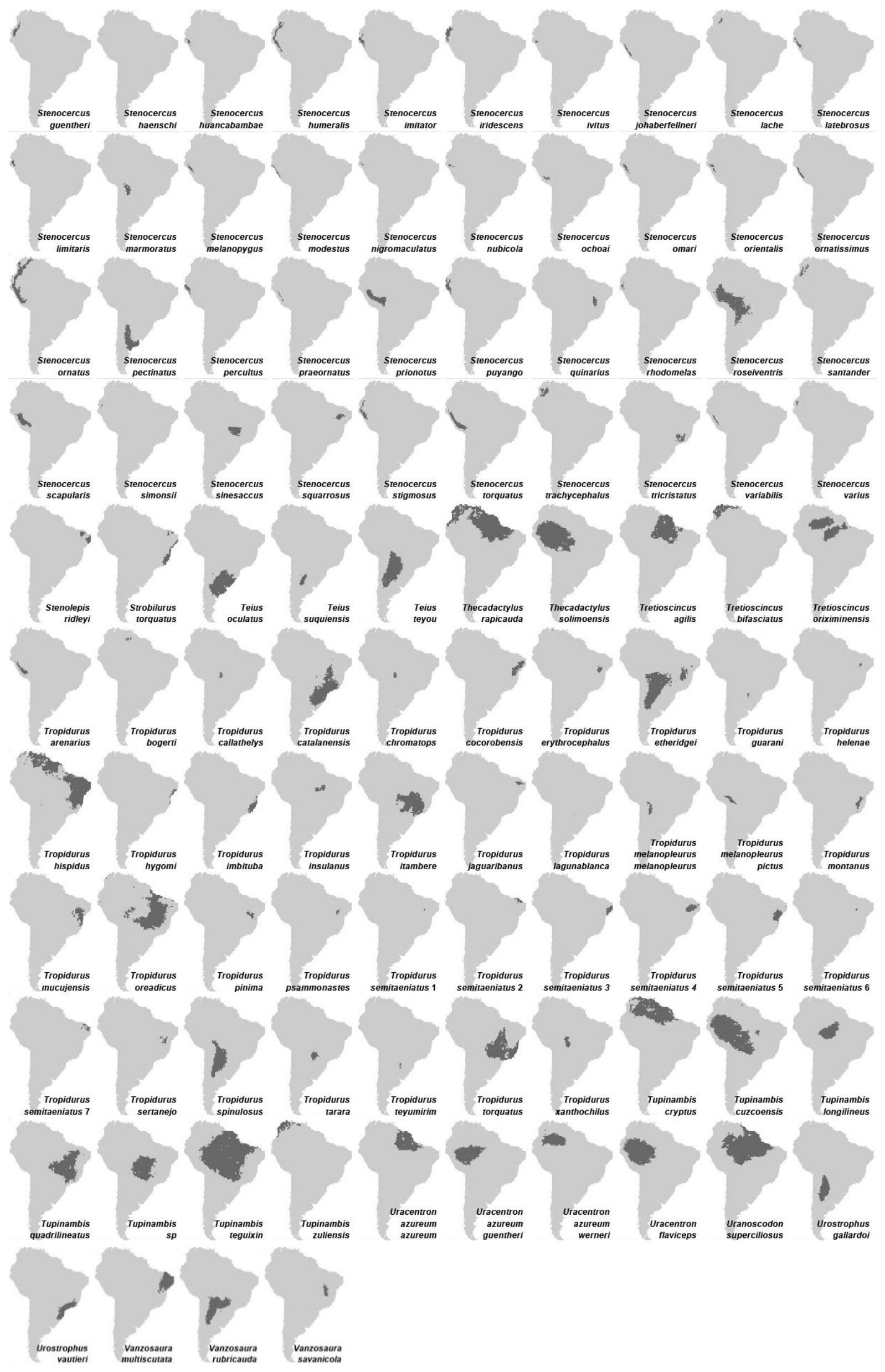




\section{Omissões}

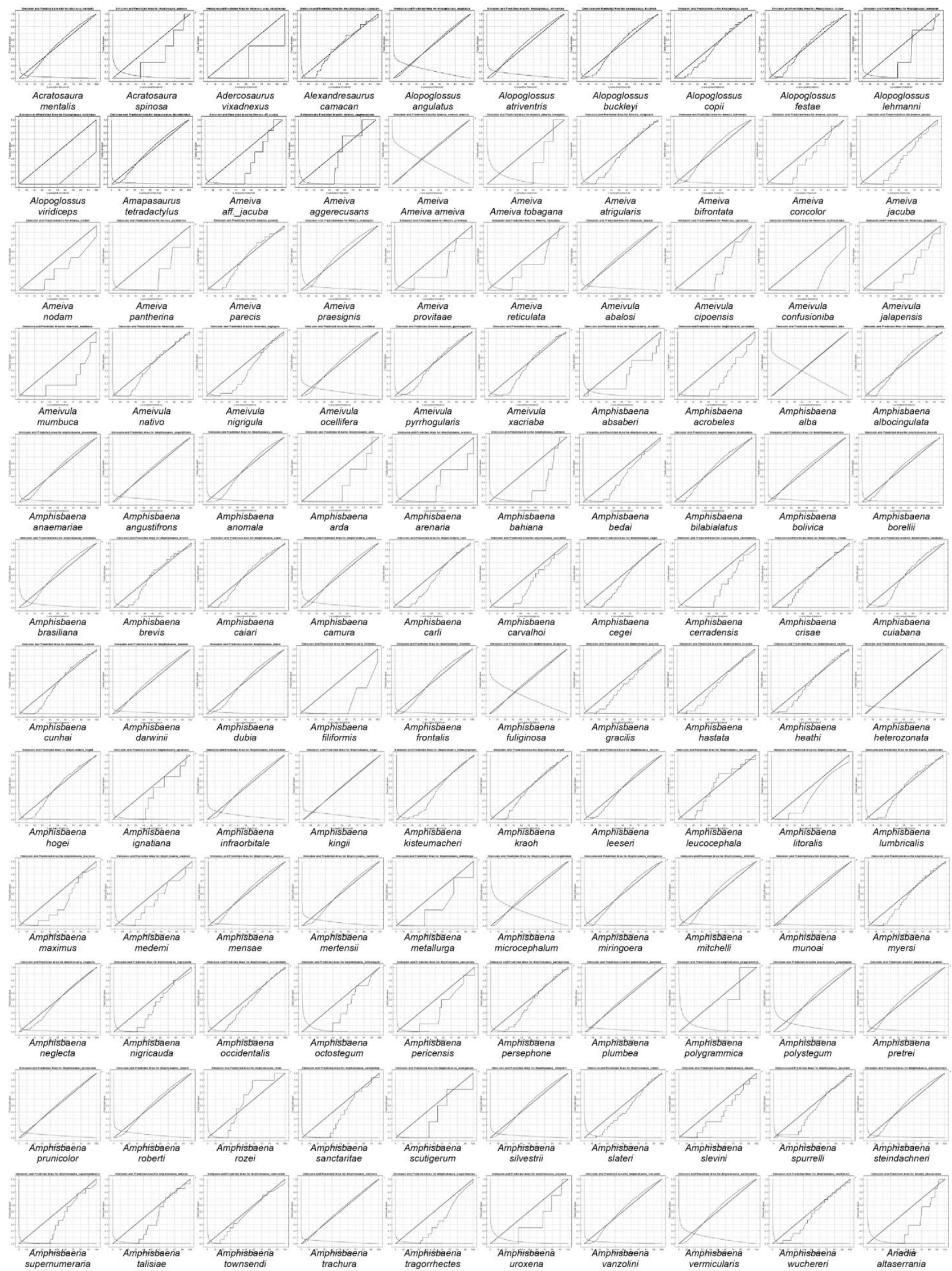




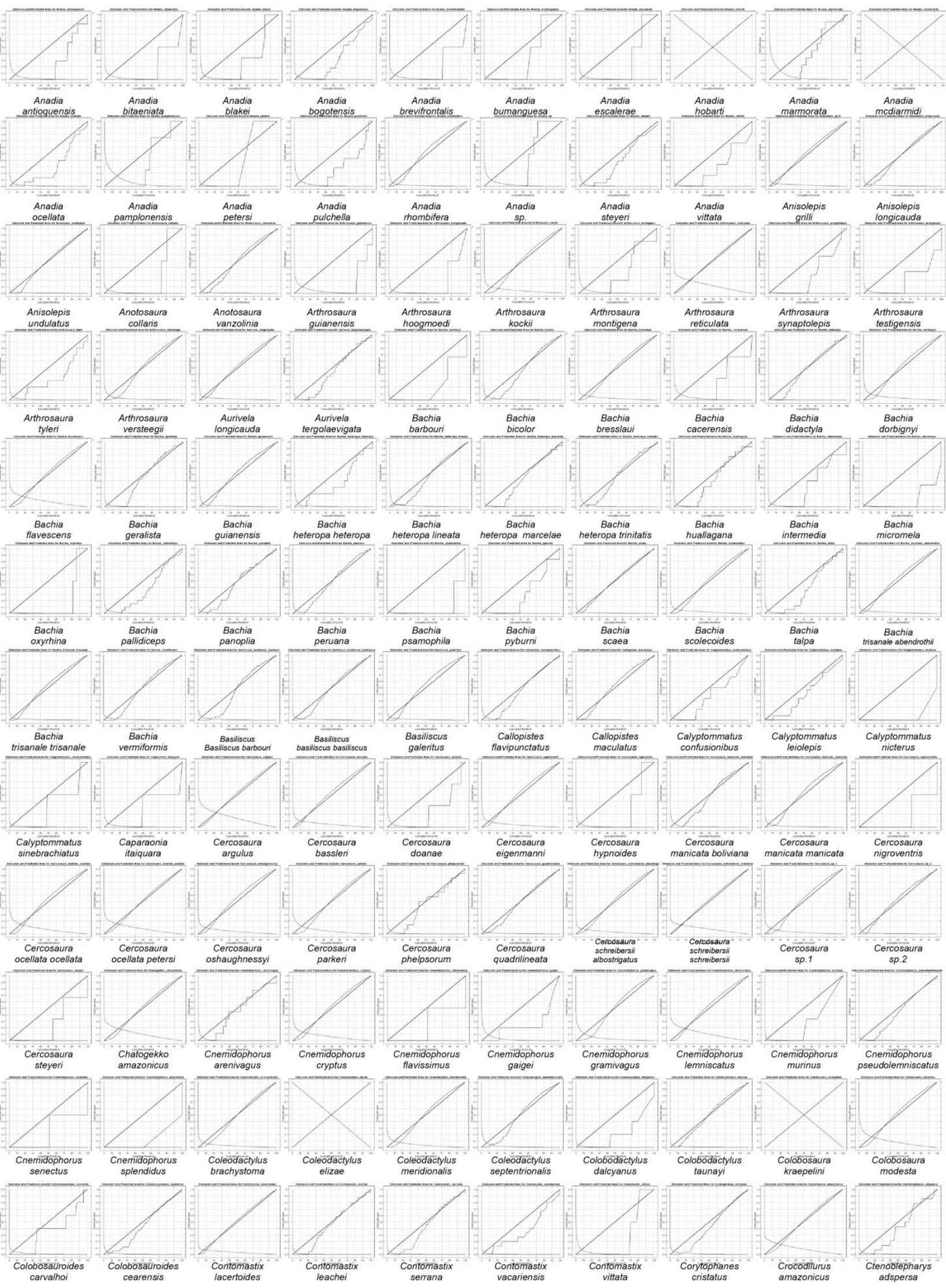




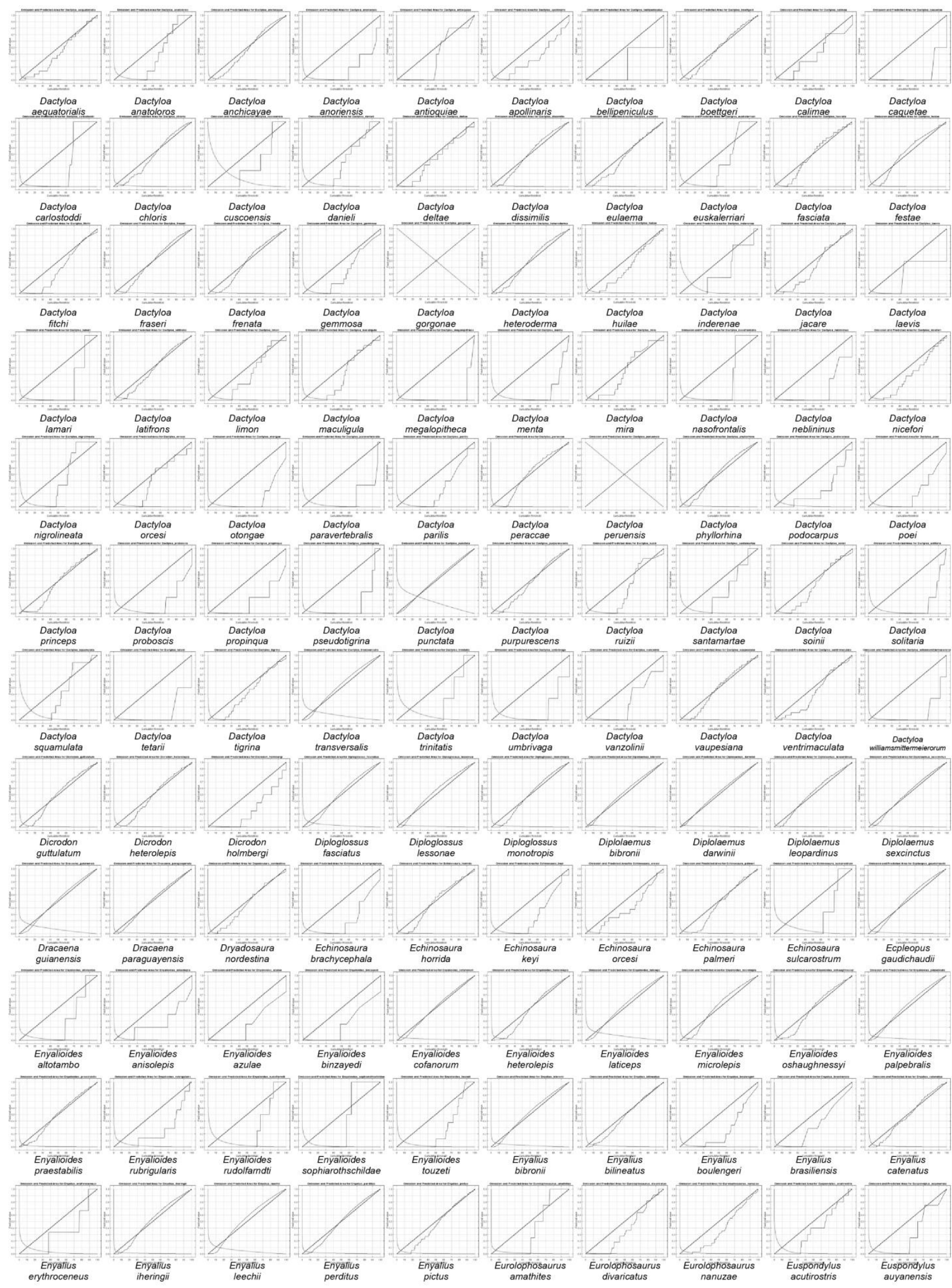




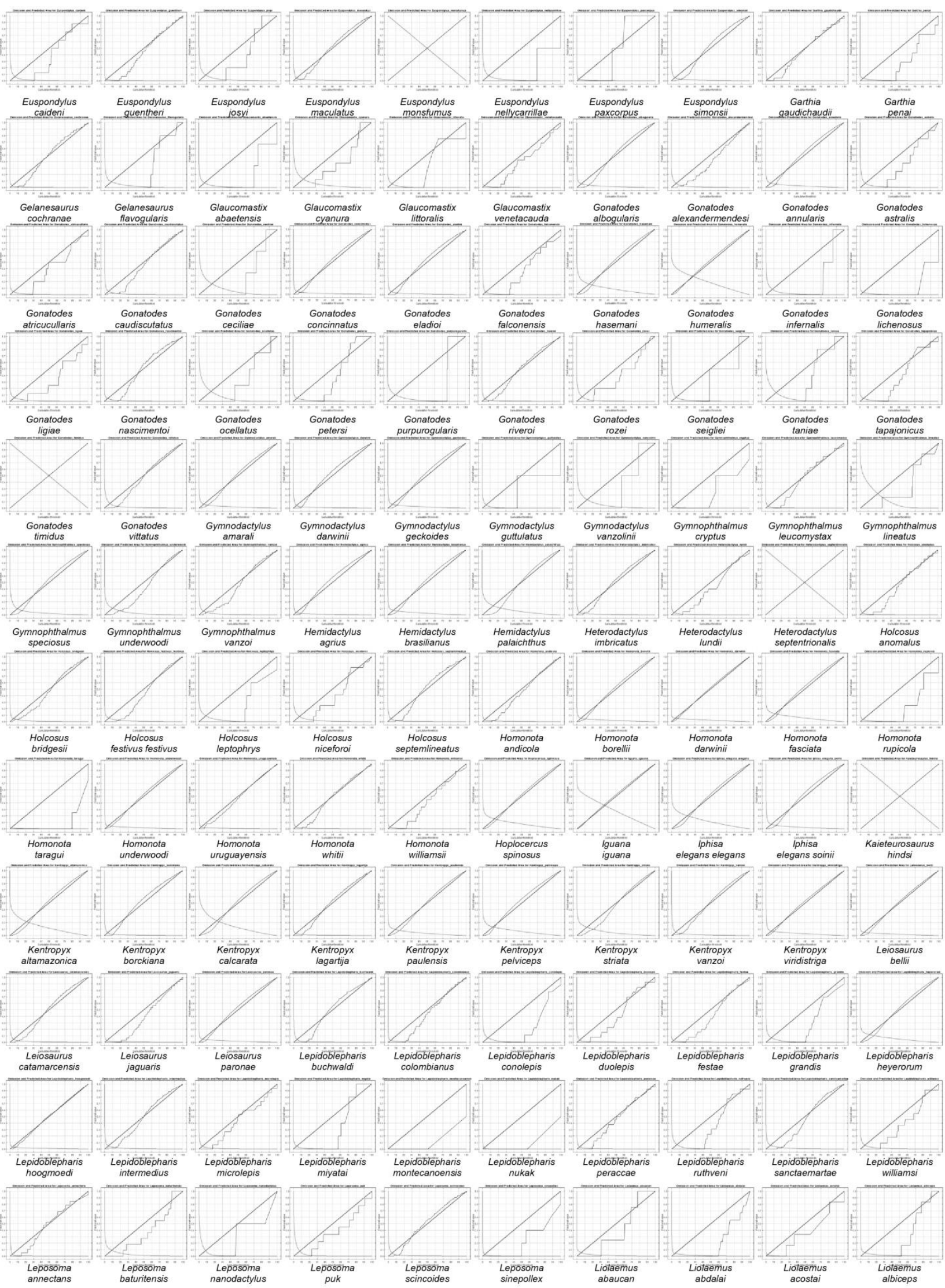




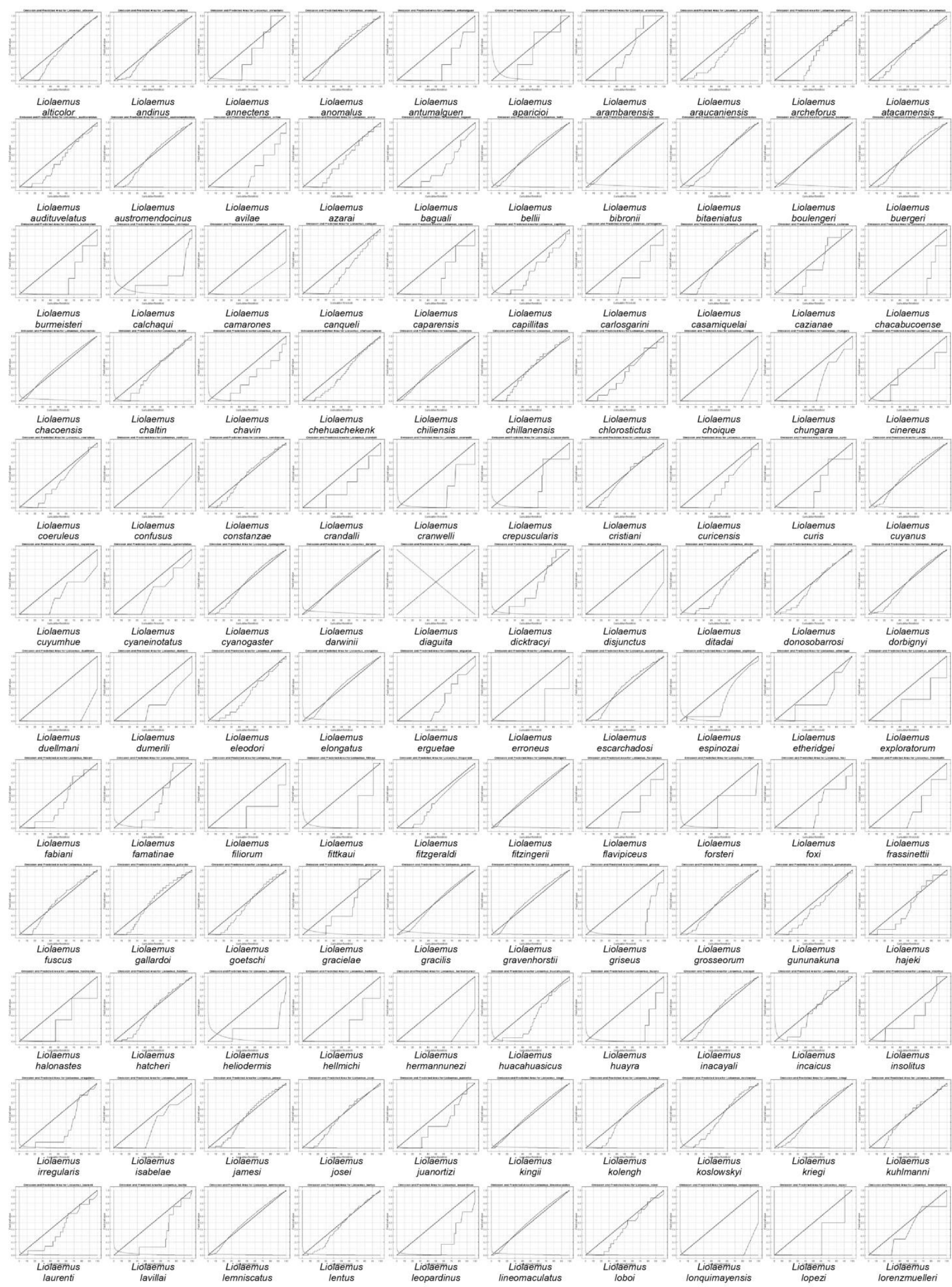




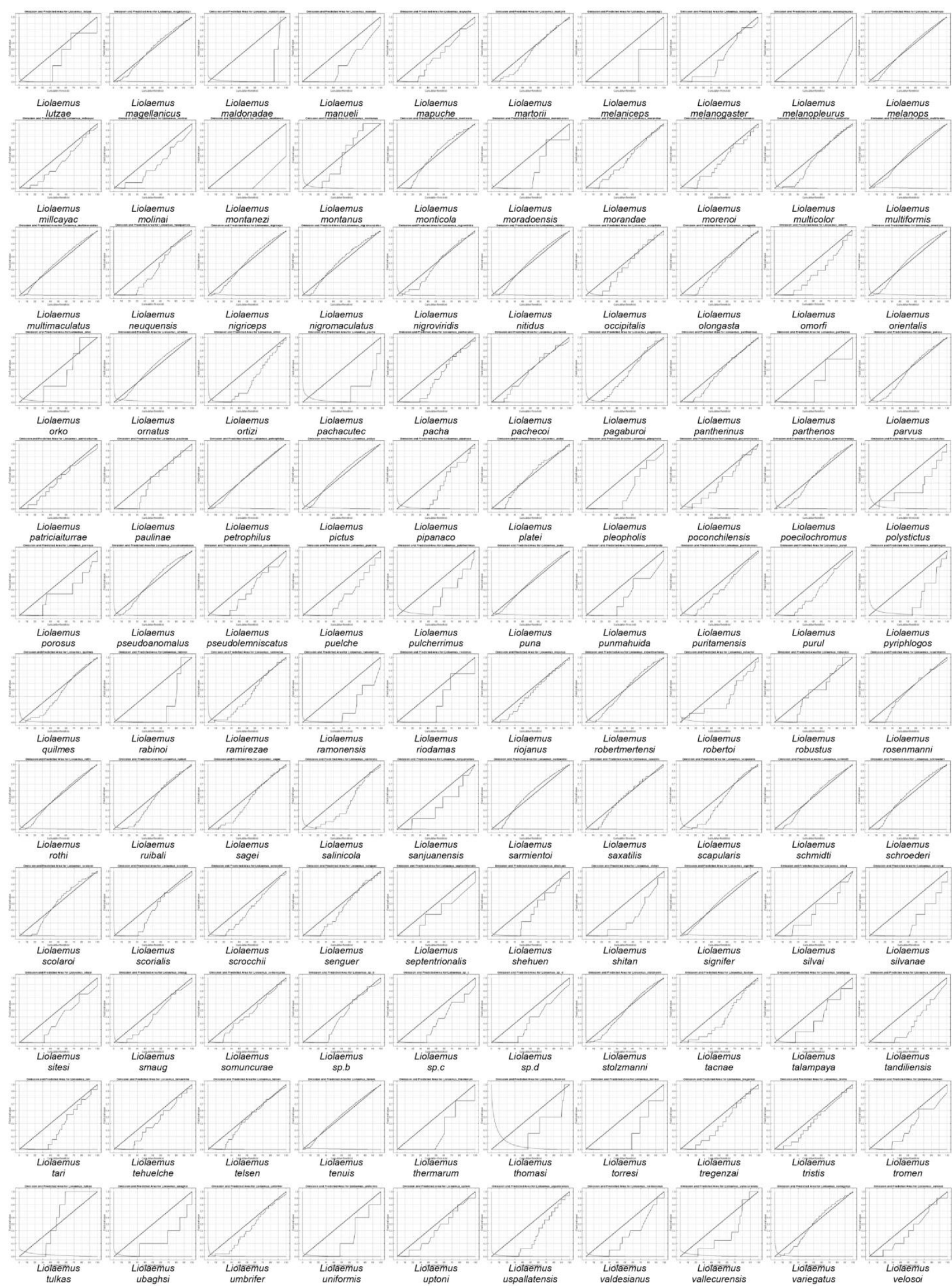




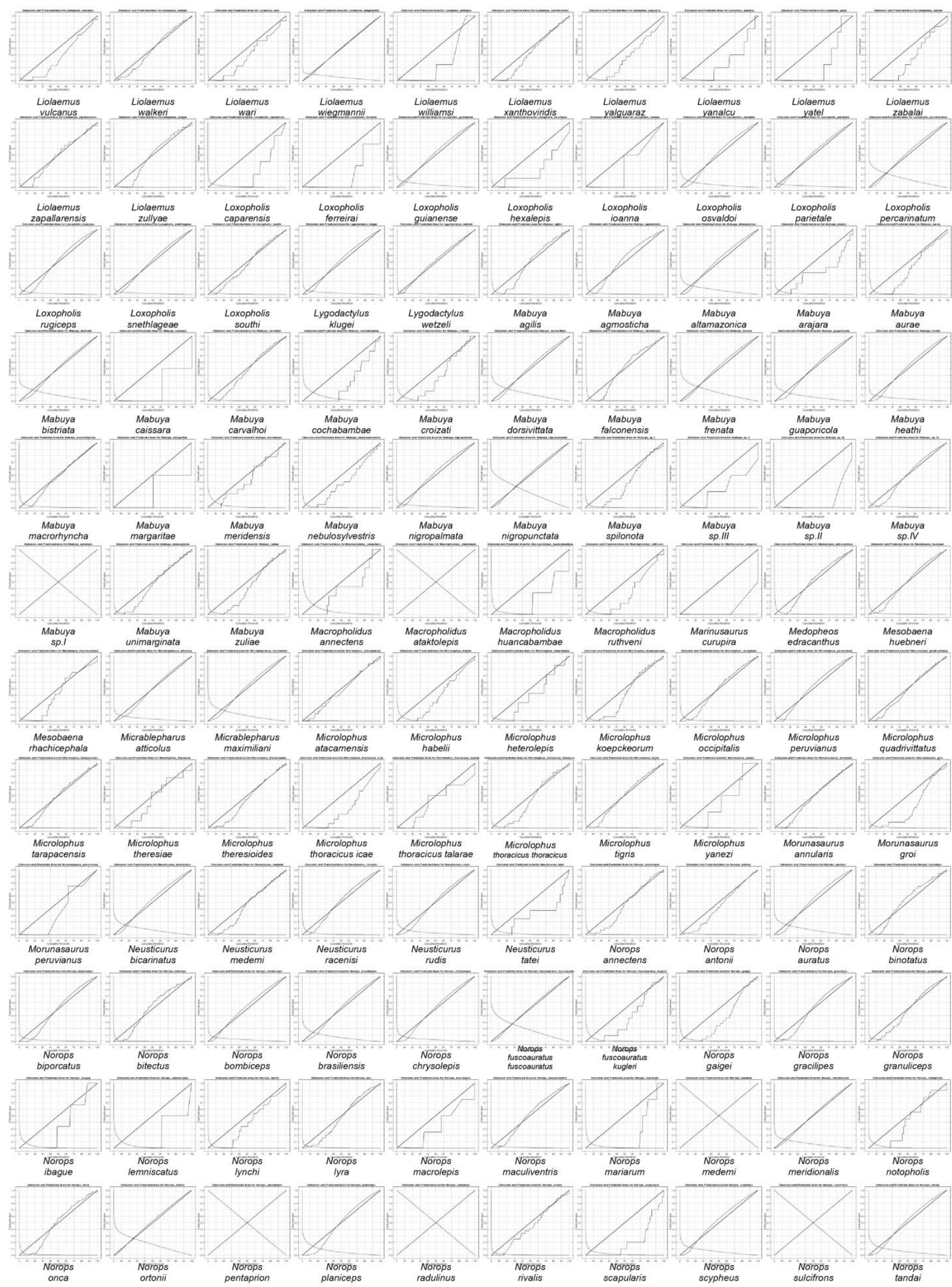




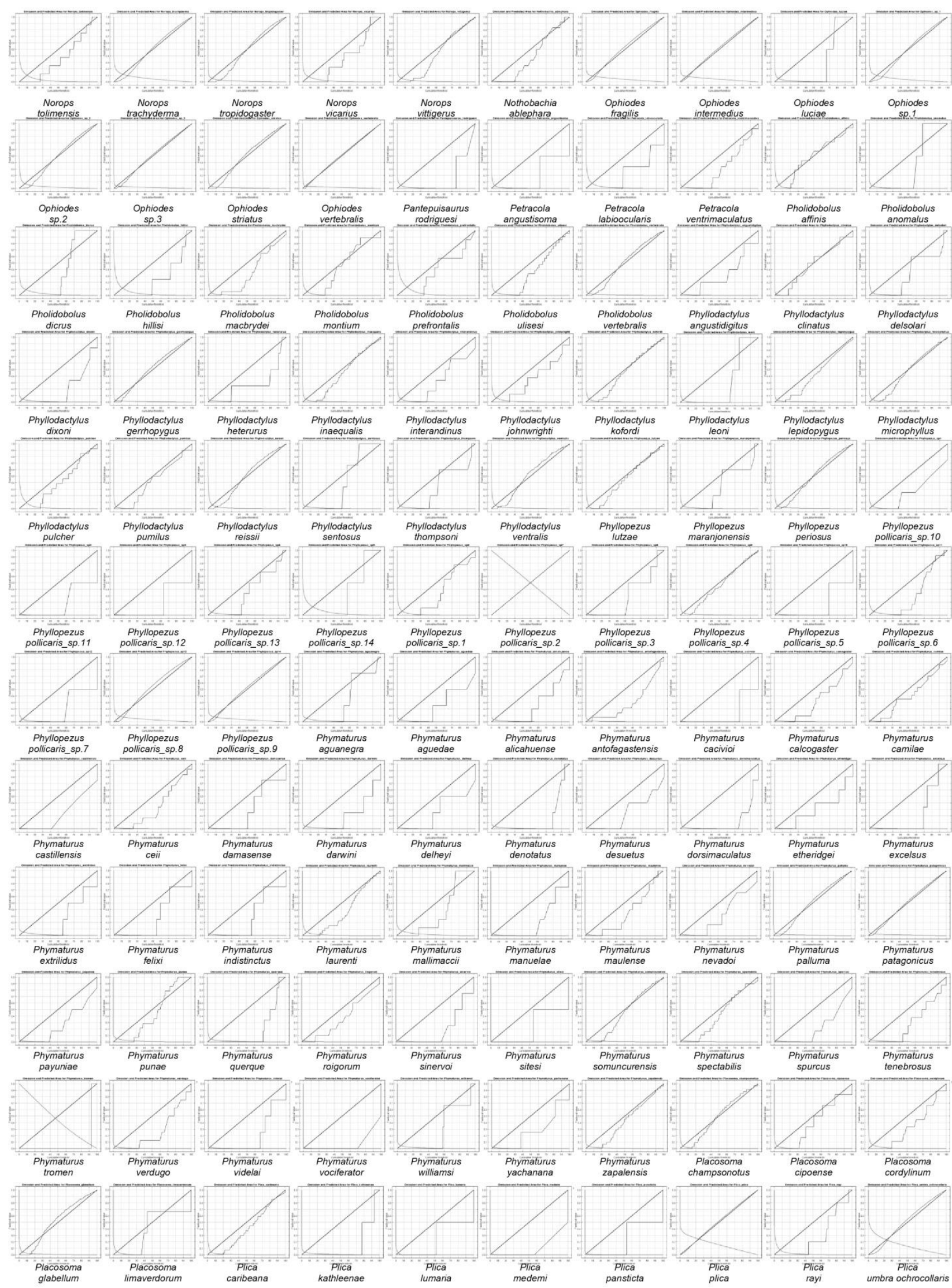




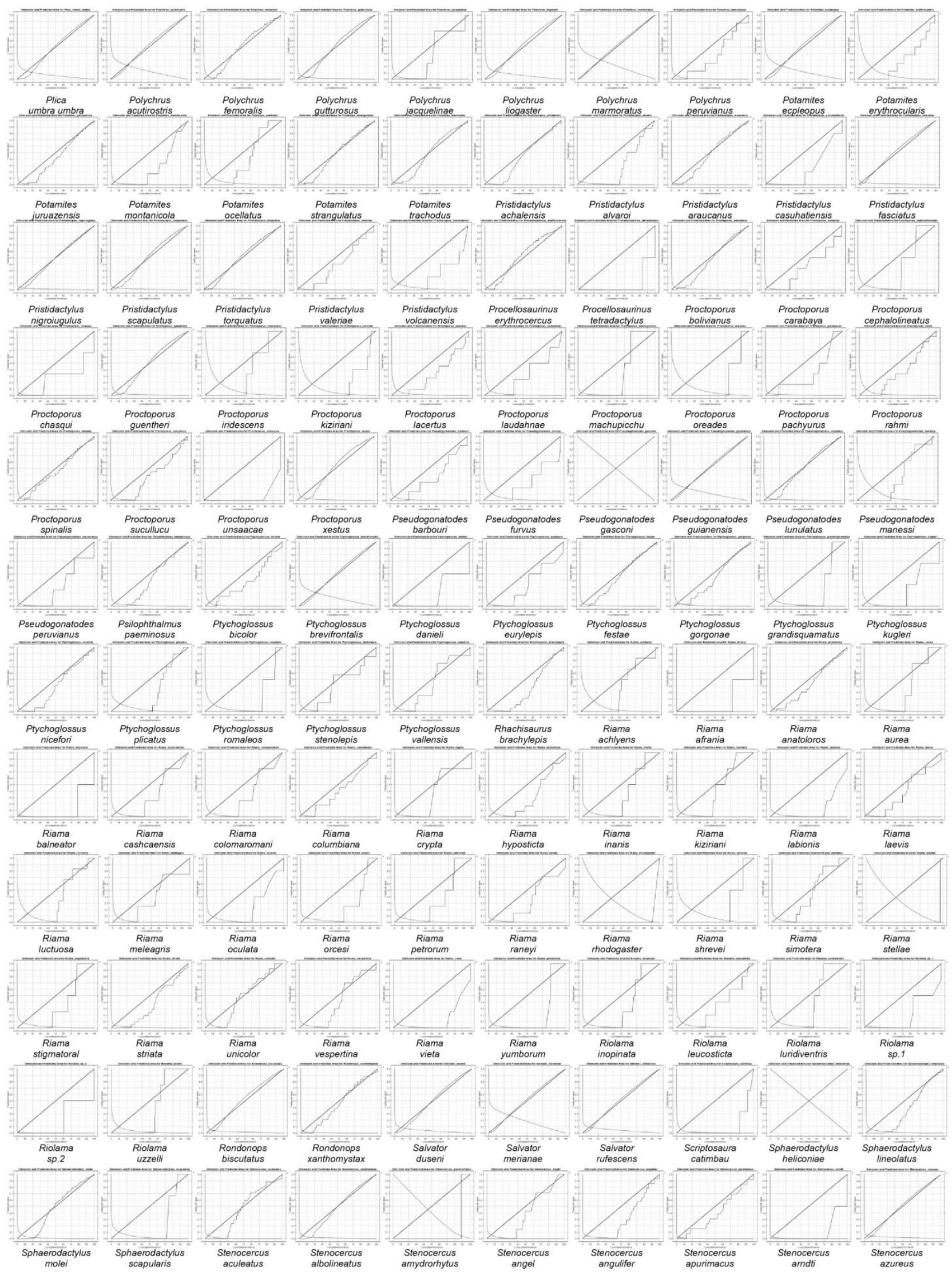




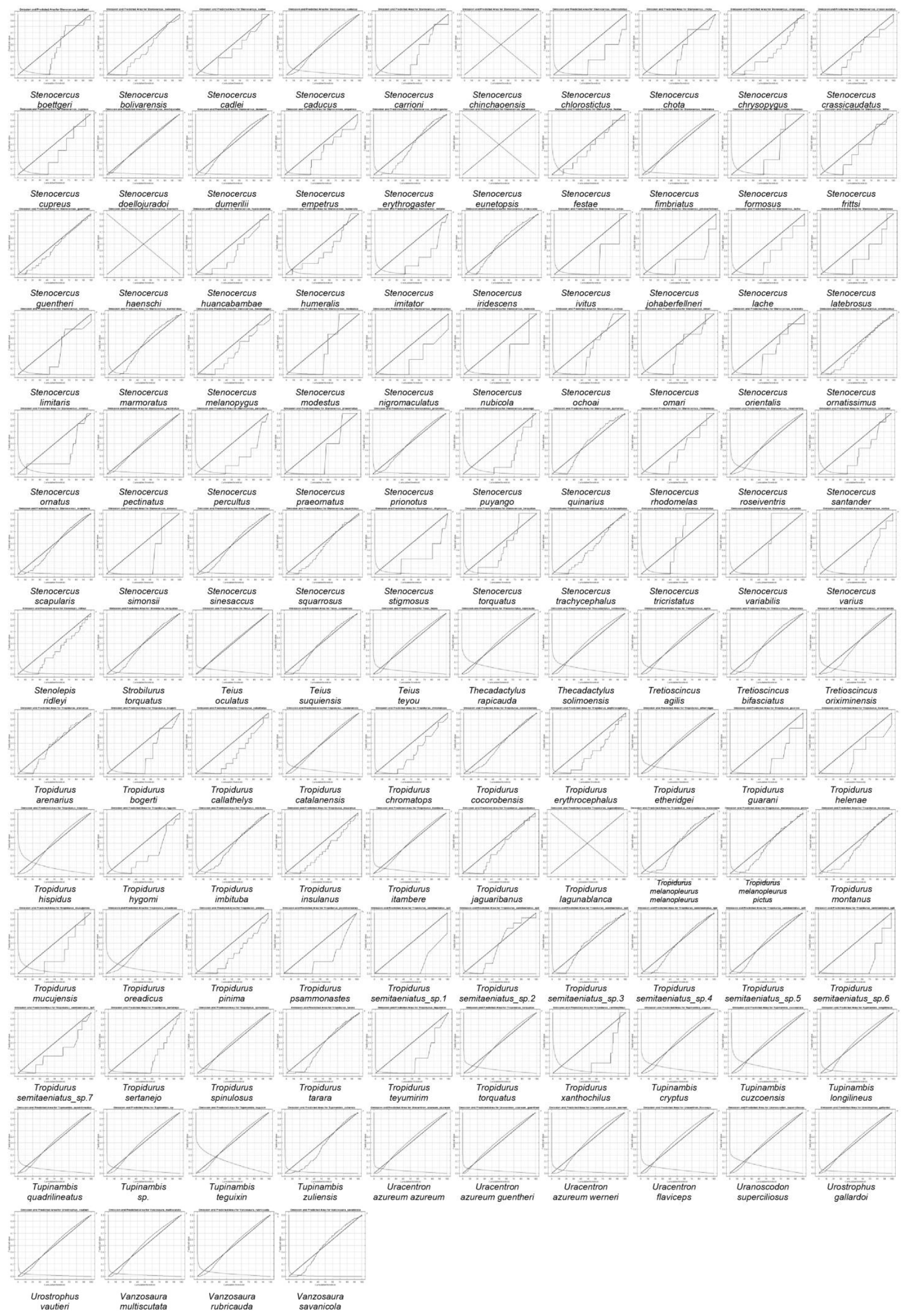




\section{Curva ROC}

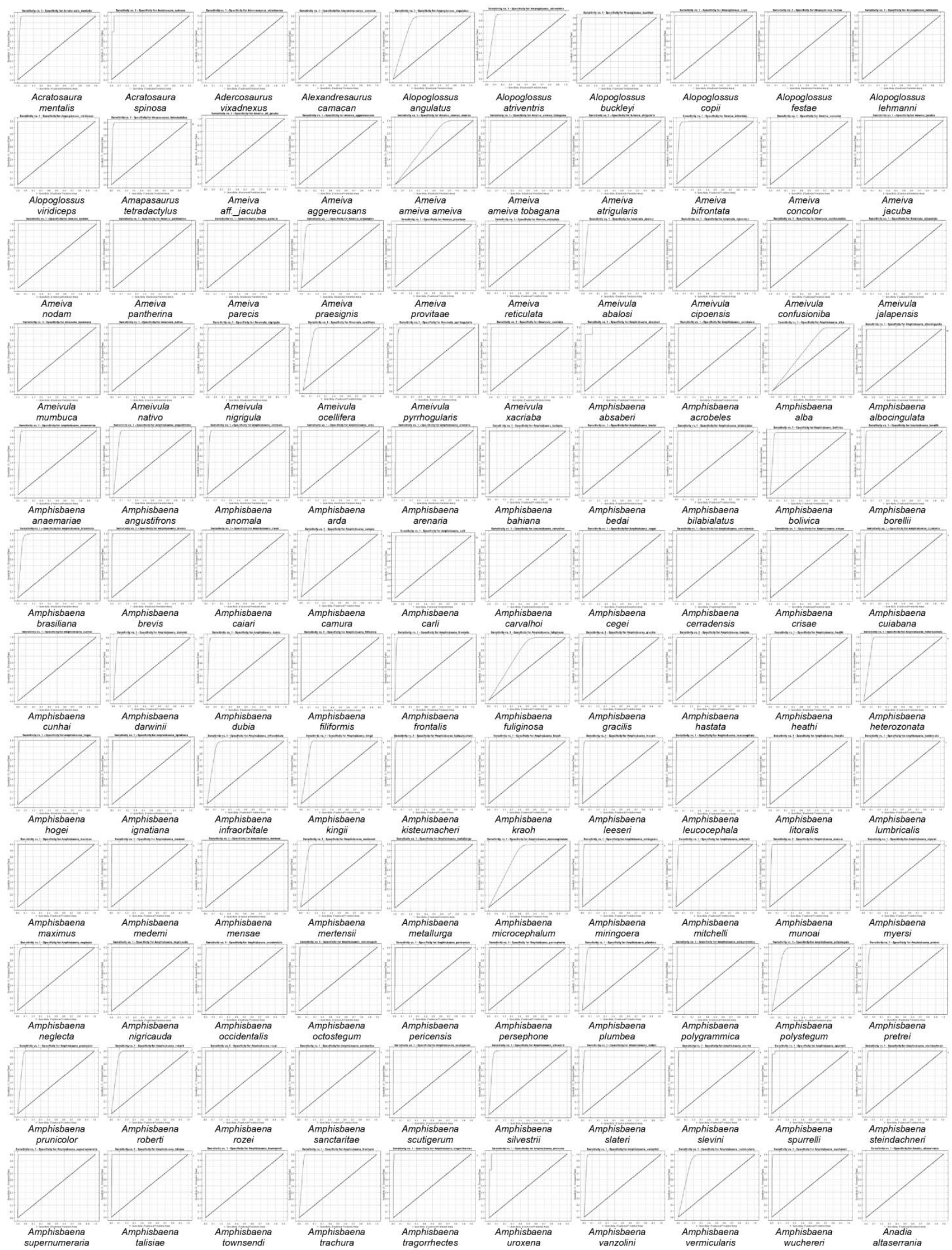




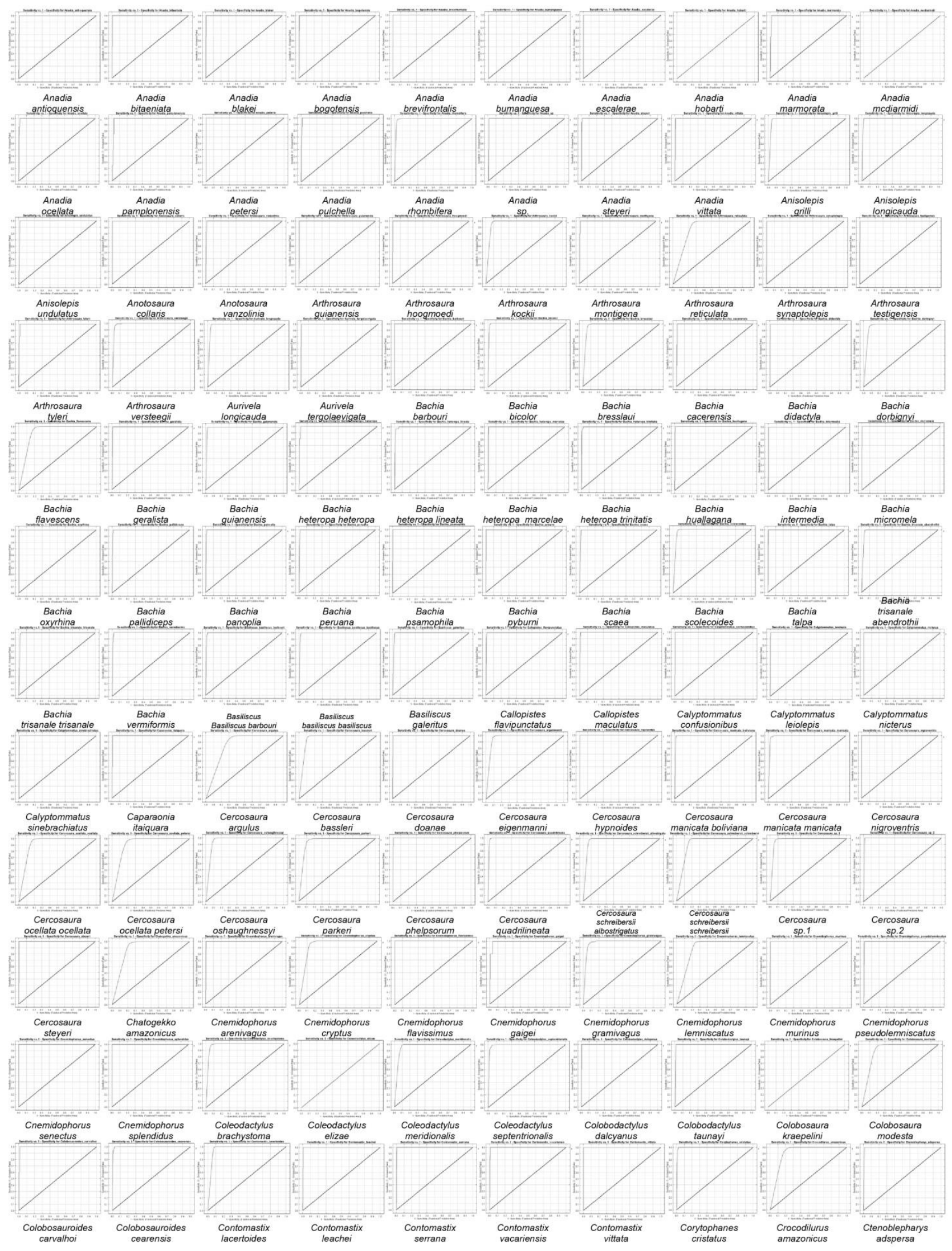




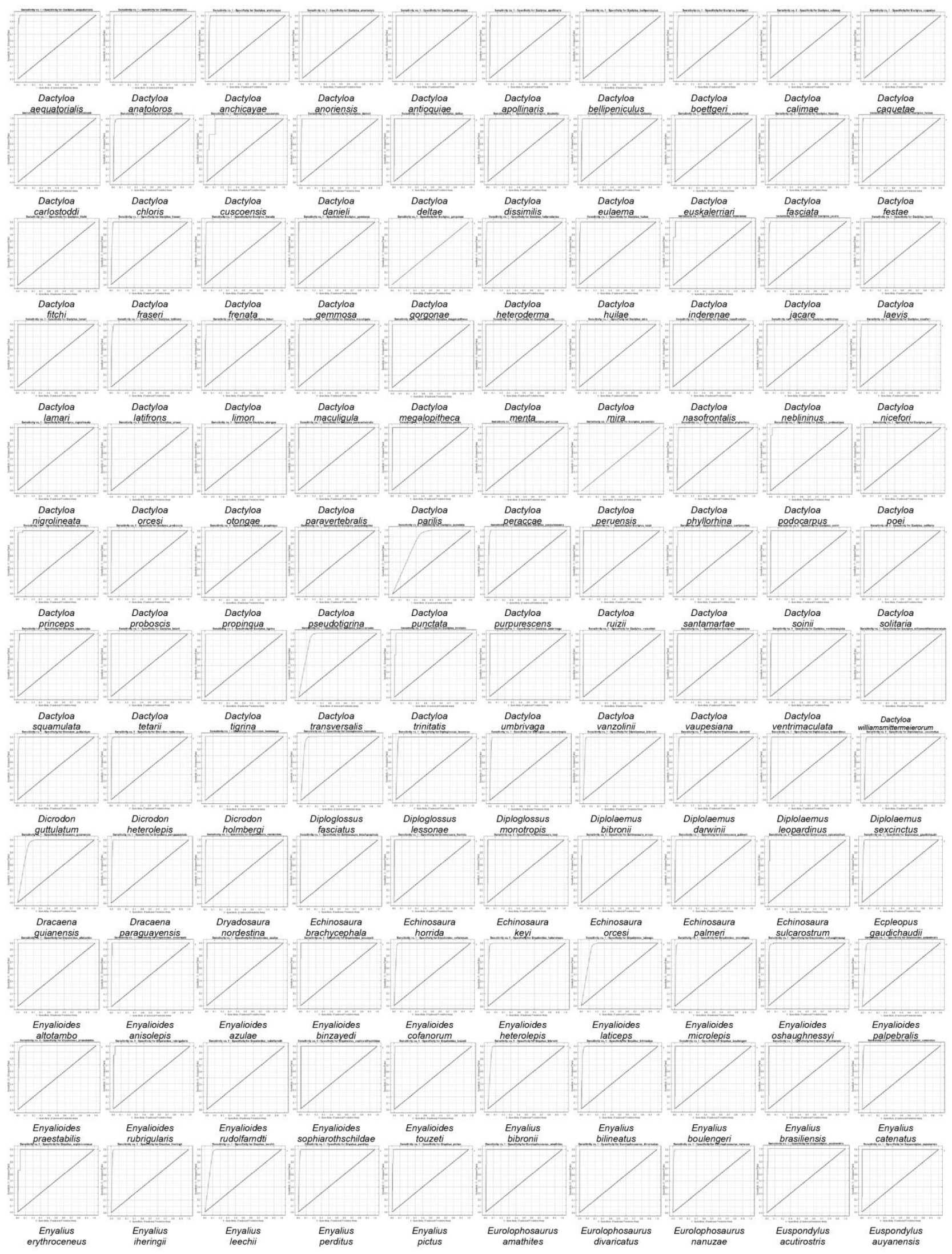









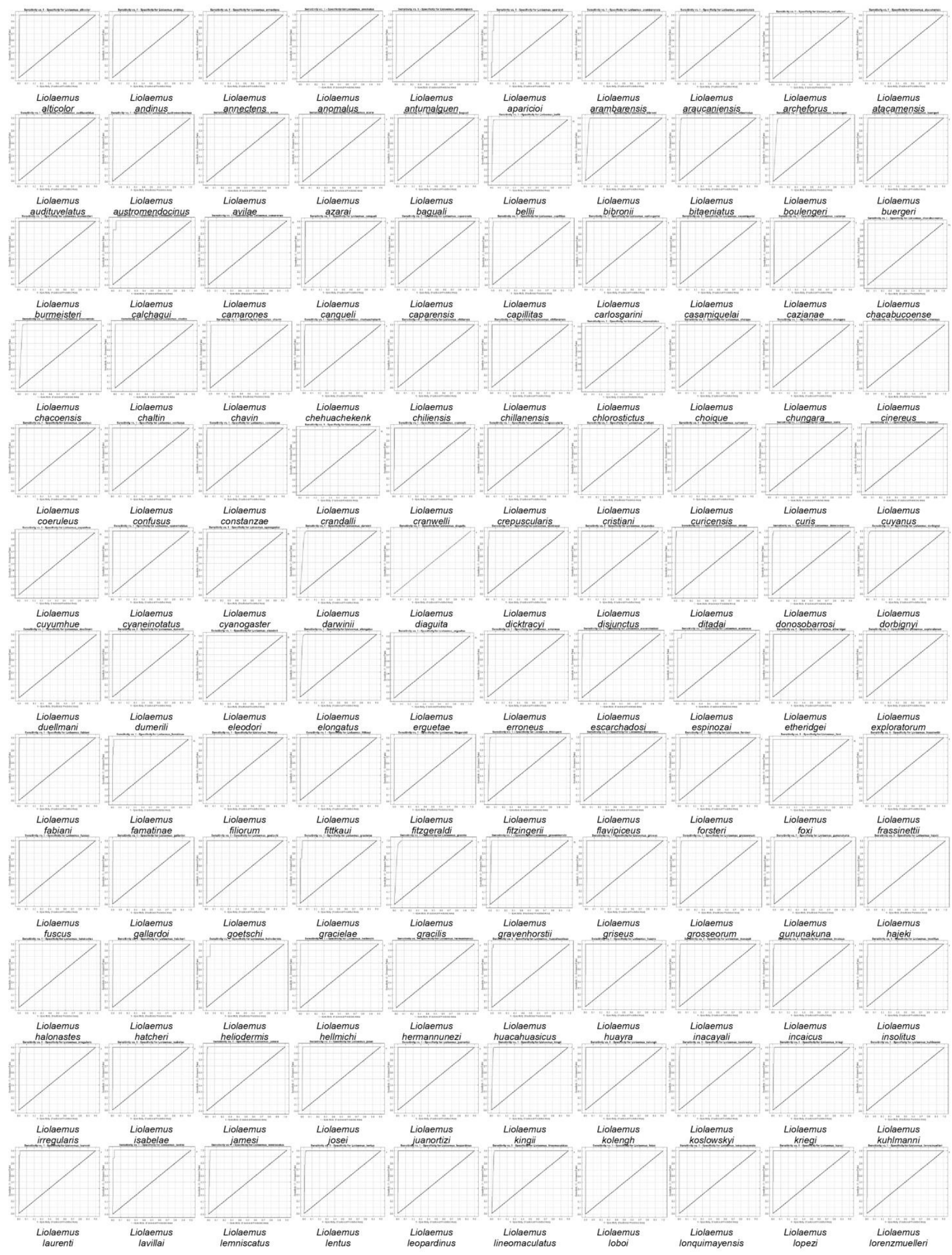




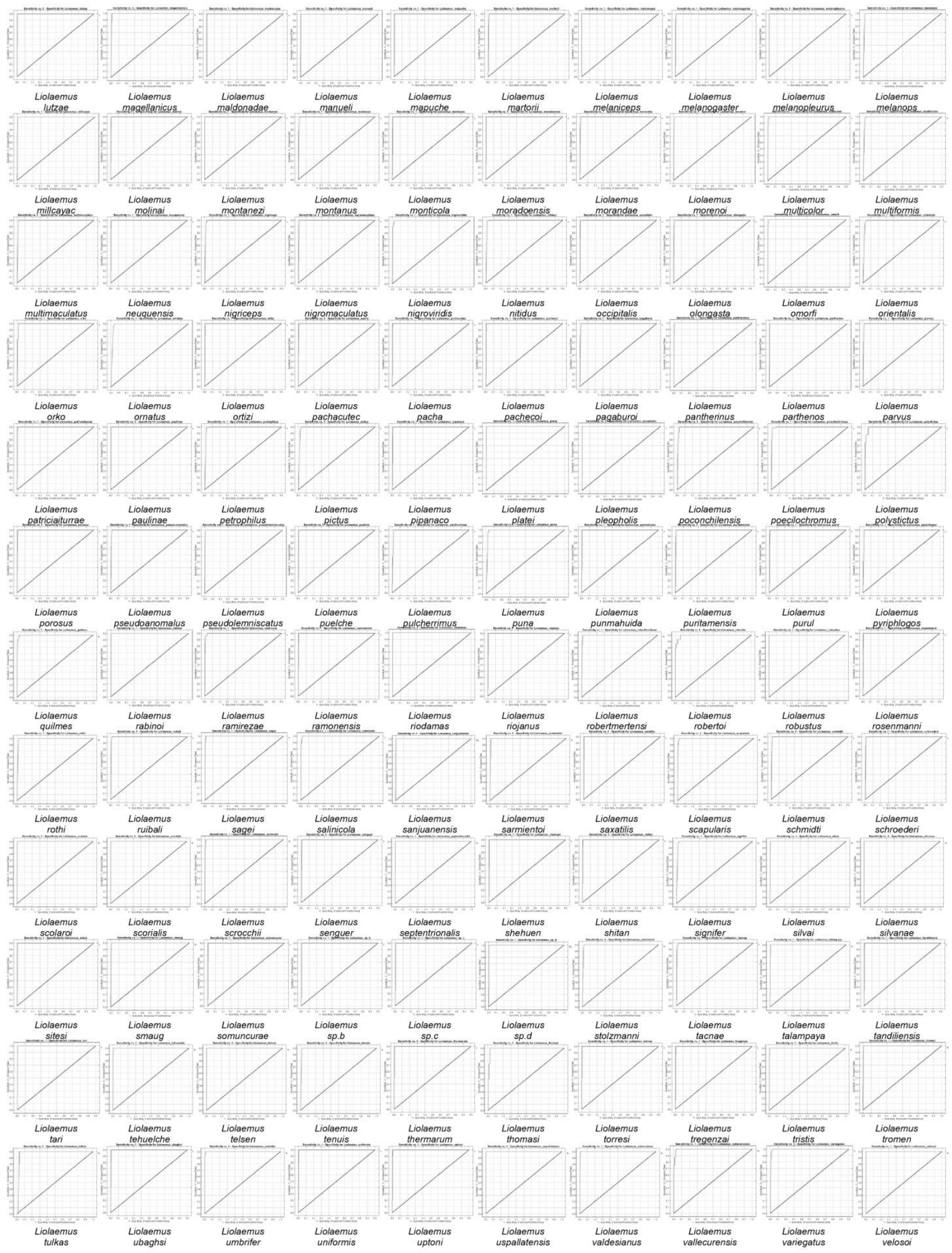




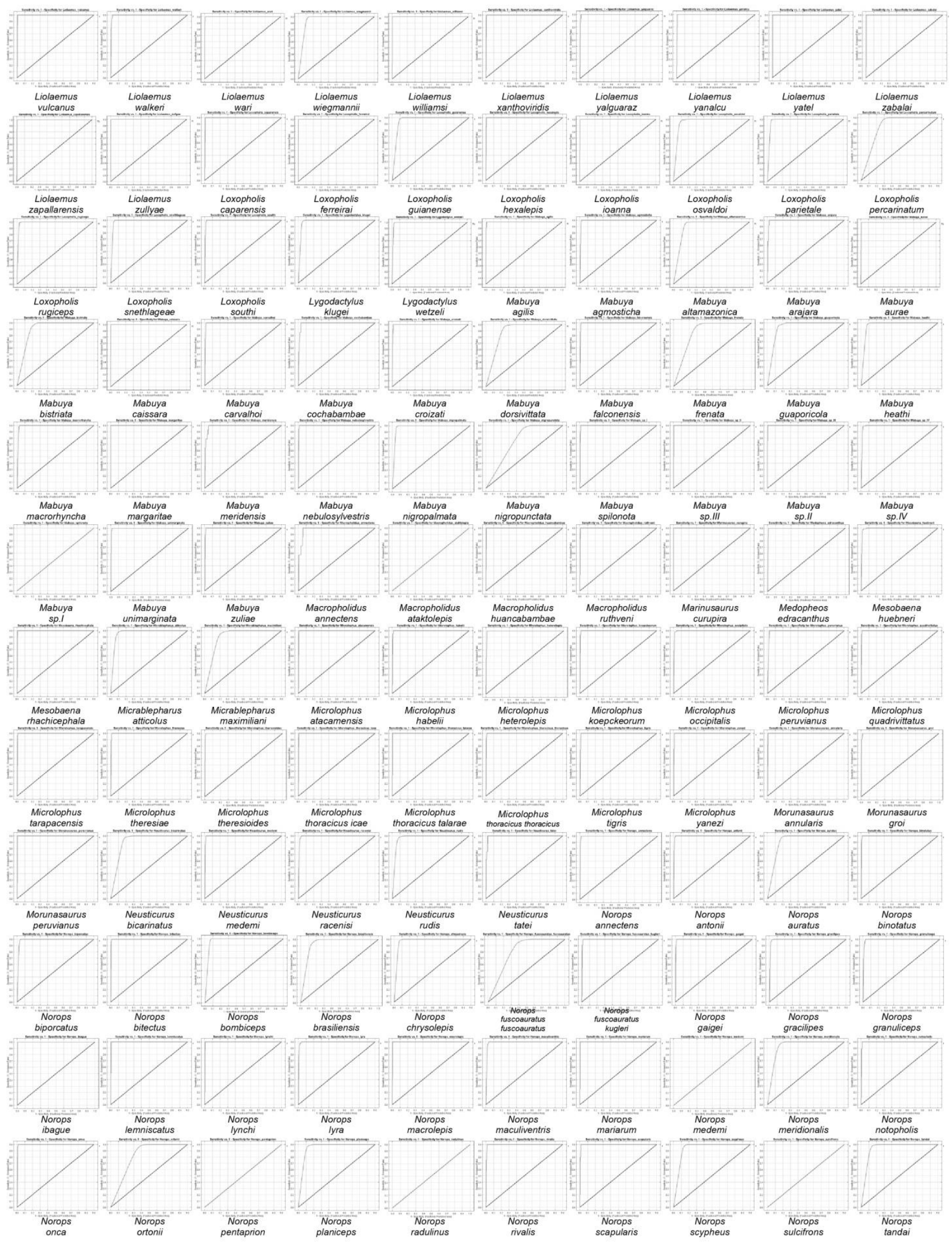




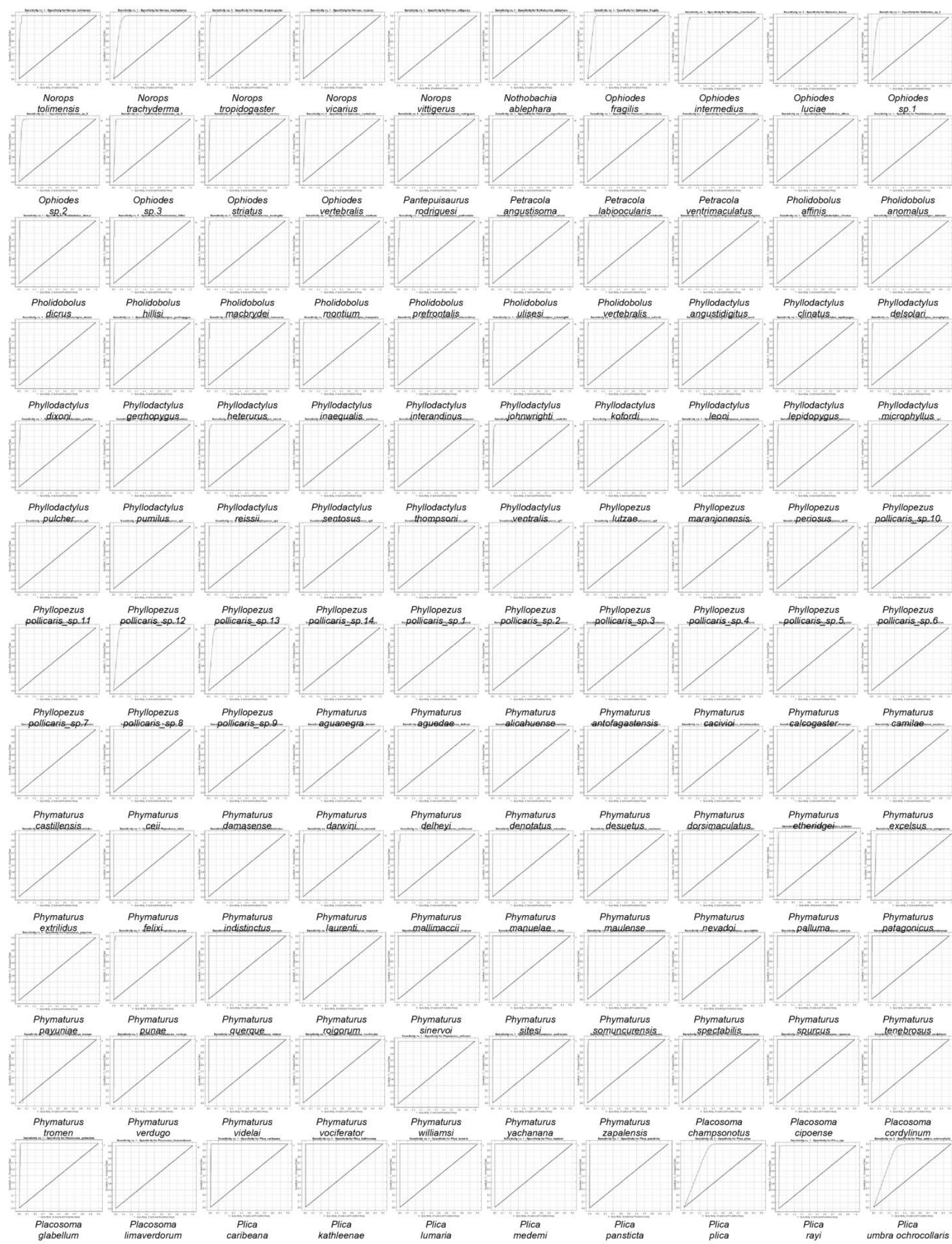




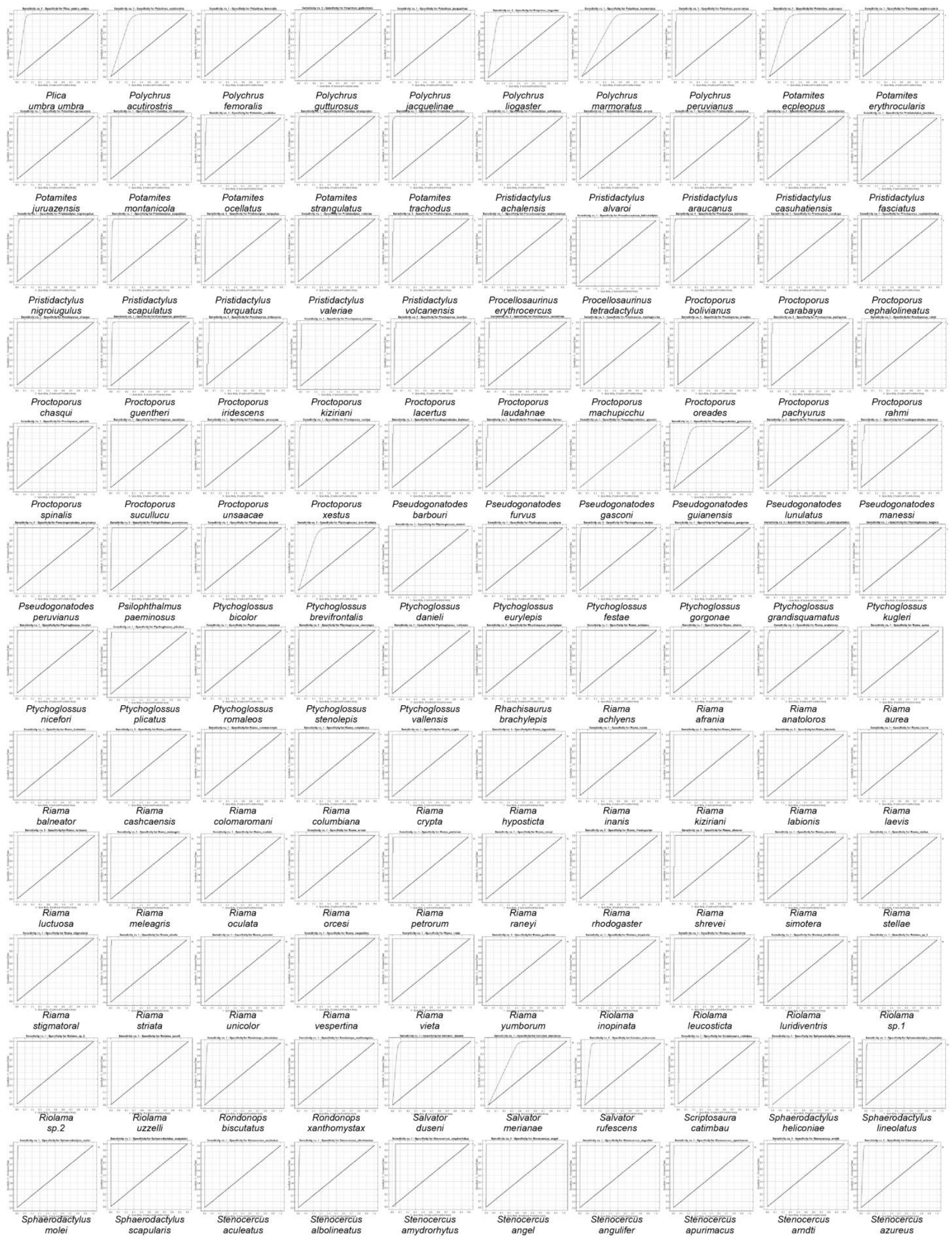




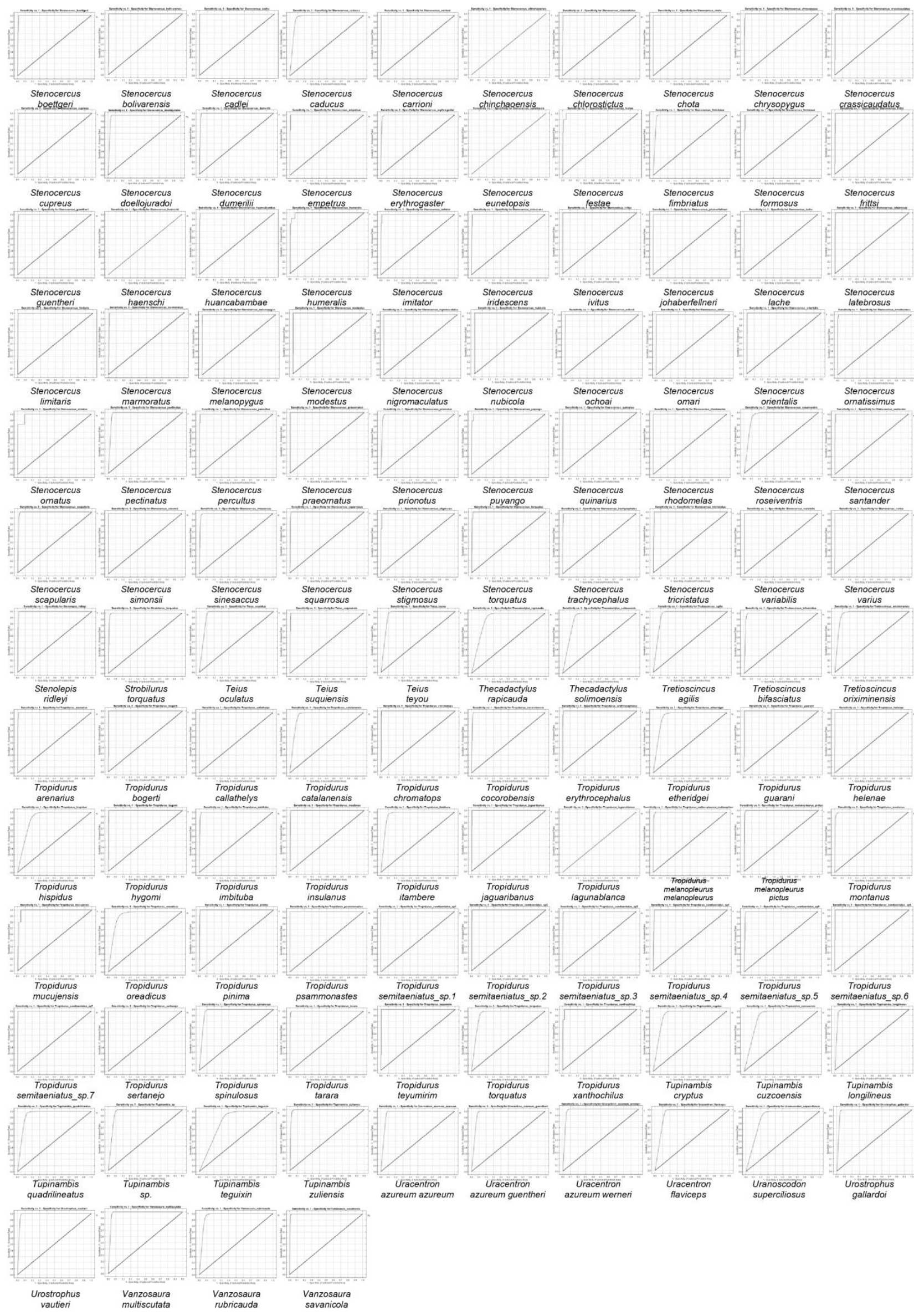

